\title{
Microvertebrados del Holoceno de sitios arqueológicos en el sur de Mendoza (República Argentina): aspectos tafonómicos y sus implicancias en la subsistencia humana
}

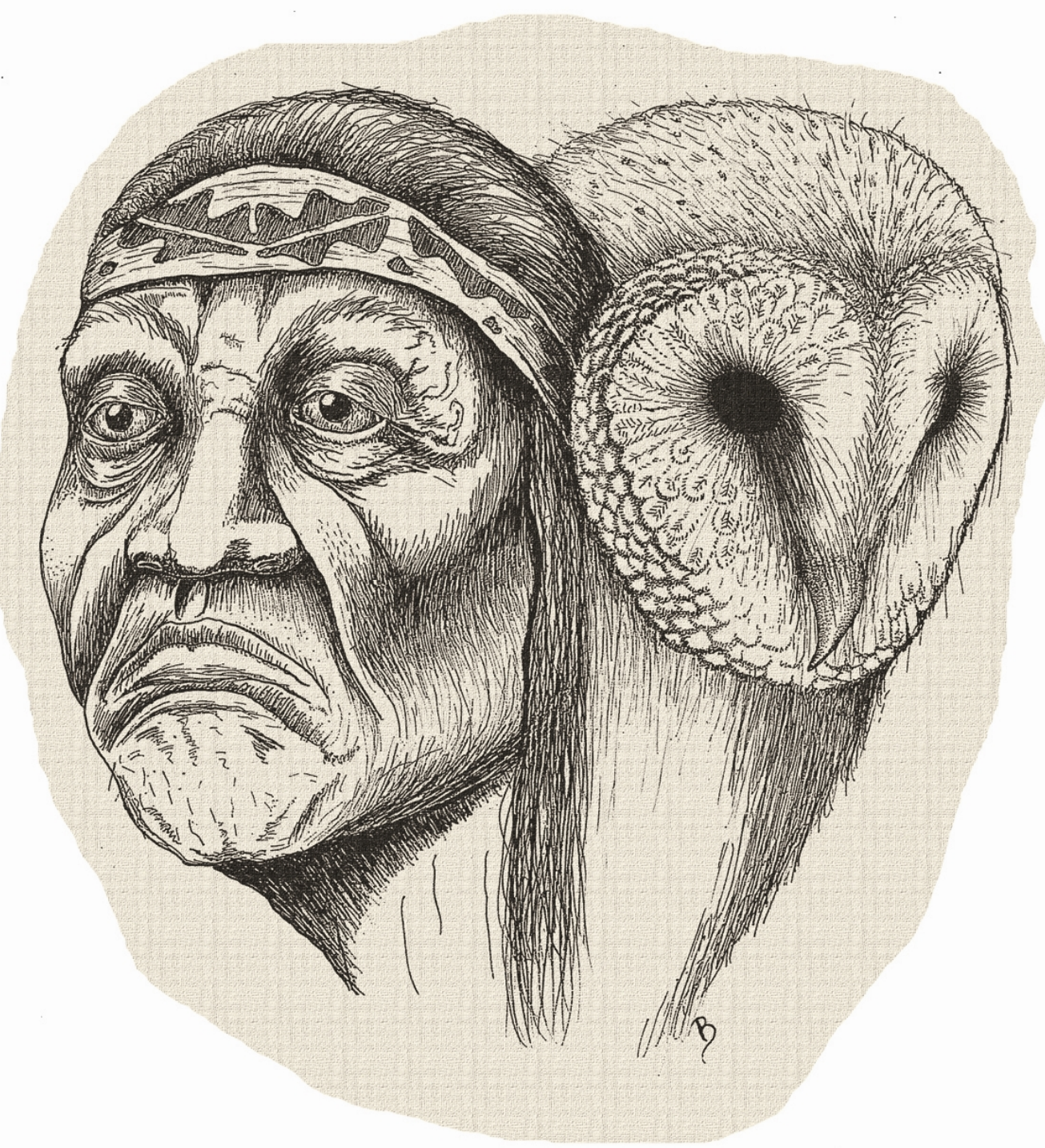

Tesis Doctoral

Presentada por: Fernando Julián Fernández

Director: Dr. Luciano José María De Santis

Codirector: Dr. Gustavo Adolfo Neme

Facultad de Ciencias Naturales y Museo, Universidad Nacional de La Plata 
Fernández, Fernando Julián

Microvertebrados del Holoceno de sitios arqueológicos en el sur de Mendoza

(República Argentina): aspectos tafonómicos y sus implicancias en la subsistencia humana. - 1a ed. - La Plata : Universidad Nacional de La Plata, 2012.

E-Book.

ISBN 978-950-34-0925-1

1. Zooarqueología. I. Título CDD 930.1

Fecha de catalogación: 16/11/2012 



\section{DEDICATORIA Y AGRADECIMIENTOS}

En principio deseo expresar mi más profundo agradecimiento a mis directores Luciano

De Santis y Gustavo Neme, quienes además de no escatimar sus conocimientos y colaboración cuando fue requerida, nunca dudaron en mi trabajo y capacidad, la cual me dio la confianza necesaria para emprender y finalizar esta investigación. Ambos directores actuaron de manera complementaria. Por un lado, Luciano De Santis me introdujo en el inagotable universo de la biología, despertando en mí una pasión por esta disciplina, la cual me llevó a comprender numerosos aspectos de los microvertebrados. Por otro lado, Gustavo Neme tanto en tareas de campo como de gabinete, me enseño a enmarcar los estudios de estos animales en una problemática de corte arqueológico. Con ambos mantuve profundas discusiones que apuntalaron cada una de las etapas de este trabajo. Sin dudas, mi conformación como zooarqueólogo se la debo a ellos.

Al técnico del laboratorio Germán Moreira, por ser un colaborador activo en varios viajes de campaña, por brindarme bibliografía, muestras comparativas y principalmente por numerosas discusiones taxonómicas y tafonómicas que hemos tenido durante las primeras etapas de este trabajo.

Otros compañeros de laboratorio que indudablemente colaboraron en diferentes maneras fueron Fernando Ballejo, Joaquín Carrera y Cesar García-Esponda. El primero de ellos, fue el mentor de varias de las figuras que ilustran este trabajo -incluso la obra de arte que retrata la portada de la tesis- preparó materiales y compartió numerosas fuentes bibliográficas. Los otros dos, me asistieron en muchas oportunidades con temas vinculados a estudios sobre ecología trófica de aves rapaces, análisis estadístico, anatomía y aportaron con bibliografía general. Asimismo, no puedo dejar de mencionar a los demás compañeros del laboratorio de Anatomía Comparada, Luis del Papa, Fabricio Idoeta y Damian Miguelisi, con quienes compartí todo este tiempo de la mejor manera posible, mateando, mirando materiales, debatiendo e intercambiando numerosa información e ideas.

Otro pilar en el cual se sostiene este trabajo son el grupo de profesionales que integran el Laboratorio del Departamento de Arqueología del Museo de Historia Natural de San Rafael, donde siempre he sido muy bien recibido. En este sentido, debo expresar que 
todas las muestras de microvertebrados tanto arqueológicas como actuales que dieron lugar a esta investigación, provienen de campañas organizadas por este laboratorio. Entre ellos Gustavo Neme, Adolfo Gil, Miguel Giardina, Clara Otaola y Adrew Ugan, fueron compañeros de campaña, de tareas de laboratorio y partícipes de discusiones sobre numerosas interpretaciones de los sitios arqueológicos. Asimismo, Mercedes Corbat, Nuria Sugrañes, Alejandra Guerci, Carina Llano, Diego Andreoni y Fernando Franchetti han acompañado en tareas de campo y han sido sujetos a varias consultas. Además, no puedo dejar de destacar a Clara Otaola quien colaboró en la corrección del abstract, con el análisis de isótopos estables y principalmente en el flujo constante de retroalimentación positiva mientras se realizaban nuestras tesis doctorales, la cual en cierta oportunidad nominé "el buen intercambio".

La consulta a numerosos profesionales de distintas orientaciones llevaron a mejorar notablemente la calidad de este trabajo. Ulyses Pardinas quien no vaciló en aportar su amplio conocimiento en temas vinculados a la biología de los roedores sigmodontinos e interpretaciones paleoambientales, cuando fue requerido (muchas veces por cierto). En la misma sintonía no puedo dejar de mencionar a Pablo Teta, un referente en los vastos temas que gobiernan el conocimiento de los micromamíferos. Claudia Montalvo y Adrián Quintana colaboraron con sus lecturas críticas en numerosas oportunidades, especialmente en aquellos temas relacionados a la tafonomía, donde claramente tienen un merecido reconocimiento de la comunidad científica. Andrew Ugan, ha sido el artífice del proyecto de investigación relacionado a los estudios de isótopos estables en muestras faunísticas y florísticas del sur de Mendoza, aportando su conocimiento y numerosos datos sobre algunas especies de roedores que fueron parte integrante de este trabajo. Ramiro Barberena y Matías Medina también me han contribuido con discusiones e intercambios de ideas.

Clelia Mosto me cedió sin compromiso una de las muestras de egagrópilas actuales (Volcán Malacara) para su estudio

Mis profesores de los cursos de postgrado y pasantías, Andrew Ugan, Diane GiffordGonzáles, Gustavo Neme, Adolfo Gil, Jorge Williams, Arturo Kerth, Elizabeth Rovere y Luis Marone, con sus miradas, ideas y conocimientos contribuyeron con mi formación profesional a lo largo de esta tesis. 
Mis compañeros de la cátedra de Zooarqueología de la Facultad de Ciencias Naturales y Museo, Luciano De Santis, Laura Miotti, Eduardo Tonni, Luis del Papa, Fabricio Idoeta, Fernando Ballejo, Mariano Santini, Luciano Prates, Andrés Izeta, Damián Miguelisi, Laura Marchioni y Lucas Richi han sido de gran ayuda en el continuo intercambio de ideas y abordajes propios de esta disciplina.

Los jurados, Ulyses Pardiñas, Víctor Durán y Eduardo Tonni, realizaron valiosas observaciones que ayudaron aclarar algunos pasajes de la tesis.

En el contexto de la vida cotidiana, mis padres jugaron un rol preponderante, sobre todo apoyando mi formación de grado y colaborando económicamente hasta que obtuve la beca doctoral del CONICET. También a ellos, a mis hermanos, tíos, primos y amigos les debo momentos de bienestar y recreación, los cuales fueron muy importantes para mantener las energías intactas para la constante tarea de investigar. Especialmente a Verónica Mautone, quien ha sabido comprender la falta de tiempo en virtud de este camino recorrido y me ha apoyado en cada etapa de la tesis. Asimismo, debo destacar que mi hermano Aníbal colaboró con la preparación de numerosas fotografías y figuras que ilustran este trabajo y mi otro hermano Daniel, me prestó su cámara fotográfica en un sinfín de oportunidades.

Esta tesis se ha desarrollado gracias al apoyo de CONICET, organismo que me otorgó las Becas Internas Doctoral Tipo 1 y Tipo 2. Por otra parte, la mayoría de la instrumentación necesaria para la realización de esta investigación fueron obtenidos a través de varios proyectos de investigación (CONICET, UNLP y Fundación Antorchas) dirigidos por mis directores.

Para finalizar, no debo dejar de reconocer que este trabajo difícilmente hubiese tenido lugar sin la colaboración de las personas e instituciones mencionadas. A todos ellos mi enorme agradecimiento y reconocimiento. 



\section{ÍNDICE}

DEDICATORIA Y AGRADECIMIENTOS ............................................................................................

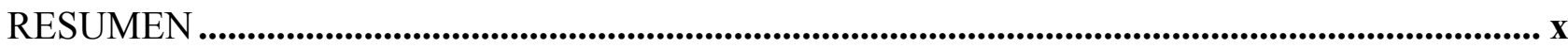

ABSTRACT

Capítulo 1: INTRODUCCIÓN..

xiv

1.1. Antecedentes y fundamentos de la investigación ..............................................................

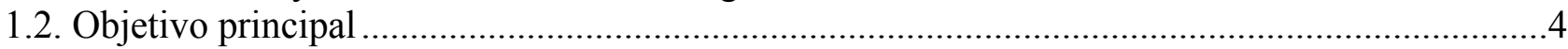

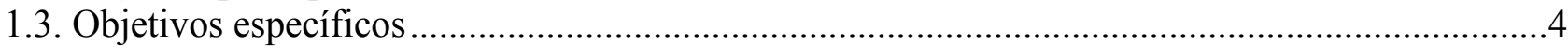

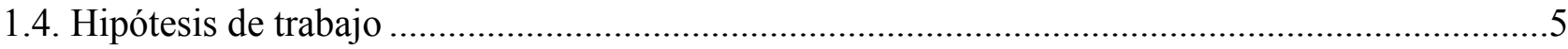

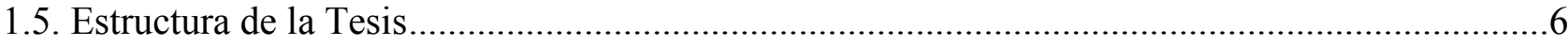

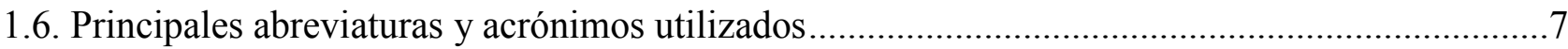

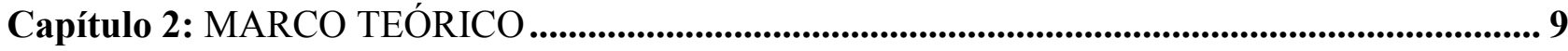

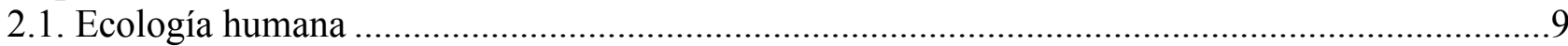

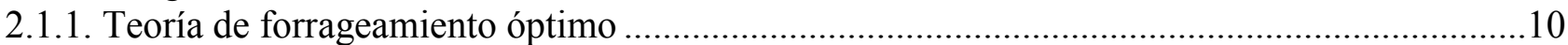

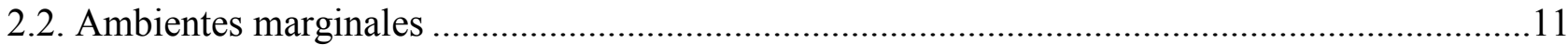

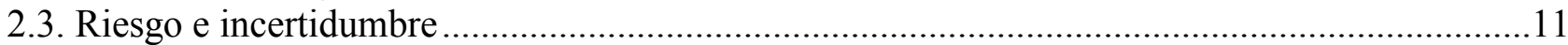

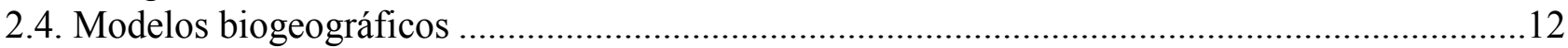

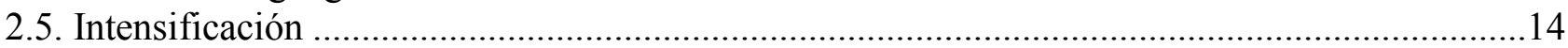

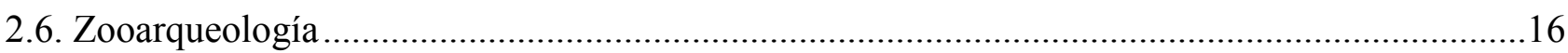

2.6.1. Consideraciones generales sobre tafonomía de microvertebrados ........................................18

Capítulo 3: ÁREA DE ESTUDIO. El ambiente en el sur de Mendoza ............................................ 21

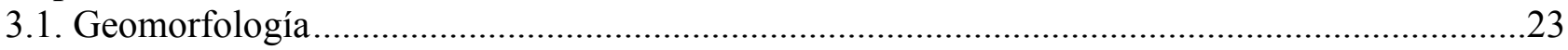

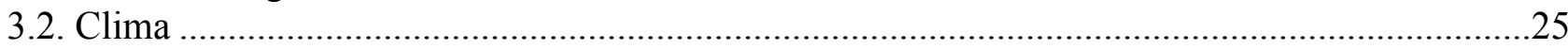

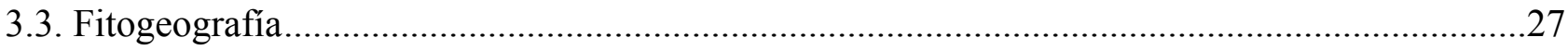

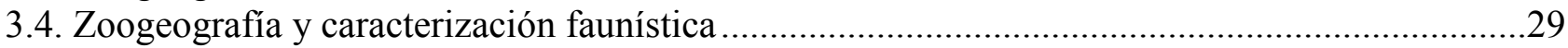

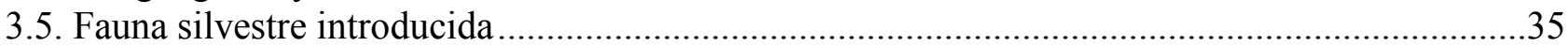

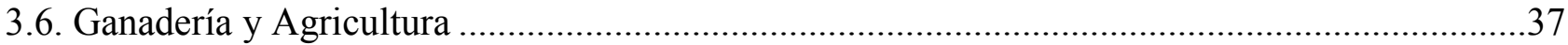

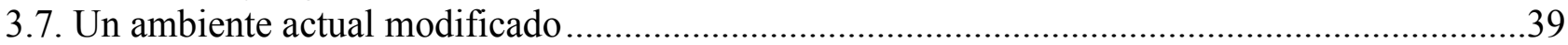

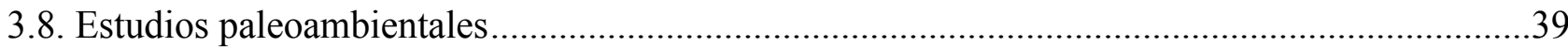

Capítulo 4: MATERIALES Y MÉTODOS ........................................................................................49

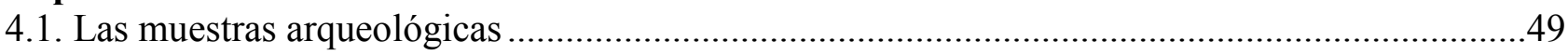

4.2. Las muestras actuales: egagrópilas y disgregados de aves rapaces ......................................51

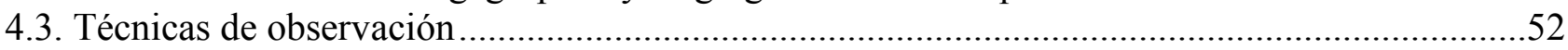

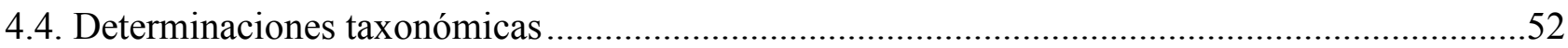

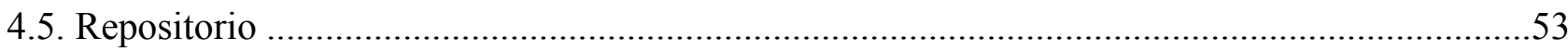

4.6. Metodología para el estudio tafonómico de micromamíferos …..............................................53

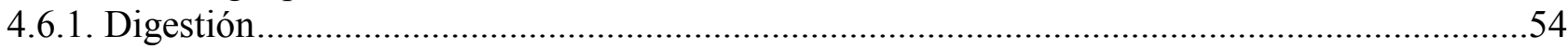

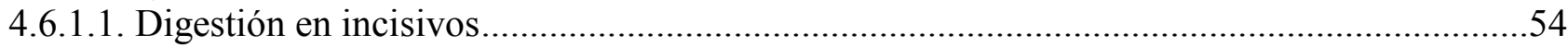

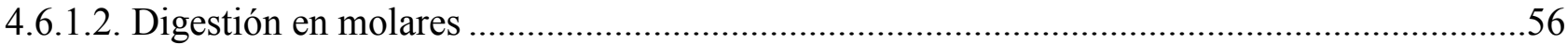

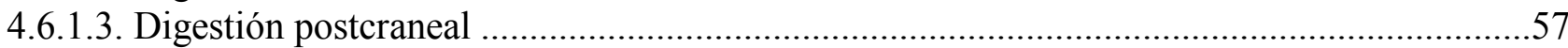

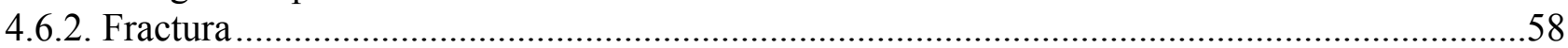

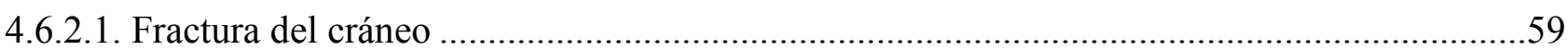

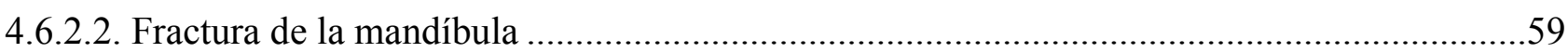

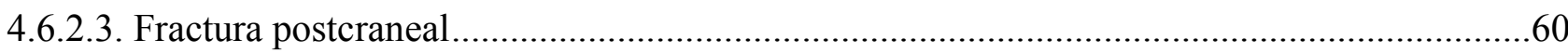

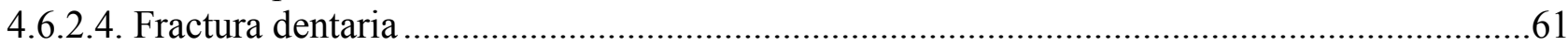

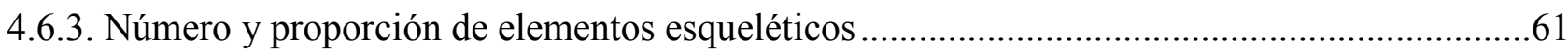

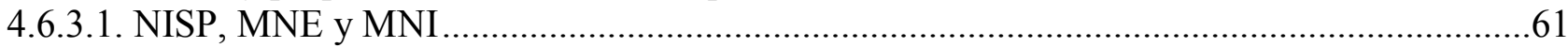




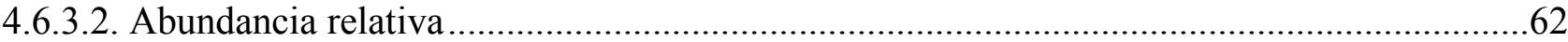

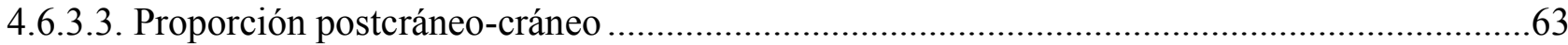

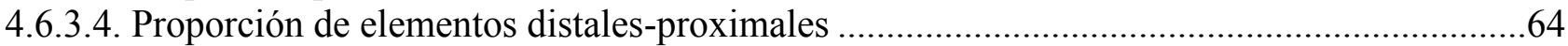

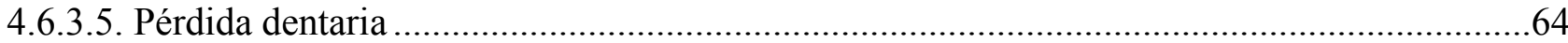

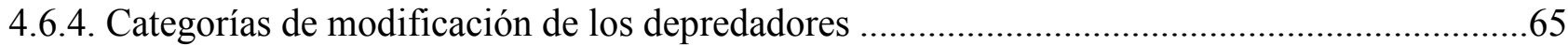

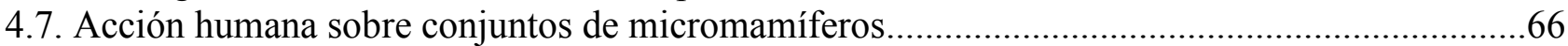

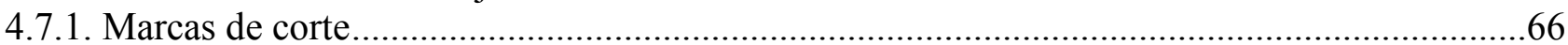

4.7.2. Corrosión digestiva, partes esqueletales y patrones de fractura ..........................................66

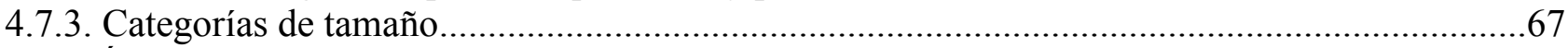

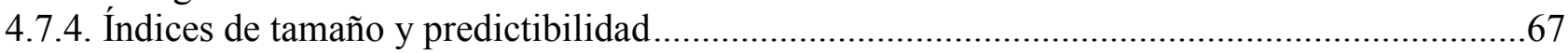

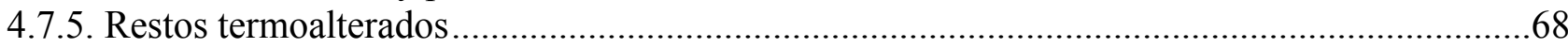

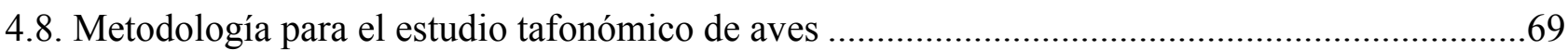

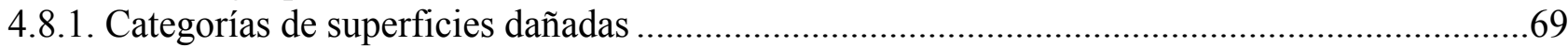

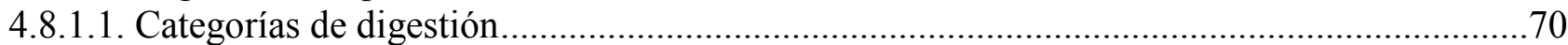

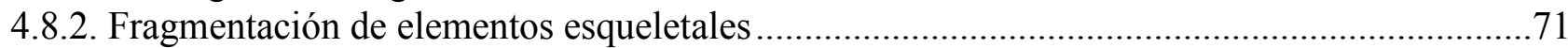

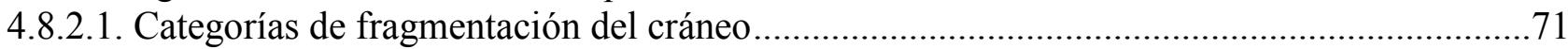

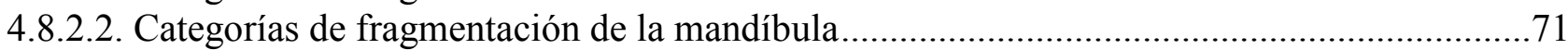

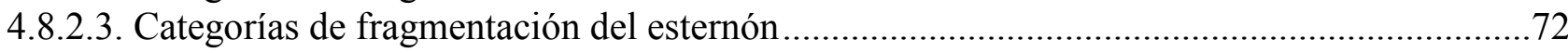

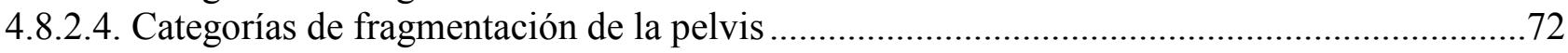

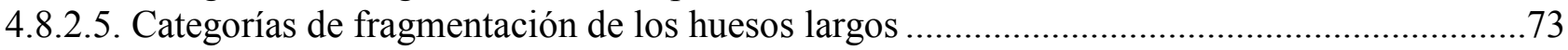

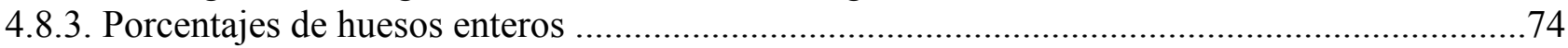

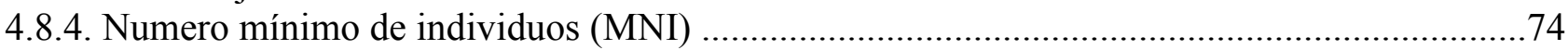

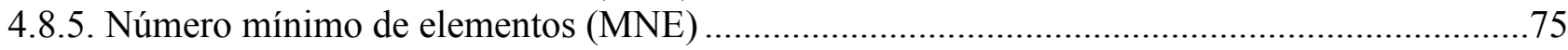

4.8.6. Relación entre elementos del miembro anterior y miembro posterior ...................................75

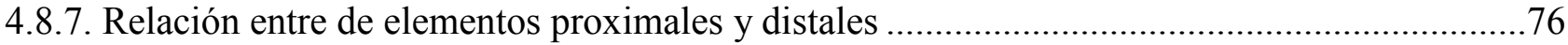

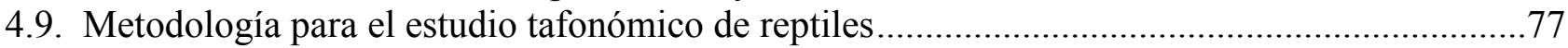

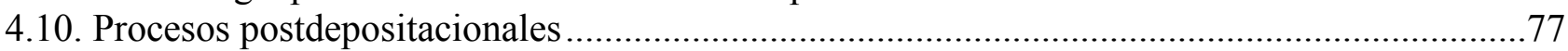

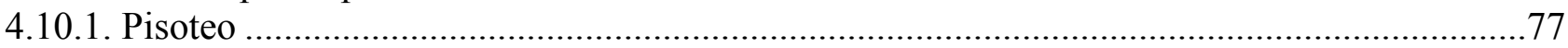

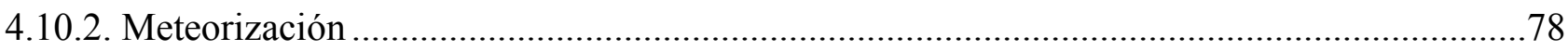

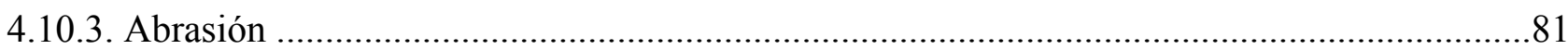

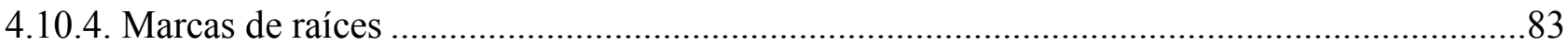

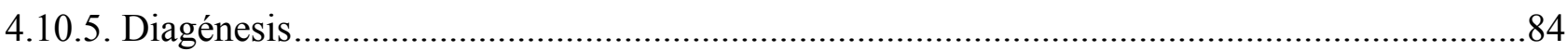

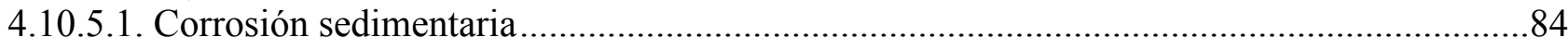

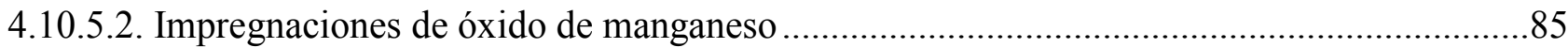

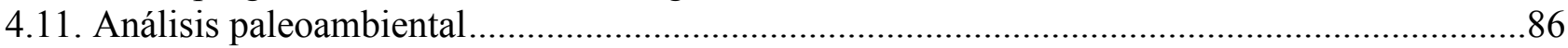

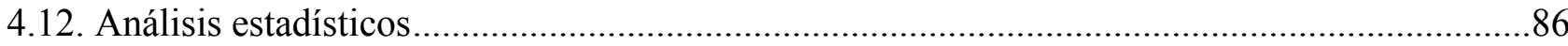

Capítulo 5: ESTADO ACTUAL DEL CONOCIMIENTO DE LOS MICROVERTEBRADOS QUE HABITAN EL SUR DE MENDOZA ..............................................................................88

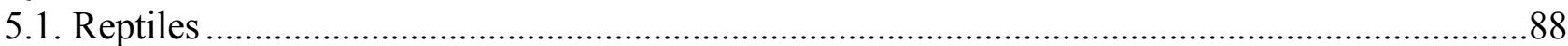

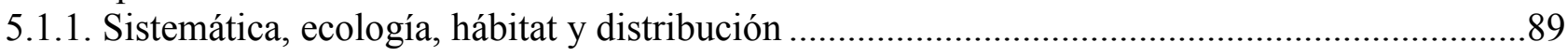

5.1.2. Características generales de la morfología cráneo-dentaria ...............................................96

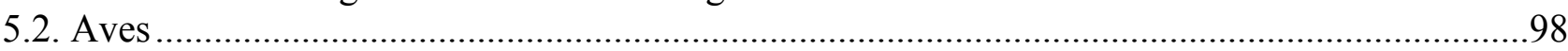

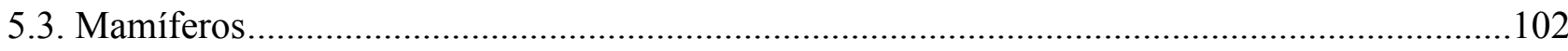

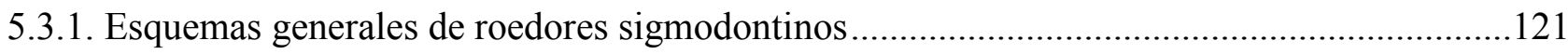

5.3.2. Patrones de distribución geográfica de los micromamíferos ...............................................188 
Capítulo 6: PRINCIPALES DEPREDADORES DE MICROVERTEBRADOS DEL SUR DE MENDOZA .197

Capítulo 7: LOS SITIOS ARQUEOLÓGICOS ............................................................................ 209

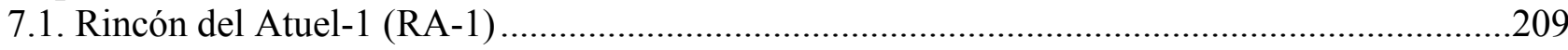

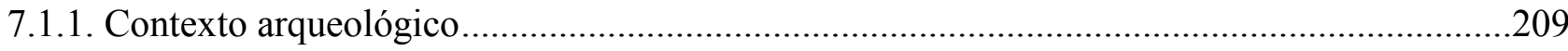

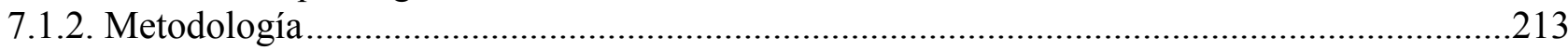

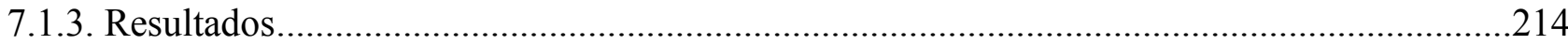

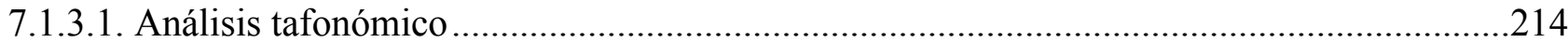

7.1.3.2. Asociación de microvertebrados de las muestras actuales ...........................................221

7.1.3.3. Asociación de microvertebrados de las muestras arqueofaunísticas .................................223

7.1.3.3.1. Cuadrículas A-1 y A-2 (Conjunto superior) .................................................................224

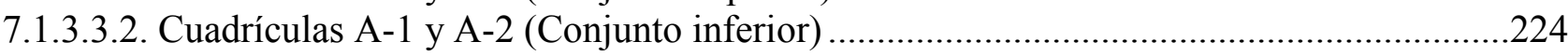

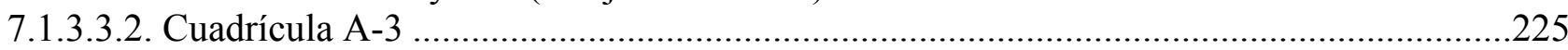

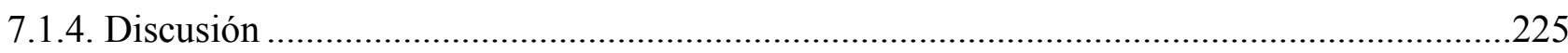

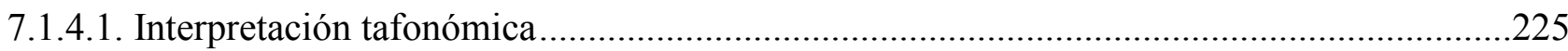

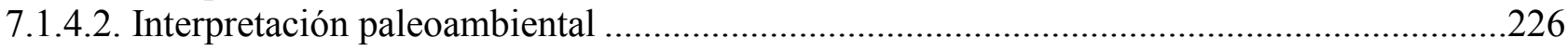

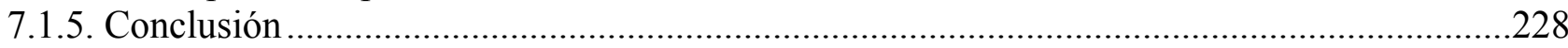

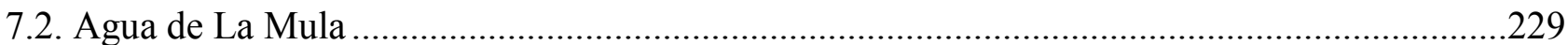

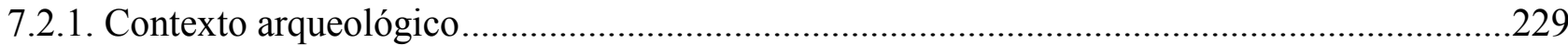

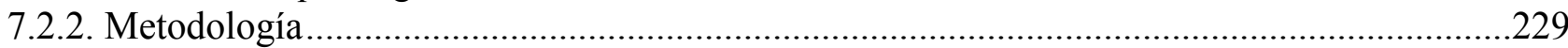

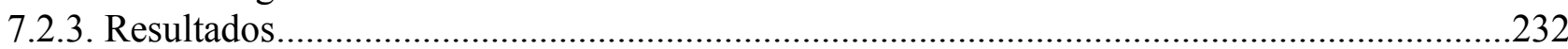

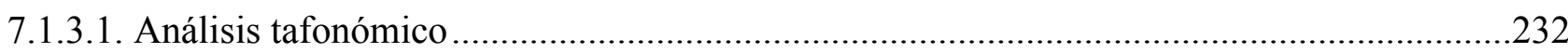

7.2.3.2. Asociación de microvertebrados de la muestra actual....................................................23

7.2.3.2.1. Egagrópilas de Geranoaetus melanoleucus .............................................................238

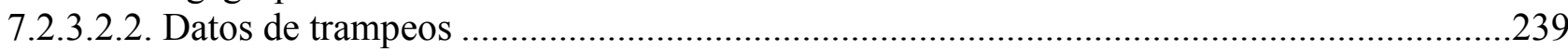

7.2.3.2.3. Síntesis de la comunidad actual de microvertebrados ..................................................240

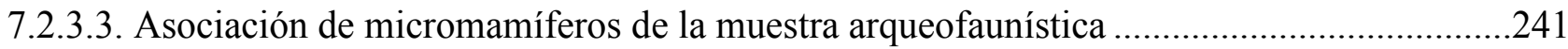

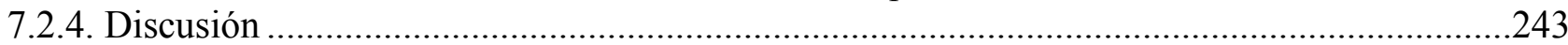

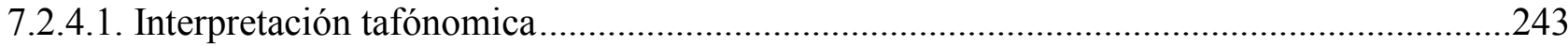

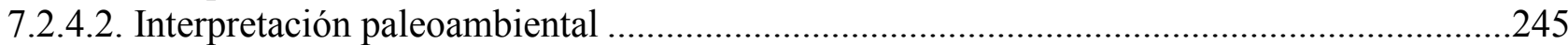

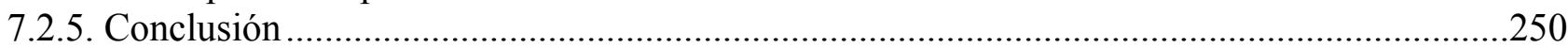

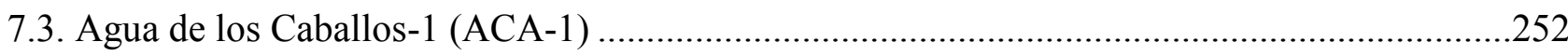

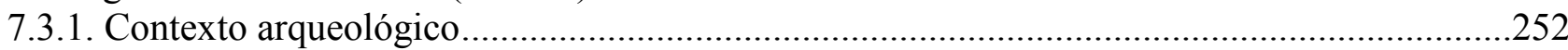

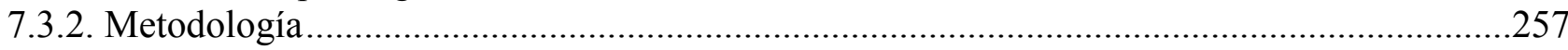

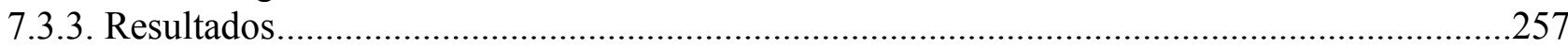

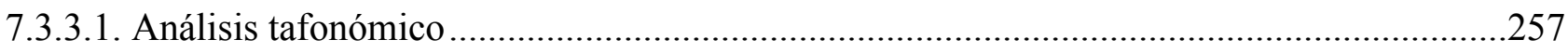

7.3.3.2. Asociación de microvertebrados de las muestras actuales ..............................................265

7.3.3.3. Asociación de los microvertebrados de las muestras arqueofaunísticas .............................265

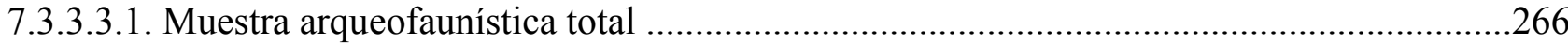

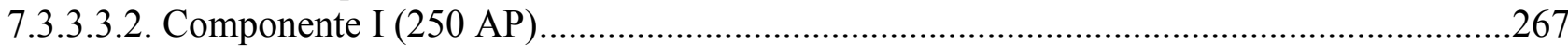

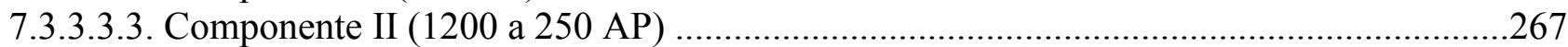

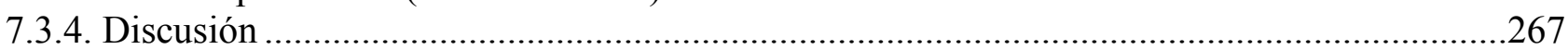

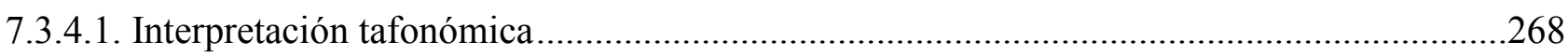

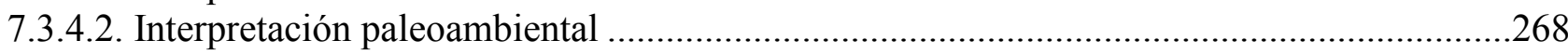

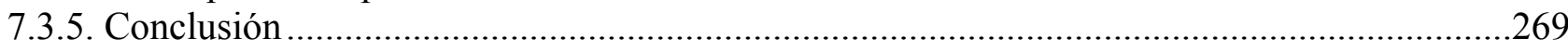

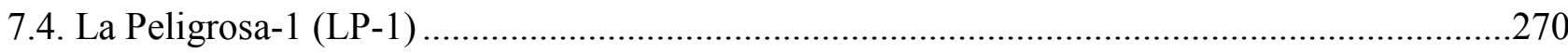




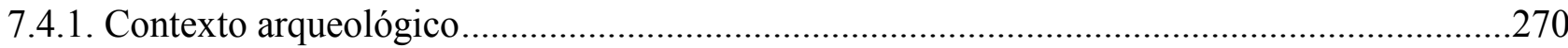

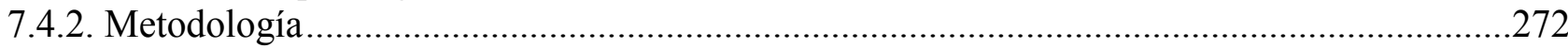

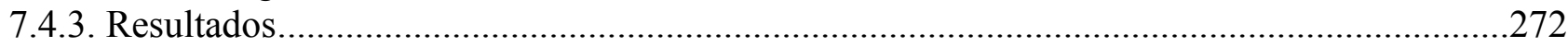

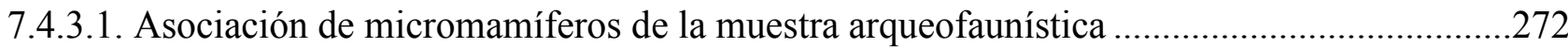

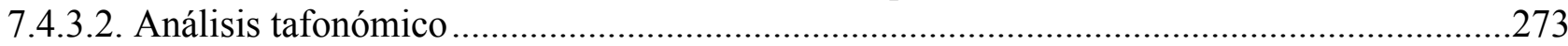

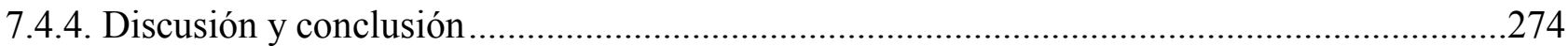

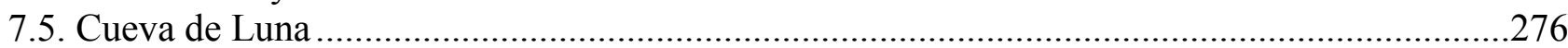

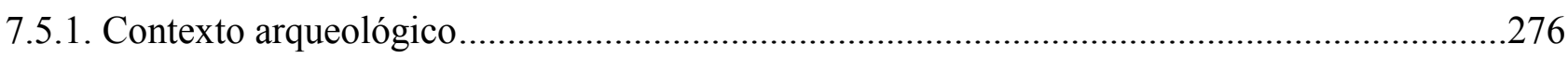

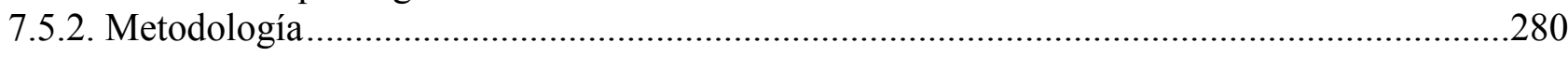

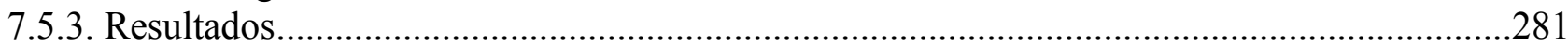

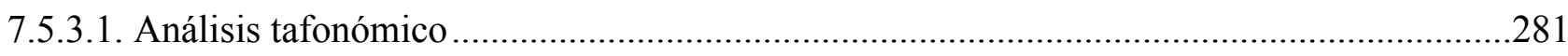

7.5.3.2. Asociación de micromamíferos de las muestras actuales...............................................285

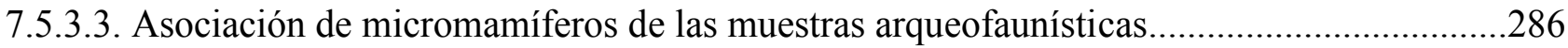

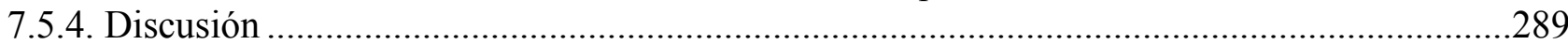

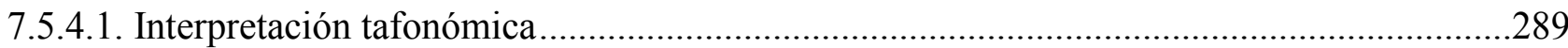

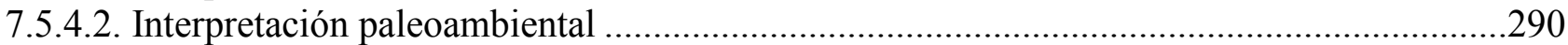

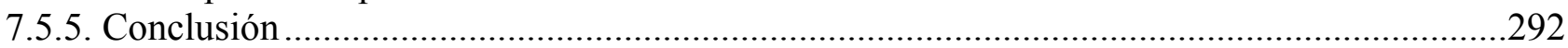

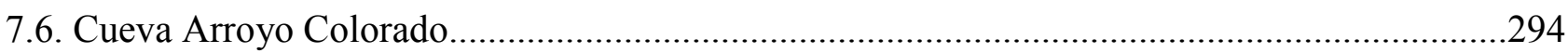

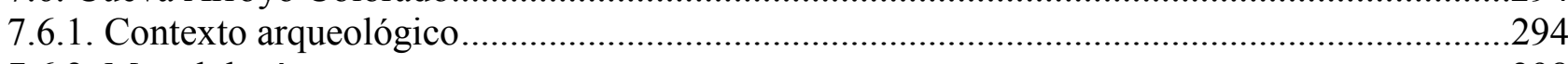

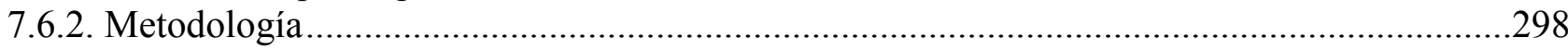

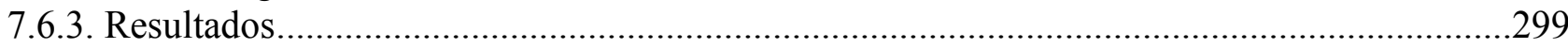

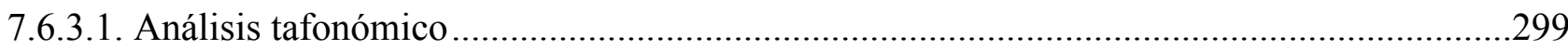

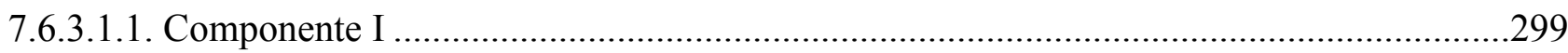

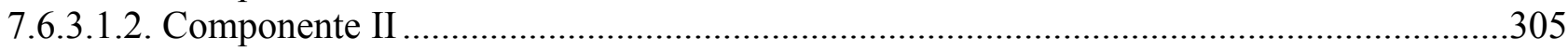

7.6.3.2. Asociación de microvertebrados de las muestras actuales ................................................307

7.6.3.3. Asociación de microvertebrados de las muestras arqueofaunísticas ..................................308

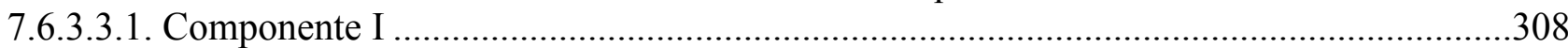

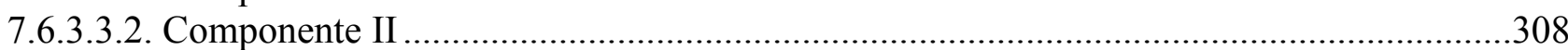

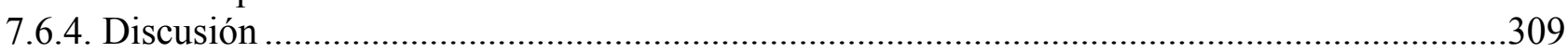

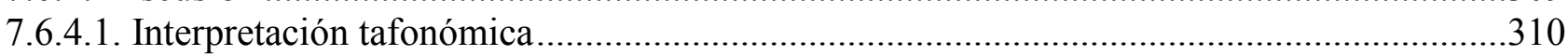

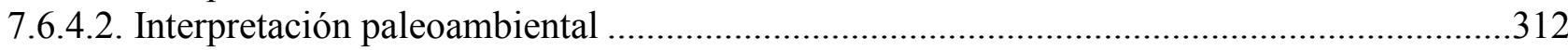

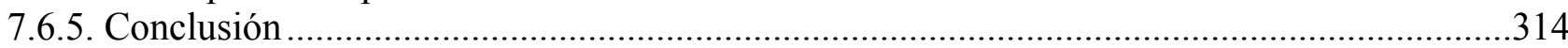

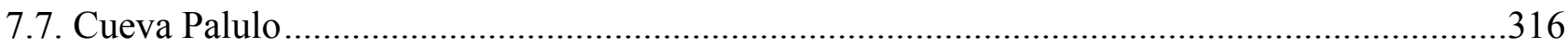

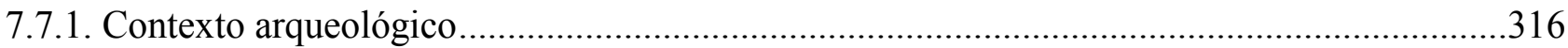

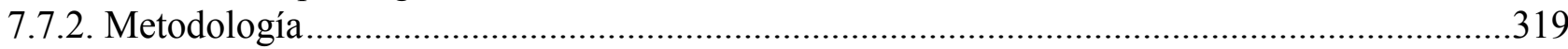

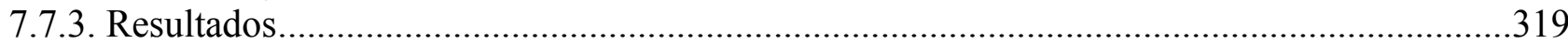

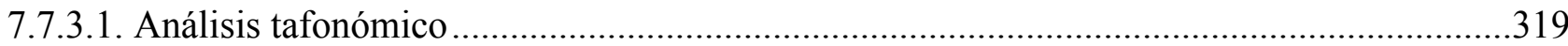

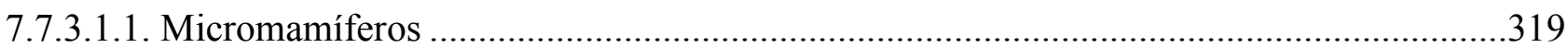

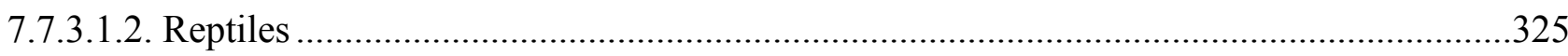

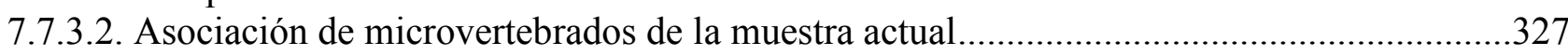

7.7.3.3. Asociación de microvertebrados de la muestra arqueofaunística.....................................328

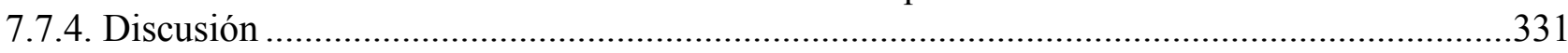

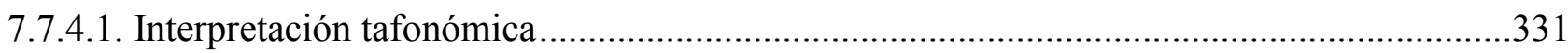

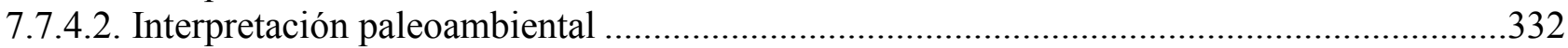

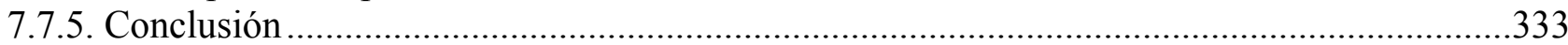

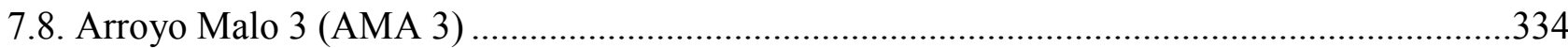

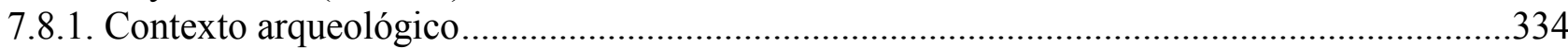




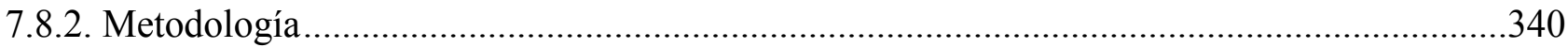

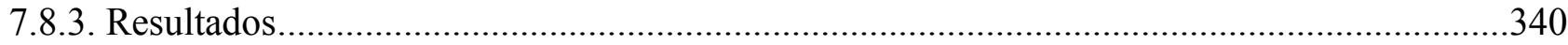

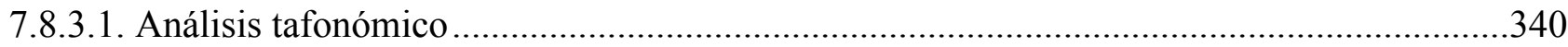

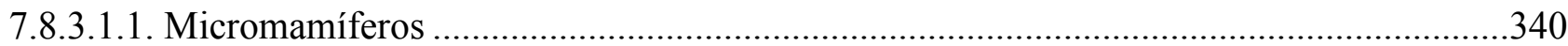

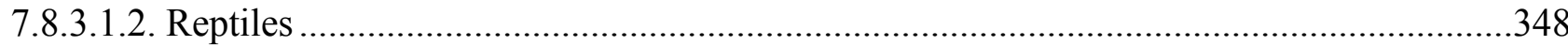

7.8.3.2. Asociación de microvertebrados de las muestras actuales ................................................351

7.8.3.3. Asociación de microvertebrados de las muestras arqueofaunísticas ...................................352

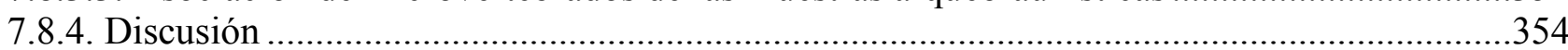

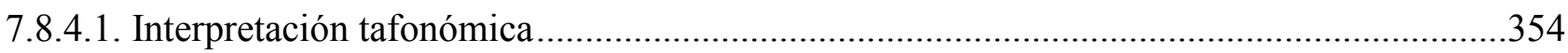

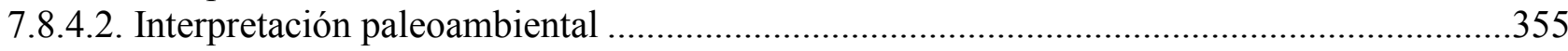

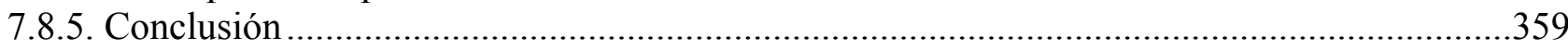

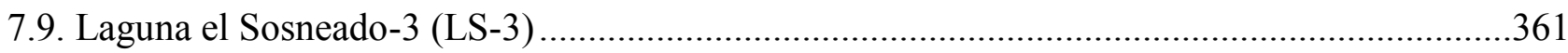

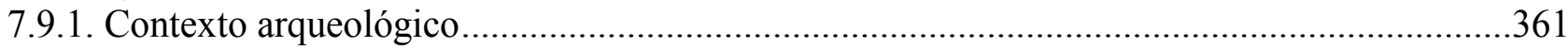

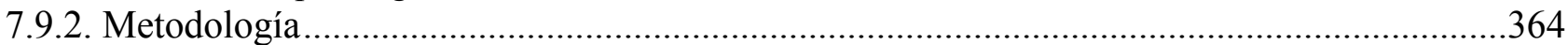

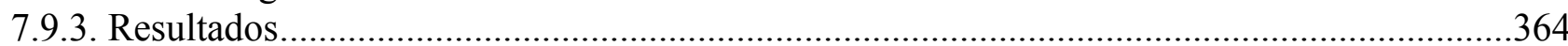

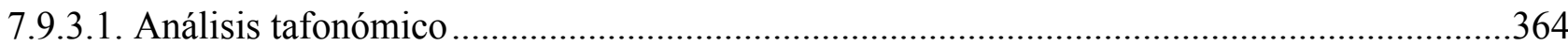

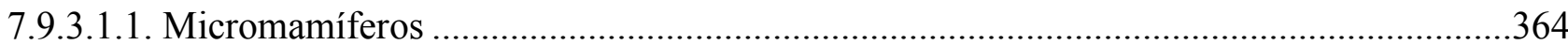

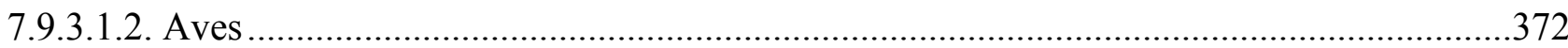

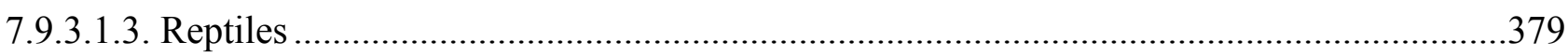

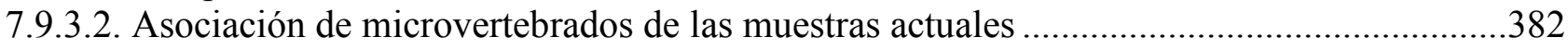

7.9.3.3. Asociación de microvertebrados de las muestras arqueofaunísticas ..................................383

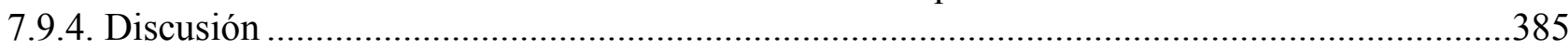

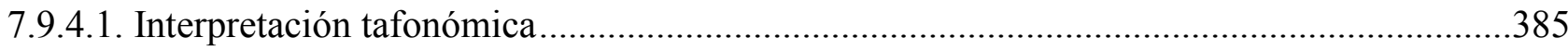

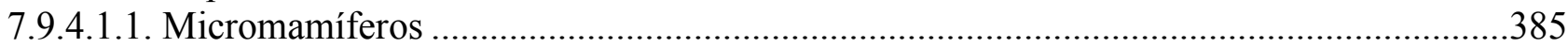

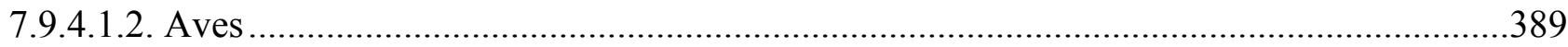

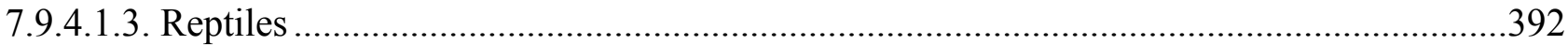

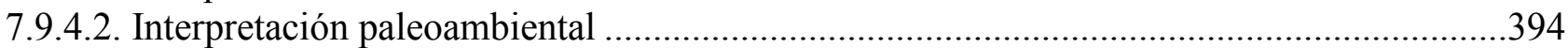

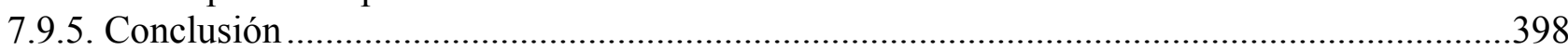

Capítulo 8: DISCUSIÓN GENERAL ............................................................................................400

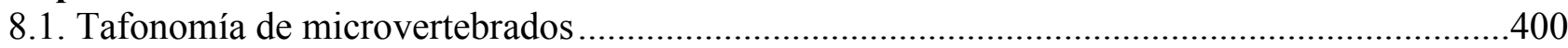

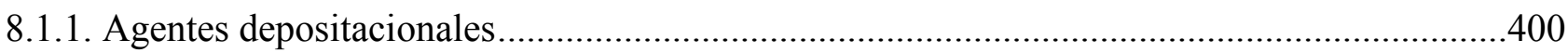

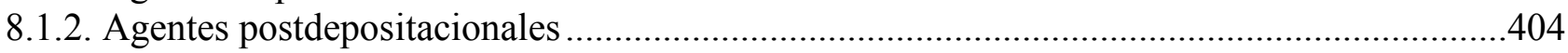

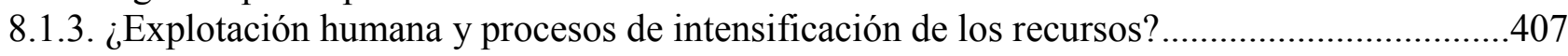

8.2. Paleoambientes en el sur de Mendoza .................................................................................414

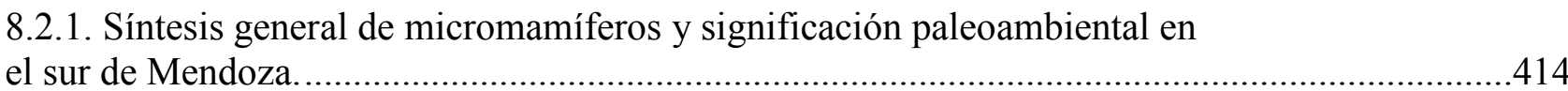

8.2.2. Micromamíferos como indicadores de deterioro Antropico...............................................428

8.2.3. Integrando información de diferentes proxies paleoambientales

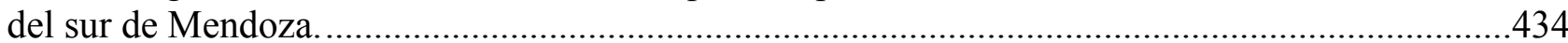

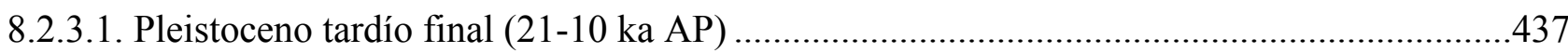

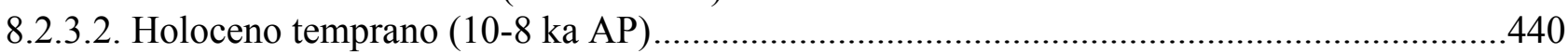

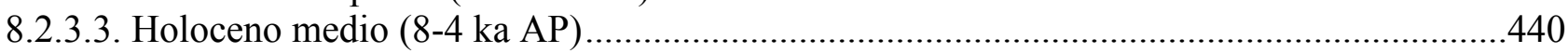

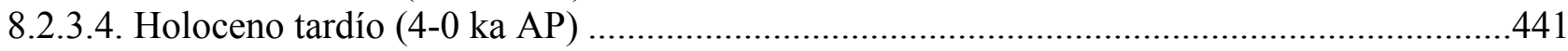

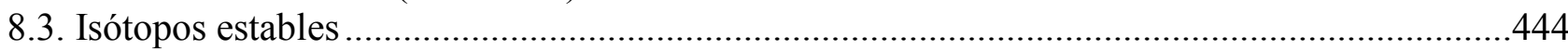

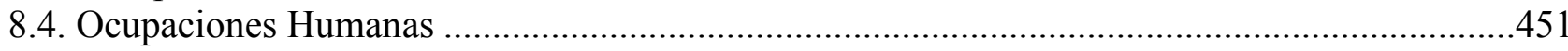


Capítulo 9: CONCLUSIONES 458 BIBLIOGRAFÍA CITADA

APÉNDICE 


\section{RESUMEN}

El principal objetivo de este trabajo de tesis doctoral es estudiar la tafonomía y significación paleoecológica de los depósitos de microvertebrados procedentes de contextos arqueológicos del sur de Mendoza y discutir el rol que cumplieron en la subsistencia humana prehispánica. En este sentido, se estudiaron nueve sitios arqueológicos. Cuatro ubicados fitogegráficamente en el desierto del Monte [Rincón del Atuel-1 (sitio a cielo abierto, 3445'31" S y 68²2'14" O, 747 m.s.n.m.); Agua de La

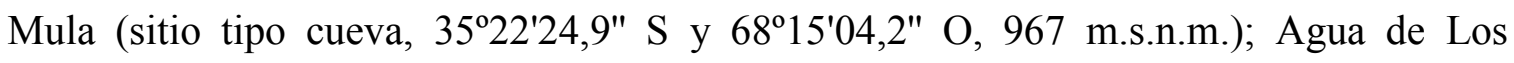
Caballos-1 (sitio tipo cueva, 3522'03" S y 68 18'07" O, 1.025 m.s.n.m.); La Peligrosa-1 (sitio a cielo abierto, 36²31'00" S y 68²31'50" O, 1.160 m.n.s.m.)]. Uno localizado en el valle medio del Río Grande y fitogeográficamente en la estepa Patagónica [Cueva de Luna (sitio tipo cueva, 3604'33,7" S y 69²3'22,9" O, 1.300 m.s.n.m.)]. Cuatro ubicados en la cuenca superior del Río Atuel y fitogeográficamente en la estepa Patagónica [Cueva Arroyo Colorado (sitio tipo cueva, 3512'10.65" S y 7004'38.91" O, 2.200 m.s.n.m.); Cueva Palulo (sitio tipo cueva, 3456'40,40" S y 6950'39,54" O, 2.304 m.s.n.m.); Arroyo Malo-3 (sitio tipo cueva, 3451'18" S y 6953'00" O, 2.160 m.s.n.m.); Laguna el Sosneado-3 (sitio tipo cueva, 34ㅇ 51' S y 69 53' O, 2.100 m.s.n.m.)].

Por otra parte, se analizaron muestras de egagrópilas de aves rapaces [principalmente de Tyto alba (lechuza de campanario) y en menor medida de Bubo magellanicus (tucúrere), Geranoaetus melanoleucus (águila mora) y Buteo polyosoma (aguilucho común)], recolectadas en las cercanías de los sitios arqueológicos. Asimismo, la información emanada de estas muestras en conjunto con datos provenientes de registros previos de los micromamíferos de la provincia de Mendoza, fueron la base para la construcción de un marco actual del conocimiento y patrones de distribución de este grupo de mamíferos en la provincia. En tal sentido, el sur de Mendoza presentó todos los taxones de micromamíferos que habitan en la provincia a excepción de una especie Puneña (Abrothrix andinus). Por otro lado, el norte de la provincia, a excepción de Euneomys chinchilloides, exhibió la ausencia de especies Patagónicas tales como Euneomys mordax, Chelemys macronyx, Loxodontomys micropus, Abrothrix longipilis, Abrothrix olivaceus y Reithrodon auritus, lo que sugiere que el centro de Mendoza podría ser el deslinde entre los elementos Puneños y Patagónicos. No obstante, la faja este de la provincia, fitogeográficamente incluida en el Monte, se mantiene sin mayores cambios en cuanto a su estructura taxonómica (e.g., Galea leucoblephara, Akodon molinae, Graomys 
griseoflavus, Calomys musculinus, Oligoryzomys flavescens). Asimismo, en el sur de Mendoza se encontraron taxones asociados a la estepa Patagónica (Lestodelphys halli, $R$. auritus, A. longipilis), tanto a la estepa Patagónica como al desierto del Monte (Thylamys pallidior, Eligmodontia spp.), a estepas Altoandinas (C. macronyx y E. mordax), tanto a estepas Patagónicas como Altoandinas (E. chinchilloides, L. micropus y Abrothrix olivaceus) y a todas las unidades fitogeográficas (Phyllotis xanthopygus y Ctenomys spp.). Finalmente, entre los hallazgos importantes, se documentó los primeros registros de Holochilus en la provincia de Mendoza (localidades Nihuil y Gruta del Indio), extendiendo su geonemia $480 \mathrm{~km}$ hacia el oeste. Un estudio taxonómico reciente de los ejemplares, indicó que corresponden a una nueva entidad específica, la cual fue nominada Holochilus lagigliai (Pardiñas, Teta, Voglino y Fernández, en prensa).

En este trabajo de tesis doctoral se analizaron tafonómicamente, se determinaron taxonómicamente y cuantificaron un número de especimenes identificados por taxón (NISP) de 16.021, un número mínimo de elementos (MNE) de 15.847 y un número mínimo de individuos (MNI) de 2.360 en las muestras arqueofaunísticas y un MNI de 1.089 en muestras actuales.

Desde un punto de vista tafonómico, el registro de marcas de corrosión digestiva ligera a moderada y los bajos niveles de pérdida de elementos (sensu Andrews, 1990), indicaron una marcada actividad de aves Strigiformes en la génesis de los ensambles de microvertebrados de numerosos sitios arqueológicos cordilleranos y de la planicie oriental (i.e, Cueva Arroyo Colorado, Laguna El Sosneado-3, Caverna de Las Brujas, Cueva de Luna, Agua de La Mula, Agua de los Caballos, Rincón del Atuel-I y La Peligrosa-I). La observación de marcas de corrosión digestiva moderada a fuerte, y la elevada pérdida de elementos y la fragmentación, sugirieron actividad de aves Falconiformes en los ensambles de los sitios cordilleranos Arroyo Malo-3 y Cueva Palulo. Por otra parte, se hallaron evidencias de actividad de mamíferos carnívoros (e.g., corrosión digestiva fuerte a extrema y alta pérdida de elementos y fragmentación) en Cueva Arroyo Colorado. En este sitio, también se encontraron marcas de corte en una tibia de Caviidae en un lapso de la secuencia $\left(1380-770{ }^{14} \mathrm{C}\right.$ años $\left.\mathrm{AP}\right)$. Esta es la única evidencia arqueológica clara de explotación de micromamíferos por parte de las poblaciones humanas. Sin embargo, la moderada frecuencia de huesos quemados, así como la abundancia de roedores del grupo de tamaño grande, plantea la posibilidad que esto pudo ocurrir en sitios como La Peligrosa-1 y Rincón del Atuel-1. 
Un proceso de intensificación de los recursos tuvo lugar en el sur de Mendoza desde el 2.000 AP. Este proceso ha sido interpretado como la consecuencia de un desbalance entre la capacidad del ambiente y el aumento demográfico de las poblaciones humanas. La sobre explotación del ambiente habría disminuido la disponibilidad de los recursos de elevado ranking (e.g., Lama guanicoe, Rhea americana, Rhea pennata) y lo que habría llevado a incluir en la dieta recursos con menor retorno calórico y mayor costo de procesamiento tales como plantas y vertebrados de mediano tamaño. Sin embargo, este proceso pudo no haber sido tan marcado como para que los cazadores-recolectores tengan que explotar este tipo de recurso intensamente, como fuera sustentado en otras regiones de Argentina (e.g., Regiones de las Sierras Centrales, Patagonia, Pampeana).

Por otra parte, se documentaron algunos procesos postdepositacionales que pudieron modificar la estructura original de los ensambles. A excepción de la meteorización y las impregnaciones por óxido de manganeso, donde se observó mayor incidencia en sitios a cielo abierto y en cuevas, respectivamente, el resto de los procesos tales como corrosión sedimentaria, pisoteo, acción de raíces y de roedores, afectaron a los restos sin relación aparente entre los distintos tipos de sitios.

En este trabajo se registraron numerosos taxones que no habían sido documentados en contextos arqueológicos previos en la provincia de Mendoza: los reptiles Pristidactylus cf. P. scapulatus, Liolaemus sp. y Homonota cf. H. darwini; el quiróptero Tadarida brasiliensis; y los roedores sigmodontinos Akodon spegazzinii, A. molinae, A. olivaceus, A. longipilis, C. macronyx, L. micropus, G. griseoflavus y E. mordax.

En los sitios arqueológicos del área cordillerana de Laguna El Sosneado-3 (2100 ${ }^{14} \mathrm{C}$ años AP-Presente) y Arroyo Malo-3 (8900 ${ }^{14} \mathrm{C}$ años AP-Presente) se observó la dominancia de los roedores sigmodontinos E. chinchilloides, P. xanthopygus y Eligmodontia sp. a lo largo de ambas secuencias, señalando ambientes de estepas arbustivas abiertas Patagónicas, con alta proporción de suelo desnudo, pedregoso y abundante roca expuesta. Se han registrado especies asociadas a vegas cordilleranas desde el Holoceno temprano al Holoceno tardío en Arroyo Malo-3 (C. macronyx y A. longipilis). Asimismo, el hallazgo del marsupial L. halli hacia 2200 AP, sugiere condiciones más Patagónicas. En Laguna El Sosneado-3, el registro de C. macronyx y L. micropus en la secuencia, con excepción hacia $600{ }^{14} \mathrm{C}$ años $\mathrm{AP}$, indica un evento más árido para esa época. Por otra parte, en el sitio cordillerano Cueva Arroyo Colorado (3200-750 ${ }^{14} \mathrm{C}$ años AP) los ensambles mostraron cierta estabilidad y fueron taxonómicamente similares a los anteriores. 
En el valle medio del Río Grande, los conjuntos exhumados de la secuencia del sitio Cueva de Luna $\left(3800{ }^{14} \mathrm{C}\right.$ años AP-Presente) presentaron especies Patagónicas (L. halli, $R$. auritus y E. chinchilloides) y otras afines al desierto del Monte (T. pallidior, $M$. australis y C. musculinus), en contraste con las muestra actuales donde únicamente se encontraron taxones Patagónicos, señalando un ambiente más árido que el actual.

Las muestras actuales de la planicie oriental están dominadas por taxones asociados al desierto del Monte. Coincidentemente, los ensambles de los sitios La Peligrosa-1 ( $\sim 1500-$ $400{ }^{14} \mathrm{C}$ años AP), Rincón del Atuel $1\left(1500-350{ }^{14} \mathrm{C}\right.$ años AP) y Agua de los Caballos (1200-250 ${ }^{14} \mathrm{C}$ años $\left.\mathrm{AP}\right)$ presentaron especies que habitan principalmente en este ambiente (T. pallidior, G. leucoblephara, M. australis, G. griseoflavus). Sin embargo, en el sitio Agua de La Mula (1600-1000 ${ }^{14} \mathrm{C}$ años AP), además de registrarse taxones del Monte, se recuperaron algunas especies Patagónicas (L. halli y R. auritus), lo que sugiere condiciones ecotonales entre estos dos biomas.

En la actualidad los ensambles de micromamíferos presentan cambios en las estructuras taxonómicas, debido al deterioro ambiental posiblemente producido por la acción del ganado domestico (principalmente Capra hircus), afianzado en el sur de Mendoza desde el siglo XIX. Esta alteración antrópica pudo haber favorecido el incremento de especies oportunistas como C. musculinus en las llanuras y A. olivaceus en la cordillera. Sin embargo, esta restructuración de los ensambles no fue tan pronunciada como en otras regiones de Argentina (e.g., Patagonia, Pampa y Puna).

Un primer acercamiento desde los isótopos estables ha permitido discutir gran parte de las hipótesis propuestas desde una línea nueva de evidencia. En coincidencia con la información tafonómica obtenida, los datos analizados sugieren que el consumo humano de Ctenomys, Galea y Microcavia no habría sido muy importante. Por otro lado, la comparación de muestras arqueológicas vs actuales sugieren una estabilidad ambiental general, con el posible avance de elementos de la estepa Patagónica en algunos sectores del desierto del Monte.

Finalmente, las diferentes características tafonómicas y cambios paleoambientales observados mediante el registro de microvertebrados recuperados de numerosos sitios arqueológicos emplazados en distintos ambientes de sur de Mendoza, fueron un aporte para explicar los alcances del proceso de intensificación de los recursos y lo modelos de ocupación humana propuestos en investigaciones previas para esta región. 


\section{ABSTRACT}

The main objetive of this study is to present an analysis of the taphonomic and paleoenvironmental significance of the microvertebrate assemblages recovered in archaeological contexts from southern Mendoza Province, and to assess its rol in prehispanic human subsistence. In order to achieve these objectives, nine archaeological sites have been studied. Four are located in the Monte desert [Rincón del Atuel-1 (openair site, 3445'31" S, 68²2'14" W, 747 m.a.s.1.); Agua de La Mula (cave site, 35²2'24,9" S, 68 15'04,2" W, 967 m.a.s.1.); Agua de Los Caballos-1 (cave site, 35²2'03" S, 68 $18^{\prime} 07^{\prime \prime} \mathrm{W}, 1.025$ m.a.s.1.); La Peligrosa-1 (open-air site, 36³1'00" S, 68³1'50" W, 1,160 m.a.s.1.)]. One is located in the middle basin of Grande River, and in the Patagonian steppe [Cueva de Luna (cave site, 3604'33,7" S, 69²4'22,9" W, 1,300 m.a.s.l.)]. Four are located in the upper basin of Atuel River, and in the Patagonian steppe [Cueva Arroyo Colorado (cave site, 35²12'10.65" S, 7004'38.91" W, 2,200 m.a.s.1.); Cueva Palulo (cave site, 3456'40,40" S, 6950'39,54" W, 2.304 m.a.s.1.); Arroyo Malo-3 (cave site, 34051'18" S, 6953'00" W, 2,160 m.a.s.1.); Laguna el Sosneado3 (cave site, $34^{\circ} 51^{\prime} \mathrm{S}, 69^{\circ} 53^{\prime} \mathrm{W}, 2,100$ m.a.s.1.)].

Additionally, pellets of raptor birds were studied [mainly from Tyto alba (barn owl), and lesser extent from Bubo magellanicus (great horned owl), Geranoaetus melanoleucus (black-chested buzzard-eagle) and Buteo polyosoma (red-backed hawk)], collected near to the archaeological sites. Moreover, the information of these samples together with data-set from previous small mammal records of Mendoza Province, were the basis to develop a frame of reference and the distribution of this group of mammals in the province. In this sense, the southern Mendoza - with the eception of one Punean species (Abrothrix andinus)- shows all the taxa that inhabit in the province. Otherwise, the northern Mendoza -with an exception of Euneomys chinchilloides- shows the absence of Patagonian species such as Euneomys mordax, Chelemys macronyx, Loxodontomys micropus, Abrothrix longipilis, Abrothrix olivaceus, and Reithrodon auritus, suggesting that central Mendoza could be the transition between Patagonian and Punean elements. However, the east fringe of the province, including at Monte desert, keeps unchanged their taxonomic structure (e.g., Galea leucoblephara, Akodon molinae, Graomys griseoflavus, Calomys musculinus, Oligoryzomys flavescens). In addition, in southern Mendoza taxa associated with Patagonian steppe were found (Lestodelphys halli, $R$. auritus, A. longipilis), to Patagonian steppe and Monte (Thylamys pallidior, Eligmodontia 
spp.), to High Andean steppe (C. macronyx and E. mordax), to Patagonian and High Andean steppes (E. chinchilloides, L. micropus and Abrothrix olivaceus), and in all of phytogeography units (Phyllotis xanthopygus and Ctenomys spp.).

Finally, the first record of Holochilus in Mendoza Province (at Nihuil and Gruta del Indio localities) is documented, extending its geographyc distribution $480 \mathrm{~km}$ to the west. A recent taxonomic study of the specimens, indicated that correspond to a new species, which was nominated Holochilus lagigliai (Pardiñas, Teta, Voglino and Fernandez, in press).

In this study, 16,021 had been identified at some level, 15,847 of minimum number of elements (MNE), and 2,360 minimum number of individuals (MNI) were taphonomically and taxonomically quantified in archaeological samples. In addition, a MNI of 1,089 were identified in recent samples.

From a taphonomic point of view, the light and moderate digestive marks finded on teeth and postcranial bones, and the lower loss of elements (sensu Andrews, 1990), suggests that the main responsable agents in many cordilleran and lowland archaeological sites were strigiformns (i.e, Cueva Arroyo Colorado, Laguna El Sosneado-3, Caverna de Las Brujas, Cueva de Luna, Agua de La Mula, Agua de los Caballos, Rincón del Atuel-I, and La Peligrosa-I). The presence of moderate to extreme digestive marks and the high loss and fragmentation elements, indicates falconiform action in Arroyo Malo-3, and Cueva Palulo assamblages. Otherwise, evidence of carnivore mammals activity at Cueva Arroyo Colorado (e.g., high to extreme digestive corrosion and high loss and fragmentation elements) were found. In this site, it also had been found cut marks on a tibia of Caviidae. This is the only clear archaeological evidence of micro-mammals related of human exploitation. However, the moderate frequency of burnt bones, and the abundance of large rodents group, suggest the possibility that this could occur in La Peligrosa-1 and Rincón del Atuel-1 archaeological sites.

An intensification process of the resources took place in southern Mendoza since 2,000 years BP. This process had been interpreted as the consequence of an imbalance between environmental carrying capacity and human population growth. It is possibly that the over-exploitation of the environment had reduced the availability of highly-ranked resources (e.g., Lama guanicoe, Rhea americana, Rhea pennata), and drove subsistence towards the inclusion of foods with lower caloric returns and higher processing costs such as some plants and medium vertebrates. However, possibly this process could not have been so pronounced to drive hunter-gatherers to exploit the small mammals, as 
occurred in other regions of Argentina (e.g., Sierras Centrales, Patagonian, Pampean regions).

Otherwise, some postdepositational processes have been documented, which could modified the original structure of the assemblages. Except for the weathering and impregnation by manganese, which have a higher incidence in open-air sites and caves, respectively, the rest of the postdepositational processes such as sedimentary corrosion, trampling, roots and rodents action, affected the remains in the same way in both kinds of sites

In this study, numerous taxa that had not been documented in other archaeological contexts in Mendoza Province, were recorded: the reptilian Pristidactylus cf. $P$. scapulatus, Liolaemus sp. and Homonota cf. H. darwini; the chiropteran Tadarida brasiliensis; and the sigmodontine rodents Akodon spegazzinii, A. molinae, A. olivaceus, A. longipilis, C. macronyx, L. micropus, G. griseoflavus, and E. mordax. In the cordilleran archaeological sites Laguna El Sosneado-3 (2100 ${ }^{14} \mathrm{C}$ years BP-Present) and Arroyo Malo-3 (8900 ${ }^{14} \mathrm{C}$ years BP-Present), E. chinchilloides, P. xanthopygus, and Eligmodontia sp. dominate, indicating Patagonian steppe with substantial open ground and rocky exposition. It has been recorded some species associated with cordilleran meadows since early Holocene at Arroyo Malo-3 (C. macronyx and A. longipilis). Moreover, the finding of marsupial L. halli around 2200 BP, suggests more Patagonian conditions. In Laguna El Sosneado-3, the record of C. macronyx and L. micropus at the secuence -with the exception around $600{ }^{14} \mathrm{C}$ years BP- indicate a more arid event during this period. Otherwise, the Cueva Arroyo Colorado $\left(3200-750{ }^{14} \mathrm{C}\right.$ years BP), assemblages show taxonomic stability, similar to the sites. mentioned previously In the middle basin of Grande River, the Cueva de Luna $\left(3800{ }^{14} \mathrm{C}\right.$ years BP-Present) assemblages are composed by Patagonian species (L. halli, R. auritus and E. chinchilloides), and other taxa associated to the Monte desert (T. pallidior, M. australis and $C$. musculinus), opposed to the recent samples, that are only constituted by Patagonian taxa, indicating a more arid environment than present times.

The recent samples of the eastern plains are mostly dominated by taxa associated to a Monte desert. In agreement with this, the archaeological assemblages of Rincón del Atuel 1 (1500-350 ${ }^{14} \mathrm{C}$ years AP), Agua de La Mula (1600-1000 ${ }^{14} \mathrm{C}$ years BP), Agua de los Caballos $\left(1,200-250{ }^{14} \mathrm{C}\right.$ years BP), and La Peligrosa-1 $\left(\sim 1500-400{ }^{14} \mathrm{C}\right.$ years BP), show species that inhabit mainly in this environment (T. pallidior, G. leucoblephara, M. australis, G. griseoflavus). However, in Agua de La Mula Patagonian species (L. halli 
and $R$. auritus) had been also found, suggesting a transitional mosaic between Monte desert and Patagonian steppe.

The recent micro-mamalian assemblages show a taxonomic restructuration, possibly related with environmental degradation by human activities, such as livestock management (mainly Capra hircus), consolidated in southern Mendoza since XIX century. This anthropic alteration could have occasioned the increments of some opportunistic species such as C. musculinus in lowlands, and A. olivaceus in highlands. However, this assemblage restructuration was not as deep as in other regions of Argentina (e.g., Patagonia, Pampa, and Puna).

A first approach from stable isotopes has allowed to discuss many of the hypotheses proposed from a new line of evidence. On one hand, in agreement with the taphonomic data, the isotopes information suggest that human consumption of Ctenomys, Galea, and Microcavia would not have been very important. On the other hand, comparison of recent vs archaeological samples indicate a general environmental stability, with the possible development of Patagonian steppe elements into some parts of Monte desert.

Finally, the different taphonomic and paleoenvironmental information provided from microvertebrate assemblages recovered from nine archaeological sites of southern Mendoza, is acontribution to explain the scope of the intensification process and the human ocupation model proposed in previous researchs for this region. 


\section{Capítulo 1}

\section{INTRODUCCIÓN}

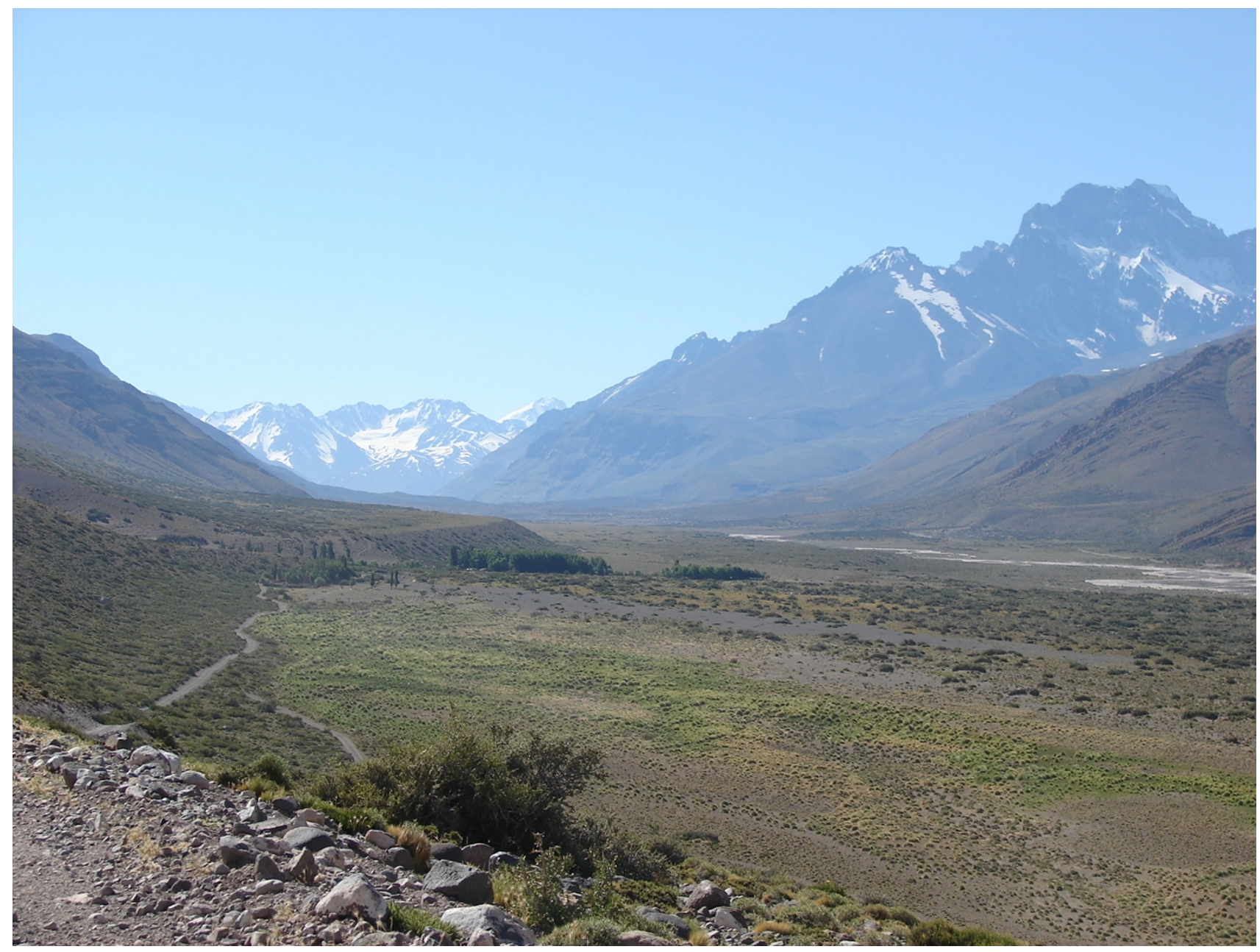





\section{INTRODUCCIÓN}

\subsection{Antecedentes y fundamentos de la investigación}

En las últimas décadas el estudio de los microvertebrados de sitios arqueológicos ha sido de gran interés en la literatura científica mundial diversificándose su aplicación hacia diferentes líneas de análisis. En general estas líneas pueden ser reunidas en tres orientaciones principales: a) el análisis de microvertebrados como parte de la dieta humana en el pasado (e.g., Bond et al., 1981; Simonetti y Cornejo, 1991; Saavedra, 1994; Quintana et al., 2002; Santiago, 2004; Acosta y Pafundi, 2005; Quintana, 2005; Teta et al., 2005a; Fernández et al., 2009a); b) el estudio de los agentes bióticos (e.g., estrigiformes, falconiformes y mamíferos carnívoros) responsables de la incorporación de los microvertebrados a los sitios arqueológicos y paleontológicos (e.g., Andrews, 1990; Fernández-Jalvo y Andrews, 1992; Stahl, 1996; Gómez et al., 1999; Gómez, 2000; Montalvo, 2002a; Fernández et al., 2009a, 2009b, 2009c; Gómez y Messineo, 2009; Scheifler, 2010; Scheifler et al., en prensa) y c) como proxy-data para el estudio de cambios ambientales (e.g., Betancourt et al., 1990; Andrews, 1990, 1995; CrivelliMontero et al., 1996; Fernández-Jalvo, 1996; Pardiñas, 1999a; Avery, 2001; Pardiñas et al., 2002, 2011a, 2011b; Teta et al., 2005a; Fernández et al., 2009a, 2011a, en prensa; Scheifler et al., en prensa).

Los primeros aportes zooarqueológicos en el sur de de Mendoza fueron llevados a cabo por Neme et al. $(1995,1999)$ principalmente en el valle medio del Río Grande y por Neme y Gil (2002) en otros sectores cordilleranos. Posteriormente, se realizaron trabajos zooarqueológicos en el alto valle del Río Atuel (Neme, 2002, 2007) y en la región de la Payunia (Gil, 2006). Finalmente, Neme y Gil (2008a) realizaron un análisis arqueofaunístico integral de numerosos sitios arqueológicos del sur de Mendoza. En líneas generales estos trabajos se enfocaron principalmente en estudios de mamíferos medianos y grandes, análisis de abundancia taxonómica y frecuencia de partes esqueletales. En los últimos años el interés de los estudios zooarqueológicos se ha extendido otros grupos de vertebrados, tales como peces (Corbat et al., 2009) y aves de mediano y gran tamaño (Giardina, 2006, 2010a, 2010b, 2010c).

Pese a este creciente desarrollo en el tema, el sur de Mendoza aún cuenta con escasos antecedentes vinculados al análisis de los microvertebrados. Existen algunas investigaciones en el sur de la provincia de Mendoza y en el norte y sur de Neuquén 
(Pearson y Pearson, 1982, 1993; Massoia, 1990; Crivelli-Montero et al., 1996; Pardiñas, 1999a; Neme et al., 2002; Teta et al., 2005a; Gasco et al., 2006; Fernández et al., 2009a, 2009b, 2009c, 2011b, en prensa; Fernández, 2010; Pardiñas y Teta, 2008). El consumo y/o utilización de los microvertebrados por los humanos, no solo ha sido registrado etnográfica y etnoarqueológicamente (e.g., Gusinde, 1982; Landt, 2007; Martínez, 2009), sino también se ha afirmado desde una perspectiva arqueológica (Bond et al., 1981; Simonetti y Cornejo, 1991; Saavedra, 1994; Fernández-Jalvo et al., 1999; Hockett y Bicho, 2000, Quintana et al., 2002; Santiago, 2004; Acosta y Pafundi, 2005; Quintana, 2005; Teta et al., 2005a; Deward y Jarardino, 2007; Fernández et al., 2009a, 2011a; entre otros). Entre los rasgos más notorios de actividad antrópica, se pueden mencionar la alta frecuencia de huesos quemados, altos niveles de fractura y alteración por ácidos gástricos y biliares, marcas de corte y alta concentración de huesos de las especies de mayor tamaño (i.e., roedores histricognatos)(Bond et al., 1981; Simonetti y Cornejo, 1991; Stahl, 1996; Pardiñas, 1999a,1999b). Sin embargo la identificación del aprovechamiento humano de los mismos no es tarea sencilla y ha generado debate en la literatura arqueológica y paleontológica (Stahl, 1982, 1996; Andrews, 1990). Los problemas en este tipo de identificación están relacionados a la ambigüedad de los indicadores (Crandall y Stahl, 1995; Fernández-Jalvo et al., 1999; Deward y Jarardino, 2007), dada la equifinalidad de muchos procesos que involucran a los conjuntos de microvertebrados.

Para el sur de Mendoza se ha planteado un cambio en el uso de la fauna hacia mediados del Holoceno tardío (últimos 2000 años AP) el cual estaría mostrando un uso creciente de taxones de tamaños mas pequeño y por ende de menor rendimiento económico (Neme, 2007; Neme y Gil, 2008b). Este cambio también trae como consecuencia un decrecimiento en el uso del guanaco (Lama guanicoe) y un consumo más intensivo de los recursos vegetales a través del tiempo (Neme, 2007; Neme y Gil, 2008b).

Dentro de este modelo regional se desprende la posibilidad de que la amplitud de dieta de los grupos humanos haya aumentado hasta incorporar a los microvertebrados, como ha sido descripto en otras regiones de Argentina para el Holoceno tardío (Pardiñas, 1999a, 1999b; Quintana et al., 2002; Santiago, 2004; Acosta y Pafundi, 2005; Quintana, 2005; Teta et al., 2005a; Prates, 2008; Medina et al., 2011, 2012; Fernández et al., 2011a; Pardiñas et al., 2011b). En este sentido, el estudio de los restos de microvertebrados provenientes de sitios arqueológicos cobra singular importancia, no 
solo desde la formación de los agregados, sino también en el papel que los microvertebrados puedan haber jugado en la economía de los grupos en cuestión.

Por otra parte se ha plateado que la región constituye el límite más austral de la dispersión de la agricultura prehispánica en Sudamérica (Lagiglia, 1999a; Gil, 1997-98, 2003, 2006; Gil et al., 2006a). En este sentido y dado que los microvertebrados son sensibles a los cambios en la composición y abundancia de la vegetación es esperable que, en las áreas antropizadas como producto de la dispersión de las prácticas agrícolas, se observe una variación de la frecuencia y diversidad de roedores autóctonos (Simonetti, 1988; Pardiñas et al., 2000; Neme et al., 2002; Saavedra y Simonetti, 2003; Teta et al., 2005a; Fernández et al., 2009a, 2009d; Pardiñas et al., 2011a, 2011b). Estas observaciones podrían ayudar, como una línea de evidencia independiente, a dilucidar aspectos de la dispersión de la agricultura prehispánica en el sur de Mendoza.

Por otro lado, los microvertebrados han mostrado su utilidad para profundizar en los procesos de formación de sitios e inferir con mayor grado de confiabilidad los agentes y procesos que intervinieron en la historia tafonómica de los depósitos (Andrews, 1990; Stahl, 1996). Una buena comprensión de las historias tafonómicas de los conjuntos de microvertebrados permitirán discutir con mayor seguridad el origen de las muestras, su probable utilización como recurso alimenticio por parte de los grupos humanos prehispánicos y a la integridad de los depósitos arqueológicos en general.

Desde la perspectiva de la Ecología Humana, el hombre constituye un elemento más del ecosistema que está en permanente interacción con el mismo y su accionar produce y ha producido profundas transformaciones en su entorno (Dincauze, 2000). En tal sentido, una profunda evaluación sobre el papel que pudieron tener las poblaciones humanas en el mismo será un importante aporte no solo desde la formación de los agregados, sino también en el papel que los microvertebrados puedan haber jugado en la economía de los grupos en cuestión. En este caso los humanos serían considerados cazadores de los microvertebrados. Una vez más el estudio tafonómico permitirá definir mejor la delgada línea que se establece entre la acción antrópica deliberada y la no antrópica.

Una parte importante de los loci utilizados por los grupos humanos, tales como las cuevas o estructuras abandonadas, corresponden a lugares donde confluyen diferentes tipos de predadores, por lo que es esperable una superposición de los registros generados por estos agentes (Stahl, 1996). Además, dado que las cuevas y aleros ofrecen protección y refugio, son susceptibles a ser reutilizados mucho más que los 
sitios a cielo abierto (Schmid, 1970; Straus, 1990). Esto significa que las unidades estratigráficas con evidencias de ocupación frecuentemente constituyen palimpsestos, resultado de la alternancia en la ocupación por parte del hombre y la fauna (Stahl, 1996; Kligmann et al., 1999; Gómez, 2000; Mondini, 2000).

Por último las características estenoicas de las especies de microvertebrados, su alta sensibilidad a los cambios ambientales y su abundancia en el registro arqueológico permiten su utilización como indicadores de las características ambientales en el pasado (Andrews, 1990, 1995; Crivelli-Montero et al., 1996; Fernández-Jalvo, 1996; Pardiñas, 1999a; Avery, 2001; Pardiñas et al., 2002; Teta et al., 2005a; Fernández et al., 2009a). Una identificación exitosa del depredador responsable de la acumulación no solo nos lleva a una contribución creciente del agregado fósil, sino también puede proveer información pertinente acerca de la interacción depredador/presa y de las condiciones ambientales en el tiempo de la depositación del agregado fósil (Stahl, 1996).

Ecología puede ser definida como la totalidad de interacciones entre organismos y su ambiente (Odum, 1983). Paleoecología, por lo tanto puede ser definida como las interacciones inferidas entre organismos del pasado y sus entonces ambientes existentes (Andrews, 1995).

Cuando hacemos interpretación paleoecológica y paleoambiental hay sesgos tafonómicos adicionales que podrían incrementar la diversidad como resultado de una mezcla de formas o tiempo promediado, o una disminución como resultado de la pérdida de especies (Andrews, 1995).

\subsection{Objetivo principal}

El objetivo de este proyecto es estudiar la tafonomía y significación paleoecológica de los depósitos de microvertebrados procedentes de contextos arqueológicos del sur de Mendoza y discutir el rol que cumplieron en la subsistencia humana prehispánica.

\subsection{Objetivos específicos}

1) Analizar la historia tafonómica de los depósitos de microvertebrados de los conjuntos arqueológicos, haciendo énfasis en la determinación de series de atributos que permitan diferenciar los agentes causantes de la acumulación y los procesos postdepositacionales sufridos por los restos. 
2) Discutir el rol que cumplieron los microvertebrados en la subsistencia humana prehispánica en el sur de Mendoza.

3) Evaluar la distribución espacio-temporal de los taxones de microvertebrados recuperados en los sitios arqueológicos de la región, como una vía de acercamiento a la paleoecología regional.

\subsection{Hipótesis de trabajo}

H- Los agentes causantes de la incorporación de los agregados de microvertebrados en sitios arqueológicos están estrechamente relacionados con las características morfológicas del sitio (sitios a cielo abierto, o en reparos como aleros o cuevas).

Los trabajos llevados adelante por diferentes investigadores han mostrado que los distintos tipos de depredadores que actúan sobre microvertebrados ocupan diferentes ambientes tanto para cazar como para consumir sus presas (Andrews, 1990; FernándezJalvo y Andrews, 1992; Stahl, 1996; Pardiñas, 1999a, 1999b). En este sentido se espera que los conjuntos de microvertebrados del sur de Mendoza respondan a las características etológicas de los depredadores intervinientes, más que a la etología de las especies de microvertebrados que habitan esos lugares, o a la acción de procesos de destrucción diferencial, etc.

H- Dadas las diferencias en el tipo de procesos postdepositacionales intervinientes, se espera una preservación diferencial de los conjuntos de microvertebrados de acuerdo a si estos se encuentran en sitios a cielo abierto; o en reparos (e.g., aleros, cuevas).

En los sitios arqueológicos, cuya morfología corresponde a la de una cueva o alero, los conjuntos de microvertebrados son mayormente afectados por procesos postdepositacionales como la corrosión por la humedad, transporte y aumento de los niveles de pisoteo debido a que son ambientes de circulación restringida (Korth, 1979; Fernandez-Jalvo 1988; Andrews, 1990; Pardiñas, 1999b). Por su parte, los conjuntos de microvertebrados en sitios arqueológicos a cielo abierto se encuentran más afectados por procesos postdepositacionales como la meteorización y transporte (Korth, 1979; Fernández-Jalvo, 1988; Andrews, 1990). 
H- Dadas las expectativas del modelo de intensificación propuesto para la región, alrededor de 2000 años AP, se espera que los sitios arqueológicos presenten evidencias de consumo de microvertebrados por parte de las poblaciones humanas.

Según se ha podido observar en diferentes conjuntos arqueofaunísticos de la región, hay una disminución en el consumo de camélidos hacia los últimos 2000 años AP, en relación al resto de las especies de animales de la región. Esto ha sido entendido como un aumento en la amplitud de dieta de las poblaciones humanas, probablemente relacionado a un desbalance entre la población y los recursos (Neme, 2007 y literatura allí citada). Este aumento en la amplitud de dieta pudo haber llevado a los grupos de cazadores recolectores a incorporar presas de menor rendimiento económico como los microvertebrados.

H- Se esperan cambios en la frecuencia y diversidad de los taxones de microvertebrados en relación a las variaciones en la estructura ambiental regional.

En este sentido cuatro cambios ambientales principales han sido propuestos hasta la fecha para todo el Holoceno. El primero de ellos, está relacionado a los procesos de cambio ocurridos hacia finales de la última glaciación (límite Pleistoceno-Holoceno) ca. 12000-10000 años AP. El segundo tiene que ver con el proceso aridización sufrido durante el Holoceno medio, ca. 8000-4000 años AP. El tercero con el establecimiento de las condiciones climáticas actuales $c a$. 4000 años AP y el cuatro con los cambios ambientales acaecidos en los últimos siglos durante la Pequeña Edad de Hielo (e.g., Markgraf, 1983; D`antoni, 1983; Stingl y Garleff, 1985; Zárate, 2002; Zárate et al., 2010 y literatura allí citada).

\subsection{Estructura de la Tesis}

Para la realización de este trabajo de tesis doctoral se han desarrollado 9 capítulos.

En el capitulo 1 se enumeran los objetivos e hipótesis de esta tesis y los antecedentes principales en el tema. En el capítulo 2 se abordan los principales conceptos teóricos vinculados a la Ecología Humana, teoría del forrageamiento óptimo, subsistencia de cazadores-recolectores en ambientes marginales, actualismo, zooarqueología y 
tafonomía de microvertebrados. En el capítulo 3 se brinda información sobre el área de estudio, describiendo la geomorfología, clima, biogeografía, sistema agropecuario, modificaciones antrópicas y paleoambientes. En el capítulo 4 se detalla la metodología adoptada para el desarrollo de esta tesis. En el capítulo 5 se expone la información actualizada del conocimiento de los principales grupos de microvertebrados que formaron parte de esta tesis, desarrollando aspectos de la biología general de los taxones, diagnosis, distribución geográfica y taxonomía, entre otros. En el capítulo 6 se describen aspectos biológicos, ecológicos y tafonómicos de los principales depredadores que habitan en el sur de Mendoza. En el capítulo 7 se realiza el análisis de los microvertebrados recuperados de los sitios arqueológicos y de las muestras actuales recolectadas cerca de los mismos, abordando aspectos tafonómicos, de subsistencia humana y paleoambientales. En el capitulo 8 se efectúa una discusión e integración de la información obtenida de los sitios arqueológicos. Por último, en el capítulo 9 se enumeran las principales conclusiones emanadas en este trabajo de tesis doctoral.

\subsection{Principales abreviaturas y acrónimos utilizados}

AP: antes del presente.

${ }^{14} \mathrm{C}$ : datación radiocarbónica.

CENPAT: Centro Nacional Patagónico.

CNP-E: Colección de Material de Egagrópilas y Afines "Elio Massoia" del Centro Nacional Patagónico (Puerto Madryn, Chubut Argentina).

ECH: ecología del comportamiento humano.

FCNYM: Facultad de Ciencias Naturales y Museo.

IADIZA: Instituto Argentino de Investigaciones de las Zonas Áridas.

Ka: 1000 años.

LP: dataciones radiocarbónicas realizadas en el Laboratorio de Tritio y Radiocarbono (LATyR), FCNYM, UNLP.

MEB: Microscopio Electrónico de Barrido.

MHNSR: Museo de Historia Natural de San Rafael.

MLP: Museo de La Plata (La Plata, Buenos Aires, Argentina).

MNE: número mínimo de elementos.

MNI: número mínimo de individuos. 
NISP: número de especimenes identificados por taxón.

NOA: Noroeste Argentino.

UNCUYO: Universidad Nacional de Cuyo.

UNLP: Universidad Nacional de La Plata. 


\section{Capítulo 2}

\section{MARCO TEÓRICO}

"Science, like art, religion, commerce, warfare, and even sleep, is based on presuppositions. It differs, however, from most other branches of human activity in that not only are the pathways of scientific thought determined by the presuppositions of the scientists but their goals are the testing and revision of old presuppositions and the creation of new..."

Gregory Bateson

[Mind and Nature: A Necessary Unity. 1979: 25] 



\section{MARCO TEÓRICO}

En este capítulo se exponen los principales conceptos teóricos que sustentan a este trabajo de tesis doctoral. En primer término se abordan los lineamientos generales de la ecología del comportamiento humano $(\mathrm{ECH})$, Teoría del Forrajeamiento Óptimo y los modelos de amplitud de dieta y elección de parches. Posteriormente se desarrollan los conceptos de ambientes marginales, riesgo e incertidumbre, modelos biogeográficos y procesos de intensificación de los recursos. Finalmente, se definen los términos de uniformitarismo, actualismo y equifinalidad en el contexto de la Zooarqueología como disciplina científica; y en forma sintética se describen aspectos generales sobre tafonomía de microvertebrados (el cual será tratado en detalle en el Capítulo 4).

\subsection{Ecología humana}

La ECH tiene su origen en la teoría evolutiva darwiniana (Mac Arthur y Pianka, 1966; Bettinger, 1991a; Kelly, 1995; entre otros). La ECH busca estudiar la variabilidad del comportamiento humano a lo largo del tiempo y como respuesta a las variaciones ambientales, donde los cambios culturales se definen como formas de adaptación fenotípica a condiciones sociales y ecológicas variables, presumiendo que la selección natural ha diseñado a los organismos para responder a las condiciones locales aumentando su adaptabilidad (Boone y Smith, 1998). Para la biología evolutiva, la conducta humana es adaptativa cuando sigue la variabilidad ambiental optimizando el ajuste del individuo, el cual se define como la tendencia a sobrevivir y a reproducirse (Boone y Smith, 1998). De modo que, los humanos tienden a optar por comportamientos en un rango de variantes para maximizar la adaptabilidad (Kelly, 1995).

Los conceptos teóricos de la ECH se aplicaron por primera vez en la arqueología durante fines de la década del 70 y principios de los 80, principalmente para explicar el cambio y la variabilidad del registro arqueológico y para analizar las estrategias de subsistencia de los grupos cazadores recolectores (Bettinger, 1991a, 2009; Kelly, 1995; Lanata, 2002; entre otros). En este sentido, la ECH puede constituir un marco teórico apropiado para discutir el rol que tuvieron los microvertebrados en la subsistencia humana prehispánica, vinculado a la propuesta de intensificación de los recursos planteada por Neme $(2002,2007,2009)$ para la región durante el Holoceno tardío. 
A partir de la ECH surge la Teoría del Forrajeamiento Óptimo con sus modelos de amplitud de dieta y de elección de parches, que se detallan a continuación.

\subsubsection{Teoría de forrageamiento óptimo}

Los modelos de optimización sobre la base de la perspectiva de la ecología evolucionista, están más orientados a mejorar nuestro entendimiento de la adaptación, que a demostrar que la selección natural produce soluciones óptimas. La teoría de forrajeamiento óptimo, se basa en líneas generales en el principio de maximización y optimización de la eficacia en el forrajeo, medida en términos de costos y beneficios (e.g., Mac Arthur y Pianka, 1966; Stephens y Krebs, 1986).

El modelo de amplitud de dieta o de selección de presas, intenta predecir el orden de selección de los recursos mientras se realiza su búsqueda para maximizar la tasa de energía en el forrajeo (Mac Arthur y Pianka, 1966; Hawkes y Connell, 1992). En este modelo los costos de búsqueda y de procesamiento son expresados en una medida de retorno energético (kilocalorías) y se incorporan en una unidad de tiempo determinada (horas, días, etc.). Ergo, cada presa se encuentra en forma aleatoria en el ambiente, tiene una cantidad de energía fija y se requiere un tiempo para cazar, procesar y consumir (Kelly, 1995). Asimismo, en el acto de forrajear es importante destacar el hecho de "buscar", "encontrar" y en el momento del encuentro, "decidir" si se toma a la presa o se continua buscando (Kelly, 1995; Bettinger, 1991a, 2009). Tanto el costo de manejo como la tasa de retorno pueden variar, como resultado de la incorporación de nueva tecnología y como consecuencia de los cambios estacionales en la composición de los recursos (Kelly, 1995). Este modelo asume la elección entre continuar o detener la búsqueda, en relación a los costos y beneficios medidos en términos de tasas de adquisición (Hawkes y Connell, 1992). La elección de presas de menor ranking energético, dependerá de cambios en la búsqueda, tasa de encuentro y manejo de las presas de mayor ranking (Hawkes y Connell, 1992). Por ende, las presas de bajo ranking pueden ser abundantes pero solo deberían ser explotadas por los foragers cuando disminuye la tasa de encuentro de las presas de alto ranking (Hawkes y Connell, 1992; Bettinger, 2009).

El modelo de elección de parches indica que los parches se ordenan en términos del retorno energético por unidad de tiempo. Este modelo a diferencia del modelo de amplitud de dieta, indica que el tiempo invertido en la búsqueda de un parche está 
incluido en el cálculo de la tasa de retorno global de ese parche. En este sentido, los foragers deben decidir si entran a un parche para explotar los recursos o continúan buscando otros parches de mayor tasa de retorno. Asimismo, el modelo de elección de parches sugiere que los foragers no regresan a un parche hasta que este haya recuperado su capacidad productiva (Kaplan y Hill, 1992; Kelly, 1995; Broughton, 2002). Por otra parte, el teorema de valor marginal predice que la cantidad óptima de tiempo para adquirir los recursos de un parche se basa en la relación entre la ganancia energética de un parche y la tasa de retorno promedio del ambiente, la cual está condicionada por la frecuencia de encuentro de los parches (Charnov, 1976; Stephens y Krebs, 1986; Burger et al., 2005). Cuando el modelo de selección de parches se utiliza junto con el teorema de valor marginal, puede predecir cuando un forager se movilizará de un parche a otro a medida que el proceso de explotación haga decrecer la tasa de retorno del parche (Bettinger, 1991; Kaplan y Hill, 1992; Kelly, 1995; Broughton, 2002).

\subsection{Ambientes marginales}

El concepto de marginalidad ambiental puede ser definido como un "ambiente pobre", con baja productividad primaria, donde son explotados cuando están en plenitud y luego de que el resto fueran explotados (Bettinger, 1991b). Sin embargo, otro concepto de marginalidad establece que los ambientes marginales no son necesariamente los ambientes más pobres en recursos, sino que son el "límite exterior de la dispersión de una población", que no se expande más allá de las capacidades biológicas, tecnológicas que limitan esa dispersión (Borrero, 2004). En tal sentido, un ambiente marginal remite a un área discontinuamente ocupada y/o explotada por poblacionales distantes (Borrero, 2004). Arqueológicamente, se puede identificar con la ausencia de campamentos base (Veth, 1993). Por último, marginalidad puede ser definida como una "cualidad relativa", en tanto un ambiente no es marginal en si mismo, sino en relación a los ambientes circundantes (Mondini y Muñoz, 2004).

\subsection{Riesgo e incertidumbre}

En su modelo biogeográfico Borrero (1989-1990), propone que la cronología y forma en la cual un área va a ser ocupada dependerá a que lugar ocupará esta dentro de la 
jerarquía ambiental de la región. Dicha jerarquía estará basada en la productividad de cada área, así como en el riesgo y la incertidumbre de la misma (Gil, 2006).

El concepto de riesgo puede ser definido como una variación impredecible de alguna variable económica o ambiental. Por su parte, el término incertidumbre hace referencia a la falta de conocimiento sobre los cambios en estas variables (Jochim, 1981; Halstead y O’Shea, 1989).

Asimismo, la variabilidad de un ambiente puede actuar aumentando el grado de incertidumbre, especialmente cuando los recursos son impredecibles, lo cual incrementa el grado del riesgo de la misma (Bryson, 1994). Las regiones desérticas se caracterizan por tener variaciones anuales, estacionales y espaciales muy fuertes, aumentando los niveles de riesgo (Gil, 2006). En este sentido, las estrategias de las poblaciones humanas en áreas desérticas deben estar preparadas para manejar altos niveles de riesgo e incertidumbres a través del desarrollo de diversas respuestas culturales y biológicas (Halstead y O'Shea, 1989).

Por otra parte, Halstead y O'Shea (1989) postulan que pueden desencadenarse cuatro mecanismos básicos como respuestas para amortiguar o disminuir el riesgo: 1) Movilidad, 2) Diversificación, 3) Almacenamiento e 4) Intercambio.

La Movilidad, es la respuesta más simple y funciona cuando una población humana migra a causa de una escasez. La Diversificación, se da cuando se explota un rango más amplio de especies de plantas y animales en áreas más amplias y variadas. El Almacenamiento, se refiere al diferimiento en el consumo de los recursos disponibles. El Intercambio, funciona en forma complementaria al almacenamiento, en donde la abundancia presente es reservada para transacciones sociales en el futuro. El mismo es un mecanismo que permite la utilización de recursos que no están inmediatamente disponibles entre los grupos humanos de una determinada región, dado que se encuentran fuera del alcance de los mismos ya sea por cuestiones de distancia, acceso, etc.

\subsection{Modelos biogeográficos}

Los modelos biogeográficos son una herramienta útil para comprender cuestiones vinculadas al poblamiento, adaptación y uso de los diferentes espacios de una región determinada. Algunos ejemplos han mostrado su utilidad dentro y fuera de la región 
para abordar estos temas (Veth, 1989; Borrero, 1989-1990, 1994-1995, 1999; Neme y Gil, 2008b).

El modelo biogeográfico de Veth (1989), aplicado para la colonización de los desiertos de Australia predice que las áreas menos marginales (e.g., sistemas pedemontanos, tierras altas de montaña y sistemas fluviales) pueden funcionar como lugares de refugio. Estas se caracterizarían por tener ocupaciones permanentes desde los momentos más tempranos. Por su parte, los corredores (e.g., grandes trayectos de tierras arenosas y pedregosas), tendrían una ocupación más temprana pero en forma no permanente, ya que serían ocupadas cuando las condiciones climáticas fueran más favorables. Por último, según el autor mencionado, las áreas de barreras infranqueables (e.g., grandes desiertos de campos de dunas), tendrían una ocupación más tardía, la cual solo ocurrirá cuando las condiciones climáticas fueran más benignas, sugiriendo adaptaciones culturales como cambios en la estructura social y en las tecnologías de las poblaciones humanas (Veth, 1989).

Por otra parte, Borrero $(1989-1990,1994-1995,1999)$ elaboró un modelo de poblamiento de la Patagonia en base a tres etapas: Exploración, Colonización y Ocupación efectiva. La etapa de Exploración implica movimiento de grupos humanos hacia zonas deshabitadas, a lo largo de rutas naturales y la utilización de localidades no óptimas. Para esta etapa se espera que se depositen pocos materiales de escasa especificidad funcional y poca discontinuidad temporal en las ocupaciones, dificultando la localización de los asentamientos. En esta etapa se evitarían las áreas menos favorables, como aquellas sujetas a alta exposición de presiones naturales, lo que sugiere que pueden quedar deshabitadas dentro de las regiones que ya han sido pobladas. Los materiales asociados a este tipo ocupaciones corresponderían a instrumentos expeditivos y probablemente desechos de reformatización (Borrero, 19941995, 2005). La etapa de Colonización corresponde a la consolidación inicial de los grupos humanos en un espacio determinado. A diferencia de la etapa anterior, el registro arqueológico tiene alta visibilidad, buena resolución y están localizados óptimamente. La localización de los asentamientos debe cumplir los requisitos que hagan viable la continuidad biológica de la población (Borrero, 1994-1995, 2005). En la etapa de Ocupación efectiva todos los ambientes deseables están ocupados. La visibilidad arqueológica es alta pero de baja resolución. Se espera un incremento en la variabilidad de la cultura material y procesos de cambio más o menos acelerados, como resultado de la adaptación a las condiciones locales. Los indicadores básicos son una mayor 
redundancia en la ocupación y mayor reiteración en el uso de ciertas estrategias de subsistencia. En esta última etapa hay saturación del espacio, lo que indicaría procesos que estarían conduciendo a las poblaciones a adaptarse a las nuevas condiciones demográficas locales y a una mayor extracción de energía por unidad de área, con la posible competencia entre poblaciones (Borrero, 1989-1990, 1994-1995, 1999, 2005).

Dentro de este marco, con el avance de los estudios paleoambientales de un área determinada, nos podemos plantear distintos interrogantes vinculados a una problemática de índole biogeográfico (Veth, 1989). En este sentido, en los ambientes afectados por ciclos de sequía como en el sur de Mendoza, los desiertos o semidesiertos pueden haber actuado como barreras geográficas, los valles fluviales extracordilleranos como corredores y los valles intermontanos y piedemontes, con menor riesgo y menor incertidumbre, como refugios (Borrero, 2002; Gil et al., 2005; Neme et al., 2005). A lo largo de los ciclos cambiantes de la estructura paleoambiental, pudieron derivar en expansiones y contracciones en el rango de acción humana (Borrero, 2002). Lo que también podría ocasionar cambios en la tecnología y en la economía de las poblaciones (Bousman, 2005).

\subsection{Intensificación}

Los modelos de la Ecología evolutiva, mediante el uso de las teorías de forrageamiento óptimo, predicen el desarrollo de mecanismos que tienden a disminuir los niveles de riesgo y maximizar la toma de energía (Bettinger, 1991b). La disminución del consumo de Lama guanicoe y el aumento de la participación de especies más pequeñas en la dieta de grupos humanos implica tanto mayores costos de explotación, ya sea procesamiento y/o captura, con menores niveles de retorno energético.

Los modelos de amplitud de dieta (Bettinger, 1991b) predicen que siempre serán elegidas aquellas presas que tengan un mayor retorno, por lo que la disminución relativa de los valores de camélidos capturados, así como el aumento en la diversidad de especies (especialmente aquellas de menor tamaño) implicaría una pérdida en la eficiencia forager (Broughton, 1994). Este tipo de cambios en la explotación de los recursos puede ocurrir, entre otras causas, como producto de un cambio tecnológico, o cuando disminuye la tasa de encuentro de una especie que está rankeada muy alto, y las tasas de encuentro del resto de las especies se mantienen constantes o aumentan. De esta 
forma las especies que antes no eran elegidas lo serán frente a este nuevo escenario ecológico de la región (Bettinger, 1991b; Broughton, 1994, Neme, 2007).

El concepto de intensificación ha sido utilizado desde hace ya varias décadas para entender una serie de cambios en el registro arqueológicos (Hayden, 1981; Bettinger y Baumhoff, 1982; Hiscock, 1994). Estos cambios en general implicaron un aumento en la cantidad de energía extraída del medio por unidad de área, a expensas de un aumento en los costos de extracción (Bettinger, 1994, 2001; Broughton, 1994, 2004).

Los principales indicadores de procesos de intensificación son un aumento de la territorialidad, la ocupación y explotación de las áreas marginales, incorporación de nuevas tecnologías, regionalización de estilos artísticos, intercambio de bienes, aparición de las estructuras de almacenamiento y una paulatina reducción de la movilidad (Hayden, 1981; Bettinger y Baumhoff, 1982; Hiscock, 1994; Broughton, 1994).

Los procesos de intensificación pueden ocurrir en diferentes direcciones y estar originados en distintas causas.

En general el concepto de intensificación en el uso de los recursos fue abordado desde dos perspectivas distintas: 1) la primera define la intensificación como especialización, donde un grupo humano se centra en un recurso explotándolo al máximo; 2) la segunda hace referencia a que los grupos de cazadores recolectores incorporan diversos recursos, incluyendo plantas y animales de mediano y pequeño tamaño.

El concepto de intensificación abordado desde la primera de las definiciones fue utilizado por Yacobaccio (2003), quien postula un uso intensivo de L. guanicoe para el NOA durante el Holoceno medio, donde un proceso de aumento de la aridez hizo que los camélidos se concentraran en los escasos lugares con agua y pasturas remanentes, lo cual los hizo más accesibles (predecibles) para las poblaciones humanas. Este proceso habría terminado con el posterior proceso de domesticación. Este proceso fue independiente al de los Andes centrales y sucedió como consecuencia de transformaciones sociales profundas en la sociedad de cazadores-recolectores.

La intensificación vista como diversificación implica la incorporación de nuevos recursos, evidenciado por una mayor diversidad en la explotación de las especies de plantas y animales. Este aumento en la diversidad de especies explotadas implica por un lado un aumento en la cantidad de energía utilizada, pero también el incremento en los costos de procesamiento (Bettinger, 2001, 2009) 
Dentro de este contexto, Neme $(2002,2007,2009)$ propone que un proceso de intensificación de los recursos tuvo lugar en la alta cuenca del Río Atuel en los últimos 2.000 años AP. A través de este proceso de intensificación se alcanzó una completa adaptación a las áreas marginales del sur de Mendoza (Neme, 2002, 2007, 2009). Sin embargo, en la región volcánica de la Payunia este proceso de intensificación, junto a la ocupación efectiva se dieron posteriormente (ca. 1000 anos AP) (Gil, 2006).

Este proceso de intensificación regional implicó una disminución en la proporción de guanacos explotados y un aumento en el uso de las especies de menor tamaño. Entre las nuevas especies incorporadas a la dieta se espera que los microvertebrados hayan tenido un rol importante en la subsistencia de los grupos humanos que habitaron el sur de Mendoza durante los últimos 2000 años AP.

\subsection{Zooarqueología}

El término arqueofauna hace referencia a una muestra de restos faunísticos recuperados de sitios arqueológicos (Lyman, 1994). La zooarqueología estudia las interacciones entre las sociedades humanas y la fauna a través del tiempo (e.g., Lyman, 1994; Gifford-Gonzales, 2001, 2007; Mengoni Goñalons, 2006-2010). No obstante, es necesario aclarar que el interés por esta disciplina trasciende a la arqueología, alcanzando principalmente a la paleontología y a la zoología, aunque con diferentes objetivos y alcances (Mengoni Goñalons, 2006-2010).

El paleontólogo ruso I.A. Efremov (1940), propuso el término tafonomía como una nueva rama de la paleontología, el cual proviene del griego taphos $=$ enterramiento y nomos = ley (las leyes del entierro), haciendo referencia al estudio sobre la transición de los restos animales desde la biósfera a la litósfera. Sin embargo, posteriormente este término fue adoptado por diversos investigadores de la arqueología y particularmente de la zooarqueología (véase Lyman, 2010 y literatura allí citada).

En la distinción entre los términos zooarqueología y arqueozoología, se destaca que el primer término da cuenta de las investigaciones de los restos faunísticos en los sitios arqueológicos, para indagar acerca de las interacciones entre los humanos y la fauna. En cambio, el segundo término apunta a utilizar los restos faunísticos de los sitios arqueológicos para estudiar el estatus evolutivo y ecológico de los animales (GiffordGonzales, 2007). 
Las investigaciones zooarqueológicas frecuentemente implican experimentos $\mathrm{u}$ observaciones de las modificaciones modernas de humanos y no-humanos sobre los restos faunísticos (Lyman, 1994). Para la mayor comprensión de la elaboración de analogías es necesario hacer un repaso de los principales conceptos rectores de donde provienen. El geólogo inglés Charles Lyell (1830), usó el término uniformitarismo escribiendo sobre la historia de la tierra. La aproximación de Lyell asume que los procesos geológicos han sido uniformes y han permanecido constantes, en su acción y efectos, sobre el transcurso completo de la historia de la tierra, donde los grandes resultados no son producto de causas catastróficas repentinas. George Simpson (1970) llamó esta asunción "uniformitarismo metodológico" (Goulp, 1965, 1979; Lyman, 1994; Gifford-Gonzales, 2001).

Por su parte, Lyman (1994) señala que el actualismo afirma la invariancia espacial y temporal de las leyes naturales, particularmente aquellas interesadas en los procesos mecánicos, químicos y físicos, siendo de este modo, equivalente al uniformitarismo metodológico. En este sentido, el actualismo denota la metodología de inferir la naturaleza de eventos del pasado por analogía con procesos observables en el presente (Lyman, 1994).

En la arqueología, la construcción de la teoría de rango medio (Binford, 1981) y la identificación de los procesos de formación de sitios (Schiffer, 1987) incluye aspectos mayores de la investigación actualística y de este modo frecuentemente toma la forma de argumento actualístico (Lyman, 1994). Las investigaciones actualísticas en la zooarqueología, a modo de inferencia por analogía, han ayudado en materia de entender los significados de los objetos del pasado, a través de nuestra experiencia en el presente (Gifford-Gonzales, 2001).

Lyman (1987), inicialmente extrae el concepto de equifinalidad del cibernetista Ludwing von Bertalanffly $(1949,1968)$, en sus escritos sobre la Teoría General de Sistemas, donde diferentes procesos producen el mismo estado final o los mismos resultados, en un sistema abierto capaz de intercambiar materiales con su entorno (Lyman, 2004). A través de las investigaciones actualísticas, los zooarqueólogos han definido huellas distintivas o características de varios actores, tales como marcas que podrían haber sido hechas por un solo agente causal, por ejemplo, un carnívoro o un humano con una herramienta de piedra. Sin embargo, las investigaciones actualísticas han mostrado que diferentes causas a veces pueden producir efectos muy similares, en términos de patrones de datos arqueofaunísticos (Gifford-Gonzales, 2001, 2007). 
Las relaciones de los patrones tafonómicos en los conjuntos arqueológicos para sus agentes causales pueden ser ambiguas. De modo que para hacer frente a los problemas de equifinalidad, es importante reconocer contexto de comportamiento de los agentes acumuladores (Gifford-Gonzales, 1991).

\subsubsection{Consideraciones generales sobre tafonomía de microvertebrados}

Los conjuntos arqueofaunísticos son el producto de una amplia multiplicidad de factores que intervienen en su formación. Los mismos interactúan de formas variadas generando sesgos en la recuperación, identificación e interpretación de las muestras.

El primer estadio en la transformación de la biocenosis (contexto de vida de los organismos) se produce con la muerte. Esto puede suceder por enfermedades, edad avanzada, accidentes y otras causas, produciendo agregados fósiles con pocas alteraciones en el tejido óseo. Sin embargo, para los microvertebrados (i.e., vertebrados $<1 \mathrm{~kg}$ de masa corporal estimada) la depredación es una causa común de muerte (Andrews, 1990; Lyman, 1994; Pinto Llona y Andrews, 1999; Stahl, 1996) y sus efectos podrían ser reconocidos por fracturas, marcas de corrosión digestiva en los dientes y restos óseos, y representación de partes esqueletales (Andrews, 1990; Bochenski et al., 1993; Bochenski, 1997, 2005; Broughton et al., 2006; Stahl, 1996). Entre los principales depredadores de microvertebrados tenemos a los mamíferos carnívoros, aves rapaces, tanto diurnas como nocturnas, y a los humanos. Los mamíferos carnívoros producen grandes modificaciones en las partes esqueletarias de sus presas, donde se puede observar marcas de dientes, altas frecuencias de restos fracturados por la acción mecánica de la masticación y destrucción extrema de las superficies óseas y dentarias, a causa de los efectos de la acción corrosiva de los ácidos gástricos y biliares (Andrews y Evans, 1983; Andrews, 1990; Stahl, 1996; Mondini, 2000, 2001; Gómez y Kaufmann, 2007; Montalvo et al., 2007, 2008). Las rapaces diurnas (Falconiformes), si bien no producen una frecuencia tan alta de fracturas como los carnívoros, sus ácidos gástricos corroen fuertemente las distintas partes del hueso, haciéndolo muchas veces no identificable (Hoffman, 1988; Andrews, 1990; Bochenski et al., 1997, 1998, 1999). Las rapaces nocturnas (Strigiformes), aunque con variaciones entre los representantes de este grupo, no dejan evidencias importantes de fractura y corrosión digestiva en los huesos (Dodson y Wexlar, 1979; Hoffman, 1988; Andrews, 1990; Bochenski y Tomek, 1994; Bochenski, 1997; Bochenski et al., 1993; Gómez, 2005; Broughton et al., 2006). 
En lo que concierne a la acción humana, se destaca principalmente las marcas de corte, la alta frecuencia de huesos quemados, altos niveles de fractura y alteración por ácidos gástricos y biliares y alta concentración de huesos de las especies de mayor tamaño (Bond et al., 1981; Simonetti y Cornejo, 1991; Stahl, 1996; Pardiñas, 1999a,1999b).

En los estadios postdepositacionales, la meteorización causa modificaciones, evidenciada por la abrasión, agrietamiento y exfoliación de las superficies óseas como producto de la pérdida de humedad y colágeno de los huesos. Además, el transporte, observado por el redondeamiento de las extremidades y protuberancias de los mismos, y el pisoteo, proporciona altos niveles de dispersión y fractura a los agregados fósiles, presentando bordes angulosos y ásperos (Behrensmeyer, 1978; Korth, 1979; Andrews, 1990; Bochenski y Tomek, 1997; Trapani, 1998; Behrensmeyer et al., 2003; FernándezJalvo y Andrews, 2003). Finalmente, luego que los huesos son enterrados podrían ser afectados por modificaciones diagenéticas, tales como el reemplazo mineral y la corrosión debida a la acidez o alcalinidad del suelo (Andrews, 1990; Lyman, 1994; Stahl, 1996; Pinto Llona y Andrews, 1999; Fernández-Jalvo et al., 2002). En los ambientes de cuevas con condiciones de humedad, los huesos también pueden ser afectados (Andrews, 1990). Las raíces de las plantas mediante la acción metabólica de hongos y bacterias podrían modificar las superficies óseas, formando marcas dendríticas superficiales y en algunos casos el daño podría ser más profundo y estructural (Lyman, 1994; Fernández-Jalvo et al., 2002). El óxido de manganeso actúa sobre los huesos formando manchas de color negro en las superficies óseas; el manganeso precipita como óxido en ambientes donde alternan ciclos de reducción-oxidación (Courty et al., 1989). Esta precipitación se produce cuando hay una saturación de estos elementos en agua y una escasez de oxígeno; el agua se estanca en el sedimento al toparse con una capa de arcillas o carbonatos que impide su filtración (Gómez et al., 1999; Gómez, 2000).

En resumen, los agentes postdepositacionales producen modificaciones en los huesos que afectan a toda la superficie de los mismos, esto difiere de la corrosión por digestión que tiene una acción usualmente localizada (Andrews, 1990; Fernández-Jalvo y Andrews, 1992; Bochenski y Tomek, 1997; Worthy, 2001; Laroulandie, 2002).

Finalmente, en la figura 2.1 se exhiben las interacciones entre los principales estudios de los microvertebrados realizados en este trabajo. 


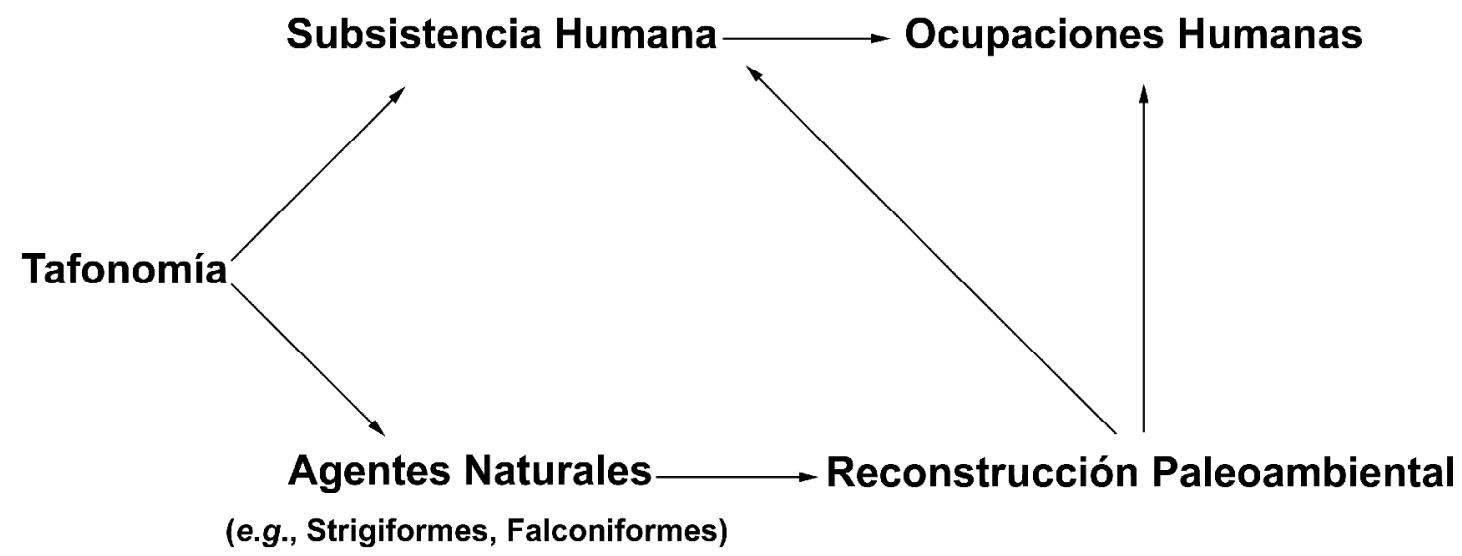

Figura 2.1. Esquema de interacciones entre los principales estudios de microvertebrados abordados en este trabajo.

En este sentido, se observa la importancia de los estudios tafonómicos para discriminar agregados de microvertebrados generados por acción humana de aquellos generados por depredadores. Estos últimos presentan mayor interés para trazar modelos paleoambientales, debido a que los depredadores -principalmente aves estrigiformes- se alimentan mayoritariamente de roedores sigmodontinos, los cuales por sus características estenoicas son sensibles a los cambios ambientales. Las interpretaciones paleoambientales constituyen una herramienta útil para entender los sistemas de subsistencia humana, que en conjunto, resultan imprescindibles para estudiar modelos de ocupaciones humanas.

Estos temas serán tratados en detalle en el capítulo 4. 


\section{Capítulo 3}

\section{ÁREA DE ESTUDIO}

\section{El ambiente del sur de Mendoza}

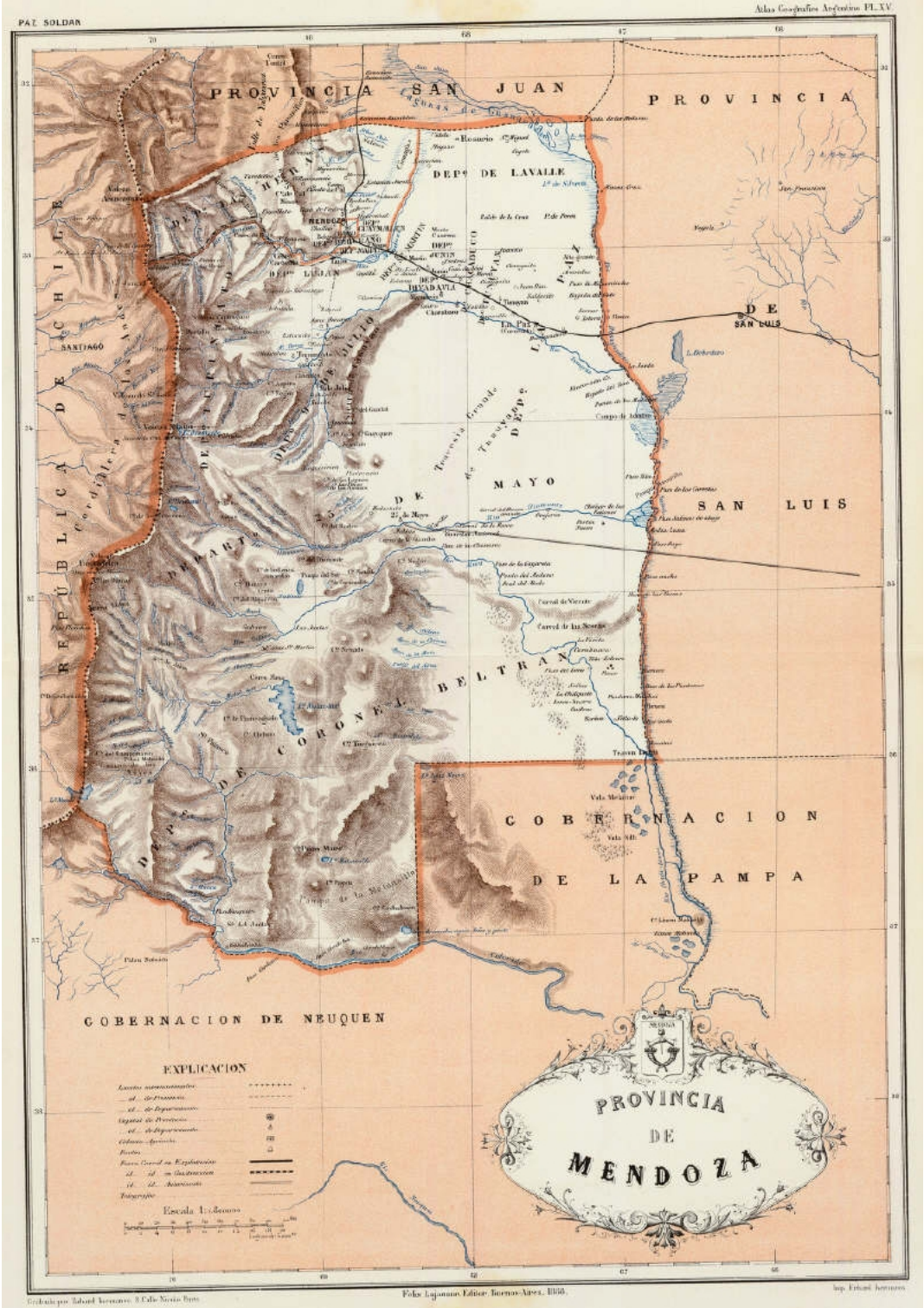

Mariano Felipe Paz Soldan

[Atlas Geográfico Argentino. 1888: 15] 



\section{3. ÁREA DE ESTUDIO. El ambiente del sur de Mendoza}

En este capítulo se realiza una descripción de las principales características ambientales y paleoambientales del sur de Mendoza. En primer término se abordan los aspectos geomorfológicos y climáticos. Posteriormente se describen los modelos biogeográficos (i.e., fitogeográfico y zoogeográfico) considerados para este estudio y la estructura faunística del área. Finalmente se reseñan los ítems con mayor incidencia en los cambios ambientales de la actualidad (i.e., ganadería y agricultura) y se detalla exhaustivamente el marco paleoambiental correspondiente al Pleistoceno tardío-Holoceno para el sur de Mendoza y áreas circundantes.

El área de estudio se enmarca dentro de la provincia de Mendoza, específicamente en su parte sur, la cuál está comprendida entre los $34^{\circ} 30^{\prime}-37^{\circ} 30^{\prime}$ Latitud Sur y $70^{\circ} 30^{\prime}-67^{\circ}$ Longitud Oeste (Figura 3.1). Se caracteriza por ser un área ambientalmente muy heterogénea, especialmente por la presencia de la cordillera de los Andes con alturas de hasta $5.000 \mathrm{~m}$ en su sector occidental, la cual imprime características topográficas y climáticas a toda la región. El piedemonte y la planicie oriental conforman las dos restantes estructuras topográficas. La presencia de la cordillera junto al predominio de los vientos provenientes del oeste, hacen del sur de Mendoza un paisaje de características áridosemiárido (Capitanelli, 1972). Los principales sistemas fluviales que drenan la región son los ríos Diamante, Atuel y Grande (Figura 3.2). 


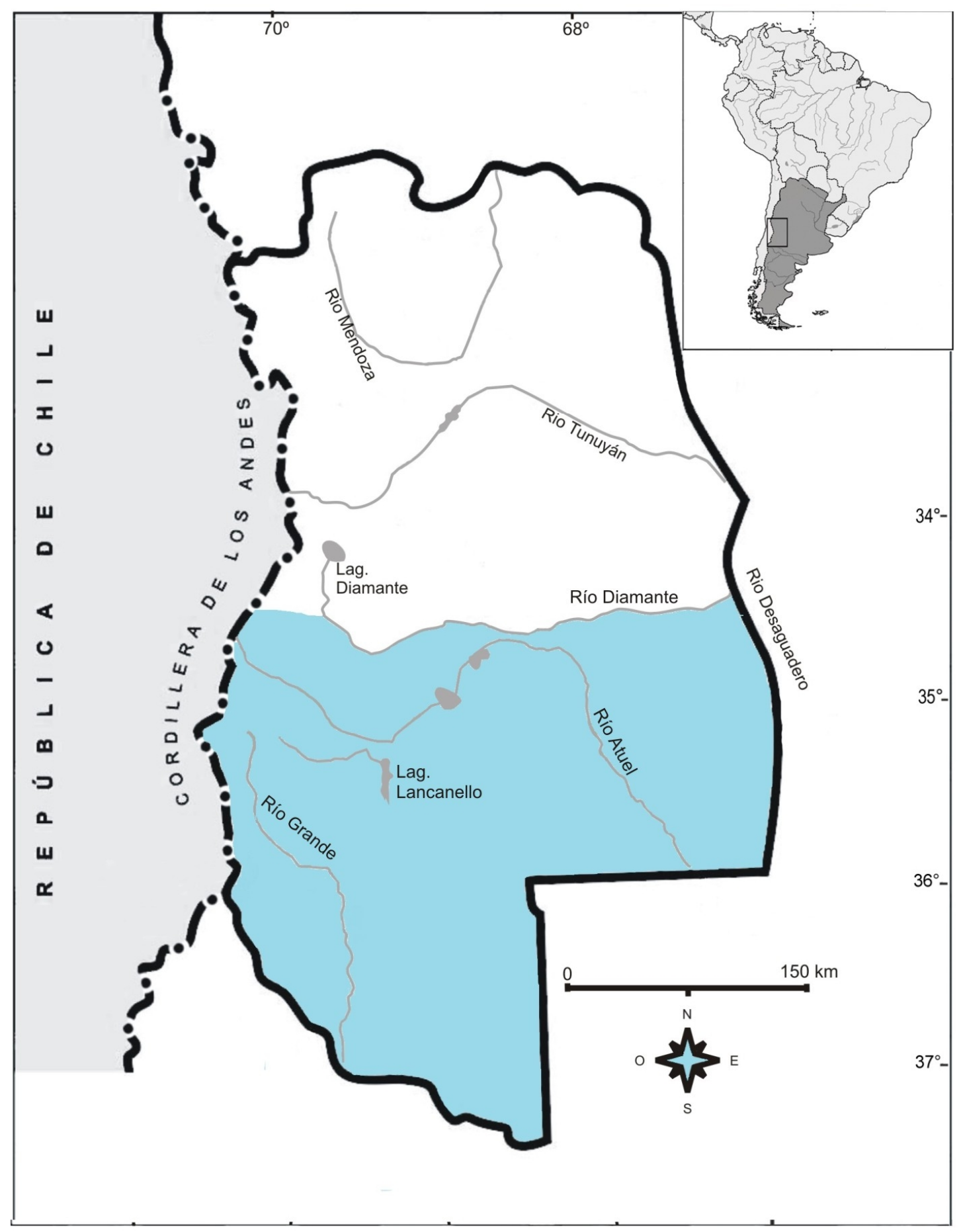

Figura 3.1. Mapa de la provincia de Mendoza mostrando el área de estudio. 


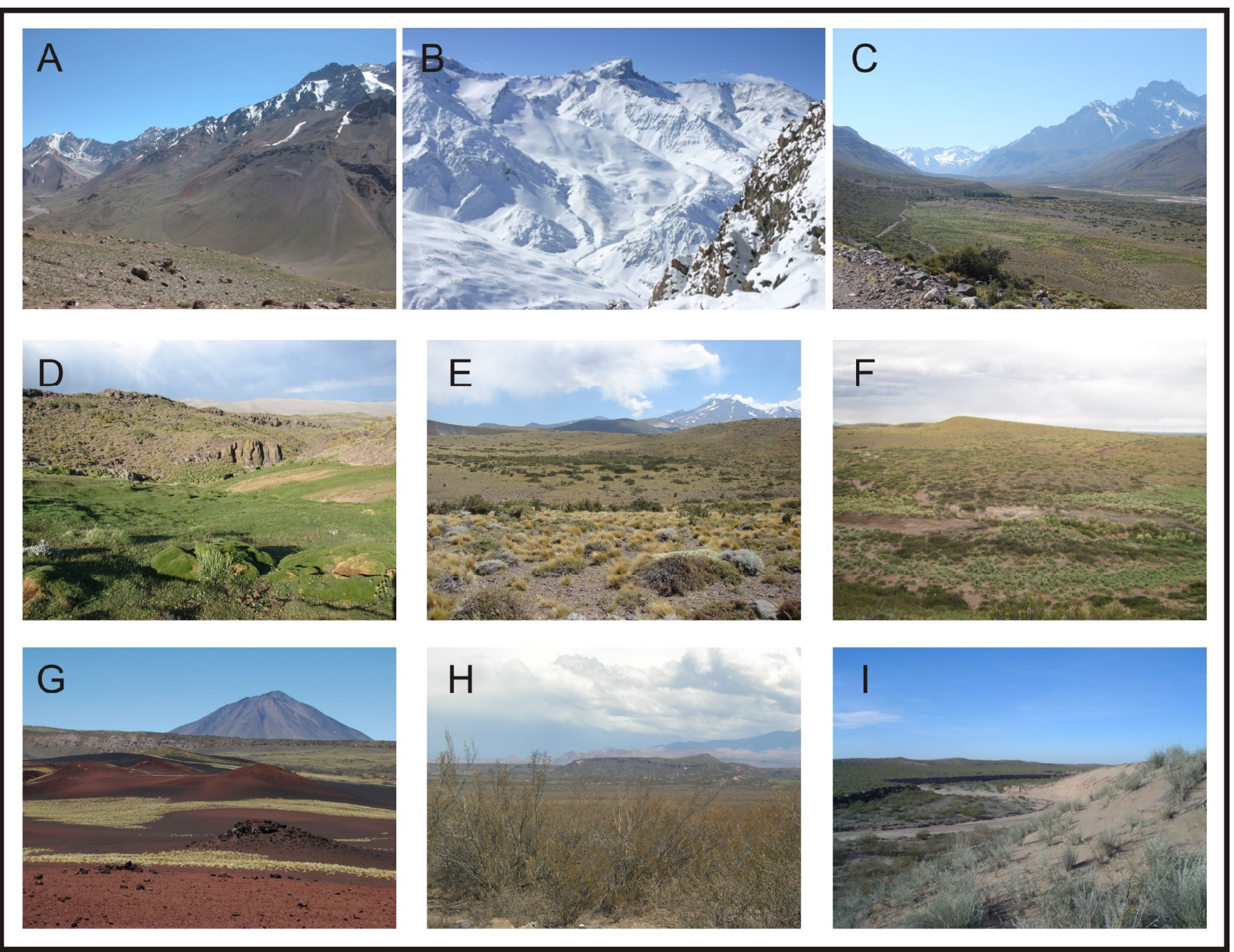

Figura 3.2. Tipos de ambientes del sur de Mendoza. A: cordillera-Altoandina; B: cordillera nevada (La Leñas); C: valle cordillerano (Atuel); D: vega cordillerana (arroyo Felipe); E: estepa Patagónica (Malargüe); F: estepa Patagónica con comunidad de higrófilas (Malargüe); G: Payunia; H: desierto del Monte (ca. Nevado). I: dunas con vegetación de Monte (San Rafael).

\subsection{Geomorfología}

Capitanelli (1972) diseño un modelo geomorfológico para la provincia de Mendoza, donde la misma puede ser subdividida en tres regiones principales: 1) región de las montañas, 2) región de las planicies y 3) región volcánica de la Payunia. 
La primera región se encuentra ubicada en el sector occidental de la provincia y comprende la extensa cadena montañosa con dirección norte-sur, donde se destaca la cordillera principal, plegamiento joven con alturas de hasta 6.900 m.s.n.m.; la cordillera frontal, macizo antiguo y discontinuo con alturas entre 6.000 y 5.000 m.s.n.m. que en el sur de Mendoza solo está representada en la cuenca del Río Diamante; y la cordillera de Uspallata o precordillera o en su parte norte, macizo antiguo con una altura media de 3.500 m.s.n.m. que no alcanza el sur de Mendoza. Está región está caracterizada por un volcanismo de arco y debido a los intensos vientos provenientes del oeste (westerlies), las erupciones de los volcanes ubicados en la vertiente chilena, cerca de la frontera internacional, influyen marcadamente en el sur de Mendoza. De norte a sur se destacan el Maipo, Cerro AzulDescabezado Grande, Planchón-Peteroa, Laguna del Maule, Tatara-San Pedro-Pellado, entre otros (Smithsonian Institution, abril 2011). Esta región es la que presenta mayor disponibilidad hídrica, debido a que cuenta con numerosos ríos y arroyos, lagunas, vertientes y nieves estacionales (Capitanelli, 1972).

La planicie abarca la parte oriental y las dos terceras partes de la provincia. Con un gradiente altitudinal que va desde $1.600 \mathrm{~m}$ en el piedemonte a $300 \mathrm{~m}$ en el Río Desaguadero. En esta región se emplazan el bloque de San Rafael, sierras y algunas cumbres aisladas como la del volcán Diamante de 2.800 m.s.n.m. La planicie está formada por sedimentos aluviales depositados por el Río Diamante y el Río Atuel, los cuales son cubiertos o se superponen por amplios campos de dunas. Debido a diversos episodios tectónicos la franja del piedemonte está compuesta por varios abanicos aluviales y superficies agradacionales y se encuentra dividida en tres depresiones bien marcadas, las cuales llevan por nombres la depresión del Mendoza-Tunuyana, en el norte de la provincia; la depresión de los Huarpes ubicada entre el área de montanea y el bloque de San Rafael; y la depresión de las salinas del Diamante y Llancanelo, en la frontera noroeste de la región volcánica de la Payunia. En esta región la disponibilidad hídrica está acotada principalmente a los cauces de los ríos Atuel, Diamante, Grande y Malargüe y en algunas vertientes focalizadas (Capitanelli, 1972).

La región volcánica de la Payunia o Payenia abarca un área extensa $\left(30.000 \mathrm{~km}^{2}\right)$ desde la depresión de la laguna de Llancanelo y el Cerro Nevado en el norte, hasta el curso del Río Grande en el oeste, el norte de Neuquén y oeste de La Pampa (Polanski, 1954). Está región 
presenta elementos de la Planicie oriental y está caracterizada por un relieve muy irregular debido al intenso vulcanismo de retroarco, campos de dunas y sistemas fluviales efímeros, destacándose principalmente los campos volcánicos del Cerro Nevado en el sector norte y del Payún-Matrú en el sur (Polanski, 1954). El Cerro Nevado (35³4'50.30"S, 68²9'03.41"O; 3810 m.s.n.m.), es el mayor edificio del campo volcánico y esta construido principalmente por traquiandesitas de ca. 1,32 Ma (Holmberg, 1973; Quidelleur et al., 2009). En este campo volcánico se han detectado numerosos conos volcánicos pequeños y 23 flujos de lava con antigüedades que varían entre ca. 2 y 1 Ma (Quidelleur et al., 2009), lo cuales previamente se habían considerado pertenecientes al Plioceno (Bermudez et al., 1993). El edificio principal del campo volcánico Payún Matru (36²5'0"S, 69¹2'0"O; 3.680 m.s.n.m.) corresponde a un estratovolcán en escudo, cuya caldera alcalina de $8 \times 10$ km tiene una antigüedad de ca. $168 \mathrm{ka}$ AP. Las erupciones basálticas de Post-caldera han producido más de 300 centros eruptivos, 30 domos de lava traquiandesíticos y grandes extensiones de coladas basálticas-traquíticas, bombas y escoriales, a lo largo de la fisura que atraviesa al volcán principal. Entre los volcanes satélites que acompañan al edificio principal se destacan el Morado hacia el oeste de ca. 2.400 m.s.n.m., el Santa María hacía el noroeste de $c a .1 .900$ m.s.n.m. y el Payun Liso hacia el sur de 3.838 m.s.n.m. (Llambías, 1966; González Díaz, 1969, 1970, 1972; Inbar y Risso, 2001; Pasquaré et al., 2008; Smithsonian Institution, abril 2011). En este campo volcánico se registraron eventos de actividad durante el Pleistoceno y Holoceno hasta ca. 7 ka AP (Germa et al., 2010). En la región de la Payunia, no hay cursos de agua permanentes, solo algunas vertientes próximas a las elevaciones más altas como el Cerro Nevado y la altiplanicie del Payun-Matrú (Capitanelli, 1972).

\subsection{Clima}

El clima de la provincia de Mendoza es muy complejo y dinámico, los diversos factores de orden geográfico producen transformaciones en la confluencia de las diferentes masas de aires que afectan a esta provincia (Capitanelli, 1967). En este sentido, para alcanzar un conocimiento elemental de la climatología de una región determinada es muy importante integrar los factores atmosféricos con los geomorfológicos (Capitanelli, 1967). 
Capitanelli (1972) en base a características del clima, relieve y la vegetación planteó cuatro unidades morfoclimáticas para la provincia de Mendoza: 1) las grandes montañas, 2) planicies, 3) el borde oriental de la gran montaña y precordillera y 4) la región volcánica de la Payunia.

La primera unidad está dominada por las masas de aire emitidas por el anticiclón del Pacífico (westerlies), con precipitaciones invernales de tipo nival. En la parte norte de la provincia las precipitaciones son escasas variando de 200 a $600 \mathrm{~mm}$., mientras que hacia el sur son más abundantes (600 a 1000 mm.). El mencionado autor realizó una división de las grandes montañas en subunidades morfoclimáticas, distinguiendo las altas cumbres y planicies por arriba de los 3.500 m.s.n.m., afectadas por un clima glaciar o periglaciar; un sector entre 3.000. y 2.000 m.s.n.m., con un clima menos glaciar o periglaciar atenuado; y finalmente por debajo de esta altitud hasta los 1.800 m.s.n.m. En las áreas de montaña del sur de Mendoza, especialmente hasta los 3.000 m.s.n.m., desaparecen las estaciones y las variaciones climáticas pueden ser divididas en dos grandes momentos con fuertes influencias para la vida animal y cultural de la región. La invernada y la veranada (Volkheimer, 1978).

La unidad de las planicies esta dominada por las masas de aire del anticiclón del Atlántico, con precipitaciones de verano que varían entre los 350 y $250 \mathrm{~mm}$. y está afectada por vientos Foehn (Zonda). La influencia de la depresión del noroeste ocasiona un régimen térmico estival y cálido en el norte de la provincia, mientras que la acción más eficiente de las masas de aire de rumbo sureste causa un régimen térmico estival más fresco en el sur. Las planicies presentan suelos poco evolucionados y con escasa materia orgánica y una físonomía del paisaje árido o semiárido, con balances hídricos deficientes durante todo el año, lo que genera el desarrollo de una vegetación del tipo Monte (ver Fitogeografía).

La unidad del borde oriental de la gran montaña y precordillera presenta un clima de transición por la confluencia de las masas de aire de la depresión del noroeste y de los centros anticiclónicos del Pacífico y del Atlántico. Esta unidad, coincidente con el piedemonte, presenta mayores temperaturas y menor régimen de precipitaciones (300 a 200 mm.) respecto de la gran montaña.

Por último, la región volcánica de La Payunia está dominada principalmente por las masas de aire del anticiclón del Pacífico en el sector oeste y central y por el anticiclón del 
antlántico en la faja este, con precipitaciones invernales de tipo pluvial y nival. Las precipitaciones anuales oscilan entre $400 \mathrm{~mm}$. y $200 \mathrm{~mm}$., definiéndola como una región árida semiárida, donde se desarrolla una vegetación de tipo Monte al este y Patagónica al oeste (ver Fitogeografía). En el área del valle del Río Grande se observan disparidades térmicas bien marcadas, con veranos templados e inviernos muy fríos. Las precipitaciones se producen especialmente durante la estación fría y los vientos son fuertes y frecuentes, principalmente en primavera y otoño. Entre la cordillera y los sistemas fluviales del Río Grande, arroyo Colorado y Río Barrancas las condiciones térmicas son más favorables y las precipitaciones frecuentemente suceden en forma de nieve.

\subsection{Fitogeografía}

De acuerdo al modelo fitogeográfico definido por Cabrera (1976), la provincia de Mendoza está comprendida por cuatro unidades fitogeográficas: Provincia Fitogeográfica del Monte, Provincia Fitogeográfica Puneña, Provincia Fitogeográfica Patagónica y Provincia Fitogeográfica Altoandina. La primera pertenece al Dominio Chaqueño y las restantes al Dominio Andino Patagónico. No obstante, en la región sur de Mendoza se encuentran presentes sólo las provincias del Monte, Patagónica y Altoandina (Figura 3.3).

La provincia del Monte coincide con la llamada Diagonal Árida Sudamericana, la cual abarca una parte importante de este subcontinente, desde el norte de Perú a lo largo de los Andes hasta el sur de Neuquén y continuando a través de la Patagonia hasta aproximadamente la desembocadura del Río Chubut (Bruniard, 1982).

Está constituida por una interfase entre diferentes elementos de circulación atmosférica, tales como los vientos del oeste de latitudes medias, una depresión estival del subcontinente y las células de alta presión subtropical de los océanos Pacifico sur y Atlántico sur (Abraham et al. 2000). El desierto del Monte ocupa la mayor parte de la superficie de Mendoza, en una amplia franja correspondiente a la planicie oriental. Se caracteriza por precipitaciones de entre 80 y $200 \mathrm{~mm}$ promedio anual, mientras que el promedio anual de temperaturas oscila de 13 a $15,5^{\circ} \mathrm{C}$. La vegetación predominante es de tipo estepa arbustiva xerófila, sammófila o halófila, dominada por zigofiláceas pertenecientes a los géneros Larrea (principalmente L. divaricada y L. cuneifolia), 
Bulnesia y Plectrocarpa. Además, son frecuentes otros arbustos como Prosopis torcuata, Prosopis alpataco, Cercidium praecox, Chuquiraga erinacea, Cassia aphylla y algunas poblaciones aisladas de especies arbóreas como Geophroea decorticans, Prosopis alba, Prosopis flexuosa y Salix humboldtiana, desarrollándose en bolsones y llanuras de suelos arenosos o pedregoso-arenosos y con escasa materia orgánica (Capitanelli, 1972; Roig, 1972; Cabrera, 1976; Cabrera y Willink, 1980).

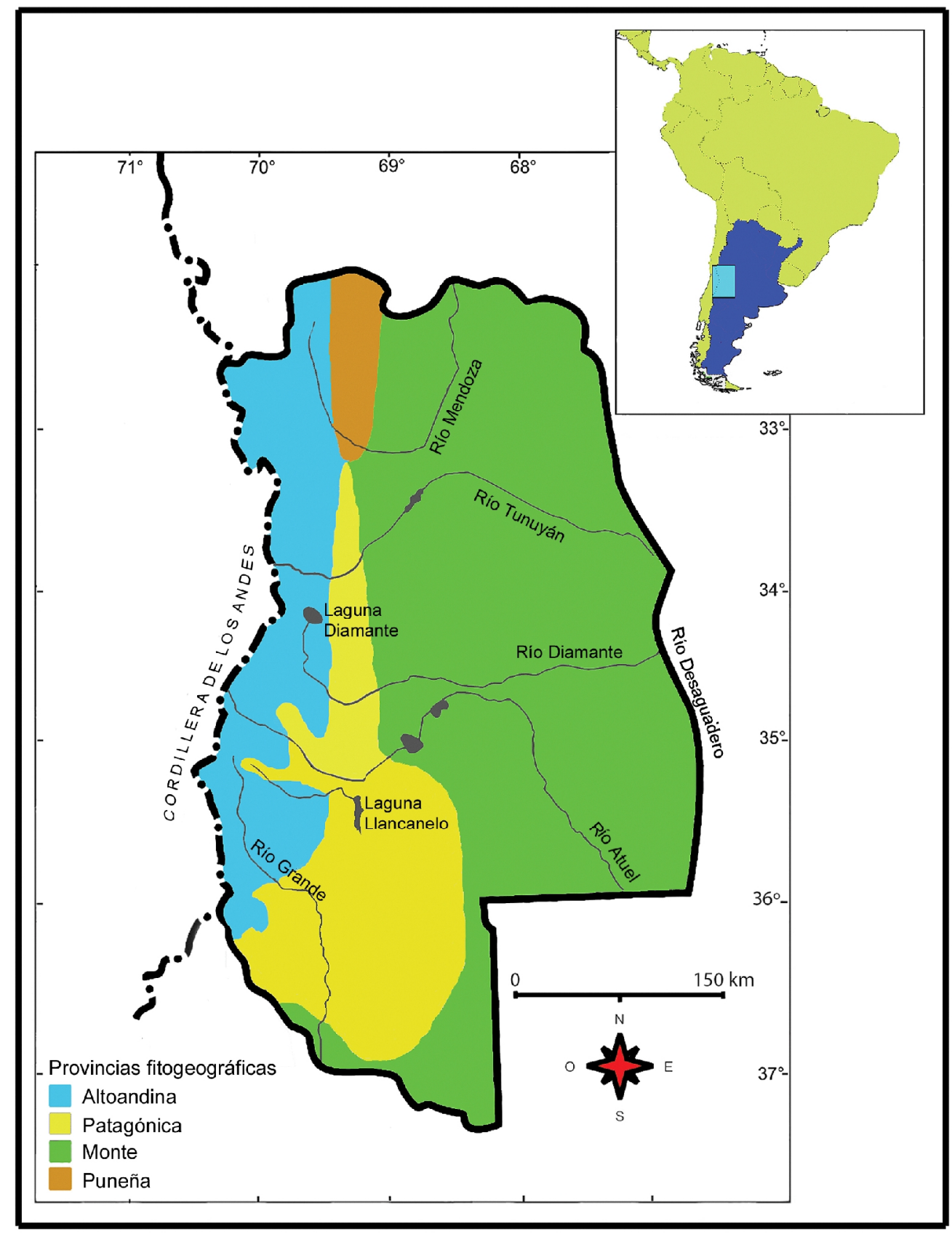

Figura 3.3. Fitogeografía de la provincia de Mendoza siguiendo a Cabrera (1976). 
La provincia Patagónica se extiende desde el nivel del mar hasta los $2.200 \mathrm{~m}$ de altitud, desde el piedemonte andino en el centro de Mendoza hacia el sur, ampliándose gradualmente hasta cubrir el sector occidental de Neuquén, Río Negro y la mayor parte de Chubut, Santa Cruz y el nordeste de Tierra del Fuego. Esta unidad se caracteriza por un clima frío y seco, con intensos vientos provenientes de las masas de aire emitidas por el anticiclón del Pacífico, con precipitaciones invernales de tipo nival (600 a $1000 \mathrm{~mm}$.), siendo la vegetación dominante las estepas arbustivas, de caméfitos y herbáceas, y también las estepas halófilas, sammófilas y las vegas, las cuales se desarrollan sobre suelos basálticos, arenosos, pedregosos y pobres en materia orgánica (Capitanelli, 1972; Cabrera, 1976). La comunidad esteparia está principalmente dominada por Mulinum spinosum, Ephedra ochreata, Chuquiraga rosulata y especies de los géneros Azorella, Adesmia, Poa, Senecio y Maihuenia (Roig, 1972; Cabrera, 1976). Es importante destacar que dentro de esta provincia fitogeográfica se encuentra el Distrito de la Payunia (sensu Cabrera, 1976), donde se desarrollan las estepas de "solupe" dominadas principalmente por E. ochreata, Lycium chilense, M. spinosum, Oligocladus patagonicus, Junellia seriphioides y Larrea nitida. En este distrito también son distintivas las formaciones de estepas de C. rosulata, a las que pueden asociarse estepas de Grindelia chiloensis, Berberis grevilleana y Senecio covasii (Roig, 1972; Cabrera, 1976).

Finalmente, la provincia Altoandina se extiende a lo largo de la cordillera de los Andes, desde el límite con Bolivia hasta Tierra del Fuego, por encima de los 2.200 hasta los 4.400 m. de altitud en el límite máximo de la cubierta vegetal. Particularmente en Mendoza aparece por arriba de los 3.000 m.s.n.m. (Cabrera, 1976). Esta unidad se caracteriza por poseer un clima frío con un régimen de precipitaciones invernales (níveas), las cuales provienen del anticiclón del Pacífico. Las estepas graminosas, de caméfitos y arbustivas predominan en esta provincia y son comunes las vegas y los semidesiertos de líquenes, destacándose los géneros Adesmia, Casia, Oxalis, Verbena y Mulinum, que se desarrollan sobre suelos rocosos, pedregosos o arenosos (Cabrera, 1976).

\subsection{Zoogeografía y caracterización faunística}


De acuerdo al modelo zoogeográfico propuesto por Ringuelet (1961) para la Argentina, la provincia de Mendoza se encuentra ubicada en la Región Neotropical y Subregión AndinoPatagónica, principalmente formando parte de los Dominios Andino, Patagónico y Central o Subandino (Figura 3.4). Esta área esta integrada principalmente por una fauna de tipo erémica*, con algunos integrantes de abolengo brasílico.

No obstante, Yepes (1936a) fue el primer autor en brindar una caracterización zoogeográfica de los mamíferos de Mendoza, definiendo dos categorías de faunas en base a diferencias en la fisiografía de la provincia: la andina y la subandina. Este autor enmarcó su estudio en relación con las provincias zoogeográficas argentinas delimitadas por Lahille (1899). En este sentido, de las ocho provincias definidas por Lahille (1899) solo dos fueron incluidas en Mendoza por el mencionado autor (Andina y Subandina). Sin embargo, Yepes (1936a) en esta primera aproximación zoogeográfica elevó hasta cinco la cantidad de provincias zoogeográficas comprendidas en Mendoza (Chilena, Andina, Subandina, Patagónica y Paraneo-Pampeana) y documenta entre otras especies al roedor Ctenomys mendocinus (tuco tuco mendocino) para la provincia Chilena; al félido Puma concolor (puma), al cánido Lycalopex culpaeus (zorro colorado), a los roedores Lagidium viscacia (chinchillón de la sierra) y Abrocoma vaccarum (rata chinchilla mendocina) para la provincia Andina; al marsupial marmosino Thylamys pallidior (marmosa pálida), al camélido Lama guanicoe (guanaco), a los félidos Puma yagouaroundi (yaguarundí) y Leopardus geoffroyi (gato montes), al cánido Lycalopex griseus (zorro gris chico), a los roedores Ctenomys pontifex (tuco tuco marrón), Microcavia australis (cuis patagónico) y Galea leucoblephara (cuis común), a los xenartros Chaetophractus vellerosus (piche llorón) y Tolypeutes matacus (mataco) para la provincia Subandina; al mustélido Lyncodon patagonicus (huroncito patagónico), a los roedores Myocastor coipus (coipo) y Dolichotis patagonum (mara), al xenartro Zaedyus pichiy (pichi patagónico) para la provincia Patagónica; y al marsupial Didelphis albiventris (comadreja overa), al félido Leopardus pajeros (gato de los pajonales), al mefítido Conepatus chinga (zorrino común), al tayasuido Tayassu tajacu (pecarí de collar), al roedor Lagostomus maximus (vizcacha), a los

\footnotetext{
* Ringuelet (1961) emplea el término de fauna erémica cuando se refiere a taxones animales que habitan en ambientes Andino-Patagónicos, en oposición a fauna brasílica o hílea de pertenencia Guayano-Brasileña.
} 
xenartros Chaetophractus villosus (peludo) y Chlamyphorus truncatus (pichiciego menor) para la provincia Paraneo-Pampeana.

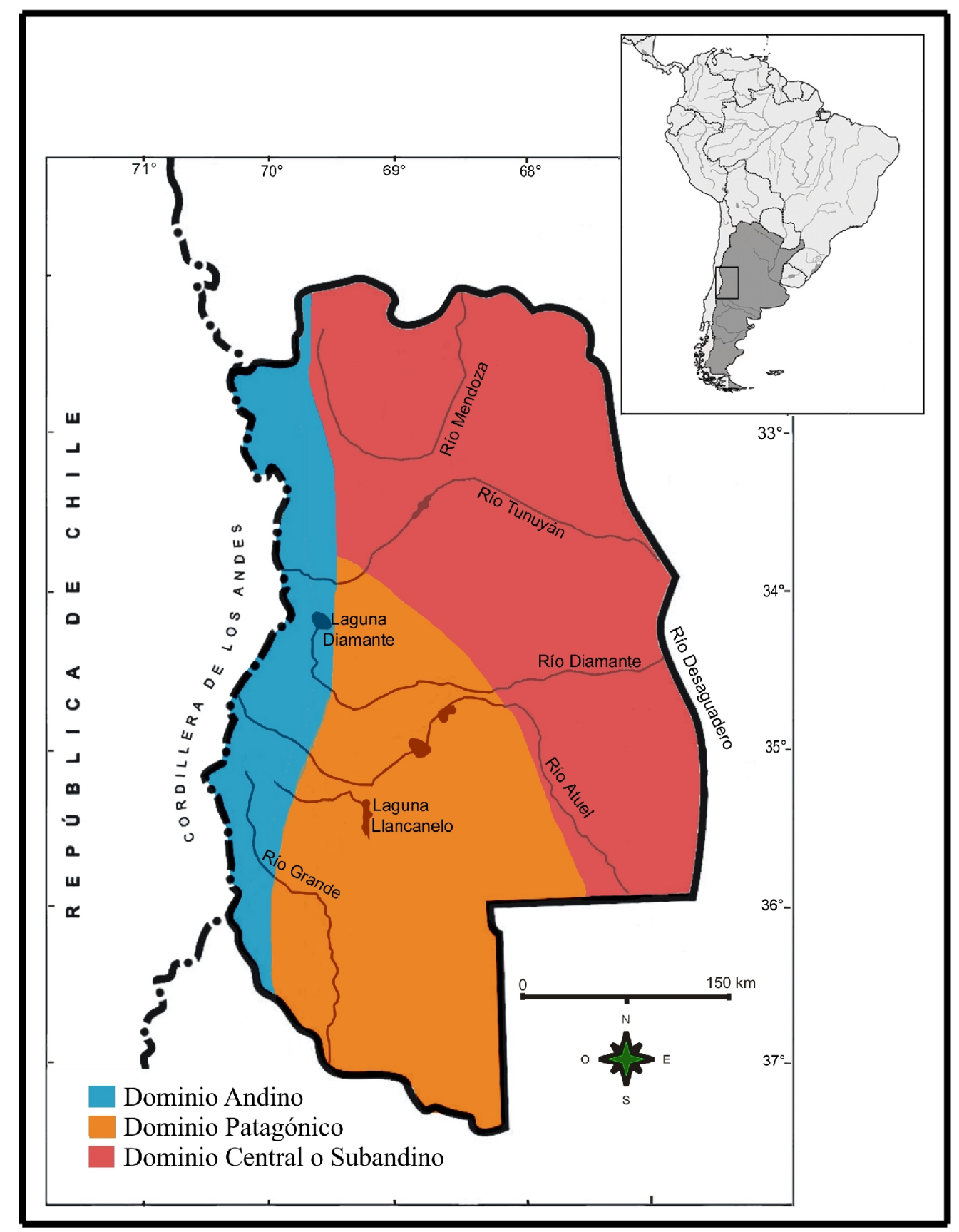

Figura 3.4. Zoogeografía de la provincia de Mendoza siguiendo a Ringuelet (1961).

Por su parte, Roig (1972) fue quién realizó un esquema zoogeográfico detallado para la provincia de Mendoza, mediante una perspectiva ecológica y geográfica del poblamiento 
de una amplia variedad faunística. En tal sentido, el autor distinguió tres unidades principales: 1) Fauna de las montañas y precordillera, 2) fauna de las llanuras y 3) fauna de la estepa Patagónica.

La primera unidad corresponde a los altos Andes, por arriba de los 2.300 m.s.n.m. hasta la terminación de la cubierta vegetal. La fauna que habita esta región se encuentra principalmente adaptada a condiciones extremas de temperatura y presión atmosférica. Se pueden evidenciar algunas asociaciones diferenciadas en distintos microambientes tales como los pastizales de altura, ubicados entre los 2.500 y los 4.000 m.s.n.m donde se reúne la mayor diversidad faunística; los peladales, los cuales están presentes desde los 3.000 hasta los 4.500 m.s.n.m. y las estepas arbustivas situadas por debajo de los 2.500 m.s.n.m., tanto en el macizo principal de los Andes, en la precordillera y en las formaciones volcánicas elevadas de la Payunia.

Entre la mastofauna de montaña se destacan los félidos P. concolor y Leopardus jacobita (gato andino), los cánidos L. culpaeus y L. griseus, el mefítido C. chinga, el camélido L. guanicoe, los roedores D. patagonum, L. viscacia, C. mendocinus y M. australis, el quiróptero Myotis dinelli (murcielaguito amarillento) y los xenartros C. villosus y Z. pichiy (Roig, 1972; Barquez et al., 2006)*.

Las aves están representadas entre otras por las paleognatas Pterocnemia pennata (choique) y Nothoprocta pentlandii (inambú silvador), los anátidos Lophoneta specularioides (pato crestón) y Merganeta armata (pato corta corriente), los charadridos Vanellus chilensis (tero común) y Nycticryphes semicollaris (aguatero), el colúmbido Metriopelia melanoptera (paloma andina), el thinocórido Attagis gayi (agachona grande), los passeriformes Geositta isabellina (caminera grande), Geositta cunicularia (caminera común), Geositta rufipennis (caminera colorada), Cynclodes fuscus (remolinera común), Cinclodes atacamensis (remolinera castaña) y Sturnella loyca (loica), y numerosas aves rapaces tales como Vultur gryphus (cóndor), Geranoaetus melanoleucus (águila mora), Buteo polysoma (aguilucho

\footnotetext{
*Las especies se nominaron siguiendo la obra compilada de Barquez et al. (2006), la cual comprende en líneas generales la clasificación taxonómica más actualizada de los mamíferos de Argentina. No obstante, para las especies que en dicha obra presentaron algún tipo de error nomenclatural, se corrigieron en base a Wilson y Reeder (2005). Los cricétidos serán tratados en detalle en el capítulo 5.
} 
común), Phalcoboenus albogularis (carancho de la sierra), Caracara plancus (carancho), Milvago chimango (chimango), Falco peregrinus (halcón peregrino), Falco sparverius (halconcito colorado) y Bubo magellanicus (tucúquere) (Roig, 1972; Olrog y Pescetti, 1991; Mazar Barnett y Pearman, 2001; Narosky y Izurieta, 2003).

Los reptiles que exhiben una distribución altitudinal bien definida son entre otros, los ofidios Bothrops neuwiedii (yarará chica) y Lystrophis semicinctus (falsa coral) y los saurios Liolaemus bibroni, Liolaemus flavipiceus (lagartijas) y Pristidactylus scapulatus (matuasto matutino) (Roig, 1972; Cei, 1986; Scolaro, 2006).

Los anfibios anuros Rhinella spinulosa (sapo andino) y Alsodes montanus (sapo) están bien representados en la cordillera andina (Roig 1972, Cei y Castro 1978).

La ictiofauna nativa característica de los arroyos y ríos de la montaña son en su mayor parte siluriformes tales como Trichomycterus borelli (bagre de torrente) y Hatcheria macraei (pique cuyano) (Ringuelet et al., 1967; Roig, 1972; Villanueva y de la Mota, 1994; Villanueva y Roig, 1995).

La segunda unidad (Fauna de las Llanuras) abarca las extensas llanuras del este, donde se observan grandes formaciones medanosas, loésicas y salitrales, que incluyen pastizales, jarillales y bosques abiertos de Prosopis spp. y G. decorticans. En el sector noreste, la fauna exhibe elementos de estirpe Chaqueño, mientras que en el sur son típicamente patagónicos y algunos provenientes de la pampasia.

Los mamíferos de las llanuras están representados entre otros por los marsupiales marmosinos $T$. pallidior y $D$. albiventris, los félidos $P$. concolor, $P$. yagouaroundi y $L$. geoffroyi, $\operatorname{los}$ xenartros $C$. vellerosus, C. villosus, $T$. matacus, Z. pichiy y C. truncatus, el quiróptero Tadarida brasiliensis (moloso común), los roedores D. patagonum, L. maximus, M. australis, G. leucoblephara, Tympanoctomys barrerae (rata vizcacha colorada) y numerosos cricétidos (ver capitulo 5) (Roig, 1972; Barquez et al., 2006).

Entre las aves más características de la llanura se encuentran las paleognatas Rhea americana (ñandú común), Eudromia elegans (martineta), Nothura darwinii (inambú pálido) y Nothura maculosa (inambú chico común), el psittaciforme Cyanoliseus patagonus (loro barranquero), las rapaces estrigiformes Tyto alba (lechuza de campanario), Athene cunicularia (lechucita de las vizcacheras), Asio flammeus (lechuzón campestre), las rapaces falconiformes Buteo albicaudatus (aguilucho cabeza negra), Parabuteo unicinctus 
(gavilán mixto), Accipiter bicolor (esparvero variado) y Cathartes aura (jote cabeza roja), los colúmbidos Zenaida auriculata (torcaza), Columbina picui (torcacita) y Columba picazuro (picazuró), el caprimúlgido Podager nacunda (ñacundá) y los passeriformes Furnarius rufus (hornero) y Pseudoseisura lophotes (cacholote castaño) (Roig, 1972; Olrog y Pescetti, 1991; Mazar Barnett y Pearman, 2001; Narosky y Izurieta, 2003).

Entre los reptiles de la llanura se encuentran el quelonio Chelonoidis chilensis (tortuga terrestre), los ofidios Bothrops ammodytoides (yarará ñata), B. neuwiedii, Micrurus pyrrhocryptus (coral), Boa constrictor (boa de las vizcacheras), Philodryas trilineata (culebra ratonera), Philodryas psammophidea (culebra arenera), los saurios Tupinambis rufescens (lagarto colorado), Homonota darwini (gecko) y especies de los géneros Teius, Pristidactylus, Diplolaemus, Leiosaurus, Liolaemus y Phymaturus (lagartijas) (Roig, 1972; Cei, 1986; Scolaro, 2006).

Los anfibios anuros que habitan la llanura forman parte de un grupo poco variado de anuros, representados por Rhinella arenarum (sapo común), Leptodactylus ocellatus (rana criolla), Leptodactylus bufonius (rana vizcachera), Pleurodema nebulosum (ranita de monte) y Odontophrynus occidentalis (escuercito) (Roig, 1972; Cei y Castro, 1978).

Entre los peces que residen en los ríos, arroyos de la llanura se hallan los siluriformes Trichomycterus heterodontum, Trichomycterus mendozensis (bagres de torrente mendocinos), Trichomycterus areolatus (bagre chico) y H. macraei, el pércido Percichthys trucha (perca) y el simbranquiforme Synbranchus marmoratus (anguila criolla) (Ringuelet et al., 1967, Roig, 1972; Villanueva y de la Mota, 1994; Villanueva y Roig, 1995).

Por último la fauna de la estepa Patagónica, comprende el extremo sur de la provincia en forma de cuña hacia el centro de la misma, incluyendo parte de los valles cordilleranos y la franja oeste de de la zona árida y volcánica de la Payunia.

La composición mastozoológica de la estepa Patagónica se destaca por la presencia entre otras especies de el marsupial Lestodelphys halli (comadrejita patagónica), el camélido L. guanicoe, los félidos P. concolor, P. yagouaroundi y L. geoffroyi, el cánido L. culpaeus, los mustélidos L. patagonicus y Galictis cuja (hurón menor), el xenartro Z. pichiy, el quiróptero T. brasiliensis, los roedores M. coipus, D. patagonum, L. maximus, C. pontifex y numerosos cricétidos (ver capítulo 5) (Roig, 1972; Barquez et al., 2006). 
Las aves de la estepa Patagónica conforman un grupo muy heterogéneo con formas tanto terrestres como acuáticas y entre las numerosas especies se hallan las paleognatas $P$. pennata y E. elegans, los passerifomes Asthenes modesta (canastero pálido), Phryngilus unicolor (yal plomizo) y Zonotrichia capensis (chingolo), los anátidos Chloephaga picta (cauquén común), Coscoroba coscoroba (coscoroba), Cygnus melanocorypha (cisne cuello negro) y Anas flavirostris (pato barcino), los podicipediformes Rollandia rolland (macá común) y Podicephorus major (macá grande), el phoenicoptériforme Phoenicopterus chilensis (flamenco austral), los ardeidos Ardea alba (garza blanca) y Ardea cocoi (garza mora), los rállidos Rallus sanguinolentus (gallineta común), Fulica leucoptera (gallareta chica) y Fulica armillata (gallareta ligas rojas) y una composición de aves rapaces similar a la observada en los ambientes anteriores (Roig, 1972; Olrog y Pescetti, 1991; Mazar Barnett y Pearman, 2001; Narosky e Izurieta, 2003).

Los reptiles de la estepa Patagónica corresponden en su mayoría a formas afines a los ambientes áridos y semi-áridos y entre otros habitan los ofidios $B$. ammodytoides y $B$. neuwiedii, y numerosos saurios tales como H. darwini, Phymaturus payuniae (lagarto cola de piche), Leiosaurus bellii (matuasto de bell), Liolaemus elongatus y Liolaemus donosobarrosi (lagartijas) (Roig, 1972; Cei, 1986; Scolaro, 2006).

Entre los anfibios que habitan la estepa Patagónica se encuentran bien representado Pleurodema bufoninum (ranita de cuatro ojos) (Roig ,1972; Cei y Castro ,1978).

Los peces que habitan en los ríos, arroyos y lagunas de la estepa Patagónica son los siluriformes T. heterodontum, T. areolatus, H. macraei y Diplomystes cuyanus (otuno cuyano), el aterínido Odonthesthes hatcheri (pejerrey patagónico) y el agnato Geotria australis (lamprea) (Ringuelet et al., 1967; Roig, 1972; Villanueva y de la Mota, 1994; Villanueva y Roig, 1995).

\subsection{Fauna silvestre introducida}

En la provincia de Mendoza son muy comunes los mamíferos silvestres introducidos como el suido Sus scrofa (jabalí) y los lagomorfos Lepus europaeus (liebre europea) y Oryctolagus cuniculus (conejo europeo) (Novillo y Ojeda, 2008). Estas especies presentan una dieta amplia, elevada taza reproductiva y alta capacidad de dispersión, produciendo un 
fuerte impacto sobre el suelo, la vegetación y la fauna nativa, y en el caso de los lagomorfos especialmente en sus equivalentes ecológicos (véase Novillo y Ojeda, 2008). $S$. scrofa se introdujo inicialmente en las provincias de La Pampa y Neuquén a principios del siglo XX y luego se dispersó por el centro-este de la Argentina y por el centro-sur de la cordillera de los Andes hasta el norte de Santa Cruz (Navas, 1987; Novillo y Ojeda, 2008). L. europaeus ingresó primeramente en la provincia de Santa Fe a fines del siglo XIX y rápidamente cubrió casi toda la extensión continental de Argentina (Bonino, 2006). La introducción de O. cuniculus en la Argentina se dio originalmente en las Islas Malvinas a fines del siglo XIX y posteriormente en el extremo sur de la Patagonia a principios del siglo XX. A mediados del siglo XX se introdujo en la provincia de Neuquén y unas décadas más tarde se expandió hasta el suroeste de la provincia de Mendoza (Bonino, 2006; Novillo y Ojeda, 2008).

Por otra parte, en la provincia de Mendoza se encuentran tres especies de múridos exóticos: Rattus norvegicus (rata parda), Rattus rattus (rata negra) y Mus musculus (ratón doméstico). Estos roedores originarios de Asia, fueron introducidos en America durante los siglos XVI y XIX en forma inadvertida, a partir de barcos provenientes de Europa (Navas, 1987; Novillo y Ojeda, 2008). Se caracterizan por ser omnívoros, de hábitos peridomésticos, muy comunes en ambientes urbanos y suburbanos de casi toda la Argentina, pudiendo habitar áreas naturales (Redford y Eisemberg, 1992; Novillo y Ojeda, 2008).

En lo que concierne a las aves, las especies exóticas silvestres más comunes en la provincia de Mendoza son el colúmbido Columba livia (paloma casera), el fasiánido Lophortyx californica (codorniz de california) y el ploceido Passer domesticus (gorrión). C. livia originaria de Europa y Asia, fue introducida a la Argentina por primera vez en Buenos Aires en el siglo XVI y luego se expandió por todo el país, tanto en zonas urbanas como en ambientes naturales. L. californica ingresó a la Argentina desde Norteamérica a mediados del siglo XX, primeramente en la provincia de Neuquén y posteriormente se dispersó por el área andina de Mendoza y San Juan. $P$. domesticus es una especie peridoméstica introducida desde Europa en la segunda mitad del siglo XIX, actualmente se lo encuentra en toda la Argentina (Navas, 1987). 
Las poblaciones de especies nativas de peces disminuyeron notablemente debido a la introducción en el siglo XX de especies exóticas tales como los salmónidos Salmo gairdnieri (trucha arco iris), oriunda de la costa oeste de Norteamérica, Salmo fario (trucha marrón), originaria de Europa y norte de África y Salvelinus fontinalis (trucha de arroyo), oriunda del noreste de América del Norte; de aterínidos como Odonthesthes bonariensis (pejerrey o flecha de plata), proveniente de Buenos Aires y Entre Ríos; y ciprínidos como Cyprinus carpio (carpa común), originaria de Asia (Ringuelet et al., 1967; Villanueva y de la Mota, 1994; Villanueva y Roig, 1995).

\subsection{Ganadería y Agricultura}

El aprovechamiento del agua de los grandes cursos fluviales de la provincia de Mendoza ha permitido el desarrollo de las actividades agrícolas. Sin embargo, la ganadería (extensiva) se concentra principalmente en áreas sin riego, en las llanuras orientales y en algunos valles cordilleranos (Abraham, 2000).

La actividad agraria más significativa de Mendoza es el cultivo de la vid (Vitis vinifera), aportando el 45\% de la producción agropecuaria de la provincia (Van den Bosch, 2008). Con 160.704 ha. cultivadas constituye la provincia vitivinícola más importante de la Argentina *. Este cultivo se desarrolla en las zonas con riego artificial (oasis) de Maipú, San Martín, Valle de Uco y San Rafael (Van den Bosch, 2008). El cultivo de olivo (Olea europaea) sigue en importancia, producido especialmente en el oasis de Maipú y concentra gran parte producción nacional (Van den Bosch, 2008).

El resto de las especies frutícola constituyen el 25\% de la actividad agrícola de la provincia (Van den Bosch, 2008). Mendoza es la primera productora nacional de cerezas (Prunus cerasus y Prunus avium), damascos (Prunus armeniaca), ciruelas (Prunus domestica), membrillos (Cydonia oblonga) y nueces (Juglans regia), y la segunda de duraznos (Prunus persica), manzanas (Malus domestica) y peras (Pyrus comnunis). Estos frutos se cultivan principalmente en el Valle de Uco y en San Rafael (Van den Bosch, 2008).

\footnotetext{
*Datos provenientes de la información estadística del Instituto Nacional de Vitivinicultura.
} 
Finalmente, la horticultura aporta el 16,4\% de la producción agrícola de Mendoza (Van den Bosch, 2008). El principal rinde hortícola de la provincia es el tomate (Lycopersicon esculentum) cultivado en el Valle de Uco y Maipú, seguido por la papa (Solanum tuberosum) cultivada en Malargüe, Valle de Uco y Uspallata, y el ajo (Allium sativum) cultivado en Maipú, Malargüe, Valle de Uco y Uspallata (Van den Bosch, 2008).

El sector sur de la provincia de Mendoza nuclea el $70 \%$ de la actividad pecuaria. Se detalla de la siguiente manera:

Los caprinos (Capra hircus) constituyen la principal actividad ganadera de la provincia, con 672.434 cabezas reúne el $17 \%$ de la producción nacional y la mayor parte se concentran en el sur de Mendoza (ca. del 75\%)*.

La producción bovina (Bos taurus), con 404.710 cabezas sigue en importancia ganadera en la provincia y ca. del $65 \%$ se encuentra en el sur de la misma*.

De 68.795 cabezas de ganado ovino (Ovis aries) que se produce en la provincia, ca. del $82 \%$ se concentra en el sector sur*.

Por su parte, el ganado equino (Equus caballus) de Mendoza integra un total de 64.029 cabezas y ca. del 65\% de las mismas se encuentran en el sur de la provincia*.

Para finalizar, el resto del ganado de la provincia, tales como porcinos (Sus scrofa), asnales (Equus hemionus) y mulares, representan un total de 22.261 cabezas y ca. del 40\% se concentran en el sector sur*.

\footnotetext{
*Datos provenientes del Censo Nacional Agropecuario 2002. Dirección de Estadísticas e Investigaciones Económicas. Ministerio de Producción, Tecnología e Innovación. Gobierno de Mendoza.
} 


\subsection{Un ambiente actual modificado}

Las actividades económicas tales como la agricultura, ganadería, minería y comercio han tenido un efecto significativo en el ambiente (Cortegoso et al., 2010). Entre ellas el pastoreo es la principal perturbación antrópica observada en el sur de Mendoza. Esta práctica mediante el consumo de plantas, la compactación del suelo por pisoteo, la eventual quema de campos y el transporte vehicular produce una marcada reducción de la cubierta vegetal y un consecuente incremento de la erosión hídrica y eólica (Butzer, 1989; Roig, 1991; Prieto y Abraham, 2000). La disminución de las especies forrajeras (principalmente gramíneas) ha favorecido, por competencia, la expansión de especies no palatables para el ganado, incluso de plantas exóticas. Este proceso origina una mayor arbustización del área y un aumento del suelo desnudo (Guevara et al., 2006). Asimismo, estos cambios importantes en el paisaje implican también modificaciones en la biodiversidad faunística asociada (Prieto y Abraham, 2000; Cortegoso et al., 2010).

La explotación ganadera en Mendoza se remonta a fines del siglo XVI. Sin embargo, este proceso no tuvo el mismo impacto en las distintas áreas y a través del tiempo (Gil et al., 2006b). Prieto y Abraham (1993-1994) proponen que entre los siglos XVII y principios del XIX el impacto antrópico sumado a los ciclos de aridez y bajas temperaturas produjo una desertificación en el área. Desde mediados del siglo XVII hasta fines del XVIII la ganadería se concentraba en los valles de Uco y Jaurúa. En 1805 la expansión de la frontera colonial hasta el Río Atuel, con la fundación el Fuerte de San Rafael se aseguró la actividad ganadera en esta área (Cortegoso et al., 2010 y bibliografía allí citada). No obstante, Gil et al. (2006b) en base a un análisis arqueofaunístico integral de numerosos sitios arqueológicos, plantean que el ganado habría sido abundante recién a partir del siglo XIX y hacia finales del mismo habría sido el recurso faunístico más importante del área, produciendo cambios substanciales en el ecosistema, principalmente en la fauna autóctona.

\subsection{Estudios paleoambientales}

En esta sección se efectuará una descripción de las condiciones ambientales imperantes durante los períodos final del Pleistoceno tardío y Holoceno en el sur de Mendoza y áreas 
lindantes, teniendo en consideración la información disponible proveniente de los estudios polínicos, sedimentológicos, dendrocronológicos, malacológicos, glaciológicos y de microvertebrados. En este sentido, el conocimiento de los antecedentes bibliográficos sobre la historia paleoambiental de la región constituye una herramienta fundamental para el desarrollo de unos de los objetivos de este trabajo de tesis doctoral, el cual intentará abordar esta temática desde el estudio de los microvertebrados. Desde una perspectiva arqueológica, la comprensión de los cambios ambientales ocurridos durante el Pleistoceno final y Holoceno puede ser muy importante para lograr un mayor entendimiento del registro arqueológico y de las interacciones humanas con su entorno (Dincauze, 2000).

El registro palinológico del sitio Gruta del Indio analizado por D’Antoni (1980, 1983) y Markgraf (1983), constituyó hasta recientemente la única secuencia para reconstruir las condiciones ambientales desde $32 \mathrm{ka}{ }^{14} \mathrm{C}$ AP hasta la actualidad en la planicie mendocina (Zárate, 2002). Este sitio es un refugio rocoso, ubicado en la localidad Rincón del Atuel en el cause medio del río homónimo. Según estos autores la principal fluctuación ambiental ocurrió entre 12-10 ka ${ }^{14} \mathrm{C}$ AP, pasando de una fisonomía de estepa Patagónica a una de tipo desierto del Monte (dominado por zigofiláceas, e.g., Larrea sp.), similar al que podemos encontrar en la actualidad; esto fue interpretado como un cambio de condiciones climáticas frías y semiáridas a una de mayor temperatura y aridez. Entre $9-5 \mathrm{ka}{ }^{14} \mathrm{C} \mathrm{AP}$ registraron que el espectro polínico está dominado por Lycium, indicando mayor humedad freática y aumento de la vegetación del desierto del Monte. Entre 5-2 ka ${ }^{14} \mathrm{C}$ AP observaron un incremento de los elementos del desierto del Monte, posiblemente ocasionado por un mayor nivel del agua del Río Atuel y una consecuente expansión del bosque ripario (principalmente $P$. flexuosa y $C$. praecox), indicando un aumento en la temperatura. Por otra parte, a pesar de que D’Antoni (1983) y Markgraf (1983) interpretaron que a partir de 3-2 ka ${ }^{14} \mathrm{C}$ AP se habría establecido la fisonomía actual de la vegetación en el área circundante a Gruta del Indio, resulta interesante destacar que estos autores advierten de un cambio importante en la secuencia polínica entre 1,6-1,2 $\mathrm{ka}{ }^{14} \mathrm{C} \mathrm{AP}$, caracterizado por un avance de las vegetación Patagónica y un retroceso de la vegetación del Monte (D’Antoni, 1980: 97; 1983: 102; Markgraf, 1983: 61). Al respecto, estos autores sugieren que esta disminución pudo deberse a actividades de explotación de leña de jarilla (Larrea) por parte de los grupos humanos que habitaban el lugar, luego de haber agotado las reservas del 
bosque ripario (Prosopis y Cercidium) de los alrededores del sitio. Esta hipótesis fue sostenida por el hallazgo realizado por Semper y Lagiglia (1968) de restos de un cierre o empalizada construido por ramas de jarilla en el interior de la Gruta. La otra posibilidad hubiera sido la ocurrencia de un descenso hídrico y térmico que pudiese eliminar al bosque ripario. De haber sido así, estos cambios tendrían que haber afectado también al resto de la comunidad, entre ellas a las jarillas.

Markgraf (1983) a partir del estudio de perfiles polínicos plantea un modelo paleoclimático para el sur de Sudamérica. Particularmente en Mendoza, además de interpretar el perfil de Gruta del Indio, analizó dos turberas (Salina 2 y Salado). En Salina 2, ubicada en el valle superior de Uspallata, observó una disminución de los elementos del Monte (especialmente Esphedra) y un aumento de las gramíneas entre $5-4 \mathrm{ka}{ }^{14} \mathrm{C}$ AP, indicando mayores niveles del agua. A partir de $3 \mathrm{ka}{ }^{14} \mathrm{C}$ AP registró una tendencia contraria, con el establecimiento de las condiciones ambientales modernas. El sitio Salado, que se encuentra en un arroyo afluente del río homónimo próximo a la localidad de los Molles, presenta un paquete sedimentario que abarca los últimos $4 \mathrm{ka}{ }^{14} \mathrm{C} \mathrm{AP}$. La autora observó que las gramíneas dominaron toda la secuencia y distinguió un cambio en $3 \mathrm{ka}{ }^{14} \mathrm{C}$ AP con la presencia de elementos polínicos más diversos hacia una zona de transición, evidenciando un cambio en la altitud entre el límite de la vegetación Andina y del Monte, un incremento en la temperatura y condiciones similares a las actuales. Estos datos son coincidentes con la información obtenida por Heusser (1983), en su análisis palinológico del distrito de los lagos de Chile en la vertiente occidental de la cordillera.

En el sector precordillerano del norte de Mendoza, García et al. (1999) y Paez y Zárate (2000) estudiaron el registro sedimentológico y polínico del sitio Agua de la Cueva y observaron el establecimiento de una estepa de gramíneas entre $12-11 \mathrm{ka}{ }^{14} \mathrm{C} \mathrm{AP}$, el desarrollo de una estepa de asteroidea con elementos Andino-Patagónicos entre 11-9 ka ${ }^{14} \mathrm{C}$ AP y aumentos de elementos de Monte-Puna entre $9-5 \mathrm{ka}^{14} \mathrm{C}$ AP.

Por su parte, Mehl (2010) analizó e integró diversos estudios previos realizados en sucesiones aluviales en el valle de Uco, en la cuenca del Río Tunuyán (e.g., Polanski, 1963; Zárate, 2002; Zárate y Paez, 2002; Zárate y Mehl, 2008). La autora observó que los depósitos aluviales de los arroyos La Estacada y Anchayuyo presentaron una agregación fluvial activa, con aportes eólicos, desde $c a .50 \mathrm{ka}$ AP (basado en dataciones OSL 
[optically stimulated luminescense]) y entre $14-10 \mathrm{ka}{ }^{14} \mathrm{C}$ AP. En este sentido, Mehl (2010) concluyó que la reactivación de los sistemas fluviales del piedemonte hacia el Pleistoceno tardío podría vincularse con cambios ambientales ocurridos luego del Último Máximo Glaciar.

Las sucesiones malacológicas en los últimos $35 \mathrm{ka}{ }^{14} \mathrm{C}$ AP en sitios del arroyo La Estacada, Río Desaguadero y Salinas del Bebedero en Mendoza y San Luis, respectivamente, registraron cambios en sus estructuras taxonómicas que permitieron reconstruir la historia paleoambiental de esta área (Gonzáles, 1994; De Francesco et al., 2007; De Francesco, 2010). Los autores citados señalan que entre $c a$. 35-31 ka ${ }^{14} \mathrm{C}$ AP un ambiente acuático somero, vinculado a un pulso cálido y húmedo. A partir de $c a .20 \mathrm{ka}{ }^{14} \mathrm{C} \mathrm{AP}$ y hasta $c a .10$ ka ${ }^{14} \mathrm{C}$ AP el ambiente era árido con escasa vegetación, desarrollándose un proceso de agradación fluvial en los ríos Mendoza y Tunuyán, los cuales transportaban sus materiales hasta el paleolago que se localizaba en la actual Salinas del Bebedero. Durante el Holoceno temprano observaron una reactivación del proceso de agradación fluvial, pero con episodios de encharcamientos. Sin embargo, la ausencia de moluscos en el Holoceno medio fue interpretada por los autores como una causa de mayor aridez ambiental. Durante el Holoceno tardío, la presencia de moluscos dulceacuícolas fue relacionada con un mejoramiento ambiental, con sistemas hídricos de encharcamientos o lagos someros y abundante vegetación asociada (De Francesco, 2010).

Chiesa et al. (2010) analizaron la sucesión sedimentaria de los perfiles La Guasquita y Río Jarilla, localizados en un sector del Río Desaguadero cercano a la desembocadura del Río Tunuyán, en la provincia de San Luis. Estos autores a partir del desarrollo de una red de drenaje de envergadura con niveles lacustres altos, indicaron incrementos en la temperatura relacionados a un proceso de deglaciación pero con precipitaciones en cordillera para el Pleistoceno tardío. No obstante, durante la transición Pleistoceno-Holoceno y el Holoceno temprano observaron una disminución del régimen fluvial y bajos niveles lacustres, posiblemente debido a un aumento en la temperatura en la planicie y a escasas precipitaciones. Los autores señalan que los cambios climáticos y el riego artificial de los últimos siglos produjeron la desvinculación hidrológica entre los ríos Desaguadero y Bermejo, la disminución del caudal del Río Tunuyán, bajantes en lagunas del sistema y la modificación geomorfológica y biótica del Río Desaguadero. 
Los estudios realizados por Tripaldi (2010) y Tripaldi et al. (2010) en los extensos campos de dunas que cubren gran parte de la planicie sanrafaelina, señalan condiciones semiáridas previas a $c a$. 21,7 ka AP (basado en datación OSL), a partir del registro de depósitos fluviales y fluvio-eólicos. Contrariamente, la reactivación de la sedimentación eólica ocurrida entre 21,7-14,4 ka AP (basado en dataciones OSL) fue entendida como un ambiente más árido que el anterior, relacionado al Último Máximo Glacial. Asimismo, los autores observaron que durante el Holoceno acaecieron episodios de reactivación eólica que indicaron períodos de mayor aridez, posiblemente durante el Holoceno medio.

Tripaldi et al. (2011) en base a registros sedimentarios de la planicie de San Rafael, señalan un proceso fluvial efímero bajo condiciones semiáridas entre $c a$. 58-39 ka AP y ca. 36-24 ka AP (basado en dataciones OSL). Además, durante ca. 24-12 ka AP (basado en dataciones OSL) documentaron una importante actividad eólica indicando un cambio climático hacia condiciones más áridas, coincidentemente con el Último Máximo Glaciar. Mercer (1982) realizó un modelo de fluctuaciones glaciarias en Chile central, donde observó un avance de los glaciares entre $19-14 \mathrm{ka}{ }^{14} \mathrm{C}$ AP y un proceso de deglaciación entre 12,5-12 ka AP, alcanzando sus límites actuales $c a .11 \mathrm{ka}{ }^{14} \mathrm{C}$ AP. Asimismo, el mencionado autor registró reavances glaciarios durante el Holoceno $\left(6,8 \mathrm{ka}{ }^{14} \mathrm{C}\right.$ AP; 4,5-4 ka ${ }^{14} \mathrm{C}$ AP; $2,8-2$ ka ${ }^{14} \mathrm{C}$ AP; 0,8 ka ${ }^{14} \mathrm{C} \mathrm{AP}$ ) y en tiempos recientes (siglos XVIII-XIX y 1.770-1.820 AD).

Por su parte, Röthlisberger (1987) sugiere un avance del glaciar Cipreses (Rancagua) en Chile central, durante el Holoceno medio.

En el alto valle del Río Atuel, cerca del Sosneado, Stingl y Garleff (1985) distinguieron cuatro fases glaciarias: 1) un período de menor glaciación luego del último Glaciar (13-10 ka ${ }^{14} \mathrm{C}$ AP) hasta el Holoceno temprano; 2) una etapa de avances glaciarios durante el Holoceno medio $\left.\left(6-4,5 \mathrm{ka}{ }^{14} \mathrm{C} \mathrm{AP}\right), 3\right)$ una rápida retracción hacia $3 \mathrm{ka}{ }^{14} \mathrm{C} \mathrm{AP}$, cuando los glaciares alcanzan su posición actual; 4) un avance marcado en el cambio de siglo XIX al XX. En la Patagonia andina húmeda, los glaciares están controlados por la temperatura (tipo Patagónico), mientras que en los Andes áridos de Cuyo están controlados por oscilaciones de humedad (tipo Cuyano) (Stingl y Garleff, 1978). En este sentido, estos autores indicaron que el avance glaciar registrado durante el Holoceno medio en la cuenca superior del Río Atuel, estaría relacionado con incrementos en los niveles de humedad. 
Lamy et al. (1999) en base a estudios de sedimentos marinos en Chile Central, registraron un clima frío y húmedo entre 28-18 ka cal AP con un intervalo frío y seco entre 26-22 cal ka AP. Posteriormente, entre 18-8 ka cal AP evidenciaron un incremento de la aridez. Durante el Holoceno medio observaron condiciones climáticas estables y aumento de la aridez en la costa. Finalmente durante el Holoceno tardío registraron mayor variabilidad climática y humedad.

Villa-Martínez y Villagrán (1997) a partir de análisis polínico en sitios de Chile central, señalan condiciones más calidas y secas hacia el $5 \mathrm{ka}{ }^{14} \mathrm{C} \mathrm{AP}$. A partir del $4 \mathrm{ka}{ }^{14} \mathrm{C} \mathrm{AP}$ observaron aumentos en los niveles de humedad y entre el 2-1 ka ${ }^{14} \mathrm{C}$ AP condiciones más frías y húmedas, similares a las actuales.

Los estudios de multiproxy en laguna Aculeo (Chile central) de Jenny et al. (2002) y VillaMartínez et al. (2003, 2004), indicaron un clima más árido y cálido hacia el 5,7 ka cal AP. Posteriormente, registraron incrementos de los niveles de la humedad y a partir del 3,2 ka cal AP observaron una intensificación de esta tendencia y establecimiento de las condiciones climáticas modernas, relacionado al evento ENSO (El Niño Southern Oscillation).

Por su parte, Cobos y Boninsegna (1983) en base información histórica de los glaciares del Río Atuel y del norte de Mendoza documentaron una retracción constante de los glaciares durante los últimos 400 años.

Asimismo, Boninsegna y Delgado de Brun (2002) estudiaron la variaciones del caudal del Río Atuel desde 1575 hasta el presente, analizando los anillos de los árboles. Los autores observaron que el caudal del río aumenta cuando se incrementa la cantidad de nieve acumulada en la cuenca superior, la cuál podría estar relacionada con la influencia del evento interanual ENSO.

En coincidencia, Masiokas et al. (2009) compilando numerosa información sobre fluctuaciones glaciarias para Chile central y Mendoza en los últimos 1000 años, indicaron que las masas de hielo eran más extensas en los siglos pasados (principalmente en el siglo XVI) y sufrieron una reducción durante el siglo $\mathrm{XX}$, posiblemente en relación con la Pequeña Edad de Hielo y la mayor frecuencia de eventos ENSO, respectivamente.

Le Quesne et al. (2009), en base a datos históricos, dendrocronológicos y glaciológicos trazan un modelo de precipitaciones para Chile central para los últimos 700 años. Estos 
autores registraron condiciones de marcada aridez durante 1440-1600 años cal. AD, condiciones húmedas entre 1500-1650 años cal. AD y en 1850 cal. AD, y una posterior disminución de las precipitaciones para los últimos 150 años.

En coincidencia con el modelo glaciar de Mercer (1982), los trabajos de Espizua (2003, 2005) sobre drift (i.e., materiales transportados por los glaciares) identificados a lo largo de los valles El Azufre y El Peñón del sistema Río Valenzuela, en la cuenca superior del Río Grande, mostraron reavances neoglaciarios durante el Holoceno. El primero de ellos ocurrió entre 5,7-4,4 ka ${ }^{14} \mathrm{C} \mathrm{AP}$, el segundo avance sucedió entre 2,5-2,2 ka ${ }^{14} \mathrm{C}$ AP y el tercero hacia $c a \cdot 0,4 \mathrm{ka}{ }^{14} \mathrm{C} \mathrm{AP}$, vinculado con la Pequeña Edad de Hielo.

Espizua (1993a, 1993b) analizó numerosos drift en el valle superior del Río Mendoza y observó que el drift Penitentes (sector del río de las Cuevas) está relacionado con el Último Máximo Glaciar entre $24,2 \pm 2$ ka AP (dataciones radiométricas ${ }^{230} \mathrm{Th} /{ }^{232} \mathrm{Th}$ ) y $22,8 \pm 3,1$ ka AP (dataciones radiométricas de series de Uranio). El drift Horcones, datado en 9,7 \pm 5 ka AP (series de Uranio) y $15 \pm 2,1$ ka AP (basado en datación TL), podría constituir según el autor la culminación del avance de la ultima glaciación. El drift Los Almacenes corresponde un reavance o estabilización glaciar, que ocurrió durante la finalización del glaciar Horcones ( 14-10 ka AP, cronología relativa), el cual estaría relacionado con el Tardiglacial. El drift Confluencia estaría vinculado tentativamente a un evento neoglaciar de fines del Holoceno medio y principios del Holoceno tardío.

Navarro et al. (2010) realizaron un análisis sedimentológico, palinológico y geomorfológico en los sitios Agua Buena y Vega de la Cueva ubicados en El Sosneado y reinterpretaron una sección de la terraza del Río Atuel previamente estudiada por Stingl y Garleff (1978). Los autores observaron que el registro de Agua Buena pertenece a la fase distal de un abanico aluvial del arroyo tributario El Bayo, el cual comenzó su proceso de agradación previamente a $c a$. 4,1 ka cal AP. Posteriormente, entre 4,1-2,8 ka cal AP, a partir del registro de niveles ricos en materia orgánica (depósito de turba) señalan el desarrollo de vegas, dominadas por Cyperaceae, Juncaceae y Poaceae, indicando condiciones más estables. Después de 2,8 ka cal AP observaron una disminución del contenido orgánico, aumentos de Chenopodiaceae y Poaceae e incrementos en la sedimentación, sugiriendo una elevada descarga fluvial y menor disponibilidad hídrica para el desarrollo de vegas cordilleranas. Además, a partir de la sección media del perfil Vega 
de la Cueva los autores indicaron que posiblemente hubo un microambiente húmedo entre 3,8-1,4 ka cal AP. Por otra parte, datos polínicos y de carbones provenientes de Laguna El Sosneado revelaron que entre 6,4-1,9 ka cal AP hubo una alta combustión de madera y el desarrollo de una estepa Patagónica, dominada por Mulinum, Chuquiraga, Adesmia, Berberis, Asteraceae y Poaceae, coherente con condiciones más húmedas y frías que en el presente. Entre 1,9-0,5 ka cal AP existen condiciones más áridas y de mayor temperatura y escasa actividad del fuego, indicada por aumentos de la vegetación dispersa de tipo ecotono Monte-Patagónica, dominada por Neosparton, Asteraceae, Poaceae, Larrea, Prosopis, Prosopidastrum y Junellia. A partir del 0,5 ka cal AP continua el ambiente de transición entre Monte y estepa Patagónica, dominado por Asteraceae, Poaceae, Chuquiraga, Adesmia, Anathrophyllum, Nassauvia y Schinus, exhibiendo un ligero repunte de la humedad y el establecimiento de las condiciones ambientales modernas (Navarro et al., 2009; Navarro y Whitlock, 2010).

Teniendo en cuenta registros geológicos y malacológicos, De Francesco y Dieguez (2006) y De Francesco (2010) efectuaron una reconstrucción paleoambiental en secciones del Río Atuel durante el Holoceno. Para el Holoceno temprano, el análisis del perfil Puesto Vicencio ubicado cerca de la laguna Llancanelo (Malargüe), fue interpretado por los autores mencionados como un paleoambiente homólogo al ambiente actual, con un sistema fluvial o lacustre de mayor circulación. Asimismo, la interpretación del perfil Villa Atuel (= perfil La Guevarina), ca. $60 \mathrm{~km}$ al sudeste de San Rafael, sugirió a estos autores condiciones similares al de Puesto Vicencio, con ambientes lacustres someros y vegetados en la planicie de inundación del cauce principal, sometidos a crecidas. Durante el Holoceno medio, la ausencia de moluscos fue entendida por los autores como un indicador de condiciones más áridas que en la actualidad. Para el Holoceno tardío, las observaciones realizadas por los autores en el perfil Puesto Moya, ca. $20 \mathrm{~km}$ aguas arriba de Puesto Vicencio, sugiere un ambiente más propicio, semejante al actual, con un cuerpo de agua muy somero y vegetado de tipo palustre.

Páez et al. (2010) interpretaron numerosos registros polínicos de diferentes ambientes de Mendoza, para realizar una reconstrucción de la vegetación y de las condiciones paleoambientales durante el Holoceno. Según los autores, para la transición Pleistoceno tardío-Holoceno temprano los registros polínicos de Agua de la Cueva (precordillera), 
arroyo La Estacada (Río Tunuyán), Gruta del Indio y La Guevarina (cuenca media del Río Atuel), indican condiciones frías y áridas con un posterior acenso de temperatura en el sector cordillerano y mayor disponibilidad hídrica en la planicie oriental. La escasez de datos polínicos con cronologías asociadas al Holoceno medio no permitió a los autores corroborar el proceso de aridización regional planteado en estudios previos. Durante el Holoceno tardío, a partir de las secuencias de polen del arroyo La Estacada, Salado y Agua Buena (cuenca superior del Atuel), los autores señalan la conformación de una fisonomía vegetal y ambiental similar a la actual. Sin embargo, también indican que en este período existió gran variabilidad ambiental, bajo la influencia del evento ENSO. En tal sentido, los autores señalan que luego de $c a \cdot 2,8 \mathrm{ka}{ }^{14} \mathrm{C}$ AP en la cuenca superior del Atuel y del Salado hubo un aumento en la disponibilidad de agua en los sistemas fluviales. Asimismo, en las secuencias del Valle de Uco registraron mayores niveles de taxones AndinoPatagónicos ca. 4-3 ka ${ }^{14} \mathrm{C}$ AP y ca. $0,5-0,4 \mathrm{ka}{ }^{14} \mathrm{C}$ AP, relacionado con descensos de temperatura.

Rojo et al. (2012) presentaron un análisis palinológico de dos secuencias aluviales holocénicas (La Escala y Brazo Abandonado) de la cuenca del Arroyo La Estacada, ubicadas en el sector pedemontano de Mendoza central $\left(33^{\circ} 27^{\prime} \mathrm{S}, 69^{\circ} 03^{\prime} \mathrm{O}\right)$. Estos autores registraron una alta abundancia de plantas relacionadas a ambientes con disponibilidad de agua entre $c a .4-3 \mathrm{ka}{ }^{14} \mathrm{C}$ AP y $0,5-0,4 \mathrm{ka}{ }^{14} \mathrm{C}$ AP y un aumento de arbustos xerófilos asociados a ambientes con menor disponibilidad hídrica. Finalmente, indican que las fluctuaciones del espectro polínico observada en las secuencias sedimentarias de la planicie de inundación, pudieron haber sido causadas en respuestas a la dinámica fluvial del arroyo. Por otra parte, Gasco et al. (2006) en base al registro de microvertebrados del sitio Caverna de Las Brujas, ubicado en Malargüe, señalan que posiblemente entre $5 \pm 0,5 \mathrm{ka}$ AP (TL) y 3,7 ka ${ }^{14} \mathrm{C}$ AP $(3,9-4,1$ ka cal AP) existieron condiciones de menor heterogeneidad ambiental, relacionados con eventos neoglaciarios ocurridos durante el Holoceno medio y que posteriormente a este período se conformó un ambiente con características semejantes a las actuales.

En el noroeste de Neuquén el registro polínico de Mallín Vaca Lauquen muestra fluctuaciones climáticas en los últimos $16 \mathrm{ka}$ cal AP (Markgraf et al., 2009). Entre 16-14,8 ka cal AP, el registro polínico es coherente con el desarrollo de una estepa arbustiva abierta 
y bosques de Nothofagus-Prumnopitysandina en la ladera de la montaña, donde se expanden los glaciares de valle. Entre 14,8-8,9 ka cal AP la secuencia se mantiene estable, con expansión de la zona boscosa, indicando condiciones de mayor humedad y temperatura, a pasar que en este segmento ocurre la transición Pleistoceno-Holoceno. Entre 8,9-5,5 ka cal AP el ambientes es más árido, con el desarrollo de Cyperaceae. Después de este intervalo, hay incrementos de la humedad y variabilidad climática, posiblemente bajo la influencia del evento ENSO y en tiempos recientes una marcada disturbación antrópica por el sobrepastoreo (Markgraf et al., 2009).

También en el norte de Neuquén, pero más hacia el centro y a pocos kilómetros del límite con Mendoza, una secuencia de micromamíferos recuperados del sitio Cueva Huenul 1 reveló cierta estabilidad climática durante la transición Pleistoceno tardío-Holoceno temprano y Holoceno tardío, aunque con una mayor heterogeneidad ambiental durante el Holoceno, incluyendo un mosaico de estepas arbustivas, peladales y áreas rocosas abiertas (Fernández et al., 2011b, en prensa). En tal sentido, es congruente con la estabilidad hallada en el segmento 14,8-8,9 ka cal AP del perfil polínico de Mallín Vaca Lauquen (cf. Markgraf et al., 2009). Sin embargo, la secuencia de micromamíferos de Cueva Huenul 1 parece no haber sido afectada por el evento frío Huelmo/Mascardi Cold Reversal, registrado entre $11,4-10,2 \mathrm{ka}{ }^{14} \mathrm{C}$ AP o 13,5-13,2 / 12,8-11,5 ka cal AP (Hajdas et al., 2003). 
Capítulo 4

\section{MATERIALES Y MÉTODOS}

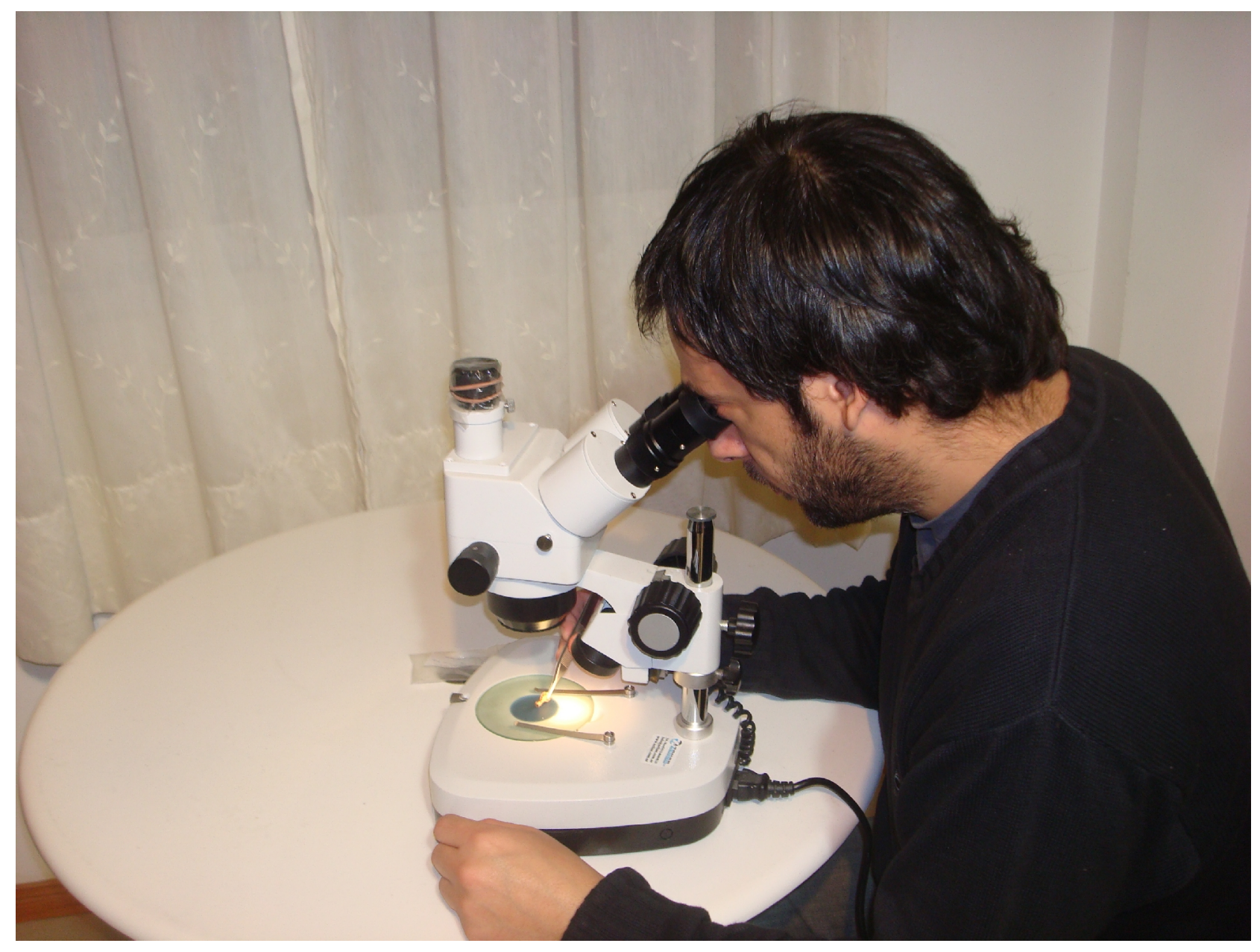





\section{MATERIALES Y MÉTODOS}

\subsection{Las muestras arqueológicas}

Las diversas muestras de microvertebrados fósiles fueron extraídas en numerosas campañas arqueológicas realizadas durante las últimas tres décadas y proveen una excelente fuente de información para alcanzar los objetivos propuestos. Cabe destacar que las mismas fueron recolectadas siguiendo procedimientos sistemáticos, con datos precisos de procedencia estratigráfica. Además las muestras de los distintos depósitos estratigráficos con presencia de microvertebrados, cuentan con fechados radiocarbónicos que permiten su ubicación cronológica. Por otra parte, los muestreos abarcaron todos los tipos de ambientes del sur de Mendoza (i.e., cordillera, Payunia, piedemonte y cauces extracordilleranos) (Figura 4.1) e incluyeron una amplia diversidad de sitios (a cielo abierto, aleros y cuevas) y de funcionalidades (campamentos base, sitios de actividades simples, bases secundarias, etc.). Algunos de ellos presentan secuencias que abarcan todo el Holoceno, lo que asegura una buena base de comparación y control para evaluar los cambios en la diversidad y/o presencia de los taxones de microvertebrados. En la tabla 4.1 se presentan los sitios arqueológicos que se incluyen en la tesis, con sus características ambientales y cronológicas.

\begin{tabular}{|lcccc|}
\hline \multicolumn{1}{|c}{ Sitios } & Cronología (en años ${ }^{14}$ C AP) & Provincias fitogeográficas & Excavación & $\begin{array}{c}\text { Muestras } \\
\text { actuales }\end{array}$ \\
\hline Rincón del Atuel 1 & $1520 \pm 70 / 330 \pm 60$ & Monte & $\mathrm{X}$ & $\mathrm{X}$ \\
Agua de La Mula 1 & $1240 \pm 60 / 1000 \pm 50$ & Monte & $\mathrm{X}$ & $\mathrm{X}$ \\
Agua de Los Caballos 1 & $1240 \pm 70 / 250 \pm 60$ & Monte & $\mathrm{X}$ & $\mathrm{X}$ \\
La Peligrosa-1 & $\sim 1500 / 400 \pm 70$ & Monte & $\mathrm{X}$ & \\
Cueva de Luna & $3830 \pm 160 / \sim 100$ & Patagónica & $\mathrm{X}$ & $\mathrm{X}$ \\
Cueva Arroyo Colorado & $3190 \pm 80 / 770 \pm 80$ & Patagónica & $\mathrm{X}$ & $\mathrm{X}$ \\
Cueva Palulo & $3100 \pm 60 / 130 \pm 33$ & Patagónica & $\mathrm{X}$ & $\mathrm{X}$ \\
Arroyo Malo 3 & $8900 \pm 60 / \sim 100$ & Patagónica & $\mathrm{X}$ & $\mathrm{X}$ \\
Laguna El Sosneado 3 & $2145 \pm 41 / 659 \pm 51$ & Patagónica & $\mathrm{X}$ & $\mathrm{X}$ \\
\hline
\end{tabular}

Tabla 4.1. Sitios arqueológicos con muestras de microvertebrados incluidos en la tesis.

Los sitios arqueológicos Arroyo Malo 3 (AMA-3) y Cueva Arroyo Colorado, ya contaban con análisis de microvertebrados, aunque poco profundos (Atencio, 2000; 
Neme et al., 2002). En tal sentido, se realizará un nuevo estudio utilizando la metodología propuesta y se ampliará la muestra en AMA-3.

Dado que los trabajos de excavación fueron realizados por diferentes investigadores, variando en alguna medida las técnicas de excavación empleadas, la obtención y la preparación de las muestras, estas serán detalladas en la metodología específica de cada sitio arqueológico. Asimismo, los fechados radicarbónicos fueron calibrados mediante el programa CalPal Online (Cologne Radiocarbon Calibration \& Paleoclimate Research Package).

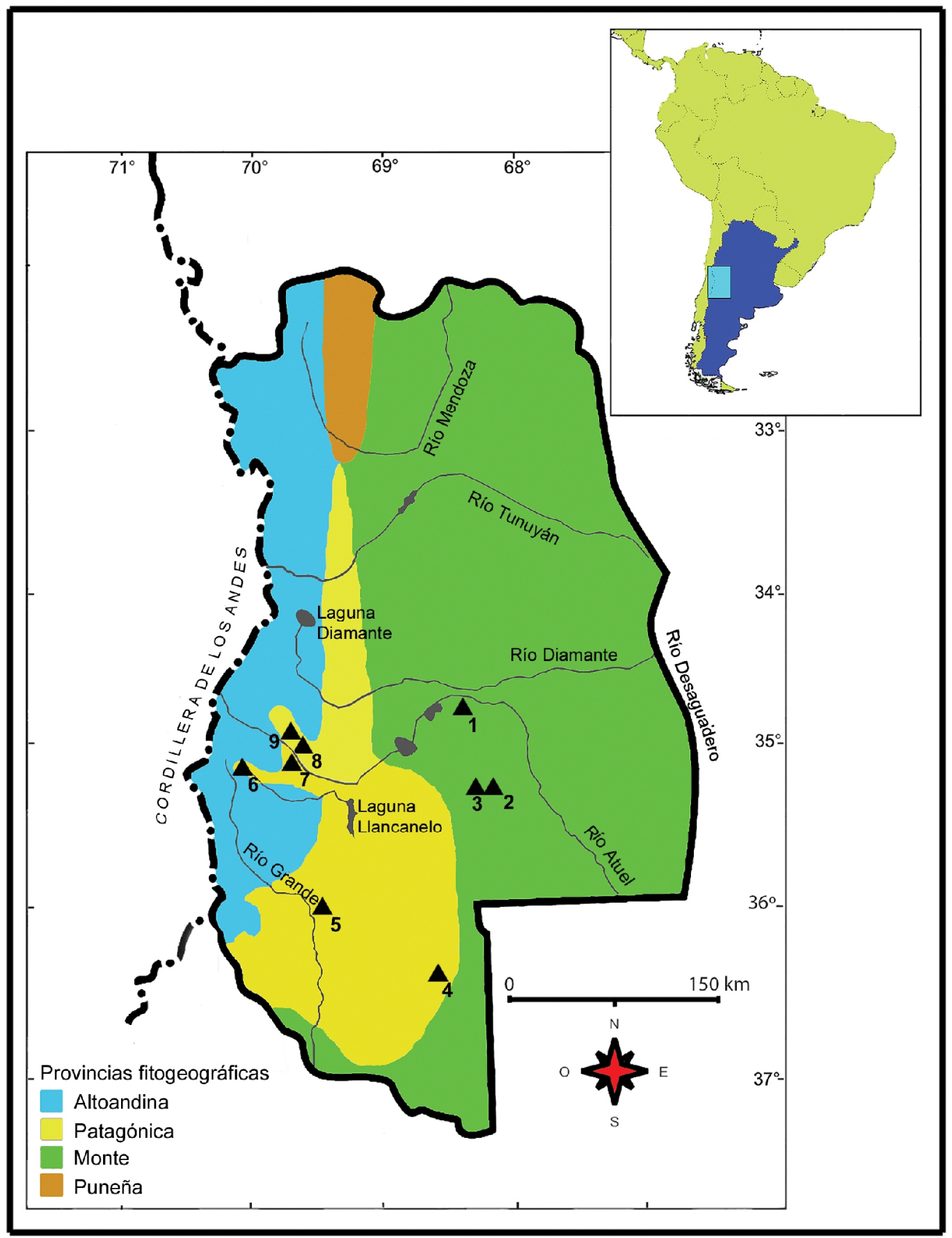


Figura 4.1. Mapa fitogeográfico (sensu Cabrera, 1976) de la provincia de Mendoza con la ubicación de los sitios arqueológicos incluidos en la tesis doctoral. 1: Rincón del Atuel-1; 2: Agua de La Mula; 3: Agua de los Caballos; 4: La Peligrosa; 5: Cueva de Luna; 6: Cueva Arroyo Colorado; 7: Cueva Palulo; 8: Arroyo Malo 3; 9: Laguna El Sosneado 3.

\subsection{Las muestras actuales: egagrópilas y disgregados de aves rapaces}

Como control actualístico, se estudiaron los contenidos óseos y dentarios de egagrópilas y disgregados de aves estrigiformes y falconiformes recolectados en las inmediaciones de los sitios arqueológicos. Se recorrieron lugares propicios para el establecimiento de aves rapaces, tales como cañadones, construcciones abandonadas, arboledas y formaciones rocosas de tipo alero o cuevas. Las egagrópilas y disgregados se ubicaron en bolsas de plástico tipo ziploc, rotuladas con el nombre de la localidad, coordenadas, fecha, colectores, especie de ave rapaz y cantidad de egagrópilas. En primer lugar se midió el largo y ancho de cada egagrópila con calibre digital e individualmente fueron disgregadas en forma manual, luego de sumergirlas en agua tibia durante unos segundos, todos los elementos anatómicos fueron separados con instrumental quirúrgico. Los elementos cráneo-dentarios fueron utilizados para las determinaciones taxonómicas y el resto de los elementos fueron conservados para estudios ulteriores de tafonomía. Finalmente, luego de realizadas las determinaciones taxonómicas, se calculó el número mínimo de individuos por taxón (MNI), a partir del elemento más abundante (ver acápite "número y proporción de elementos esqueléticos").

Algunas especies de aves rapaces han sido consideradas buenas estimadoras de las comunidades de micromamíferos de un área determinada y las egagrópilas que producen han sido utilizadas ampliamente como parámetro actualístico en estudios paleoambientales (e.g., Pardiñas, 1999a; Udrizar Sauthier, 2009; Fernández et al., 2011a). Sin embargo, hay que tener en cuenta los sesgos derivados de sus hábitos y preferencias en la caza. En este estudio se utilizaron principalmente muestras de egagrópilas de rapaces nocturnas (Tyto alba y Bubo magellanicus) y en menor medida de rapaces diurnas (Geranoaetus melanoleucus y Buteo polyosoma) (Figura 4.2). T. alba y $B$. magellanicus se caracterizan por tener una dieta basada principalmente en el consumo de micromamíferos y un radio de caza promedio de 3-5 $\mathrm{km}$ (véase Bellocq, 2000; Nabte et al., 2006 y literatura citada en estos trabajos) y entre los sesgos que 
originan se destacan una subrepresentación de micromamíferos estrictamente diurnos y aquellos de tamaño grande ( $>150 \mathrm{~g}$ ) y una mayor proporción de especies que ocupan ambientes abiertos con elevada exposición (Pardiñas, 1999a; Pardiñas et al., 2003; entre otros).

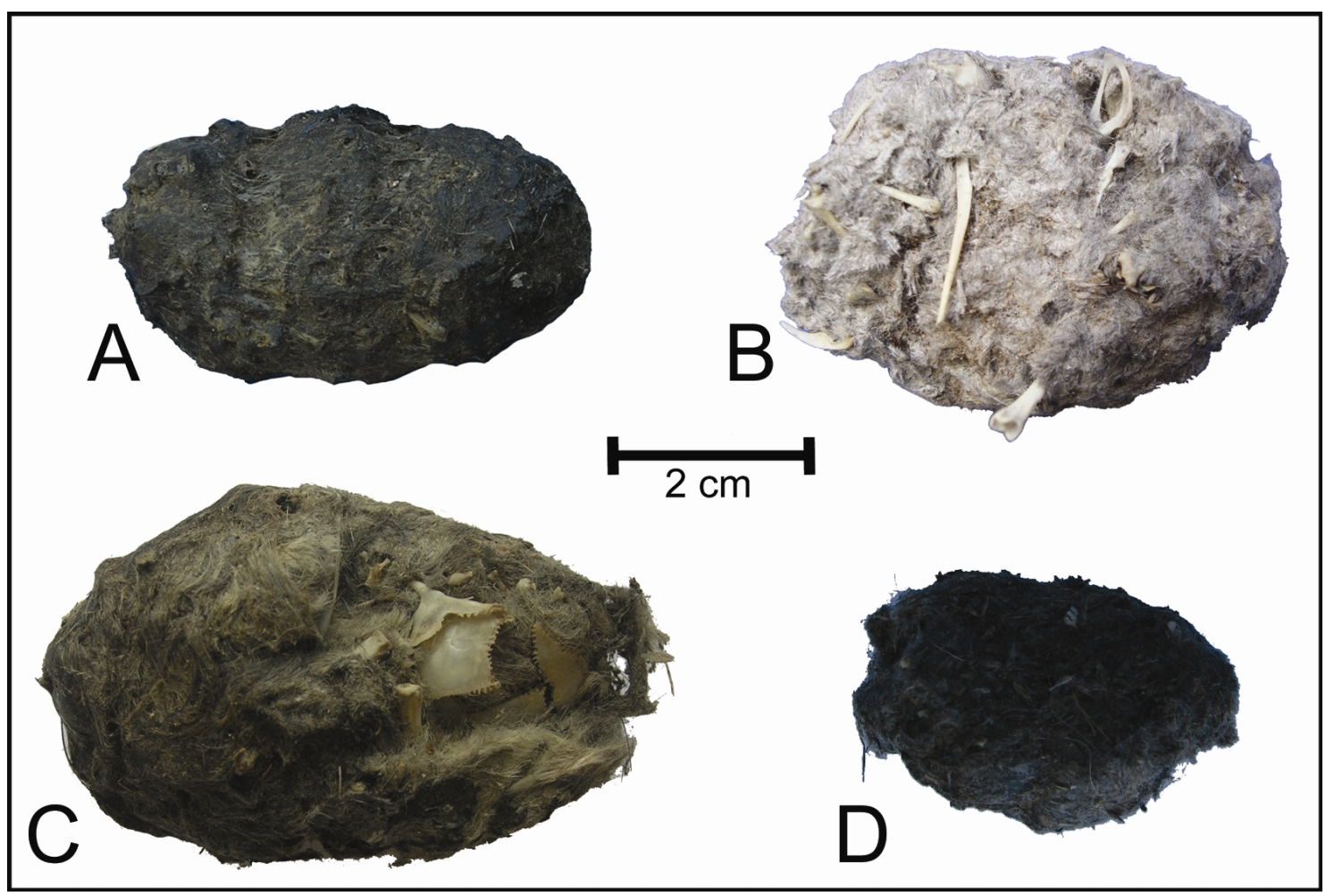

Figura 4.2. Ejemplos de egagrópilas de las distintas aves rapaces con muestras en esta tesis. A: Tyto alba. B: Bubo magellanicus. C: Geranoaetus melanoleucus. D: Buteo polyosoma.

\subsection{Técnicas de observación}

Todos los restos óseos y dentarios se observaron bajo lupa binocular Arcano mediante un sistema de zoom de 20 × 4 aumentos. Los restos más significativos se seleccionaron para ser fotografiados con Microscopio Electrónico de Barrido (MEB) del Museo de Ciencias Naturales de La Plata. Posteriormente, se utilizaron los programas de computación Corel y Fotoshop para la preparación de las imágenes.

\subsection{Determinaciones taxonómicas}

La precisión en que los restos arqueofaunísticos pueden ser identificados está afectada por una combinación de 1) el tipo de elemento recuperado y su importancia diagnóstica 
para la clasificación zoológica y 2) el grado relativo de preservación, el cual se encuentra vinculado a la anatomía esqueletal y a la historia tafonómica del elemento (Stahl, 1996).

La determinación de los roedores sigmodontinos se realizó sobre especímenes cráneodentarios y para el resto de los microvertebrados, además se usaron los huesos largos.

Se utilizó material de referencia de las colecciones del Museo de Ciencias Naturales de La Plata, del Museo Argentino de Ciencias Naturales "B. Rivadavia", del Museo de Historia Natural de San Rafael. Asimismo, se consultó bibliografía específica (i.e., Hershkovitz, 1962; Marshall, 1977; Pearson y Christie, 1991; Baumel y Witmer, 1993; Pearson, 1995; Steppan, 1995; Frost et al., 2001; Martin, 2008; Fernández et al., 2011c).

Los rasgos diagnósticos propios de cada taxón, serán expuestos en detalle en el capítulo 5 , en el cuál se realiza una descripción de los microvertebrados.

Finalmente, se destaca que se seleccionó un ejemplar de referencia por cada taxón en todas las muestras analizadas y se rotuló en forma separada todos los restos que han sido fotografiados en la tesis. Este tipo de tarea es muy importante para facilitar las potenciales revisiones futuras de los materiales.

\subsection{Repositorio}

Todas las muestras analizadas en esta tesis doctoral fueron depositadas en la Colección de Museo de Historia Natural de San Rafael (acrónimo MHNSR). En el Apéndice I se brinda un listado de cada una de las muestras con sus catálogos correspondientes.

\subsection{Metodología para el estudio tafonómico de micromamíferos}

En el marco de los estudios tafonómicos se siguió la metodología y clasificación utilizada por Andrews (1990) y Fernández-Jalvo y Andrews (1992). Esta clasificación distingue cinco categorías de modificación sobre restos óseos y dentarios (i.e., ligera, moderada, intermedia, fuerte y extrema), las cuales incluyen a las aves Strigiformes, Falconiformes y a los mamíferos carnívoros. Cuando los autores mencionados realizaron esta clasificación, dentro del órden Falconiformes se incluía a las familias Falconidae y Accipritidae. Actualmente, la última Familia fue elevada al órden 
Accipitriformes (ver Capítulo 6). No obstante, para que las comparaciones sean más claras, cuando se hace referencia a las aves Falconiformes se está incluyendo tanto a Falconidae como Accipritidae.

Esta metodología contempla un variado conjunto de caracteres para analizar:

\subsubsection{Digestión}

Los procesos digestivos de aves rapaces y mamíferos carnívoros producen efectos diferenciales de corrosión sobre los restos óseos y dentarios (Andrews, 1990). Estas diferencias están dadas, debido a que el nivel de acidez estomacal varía entre especies. De este modo, el $\mathrm{Ph}$ de los jugos gástricos de Strigiformes oscila entre 2,5 a 2,2, mientras que en Falconiformes fluctúa entre 1,8 a 1,3 (Duke et al., 1975). En parte como resultado de esto, se ha encontrado que la digestión de los Falconiformes causan mayores modificaciones sobre los restos que la encontrada en los agregados de presas de Strigiformes (Andrews, 1990). Asimismo, los mamíferos carnívoros y humanos producen niveles más extremos de digestión a causa de los ácidos gástricos y biliares (Andrews y Evans, 1983; Crandall y Stahl, 1995).

\subsubsection{Digestión en incisivos}

La digestión ha sido observada distinguiendo los incisivos aislados de los que se encuentran implantados en mandíbulas y maxilares. Esta distinción se debe a que los incisivos aislados presentan toda la superficie del diente alterada, en cambio los incisivos que se mantiene in situ, solo muestran alteración en las superficies expuestas (Andrews, 1990; Fernández-Jalvo y Andrews, 1992).

La digestión afecta más a los extremos de los dientes y al esmalte dentario que a la dentina y hueso (Andrews, 1990). La digestión de los incisivos se mide en base al grado de digestión y las proporciones de los incisivos afectados (Andrews, 1990; FernándezJalvo y Andrews, 1992). Estos autores, proponen cuatro categorías de corrosión digestiva sobre incisivos (Figura 4.3):

Ligera: presenta bajas frecuencias de incisivos digeridos (8 a 13\%). La digestión afecta a toda la superficie del esmalte, exhibiendo de un ligero a moderado poseado. En 
algunos casos la corrosión se concentra en los extremos de los incisivos, donde el esmalte está totalmente removido (característicos de los incisivos in situ). La dentina podría estar ligeramente alterada, mostrando un contorno ondulado.

Moderada: las frecuencias de elementos afectados varía de 20 a 30\%. La superficie del esmalte se encuentra más extensivamente afectada, y la dentina también está modificada con una superficie ondulada. El esmalte se mantiene en todo el diente, excepto en la parte oclusal.

Fuerte: la mayor parte de los incisivos están alterados (50 a 70\%). La digestión altera tanto al esmalte como a la dentina, la cual presenta una superficie ondulada, y el esmalte aparece reducido en pequeños islotes sobre la dentina.

Extrema: casi todos los elementos están alterados (60 a 100\%). La digestión se extiende sobre todo el diente. Algunos muestran todo el esmalte removido, dejando un estrecho centro de dentina, mientras que otros presentan pequeños islotes separados por áreas de dentina. Otras veces, la dentina se encuentra tan afectada que colapsa por su propio peso, siendo muy difícil la identificación del elemento.

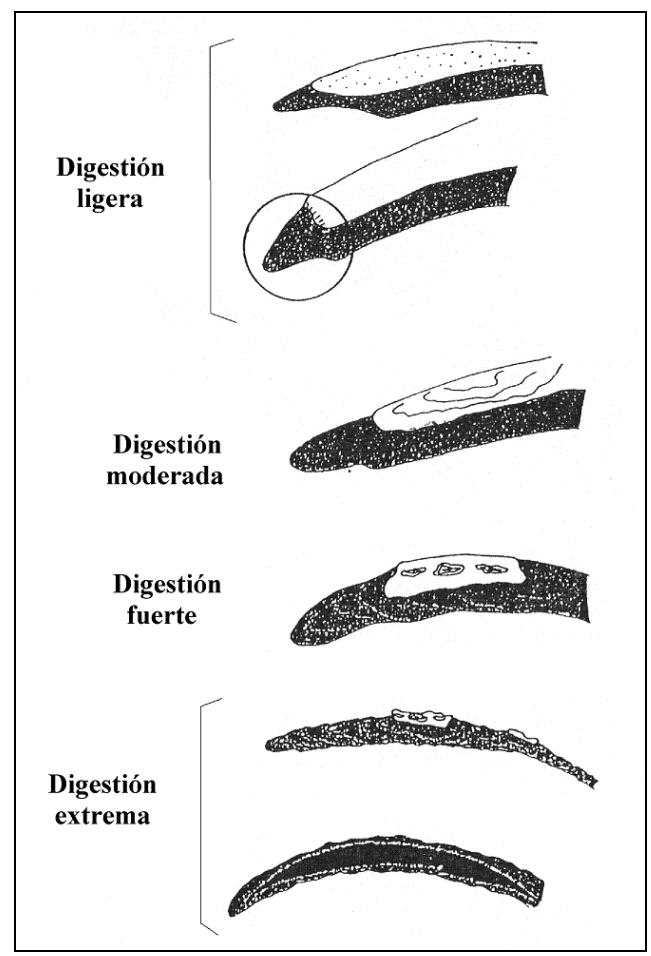

Figura 4.3. Categorías de digestión en incisivos. En: Fernández-Jalvo y Andrews (1992: 413). 


\subsubsection{Digestión en molares}

En este caso también se observó la corrosión digestiva distinguiendo entre molares aislados y molares in situ.

La digestión en los molares posee una mayor variabilidad que en los incisivos debido a las diferencias en la morfología del diente, en el grosor y en el recubrimiento del esmalte que posee cada taxón (Andrews, 1990).

La digestión de los molares se mide en base al grado de digestión y las proporciones de los molares afectados (Andrews, 1990; Fernández-Jalvo y Andrews, 1992). Estos autores, proponen cuatro categorías de corrosión digestiva sobre molares (Figura 4.4):

Ligera: presenta muy bajas frecuencias de elementos digeridos (0 a 3\%). En múridos y cricétidos, el esmalte está suavizado y el contorno de las cúspides está más redondeado. En Microtus (Cricetidae, Arvicolinae, con distribución Holártica), la digestión puede afectar directamente a las esquinas oclusales de los ángulos salientes de los dientes, sin penetrar por debajo de los márgenes alveolares. Por lo tanto, las esquinas de los dientes están redondeadas y los ángulos salientes aplanados.

Moderada: presenta bajas frecuencias de elementos alterados (4 a 6\%). En múridos y cricétidos, la superficie del esmalte muestra un poseado. En Microtus el esmalte puede desaparecer en los bordes de la superficie de contacto y en las cúspides oclusales.

Fuerte: las frecuencias de elementos digeridos varía de 18 a 22\%. En múridos y cricétidos, la superficie del diente está fuertemente poseada y el esmalte en muchas áreas desaparece. En Microtus, las esquinas de los dientes están fuertemente redondeadas y la digestión penetra profundamente removiendo el esmalte en los ángulos salientes, y quedando la dentina expuesta y aplanada.

Extrema: la mayor parte de los elementos están alterados (50 a 100\%). En múridos y cricétidos, la digestión es mucho más fuerte y el esmalte ha sido removido en gran parte del diente. En Microtus, el daño en el esmalte también se extiende a lo largo de los ángulos salientes, pero hay evidencias de digestión en la dentina. 


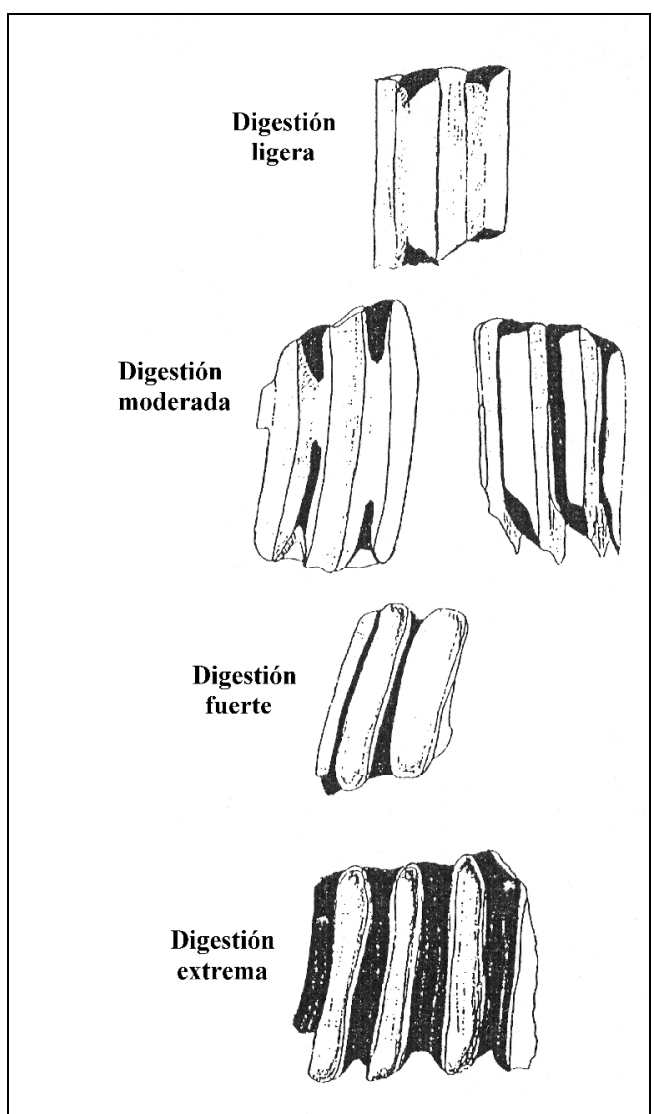

Figura 4.4. Categorías de digestión en molares. En: Fernández-Jalvo y Andrews (1992: 412).

\subsubsection{Digestión postcraneal}

Andrews (1990) y Fernández-Jalvo y Andrews (1992) proponen identificar la digestión postcraneal sobre la epífisis proximal del fémur y sobre la epífisis distal del húmero, calculando las proporciones de los elementos afectados. Considerando que algunas muestras comprendidas en esta tesis no cuentan con un número representativo de dichos elementos, en esos casos se optó por analizar todos los elementos postcraneales. Las marcas de corrosión digestiva sobre el esqueleto postcraneal pueden confundirse con las huellas dejadas por los procesos postdepositacionales. Las diferencias radican en que los agentes postdepositacionales producen modificaciones en los especímenes óseos afectando de igual forma a toda la superficie de los mismos, en cambio, la corrosión por digestión tiene una acción usualmente localizada en las superficies de articulación de los huesos, además en ciertas ocasiones los extremos de los huesos y los bordes de fractura pueden estar redondeados (Andrews, 1990; Fernández-Jalvo y Andrews, 1992).

Estos autores distinguen cuatro categorías de corrosión digestiva postcraneal: 
Ligera: presenta bajas frecuencias en huesos de adultos (6 a 20\%). La digestión afecta casi exclusivamente a las superficies articulares y ocasionalmente se extiende a lo largo de la epífisis, pero nunca alcanza la diáfisis.

Moderada: presenta altas frecuencias en huesos de adultos (25 a 50\%). La digestión afecta a toda la epífisis y puede penetrar en la diáfisis a través de la epífisis. La corrosión produce más alteración en la superficie de la diáfisis, exhibiendo un aspecto de abrasionado o pulido, con bordes de fractura ligeramente redondeados.

Fuerte: casi todos los huesos están afectados (50 a 75\%). La mayor parte de los mismos están fracturados, tienen las superficies redondeadas, las diáfisis onduladas y presentan las epífisis fuertemente digeridas. Asimismo, los bordes de fractura muestran evidencias de estar redondeados con un reborde fino.

Extrema: en líneas generales se acrecientan los rasgos observados en la categoría anterior (75 a 100\%). Todos los huesos están afectados. Las superficies de la diáfisis está muy ondulada y los bordes de fractura están muy redondeados, sin embargo, el borde de fractura es mucho más grueso que en la categoría anterior.

\subsubsection{Fractura}

En este trabajo, se analizó el grado de fractura de los restos craneales y postcraneales, considerando por un lado los restos completos y por otro las diferentes porciones.

Los patrones de fractura pueden estar ligados a los hábitos de ingestión de los depredadores (Andrews, 1990). Muchas especies de estrigiformes tragan a sus presas enteras, generando fracturas mínimas en los elementos esqueletales. En contraste, los mamíferos carnívoros mastican a sus presas y los falconiformes las desmiembran, previamente a la ingesta, originando ensambles de micromamíferos con mayores proporciones de huesos fracturados (Andrews, 1990).

No obstante, los procesos postdepositacionales (e.g., pisoteo), pueden perturbar la composición original del ensamble, produciendo entre otras, altos niveles de fracturas (Matthews et al., 2006). Por esta razón, la fractura de elementos no debe analizarse en forma aislada (Andrews, 1990). 


\subsubsection{Fractura del cráneo}

La fracturación del cráneo, han sido analizada siguiendo la clasificación propuesta por Andrews (1990). Como se ilustra en la figura 4.5, el autor categoriza al cráneo en cuatro tipos de fractura (A, B, C, D). Las dos primeras categorías (A y B), se consideran como cráneos completos, a pesar de que la segunda (B) está definida por la carencia de la fracción posterior de la base del cráneo, esto se debe a que se asume que los cráneos siempre presentan un mínima ruptura (Andrews, 1990); (C) maxilares con arcos zigomáticos y (D) maxilares sin zigomáticos. Por otra parte, se considera la ausencia y presencia de incisivos y molares de los maxilares.

Para este análisis, se calcula la proporción de cada categoría de fractura (FernándezJalvo y Andrews, 1992).

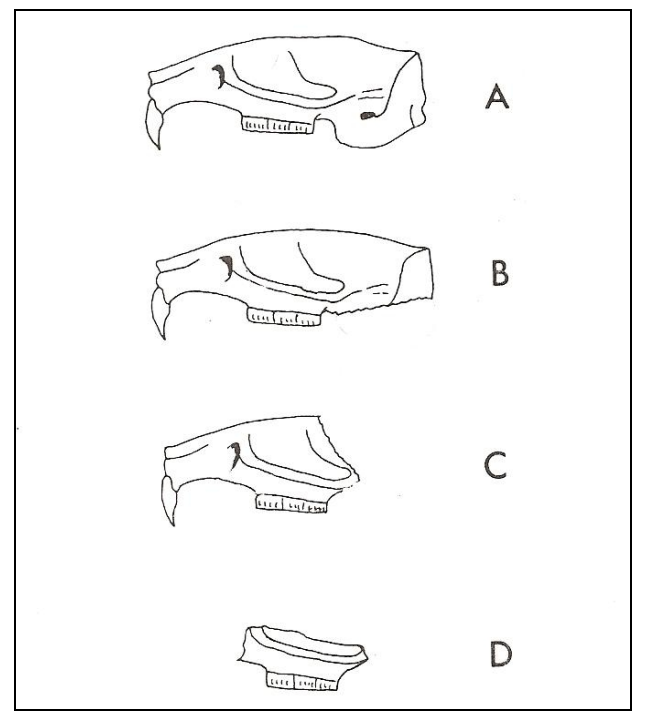

Figura 4.5. Categorías de fractura del cráneo. En: Andrews (1990: 53).

\subsubsection{Fractura de la mandibula}

Las fracturas de las mandíbulas, han sido analizadas siguiendo la clasificación propuesta por Andrews (1990). De la misma manera que en el caso anterior, el autor categoriza a la mandíbula en cuatro tipos de fracturas (A, B, C, D) (Figura 4.6). La categoría (A), está definida como mandíbulas completas; (B) mandíbulas con procesos angular y coronóides rotos; (C) mandíbulas sin rama ascendente y (D) mandíbulas sin rama ascendente y borde inferior roto. Al igual que en los cráneos también se considera la ausencia y presencia de incisivos y molares. 
Para este análisis, se calcula la proporción de cada categoría de fractura (FernándezJalvo y Andrews, 1992).

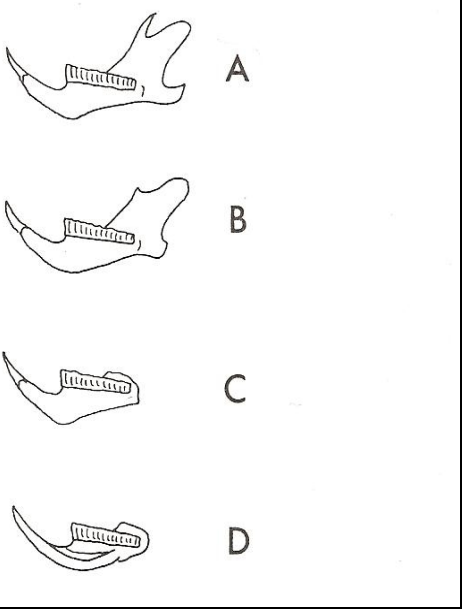

Figura 4.6. Categorías de fractura de la mandíbula. En: Andrews (1990: 56).

\subsubsection{Fractura postcraneal}

Las fracturas postcraneales, han sido analizadas siguiendo la clasificación propuesta por Andrews (1990). El autor considera a los húmeros, fémures, cúbitos y tibias como unidades anatómicas para este análisis. Esta clasificación se basa en la separación de cada elemento en completos, segmento proximal, diáfisis y segmento distal. Estas clases de fracturas están definidas en la figura 4.7.

Para este análisis, se calcula la proporción de cada clase de fractura (Fernández-Jalvo y Andrews, 1992).

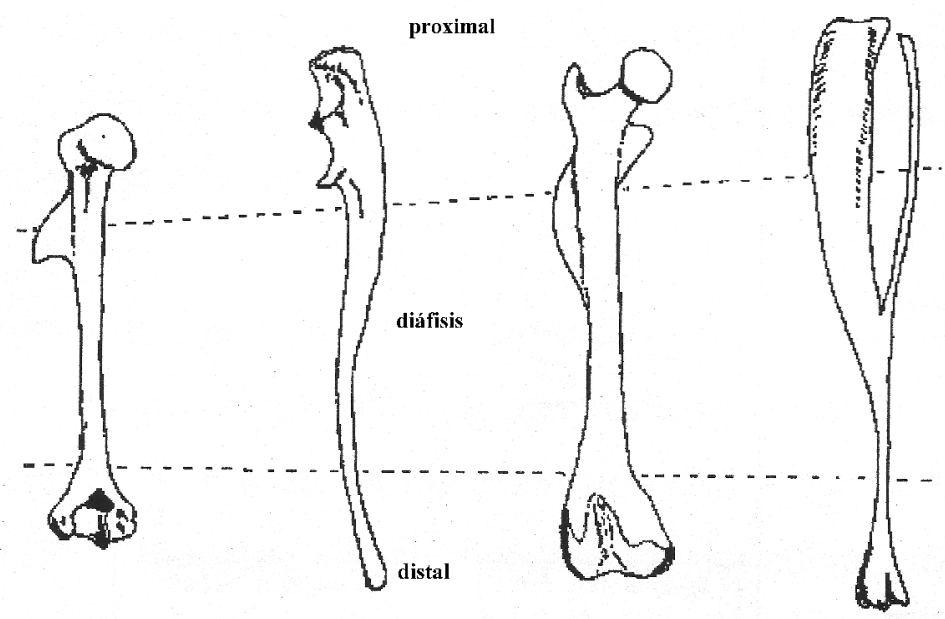

Figura 4.7. Categorías de fractura en elementos postcraneales. En: Andrews (1990: 51). 


\subsubsection{Fractura dentaria}

Las fracturas en los dientes incluyen, tanto las rupturas trasversales como las longitudinales y se asume una sola fractura por diente (Andrews, 1990; FernándezJalvo y Andrews, 1992). Se calcula separadamente para incisivos y molares, y para dientes aislados e in situ (Andrews, 1990; Fernández-Jalvo y Andrews, 1992).

Las fracturas en dientes, a veces están asociadas con procesos digestivos, los cuales debilitan la estructura del esmalte y la dentina, aumentado la fragilidad del diente. Por esta razón, la fractura en dientes aislados es mayor que en los dientes in situ (Andrews, 1990).

La proporción de dientes rotos in situ (i.e., analizado separadamente para incisivos y molares) se obtiene mediante la relación entre el número de dientes que están fracturados en las mandíbulas y maxilares, con el número de dientes presentes en ellos. Utilizamos el mismo procedimiento para obtener la proporción de dientes rotos aislados.

\subsubsection{Número y proporción de elementos esqueléticos}

Se calcularon el número de especímenes óseos determinados por taxón (NISP), el número mínimo de elementos esqueléticos (MNE) y el número mínimo de individuos (MNI) (Grayson, 1984; Lyman, 1994). Además, se calcularon la abundancia relativa para cada elemento y cinco índices que evalúan las relaciones entre las distintas partes esqueletales. Los resultados obtenidos de estos índices, se expresan en valores numéricos, los cuales cuanto más se aproximan a 100, mayor es el equilibrio entre los elementos (Andrews, 1990).

\subsubsection{1. $N I S P, M N E$ y $M N I$}

Dentro de las medidas de abundancia taxonómica se calculó el NISP para cada taxón y para el total de la muestra, teniendo en cuenta todos los restos óseos identificados (Grayson, 1984; Lyman, 1994). 
Como medida de abundancia anatómica se calculó eL MNE para cada elemento separadamente, teniendo en cuenta la suma de los huesos completos y las partes proximales o distales (tanto izquierdos como derechos) (Grayson, 1984; Lyman, 1994). La otra de abundancia taxonómica que se calculó fue el MNI, la cual se obtuvo para cada taxón y para el total de la muestra, teniendo en cuenta la lateralidad del elemento más frecuente (Grayson, 1984; Lyman, 1994).

Donde:

Elemento: es un hueso o diente anatómicamente completo del esqueleto de un animal (Lyman, 1994).

Especímen: se refiere a una parte arqueológica o paleontológica que puede consistir en un hueso completo o fragmento del mismo; un diente completo o fragmento del mismo (Lyman, 1994).

En este trabajo de tesis doctoral se analizaron tafonómicamente, se determinaron taxonómicamente y cuantificaron un NISP de 16.021, un MNE de 15.847 y un MNI de 2.360 en las muestras arqueofaunísticas y un MNI de 1.089 en muestras actuales.

\subsubsection{Abundancia relativa}

Se evaluó la abundancia relativa de los elementos esqueléticos, considerando la representatividad de cada uno de ellos en el marco del número mínimo de individuos (Andrews, 1990; Fernández-Jalvo y Andrews, 1992):

\section{$\mathbf{R i}=\underline{\text { MNEi }} \times 100$ Ei x MNI}

Donde:

Ri: Abundancia relativa de un elemento particular, MNI: Número mínimo de individuos, MNEi: Número mínimo de elementos esqueléticos particulares en la muestra, Ei: Número esperado de ese elemento esquelético en un individuo.

Para este análisis, se tuvieron en cuenta los siguientes elementos anatómicos: 
Maxilares, mandíbulas, molares sueltos, incisivos sueltos, vértebras, costillas, escápulas, húmeros, radios, cúbitos, pelvis, sacros, fémures, tibias, peronés, calcáneos, astrálagos, metapodios y falanges.

\subsubsection{Proporción postcráneo-cráneo}

Andrews (1990) y Gómez (2007) observaron que la mayoría de los ensambles derivados de estrigiformes presentaban proporciones más elevadas de elementos postcraneales. Contrariamente, estos autores sostienen que los falconiformes y mamíferos carnívoros se diferencian porque en general producen conjuntos con mayor cantidad de elementos craneales.

En orden de analizar las relaciones entre elementos craneales y postcraneales se calcularon dos índices propuestos por Andrews (1990). El primero (a), compara el número de elementos proximales (fémur y húmero), con el número de mandíbulas y maxilares. El segundo (b), compara un número mayor de elementos postcraneales (fémur, tibia, húmero, radio y cúbito), con mandíbulas, maxilares y también con molares aislados (Andrews, 1990).

$$
\begin{aligned}
& \text { a- } \frac{\mathbf{f}+\mathbf{h}}{\mathrm{md}+\mathbf{m x}} \times 100 \\
& \text { b- } \frac{P c}{\mathrm{c}}=\frac{(\mathbf{f}+\mathbf{t}+\mathbf{h}+\mathbf{r}+\mathbf{c}) \times 16}{(\mathbf{m d}+\mathbf{m x}+\mathbf{m}) \times 10} \times 100
\end{aligned}
$$

Donde:

Pc: Postcráneo, c: cráneo, f: fémur, t: tibia, h: húmero, r: radio, c: cúbito, md: mandíbula, mx: maxilar, m: molares aislados.

Existe una desigualdad entre los elementos craneales y los postcraneales, los cuales están representados por 16 y por 10 elementos respectivamente. Por esta razón, al segundo índice (b), se le aplica un factor de corrección, multiplicando los elementos craneales por 10 y los postcraneales por 16 (Andrews, 1990). 
En el cálculo de esto índices no se tuvo en cuenta a los marsupiales porque poseen distintas fórmulas dentarias, los cuales dificultan su aplicación con el algoritmo pc/c (b). Este algoritmo fue planteado para micromamíferos con un premolar y dos molares, por lo cual se lleva al valor de corrección a 16 para el cráneo (maxilares, mandíbulas y molares). En el caso de predominar micromamíferos con un premolar y tres molares (e.g., roedores histricognatos como Ctenomys spp., Galea leucoblephara y Microcavia australis) el valor de corrección 16 de la fórmula, debería ser reemplazado por 20.

\subsubsection{Proporción de elementos distales-proximales}

Los ensambles originados por depredadores presentan una mayor pérdida de elementos distales de los miembros, debido a que son más frágiles que los elementos proximales (Andrews, 1990). Por esta razón, para observar las relaciones entre elementos distales y proximales de los miembros se calculó el siguiente índice propuesto por Andrews (1990):

$$
\frac{t+r}{f+h} \times 100
$$

Donde: t: tibia, r: radio, f: fémur, h: húmero.

\subsubsection{Pérdida dentaria}

Andrews (1990) y Gómez (2007) observaron una mayor proporción de molares e incisivos retenidos en sus alvéolos en restos consumidos por estrigiformes y una elevada perdida de dientes en ensambles originados por falconiformes y mamíferos carnívoros.

En orden de evaluar la proporción relativa de dientes aislados Andrews (1990), propone dos índices. El primero (a), compara el número de molares aislados en los conjuntos, con los alvéolos vacíos de los maxilares y mandíbulas de la muestra conocida. De la misma manera, el segundo (b), compara el número de incisivos aislados, con los alvéolos vacíos de los maxilares y mandíbulas. Valores mayores a 100 implican que hubo una pérdida de dientes en la muestra (Andrews, 1990). 
a- $\quad$ alv $\mathbf{m x}+$ alv md $\times 100$

m

\section{b- alv $\mathbf{m x}+$ alv md $x 100$}

i

Donde:

alv mx: alvéolos maxilares (Andrews lo denomina así, sin embargo correspondería a los premaxilares, debido a que los incisivos superiores se implantan en los mismos), alv md: alvéolos mandibulares, m: molares, i: incisivos.

\subsubsection{Categorías de modificación de los depredadores}

Andrews (1990), en base a estudios actualísticos y tomando en consideración todos los rangos de modificación analizados, establece una clasificación de los depredadores en cinco grupos:

Modificación ligera: Tyto alba, Nyctea scandiaca, Bubo lacteus, Strix nebulosa, Asio flammeus, Asio clamator (Carrera y Fernández, 2010).

Modificación intermedia: Bubo bubo, Bubo africanus, Bubo virginianus (Gómez, 2005), Strix aluco.

Modificación moderada: Athene noctua, Athene cunicularia (Montalvo y Tejerina, 2009), Falco tinnunculus, Falco peregrinus.

Modificación fuerte: Circus cyaneus, Nyctea scandiaca, Ichneumia albicauda, Canis latrans, Genetta genetta, Octocyon megalopis, Milvus milvus, Buteo buteo, Buteo polyosoma (Iglesias, 2009), Aegypius occipitales, Caracara plancus (Montalvo y Tallade, 2009), Leopardus geoffroyi (Gomez, 2007; Alvarez et al., en prensa; Montalvo et al., en prensa a)

Modificación extrema: Martes martes, Canis latrans, Vulpes vulpes, Alopex lagopus, Lycalopex griseus (Gómez y Kaufmann, 2007), Puma concolor (Montalvo et al., 2007), 
Conepatus chinga (Montalvo et al., 2008), Homo sapiens (Crandall y Stahl, 1995; Deward y Jarardino, 2007).

\subsection{Acción humana sobre conjuntos de micromamíferos}

Para detectar la posible actividad antrópica sobre los conjuntos de microvertebrados recuperados de los sitios arqueológicos se tuvieron en cuenta los siguientes atributos metodológicos: marcas de corte, termoalteración, corrosión digestiva, partes esqueletales, patrones de fractura y tipos de taxones recuperados.

\subsubsection{Marcas de corte}

Las marcas de corte son alargadas, lineales de longitud y ancho variable, presentan un fondo cuya sección transversal tiene forma de "V" con microestrías paralelas. Asimismo, las marcas de corte presentan direccionalidad con orientación paralela o sub-paralela, ubicadas en sectores del hueso asociado a inserciones musculares (Shipman y Rose, 1983).

En este trabajo se observaron las huellas de corte según su disposición, orientación y profundidad, siguiendo a Quintana (2005). El mencionado autor, estudiando los microroedores recuperados de sitios arqueológicos de las Sierras de Tandilia, pudo identificar tres tipos de marcas de corte:

1. Marcas cortas y poco profundas, dispuestas en forma oblicua o transversal al eje de los huesos largos. Estos tipos de marcas se relacionan con la actividad de cuereo (Quintana, 2005).

2. Marcas excepcionalmente largas y longitudinales al eje del hueso. Esta clase de marcas han sido asociadas a la acción de descarne (Quintana, 2005).

3. Marcas cortas, paralelas y dispuestas en grupos. Esta categoría se corresponde con la fisonomía de los raspados (Quintana, 2005).

\subsubsection{Corrosión digestiva, partes esqueletales y patrones de fractura}

Deward y Jarardino (2007), a partir de restos de micromamíferos recuperados de un sitio arqueológico y de la cavidad abdominal de un esqueleto humano y Crandall y 
Stahl (1995) en base a un trabajo experimental, realizaron un estudio tafonómico de micromamíferos consumidos por Homo sapiens. Estos autores mostraron que los micromamíferos consumidos por $H$. sapiens presentan evidencias de elevada corrosión digestiva y fractura esqueletal. Los autores concluyen que los humanos pueden incluirse en la categoría de modificación extrema (sensu, Andrews, 1990). Por otra parte, Deward y Jarardino (2007) observaron dos patrones contrastantes de abundancia relativa de partes esqueletales, entre los restos provenientes de la cavidad abdominal del esqueleto humano y aquellos exhumados del sitio arqueológico. El primero se caracterizó por la ausencia de restos craneales y abundancia de húmeros, fémures y tibias; y el segundo por la abundancia de elementos craneales y una marcada escasez de restos postcraneales. Este patrón fue interpretado por los autores como un descarte del cráneo de los micromamíferos previamente a ser consumidos.

\subsubsection{Categorías de tamaño}

Los micromamíferos (mamíferos $<1 \mathrm{~kg}$ ), se dividieron en tres categorías de tamaño: chico (<50 g.), mediano (entre 50 y 150 g.) y grande ( $>150$ g) (modificado de Pardiñas, 1996-1998).

La primera categoría esta conformada por los marsupiales Lestodelphys halli y Thylamys pallidior y los roedores sigmodontinos Akodon spegazzinii, Akodon molinae, Abrothrix olivaceus, Abrothrix longipilis, Abrothrix andinus, Chelemys macronyx, Oligoryzomys flavescens, Oligoryzomys longicaudatus, Calomys musculinus y Eligmodontia spp. La segunda por los sigmodontinos Phyllotis xanthopygus, Graomys griseoflavus, Loxodontomys micropus, Reithrodon auritus, Euneomys chinchilloides y Euneomys mordax. La tercera por los roedores histricognatos Galea leucoblephara, Microcavia australis y Ctenomys spp.

\subsection{4. Índices de tamaño y predictibilidad}

En base a las categorías de tamaño Pardiñas (1999b) desarrolló un índice para evaluar la acción de aves rapaces en la génesis de los conjuntos de micromamíferos, diferenciando los conjuntos generados por rapaces nocturnas (Strigiformes), de aquellos depositados por rapaces diurnas (Falconiformes): 
Índice de tamaño (IT) $=($ MNI Pequeños + MNI Medianos $) /($ MNI Grandes $) \times 100$ (modificado de Pardiñas, 1999b).

En este estudio se utilizó este índice para distinguir conjuntos de micromamíferos acumulados por humanos, de aquellos generados por rapaces. En tal sentido, valores por encima de 100 indicaría acción de aves rapaces y por debajo de este número podría señalar actividad antrópica. Esto se debe a que en contraste con la mayoría de las aves rapaces, los humanos depredan sobre los micromamíferos de mayor tamaño.

Por otra parte, Pardiñas (1999b) propone otro índice para avaluar la actividad antrópica: Índice de predictabilidad (IP) $=($ MNI Coloniales + MNI Gregarios + MNI Agrupados) / (MNI Crípticos + MNI Solitarios) x 100. Donde los roedores cávidos se incluyen en las categorías de Coloniales y Gregarios, Ctenomys spp. en la de Agrupados y los sigmodontinos corresponden generalmente a la categoría de Crípticos y Solitarios.

Cuando los valores están por encima de 100 podría señalar concentraciones producidas por humanos y de aves rapaces diurnas y por debajo de este número indicaría acción de rapaces nocturnas (Pardiñas, 1999b).

\subsubsection{Restos termoalterados}

Pardiñas (1999b) propone cuatro aspectos a tener en cuenta cuando se hacen interpretaciones sobre restos termoalterados de micromamíferos provenientes de sitios arqueológicos: a) taxones involucrados; b) números de elementos involucrados; c) categoría de alteración térmica y d) tipos de elementos afectados. En síntesis estos aspectos fueron descriptos de la siguiente forma:

a) los huesos quemados como producto del consumo humano, deberían corresponder mayormente a micromamíferos de tamaño grande ( $G$. leucoblephara, $M$. australis y Ctenomys spp.), en detrimento de roedores de menor tamaño como los sigmodontinos.

b) Cuando la cantidad de restos termoalterados alcanza el $20 \%$ del total de la muestra, puede asociase alguna actividad antrópica, considerando también que cumpla con el aspecto anterior.

c) establece tres categorías de alteración térmica: huesos quemados, huesos quemados en sus extremos y huesos levemente termoalterados. La primera abarca a los que 
exhiben la superficie externa de color negro o gris blanquecino (calcinados) en más de un $50 \%$, la segunda incluye a los huesos largos termoalterados parcialmente en los extremos de la diáfisis y en las epífisis y la tercera es una categoría intermedia entre los huesos quemados y los no alterados térmicamente, en donde presentan una coloración castaña oscura.

d) en los conjuntos de huesos quemados como producto del consumo humano, puede haber un mayor nivel de incidencia sobre las tibias, donde pueden concentrarse en el extremo de la diáfisis distal. Esta característica puede asociarse con un modelo de cocción donde la temperatura produce una retracción de la musculatura en los sectores distales apendiculares, las cuales pueden quedar directamente expuestas al fuego.

\subsection{Metodología para el estudio tafonómico de aves}

En la mayoría de las aves, los huesos son huecos, tienen las paredes delgadas, son muy porosos y presentan trabéculas diagonales que los refuerzan e impiden que se arqueen (denominada estructura o armazón de Warren) (Kardong 1999; Young 1971). La matriz ósea está formada por haces de fibras colágenas finas y paralelas y un mayor porcentaje de sales minerales de calcio (Devillers y Clairambault 1977). Por lo tanto, tienden a ser más ligeros y más quebradizos que los huesos de otros grupos de vertebrados (Duke et al. 1973). En general los huesos de las aves sufren una alteración digestiva semejante a la observada en huesos de mamíferos, aunque con mayores porcentajes de incidencia (Bochenski y Tomek, 1997). Asimismo, estos investigadores coinciden con Andrews (1990) y Fernández-Jalvo y Andrews (1992) en que los efectos de los procesos postdepositacionales pueden distinguirse de la corrosión digestiva, por su acción más uniforme sobre las superficies de los huesos.

\subsubsection{Categorías de superficies dañadas}

En el marco de los estudios tafonómicos se observaron las superficies de los huesos, siguiendo las categorías de superficies dañadas propuestas por Bochenski y Tomek (1997), en base a estudios sobre egagrópilas de aves rapaces:

\section{(1) Superficie del hueso (epífisis y diáfisis):}




\section{A: Sin daño.}

B: Redondeada: caracterizada con hoyos y depresiones con bordes redondeados. Este tipo de modificación se asocia fundamentalmente a acción digestiva, aunque podría originarse por corrosión sedimentaria.

C: Aguda: distinguida por hoyos y depresiones con bordes agudos, ásperos y hundidos. Asociada en general a procesos postdepositacionales, aunque podría producirse por acción digestiva.

\section{(2) Fractura:}

A: Aguda: caracterizada con ángulos agudos y ásperos al eje de la diáfisis. Este tipo de fractura se vincula a procesos postdepositacionales.

B: Redondeada: distinguida por ángulos redondeados y frecuentemente adelgazados, siendo la superficie de fractura suave. Asociada a acción digestiva.

\subsubsection{Categorías de digestión}

Tomando en consideración el grado y frecuencias de digestión de distintas especies de aves rapaces, Bochenski et al. (1998) reconocen tres categorías de digestión postcraneal (i.e., tomando solo fémures):

Categoría 1: produce bajas frecuencias de digestión ( 0 a 10\%) en las diáfisis, y relativamente bajas frecuencias en las epífisis (29 a 55\%). Incluye especies de Strigiformes (e.g., Nyctea scandiaca y Asio otus).

Categoría 2: se distingue por sus altas frecuencias de digestión en las diáfisis (15 a $33 \%$ ) y en las epífisis (82 a 84\%). Incluye especies de Strigiformes (e.g., Bubo bubo y Strix aluco). 
Categoría 3: no solo produce mayores frecuencias de elementos alterados, sino que en algunos casos el grado de modificación es mayor. El 56\% de las diáfisis y el 96\% de las epífisis de los fémures están dañados. Incluye especies de Falconiformes (e.g., Falco rusticolus).

\subsubsection{Fragmentación de elementos esqueletales}

Los huesos fueron categorizados en clases de fragmentación diferenciadas por Bochenski et al. (1993) sobre la base de un estudio tafonómico de egagrópilas de Strigiformes. La fragmentación de los huesos largos fue expresada en porcentajes. No obstante, los huesos del esqueleto axial fueron tan escasos que se pronunciaron en números absolutos.

\subsubsection{Categorías de fragmentación del cráneo}

Las categorías de fragmentación del cráneo propuestas por Bochenski et al. (1993), están definidas en la figura 4.8 .

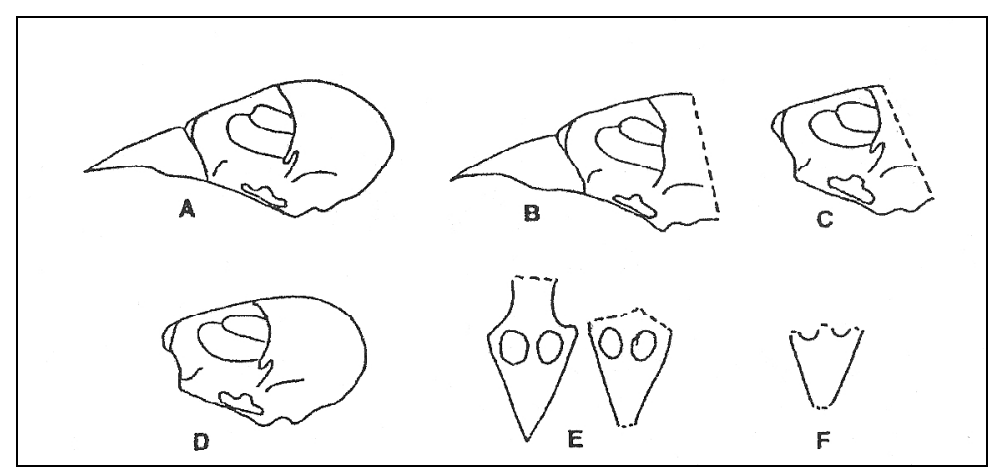

Figura 4.8. Categorías de fragmentación del cráneo. A: cráneo completo. B: cráneo completo, sin parte posterior. C: bóveda craneal sin parte posterior. D: bóveda craneal. E: pico completo. F: fragmento del pico. En: Bochenski et al. (1993: 315).

\subsubsection{Categorías de fragmentación de la mandíbula}

Las categorías de fragmentación de la mandíbula propuestas por Bochenski et al. (1993), están definidas en la figura 4.9. 


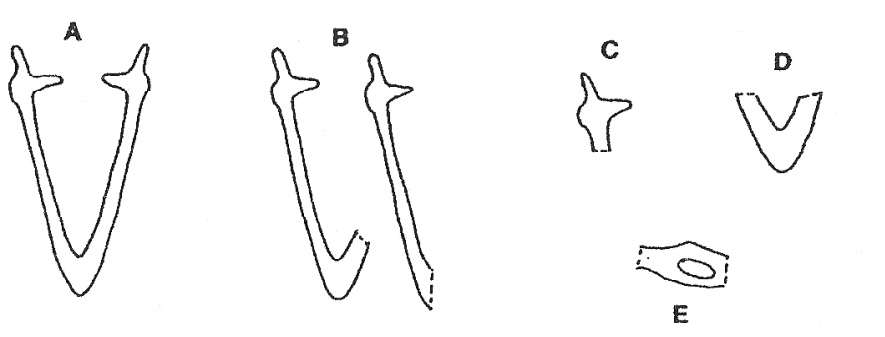

Figura 4.9. Categorías de fragmentación de la mandíbula. A: completa (i.e., ambas mandíbulas). B: una rama mandibular. C: porción articular. D: extremo de la mandíbula. E: porción media de la mandíbula. En: Bochenski et al. (1993: 315).

\subsubsection{Categorías de fragmentación del esternón}

Las categorías de fragmentación del esternón propuestas por Bochenski et al. (1993), están definidas en la figura 4.10.

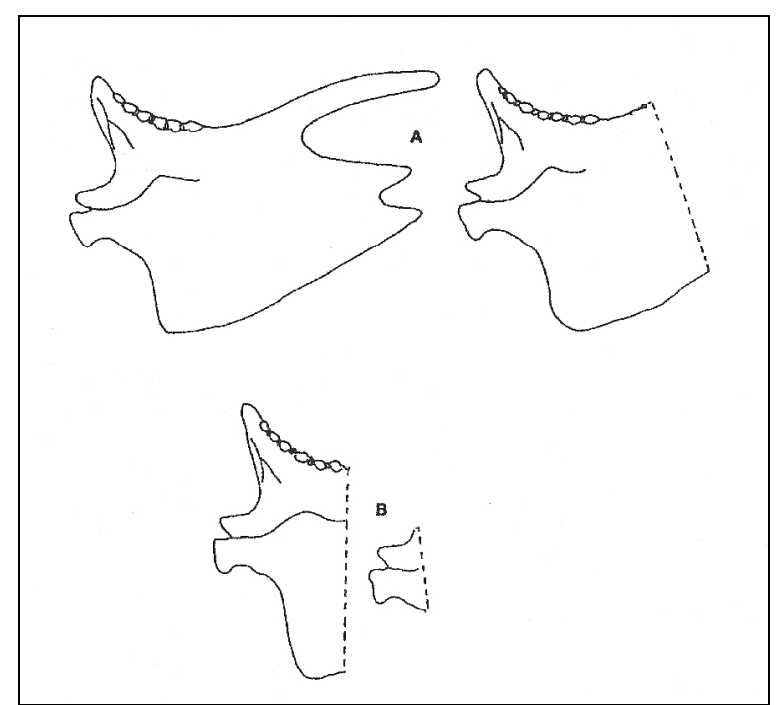

Figura 4.10. Categorías de fragmentación del esternón. A: más de la mitad del esternón (incluye esternón completo). B: menos de la mitad del esternón. En: Bochenski et al. (1993: 316).

\subsubsection{Categorías de fragmentación de la pelvis}

Las categorías de fragmentación de la pelvis propuestas por Bochenski et al. (1993), están definidas en la figura 4.11. 


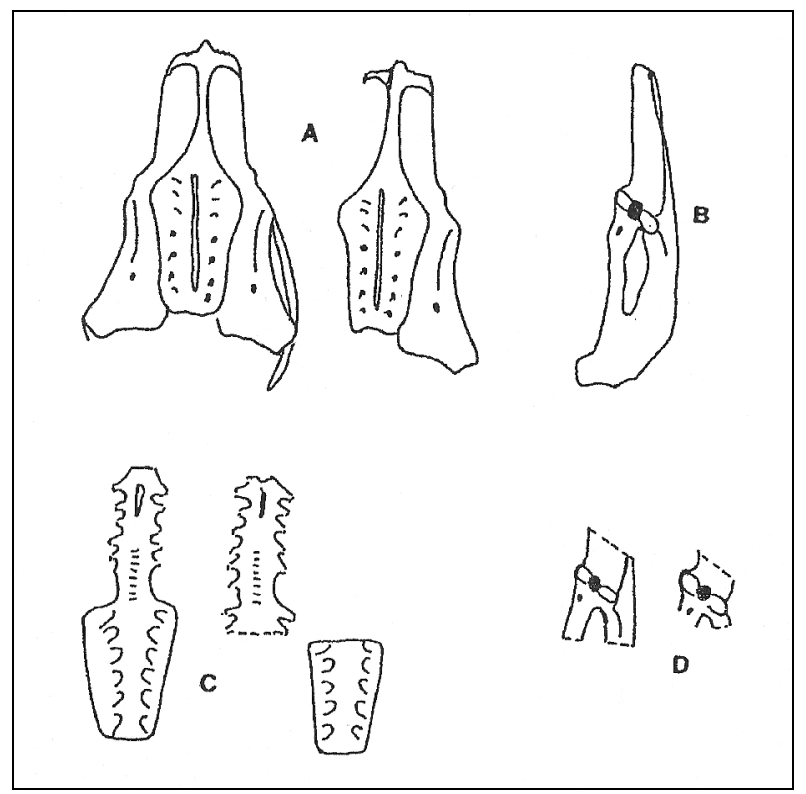

Figura 4.11. Categorías de fragmentación de la pelvis. A: sinsacro con uno o dos huesos del íleon, isquion y pubis (incluye pelvis completa). B: Huesos íleon, isquion y pubis. C: sinsacro entero o parcial. D: región del acetábulo. En: Bochenski et al. (1993: 316).

\subsubsection{Categorías de fragmentación de los huesos largos}

Las categorías de fragmentación de los huesos largos propuestas por Bochenski et al. (1993), están definidas en la figura 4.12. Para simplificar, los autores incluyen dentro de esta categoría de fragmentación tanto a los huesos de los miembros, como al coracoides, escápula y primera falange digital mayor.

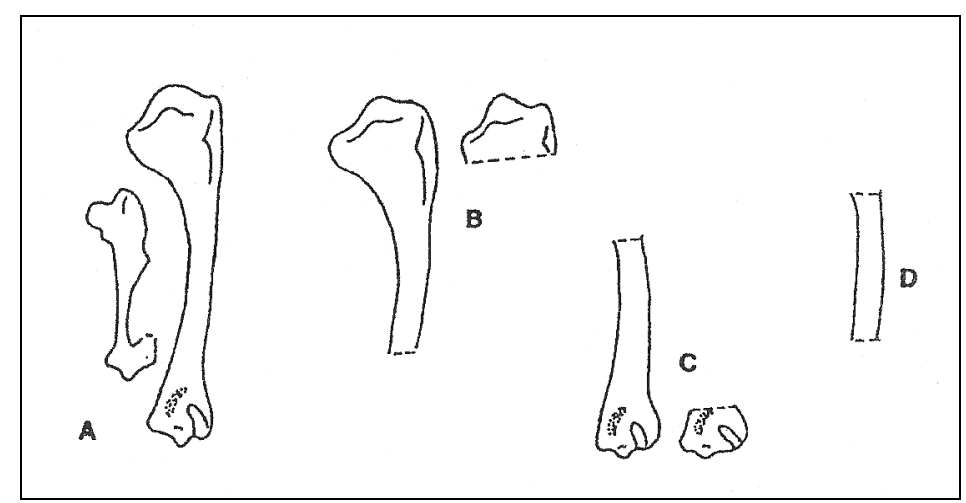

Figura 4.12. Categorías de fragmentación de los huesos largos. A: huesos completos. B: epífisis proximal con o sin diáfisis. C: epífisis distal con o sin diáfisis. D: diáfisis. En: Bochenski et al. (1993: 317). 


\subsubsection{Porcentajes de huesos enteros}

Esta proporción fue calculada comparando la parte de elementos completos con el número total de fragmentos de un tipo particular de hueso. Las especies de aves rapaces pueden ser reunidas en tres grupos, de acuerdo al daño que producen sobre los huesos:

Grupo 1: los huesos se encuentran muy fragmentados; y en muchos casos la parte de elementos completos está por debajo del 30\%. Incluye restos óseos de egagrópilas de especies de Falconiformes (e.g., Falco rusticolus, Aquila adalberti).

Grupo 2: en este grupo intermedio, los porcentajes de huesos completos varían de 30 a $60 \%$. Incluye restos óseos de egagrópilas de especies de Strigiformes (e.g., Bubo bubo, Strix aluco).

Grupo 3: los huesos se encuentran poco fragmentados y la parte de elementos completos está por arriba del 60\%. Incluye restos óseos no ingeridos de especies de Falconiformes (e.g., Falco peregrinus, Falco rusticolus, Aquila chrysaetos, Aquila heliaca) y restos óseos de egagrópilas de una especie de Strigiformes (Asio otus).

\subsubsection{Numero mínimo de individuos (MNI)}

Con el objetivo de identificar el agente acumulador, se realizó el cálculo del número mínimo de individuos (MNI), siguiendo la propuesta de Bochenski et al. (1993). El MNI fue calculado para cada elemento separadamente. Los resultados se presentan como números absolutos (i.e., MNI Elemento) y como porcentajes con respecto a los elementos con los valores más altos de MNI. (i.e., Total MNI\%). Para este cálculo todos los taxones se tomaron en forma conjunta, sin determinar las especies; y los fragmentos proximales y distales se trataron separadamente. Aunque este procedimiento seguramente subestime el valor del MNI, el error, sería similar para cada tipo de elemento; y esto podría significar un ahorro de mucho tiempo en el análisis (Bochenski et al., 1993).

Por otro lado, si bien el MNI es una medida de abundancia taxonómica, calculado de esta forma su utilidad para indagar acerca del agente acumulador de agregados óseos de 
aves de pequeño tamaño, ha sido ampliamente sustentada en numerosos trabajos (véase Bochenski, 1997, 2005; Bochenski et al., 1993, 1997, 1998, 1999, 2009; Bochenski y Tomek, 1994; Bochenski y Nekrasov, 2001; Bochenski y Tornberg, 2003; entre otros).

\subsubsection{Número mínimo de elementos (MNE)}

El número mínimo de elementos (MNE) fue calculado para cada elemento separadamente, expresado en números absolutos y en porcentajes (Bochenski et al., 1993).

\subsubsection{Relación entre elementos del miembro anterior y miembro posterior}

Como una forma de evaluar el origen de las acumulaciones estudiadas y siendo especialmente útil para discriminar entre conjuntos formados por aves rapaces, de aquellos originados por la acción antrópica (Ericson, 1987, Bochenski, 2005), se efectuó el cálculo de la relación entre elementos del miembro anterior y miembro posterior propuesto por Ericson (1987). Este cómputo denominado por Ericson (1987) como "wing / leg ratio", se realiza dividiendo el número de fragmentos del miembro anterior (húmero, cúbito y carpometacarpo) con la suma de fragmentos del miembro anterior y del miembro posterior (fémur, tibia y tarsometatarso).

El cálculo se expresó en porcentaje y se utilizó la prueba de Chi-cuadrado para evaluar la posible desviación del 50\% esperado (proporción 1:1) (Ericson, 1987; Livingston, 1989).

$$
\frac{\mathbf{h + c + c m}}{\mathbf{h}+\mathbf{c}+\mathbf{c m}+\mathbf{f}+\mathbf{t}+\mathbf{t m}}
$$

Donde: h: húmero, c: cúbito, cm: carpometacarpo, f: fémur, t: tibiotarso, tm: tarsometatarso.

A partir de este cálculo y utilizando información generada de estudios previos de egagrópilas y restos no ingeridos de aves rapaces, Bochenski y Nekrasov (2001) distinguen cuatro grupos: 
Grupo I: los elementos del miembro anterior y posterior presentan la misma frecuencia (relación 1:1). Incluye restos óseos de egagrópilas de especies de Strigiformes y Falconiformes (e.g., Asio otus, Falco rusticolus).

Grupo II: presentan un ligero predominio de elementos del miembro anterior (5357\%). Incluye restos óseos de egagrópilas de Strigiformes (e.g., Bubo bubo, Strix aluco) y restos no ingeridos de especies de Falconiformes (e.g., Aquila chrysaetos).

Grupo III: presentan un predominio fuerte de elementos del miembro anterior (6689\%). Incluye restos no ingeridos de especies de Falconiformes (e.g., Aquila heliaca, Haliaeetus albicilla, Aquila chrysaetos).

Grupo IV: prevalecen los elementos del miembro posterior. Incluye restos óseos de egagrópilas de especies de Falconiformes (e.g., Aquila heliaca).

\subsubsection{Relación entre elementos proximales y distales}

La relación entre elementos proximales y distales del esqueleto, fue calculada dividiendo el número de fragmentos proximales (escápula, coracoides, húmero, fémur y tibiotarso) con la suma de fragmentos proximales y distales (cúbito, radio, carpometacarpo y tarsometatarso). El cálculo se expresó en porcentaje y se utilizó la prueba de Chi-cuadrado para evaluar la posible desviación del 50\% esperado (proporción 1:1) (Bochenski y Nekrasov, 2001; Bochenski, 2005).

$$
\frac{e+c d+h+f+t}{e+c d+h+f+t+c+r+c m+t m}
$$

Donde: e: escápula, cd: coracoides, h: húmero, f: fémur, t: tibiotarso, c: cúbito, r: radio; cm: carpometacarpo, tm: tarsometatarso.

A partir de este cálculo, Bochenski y Nekrasov (2001) en base a estudios previos de egagrópilas y restos no ingeridos de aves rapaces distinguen tres grupos: 
Grupo I: los elementos proximales y distales presentan la misma frecuencia (relación 1:1). Incluye restos óseos de egagrópilas de especies de Falconiformes (e.g., Falco rusticolus y Aquila heliaca).

Grupo II: el predominio de elementos proximales es de 56-64\%. Incluye restos óseos de egagrópilas de Strigiformes (e.g., Bubo bubo, Strix aluco, Asio otus) y restos no ingeridos de especies de Falconiformes (e.g., Aquila heliaca, Haliaeetus albicilla).

Grupo III: los elementos proximales sobrepasan el 80\%. Incluye restos no ingeridos de especies de Falconiformes (e.g., Aquila chrysaetos).

\subsection{Metodología para el estudio tafonómico de reptiles}

Si bien no existe una metodología específica para el estudio tafonómico de restos óseos de reptiles de pequeño tamaño, en este estudio se siguieron los lineamientos generales empleados en el único trabajo basado en un análisis tafonómico de este tipo de vertebrados (Castillo et al., 2001), el cual tuvo lugar en el sitio paleontológico La Cueva del Llano, en las Islas Canarias (España). Los autores mencionados aplican algunos de los aspectos metodológicos propuestos por Andrews (1990) en el estudio de micromamíferos. En este sentido, se analizaron la abundancia relativa de los elementos esqueletales, fragmentación de algunos huesos largos (i.e., fémur, húmero, tibia y cúbito) y corrosión digestiva en todos los elementos esqueletales. Asimismo, se calcularon dos índices: el primero para comparar la proporción de elementos postcraneales respecto de los elementos craneales [(húmero + fémur) / (mandíbula + maxilar)] x 100 y el segundo para evaluar la relación entre los elementos distales y proximales de los miembros [(tibia + radio) / (fémur + húmero)] x 100.

\subsection{Procesos postdepositacionales}

\subsubsection{Pisoteo}


El pisoteo es un proceso mecánico que generalmente ocurre en forma previa a su entierro, por el cuál los restos óseos y dentarios se friccionan con el sedimento, debido a la fuerza ejercida por el tránsito de los animales y humanos.

En base a estudios experimentales sobre restos de micromamíferos, Andrews (1990) observó que el pisoteo es un proceso muy destructivo y del cual emergen patrones de fractura característicos. Entre estos podemos mencionar: la ausencia de cráneos completos, reducción del número de maxilares, considerable pérdida de dientes de las mandíbulas (implicando un aumento en el número de dientes aislados), alto grado de fractura y cierta pérdida de elementos postcraneales, pero con alta supervivencia de los elementos más pequeños.

Diversos experimentos conducidos por Courtin y Villa (1982), Behrensmeyer et al. (1986), Olsen y Shipman (1988), Fiorillo (1989) y Domínguez-Rodrigo et al. (2009), sobre los efectos del pisoteo en restos de mamíferos grandes, han demostrado que este proceso puede originar marcas de rasgado producto de la fricción contra el sedimento, las cuales pueden ser diferenciarlas de aquellas producidas por instrumentos líticos (Denys, 2002). Las marcas producidas por pisoteo son superficiales, tienen una orientación transversal al hueso, con una ubicación mucha más azarosa que las marcas de corte. A diferencia de las marcas de corte, el fondo es poco profundo, con una sección curva en forma de "U" o plana. Generalmente carecen de estrías paralelas, aunque pueden presentar microestrías interiores y levantamientos laterales (Lyman, 1994; Domínguez-Rodrigo et al., 2009).

Asimismo, el pisoteo proporciona altos niveles de dispersión y fractura en los agregados fósiles, los restos presentan bordes angulosos y ásperos (Andrews, 1990); por el contrario, los restos óseos fracturados e ingeridos por depredadores, presentan bordes redondeados, suaves y con huellas de corrosión digestiva (Andrews, 1990; Bochenski y Tomek, 1997). Este tipo de proceso es habitual en las cuevas, debido a que son unidades espaciales de circulación restringida (Pardiñas, 1999a, 1999b).

\subsubsection{Meteorización}

Behrensmeyer (1978) en su definición de meteorización incluye tanto agentes físicos como químicos, operando ambos sobre la superficie y dentro del suelo. Sin embargo, para Andrews (1990) la meteorización se refiere solo a los agentes físicos tales como el 
sol, viento, lluvia y cambios de temperatura, de modo que los efectos del entierro y la corrosión del suelo son parte de los procesos diagenéticos.

Se observaron los efectos de la exposición de los restos óseos y dentarios a los agentes meteóricos (i.e., la radiación ultravioleta (UV) del sol, el viento, la lluvia y los cambios de temperatura), siguiendo la propuesta de estadios de meteorización de Andrews (1990) para los restos de micromamíferos y la de Bochenski y Tomek (1997) para los restos de aves pequeñas.

Con el propósito de graduar la intensidad y las alteraciones, Behrensmeyer (1978) ha establecido seis estadios de meteorización para mamíferos grandes en diferentes ambientes tropicales africanos (i.e., Amboseli Park, Kenia). Asimismo, Andrews (1990) propone cuatro estadios de meteorización para micromamíferos en un clima templado y húmedo (i.e., Stratton Dorset, Inglaterra). Por su parte, Bochenski y Tomek (1997) distinguen dos estadios de meteorización para aves pequeñas en dos ambientes de transición, secos y templados (i.e., Záskogo Cave, Bulgaria y Ciemna Cave, Polonia).

En la tabla 4.2 se pueden observar los patrones de meteorización de micromamíferos descriptos por Andrews (1990) y los de aves diferenciados por Bochenski y Tomek (1997). Asimismo, son comparados con los patrones de meteorización de mamíferos grandes distinguidos por Behrensmeyer (1978).

La alteración por meteorización en huesos y dientes de mamíferos, está caracterizada por la presencia de agrietamientos, resquebrajamientos, astillas y exfoliaciones de las superficies (Behrensmeyer, 1978; Andrews, 1990); mientras que en huesos de aves pequeñas, se caracterizan por hoyos concéntricos y depresiones con bordes agudos y exfoliaciones en las superficies (Bochenski y Tomek, 1997).

Las diferencias existentes entre los resultados de Behrensmeyer (1978) y Andrews (1990) podrían deberse al clima o condiciones locales del área de experimentación (Cáceres, 2002). La primera realizó su estudio en la sabana africana, mientras que el segundo experimentó en áreas templadas y húmedas. Por ende, el tiempo necesario para la aparición de los primeros agrietamientos es mucho mayor en un ambiente húmedo (Bennàsar Serra, 2005). 


\begin{tabular}{|c|c|c|c|c|c|c|}
\hline Estadio & $\begin{array}{c}\text { Macromamíferos } \\
\text { Behrensmeyer (1978) }\end{array}$ & años & $\begin{array}{l}\text { Micromamíferos } \\
\text { Andrews (1990) }\end{array}$ & años & $\begin{array}{c}\text { Aves } \\
\text { Bochenski y Tomek (1997) }\end{array}$ & años \\
\hline $\mathbf{0}$ & No hay modificación & $0-1$ & No hay modificación & $0-2$ & No hay modificación & $0-4+$ \\
\hline 1 & $\begin{array}{l}\text { Agrietamiento paralelo a } \\
\text { la } \\
\text { estructura fibrosa, las } \\
\text { superficies de articulación } \\
\text { pueden exhibir un } \\
\text { agrietamiento en mosaico. } \\
\text { Podría haber grasa y } \\
\text { tejidos epidérmicos. }\end{array}$ & $0-3$ & $\begin{array}{l}\text { Ligero agrietamiento } \\
\text { paralelo a la estructura } \\
\text { fibrosa. Dientes con } \\
\text { dentina resquebrajada. }\end{array}$ & $1-5$ & $\begin{array}{l}\text { Epífisis con uno o más } \\
\text { hoyitos con bordes ásperos. } \\
\text { Diáfísis sin modificación o } \\
\text { solo con hoyitos con bordes } \\
\text { ásperos, o depresiones con } \\
\text { bases ásperas. Las fracturas } \\
\text { podrían ser agudas y } \\
\text { redondeadas, o semi- } \\
\text { redondeadas. Podría haber } \\
\text { tendones y plumas. }\end{array}$ & $1-4+$ \\
\hline 2 & $\begin{array}{l}\text { Exfoliación concéntrica, } \\
\text { usualmente asociada a } \\
\text { grietas con pérdida de } \\
\text { tejido cortical. Podría } \\
\text { haber restos de cartílagos, } \\
\text { ligamentos y piel. }\end{array}$ & $2-6$ & $\begin{array}{l}\text { Agrietamiento más } \\
\text { extensivo, pero poca } \\
\text { exfoliación. Dientes con } \\
\text { un pronunciado astillado } \\
\text { y agrietamiento. }\end{array}$ & $3-5+$ & $\begin{array}{l}\text { Epífisis con un poseado } \\
\text { extenso y con hoyos grandes } \\
\text { y chicos con bordes agudos } \\
\text { y ásperos; y depresiones con } \\
\text { bordes ásperos. Exfoliación } \\
\text { concéntrica. Fractura aguda } \\
\text { y áspera, muy frágil. No hay } \\
\text { tendones ni plumas. }\end{array}$ & $\begin{array}{c}\text { 1-a } \\
\text { muchos } \\
\text { años }\end{array}$ \\
\hline 3 & $\begin{array}{l}\text { El tejido compacto está } \\
\text { homogeneamente } \\
\text { alterado, } \\
\text { resultando en una textura } \\
\text { fibrosa. La meteorización } \\
\text { penetra } 1,5 \mathrm{~mm} \text {. }\end{array}$ & $4-15$ & $\begin{array}{l}\text { Agrietamiento profundo } \\
\text { y pérdida de algunos } \\
\text { segmentos profundos } \\
\text { o escamas entre grietas. } \\
\text { Dientes con agritamiento } \\
\text { extensivo. }\end{array}$ & $4-5+$ & & \\
\hline 4 & $\begin{array}{l}\text { Superficie muy fibrosa } \\
\text { y ásperas, con } \\
\text { desprendimientos de } \\
\text { astillas. La meteorización } \\
\text { penetra en el interior de } \\
\text { las cavidades }\end{array}$ & $6-15$ & & & & \\
\hline 5 & $\begin{array}{l}\text { Destrucción del resto } \\
\text { in situ con grandes astillas } \\
\text { a su alrededor. }\end{array}$ & $6-15$ & & & & \\
\hline
\end{tabular}

Tabla 4.2. Cuadro comparativo de los estadios de meteorización de restos de mamíferos grandes (Behrensmeyer, 1978), de micromamíferos (Andrews, 1990) y de aves pequeñas (Bochenski y Tomek, 1997). Los restos de mamíferos grandes fueron expuestos en clima tropical, los restos de micromamíferos en clima templado y húmedo y los restos de aves en clima de transición, seco y templado. En Bochenski y Tomek (1997: $384)$. 
Los estadios de meteorización propuestos por estos autores son operativos para el análisis de los conjuntos faunísticos, sin embargo hay que tener en cuenta que sus investigaciones fueron realizadas en ambientes diferentes a los del sur de Mendoza y por ende, los agentes meteóricos posiblemente incidirán de manera distinta sobre los restos.

\subsubsection{Abrasión}

La abrasión es la remoción del material del hueso causada por el impacto de partículas sedimentarias (Shipman y Rose, 1988). Es el resultado de cualquier agente que erosiona los bordes y la superficie del hueso a través de la aplicación de una fuerza física (Lyman, 1994). En este sentido, se opone a cualquier tipo de disolución química que pueda afectar al hueso (Behrensmeyer et al., 1989). Sus rasgos principales son la presencia de redondeamientos, pulidos y estriación microscópica en las superficies óseas (Korth, 1979; Andrews, 1990; Lyman, 1994; entre otros).

En orden de observar los diferentes tipos de abrasión sobre restos de microvertebrados se han realizado numerosos experimentos (e.g., Korth, 1979; Andrews, 1990, 1995; Fernández-Jalvo, 1992; Trapani, 1998; Pinto y Andrews, 1999; Fernández-Jalvo y Andrews, 2003; Smoke y Stahl, 2004).

El transporte hídrico en cualquier tipo de sedimento produce abrasión, manifestada como redondeamiento y pulido de toda la superficie del hueso, afectando más a las protuberancias, crestas prominentes o a los bordes previamente fracturados (en sedimentos más gruesos se reduce el tiempo que necesita para modificarse, pero el resultado es el mismo). Este tipo de modificación es diferente a la resultante de la digestión donde la superficie afectada está localizada en sectores puntuales del hueso (Pinto y Andrews, 1999).

Trabajos experimentales conducidos por Korth (1979) y Fernández-Jalvo y Andrews (2003), observaron bajos grados de fracturas, donde solo las proyecciones y articulaciones fueron afectadas y con escasas evidencias de pulido. Los autores mencionados destacan que el transporte hídrico suele producir hoyos en la cara externa de las mandíbulas de los micromamíferos. Asimismo, estos autores y Andrews (1995) registraron que el grado de redondeamiento de los huesos dependía del tamaño de los clastos. 
Por otra parte, Andrews (1990) en un experimento para analizar la abrasión en restos de micromamíferos, sin utilizar agua, observó altos niveles de fractura, donde las ramas ascendentes y el borde anterior de las mandíbulas estaban rotas, los molares se desprendieron de los alvéolos y los dientes estaban ligeramente resquebrajados. Además, este autor registró que el peroné estaba separado de la tibia y había sufrido algunas modificaciones en las cabezas del fémur.

Posteriormente, Andrews (1990) introduce piedras grandes en el mismo experimento (i.e., dos piedras de 368g). Despues de una hora el autor observó que los cráneos y mandíbulas estaban completamente fracturados, los dientes estaban astillados principalmente en las raíces, y algunos estaban fracturados. Por su parte los huesos largos presentaron fracturas en las diáfisis y/o en las epífisis. Pasadas tres horas de experimentación, solo pudo recuperar epífisis o diáfisis muy fracturadas, incluyendo a los elementos más pequeños como falanges y metapodios, y ninguno de los elementos estaba redondeado, pero si dentados (Andrews, 1990).

Realizando experimentos sobre transporte diferencial de partes esqueletales en flujos de agua, Korth (1979) registró tres grupos diferentes de acuerdo a su factibilidad de transporte. En el primero los elementos más ligeros son transportados, tales como las vértebras, pelvis, costillas, escápula y falanges. En segundo lugar, cuando aumenta la corriente de agua, son transportados los huesos largos, calcáneo y astrágalo. Finalmente, el tercer grupo, se desplaza cuando ocurren los valores más altos del flujo de energía hídrica. En este caso se transportan las mandíbulas y dientes (Korth, 1979). No obstante, hay otros parámetros actuando en contextos sedimentarios que podrían afectar los resultados, tales como la velocidad y turbulencia del agua, los tipos de sustrato, la topografía y la morfología de los huesos (Fernández-Jalvo y Andrews, 2003).

Una característica distintiva de la abrasión en restos de micromamíferos consiste en la formación de hoyos en cara externa de la mandíbula, por debajo de la serie dentaria (Korth, 1979; Fernández-Jalvo y Andrews, 2003). Es interesante destacar que las egagrópilas se desintegran en el agua y los huesos contenidos en ellas se dispersan (Korth, 1979).

Por otro lado, Trapani (1998) al analizar el transporte hidrodinámico en huesos de aves (especialmente Columba livia), observó diferencias con respecto a los huesos de otros taxones de aves. A diferencia de lo que ocurre con los mamíferos registró que el cráneo 
es el elemento que se dispersa con más facilidad. Además, este autor observó que las vértebras y costillas también son elementos que se dispersan rápidamente, como sucede en los mamíferos y que posteriormente se dispersan los huesos largos y la escápula.

Smoke y Stahl (2004) en su análisis experimental sobre restos de microvertebrados provenientes de egagrópilas de Strigiformes, muestran que los huesos compactados por la presión del sedimento presentaban modificaciones variables, la cuales dependen del tamaño de grano del sedimento, exhibiendo un daño más grande en sedimentos de grano fino que los de grano grueso. Esto es probablemente porque en el sedimento de grano fino se incrementa la superficie de contacto. Bajo condiciones similares, el autor encontró que los huesos no digeridos presentaron relativamente poco daño y los elementos más frágiles como la escápula se fracturan tempranamente bajo la compactación. No obstante, registró que las fracturas de la parte media de la diáfisis o las fracturas transversas en las vértebras aparecen posteriormente cuando se incrementa la presión del sedimento.

\subsubsection{Marcas de raíces}

Después del entierro, los huesos pueden ser afectados por la acción de raíces de las plantas (Lyman, 1994). Basado en un mecanismo de alteración químico y físico, las superficies de los huesos pueden ser alteradas (Courty et al., 1989; Fernández-Jalvo et al., 2002). La asociación simbiótica entre las raíces de plantas y los hongos (Micorrizae) o bacterias (Rhizobium) actúan como agentes de descomposición química de nutrientes orgánicos y minerales (Courty et al., 1989). Estas simbiosis son importantes para el crecimiento de la planta, y están implicadas en el proceso de fijación del nitrógeno (Fernández-Jalvo et al., 2002). Estos hongos absorben y le transfieren a la raíz de la planta principalmente fósforo, y también zinc, manganeso y cobre (Fernández-Jalvo et al., 2002).

Además de presentar alguna pérdida del elemento químico original de los tejidos del hueso por la acción metabólica de los hongos y bacterias de la raíz, también se produce un daño estructural por la marca de raíz, aumentando la porosidad de hueso (Fernández-Jalvo et al., 2002).

Existen dos tipos de marcas de raíces. El primer tipo de huella bioerosiva, corresponde a pequeñas marcas dendríticas superficiales, las cuales constituyen canales en forma de 
“U”, con ramas principales y bifurcadas de 0,15 a 1mm de ancho (Andrews, 1990; Lyman, 1994). Esta categoría de marcas de raíces se denomina "Sphenoichnia" e indica el desarrollo de una cubierta herbácea, durante la formación del suelo cuando los huesos fueron depositados y enterrados (Montalvo, 2002b).

El segundo tipo de huella bioerosiva se denomina "Corrosichnia", se caracteriza por ser más grande que la anterior, con más $1,5 \mathrm{~mm}$ de ancho y casi sin bifurcaciones. Presenta contornos muy irregulares, exhibiendo un alto grado de corrosión (Rattallack, 1983, 1990). Este tipo de marca se asocia a la actividad de raíces en tiempos recientes (Montalvo, 2002b).

\subsubsection{Diagénesis}

Después del entierro, los huesos pueden ser afectados por agentes físico-químicos que podrían ocasionar importantes cambios en la estructura mineral y orgánica de los mismos (Lyman, 1994; Gutiérrez, 2001, 2007; Denys, 2002; y literatura citada en estos trabajos).

El nivel de alteración de los huesos aumenta a lo largo del tiempo y está asociado por un lado, con la estructura química y molecular, la forma, el tamaño y la porosidad; y por otro lado, con la acción de microorganismos, la temperatura, el pH del sedimento y el agua. De modo que, la combinación de estos factores ocasionan una debilidad en el vínculo de la fracción orgánica (ca. 20\%) y la fracción mineral (ca. 80\%) del hueso (Gutiérrez, 2001, 2007). Asimismo, los materiales óseos pueden incorporar elementos por absorción en la superficie de la matriz mineral, por reemplazo de los iones estructurales en los cristales de bioapatita y por precipitación dentro de los poros en la estructura del hueso (Gutiérrez, 2001, 2007).

En las muestras analizadas en esta tesis se pudieron observar algunos de los procesos diagenéticos que afectan a los conjuntos faunísticos, tales como la corrosión sedimentaria y las impregnaciones por óxidos de manganeso, las cuales se detallan a continuación.

\subsubsection{Corrosión sedimentaria}


La corrosión sedimentaria es un proceso que puede modificar a los huesos antes o después de estar enterrados (Fernández-Jalvo et al., 2002). Este tipo de alteración es una modificación química que se produce principalmente por la acidez o alcalinidad del suelo (Andrews, 1990). Los huesos y dientes pueden ser corroídos en sedimentos por debajo de un Ph 4 (Andrews, 1990). La acidez afecta esencialmente a los componentes inorgánicos de los huesos y dientes y en menor medida a la parte orgánica de los mismos. En cambio la alcalinidad altera principalmente a los componentes orgánicos, mientras que el material inorgánico apenas se modifica (Andrews, 1990).

Trabajos experimentales realizados por Fernández-Jalvo (1992) y Fernández-Jalvo et al. (2002) han mostrado que los sedimentos altamente alcalinos ( $\mathrm{Ph} \mathrm{9-14)} \mathrm{producen}$ alteraciones en los restos, tales como agrietamientos en mosaico de las dentinas y descamaciones de las superficies de los huesos, mientras que el esmalte no es afectado. Esto sugiere que la proteína de colágeno es el principal componente afectado por exposición a ambientes altamente alcalinos por largos períodos de tiempo (FernándezJalvo et al., 2002).

En lo que concierne a los huesos de aves, en suelos con $\mathrm{Ph}$ alcalinos también se alteran, exhibiendo hoyos y bordes de fractura redondeados (Bochenski y Tomek, 1994).

Por otro lado, cabe mencionar que bajo condiciones de permanente humedad en el sedimento, los huesos de micromamíferos son afectados en su totalidad, mientras que en condiciones de sequedad, son mejor preservados (Andrews, 1990). Los iones de hidrógeno del agua ácida pueden reemplazar el calcio y provocar su percolación. Además, el agua puede producir la disolución y recristalización de la fracción mineral ósea en el transporte de los iones y en la hidrólisis de la proteína (Gutiérrez, 2001, 2007).

La corrosión sedimentaria puede ser distinguida de los efectos de la digestión, debido a que altera a toda la superficie del hueso, mientras que la corrosión por digestión tiene una acción usualmente localizada (Andrews 1990; Fernández-Jalvo y Andrews 1992; Bochenski y Tomek 1997; Worthy 2001).

\subsubsection{Impregnaciones de óxido de manganeso}

Las impregnaciones por óxidos de manganeso es un proceso que actúa sobre los restos formando manchas de color negro en las superficies de los mismos. El manganeso 
precipita como óxido en ambientes donde alternan ciclos de reducción-oxidación (Courty et al., 1989). Esta precipitación se produce cuando existe una saturación de estos elementos en agua y una escasez de oxígeno. Este tipo de proceso es común en sitios donde ocurren oscilaciones del nivel freático o encharcamientos de agua (Gómez et al., 1999; Gómez, 2000). Potter y Rossman (1979) y Dorn y Oberlander (1981) en base a investigaciones en ambientes desérticos, sugieren que las impregnaciones por óxidos de manganeso se producen por acción bacteriana. Algunas bacterias se concentran en ambientes húmedos y anaeróbicos con un $\mathrm{Ph}$ neutro o levemente básico. Para su nutrición, estas bacterias metabolizan los minerales hallados en las arcillas y en los huesos, precipitando sobre ellos las impregnaciones de óxido de manganeso (Bennàsar Serra, 2005).

\subsection{Análisis paleoambiental}

El análisis paleoambiental se fundamenta en el uso de los microvertebrados (en particular la presencia-ausencia de ciertas especies estenoicas) como indicadores de condiciones ambientales. Esto permite una aproximación paleoecológica en función de los requerimientos ambientales y de distribución conocidos para los mismos y de las variaciones en la abundancia relativa, expresadas en valores de MNI. Este método está afectado fundamentalmente por los procesos de agregación de las muestras y sus trayectorias tafonómicas (Pardiñas, 1999a). De este modo, cambios temporales en la abundancia y distribución de los taxones de microvertebrados podrían revelar la naturaleza de los ambientes en el tiempo de depositación (Simonetti, 1989; Andrews, 1995; Pardiñas, 1999a; Teta et al., 2005a).

Las muestras arqueofaunísticas fueron comparadas con muestras de egagrópilas de aves rapaces mediante el supuesto teórico del método de análogos modernos (Overpeck et al., 1985).

\subsection{Análisis estadísticos}

Las riquezas taxonómicas fueron relacionadas con los tamaños de las muestras, utilizando el coeficiente de correlación por rangos de Spearman $\left(r_{s}\right)$. Se utilizó este tipo 
de prueba no paramétrica debido a que estadísticamente los valores de las muestras no tienen una distribución normal.

Para realizar las inferencias paleoambientales se calcularon diferentes índices que permiten comparar los conjuntos de una forma más confiable y segura. De esta forma, se calculó la diversidad específica mediante el índice de Shannon y Weaver $\left(\mathrm{H}^{\prime}=-\Sigma \mathrm{p}_{i}\right.$ $\ln \mathrm{p}_{i}$ ), donde $\mathrm{p}_{i}$ es la proporción de cada especie en la muestra. El rango de valores varía desde 1 hasta $\ln \mathrm{S}$ ( $\mathrm{S}=$ riqueza específica), siendo esta última la mayor diversidad. Este índice tiene la ventaja de estar poco afectado por el tamaño de la muestra (Krebs, 1989). Además, se utilizó el índice de equitatividad $\left(\mathrm{J}=\mathrm{H}^{\prime} / \mathrm{H}_{\max }\right)$, donde $\mathrm{H}_{\max }=\ln \mathrm{S}$. Los valores varían de 0 a 1 , cuando más se aproxima a la unidad más uniformemente están representadas las especies (Krebs, 1989).

Se efectuó un análisis de componentes principales (PCA), en orden de indagar acerca de las relaciones multivariadas entre las muestras, tanto arqueológicas como actuales. Los principales componentes fueron extraídos de una matriz de correlación y se calculó utilizando el MNI\%. Para la obtención del PCA se tuvo en cuenta solo los taxones de micromamíferos por considerarse los más sensibles a los cambios ambientales.

Finalmente, se realizaron análisis de agrupamiento (Cluster Analysis) mediante la medida de similitud Jaccard para datos binarios (presencia-ausencia) y mediante Euclidean distance para datos cuantitativos. Los agrupamientos fueron graficados a través del método de unión de distancias promedios entre todos los miembros de los pares de grupos (UPGMA-Unweighted pair-group average) Asociado a esto, se calculó en coeficiente de correlación cofenética (ccc), como medida de distorsión de los datos forzados por el agrupamiento.

Estos cálculos estadísticos fueron llevados a cabo mediante el programa PAST (PAleontological STatistics) versión 2.07, de uso común en paleoecología y paleontología (Hammer, 1999-2011). 



\section{Capítulo 5}

\section{ESTADO ACTUAL DEL CONOCIMIENTO DE LOS MICROVERTEBRADOS QUE HABITAN EN MENDOZA}

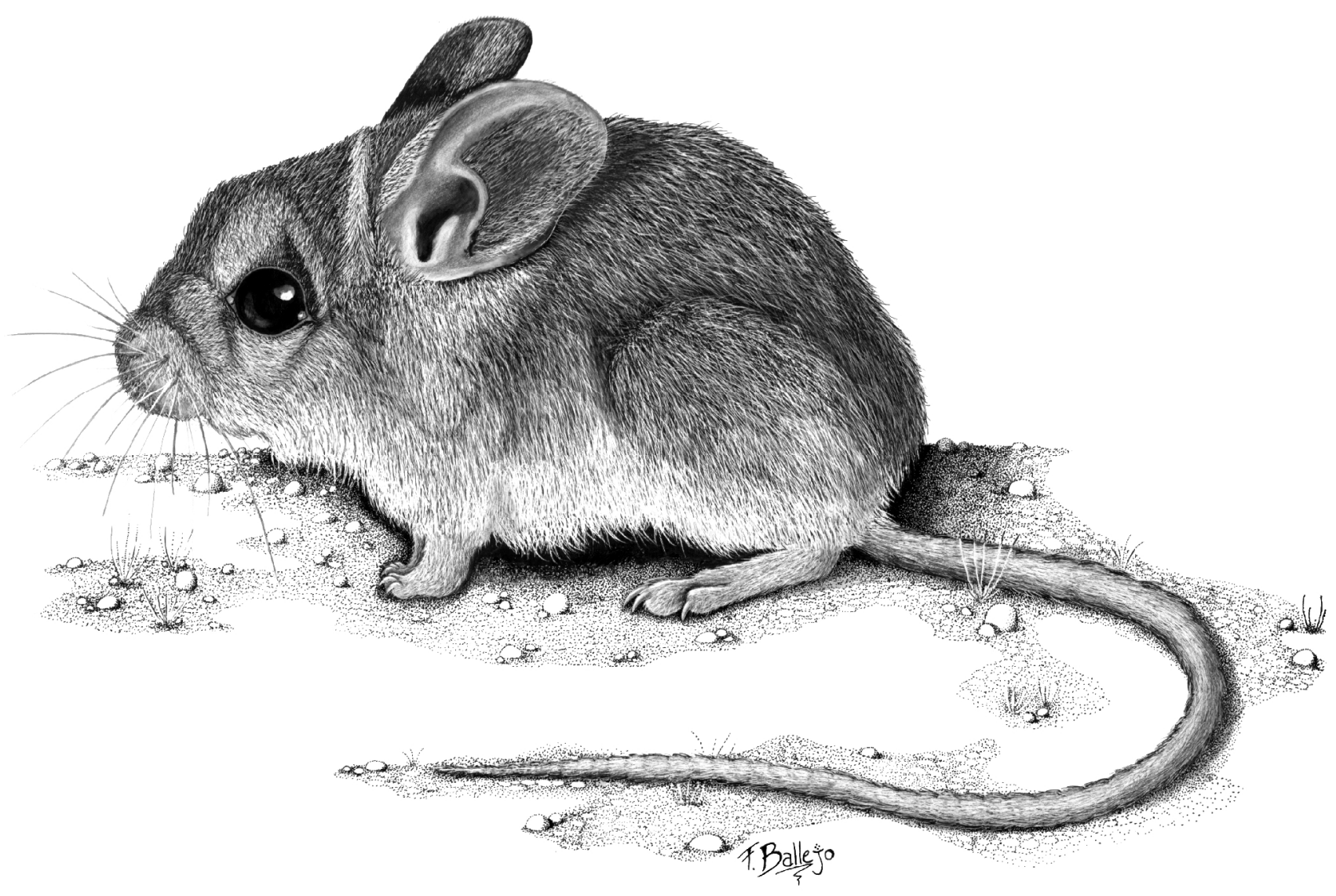

Ejemplar de Eligmodontia typus ilustrado por Fernando Ballejo

"Es indudable que por su abolengo no existe una fauna argentina sino un conjunto plural. Existen distintos orígenes y varias estirpes..."

Raúl A. Ringuelet

[Rasgos Fundamentales de la Zoogeografía Argentina. 1961: 3] 



\section{ESTADO ACTUAL DEL CONOCIMIENTO DE LOS MICROVERTEBRADOS QUE HABITAN EN MENDOZA}

La provincia de Mendoza presenta numerosas especies de microvertebrados, incluyendo anuros, reptiles, aves y mamíferos, los cuales recibieron una dispar atención por parte de las investigaciones científicas a la fecha. En este capítulo se expondrán las principales características de los microvertebrados presentes en la provincia de Mendoza, en base a información preexistente y datos aportados por el autor. No obstante, cada grupo de microvertebrados tuvo un tratamiento específico y diferenciado, dependiendo de su representación en las muestras estudiadas y su utilidad en términos de reconstrucciones paleoambientales.

En el caso de los reptiles, se realizó una lista completa de los taxones registrados en el sur de Mendoza, resumiendo datos sobre hábitats y distribución geográfica. Para el caso de las aves, por tratarse de un grupo con registro minoritario en los ensambles estudiados, solo se mencionaran algunas características generales sobre hábitat y distribución geográfica de aquellos taxones recuperados de los sitios arqueológicos y muestras actuales.

Finalmente, se realiza un listado completo de las localidades de registro taxones de micromamíferos presentes en la provincia de Mendoza. Se describen los rasgos morfológicos diagnósticos (los rasgos más conspicuos se resaltaron en letra cursiva), distribución geográfica, hábitat y se realizan comentarios taxonómicos para cada taxón. Para el caso de los roedores cricétidos sigmodontinos, por tratarse del grupo con registro mayoritario en los ensambles estudiados se realizaron ilustraciones cráneodentarias.

La información vertida a lo largo de este capítulo constituirá en gran medida la base de las inferencias paleoambientales que se efectuarán en esta tesis.

\subsection{Reptiles}

En la actualidad el sur de la provincia de Mendoza cuenta con una amplia diversidad de saurios, exhibiendo 24 especies distribuidas en 4 familias y 9 géneros. En su mayor parte corresponden a especies con requerimientos ecológicos afines a ambientes áridos y semiáridos (Cei, 1986). Se excluirá del análisis a Tupinambis rufescens (Günther, 1871) por exceder el $1 \mathrm{~kg}$ de peso. 
El criterio taxonómico y sistemático adoptado es el sustentado en Frost et al. (2001), en base a detallados datos moleculares y morfológicos.

\subsubsection{Sistemática, ecología, hábitat y distribución}

Clase Reptilia Laurenti, 1768.

Subclase Lepidosauria Duméril y Bibron, 1839.

Orden Squamata Merrem, 1820.

Suborden Sauria Marcartney, 1802.

Infraorden Iguania Cope, 1864.

Familia Leiosauridae Frost, Etheridge, Janies y Titus, 2001.

Género Pristidactylus Fitzinger, 1843.

Pristidactylus araucanus (Gallardo, 1964).

Localidad tipo: Laguna Blanca, Zapala, Neuquén.

Ecología y hábitat: de hábitos diurnos, con alimentación insectívora, principalmente formícidos y coleópteros. Se encuentra asociado a mesetas basálticas, suelos rocosos y escoriales; con vegetación xerófila de estepa Patagónica y en ecotonos con el desierto del Monte.

Distribución: abarca una franja desde el sudeste de la provincia de Mendoza hasta el sur de Neuquén, extendiéndose a lo largo del límite con las provincias de Río Negro y La Pampa.

Bibliografía consultada: Gallardo, 1964; Cei, 1986; Cei et al., 2001, 2004; Scolaro, 2006.

Pristidactylus fasciatus (D'Orbigny y Bibron, 1837).

Localidad tipo: Carmen de Patagones, Buenos Aires.

Ecología y hábitat: habita en cuevas y se alimenta de insectos, principalmente coleópteros. Se asocia a estepas arbustiva psamófila del desierto del Monte.

Distribución: desde La Rioja a Río Negro, a través de San Juan, Mendoza y La Pampa, en una amplia franja de territorios del desierto del Monte.

Bibliografía consultada: Gallardo, 1964; Cei, 1986; Cei et al., 2001, 2004; Scolaro, 2006. 
Pristidactylus scapulatus (Burmeister, 1861).

Localidad tipo: Sierra de Uspallata a 3000 m.s.n.m., Mendoza

Ecología y hábitat: de hábitos diurnos, con alimentación insectívora, principalmente coleópteros). Se encuentra en roquedales del piedemonte cordillerano y estepas arbustivas de altos Andes.

Distribución: desde el norte hasta el centro sur de la provincia de Mendoza.

Bibliografía consultada: Gallardo, 1964; Etheridge y Williams, 1985; Cei, 1986; Cei et al., 2001, 2004; Scolaro, 2006.

Género Diplolaemus Bell, 1843.

Diplolaemus sexcinctus Cei, Scolaro y Videla, 2003.

Localidad tipo: Mta. Pedregosa, Las Bayas, Río Negro.

Ecología y hábitat: posee alimentación carnívora, principalmente artrópodos y saurios.

Se asocia a ambientes de la estepa Patagónica y en ecotonos con el desierto de Monte. Preferencia por pedregales y escoriales volcánicos.

Distribución: desde el centro de Mendoza hasta el sur de la provincia de Chubut. Alcanza altitudes máximas de $1800 \mathrm{~m}$.

Bibliografía consultada: Gallardo, 1961; Cei, 1986; Cei et al., 2003; Scolaro, 2005.

Género Leiosaurus Duméril y Bibron, 1837.

Leiosaurus bellii Duméril y Bibron, 1837.

Localidad tipo: Mexique (SIC).

Ecología y hábitat: de hábitos crepusculares, con alimentación carnívora. Se asocia a ambientes de la estepa Patagónica y en ecotonos con el desierto de Monte. Preferencia por suelos arenosos con mantos de rodados.

Distribución: desde la costa centro sur de Santa Cruz hasta el sur de Mendoza, alcanzando altitudes máximas de $1800 \mathrm{~m}$.

Bibliografía consultada: Gallardo, 1961; Donoso Barros, 1965; Cei, 1973, 1986; Frost et al., 2001; Scolaro, 2006.

Familia Leiolaemidae Frost, Etheridge, Janies y Titus, 2001.

Género Liolaemus Wiegmann, 1834.

Liolaemus austromendocinus Cei, 1974. 
Localidad tipo: $70 \mathrm{Km}$ al sur del L. Nihuil, Mendoza.

Ecología y hábitat: posee alimentación insectívora. Preferencia por biotopos con suelos arenosos y escoriales de basalto. Observados en ambientes entre 1600 y 2000 m.s.n.m. con vegetación xerófila de estepa Patagónica y en ecotonos con el desierto del Monte.

Distribución: se extiende por una franja angosta, desde el norte de Mendoza hasta el sur de Neuquén.

Bibliografía consultada: Cei, 1974, 1986, Scolaro, 2006.

Liolaemus buergeri Werner, 1907.

Localidad tipo: Planchón, Curicó, Chile.

Ecología y hábitat: posee alimentación omnívora e insectívora. Se encuentra en biotopos húmedos en proximidad de arroyos, lagunas y mallines de estepa Patagónica.

Distribución: se extiende por una franja desde el norte de Mendoza hasta el centro sur de Neuquén. Incluye Chile central.

Bibliografía consultada: Cei, 1986; Scolaro, 2006.

Liolaemus donosobarrosi (Cei, 1974).

Localidad tipo: La Matancilla, Malargüe, Mendoza.

Ecología y hábitat: Posee alimentación insectívora. Se asocian a estepas arbustiva psamófila del desierto del Monte y en ecotonos con estepa Patagónica.

Distribución: Acotado al área que comprende los límites entre las provincias de Mendoza, La Pampa, Río Negro y Neuquén.

Bibliografía consultada: Cei, 1974, 1986; Scolaro, 2006.

Liolaemus grosseorum Etheridge, 2001.

Localidad tipo: Costa del Lago Nihuil, San Rafael, Mendoza.

Ecología y hábitat: se asocian a estepas arbustiva psamófila y xerófilas del desierto del Monte y en ecotonos con estepa Patagónica. Su población disminuye en ambientes antropizados.

Distribución: desde el sur de Mendoza hasta el sudoeste de La Pampa alcanzando el límite con la provincia de Río Negro. 
Bibliografía consultada: Etheridge, 2001; Avila et al., 2002; Scolaro, 2006.

Liolaemus josei Abdala, 2005.

Localidad tipo: Puente El Zampal, ruta Nacional 40, Malargüe, Mendoza.

Ecología y hábitat: se encuentra en suelos arenosos y con rocas volcánicas sueltas de la Payunia. Asociada a estepas arbustiva psamófila y xerófilas del desierto del Monte y en ecotonos con estepa Patagónica.

Distribución: acotada un sector del sur de Mendoza alcanzando el límite con la provincia de Neuquén.

Bibliografía consultada: Abdala, 2005; Scolaro, 2006.

Liolaemus wiegmannii (Duméril y Bibron, 1837).

Localidad tipo: "Chili".

Ecología y hábitat: es de hábitos diurnos y posee alimentación insectívora. Es muy versátil, ocupando multiplicidad de ambientes, con preferencia a biotopos semidesérticos con suelos arenosos. Especie adaptada a áreas antropizadas.

Distribución: muy extensa, desde el sur de Brasil, todo Uruguay, Corrientes, Entre Ríos, Buenos Aires, La Pampa, San Luis, Mendoza, Córdoba, Tucumán y Jujuy. También en Isla Ascención, cerca de África.

Bibliografía consultada: Cei, 1993; Carreira et al., 2005; Scolaro, 2006.

Liolaemus darwinii Bell, 1843.

Localidad tipo: Bahía Blanca, Buenos Aires

Ecología y hábitat: es una especie cavadora con alimentación insectívora. Es típico de la vegetación xerófila del desierto del Monte, dominados por las jarillas (Larrea spp.). Preferencia por áreas con suelos arenosos.

Distribución: es muy amplia abarcando el desierto del Monte desde Salta hasta la costa norte de Chubut.

Bibliografía consultada: Yapur y Gutiérrez, 1979; Videla, 1983; Cei, 1986, 1993; Cei y Scolaro, 1999; Etheridge, 1993, 2000; Scolaro, 2005. 
Liolaemus elongatus koslowsky, 1896

Localidad tipo: Territorio de Chubut (cordilleras) (SIC).

Ecología y hábitat: frecuente en ambientes rocosos y húmedos con arbustos achaparrados. Presente en el bosque de Nothofagus spp., en la estepa Patagónica y áreas ecotonales.

Distribución: abarca una franja cordillerana desde San Juan hasta el sur de la provincia de Chubut. Alcanza los 4000 m.s.n.m.

Bibliografía consultada: Cei, 1974; Ibargüengoitía y Cussac, 2002; Espinoza y Lobo, 2003; Scolaro, 2005.

Liolaemus gracilis Bell, 1843.

Localidad tipo: Puerto Deseado, Santa Cruz.

Ecología y hábitat: posee alimentación insectívora. Es frecuente en suelos arenosos del desierto del Monte y la estepa Patagónica.

Distribución: desde el sur de Brasil hasta Puerto Deseado en la provincia de Santa Cruz. Incluye las provincias de Mendoza, La Pampa y Neuquén y las costas de Buenos Aires, Río Negro y Chubut.

Bibliografía consultada: Scolaro, 1976, 2005; Cei, 1986.

Liolaemus bibroni Bell, 1843.

Localidad tipo: Puerto Deseado, Santa Cruz.

Ecología y hábitat: posee alimentación insectívora. Es una especie Andino Patagónica, en donde habita multiplicidad de ambientes. Con preferencia a sitios con suelos arenosos y pedregosos.

Distribución: desde el norte de Mendoza hasta el centro sur de la provincia de Santa Cruz.

Bibliografía consultada: Cei, 1973, 1986; Scolaro, 1976, 2005; Videla, 1983.

Liolaemus boulengeri Koslowsky, 1898.

Localidad tipo: territorios de Chubut y Neuquén (SIC). 
Ecología y hábitat: posee alimentación insectívora. Habita multiplicidad de ambientes de la Patagonia. Con preferencia a zonas con suelos arenosos, arcillosos y pedregosos. Es muy común en ecotonos del desierto del Monte y estepa Patagónica

Distribución: desde el norte de Mendoza hasta el centro sur de la provincia de Santa Cruz.

Bibliografía consultada: Cei, 1973, 1986; Scolaro, 2005.

Liolaemus duellmani Cei, 1978.

Localidad tipo: Paso El Choique (2000 a 2400 m.s.n.m.), Mendoza.

Ecología y hábitat: habita ambientes xéricos, con suelos basaltitos y arenosos de la cordillera del sur de Mendoza.

Distribución: restriguida al área cordillerana del sur de la provincia de Mendoza.

Bibliografía consultada: Cei, 1978.

Liolaemus flavipiceus (Cei y Videla, 2003).

Localidad tipo: cerca del Paso Pehuenche (2500 m.s.n.m.), Dpto. Malargüe, Mendoza.

Ecología y hábitat: se ha encontrado en ambientes de altos Andes del sur de Mendoza, en la zona limítrofe con Chile.

Distribución: restriguida al área cordillerana del sur de la provincia de Mendoza.

Bibliografía consultada: Cei y Videla, 2003.

Género Phymaturus Gravenhorst, 1837.

Phymaturus verdugo Cei y Videla, 2003.

Localidad tipo: nacientes del Río Grande, Volcán Peteroa, Mendoza.

Ecología y hábitat: posee alimentación herbívora. Frecuente en la estepa Patagónica en microhábitat de roquedales cerca de cuerpos de agua.

Distribución: restriguida al área cordillerana del sur de Mendoza en el límite con la provincia de Neuquén.

Bibliografía consultada: Cei y Videla, 2003; Scolaro, 2006.

Phymaturus payuniae Cei y Castro, 1973. 
Localidad tipo: meseta $c a$.Volcán Payún, Malargüe, Mendoza.

Ecología y hábitat: posee alimentación herbívora. Habita en las gritas de los cordones de lava meteorizados y en los escoriales de la Payunia. Fitogeográficamente, ocurre en el ecotono entre el desierto del Monte y la estepa Patagónica.

Distribución: restriguida un sector de la Payunia en el limite de las provincias de Mendoza y Neuquén. Alcanza una altitud de $1800 \mathrm{~m}$.

Bibliografía consultada: Cei y Castro, 1973; Cie, 1986; Scolaro, 2006.

Infraorden Scincomorpha Camp, 1923.

Familia Teiidae Gray, 1827.

Género Teius Merrem, 1820.

Teius oculatus (D'Orbigny y Bibron, 1837).

Localidad tipo: Montevideo, Uruguay.

Ecología y hábitat: construye cuevas por debajo de rocas y troncos. Posee alimentación insectívora, principalmente larvas de coleópteros. Habita en multiplicidad de ambientes. Preferencia por biotopos de roquedales cerca a cuerpos de aguas.

Distribución: desde el sur de Brasil, Paraguay, Uruguay, hasta la costa norte de la provincia de Río Negro en Argentina.

Bibliografía consultada: Acosta et al., 1991; Cei, 1993; Martoni y Acosta, 1994; Blanco y Acosta, 1998; Ávila, 2002; Scolaro, 2006; Cabrera, 2009.

Género Cnemidophorus (Linnaeus, 1758).

Cnemidophorus longicaudus Bell, 1843.

Localidad tipo: Bahía Blanca, Argentina.

Ecología y hábitat: de hábitos diurnos, con alimentación principalmente insectívora. Especie característica del desierto del Monte. Preferencia por ambientes xéricos con suelos arenosos y con arbustos abiertos (e.g., géneros Poa y Stipa).

Distribución: es una especie común en el oeste argentino. Desde Catamarca hasta el nordeste de Santa Cruz.

Bibliografía consultada: Gallardo, 1966; Cei, 1986,1993; Scolaro, 2005; Cabrera, 2009 .

Infraorden Gekkota Cuvier, 1817. 
Familia Gekkonidae Gray, 1825.

Género Homonota Gray, 1845.

Homonota darwini Boulenger, 1885.

Localidad tipo: Puerto Deseado, Santa Cruz.

Ecología y hábitat: de hábitos nocturnos, con alimentación insectívora. Habita multiplicidad de ambientes de la Patagonia. Especie adaptada a áreas antropizadas.

Distribución: desde el centro de Mendoza hasta el centro sur de la provincia de Santa Cruz.

Bibliografía consultada: Kluge, 1964; Cei, 1978, 1986; Casalins e Ibargüengoytía, 2004, Scolaro, 2005.

\subsubsection{Características generales de la morfología cráneo-dentaria}

Las siguientes descripciones morfológicas se realizaron en base a consulta bibliográfica (i.e., Etheridge, 1958; Peters y Donoso Barros, 1970; Cei, 1986, 1993; Alvarez et al., 1987; Estes et al., 1988; Frost y Etheridge, 1989; Etheridge, 1995; Estes y Williams, 1998; Frost et al., 2001; Albino, 2005, 2008; Albino y Kligmann, 2007) y a la observación ejemplares de pertenecientes a la Colección Herpetológica del Museo de Ciencias Naturales de La Plata.

\section{Leiosauridae}

Los representantes de esta Familia presentan las siguientes características diagnósticas en la morfología cráneo-dentaria: superficie craneana fuertemente rugosa; surco de Meckel mandibular cerrado; dientes palatinos generalmente presentes (con la excepción del género Diplolaemus) (Cei, 1986; Frost et al., 2001).

Por su parte, las especies del género Pristidactylus exhiben dientes tricúspides en los premaxilares, los dientes presentan una gran cúspide central, con cúspides secundarias muy reducidas y separadas por surcos poco evidentes. En cambio, en especies del género Phymaturus existen mas de dos cúspides accesorias, las cuales se encuentran muy expandidas anteroposteriormente y separadas de la cúspide central por surcos bien delimitados, profundos y extensos (Cei, 1986; Etheridge, 1995; Estes y Williams, 1998; Frost et al., 2001; Albino, 2005; 2008; Albino y Kligmann, 2007). 


\section{Leiolaemidae}

Los representantes de esta Familia presentan las siguientes características diagnósticas en la morfología cráneo-dentaria: mandíbula con lámina ancha; expansión del coronoides; esplineal alargado (Cei, 1986; Frost et al., 2001).

Por su parte, las especies del género Phymaturus exhiben huesos nasales cubiertos por las espinas premaxilares; esplineal largo; dientes premaxilares tricúspides; dientes marginales anchos y cuadricúspides (las cúspides accesorias están expandidas anteroposteriormente) (Etheridge, 1958; Cei, 1986). Asimismo las especies del género Liolaemus se diferencian por presentar una mandíbula parcialmente prognata; aberturas timpánicas pequeñas; rugosidades moderadas en los huesos de la bóveda dérmica; techo parietal de forma trapezoidal, ligeramente más ancho posterior que anteriormente; dentario no expandido sobre la superficie labial del coronoides; expansión posterior del dentario; proceso labial del coronoides muy desarrollado, anclado sobre una muesca claramente visible sobre la superficie del dentario; esplenial extendido anteriormente más que $1 / 6$ y menos que $1 / 2$ de la longitud de la serie dentaria; canal de Meckel abierto; dientes tricúspides alineados, con una cúspide central alta y un par de cúspides secundarias pequeñas y redondeadas, separadas por surcos bien delimitados, profundos y extensos, marcadamente pleurodontes de márgenes subparalelos, no fusionados inferiormente por tejido óseo, ausencia de forámenes de reabsorción y cemento en la base de los dientes (aspecto diferenciable de Teiidae) y espina premaxilar claramente solapada dorsalmente por los nasales (Etheridge, 1958; Cei, 1986; Frost y Etheridge, 1989; Etheridge, 1995; Estes y Williams, 1998; Frost et al., 2001; Albino, 2005, 2008; Albino y Kligmann, 2007).

\section{Teiidae}

Los representantes de esta Familia presentan las siguientes características diagnosticas en la morfología cráneo-dentaria: hipertrofia del hueso esplenial; relativa reducción del dentario; ausencia de rugosidades en los huesos de la bóveda dérmica; agrandamiento de los vómeres, los cuales se acercan considerablemente a los pterigoides; contacto anterolateral del hueso ectopterigoides con el palatino; restricción de la fenestra supraorbital; contacto del yugal y escamoso por arriba del arco supratemporal; amplia participación de los prefrontales en la espaciosa fenestra orbitonasal, renovación de los 
dientes en cavidades subcirculares profundas, en las cuales es notable la acumulación de cemento (Cei, 1986; Frost et al., 2001).

El género Teius presenta un cráneo abovedado en norma lateral; relativo desarrollo del coronoides; dientes posteriores bicúspides comprimidos transversalmente; dientes anteriores con una sola cúspide, los cuales esta comprimidos lateralmente e inflexionados hacia atrás. Asimismo, T. oculatus se distingue por exhibir una fusión del postfrontal y postorbital (en T. tejou se encuentran separados) (Cei, 1986; Alvarez et al., 1987).

\section{Gekkonidae / Homonota darwini}

Esta especie presentan las siguientes características diagnosticas en la morfología cráneo-dentaria: cráneo deprimido y delgado; nasales desarrollados y nunca fusionados; frontal prevalentemente único; contacto reducido entre los huesos pterigoides-palatino y palatino-vómer; foramen óseo del trigémino; proceso maxilares anteromedianos muy extendido entre maxilares y vómer; hueso cuadrado relativamente grande (i.e., ancho y largo); Dentario grácil y distalmente aguzado; surco meckeliano totalmente cerrado; dientes pequeños pleurodontes, abundantes (22-23), tupidos, cilíndricos, con una sola cúspide y de posición marginal (Cei, 1986; Estes et al., 1988; Abdala, 1992; Albino, 2008).

\subsection{Aves}

El criterio sistemático utilizado sigue a Mazar Barnett y Pearman (2001).

Clase Aves Linnaeus, 1758.

Orden Passeriformes (Linnaeus, 1758).

Familia Furnariidae (Gray, 1840).

Género Upucerthia Geoffroy Saint-Hilaire, 1832.

Upucerthia dumetaria Geoffroy Saint-Hilaire, 1832.

Upucerthia dumetaria (bandurrita común) es una especie abundante en zonas con suelos pedregosos bajo condiciones áridas, desde el nivel del mar hasta los $3000 \mathrm{~m}$ de altitud 
(Olrog y Pescetti, 1991). En Mendoza encuentra en estepas Altoandinas, Patagónicas y del desierto del Monte (Mazar Barnett y Pearman, 2001; Narosky e Izurieta, 2003).

Género Cinclodes Gray, 1840.

Cinclodes fuscus (Vieillot, 1818).

Cinclodes fuscus (remolinera común) habita en multiplicidad de ambientes (Olrog y Pescetti, 1991; Mazar Barnett y Pearman, 2001), siendo frecuente en arroyos y lagunas de estepas Patagónicas y Altoandinas (Narosky y Izurieta, 2003).

Cinclodes patagonicus (Gmelin, 1789).

Cinclodes patagonicus (remolinera araucana) es una especie esencialmente Andino Patagónica y esta vinculada ampliamente con ambientes acuáticos (Olrog y Pescetti, 1991; Mazar Barnett y Pearman, 2001; Narosky e Izurieta, 2003).

Género Asthenes Reichenbach, 1853.

Asthenes dorbignyi (Reichenbach, 1853).

Asthenes dorbignyi (canastero rojizo) habita en estepas Altoandinas y estepas arbustivas del desierto del Monte (Mazar Barnett y Pearman, 2001). El hallazgo de restos referidos a esta especie constituye el primer registro arqueológico para Mendoza.

Asthenes baeri (Berlepsch, 1906).

Asthenes baeri (canastero chaqueño) presenta una amplia distribución en el centro y norte de Argentina, evitando la franja Andina. En Mendoza es frecuente en el desierto del Monte (Olrog y Pescetti, 1991; Mazar Barnett y Pearman, 2001; Narosky e Izurieta, 2003).

Género Pseudoseisura Reichenbach, 1853.

Pseudoseisura gutturalis (Orbigny y Lafresnaye, 1838). 
Pseudoseisura gutturalis (cacholote pardo) es un ave endémica de Argentina, siendo frecuente en la estepa Patagónica y en el desierto del Monte, con algunos registros aislados en la estepa Altoandina (Mazar Barnett y Pearman, 2001).

Género Leptasthenura Reichenbach, 1853.

Leptasthenura platensis Reichenbach, 1853.

Leptasthenura platensis (coludito copetón) exhibe una extensa distribución en el centro y norte de la Argentina, evitando la franja Andina. En Mendoza es frecuente en el desierto del Monte y poco común en la estepa Patagónica (Olrog y Pescetti, 1991; Mazar Barnett y Pearman, 2001; Narosky e Izurieta, 2003).

Género Lessonia Swainson, 1832.

Lessonia rufa (Gmelin, 1789).

Lessonia rufa (sobrepuesto común) presenta una amplia distribución, aunque comúnmente asociada a cuerpos de agua (Olrog y Pescetti, 1991; Mazar Barnett y Pearman, 2001; Narosky y Izurieta, 2003).

Familia Emberizidae Vigors, 1825.

Género Zonotrichia Swainson, 1832.

Zonotrichia capensis (Statius Muller, 1776).

Zonotrichia capensis (chingolo) habita en multiplicidad de ambientes, siendo común en áreas rurales y urbanas (Olrog y Pescetti, 1991; Mazar Barnett y Pearman, 2001; Narosky e Izurieta, 2003).

Género Ammodramus Swainson, 1827.

Ammodramus humeralis (Bosc, 1792).

Ammodramus humeralis (cachilo ceja amarilla) habita multiplicidad de ambientes y en el sur de Mendoza se lo puede encontrar en estepas arbustivas del desierto del Monte (Mazar Barnett y Pearman, 2001). Es un ave abundante en áreas rurales (Narosky y Izurieta, 2003). 
Género Phrygilus Cabanis, 1844.

Phrygilus fruticeti (Kittlitz, 1832).

Phrygilus fruticeti (yal negro) es frecuente en estepas Altoandinas, Patagónicas y estepas arbustivas del desierto del Monte (Mazar Barnett y Pearman, 2001).

Género Sicalis Boie, 1828.

Sicalis es un género que en la provincia de Mendoza presenta dos especies una amplia variedad de ambientes [S. luteola (misto) y S. flaveola (jilguero dorado)] y una especie restringida a la estepa Altoandina [S. auriventris (jilguero grande)] (Mazar Barnett y Pearman, 2001).

Familia Icteridae Vigors, 1825.

Género Agelaioides Cassin, 1866.

Agelaioides badius (Vieillot, 1819).

Agelaioides badius (tordo musico) ocupa gran variedad de ambientes (Mazar Barnett y Pearman, 2001).

Género Agelaius Vieillot, 1816.

Agelaius thilius (Molina, 1782).

Agelaius thilius (varillero ala amarilla) presenta una amplia distribución, aunque siempre asociada con ámbitos lagunares (Olrog y Pescetti, 1991; Mazar Barnett y Pearman, 2001; Narosky y Izurieta, 2003).

Familia Mimidae Bonaparte, 1853.

Género Mimus Boie, 1826.

Mimus (calandrias) es un género que en el sur de Mendoza está representado por tres especies: M. triurus, M. saturninus y M. patagonicus (Orbigny y Lafresnaye, 1837). Las dos primeras habitan en numerosos ambientes desde el norte de la Patagonia hasta el 
norte de Argentina y la tercera es frecuente en ambientes Andino-Patagónicos (Mazar Barnett y Pearman, 2001; Narosky y Izurieta, 2003).

Familia Cardinalidae Ridgway, 1901.

Género Saltator Vieillot, 1816.

Saltator aurantiirostris Vieillot, 1817.

Saltator aurantiirostris (pepitero de collar) ocupa una amplia variedad de ambientes (Olrog y Pescetti, 1991; Mazar Barnett y Pearman, 2001; Narosky y Izurieta, 2003). En Mendoza es frecuente en el desierto del Monte y en la estepa Altoandina (Mazar Barnett y Pearman, 2001).

Orden Columbiformes (Latham, 1790).

Familia Columbidae (Illiger, 1812).

Género Metriopelia Bonaparte, 1855.

Metriopelia melanoptera (Molina, 1782).

Metriopelia melanoptera (palomita cordillerana) habita principalmente estepas Altoandinas y Patagónicas (Olrog y Pescetti, 1991; Mazar Barnett y Pearman, 2001; Narosky e Izurieta, 2003), siendo menos frecuente en estepas arbustivas del desierto del Monte (Mazar Barnett y Pearman, 2001).

Género Zenaida Bonaparte, 1838.

Zenaida auriculata (Des Murs, 1847).

Zenaida auriculata (torcaza) habita en multiplicidad de ambientes, incluso en áreas rurales y urbanas (Mazar Barnett y Pearman, 2001; Narosky e Izurieta, 2003).

\subsection{Mamíferos}

En la tabla 5.1 y figura 5.1 se brindan las localidades de muestreo de los micromamíferos para la provincia de Mendoza. Las localidades registradas en este trabajo fueron georeferenciadas con GPS. Para el caso de las localidades publicadas anteriormente y con coordenadas no detalladas por los autores, se ubicaron mediante el 
uso del software Google Earth. Asimismo, se especifica tipo de muestreo (trampeo o egagrópilas), unidad fitogeográfica, altitud y fuente bibliográfica.

\begin{tabular}{|c|c|c|c|c|c|c|}
\hline $\mathbf{N}^{\circ}$ & Localidad & Coordenada & Alt. & U. Fitogr. & $\begin{array}{l}\text { Tipo de } \\
\text { Muestra }\end{array}$ & Fuente bibliográfica \\
\hline 1 & $2 \mathrm{Km}$ al $\mathrm{N}$ de Villa Seca & $33^{\circ} 32^{\prime} \mathrm{S}$ y $69^{\circ} 10^{\prime} \mathrm{O}$ & 1.000 & Patagónica & Trampeo & Sage et al. 1986 \\
\hline 2 & $2 \mathrm{~km}$ al sur de Villavicencio Ruta 32 & $32^{\circ} 31^{\prime}$ 'S y $68^{\circ} 59^{\prime} \mathrm{O}$ & 1.600 & Puneña & Trampeo & Braun et al. 2000 \\
\hline 3 & $3 \mathrm{Km}$ al S de Laguna Diamante & $34^{\circ} 13^{\prime} \mathrm{S}$ y $69^{\circ} 43^{\prime} \mathrm{O}$ & 3.400 & Altoandina & Trampeo & Sage et al. 1986 \\
\hline 4 & $5,7 \mathrm{Km}$ al NO de Villavicencio & $32^{\circ} 29^{\prime} \mathrm{S}$ y $69^{\circ} 02^{\prime} \mathrm{O}$ & 2.600 & Puneña & Trampeo & Wilkins y Cunningham 1993 \\
\hline 5 & $6 \mathrm{~km}$ al NO de Las Leñas & $35^{\circ} 06^{\prime} \mathrm{S}, 70^{\circ} 07^{\prime} \mathrm{O}$ & 2.950 & Altoandina & Trampeo & Jayat et al. 2006 \\
\hline 6 & $6 \mathrm{~km}$ al $\mathrm{S}$ de Las Leñas & $\begin{array}{c}35^{\circ} 11^{\prime} 59^{\prime \prime} \mathrm{S} \text { y } \\
70^{\circ} 3{ }^{\prime} 27^{\prime \prime O}\end{array}$ & 2.200 & Patagónica & Egagrópilas & Este trabajo \\
\hline 7 & $7 \mathrm{~km} \mathrm{~S}$ de Uspallata & $32^{\circ} 39^{\prime} \mathrm{S}$ y $69^{\circ} 20^{\prime} \mathrm{O}$ & 2.200 & Puneña & Trampeo & Martin 2009 \\
\hline 8 & 10 km al N de Gaspar Campos & $34^{\circ} 39^{\prime} \mathrm{S}, 67^{\circ} 26^{\prime} \mathrm{O}$ & 460 & Monte & Trampeo & Barquez et al. 1999 \\
\hline 9 & $10 \mathrm{~km}$ al Oeste de Bardas Blancas & $\begin{array}{c}35^{\circ} 52^{\prime} 28^{\prime \prime S} \text { y } \\
69^{\circ} 52^{\prime} 46^{\prime \prime} \mathrm{O}\end{array}$ & 1.192 & Patagónica & Egagrópilas & Pardiñas et al. 2008 \\
\hline 10 & $15 \mathrm{~km}$ al O de la Capital de Mendoza & $32^{\circ} 53^{\prime} \mathrm{S}$ y $69^{\circ} 00^{\prime} \mathrm{O}$ & 1.500 & Monte & Trampeo & Massarini et al. 1991 \\
\hline 11 & $18,5 \mathrm{Km}$ al $\mathrm{N}$ de Mendoza & $32^{\circ} 44^{\prime} \mathrm{S}$ y $68^{\circ} 51^{\prime} \mathrm{O}$ & 746 & Monte & Trampeo & Wilkins y Cunningham 1993 \\
\hline 12 & 25 de Mayo & $34^{\circ} 35^{\prime} \mathrm{S}$ y $68^{\circ} 33^{\prime} \mathrm{O}$ & 820 & Monte & Trampeo & Pearson y Lagiglia 1992 \\
\hline 13 & $35 \mathrm{Km}$ al ONO de 25 de Mayo & $34^{\circ} 27^{\prime} \mathrm{S}$ y $68^{\circ} 50^{\prime} \mathrm{O}$ & 1.600 & Monte & Trampeo & Pearson y Lagiglia 1992 \\
\hline 14 & 45 NE Volcán Peteroa & $35^{\circ} 05^{\prime} \mathrm{S}$ y $70^{\circ} 05^{\prime} \mathrm{O}$ & 3.000 & Altoandina & Trampeo & Jayat et al. 2006 \\
\hline 15 & $50 \mathrm{~km}$ al NO de San Rafael & $34^{\circ} 15^{\prime} \mathrm{S}$ y $68^{\circ} 40^{\prime} \mathrm{O}$ & 1.140 & Monte & Egagrópilas & Nabte et al. 2006 \\
\hline 16 & Agua de La Mula & $\begin{array}{c}35^{\circ} 22^{\prime} 34^{\prime \prime S ~ y ~} \\
68^{\circ} 14^{\prime} 42^{\prime \prime O}\end{array}$ & 970 & Monte & $\begin{array}{l}\text { Egagrópilas } \\
\text { Trampeo }\end{array}$ & Este trabajo \\
\hline 17 & Agua de Las Avispas & $33^{\circ} 04^{\prime} \mathrm{S}$ y $69^{\circ} 07^{\prime} \mathrm{O}$ & 1.410 & Monte & Trampeo & Massoia 1981a \\
\hline 18 & Anchoris & $33^{\circ} 19^{\prime} \mathrm{S}$ y $68^{\circ} 54^{\prime} \mathrm{O}$ & 940 & Monte & Egragrópilas & Rosi 1983 \\
\hline 19 & Arroyito & $32^{\circ} 49^{\prime} \mathrm{S}$ y $67^{\circ} 17^{\prime} \mathrm{O}$ & 475 & Monte & Trampeo & Ojeda et al. 1996 \\
\hline 20 & Arroyo Panchino I & $\begin{array}{c}34^{\circ} 56^{\prime} 45^{\prime \prime} \mathrm{S} \text { y } \\
69^{\circ} 50^{\prime} 55^{\prime \prime} \mathrm{O}\end{array}$ & 2.341 & Patagónica & Egragrópilas & Este trabajo \\
\hline 21 & Arroyo Panchino II & $\begin{array}{c}34^{\circ} 56^{\prime} 37 \mathrm{~S} \text { y } \\
69^{\circ} 50^{\prime} 7 " \mathrm{O}\end{array}$ & 2.270 & Patagónica & Egragrópilas & Este trabajo \\
\hline 22 & Arroyo Malo & $\begin{array}{c}34^{\circ} 51^{\prime} 18^{\prime \prime S} \text { y } \\
69^{\circ} 53^{\prime} 00^{\prime \prime O}\end{array}$ & 2.190 & Patagónica & Egagrópilas & Este trabajo \\
\hline 23 & Barrancas & $33^{\circ} 6$ 'S y $68^{\circ} 43^{\prime} \mathrm{O}$ & 750 & Monte & Egagrópilas & Rosi (1983) \\
\hline 24 & Blanco Encalada & $33^{\circ} 02^{\prime} \mathrm{S}$ y $69^{\circ} 00^{\prime} \mathrm{O}$ & 1.100 & Monte & Trampeo & Rosi et al. 2002 \\
\hline 25 & Cacheuta & $33^{\circ} 01^{\prime} \mathrm{S}$ y $69^{\circ} 07^{\prime} \mathrm{O}$ & 1.330 & Monte & Trampeo & Rosi et al. 1992; Barquez et al. 1999 \\
\hline 26 & Canota & $32^{\circ} 34^{\prime} \mathrm{S}$ y $69^{\circ} 02^{\prime} \mathrm{O}$ & 1.500 & Puneña & Trampeo & Rosi et al. 2002 \\
\hline 27 & Casa de Piedra, Sierras de Uspallata & $32^{\circ} 20^{\prime} \mathrm{S}$ y $69^{\circ} 13^{\prime} \mathrm{O}$ & 2.180 & Puneña & Trampeo & Contreras y Rosi 1981 \\
\hline 28 & Caverna de Las Brujas & $35^{\circ} 45^{\prime} \mathrm{S}$ y $69^{\circ} 49^{\prime} \mathrm{O}$ & 1.800 & Patagónica & Egagrópilas & Gasco et al. 2006 \\
\hline 29 & Cerro Colorado & $35^{\circ} 31^{\prime} \mathrm{S}$ y $69^{\circ} 57^{\prime} \mathrm{O}$ & 2.730 & Altoandina & Trampeo & Alarcón et al. 2011 \\
\hline 30 & Cerro El Tunduqueral & $32^{\circ} 32^{\prime} \mathrm{S}$ y $69^{\circ} 17^{\prime} \mathrm{O}$ & 2.061 & Puneña & Trampeo & Rosi et al. 2002 \\
\hline 31 & Cerro de La Gloria & $32^{\circ} 53^{\prime} \mathrm{S}$ y $68^{\circ} 53^{\prime} \mathrm{O}$ & 984 & Monte & Trampeo & Rosi et al. 2002 \\
\hline 32 & Cerro Melón & $32^{\circ} 50^{\prime} \mathrm{S}$ y $68^{\circ} 52^{\prime} \mathrm{O}$ & 850 & Monte & Trampeo & Rosi et al. 2002 \\
\hline 33 & Chacras de Coria & $32^{\circ} 45^{\prime} \mathrm{S}$ y $69^{\circ} 00^{\prime} \mathrm{O}$ & 1.900 & Monte & Trampeo & Massoia 1981a; Birney et al. 1996 \\
\hline 34 & Colonia 25 de Mayo & $34^{\circ} 37^{\prime} \mathrm{S}$ y $68^{\circ} 20^{\prime} \mathrm{O}$ & 700 & Monte & Trampeo & Rosi 1983 \\
\hline 35 & Colonia Alto del Algarrobal & $34^{\circ} 36^{\prime} \mathrm{S}$ y $68^{\circ} 08^{\prime} \mathrm{O}$ & 575 & Monte & Trampeo & Contreras y Rosi 1980c \\
\hline 36 & Cuadro Nacional & $34^{\circ} 37^{\prime} \mathrm{S}$ y $68^{\circ} 17^{\prime} \mathrm{O}$ & 660 & Monte & Trampeo & Rosi 1983 \\
\hline 37 & Cuenca Piloto del IADIZA & $32^{\circ} 53^{\prime} \mathrm{S}$ y $68^{\circ} 53^{\prime} \mathrm{O}$ & 860 & Monte & Trampeo & Rosi 1983 \\
\hline 38 & Cuesta de los Terneros & $34^{\circ} 42^{\prime} \mathrm{S}$ y $68^{\circ} 35^{\prime} \mathrm{O}$ & 1.150 & Monte & Trampeo & Rosi 1983 \\
\hline
\end{tabular}

Tabla 5.1. Localidades de registro de micromamíferos en la provincia de Mendoza. 


\begin{tabular}{|c|c|c|c|c|c|c|}
\hline $\mathbf{N}^{\circ}$ & Localidad & Coordenada & Alt. & U. Fitogr. & $\begin{array}{l}\text { Tipo de } \\
\text { Muestra }\end{array}$ & Fuente bibliográfica \\
\hline 39 & Desaguadero & $33^{\circ} 24^{\prime} \mathrm{S}$ y $67^{\circ} 10^{\prime} \mathrm{O}$ & 460 & Monte & Trampeo & Rosi et al. 2002 \\
\hline 40 & El Algarrobal & $32^{\circ} 49^{\prime} \mathrm{S}$ y $68^{\circ} 46^{\prime} \mathrm{O}$ & 690 & Monte & Trampeo & Contreras et al. 1977 \\
\hline 41 & El Challao & $32^{\circ} 50^{\prime} \mathrm{S}$ y $68^{\circ} 52^{\prime} \mathrm{O}$ & 850 & Monte & Trampeo & Barquez et al. 1999 \\
\hline 42 & El Manzano Histórico & $33^{\circ} 36^{\prime} \mathrm{S}$ y $69^{\circ} 22^{\prime} \mathrm{O}$ & 1.700 & Altoandina & Trampeo & Massoia 1981a \\
\hline 43 & El Nihuil & $35^{\circ} 02^{\prime} \mathrm{S}$ y $68^{\circ} 40^{\prime} \mathrm{O}$ & 1.300 & Monte & Trampeo & Rosi 1983; Este trabajo \\
\hline 44 & El Salto & $32^{\circ} 29^{\prime} \mathrm{S}$ y $69^{\circ} 05^{\prime} \mathrm{O}$ & 2.800 & Puneña & Trampeo & Rosi et al. 2002 \\
\hline 45 & General Alvear & $34^{\circ} 58^{\prime} \mathrm{S}$ y $67^{\circ} 41^{\prime} \mathrm{O}$ & 475 & Monte & Trampeo & Roig 1965; Martínez et al. 2010 \\
\hline 46 & Gruta del Indio & $34^{\circ} 45^{\prime} \mathrm{S}$ y $68^{\circ} 21^{\prime} \mathrm{O}$ & 700 & Monte & Egagrópilas & Este trabajo \\
\hline 47 & Guanacache & $32^{\circ} 09^{\prime} \mathrm{S}, 68^{\circ} 12^{\prime} \mathrm{O}$ & 540 & Monte & Trampeo & Ojeda 2010 \\
\hline 48 & Huayquerías del Oeste & $33^{\circ} 38^{\prime} \mathrm{S}$ y $68^{\circ} 26^{\prime} \mathrm{O}$ & 950 & Monte & Trampeo & Pardiñas 1999a \\
\hline 49 & Ing. Gustavo André & $32^{\circ} 42^{\prime} \mathrm{S}$ y $68^{\circ} 18^{\prime} \mathrm{O}$ & 600 & Monte & Trampeo & Rosi 1983 \\
\hline 50 & Laguna de la Niña Encantada & $\begin{array}{l}35^{\circ} 09^{\prime} 38^{\prime \prime} \mathrm{S} \text { y } \\
69^{\circ} 52^{\prime} 09^{\prime \prime} \mathrm{O}\end{array}$ & 1.826 & Patagónica & Egagrópilas & $\begin{array}{l}\text { Massoia et al. 1994; } \\
\text { Nabte et al. 2006; Pardiñas et al. } 2008\end{array}$ \\
\hline 51 & Laguna El Sosneado & $\begin{array}{l}34^{\circ} 50^{\prime} 34^{\prime \prime} \mathrm{S} \mathrm{y} \\
69^{\circ} 54^{\prime} 34^{\prime \prime O}\end{array}$ & 2.160 & Patagónica & Egagrópilas & Este trabajo \\
\hline 52 & La Gemela & $33^{\circ} 05^{\prime} \mathrm{S}$ y $69^{\circ} 04^{\prime} \mathrm{O}$ & 1.245 & Monte & Trampeos & Massoia 1981a \\
\hline 53 & La Horqueta 1 & $34^{\circ} 23^{\prime} \mathrm{S}$ y $67^{\circ} 35^{\prime} \mathrm{O}$ & 480 & Monte & Egagrópilas & Rosi 1983 \\
\hline 54 & La Horqueta 2 & $34^{\circ} 13^{\prime} \mathrm{S}$ y $67^{\circ} 10^{\prime} \mathrm{O}$ & 430 & Monte & Egagrópilas & Rosi 1983 \\
\hline 55 & La Llave Vieja & $34^{\circ} 33^{\prime} \mathrm{S}$ y $67^{\circ} 58^{\prime} \mathrm{O}$ & 550 & Monte & Trampeo & Contreras y Rosi 1980a \\
\hline 56 & $\mathrm{La} \mathrm{Paz}$ & $33^{\circ} 27^{\prime} \mathrm{S}$ y $67^{\circ} 32^{\prime} \mathrm{O}$ & 510 & Monte & Trampeo & Lawrence 1941 \\
\hline 57 & La Pega & $32^{\circ} 48^{\prime} \mathrm{S}$ y $68^{\circ} 40^{\prime} \mathrm{O}$ & 630 & Monte & Trampeo & $\begin{array}{l}\text { e.g., Contreras y Rosi } 1980 \mathrm{~b} ; \\
\text { Braun et al. } 2000\end{array}$ \\
\hline 58 & La Pasarela & $\begin{array}{l}36^{\circ} 18^{\prime} 46^{\prime \prime} \mathrm{S} \text { y } \\
69^{\circ} 40^{\prime} 03^{\prime \prime} \mathrm{O}\end{array}$ & 1.250 & Patagónica & Egagrópilas & Pardiñas et al. 2008 \\
\hline 59 & La Puntilla & $32^{\circ} 57^{\prime} \mathrm{S}$ y $68^{\circ} 51^{\prime} \mathrm{O}$ & 800 & Monte & Trampeo & Rosi et al.(1992 \\
\hline 60 & La Valenciana & $35^{\circ} 33^{\prime} \mathrm{S}$ y $69^{\circ} 54^{\prime} \mathrm{O}$ & 2.100 & Patagónica & Trampeo & Riberón 2011 \\
\hline 61 & Las Aguaditas & $34^{\circ} 43^{\prime} \mathrm{S}$ y $68^{\circ} 05^{\prime} \mathrm{O}$ & 550 & Monte & Trampeo & Massoia 1981a \\
\hline 62 & Las Catitas & $33^{\circ} 18^{\prime} \mathrm{S}$ y $68^{\circ} 02^{\prime} \mathrm{O}$ & 590 & Monte & Egagrópilas & Rosi 1983 \\
\hline 63 & Las Higueras & $32^{\circ} 30^{\prime}$ S y $68^{\circ} 55^{\prime} \mathrm{O}$ & 1.125 & Monte & Trampeo & Rosi et al. 1996 \\
\hline 64 & Las Lajas & $32^{\circ} 48^{\prime}$ S y $68^{\circ} 55^{\prime} \mathrm{O}$ & 1.000 & Monte & Trampeo & Rosi et al. 1992 \\
\hline 65 & Lavalle & $32^{\circ} 43^{\prime} \mathrm{S}$ y $68^{\circ} 36^{\prime} \mathrm{O}$ & 600 & Monte & Trampeo & Barquez et al. 1999 \\
\hline 66 & Los Frisos & $\begin{array}{l}36^{\circ} 28^{\prime} 20^{\prime \prime} \mathrm{S} \mathrm{y} \\
69^{\circ} 38^{\prime} 54^{\prime \prime} \mathrm{O} \\
\end{array}$ & 1.101 & Patagónica & Egagrópilas & Pardiñas et al. 2008 \\
\hline 67 & Los Parlamentos & $35^{\circ} 02^{\prime} \mathrm{S}$ y $69^{\circ} 20^{\prime} \mathrm{O}$ & 1.400 & Patagónica & Trampeo & Barquez et al. 1999 \\
\hline 68 & Luján de Cuyo & $33^{\circ} 02^{\prime} \mathrm{S}$ y $68^{\circ} 52^{\prime} \mathrm{O}$ & 930 & Monte & Trampeo & Martínez et al. 2010 \\
\hline 69 & Malargüe & $35^{\circ} 28^{\prime} \mathrm{S}$ y $69^{\circ} 35^{\prime} \mathrm{O}$ & 1.412 & Patagónica & Trampeo & Barquez et al. 1999 \\
\hline 70 & Malargüe (24 km al SE) & $35^{\circ} 41^{\prime} \mathrm{S}$ y $69^{\circ} 28^{\prime} \mathrm{O}$ & 1.440 & Patagónica & Trampeo & Ojeda et al. 1996 \\
\hline 71 & Mendoza (Capital) & $32^{\circ} 54^{\prime} \mathrm{S}$ y $68^{\circ} 50^{\prime} \mathrm{O}$ & 765 & Monte & Trampeo & Barquez et al. 1999 \\
\hline 72 & Papagallos & $32^{\circ} 54^{\prime} \mathrm{S}$ y $68^{\circ} 57^{\prime} \mathrm{O}$ & 1.180 & Monte & Trampeo & Roig y Reig 1969 \\
\hline 73 & Paramillos de Uspallata & $32^{\circ} 29^{\prime} \mathrm{S}$ y $69^{\circ} 08^{\prime} \mathrm{O}$ & 3.000 & Puneña & Trampeo & Rosi et al. 1992 \\
\hline 74 & Parque Provincial Aconcagua 1 & $32^{\circ} 49^{\prime} \mathrm{S}$ y $69^{\circ} 56^{\prime} \mathrm{O}$ & 2.850 & Altoandina & Egagrópilas & Pardiñas et al. 2010 \\
\hline 75 & Parque Provincial Aconcagua 2 & $32^{\circ} 49^{\prime} \mathrm{S}$ y $69^{\circ} 55^{\prime} \mathrm{O}$ & 2.771 & Altoandina & Egagrópilas & Pardiñas et al. 2010 \\
\hline 76 & Paso de Las Carretas & $34^{\circ} 01^{\prime} \mathrm{S}$ y $69^{\circ} 01^{\prime} \mathrm{O}$ & 1.180 & Monte & Trampeo & Contreras y Rosi 1980a \\
\hline 77 & Pichiciego & $33^{\circ} 35^{\prime} \mathrm{S}$ y $68^{\circ} 04^{\prime} \mathrm{O}$ & 600 & Monte & Egagrópilas & e.g., Rosi 1983 \\
\hline 78 & \begin{tabular}{|l|} 
Potrerillos \\
\end{tabular} & $32^{\circ} 57^{\prime} \mathrm{S}$ y $69^{\circ} 12^{\prime} \mathrm{O}$ & 1.400 & Altoandina & Trampeo & Massoia 1981a; Rosi 1983 \\
\hline 79 & Puente Barrancas & $33^{\circ} 04^{\prime} \mathrm{S}$ y $68^{\circ} 45^{\prime} \mathrm{O}$ & 780 & Monte & Trampeo & Rosi et al. 2002 \\
\hline 80 & Puente del Inca & $32^{\circ} 49^{\prime} \mathrm{S}$ y $69^{\circ} 54^{\prime} \mathrm{O}$ & 2.720 & Altoandina & Trampeo & $\begin{array}{l}\text { Thomas 1920; Massoia 1981a; } \\
\text { Contreras y Rosi } 1981\end{array}$ \\
\hline
\end{tabular}

Tabla 5.1. (continuación) Localidades de registro de micromamíferos en la provincia de Mendoza. 


\begin{tabular}{|c|c|c|c|c|c|c|}
\hline $\mathbf{N}^{\circ}$ & Localidad & Coordenada & Alt. & U. Fitogr. & $\begin{array}{l}\text { Tipo de } \\
\text { Muestra }\end{array}$ & Fuente bibliográfica \\
\hline 81 & Puente La Horqueta & $34^{\circ} 11^{\prime} \mathrm{S}$ y $66^{\circ} 46^{\prime} \mathrm{O}$ & 400 & Monte & Egagrópilas & Rosi 1983 \\
\hline 82 & Puesto de Lima & $32^{\circ} 544^{\prime} \mathrm{S}$ y $69^{\circ} 01^{\prime} \mathrm{O}$ & 1.600 & Monte & Trampeo & $\begin{array}{l}\text { Contreras y Rosi 1980b; Massoia } \\
\text { 1981a }\end{array}$ \\
\hline 83 & Puesto Jarilla & $33^{\circ} 14^{\prime} \mathrm{S}$ y $69^{\circ} 05^{\prime} \mathrm{O}$ & 1.400 & Monte & Trampeo & Rosi et al. 2002 \\
\hline 84 & Puesto Punta del Agua & $35^{\circ} 34^{\prime} \mathrm{S}$ y $68^{\circ} 03^{\prime} \mathrm{O}$ & 800 & Monte & Trampeo & Martin 2009 \\
\hline 85 & Puntas de Vacas & $32^{\circ} 51^{\prime} \mathrm{S}$ y $69^{\circ} 45^{\prime} \mathrm{O}$ & 2.550 & Altoandina & Trampeo & $\begin{array}{l}\text { Pearson (1958); Massoia 1981a; } \\
\text { Contreras y Rosi } 1981\end{array}$ \\
\hline 86 & Quebrada de Jaguelitos & $32^{\circ} 37^{\prime} \mathrm{S}$ y $69^{\circ} 09^{\prime} \mathrm{O}$ & 3.000 & Puneña & Trampeo & Sage et al. 1986 \\
\hline 87 & Quebrada del Toro & $32^{\circ} 37^{\prime} \mathrm{S}$ y $69^{\circ} 02^{\prime} \mathrm{O}$ & 1.875 & Puneña & Trampeo & Massoia 1981a \\
\hline 88 & Reserva de Biósfera Ñacuñan & $34^{\circ} 02^{\prime} \mathrm{S}$ y $67^{\circ} 58^{\prime} \mathrm{O}$ & 580 & Monte & Trampeo & $\begin{array}{l}\text { e.g., Contreras y Rosi 1980a; } \\
\text { Corbalán y Ojeda } 2005\end{array}$ \\
\hline 89 & Reserva Natural de Llancanelo & $35^{\circ} 38^{\prime}$ 'S y $69^{\circ} 11^{\prime} \mathrm{O}$ & 1.340 & Patagónica & Trampeo & Pardiñas et al. $2011 \mathrm{c}$ \\
\hline 90 & Reserva Telteca & $32^{\circ} 20^{\prime}$ S y $67^{\circ} 45^{\prime} \mathrm{O}$ & 520 & Monte & Trampeo & Barquez et al. 1999 \\
\hline 91 & Reserva Telteca, sobre Ruta 142 & $32^{\circ} 27^{\prime} \mathrm{S}$ y $68^{\circ} 07^{\prime} \mathrm{O}$ & 534 & Monte & Trampeo & Rosi et al. 2002 \\
\hline 92 & Rincón del Atuel & $34^{\circ} 45^{\prime} \mathrm{S}, 68^{\circ} 37^{\prime} \mathrm{O}$ & 1.200 & Monte & Trampeo & $\begin{array}{l}\text { Reubicada de } \\
\text { Contreras, J.F. y M.I. Rosi 1980a }\end{array}$ \\
\hline 93 & Río Seco La Hedionda & $34^{\circ} 29^{\prime} \mathrm{S}$ y $68^{\circ} 33^{\prime} \mathrm{O}$ & 940 & Monte & Egagrópilas & Massoia et al. 1997 \\
\hline 94 & San Ignacio & $32^{\circ} 54$ 'S y $68^{\circ} 54^{\prime} \mathrm{O}$ & 850 & Monte & Trampeo & Rosi et al. 1992 \\
\hline 95 & Salinas del Diamante & $34^{\circ} 56^{\prime} \mathrm{S}$ y $68^{\circ} 52^{\prime} \mathrm{O}$ & 1.288 & Monte & Trampeo & Martin 2009 \\
\hline 96 & Tambillos & $32^{\circ} 23^{\prime} \mathrm{S}$ y $69^{\circ} 25^{\prime} \mathrm{O}$ & 2.400 & Puneña & Trampeo & Rosi et al. 2002 \\
\hline 97 & Tupungato & $33^{\circ} 16$ 'S y $69^{\circ} 05^{\prime} \mathrm{O}$ & 1.300 & Monte & Trampeo & Martin 2009 \\
\hline 98 & Uspallata & $32^{\circ} 35^{\prime} \mathrm{S}$ y $69^{\circ} 22^{\prime} \mathrm{O}$ & 1.900 & Puneña & Trampeo & Barquez et al. 1999 \\
\hline 99 & Valle del Sol & $33^{\circ} 00^{\prime}$ S y $69^{\circ} 21^{\prime} \mathrm{O}$ & 3.100 & Altoandina & Trampeo & Rosi 1983 \\
\hline 100 & Valle Grande 1 & $32^{\circ} 50^{\prime}$ S y $68^{\circ} 28^{\prime} \mathrm{O}$ & 850 & Monte & Trampeo & Massoia 1981a; Rosi 1983 \\
\hline 101 & Valle Grande 2, $25 \mathrm{~km}$ de Rama Caída & $34^{\circ} 48^{\prime} \mathrm{S}$ y $68^{\circ} 29^{\prime} \mathrm{O}$ & 790 & Monte & Trampeo & Massoia 1981a \\
\hline 102 & Valle Hermoso & $35^{\circ} 09^{\prime} \mathrm{S}$ y $70^{\circ} 10^{\prime} \mathrm{O}$ & 2.460 & Altoandina & Trampeo & Ojeda et al. 2005; Jayat et al. 2006 \\
\hline 103 & Villavicencio & $32^{\circ} 31^{\prime} \mathrm{S}$ y $69^{\circ} 01^{\prime} \mathrm{O}$ & 1.980 & Puneña & Trampeo & Massoia 1981a \\
\hline 104 & Vistalva & $32^{\circ} 54^{\prime} \mathrm{S}$ y $68^{\circ} 53^{\prime} \mathrm{O}$ & 930 & Monte & Trampeo & Massoia 1981a; Rosi 1983 \\
\hline 105 & Volcán Malacara & $\begin{array}{l}35^{\circ} 47^{\prime} 26^{\prime \prime S} \text { y } \\
69^{\circ} 29^{\prime} 13^{\prime \prime O} \\
\end{array}$ & 1.750 & Patagónica & Egagrópilas & Este trabajo \\
\hline 106 & Volcán Morocho & $35^{\circ} 36^{\prime} \mathrm{S}$ y $69^{\circ} 12^{\prime} \mathrm{O}$ & 1.300 & Patagónica & Egagrópilas & Pardiñas et al. 2008 \\
\hline 107 & Zapata & $33^{\circ} 29^{\prime} \mathrm{S}$ y $68^{\circ} 59^{\prime} \mathrm{O}$ & 870 & Monte & Trampeo & Rosi 1983 \\
\hline
\end{tabular}

Tabla 5.1. (continuación) Localidades de registro de micromamíferos en la provincia de Mendoza. 


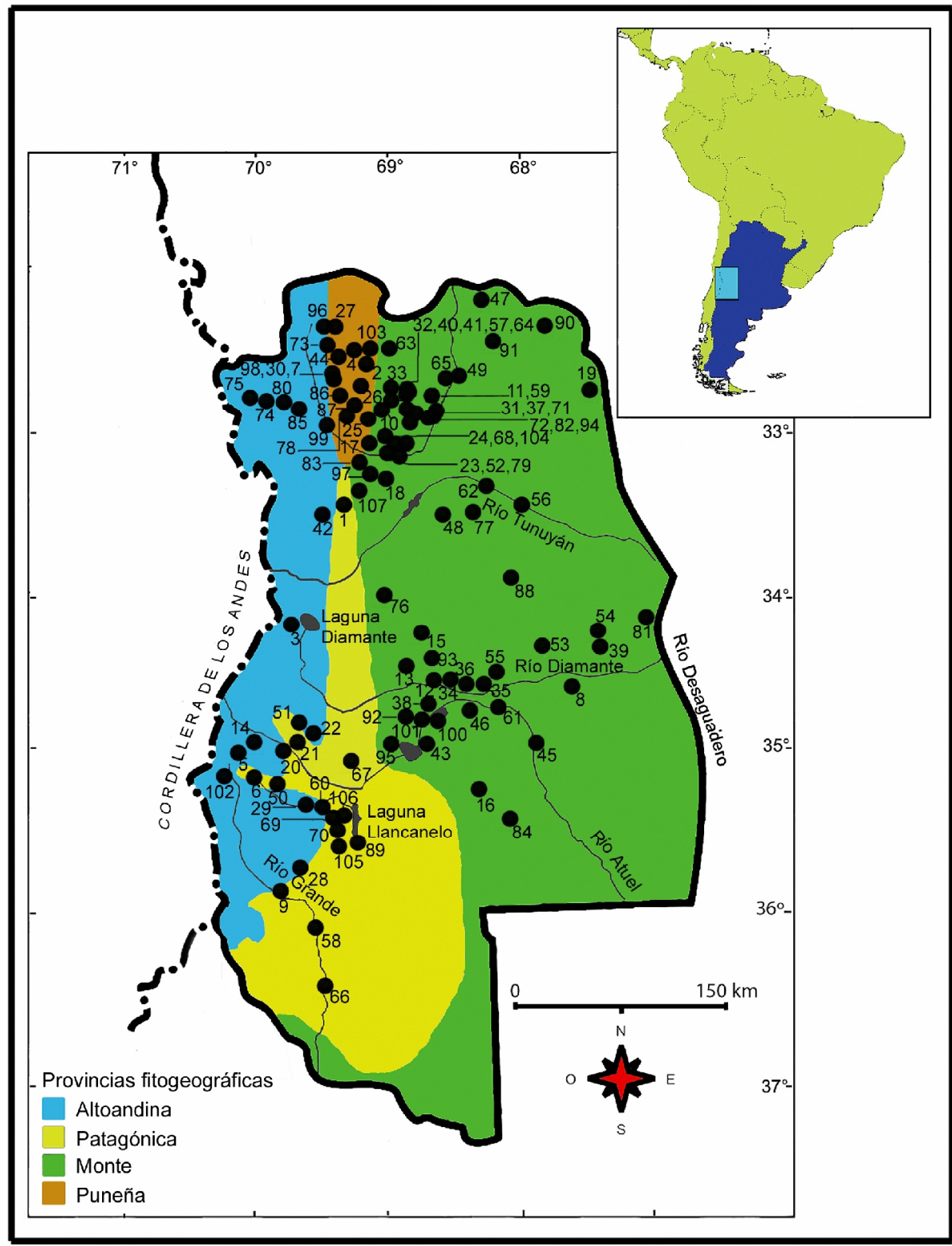

Figura 5.1. Localidades de registro de micromamíferos en la provincia de Mendoza.

Clase Mammalia Linnaeus, 1758.

Orden Didelphimorphia Gill, 1872.

Familia Didelphidae Gray, 1821.

Subfamilia Didelphinae Gray, 1821.

Género Lestodelphys Tate, 1934.

Lestodelphys halli (Thomas, 1921).

Localidad tipo: Estancia La Madrugada, provincia de Santa Cruz.

Características generales: Lestodelphys halli (comadrejita patagónica) es el marsupial viviente con distribución mas austral, habitando desde Mendoza hasta el norte de Santa 
Cruz. L. halli es la única especie viviente del género (e.g., Flores, 2006). Existe una especie fósil [Lestodelphys juga (Ameghino, 1889); Plioceno tardío-Pleistoceno tardío], proveniente de Córdoba y Buenos Aires, reconocida como entidad plena por Goin (1991) y puesta en duda por el mismo autor en trabajos posteriores (Goin, 1995, 1999). No obstante, Martin (2008) en base a caracteres morfológicos y morfométricos revalidó taxonomicamente a esta especie extinta. L. halli, es una especie principalmente carnívora y nocturna, endémica de la estepa Patagónica con poblaciones relictuales en el desierto del Monte (e.g., Udrizar Sauthier et al., 2007; Martin, 2008; Martin et al., 2008; Formoso et al., 2011).

Provincias comprendidas: Mendoza, La Pampa, Neuquén, Río Negro, Chubut y Santa Cruz

Localidades registradas en Mendoza: 15, 28, 33, 48. Figura 5.2.

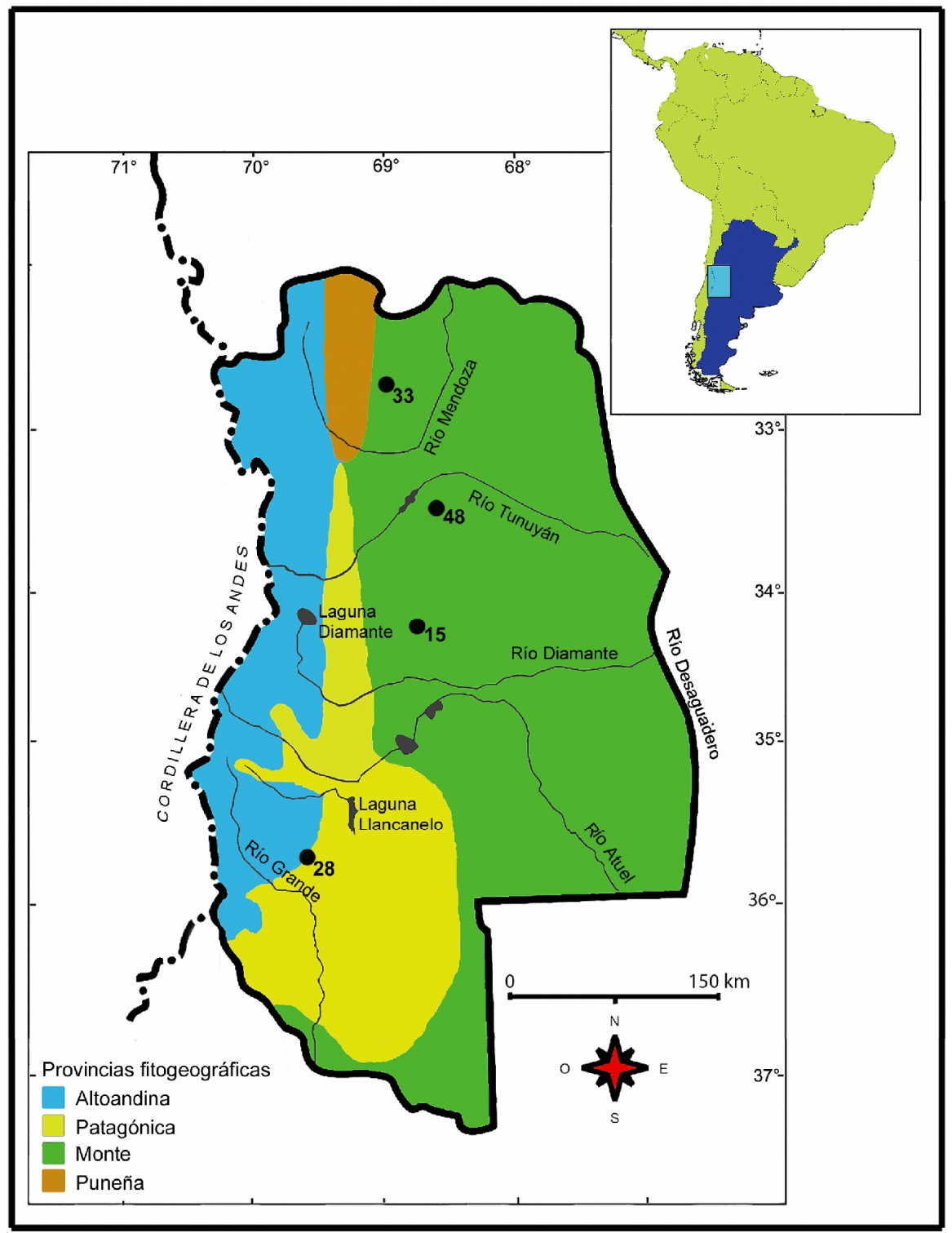

Figura 5.2. Localidades de registro de Lestodelphys halli en la provincia de Mendoza. 
Descripción: cráneo con rostro corto; arcos cigomáticos robustos y expandidos lateralmente; bulas timpánicas grandes; rama mandibular fuertemente curvada en la parte ventral; caninos robustos; forámenes posterolaterales muy grandes y ovalados; premolares superiores e inferiores aumentan su tamaño del $1^{\circ}$ al $3^{\circ}$, sin diastemas; molares superiores comprimidos anteroposteriormente; protocono reducido, paracono extremadamente reducido y matacono grande; repisa estilar bien desarrollada, siendo casi la mitad de la superficie oclusal; primer premolar muy reducido; premolares superiores e inferiores aumentando su tamaño del $1^{\mathrm{o}}$ al $3^{\mathrm{o}}$; molares inferiores con talónidos reducidos, comprimidos lateralmente; cíngulo anterobasal bien desarrollado; protocónido muy grande (Marshall, 1877; Martin, 2008).

Especies similares: Thylamys pallidior. L. halli posee dientes y alvéolos de mayor tamaño. La mandíbula de $L$. halli, en comparación es más robusta y convexa en su borde inferior. Presenta el protocono menos conspicuo que y talónidos más reducido que en T. pallidior.

Observaciones: a pesar que los escasos registros de esta especie en la provincia de Mendoza se encuentran en su mayoría en ambientes del Monte, su vinculación con la estepa Patagónica ha sido largamente sustentada en numerosos trabajos, llevando considerar a este tipo de registros, como poblaciones relictuales de distribuciones previas mas amplias (e.g., Udrizar Sauthier et al., 2007; Martin, 2008; Martin et al., 2008).

Género Thylamys Gray, 1843.

Thylamys pallidior (Thomas, 1902).

Localidad tipo: Paso de Tacna, camino al Lago Titicaca, Perú (Ojeda, 2006).

Características generales: Thylamys pallidior (marmosa pálida) es un marsupial terrestre de pequeño tamaño que se distribuye desde el sur de Perú, Bolivia, centro-oste de Argentina y sudeste de Buenos Aires hasta el sur de Chubut (Diaz y Teta, 2011). Su distribución se ajusta en gran medida a la Diagonal Árida Sudamericana. En Patagonia es frecuente en el desierto del Monte y exhibe algunos registros en la estepa Patagónica (Pardiñas et al., 2003; Martin, 2009; Formoso et al., 2011). Es un marsupial principalmente nocturno y presenta una dieta omnívora-insectívora (Ojeda y Tabeni, 2009). Martin (2009) en base a caracteres morfológicos y morfometricos, sugiere revalidar el nombre Thylamys fenestrae (Marelli, 1932) para poblaciones de La Pampa. 
Sin embargo, datos genéticos y morfológicos aportados por Giarla et al. (2010) y Formoso et al. (2011) receptivamente, indican que $T$. fenestrae es un sinónimo junior de T. pallidior.

Provincias comprendidas: Jujuy, Salta, Tucumán, Catamarca, La Rioja, San Juan, Córdoba, San Luis, Mendoza, La Pampa, Buenos Aires, Neuquén, Río Negro y Chubut. Localidades registradas en Mendoza: 7, 9, 16, 20, 22, 28, 46, 50, 51, 58, 66, 84, 88, 93, 95, 97, 105, 106. Figura 5.3.

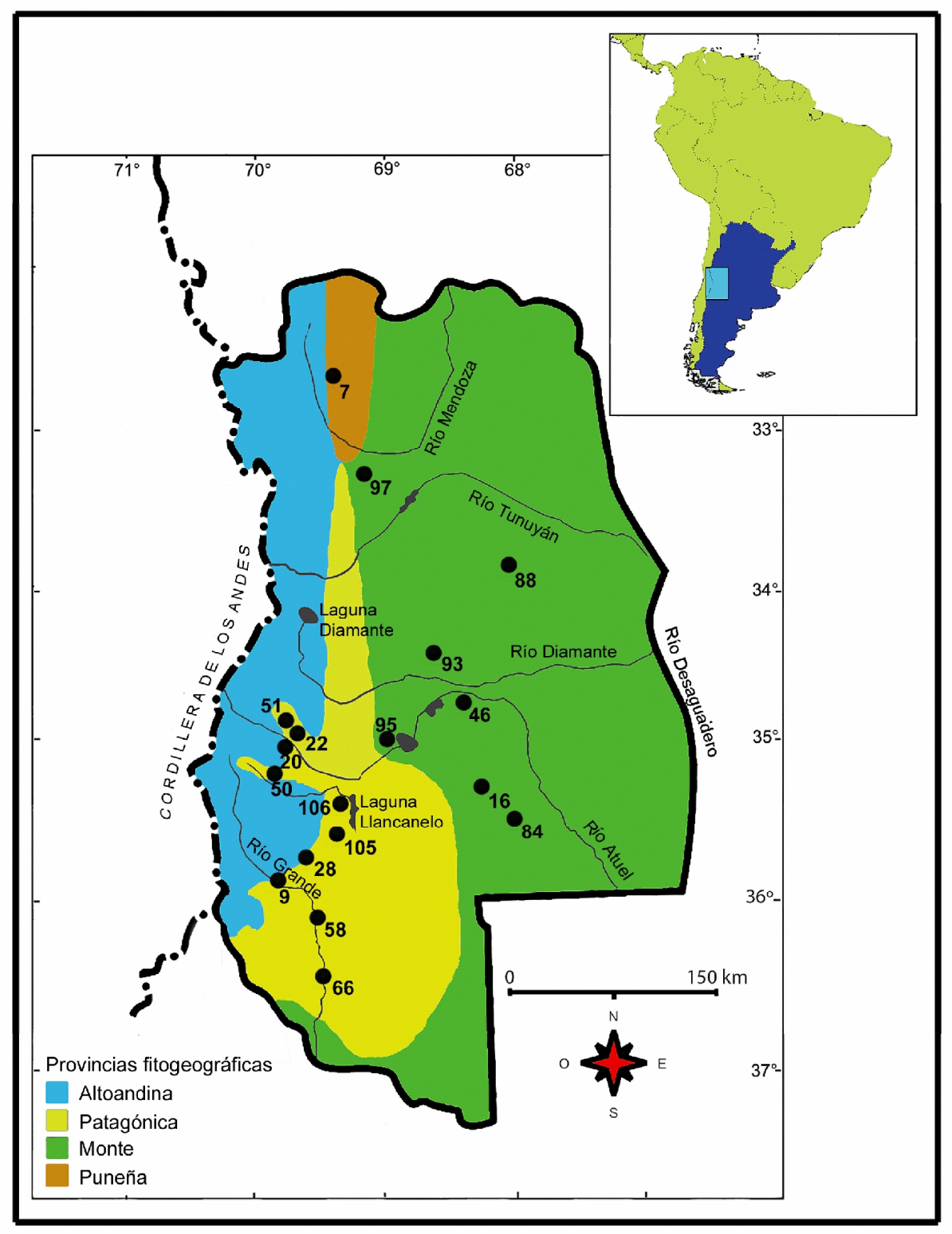

Figura 5.3. Localidades de registro de Thylamys pallidior en la provincia de Mendoza.

Descripción: cráneo ligeramente comprimido lateralmente y alargado en sentido anteroposterior; rostro bajo y aguzado; bulas timpánicas grandes; fenestras maxilares y palatinas grandes; mandíbula grácil; rama horizontal baja; rama ascendente con borde 
anterior casi recto; amplio ectoflexo en el M3; compresión anteroposterior del M; gran desarrollo del cíngulo anterobasal; reducción del talónido del M4 (Martin, 2008).

Especies similares: Lestodelphys halli, Thylamys pusillus (Desmarest, 1804). En cuanto a la morfología del cráneo $T$. pallidior se distingue de $T$. pusilla por tener una cresta supraorbital suave y redondeada, una constricción postorbital poco pronunciada y grandes fenestras maxilares y palatinas (Tate, 1933; Martin, 2009).

Observaciones: en Mendoza es abundate en el desierto del Monte y en la estepa Patagónica, con un registro aislado en ambiente Puneño y ausente en sectores Altoandinos.

Orden Chiroptera Blumenbach, 1779.

Familia Molossidae Gervais, 1856.

Genero Tadarida Refinesque, 1814.

Tadarida brasiliensis (I. Geoffroy Saint-Hilaire, 1824).

\section{Localidad tipo: Curitiba, Paraná, Brasil.}

Características generales: Tadarida brasiliensis (moloso común) es un murciélago insectívoro y migratorio que se distribuye desde el centro de EEUU, Centroamérica, los Andes de Sudamérica, Paraguay, sur de Brasil y Uruguay, hasta el centro de Chile y Norpatagonia Argentina, habitando en multiplicidad de ambientes, incluso en áreas urbanas (Barquez, 2006; Barquez et al., 1999, 2011a). Es una de las especies de murciélagos más común de la Argentina (Barquez et al., 1999).

Provincias comprendidas: Jujuy, Salta, Formosa, Tucumán, Catamarca, Misiones, Santiago del Estero, La Rioja, San Juan, Córdoba, Santa Fe, Entre Ríos, San Luis, Mendoza La Pampa, Buenos Aires, Neuquén, Río Negro y Chubut.

Localidades registradas en Mendoza: 8, 16, 46, 57, 65, 67, 71, 88, 98. Figura 5.4.

Descripción: cráneo aplanado; rostro angosto; lagrimal con surco visible; cresta sagital ausente o obsoleta; arcos zigomáticos delgados; paladar fuertemente emarginado anteriormente; escotadura palatina angosta y con su borde posterior ligeramente cóncavo; proceso angular no se separa de la mandíbula y tiene la misma longitud que el cóndilo mandibular, confiriéndole una forma cuadrangular a la rama vertical; incisivos superiores convergentes hacia los extremos; caninos largos y aguzados; molares con tamaño similar, con trigónidos y talónidos evidentes (Barquez et al., 1999). 


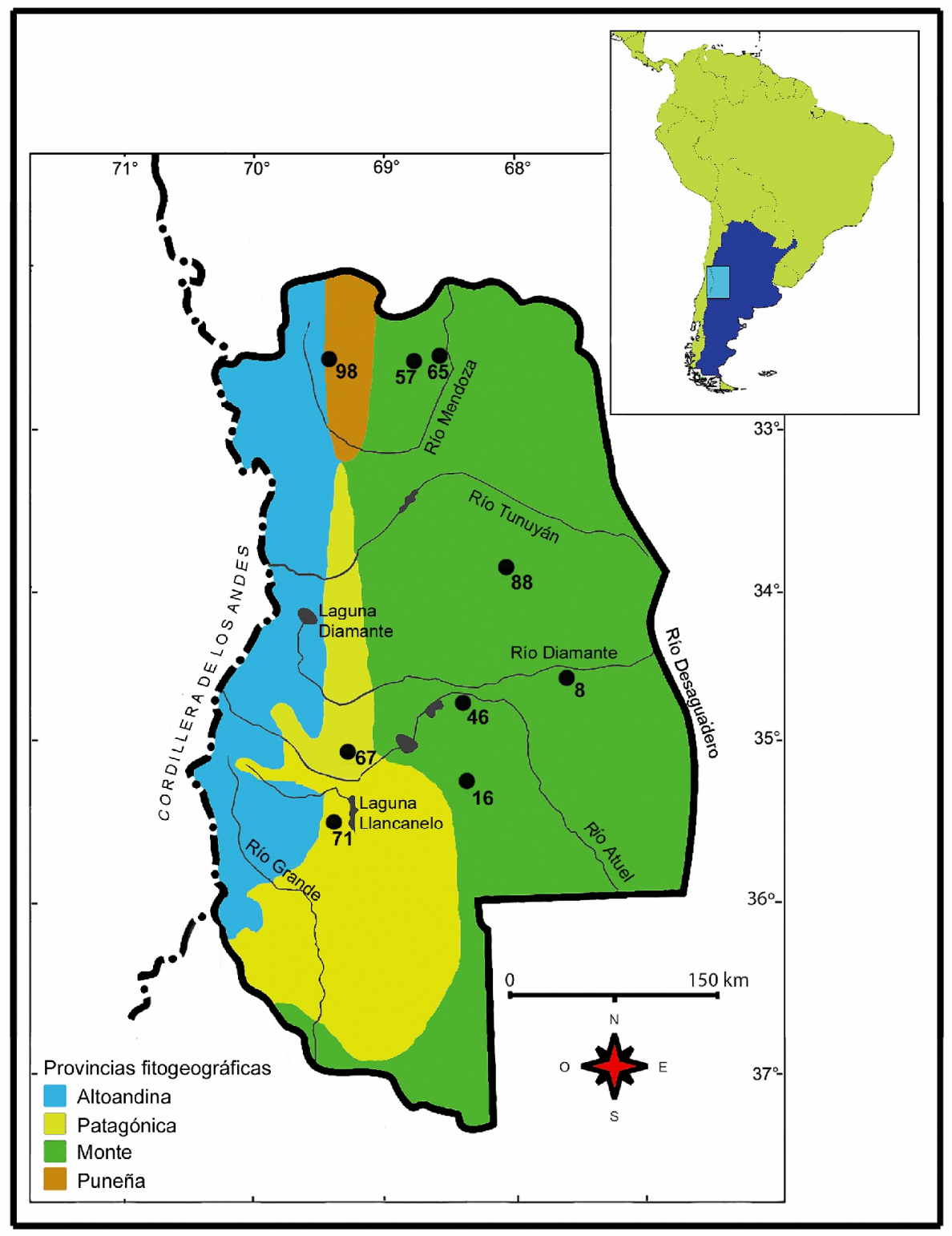

Figura 5.4. Localidades de registro de Tadarida brasiliensis en la provincia de Mendoza.

Especies similares: Eumops patagonicus Thomas, 1924, sin registro en la provincia de Mendoza.

Observaciones: en Mendoza está presente en casi todos los ambientes menos en estepas Altoandinas.

Familia Vespertilionidae Gray, 1821.

Genero Myotis Kaup, 1829.

Características generales: el género Myotis presenta dificultades considerables a la hora de realizar las determinaciones de las formas específicas (Barquez, 2006), más aun 
cuando consideramos restos craneanos (Barquez et al., 1999). De las 10 especies de Myotis identificadas para la Argentina, actualmente se reconoce solo a Myotis dinellii Thomas, 1902 (murcielaguito común) para la provincia de Mendoza, la cual presenta su Terra Typica en Tucumán. Anteriormente, se la consideraba como subespecie de Myotis levis (I. Geoffroy Sain-Hilaire, 1824) (Barquez et al., 1999). Sin embargo, el hallazgo de ambas formas con diferencias morfológicas marcadas habitando en simpatría, confirmaron la validez de M. dinellii (Barquez, 2006; Barquez et al., 2011b). Esta especie se distribuye desde el centro de Bolivia hasta la provincia de Neuquén en la Argentina, habitando en una amplia variedad de ambientes (Barquez y Diaz, 2011).

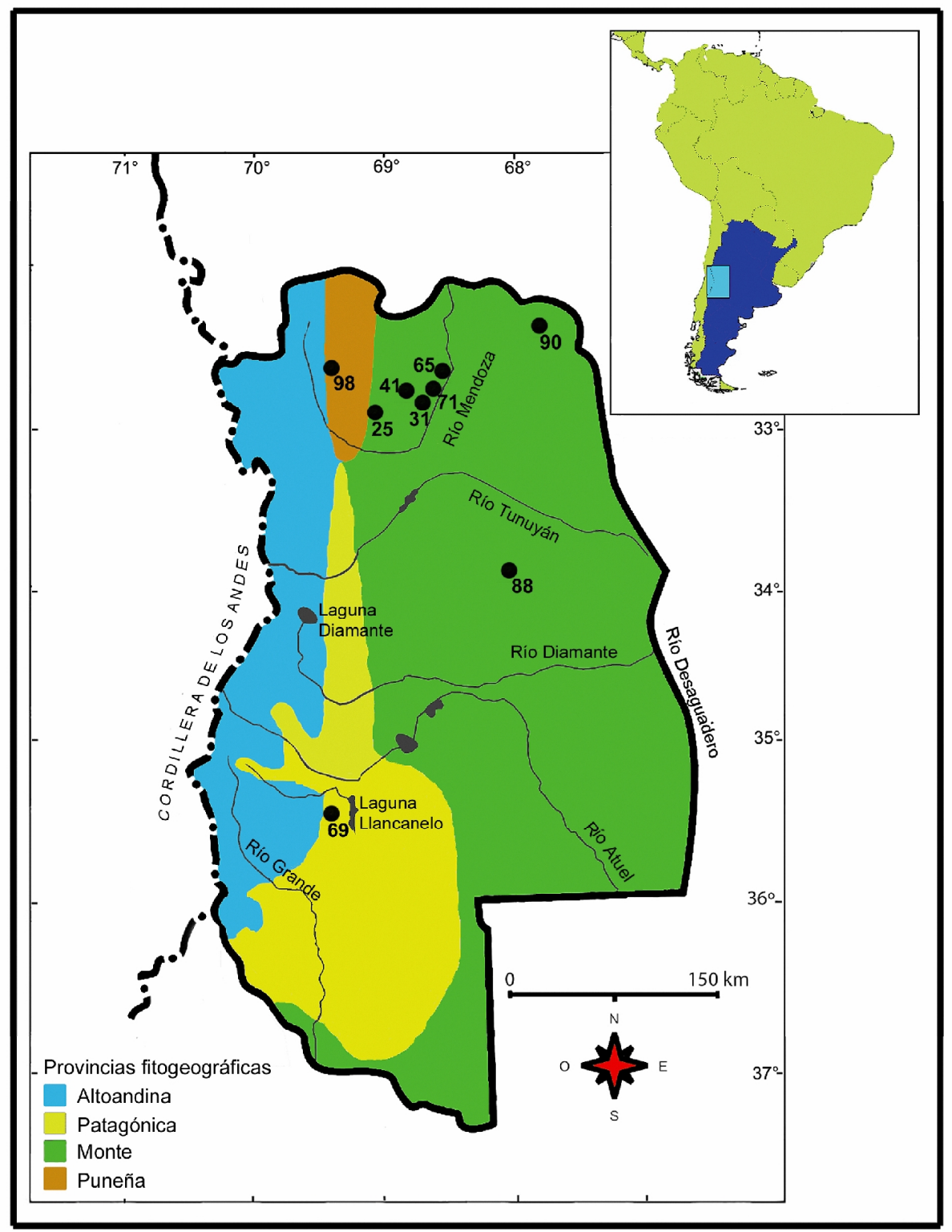

Figura 5.5. Localidades de registro de Myotis en la provincia de Mendoza. 
Provincias comprendidas: Jujuy, Salta, Tucumán, Catamarca, La Rioja, Santiago del Estero, San Juan, Córdoba, Entre Ríos, San Luis, Mendoza, La Pampa, Buenos Aires y Neuquén.

Localidades registradas en Mendoza: 25, 31, 41, 65, 69, 71, 88, 90, 98. Figura 5.5.

Descripción: cráneo bastante robusto; rostro alongado; constricción interorbital angosta; cresta sagital generalmente baja; caja craneana globosa; tres premolares superiores e inferiores.

Observaciones: en Mendoza habita en simpatría con T. brasiliensis, estando presente el Monte, estepa Patagónica y Puneña.

Suborden Hystricomorpha Brandt, 1855.

Infraorden Hystricognathi Tullberg, 1899.

Familia Caviidae Waterhouse, 1830.

Subfamilia Caviinae Gray, 1821.

Género Galea Meyen, 1832.

Galea leucoblephara (Burmeister, 1861).

Localidad tipo: la localidad tipo de esta especie tiene una historia larga de correcciones y finalmente Yepes (1936b) la restringe a Mendoza.

Características generales: Galea leucoblephara (cuis común) es un roedor diurno y crepuscular (Dunnum et al., 2011). El género Galea se distribuye desde el sur de Perú, Bolivia, oeste de Paraguay, noroeste y centro de Argentina hasta el nordeste de la provincia de Santa Cruz (Dunnum et al., 2011). G. leucoblephara tradicionalmente era nominada como Galea musteloides (Meyen, 1832). Sin embargo, estudios recientes realizados por Dunnum y Salazar-Bravo (2010) en base a datos genéticos moleculares distinguen de tres clados: 1) restringen a G. musteloides para poblaciones de las tierras altas de noroeste de Bolivia, sudeste de Perú y extremo noreste de Chile; 2) elevan a G. leucoblephara para poblaciones de tierras bajas de Bolivia, Paraguay y Argentina central; 3) elevan a Galea comes Thomas, 1919, para poblaciones de la región Andina del sur de Bolivia y norte de Argentina. Dentro del clado G. leucoblephara diferencian 3 subclados, siendo Galea l. leucoblephara el correspondiente a la provincia de Mendoza. En Patagonia es frecuente en el desierto del Monte y presenta algunos registros en la estepa Patagónica (Pardiñas et al., 2001, 2003; Agnolin et al., 2007). 
Provincias comprendidas: Tucumán, Catamarca, Santiago del Estero, La Rioja, San Juan, Córdoba, San Luis, Mendoza, La Pampa, Buenos Aires, Neuquén, Río Negro, Chubut y Santa Cruz.

Localidades registradas en Mendoza: 16, 33, 88. Figura 5.6.

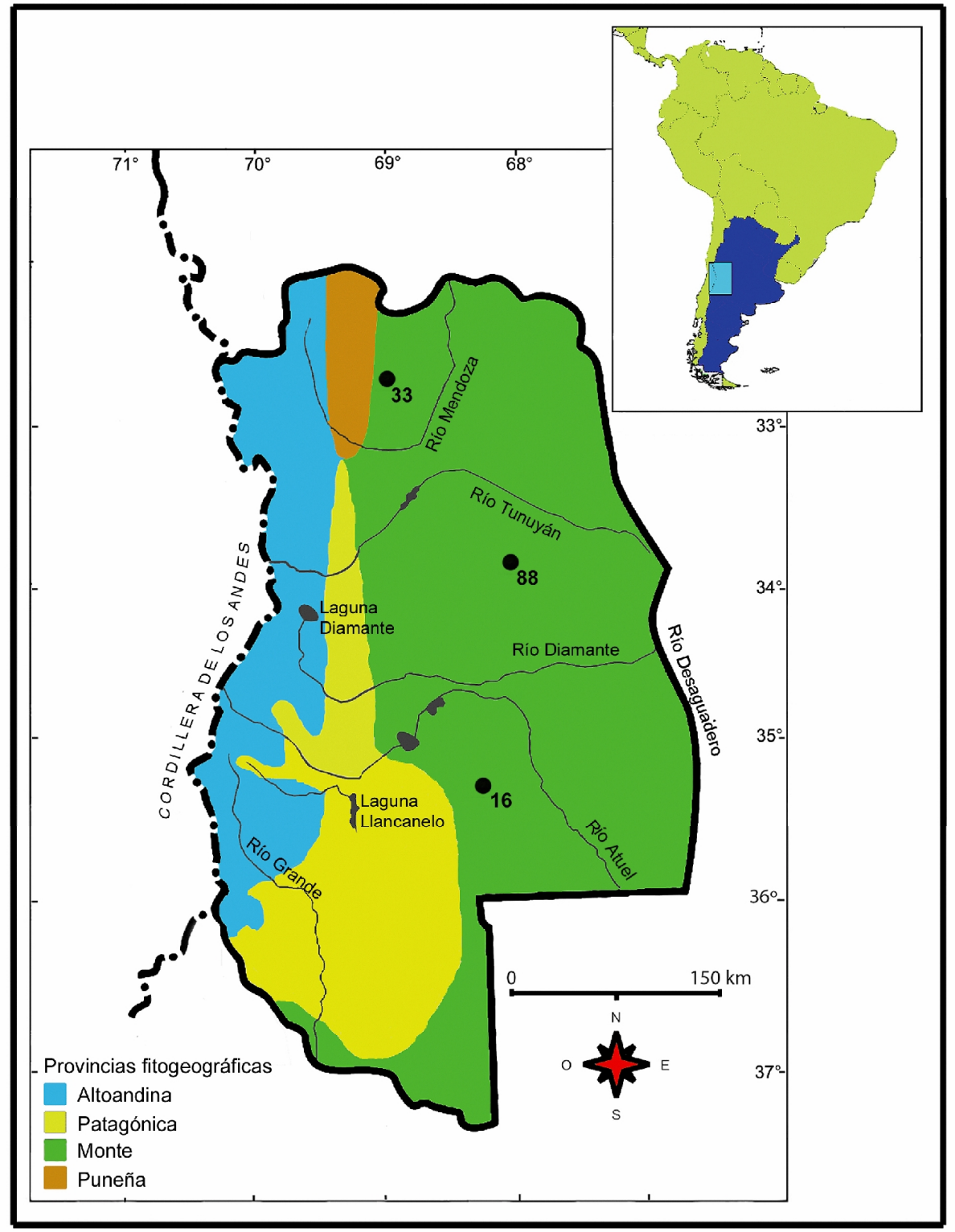

Figura 5.6. Localidades de registro de Galea leucoblephara en la provincia de Mendoza.

Descripción: caja craneana estrecha; rostro estrecho y alargado; arcos zigomáticos pocos expandidos lateralmente; forámenes incisivos cortos y de tamaño chico, con los extremos posteriores subcuadrado y alejados del inicio de la serie dentaria; cresta masetérica se extiende un poco más anteriormente, llegando a la altura del pm4; cóndilo mandibular bajo; escaso desarrollo de la escotadura sigmoidea; incisivos de color 
anaranjado; dos hendiduras externas en los molariformes (Kraglievich, 1930; Cabrera, 1953; Solmsdorff et al., 2004).

Especies similares: Microcavia australis. G. leucoblephara se distingue principalmente de esta especie por presentar incisivos anaranjados y por la mayor extensión de la porción anterior de la cresta masetérica (ver M. australis).

Observaciones: los resgistros aislados en Mendoza se restriguen al desierto del Monte. Extiste una cita para otra localidad del Monte muy cercana a San Rafael [Río Seco La Hedionda (Localidad 93)], asignada por Massoia et al. (1997) como dudosa “Galea ?”.

Género Microcavia H. Gervais y Ameghino, 1880.

Microcavia australis (I. Geoffroy Saint-Hilaire y d'Orbigny, 1833).

Localidad tipo: cercanías de la parte inferior del Río Negro.

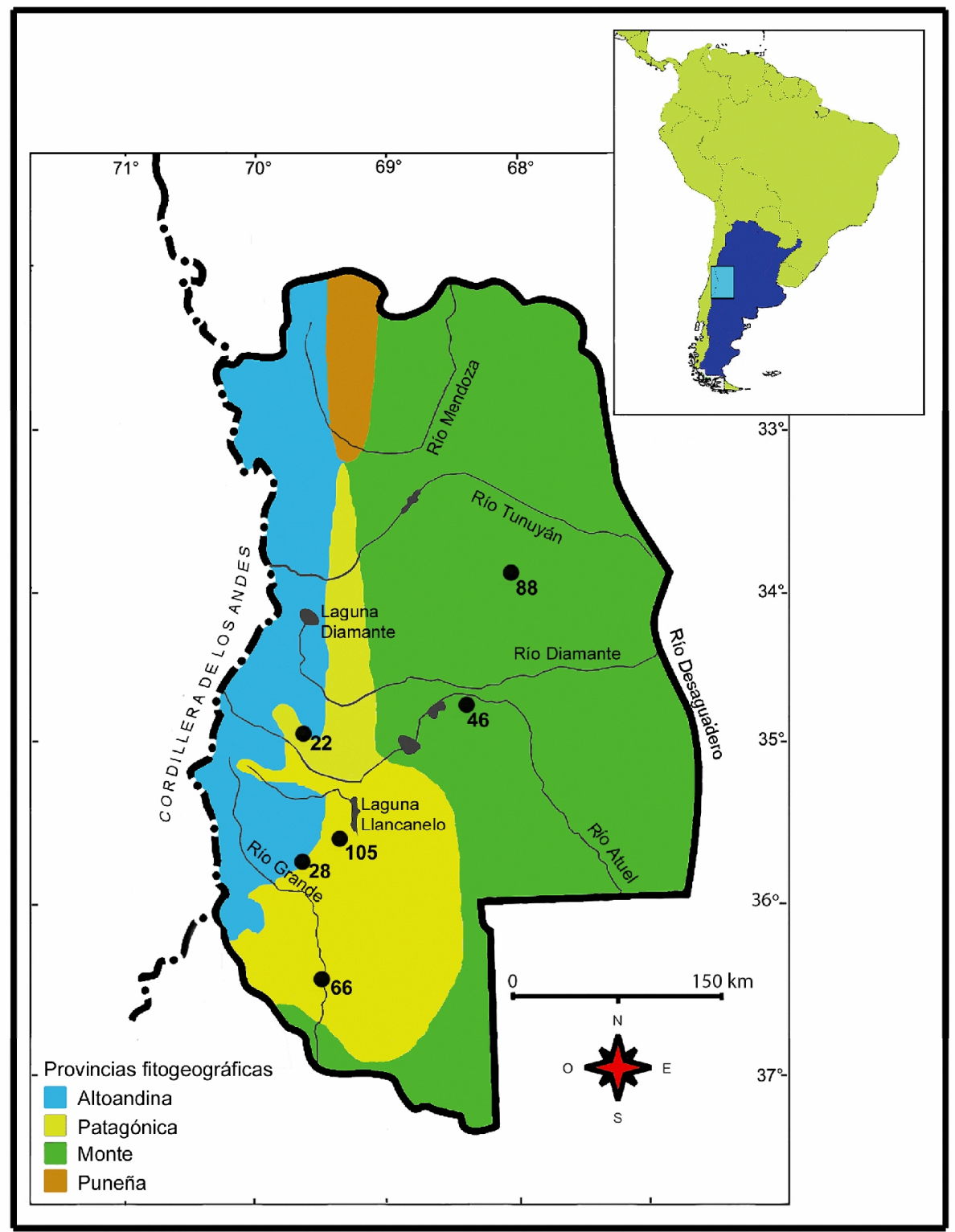


Figura 5.7. Localidades de registro de Microcavia australis en la provincia de Mendoza.

Características generales: Microcavia australis (cuis chico) es un roedor diurno que se distribuye desde Jujuy, centro-oeste de la Argentina hasta el sur de Santa Cruz (Pardinas y Ojeda, 2011). Es un elemento típico de valles y tierras bajas áridas y semi-áridas, ampliamente distribuido en el desierto del Monte y en la estepa Patagónica (Tognelli et al., 2001). Las colonias se protegen debajo de la vegetación achaparrada $\mathrm{y}$ frecuentemente trepan árboles y arbustos para alimentarse (Ojeda, 2006).

Provincias comprendidas: Jujuy, Salta, Tucumán, Catamarca, Chaco, Santiago del Estero, La Rioja, San Juan, Córdoba, Santa Fe, Entre Ríos, San Luis, Mendoza, La Pampa, Buenos Aires, Neuquén, Río Negro, Chubut y Santa Cruz.

Localidades registradas en Mendoza: 22, 28, 46, 66, 88, 105. Figura 5.7.

Descripción: incisivos de color crema; repisa masetérica paralela a la serie dentaria sobre la parte media-labial de la mandíbula y termina anteriormente a la altura del $\mathrm{m} 1$; forámenes incisivos grandes y alargados, alcanzan la base del inicio de la serie dentaria y su porción posterior es redondeada.

Especies similares: Galea leucoblephara.

Observaciones: en Mendoza se encuentra en ambientes de estepa Patagónica y del Monte.

Superfamilia Octodontoidea Waterhouse, 1839.

Familia Ctenomyidae Lesson, 1842.

Género Ctenomys Blainville, 1826.

Características generales: Ctenomys es el único género viviente de la familia Ctenomyidae y se distribuye desde el centro-este de Perú y sudeste de Brasil hasta el extremo sur de Argentina y Chile (Rosi et al., 2002; Parada et al., 2011). De las 42 especies de tuco-tucos descriptas para la Argentina, solo tres están representadas en la provincia de Mendoza: Ctenomys mendocinus Philippi, 1869, Ctenomys validus Contreras, Roig y Suzarte, 1977 y Ctenomys pontifex Thomas, 1918 (Bidau, 2006). Las tres especies poseen sus localidades típicas en la provincia de Mendoza, siendo $c a$. de la ciudad de Mendoza para C. mendocinus, El Algarrobal para C. validus y Fuerte de San Rafael para C. pontifex. No obstante, en el último caso Pearson y Lagiglia 
(1992) reestablecieron su ubicación en las proximidades del Volcán Peteroa (ca. 200 Km al sudoeste de San Rafael, Mendoza).

El estatus taxonómico Ctenomys en la provincia de Mendoza es poco claro. Para $C$. validus, especie aparentemente endémica del norte de Mendoza, existe muy escasa información sobre su taxonomía, distribución y ecología (Bidau et al., 2011). Recientemente, Parada et al. (2011) en base a análisis moleculares identificaron 8 grupos de especies de Ctenomys, donde C. mendocinus fue incluida en el grupo mendocinus, previamente nominado por Massarini et al. (1991). Aunque la forma nominal C. pontifex no fue evaluada por ninguno de los autores, Parada et al. (2011) sugieren que podría incluirse al grupo mendocinus. Finalmente, Ctenomys eremophilus (Contreras y Roig, 1975) con registro restringido a la Reserva de Biósfera Nacuñán (Localidad 88), fue considerada un nomen nudum por falta de una descripción formal (Galliari et al., 1996). Son roedores cavadores y comunes en hábitats abiertos, que requieren suelos arenosos para poder realizar sus galerías (Bidau, 2006). Rosi et al. (1996, 2000), al estudiar las estructuras de los sistemas de galerías de C. mendocinus en dos ambientes de Mendoza, observaron un patrón similar entre ambas: un eje principal compuesto por segmentos cortos y rectos, cámaras de reposo-alimentación y una cámara nido, más grande y a mayor profundidad $(0,64 \mathrm{~m})$.

Localidades registradas en Mendoza: 1, 3, 4, 6, 9, 10, 11, 12, 13, 14, 15, 20, 21, 22, $24,25,26,28,30,31,32,33,39,44,46,50,51,59,63,64,66,72,73,79,83,86,88$, 91, 93, 94, 96, 105. Figura 5.8.

Descripción: cráneo ancho y cuadrangular; arco zigomático robusto; rostro corto y angosto; foramen infraobital subcudrangular; proceso yugal superior conspicuo, en la porción posterior del arco zigomático; bulas timpánicas ubicadas de manera oblicua respecto del eje del cráneo, grandes, de estructura piriforme y estrechas anteriormente; mandíbula robusta con fuerte estricognatía, debida a la gran expansión externa de la cresta masetérica y de la rama ascendente; proceso coronoides orientado hacia atrás por encima del cóndilo; incisivos anaranjados, incisivos superiores cortos y robustos; incisivos inferiores con raíz muy amplia formando un arco, hasta la base del cóndilo; molariformes de aspecto reniforme, con cúspides y flexos muy reducidos; premolares levemente más grande que los primeros molares y último molar notablemente reducido (De Santis et al., 1998). 


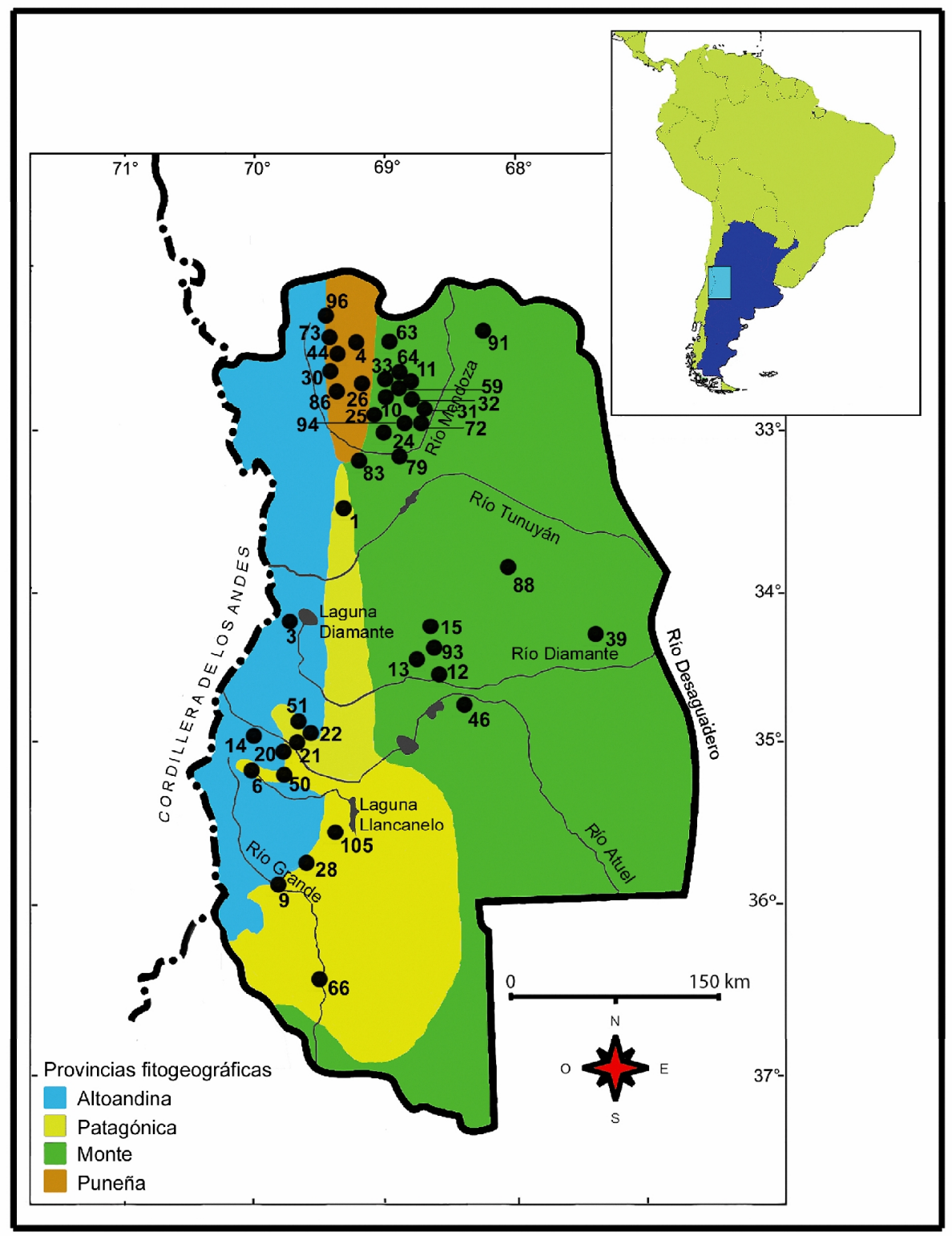

Figura 5.8. Localidades de registro de Ctenomys en la provincia de Mendoza.

Observaciones: el género Ctenomys se encuentra presente en prácticamente en todos los ambientes de Mendoza.

Familia Octodontidae Waterhouse, 1840.

Género Tympanoctomys Yepes, 1942.

Tympanoctomys barrerae (Lawrence, 1941).

Localidad tipo: La Paz, Mendoza. 


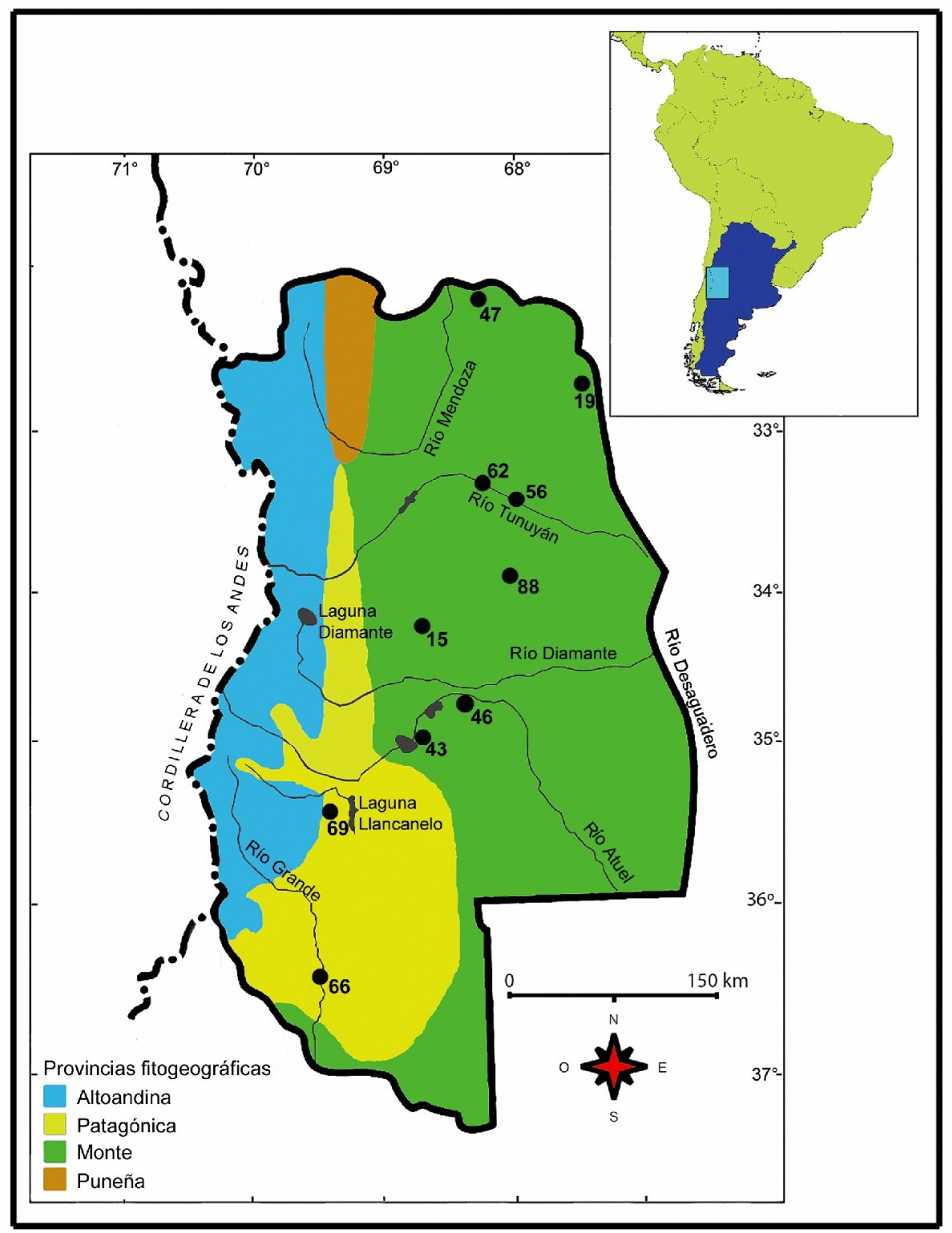

Figura 5.9. Localidades de registro de Tympanoctomys barrerae en la provincia de Mendoza.

Características generales: Tympanoctomys barrerae (rata vizcacha colorada) es un roedor octodóntido solitario con características fisiológicas, morfológicas y un comportamiento fosorial, que le proporcionan una adaptación extrema a los ambientes áridos (Mares et al., 1997; Ojeda et al., 1996, 1999; Diaz et al., 2000). Esta especie presenta poblaciones aisladas desde el Parque Nacional Ischigualasto en la provincia de La Rioja hasta la Patagonia Central en la provincia de Chubut, habitando en dunas y salitrales, insertos en el desierto del Monte y ecotonos Monte-estepa Patagónica (Justo et al., 1985; Gallardo et al., 2009; Udrizar Sauthier et al., 2009). No obstante, Udrizar Sauthier et al. (Ms. en preparación) proponen que las poblaciones de Chubut se diferencian de $T$. barrerae y pertenecen a otra especie. Se alimenta principalmente de 
plantas halófitas pertenecientes a la familia Chenopodiaceae, tales como Atriplex, Heterostachys y Suaeda (Torres-Mura et al., 1989; Ojeda et al., 1996; Gianonni et al., 2000).

Los escasos hallazgos fósiles de Tympanoctomys fueron interpretados como poblaciones relictuales de distribuciones previas más amplias (Verzi et al., 2002; Udrizar Sauthier et al., 2009), cuya retracción en Patagonia central pudo haber sido un proceso muy reciente ( $<100$ años), posiblemente vinculado a la actividad pecuaria de ovicápridos (Udrizar Sauthier et al., 2009). El género Tympanoctomys contiene tres especies vivientes [T. barrerae, T. aureus (Mares, Braun, Barques y Diaz, 2000) y $T$. loschachalerosum (Mares, Braun, Barques y Diaz, 2000)] y una especie fósil [T. cordubensis (Ameghino, 1888)] (Verzi et al., 2002; Díaz y Verzi, 2006). Sin embargo, el estatus taxonómico de $T$. aureus y $T$. loschachalerosum se encuentra en revisión (Agustina Ojeda com. pers. Marzo 2011).

Provincias comprendidas: San Juan, Mendoza, La Pampa, Neuquén y Chubut.

Localidades registradas en Mendoza: 15, 19, 43, 45, 47, 56, 62, 66, 69, 88. Figura 5.9 .

Descripción: cráneo de aspecto piriforme en vista dorsal, debido a la expansión lateral de la región timpánica; rostro corto; frontales divergentes; parietales globosos; bulas timpánicas siendo casi la mitad de la longitud del cráneo; arcos zigomáticos cortos; paladar estrecho y corto, debido a la extensión de la fosa mesopterigoidea hasta el borde anterior del M2; mandíbula corta, robusta y con sus ramas divergentes, recuerda a Ctenomys; proceso coronoides orientado hacia atrás, levemente por encima del cóndilo; incisivos anchos y de color naranja; incisivos superiores opistodontes; molares euhipsodontes; molariformes en forma de ' 8 ', comprimidos anteroposteriomente (De Santis et al., 1991).

Especies similares: Octomys mimax Thomas, 1920. T. barrerae se diferencia de $O$. mimax principalmente porque presenta un mayor desarrollo de bulas timpánicas, frontales divergentes, ramas mandibulares más divergentes y molariformes comprimidos anteroposteriormente (De Santis et al., 1991).

Observaciones: en Mendoza la mayor parte de los registros se encuentran en el desierto del Monte y menor medida en la estepa Patagónica. El registro de T. barrerae en Gruta del Indio, corresponde a un resto craneano y otro mandibular recuperados del piso de la cueva (ver Apéndice). No osbtante, la coloracion marrón y las marcas de raices de los 
especímenes podría indicar su asociación a un contexto arqueológico (ver tambien Holochilus sp.).

Orden Rodentia Bowdich, 1821.

Suborden Myomorpha Brandt, 1855.

Superfamilia Muroidea Illiger, 1811.

Familia Cricetidae Fischer, 1817.

Subfamilia Sigmodontinae Wagner, 1843.

Los roedores de la familia Cricetidae presentan distribución cosmopolita, siendo la subfamilia Sigmodontinae un grupo que tiene representación mayoritaria actual en Sudamérica (Reig, 1981).

Asimismo, los roedores sigmodontinos son uno de los grupos de mamíferos más diversos y complejos, constituyendo aproximadamente el $20 \%$ de las especies de este subcontinente (Pardiñas et al., 2002; D’Elía et al., 2007). Actualmente se reconocen nueve tribus dentro de los Sigmodontinae (Musser y Carleton, 2005; D'Elía et al., 2007), cinco de las cuales se distribuyen en la provincia de Mendoza (i.e., Akodontini, Abrotrichini, Oryzomyini, Phyllotini y Reithrodontini).

En cuanto al registro fósil, la región Pampeana exhibe los hallazgos de roedores sigmodontinos más antiguos de Argentina y Sudamérica, correspondientes al Mioceno más tardío (5,75 - 5,8 Ma; Montalvo et al., 2000; Montalvo, 2002; Verzi y Montalvo, 2008) y Plioceno inferior (5,33 Ma; Reig, 1978; Pardiñas y Tonni, 1998). Sin embargo, la antigüedad de estos roedores en Sudamérica es un tema que en la actualidad se encuentra en discusión (Prevosti y Pardiñas, 2009 y referencias allí citadas).

\subsubsection{Esquemas generales de roedores sigmodontinos}

En este acápite se detallará mediante ilustraciones las principales características cráneodentarias para el reconocimiento de los roedores sigmodontinos (Figuras 5.105.19). 


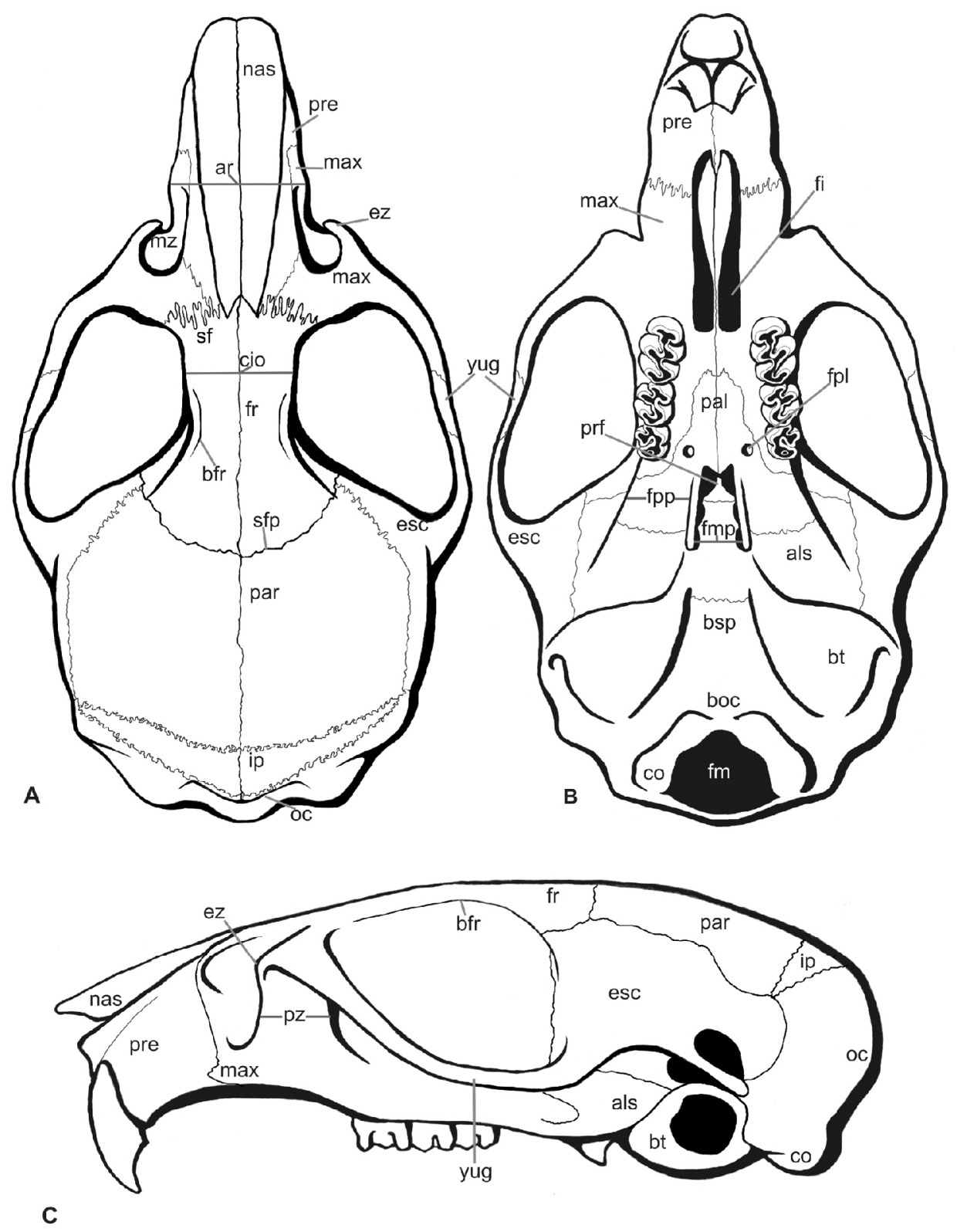

Figura 5.10. Vistas del cráneo. A: dorsal. B: ventral. C: lateral.

Referencias: als: aliesfenoides; ar: ancho del rostro; bfr: borde del frontal; boc: basioccipital; bsp: basiesfenoides; bt: bulla timpánica; cio: constricción interorbital; co: cóndilo occipital; esc: escamoso; ez: espina zigomática; fi: foramen incisivo; fm: foramen magnum; fmp: fosa mesopterigoidea; fpl: foramen palatal posterolateral; fpp: fosa parapterigoidea; fr: frontal; ip: interparietal; max: maxilar; mz: muesca zigomática; nas: nasales; oc: occipital; pal: palatino; par: parietal; pre: premaxilar; prf: presfenoides; pz: placa zigomática; sf: senos frontales; sfp: sutura frontoparietal; yug: yugal. 


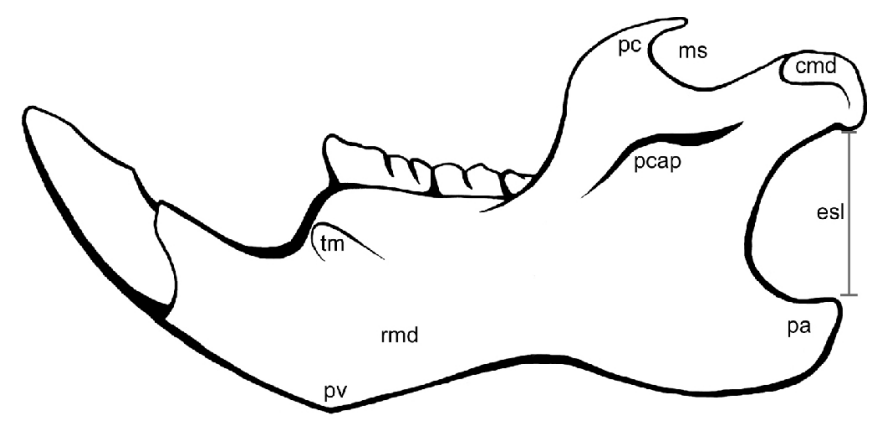

Figura 5.11. Mandíbula en vista labial.

Referencias: cmd: cóndilo mandibular; esl: escotadura semilunar; ms: muesca sigmoidea; pa: proceso angular; pc: proceso coronoides; pcap: proyección capsular; pv: proceso ventromedial; rmd: rama mandibular; tm: tubérculo maséterico.
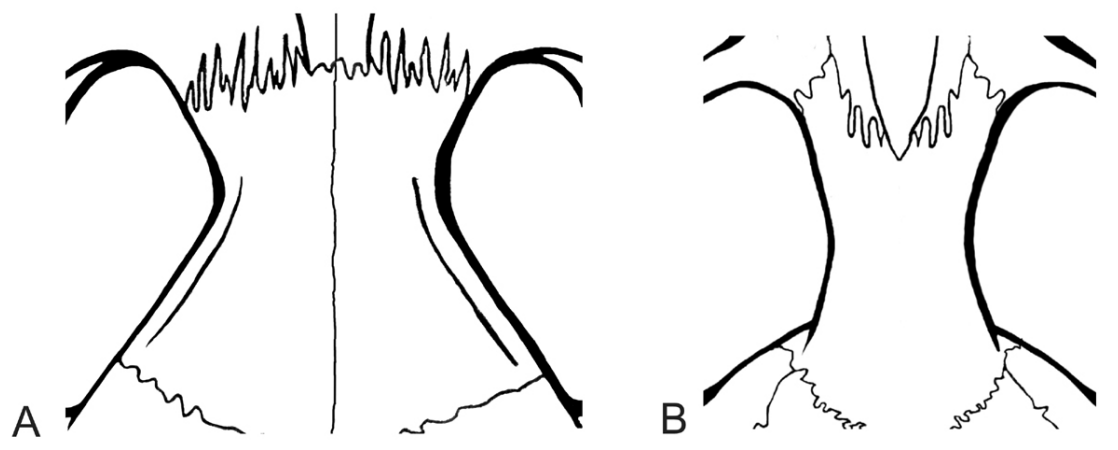

Figura 5.12. Bordes de la región supraorbital (sensu Steppan, 1995: figura 13: página 31). A: tipo divergente (Graomys griseoflavus). B: tipo paralelo (Phyllotis xanthopygus).

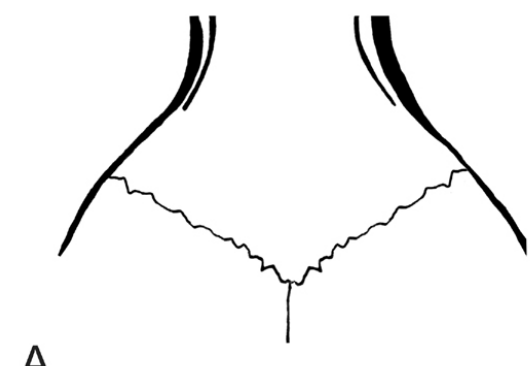

A

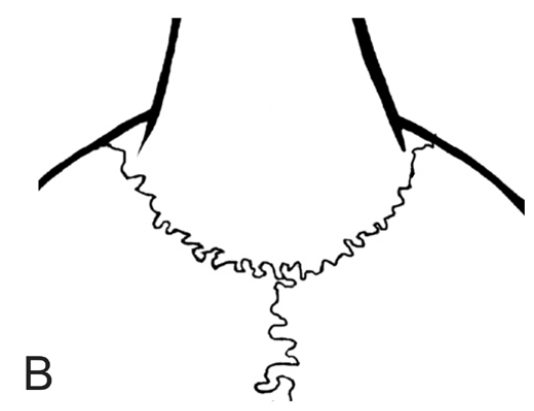

Figura 5.13. Tipos de sutura frontoparietal (sensu Steppan, 1995: figura 13: página 31). A: en forma de "V" (Reithrodon auritus). B: en forma de "U" (Phyllotis xanthopygus). 


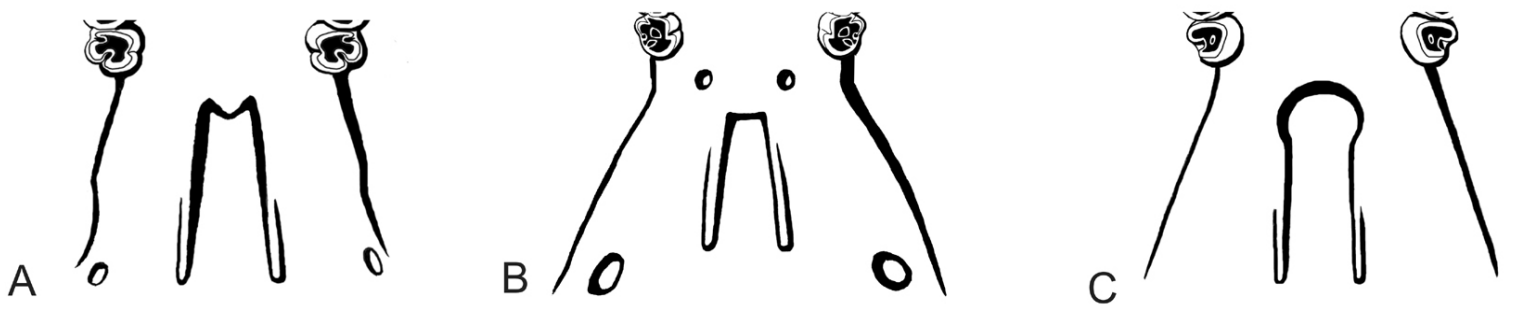

Figura 5.14. Tipos de borde anterior de la fosa mesopterigoidea. A: en forma de "M" (Akodon iniscatus). B: recto (Oligoryzomys longicaudatus). C: redondeados (Phyllotis xanthopygus).

Tipos de paladar sensu Hershkovitz (1962)

Paladar corto: cuando el borde anterior de la fosa mesopterigoidea (borde medio posterior de los palatinos) no se extiende detrás del plano posterior del tercer molar.

Paladar largo: cuando el borde anterior de la fosa mesopterigoidea (borde medio posterior de los palatinos) se extiende por detrás del plano posterior del tercer molar.

Paladar ancho: cuando la distancia entre los bordes internos de los primeros molares es mayor que la longitud del primer molar.

Paladar angosto: cuando la distancia entre los bordes internos de los primeros molares es menor que la longitud del primer molar.
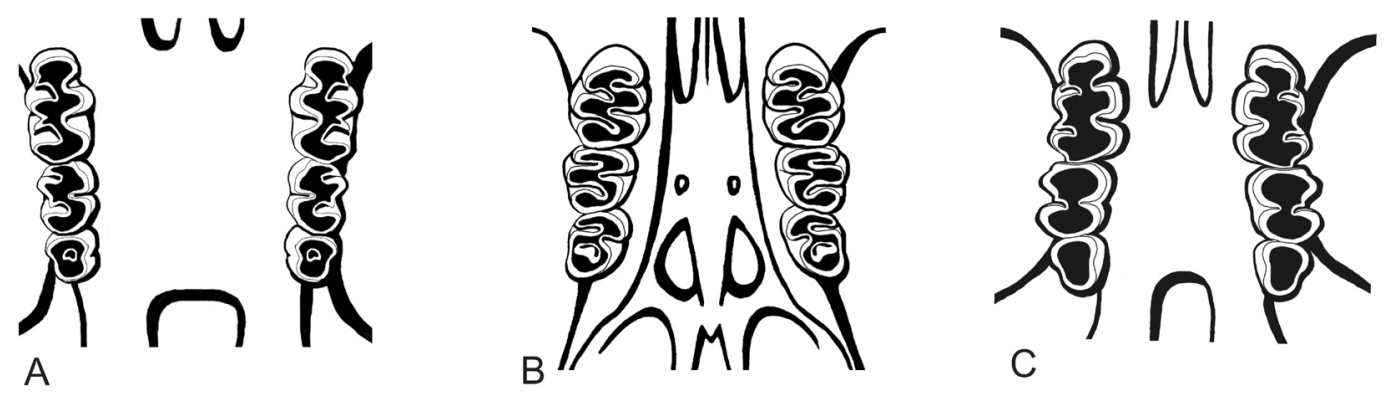

Figura 5.15. Tipos de paladar. A: ancho y largo (Abrothrix longipilis). B: angosto y largo (Reithrodon auritus). C: angosto y corto (Akodon spegazzinii). 

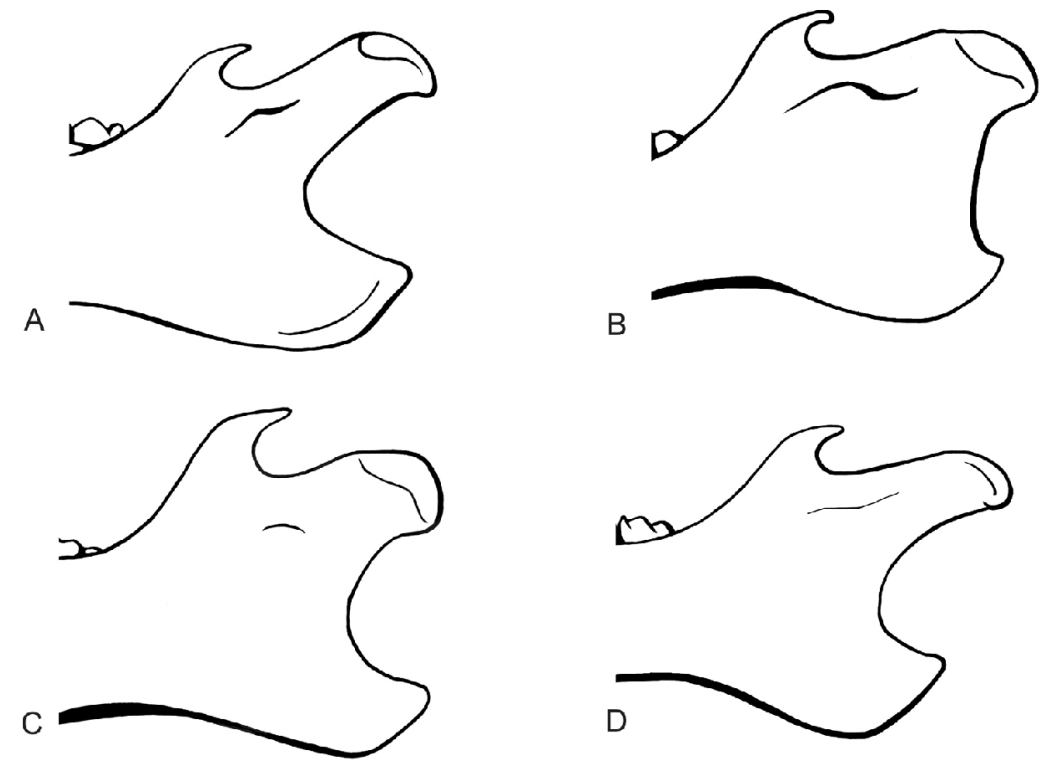

Figura 5.16. Tipos de escotadura semilunar. A: excavada (Reithrodon auritus). B: no excavada (Oligoryzomys flavescens). C: simétrica (Calomys musculinus). D: asimétrica (Eligmodontia spp.).

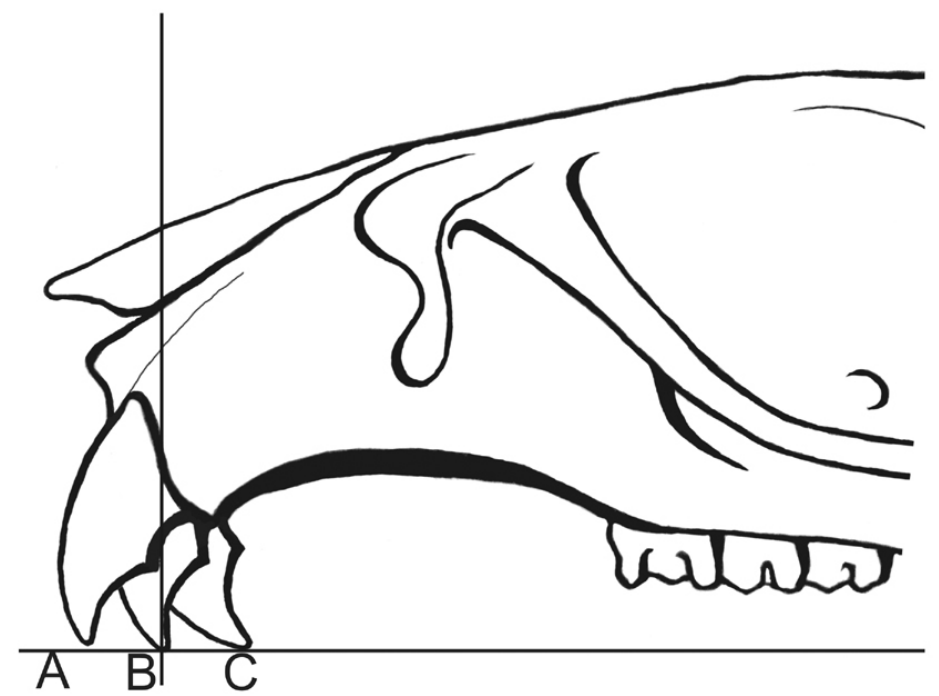

Figura 5.17. Orientación de los incisivos superiores (sensu Hershkovitz 1962: figura 19: página 103). A: proponte. B: ortodonte. C: opistodonte. 

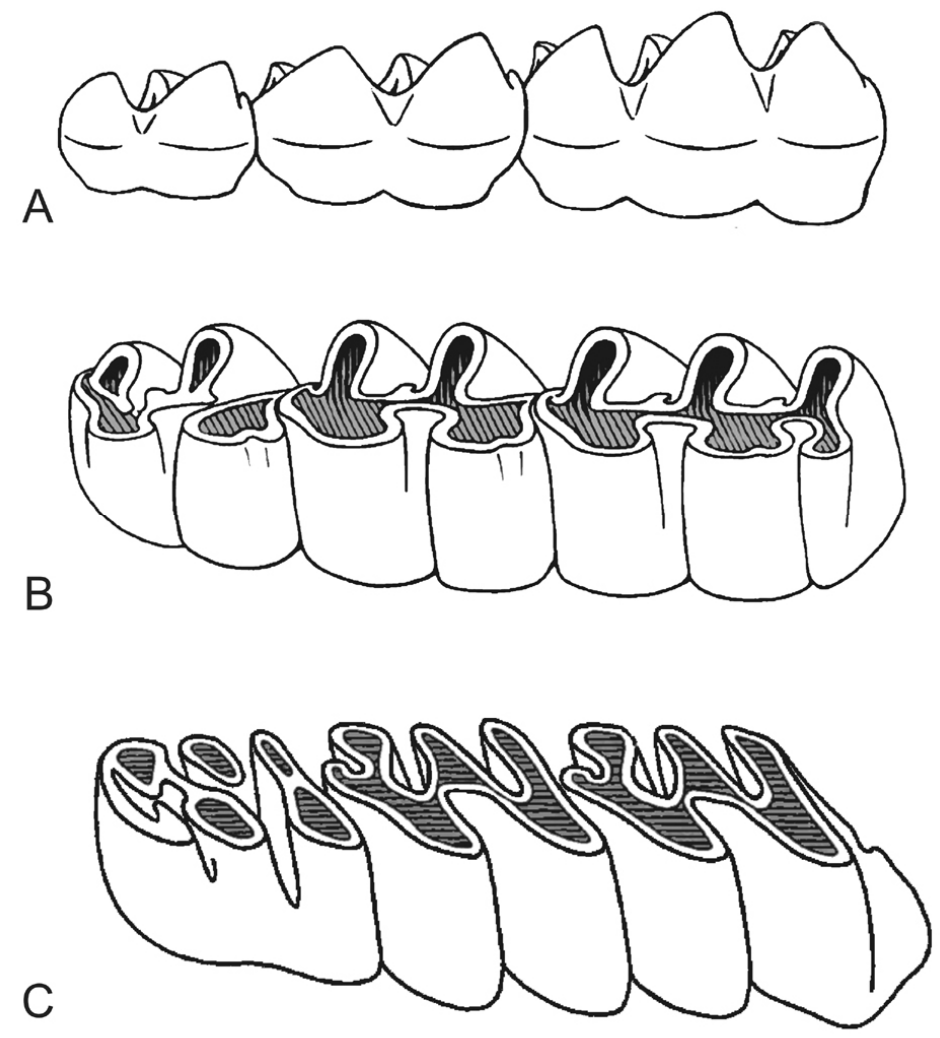

Figura 5.18. Tipos de coronas de los molares. Tomado de Hershkovitz (1962: figura 14: página 87). A: molares crestados. B: molares aterrazados. C: molares planos. 

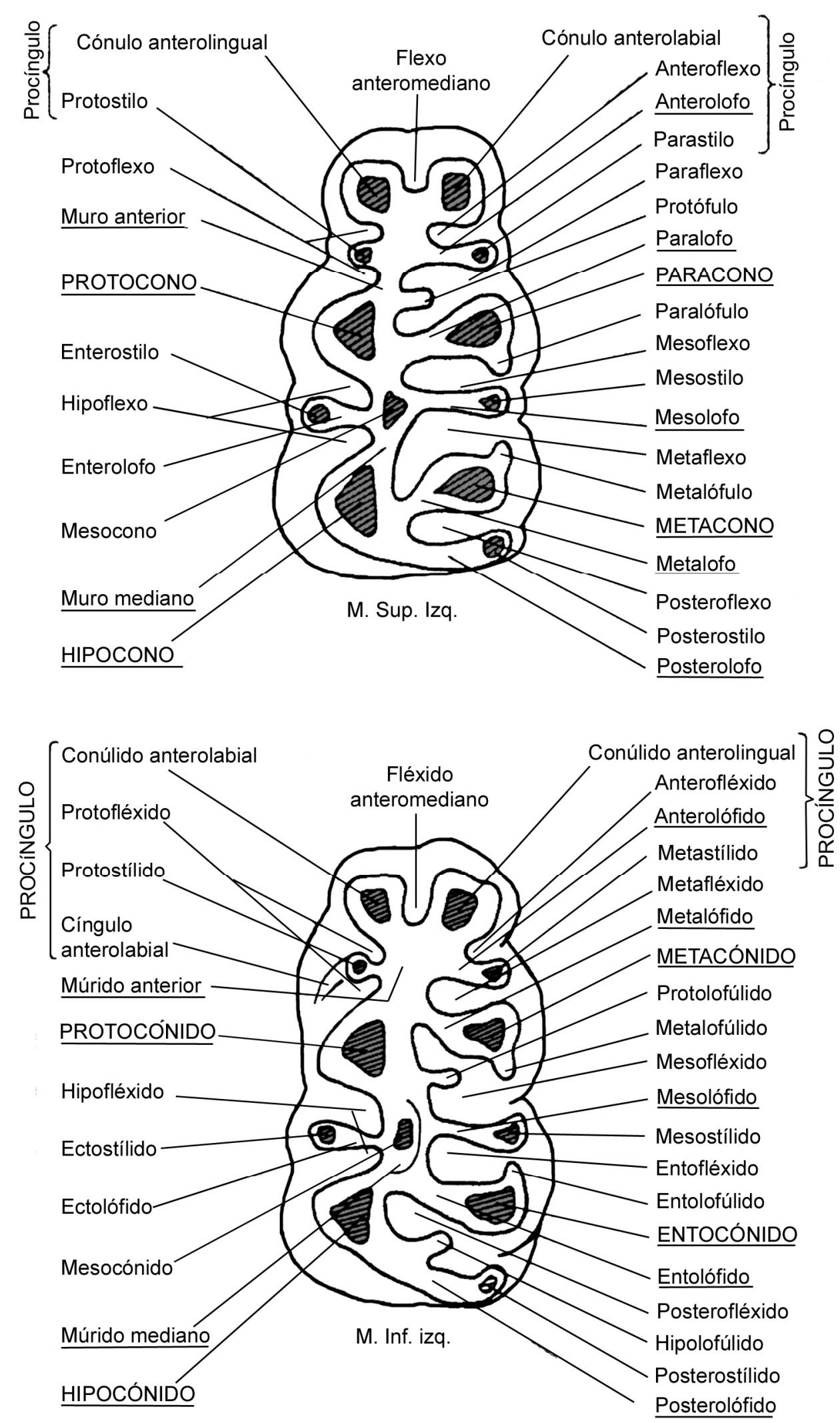

Figura 5.19. Esquema general idealizado de las superficies oclusales del primer molar superior e inferior de los roedores cricétidos. Traducido al español de (Reig 1977: figura 1: página 166). 


\section{Tribu Akodontini Vorontsov, 1959.}

Es una de las tribus más diversas, conformada por un grupo de sigmodontinos con morfología variada y ampliamente distribuidos por Sudamérica, a excepción de la Amazonía, ocupando múltiples ambientes en tierras altas y bajas (Pardiñas et al., 2002). Son roedores de pequeño y mediano tamaño (Reig, 1987). En Argentina se han registrado 10 géneros, de los cuales sólo uno se encuentra en Mendoza (Akodon).

En cuanto a la morfología cráneo-dentaria, los representantes de esta tribu, se distinguen por la siguiente combinación de caracteres: mesolofo y mesolófido reducidos o vestigiales cuando estan presentes, frecuentemente completa o parcialmente unidos al paralofo o entolófido, y sólo muestran un remanente terminal usualmente unido al mesostilo o mesostílido; posterolofo unido al metalofo, y posteroflexo usualmente obsoleto; placa zigomática poco o moderadamente desarrollada, nunca muy alta $\mathrm{y}$ fuertemente proyectada antes de la constricción interorbital; paladar amplio, corto a moderadamente largo; foramen incisivo generalmente largo, extendido posteriormente detrás del plano anterior del M1 (Reig, 1987).

Género Akodon Meyen, 1833.

Akodon molinae Contreras, 1968.

Localidad tipo: Vivero del Ministerio de Asuntos Agrarios, Laguna Chasicó, Buenos Aires.

Características generales: Akodon molinae (ratón rojizo) es un akodontino, nocturno y diurno, cursorial. Es omnívoro con tendencia a insectívoro y presenta un peso promedio de 31,8 g. Es una especie frecuente en ambientes xerófitos del desierto del Monte, Espinal y en el ecotono Monte y estepa Patagónica. Se encuentra asociado a estepas arbustivas y subarbustivas con dominancia de Larrea spp. y a pajonales de gramíneas cercanos a cuerpos de agua. En el desierto del Monte del centro-este de Mendoza encuentra su hábitat óptimo en el jarillal. Varios autores plantean su posible conespecificidad con A. dolores (véase Wittouck et al. 1995, Tiranti 1996, 1998, Braun et al. 2008), la cual presenta distribución en las provincias de San Luis y Córdoba, donde se encuentra la localidad tipo (Yacanto).

Provincias comprendidas: Buenos Aires, Córdoba, Chubut, La Pampa, Mendoza, Río Negro y San Luis. 
Localidades registradas en Mendoza: 15, 16, 35, 36, 38, 46, 51, 55, 57, 61, 76, 88, 92 , 93, 101. Figura 5.20.

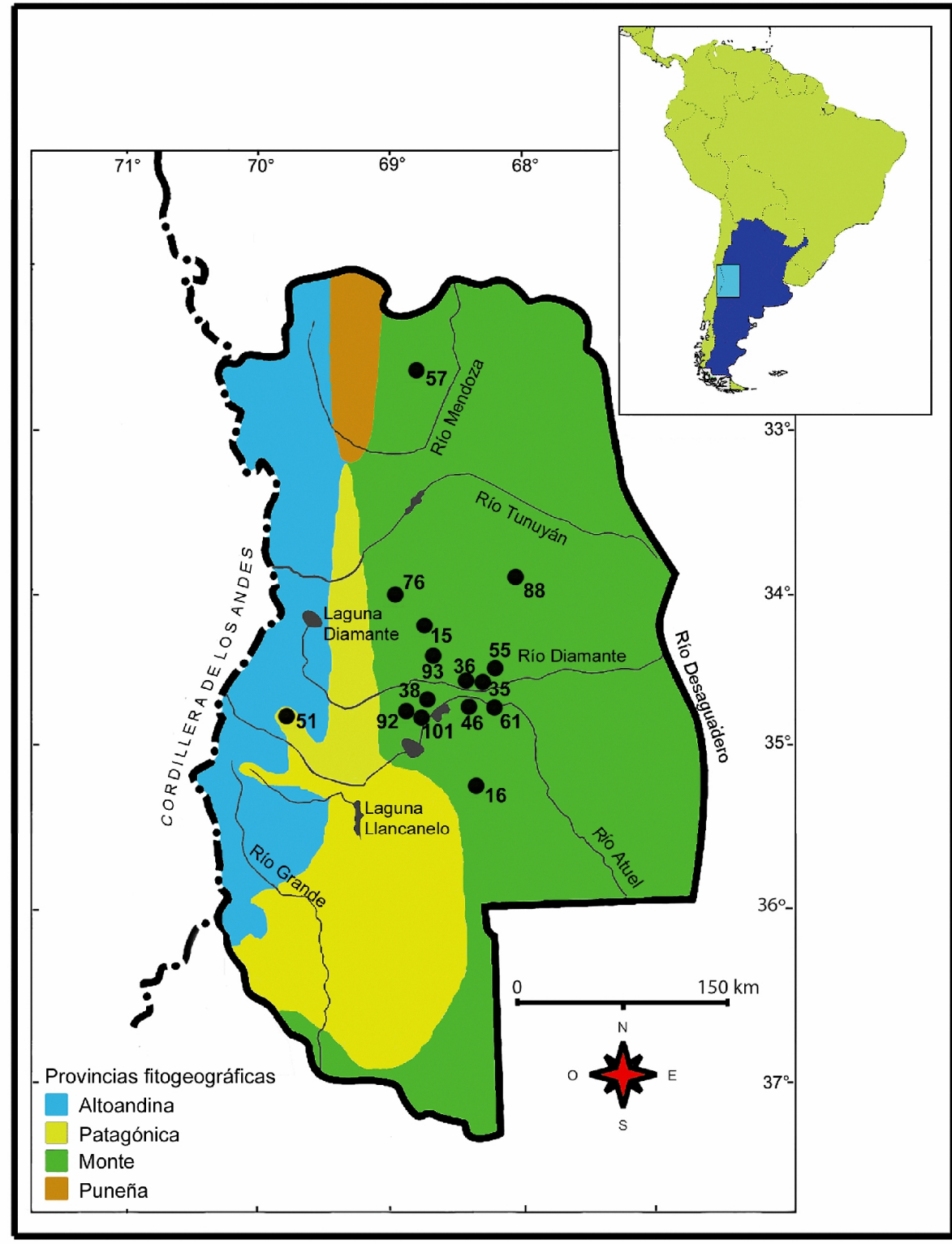

Figura 5.20. Localidades de registro de Akodon molinae en la provincia de Mendoza.

Descripción: cráneo robusto con perfil subabovedado en norma lateral; bordes de los frontales subcuadrados y paralelos; senos frontales inflados; constricción interorbital ancha y ligeramente más angosta que el ancho del rostro; sutura frontoparietal en forma de "U" abierta; muesca zigomática amplia y profunda; placa zigomática ancha, con el borde anterior convexo; foramen incisivo extendido posteriormente hasta el nivel del protocono y paracono del M1; paladar largo y ancho; fosa mesopterigoidea con bordes paralelos; borde anterior de la fosa mesopterigoidea subredondeado; amplitud de la fosa mesopterigoidea igual que la amplitud de la fosa parapterigoidea; proceso 
coronoides corto, de base robusta e inflexionado hacia atrás, por encima del cóndilo mandibular; escotadura semilunar excavada y casi simétrica; incisivos superiores ortodontes; series dentarias superiores paralelas; molares robustos con un marcado desarrollo del protostilo/ido; $\mathrm{M} 1 / \mathrm{m} 1$ con procíngulo dividido por un flexo/ido anteromediano. Figura 5.21.
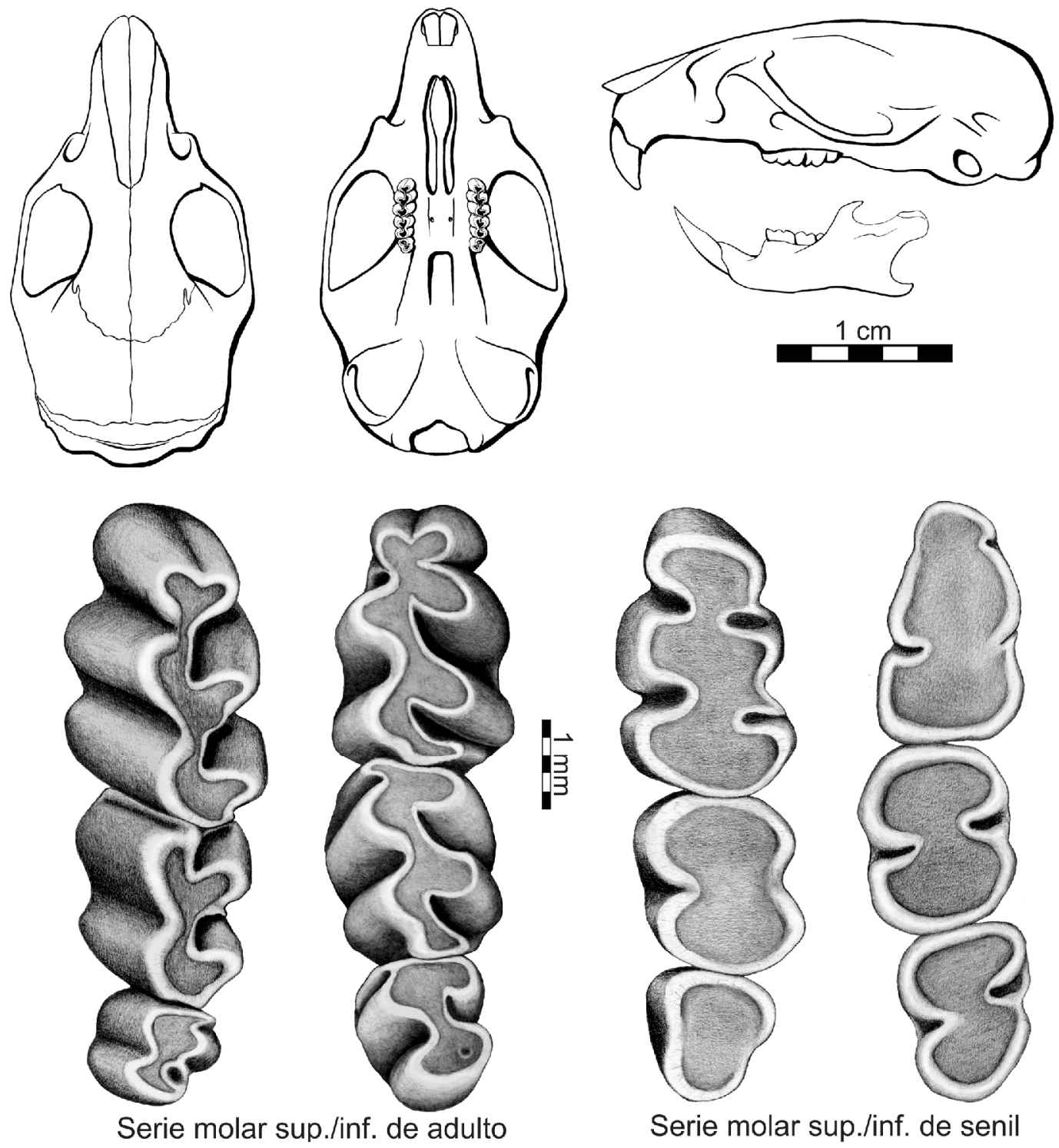

Serie molar sup./inf. de senil

Figura 5.21. Esquemas cráneo-dentarios de Akodon molinae.

Especies similares: como parte del grupo varius de Akodon propuesto por Myers (1989), presenta semejanzas con los integrantes de dicho grupo (e.g., A. dolores, A. neocenus, $A$. varius, $A$. simulator, A. toba).

Observaciones: en Mendoza es abundante en el desierto del Monte, con un registro aislado en la estepa Patagónica. 
Bibliografía consultada: Contreras, 1968; Contreras y Rosi, 1980a; Massoia, 1981a; Myers, 1989; Redford y Eisenberg, 1992; Wittouck et al., 1995; Tiranti, 1996, 1998, Massoia et al., 1997; Braun et al., 2000; Pardiñas et al., 2003, 2006a; Corbalán, 2004; Corbalán y Ojeda, 2004, 2005; Corbalán et al., 2006; Nabte et al., 2006, 2009; Braun et al., 2008; Fernández et al., 2008, 2009b; García-Esponda et al., 2009, Ojeda y Tabeni, 2009; Fernández, 2010.

Akodon spegazzinii Thomas, 1897.

Localidad Tipo: Lower Cachi, Salta.

Características generales: Akodon spegazzinii es un akodontino nocturno, cursorial y cuadrúpedo. Es omnívoro con tendencia a insectívoro y presenta un peso promedio de 25 g. Su distribución y dominio ecológico van desde Salta hasta el sur de Mendoza, con un rango altitudinal entre 400 y alrededor de $3.500 \mathrm{~m}$, ocupando ambientes áridos de la estepa Patagónica, desierto del Monte, Puna y altos Andes, hasta áreas selváticas de las Yungas y en ecotonos con el bosque xerófilo Chaqueño (e.g., Jayat, 2009; Fernández, 2010; Jayat et al., 2010; Pardiñas et al., 2011c). Numerosos autores consideran a Akodon tucumanensis, Akodon alterus y Akodon oenos como subespecies de A. spegazzinii. Para el caso de A. oenos, por tratarse de una especie descripta para la provincia de Mendoza es necesario realizar un comentario detallado. Este akodontino fue descripto por Braun et al. (2000) sobre la base de ejemplares clasificados por Contreras y Rosi como "Akodon minoprioi" (in schedis) y al no ser formalmente publicado pasó a ser un nomen nudum (Galliari et al., 1996). Asimismo, los ejemplares de A. varius neocenus referidos en Bianchi y Contreras (1968), Bianchi et al. (1971), Contreras y Rosi (1980) y Apfelbaum y Reig (1989) han quedado en interdicto con la descripción de A. oenos de Braun et al. (2000). Recientes investigaciones realizadas por Pardiñas et al. (2011c), en base a extensas comparaciones morfológicas y moleculares, plantean la inclusión de A. oenos dentro del grupo boliviensis de Akodon y como sinónimo junior de A. spegazzinii. Los escasos registros actuales en Mendoza, muestran que se distribuye desde el centro-norte, en ambientes áridos del desierto del Monte y Puna altamente modificados por viñedos y olivares (La Pega 32 $48^{\prime} \mathrm{S}, 62^{\circ} 48^{\prime} \mathrm{O}$, localidad tipo de A. oenos, Braun et al., 2000; $2 \mathrm{~km}$ al sur de Villavicencio 32³1' S, 68 59' O, Braun et al., 2000; Puesto de Lima 32 $54^{\prime}$ S, 6901' O, Contreras y Rosi, 1980b), hasta el sur-oeste en un humedal del piedemonte de la región volcánica de la 
Payunia, incluida en una matriz semiárida de la estepa Patagónica (Reserva Natural Llancanelo 3538' S, 69¹1' O; Pardiñas et al., 2011c).

Provincias comprendidas: Salta, Tucumán, Catamarca, La Rioja, Mendoza.

Localidades registradas en Mendoza: 2, 57, 82, 89. Figura 5.22.

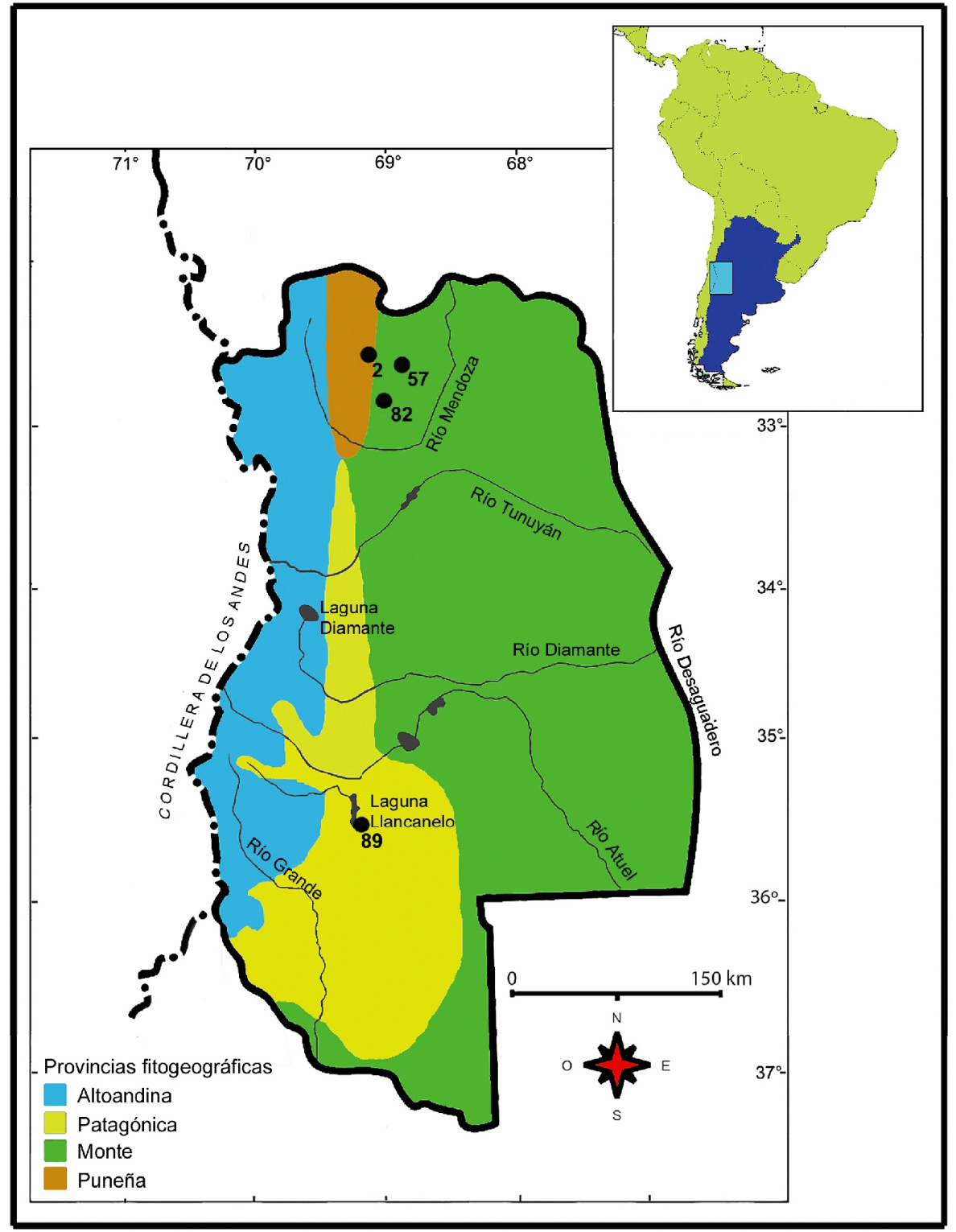

Figura 5.22. Localidades de registro de Akodon spegazzinii en la provincia de Mendoza.

Descripción: cráneo con perfil abovedado en norma lateral; bordes de los frontales redondeados y subparalelos; constricción interorbital igual al ancho del rostro; sutura frontoparietal en forma de "U" abierta; muesca zigomática moderadamente amplia y profunda; placa zigomática moderadamente ancha y con el borde anterior recto; foramen incisivo extendido posteriormente hasta el nivel del protocono y paracono del MI; paladar corto y angosto; fosa mesopterigoidea con bordes paralelos; borde anterior 
de la fosa mesopterigoidea redondeado; amplitud de la fosa mesopterigoidea igual que la amplitud de la fosa parapterigoidea; proceso coronoides corto, de base robusta e inflexionado hacia atrás, por encima del cóndilo mandibular; rama mandibular delgada; escotadura semilunar poco excavada y asimétrica; proyección capsular conspicua y por debajo de la muesca sigmoidea; incisivos superiores ortodontes; series dentarias superiores paralelas; molares robustos; $\mathrm{M} 1 / \mathrm{m} 1$ con procíngulo con flexo/ido anteromediano que se vuelve menos obvio y obsoleto con la edad; paraestilo, anterolofo, mesolofo, mesoestilo y cónulo anterolabial presentes; M3 presenta la mitad de longitud del M2; m1 con cúspides de tamaños similares y dispuestas diagonalmente; conúlido anterolabial presente y se vuelve obsoleto en individuos seniles; $\mathrm{m} 3$ con protocónidos, metacónidos e hipocónidos bien desarrollados. Figura 5.23.
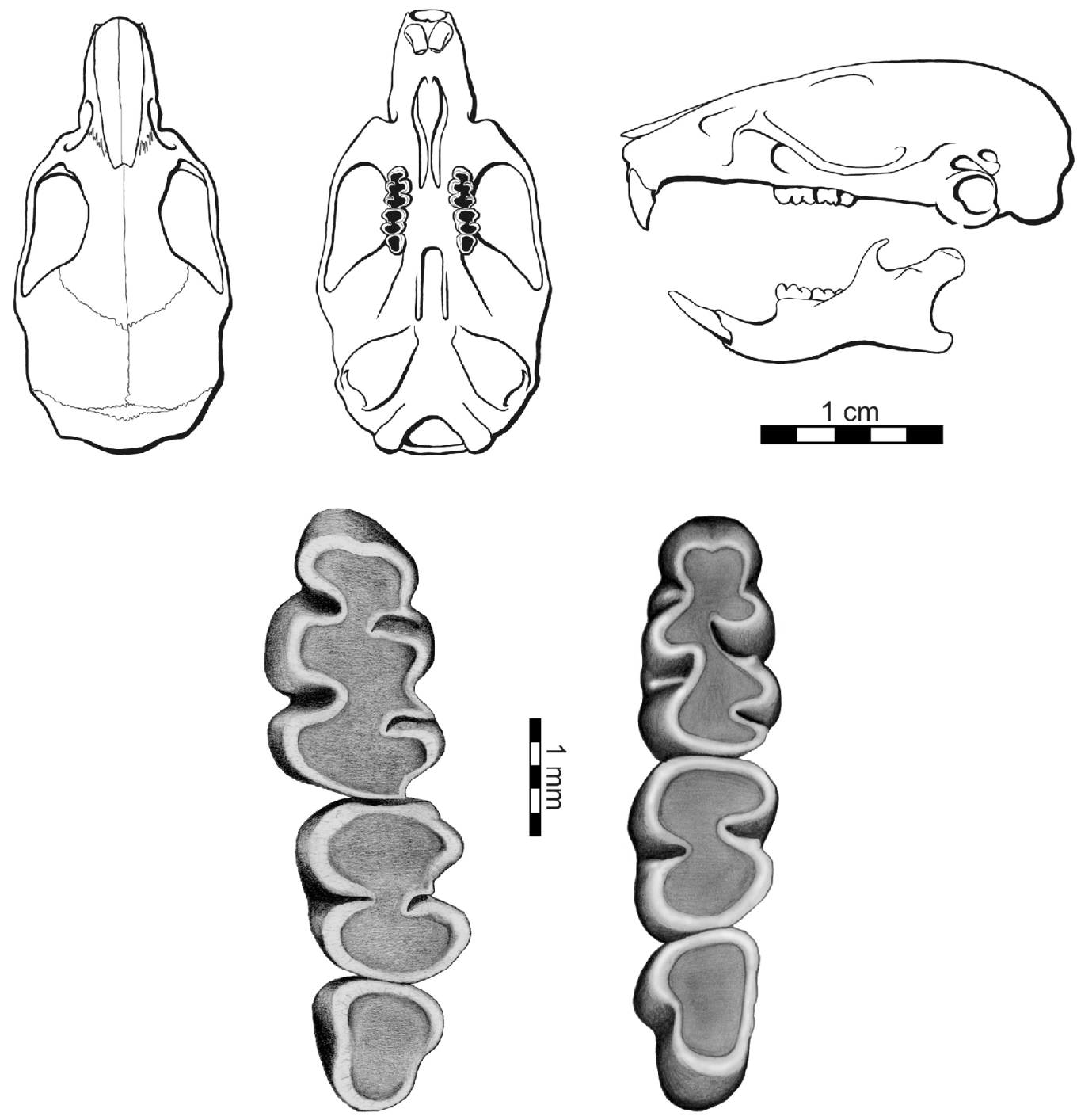

Serie molar superior

Serie molar inferior

Figura 5.23. Esquemas cráneo-dentarios de Akodon spegazzinii. 
Observaciones: en Mendoza habita en simpatría con $A$. molinae, aunque aparentemente podría asociarce también a ambientes más húmedos.

Especies similares: morfológicamente se acerca más a las especies que conforman el grupo de Akodon boliviensis (e.g., A. boliviensis, A. caenosus, A. sylvanus y A. polopi), sin distribución en Mendoza.

Bibliografía consultada: Contreras y Rosi, 1980b; Galliari et al., 1996; Braun et al., 2000; Pardiñas et al., 2006a; Jayat, 2009; Ojeda y Tabeni, 2009; Pardiñas, 2009; Jayat et al., 2010; Pardiñas et al., 2011c; Fernández, 2010.

Akodon iniscatus Thomas, 1919.

Localidad tipo: restringida a Estancia Valle Huemules, en el valle homónimo (Río Senguer, Chubut, Argentina).

Características generales: Akodon iniscatus (ratón patagónico) es un akodontino crepuscular y nocturno; cursorial. Es herbívoro y presenta un peso promedio de $21 \mathrm{~g}$. Si bien A. iniscatus presenta una amplia distribución en Patagonia, ocupando preferentemente ambientes de la estepa Patagónica y del desierto del Monte, en Buenos Aires, el avance de los agroecosistemas y la consecuente pérdida de hábitats naturales, en especial de los arbustivos, habrían contribuido al retroceso de poblaciones de esta especie. El estatus taxonómico de A. iniscatus se encuentra en discusión, recientemente Smith y Patton (2007) en base a estudios moleculares (i.e., variación del gen mitocondrial citocromo $b$ ) plantean la posible conespecificidad de A. iniscatus y $A$. nucus Thomas y Saint Leger, 1926 (ver Pardiñas, 2009 para una discusión detallada). Provincias comprendidas: Mendoza, Buenos Aires, La Pampa, Río Negro, Chubut, San Cruz.

Localidades registradas en Mendoza: 45. Figura 5.24. 


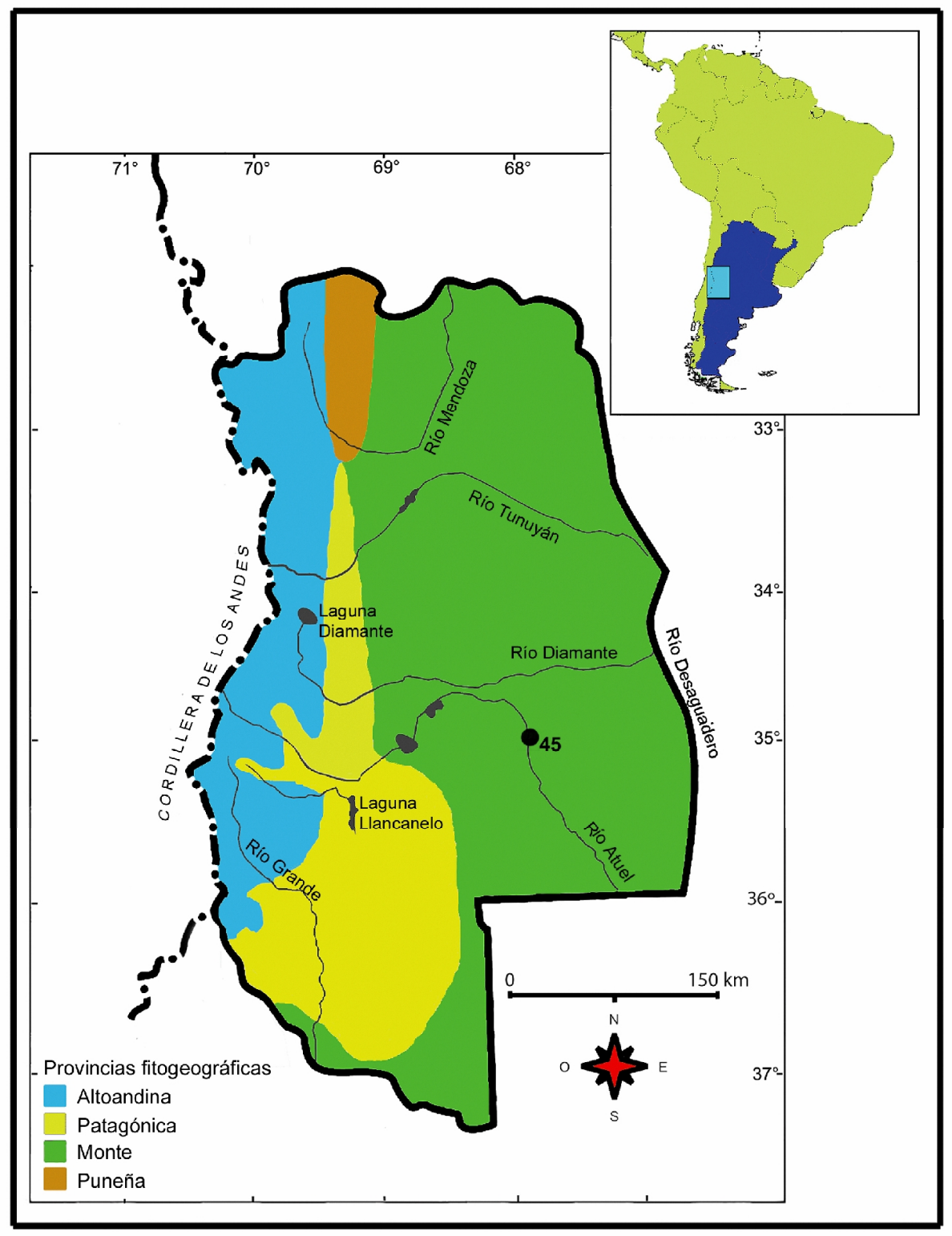

Figura 5.24. Localidades de registro de Akodon iniscatus en la provincia de Mendoza.

Descripción: cráneo con perfil abovedado en norma lateral; bordes de los frontales redondeados y moderadamente divergentes; senos frontales inflados; constricción interorbital ligeramente más angosta que el ancho del rostro, el cual es corto, de base ancha y extremo aguzado; sutura frontoparietal en forma de "U" bien abierta; placa zigomática moderadamente ancha y con el borde anterior recto; forámenes incisivos extendidos posteriormente hasta el nivel del hipocono del M1; paladar largo y ancho; fosa mesopterigoidea con bordes subparalelos; borde anterior de la fosa mesopterigoidea en forma de " $\mathrm{M}$ "; amplitud de la fosa mesopterigoidea levemente menor que la amplitud de la fosa parapterigoidea; proceso coronoides de base ancha e inflexionado hacia atrás, por encima del cóndilo mandibular; escotadura semilunar 
moderadamente excavada y asimétrica; sin tubérculo maséterico; proyección capsular inconspicua; incisivos superiores opistodontes; fórmula alveolar: serie dentaria inferior 3,2,2; M1/m1 están divididos por un flexo/ido anteromediano moderado que determina dos cónulos/idos, el labial mayor que el lingual (rasgo compartido con muchas especies de Akodon); M1 con parastilo presente; m1 con protostílido bien marcado. Figura 5.25.
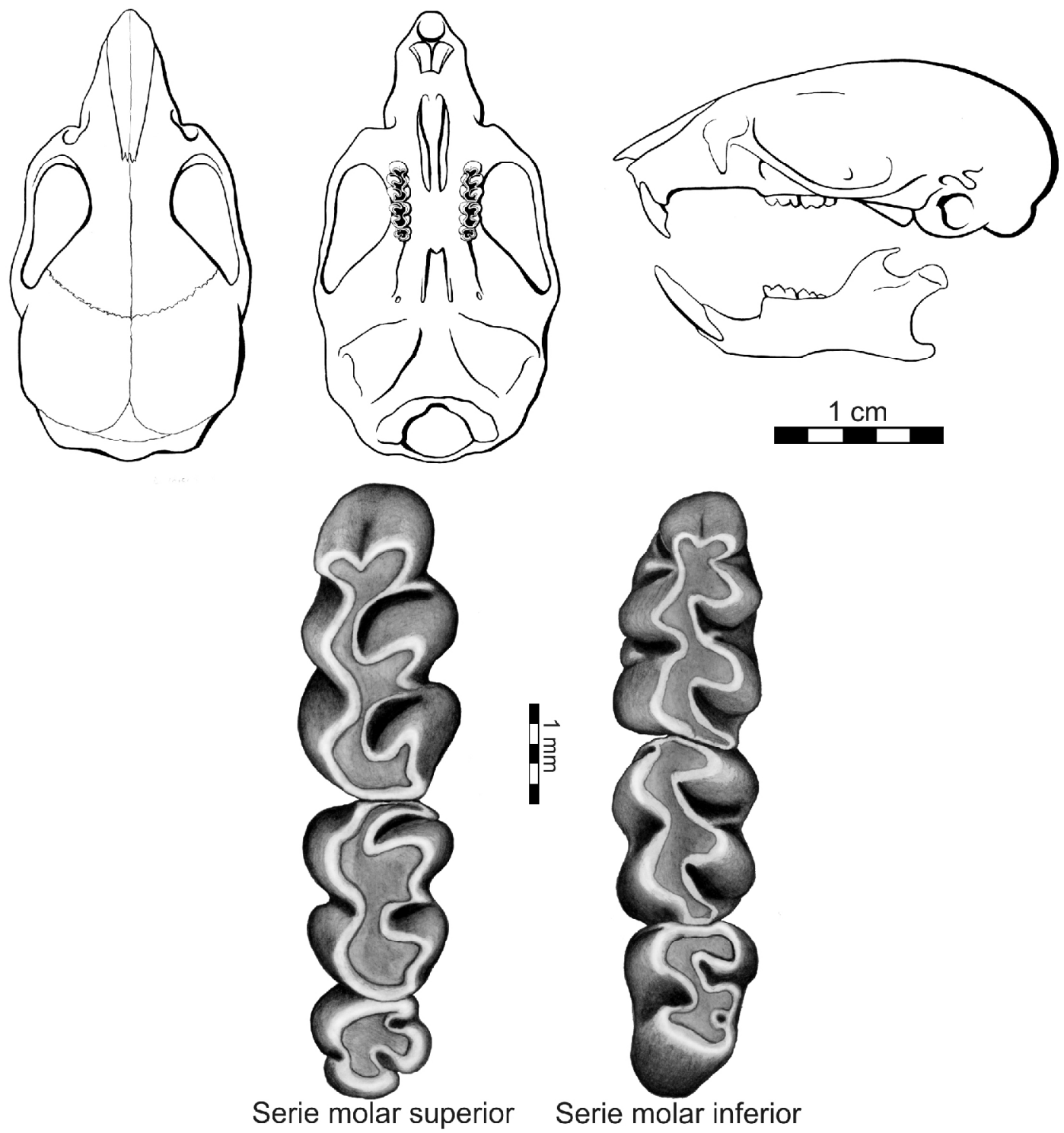

Figura 5.25. Esquemas cráneo-dentarios de Akodon iniscatus.

Especies similares: Abrothrix olivaceus. La presencia del fléxido anteromediano en el $\mathrm{m} 1 \mathrm{y}$ dos raíces en el alvéolo del $\mathrm{m} 2$ de $A$. iniscatus, son rasgos diagnósticos para diferenciar ambas especies. 
Observaciones: el único registro documentado de $A$. iniscatus en la provincia de Mendoza se encuentra en el desierto del Monte. Massoia (1994) determinó a esta especie con dudas (indicada con “?”) para Laguna de La Niña Encantada (Localidad 50). Rapoport et al. (2001) mencionan a A. iniscatus para una localidad ubicada en el límite sur de Mendoza (Cerro la Teta), sin embargo no detallan como obtuvieron el material, ni en donde se encuentra depositado, por lo que su presencia en el lugar necesita su confirmación. Por otra parte, es interesante destacar el registro de $A$. iniscatus en la provincia de La Pampa, muy cerca del límite con Mendoza (Tiranti, 1989). Finalmente, diversas localidades de A. nucus a lo largo de la provincia del Neuquén hasta su límite norte (véase Pardiñas, 2009), sugieren su presencia en el extremo sur de la provincia de Mendoza.

Bibliografía consultada: Thomas, 1919; Cabrera, 1961; Roig, 1965; Massoia, 1981a; Tiranti, 1989; Massoia et al. 1994; Saba et al., 1995; Pardiñas y Galliari, 1999; Rapoport et al., 2001; Pardiñas et al., 2003, 2004, 2006a, 2009; Pardiñas, 2009; Udrizar Sauthier y Pardiñas, 2006; Smith y Patton, 2007; Udrizar Sauthier, 2009.

Tribu Abrotrichini D'Elía, Pardiñas, Teta y Patton, 2007.

Recientemente D'Elía et al. (2007) reconocieron y describieron formalmente una nueva tribu de roedores sigmodontinos. Esta tribu corresponde a un grupo de roedores que tradicionalmente se ubicaba dentro de los Akodontini (Reig, 1987; entre otros), representados por una baja diversidad de taxones de distribución esencialmente andina y patagónica (Pardiñas et al., 2002; D’Elía et al. 2007). Son roedores de pequeño y mediano tamaño (aproximadamente entre 20g y 75g) (D'Elía et al., 2007). En Argentina se han registrado cuatro géneros, de los cuales dos se hallan en Mendoza (Abrothrix y Chelemys).

En cuanto a la morfología cráneo-dentaria, los representantes de esta tribu se distinguen por la siguiente combinación de caracteres: nasales y premaxilares ligeramente proyectados hacia los incisivos; nasales tan largos como los frontales; placa zigomática típicamente angosta, con el borde superior reducido o ausente; paladar largo; borde anterior de la fosa mesopterigoidea recto; rama mandibular generalmente grácil y elongada (con la excepción de Chelemys); incisivos superiores amplios y no acanalados; molares superiores e inferiores con cúspides labiales y linguales dispuestas en forma opuesta o ligeramente alternadas de a pares; $\mathrm{M} 1 / \mathrm{m} 1$ con procíngulo reducido en forma 
de abanico y anteroflexo superficial o ausente; M1 con flexo anteromediano muy superficial u obsoleto; paraflexo y metaflexo fuertemente orientado transversalmente o hacia atrás; paracono globoso y orientado hacia adelante; M3 reducido, de contorno subcilíndrico (con la excepción de Chelemys) y con un anillo interno de esmalte como una foseta (D'Elía et al., 2007).

Género Abrothrix Waterhouse, 1837.

Abrothrix longipilis (Waterhouse, 1837).

Localidad tipo: Coquimbo, Chile.

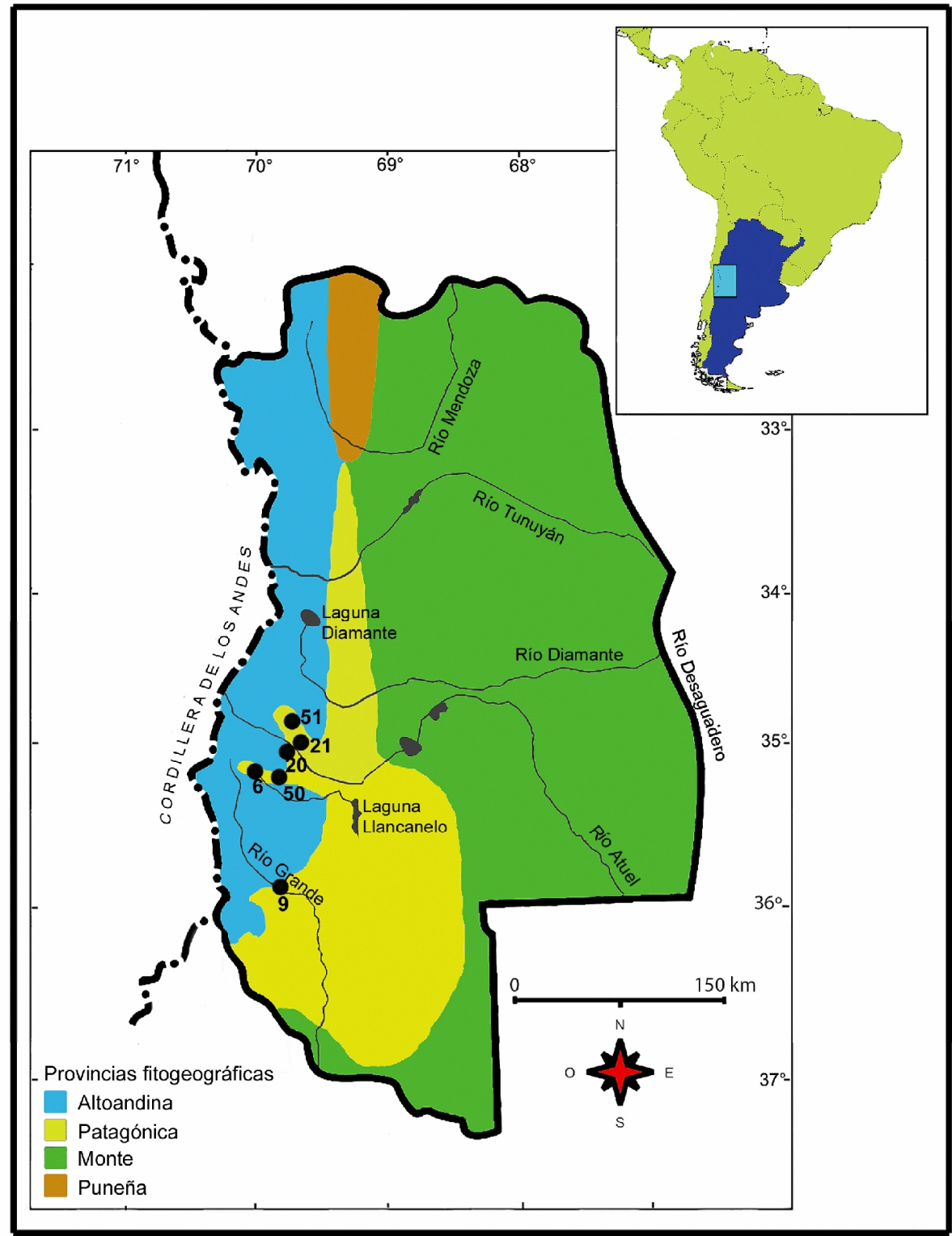

Figura 5.26. Localidades de registro de Abrothrix longipilis en la provincia de Mendoza. 
Características generales: Abrothrix longipilis (ratón de pelos largos) es un abrotriquino diurno y nocturno, cursorial, construye madrigueras y es buen trepador. Es frugívoro y omnívoro y presenta un peso promedio de $30 \mathrm{~g}$. Se encuentra en gran variedad de microambientes desde bosques y estepas patagónicas con limitada humedad y en vegas cordilleranas. Gallardo et al. (1988) y Spotorno et al. (2000) en base a evidencias cariotípicas y moleculares sugieren su conespecificidad con Abrothrix sanborni Osgood, 1943. Lesa et al. (2010) en base a secuencias de ADN mitocondrial gen citocromo $b$ observaron que las poblaciones de $A$. longipilis presentaron divergencias respecto de las poblaciones de Chile Central y Patagónicas-Fueguinas. Las poblaciones de esta especie se expandieron posteriormente al Último Máximo Glaciar y las correspondientes a latitudes mayores posiblemente fueron más susceptibles a los cambios climáticos (Lesa et al., 2010).

Provincias comprendidas: Chubut, Mendoza, Neuquén, Río Negro, Santa Cruz y Tierra del Fuego.

Localidades registradas en Mendoza: 6, 9, 20, 21, 50, 51. Figura 5.26.

Descripción: cráneo alargado, con perfil subaplanado en norma lateral; nasales y premaxilares alargados; constricción interorbital ligeramente mayor que el ancho del rostro; bordes de los frontales moderadamente redondeados y subparalelos; sutura frontoparietal en forma de "U" bien abierta; placa zigomática angosta y alta, con el borde anterior recto y vertical; foramen incisivo extendido posteriormente hasta el nivel del procíngulo del M1; paladar largo y ancho; fosa mesopterigoidea con bordes paralelos; borde anterior de la fosa mesopterigoidea ancho y casi recto; amplitud de la fosa mesopterigoidea igual que la amplitud de la fosa parapterigoidea; mandibula delgada, moderadamente baja y alargada, con una curvatura marcada en la parte media inferior de la rama mandibular; proceso coronoides largo e inflexionado hacia atrás, por encima del cóndilo mandibular; proyección capsular inconspicua; escotadura semilunar asimétrica; incisivos robustos; incisivos superiores ortodontes; series dentarias superiores paralelas; fórmula alveolar: serie dentaria superior 4,3,3 / serie dentaria inferior 2-3,2,2; molares robustos; M1/m1 con procíngulo corto, en forma de abanico y con anteroflexo/ido superficial o ausente; M1 con protoflexo amplio y moderadamente orientado hacia el centro del diente; M1 con paraflexo y metaflexo orientado hacia atrás; M3 reducido, de contorno subcilíndrico y con un anillo interno de esmalte. Figura 5.27. 
Especies similares: Abrothrix olivaceus. Una diferencia importante es que A. longipilis es de mayor tamaño y con molares más grandes que A. olivaceus. Asimismo, la forma baja y alargada de la mandíbula de $A$. longipilis es un rasgo diagnóstico para diferenciar ambas especies.
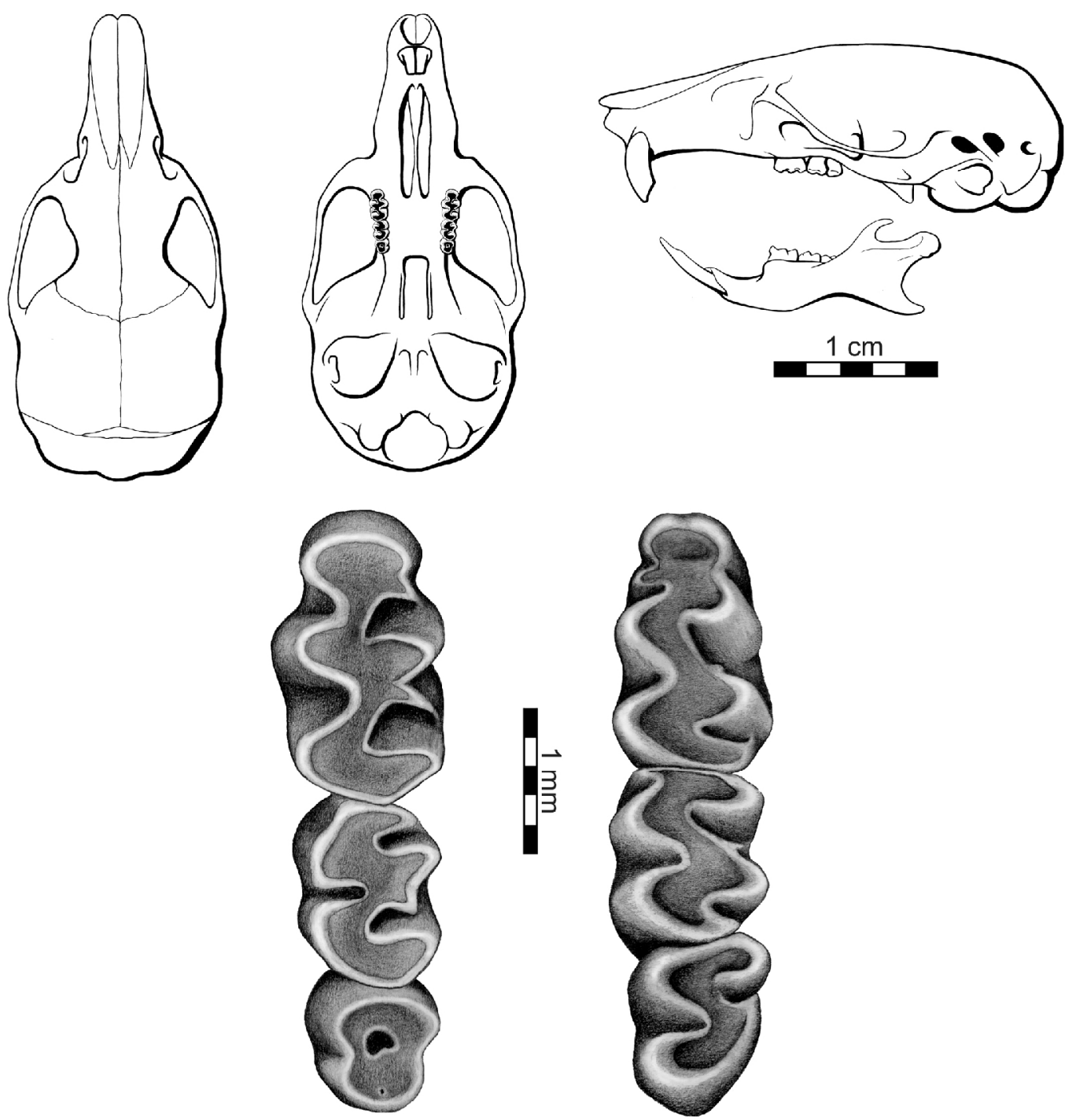

Serie molar superior

Serie molar inferior

Figura 5.27. Esquemas cráneo-dentarios de Abrothrix longipilis.

Observaciones: en Mendoza también está documentado para áreas rocosas con arbustos dispersos y vegas, enmarcadas dento de estepas Patagónicas de elevada altitud de la parte sudoeste de la provincia.

Bibliografía consultada: Osgood, 1943; Massoia, 1981a; Pearson y Pearson, 1982; Pearson, 1983, 1995, Reig, 1987; Gallardo et al., 1988; Monjeau, 1989; Massoia et al., 
1994; Spotorno et al., 2000; Ortiz et al., 2004; Nabte et al., 2006; Teta et al., 2006; D'Elía et al., 2007; Pardiñas et al., 2008; Fernández et al., 2009a, 2009b; Udrizar Sauthier, 2009; Lesa et al., 2010.

Abrothrix olivaceus (Waterhouse, 1837).

Localidad tipo: Valparaíso, Chile.

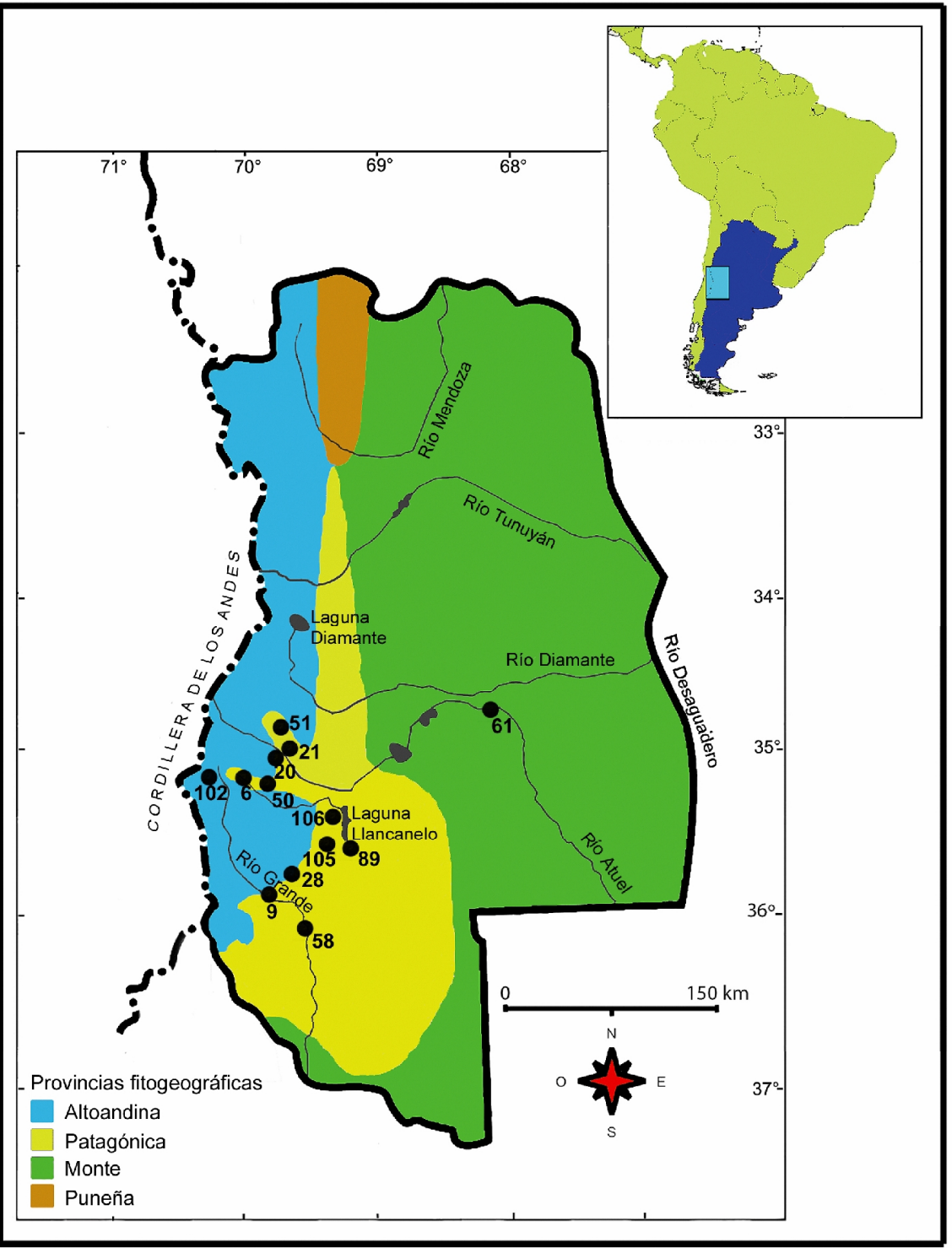

Figura 5.28. Localidades de registro de Abrothrix olivaceus en la provincia de Mendoza.

Características generales: Abrothrix olivaceus (ratón oliváceo) es un abrotriquino nocturno y diurno, cursorial y es buen trepador. Es omnívoro y presenta un peso promedio de $21 \mathrm{~g}$. Está asociado a una amplia variedad de hábitats, incluyendo matorrales semi-áridos, estepas arbustivas, pastizales, bosque denso de Nothofagus spp. 
y vegas cordilleranas. Es frecuente en la estepa patagónica, siendo abundante en áreas disturbadas por el sobrepastoreo (e.g., Cueto et al., 2008). Pearson y Smith (1999) y Smith et al. (2001) han incluido en la sinonimia de esta especie a Abrothrix mansoensis De Santis y Justo, 1980 y a A. xanthorhinus (Waterhouse, 1837). Abud (2011) a partir de la secuencias de ADN mitocondrial gen citocromo $b$ pudo diferenciar cuatro clados de A. olivaceus: Norte de Chile, Patagonia continental, Mendoza y Tierra del Fuego.

Provincias comprendidas: Chubut, Mendoza, Neuquén, Río Negro, Santa Cruz y Tierra del Fuego.

Localidades registradas en Mendoza: 6, 9, 20, 21, 28, 50, 51, 58, 61, 89, 102, 105, 106. Figura 5.28.

Descripción: cráneo con perfil abovedado en norma lateral; nasales alargados; bordes de los frontales moderadamente redondeados y subparalelos; senos frontales inflados; constricción interorbital igual que el ancho del rostro; sutura frontoparietal en forma de "U" bien abierta; placa zigomática angosta y con el borde anterior recto; foramen incisivo extendido posteriormente hasta el nivel del protocono y paracono del M1; paladar ancho y moderadamente corto; fosa mesopterigoidea con bordes paralelos; borde anterior de la fosa mesopterigoidea redondeada; amplitud de la fosa mesopterigoidea igual que la amplitud de la fosa parapterigoidea; proceso coronoides inflexionado hacia atrás y por encima del cóndilo mandibular; escotadura semilunar excavada y simétrica; sin tubérculo masetérico; proyección capsular inconspicua; incisivos superiores ortodontes; series dentarias superiores subparalelas; fórmula alveolar: serie dentaria superior 4,3,3 / serie dentaria inferior 2-3,3,2; M1/m1 con procingulo reducido en forma de abanico y con anteroflexo/ido superficial o ausente; M1 con paraflexo y metaflexo fuertemente orientado hacia atrás y con paracono globoso; M3 reducido; de contorno subcilíndrico. Figura 5.29.

Especies similares: Abrothrix longipilis, A. andinus y Akodon iniscatus.

Observaciones: los registros en Mendoza muestra su relacion con ambientes de estepas Patagonicas y Altoandinas de la parte sudoeste de la provincia. No obstante, el unico registro en el Monte (Massoia, 1981a), puede considerarse dudoso debido a su carácter extralimital.

Bibliografía consultada: Massoia, 1981a; Pearson, 1983, 1995, Monjeau, 1989; Massoia et al., 1994; Lozada et al., 1996; Pardiñas, 1999; Pearson y Smith, 1999; Figueroa Rojas et al., 2001; Smith et al., 2001; Teta et al., 2005, 2006; Gasco et al., 
2006; Nabte et al., 2006; D'Elía et al., 2007; Cueto et al., 2008; Pardiñas et al., 2008; Fernández et al., 2009a, 2009b; Udrizar Sauthier, 2009; Abud, 2011.
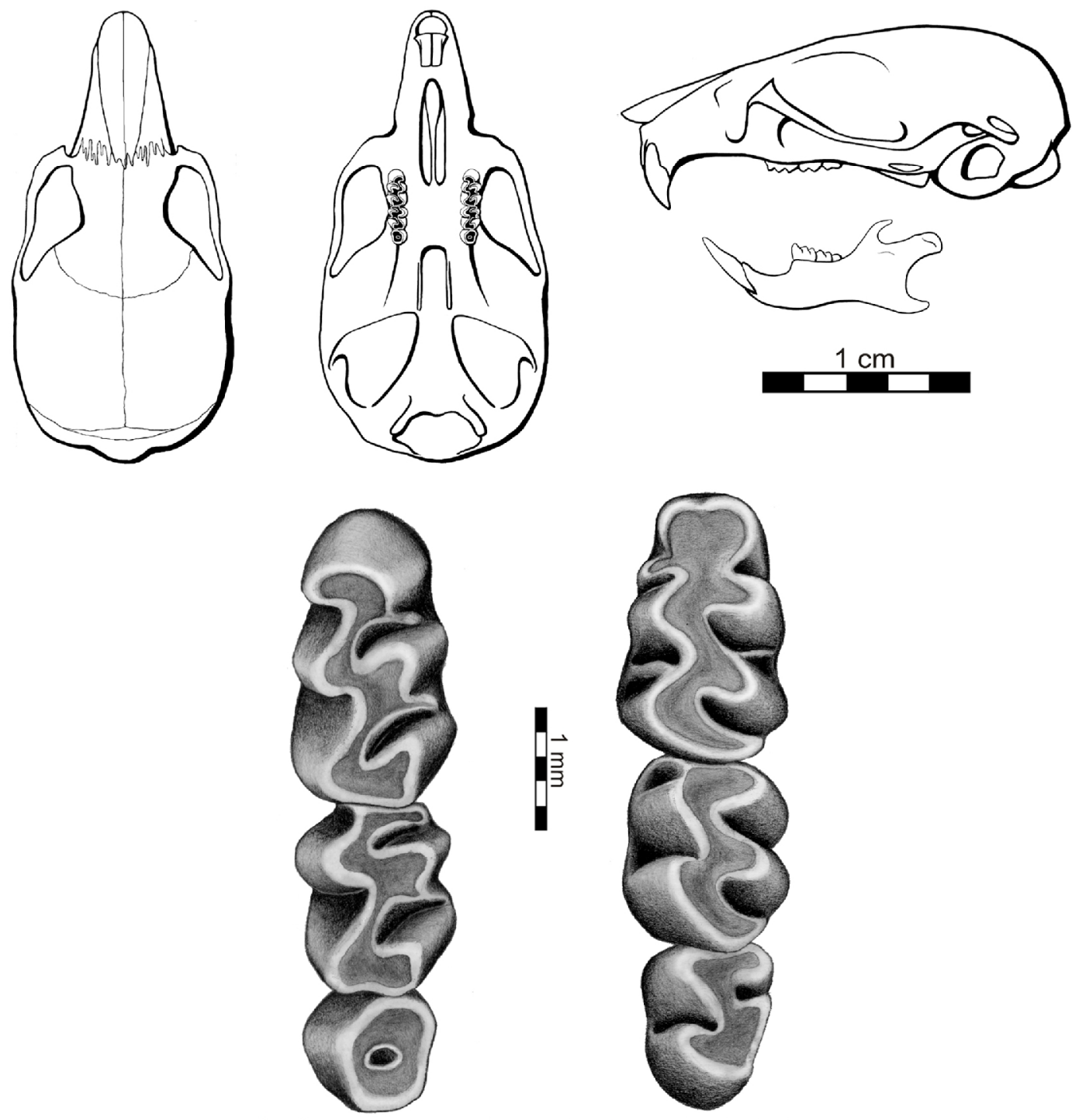

Serie molar superior Serie molar inferior

Figura 5.29. Esquemas cráneo-dentarios de Abrothrix olivaceus.

Abrothrix andinus (Philippi, 1858).

Localidad tipo: circunscrita por Osgood (1943) a la zona de altos Andes en la provincia de Santiago, Chile.

Características generales: Abrothrix andinus (ratón andino) es un abrotriquino diurno y nocturno que construye madrigueras. Es omnívoro y presenta un peso promedio de 23,7 g. Preferentemente ocupa áreas de los altos Andes, desde 2500 hasta por encima de 
los $4500 \mathrm{~m}$ de altitud. En Mendoza es frecuente en roquedales de valles y quebradas andinas y precordilleranos, con escasa cobertura vegetal pero con cierto grado de protección. Especie pobremente conocida y con escasos registros. Su estatus taxonómico es poco claro. Osgood (1943) incluye en la sinonimia de esta especie a $A$. gossei Thomas, 1920, la cual presenta su localidad tipo en Puente del Inca, Mendoza; pudiendo la misma corresponder a una especie válida (Pardiñas com. pers., 2009).

Provincias comprendidas: Jujuy, Salta, Tucumán, Catamarca, La Rioja, San Juan y Mendoza.

Localidades registradas en Mendoza: 27, 80, 85. Figura 5.30.

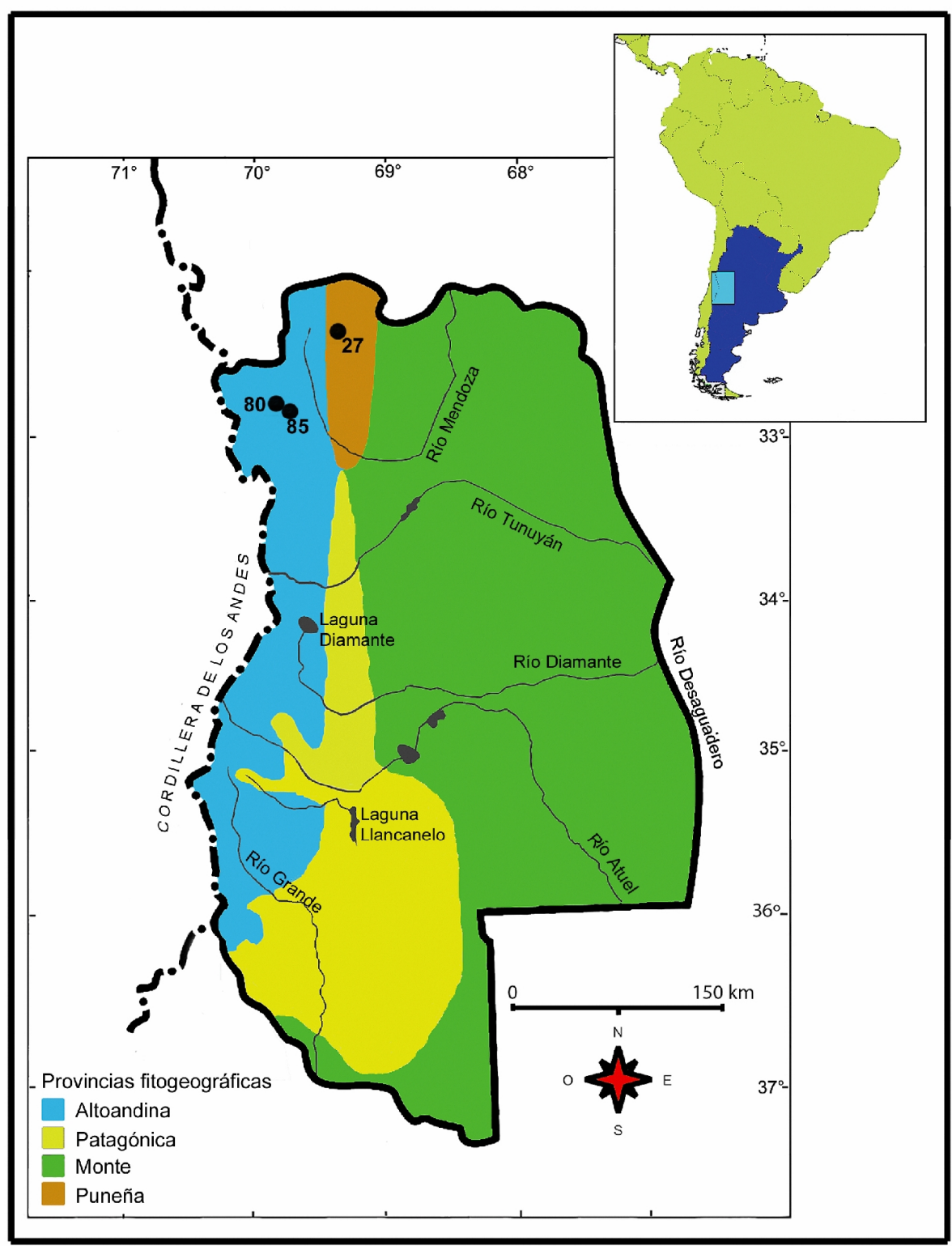

Figura 5.30. Localidades de registro de Abrothrix andinus en la provincia de Mendoza. 
Descripción: cráneo con perfil subabovedado en norma lateral; bordes de los frontales moderadamente redondeados y subparalelos; constricción interorbital igual que el ancho del rostro; sutura frontoparietal en forma de "U" abierta; placa zigomática angosta, con el borde anterior recto y vertical; foramen incisivo extendido posteriormente hasta el nivel de la parte anterior del procíngulo del M1; paladar largo y ancho; fosa mesopterigoidea con bordes paralelos; borde anterior de la fosa mesopterigoidea redondeado; amplitud de la fosa mesopterigoidea menor que la de la fosa parapterigoidea; proceso coronoides inflexionado hacia atrás y levemente por encima del cóndilo mandibular; escotadura semilunar excavada y simétrica; proyección capsular conspicua; incisivos superiores levemente opistodontes; series dentarias superiores paralelas; molares chicos; $\mathrm{M} 1 / \mathrm{m} 1$ con procíngulo corto, en forma de abanico y anteroflexo superficial o ausente; M1 con protoflexo moderadamente amplio y levemente orientado hacia el centro del diente; M1 con paraflexo y metaflexo orientado hacia atrás; M3 reducido; de contorno subcilíndrico y con anillo interno de esmalte. Figura 5.31.

Especies similares: Abrothrix olivaceus. Una diferencia notable respecto de esta especie es que $A$. andinus presenta los molares más chicos.

Observaciones: los escasos registro en Mendoza, se encuentran en ambientes Altoandinos y Puneños de la parte norte de la provincia.

Bibliografía consultada: Thomas, 1920; Osgood, 1943; Cabrera, 1961; Roig, 1972; Mann Fisher, 1978; Contreras y Rosi, 1981; Massoia, 1981a; Reig, 1987; Redford y Eisenberg, 1992; Teta et al., 2006; D'Elía et al., 2007. 

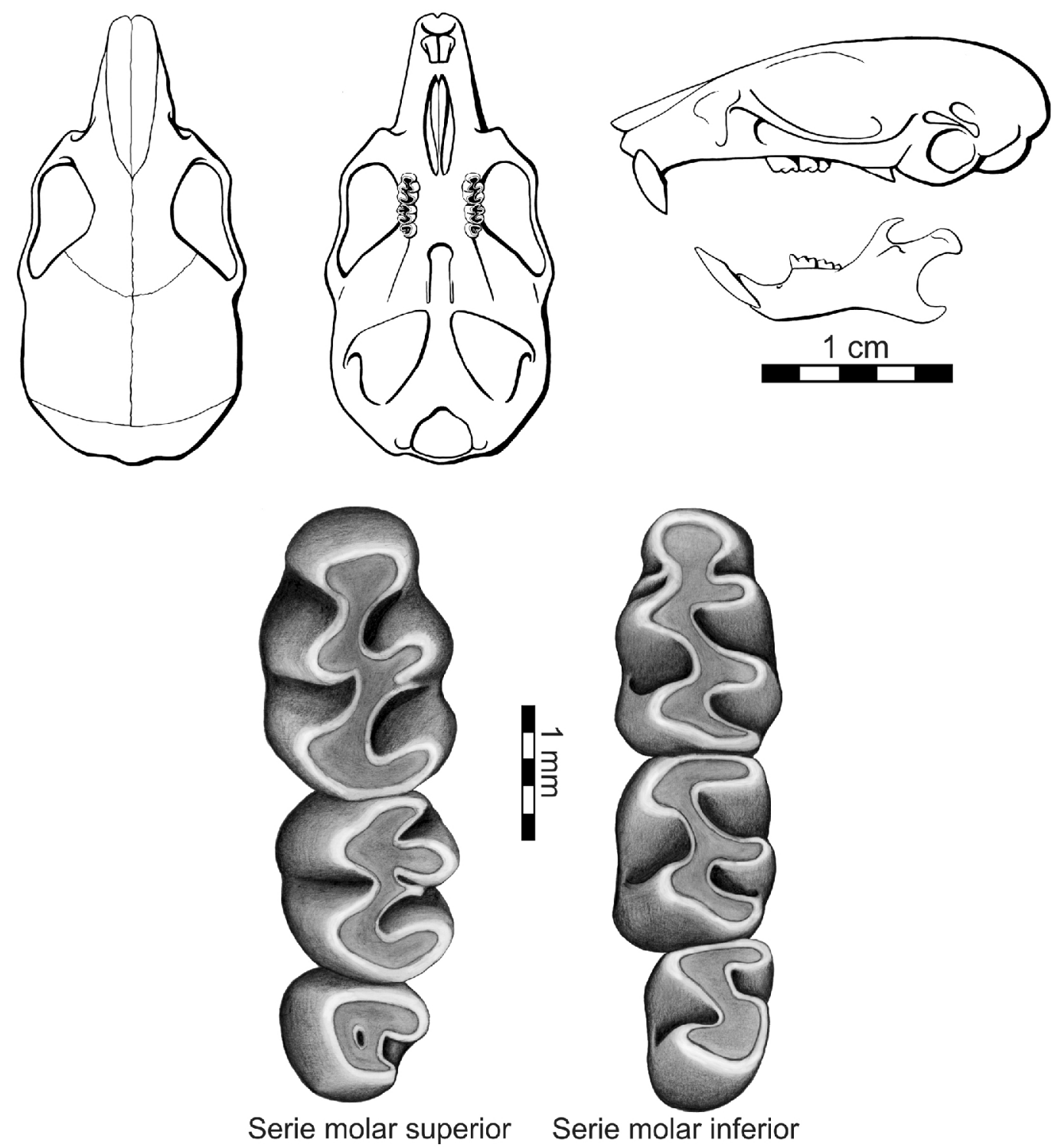

Figura 5.31. Esquemas cráneo-dentarios de Abrothrix andinus.

Género Chelemys Thomas, 1903.

Chelemys macronyx (Thomas, 1894).

Localidad tipo: Fuerte de San Rafael, Mendoza. Sin embargo, Pearson y Lagiglia (1992) advierten sobre su posible ubicación en las proximidades del volcán Peteroa ( $c a$. $200 \mathrm{Km}$ al sudoeste de San Rafael, Mendoza).

Características generales: Chelemys macronyx (ratón topo grande) es un abrotriquino diurno y nocturno, semifosorial y que puede vivir en colonias. Es principalmente hervívoro y presenta un peso promedio de 40,3 g. En Norpatagonia es frecuente en ambientes húmedos de Nothofagus spp. y en vegas cordilleranas. En Mendoza está 
documentado principalmente en vegas de altos Andes. En la sinonimia de esta especie se incluyen varias formas nominales (e.g., alleni, fumosus, vestitus), consideradas por Cabrera (1961) como subespecíficas, cuyos estatus aún no han sido aclarados. Alarcón et al. (2011) en base de la secuencias de ADN mitocondrial gen citocromo $b$, observó dos clados para C. macronyx, uno al norte en localidades de altos Andes desde Mendoza hasta el norte de Neuquén y otro clado en altitudes medias y bajas desde el noroeste de Neuquén hasta el sur de su rango de distribución. Según el planteo filogeográfico de estos autores el clado del norte presentó poblaciones más estables y menos expansivas y sugieren la nominación subespecífica de C. m. macronyx y la revalidación de $C . m$. vestitus para el clado del sur, considerando a C. m. alleni sinónimo junior de esta última. Las poblaciones de C. macronyx registradas en la estepa Patagónica fueron interpretadas por los autores mencionados como relictuales de distribuciones previas más amplias.

Provincias comprendidas: Chubut, Mendoza, Neuquén, Río Negro y Santa Cruz.

Localidades registradas en Mendoza: 5, 6, 14, 28, 29, 50, 51, 102. Figura 5.32.

Descripción: cráneo robusto y ancho; cráneo con perfil subabovedado en norma lateral; bordes de los frontales redondeados y sub-paralelos; senos frontales inflados; constricción interorbital igual al ancho del rostro; sutura frontoparietal en forma de " $U$ " abierta; placa zigomática moderadamente ancha, con el borde anterior casi recto y ligeramente inclinado hacia atrás; foramen incisivo extendido posteriormente hasta el nivel de la parte anterior del procíngulo del M1; paladar moderamente ancho y largo; fosa mesopterigoidea con bordes paralelos; borde anterior de la fosa mesopterigoidea recto; amplitud de la fosa mesopterigoidea igual que la amplitud de la fosa parapterigoidea; mandibula robusta con proceso coronoides largo e inflexionado hacia atrás y por encima del cóndilo mandibular, el cual está orientado medialmente; escotadura semilunar poco excavada y casi simétrica; proyección capsular conspicua; foramen mentoniano visible en norma lateral; incisivos superiores robustos $y$ ortodontes, blancos o pálidos; series dentarias superiores paralelas; fórmula alveolar: serie dentaria superior 4-3,3,2 / serie dentaria inferior 3,2,2; molares robustos; molares con cúspides bajas; en adultos las cúspides son redondeadas sin islas de esmalte en el interior de la superficie oclusal; M1/m1 con procíngulo corto, en forma de abanico y con anteroflexo/ido ausente o superficial; M1 con flexo anteromediano ausente; $\mathrm{m} 1$ con fléxido anteromediano presentes en juveniles; M1 con protoflexo moderadamente amplio y levemente orientado hacia el centro del diente; M1 con 
paraflexo y metaflexo orientados hacia atrás; M3 con un anillo interno de esmalte; $m 3$ de forma sigmoidea. Figura 5.33.

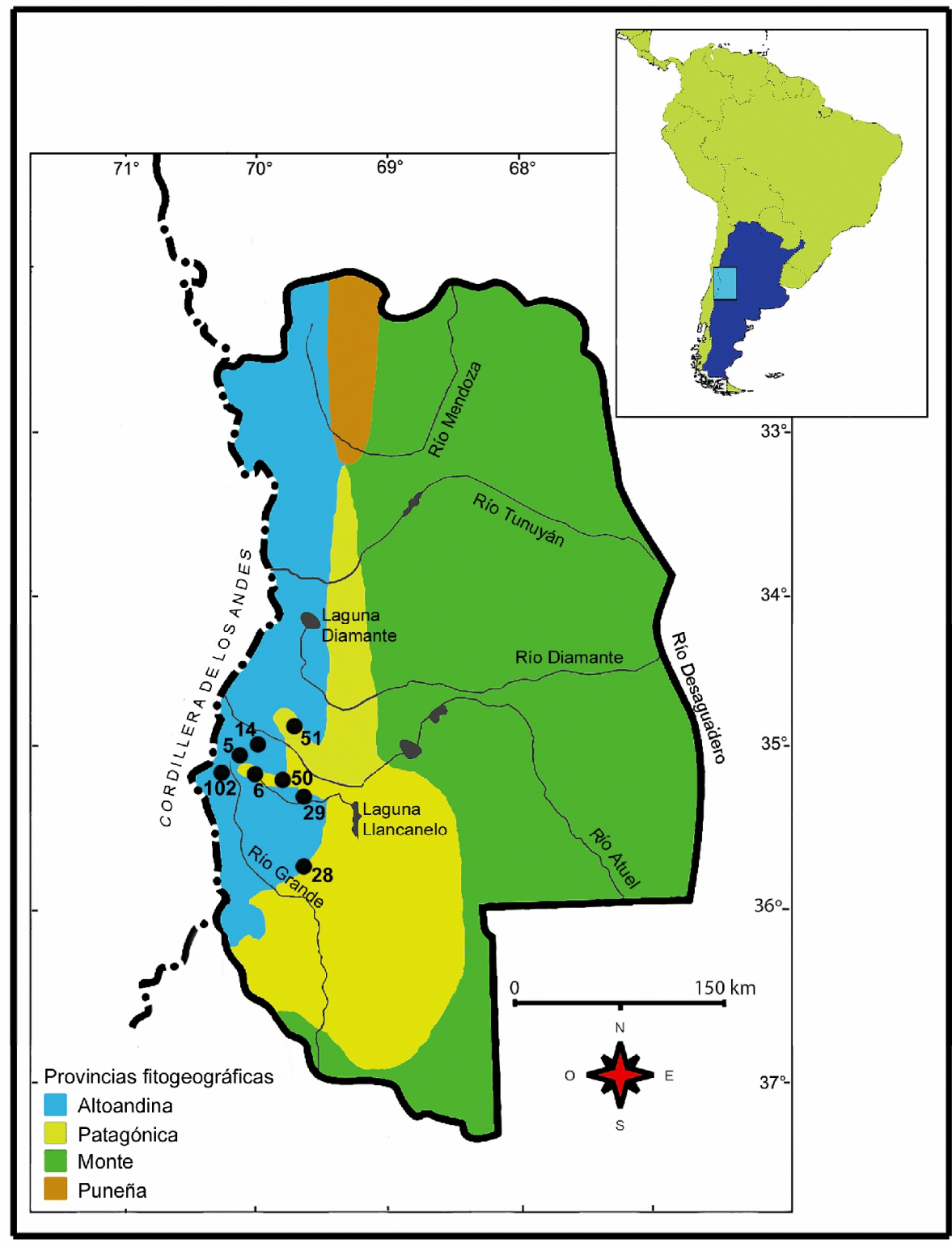

Figura 5.32. Localidades de registro de Chelemys macronyx en la provincia de Mendoza.

Especies similares: esta especie es la que presenta mayores diferencias con respecto a los demás miembros de la tribu Abrotrichini.

Observaciones: los registros en Mendoza se asocian con ambientes de estepas Patagonicas y Altoandinas de la parte sudoeste de la provincia.

Bibliografía consultada: Osgood, 1943; Mann Fischer, 1978; Massoia, 1981a; Pearson, 1984; Reig, 1987; Monjeau, 1989; Pearson y Lagiglia, 1992; Massoia et al., 1994; Pearson, 1995; Figueroa Rojas et al., 2001; Ojeda et al., 2005; Gasco et al., 2006; 
Jayat et al., 2006; Nabte et al., 2006; Teta et al., 2006; D'Elía et al., 2007; Pardiñas et al., 2008; Fernández et al., 2009a, 2009b; Udrizar Sauthier, 2009; Alarcón et al., 2011.
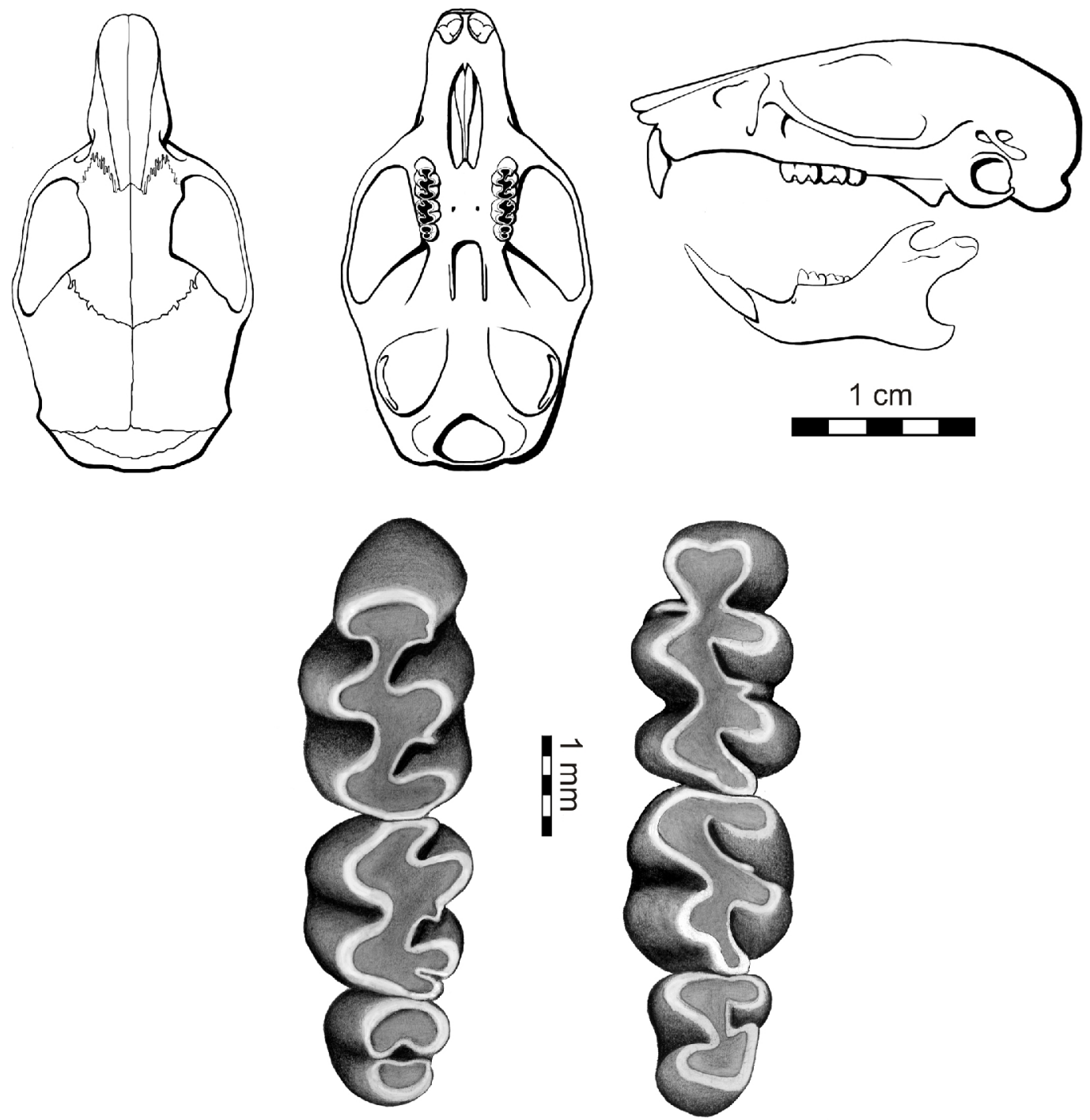

Serie molar superior Serie molar inferior

Figura 5.33. Esquemas cráneo-dentarios de Chelemys macronyx.

\section{Tribu Oryzomyini Vorontsov, 1959 (sensu Voss y Carleton, 1993).}

Es la tribu más diversa y con mayor distribución geográfica de la subfamilia, abarcando Sudamérica, Mesoamérica, sur de Norteamérica y regiones insulares como las Galápagos y las Antillas. Este grupo de roedores ocupa ambientes tropicales, subtropicales, pastizales, estepas y bosques (Pardiñas et al., 2002). En Argentina se han registrado 10 géneros, de los cuales, sólo dos se encuentran en Mendoza (Oligoryzomys y Holochilus). 
En cuanto a la morfología cráneo-dentaria, los representantes de esta tribu se distinguen por la siguiente combinación de caracteres: extensión de los nasales posterior a los lagrimales; paladar largo (con la excepción de Holochilus) y con forámenes palatales posterolarales bien desarrollados; molares tetralofodontes (e.g., Holochilus, Pseudoryzomys y Zygodontomys, sin distribución en Mendoza) y pentalofodontes con mesolofo/ido bien desarrollados (excepto Holochilus) (Voss y Carleton, 1993).

Género Oligoryzomys Bangs, 1900.

Oligoryzomys flavescens (Waterhouse, 1837).

Localidad Tipo: Maldonado, Uruguay.

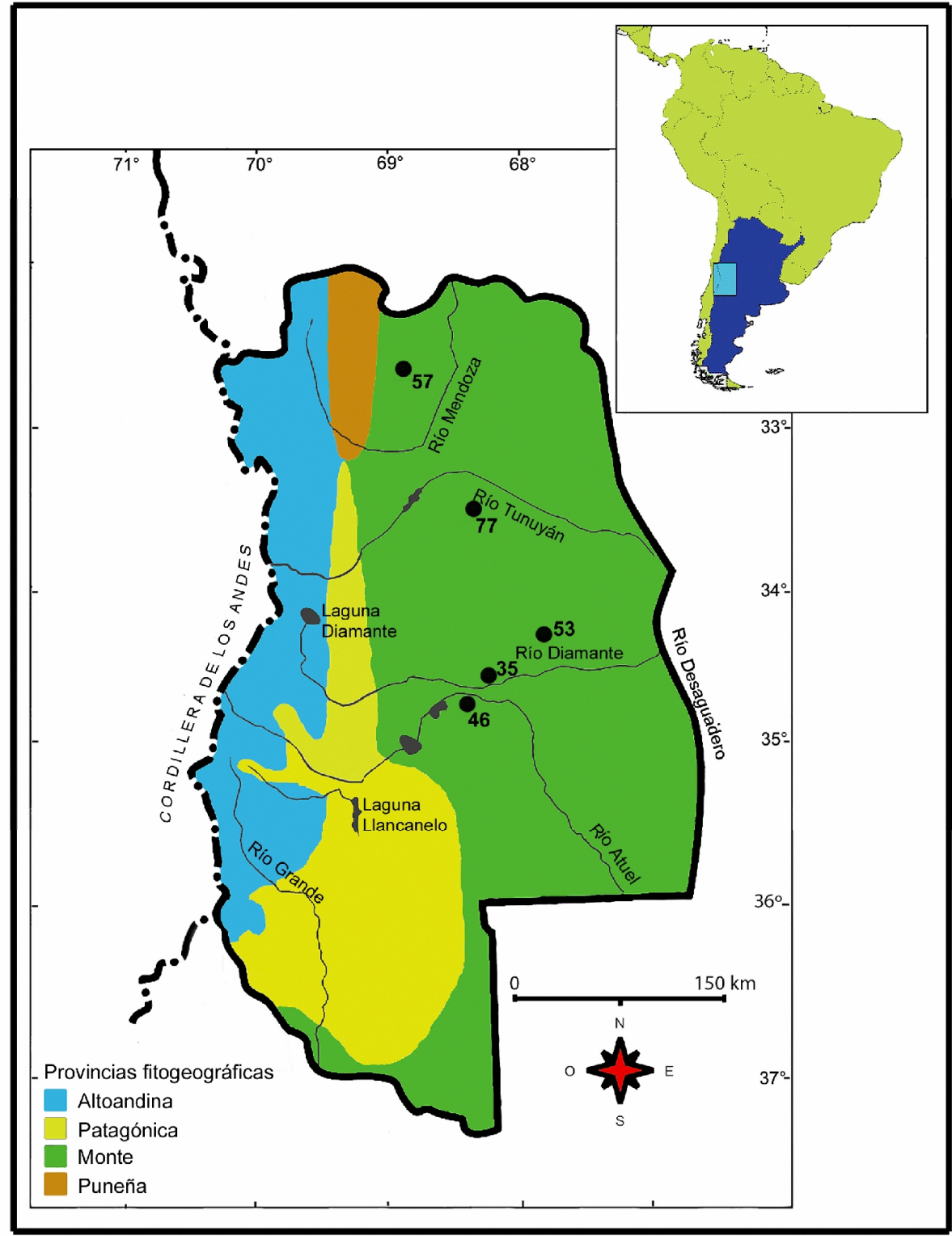

Figura 5.34. Localidades de registro de Oligoryzomys flavescens en la provincia de Mendoza. 
Características generales: Oligoryzomys flavescens (colilargo chico) es un oryzomino nocturno y saltador. Es omnívoro y presenta un peso promedio de 23,3 g. Es una especie común en el centro y este de Argentina, se asocia a áreas abiertas con pastizales en relación a cuerpos de agua, siendo un roedor típico de los agroecosistemas pampeanos. En Mendoza, está asociado a ambientes áridos y del desierto del Monte, con preferencia por sectores con vegetación arbustiva y herbácea cercanos a fuentes de agua. Recientes estudios moleculares sobre especies de Oligoryzomys con distribución en Argentina señalan que $O$. flavescens conforma tres clados cercanamente relacionados y de este modo, probablemente forme parte de un complejo de especies crípticas (Rivera et al., 2007).

Provincias comprendidas: Buenos Aires, Catamarca, Córdoba, Corrientes, Entre Ríos, Jujuy, La Pampa, Chubut, Mendoza, Misiones, Salta, San Luis, Tucumán.

Localidades registradas en Mendoza: 35, 46, 53, 57, 77. Figura 5.34.

Descripción: cráneo con perfil abovedado en norma lateral; bordes de los frontales subcuadrados y paralelos; constricción interorbital ligeramente menor que el ancho del rostro; sutura frontoparietal en forma de " $V$ " abierta; placa zigomática alta, con bordes rectos y paralelos; foramen incisivo extendido posteriormente hasta la base del procíngulo del M1; paladar largo y ancho; fosa mesopterigoidea con bordes paralelos; borde anterior de la fosa mesopterigoidea casi recto; amplitud de la fosa mesopterigoidea casi igual que la amplitud de la fosa parapterigoidea; mandíbula corta y robusta; proceso coronoides corto, de base ancha e inflexionado hacia atrás y levemente por encima del cóndilo mandibular; escotadura semilunar no excavada y simétrica; proyección capsular conspicua; incisivos superiores opistodontes; series dentarias superiores paralelas; molares cuadrangulares con cúspides redondeadas bien marcadas; M1 presenta corona crestada y contorno subelíptico; procíngulo amplio y flexo anteromediano; el anterolofo está unido con el paralofo, y el mesolofo se conserva con posición transversa; M1/m1 y M2/m2 son característicos por presentar conos/idos aislados en la cara labial y lingual, respectivamente; M3 con un islote central de esmalte; $\mathrm{m} 3$ casi tan grande como el $\mathrm{m} 2$ y subcuadrados; las raíces de los alvéolos están alineadas y presentan un tamaño uniforme. Figura 5.35.

Especies similares: Oligoryzomys longicaudatus.

Observaciones: los escasos registros en Mendoza se encuentran en ambientes del desierto del Monte. Por otra parte, los registros más australes para la subespecie O.f. occidentalis, nominada por Contreras y Rosi (1980c), corresponden a la provincia de 
Mendoza, donde se encuentra su localidad tipo (Colonia Alto del Algarrobal: Localidad $35)$.
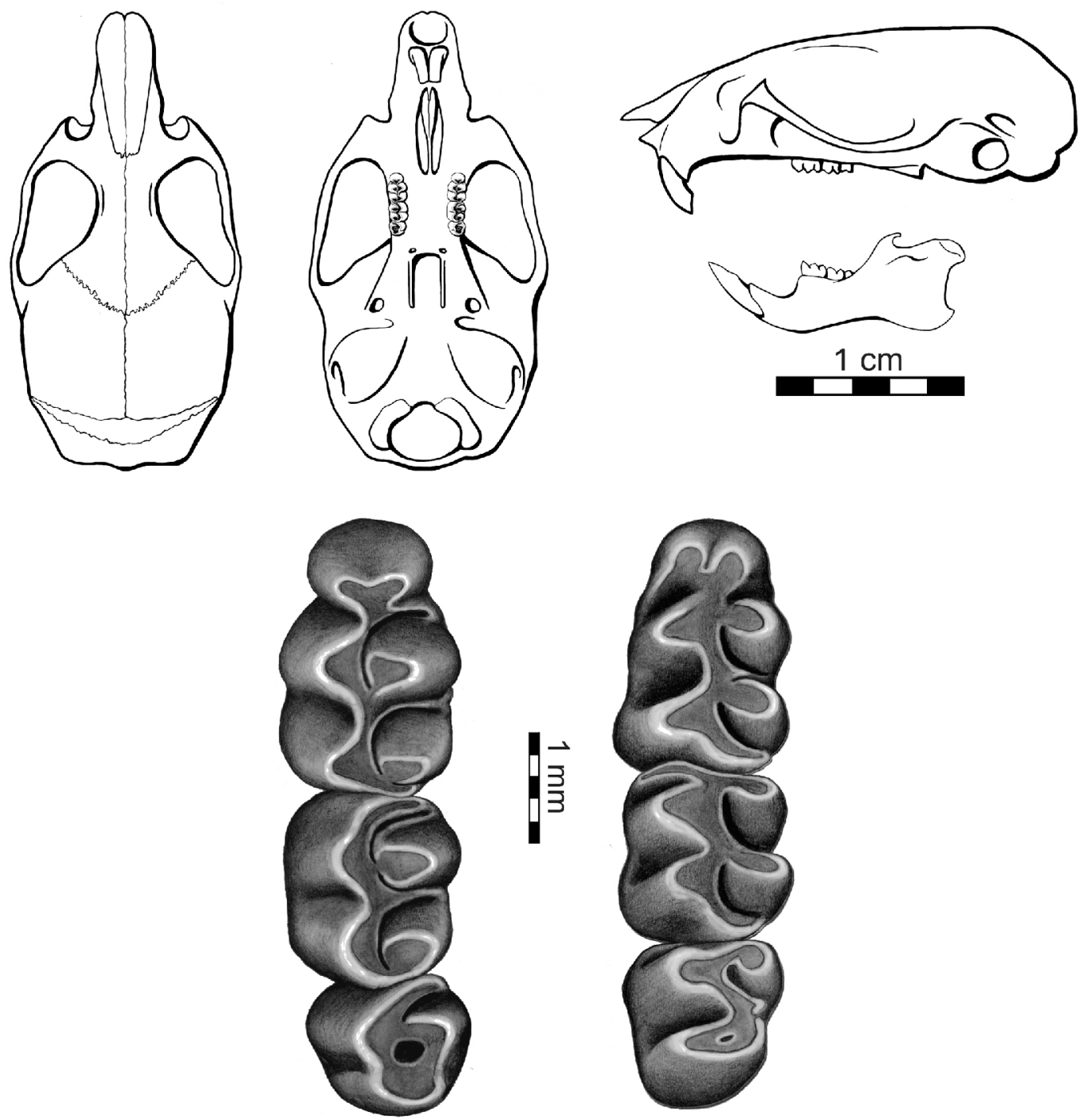

Serie molar superior Serie molar inferior

Figura 5.35. Esquemas cráneo-dentarios de Oligoryzomys flavescens.

Bibliografía consultada: Massoia, 1973a; Contreras y Rosi, 1980c; Massoia, 1981a; Carleton y Musser, 1989; Redford y Eisenberg, 1992; Pardiñas et al., 2004; Cirignoli et al., 2006; Fernández et al., 2009b.

Oligoryzomys longicaudatus (Bennett, 1832).

Localidad Tipo: Valparaíso, Chile. 


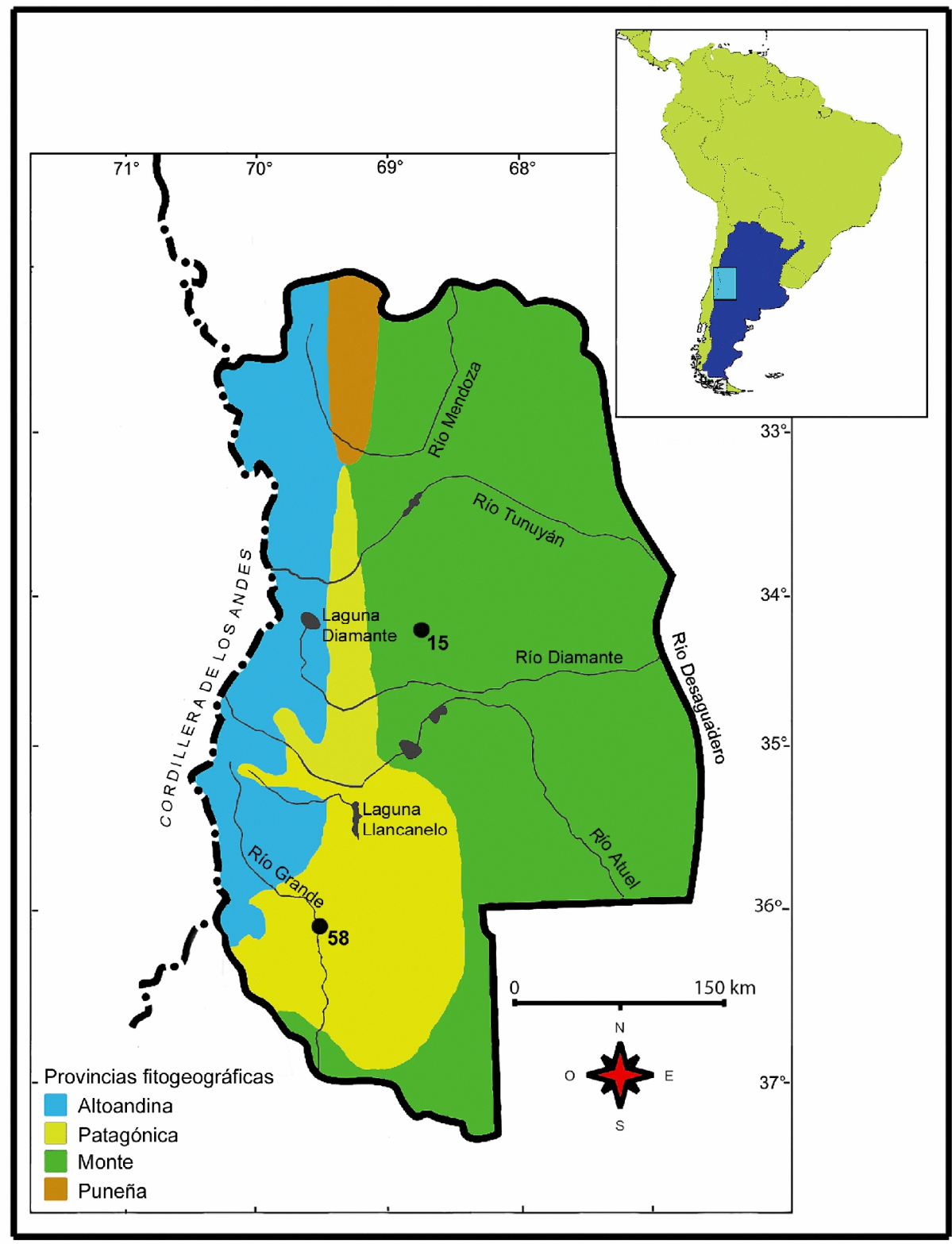

Figura 5.36. Localidades de registro de Oligoryzomys longicaudatus en la provincia de Mendoza.

Características generales: Oligoryzomys longicaudatus (colilargo común) es un oryzomino nocturno, cursorial y es buen trepador. Es granívoro, herbívoro e insectívoro y presenta un peso promedio de $27,7 \mathrm{~g}$. Es frecuente en los bosques subantárticos, siendo común en áreas cordilleranas y precordilleranas. También, ocupa ambientes arbustivos de la estepa Patagónica en cercanías a cuerpos de agua y en el desierto del Monte y Espinal. La validez de $O$. longicaudatus ha sido reconocida, incluyendo varias subespecies (e.g., O. l. longicaudatus, O. l. phillipi, O. l. pampanus) (Massoia, 1973b; Gallardo y Patterson, 1985; Gallardo y Palma, 1990). Sin embargo, recientes estudios 
moleculares son coherentes con la asignación de una sola forma de O. longicaudatus, tanto del lado chileno como argentino (Palma et al., 2005). Asimismo, estos últimos autores indicaron que varios de los ejemplares de $O$. magellanicus recolectados del extremo sur de la Patagonia corresponden a O. longicaudatus, extendiendo la distribución geográfica de esta última especie hasta el sur de Santa Cruz y Tierra del Fuego. Sin embargo, la delimitación de la distribución geográfica de estas dos especies aún no está bien definida (Palma et al., 2007).

Provincias comprendidas: Buenos Aires, Chubut, La Pampa, Mendoza, Neuquén, Río Negro, Santa Cruz y Tierra del Fuego.

Localidades registradas en Mendoza: 15, 58. Figura 5.36.

Descripción: esta especie comparte la mayoría de las características cráneo-dentarias con $O$. flavescens, diferenciandose principalmente por: mayor tamaño, incluso por la presencia de molares más grandes, lo cual deriva en una serie molar más larga; escotadura semilunar ligeramente más excavada; fórmula alveolar: serie dentaria superior 3,3,3 / serie dentaria inferior 2,2,2. Figura 5.37.

Especies similares: Oligoryzomys flavescens.

Observaciones: en Mendoza presenta solamente un registro en Monte y otro en la estepa Patagónica, en la parte centro y sur de la provincia, respectivamente.

Bibliografía consultada: Massoia, 1973a, 1973b; Mura y Gonzáles, 1982; Pearson y Pearson, 1982; Pearson 1983, 1995; Gallardo y Patterson, 1985; Monjeau, 1989; Gallardo y Palma, 1990; Redford y Eisenberg, 1992; López et al., 1996; Guthmann et al., 1997; Pardiñas et al., 2003, 2008; Ortiz et al., 2004; Palma et al., 2005, 2007; Cirignoli et al., 2006; Nabte et al., 2006; Carbajo y Pardiñas, 2007; Udrizar Sauthier, 2009. 

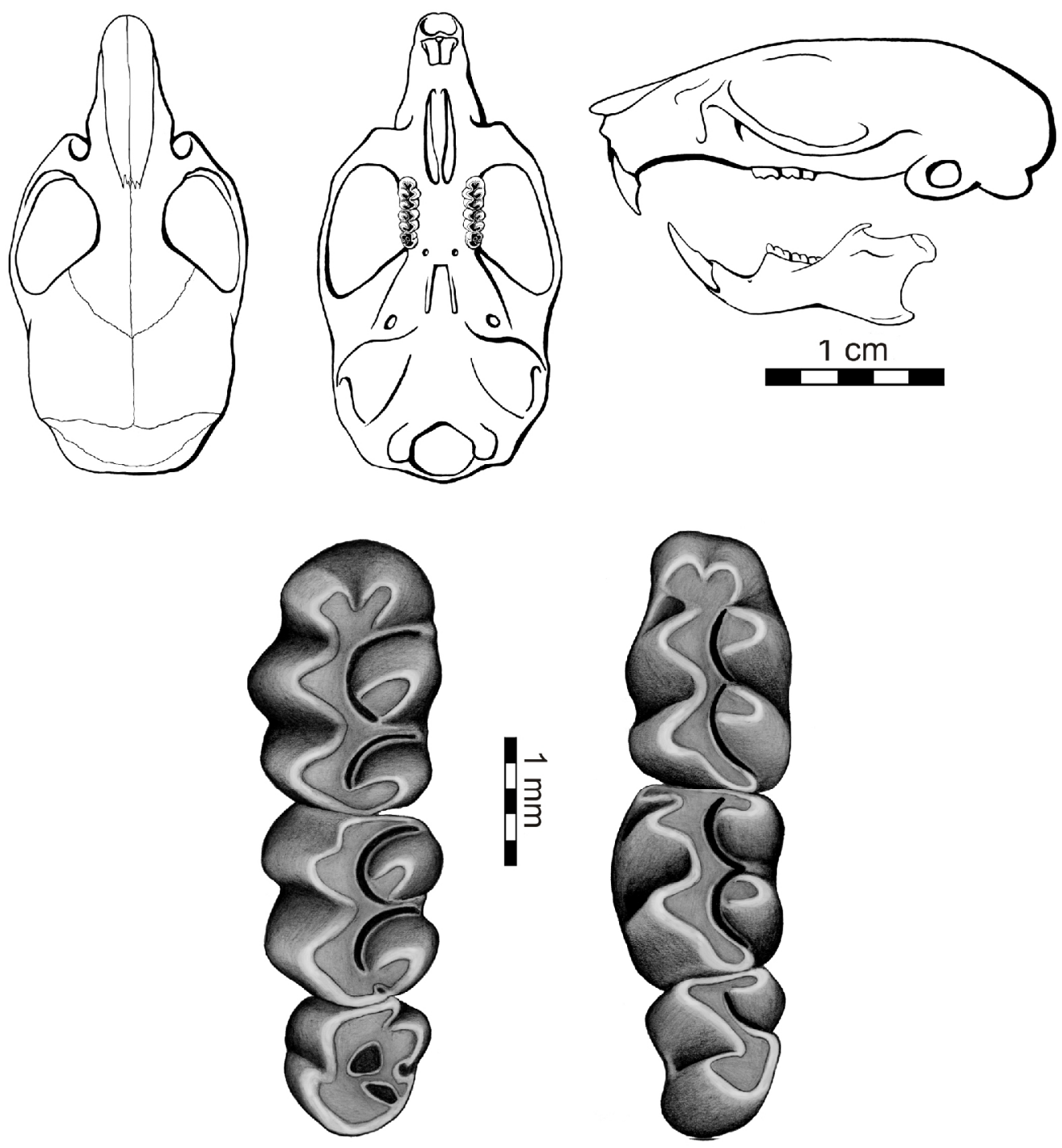

Serie molar superior Serie molar inferior

Figura 5.37. Esquemas cráneo-dentarios de Oligoryzomys longicaudatus.

Género Holochilus Brandt, 1835.

Holochilus lagigliai sp. nov. Pardiñas, Teta, Voglino y Fernández, en prensa.

Características generales: las especies que integran el género Holochilus son de gran tamaño, presentan hábitos nocturnos y anfibios. El estatus taxonómico de Holochilus es poco claro y en este sentido investigadores especialistas destacan que este género necesita una revisión detallada (Pardiñas y Teta, 2011). Hasta recientemente se reconocian tres especies vivientes de Holochilus, H. brasiliensis (Desmarest, 1819), H. chacarius Thomas, 1906 y H. sciureus Wagner, 1842, los cuales contienen una lista 
larga de sinónimos (véase Musser y Carleton, 2005). En Argentina se distribuyen $H$. brasiliensis y $H$. chacarius. Por un lado, $H$. brasiliensis habita habientes más humedos del centro-este de Argentina y Paraguay, Uruguay y sudeste de Brasil. Por otro lado, $H$. chacarius ocurre en ambientes más aridos del centro-oste del Chaco argentino, paraguayo y boliviano. Ambas especies son simpátricas en nordeste de la Region Pampeana, centro y este del Chaco y Espinal. No obstante, un estudio taxonómico reciente señala que los ejemplares de Mendoza presentados en este trabajo, corresponden a una nueva especie (Pardiñas, Teta, Voglino y Fernández, en prensa).

Provincias comprendidas: Mendoza, Córdoba, Buenos Aires, Santa Fe, Corrientes, Entre Ríos, Misiones,Chaco, Formosa, Santiago del Estero, Tucumán, Salta, Jujuy.

Localidades registradas en Mendoza: 43, 46. Figura 5.38.

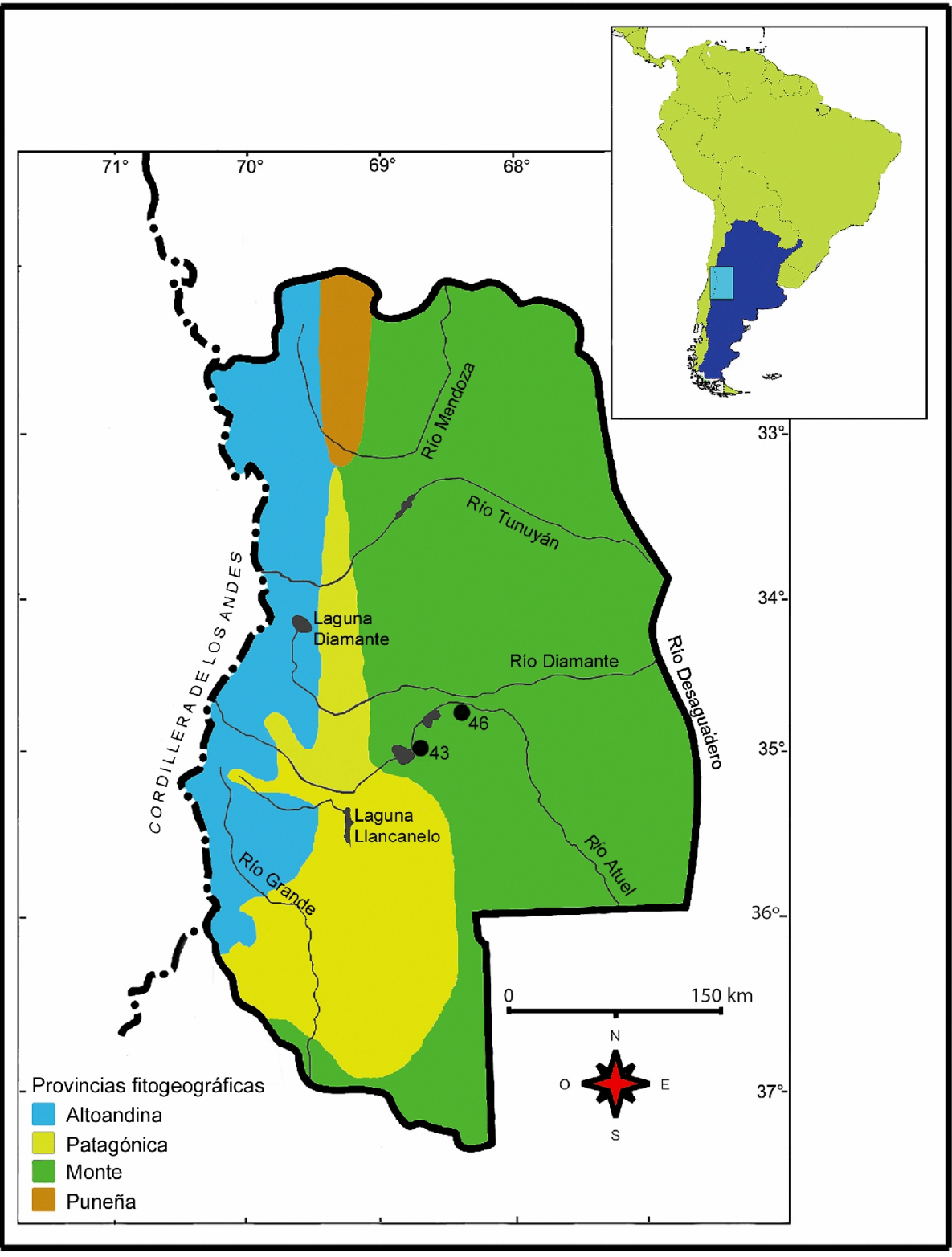


Figura 5.38. Localidades de registro de Holochilus lagigliai sp. nov. en la provincia de Mendoza.

\section{Descripción:}

Por un lado, H. brasiliensis presenta las crestas masetéricas superior e inferior bien marcadas y reunidas formando un reborde único, a la altura de la raíz posterior del $\mathrm{m} 1$ y por debajo del foramen mentoniano; molares laminares con las principales cúspides opuestas; M3 triangular y con hipoflexo; molares superiores e inferiores con mesolofo/ido presente aunque vestigial; bordes labiales y linguales de los lofos/lófidos redondeados; procíngulo del $\mathrm{m} 1$ en forma de abanico con fosétida antero-interna grande y ubicada centralmente en el procíngulo del $\mathrm{ml}$; proto e hipocónido con áreas subiguales de contorno casi triangular en el $\mathrm{ml}$; metafléxido bien desarrollado, alcanzando la línea media del $\mathrm{m} 1 ; \mathrm{m} 2$ subcuadrangular en vista oclusal y $\mathrm{m} 3$ sigmoide; longitud de la serie dentaria superior $>8 \mathrm{~mm}$.

Por su parte, H. chacarius se diferencia de $H$. brasiliensis por presentar la confluencia de las ramas inferior y superior de la cresta masetérica a la altura del extremo anterior del $\mathrm{ml}$ y a nivel del foramen mentoniano, molares con las principales cúspides alternadas, el desplazamiento labial del la fosétida antero-interna del $\mathrm{m} 1$ respecto al eje central del diente; el escaso desarrollo del metafléxido del $\mathrm{m} 1$ sin alcanzar la línea media; mesolofo/lófido ausente en los molares superiores/inferiores y longitud de la serie dentaria superior $<8 \mathrm{~mm}$.

Un estudio taxonómico de los ejemplares de Mendoza, indicó que corresponden a una nueva entidad específica, la cual fue nominada Holochilus lagigliai (cf. Pardiñas, Teta, Voglino y Fernández, en prensa). Este nuevo taxón se caracteriza por tener una cola corta; placa zigomática ancha con el extremo anterodorsal redondeado; paladar óseo sin excrecencias; M1 con procígulo subelíptico, parastilo y protostilo presentes y mesolofostilo bien desarrollado; M3 sin hipoflexo e hipocono y más corto que el M2; $\mathrm{m} 1$ con fosétida antero-interna abierta y desplazada labialmente (Pardiñas, Teta, Voglino y Fernández, en prensa). En este sentido, los autores esgrimen que la morfología de $H$. lagigliai exhibe una combinación entre los grupos de especies de $H$. brasiliensis y H. sciureus definidos por Massoia (1971, 1976, 1981). 


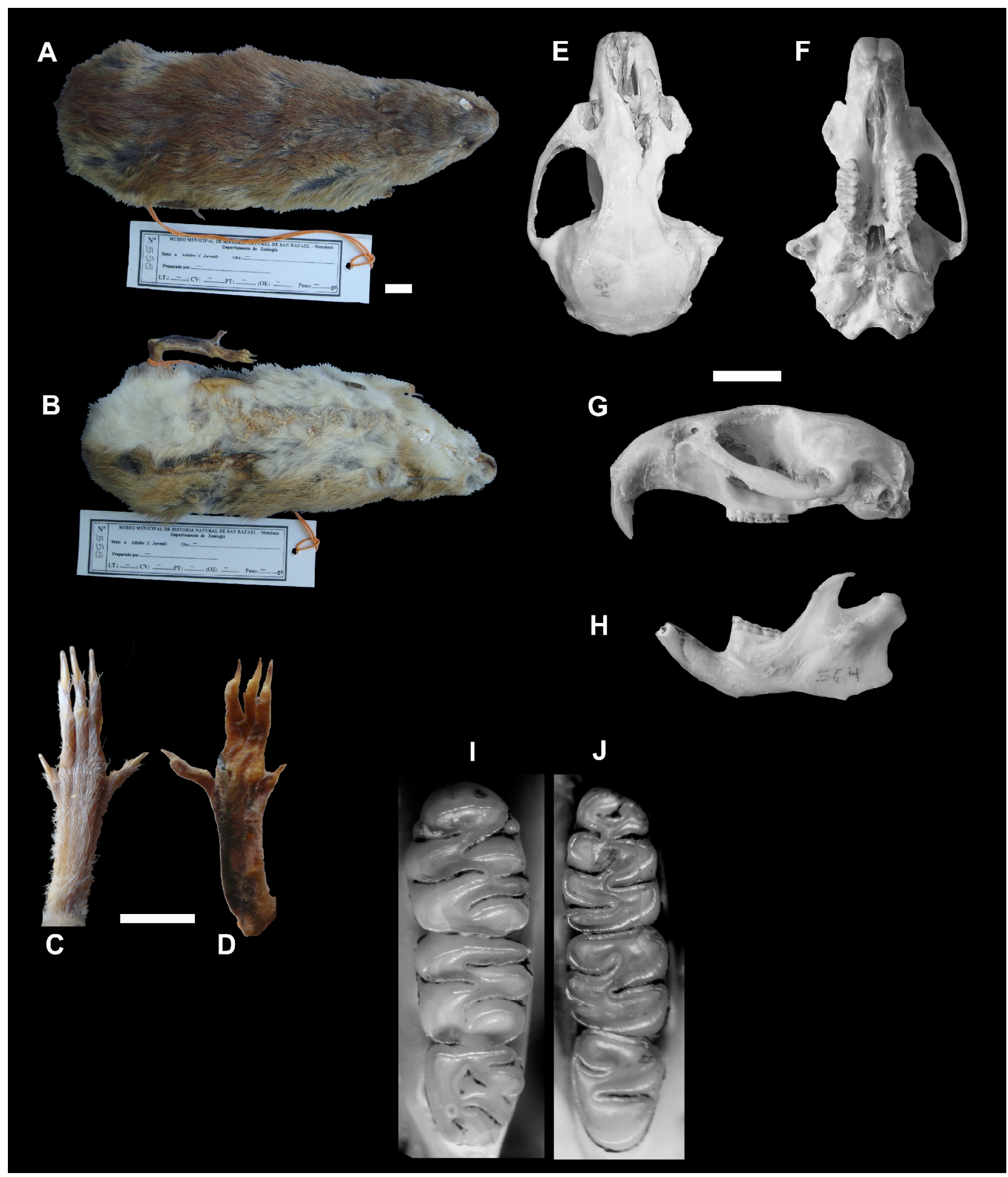

Figura 5.39. Holotipo de Holochilus lagigliai sp. nov. hallado en el Nihuil (Localidad 43). A: vista dorsal de la piel (MHNSR-558). B: vista ventral de la piel. C: detalle del autopodio posterior en vista dorsal. D: detalle del autopodio posterior en vista ventral. C: vista dorsal del cráneo (MHNSR-564). D: vista ventral del cráneo. E: vista lateral del cráneo. F: vista labial de la mandíbula. G: serie molar superior (longitud: 8,09 mm). H: serie molar inferior (longitud: 8,65 mm). Escalas A-H: $1 \mathrm{~cm}$. 


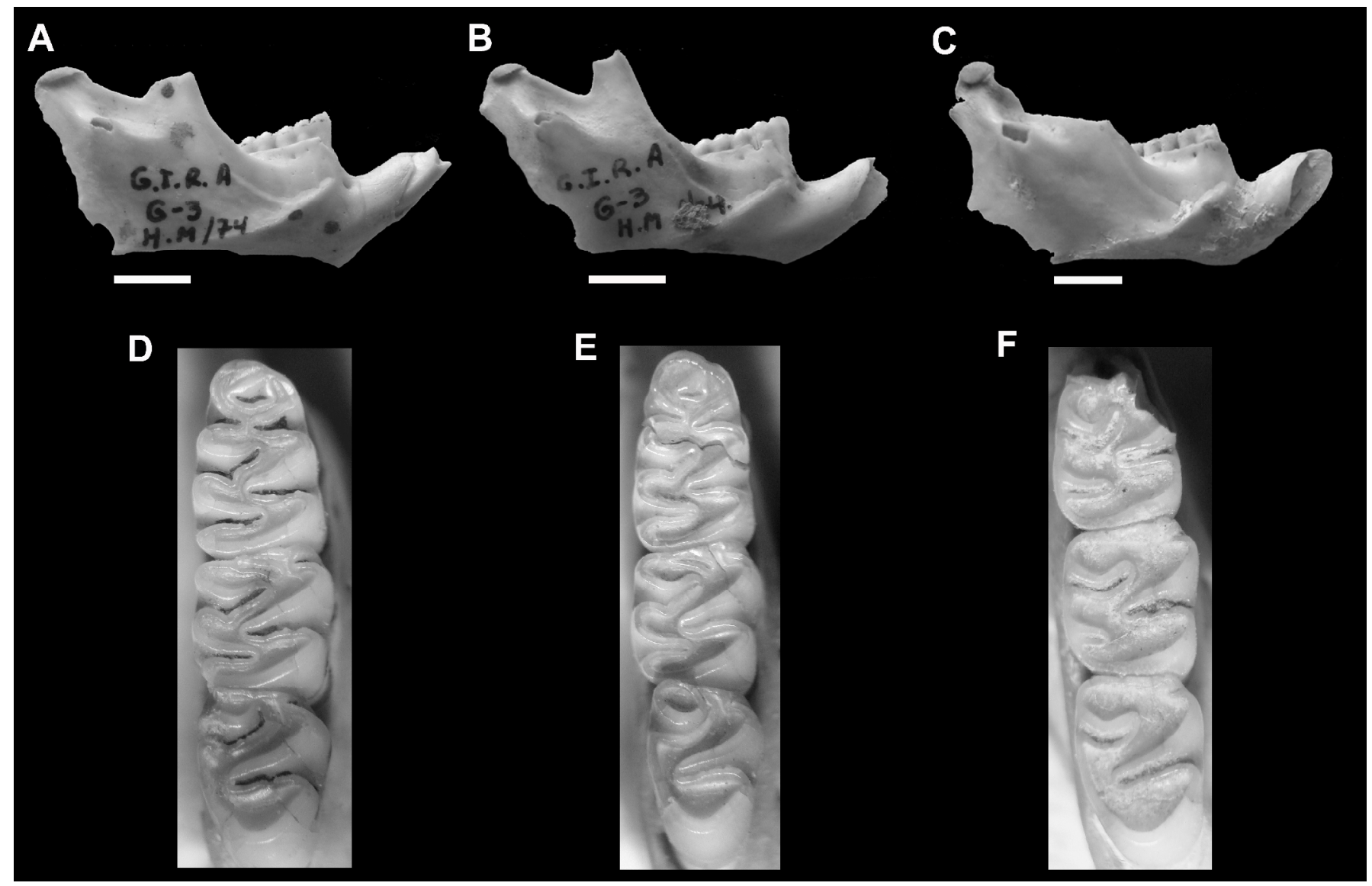

Figura 5.40. Ejemplares de Holochilus lagigliai sp. nov. recuperados de Gruta del Indio (Localidad 46). A: vista labial de mandibula (MHNSR-231). B: vista labial de mandibula (MHNSR-650). C: vista labial de mandibula (MHNSR-674). D: serie molar inferior (MHNSR-231; longitud: 9,09 mm.). E: serie molar inferior (MHNSR-650; longitud: 9,01 mm.). F: serie molar inferior (MHNSR-674; longitud: 8,66 mm.). Escalas A-C: 5 mm.

Observaciones: las localidades de $H$. lagigliai que se mencionan en este trabajo, constituyen los primeros registros para el género documentados para la provincia de Mendoza, extendiendo su geonemia ca. $480 \mathrm{~km}$ hacia el oeste. No obstante, es importante realizar algunos comentarios biogeográficos y acerca de los contextos de colecta de los ejemplares.

Ambas localidades de registro se encuentran en ambientes del desierto del Monte vinculados a cuerpos de agua permanentes (valle medio del Río Atuel). Por un lado, en el Nihuil se colectó un ejemplar hace 57 años (ver Apéndice). A pesar que en las últimas décadas no se registraron mayores cambios ambientales, es necesario chequear su presencia actual en el área. Por otro lado, en Gruta del Indio se colectaron restos mandibulares aislados en el suelo de la cueva hace más de 30 años (ver Apéndice). La presencia de marcas de corrosión digestiva y manchas de oxido de manganeso, sugiere que los mismos fueron acumulados por aves rapaces y que podrían corresponder a un 
contexto arqueológico, producto de la remoción de los niveles edáficos superficiales. Esta hipótesis se robustece teniendo en cuenta que no se halló ningún ejemplar de Holochilus en una muestra de egagrópilas de Bubo magellanicus proveniente del mismo sitio (ver Apéndice).

La distribución más austral de $H$. brasiliensis hacia la Patagonia septentrional en el Holoceno tardío, fue interpretada por diversos autores como el aprovechamiento de esta especie de los grandes sistemas fluviales como corredores biológicos en un contexto paleoambiental más húmedo (Pardiñas, 1999a; Teta et al., 2005a; Fernández et al., 2011; Pardiñas y Teta, 2011). Esta forma de ingreso a ambientes Patagónicos pudo darse también hacia Mendoza, en el sentido este-oste. A través del Río Colorado (actualmente la distribución más austral de $H$. brasiliensis se encuentra en la desembocadura de este río; Formoso et al., 2010) y la cuenca fluvial Vinchina-BermejoDesaguadero-Salado, hasta alcanzar uno de sus tributarios importantes (Río Atuel) en su parte media. En líneas generales, las condiciones climáticas en la faja este de Mendoza durante el Quaternario tardío fluctuaron entre áridas y semi-áridas (ver Capítulos 2 y 8), sugiriendo que $H$. lagigliai podría habitar estos tipos de ambientes, en el caso de presentar disponibilidad de cursos de agua permanentes. No obstante, desde el siglo XVII los ciclos de aridez y bajas temperaturas asociados a la Pequeña Edad de Hielo y el impacto antrópico (principalmente desde los siglos XIX y XX, por la actividad ganadera y controles hídricos, mediante construcción de embalses y sistemas de riego), produjeron una mayor desertificación del área y disminuciones de los caudales de los principales ríos, lagunas y bañados (e.g., lagunas del Rosario; lagunas de Huanacache; bañados del Atuel) y la eventual desconexión de la cuenca Vinchina-BermejoDesaguadero-Salado (Roig, 1991; Chiesa et al., 2010). Asimismo, se estima que este sistema hídrico perdió gran parte de su influencia sobre la cuenca inferior del Río Colorado durante el Pleistoceno superior (asociado a menores niveles de deshielo) y posteriormente en tiempos históricos relacionado principalmente a factores antrópicos descriptos anteriormente (Spalleti e Isla, 2003). En este sentido, poblaciones de este taxón anfibio podrían haber ingresado al territorio mendocino, en tiempos históricos o antes del Pleistoceno superior, cuando aun existían mayores vinculaciones en la cuenca Bermejo-Desaguadero-Salado y con la cuenca del Río Colorado, resultando en poblaciones relictuales en tiempos recientes. En relación a esto, se destaca los registros aislados de otra formas anfibias y de abolengo brasílico como el marsupial didélfido Lutreolina crassicaudata (Desmarest, 1804), en el noreste de la provincia (Roig, 1991; 
Flores et al., 2007) y de Myocastor coypus (Molina, 1782) e Hydrochoerus hidrochaeris (Linnaeus, 1766), en los ríos Atuel y Diamante (Roig, 1991).

Bibliografía consultada: Hershkovitz, 1955; Massoia, 1971, 1976, 1981; Roig, 1991; Pardiñas y Galliari, 1998; Pardiñas, 1999a; Spalleti e Isla, 2003; Voglino et al., 2004; Musser y Carleton, 2005; Flores et al. 2007; Chiesa et al., 2010; Teta et al. 2005b; Pardiñas y Teta, 2011; Pardiñas et al., en prensa.

\section{Tribu Phyllotini Vorontsov, 1959.}

Es la tercera tribu más diversa de la subfamilia; se distribuyen a lo largo de los Andes y tierras bajas del cono sur de Sudamérica, principalmente en ambientes de pastizales, desiertos y semi-desiertos (Pardiñas et al., 2002). En Argentina se han registrado nueve géneros, de los cuales cinco se encuentran actualmente en Mendoza (Phyllotis, Graomys, Loxodontomys, Calomys y Eligmodontia).

En cuanto a la morfología cráneo-dentaria, los representantes de esta tribu exhiben frecuentemente la siguiente combinación de caracteres: fosa pterigoidea relativamente más ancha que la fosa mesopterigoidea, la cual presenta forma de " $U$ " invertida o de "M"; procesos pterigoides paralelos o levemente divergentes posteriormente; vacuidades esfenopalatinas muy abiertas; forámenes incisivos largos y delgados extendidos posteriormente hasta la porción anterior de los primeros molares; extensión posterior de los premaxilares y nasales sub-igual; bordes del supraorbital cuadrados y agudos, nunca redondeados; placa zigomática comparativamente alta y amplia, con el borde anterior plano, ligeramente convexo o cóncavo; incisivos no acanalados; molares con pérdida completa de los mesolofos/idos; ectolofo, anterolofo ausente; superficie oclusal del M2 cuadrada o en contorno rectangular; procíngulo del m1 no aislado de las cúspides por confluencia del protofléxido y el metafléxido; hipoflexo y paraflexos bien abiertos; paraflexo del M3 reducido o ausente; metafléxido del m3 obsoleto o ausente (Hershkovitz, 1962; Olds y Anderson, 1989; Steppan, 1995).

Género Phyllotis Waterhouse, 1837.

Phyllotis xanthopygus (Waterhouse, 1837)

Localidad Tipo: Puerto Santa Cruz, $c a$ a la desembocadura del río homónimo, Santa Cruz. 


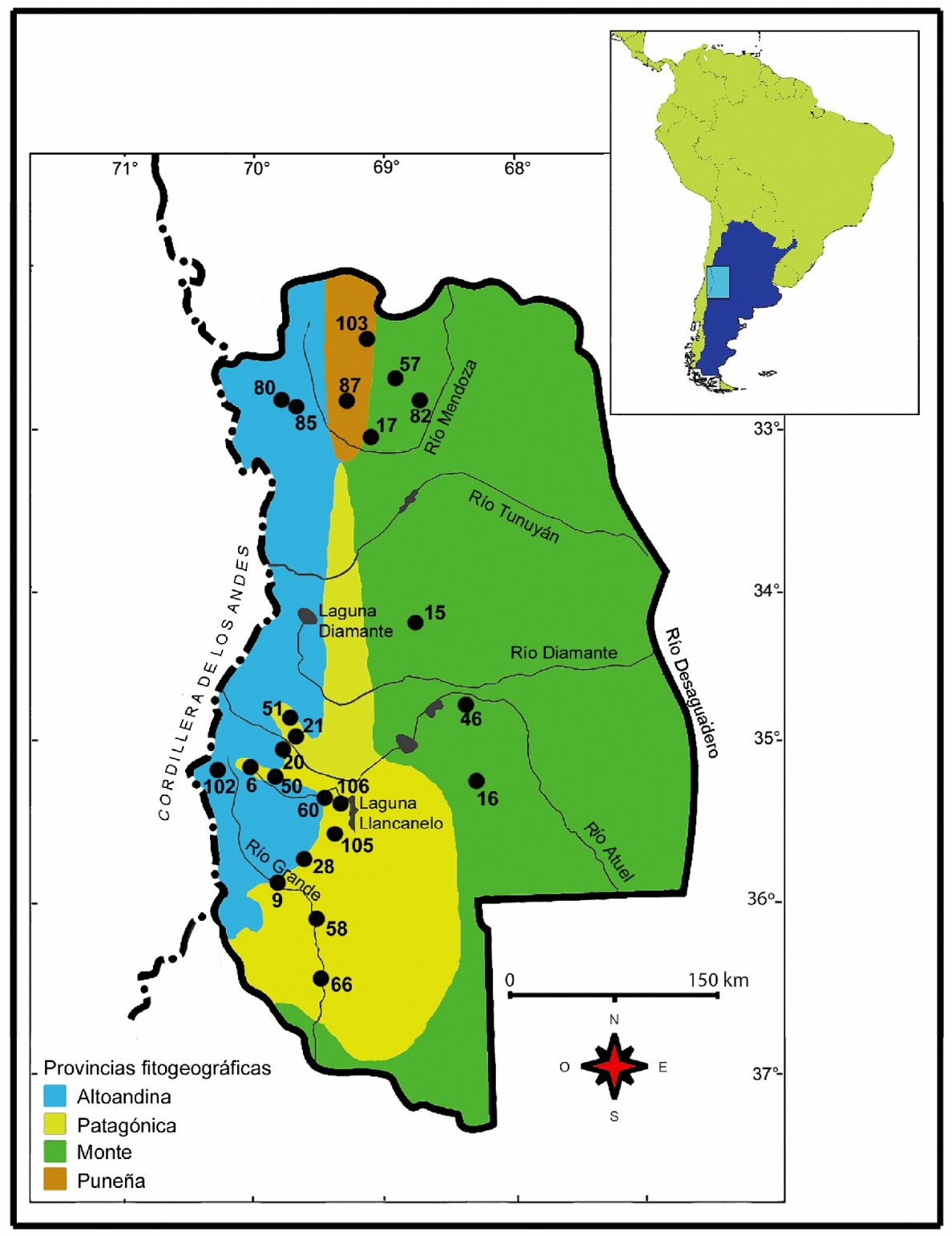

Figura 5.41. Localidades de registro de Phyllotis xanthopygus en la provincia de Mendoza.

Características generales: Phyllotis xanthopygus (pericote panza gris) es un filotino nocturno, cursorial y trepador. Es omnívoro y presenta un peso promedio de 57,5 g. Se encuentra asociado a pastizales con afloramientos rocosos, en ambientes desérticos y semidesérticos. Es un roedor abundante en áreas andinas. Phyllotis es uno de los géneros más diversos de los sigmodontinos (Kramer et al., 1999). Muchas de las poblaciones actualmente asignadas a $P$. xanthopygus, fueron consideradas como $P$. darwini (Pearson, 1958; Hershkovitz, 1962). Para la Argentina se han reconocido cuatro subespecies ( $P . x$. xanthopygus, $P . x$. vaccarum, $P . x$. ricardulus y $P . x$. rupestris) (Steppan, 1998; Díaz et al., 2006). En Mendoza, estudios moleculares recientes basados en secuencias de ADN mitocondrial gen citocromo $b$ confirman la subespecie $P$. $x$. 
vaccarum como parte del clado del este de los Andes (Riverón, 2011). Este autor plantea que posiblemente entre las provincias de Neuquén y Mendoza se ubicó el refugio norte de poblaciones más estables y diversas de esta especie, a partir del cual se expandió hacia el sur del río Negro, donde disminuyeron sus poblaciones durante el Holoceno por un proceso de mayor arbustización postglaciar.

Provincias comprendidas: Buenos Aires, Catamarca, Córdoba, Chubut, Jujuy, La Pampa, La Rioja, Mendoza, Neuquén, Río Negro, Salta, San Juan, San Luis, Santa Cruz, Santiago del Estero y Tucumán.

Localidades registradas en Mendoza: 6, 9, 15, 16, 17, 20, 21, 28, 46, 50, 51, 57, 58, $60,66,80,82,85,87,102,103,105,106$. Figura 5.41.

Descripción: cráneo con perfil aplanado en norma lateral; bordes de los frontales cuadrados y paralelos; constricción interorbital ligeramente menor que el ancho del rostro; sutura frontoparietal en forma de "U" abierta; placa zigomática alta y amplia, con el borde anterior recto y levemente inclinado hacia atrás; foramen incisivo extendido posteriormente hasta el nivel del procíngulo del M1; paladar largo y ancho; fosa mesopterigoidea con bordes paralelos; borde anterior de la fosa mesopterigoidea casi recto; amplitud de la fosa mesopterigoidea menor que la amplitud de la fosa parapterigoidea; proceso coronoides robusto e inflexionado hacia atrás y levemente por encima del cóndilo mandibular; muesca sigmoidea redondeada; escotadura semilunar excavada y asimétrica; incisivos superiores ortodontes; series dentarias superiores paralelas; fórmula alveolar: serie dentaria superior 4,3,3-2 / serie dentaria inferior 4,32, 2; molares con coronas planas; M1 con procíngulo triangular, nunca biconulado; M2/m2 en forma de "8"; M3 con anteroflexo ausente o reducido; M2 y M3 con mesoflexo vestigial; $m 1$ con cierre temprano del protofléxido, lo que determina el desarrollo de un anillo de esmalte en la porción anterolabial; $\mathrm{m} 1$ nunca con procíngulo biloconulado; m2 y m3 con procíngulo obsoleto. Figura 5.42.

Especies similares: Graomys griseoflavus y Loxodontomys micropus. 

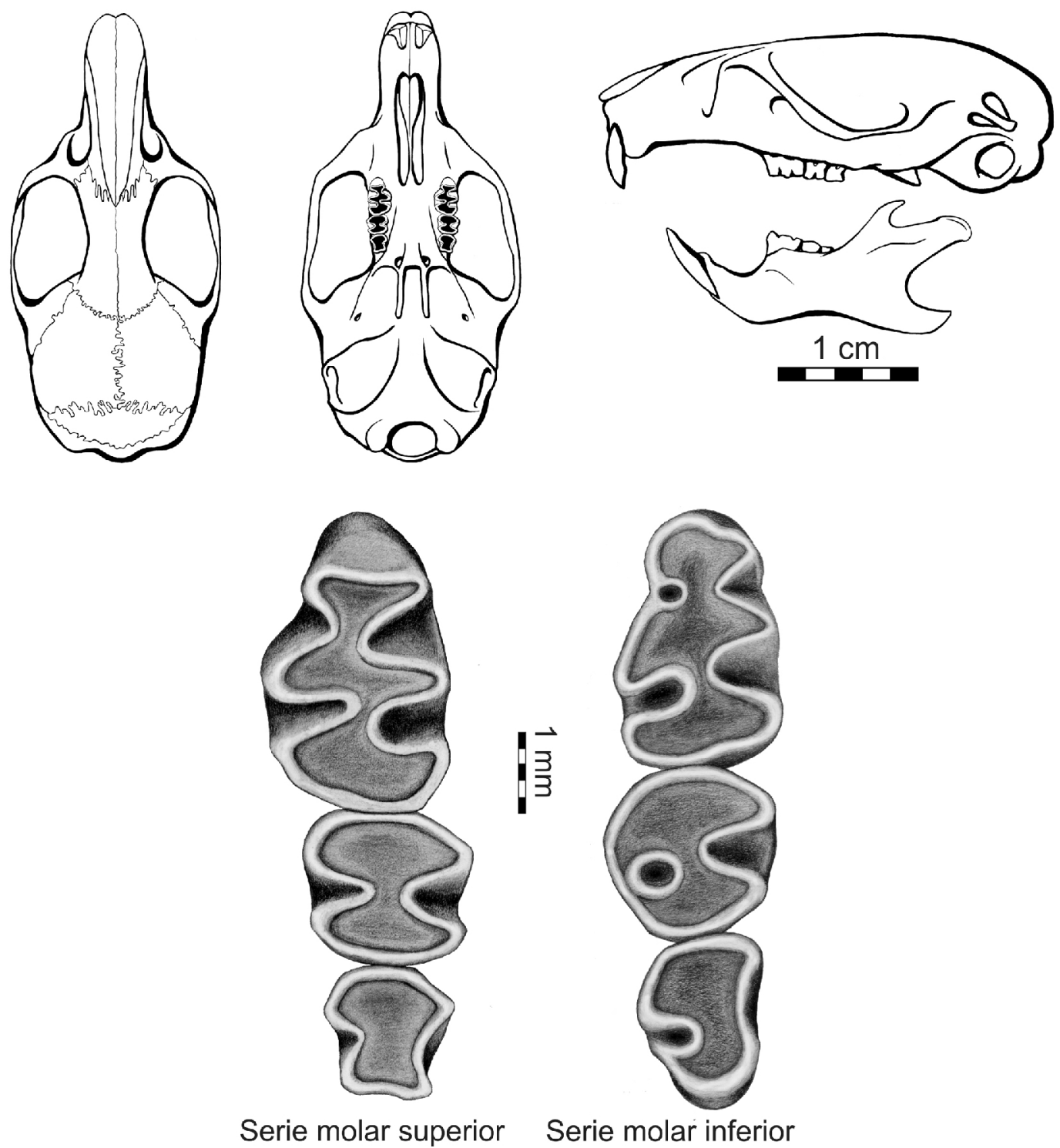

Figura 5.42. Esquemas cráneo-dentarios de Phyllotis xanthopygus.

Observaciones: en Mendoza está presente en todos los ambientes, aunque siempre asociado a afloramientos rocosos.

Bibliografía consultada: Pearson, 1958, 1995; Hershkovitz, 1962; Massoia, 1981a; Redford y Eisenberg, 1992; Massoia et al., 1994; Steppan, 1995, 1998; Kramer et al., 1999; Rapoport et al., 2001; Neme et al., 2002; Díaz et al., 2006; Gasco et al., 2006; Nabte et al., 2006; Pardiñas et al., 2008; Fernández et al., 2009a, 2009b; Udrizar Sauthier, 2009, Fernández, 2010, Riverón, 2011.

Género Graomys Thomas, 1916.

Graomys griseoflavus (Waterhouse, 1837). 
Localidad tipo: Desembocadura del río Negro, Río Negro.

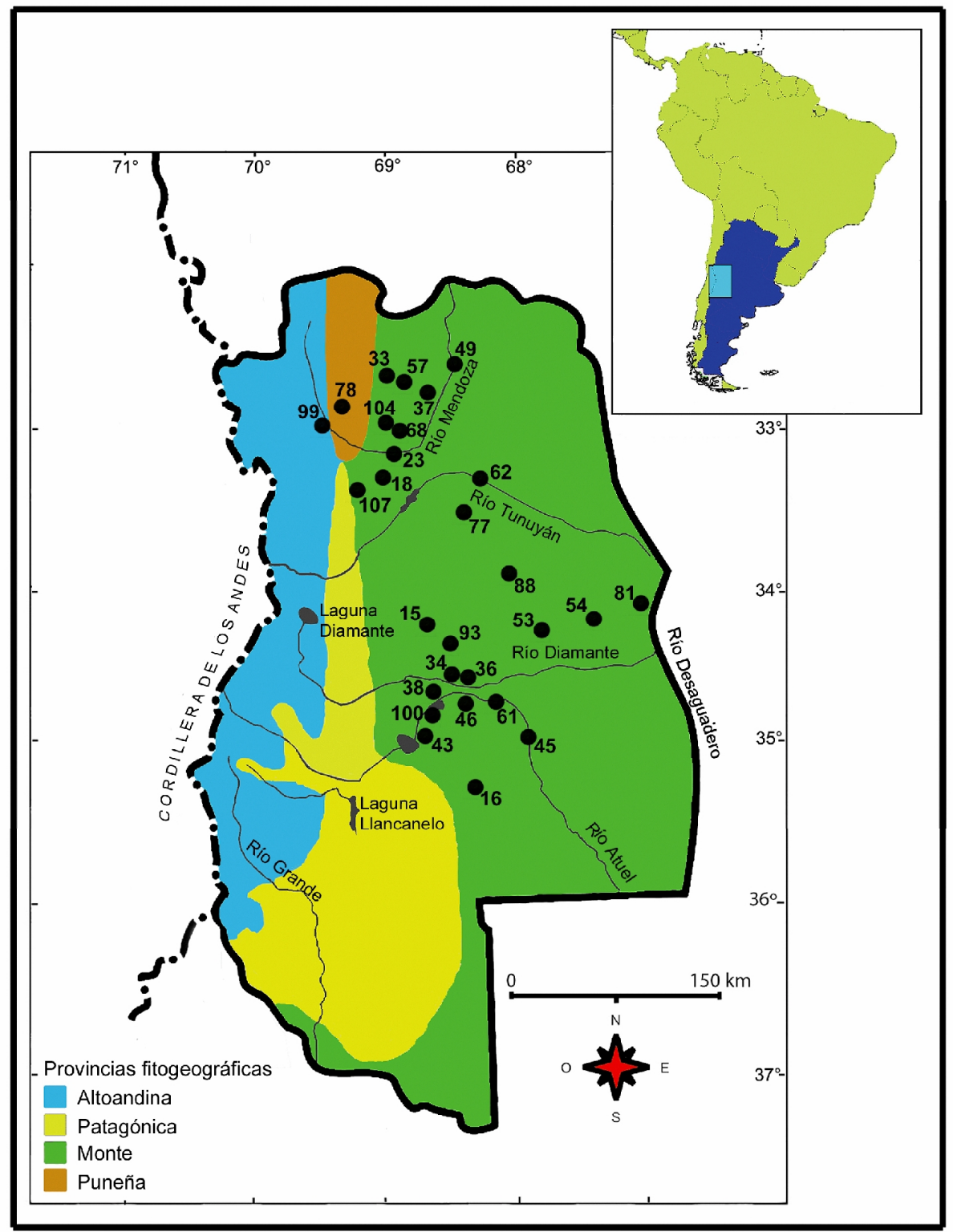

Figura 5.43. Localidades de registro de Graomys griseoflavus en la provincia de Mendoza.

Características generales: Graomys griseoflavus (pericote común) es un filotino nocturno, escansorial y saltador. Es principalmente folívoro y presenta un peso promedio de $56 \mathrm{~g}$. Se encuentra en gran variedad de ambientes aunque es más abundante en regiones con vegetación arbórea o arbustiva bajo condiciones semidesérticas a desérticas, desde el nivel del mar hasta los $2000 \mathrm{~m}$ de altitud. Ligado al matorral arbustivo esclerófilo del Monte y Espinal, con dominancia de Larrea spp. y Prosopis spp. En Patagonia su distribución está casi restriguida al desierto del Monte y su ocurrencia en la estepa Patagonica está asociada a los margenes de los principales 
rios, donde suelen penentran elementos del Monte. Díaz et al. (2006) sugieren que esta especie necesita una revisión taxonómica, debido al alto rango de variaciones morfológicas registrado en diferentes poblaciones, sumado al estatus desconocido de algunas formas afines incluidas en su sinonimia (e.g., cachinus y chacoensis). Asimismo, estudios moleculares realizados por Steppan et al. (2007), indican la existencia de al menos tres especies de Graomys, donde G. griseoflavus está más cercanamente relacionado a G. domorum (Thomas, 1902) que a G. centralis (Thomas, 1902). Recientemente, Martinez y Di Cola (2011) pudieron diferenciar a G. griseoflavus y G. chacoensis en base a datos morfométricos y distribucionales.

Provincias comprendidas: Buenos Aires, Catamarca, Chaco, Chubut, Formosa, Jujuy, La Pampa, La Rioja, Mendoza, Neuquén, Río Negro, Salta, San Juan, San Luis, Santa Cruz, Santiago del Estero y Tucumán.

Localidades registradas en Mendoza: 15, 16, 18, 23, 33, 34, 36, 37, 38, 43, 45, 46, 49, $53,54,57,61,62,68,77,78,81,88,93,99,100,104,107$. Figura 5.43 .

Descripción: cráneo con perfil aplanado en norma lateral; bordes de los frontales cuadrados y divergentes; constricción interorbital mayor que el ancho del rostro; sutura frontoparietal en forma de "V" bien abierta; espina zigomática moderadamente desarrollada; placa zigomática amplia, con el borde anterior cóncavo; foramen incisivo extendido posteriormente hasta el nivel del procíngulo del M1; paladar largo y moderadamente ancho; fosa mesopterigoidea con bordes paralelos; borde anterior de la fosa mesopterigoidea en forma de "M"; amplitud de la fosa mesopterigoidea menor que la de la fosa parapterigoidea; proceso coronoides corto, robusto e inflexionado hacia atrás, llegando a nivel del cóndilo mandibular, el cual está orientado medialmente; muesca sigmoidea reducida; proyección capsular conspicua; escotadura semilunar excavada y asimétrica; incisivos superiores ortodontes; series dentarias superiores paralelas; fórmula alveolar: serie dentaria inferior 4,3,3; molares con superficies oclusales planas, los superiores con tendencia a la laminación y los inferiores con cúspides triangulares; M1 con corona baja y patrón trilofodonte; M1 con procíngulo en forma triangular, el ápice dirigido hacia atrás y el flexo anteromediano levemente evidente; M2 en forma de " $E$ "; M2 con anterolofo y paraflexo bien desarrollados; M3 tiende a estar dividido por la confluencia del hipoflexo-mesoflexo; $m 1$ con cíngulo anterolabial presente y con apertura labial del protofléxido; $\mathrm{m} 2$ con protofléxido bien desarrollado. Figura 5.44. 

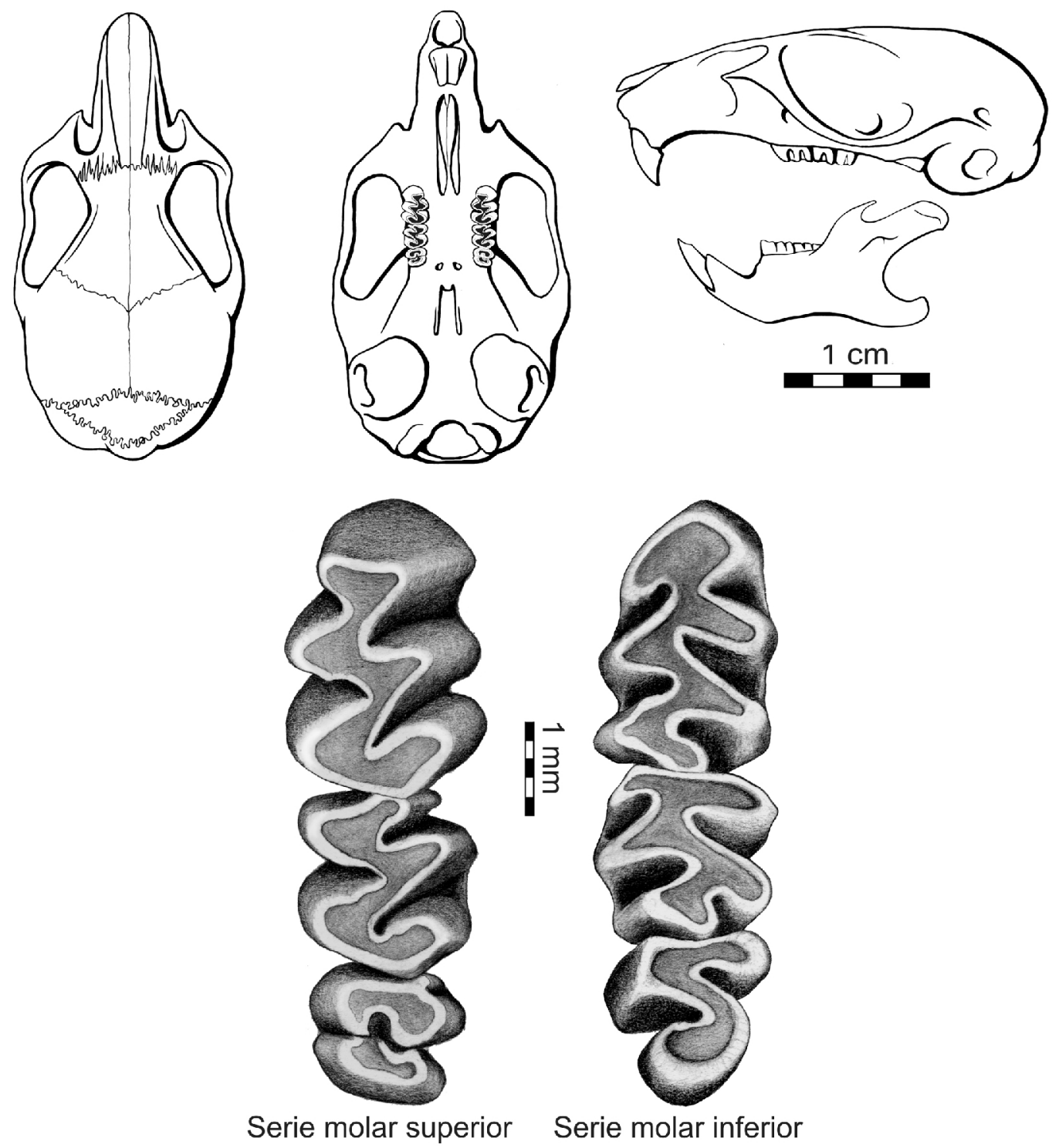

Figura 5.44. Esquemas cráneo-dentarios de Graomys griseoflavus.

Especies similares: Phyllotis xanthopygus. La presencia de la apertura labial del protofléxido en G. griseoflavus, la morfología del proceso coronoides y la cantidad de raíces en el alveolo del $\mathrm{m} 3$ son rasgos diagnósticos para diferenciar ambas especies.

Observaciones: en Mendoza es muy abundante en ambientes del desierto del Monte, con resgistros aislados en sectores Puneños y Altoandinos de la parte norte de la provincia.

En el desierto del Monte del centro-este de Mendoza encuentra su hábitat óptimo en el algarrobal.

Bibliografía consultada: De La Barrera, 1939, 1940, 1941; Hershkovitz, 1962; Roig, 1962, 1965; Contreras, 1979; Massoia, 1981a; Rosi, 1983; Steppan, 1995; Massoia et 
al., 1997; Pardiñas, 1999; Neme et al., 2002; Corbalán, 2004; Pardiñas et al., 2004; Corbalán y Ojeda, 2004, 2005; Corbalán et al., 2006; Díaz et al., 2006; Nabte et al., 2006; Steppan et al., 2007; Fernández et al., 2009a, 2009b; Udrizar Sauthier, 2009; Martínez et al., 2010a; Martínez y Di Cola, 2011; Udrizar Sauthier et al., 2011.

Género Loxodontomys Osgood, 1947.

Loxodontomys micropus (Waterhouse, 1837).

Localidad tipo: de ambigua definición. Indicada para algún punto del río Santa Cruz.

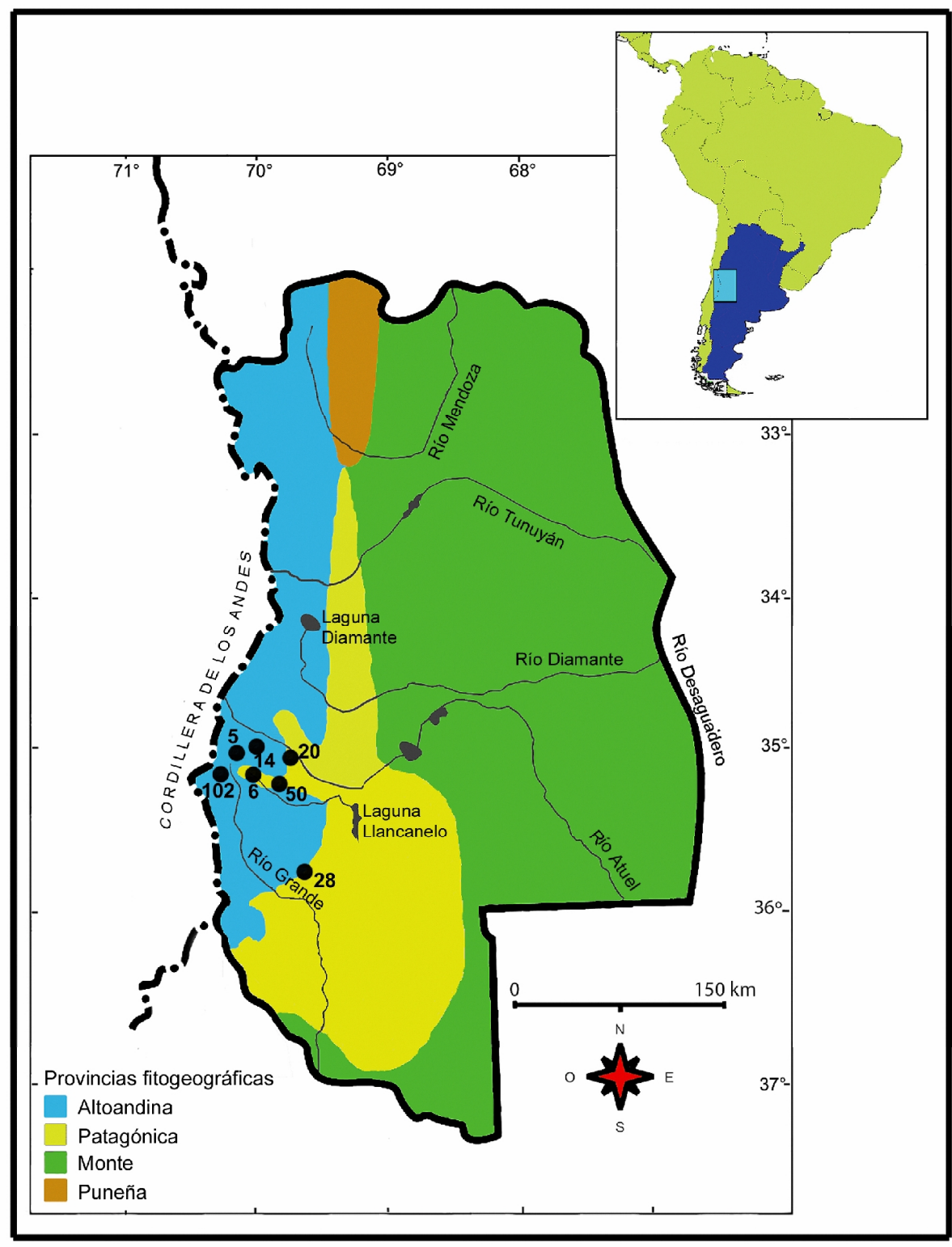

Figura 5.45. Localidades de registro de Loxodontomys micropus en la provincia de Mendoza. 
Características generales: Loxodontomys micropus (pericote sureño) es un filotino nocturno, construye madrigueras y es buen trepador. Es herbívoro, granívoro y frugívoro y presenta un peso promedio de $63 \mathrm{~g}$. Está presente en áreas de vegetación densa, tanto en bosques como en estepas arbustivas de cordillera y piedemonte, estepas patagónicas y herbáceas con elevada humedad y en mallines ecotonales. Esta especie anteriormente estaba incluida en los géneros Phyllotis y Auliscomys (Simonetti y Spotorno, 1980). Braun (1993) y Steppan (1995) describen y revalidan el género Loxodontomys. Cañón et al. (2010) en un reciente estudio filogeográfico a partir de ADN mitocondrial gen citocromo $b$ registraron cuatro clados para L. micropus, los cuales se diferenciaron posiblemente durante el Último Máximo Glaciar. Las poblaciones de Mendoza formarían parte del clado norte junto con las de Chubut, Neuquén y las de algunas regiones de Chile (Araucanía, Bio Bio, Maule y Los Lagos). Cuando los glaciares se retrajeron L. micropus colonizó las áreas de distribución actual, quedando algunas poblaciones relictuales hacie el este de la Patagonia (Teta et al., 2009).

Provincias comprendidas: Santa Cruz, Chubut, Río Negro, Neuquén, Mendoza.

Localidades registradas en Mendoza: 5, 6, 14, 20, 28, 50, 102. Figura 5.45.

Descripción: cráneo robusto con perfil abovedado en norma lateral; bordes de los frontales marcados, subcuadrados y paralelos o ligeramente cóncavos; constricción interorbital menor que el ancho del rostro; sutura frontoparietal en forma de "U" abierta; muesca zigomática conspicua; placa zigomática alta y angosta, con el borde anterior ligeramente cóncavo; foramen incisivo bien abierto, extendido posteriormente hasta el nivel del procíngulo del M1; paladar moderadamente largo y ancho; fosa mesopterigoidea con bordes subparalelos; borde anterior de la fosa mesopterigoidea en forma de "M"; amplitud de la fosa mesopterigoidea menor que la amplitud de la fosa parapterigoidea; mandíbula robusta y corta; proceso coronoides de base ancha e inflexionado hacia atrás y levemente por encima del cóndilo mandibular; escotadura semilunar excavada y casi simétrica; proyección capsular conspicua; proceso ventromedial de la rama mandibular en ángulo agudo; incisivos superiores robustos y amarillos, hiperhipsodontes y con fisura tripartita en la dentina en forma de $Y$; incisivos superiores opistodontes; series dentarias superiores moderadamente divergentes; fórmula alveolar: serie dentaria superior 4-3,3,2 / serie dentaria inferior 4-3,2,2; molares con coronas planas; M1/m1 con procíngulos subelípticos; procíngulo del ml unido con el resto del diente mediante un puente angosto (=múrido anterior); 
M2 y M3 con procíngulos bien desarrollados; M3 con hipoflexo más reducido que en el $\mathrm{M} 2 ; \mathrm{m} 1$ con cíngulo anterolabial conspicuo; $M 2 / m 2$ en forma de " $E$ "; $\mathrm{m} 2$ con protofléxido marcado como un surco; $\mathrm{m} 3$ tan largo como el m2. Figura 5.46.
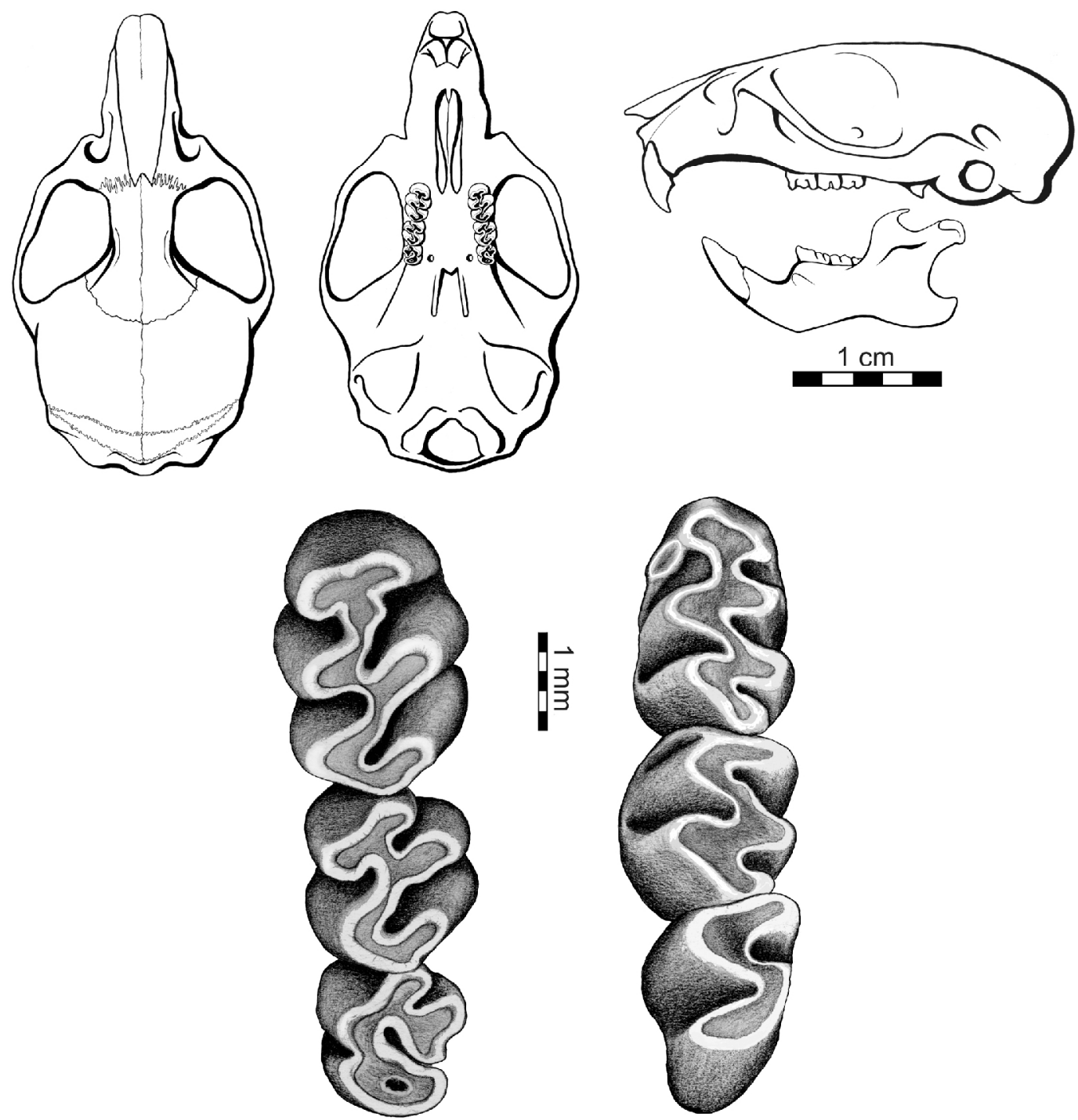

Serie molar superior

Serie molar inferior

Figura 5.46. Esquemas cráneo-dentarios de Loxodontomys micropus.

Especies similares: Phyllotis xanthopygus.

Observaciones: en Mendoza está documentado en estepas Patagónicas y Altoandinas de la parte sudoeste de la provincia.

Bibliografía consultada: Hershkovitz, 1962; Simonetti y Spotorno, 1980; Pearson 1983, 1995; Braun, 1993; Steppan, 1995; Figueroa Rojas et al., 2001; Ortiz et al., 2004; Díaz et al., 2006; Gasco et al., 2006; Jayat et al., 2006; Pardiñas et al., 2008; Udrizar 
Sauthier et al., 2008; Teta et al., 2009; Fernández et al., 2009a, 2009b; Udrizar Sauthier, 2009; Cañón et al., 2010.

Género Calomys Waterhouse, 1837.

Calomys musculinus (Thomas, 1913).

Localidad tipo: Maimará, Jujuy.

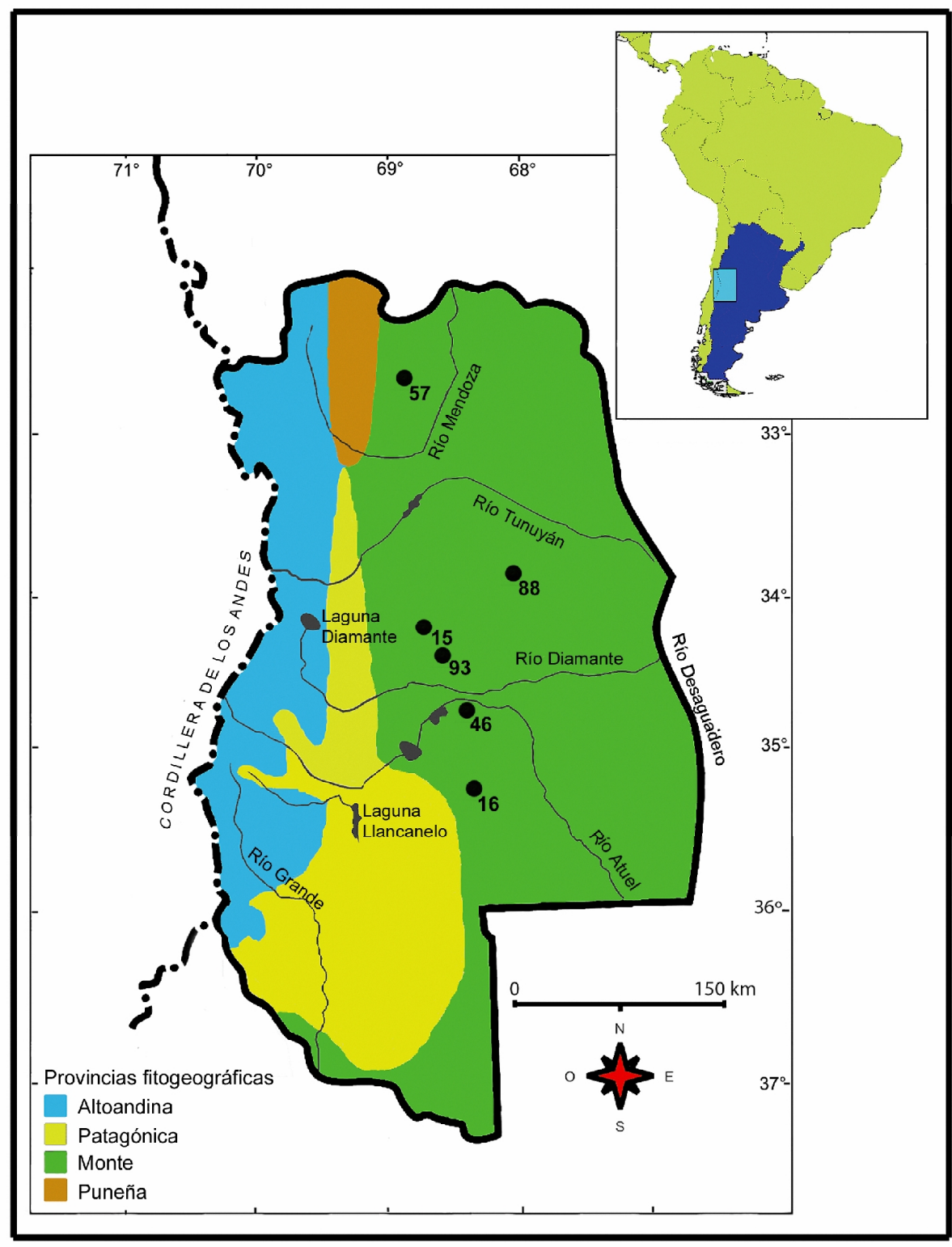

Figura 5.47. Localidades de registro de Calomys musculinus en la provincia de Mendoza.

Características generales: Calomys musculinus (laucha bimaculada) es un filotino nocturno, cursorial y cuadrúpedo. Es omnívoro, con tendencia a la granivoría y presenta un peso promedio de 15,5 g. Exhibe una amplia distribución, ocupando multiplicidad de 
ambientes. La dominancia de este roedor en ciertas localidades de la Patagonia ha sido asociada a un proceso de antropización ambiental, principalmente producido por el sobrepastoreo. En base a evidencia molecular Salazar-Bravo et al. (2001) argumentaron que Calomys musculinus es una sola forma ampliamente distribuida.

Provincias comprendidas: Buenos Aires, Catamarca, Córdoba, Chaco, Chubut, Formosa, Jujuy, La Pampa, La Rioja, Mendoza, Neuquén, Salta, San Juan, San Luis, Santa Cruz, Santa Fe, Santiago del Estero y Tucumán.

Localidades registradas en Mendoza: 15, 16, 46, 57, 88, 93. Figura 5.47.

Descripción: cráneo con perfil abovedado en norma lateral; nasales y premaxilares cortos; bordes de los frontales cuadrados y divergentes; constricción interorbital ligeramente mayor que el ancho del rostro; sutura frontoparietal en forma de "U" abierta; placa zigomática baja, con el borde anterior ligeramente cóncavo; margen posterior de la placa zigomática nace a la misma altura que el M1; foramen incisivo extendido posteriormente hasta el nivel del paracono y protocono del M1; paladar largo y ancho; fosa mesopterigoidea con bordes paralelos; borde anterior de la fosa mesopterigoidea casi recto; amplitud de la fosa mesopterigoidea menor que la amplitud de la fosa parapterigoidea; proceso coronoides robusto e inflexionado hacia atrás, por encima del cóndilo mandibular; escotadura semilunar moderadamente excavada y simétrica; tubérculo maséterico marcado, auque no tan conspicuo como en Eligmodontia; incisivos superiores ligeramente opistodontes; series dentarias superiores levemente convergentes; fórmula alveolar: serie dentaria superior 4,3,3 / serie dentaria inferior 4,3,3; molares con coronas crestadas y patrón trilofodonte, con cúspides primarias en posición opuesta; molares superiores con posteroflexo reducido; $\mathrm{Ml} / \mathrm{ml}$ con procíngulo biconulado, con flexo/ido anteromediano bien desarrollado, determinando un cónulo/ido labial de mayor tamaño que el lingual; M2 con metaflexo muy amplio en sentido antero-posterior y con anteroflexo bien evidente; M2 y M3 con paraflexo bien desarrollado; M3 con hipoflexo unido al metaflexo; $\mathrm{m} 1$ con cíngulo labial conectando, como un reborde bien desarrollado, al procíngulo; m2 subcuadrado, con metafléxido presente; $\mathrm{m} 3$ con metafléxido reducido. Figura 5.48.

Especies similares: Eligmodontia spp. Una diferencia importante es que C. musculinus presenta los molares más chicos, tres raíces en el alvéolo del $\mathrm{m} 3$, proceso coronoides más grande y rostro más corto.

Observaciones: en Mendoza es común en el desierto del Monte y en el centro oeste de la provincia encuentra su hábitat óptimo en el jarillal. 

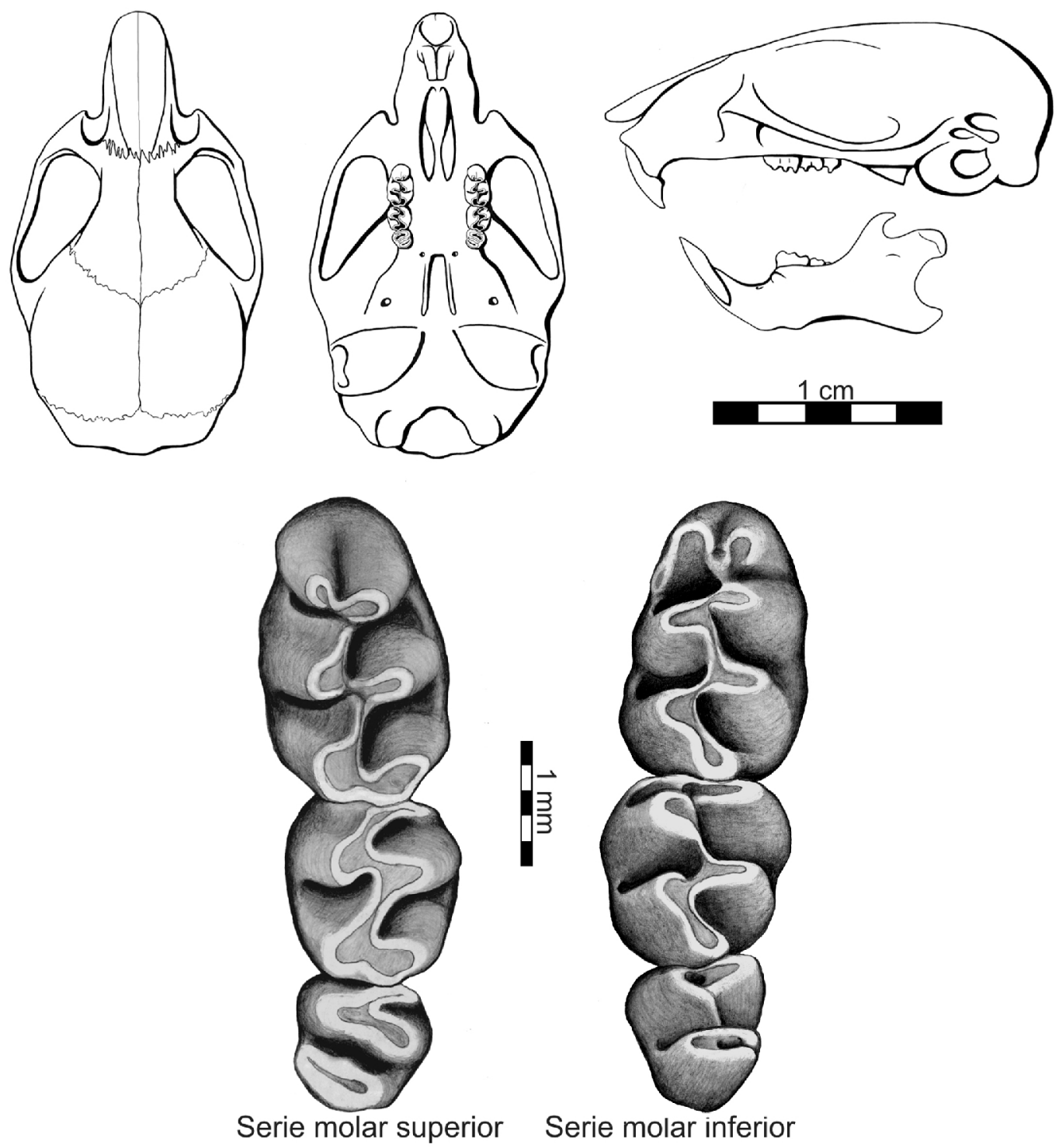

Figura 5.48. Esquemas cráneo-dentarios de Calomys musculinus.

Bibliografía consultada: Hershkovitz, 1962; Contreras y Roig, 1972; Contreras y Rosi, 1980b; Olds, 1988; Redford y Eisenberg, 1992; Pearson, 1995; Steppan, 1995; Pardiñas et al., 2000; Salazar-Bravo et al., 2001; Corbalán, 2004; Pardiñas et al., 2000, 2004; Corbalán y Ojeda, 2004, 2005; Corbalán et al., 2006; Díaz et al., 2006; Nabte et al., 2006; Fernández et al., 2009b; Ojeda y Tabeni, 2009; Udrizar Sauthier, 2009.

Género Eligmodontia Cuvier, 1837.

Localidad tipo: E. morgani Allen 1901, Cañones basaltitos del Arroyo Else a $80 \mathrm{~km}$ al SE del Lago Buenos Aires, Santa Cruz, Argentina / E. moreni Thomas 1896, Chilecito, La Rioja, Argentina / E. typus Cuvier 1837, Buenos Aires, Argentina. 


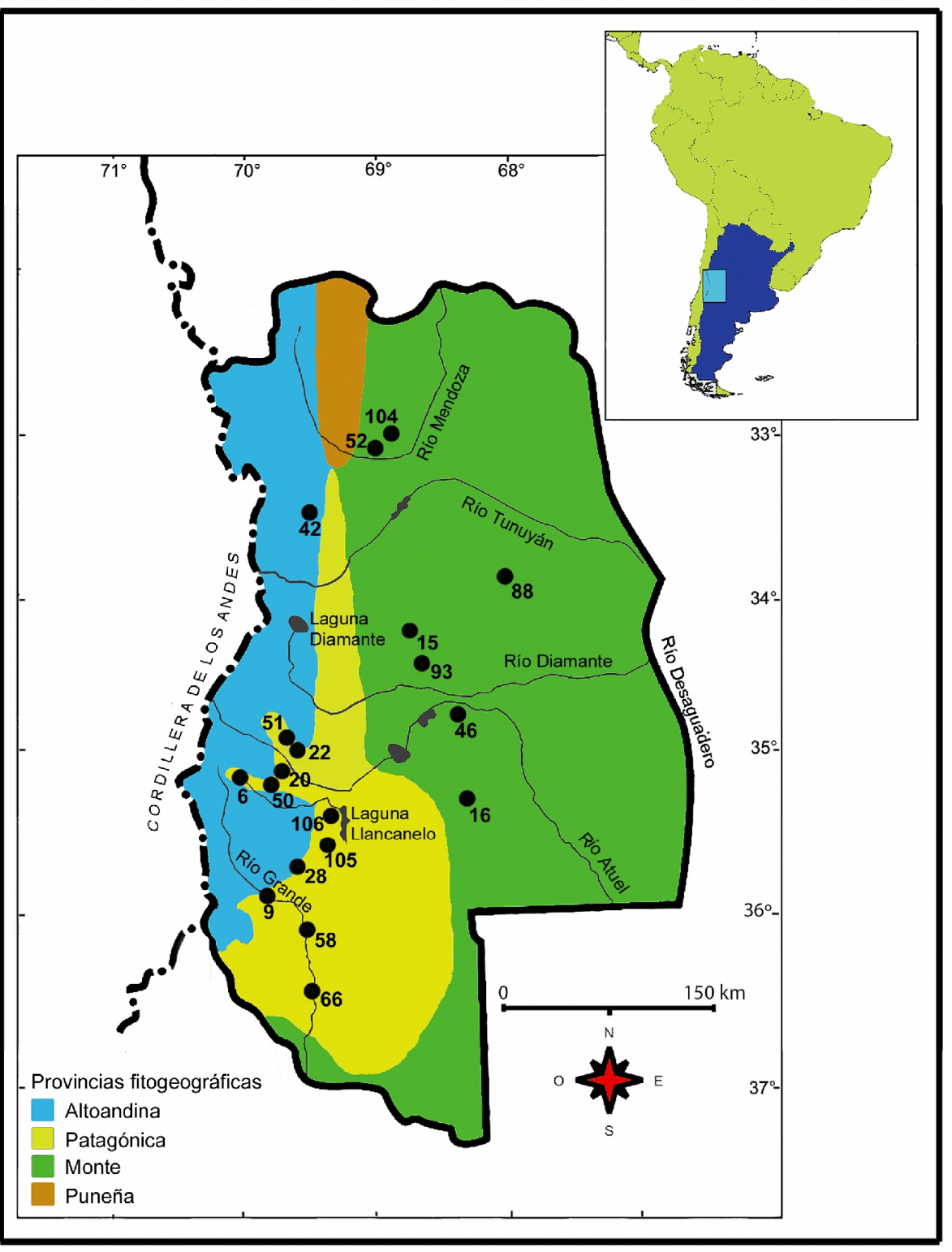

Figura 5.49. Localidades de registro de Eligmodontia en la provincia de Mendoza.

Características generales: Eligmodontia (lauchas colilargas) es un filotino nocturno, cursorial y saltador. Es omnívoro y presenta un peso promedio de $21 \mathrm{~g}$. Las especies de este género son propias de ecosistemas áridos y semi-áridos. En el sudoeste de Mendoza se encuentran bien representadas Eligmodontia morgani, E. moreni y E. typus. La primera se asocia a la estepa Patagónica y las otras dos al desierto del Monte. En base a evidencias cariotípicas Eligmodontia morgani (Kelt et al., 1991), E. moreni (Spotorno et al. 1994) y E. typus (Tiranti, 1997) fueron reconocidas como especies plenas. Mares et al. (2008) a partir de ADN mitocondrial gen citocromo $b$ registraron dos clados mayores de Eligmodontia (Andino y no Andino) y seis menores [E. typus (tierras bajas), E. typus (tierras altas), E. morgani, E. puerulus, E. moreni y E. hirtipes]. 
Recientemente, Pardiñas y Teta (2010) en base a caracteres morfológicos y métricos plantean que Graomys hypogaeus Cabrera, 1934 se considere sinonimo junior de $E$. moreni.

Provincias comprendidas: Buenos Aires, Catamarca, Jujuy, La Rioja, Salta, Tucumán, Chubut, La Pampa, San Juan, Mendoza, Neuquén, Río Negro y Santa Cruz. Sólo se considera las especies que se encuentran en Mendoza.

Localidades registradas en Mendoza: 6, 9, 15, 16, 20, 22, 28, 42, 46, 50, 51, 52, 58, $66,88,93,104,105,106$. Figura 5.49.

Descripción: cráneo con perfil abovedado en norma lateral; bordes de los frontales cuadrados y divergentes; nasales alargados y angostos; constricción interorbital mayor que el ancho del rostro; sutura frontoparietal en forma de "U" bien abierta; placa zigomática moderadamente alta y amplia, con el borde anterior levemente cóncavo; foramen incisivo extendido posteriormente hasta el nivel del procíngulo del M1; paladar largo y ancho; fosa mesopterigoidea con bordes subdivergentes; borde anterior de la fosa mesopterigoidea casi recto; amplitud de la fosa mesopterigoidea menor que la amplitud de la fosa parapterigoidea; proceso coronoides robusto e inflexionado hacia atrás, ligeramente por encima del cóndilo mandibular; escotadura semilunar excavada y asimétrica; tubérculo maséterico bien marcado; proyección capsular conspicua; incisivos superiores opistodontes; series dentarias superiores paralelas; fórmula alveolar: serie dentaria superior 4,3,3-2 / serie dentaria inferior 4-3,3,2; molares con coronas aterrazadas y cúspides primarias en posición alternada; M1 con flexo anteromediano poco evidente; M2 en forma de "E"; M2 con anterolofo bien desarrollado; $\mathrm{m} 2$ con posterlófido evidente. Figura 5.50.

Especies similares: Calomys musculinus.

Observaciones: la realización de esta ficha a nivel de género obedece a que los restos exhumados de sitios arqueológicos frecuentemente están fragmentados y en este caso por carecer de rasgos morfológicos craneanos diagnósticos, resulta imposible arribar a su determinación específica. El género Eligmodontia se encuentra en casi todos los ambientes de Mendoza, evitando sectores Altoandinos. En el desierto del Monte del centro-este de Mendoza, E. typus encuentra su hábitat óptimo en el medanal. 

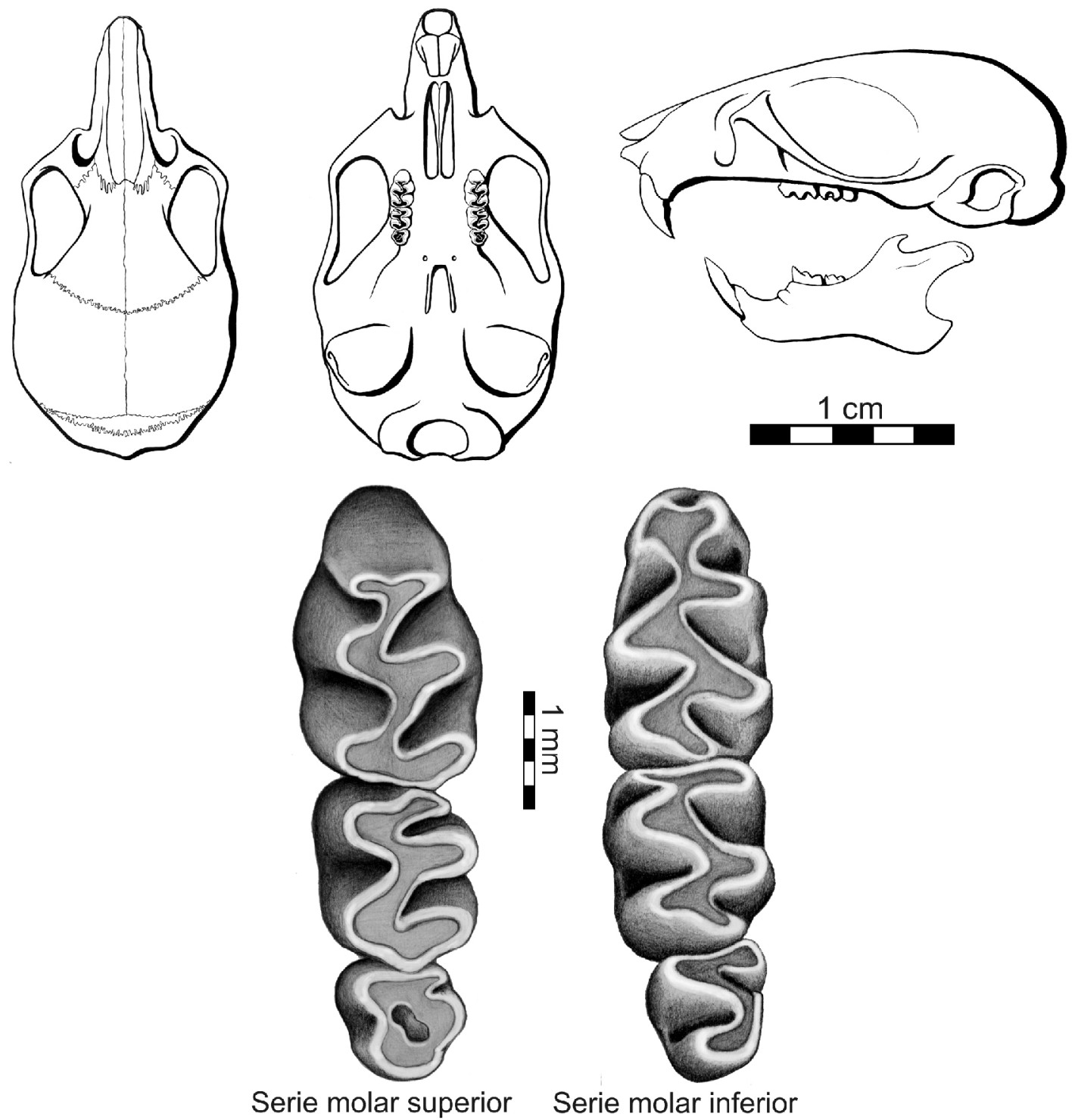

Figura 5.50. Esquemas cráneo-dentarios de Eligmodontia.

Bibliografía consultada : Hershkovitz, 1962; Massoia, 1981a; Kelt et al., 1991; Massoia et al., 1994; Spotorno et al., 1994; Pearson, 1995; Steppan, 1995; Massoia et al., 1997; Sikes et al., 1997; Tiranti, 1997; Neme et al., 2002; Corbalán, 2004; Corbalán y Ojeda, 2004, 2005; Lanzone y Ojeda, 2005; Corbalán et al., 2006; Díaz et al., 2006; Gasco et al., 2006; Nabte et al., 2006; Mares et al., 2008; Pardiñas et al., 2008; Fernández et al., 2009a, 2009b; Ojeda y Tabeni, 2009; Udrizar Sauthier, 2009; Fernández, 2010; Pardiñas y Teta, 2010.

Tribu Reithrodontini Vorontsov, 1959. 
Estudios filogenéticos en base a secuencias de ADN mitocondrial y nuclear sostienen que Reithrodontini es una tribu monotípica representada por el género Reithrodon (Smith y Patton, 1999; D’Elía, 2003). No obstante, tradicionalmente este género era incluido en la tribu Phyllotini (e.g., Steppan 1995).

Género Reithrodon Waterhouse, 1837.

Reithrodon auritus (Fischer, 1814).

Localidad Tipo: restringida por Hershkovitz (1959) al Sur del Río de la Plata (Buenos Aires, Argentina). No obstante, Fischer (1814) lo ubica en Las Pampas al Sur de Buenos Aires.

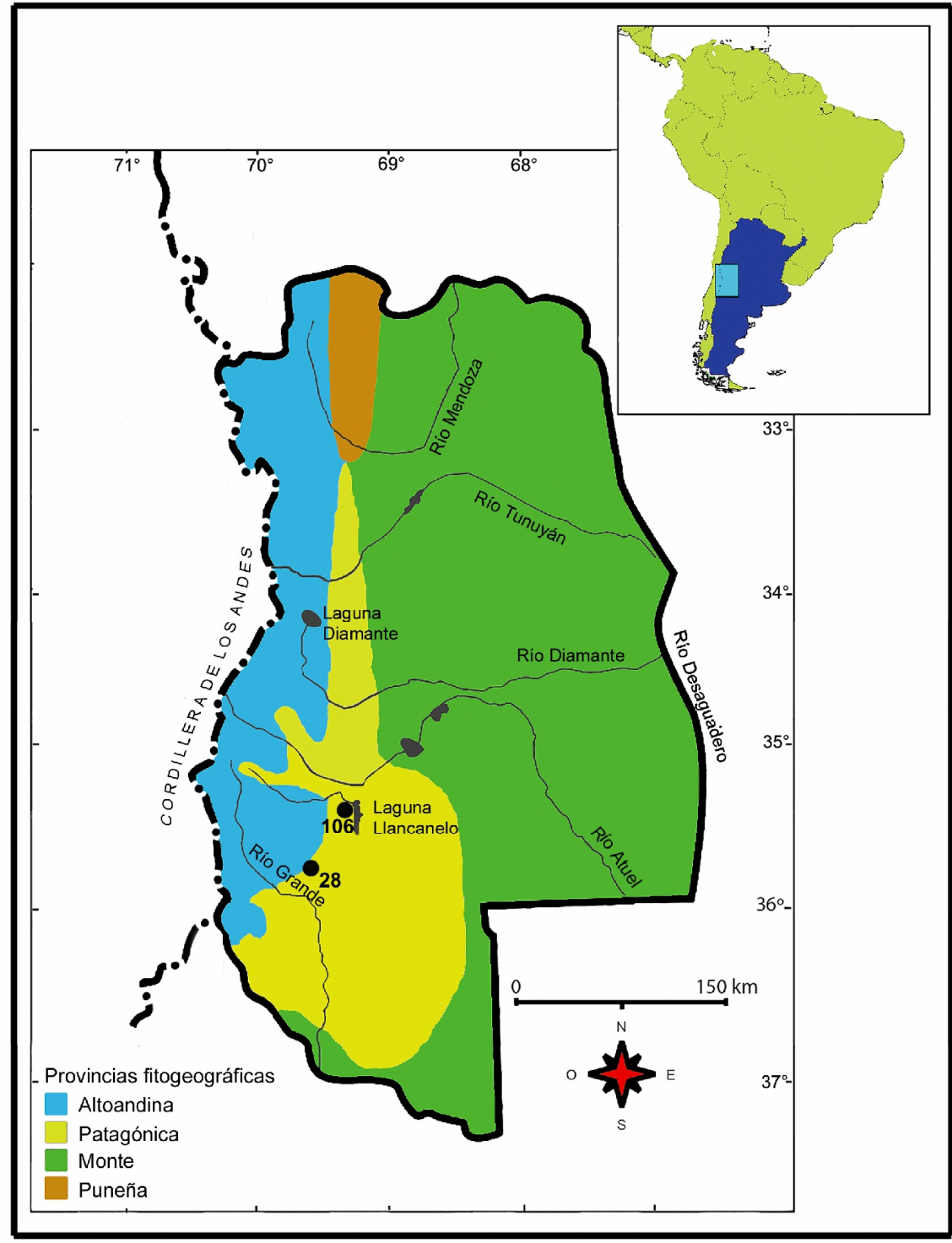

Figura 5.51. Localidades de registro de Reithrodon auritus en la provincia de Mendoza. 
Características generales: Reithrodon auritus (rata conejo) es un reitrodontino crepuscular y nocturno, semi-fosorial y cavador. Es herbívoro y presenta un peso promedio de 80,1 g. Esta especie es más abundante en la estepa Patagónica que en el desierto del Monte. En Norpatagonia ocupa pastizales densos de hierbas cortas y estepas arbustivo-graminosas de cobertura moderada.

Provincias comprendidas: Buenos Aires, Catamarca, Córdoba, Chubut, Jujuy, La Pampa, Mendoza, Neuquén, Río Negro, Santa Cruz, Tierra del Fuego y Tucumán.

Localidades registradas en Mendoza: 28, 106. Figura 5.49.

Descripción: cráneo con perfil abovedado en norma lateral; bordes de los frontales cuadrados y paralelos; constricción interorbital igual que el ancho del rostro; constricción interorbital bien marcada y desplazada hacia atrás, de modo que la caja craneana es muy corta; sutura frontoparietal en forma de "V" abierta; espina zigomática bien marcada; placa zigomática con el borde anterior bien cóncavo; foramen incisivo extendido posteriormente hasta el nivel del protocono y paracono del M1; paladar angosto y largo; foramen palatal posterolateral muy desarrollado; fosa mesopterigoidea con bordes divergentes; borde anterior de la fosa mesopterigoidea en forma de "M"; amplitud de la fosa mesopterigoidea menor que la amplitud de la fosa parapterigoidea; ambas fosas son bien profundas; mandibula robusta, con un surco amplio en la cara interna del cóndilo mandibular; crestas masetéricas unidas a la altura de la mitad posterior del m1, formando reborde único casi hasta alcanzar el foramen mentoniano; proceso coronoides corto y moderadamente inflexionado hacia atrás, por debajo del cóndilo mandibular; escotadura semilunar excavada y casi simétrica; incisivos superiores opistodontes, con un surco longitudinal de posición central; series dentarias superiores divergentes; fórmula alveolar: serie dentaria superior 5-4,3,4-3 / serie dentaria inferior 4,3,3-2; molares hipsodontes, laminados y de corona plana; M1 con patrón trilofodonte, protocono e hipocono sub-iguales; M3 con buen desarrollo del mesoflexo; $m 1$ con procíngulo subtriangular; $\mathrm{m} 2$ con protofléxido poco desarrollado. Figura 5.52.

Especies similares: Euneomys spp.

Observaciones: en Mendoza los escasos registros se encuentran en ambientes de estepa Patagónica, en la parte sur de la provincia. 

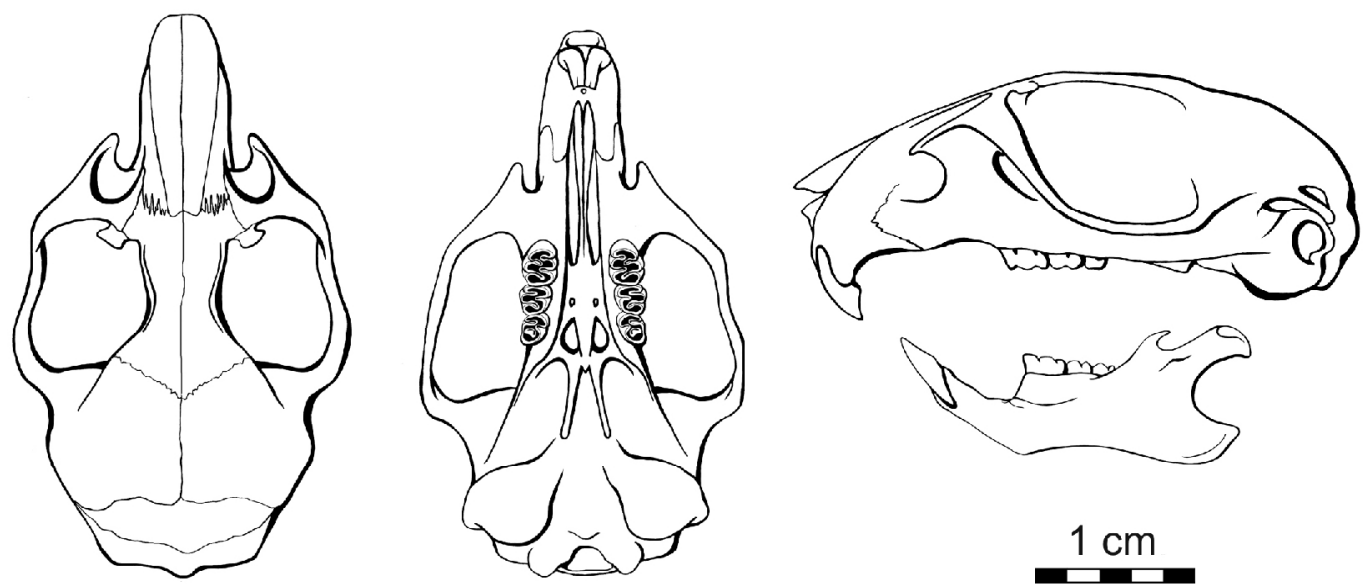

$1 \mathrm{~cm}$

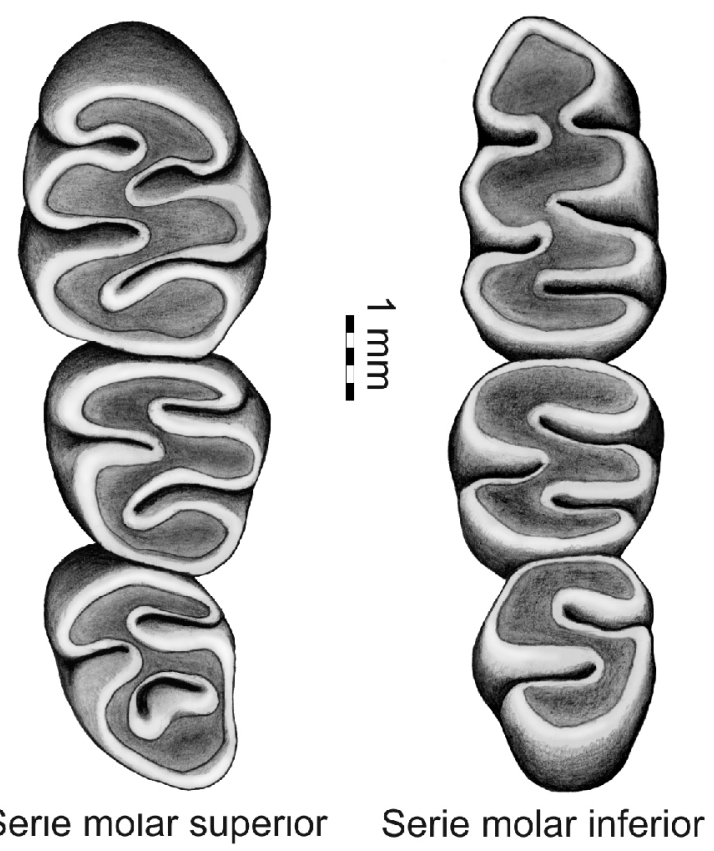

Figura 5.52. Esquemas cráneo-dentarios de Reithrodon auritus.

Bibliografía consultada: Fischer, 1814; Osgood, 1943; Hershkovitz, 1959; Cabrera, 1961; Massoia, 1981a; Pearson, 1988, 1995; Monjeau, 1989; Steppan, 1995; Guthmann et al., 1997; Smith y Patton, 1999; Pardiñas y Galliari, 2001; D’Elía, 2003; Pardiñas et al., 2003, 2006b, 2008; Gasco et al., 2006; Jayat et al., 2006; Udrizar Sauthier, 2009.

\section{Incertae Sedis}

Hay ciertos géneros que no se relacionan cercanamente a ningún otro género en particular; de este modo, se hace dificultosa su inclusión a nivel supragenérico (Pardiñas et al., 2002; D'Elía et al., 2006). Este es, por ejemplo, el caso de Euneomys, que en la 
provincia de Mendoza está representado por dos especies: E. chinchilloides y E. mordax. No obstante, tradicionalmente este género ha sido incluido en la tribu Phyllotini dentro del grupo Reithrodon (e.g., Hershkovitz, 1962; Steppan, 1995). Recientemente, Martínez et al. (2012) en base a estudios de marcadores genéticos nucleares y mitocodriales, plantean que Euneomys junto a otros dos géneros incertae sedis (Irenomys Thomas, 1919 y Neotomys Thomas, 1894) forma un grupo monofilético. Estos autores señalan, que esta información podría ser el inicio para la definición de una nueva tribu de roedores sigmodontinos que incluya a estos géneros, aunque destacan que se necesitan más datos moleculares y morfológicos para formalizar la descripción de la tribu.

Género Euneomys Coues, 1874.

Euneomys chinchilloides (Waterhouse, 1839).

Localidad tipo: Tierra del Fuego, orilla del estrecho de Magallanes, cerca de su entrada oriental, Chile (véase discusión Osgood, 1943).

Características generales: Euneomys chinchilloides (ratón peludo castaño) es un roedor nocturno y cursorial. Es herbívoro y presenta un peso promedio de $85 \mathrm{~g}$. Ocupa tanto ambientes del desierto del Monte como de la estepa Patagónica, desde el nivel del mar hasta $2300 \mathrm{~m}$ de altitud. Es una especie con preferencia a los hábitats relativamente abiertos, con suelos pedregosos y escasa vegetación. Es un roedor propio de los mallines cordilleranos por encima de los $2000 \mathrm{~m}$ de altitud. El estatus taxonómico del género Euneomys es poco claro. Raise y Gallardo (1990) y Pearson y Christie (1991) son los más recientes revisores del género, ambos coinciden en referirse a $E$. chinchilloides y E. mordax para algunas muestras de la Patagonia argentina y chilena. Sin embargo, difieren en cuanto que Pearson y Christie (1991) consideraron a E. noei Mann, 1944 como conespecífico de E. mordax, mientras que Raise y Gallardo (1990) lo trataron, junto con E. petersoni Alen, 1903, como sinónimo subjetivo de $E$. chinchilloides, hipótesis no corroborada con las característica morfológicas del holotipo. Por otra parte, Musser y Carleton (2005) restringen la forma nominal de $E$. chinchilloides para poblaciones de Tierra del Fuego y asignan a E. petersoni para las muestras del continente, hipótesis que aún no ha sido testeada. Para finalizar, es interesante destacar que Ojeda et al. (2005) registraron especímenes de E. chinchilloides 
provenientes de Valle Hermoso (Localidad 102), con diferentes cariotipos respecto de ejemplares asignados a esta especie por Raise y Gallardo (1990).

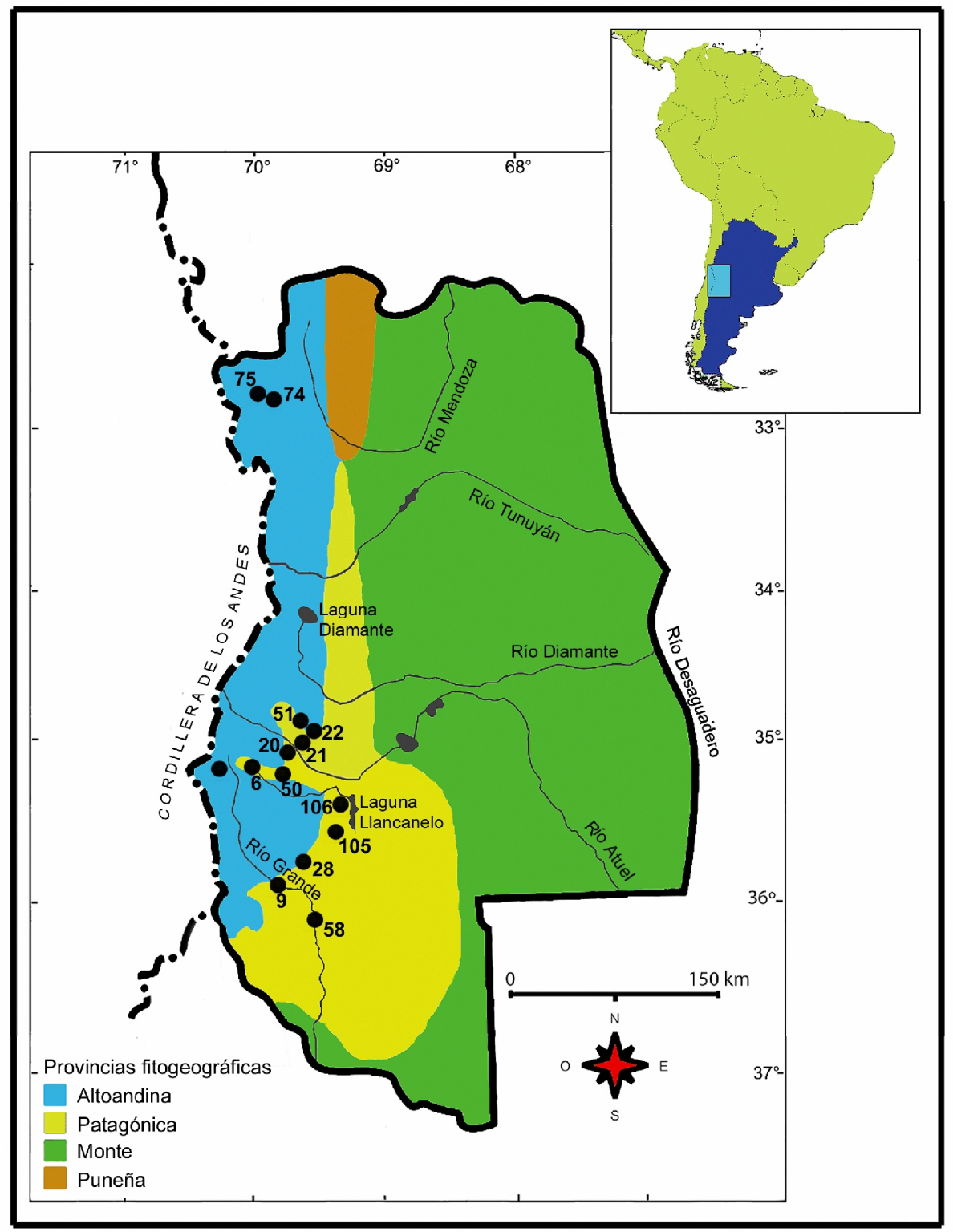

Figura 5.53. Localidades de registro de Euneomys chinchilloides en la provincia de Mendoza.

Provincias comprendidas: San Juan, Mendoza, Neuquén, Río Negro, Chubut, Santa Cruz y Tierra del Fuego.

Localidades registradas en Mendoza: 6, 9, 20, 21, 22, 28, 50, 51, 58, 74, 75, 102, 105, 106. Figura 5.53.

Descripción: cráneo con perfil abovedado en norma lateral; bordes de los frontales bien marcados, cuadrados y paralelos; constricción interorbital levemente menor que el ancho del rostro; nasales angostos en su parte anterior; sutura frontoparietal corta y en forma "U" bien abierta; placa zigomática alta, con el borde anterior recto y vertical; 
foramen incisivo extendido posteriormente hasta el nivel del procíngulo del M1; paladar angosto y largo; depresión palatal desarrollada, con contorno subelíptico; fosa mesopterigoidea con bordes subparalelos; borde anterior de la fosa mesopterigoidea en forma de "M"; amplitud de la fosa mesopterigoidea menor que la amplitud de la fosa parapterigoidea; mandíbula robusta, con el proceso coronoides moderadamente inflexionado hacia atrás, llegando a nivel del cóndilo mandibular; escotadura semilunar excavada y casi simétrica; proyección capsular conspicua; incisivos superiores ortodontes, con un surco longitudinal en posición lateral; series dentarias superiores divergentes; fórmula alveolar: serie dentaria superior 3,3,2 / serie dentaria inferior 2,2,2; molares laminados y de corona plana; ml con procíngulo separado por la fusión del protofléxido y metafléxido (ausencia del múrido anterior), con fléxido anteromediano bien marcado; M2/m2 en forma de " $S$ "; $\mathrm{m} 3$ casi tan grande como el $\mathrm{m} 2$. Figura 5.54.

Especies similares: Euneomys mordax.

Observaciones: en Mendoza es abundante en ambientes de estepas Patagónicas y Altoandinas en el norte y sur de la provincia.

Bibliografía consultada: Osgood, 1943; Hershkovitz, 1962; Pine et al., 1979; Pearson y Christie, 1991; Massoia et al., 1994; Ojeda et al., 2005; Pearson, 1995; Steppan, 1995; D'Elía et al., 2006; Gasco et al., 2006; Nabte et al., 2006; Pardiñas et al., 2008, 2010a; Fernández et al., 2009a, 2009b; Udrizar Sauthier, 2009. 

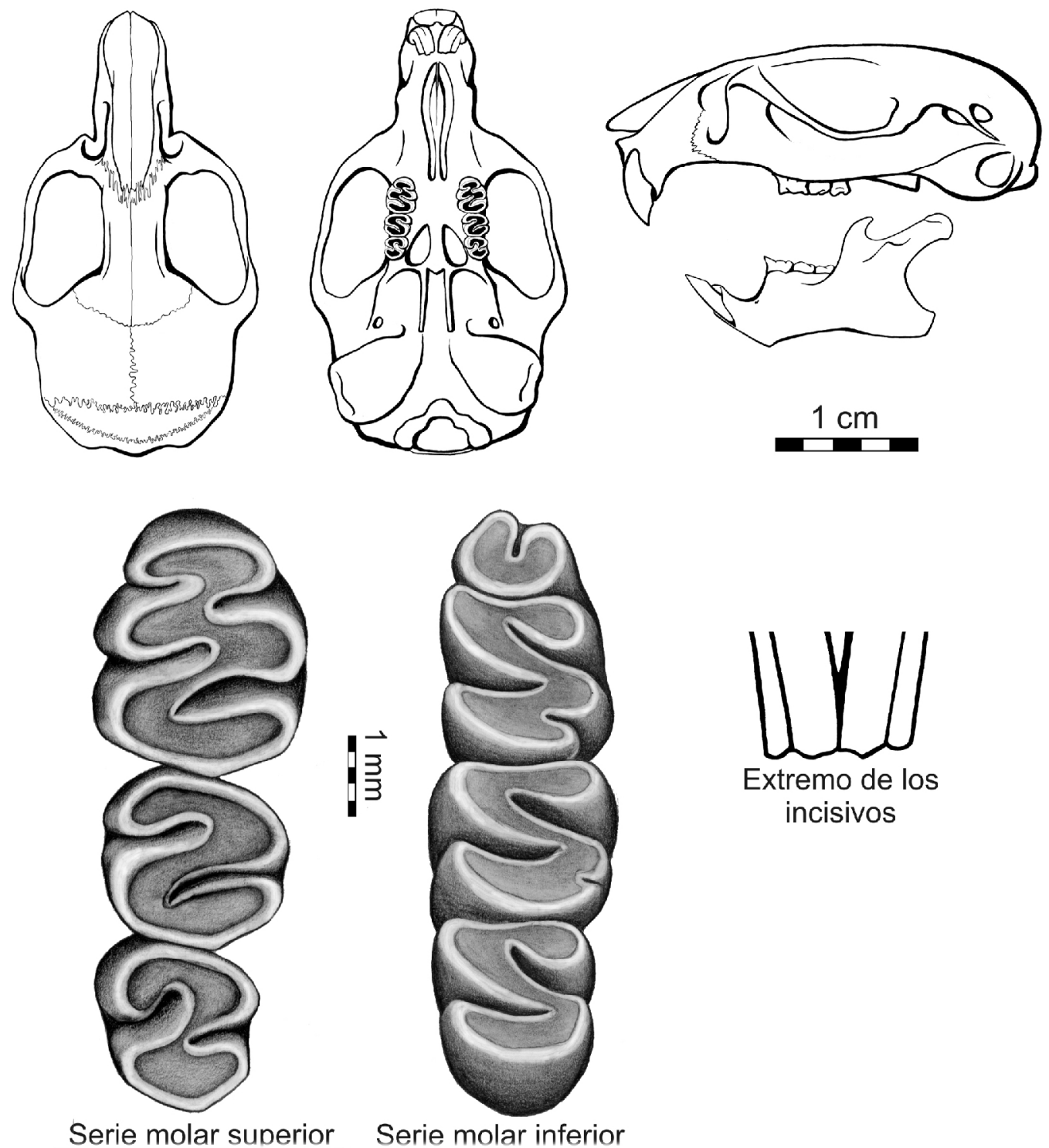

Serie molar superior

Serie molar inferior

Figura 5.54. Esquemas cráneo-dentarios de Euneomys chinchilloides.

Euneomys mordax Thomas, 1912.

Localidad tipo: Fuerte de San Rafael, Mendoza. Sin embargo, Pearson y Lagiglia (1992) advierten sobre su posible ubicación en las proximidades del volcán Peteroa ( $c a$. 200 Km sudoeste de San Rafael, Mendoza). 


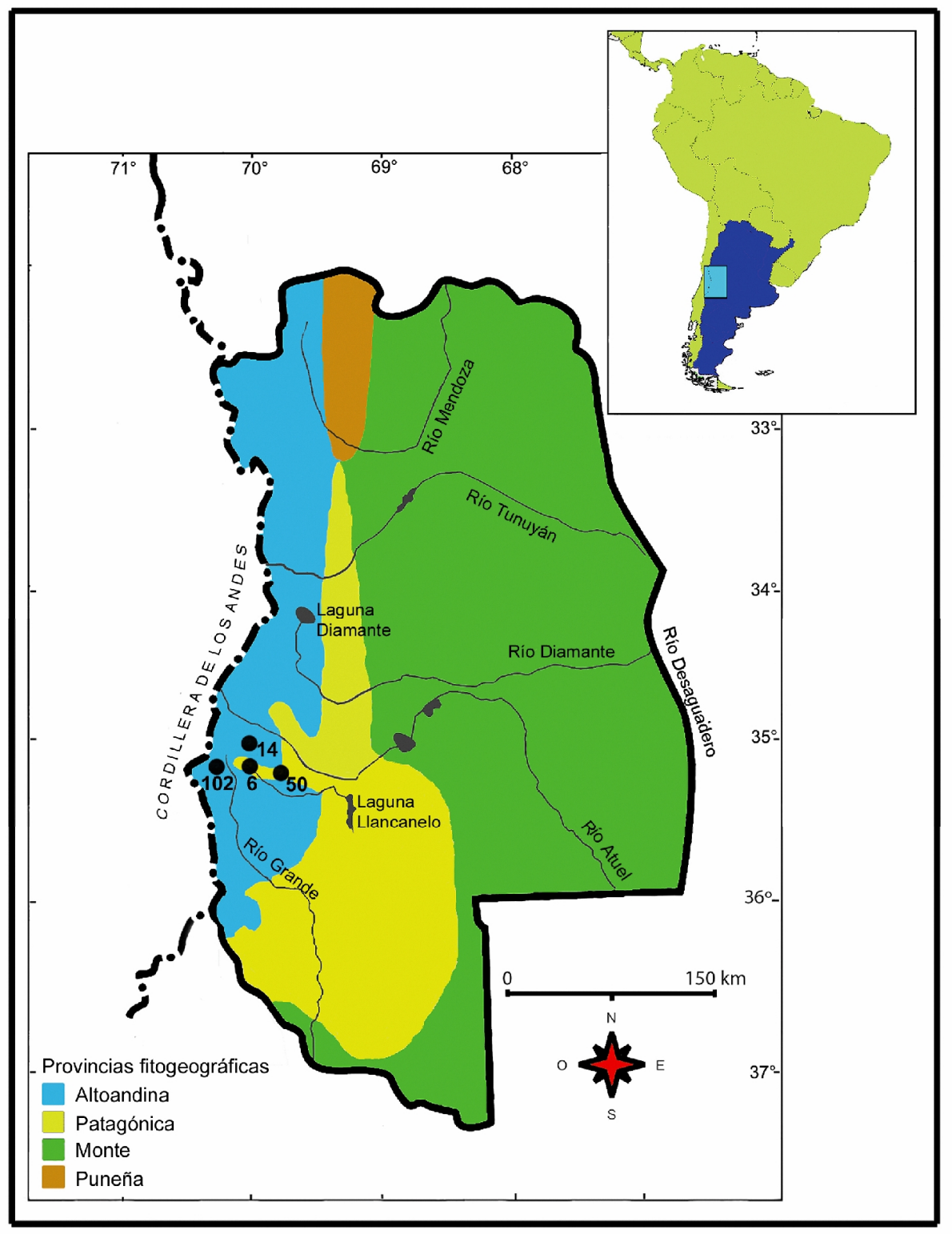

Figura 5.55. Localidades de registro de Euneomys mordax en la provincia de Mendoza.

Características generales: Euneomys mordax (ratón peludo oscuro) es un roedor nocturno y cursorial. Es herbívoro y presenta un peso promedio de $85 \mathrm{~g}$. Está presente en los bosques patagónicos, en turberas y vegas de altura, por encima de $1700 \mathrm{~m}$ de altitud, con suelos desarrollados y cobertura completa.

Provincias comprendidas: Mendoza y Neuquén.

Localidades registradas en Mendoza: 6, 14, 50, 102. Figura 5.55.

Descripción: esta especie comparte la mayoría de las características cráneo-dentarias con E. chinchilloides, a excepción de las siguientes: Nasales más amplios en la parte anterior; depresión palatal aún más desarrollada; incisivos superiores con un surco 
longitudinal de posición más central; caja craneana menos globosa; placa zigomática ligeramente más amplia. Figura 5.56.
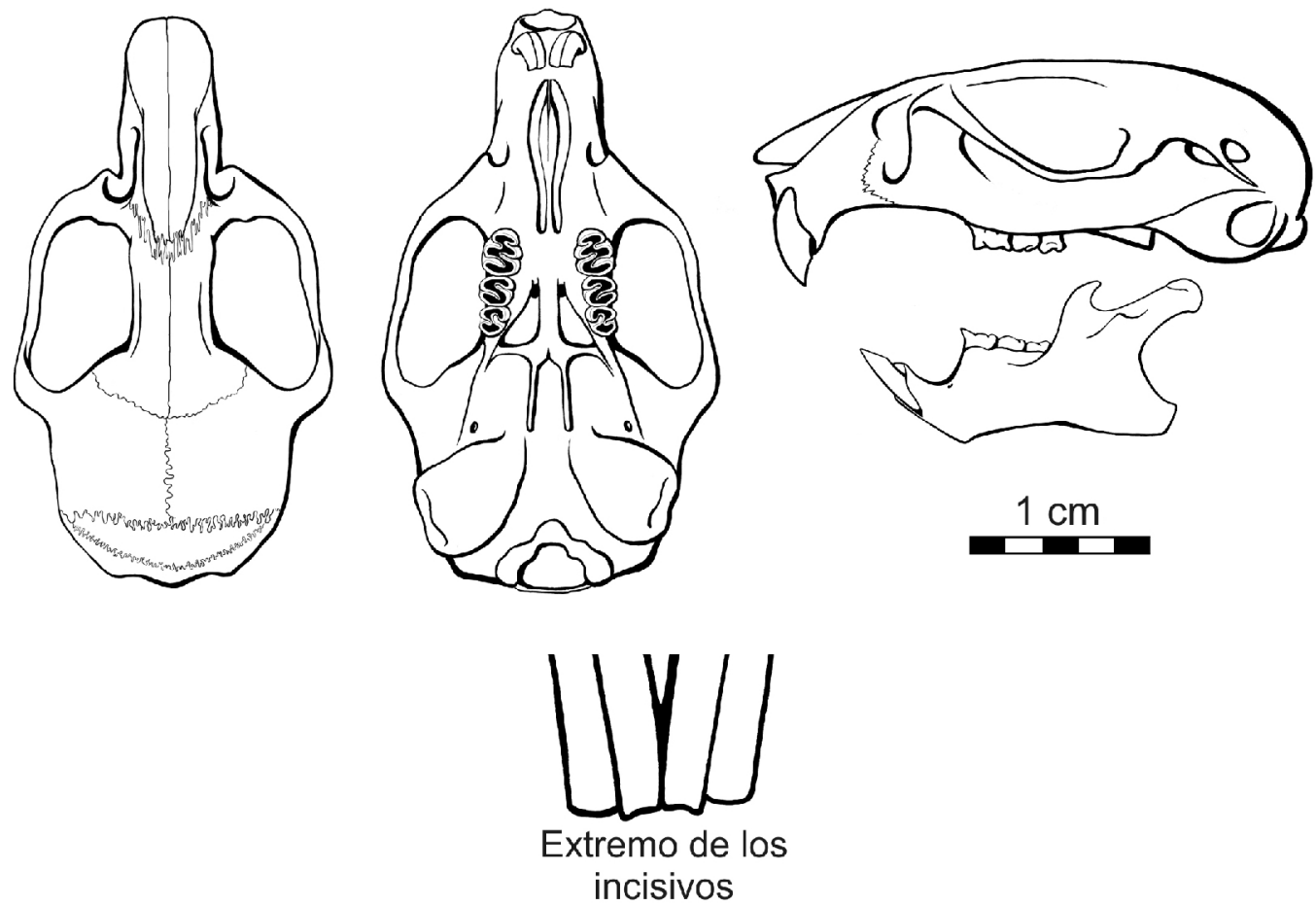

Figura 5.56. Esquemas cráneo-dentarios de Euneomys mordax.

Especies similares: Euneomys chinchilloides.

Observaciones: en Mendoza habita en simpatría con E. chinchilloides en ambientes de estepa Patagónica y Altoandinas de la parte sudoeste de la provincia.

Bibliografía consultada: Pine et al., 1979; Massoia, 1981a; Pearson y Christie, 1991; Pearson y Lagiglia, 1992; Pardiñas, 1999; Neme et al., 2002; Ojeda et al., 2005; D' Elía et al., 2006; Jayat et al., 2006; Pardiñas et al., 2008; Fernández et al., 2009a, 2009b.

\section{Anexo}

En este apartado se realiza una sinopsis de aquellas especies de roedores sigmodontinos que no tienen un registro concreto en la provincia de Mendoza, pero que dada su distribución cercana a la misma y por afinidad ecológica podrían encontrarse. Para el caso de Loxodontomys pikumche por tratarse de una especie cuyo estatus taxonómico fuera recientemente discutido, se realizó una ficha estandar. 
Tribu Phyllotini

Loxodontomys pikumche Spotorno, Cofre, Manríquez, Vilina, Marque y Walker, 1998.

Localidad tipo: Cajón del Río Maípo, Chile.

Características generales: Loxodontomys pikumche (pericote pikumche) es un akodontino posiblemente nocturno y presenta un peso promedio de 57,6 g. Ocupa áreas con abundantes arbustos espinosos mezclados con pastizales. En Mendoza se ha documentado recientemente en Las Leñas a lo largo de pendientes rocosas, constituyendo hasta el momento el único registro para la Argentina.

Provincias comprendidas: Mendoza.

Descripción: esta especie comparte la mayoría de las características cráneo-dentarias con L. micropus, a excepción de las siguientes: Borde anterior de la placa zigomática recto; foramen incisivo más abierto; borde anterior de la fosa mesopterigoidea en forma de "M" más atenuada; proceso coronoides más corto; proceso ventromedial de la rama mandibular redondeado; incisivos superiores robustos con una fisura corta en la dentina en forma de coma; incisivos superiores opistodontes; series dentarias paralelas; fórmula alveolar: serie dentaria superior 4-3,3,3 / serie dentaria inferior 4-3,3,3. Figura 5.57.

Especies similares: Loxodontomys micropus.
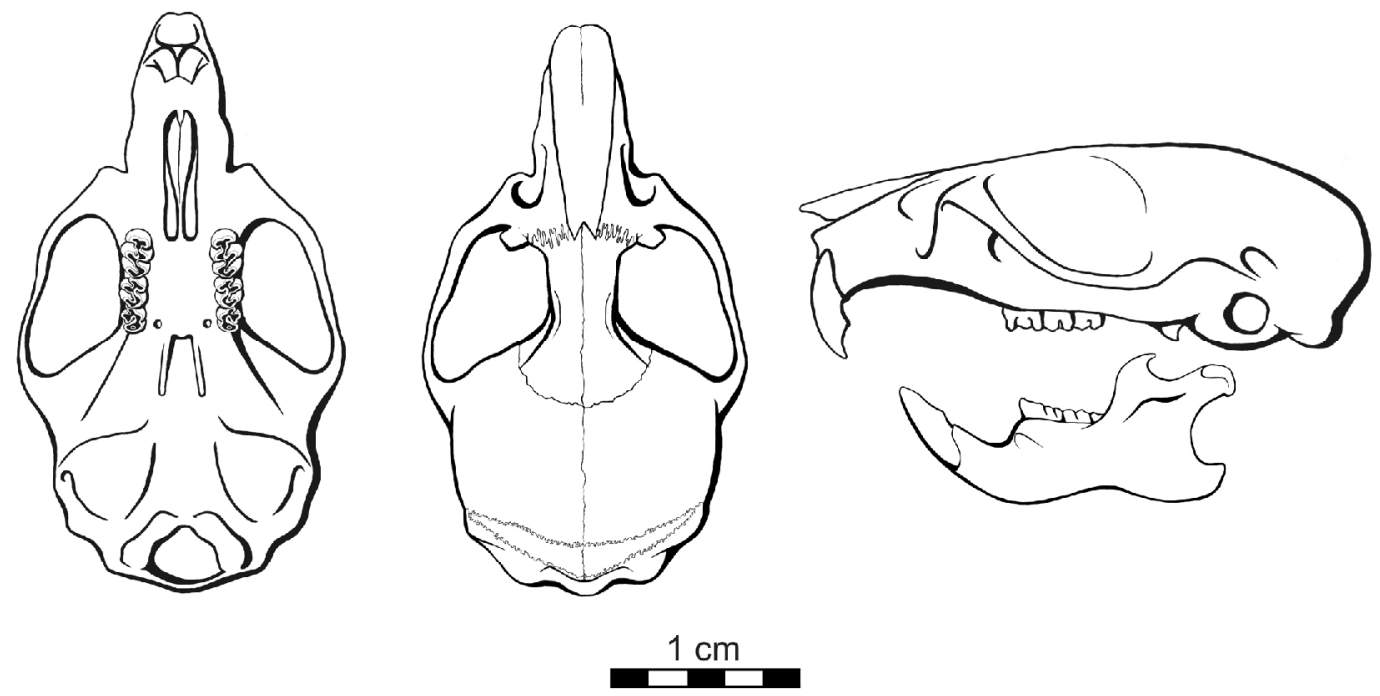

Figura 5.57. Esquemas cráneo-dentarios de Loxodontomys pikumche. 
Observaciones: Cañón et al. (2010) en base a estudios de ADN mitocondrial gen citocromo $b$, plantean que L. pikumche podría ser sinónimo junior de L. micropus. Recientemente, Teta et al. (2011) señalaron numerosas incoherencias entre los ejemplares de la serie tipo de L. pikumche. Entre ellas, destacaron que la piel del holotipo corresponde a un Loxodontomys y el cráneo a un Phyllotis xanthopygus, incluso que uno de los ejemplares de la serie pertenecia a un Chelemys macronyx. Por otra parte, la evidencia cariotípica reportada por Spotorno et al. (1998) muestra diferencias con L. micropus. En este sentido, Teta et al. (2011) plantean que hasta que no se haga revision exhaustiva de esta especie, la forma nominal L. pikumche se mantenga unicamente para la piel del holotipo. Finalmente, estos autores argumentan que los caracteres morfologicos para diferenciar L. pikumche de L. micropus pase a un segundo plano. Por estos motivos, hasta que no se aclare el estatus de L. pikumche los unicos especimenes, identificados mediante caracteres craneanos, en Las Leñas, Mendoza (35'06'25.9' 'S, 70 05'57.9' 'O, 2460 m.s.n.m.; Novillo et al., 2009), deben tomarse con la debida cautela.

Bibliografía consultada: Spotorno et al., 1998, Novillo et al., 2009, Teta et al., 2009, 2011, Cañón et al., 2010.

Salinomys delicatus Braun y Mares, 1995

Es un pequeño filotino pobremente conocido, con una distribución acotada a las provincias de Catamarca, La Rioja, San Juan y San Luis, con localidad tipo en esta última (Pampa de las Salinas). Los escasos registros de esta especie la asocian a salitrales y ambientes de dunas del desierto del Monte y áreas ecotonales del Monte y el bosque xerófilo Chaqueño (e.g., Braun y Mares, 1995; Ojeda et al., 2001; Lanzone et al., 2005).

Andalgalomys olroigi Williams y Mares, 1978.

Es un filotino escasamente conocido. Presenta registros en las provincias de San Luis, La Rioja y Catamarca, donde se encuentra la localidad tipo (ca. de Andalgalá). Es un roedor endémico del Dominio Chaqueño y habita principalmente en ambientes desérticos del Monte y en áreas ecotonales entre el Monte y el bosque xerófilo 
Chaqueño (Williams y Mares, 1978; Mares y Braun, 1996). Asimismo, ha sido observada su co-ocurrencia con Salinomys delicatus (Braun y Mares 1995; Mares y Braun, 1996; Ojeda et al., 2001). Es interesante mencionar que García (2003) en base a evidencias cariotípicas y moleculares incluyó en la sinonimia de esta especie a A. roigi Mares y Braun, 1996. Por otra parte, el estatus taxonómico del género Andalgalomys ha sido objeto de numerosas discusiones; en tal sentido, Steppan (1995) y Steppan y Sullivan (2000) plantean su sinonimia con Graomys. Por el contrario, Braun (1993) y Mares y Braun (1996) en sus contribuciones argumentan la retención de Andalgalomys como género distinto de Graomys. Recientes estudios moleculares confirmaron la separación de ambos géneros, conformando clados distintos y acercándolo más a Salinomys (Anderson y Yates, 2000; García, 2003; Steppan et al., 2007). Cabe aclarar que para la provincia de Mendoza, Neme et al. (2002) documentaron un ejemplar de Andalgalomys sp. exhumado del sitio arqueológico Arroyo Malo 3, con una antigüedad de $c a$. de 8900 años ${ }^{14} \mathrm{C}$ AP. Sin embargo, en este trabajo se demostró que el mismo corresponde a un individuo juvenil de Phyllotis xanthopygus (ver Capítulo 7).

Graomys centralis (Thomas, 1902).

Es un filotino pobremente conocido, con distribución en las provincias de Catamarca, La Rioja, Santiago del Estero, Santa Fé, San Luis y Córdoba, donde se encuentra la localidad tipo (Cruz del Eje). Habita principalmente en ambientes del Espinal, bosque xerófilo Chaqueño y en el ecotono con el desierto del Monte (Díaz et al., 2006; Lanzone et al., 2007). Su estatus taxonómico es poco claro. Lanzone et al. (2007) en base a estudios cariotípicos propone su sinonimia con Graomys medius (Thomas, 1919). Hasta el presente no se ha realizado la revaluación del estatus de otras formas afines (edithae y chacoensis), la cual es necesaria para la revalidación definitiva de G. centralis (Díaz et al., 2006 y literatura allí citada). Asimismo, Lanzone et al. (2007) y Martínez et al. (2010) plantean la posibilidad de la existencia de una sola entidad para los ambientes del Chaco, hipótesis que aún no ha sido testeada.

\subsubsection{Patrones de distribución geográfica de los micromamíferos}

Para explicar los patrones de distribución de los taxones de micromamíferos se tuvo en cuenta toda la información obtenida a partir de las 107 localidades de registro. Se 
realizó un análisis de agrupamiento sobre la base de una matriz de presencia-ausencia de 24 taxones y nueve sectores seleccionados por características geográficas y ambientales (Figuras 5.58 y 5.59).

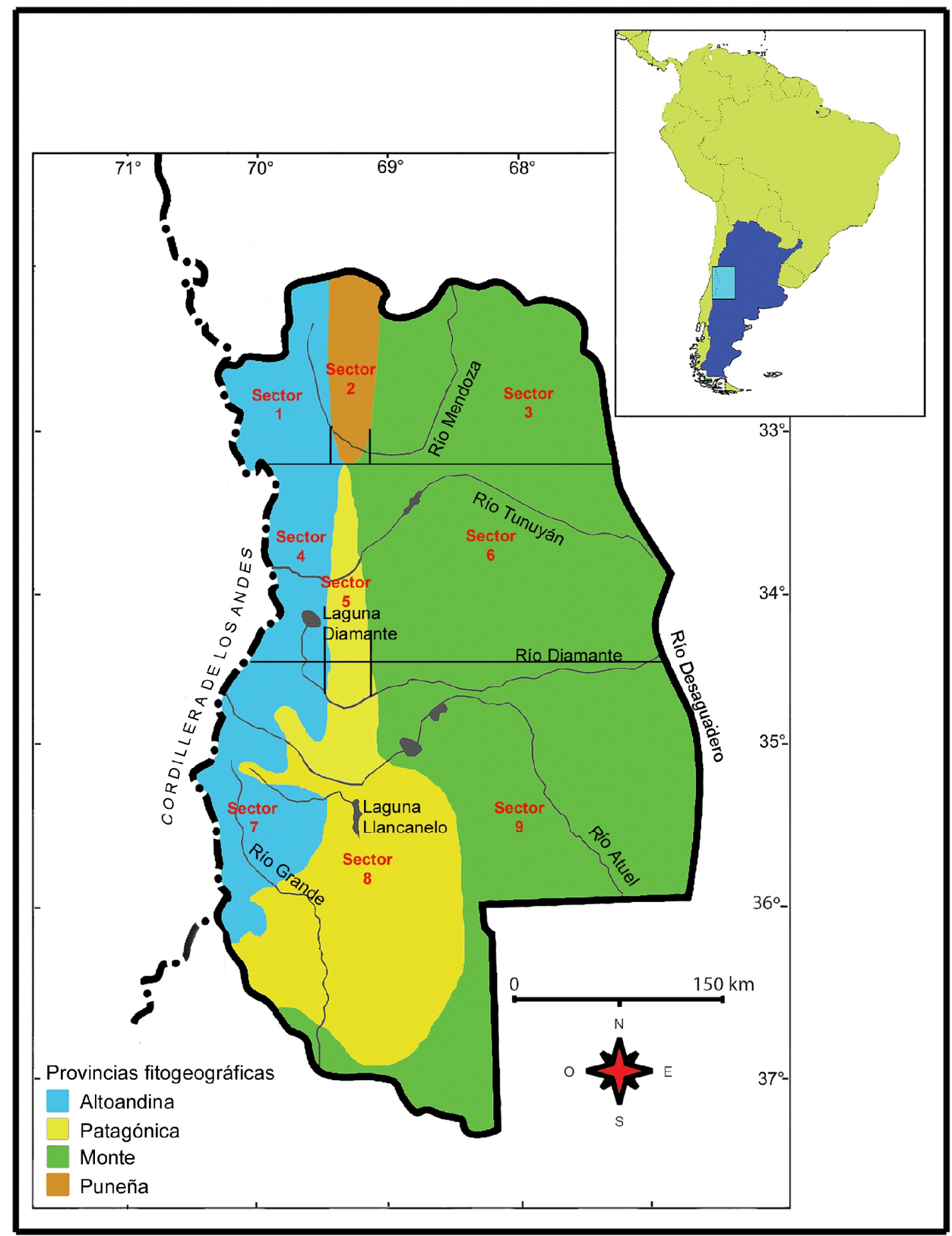

Figura 5.58. Mapa de la provincia de Mendoza mostrando los sectores seleccionados en este trabajo. Los límites oeste-este de los sectores, coinciden con las fronteras fitogeográficas sensu Cabrera (1976). 

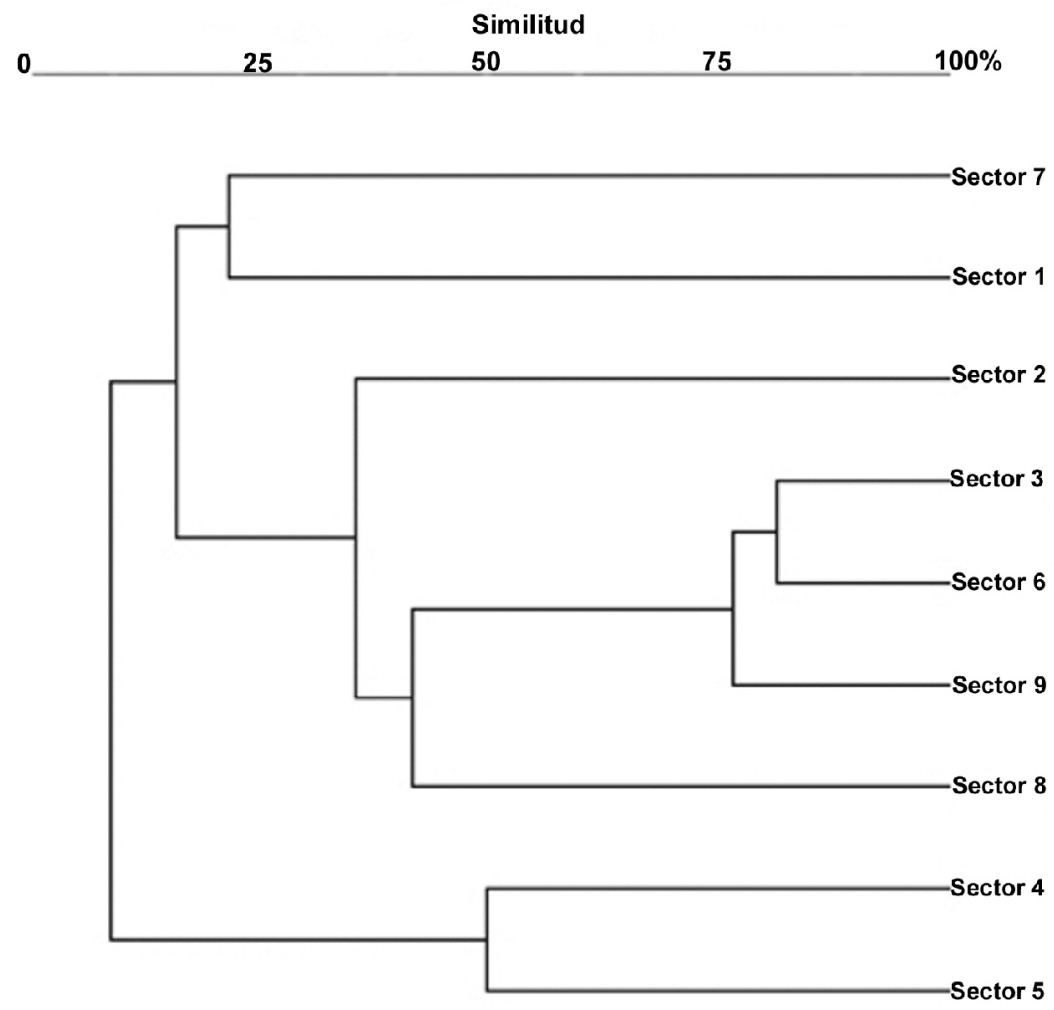

Figura 5.59. Relaciones fenéticas entre sectores definidos en este trabajo [matriz básica de presencia-ausencia; Cluster Analysis, medida de similitud Jaccard, método de unión de distancias promedios entre todos los miembros de los pares de grupos (UPGMA-Unweighted pair-group average), $c c c=0,9514]$.

Su topología exhibe en líneas generales que los sectores vinculados al Monte presentan un alto grado de similitud y se encuentran más asociados a los sectores Puneño y Patagónico de la parte norte y sur de la provincia, respectivamente. Estas asociaciones pueden explicarse en términos de áreas de transición existentes entre las mencionadas unidades biogegráficas. Por otra parte, los sectores Altoandino y Patagónico del centro de Mendoza forman un grupo bien diferenciado del resto. Asimismo, existe una diferenciación de los sectores Altoandinos del norte y sur de la provincia con el resto de los sectores.

Sector 1: Norte de Mendoza, Altoandina: se registraron cuatro taxones. Las muestras de este sector son muy escasas, lo cual dificulta la realización de interpretaciones. Aparentemente, los principales elementos son Phyllotis xanthopygus, Euneomys chinchilloides y Abrothrix andinus.

Sector 2: Norte de Mendoza, Puneña: se registraron ocho taxones. Con la debida prudencia por el tamaño chico de las muestras, Phyllotis xanthopygus y Abrothrix andinus parecen ser las especies típicas de este sector. 
Sector 3: Norte de Mendoza, Monte: se registraron 14 taxones. Presenta numerosas especies características (e.g., Graomys griseoflavus, Akodon spegazzinii, Calomys musculinus).

Sector 4: Centro de Mendoza, Altoandina: se registraron solo dos taxones en las exiguas muestras existentes (Ctenomys spp. y Eligmodontia spp).

Sector 5: Centro de Mendoza, Patagónica: se registró un taxón (Ctenomys spp.).

Sector 6: Centro de Mendoza, Monte: se registraron 15 taxones. Presenta numerosas especies características (e.g., Microcavia australis, Graomys griseoflavus, Thylamys pallidior, Akodon molinae, Calomys musculinus, Eligmodontia spp.).

Sector 7: Sur de Mendoza, Altoandina: se registraron siete taxones. Las especies típicas son Chelemys macronyx, Euneomys mordax, Phyllotis xanthopygus, Loxodontomys micropus.

Sector 8: Sur de Mendoza, Patagónica: se registraron 19 taxones. Presenta numerosas especies características (e.g., Euneomys chinchilloides, Phyllotis xanthopygus, Abrothrix olivaceus, Abrothrix longipilis, Thylamys pallidior).

Sector 9: Sur de Mendoza, Monte: se registraron 12 taxones en escasa cantidad de muestras. Presenta numerosas especies características (e.g., Thylamys pallidior, Akodon molinae, Graomys griseoflavus, Calomys musculinus, Galea leucoblephara).

En la figura 5.60 se grafica la variación de la riqueza taxonómica de micromamíferos por sector y su relación con la riqueza promedio de todos los sectores. En términos generales se observa un patrón de crecimiento en sentido oeste-este en el norte y centro de la provincia y hacia los extremos norte y sur de la misma. Los sectores Altoandinos fueron los más pobres y todos los sectores correspondientes al Monte se encontraron por encima de la riqueza media. No obstante, el sector Patagónico sur fue el que exhibió mayor riqueza.

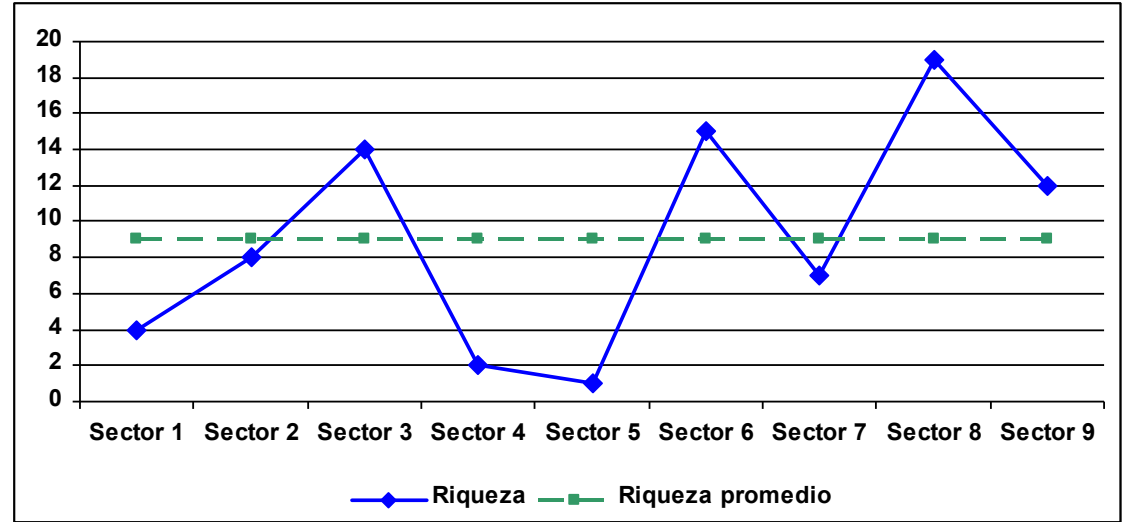

Figura 5.60. Variación de la riqueza taxonómica de los micromamíferos por sectores definidos en este trabajo. 
En base a la información obtenida se graficaron las ditribuciones geográficas de los taxones de micromamíferos no voladores que habitan actualmente en Mendoza a lo largo de gradientes oeste-este en el norte, centro y sur de la provincia (Figuras 5.61-5.63).

\section{Norte de Mendoza}

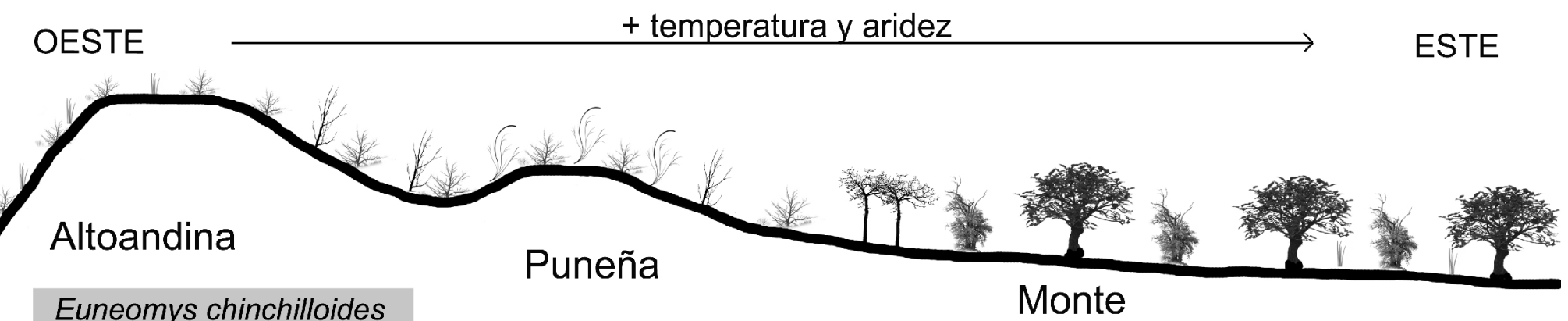

Abrothrix andinus

Phyllotis xanthopygus

\begin{tabular}{l} 
Graomys griseoflavus \\
Ctenomys spp. \\
\hline Thylamys pallidior \\
Akodon spegazzinii
\end{tabular}

\begin{tabular}{|c|}
\hline Eligmodontia spp. \\
\hline Calomys musculinus \\
\hline Akodon molinae \\
\hline Galea leucoblephara \\
\hline Oligoryzomys flavescens \\
\hline Tympanoctomys barrerae \\
\hline Lestodelphys halli \\
\hline
\end{tabular}

Figura 5.61. Distribución esquemática de los taxones de micromamíferos no voladores en un gradiente oeste-este en el norte provincia de Mendoza. 


\section{Centro de Mendoza}

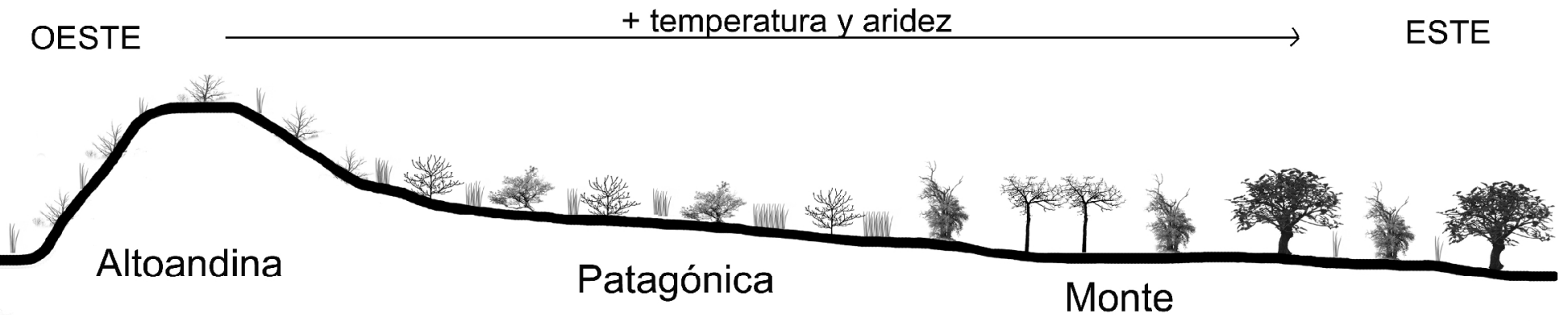

Ctenomys spp.

Eligmodontia spp.

\section{Phyllotis xanthopygus}

Lestodelphys halli

Thylamys pallidior
Microcavia australis
Graomys griseoflavus
Galea leucoblephara
Tympanoctomys barrerae
Oligoryzomys flavescens
Akodon molinae
Calomys musculinus

Figura 5.62. Distribución esquemática de los taxones de micromamíferos no voladores en un gradiente oeste-este en el centro de la provincia de Mendoza. 


\section{Sur de Mendoza}

OESTE

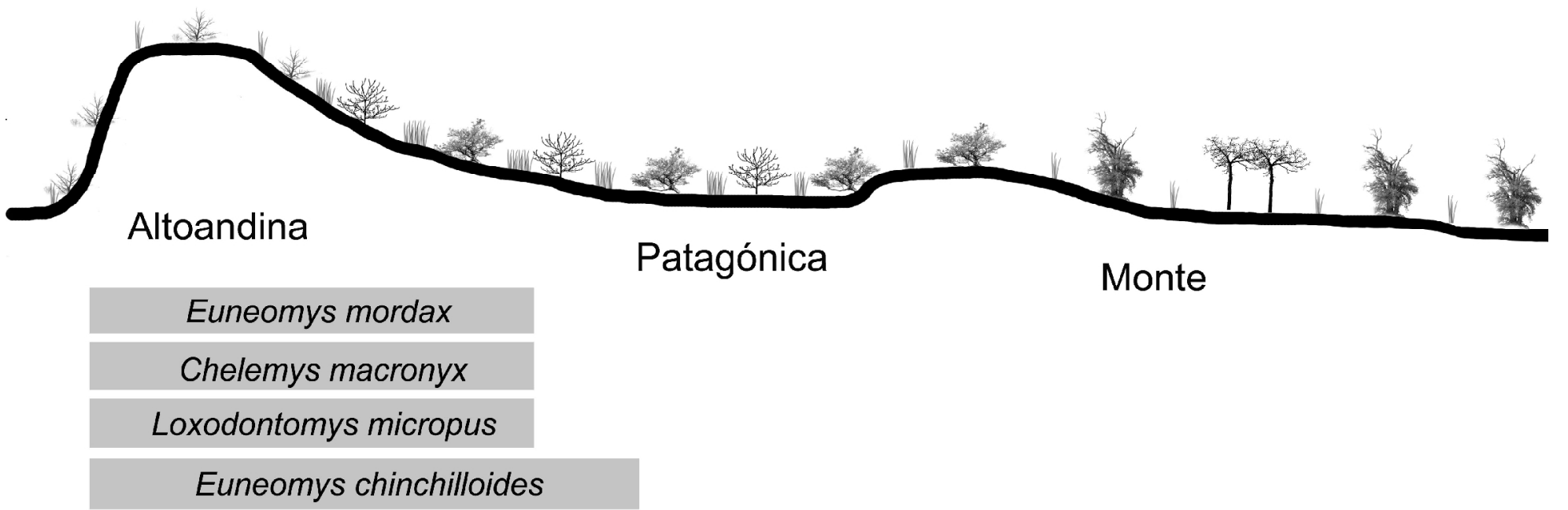

Abrothrix olivaceus

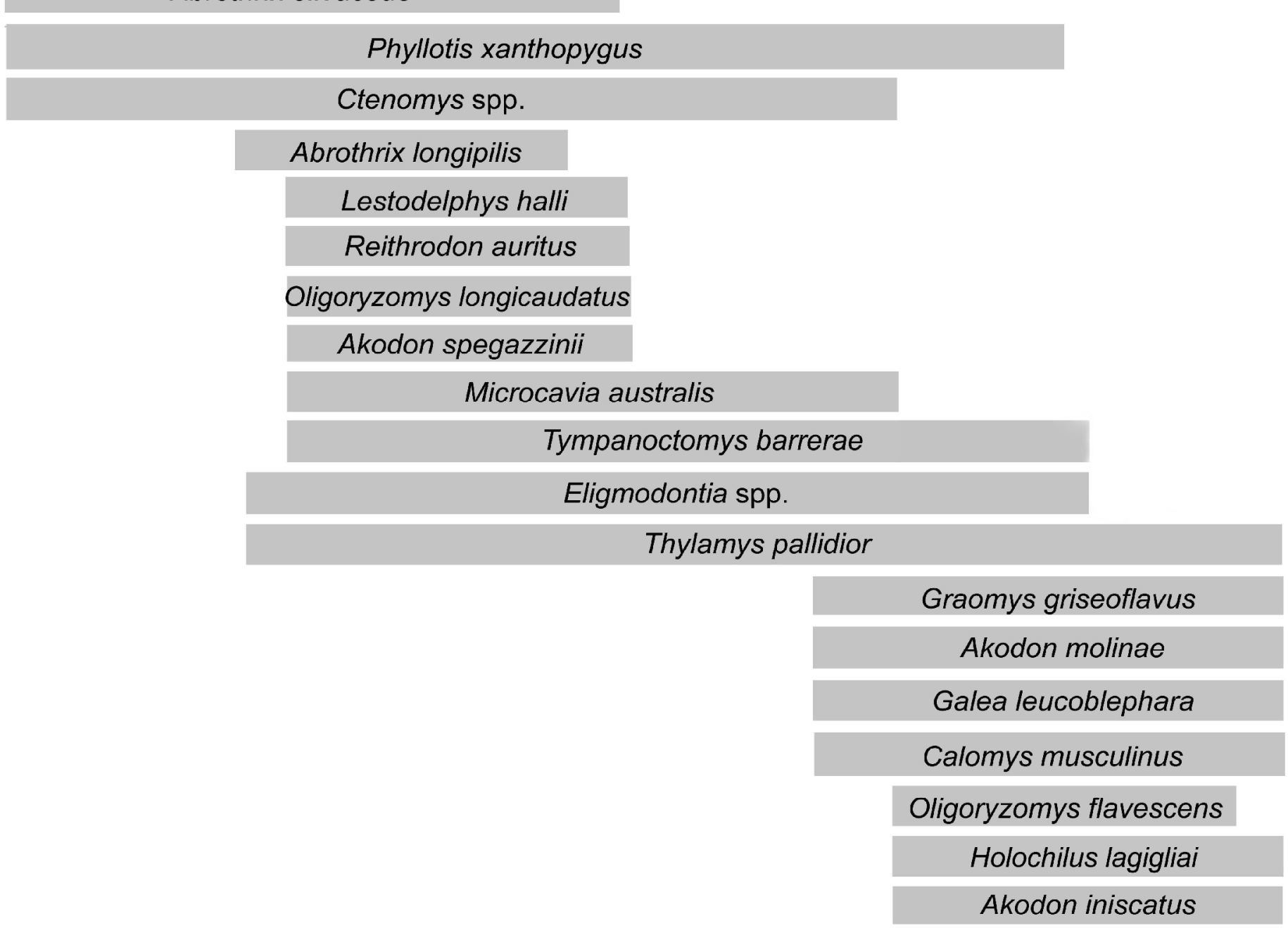

Figura 5.63. Distribución esquemática de los taxones de micromamíferos no voladores en un gradiente oeste-este en el sur de la provincia de Mendoza. 
A pesar de aun existen numerosos vacios en el conocimiento de los micromamíferos en varios de los sectores definidos, podemos observar a excepción de $A$. andinus, el sur de Mendoza presentó todos los taxones de micromamiferos que habitan en la provincia. Sin embargo, el norte de Mendoza exhibió numerosas ausencias (E. mordax, $C$. macronyx, L. micropus, A. longipilis, A. olivaceus, $R$. auritus).

La explicación más plausible para entender esta riqueza diferencial entre ambos extremos de la provincia, puede estar dada en que el sudoeste de Mendoza contistuye en lineas generales la última expresión de numerosas especies Patagónicas tales como $E$. mordax, C. macronyx, L. micropus, A. longipilis y A. olivaceus, siendo E. chinchilloides la única especie Patagónica que llega hasta el norte de Mendoza, incluso sudoeste de San Juan (Pardiñas et al., 2010a; Vianna et al., 2011). Por el contrario, el noroeste de Mendoza con la presencia de $A$. andinus muestra el último rastro de elementos Puneños. No obstante, la faja este de la provincia se mantiene sin mayores cambios en cuanto a presencia de taxones de micromamíferos, posiblemente debido a su homogeneidad ambiental (i.e., Monte).

En la figura 5.64 se ilustra los resultados de un análisis de componentes principales (PCA), realizado mediante la selección de las muestras de micromamíferos más representativas de Mendoza.

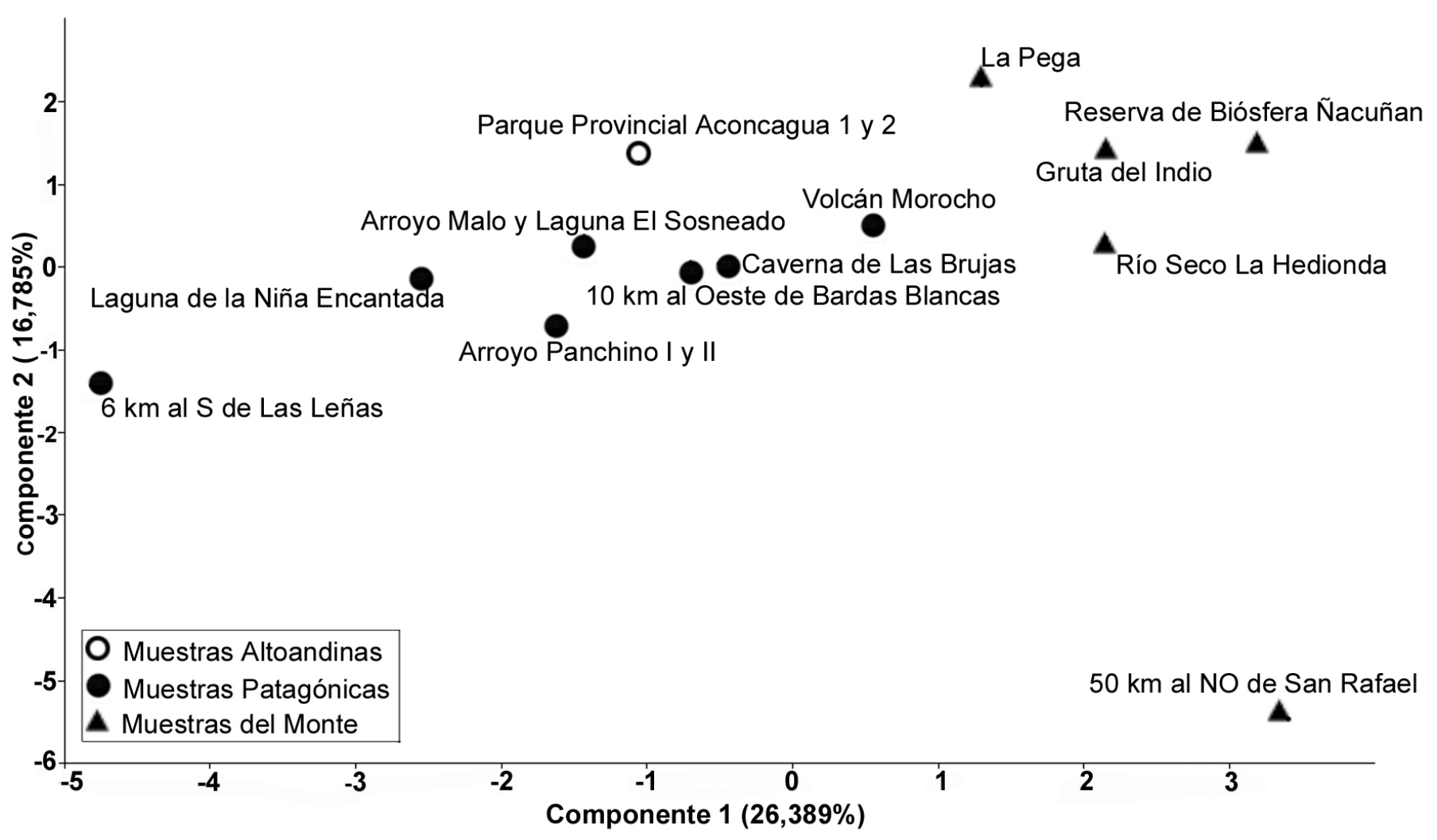


Figura 5.64. Gráfico de las muestras actuales de micromamíferos (más representativas) sobre el plano definido por los ejes 1 y 2 de un análisis de componente principal.

La ubicación espacial de la mayor parte de los ensambles entre los ejes determinados por los dos primeros componentes principales, muestran una disposición quasigeográfica, tanto en sentido oeste-este como norte-sur. El primer componente principal (26,389\% de la varianza) exhibe una separación entre los ensambles compuestos de micromamíferos típicamente asociados al desierto del Monte hacia la derecha y aquellos vinculados a ambientes Andino-Patagónicos hacia la izquierda. Este eje tambien corrobora lo expresado anteriormente de que los ensambles del Monte parecen no sufrir mayores cambios a los largo de la franja este de la provincia de Mendoza. El segundo componente principal $(16,785 \%$ de la varianza) marca el alejamiento (hacia abajo) de uno de los ensambles asociados al Monte, posiblemente debido al carácter heterogéneo de esa muestra, con la incorporación de L. halli y O. longicaudatus como elementos distintivos. Finalmente, el segundo componente representa, en la parte superior del grafico, aquellas muestras Altoandinas del noroeste que podrían estar indicando el deslinde entre los ensambles de micromamíferos Puneños y Patagónicos. 



\section{Capítulo 6}

\section{PRINCIPALES DEPREDADORES DE MICROVERTEBRADOS DEL SUR DE MENDOZA}

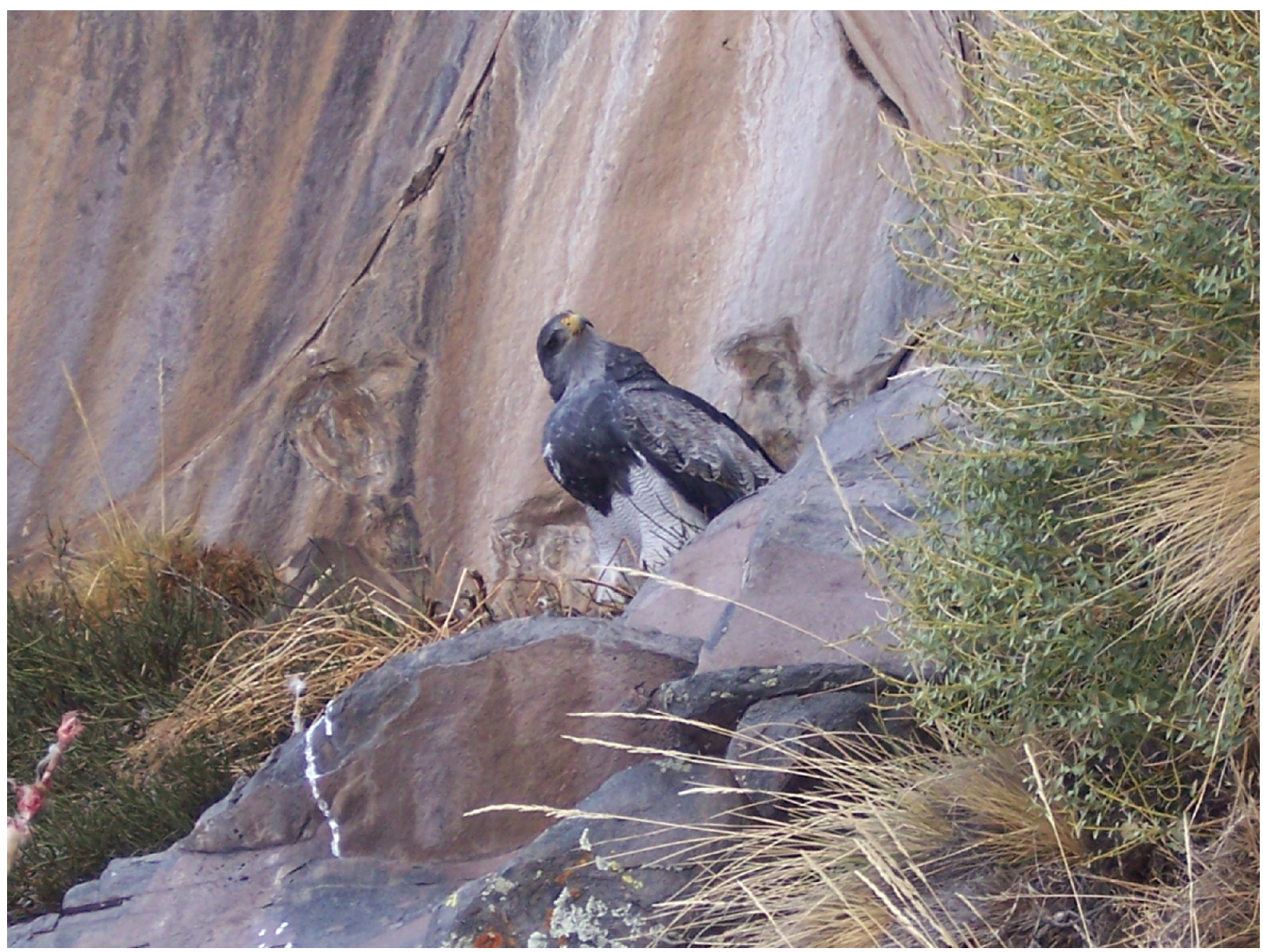

Fotografía de Geranoaetus melanoleucus en el reparo rocoso del sitio arqueológico Arroyo Malo-3. Tomada por Gustavo Neme. 



\section{PRINCIPALES DEPREDADORES DE MICROVERTEBRADOS DEL SUR DE MENDOZA}

En el sur de la provincia de Mendoza se distribuyen un grupo variado de depredadores de microvertebrados. En la actualidad esta área cuenta con seis especies de aves Strigiformes, ocho de Accipitriformes, ocho de Falconiformes, cinco de mamíferos Felidae, dos de Canidae, uno de Mephitidae y dos de Mustelidae.

A continuación se describen sumariamente aspectos biológicos, ecológicos y tafonómicos de los principales depredadores de microvertebrados que habitan en el sur de Mendoza. El criterio sistemático empleado para las aves corresponde a la propuesta de Mazar Barnett y Pearman (2001) y modificaciones acordes a la literatura ulterior y para los mamíferos se sigue a Wilson y Reeder (2005) y Barquez et al. (2006).

Clase Aves Linnaeus, 1758.

Orden Strigiformes (Wagler, 1830).

Familia Tytonidae Ridgway, 1914.

Género Tyto Billberg, 1828.

Tyto alba (Scopoli, 1769).

Tyto alba (lechuza de campanario) es un estrigiformes de mediano tamaño (280-450 g.), que presenta la mayor distribución mundial de todo el órden, habita en multiplicidad de ambientes, incluyendo zonas antropizadas y urbanas, siendo más abundantes en áreas abiertas (e.g., Mikkola, 1983; Burton, 1984; Taylor, 2004). Frecuentemente, hace sus nidos en cuevas, refugios rocosos y también en estructuras construidas por humanos y dependiendo de la disponibilidad de presas puede presentar un home range de entre $1 \mathrm{y}$ $3 \mathrm{~km}^{2}$ (Mikkola, 1983; Burton, 1984; Taylor, 2004). Es una lechuza crepuscular y nocturna que se alimenta principalmente de micromamíferos y ocasionalmente de otros microvertebrados e insectos, con un tamaño promedio de presas variando entre 12,6 y 360 g. (Bellocq, 2000 y literatura allí citada). Además, T. alba ha mostrado una elevada variabilidad dietaria espacio-temporal, posiblemente debido a la depredación estacional y por su carácter de cazador oportunista (véase Bellocq, 2000). Buenos ejemplos de esto lo constituyen los casos registrados de alto consumo de Cavia sp. (Aliaga-Rossel y 
Tarifa, 2005), de quirópteros (Romano et al., 2002) de anfibios anuros (Fernández et al., 2009e) y de aves (Noriega et al., 1993).

Por otra parte, datos emanados por estudios tafonómicos sobre restos de microvertebrados acumulados por $T$. alba, muestran que este lechuza produce modificaciones ligeras, tanto en peces (Broughton et al., 2006), como en anfibios (Pinto Llona y Andrews, 1999), reptiles (Castillo et al., 2001), aves (Fernández et al. 2009c) y micromamíferos (Andrews, 1990; Gómez, 2007; Fernández et al., 2009a).

Finalmente, es importante destacar, que T. alba se considera el mayor acumulador de restos de microvertebrados hallados en cuevas y refugios rocosos tanto en contextos actuales como arqueofaunísticos (e.g., Andrews, 1990; Saavedra y Simonetti, 1998).

Familia Strigidae Leach, 1820.

Género Bubo Dumeril, 1805.

Bubo magellanicus (Lesson, 1928).

Bubo magellanicus (tucúquere) es un estrigiformes de gran tamaño (650-1500 g.), que se distribuye por la franja Andina desde el centro de Perú hasta el extremo sur de Chile y Argentina, habitando variedad de ambientes abiertos y en bosques (e.g., Marks et al., 1999). Construye sus nidos en salientes rocosas, acantilados, árboles, arbustos y dependiendo de la disponibilidad de presas puede presentar un home range de entre ca. 1 y $5 \mathrm{~km}^{2}$ (Marks et al., 1999). Es una rapaz crepuscular nocturna y oportunista, que se caracteriza por tener una dieta basada principalmente en el consumo de micromamíferos, en menor término depreda sobre aves, anfibios e insectos, con un tamaño de presas muy variable entre 15 y 300 g. (Trejo y Grigera, 1998; Udrizar Sauthier et al., 2005; Nabte et al., 2006; Bó et al., 2007). Es interesante notar que Nabte et al. (2006), observaron una marcada variabilidad espacio-temporal en la dieta de esta lechuza en un gradiente latitudinal de la Patagonia Argentina.

El análisis tafonómico realizado por Fernández et al. (2009b), registraron que $B$. magellanicus produce modificaciones moderadas en ensambles de aves (Categoría II, sensu Bochenski et al., 1998), similares al de su par congenérico Bubo virginianus (ñacurutú), el cual fuera estudiado en base a restos de micromamíferos (Gómez, 2005, 2007).

Género Asio Brisson, 1760. 
Asio flammeus (Pontoppidan, 1763).

Asio flammeus (lechuzón campestre) es un estrigiformes de mediano tamaño (206475g.). Presenta amplia distribución en el Mundo, incluyendo todos los continentes menos Oceanía y Antártida, siendo frecuente en gran variedad de ambientes abiertos (Clark, 1975; Mikkola, 1983). Hace sus nidos en lugares a cielo abierto en la tierra o en árboles y presenta un home range de hasta $1 \mathrm{~km}^{2}$ (Mikkola, 1983). Es una lechuza crepuscular, nocturna y oportunista, que consume principalmente micromamíferos y en menor medida depreda sobre aves e insectos, con un tamaño promedio de presas pequeño de entre 20 y 24 g. (Mikkola, 1983; Rau et al., 1992; Hogan et al., 1996; Martínez et al., 1998; Cirignoli et al., 2001; Bó et al., 2007).

Es interesante destacar, que esta lechuza puede compartir su percha con falcónidos, donde sus egagrópilas se pueden mezclar, pudiendo ocasionar problemas potenciales en estudios sobre tafonomía, dieta y reconstrucciones paleoambientales (Andrews, 1990). Estudios tafonómicos realizados por Andrews (1990) y Gómez (2007) sugieren que $A$. flammeus produce modificaciones ligeras en ensambles de micromamíferos (Categoría I, sensu Andrews, 1990), aunque con niveles de destrucción levemente más altos que $T$. alba.

Género Athene Boie, 1822.

Athene cunicularia (Molina, 1782).

Athene cunicularia (lechucita de las vizcacheras) es un estrigiformes de pequeño tamaño (170-214g.). Exhibe una amplia distribución en América, desde el sur de Canadá hasta el sur Chile y Argentina, ocupando gran variedad de ambientes abiertos y siendo abundante en zonas rurales (e.g., Burn, 1999). Anida en pozos en la tierra y presenta un home range de entre $<1 \mathrm{~km}^{2}$ hasta $4,8 \mathrm{~km}^{2}$, dependiendo de la oferta de presas (Sissons et al., 2001 y literatura allí citada). Es una lechuza diurna, crepuscular y nocturna, con una dieta que sido definida como generalista y oportunista, orientada hacia el consumo de insectos $y$ en menor medida depreda micromamíferos (principalmente roedores sigmodontinos), aves, reptiles y anfibios (e.g., Bellocq, 1987; Andrade et al., 2004, 2010; Nabte et al., 2008).

Estudios tafonómicos indican que $A$. cunicularia produce modificaciones de ligera a moderadas (Categorías I y II, sensu Andrews, 1990) en ensambles de micromamíferos 
(Gómez, 2007; Montalvo y Tejerina, 2009) y modificaciones moderadas en conjuntos de anfibios (Montalvo y Tejerina, 2009). Por otra parte, Montalvo et al. (en prensa b) en un experimento sobre el transporte del viento observaron que las egagrópilas de esta especie se dispersaban más fácilmente que las egagrópilas de T. alba, debido a su menor tamaño. Asimimo, estos autores registraron que la dispersión por viento influye significativamente en la disgregación de las egagrópilas.

Orden Accipitriformes Vieillot, 1816.

Familia Accipitridae Vigors, 1824.

Género Geranoaetus Kaup, 1844.

Geranoaetus melanoleucus (Vieillot, 1819).

Geranoaetus melanoleucus (águila mora) es un accipítrido de gran tamaño (16703170g.). Presenta amplia distribución en Sudamérica, desde el sur de los Andes Colombianos y Ecuador hasta el extremo sur de Chile y Argentina, habitando en multiplicidad de ambientes (White et al., 1994). Realiza sus nidos en salientes rocosas y árboles (White et al., 1994). Es un águila diurna, generalista y oportunista, que se alimenta principalmente de micromamíferos y secundariamente de aves, reptiles e insectos. Estudios realizados en Argentina y Chile han mostrado que esta rapaz, dependiendo de la oferta de presas, puede consumir abundantes lagomorfos introducidos en detrimento de roedores nativos (e.g., Iriarte et al., 1990a; Hiraldo et al., 1995; Trejo et al., 2006).

Hasta el presente no se cuenta con información tafonómica sobre G. melanoleucus.

Género Buteo Lacépède, 1799.

Buteo polyosoma (Quoy y Gaimard, 1824).

Buteo polyosoma (aguilucho común) es un accipítrido de mediano tamaño (800-1800g). Se distribuye a través de Sudamérica desde los Andes centrales en Colombia hasta el extremo sur de Chile y Argentina, ocupando una amplia variedad de ambientes desde los altos Andes hasta el nivel de mal en Patagonia. Anida en salientes rocosas, árboles y arbustos (White et al., 1994). Es una rapaz diurna y generalista, orientada hacia el consumo de micromamíferos (principalmente roedores sigmodontinos) y en menor medida depreda, aves, reptiles, anfibios e invertebrados, con un tamaño promedio de 
presas de 44,8 g. (e.g., White et al., 1994; Figueroa Rojas et al., 2003; Baladrón et al., 2006; Bó et al., 2007).

El análisis tafonómico realizado por Iglesias (2009) sobre restos de micromamíferos ingeridos por $B$. polyosoma, mostró que esta rapaz produce niveles de modificación fuerte (Categoría IV, sensu Andrews, 1990).

Orden Falconiformes Sharpe, 1874.

Familia Falconidae Leach, 1820.

Género Caracara Merrem, 1826.

Caracara plancus (Miller, 1777).

Caracara plancus (carancho) es un falcónido de gran tamaño (900-1600g). Se distribuye a través de América, desde el sur de Perú hasta el extremo sur de Chile y Argentina, habitando en multiplicidad de ambientes, tanto en áreas naturales como urbanas (White et al., 1994). Construye sus nidos en árboles y arbustos y presenta un home range $>3 \mathrm{~km}^{2}$ (Morrison, 1998). Es un depredador diurno, generalista, oportunista, carroñero y cazador, que se alimenta principalmente de vertebrados grandes, medianos y chicos y artrópodos. Entre los microvertebrados caza roedores, lagomorfos, aves, reptiles, anfibios y peces (White et al., 1994; Travaini et al., 2001; Vargas et al., 2007; Montalvo y Tallade, 2010).

Se destaca que en la actualidad, C. plancus suele aprovechar los basureros antrópicos para alimentarse (White et al., 1994, Yorio y Giaccardi, 2002). Esta característica podría tener implicancias tafonómicas, debido a que un caso similar pudo tener lugar en tiempos pasados, donde grupos de caranchos se acercaban a los depósitos de basura para alimentarse, de modo que los restos acumulados por esta rapaz se mezclen con los dejados por los humanos (Montalvo et al., 2011).

Estudios tafonómicos actualísticos efectuados por Gómez (2007), Montalvo y Tallade (2009, 2010) indicaron que C. plancus produce modificaciones fuertes sobre restos de micromamíferos recuperados de egagrópilas (Categoria IV sensu Andrews, 1990). No obstante, Montalvo y Tallade $(2009,2010)$ registraron bajos niveles de modificación en restos de micromamíferos no ingeridos por esta rapaz. Finalmente, Montalvo et al. (2011) observaron características similares al analizar restos de aves no ingeridas y de egagrópilas de C.plancus. 
Género Milvago Spix, 1824.

Milvago chimango (Vieillot, 1816).

Milvago chimango (chimango) es un falcónido de pequeño y mediano tamaño (250300g). Se distribuye por Sudamérica, desde el sur de Brasil, Paraguay y Uruguay, hasta el extremo sur de Chile y Argentina, habitando en numerosos ambientes, con preferencia a los de tipo abierto, como estepas graminosas y arbustivas, siendo abundante en áreas rurales y periurbanas (White et al., 1994). Anida en los árboles, arbustos y acantilados y presenta un home range $>3 \mathrm{~km}^{2}$. Es un depredador diurno, generalista, oportunista, carroñero y cazador, que consume principalmente invertebrados y secundariamente mamíferos, aves, reptiles, anfibios y peces (e.g., Yáñez et al., 1982; Cabezas y Schlatter, 1987; Biondi et al., 2005).

Cabe destacar, que $M$. chimango presenta un comportamiento similar al de C. plancus y también suele aprovechar los basureros antrópicos para alimentarse (White et al., 1994, Yorio y Giaccardi, 2002), incluso algunos estudios indican que $M$. chimango incrementa sus poblaciones en áreas impactadas por humanos (Cabezas y Schlatter, 1987; Donázar et al., 1993; Biondi et al., 2005), confiriéndole implicancias tafonómicas semejantes a las de C. plancus (Gómez, 2007).

Género Falco Linnaeus, 1758.

Falco peregrinus Tunstall, 1771.

Falco peregrinus (halcón peregrino) es un falcónido de gran tamaño (440-1.500g.). Presenta una amplia distribución mundial, incluyendo toda la Argentina, habitando en multiplicidad de ambientes, tanto en áreas naturales como urbanas (Brown, 1976; Ratcliffe, 1980). Realiza sus nidos en salientes rocosas, árboles, incluso en altos edificios urbanos y presenta un home range de ca. $5 \mathrm{~km}^{2}$ (Brown, 1976; Ratcliffe, 1980). Es un halcón diurno, oportunista, que se alimenta principalmente de aves de mediano tamaño y en menor medida de micromamíferos, reptiles y anfibios (Brown, 1976; Ratcliffe, 1980; Mc Nutt, 1981; Ellis et al., 2002).

Estudios tafonómicos realizados por Andrews (1990), plantean que F. peregrinus produce modificaciones moderadas en ensambles de micromamíferos (Categoría II, sensu Andrews, 1990). No obstante, el mencionado autor destaca que este halcón no puede considerarse un importante acumulador de micromamíferos. 
Falco sparverius Linnaeus, 1758.

Falco sparverius (halconcito colorado) es un falcónido de pequeño tamaño (100-170g.). Exhibe una amplia distribución en América, desde Alaska hasta el extremo sur de la Argentina, habitando en gran variedad de ambientes, tanto en áreas naturales como suburbanas (Brown, 1976; Cade, 1982; White et al., 1994). Anida en salientes rocosas, árboles y construcciones realizadas por humanos y presenta un home range de entre $1 \mathrm{y}$ 2,5 km² (Brown, 1976; Cade, 1982; White et al., 1994). Es un halcón diurno, oportunista, que consume principalmente insectos y secundariamente micromamíferos, aves y reptiles (e.g., Beltzer, 1990; Sarasola et al., 2003; Figueroa Rojas y Soraya Corales Stappung, 2004).

Hasta el presente no se cuenta con información tafonómica sobre $F$. sparverius.

Clase Mammalia Linnaeus, 1758.

Orden Carnivora Bowdich, 1821.

Familia Felidae Fisher, 1917.

Género Puma Jardine, 1834.

Puma concolor (Linnaeus, 1771).

Puma concolor (puma) es el segundo félido más grande de Sudamérica (35-100 kg.). Se distribuye desde el centro-este de Canadá hasta el sur de Chile y sur de la provincia de Santa Cruz en Argentina, habitando multiplicidad de ambientes desde el nivel del mar hasta 4.500 m.s.n.m. (Currier, 1983). Realiza sus madrigueras en cuevas, refugios rocosos y también en lugares a cielo abierto, entre las rocas o en la vegetación densa y presenta un home range promedio de entre 35 y $100 \mathrm{~km}^{2}$ (e.g., Pierce y Bleich, 2003; Martín y Borrero, 2007; Caso et al., 2008a). Es un depredador solitario, territorial y generalmente nocturno, que incluye una amplia variedad de presas en su dieta. Consume principalmente animales grandes como camélidos, cérvidos, reídos y tayasuidos, aunque los animales de mediano tamaño como armadillos, liebres y roedores son una parte importante de su dieta. Sin embargo, en el sur de Sudamérica los micromamíferos, tales como Galea leucoblephara, Ctenomys spp. y algunos sigmodontinos fueron altamente consumidos, aunque en términos de biomasa la importancia de este grupo de roedores es relativamente menor (Iriarte et al., 1990b, 1991; Rau et al., 1991). 
El rol de $P$. concolor como agente acumulador de restos faunísticos en sitios arqueológicos ha sido analizado en diversas investigaciones en América (e.g., Mondini y Muñoz, 2008; Montalvo et al., 2007; Muñoz et al., 2008; Stiner et al., 2012), incluyendo algunas de la región Patagónica (e.g., Borrero y Martín, 1996; Borrero et al., 2005; Martín y Borrero, 2007; Fernández et al., 2011a).

Montalvo et al. (2007) y Stiner et al. (2012), en base a estudios tafonómicos sobre restos óseos de mamíferos consumidos por $P$. concolor, registraron que este depredador producía altos valores de destrucción sobre los huesos de mamíferos medianos y grandes, sin embargo, observaron que los restos de micromamíferos exhibieron una gradación en la preservación, incluyendo tanto restos con alta modificación, como restos bien preservados. Montalvo et al. (2007), postulan que estas diferencias podrían deberse a que los microvertebrados fueron ingeridos enteros, sin masticación previa. Además, registraron un sesgo de elementos craneales con respecto a los postcraneales, alta representación de mandíbulas y baja representación de vértebras. Por su parte, Gomez (2007) en base a exiguos restos de micromamíferos recuperados de dos fecas de $P$. concolor, sugiere que este félido se incluya en las categorías de modificación fuerte y extrema (sensu Andrews, 1990).

Puma yagouaroundi (É. Geoffroy Saint-Hilaire, 1803).

Puma yagouaroundi (yaguarundí) es un félido de entre 2 y $4 \mathrm{~kg}$ de masa corporal estimada. Se distribuye desde el sur de Norteamérica hasta el centro de Argentina, ocupando gran variedad hábitats por debajo de los 2.200 m.s.n.m. (e.g., Olivera, 1994; Perovic et al., 2006; Caso et al., 2008b). Frecuentemente, realiza sus madrigueras en los árboles y presenta un home range promedio de $100 \mathrm{~km}^{2}$ (e.g., Caso et al., 2008b). Es un depredador diurno y oportunista, que consume principalmente micromamíferos, aves y reptiles (e.g., Caso et al., 2008b).

El análisis tafonómico realizado por Gómez et al. (2007) en base a dos fecas de $P$. yagouaroundi, mostró que este félido tiende a preservar más los elementos del cráneo de sus presas, produce altos niveles de fractura, elevada pérdida dentaria y corrosión digestiva con valores que oscilan entre moderada, fuerte y extrema.

Género Leopardus Gray, 1842.

Leopardus geoffroyi (d'Orbigny y Gervais, 1844). 
Leopardus geoffroyi (gato montes) alcanza una masa corporal de 4 o $5 \mathrm{~kg}$. Comprende una distribución desde el sudeste de Bolivia, Paraguay, sur de Brasil y Uruguay hasta sur de Chile y sur de la provincia de Santa Cruz en Argentina, donde habita en amplia variedad de ambientes desde las tierras bajas hasta 3.300 m.s.n.m. Hace sus madrigueras en cavidades debajo de las raíces de los árboles y presenta un home range promedio de entre 2,5 y 3,4 km² (e.g., Ximenez, 1975; Nowak y Paradiso, 1983; Lucherini et al., 2008). Es un depredador nocturno y oportunista, que puede consumir una amplia variedad de presas tales como mamíferos medianos y chicos, aves, reptiles, anfibios, peces e insectos (e.g., Nowak y Paradiso, 1983; Manfredi et al., 2004; Bisceglia et al., 2008; Lucherini et al., 2008).

Los estudios tafonómicos experimentales realizados por (Gómez, 2007), sobre restos de huesos y dientes de micromamíferos recuperados de dos fecas de L. geoffroyi, ubican a este félido dentro de la categoría de depredadores de modificación fuerte (Categoría IV, sensu Andrews, 1990). En coincidencia, Montalvo et al. (en prensa a) mediante el análisis de restos de micromamíferos consumidos por este félido durante distintas estaciones anuales del centro de Argentina (Santa Rosa, La Pampa), observaron que produce corrosión digestiva fuerte. Recientemente, Álvarez et al. (en prensa), en base a un estudio experimental sobre resto de lepóridos no ingeridos por L. geoffroyi, observaron que este félido produce altos niveles de fractura en las vértebras, costillas, escápulas, cráneos y epífisis de huesos largos. Asimismo, registraron elevadas frecuencias de marcas de dientes en pelvis, escápulas, mandíbulas y huesos largos.

Leopardus pajeros (Desmarest, 1816).

Leopardus pajeros (gato de los pajonales) es un félido sudamericano de pequeño tamaño (2-3,7 kg.). Se distribuye desde Ecuador, oeste de Perú, Bolivia, centro de Brasil, oeste de Paraguay y Uruguay hasta el sur de Chile y Argentina, ocupando multiplicidad de ambientes desde el nivel del mar hasta los 5000 m.s.n.m (e.g., GarcíaPerea, 1994; Sunquist y Sunquist, 2002; Pereira et al., 2008. Realiza sus madrigueras en cuevas y presenta un home range de $19,5 \mathrm{~km}^{2}$. Es una especie solitaria, diurna y nocturna, que depreda principalmente micromamíferos y aves (e.g., Walker et al., 2007; Pereira et al., 2008). Es interesante destacar, que para el sur de Mendoza GarcíaEsponda et al. (2009), en base a un análisis de fecas de L. pajeros de Laguna El 
Sosneado, observaron que los roedores sigmodontinos fueron el ítem más importante en la dieta, seguidos por Ctenomys, pequeños reptiles y aves.

Hasta el presente no se cuenta con información tafonómica sobre L. pajeros.

Leopardus jacobita (Cornalia, 1865).

Leopardus jacobita (gato andino) es un pequeño y poco frecuente félido Sudamericano de entre 3 y $6 \mathrm{~kg}$. de masa corporal estimada. Su distribución es muy fragmentada, desde el sur de Perú, centro-oeste de Bolivia hasta el centro de Chile y centro-oeste de Argentina, habitando en ambientes de Puna y altos Andes, alcanzando los 4.400 m.s.n.m. (e.g., Perovic et al., 2006; Acosta et al., 2008). Esta especie hace sus madrigueras en roquedales y cuevas y presenta un home range de $65,5 \mathrm{~km}^{2}$. Es un depredador principalmente solitario, crepuscular y nocturno, que consume primariamente roedores medianos y chicos, aunque las aves y reptiles pueden ser parte integrante de su dieta (e.g., Walker et al., 2007; Acosta et al., 2008).

Hasta el presente no se cuenta con información tafonómica sobre L. jacobita.

Familia Canidae Fischer, 1817.

Género Lycalopex Burmeister, 1854.

Lycalopex culpaeus (Molina, 1782).

Lycalopex culpaeus (zorro colorado) es el segundo cánido mas grande de Sudamérica (5-7 kg). Es una especie principalmente Andino-Patagónica, con distribución desde el norte de Colombia hasta Tierra del Fuego (e.g., Redford y Eisenberg, 1992; Jiménez y Novaro, 2004; Jiménez et al., 2008a). En Patagonia alcanza las tierras bajas costeras, posiblemente favorecido por el avance del ganado ovino en las últimas cententurias (e.g., Crespo y De Carlo, 1963). Hace sus madrigueras en roquedales y cuevas y presenta un home range de entre 4,5-8,9 $\mathrm{km}^{2}$ (Jiménez y Novaro, 2004). Es una especie oportunista, omnívora, que presenta una gran amplitud de dieta, siendo los roedores y lagomorfos las presas más comunes, aunque también incluye reptiles, aves, insectos y frutos (e.g., Medel y Jaksic, 1988; Marquet et al., 1993; Martínez et al., 1993; Jaksic, 1997; Jiménez y Novaro, 2004; Silva et al., 2005).

Hasta el presente no se cuenta con información sobre tafonomía de restos de microvertebrados depredados por L. culpaeus. 
Lycalopex griseus (Gray, 1837).

Lycalopex griseus (zorro gris chico) pequeño cánido sudamericano de entre 2,5 y 4,5 kg de masa corporal estimada. Se extiende a ambos lados de la cordillera de los Andes, desde el norte Chile y Argentina hasta Tierra del Fuego donde fue introducido, habitando gran variedad de ambientes, generalmente en tierras bajas (González del Solar y Rau, 2004; Díaz y Lucherini, 2006a; Jiménez et al., 2008b). Realiza sus madrigueras en cuevas o depresiones protegidas y presenta un home range de $c a .3 \mathrm{~km}^{2}$ (González del Solar y Rau, 2004). Es un depredador omnívoro que presenta una dieta amplia, pudiendo alimentarse de mamíferos medianos, micromamíferos, aves, reptiles, insectos y frutos (Medel y Jaksic, 1988; Redford y Eisenberg, 1992; González del Solar y Rau, 2004; Rau et al., 1995).

Gómez y Kaufmann (2007) en un estudio tafonómico sobre restos óseos ingeridos por L. griseus, registraron que esta especie exhibió niveles de modificación extrema (Categoría V, sensu Andrews, 1990), principalmente por la acción de ácidos digestivos y efectos de la masticación.

Familia Mephitidae Bonaparte, 1845.

Género Conepatus Gray, 1837.

Conepatus chinga (Molina, 1782).

Conepatus chinga (zorrino común) es un pequeño carnívoro sudamericano de entre 1,5 y $3 \mathrm{~kg}$. de masa corporal estimada (Redford y Eisenberg, 1992). Habita en una amplia variedad de ambientes abiertos, desde el sur de Perú, Bolivia y oeste de Paraguay hasta el centro de Chile y sur de Neuquén en Argentina, presentando poblaciones aisladas en sur de Brasil y Uruguay (Díaz y Lucherini, 2006b; Emmons y Helgen, 2008). Hace sus madrigueras excavando pozos a cielo abierto y presenta un home range de entre 0,6-2,4 $\mathrm{km}^{2}$ (Donadio et al., 2001; Castillo et al., 2011). Es una especie solitaria nocturna y generalista, que consume principalmente artrópodos y micromamíferos $\mathrm{y}$ ocasionalmente anélidos, anfibios, reptiles, carroña y huevos de aves (Travaini et al., 1998; Novaro et al., 2000; Donadío et al., 2004 Montalvo et al., 2008).

Gómez (2007) y Montalvo et al. (2008) al analizar tafonomicamente huesos consumidos por $C$. chinga registraron que este depredador presentó niveles de 
modificación extrema (Categoría V, sensu Andrews, 1990), principalmente por la acción de ácidos digestivos y efectos de la masticación. 


\section{Capítulo 7}

\section{LOS SITIOS ARQUEOLÓGICOS}

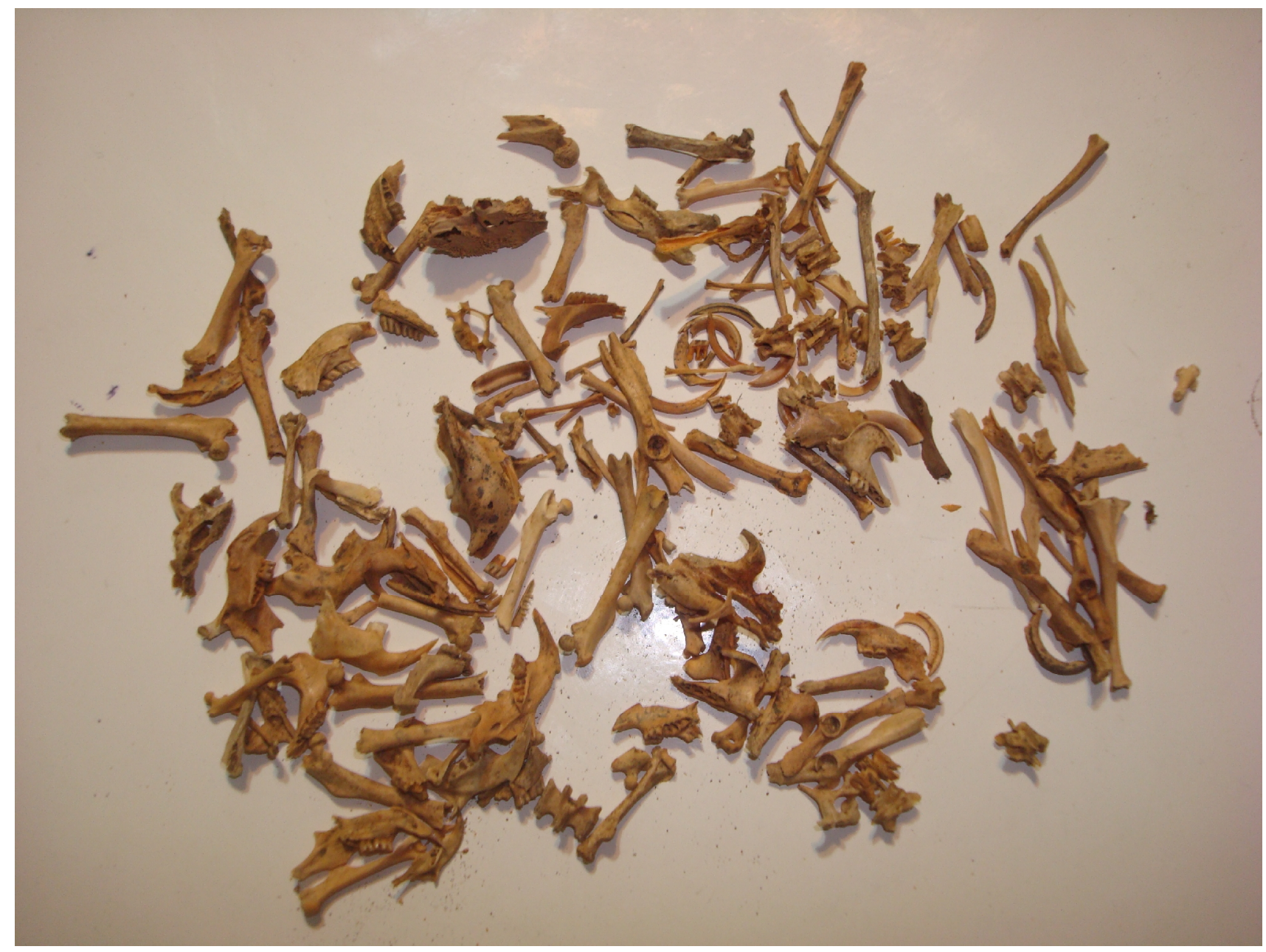





\section{LOS SITIOS ARQUEOLÓGICOS}

En este capítulo se estudian los ensambles de microvertebrados exhumados de los sitios arqueológicos que forman parte de esta tesis (Capítulo 4, Tabla 4.1 y Figura 4.1). En cada sitio, se analizan exhaustivamente los procesos tafonómicos intervinientes teniendo en cuenta los contextos arqueológicos particulares. Dado que los sitios fueron excavados por diferentes investigadores, siguiendo metodologías distintas, el grado de resolución alcanzado en relación a los procesos tafonómicos fue dispar. Posteriormente, se evalúan las estructuras taxonómicas de los ensambles para interpretar la historia paleambiental de cada sitio, considerando las limitaciones muéstrales y sesgos tafonómicos que presentan. Para este fin, también se analizaron muestras de egagrópilas de aves rapaces.

\subsection{Rincón del Atuel-1 (RA-1)}

\subsubsection{Contexto arqueológico}

Rincón del Atuel-1 (RA-1) es un sitio arqueológico a cielo abierto, ubicado en la localidad homónima, ca. de $30 \mathrm{~km}$ al sur de San Rafael (3445'31" S y 68²2'14" O; 747 m.s.n.m.). Se emplaza sobre una terraza aluvial a pocos kilómetros de la salida extraserrana del Río Atuel, a $500 \mathrm{~m}$ del sitio Gruta del Indio, en donde comienza la Planicie Sanrafaelina (Figura 7.1A).

Lagiglia (1956) presentó los primeros datos sobre el sitio arqueológico RA-1 y durante las décadas posteriores, los estudios en torno a este sitio se enfocaron en los materiales superficiales. En la década de 1970, se recuperaron entierros humanos en el sitio (Lagiglia, 1977). En el año 2001, personal del Museo de Historia Natural de San Rafael realizó una excavación en el sitio como consecuencia de la importancia de esta Localidad en las investigaciones sobre la historia cultural de la región (Lagiglia, 1977, 1980, 1999a).

Se excavaron 3 cuadrículas contiguas cubriendo $c a .12 \mathrm{~m}^{2}$, extrayendo 28 niveles artificiales de $5 \mathrm{~cm}$ y zarandeando los materiales por sectores de $1 \mathrm{~m} \mathrm{x} 1 \mathrm{~m}$ (Dieguez et al., 2004; Gil et al., 2008). Figura 7.1B.

La cronología del sitio (Tabla 7.1), fue presentada y discutida por Dieguez et al. (2004) y posteriormente por Gil et al. (2008). 


\begin{tabular}{|l|c|c|c|c|c|c|}
\hline Procedencia & Unidad & Sector & Muestra & Código & Datación & Calibrado \\
\hline A2 (9-10) & E & Sur & Carbón & LP-1341 & $1480 \pm 70$ & $1329-1477$ \\
A2 (17-18) & G & Sur & Carbón & LP-1354 & $1520 \pm 70$ & $1355-1502$ \\
A3 (9SE/SO-10SE/SO) & J & Centro & Carbón & LP-1355 & $1030 \pm 70$ & $850-1031$ \\
A3 (5NE) & K & Norte & Carbón & LP-1338 & $330 \pm 60$ & $329-464$ \\
A3 (16NE) & K & Norte & Carbón & LP-1349 & $780 \pm 70$ & $680-784$ \\
A3 (24NO) & H & Norte & Carbón & LP-1351 & $1040 \pm 60$ & $896-1033$ \\
Estructura carbonosa & Hornillo 1 & & Carbón & LP-1489 & $1430 \pm 70$ & $1301-1400$ \\
Entierros humanos & AF-500 & & Hueso & LP-1370 & $1760 \pm 70$ & $1596-1779$ \\
\hline A3 (8NE) & K & Norte & Cerámica & UCTL-1478 & $1175 \pm 80$ & - \\
A2 (3NE & C & Sur & Cerámica & UCTL-1479 & $980 \pm 100$ & - \\
\hline
\end{tabular}

Tabla 7.1. Fechados ${ }^{14} \mathrm{C}$ y TL del sitio RA-1. Modificado de Dieguez et al. (2004: 76) y Gil et al. (2008: 117).
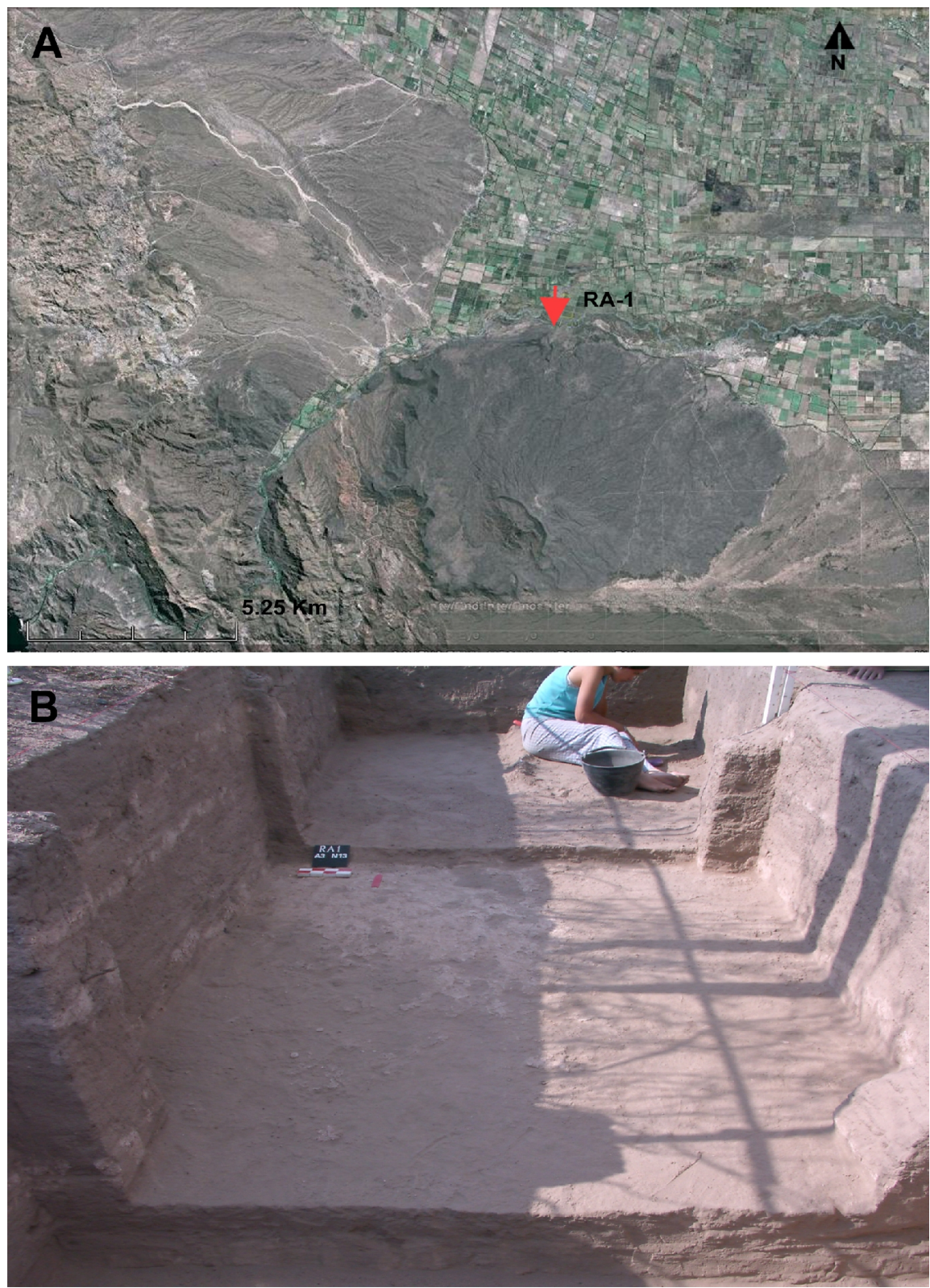

Figura 7.1. Sitio arqueológico RA-1. A: ubicación del sitio. B: cuadrículas excavadas. 
La composición litoestratigráfica del sitio fue descripta por Dieguez et al. (2004) (Figura 7.2). Los autores observaron en las cuadrículas A-1 y A-2 una sucesión de paquetes de arena separados por niveles arcillosos de espesor variable entre $5 \mathrm{~cm}$ y 20 cm (unidades A, B, C, D, E, F, G). Sin embargo, registraron que esta secuencia estaba alterada en la cuadrícula A-3 por la presencia de un rasgo negativo, en forma de "U" (Unidad J), con un relleno sedimentario diferente por su granulometría a los sedimentos adyacentes (Dieguez et al., 2004). La base de dicha unidad se apoya sobre un sedimento homogéneo, común a todos los sectores (Unidad H). En el sector norte de la cuadrícula A-3, los autores observaron un patrón estratigráfico diferente al resto de las paredes de la excavación (Unidad K); solo distinguieron, en forma fragmentaria, el último nivel arcilloso (Unidad F) y lo interpretaron como un proceso de bioturbación intenso (Dieguez et al., 2004).

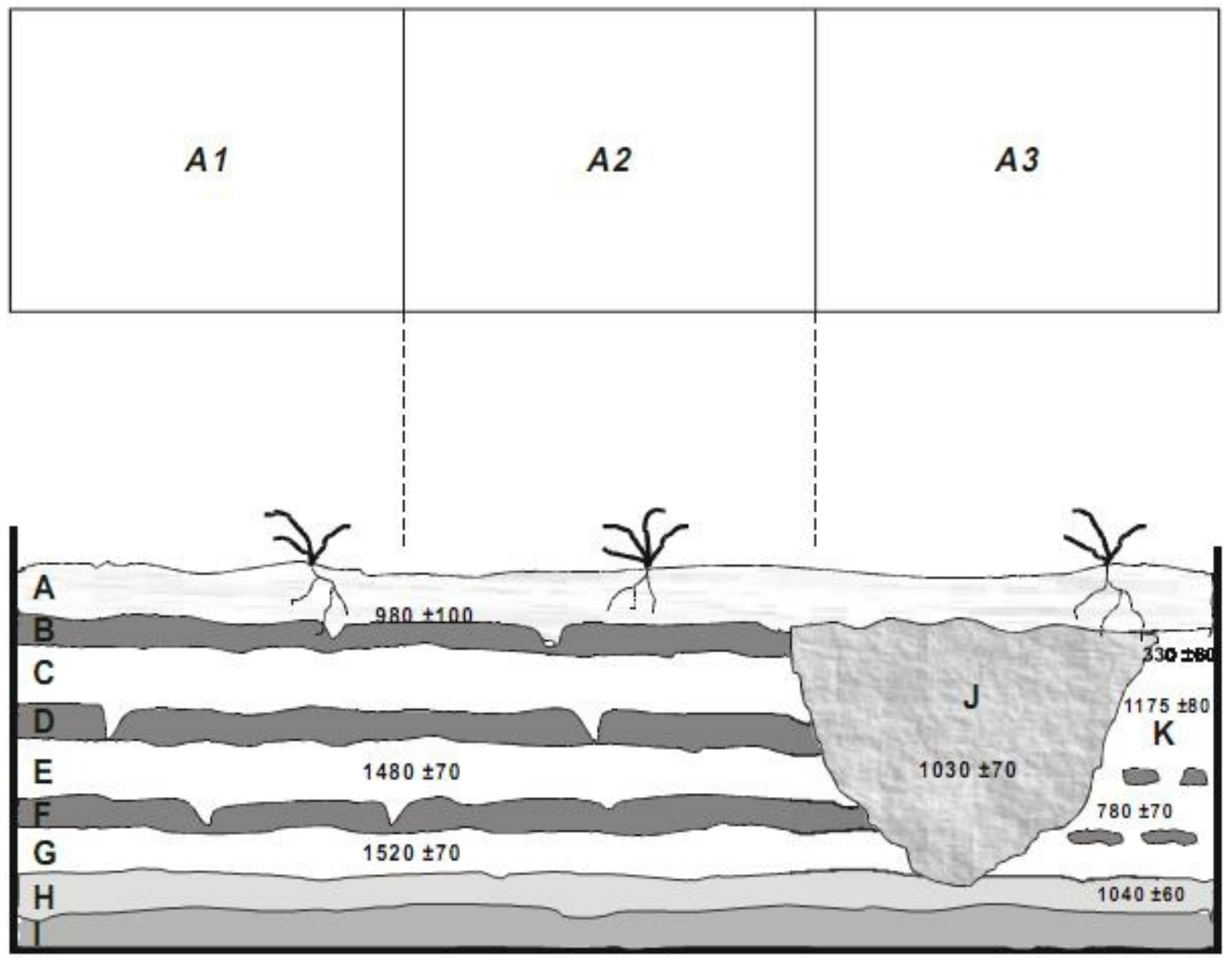

Figura 7.2. Vista en planta de las unidades con sus estratigrafías, incluyendo las dataciones cronológicas en ${ }^{14} \mathrm{C}$ y TL. Tomado de Dieguez et al. (2004: 74). 
Los autores citados plantean que desde la depositación de la unidad $\mathrm{H}$, el sitio pudo haber integrado la planicie de inundación del Río Atuel. Las unidades B, C, D, E, F, y $\mathrm{G}$, habrían sido parte de ciclos sedimentarios compuestos alternativamente por un estrato arenoso y otro arcilloso (Dieguez et al., 2004). Según los autores, estos ciclos estarían asociados a episodios aluviales posiblemente producto de las inundaciones de la planicie del Río Atuel. La Unidad A, de matriz arenosa, constituiría el suelo actual y la Unidad J, un sedimento de matriz muy diferente al resto del sitio, se habría depositado temporalmente luego de la Unidad B (Dieguez et al., 2004). La relación de proximidad espacial entre el rasgo negativo rellenado por el sedimento de la Unidad $\mathbf{J}$ y la alta bioturbación observada en $\mathrm{K}$, sugiere la presencia de un "basurero" (Dieguez et al., 2004), cuyo contenido orgánico podría haber facilitado el ingreso de animales bioturbadores (Gil et al., 2008). Por su parte, las unidades I y J tendrían elementos seleccionados por procesos fluviales (Dieguez et al., 2004).

Gil et al. (2008) en base a información cronoestratigráfica, registro lítico, datos del hornillo y de los esqueletos humanos, plantearon la existencia de dos conjuntos arqueológicos. El Conjunto superior incluye el registro de las unidades A, B, C y K, es somero (ca. 1000-1200 años ${ }^{14} \mathrm{C}$ AP), tiene mayor diversidad y densidad de restos. El material cerámico se deposita casi totalmente en este conjunto, se exhibe un aumento de rocas no locales (i.e., obsidiana) y también de fragmentos malacológicos (Gil et al., 2008). El Conjunto inferior contiene las unidades D, E, F, G, H, contrariamente presenta buena resolución temporal (ca. 1200-1500/1700 años ${ }^{14} \mathrm{C}$ AP) y menor densidad de hallazgos arqueológicos. A este segundo conjunto corresponde los esqueletos humanos y el "hornillo 1" (Gil et al., 2008).

En cuanto al registro arqueobotánico, Gil et al. (2008) señalan la presencia de restos vegetales característicos del desierto del Monte (e.g., Larrea divaricada) en ambos conjuntos culturales, aunque sugieren que no fueron utilizados en la subsistencia. Asimismo, se recuperó un resto de maíz (Zea mays) en cada conjunto y numerosos restos indeterminados que presentaron evidencias de termoalteración, lo que fue sugerido por los autores citados como un posible uso por parte de las poblaciones humanas que habitaron RA-1. En este sentido, los resultados isotópicos obtenidos por Gil et al. (2008) a partir de los restos humanos provenientes del conjunto inferior exhibieron valores mixtos, cercanos al límite inferior de las dietas que incluyen alta proporción de recursos $\mathrm{C}_{4}$ como el maíz, aún mayores que en individuos contemporáneos de la región (Gil et al., 2006a). Este conjunto relacionado con 
elementos agrícolas mostraría ocupaciones más efímeras que las del conjunto superior (Gil et al., 2008). Simultáneamente, la única especie exótica exhumada en RA-1 (Unidad A) fue Salsola kali (cardo ruso), la cual actualmente se encuentra en las inmediaciones del sitio (Gil et al., 2008).

Por su parte, los cuerpos humanos corresponden a 4 individuos que se encontraban en disposición E-O, mirando hacia arriba (Lagiglia, 1977). El conjunto óseo postcraneal recuperado estaba muy fragmentado y la única patología observada fue hipoplasia dental en dos individuos (Gil et al., 2008), siendo un valor elevado en el contexto de la región (Novellino y Gil, 2007).

El análisis zooarqueológico general del sitio fue realizado por Gil et al. (2008). Se exhumaron 1.137 especimenes y debido a su alta fragmentación el 92,3\% de los mismos no pudieron determinarse taxonómicamente (Gil et al., 2008). La mayor frecuencia de huesos se registró en la Unidad K, siguiendo la Unidad A (Conjunto superior). La Unidad K es la única que contiene camélidos (Lama sp.), liebre patagónica (Dolichotis patagonum) y peces (Teleostei). Asimismo, resulta interesante destacar que los dos fragmentos (mandíbula y pélvis) asignados a D. patagonum se recuperaron a distintas profundidades en el sector NE de la cuadrícula A-3 dentro de la Unidad K, no exhibieron marcas antrópicas y presentaron similar meteorización (Gil et al., 2008). Esta especie de mediano tamaño presenta hábitos fosoriales y puede ser considerada como potencial bioturbadora junto a otros roedores del área (Campos et al., 2001). En tal sentido, Gil et al. (2008) sugieren que los restos de esta especie ingresaron al sitio por causas naturales y no por acción humana. Para finalizar, se registraron exiguos restos de dasipódidos en ambos conjuntos y de reídos en el Conjunto inferior (Gil et al., 2008).

En síntesis, los cambios evidenciados en RA-1 a partir de los $1200-1000$ años ${ }^{14} \mathrm{C}$ AP, coinciden con la cronología propuesta para el incremento en las ocupaciones de la región (Gil, 2006; Neme et al., 2005) y con la incorporación del maíz en forma generalizada (Gil, 2003; Gil et al., 2006a).

\subsubsection{Metodología}

Debido a la mencionada complejidad cronoestratigráfica y cultural, para el análisis de micromamíferos se estudiaron conjuntamente los materiales provenientes de las cuadrículas A-1 y A-2 y se compararon con aquellos recuperados de la cuadrícula A-3. 
Asimismo, las cuadrículas A-1 y A-2 se analizaron teniendo en cuenta los conjuntos arqueológicos definidos por Gil et al. (2008).

Como parámetros actualísticos se estudiaron una muestra de egagrópilas disgregadas de Bubo magellanicus (tucúrere), las cuales fueron recolectadas a $500 \mathrm{~m}$. del sitio arqueológico [Localidad Gruta del Indio (ver apéndice)] y una muestra de 40 egagrópilas de Tyto alba localizada $34 \mathrm{~km}$ al noroeste del sitio, proveniente de la literatura científica [Localidad Río Seco La Hedionda (ver apéndice)].

\subsubsection{Resultados}

\subsubsection{Análisis tafonómico}

El 20\% de todos los especímenes exhumados de RA-1 sufrieron algún tipo de corrosión digestiva (Conjunto superior: 46,9\%; Conjunto inferior: 9,1\%; Cuadrícula 3: 13\%), los cuales se concentraron en la categoría ligera y solo en algunos casos en las categorías moderada y fuerte (Tabla 7.2).

Los materiales fueron analizados en forma integral dado que son demasiado escasos para su posible comparación en cada ítem. En el Conjunto superior no se registraron dientes con evidencias de digestión, aunque si en los elementos postcraneales (Figura 7.3A y B). En el Conjunto inferior se observó un fémur con marcas de digestión fuerte. Finalmente, en la Cuadrícula 3 se recuperaron tanto dientes como restos postcraneales principalmente con huellas de digestión ligeras.

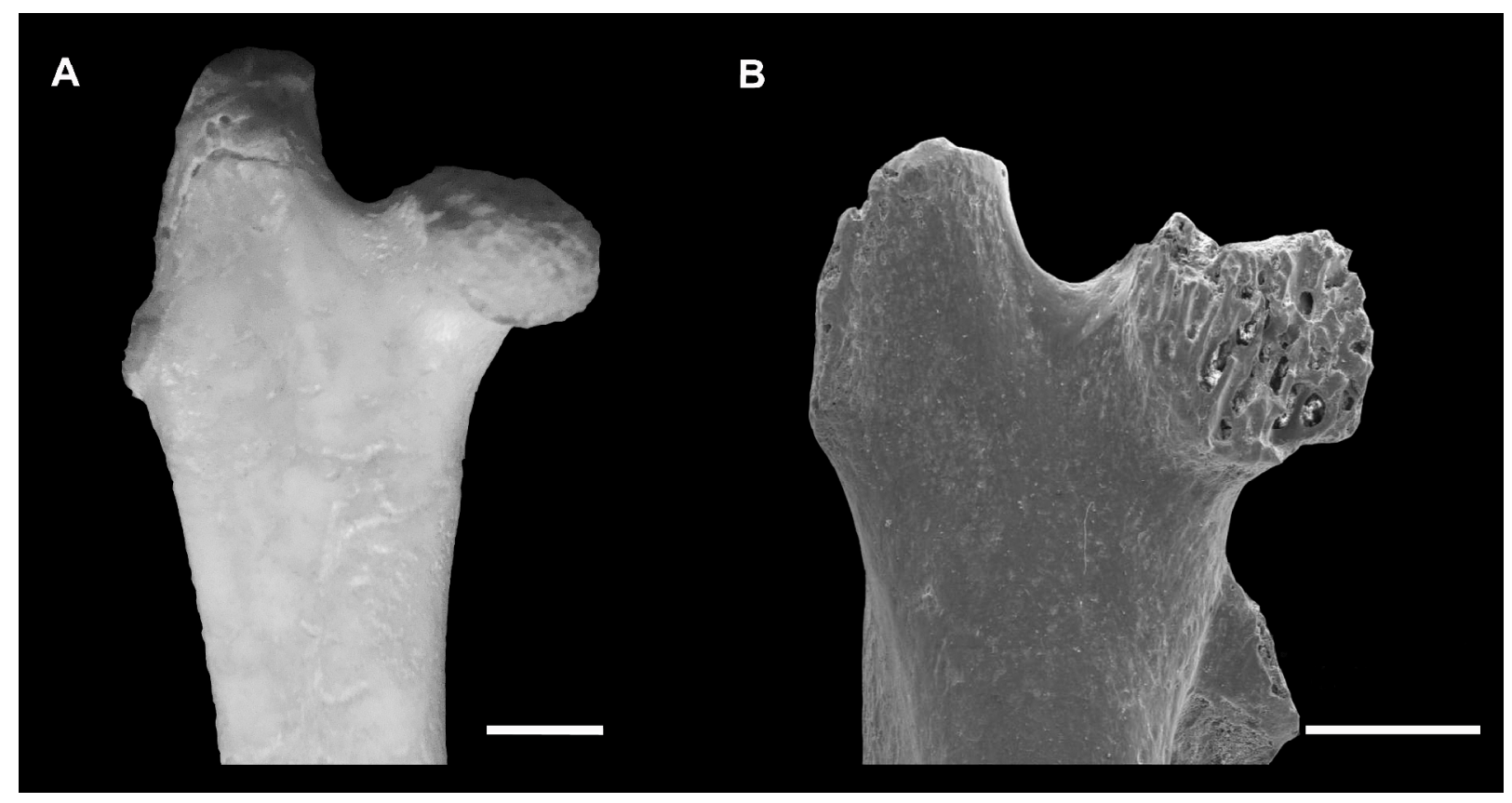


Figura 7.3. Elementos postcraneales con marcas de corrosión digestiva en RA-1. A: Fémur de Caviidae exhibiendo corrosión ligera en epífisis y marcas de raíces en la diáfisis (Cuadricula A-2, Unidad A). B: Fémur de Sigmodontinae mostrando corrosión moderada en la epífisis (Cuadricula A-1, Unidad A). Escalas: 2 mm.

\begin{tabular}{|c|c|c|c|c|c|c|c|c|c|c|}
\hline \multirow{3}{*}{ RA-1 } & \multicolumn{10}{|c|}{ Clases de digestión sensu Andrews (1990) } \\
\hline & \multicolumn{2}{|c|}{ Ausente } & \multicolumn{2}{|c|}{ Ligera } & \multicolumn{2}{|c|}{ Moderada } & \multicolumn{2}{|c|}{ Fuerte } & \multicolumn{2}{|c|}{ Extrema } \\
\hline & $(\mathrm{N})$ & $\%$ & $(\mathrm{~N})$ & $\%$ & $(\mathrm{~N})$ & $\%$ & $(\mathrm{~N})$ & $\%$ & $(\mathrm{~N})$ & $\%$ \\
\hline A-1 y A-2 (Conj. sup.) & & & & & & & & & & \\
\hline Digestión dentaria & & & & & & & & & & \\
\hline Incisivos in situ & - & - & - & - & - & - & - & - & - & - \\
\hline Incisivos aislados & 3 & 100 & - & - & - & - & - & - & - & - \\
\hline Incisivos Total & 3 & 100 & - & - & - & - & - & - & - & - \\
\hline Molares in situ & 6 & 100 & - & - & - & - & - & - & - & - \\
\hline Molares aislados & 1 & 100 & - & - & - & - & - & - & - & - \\
\hline Molares Total & 7 & 100 & - & - & - & - & - & - & - & - \\
\hline Digestión Postcraneal & & & & & & & & & & \\
\hline Fémur (epífisis proximal) & - & - & 1 & 50 & 1 & 50 & - & - & - & - \\
\hline Húmero (epífisis distal) & 1 & 50 & 1 & 50 & - & - & - & - & - & - \\
\hline Resto de los elementos & 16 & 44,4 & 20 & 55,6 & - & - & - & - & - & - \\
\hline A-1 y A-2 (Conj. inf.) & & & & & & & & & & \\
\hline Digestión dentaria & & & & & & & & & & \\
\hline Incisivos in situ & 1 & 100 & - & - & - & - & - & - & - & - \\
\hline Incisivos aislados & 3 & 100 & - & - & - & - & - & - & - & - \\
\hline Incisivos Total & 4 & 100 & - & - & - & - & - & - & - & - \\
\hline Molares in situ & 2 & 100 & - & - & - & - & - & - & - & - \\
\hline Molares aislados & - & - & - & - & - & - & - & - & - & - \\
\hline Molares Total & 2 & 100 & - & - & - & - & - & - & - & - \\
\hline Digestión Postcraneal & & & & & & & & & & \\
\hline Fémur (epífisis proximal) & - & - & - & - & - & - & 1 & 100 & - & - \\
\hline Húmero (epífisis distal) & 1 & 100 & - & - & - & - & - & - & - & - \\
\hline Resto de los elementos & - & - & - & - & - & - & - & - & - & - \\
\hline A-3 & & & & & & & & & & \\
\hline Digestión dentaria & & & & & & & & & & \\
\hline Incisivos in situ & 4 & 66,7 & 2 & 33,3 & - & - & - & - & - & - \\
\hline Incisivos aislados & 27 & 93,1 & 2 & 6,9 & - & - & - & - & - & - \\
\hline Incisivos Total & 31 & 88,6 & 4 & 11,4 & - & - & - & - & - & - \\
\hline Molares in situ & 72 & 100 & - & - & - & - & - & - & - & - \\
\hline Molares aislados & 9 & 100 & - & - & - & - & - & - & - & - \\
\hline Molares Total & 81 & 100 & - & - & - & - & - & - & - & - \\
\hline Digestión Postcraneal & & & & & & & & & & \\
\hline Fémur (epífisis proximal) & 5 & 41,7 & 4 & 33,3 & 2 & 16,7 & 1 & 8,3 & - & - \\
\hline Húmero (epífisis distal) & 3 & 75 & 1 & 25 & - & - & - & - & - & - \\
\hline Resto de los elementos & 92 & 87,6 & 12 & 11,4 & - & - & 1 & 1 & - & - \\
\hline
\end{tabular}

Tabla 7.2. Representación de las distintas categorías de corrosión digestiva en micromamíferos de los conjuntos arqueológicos de RA-1. 
La abundancia relativa promedio de partes esqueletarias en todas las muestras fue muy baja. A pesar de encontrar algunas diferencias entre las muestras, los maxilares, mandíbulas, fémures y húmeros estuvieron bien representados, contrariamente a los elementos del autopodio (Tabla 7.3 y Figura 7.4).

El 62,9\% de todos los especímenes recuperados de RA-1 estaban fracturados (Conjunto superior: 40,8\%; Conjunto inferior: 90,1\%; Cuadrícula 3: 67\%).

En la tabla 7.4 se muestra los distintos tipos de fractura en los elementos contemplados en la metodología propuesta por Andrews (1990) y Andrews y Fernández (1992). Dado que los materiales provenientes de las cuadrículas A-1 y A-2 son muy escasos, se decidió realizar el análisis principalmente con los restos provenientes de la Cuadrícula A-3.

\begin{tabular}{|l|cc|cc|cc|}
\hline Elemento / procedencia & \multicolumn{2}{|c|}{ A-1 y A-2 (Conj. sup.) } & \multicolumn{2}{|c|}{ A-1 y A-2 (Conj. inf.) } & \multicolumn{2}{|c|}{ A-3 } \\
MNE & $\begin{array}{c}\text { Abundancia } \\
\text { relativa }\end{array}$ & MNE & $\begin{array}{c}\text { Abundancia } \\
\text { relativa }\end{array}$ & MNE & $\begin{array}{c}\text { Abundancia } \\
\text { relativa }\end{array}$ \\
\hline Maxilar & 2 & 10 & 2 & 9,1 & 13 & 12,3 \\
Mandíbula & 2 & 10 & 1 & 4,5 & 13 & 12,3 \\
Incisivos aislados & 3 & 7,5 & 3 & 6,8 & 29 & 13,7 \\
Molares aislados & 1 & 0,7 & - & - & 9 & 1,1 \\
Vértebras & 16 & 5,3 & - & - & 31 & 1,9 \\
Costillas & 3 & 1,2 & - & - & 10 & 0,8 \\
Escápula & 2 & 10 & - & - & 10 & 9,4 \\
Húmero & 2 & 10 & 2 & 9,1 & 5 & 4,7 \\
Cúbito & 1 & 5 & - & - & 6 & 5,7 \\
Radio & 1 & 5 & - & - & 6 & 5,7 \\
Pelvis & 2 & 10 & - & - & 12 & 11,3 \\
Fémur & 3 & 15 & 3 & 13,6 & 13 & 12,3 \\
Tibia & 3 & 15 & - & - & 9 & 8,5 \\
Calcáneo & - & - & - & - & 1 & 0,9 \\
Astrágalo & 2 & 10 & - & - & - & - \\
Metapodio & 6 & 3 & - & - & 15 & 1,4 \\
Falanges & - & - & - & - & 3 & 0,1 \\
\hline Total & 49 & & 11 & & 185 & 6 \\
Promedio & & 6,9 & & 2,5 & & 6 \\
\hline
\end{tabular}

Tabla 7.3. Número mínimo de elementos (MNE) y abundancia relativa, para los ensambles de micromamíferos de los conjuntos arqueológicos de RA-1. 


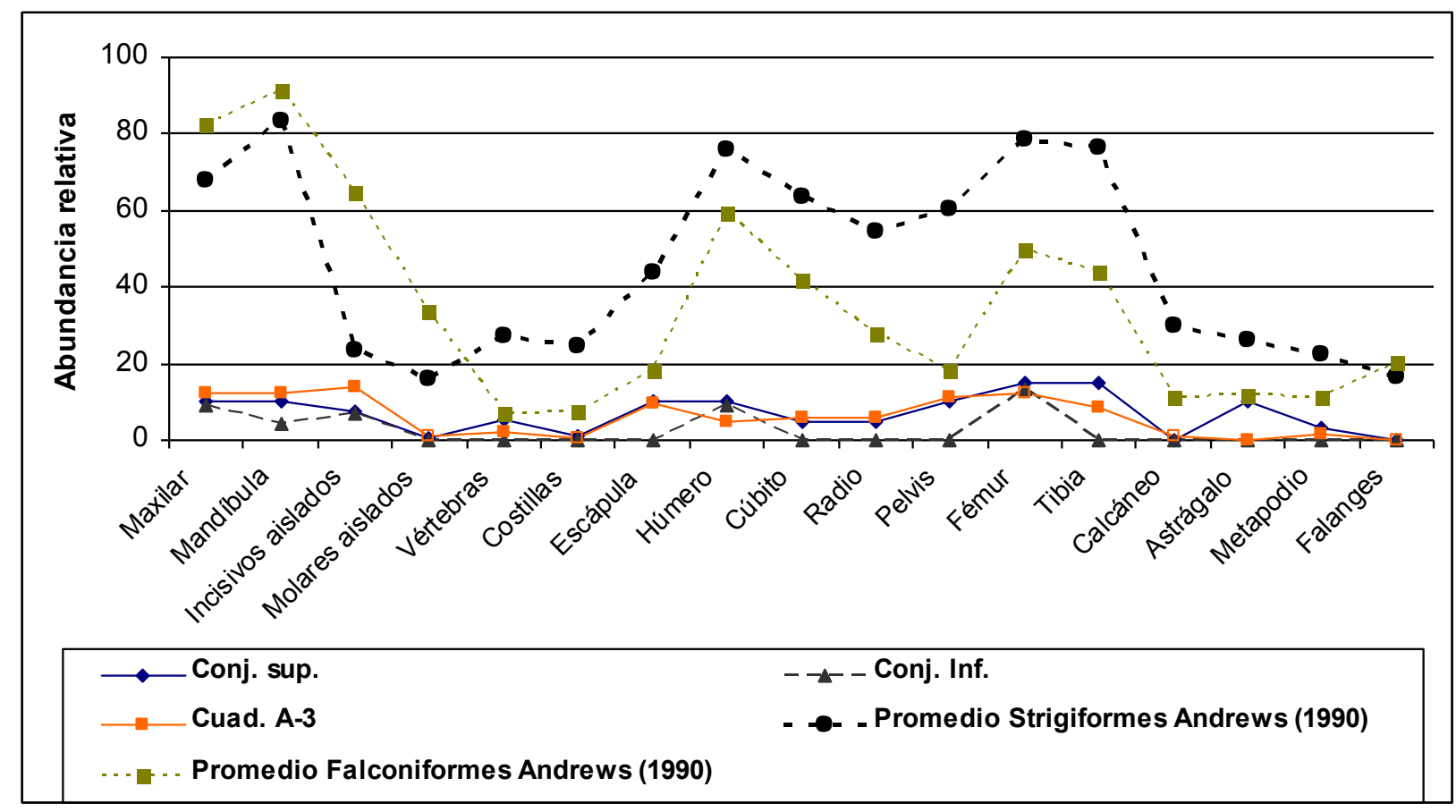

Figura 7.4. Valores de abundancia relativa de los diferentes elementos anatómicos de los conjuntos de RA-1, comparados con el promedio de Strigiformes y de Falconiformes de Andrews (1990).

No se recuperaron cráneos completos en ninguna de las muestras. Todos correspondieron a maxilares sin arcos zigomáticos. Además, en la Cuadrícula A-3 se registró que un 25\% de los molares se desprendieron de los maxilares. Se encontraron solo dos mandíbulas completas en la Cuadrícula A-3. Se registraron escasas mandíbulas en toda la muestra arqueológica como para realizar un análisis detallado. No obstante, se encontraron sobre todo sin rama ascendente y con el borde inferior roto, aunque con buena parte de los molares e incisivos retenidos en sus alvéolos.

A pesar de lo exigua de la muestra, en la Cuadrícula A-3 se pudo observar que la mayoría de los molares y la mitad de los incisivos se encontraron completos.

El nivel de fractura de los elementos postcraneales fue alto en la Cuadrícula A-3, de modo que solo el $20 \%$ de los húmeros, fémures, tibias y cúbitos estaban completos. También se observó una preservación diferencial de los segmentos proximales en fémures y en cubitos, contrariamente a una mejor conservación de los segmentos distales en húmeros y tibias.

Una proporción levemente mayor de los elementos postcraneales rotos recuperados de todas las muestras presentó superficies de fractura con ángulos agudos y bordes ásperos (Tabla 7.5). 


\begin{tabular}{|c|c|c|c|c|c|c|}
\hline & \multicolumn{2}{|c|}{ A-1 y A-2 (Conj. sup.) } & \multicolumn{2}{|c|}{ A-1 y A-2 (Conj. inf.) } & \multicolumn{2}{|c|}{ A-3 } \\
\hline & $\mathrm{N}$ & $\%$ & $\mathrm{~N}$ & $\%$ & $\mathrm{~N}$ & $\%$ \\
\hline \multicolumn{7}{|l|}{ Fractura de cráneos } \\
\hline Cráneos completos & - & - & - & - & - & - \\
\hline Maxilares con arcos zigomáticos & - & - & - & - & - & - \\
\hline Maxilares sin arcos zigomáticos & 2 & 100 & 2 & 100 & 13 & 100 \\
\hline Pérdida de molares de maxilares & 1 & 25 & 2 & 66,7 & 13 & 25,5 \\
\hline Pérdida de incisivos de premaxilares & - & - & - & - & - & - \\
\hline \multicolumn{7}{|l|}{ Fractura de mandíbulas } \\
\hline Mandíbulas completas & - & - & - & - & 2 & 15,4 \\
\hline Mandíbulas con rama ascendente rota & - & - & - & - & 3 & 23,1 \\
\hline Mandíbulas sin rama ascendente & 2 & 100 & 1 & 100 & 2 & 15,4 \\
\hline Mandíbulas sin rama ascendente y borde inferior roto & - & - & - & - & 6 & 46,1 \\
\hline Pérdida de molares de las mandíbulas & 4 & 57,1 & 2 & 66,7 & 6 & 15 \\
\hline Pérdida de incisivos de la mandíbulas & 1 & 50 & - & - & 3 & 42,9 \\
\hline \multicolumn{7}{|l|}{ Fractura de dientes } \\
\hline Molares rotos in situ & - & - & - & - & 6 & 8,3 \\
\hline Molares aislados rotos & - & - & - & - & 7 & 77,8 \\
\hline Total de molares rotos & - & - & - & - & 13 & 16 \\
\hline Incisivos rotos in situ & - & - & - & - & 2 & 50 \\
\hline Incisivos aislados rotos & 1 & 33,3 & 2 & 66,7 & 15 & 51,7 \\
\hline Total de incisivos rotos & 1 & 33,3 & 2 & 50 & 17 & 51,5 \\
\hline \multicolumn{7}{|l|}{ Fractura de Postcráneo } \\
\hline \multicolumn{7}{|l|}{ Fémur } \\
\hline Completo & 1 & 33,3 & 1 & 33,3 & 2 & 14,3 \\
\hline Segmento proximal & 1 & 33,3 & - & - & 10 & 71,4 \\
\hline Diáfisis & - & - & 1 & 33,3 & 2 & 14,3 \\
\hline Segmento distal & 1 & 33,3 & 1 & 33,3 & - & - \\
\hline \multicolumn{7}{|l|}{ Húmero } \\
\hline Completo & 2 & 100 & - & - & 2 & 40 \\
\hline Segmento proximal & - & - & 1 & 33,3 & - & - \\
\hline Diáfisis & - & - & 1 & 33,3 & 1 & 20 \\
\hline Segmento distal & - & - & 1 & 33,3 & 2 & 40 \\
\hline \multicolumn{7}{|l|}{ Tibia } \\
\hline Completo & 2 & 66,7 & - & - & 1 & 11,1 \\
\hline Segmento proximal & - & - & - & - & 1 & 11,1 \\
\hline Diáfisis & 1 & 33,3 & - & - & 1 & 11,1 \\
\hline Segmento distal & - & - & - & - & 6 & 66,7 \\
\hline \multicolumn{7}{|l|}{ Cúbito } \\
\hline Completo & 1 & 100 & - & - & 2 & 33,3 \\
\hline Segmento proximal & - & - & - & - & 4 & 66,7 \\
\hline Diáfisis & - & - & - & - & - & - \\
\hline Segmento distal & - & - & - & - & - & - \\
\hline
\end{tabular}

Tabla 7.4. Fractura de elementos craneales, dentarios y postcraneales, para los micromamíferos provenientes de los conjuntos arqueológicos de RA-1. 


\begin{tabular}{|c|c|c|c|c|c|c|}
\hline \multirow{2}{*}{$\begin{array}{l}\text { Tipos de Fractura en postcraneal } \\
\text { (Fémur, húmero, tibia y cúbito) }\end{array}$} & \multicolumn{2}{|c|}{ A-1 y A-2 (Conj. sup) } & \multicolumn{2}{|c|}{ A-1 y A-2 (Conj. inf) } & \multicolumn{2}{|c|}{ A-3 } \\
\hline & $\mathrm{N}$ & $\%$ & $\mathrm{~N}$ & $\%$ & $\mathrm{~N}$ & $\%$ \\
\hline Fracturas con ángulos agudos y bordes ásperos & 2 & 66,7 & 3 & 60 & 15 & 55,6 \\
\hline Fracturas espiral o longitudinal con bordes suaves & 1 & 33,3 & 2 & 40 & 12 & 44,4 \\
\hline
\end{tabular}

Tabla 7.5. Tipos de fractura para los elementos postcraneales de los conjuntos de micromamíferos de RA-1.

Como se ilustra en la tabla 7.6, el resto de los elementos presentaron un grado de fractura variable. Algunos elementos se encontraron con altos porcentajes de fractura (i.e., escápulas, pelvis, metapodios) y otros se recuperaron mayormente completos (i.e., vértebras, astrágalos, falanges.

\begin{tabular}{|l|cc|lc|cc|}
\hline \multirow{2}{*}{$\begin{array}{l}\text { Fractura postcraneal (otros } \\
\text { elementos) }\end{array}$} & \multicolumn{2}{|c|}{ A-1 y A-2 (Conj. sup.) } & \multicolumn{2}{|c|}{ A-1 y A-2 (Conj. inf.) } & \multicolumn{2}{|c|}{ A-3 } \\
\hline Vértebras & N & $\%$ & N & $\%$ & N & $\%$ \\
Costillas & 4 & 23,5 & - & - & 5 & 16,2 \\
Escápula & 1 & 33,3 & - & - & 6 & 60 \\
Radio & 2 & 100 & - & - & 10 & 100 \\
Pelvis & - & - & - & - & 3 & 50 \\
Calcáneo & 2 & 100 & - & - & 12 & 100 \\
Astrágalo & - & - & - & - & - & - \\
Metapodio & - & - & - & - & - & - \\
Falanges & 1 & 16,7 & - & - & 15 & 100 \\
\hline
\end{tabular}

Tabla 7.6. Fractura del resto de los elementos postcraneales de micromamíferos recuperados de los conjuntos de RA-1.

Los valores obtenidos a partir de los índices calculados se exhiben en la tabla 7.7. En algunos casos no fueron calculados por falta de datos. El primer índice que evalúa la relación entre elementos postcraneales y craneales sugiere una mejor preservación de los primeros tanto en el Conjunto superior como en la Cuadrícula A-3, mientras que el segundo índice mostró una representación pareja entre ambos en el Conjunto superior y una disminución de los elementos postcraneales en la Cuadrícula A-3. El índice que valora la relación entre elementos distales y proximales de los miembros indica un equilibrio en el Conjunto superior y una pérdida de elementos proximales en la Cuadrícula A-3. En cuanto a los índices de pérdida dentaria, debido a datos insuficientes, solo pudo ser calculado el que evalúa la proporción de molares aislados en la Cuadrícula A-3, mostrando que la mayor parte de los molares estaba retenidos de sus alvéolos.

Los índices IT e IP -calculado para la Cuadrícula A-3- indicaron una mayor proporción de microvertebrados de mayor tamaño y gregarios o coloniales. 


\begin{tabular}{|l|c|c|c|}
\hline & A-1 y A-2 (Conj. sup.) & A-1 y A-2 (Conj. inf.) & A-3 \\
\hline Postcráneo / Cráneo & 320 & - & \\
$\mathrm{f}+\mathrm{t}+\mathrm{h}+\mathrm{r}+\mathrm{c} / \mathrm{mx}+\mathrm{mb}+\mathrm{m}$ & 100 & - & 222,8 \\
$\mathrm{~h}+\mathrm{f} / \mathrm{mx}+\mathrm{mb}$ & & - & 69,2 \\
Elementos distales / proximales & 100 & - & 120 \\
$\mathrm{t}+\mathrm{r} / \mathrm{f}+\mathrm{h}$ & & - & \\
Pérdida de dientes & - & - & - \\
Alvéolos mx+ alvéolos mb/m & - & - & 73,5 \\
Alvéolos mx+ alvéolos mb/i & - & $-46,4$ \\
Índice de Tamaño (IT) & - & - & 168,2 \\
Índice de Predictibilidad (IP) & & - & \\
\hline
\end{tabular}

Tabla 7.7. Valores de los índices calculados en los conjuntos arqueológicos de RA-1.

Referencias: f: fémur; t: tibia; h: húmero; r: radio; c: cúbito; mx: maxilar; mb: mandíbula; m: molar; i: incisivo.

No se recuperaron restos con marcas de corte en toda el área excavada aunque si se registraron un 5,3\% de restos termoalterados, sobre el NISP total [Conjunto superior $=1$ $(2 \%)$; Conjunto inferior $=1(9,1 \%) ;$ Cuadricula A-3 = 11 (5,9\%), Figura 7.5A y B.].

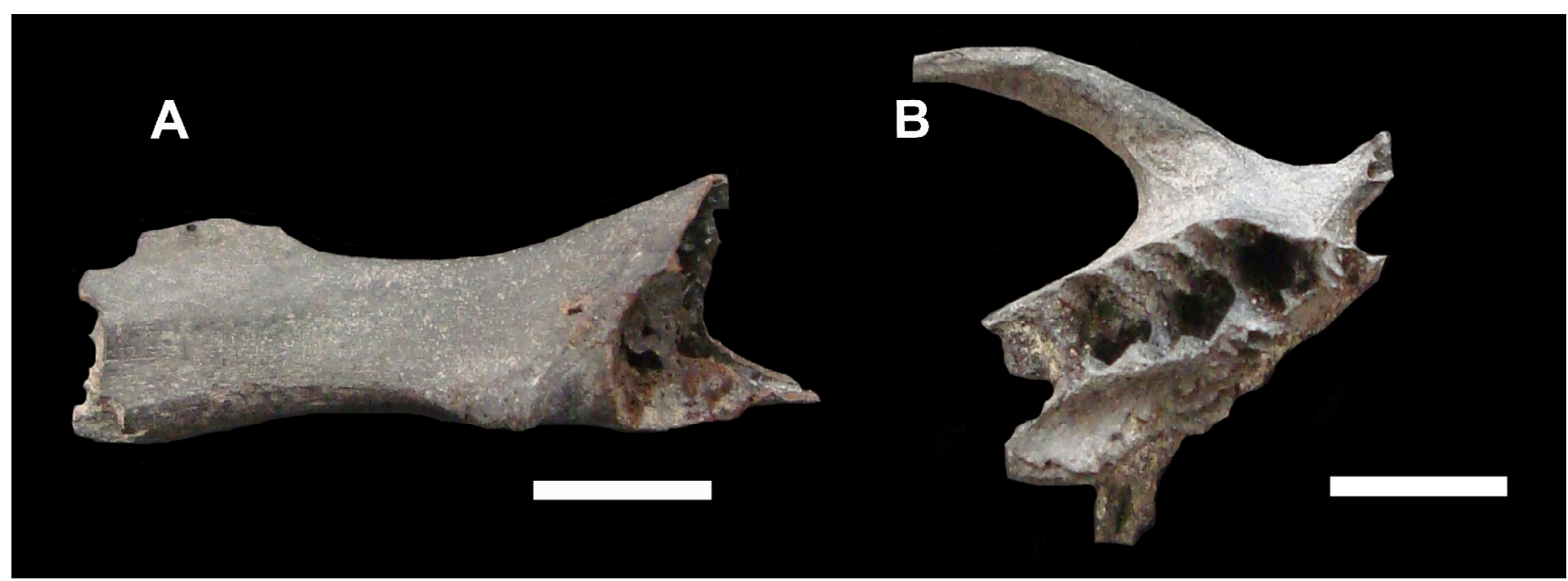

Figura 7.5. Restos óseos con evidencias de termoalteración en RA-1. A: fragmento anterior de pelvis de Caviidae (Cuadrícula A-3, Unidad E). B: fragmento de maxilar y arco zigomático de Microcavia australis (Cuadrícula A-3, Unidad H). Escalas: $5 \mathrm{~mm}$.

Únicamente se encontraron restos con evidencias de meteorización en el Conjunto superior (Estadio I = 4, Estadio II = 3; sensu Andrews, 1990). Se registraron restos con marcas de raíces (i.e., Sphenoichnia), mayormente en la Cuadricula 3 [Conjunto superior $=2(4,1 \%)$, Figura 7.3A; Conjunto inferior $=1(9,1 \%)$; Cuadricula A3 = 51 $(27,3 \%)]$. No se recuperaron especímenes con manchas de óxido de manganeso en la muestra. Sin embargo, se hallaron restos con evidencias de corrosión sedimentaria en el 
Conjunto inferior $(18,2 \%)$ y en la Cuadrícula 3 (22,5\%). No se registraron evidencias de redondeamiento en los extremos y protuberancias de los restos óseos y dentarios.

\subsubsection{Asociación de microvertebrados de las muestras actuales}

Como se ilustra en la tabla 7.8, el ensamble de microvertebrados de la muestra de Gruta del Indio está conformado principalmente por roedores sigmodontinos, siendo Eligmodontia sp., Calomys musculinus y Graomys griseoflavus los taxones más representados, seguidos por Phyllotis xanthopygus, Akodon molinae y Oligoryzomys flavescens. En bajas proporciones se registraron los roedores histricognatos (Ctenomys sp. y Microcavia australis) y los quirópteros (Myotis sp. y Tadarida brasiliensis). Se destaca el elevado porcentaje correspondiente al marsupial Thylamys pallidior. Con frecuencias menores se encuentran anuros indeterminados, saurios indeterminados y aves paseriformes (Asthenes cf. A. baeri, Asthenes cf. A. dorbignyi, Leptasthenura platensis, Lessonia rufa, Mimus sp., Sicalis sp. y Phrygilus fruticeti). Por su parte, el ensamble de Río Seco La Hedionda comparte numerosas especies de micromamíferos, con las excepciones de $M$. australis y $P$. xanthopygus. Asimismo, presenta dominancia de G. griseoflavus, Eligmodontia y Ctenomys y exhibe algunos taxones exóticos como lepóridos y el múrido Rattus sp. El índice de diversidad de Shannon arrojó valores semejantes entre ambas muestras actuales.

En síntesis, los ensambles están conformados principalmente por especies de micromamíferos afines al desierto del Monte (i.e., T. pallidior, C. musculinus, G. griseoflavus, A. molinae y), junto con taxones ampliamente distribuidos en ambientes de estepas arbustivas abiertas con afloramientos rocosos en Mendoza (M. australis y $P$. xanthopygus Eligmodontia sp.) y otro asociado a pastizales en relación a cuerpos de agua y frecuente en el centro-este de Argentina (i.e., O. flavescens). Es interesante destacar, que el hallazgo de un solo ejemplar de O. flavescens en la muestra de Gruta del Indio coincide con lo señalado por Contreras y Rosi (1980c). Estos autores esgrimen que las poblaciones de este especie en la provincia de Mendoza son muy reducidas, contrariamente a lo que ocurre en la región Pampeana, donde este roedor constituye uno de los elementos descollantes de los agroecosistemas Bonaerenses (e.g., Pardiñas, 1999a; Pardiñas et al., 2010b, 2010c; Teta et al., 2010; Fernández et al., 2012). Asimismo, si el registro de O. flavescens de Gruta del Indio corresponde a la subespecie descripta por Contreras y Rosi (1980c) como O.f. occidentalis, constituiría 
la localidad más austral conocida, ca. $25 \mathrm{~km}$ al sudoeste de la localidad tipo (Colonia Alto del Algarrobal).

\begin{tabular}{|c|c|c|c|c|}
\hline Taxón / Procedencia & 1 & $\%$ & \multicolumn{2}{|l|}{2} \\
\hline Amphibia / Anura indet. & 6 & 1,3 & 3 & 5,4 \\
\hline $\begin{array}{l}\text { Reptilia / Sauria indet. } \\
\text { Aves }\end{array}$ & 5 & 1,1 & 0 & 0 \\
\hline Passeriformes / Furnaridae indet. & 7 & 1,5 & 8 & 14,5 \\
\hline Asthenes cf. A. baeri & 2 & 0,4 & 0 & 0 \\
\hline Asthenes cf. A. dorbignyi & 1 & 0,2 & 0 & 0 \\
\hline Asthenes sp. & 2 & 0,4 & 0 & 0 \\
\hline Leptasthenura platensis & 1 & 0,2 & 0 & 0 \\
\hline Lessonia rufa & 1 & 0,2 & 0 & 0 \\
\hline Tyranidae indet. & 2 & 0,4 & 0 & 0 \\
\hline Mimus sp. & 1 & 0,2 & 0 & 0 \\
\hline Emberizidae indet. & 1 & 0,2 & 0 & 0 \\
\hline Sicalis sp. & 2 & 0,4 & 0 & 0 \\
\hline Phrygilus fruticeti & 1 & 0,2 & 0 & 0 \\
\hline Mammalia & & & & \\
\hline Didelphimorphia & & & & \\
\hline Thylamys pallidior & 56 & 12,3 & 1 & 1,8 \\
\hline Chiroptera indet. & 4 & 0,9 & 0 & 0 \\
\hline Myotis sp. & 5 & 1,1 & 0 & 0 \\
\hline Tadarida brasiliensis & 2 & 0,4 & 0 & 0 \\
\hline Rodentia & & & & \\
\hline Ctenomyidae & & & & \\
\hline $\begin{array}{l}\text { Ctenomys sp. } \\
\text { Caviidae }\end{array}$ & 7 & 1,5 & 7 & 12,7 \\
\hline Microcavia australis & 4 & 0,9 & 0 & 0 \\
\hline Cricetidae / Sigmodontinae & & & & \\
\hline Akodon molinae & 17 & 3,7 & 4 & 7,3 \\
\hline Graomys griseoflavus & 73 & 16,0 & 14 & 25,5 \\
\hline Phyllotis xanthopygus & 22 & 4,8 & 0 & 0 \\
\hline Calomys musculinus & 97 & 21,2 & 5 & 9,1 \\
\hline Eligmodontia sp. & 137 & 30,0 & 8 & 14,5 \\
\hline Oligoryzomys flavescens & 1 & 0,2 & 2 & 3,6 \\
\hline Muridae & & & & \\
\hline Rattus sp. & 0 & 0,0 & 2 & 3,6 \\
\hline Lagomorpha/Leporidae indet. & 0 & 0,0 & 1 & 1,8 \\
\hline Total & 457 & & 55 & \\
\hline Riqueza & 20 & & 11 & \\
\hline$H^{\prime}$ & 1,96 & & 2,19 & \\
\hline Equitatividad & 0,65 & & 0,81 & \\
\hline
\end{tabular}


Tabla 7.8. Muestras actuales (expresadas en MNI y MNI\%). 1: Gruta del Indio; 2: Río Seco La Hedionda (Massoia et al., 1997).

Por su parte, T. brasiliensis presenta amplia distribución y habita gran variedad de ambientes. Finalmente, en lo que concierne a las aves, Asthenes dorbignyi, Asthenes baeri, Leptastenura platensis, Lessonia rufa, Sicalis sp. y Mimus sp. se encuentran tanto en ambientes de estepa Patagónica como del desierto de Monte.

\subsubsection{Asociación de microvertebrados de las muestras arqueofaunisticas}

Se analizaron 259 especímenes, 53 correspondientes al Conjunto superior, 11 al Conjunto inferior y 195 a la Cuadricula A-3. La información correspondiente a las abundancias relativas de los microvertebrados por muestras arqueofaunísticas (expresadas como valores de NISP, MNE y MNI) se detalla en la tabla 7.9.

\begin{tabular}{|c|c|c|c|c|c|c|c|c|c|c|c|c|}
\hline \multirow[t]{2}{*}{ Taxones / Procedencia } & \multicolumn{6}{|c|}{ Cuadrículas A-1 y A-2 (Conj. sup) } & \multicolumn{6}{|c|}{ Cuadrículas A-1 y A-2 (Conj. inf) } \\
\hline & NISP & $\%$ & MNE & $\%$ & MNI & $\%$ & NISP & $\%$ & MNE & $\%$ & MNI & $\%$ \\
\hline $\begin{array}{l}\text { Reptilia / Sauria indet. } \\
\text { Aves }\end{array}$ & 3 & 5,7 & 3 & 5,8 & 1 & 9,1 & - & - & - & - & - & - \\
\hline $\begin{array}{l}\text { Passeriformes indet. } \\
\text { Tyrannidae }\end{array}$ & - & - & - & - & - & - & - & - & - & - & - & - \\
\hline Pitangus sulphuratus & - & - & - & - & - & - & - & - & - & - & - & - \\
\hline Emberizidae indet. & - & - & - & - & - & - & - & - & - & - & - & - \\
\hline Columbiformes indet. & - & - & - & - & - & - & - & - & - & - & - & - \\
\hline Zenaida auriculata & - & - & - & - & - & - & - & - & - & - & - & - \\
\hline Mammalia & & & & & & & & & & & & \\
\hline Didelphimorphia & & & & & & & & & & & & \\
\hline Thylamys pallidior & - & - & - & - & - & - & - & - & - & - & - & - \\
\hline Chiroptera indet. & - & - & - & - & - & - & - & - & - & - & - & - \\
\hline Rodentia & & & & & & & & & & & & \\
\hline Ctenomyidae & & & & & & & & & & & & \\
\hline Ctenomys sp. & 1 & 1,9 & 1 & 1,9 & 1 & 9,1 & 1 & 9,1 & 1 & 9,1 & 1 & 14,3 \\
\hline Caviidae indet. & 18 & 34 & 17 & 32,7 & 3 & 27,3 & 3 & 27,3 & 3 & 27,3 & 3 & 42,9 \\
\hline Microcavia australis & 2 & 3,8 & 2 & 3,8 & 2 & 18,2 & - & - & - & - & - & - \\
\hline Galea leucoblephara & - & - & - & - & - & - & - & - & - & - & - & - \\
\hline Cricetidae / Sigmodontinae indet. & 27 & 50,9 & 27 & 51,9 & 2 & 18,2 & 5 & 45,4 & 5 & 45,4 & 2 & 28,6 \\
\hline Graomys griseoflavus & 1 & 1,9 & 1 & 1,9 & 1 & 9,1 & - & - & - & - & - & - \\
\hline Phyllotis xanthopygus & 1 & 1,9 & 1 & 1,9 & 1 & 9,1 & - & - & - & - & - & - \\
\hline Eligmodontia sp. & - & - & - & - & - & - & 2 & 18,2 & 2 & 18,2 & 1 & 14,3 \\
\hline Total & 53 & & 52 & & 11 & & 11 & & 11 & & 7 & \\
\hline Riqueza & & & & & 5 & & & & & & 3 & \\
\hline$H^{\prime}$ & & & & & 1,41 & & & & & & 1 & \\
\hline Equitatividad & & & & & 0,87 & & & & & & 0,91 & \\
\hline
\end{tabular}


Tabla 7.9. Composición taxonómica de los ensambles de microvertebrados de los conjuntos arqueológicos de RA-1 (expresada en NISP, MNE y MNI).

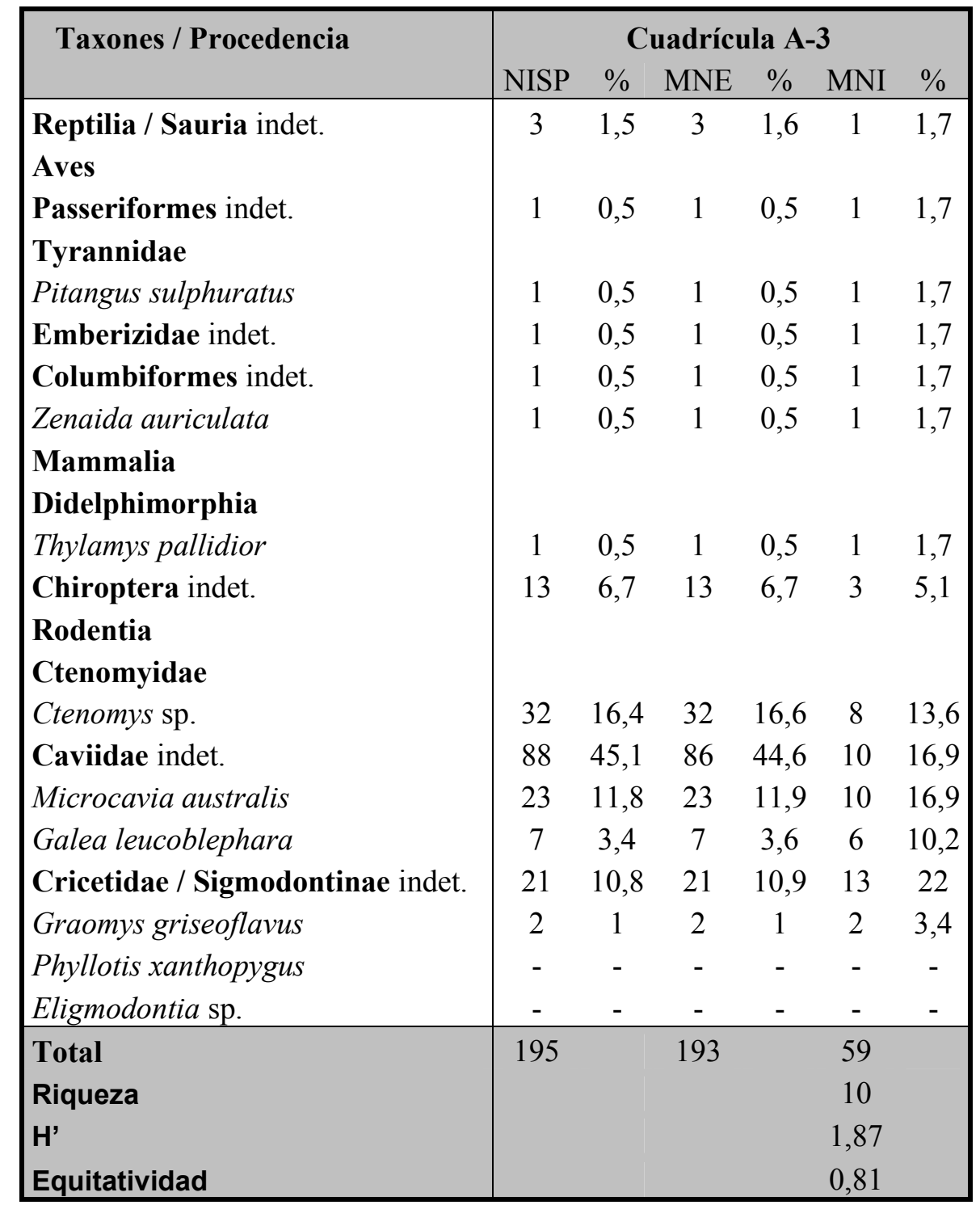

Tabla 7.9. (Continuación) Composición taxonómica de los ensambles de microvertebrados de los conjuntos arqueológicos de RA-1 (expresada en NISP, MNE y MNI).

\subsection{Cuadrículas A-1 y A-2 (Conjunto superior)}

El ensamble está integrado principalmente por micromamíferos, tanto por roedores histricognatos (Ctenomys sp. M. australis) como por sigmodontinos (G. griseoflavus y P. xanthopygus). Asimismo, se registró un saurio indeterminado. El índice de diversidad de Shannon arrojó un valor de 1,414 (Tabla 7.9).

\subsection{Cuadrículas A-1 y A-2 (Conjunto inferior)}


En este conjunto se recuperaron escasos resto de roedores (Ctenomys sp. y Eligmodontia sp.) (Tabla 7.9).

\subsection{Cuadrícula $A-3$}

Como se ilustra en la tabla 7.9, el ensamble de microvertebrados está dominado por roedores histricognatos ( $M$. australis, Galea leucoblephara y Ctenomys sp.). Los roedores sigmodontinos (G. griseoflavus), quirópteros indeterminados y el marsupial $T$. pallidior completan el elenco de micromamíferos. También se recuperaron un saurio indeterminado, aves paseriformes (Pitangus sulphuratus) y columbiformes (Zenaida auriculata).

En este ensamble se registraron valores de diversidad $(1,87)$ y riqueza taxonómica $(10)$ mayores que los ensambles provenientes de las Cuadrículas A-1 y A-2, pero menores que en la muestra actual (Tabla 7.9).

\subsubsection{Discusión}

\subsubsection{Interpretación tafonómica}

Por un lado, la abundancia de micromamíferos de tamaño grande y gregarios o coloniales en sitio a cielo abierto plantea la posibilidad que estamos ante la presencia de una acumulación antrópicas. Sin embargo, la ausencia de marcas de corte y la escasez de restos quemados, no nos permite corroborar esta asunción, aunque tampoco descartarla. Por otro lado, la presencia de marcas de corrosión digestiva, principalmente en la categoría ligera y en menor medida en las categorías moderada y fuerte, sugiere que aves Strigiformes intervinieron en la formación de los ensambles de micromamíferos de las distintas unidades. En este sentido, debido a que RA-1 es un sitio a cielo abierto ubicado en la terraza aluvial del río y por la abundancia de micromamíferos grandes en los ensambles, posiblemente Bubo magellanicus haya sido el agente acumulador (Andrews, 1990; Gómez, 2005, 2007). Este búho es una rapaz nocturna y oportunista que puede anidar o percharse en acantilados, árboles y arbustos a cielo abierto, depreda sobre un espectro de presas tamaño más grande que otras lechuzas que habitan en la zona y produce niveles de modificación moderados (ver Capitulo 6). Asimismo, se recuperaron restos fracturados tanto con superficies de fracturas con 
ángulos agudos y bordes ásperos como con ángulos redondeados y bordes suaves, indicando que una parte de los mismos pudo producirse por pisoteo (apoyado en que los elementos más chicos se encontraron enteros) y otra parte por la acción predadora de aves rapaces. En este sentido, los estudios tafonómicos realizados con egagrópilas del genero Bubo, señalan que estas aves producen mayores niveles de fractura (Andrews, 1990; Gómez, 2005, 2007). En tanto, los otros atributos tafonómicos analizados tales como los patrones de frecuencias relativas de partes esqueletales e índices son muy difíciles de comparar debido la falta de datos en algunos conjuntos, los cuales posiblemente hayan sido alterados posteriormente a ser depositados por procesos tales como el pisoteo.

Resulta interesante destacar, que los restos recuperados de la Cuadricula A-3 fueron más afectados por procesos postdepositacionales, tales como la acción de raíces y corrosión sedimentaria. Estos resultados pueden relacionarse con el alto contenido orgánico y los altos niveles de alteración con rellenos sedimentarios registrados en esta unidad (Dieguez et al., 2004), de manera que facilite el ingreso de raíces en el registro arqueológico. Asimismo, la corrosión sedimentaria pudo deberse tanto a efecto del PH como a la humedad (Andrews, 1990). Dieguez et al. (2004), interpretaron esta unidad como un "basurero" y dado por la remoción de sus materiales, habría facilitado el ingreso de animales bioturbadores. Sin embargo, no se encontraron esqueletos articulados que nos permitan corroborar esta hipótesis desde la acción de roedores fosoriales como Ctenomys. Por su parte los restos provenientes del Conjunto superior fueron más afectados por los agentes meteóricos, indicando que tuvieron una exposición más prolongada en superficie.

Finalmente, no se recuperaron restos con impresiones de óxido de manganeso, abrasión por transporte hídrico, desplazamientos y rozamientos de los restos contra el sedimento, indicando buena preservación en todas las muestras (Korth, 1979; Andrews, 1990; Fernández-Jalvo y Andrews, 2003); a pesar de que Dieguez et al. (2004), encontraron elementos seleccionados por procesos fluviales la Cuadricula A-3.

\subsubsection{Interpretación paleoambiental}

En la figura 7.6 se detallan las frecuencias relativas de los taxones de micromamíferos en las muestras estudiadas. 
Hay una correlación positiva alta y significativa entre la riqueza taxonómica y el tamaño de las muestras $(r=1 ; \mathrm{p}>0)$, esta situación sumando a los bajos valores de MNI, limita el alcance de las conclusiones. No obstante, se realizaron algunos comentarios en base a la presencia de determinados taxones.

Los escasos restos recuperados del Conjunto inferior ( $c a \cdot 1,7 / 1,5-1,2 \mathrm{ka}{ }^{14} \mathrm{C}$ AP) no permiten realizar interpretaciones paleoambientales. No obstante, en el Conjunto superior ( $c$. 1,2-1 ka AP), la presencia de M. australis, G. griseoflavus y $P$. xanthopygus, sugieren un ambiente rocoso afín al desierto del Monte. Asimismo, el registro de $M$. australis, G. leucoblephara, G. griseoflavus y $T$. pallidior en la Cuadrícula A-3 ( 1,2-0,3 ka ${ }^{14} \mathrm{C}$ AP) indican un ambiente del desierto del Monte. Coincidentemente, Gil et al. (2008) registraron restos vegetales característicos del desierto del Monte (e.g., Larrea divaricada, Geoffroea decorticans, Prosopis sp.) a lo largo de toda la secuencia, incluyendo la Cuadricula A-3.

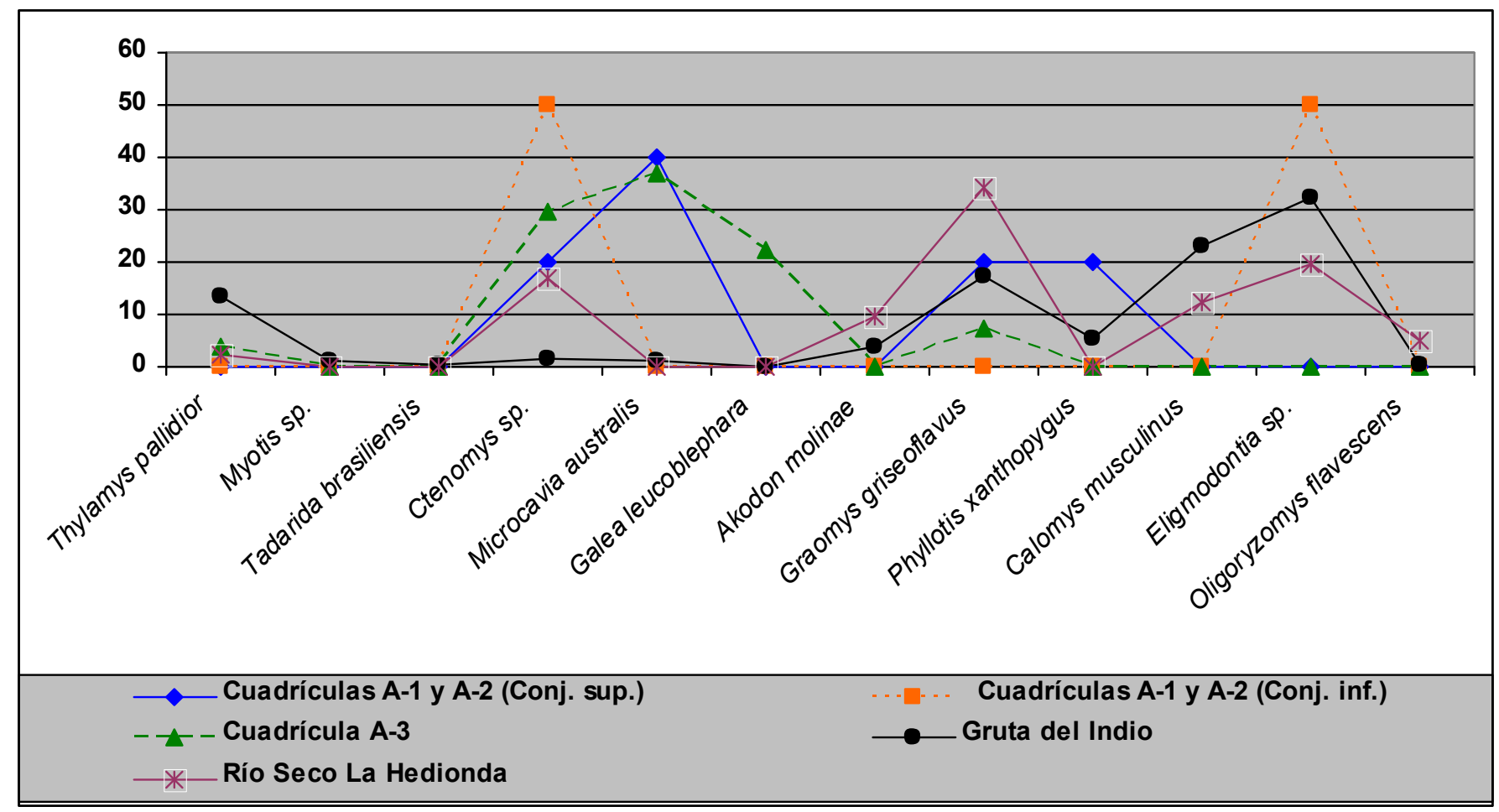

Figura 7.6. Comparación de las frecuencias relativas de los taxones de micromamíferos recuperados de RA-1 y el parámetro actualístico.

Resulta interesante destacar, la ausencia de A. molinae, O. flavescens y C. musculinus a lo largo de la secuencia, aspecto que podría estar asociado al deterioro antrópico que sufren los ambientes actuales principalmente por el sobrepastoreo. Frecuencias elevadas 
de C. musculinus y $O$. flavescens han sido documentadas en numerosas localidades de la Región Pampeana, altamente impactadas por la actividad agrícola (ver Capítulo 8 para más detalle).

Otro aspecto llamativo y de difícil interpretación, es la presencia de G. leucoblephara en el contexto arqueológico y su ausencia en las muestras actuales, debido a que es un roedor que en Mendoza presenta registros únicamente en el desierto del Monte (ver Capítulo 5).

\subsubsection{Conclusión}

Las evidencias tafonómicas, indican que los ensambles de microvertebrados fueron acumulados principalmente por aves Strigiformes, posiblemente B. magellanicus. Sin embargo, dado que el conjunto se encuentra en un sitio arqueológico, no se descarta la posibilidad de que los grupos humanos hayan explotado algunos micromamíferos, como G. leucoblephara, M. australis y Ctenomys sp.

El alto contenido orgánico y los rellenos sedimentarios registrados en la Cuadricula A3 , beneficiaron el ingreso de raíces, que afectaron a los restos óseos. Contrariamente, los restos recuperados del Conjunto superior fueron más afectados por los agentes meteóricos, indicando que tuvieron un enterramiento más lento.

Desde el punto de vista paleoambiental, a pesar de los distintos tamaños de las muestras, se observó que un ambiente del tipo desierto del Monte se mantuvo constante por lo menos desde el 1,2 ka ${ }^{14} \mathrm{C}$ AP hasta la actualidad. Sin embargo, es posible que en el presente el ambiente se encuentre modificado por la acción del ganado doméstico. 


\subsection{Agua de La Mula}

\subsubsection{Contexto arqueológico}

El sitio arqueológico Agua de La Mula fue escavado por un equipo de profesionales y estudiantes dirigidos por el Dr. Humberto Lagiglia en el año 1987. A pesar de que han transcurrido más de dos décadas, no se ha publicado un detalle del registro arqueológico. Se cuenta con algunos datos generales del sitio en los trabajos de Lagiglia (1999b) y Gil (2006).

Este sitio es una cueva de basalto ubicada en el fondo de una quebrada, en las

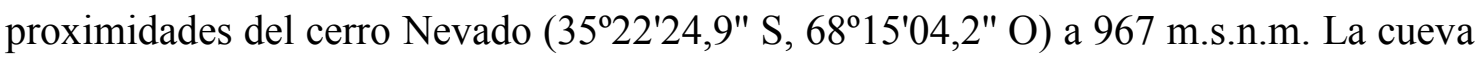
presenta una abertura de 3,86 $\mathrm{m}$ de ancho y 2,53 $\mathrm{m}$ de altura, alcanzando en su interior un máximo de 7,4 m de ancho y $9 \mathrm{~m}$ de profundidad (Figura 7.7 A-C). Se recuperó una importante cantidad de material arqueológico entre los que puede mencionarse la presencia de restos de plantas domésticas de Zea mays (maíz) y Cucurbita sp. (zapallo), aunque no cuantitativamente significativos para considerar un uso intensivo de los mismos (Lagiglia, 1999b; Gil, 2006). Es interesante destacar que en prospecciones posteriores efectuadas por Gil en octubre de 1995, se hallaron expresiones de arte rupestre en las proximidades del puesto homónimo.

Tres fechados radiocarbónicos realizados por Lagiglia (1999a) sobre restos de carbón arrojaron edades de $1610 \pm 60$ años ${ }^{14} \mathrm{C}$ AP (muestra LP-563; Nivel 10; 1430-1571 años cal AP), $1260 \pm 60$ años ${ }^{14} \mathrm{C}$ AP (muestra LP-620; Nivel 10; 1110-1258 años cal AP) y $1000 \pm 50$ años ${ }^{14} \mathrm{C}$ AP (muestra LP-973; Nivel 5; 836-957 años cal AP).

\subsubsection{Metodología}

En el contexto de la excavación dirigida por Lagiglia, se extrajeron diez niveles artificiales de $10 \mathrm{~cm}$ cada uno. En esa oportunidad se recuperaron restos cráneomandibulares de micromamíferos correspondientes a los niveles 4, 5, 6, 7, 9 y 10 (NISP $=1.026, \mathrm{MNE}=1.026, \mathrm{MNI}=491)$, sin embargo, los elementos postcraneales y los dientes aislados no fueron exhumados.

En el marco de los estudios tafonómicos se siguió la metodología y clasificación utilizada por Andrews (1990) y Fernández-Jalvo y Andrews (1992). Esta clasificación distingue cuatro categorías de modificación sobre restos óseos y dentarios (i.e., ligera, 
moderada, fuerte y extrema). No obstante, buena parte de la metodología propuesta por estos autores no se pudo aplicar debido a la ausencia de elementos postcraneales y dientes aislados.

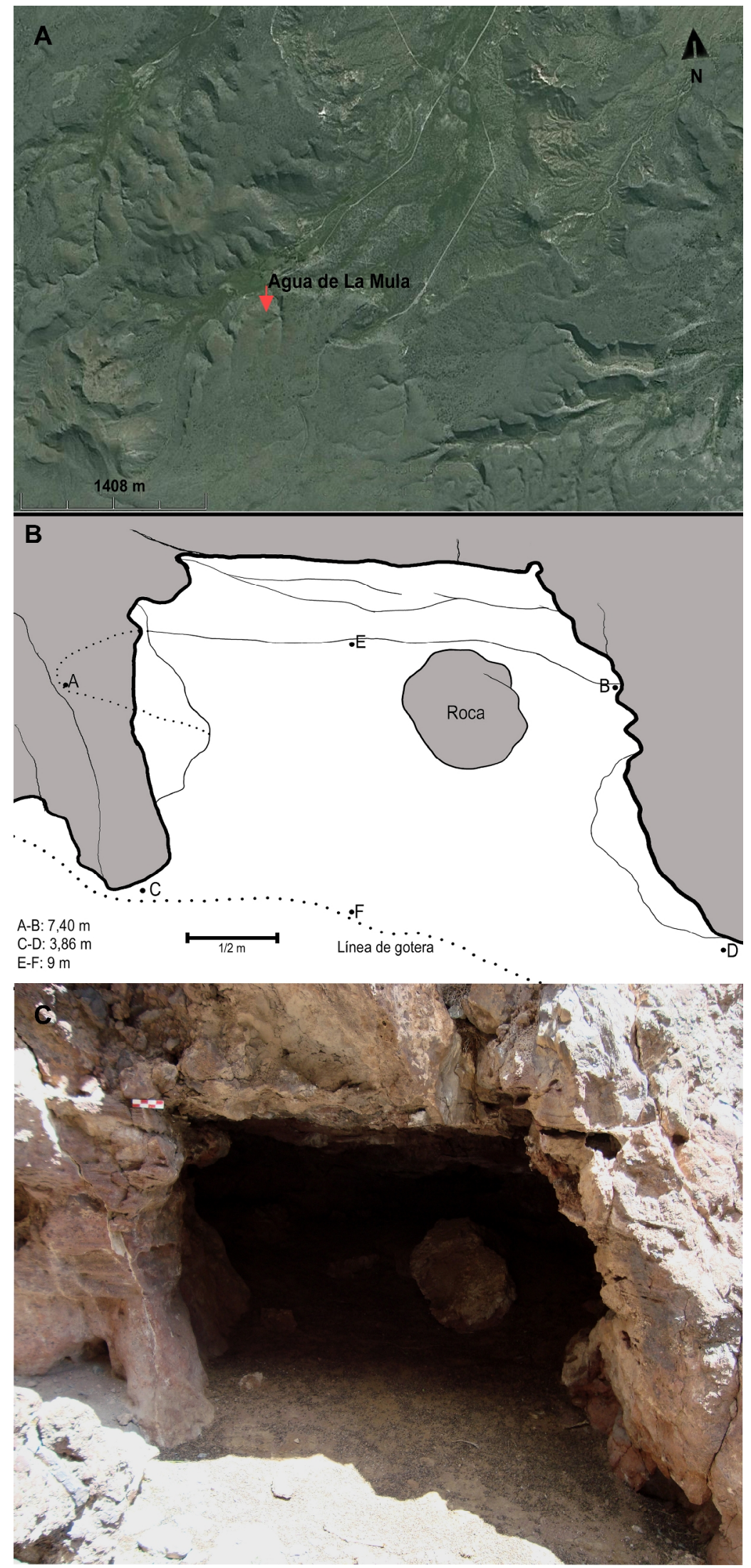


Figura 7.7. Sitio arqueológico Agua de La Mula. A: ubicación del sitio. B: vista en planta del sitio. C: vista de la entrada a la cueva.

En este sentido, se observaron marcas de corrosión digestiva en las superficies de los restos dentarios (i.e., incisivos y molares in situ). Asimismo, se calcularon los índices que evalúan la proporción de dientes aislados. Por otra parte, se analizó el grado de fractura de los restos craneales, contabilizando los restos completos y las diferentes porciones. Finalmente, siguiendo a Pardiñas (1999b) se cuantificaron los especimenes con restos de pelos provenientes de egagrópilas.

Teniendo como objetivo la comparación de los ensambles de micromamíferos provenientes del sitio arqueológico con la comunidad de micromamíferos vivientes en el área, se estudió una muestra de 22 egagrópilas de Geranoaetus melanoleucus (águila mora) recolectada en octubre del 2009 en otra quebrada a $600 \mathrm{~m}$ del sitio arqueológico. [Localidad Agua de La Mula (ver apéndice)].

Para el mismo fin, se analizaron datos provenientes de trampeos realizados cerca del sitio, utilizando trampas de captura viva tipo Sherman y jaulas. Las mismas se dispusieron en tres grupos de 25 , en distintos microhábitats (jarillal, vega-pastizal y roquedal, Figura 7.8), durante una semana en octubre del 2009 [Localidad Agua de La Mula (ver apéndice)].

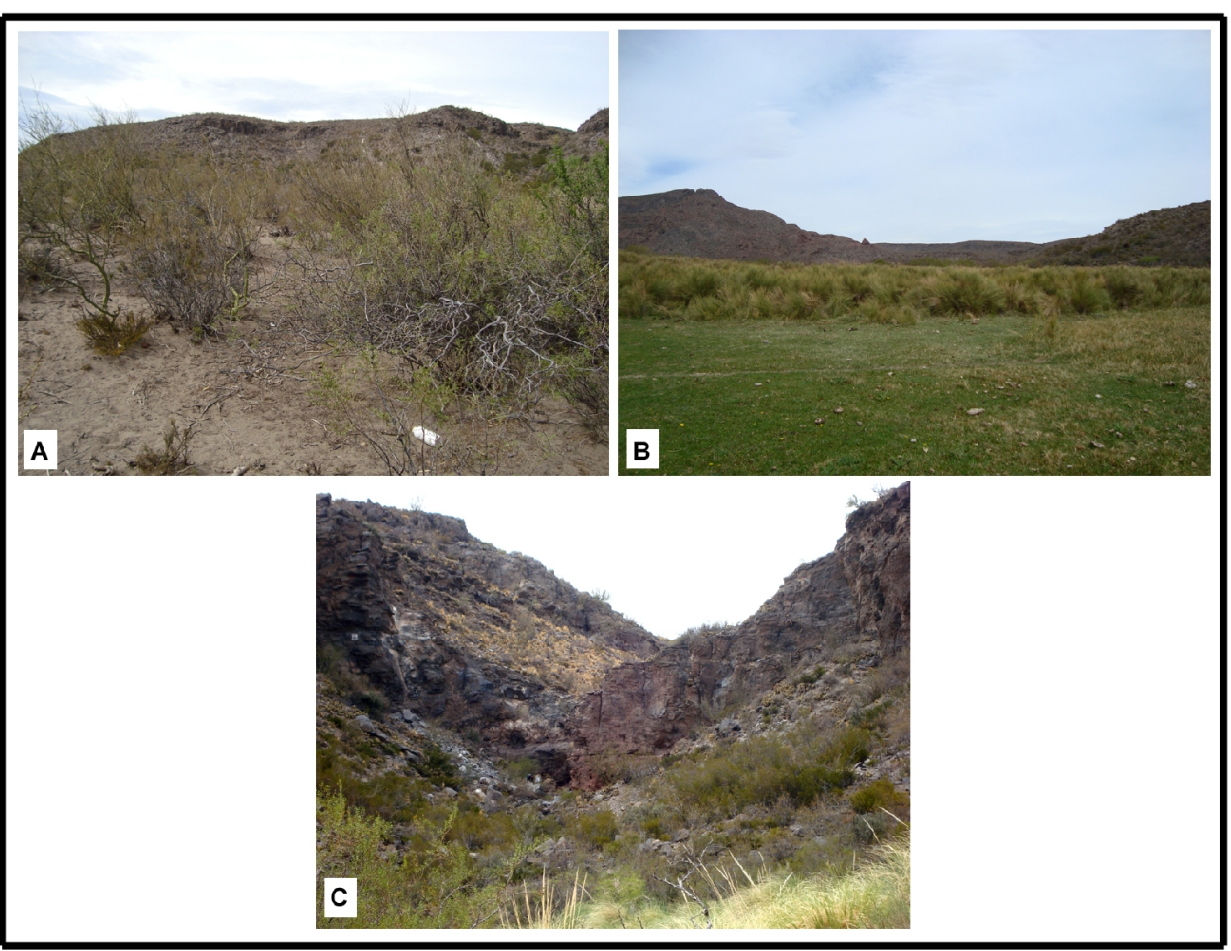

Figura 7.8. Tipos de microhábitas muestreados. A: jarillal. B: vega-pastizal. C: roquedal. 


\subsubsection{Resultados}

\subsubsection{Análisis tafonómico}

Se recuperaron 9 egagrópilas procedentes de todos los niveles que contenían restos de micromamíferos (Figura 8.8 A y B). Asimismo, en toda la muestra se observaron cerca de la mitad de elementos con presencia de pelos provenientes de egagrópilas, siendo el nivel 5 el que exhibió mayor porcentaje de los mismos, mientras que el nivel 7 fue el que mostró menor cantidad de elementos con restos de pelos (Figura 7.8 C-E y Figura 7.9). Por otra parte, se destaca que los elementos asignados a roedores histricognatos fueron los que presentaron mayor proporción de restos con pelos en todos los niveles, con un promedio de 67,7\% y alcanzando $c a$. del 90\% en los niveles 4 y 5 (Figura 7.10). El 13,5\% de los incisivos y molares in situ sufrieron corrosión digestiva, comprendidos principalmente en la categoría de modificación ligera y en menor medida en las categorías moderada y fuerte (Tabla 7.10; Figura 7.7 F y G; Figura 7.11).

De esta manera, en la mayoría de los incisivos la corrosión se concentró en los extremos y en menor proporción se extendió a lo largo de la superficie de los mismos, dejándola ondulada y con el esmalte reducido en pequeños islotes sobre la dentina. Por su parte, casi todos los molares que tenían marcas de corrosión, exhibieron cúspides con un contorno más redondeado y sólo en pocos casos el esmalte mostró un ligero poseado. Asimismo, se destaca que en los niveles 5 y 6 se observó mayor porcentaje de restos modificados por acción digestiva y contrariamente los restos recuperados de los niveles 4 y 7 fueron los menos afectados (Figura 7.11). 


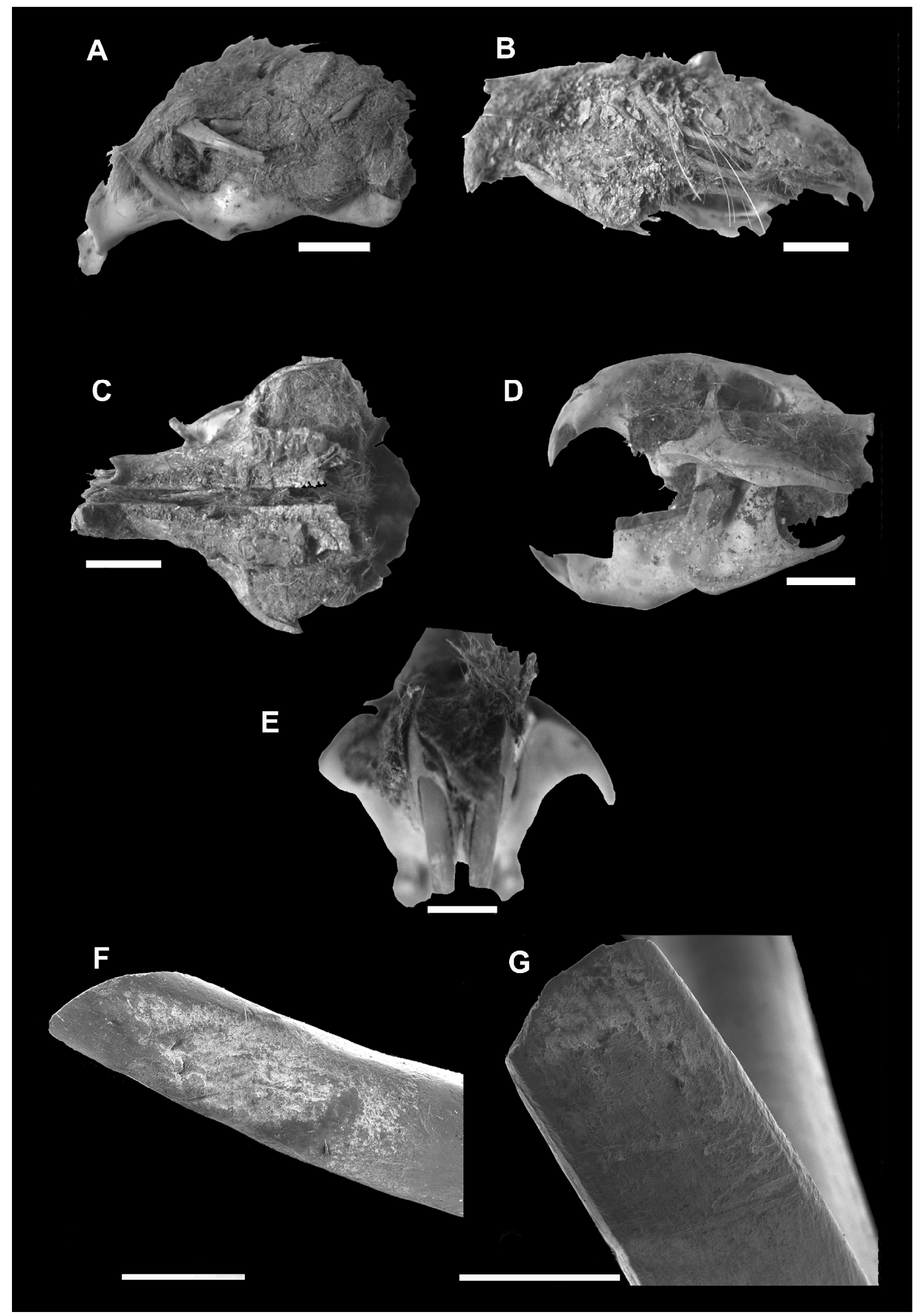


Figura 7.8. Ejemplos de evidencias de acción de aves rapaces en los distintos niveles de Agua de La Mula. A: egagrópila fósil (Nivel 6). B: egagrópila fósil (Nivel 7). C: vista ventral del cráneo de Phyllotis xanthopygus con restos de pelos de egagrópilas (Nivel 5). D: cráneo y mandíbulas articulados de Ctenomys sp. con restos de pelos (Nivel 4). E: cráneo con restos de pelos, mostrando corrosión ligera en el extremo de los incisivos (Nivel 6). F: corrosión digestiva moderada en incisivo de Sigmodontinae (Nivel 6). G: corrosión ligera en incisivo de Ctenomys sp. (Nivel 10). Escalas A-E: 5 mm; escalas F y G: 1 mm.

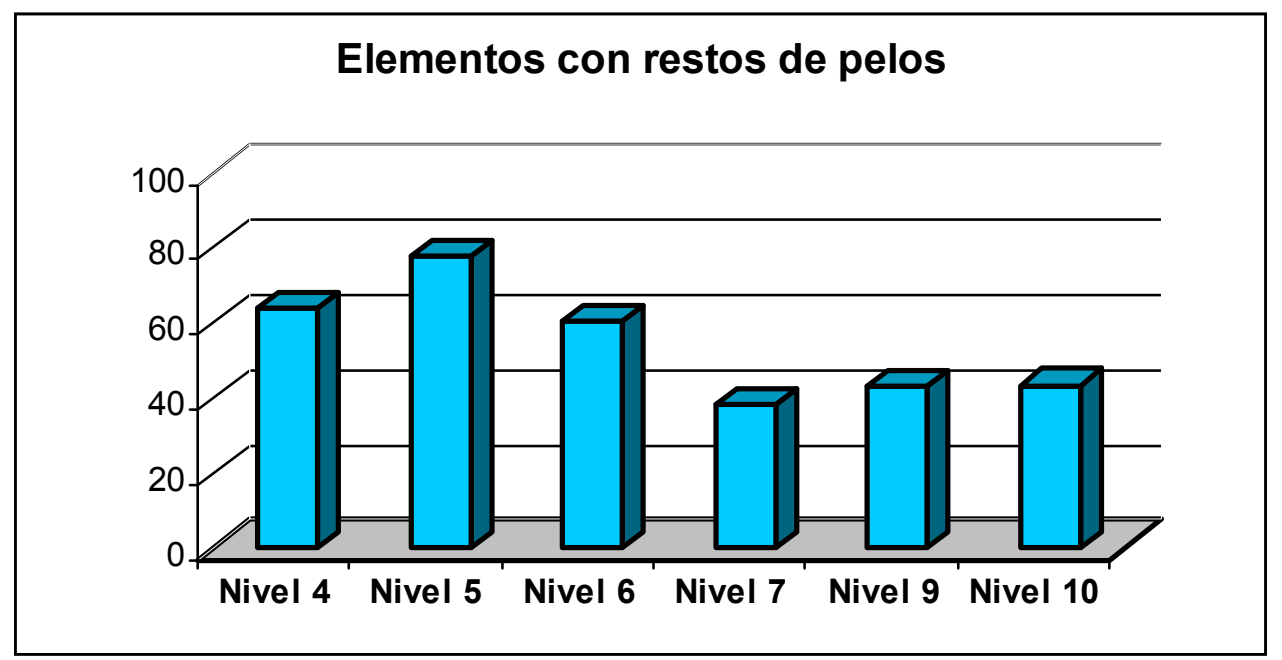

Figura 7.9. Porcentajes de elementos con restos de pelos recuperados de los distintos niveles portadores de micromamíferos de Agua de La Mula.

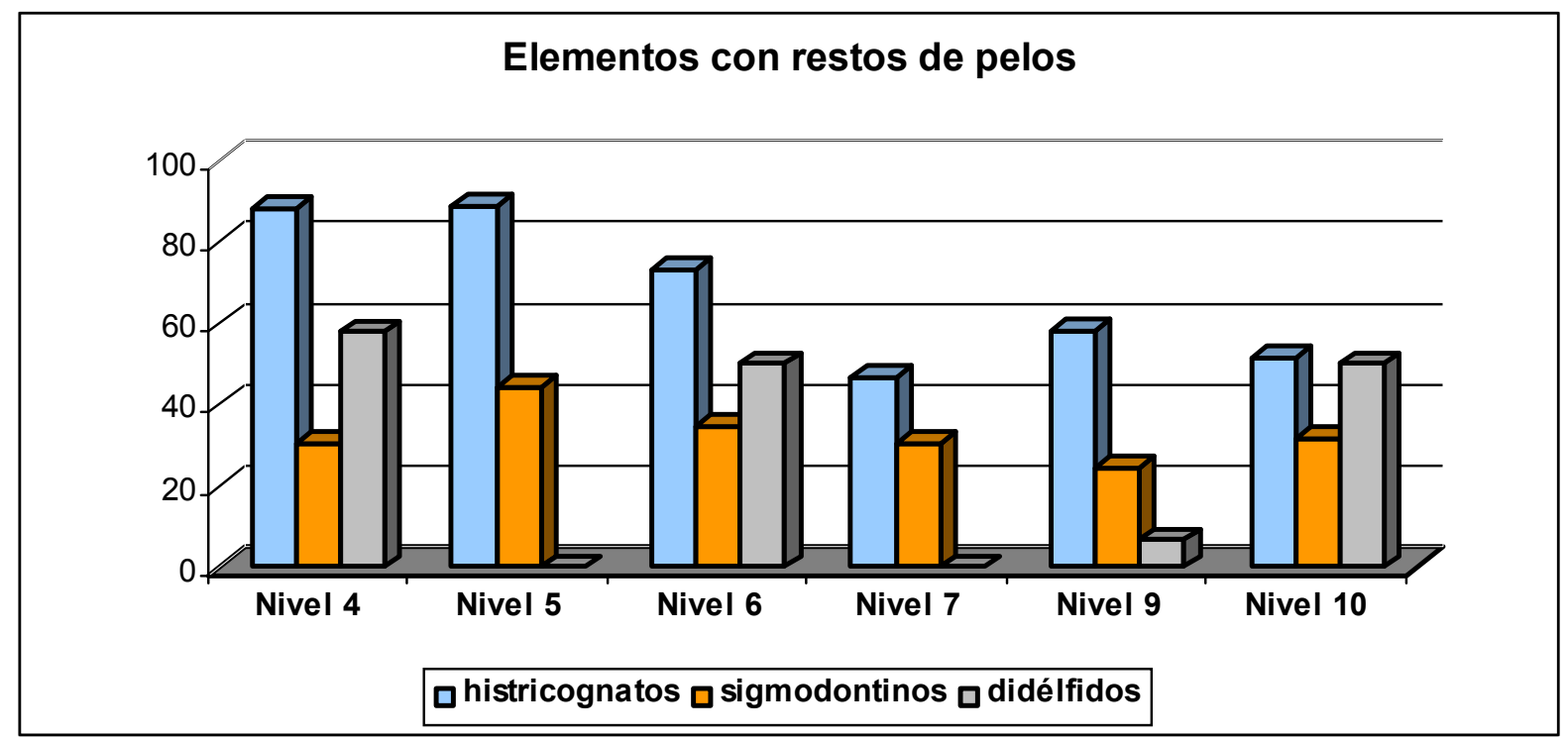

Figura 7.10. Comparación de los porcentajes de elementos con restos de pelos en los grupos de micromamíferos recuperados de los distintos niveles de Agua de La Mula. 


\begin{tabular}{|c|c|c|c|c|c|c|c|c|c|c|}
\hline \multirow{3}{*}{ Agua de La Mula } & \multicolumn{10}{|c|}{ Clases de digestión sensu Andrews (1990) } \\
\hline & \multicolumn{2}{|c|}{ Ausente } & \multicolumn{2}{|c|}{ Ligera } & \multicolumn{2}{|c|}{ Moderada } & \multicolumn{2}{|c|}{ Fuerte } & \multicolumn{2}{|c|}{ Extrema } \\
\hline & $(\mathrm{N})$ & $\%$ & $(\mathrm{~N})$ & $\%$ & $(\mathrm{~N})$ & $\%$ & $(\mathrm{~N})$ & $\%$ & $(\mathrm{~N})$ & $\%$ \\
\hline Incisivos in situ & & & & & & & & & & \\
\hline Nivel 4 & 73 & 80,2 & 18 & 19,8 & - & - & - & - & - & - \\
\hline Nivel 5 & 48 & 65.7 & 24 & 32,9 & 1 & 1,4 & - & - & - & - \\
\hline Nivel 6 & 128 & 71,1 & 46 & 25,5 & 4 & 2,2 & 2 & 1,1 & - & - \\
\hline Nivel 7 & 90 & 80,4 & 22 & 19,6 & - & - & - & - & - & - \\
\hline Nivel 9 & 96 & 73,3 & 31 & 23,1 & 7 & 5,2 & - & - & - & - \\
\hline Nivel 10 & 23 & 67,6 & 9 & 26,5 & 2 & 5,9 & - & - & - & - \\
\hline Total & 458 & 70,2 & 150 & 23 & 14 & 2,1 & 2 & 0,3 & - & - \\
\hline Molares in situ & & & & & & & & & & \\
\hline Nivel 4 & 270 & 89,1 & 32 & 10,5 & 1 & 0,4 & - & - & - & - \\
\hline Nivel 5 & 205 & 87,6 & 29 & 12,4 & - & - & - & - & - & - \\
\hline Nivel 6 & 356 & 89 & 44 & 11 & - & - & - & - & - & - \\
\hline Nivel 7 & 274 & 97,2 & 8 & 2,8 & - & - & - & - & - & - \\
\hline Nivel 9 & 323 & 93,9 & 17 & 4,9 & 4 & 1,2 & - & - & - & - \\
\hline Nivel 10 & 82 & 94,2 & 5 & 5,8 & - & - & - & - & - & - \\
\hline Total & 1510 & 91,5 & 135 & 8,2 & 5 & 0,3 & - & - & - & - \\
\hline
\end{tabular}

Tabla 7.10. Representación de las distintas categorías de corrosión digestiva en dientes de micromamíferos recuperados de los distintos niveles de Agua de La Mula.

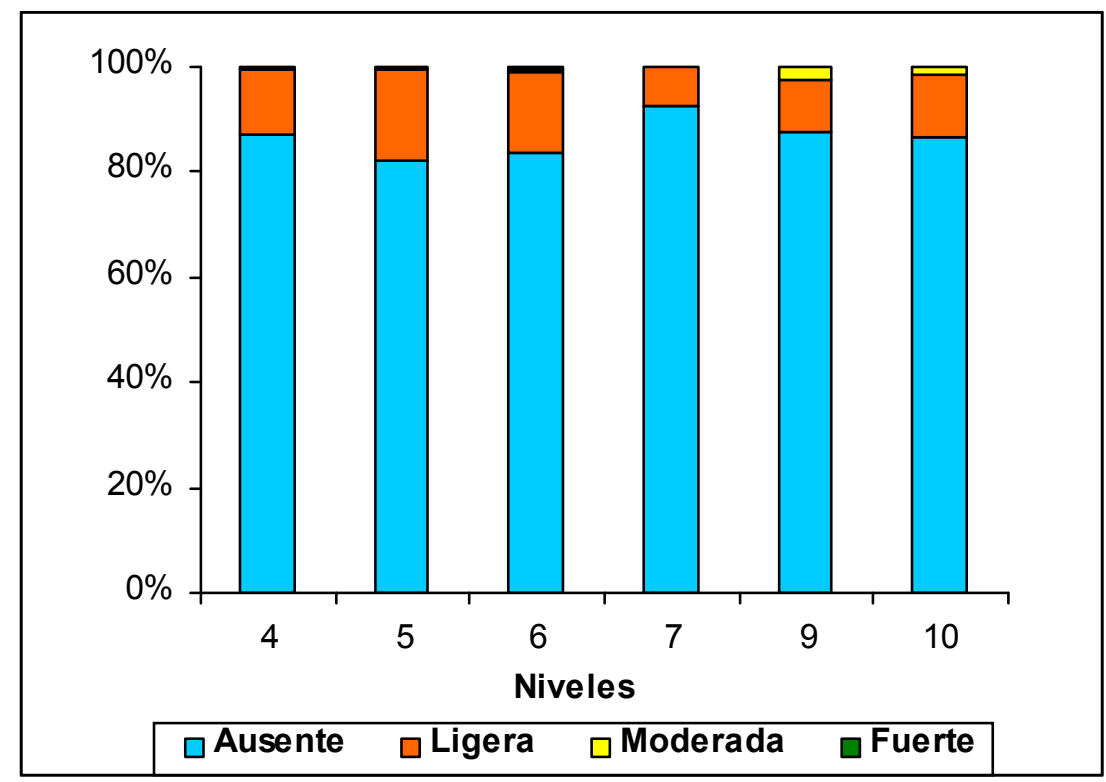

Figura 7.11. Comparación de los porcentajes de las categorías de corrosión digestiva por niveles portadores de restos de micromamíferos de Agua de La Mula.

En la tabla 7.11 se exhiben los distintos tipos de fractura craneal y dentaria.

Circa del 20\% de los cráneos estaban completos y la mayoría de ellos se encontraron 
muy fracturados, perdiendo los huesos de la bóveda y una parte de los mismos correspondieron a maxilares sin zigomáticos. En los niveles 7, 9 y 10 se observaron mayor grado de ruptura, mientras que los cráneos recuperados del nivel 5 fueron los que mostraron mayor preservación.

Un elevado porcentaje de los incisivos y molares se perdieron de los premaxilares y maxilares, respectivamente. Asimismo, los cráneos exhumados del nivel 7 fueron los que presentaron mayor pérdida dentaria, mientras que en el nivel 10 se recuperaron premaxilares y maxilares con el más alto porcentaje de retención dentaria.

Más de la mitad de las mandíbulas se hallaron completas y una alta proporción de las que estaban fracturadas conservaron las ramas ascendentes, mientras que un porcentaje menor presentaron el borde inferior de la rama mandibular rota. Además, cabe destacar que las mandíbulas procedentes de los niveles 4 y 5 fueron las que exhibieron mejor grado de integridad y contrariamente, las provenientes de los niveles 7, 9 y 10, las que mostraron mayor fracturación.

\begin{tabular}{|l|c|c|c|c|c|c|c|}
\hline & Nivel 4 & Nivel 5 & Nivel 6 & Nivel 7 & Nivel 9 & Nivel 10 & Total \\
\hline Fractura de cráneos & & & & & & & \\
Cráneos completos & 28,6 & 43,3 & 23,3 & 23,5 & 9,1 & - & 21,3 \\
Maxilares con arcos zigomáticos & 10,5 & 10 & 34,4 & 11,8 & 31,8 & 57,1 & 25,9 \\
Maxilares sin arcos zigomáticos & 60,7 & 46,7 & 42,2 & 64,7 & 59,1 & 42,9 & 52,7 \\
Pérdida de molares de maxilares & 56 & 69,5 & 66,1 & 77,3 & 62,4 & 34,3 & 60,9 \\
Pérdida de incisivos de premaxilares & 52,8 & 60 & 62,2 & 83,3 & 77 & 50 & 64,2 \\
\hline Fractura de mandíbulas & & & & & & & \\
Mandíbulas completas & 71,4 & 65,4 & 60,6 & 41,3 & 50,5 & 51,1 & 56,7 \\
Mandíbulas con rama ascendente rota & 23,3 & 30,8 & 24,2 & 41,3 & 39,2 & 44,7 & 33,9 \\
Mandíbulas sin rama ascendente & 5,3 & 3,8 & 12,1 & 13 & 9,1 & 4,2 & 7,9 \\
Mandíbulas sin rama ascendente y borde inferior roto & - & - & 3 & 4,3 & 1,1 & - & 1,4 \\
Pérdida de molares de las mandíbulas & 58,3 & 46 & 64,9 & 70,5 & 71,9 & 64,9 & 62,7 \\
Pérdida de incisivos de la mandíbulas & 36 & 34,6 & 31,3 & 41,9 & 30,5 & 33,3 & 34,6 \\
\hline Fractura de dientes & & & & & & & \\
Incisivos rotos in situ & - & - & 3 & 4,5 & 4,5 & - & 2 \\
Molares rotos in situ & 0,3 & - & 3 & 1,1 & 2,9 & 0,01 & 1,2 \\
\hline
\end{tabular}

Tabla 7.11. Porcentajes de fractura de cráneos, mandíbulas y dientes, recuperados de los niveles portadores de micromamíferos de Agua de La Mula.

Un elevado porcentaje de los molares se perdieron de las mandíbulas, sin embargo, la mayor parte de los incisivos se mantuvieron en las mismas. Asimismo, el nivel 7 fue el que presentó la proporción más alta de pérdida dentaria, mientras que en los niveles 5 y 9 se observaron mayor retención de molares e incisivos, respectivamente. 
Como se ilustra en la figura 7.12, existe una marcada diferencia entre la preservación del cráneo y las mandíbulas, posiblemente causada por la mayor robustez de esta última.

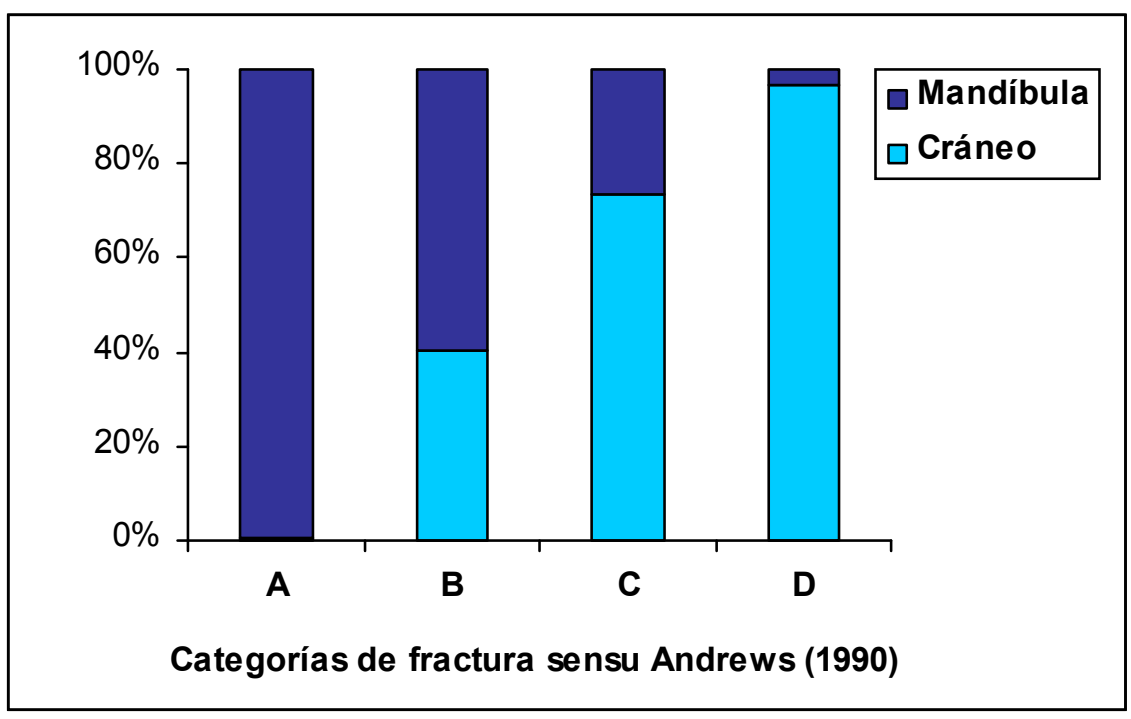

Figura 7.12. Comparación entre porcentajes de las categorías de fractura en cráneos y mandíbulas.

Los índices que evalúan la proporción relativa de dientes aislados, se realizaron por un lado teniendo en cuenta todos los roedores y por el otro en histricognatos $\mathrm{y}$ sigmodontinos por separado (Tabla 7.12). En este sentido, tomando los roedores como un solo conjunto, se observó una pérdida de molares en todos los niveles (alcanzando su mayor expresión en el nivel 7) y contrariamente una alta proporción de incisivos se mantuvieron en sus alvéolos, a excepción del nivel 7 que presentó valores similares. Sin embargo, cuando se calcularon los valores de estos índices en ambos grupos de roedores, se pudieron observar diferencias notables.

\begin{tabular}{|l|c|c|c|c|c|c|c|}
\hline \% de dientes aislados & Nivel 4 & Nivel 5 & Nivel 6 & Nivel 7 & Nivel 9 & Nivel 10 & Total \\
\hline Total roedores & & & & & & & \\
alvéolos mx+ alvéolos mb/m & 136,8 & 125,6 & 189,8 & 259,9 & 227,2 & 145,4 & 180,8 \\
alveolos mx+ alveolos mb/i & 78,2 & 81,3 & 90,8 & 100 & 74,1 & 57,1 & 80,3 \\
\hline Histricognatos & & & & & & & \\
alvéolos mx+ alvéolos mb/m & 203,3 & 140 & 283,1 & 534,6 & 370,6 & 314,3 & 307,6 \\
alveolos mx+ alveolos mb/i & 123,8 & 114,9 & 113,5 & 182,6 & 97,4 & 100 & 122 \\
\hline Sigmodontinos & & & & & & & \\
alvéolos mx+ alvéolos mb/m & 62,8 & 47,4 & 65,7 & 96,3 & 93,3 & 48,9 & 69,1 \\
alveolos mx+ alveolos mb/i & 35,5 & 25 & 50,8 & 37,7 & 44,1 & 25 & 36,4 \\
\hline
\end{tabular}

Tabla 7.12.Valores de los índices de proporción de dientes aislados para los grupos de roedores recuperados de los distintos niveles de Agua de La Mula. 
Referencias: mx: maxilar; mb: mandíbula; m: molar; i: incisivo.

De modo que, en forma opuesta a lo que ocurrió en los sigmodontinos, en los roedores histricognatos se registró una mayor pérdida dentaria en todos los niveles. Asimismo, en ambos grupos de roedores, el nivel 5 fue el que mostró más cantidad de molares retenidos en sus maxilares y mandíbulas.

Los índices IT e IP, dieron valores que señalan que sólo el nivel 4 contiene mayoritariamente micromamíferos de tamaño chico y solitarios (Tabla 7.13).

\begin{tabular}{|l|c|c|c|c|c|c|c|}
\hline & Nivel 4 & Nivel 5 & Nivel 6 & Nivel 7 & Nivel 9 & Nivel 10 & Total \\
\hline Índice de Tamaño (IT) & 122,2 & 44,4 & 76,8 & 96,3 & 85,5 & 100 & 81,8 \\
Índice de Predictibilidad (IP) & 81,8 & 225 & 134,6 & 107,8 & 117 & 100 & 124,2 \\
\hline
\end{tabular}

Tabla 7.13. Valores de los índices de tamaño y predictibilidad.

Por otra parte, se destaca que no se registraron restos con marcas de corte y sólo tres elementos ( $c a .0,3 \%)$ del total de la muestra estaban termoalterados, los cuales fueron recuperados de los niveles 6 y 7.

En cuanto a los procesos postdepositacionales, no se registraron restos meteorizados. Tampoco se observaron elementos con marcas de raíces, ni con evidencias de abrasión hídrica, desplazamientos y rozamientos de los restos contra el sedimento (sensu, Korth, 1979; Fernández-Jalvo y Andrews, 2003). No obstante, se hallaron elementos con corrosión sedimentaria únicamente en los niveles 7 (1,9\%) y 9 (4,6\%) e impresiones por óxidos de manganeso también en los niveles 7 (9,3\%) y $9(13,7 \%)$.

\subsubsection{Asociación de microvertebrados de la muestra actual}

\subsection{Egagrópilas de Geranoaetus melanoleucus}

Como se ilustra en la tabla 7.14, el ensamble de microvertebrados de la muestra actual de egagrópilas de G. melanoleucus está conformado principalmente por micromamíferos, caracterizados por un roedor sigmodontino (Graomys griseoflavus), un cávido (Galea leucoblephara), un quiróptero (Tadarida brasiliensis) y un juvenil de un lagomorfo introducido. También, se hallaron restos de aves correspondientes a paseriformes indeterminados y un emberizido (Saltator aurantiirostris). 


\begin{tabular}{|l|cc|}
\hline Taxón / Procedencia & \multicolumn{2}{|c|}{ Agua de La Mula } \\
& MNI & $\%$ \\
\hline Aves & 5 & 25 \\
Passeriformes indet. & 1 & 5 \\
Saltator aurantiirostris & 3 & 15 \\
Mammalia indet. & & \\
Chiroptera & 1 & 5 \\
Tadarida brasiliensis & & \\
Rodentia & & \\
Caviidae & 3 & 15 \\
Galea leucoblephara & & \\
Cricetidae/Sigmodontinae & 5 & 25 \\
Graomys griseoflavus & 2 & 10 \\
Lagomorpha/Leporidae indet. & 20 \\
\hline Total
\end{tabular}

Tabla 7.14. Composición taxonómica del ensamble actual micromamíferos proveniente de la muestra de Geranoaetus melanoleucus (expresada en MNI y MNI\%).

\subsection{Datos de trampeos}

La información correspondiente a los datos de trampeos por microhábitat se exhibe en la tabla 7.15 .

\begin{tabular}{|l|c|c|c|}
\hline Taxones / microhábitats & Jarillal & Vega-pastizal & Roquedal \\
\hline $\begin{array}{l}\text { Didelphimorphia } \\
\text { Thylamys pallidior } \\
\text { Rodentia }\end{array}$ & - & 1 & - \\
Caviidae & & & \\
Galea leucoblephara & - & 5 & - \\
Cricetidae & - & 1 & - \\
Akodon molinae & & 2 & 2 \\
Phyllotis xanthopygus & - & 1 & - \\
Calomys musculinus & 2 & 10 & 2 \\
\hline Eligmodontia sp. & 2 & & - \\
\hline Total &
\end{tabular}

Tabla 7.15. Datos de trampeos discriminados según los microhábitats muestreados.

Se capturaron 14 individuos, correspondientes a seis taxones, en las siguientes proporciones: G. leucoblephara (35,7\%), Eligmodontia sp. (21,4\%), Phyllotis xanthopygus (14,3\%), Calomys musculinus (14,3\%), Akodon molinae (7,1\%) у Thylamys pallidior $(7,1 \%)$. Si bien estos datos son exiguos y no permiten realizar mayores interpretaciones, se puede observar una marcada diferencia entre los distintos 
microhábitats relevados. En este sentido, la vega-pastizal con la presencia de cinco taxones (G. leucoblephara, Calomys musculinus, Eligmodontia sp., A. molinae y $T$. pallidior) fue el que presentó mayor riqueza taxonómica. Mientras que en el roquedal y en el jarillal se capturaron un solo taxón ( $P$. xanthopygus y Eligmodontia sp., respectivamente).

\subsection{Sintesis de la comunidad actual de microvertebrados}

Tomando ambas fuentes de información, la comunidad actual de microvertebrados está integrada principalmente por roedores sigmodontinos, siendo G. griseoflavus el más abundante, seguido por Eligmodontia sp., P. xanthopygus, C. musculinus y A. molinae. Asimismo, el roedor cávido ( $G$. leucoblephara) estuvo bien representado. Con frecuencias menores a este ensamble lo acompañan un quiróptero (T. brasiliensis), un marsupial (T. pallidior), un lagomorfo introducido y una especie de ave paseriforme $(S$. aurantiirostris). El índice de diversidad de Shannon arrojó un valor 2,022 (Tabla 7.16).

\begin{tabular}{|l|cc|}
\hline Taxón / Procedencia & \multicolumn{2}{|c|}{$\begin{array}{c}\text { Agua de La Mula } \\
\text { MNI }\end{array}$} \\
\hline Aves & & \\
Passeriformes indet. & 5 & 14,7 \\
Saltator aurantiirostris & 1 & 2,9 \\
Mammalia indet. & 3 & 8,8 \\
Didelphimorphia & & \\
Thylamys pallidior & 1 & 2,9 \\
Chiroptera & & \\
Tadarida brasiliensis & 1 & 2,9 \\
Rodentia & & \\
Caviidae & & \\
Galea leucoblephara & 8 & 23,5 \\
Cricetidae/Sigmodontinae & & \\
Akodon molinae & 1 & 2,9 \\
Calomys musculinus & 2 & 5,9 \\
Phyllotis xanthopygus & 2 & 5,9 \\
Graomys griseoflavus & 5 & 14,7 \\
Eligmodontia sp. & 3 & 8,8 \\
Lagomorpha /Leporidae indet. & 2 & 5,9 \\
\hline Total & 34 & \\
Riqueza & 10 & \\
H' & 2,022 & \\
Equitatividad & 0,8782 \\
\hline
\end{tabular}


Tabla 7.16. Composición taxonómica del ensamble actual de micromamíferos proveniente de la muestra de Geranoaetus melanoleucus y datos de trampeos (expresada en MNI y MNI\%).

Este ensamble muestra una clara dominancia de taxones asociados al desierto del Monte (G. griseoflavus, A. molinae, C. musculinus, G. leucoblephara у T. pallidior); con el agregado de elementos ampliamente distribuidos en Patagonia y frecuentes en ambientes xéricos, asociados a estepas arbustivas abiertas con afloramientos rocosos (P. xanthopygus y Eligmodontia sp.). Por su parte, T. brasiliensis es un quiróptero con una amplia distribución que ocupa una multiplicidad de ambientes.

\subsubsection{Asociación de micromamíferos de la muestra arqueofaunística}

La información correspondiente a las abundancias relativas de los micromamíferos de la muestra arqueofaunística (expresadas como valores de NISP y MNI) se detalla en la tabla 7.17 y 7.18 .

\begin{tabular}{|c|c|c|c|c|c|c|c|c|c|c|c|c|c|c|}
\hline Cronología (en ka) & 1 & & & & & & & & & & 1,6 & & & \\
\hline Niveles / \% & 4 & $\%$ & 5 & $\%$ & 6 & $\%$ & 7 & $\%$ & 9 & $\%$ & 10 & $\%$ & Total & $\%$ \\
\hline $\begin{array}{l}\text { Mammalia } \\
\text { Didelphimorphia }\end{array}$ & & & & & & & & & & & & & & \\
\hline allidior & 18 & 11,2 & 1 & 0,9 & 11 & 4,3 & 11 & 5 & 15 & 6,5 & - & - & 56 & 5,5 \\
\hline $\begin{array}{l}\text { Lestodelphys halli } \\
\text { Chiroptera }\end{array}$ & 1 & 0,6 & - & - & 1 & 0,4 & 2 & 0,9 & - & - & 2 & 3,8 & 6 & 0,6 \\
\hline $\begin{array}{l}\text { Tadarida brasiliensis } \\
\text { Rodentia } \\
\text { Ctenomyidae }\end{array}$ & - & - & - & - & 1 & 0,4 & 1 & 0,4 & - & - & - & - & 2 & 0,2 \\
\hline $\begin{array}{l}\text { Ctenomys sp. } \\
\text { Caviidae }\end{array}$ & 67 & 41,6 & 62 & 56,9 & 142 & 55,7 & 88 & 40,4 & 96 & 41,7 & 25 & 47,2 & 480 & 46,8 \\
\hline Microcavia australis & 6 & 3,7 & 5 & 4,6 & 25 & 9,8 & 21 & 9,6 & 15 & 6,5 & 4 & 7,5 & 76 & 7,4 \\
\hline $\begin{array}{l}\text { Galea leucoblephara } \\
\text { Cricetidae / Sigmodontinae }\end{array}$ & 10 & 6,2 & 14 & 12,8 & - & - & 13 & 6 & 23 & 10 & - & - & 60 & 5,8 \\
\hline Akodon molinae & 6 & 3,7 & 2 & 1,8 & 3 & 1,2 & 2 & 0,9 & 3 & 1,3 & - & - & 16 & 1,56 \\
\hline egazzinii & - & - & 1 & 0,9 & 1 & 0,4 & - & - & - & - & - & - & 2 & 0,2 \\
\hline Calomys musculinus & - & - & - & - & - & - & 2 & 0,9 & - & - & - & - & 2 & 0,2 \\
\hline Phyllotis xanthopygus & 18 & 11,2 & 12 & 11 & 43 & 16,9 & 29 & 13,3 & 59 & 25,7 & 8 & 15,1 & 169 & 16,5 \\
\hline Graomys griseoflavus & 31 & 19,3 & 8 & 7,4 & 19 & 7,4 & 42 & 19,3 & 15 & 6,5 & 14 & 26,4 & 129 & 12,6 \\
\hline & 3 & 1,9 & 4 & 3,7 & 6 & 2,4 & 4 & 1,8 & 3 & 1,3 & - & - & 20 & 1,9 \\
\hline Reithrodon auritus & 1 & 0,6 & - & - & 3 & 1,2 & 3 & 1,4 & 1 & 0,4 & - & - & 8 & 0,8 \\
\hline Total & 161 & & 109 & & 255 & & 218 & & 230 & & 53 & & 1026 & \\
\hline
\end{tabular}


Tabla 7.17. Composición taxonómica cualitativa y cuantitativa del ensamble de micromamíferos por niveles arqueológicos de Agua de La Mula (expresada en NISP).

\begin{tabular}{|c|c|c|c|c|c|c|c|c|c|c|c|c|c|c|}
\hline \multirow{2}{*}{\begin{tabular}{|l} 
Cronología (en ka) \\
Niveles / \% \\
\end{tabular}} & \multicolumn{10}{|l|}{1} & \multicolumn{2}{|l|}{1,6} & \multirow[b]{2}{*}{ Total } & \multirow[b]{2}{*}{$\%$} \\
\hline & 4 & $\%$ & 5 & $\%$ & 6 & $\%$ & 7 & $\%$ & 9 & $\%$ & 10 & $\%$ & & \\
\hline $\begin{array}{l}\text { Mammalia } \\
\text { Didelphimorphia }\end{array}$ & & & & & & & & & & & & & & \\
\hline Thylam & 8 & 10 & 1 & 1,9 & 6 & 5,4 & 7 & 6,6 & 9 & 7,8 & - & - & 31 & 6,3 \\
\hline $\begin{array}{l}\text { Lestodelphys halli } \\
\text { Chiroptera }\end{array}$ & 1 & 1,3 & - & - & 1 & 0,9 & 2 & 1,9 & - & - & 1 & 3,8 & 5 & 1 \\
\hline Tadarida brasiliensis & - & - & - & - & 1 & 0,9 & 1 & 0,9 & - & - & - & - & 2 & 0,4 \\
\hline $\begin{array}{l}\text { Rodentia } \\
\text { Ctenomyidae }\end{array}$ & & & & & & & & & & & & & & \\
\hline $\begin{array}{l}\text { Ctenomys sp. } \\
\text { Caviidae }\end{array}$ & 30 & 37,5 & 26 & 50 & 56 & 50 & 39 & 36,8 & 44 & 38,3 & 11 & 42,3 & 206 & 41,9 \\
\hline iia australis & 2 & 2,5 & 3 & 5,8 & 13 & 11,6 & 9 & 8,5 & 9 & 7,8 & 2 & 7,7 & 38 & 7,7 \\
\hline Galea leucoblephara & 4 & 5 & 7 & 13,5 & - & - & 6 & 5,7 & 9 & 7,8 & - & - & 26 & 5,3 \\
\hline $\begin{array}{l}\text { Cricetidae / Sigmodontinae } \\
\text { Akodon molinae }\end{array}$ & 5 & 6,2 & 1 & 1,9 & 2 & 1,8 & 1 & 0,9 & 2 & 1,7 & - & - & 11 & 2,2 \\
\hline Akodon spegazzinii & - & - & 1 & 1,9 & 1 & 0,9 & - & - & - & - & - & - & 2 & 0,4 \\
\hline Calomys $n$ & - & - & - & - & - & - & 2 & 1,9 & - & - & - & - & 2 & 0,4 \\
\hline Phyllotis xanthopygus & 10 & 12,5 & 5 & 9,6 & 17 & 15,2 & 13 & 12,3 & 28 & 24,3 & 6 & 23,1 & 79 & 16,1 \\
\hline griseoflavus & 17 & 21,2 & 5 & 9,6 & 8 & 7,1 & 23 & 21,7 & 10 & 8,7 & 6 & 23,1 & 69 & 14,1 \\
\hline Eligmodontia sp. & 2 & 2,5 & 3 & 5,8 & 5 & 4,5 & 2 & 1,9 & 3 & 2,6 & - & - & 15 & 3,1 \\
\hline Reithrodon auritus & 1 & 1,3 & - & - & 2 & 1,8 & 1 & 0,9 & 1 & 0,9 & - & - & 5 & 1 \\
\hline Total & 80 & & 52 & & 112 & & 106 & & 115 & & 26 & & 491 & \\
\hline Riqueza & & & & & & & & & & & & & 13 & \\
\hline & & & & & & & & & & & & & 1,815 & \\
\hline Equitativi & & & & & & & & & & & & & 0,707 & \\
\hline
\end{tabular}

Tabla 7.18. Composición taxonómica cualitativa y cuantitativa del ensamble de micromamíferos por niveles arqueológicos de Agua de La Mula (expresada en MNI).

El ensamble está integrado por un dominio de roedores histricognatos (Ctenomys sp., Microcavia australis y G. leucoblephara) y entre ellos Ctenomys sp. es el taxón más representado de toda la muestra. Los roedores sigmodontinos continúan en abundancia, siendo P. xanthopygus y G. griseoflavus las especies más frecuentes, seguidas por Eligmodontia sp., A. molinae, Reithrodon auritus, Akodon spegazzinii y C. musculinus. Con frecuencias menores se encuentran el quiróptero (T. brasiliensis) y los marsupiales (T. pallidior y Lestodelphys halli). El índice de diversidad de Shannon arrojó un valor 1,815 , levemente más bajo que la muestra actual de microvertebrados, lo que sugiere que los taxones tienen una representación menos pareja. Sin embargo, la muestra 
arqueofaunística exhibió mayor riqueza taxonómica y aún es más notorio si tenemos en cuenta los micromamíferos solamente.

\subsubsection{Discusión}

\subsubsection{Interpretación tafónomica}

En primer término es interesante destacar el registro de egagrópilas y de numerosos elementos con restos de pelos en todos los niveles portadores de micromamíferos (Figura 7.8 A-E). El hallazgo de egagrópilas fósiles constituye un indicador directo de que las aves rapaces intervinieron en la formación del ensamble de micromamíferos (Andrews, 1990; Pardiñas, 1999b).

Los valores de corrosión digestiva registrados en todos los niveles portadores de micromamíferos, son coincidentes con este tipo de alteraciones observadas en muestras de micromamíferos producidas por aves estrigiformes de Argentina y otras partes del mundo (véase Andrews, 1990; Gómez, 2005, 2007; Carrera y Fernández, 2010; entre otros). En tal sentido, Tyto alba, Bubo magellanicus, Asio flammeus y Athene cunicularia son las lechuzas y búhos que habitan en el área de estudio (ver Capítulo 6). No obstante, el análisis por niveles, nos sugiere que intervinieron más de una especie en la génesis de las acumulaciones de micromamíferos. Por un lado, los restos recuperados de los niveles 4, 7, 9 y 10 con los valores más bajos de digestión (Tabla 7.10, Figura 7.8 E y G y Figura 7.11), recuerda a los ensambles originados por lechuzas que producen bajos porcentajes de corrosión ligera como T. alba (e.g., Andrews, 1990; Gómez, 2007; Fernández et al., 2009a). Por otro lado, los restos provenientes de los niveles 5 y 6 , con mayores grados y porcentajes de digestión que los anteriores (Tabla 7.10, Figura 7.8 F y Figura 7.11), se acercan más a los valores registrados por Gómez (2007) en muestras de micromamíferos generadas por A. flammeus; aunque no llegan a alcanzar los niveles de digestión registrados en las acumulaciones de otras estrigiformes que habitan el área, como A. cunicularia (Gómez, 2007; Montalvo y Tejerina, 2010) y B. magellanicus (Fernández et al., 2009b). Si bien en este último caso los autores citados analizaron restos de aves consumidos por B. magellanicus, llegaron a la conclusión que este búho produce valores similares de alteración al de su par congenérico B. virginianus, el cual fuera estudiado en base a restos de micromamíferos (Gómez, 2005, 2007). 
En congruencia, las aves estrigiformes posiblemente sean las rapaces que más contribuyen a acumular restos de micromamíferos en sitios arqueológicos $\mathrm{y}$ paleontológicos de tipo cueva o refugio rocoso (e.g. Andrews, 1990) y entre ellas, $T$. alba ocupa un lugar central (Andrews, 1990; Saavedra y Simonetti, 1998; entre otros). Los valores de los índices IT e IP son consecuencia de un MNI elevado de roedores histricognatos en todos los niveles a excepción del nivel 4 (Tablas 7.13, 7.17 y 7.18). Cabe destacar, que entre otras cosas, la dominancia de este grupo de roedores en ensambles arqueológicos fue relacionado con el consumo humano (véase Simonetti y Cornejo, 1991; Pardinas 1999a y b; Quintana et al., 2002; Santiago, 2004; Acosta y Pafundi, 2005; Quintana, 2005; Teta et al., 2005a). Sin embargo, en Agua de La Mula no se registraron marcas de corte y solo tres elementos estaban termoalterados; asimismo, los elementos asignados a este grupo de roedores fueron los que presentaron mayores proporciones de restos de pelos de egagrópilas en todos los niveles (Figura 7.10), indicando que fueron incorporados al sitio por aves rapaces y no por humanos. Además, T. alba ha mostrado una elevada variabilidad dietaria espacio-temporal, posiblemente debido a la depredación estacional y por su carácter de cazador oportunista (ver Capítulo 6). Un buen ejemplo de esto lo constituye el caso registrado por Aliaga-Rossel y Tarifa (2005) en donde los cuises (Cavia sp.) representaron el componente principal de la dieta de esta lechuza en el noroeste de Bolivia. Pardiñas (1999a, 1999b) y Pardiñas y Teta (ms. enviado), indicaron sesgos tafonómicos relacionados a técnicas de excavación para explicar la abundancia de roedores histricognatos en el registro arqueofaunístico. Esta hipótesis fue sustentada por los autores, en torno a que este grupo de roedores presentan cráneos y mandíbulas más robustas y por ende más resistentes a procesos postdepositacionales como el pisoteo, que los roedores sigmodontinos. En coincidencia, como se mencionó anteriormente (ver sección 7.2.1), en Agua de La Mula sólo se exhumaron los restos craneales y posiblemente la abundancia de roedores histricognatos registrada en el sitio puede asociarse a este tipo de proceso registrado en el sitio (ver abajo).

La extensiva fractura observada principalmente en cráneos y en menor medida en las mandíbulas (debido a su robustez diferencial; Figura 7.12), además de la elevada pérdida de molares registrada en todos los niveles portadores de micromamíferos, acentuado en los niveles 7 y 9 (Tablas 7.11 y 7.12), son inconsistentes con el bajo porcentaje de digestión evidenciado en los dientes (Tabla 7.10). Al respecto, tanto Andrews (1990) como Gómez (2007) observaron bajos niveles de fractura y pérdida 
dentaria en numerosos ensambles originados por estrigiformes. Por ende, posiblemente esta situación pudo estar mayormente asociada a procesos postdepositacionales como el pisoteo, que por los agentes acumuladores, de modo que estos procesos son comunes en sitios tipo cueva o refugio rocoso, debido a que son espacios de circulación restringida (e.g., Andrews, 1990; Pardiñas, 1999b).

Por otra parte, es interesante destacar que no se observaron mayores incidencias de procesos postdepositacionales afectando a la muestra arqueofaunística. En este sentido, la ausencia de elementos meteorizados en toda la muestra indica que los mismos tuvieron un enterramiento rápido, luego de haber sido alterados por el pisoteo. Además, las cuevas permiten que los restos estén más protegidos de los agentes meteóricos (Andrews, 1990; Pardiñas, 1999b).

No obstante, otros agentes postdepositacionales que tuvieron lugar en la formación del ensamble fueron, la corrosión por humedad del suelo y el óxido de manganeso, los cuales afectaron a los restos provenientes de los niveles 7 y 9. Andrews (1990) observó que bajo condiciones de permanente humedad en el sedimento, los huesos de micromamíferos presentaron corrosión abarcando casi toda la superficie. En coincidencia, los restos afectados por óxido de manganeso se recuperaron de los mismos niveles, en tal sentido, las impregnaciones por óxidos de manganeso se producen cuando alternan ciclos de reducción-oxidación (Courty et al., 1989), siendo un proceso común en sitios donde existen oscilaciones del nivel freático o encharcamientos de agua (Gómez et al., 1999; Gómez, 2000).

\subsubsection{Interpretación paleoambiental}

Hay una correlación positiva alta y significativa entre la riqueza taxonómica y el tamaño de las muestras $\left(\mathrm{r}_{\mathrm{s}}=0,81 ; \mathrm{p}>0,05\right)$, esta situación sumado a lo escaso de la muestras actuales limita el alcance de las conclusiones.

En la figura 7.13 se detallan las frecuencias relativas de los taxones de micromamíferos en las muestras estudiadas. 


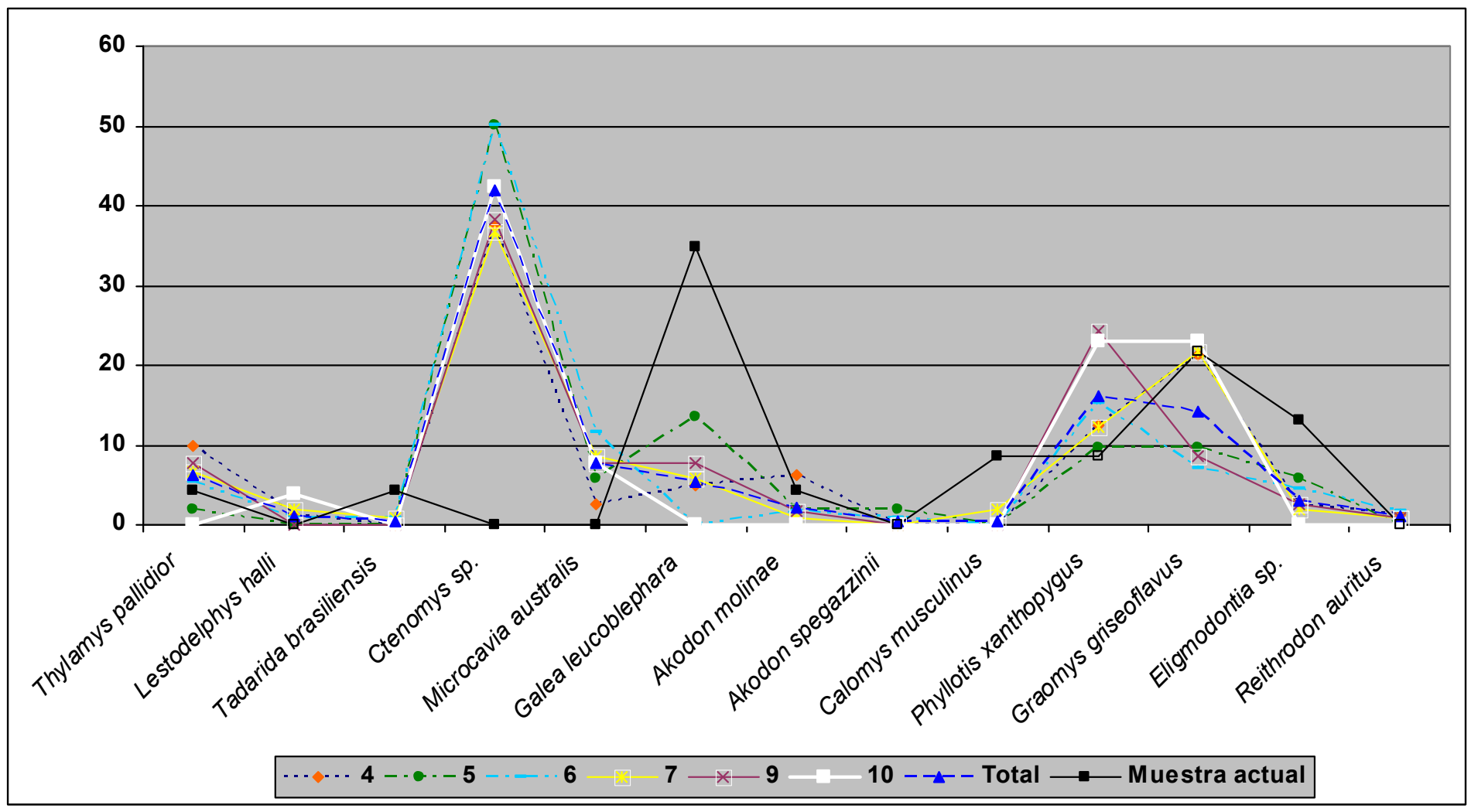

Figura 7.13. Comparación de las frecuencias relativas de los taxones de micromamíferos recuperados de los niveles Agua de La Mula y el parámetro actualístico.

Las presencias de A. molinae, G. griseoflavus, C. musculinus, G. leucoblephara y $T$. pallidior en distintos momentos de la secuencia, indican que el conjunto de micromamíferos del sitio arqueológico Agua de La Mula durante el lapso de ca. 1,6-1 ka ${ }^{14} \mathrm{C}$ AP está asociado al desierto del Monte y a la Diagonal Árida Sudamericana. Por su parte, los registros de $P$. xanthopygus en toda la secuencia (aumentando su frecuencia hacia los niveles más profundos) y Eligmodontia sp. (en bajas frecuencias), señalan ambientes afines a estepas arbustivas abiertas con abundante roca expuesta. Igualmente, resulta interesante destacar el hallazgo de restos asignados a L. halli en los niveles 4, 6, 7 y 10 (Figura 7.14), un marsupial ampliamente distribuido en la estepa Patagónica (e.g., Marshal, 1977; De Santis et al., 1995; Udrizar Sauthier et al., 2007; Martin, 2008; Martin et al., 2008; Formoso et al., 2011), con exiguos registros en el desierto del Monte, ubicados en las provincias de Mendoza (Chacras de Coria, Birney et al., 1996; Huayquerías del Oeste, Pardiñas, 1999a; 50 km N San Rafael, Nabte et al., 2006), La Pampa (Lihué Calel; 3802' S, 65³5' O, Birney et al., 1996) y Río Negro (Choele Choel, 39 ${ }^{\circ} 16^{\prime} \mathrm{S}, 6^{\circ} 41^{\prime} \mathrm{O}$, Marshal, 1977), las cuales fueron consideradas como poblaciones relictuales de distribuciones más amplias en épocas del Holoceno, 
representando hábitats no óptimos para esta especie (Udrizar Sauthier et al., 2007; Martin, 2008; Martin et al., 2008). En este sentido, se plantean dos probables escenarios que podrían explicar la ocurrencia de este marsupial en el sitio arqueológico y su ausencia en el ensamble actual: 1) poblaciones relictuales de L. halli habitando en este lugar entre $c a .1,6-1 \mathrm{ka}{ }^{14} \mathrm{C}$ AP; 2) un avance de la estepa Patagónica conformando un área ecotonal entre este ambiente y el desierto del Monte durante este lapso temporal, caracterizado por la influencia alternada del anticiclón del Pacífico (precipitaciones invernales) y el anticiclón del Atlántico (precipitaciones estivales), produciendo un clima más húmedo y frío que el actual, lo cual pudo haber ocasionado una migración de esta especie hacia el área donde se encuentra el sitio, extinguiéndose con posterioridad, posiblemente por el retroceso de la estepa Patagónica, retornando las condiciones más cálidas y áridas como las actuales.

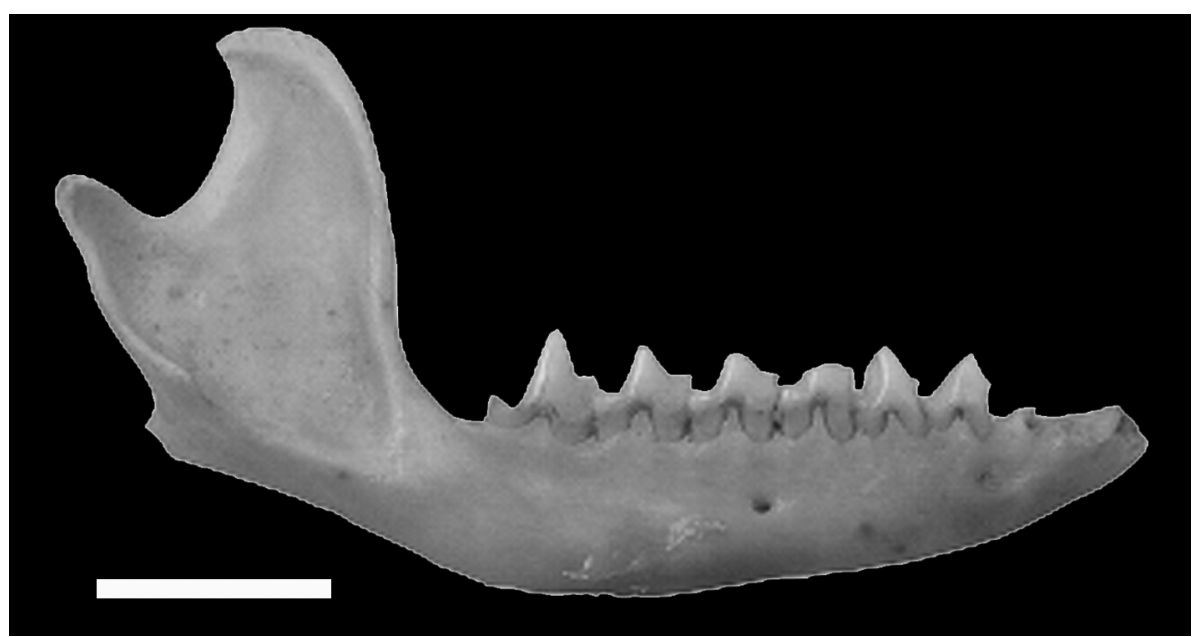

Figura 7.14. Vista labial de la mandíbula de Lestodelphys halli recuperada de Agua de La Mula (MHNSR-15.001, Nivel: 6). Escala: 5 mm.

Esta última explicación, estaría robustecida por la presencia de $R$. auritus en los niveles 4, 6, 7 y 9 y su ausencia en el ensamble actual, siendo un sigmodontino asociado a ambientes abiertos, con el desarrollo de pastizales en relación a cuerpos de agua, con abundantes registros en estepas pampeanas y patagónicas y en menor medida en el desierto del Monte (ver Capítulo 5). A su vez, en la provincia de Mendoza existen solo dos registros de este roedor, relacionados a áreas abiertas en la estepa Patagónica (ver Capítulo 5). Pardiñas et al. (2003) proponen que la ausencia de $R$. auritus en el desierto del Monte de Mendoza y oeste de la provincia de La Pampa, puede deberse a algún tipo de restricción térmica. Asimismo, el registro de M. australis -un histricognato que en el 
sur de Mendoza habita tanto en ambientes de estepa Patagónica como en el Monte- a lo largo de la secuencia arqueológica y su ausencia en el contexto actual, es congruente este modelo planteado. Finalmente, de forma coherente con lo observado en el ensamble arqueológico, los ambientes de ecotonos en general presentan una mayor riqueza específica, debido a que intervienen especies de los ambientes implicados (Odum y Barret, 2006).

Por su parte, el registro de L. halli en el sitio arqueológico Arroyo Malo 3, ubicado en un ambiente cordillerano del centro-oeste de Mendoza para el Holoceno tardío (ca. 3800 y 2200 años radiocarbónicos AP) y su ausencia en el ensamble actual, sugieren una distribución más amplia de esta especie para el Holoceno tardío. En coincidencia, estudios realizados por otros autores muestran que este marsupial experimentó procesos de retracción en la actualidad en otras áreas de la Patagonia y en la Pampasia (sensu Ringuelet, 1961), vinculados a repliegues de la estepa Patagónica. En este sentido, Perrotta y Pereda, (1987) hallaron L. halli en el sitio Alero IV del Tromen en el centro de la provincia de Neuquén para el Holoceno tardío (ca. 3600 y 2800 años radiocarbónicos AP), sin embargo, esta especie en la actualidad solo se ha registrado hacia el sur de Neuquén (véase Martin, 2008; Martin et al., 2008). Asimismo, las variaciones corológicas de esta especie durante el Holoceno fueron analizadas en detalle por Udrizar Sauthier (2009), sobre la base de intensos muestreos actuales y paleontológicos a lo largo del valle del río Chubut y en depósitos superficiales del sector de médanos del noreste de la provincia homónima. Este autor observó una notable retracción en la distribución geográfica de este marsupial en la actualidad, desapareciendo de Península Valdés, alrededores de Puerto Madryn y del valle inferior del río Chubut. Por su parte, la ausencia de L. halli en ensambles actuales del centro y sur de la provincia de Buenos Aires (véase Pardinas et al., 2004) y su ocurrencia en sitios arqueológicos y paleontológicos de la misma zona, en distintos momentos del Holoceno, fueron planteados como eventos climáticos más áridos y fríos que los actuales (Prado et al., 1998; Tonni et al., 1999; Goin, 2001; entre otros).

Es importante discutir este análisis con la información paleoambiental disponible del registro palinológico del sitio Gruta del Indio analizado por D’Antoni (1983). Este sitio es un refugio rocoso, ubicado en la localidad Rincón del Atuel en el cause medio del río

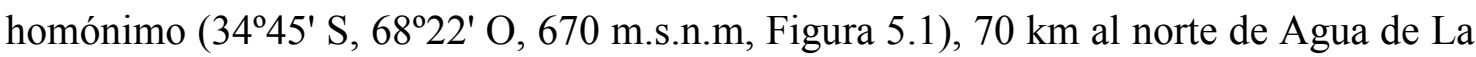
Mula. Si bien Gruta del Indio no se encuentra en la región volcánica de la Payunia, está próxima a ella y se incluye dentro del desierto del Monte, con la presencia de 
micromamíferos propios de este ambiente (ver Tabla 7.8), confiriéndole similitudes con el área del sitio aquí estudiado. A pesar de que D’Antoni $(1980,1983)$ y Markgraf (1983) interpretaron que a partir de $c a .3 \mathrm{ka}{ }^{14} \mathrm{C}$ AP se habría establecido la fisonomía actual de la vegetación en el área circundante a Gruta del Indio, resulta interesante destacar que estos autores advierten un cambio importante en la secuencia polínica entre 1,6 y 1,2 ka ${ }^{14} \mathrm{C}$ AP, caracterizado por un avance de las vegetación patagónica, evidenciado por el aumento de los sistemas de formas de vida (sensu Raunkiaer, 1934) Hemicryptophyta (hierbas andinas y pastos, e.g., Poaceae), Geophyta (hierba perennes, e.g., Cyperaceae) y Chamaephyta (hierbas perennes y subarbustivas, e.g., Adesmia). Asimismo, observaron un retroceso de la vegetación del Monte debido a la disminución de las Nanophanerophyta (arbustos, e.g., Larrea) (D'Antoni, 1980: 97; 1983: 102; Markgraf, 1983: 61). Al respecto, estos autores sugieren que esta disminución pudo deberse a actividades de explotación de leña de jarilla (Larrea) por parte de los grupos humanos que habitaban en el lugar, luego de haber agotado las reservas del bosque ripario (Prosopis y Cercidium) de los alrededores del sitio. Esta hipótesis fue sostenida por el hallazgo realizado por Semper y Lagiglia (1968) de restos de un cierre o empalizada construido por ramas de jarilla en el interior de la Gruta y además, por el caso de que un descenso hídrico y térmico que pudiese eliminar al bosque ripario, tendría que haber afectado también al resto de la comunidad, entre ellas a las jarillas. No obstante, si bien como argumenta el autor, entre el lapso 1,6 y 1,2 $\mathrm{ka}{ }^{14} \mathrm{C}$ AP se mantiene la vegetación del Monte, se advierte un avance de la vegetación patagónica, lo cual podría indicar un ambiente de ecotono entre ambos sistemas, en coincidencia con lo evidenciado en el ensamble de micromamíferos recuperados en Agua de La Mula en similar intervalo temporal.

Otro punto de interés lo establece el hallazgo de dos cráneos asignados a A. spegazzinii, un akondotino sin previo registro fósil en la provincia de Mendoza. Los escasos registros actuales en Mendoza, muestran que se distribuye desde el centro-norte, en ambientes áridos del desierto del Monte y Puna altamente modificados por viñedos y olivares (La Pega, Braun et al., 2000; $2 \mathrm{~km}$ al sur de Villavicencio, Braun et al., 2000; Puesto de Lima, Contreras y Rosi, 1980b), hasta el sur-oeste en un humedal del piedemonte de la región volcánica de la Payunia, incluida en una matriz semiárida de la estepa Patagónica (Reserva Natural Llancanelo, Pardiñas et al. 2011c).

Cabe destacar que hasta fines del año 2010, los registros de $A$. spegazzinii en la provincia de Mendoza eran considerados bajo la forma nominal de Akodon oenos. Sin 
embargo, recientes investigaciones realizadas por Pardiñas et al. (2011c) en base a extensas comparaciones morfológicas y moleculares, plantearon la conespecificidad de ambas entidades (ver Capitulo 5 para una discusión detallada). Por otra parte, muchos restos fósiles fueron identificados como $A$. spegazzinii en varios sitios paleontológicos y arqueológicos del Noroeste argentino: La Angostura $\left(26^{\circ} 56^{\prime} \mathrm{S}, 6^{\circ} 42^{\prime} \mathrm{O}\right.$, Tucumán; Pleistoceno medio-superior; Ortiz, 2001; Ortiz y Pardiñas, 2001), Tafí del Valle (26 51'S, 65²43'O, Tucumán; límite Pleistoceno-Holoceno; Ortiz y Jayat, 2007), Ruinas Jesuíticas de San José de Lules (2654'26"S, 65¹9'30"O, Tucumán; Holoceno tardío; Ortiz, 2000), Las Mascaras $\left(27^{\circ} 00^{\prime} 53 " \mathrm{~S}, 6^{\circ} 44^{\prime} 30^{\prime \prime} \mathrm{O}\right.$, Catamarca; Holoceno tardío; Ortiz et al., 2012) y Las Juntas $\left(28^{\circ} 06^{\prime} 36^{\prime \prime} \mathrm{S}, 6^{\circ} 53^{\prime} 54^{\prime \prime} \mathrm{O}\right.$, Catamarca; límite Pleistoceno-Holoceno; Ortiz et al., 2011a), $835 \mathrm{~km}$ al norte de Agua de La Mula. Finalmente, el registro fósil de A. spegazzinii en el sitio arqueológico Agua de La Mula, en un contexto paleoambiental de transición entre el desierto del Monte y la estepa Patagónica, nos sugiere que esta especie actualmente podría estar presente en este tipo de ambientes, los cuales son frecuentes en la Payunia, siendo una región prácticamente inexplorada (Fernández, 2010).

Estas interpretaciones paleoambientales pueden asociarse con los patrones de ocupaciones humanas observados en estudios previos (i.e., Gil, 2006). En este sentido, el mejoramiento ambiental registrado entre $c a .1,6-1 \mathrm{ka}{ }^{14} \mathrm{C} \mathrm{AP}$, coincide con el período de ocupaciones humanas efectivas (sensu Borrero, 1994, 1995) en La Payunia [ver Capítulo 8 (ítem 8.3) para una discusión detallada].

\subsubsection{Conclusión}

El análisis tafonómico integral nos permite postular que los grupos humanos no habrían intervenido en la acumulación de los micromamíferos del sitio Agua de La Mula. Por el contrario, se plantea que los mismos habrían tenido su origen en la actividad depredadora de aves estrigiformes, siendo T. alba la principal especie involucrada en los niveles 4, 7, 9 y 10 y A. flammeus en los niveles 5 y 6 sin descartar la posible participación de otras especies de lechuzas.

Los agentes y procesos postdepositacionales que tuvieron lugar en la formación del ensamble fueron el pisoteo, la corrosión por humedad del suelo y el óxido de manganeso, los cuales tuvieron mayor incidencia en los niveles 7 y 9 , contribuyendo a alterar la composición original del conjunto cuando fue depositado. Asimismo, la nula 
representación de restos meteorizados indica que tuvieron un enterramiento rápido, luego de haber sido alterados por el pisoteo, tipo de evento habitual en las cuevas o refugios rocosos.

A modo de síntesis la interpretación paleoambiental de la secuencia de micromamíferos de Agua de la Mula puede delinearse de la siguiente manera:

En general las especies identificadas en el registro arqueológico corresponden a aquellas afines al desierto del Monte y que pueden encontrarse hoy en el área, a excepción de algunas formas asociadas a la estepa Patagónica (L. halli y R. auritus). Por este motivo se plantea que posiblemente hubo un avance de la estepa Patagónica, conformando un área ecotonal entre este ambiente y el desierto del Monte durante el intervalo 1,6-1 ka ${ }^{14} \mathrm{C}$ AP, caracterizado por la influencia alternada del anticiclón del Pacífico (precipitaciones invernales) y el anticiclón del Atlántico (precipitaciones estivales), produciendo un clima posiblemente más húmedo y frío que el actual, en coincidencia con la ocupación efectiva de la Payunia. 


\subsection{Agua de los Caballos-1 (ACA-1)}

\subsubsection{Contexto arqueológico}

El sitio arqueológico Agua de los Caballos-1 (ACA-1) fue escavado en enero de 1996, por un equipo dirigido por Adolfo Gil en el contexto de desarrollo de su plan de Tesis Doctoral. El sitio es un alero rocoso que se localiza en la margen izquierda del arroyo homónimo (3522'03" S y 68 18'07" O; 1.025 m.s.n.m.) (Figura 7.15), el cual es poco caudaloso, permanente y recorre el faldeo del Cerro Nevado en dirección noreste (Gil, 2006).

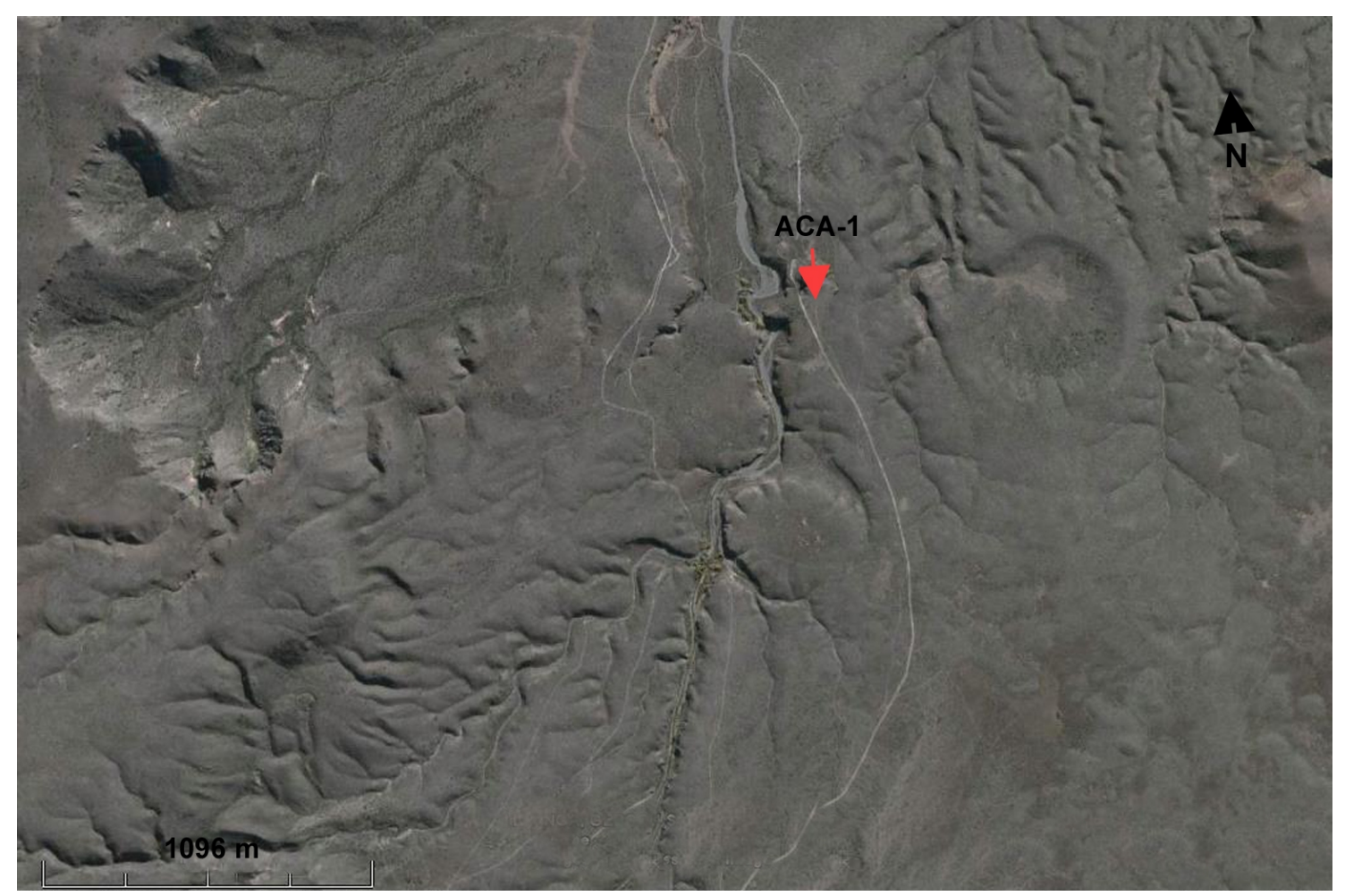

Figura 7.15. Ubicación del sitio arqueológico Agua de Los Caballos-1.

El alero esta constituido de basalto desarrollado en la Formación Coyocho durante el Pleistoceno superior (Nuñez, 1979). Presenta la abertura hacia el este y tiene una superficie de $6.5 \mathrm{~m}^{2}$ (Figura 7.16 Ay B) (Gil, 2006). En las paredes internas y externas se registraron pinturas rupestres denominadas por Lagiglia como "arrastres de dedos", en la gama del rojo, blanco y negro (Gil, 1998).

Durante la excavación, se realizó una cuadrícula de 2 m x 2 m denominada A-1 (Figura 7.16 C). 

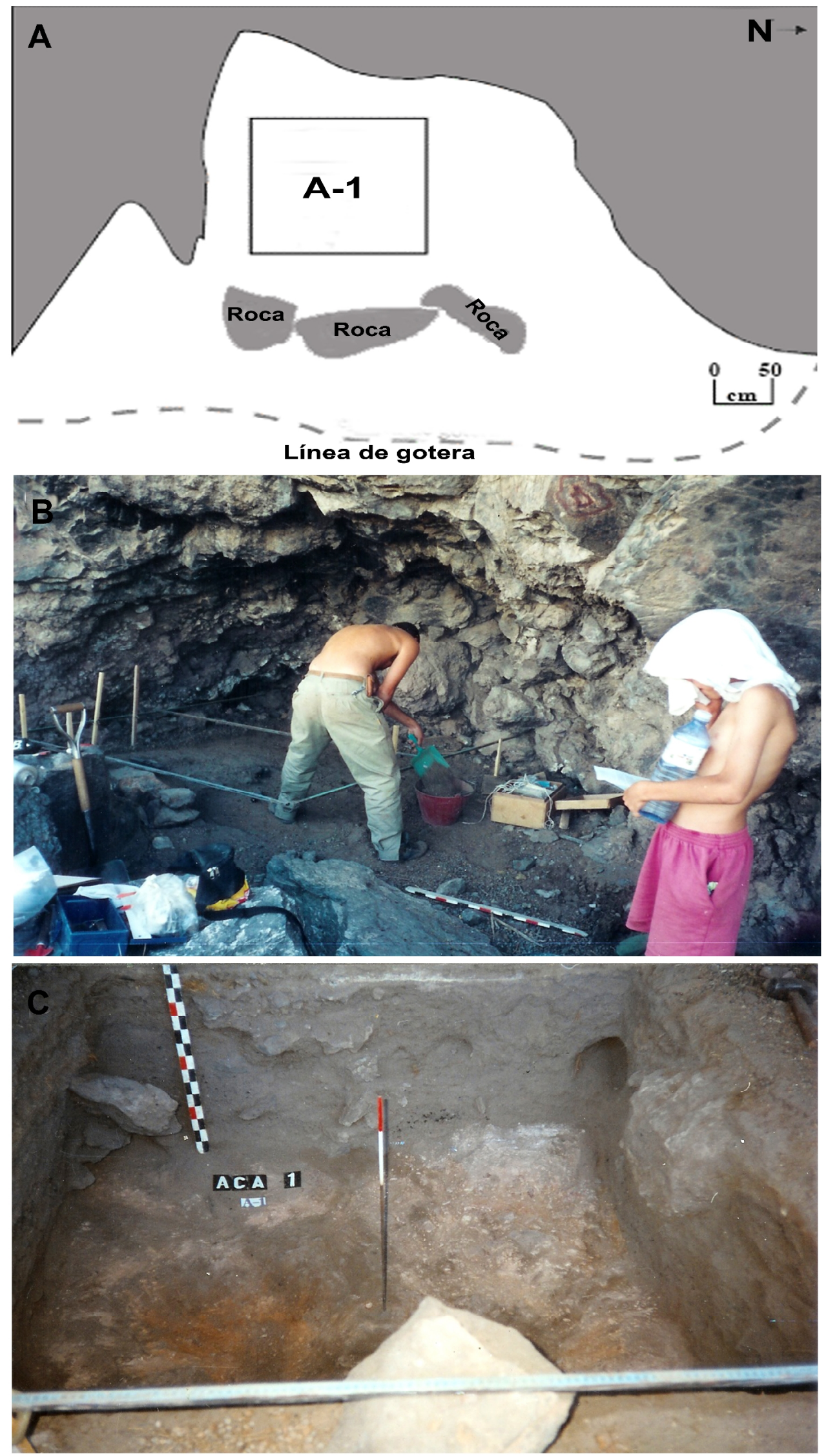

Figura 7.16. Sitio arqueológico ACA-1. A: vista en planta del sitio, tomada de Gil (2006: 48). B: vista del refugio. C: vista de la cuadrícula A-1. 
Se excavaron 17 niveles artificiales de $5 \mathrm{~cm}$ cada uno hasta alcanzar la roca madre. Los hallazgos se recuperaron en zaranda de $2 \mathrm{~mm}$ (Gil, 2006). Cabe destacar que durante la excavación se registraron posibles perturbaciones por actividad de animales fosoriales (Gil, 2006). Los primeros dos niveles consisten en guano compacto (estrato $A$ ) y los cuatro siguientes (estratos $B$ y $B^{\prime}$ ) en sedimento fino con guano de ovicápridos. El resto de los mismos corresponde a un sedimento limo arenoso combinado con algunos clastos grandes y acumulaciones de gramíneas, denominado estrato $C$ (Gil, 2006).

La tabla 7.19 exhibe todos los fechados obtenidos en ACA-1. En relación a esto, Gil (2006) estableció tres unidades cronoestratigráficas (Figura 7.17). En tal sentido, la muestra fechada en $c a$. 250 años AP subyace a los estratos $A, B$ y $B$, por lo que se estimó una cronología reciente (Período Hispano Indígena). El estrato $C$, presenta fechados secuenciales que varían desde $c a$. 1200 años AP hasta $c a$. 250 años AP. Asimismo, la muestra LP-950 perteneciente a una posible estructura de fogón, resultó discordante con los demás fechados de la secuencia. Para interpretar este dato, el autor citado envió otra muestra del mismo nivel pero de otro sector (LP-1037), la cual resultó coherente con el resto de la estratigrafía (640 \pm 60 años AP). Gil (2006) propuso dos posibles explicaciones para dilucidar estas diferencias: perturbación por acción de animales fosoriales que alteraron la asociación de LP-950 o un problema estratigráfico no detectado (e.g., pozos antrópicos para fogones, limpieza del área u otros). En base a la observación de perturbaciones postdepositacionales en el nivel 12, este autor se inclinó por la primera explicación.

\begin{tabular}{|c|c|c|c|c|}
\hline Nivel & Muestras & Código & ${ }^{14}$ C & Calibrado \\
7 & Carbón Vegetal & LP-962 & $250 \pm 60$ & $160-412$ \\
10 & Maíz & AA-26196 & $365 \pm 40$ & $345-478$ \\
12 & Carbón Vegetal & LP-950 & Moderno & \\
12 & Carbón Vegetal & LP-1037 & $640 \pm 60$ & $569-658$ \\
14 & Maíz & AA-26194 & $740 \pm 40$ & $671-716$ \\
16 & Carbón Vegetal & LP-794 & $1240 \pm 70$ & $1084-1248$ \\
\hline
\end{tabular}

Tabla 7.19. Fechados ${ }^{14} \mathrm{C}$ de ACA-1. Tomado de Gil (2006: 50). 


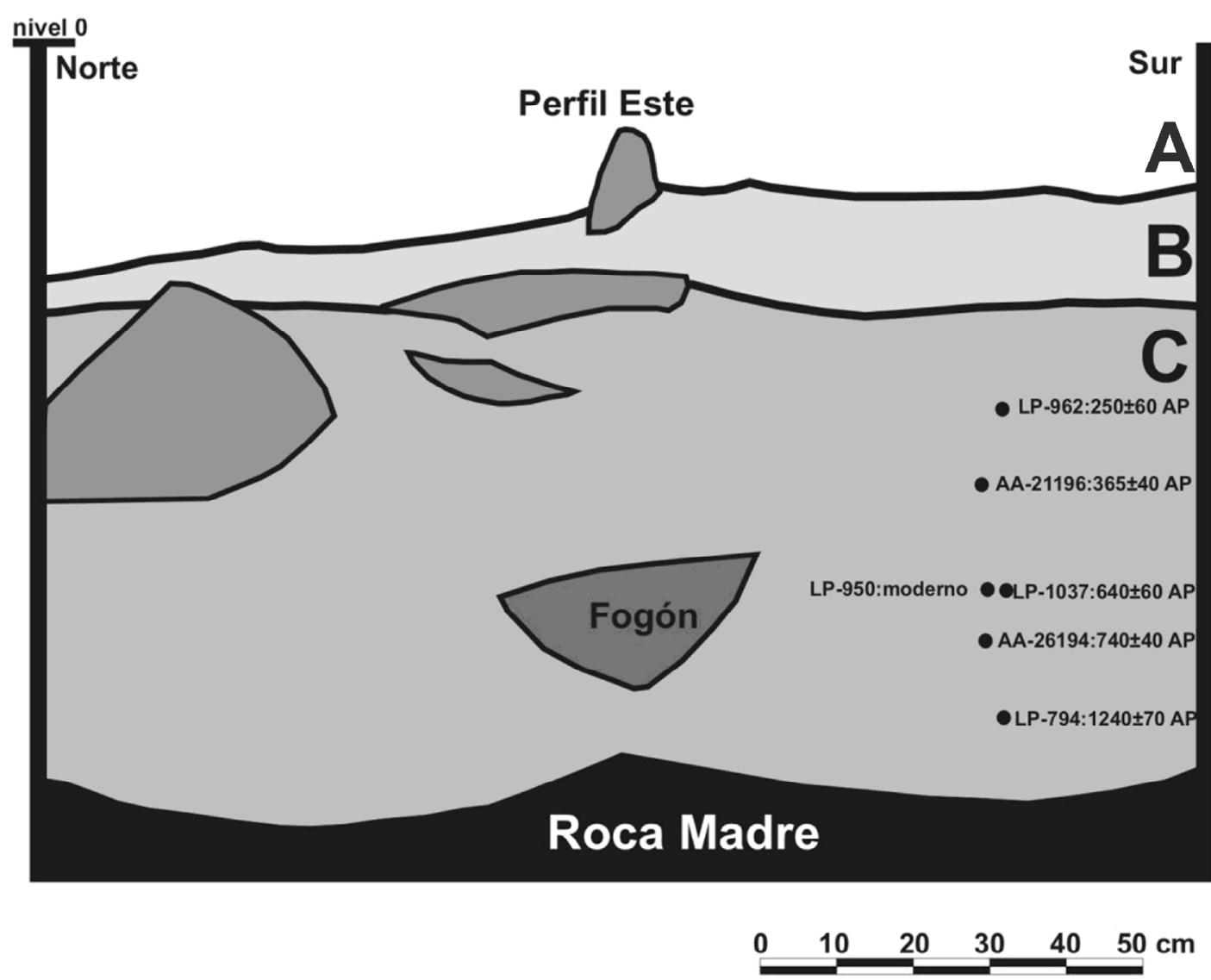

Figura 7.17. Cronoestratigrafía de ACA-1. Esquema inferido para unidad A-1 (perfil Este). Tomado de Gil (2006: 51).

El análisis de los ensambles de microvertebrados exhumados del sitio arqueológico ACA-1, sigue la división cronológica y cultural previamente establecida por Gil (2006). En este sentido, utilizando criterios cronológicos, tecnológicos y densidad de materiales arqueológicos el autor citado dividió la secuencia de ACA-1 en dos componentes culturales. El Componente I (niveles 0 a 6) cronológicamente posterior a ca. $250{ }^{14} \mathrm{C}$ años AP (Período Hispano Indígena, sensu Durán, 1997). Está caracterizado por un predominio de obsidiana (en productos de talla e instrumentos), cerámica de espesores más delgados y un sensible aumento en la diversidad taxonómica (florística y faunística), respecto de los niveles anteriores. El Componente II (niveles 7 a 17) comprendido temporalmente entre ca. 1200 años ${ }^{14} \mathrm{C}$ AP y ca. 250 años ${ }^{14} \mathrm{C}$ AP fue considerado como una sola unidad, por no presentar cambios significativos entre los niveles, aunque sí un marcado contraste con el registro posterior a los 250 años AP (Componente I), exhibiendo una menor diversidad arqueológica y algunas diferencias como el hallazgo de puntas de proyectil completas (Gil, 2006). 
Gil (2006) plantea que ACA-1 presenta un grado de resolución e integridad media (sensu Martínez, 1999). En este sentido, el refugio rocoso exhibió ocupaciones continuas a lo largo de los últimos 1200 años ${ }^{14} \mathrm{C}$ AP, aunque las mismas no han sido extensas, el tipo y diversidad de tareas y la densidad de evidencias muestran que el sitio tampoco fue utilizado en forma efímera (Gil, 2006). Además, existe una afinidad entre estratigrafía, cronología y tipo de evidencia, pero se registraron perturbaciones de animales fosoriales y un fechado ${ }^{14} \mathrm{C}$ anómalo, que no explicaría una alta integridad (Gil, 2006).

En términos generales, debido a la diversidad de elementos arqueológicos y las distintas actividades de las que éstos derivan, Gil (2006) postuló que ACA-1 corresponde a un sitio de actividades múltiples, donde se realizaron en forma casi continua entre $c a .1200$ años ${ }^{14} \mathrm{C}$ AP y 250 años ${ }^{14} \mathrm{C}$ AP, tareas de talla, reacondicionamiento de instrumentos, procesamiento de animales, recolección vegetal y molienda, uso ritual, entre otras; produciéndose algunos cambios del registro en los últimos 250 años ${ }^{14} \mathrm{C}$ AP (Gil, 2006). En relación al registro de cultivos prehispánicos como Zea mays (maíz) y Cucurbita sp. (zapallo), Gil (1997-1998, 2006) propone que si bien fueron consumidos en el lugar evidenciado por la ausencia de granos, fragmentación y asociación con otros ítems tecnológicos y restos alimenticios; no necesariamente se produjeron en las inmediaciones del sitio. Esto se debe a que la proporción de estos restos es mínima respecto a los otros recursos vegetales y cronológicamente han sido fechados entre $c a$. 750 años ${ }^{14} \mathrm{C}$ AP y 350 años ${ }^{14} \mathrm{C}$ AP. Asimismo, en el Componente I (Período Hispano Indígena) se registraron una mayor proporción de estas especies, con el agregado de plantas domésticas no americanas como nueces (Juglans regia) y duraznos (Prunus persica) (Gil, 2006). No obstante, este autor observó que los restos de animales y vegetales sugieren una explotación local de los recursos (Gil, 2006). Una discusión detallada sobre el uso de los cultivos en el sur de Mendoza se encuentra en los trabajos de Gil (1997-1998, 2006) y Neme y Gil (2008a), entre otros.

Para finalizar, los primeros datos sobre el registro faunístico del sitio fueron dados a conocer por Gil (2006). En líneas generales en su análisis se observa un alto porcentaje de especímenes (64\%) no identificados taxonómicamente. El resto corresponden mayormente a mamíferos (principalmente Lama sp., Lama guanicoe, Conepatus sp. y Dasypodidae) y en menor medida aves (principalmente Zenaida auriculata, Eudromia elegans y Rhea pennata) y reptiles (Testudinidae). A excepción de los rheídos y los mamíferos carnívoros, se distribuyeron en forma más o menos continua a los largo de 
toda la secuencia (Gil, 2006). En base a la representación anatómica de los camélidos (Lama sp. y L. guanicoe) en el sitio, Gil (2006) discute algunas tendencias sobre la funcionalidad del mismo considerando la información por grupos de niveles. En tal sentido, las partes más registradas (ca. 50\%) son los extremos distales de los miembros, cuyo valor económico es bajo; en abundancia siguen los especimenes del cráneo, pelvis y un fragmento del extremo proximal (Gil, 2006). El autor citado observó que a pesar de que no hubo grandes variaciones entre los distintos grupos de niveles, se destaca que los especimenes de mayor valor económico se hallaron en los más recientes (Componente I). Por su parte, Giardina (2010) propuso un origen múltiple para los ensambles avifaunísticos de ACA1, documentando evidencias de acción de mamíferos carnívoros, aves rapaces y de grupos humanos.

\subsubsection{Metodología}

Se estudiaron tafonómicamente y taxonómicamente cada componente cultural por separado y dado que las muestras fueron escasas también se analizaron en forma conjunta. Debido a la cercanía con el sitio arqueológico Agua de La Mula, el parámetro actualístico corresponde al analizado en aquel sitio [Localidad Agua de La Mula (ver apéndice)].

\subsubsection{Resultados}

\subsubsection{Análisis tafonómico}

El $24,1 \%$ de todos los especímenes exhumados de ACA-1 sufrieron algún tipo de corrosión digestiva, los cuales se concentraron en la categoría ligera y solo en algunos casos en las categorías moderada y fuerte. Precisamente en el Componente I fue del 21,7\% y en el Componente II alcanzó el 25\% del total. En la tabla 7.20 se exhibe la cantidad de restos con marcas de corrosión teniendo en cuenta aquellos contemplados en la propuesta metodológica realizada por Andrews (1990) y Fernández-Jalvo y Andrews (1992). 


\begin{tabular}{|c|c|c|c|c|c|c|c|c|c|c|}
\hline \multirow{3}{*}{ ACA-1 } & \multicolumn{10}{|c|}{ Clases de digestión sensu Andrews (1990) } \\
\hline & \multicolumn{2}{|c|}{ Ausente } & \multicolumn{2}{|c|}{ Ligera } & \multicolumn{2}{|c|}{ Moderada } & \multicolumn{2}{|c|}{ Fuerte } & \multicolumn{2}{|c|}{ Extrema } \\
\hline & $(\mathrm{N})$ & $\%$ & $(\mathrm{~N})$ & $\%$ & $(\mathrm{~N})$ & $\%$ & $(\mathrm{~N})$ & $\%$ & $(\mathrm{~N})$ & $\%$ \\
\hline \multicolumn{11}{|l|}{ Componente I } \\
\hline \multicolumn{11}{|l|}{ Digestión dentaria } \\
\hline Incisivos in situ & 1 & 100 & - & - & - & - & - & - & - & - \\
\hline Incisivos aislados & - & - & - & - & - & - & - & - & - & - \\
\hline Incisivos Total & 1 & 100 & - & - & - & - & - & - & - & - \\
\hline Molares in situ & 1 & 100 & - & - & - & - & - & - & - & - \\
\hline Molares aislados & - & - & - & - & - & - & - & - & - & - \\
\hline Molares Total & 1 & 100 & - & - & - & - & - & - & - & - \\
\hline \multicolumn{11}{|l|}{ Digestión Postcraneal } \\
\hline Fémur (segmento proximal) & 2 & 40 & 2 & 40 & 1 & 20 & - & - & - & - \\
\hline Húmero (segmento distal) & - & - & - & - & - & - & 1 & 100 & - & - \\
\hline \multicolumn{11}{|l|}{ Componente II } \\
\hline \multicolumn{11}{|l|}{ Digestión dentaria } \\
\hline Incisivos in situ & - & - & 2 & 100 & - & - & - & - & - & - \\
\hline Incisivos aislados & 4 & 100 & - & - & - & - & - & - & - & - \\
\hline Incisivos Total & 4 & 66,7 & 2 & 33,3 & - & - & - & - & - & - \\
\hline Molares in situ & 5 & 38,5 & 8 & 61,5 & - & - & - & - & - & - \\
\hline Molares aislados & - & - & - & - & - & - & - & - & - & - \\
\hline Molares Total & 5 & 38,5 & 8 & 61,5 & - & - & - & - & - & - \\
\hline Digestión Postcraneal & & & & & & & & & & \\
\hline Fémur (segmento proximal) & 3 & 33,3 & 4 & 44,4 & 2 & 22,2 & - & - & - & - \\
\hline Húmero (segmento distal) & 1 & 50 & 1 & 50 & - & - & - & - & - & - \\
\hline
\end{tabular}

Tabla 7.20. Representación de las distintas categorías de corrosión digestiva en micromamíferos de los componentes arqueológicos de ACA-1.

Dado que los restos son demasiado exiguos para su posible comparación en cada ítem, se decidió analizarlos en forma integral. En el Componente I no se registró dientes con evidencias de digestión, aunque si en los elementos postcraneales (Figura 7.18 A). Por su parte, en el Componente II el 52,6\% de los restos dentarios se encontraron digeridos correspondientes a la categoría ligera y el 54,5\% de los elementos postcraneales presentaron huellas de corrosión digestiva principalmente en la categoría ligera y en menor medida en la categoría moderada (Figura 7.18 B). 


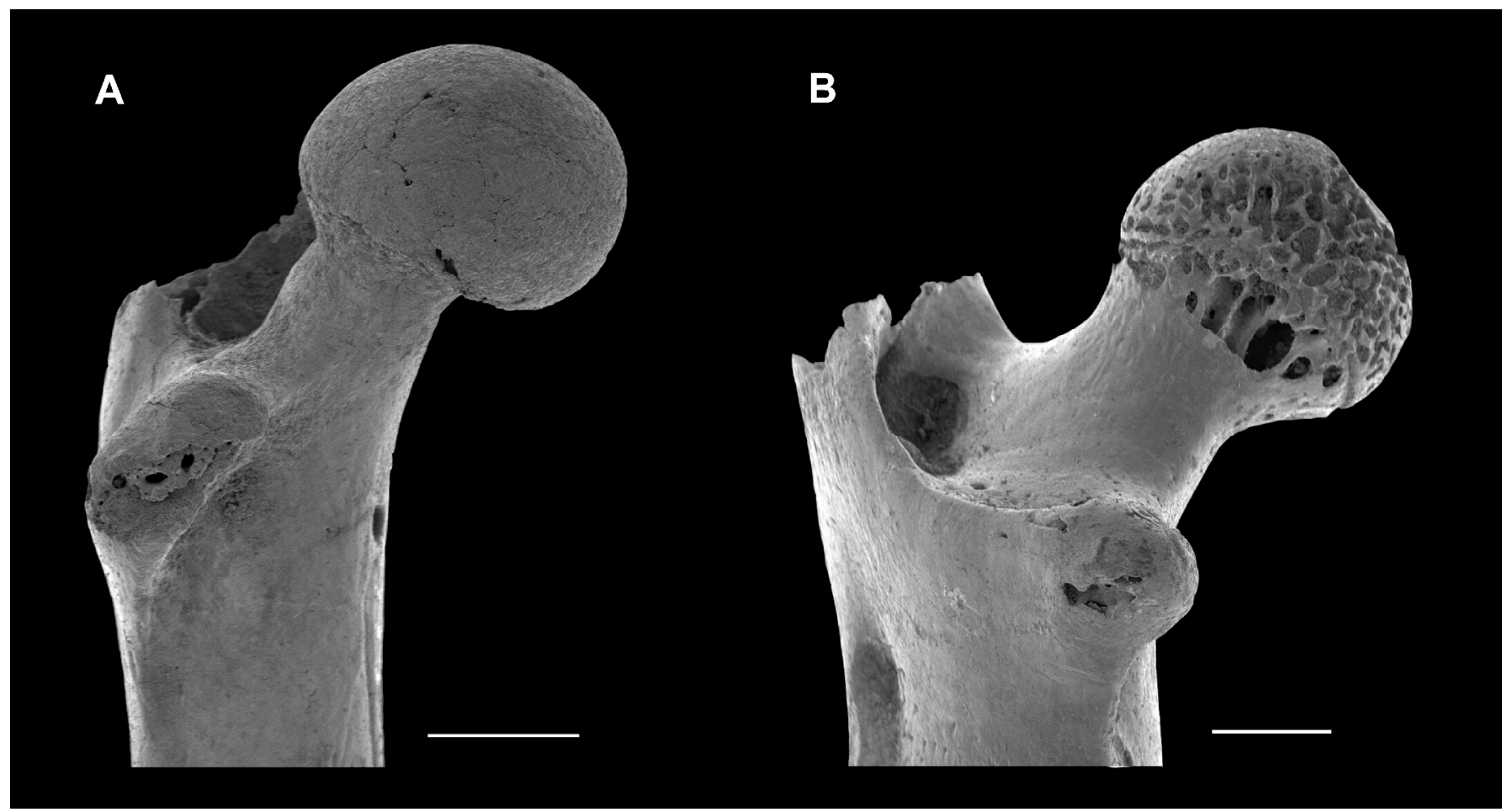

Figura 7.18. Elementos postcraneales con evidencias de distintos tipos de corrosión digestiva. A: fémur de Sigmodontinae con marcas de corrosión ligera en la epífisis (Componente I, Nivel 6). B: fémur de Caviidae con marcas de corrosión modera en la epífisis (Componente II, Nivel 14). Escalas: $1 \mathrm{~mm}$.

La abundancia relativa promedio en ambos componentes fue baja, siendo levemente mayor en el Componente II. En los dos componentes se observa un patrón similar de representación de partes esqueletarias, donde los elementos más abundantes fueron los maxilares, pelvis, fémur y tibia (Tabla 7.21 y Figura 7.19).

El $56,3 \%$ de todos los especímenes recuperados de ACA-1 estaban fracturados. A su vez, el Componente I (86,9\%) presentó mayor porcentaje de fractura que el Componente II $(45,3 \%)$. 


\begin{tabular}{|l|cc|cc|}
\hline Elementos / Procedencia & \multicolumn{2}{|c|}{ Componente I } \\
MNE & $\begin{array}{c}\text { Abundancia } \\
\text { relativa }\end{array}$ & \multicolumn{2}{c|}{ Componente II } \\
MNE & $\begin{array}{c}\text { Abundancia } \\
\text { relativa }\end{array}$ \\
\hline Premaxilar & - & - & 3 & 15 \\
Maxilar & 3 & 25 & 8 & 40 \\
Mandíbula & 1 & 8,3 & 6 & 30 \\
Incisivos aislados & - & - & 4 & 10 \\
Molares aislados & - & - & - & - \\
Vértebras & 2 & 1,1 & 12 & 4 \\
Costillas & - & - & - & - \\
Escápula & 1 & 8,3 & 2 & 10 \\
Húmero & 1 & 8,3 & 2 & 10 \\
Cúbito & - & - & - & - \\
Radio & 1 & 8,3 & - & - \\
Pelvis & 7 & 58,3 & 4 & 20 \\
Fémur & 5 & 41,6 & 10 & 50 \\
Tibia & 2 & 16,6 & 8 & 40 \\
Metapodio & - & - & 1 & 0,5 \\
Calcáneo & - & - & - & - \\
Astrágalo & - & - & - & - \\
Falanges & - & - & 3 & 0,5 \\
Hueso largo indet. & - & - & 1 & \\
\hline Total & 23 & 175,8 & 64 & 230 \\
Promedio & & 9,8 & & 12,8 \\
\hline
\end{tabular}

Tabla 7.21. Número mínimo de elementos (MNE) y abundancia relativa de los ensambles de micromamíferos por componentes de ACA-1 y en la muestra total.

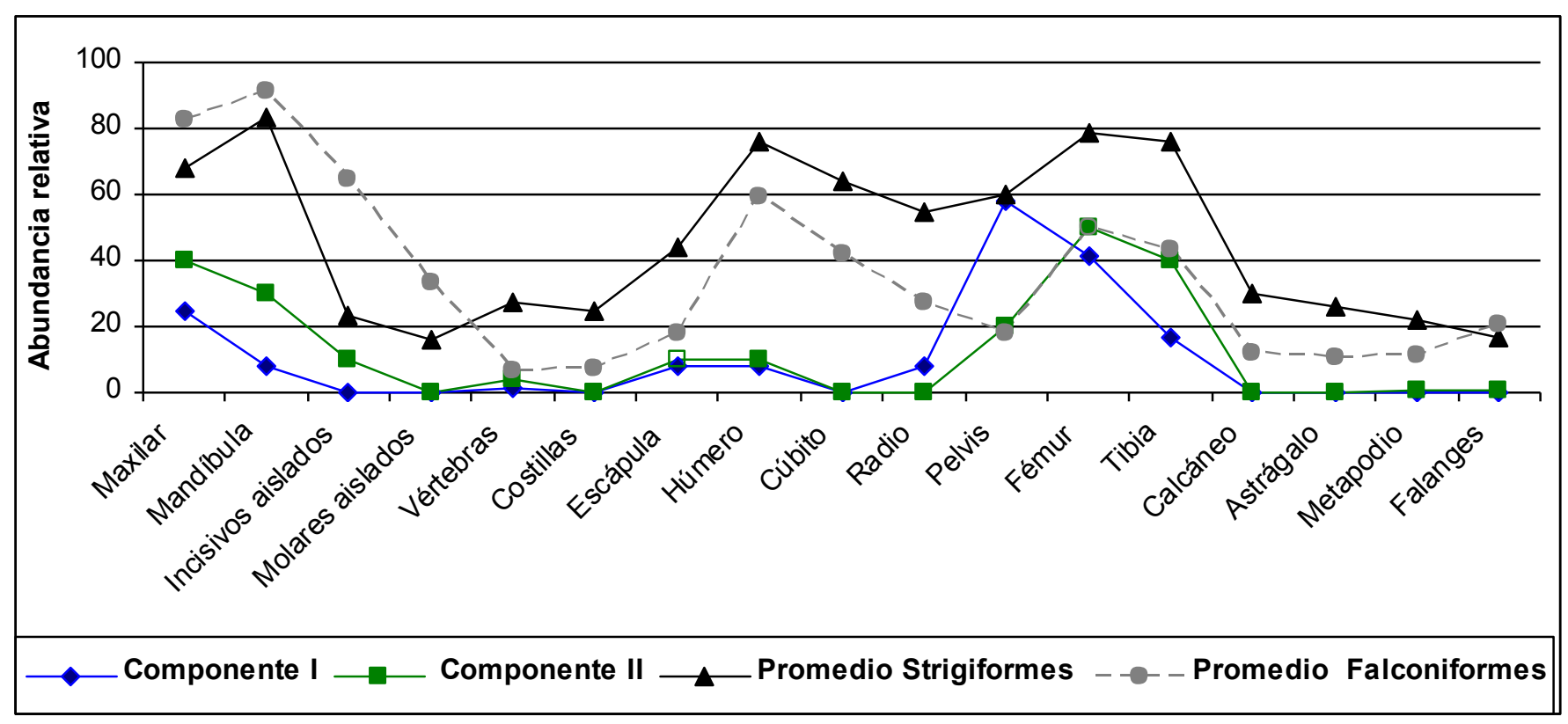

Figura 7.19. Valores de abundancia relativa de los diferentes elementos anatómicos de los componentes de ACA-1, comparados con el promedio de Strigiformes y Falconiformes realizado por Andrews (1990). 
La tabla 7.22 muestra los distintos tipos de fractura en los elementos contemplados en la metodología propuesta por Andrews (1990) y Andrews y Fernández (1992). No se recuperaron cráneos completos en ninguno de los dos componentes; la mayor parte de ellos correspondieron a maxilares sin arcos zigomáticos y a fragmentos de premaxilares y maxilares. Asimismo, no se registraron pérdidas dentarias en el Componente I, aunque si se encontraron entre los premaxilares y maxilares del Componente II. En líneas generales no se hallaron diferencias importantes entre ambos componentes, solo un leve aumento de los niveles de ruptura en el Componente I.

Se registraron escasas mandíbulas en toda la muestra arqueológica como para realizar un análisis detallado, no obstante, se destaca que las mismas se encontraron muy fragmentadas con elevada pérdida de molares en ambos componentes, hallándose una sola mandíbula completa recuperada del Componente II. A pesar de lo exiguo de la muestra, se puede observar que la mayoría de los molares e incisivos se encontraron completos.

El nivel de fractura de los elementos postcraneales fue alto, de modo que solo el $25 \%$ de los húmeros, fémures y tibias estaban completos. También se observó una marcada preservación diferencial de los segmentos proximales del fémur. Por otra parte, los metapodios y falanges estaban completos y se registró una sola vértebra fracturada. No obstante, los elementos más frágiles como las cinturas presentaron un alto grado de ruptura (Tabla 7.23$)$.

Además, se destaca que una mayor proporción de los elementos postcraneales rotos recuperados de ambos componentes presentaron superficies de fracturas con ángulos agudos y bordes ásperos (Tabla 7.24). 


\begin{tabular}{|c|c|c|c|c|}
\hline & \multicolumn{2}{|c|}{ Componente I } & \multicolumn{2}{|c|}{ Componente II } \\
\hline & $\mathrm{N}$ & & $\mathrm{N}$ & $\%$ \\
\hline \multicolumn{5}{|l|}{ Fractura de cráneos } \\
\hline Cráneos completos & - & - & - & - \\
\hline Maxilares con arcos zigomáticos & - & - & 1 & 12,5 \\
\hline Maxilares sin arcos zigomáticos & 2 & 66,6 & 6 & 75 \\
\hline Fragmentos menores & 1 & 33,3 & 1 & 12,5 \\
\hline Pérdida de molares de maxilares & - & - & 11 & 57,9 \\
\hline Pérdida de incisivos de premaxilares & - & - & 3 & 75 \\
\hline \multicolumn{5}{|l|}{ Fractura de mandíbulas } \\
\hline Mandíbulas completas & - & - & 1 & 20 \\
\hline Mandíbulas con rama ascendente rota & - & - & - & - \\
\hline Mandíbulas sin rama ascendente & - & - & - & - \\
\hline Mandíbulas sin rama ascendente y borde inferior roto & 1 & 100 & 4 & 80 \\
\hline Pérdida de molares de las mandíbulas & 2 & 66,6 & 7 & 63,6 \\
\hline Pérdida de incisivos de la mandíbulas & - & - & 3 & 75 \\
\hline \multicolumn{5}{|l|}{ Fractura de dientes } \\
\hline Molares rotos in situ & - & - & - & - \\
\hline Molares aislados rotos & - & - & - & - \\
\hline Total de molares rotos & - & - & - & - \\
\hline Incisivos rotos in situ & - & - & - & - \\
\hline Incisivos aislados rotos & - & - & 1 & 25 \\
\hline Total de incisivos rotos & - & - & 1 & 16,7 \\
\hline \multicolumn{5}{|l|}{ Fractura de Postcráneo } \\
\hline \multicolumn{5}{|l|}{ Fémur } \\
\hline Completo & 1 & 20 & 2 & 28,6 \\
\hline Segmento proximal & 4 & 80 & 5 & 71,4 \\
\hline Diáfisis & - & - & - & - \\
\hline Segmento distal & - & - & - & - \\
\hline \multicolumn{5}{|l|}{ Húmero } \\
\hline Completo & - & - & 1 & 100 \\
\hline Segmento proximal & - & - & - & - \\
\hline Diáfisis & - & - & - & - \\
\hline Segmento distal & 1 & 100 & - & - \\
\hline \multicolumn{5}{|l|}{ Tibia } \\
\hline Completo & - & - & - & - \\
\hline Segmento proximal & 1 & 50 & - & - \\
\hline Diáfisis & - & - & 1 & 16,7 \\
\hline Segmento distal & 1 & 50 & 5 & 83,3 \\
\hline \multicolumn{5}{|l|}{ Cúbito } \\
\hline Completo & - & - & - & - \\
\hline Segmento proximal & - & - & - & - \\
\hline Diáfisis & - & - & - & - \\
\hline Segmento distal & - & - & - & - \\
\hline
\end{tabular}


Tabla 7.22. Fractura de elementos craneales, dentarios y postcraneales, para los micromamíferos recuperados de los componentes de ACA-1.

\begin{tabular}{|l|cc|cc|}
\hline Fracturas postcraneal & Componente & I & Componente & II \\
(otros elementos) & $\mathrm{N}$ & $\%$ & $\mathrm{~N}$ & $\%$ \\
\hline Vértebras & - & - & 1 & 12,5 \\
Escápula & 1 & 100 & 2 & 100 \\
Radio & 1 & 100 & - & - \\
Pelvis & 7 & 100 & 3 & 75 \\
Metapodio & - & - & - & - \\
Falanges & - & - & - & - \\
\hline
\end{tabular}

Tabla 7.23. Fractura del resto de los elementos postcraneales de micromamíferos recuperados de los componentes de ACA-1.

\begin{tabular}{|l|cc|cc|cr|}
\hline Tipos de Fractura en postcraneal & \multicolumn{2}{|c|}{ Componente I } & \multicolumn{2}{|c|}{ Componente II } & \multicolumn{2}{|c|}{ Muestra Total } \\
& NISP & $\%$ & NISP & $\%$ & NISP & $\%$ \\
\hline Fractura irregular con bordes & 12 & 75 & 16 & 84,2 & 28 & 80 \\
angulosos y ásperos & & & & & & \\
\hline $\begin{array}{l}\text { Fractura espiral o longitudinales } \\
\text { con bordes suaves }\end{array}$ & 4 & 25 & 3 & 15,8 & 7 & 20 \\
\hline
\end{tabular}

Tabla 7.24. Tipos de fractura para los elementos postcraneales de micromamíferos recuperados por componentes y en la muestra total de ACA-1.

Los valores obtenidos a partir de los índices calculados se exhiben en la tabla 7.25. En el Componente I los dos índices que evalúan la relación entre elementos postcraneales y craneales sugieren una mejor preservación de los primeros, mientras que en el Componente II se observa una disminución de los elementos postcraneales. El índice que valora la relación entre elementos distales y proximales de los miembros indica una pérdida de elementos proximales en ambos componentes. En cuanto a los índices de pérdida dentaria, se aclara que debido a datos insuficientes, solo se pudo calcular el que evalúa la proporción de molares aislados en el Componente II, el cual mostró que la mayor parte de los molares se desprendieron de sus alvéolos.

Los índices IT e IP indicaron una mayor proporción de microvertebrados de menor tamaño y solitarios, aunque se destaca que en el Componente II, tanto estos grupos de microvertebrados como los coloniales o agrupados tuvieron una representación más pareja. 


\begin{tabular}{|l|c|c|}
\hline & Componente I & Componente II \\
\hline Postcráneo / Cráneo & & \\
{$[(\mathrm{f}+\mathrm{t}+\mathrm{h}+\mathrm{r}+\mathrm{c}) \times 16 /(\mathrm{mb}+\mathrm{mx}+\mathrm{m}) \times 10] \times 100$} & 360 & 228 \\
{$[(\mathrm{~h}+\mathrm{f}) /(\mathrm{mb}+\mathrm{mx})] \times 100$} & 150 & 85,7 \\
Elementos distales / proximales & 50 & 66,7 \\
{$[(\mathrm{t}+\mathrm{r}) /(\mathrm{f}+\mathrm{h})]$ x 100 } & & \\
Pérdida de dientes & - & 150 \\
$\%$ molares aislados & - & - \\
$\%$ incisivos aislados & 200 & 120 \\
Índice de Tamaño (IT) & 50 & 83,3 \\
Índice de Predictibilidad (IP) & & \\
\hline
\end{tabular}

Tabla 7.25. Valores de los índices calculados en los componentes de ACA-1.

Referencias: f: fémur; t: tibia; h: húmero; r: radio; c: cúbito; mx: maxilar; mb: mandíbula; m: molar.

Por otra parte, se destaca que en ninguno de los dos componentes se registraron restos termoalterados ni con marcas de corte. Como se ilustra en la figura 7.20, un bajo porcentaje de los restos exhibieron evidencias de meteorización. Asimismo, si bien no se observa una diferencia marcada entre los porcentajes de los especímenes afectados, en el Componente II se hallaron algunos restos en el estadio de meteorización III.

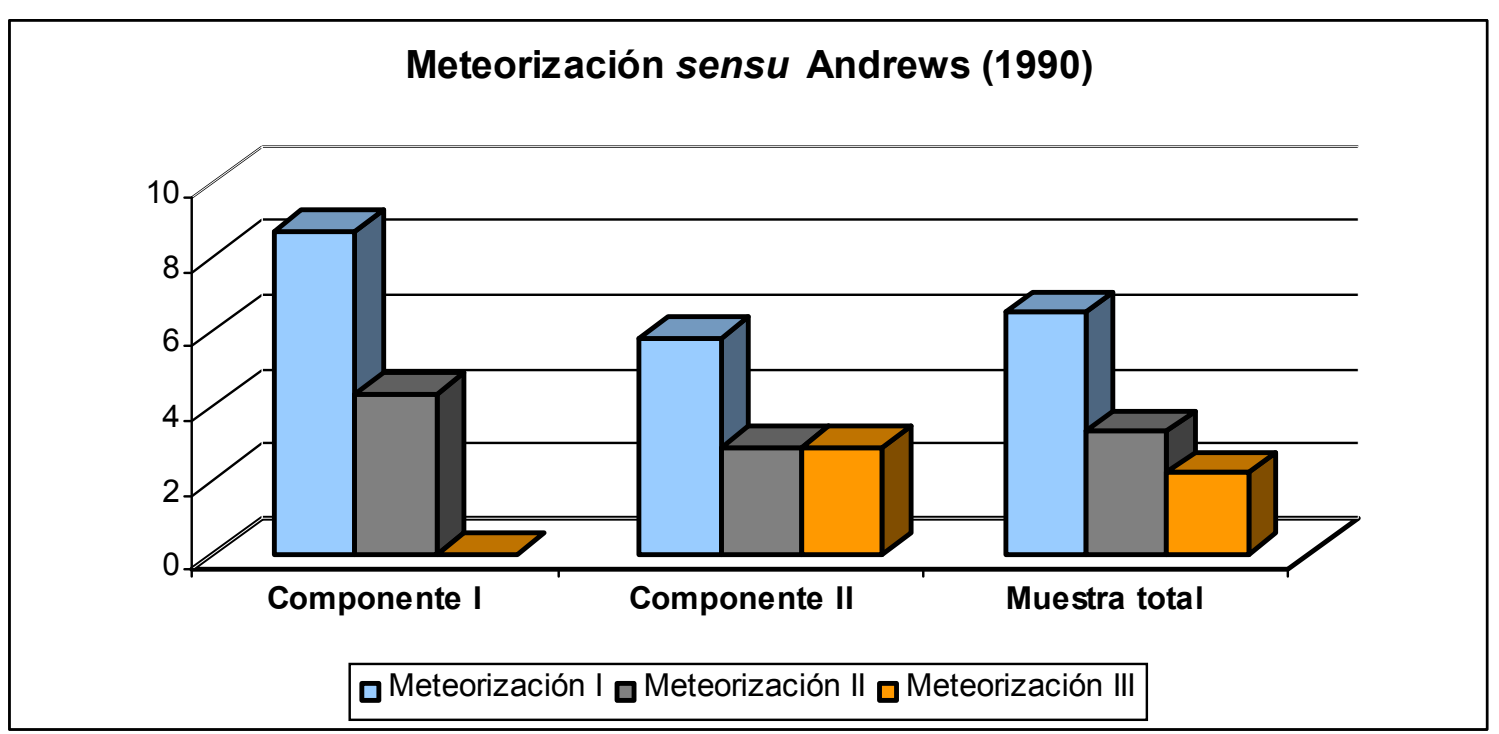

Figura 7.20. Porcentajes de restos en estadios de meteorización sensu Andrews (1990) por componentes y en la muestra total de ACA-1.

Por otro lado, se registró un solo resto óseo con marcas de raíces (i.e., Sphenoichnia), correspondiente al Componente II. Asimismo, no se recuperaron especímenes con manchas de óxido de manganeso en toda la muestra. No obstante, el 5,4\% de todos los 
restos recuperados de ACA-1 mostró evidencias de corrosión sedimentaria, siendo el Componente I (13\%) más afectado que el Componente II $(2,9 \%)$. No se hallaron evidencias de redondeamiento en los extremos y protuberancias de los restos óseos y dentarios.

En lo que concierne a la aves todos los restos se recuperaron en el Componente I y dado lo exiguo de la muestra $(\mathrm{N}=3)$ no se pudo realizar un análisis detallado como se propuso en el capítulo de Metodología. Los especímenes corresponden a una porción distal más diáfisis de cúbito asignado a $Z$. auriculata con fractura redondeada; un húmero completo determinado como Oscinae indeterminado y un fragmento de pélvis (íleon y acetábulo) indeterminada, con una marca de roedor. En ninguno de los casos se registraron modificaciones antrópicas ni acción digestiva de aves rapaces.

\subsubsection{Asociación de microvertebrados de las muestras actuales}

Como se mencionó en la metodología (sección 7.3.2) el parámetro actualístico utilizado fue el mismo que el del sitio Agua de La Mula, por ende, para un datalle de la misma véase sección 7.2.3.2

\subsubsection{Asociación de los microvertebrados de las muestras arqueofaunísticas}

Se analizaron 97 especímenes, 26 correspondientes al Componente I y 71 al Componente II. La información correspondiente a las abundancias relativas de los microvertebrados por componente de la muestra arqueofaunística (expresadas como valores de NISP, MNE y MNI) se detalla en la tabla 7.26. 


\begin{tabular}{|c|c|c|c|c|c|c|c|c|c|}
\hline \multirow[t]{2}{*}{ Taxones / Procedencia } & \multirow[b]{2}{*}{ NISP } & Componente & \multirow{2}{*}{$\begin{array}{l}\text { I } \\
\mathrm{MNI}\end{array}$} & \multirow[b]{2}{*}{ NISP } & \multirow{2}{*}{$\begin{array}{c}\text { Componente } \\
\mathrm{MNE}\end{array}$} & \multirow{2}{*}{$\begin{array}{l}\text { II } \\
\text { MNI }\end{array}$} & \multicolumn{3}{|c|}{ Muestra total } \\
\hline & & MNE & & & & & NISP & MNE & MNI \\
\hline Amphibia / Anura indet. & - & - & - & 1 & 1 & 1 & 1 & 1 & 1 \\
\hline Reptilia / Sauria indet. & & & & 1 & 1 & 1 & 1 & 1 & 1 \\
\hline Aves indet. & 1 & 1 & 1 & - & - & - & 1 & 1 & 1 \\
\hline $\begin{array}{l}\text { Passeriformes / Oscinae indet. } \\
\text { Columbiformes }\end{array}$ & 1 & 1 & 1 & - & - & - & 1 & 1 & 1 \\
\hline $\begin{array}{l}\text { Zenaida auriculata } \\
\text { Mammalia }\end{array}$ & 1 & 1 & 1 & - & - & - & 1 & 1 & 1 \\
\hline $\begin{array}{l}\text { Rodentia indet. } \\
\text { Ctenomyidae }\end{array}$ & 3 & 3 & 1 & 20 & 16 & 1 & 23 & 19 & 2 \\
\hline Ctenomys sp. & - & - & - & 2 & 2 & 1 & 2 & 2 & 1 \\
\hline Caviidae indet. & 10 & 10 & 2 & 24 & 23 & 2 & 34 & 33 & 4 \\
\hline Microcavia australis & - & - & - & 1 & 1 & 1 & 1 & 1 & 1 \\
\hline Galea leucoblephara & - & - & - & 1 & 1 & 1 & 1 & 1 & 1 \\
\hline Cricetidae / Sigmodontinae indet. & 9 & 9 & 2 & 19 & 19 & 2 & 28 & 28 & 4 \\
\hline Phyllotis xanthopygus & - & - & - & 1 & 1 & 1 & 1 & 1 & 1 \\
\hline Graomys griseoflavus & 1 & 1 & 1 & - & - & - & 1 & 1 & 1 \\
\hline Eligmodontia sp. & - & - & - & 1 & 1 & 1 & 1 & 1 & 1 \\
\hline Total & 26 & 26 & 9 & 70 & 65 & 11 & 96 & 91 & 20 \\
\hline Riqueza & & & 4 & & & 7 & & & 10 \\
\hline $\mathbf{H}^{\prime}$ & & & 1,321 & & & 2,02 & & & 2,26 \\
\hline Equitatividad & & & 0,953 & & & 0,971 & & & 0,9426 \\
\hline
\end{tabular}

Tabla 7.26. Composición taxonómica de los ensambles de microvertebrados de ACA-1 (expresada en NISP, MNE y MNI).

\subsection{Muestra arqueofaunística total}

El ensamble total de la muestra arqueofaunística está dominado por micromamíferos.

Entre ellos, igualmente representados se encuentran los roedores histricognatos ( $G$. leucoblephara, M. australis y Ctenomys sp.) y los roedores sigmodontinos ( $G$. griseoflavus, P. xanthopygus y Eligmodontia sp.). Con porcentajes menores, un saurio indeterminado, un anuro indeterminados y las aves (Z. auriculata y Oscinae indeterminado) completan el elenco de los microvertebrados (Figura 7.21).

El índice de diversidad de Shannon arrojó un valor de 2,26 (Tabla 7.26). El cual fue similar al de la muestra actual. 


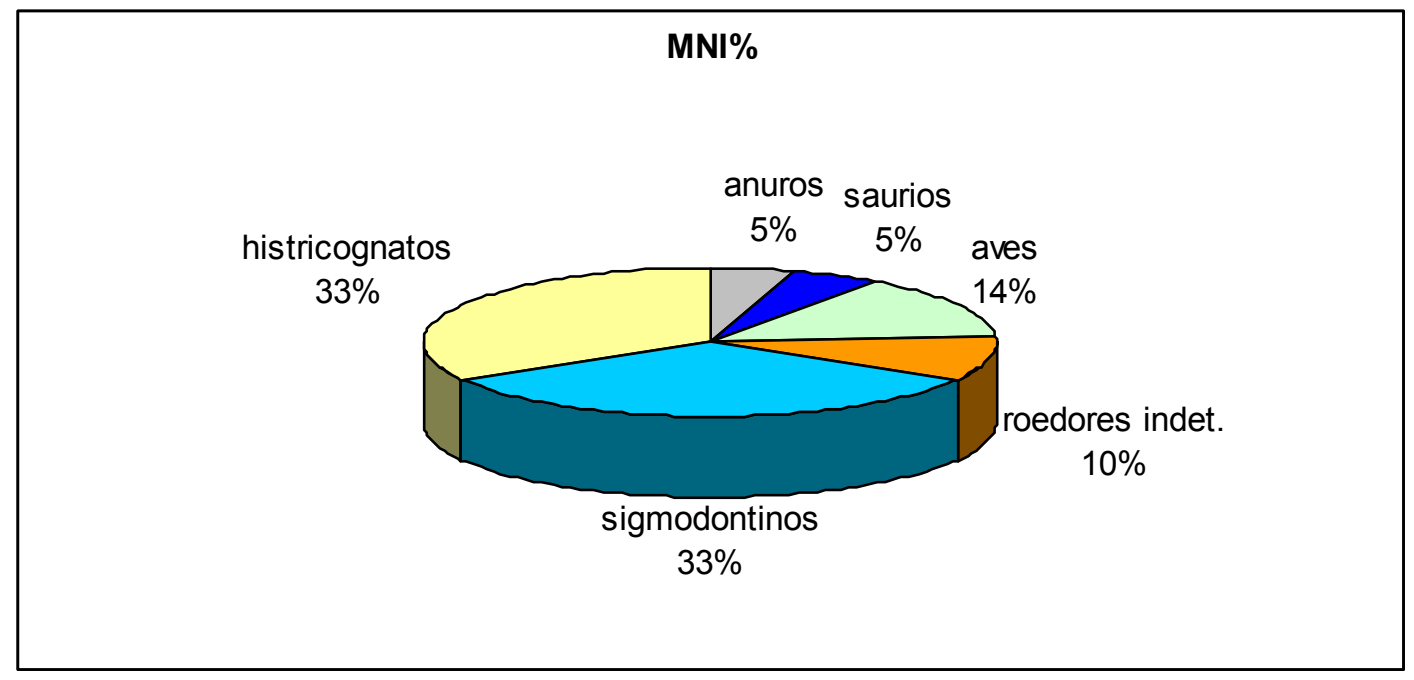

Figura 7.21. Distribución del MNI\% por grupos de microvertebrados de la muestra arqueofaunística total.

\subsection{Componente I ( 250 años $\left.{ }^{14} C A P\right)$}

El ensamble está integrado principalmente por micromamíferos, siendo los roedores sigmodontinos (G. griseoflavus) y los roedores cávidos indeterminados los grupos registrados. Con menor frecuencia se encuentran las aves, las cuales corresponden a un colúmbido (Z. auriculata), un paseriforme (Oscinae indeterminado) y un resto indeterminado. El índice de diversidad de Shannon arrojó un valor de 1,321 (Tabla 7.26).

7.3.3.3.3. Componente II (1200 - 250 años $\left.{ }^{14} C A P\right)$

Este ensamble también está integrado esencialmente por micromamíferos. Los roedores histricognatos (Ctenomys sp., Microcavia australis y G. leucoblephara) son los más representados, seguidos por los roedores sigmodontinos ( $P$. xanthopygus $\mathrm{y}$ Eligmodontia sp). Con abundancias menores se encuentran un saurio y un anuro indeterminados. Asimismo, en este componente se observó mayor riqueza taxonómica. Tanto el índice de diversidad de Shannon $(2,02)$ como la riqueza taxonómicas fueron mayores que las del Componente I (Tabla 7.26).

\subsubsection{Discusión}




\subsubsection{Interpretación tafonómica}

La ausencia de marcas de corte y de restos quemados, indican que los grupos humanos no participaron en la génesis de los ensambles de microvertebrados de ACA-1. Asimismo, el registro de evidencias de corrosión digestiva, principalmente ligera, coincide con los estudios actualísticos realizados en base a egagrópilas de aves Strigiformes (Andrews, 1990; Gómez, 2007). Sin embargo, los altos niveles de fractura, los patrones de abundancias relativas de partes esqueletales y los valores de los índices, no coinciden exactamente con los valores obtenidos por Andrews (1990). Posiblemente, procesos postdepositacionales comunes en sitios de cuevas, tales como el pisoteo pudieron alterar la composición original de los ensambles. Esta interpretación se apoya en que los elementos más chicos (i.e, vértebras, metapodios y falanges) se encontraron completos, tal como fuera demostrado por los estudios experimentales realizados por Andrews (1990).

No obstante, los ensambles parecen no haber sido afectados o fueron escasamente afectados, por otros tipos de procesos postdepositaciones como meteorización, acción de raíces, oxido de manganeso, abrasión por transporte hídrico, desplazamientos y rozamientos de los restos contra el sedimento (Korth, 1979; Andrews, 1990; Fernández-Jalvo y Andrews, 2003), indicando buena preservación y rápido enterramiento, previamente a ser afectados por el pisoteo. Únicamente, como característica distintiva del contexto postdepositacional se encontraron algunos restos con evidencias de corrosión sedimentaria -mayoritariamente en el Componente Iproducto de la humedad del suelo (Andrews, 1990).

Finalmente, no se encontraron esqueletos articulados de Ctenomys sp., que pudiera explicar algún tipo de muerte natural en el sitio, teniendo en consideración las evidencias registradas por Gil (2006) de perturbaciones de animales fosoriales en el Componente II.

\subsubsection{Interpretación paleoambiental}

Debido a lo escaso de la muestra del Componente I, resulta difícil establecer las posibles diferencias con el Componente II y la muestra actual, limitando el alcance de las conclusiones. En este sentido, se realizan algunos comentarios sobre la presencia de las especies de micromamíferos. 
La presencia de G. griseoflavus en el Componente I $\left(0,25 \mathrm{ka}{ }^{14} \mathrm{C} \mathrm{AP}\right)$, de $G$. leucoblephara y M. australis en el Componente II (1,2-0,25 ka ${ }^{14} \mathrm{C}$ AP) sugiere que los ensambles de micromamíferos del sitio ACA-1 están asociados al desierto del Monte y a la Diagonal Árida Sudamericana. Asimismo, con el agregado de elementos ampliamente distribuidos en Patagonia y frecuentes en ambientes xéricos, asociados a estepas arbustivas abiertas con afloramientos rocosos en el Componente II ( $P$. xanthopygus y Eligmodontia sp.). Esto coincide en líneas generales con el ensamble de micromamíferos recuperados de la muestra actual, el cual se encuentra asociado principalmente al desierto del Monte.

\subsubsection{Conclusión}

Las evidencias tafonómicas, indican que los ensambles de microvertebrados tuvieron su origen principalmente por la actividad depredadora de aves Strigiformes. Asimismo, los restos tuvieron un enterramiento rápido, previamente a ser afectados por el pisoteo. Una vez incorporados a la litosfera, algunos restos-principalmente aquellos provenientes del Componente I- fueron alterados por efectos de la humedad del suelo.

Paleoambientalmente, no se detectaron cambios en los ensambles de micromamíferos del sitio ACA-1 respecto de la estructura taxonómica del ensamble actual, indicando un ambiente abierto y rocoso afín al desierto del Monte desde $1,2 \mathrm{ka}{ }^{14} \mathrm{C}$ AP hasta momentos recientes. 


\subsection{La Peligrosa-1 (LP-1)}

\subsubsection{Contexto arqueológico}

La Peligrosa-1 (LP-1) es un sitio arqueológico a cielo abierto, ubicado en las inmediaciones del puesto Cerna, en una zona medanosa con coladas lávicas, a $500 \mathrm{~m}$ de una fuente hídrica permanente, focal y de poco caudal de la Localidad La Peligrosa (36³1'00" S y 68³1'50" O; 1.160 m.n.s.m.) (Figura 7.22 A y B).

Los trabajos de campo se realizaron en enero de 1998 y estuvieron a cargo de Adolfo Gil, enmarcados dentro del desarrollo de su plan de tesis doctoral. Se efectuó un sondeo constituido por una cuadrícula de 1 x 1 (Figura 7.22 C) y se excavaron 13 niveles artificiales de $5 \mathrm{~cm}$ cada uno (Gil, 2006). Las dataciones radiocarbónicas arrojaron 400 \pm 70 años ${ }^{14} \mathrm{C}$ AP (LP-1474; Nivel 3; 348-501 años cal AP) y $640 \pm 70$ años ${ }^{14} \mathrm{C}$ AP (LP1513; Nivel 7; 567-661 años cal AP). No obstante, las muestras de los niveles inferiores carecieron de colágeno suficiente (Gil 2006). A pesar que no se cuenta con cronologías absolutas para dichos niveles, Gil (2006) en base al registro de tecnología cerámica los ubicó temporalmente dentro del Holoceno tardío, posiblemente en los últimos 15001000 años AP.

Si bien la excavación es preliminar y no se cuenta con una información estratigráfica detallada, se pudo observar una matriz arenosa homogénea en toda la secuencia (Gil, 2006).

Se recuperaron diversos materiales arqueológicos, entre los que se destacan productos de talla, instrumentos, tiestos cerámicos, especímenes óseos, cáscaras de huevos, piedras de bezoar y escasos restos arqueobotánicos (Gil, 2006).

Es importante destacar que las características de los materiales estudiados no exhibieron cambios significativos a lo largo de la secuencia (Gil, 2006). En el sitio se efectuaron tareas de talla lítica, utilización de contenedores cerámicos y procesamiento y/o consumo de animales (Gil, 2006). En base a esta diversidad de actividades, la amplia distribución superficial del registro y la cantidad de ítems recuperados en estratigrafía Gil (2006) propone que LP-1 funcionaría como un campamento de actividades múltiples, posiblemente un campamento base. Asimismo, el autor citado teniendo en cuenta que el sitio es un campamento a cielo abierto, enterrado en una matriz arenosa similar a un médano y que presenta varias ocupaciones poco extensas planteó que el 
registro arqueológico es de baja integridad y de resolución media a baja (sensu Martínez, 1999).
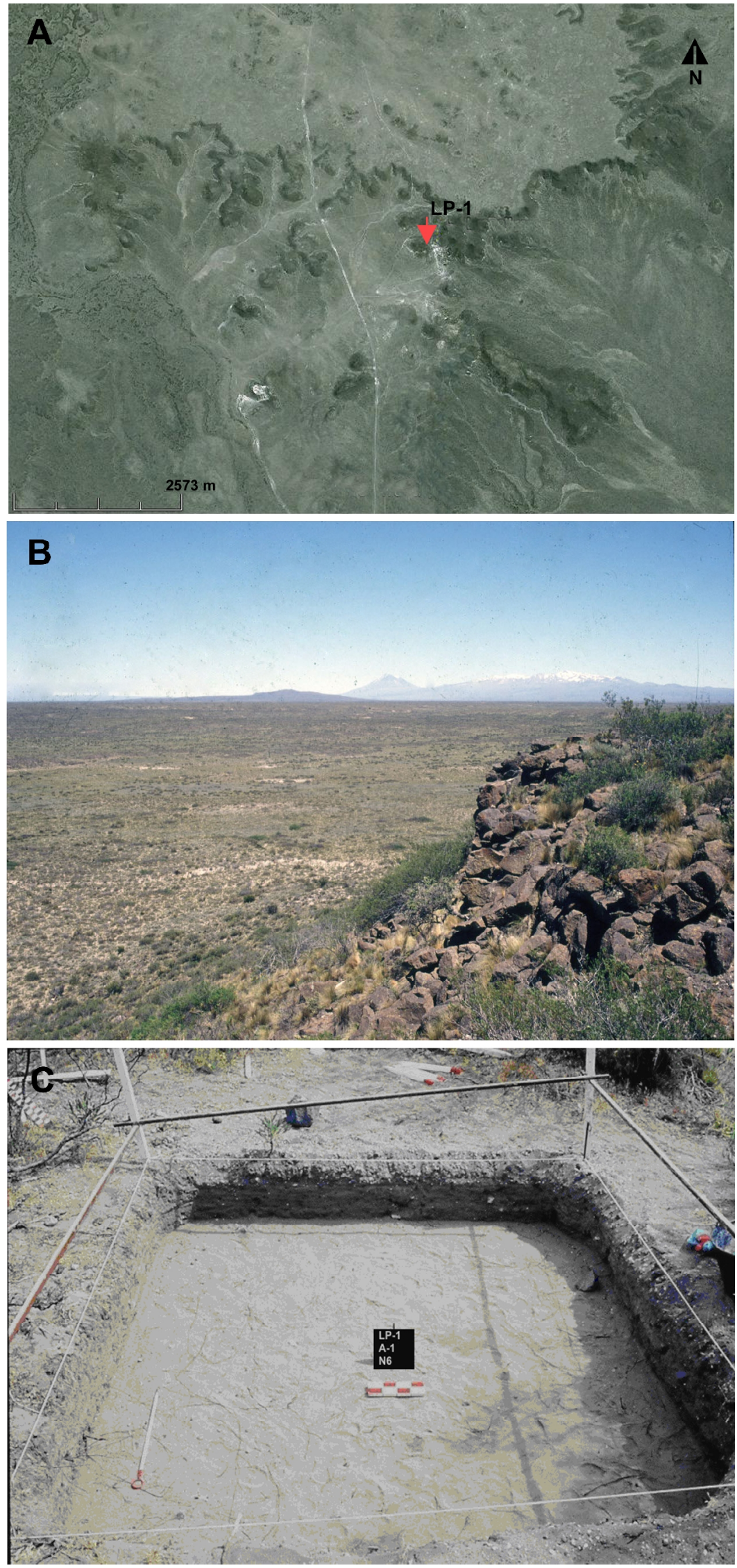
Figura 7.22. Sitio arqueológico La Peligrosa-1 (LP-1). A: ubicación del sitio. B: detalle del ambiente. C: vista de la cuadrícula analizada, tomada de Giardina (2010: 234).

El registro zooarqueológico preliminar del sitio fue dado a conocer por Gil (2006). En su correspondiente análisis se observa un alto porcentaje (91\%) de especímenes no identificados taxonómicamente, principalmente a causa de la elevada fragmentación registrada (Gil, 2006). El porcentaje restante está representado por mamíferos indeterminados $(5 \%)$, rodentia indeterminados $(1 \%)$, dasipódidos indeterminados $(1 \%)$, camélidos (Lama sp.; 2\%) y reídos indeterminados (1\%). Este conjunto taxonómico se mantuvo básicamente constante cualitativamente y cuantitativamente a lo largo de toda la secuencia (Gil, 2006). Por su parte Giardina (2010), registró numerosos fragmentos de cáscaras de huevos de rheídos, posiblemente incorporados por consumo humano.

\subsubsection{Metodología}

Debido a lo exiguo de la muestra, no se pudo realizar un estudio tafonómico detallado. En tal sentido, se efectuó un análisis descriptivo teniendo en cuenta las principales variables tafonómicas: corrosión digestiva, termoalteración, meteorización, marcas de raíces, impresiones por óxido de manganeso, fractura y corrosión sedimentaria. Por otra parte, además de lo exiguo de la muestra, se recuperaron muy escasos restos diagnósticos, lo que implicó que se pudo identificar una sola especie, limitando la posibilidad de un análisis paleoambiental para este sitio.

\subsubsection{Resultados}

\subsubsection{Asociación de micromamíferos de la muestra arqueofaunística}

Los escasos restos de micromamíferos recuperados del sitio LP-1 (NISP=24, MNE=24, $\mathrm{MNI}=12$ ) permitieron identificar una especie de roedor histricognato principalmente asociado al desierto del Monte (Galea leucoblephara) y un roedor sigmodontino indeterminado (Tabla 7.27). 


\begin{tabular}{|l|ccc|}
\hline Taxones / Procedencia & \multicolumn{3}{|c|}{ La Peligrosa } \\
& NISP & MNE & MNI \\
\hline Rodentia indet. & 16 & 16 & 7 \\
Caviidae indet. & 4 & 4 & 3 \\
Galea leucoblephara & 1 & 1 & 1 \\
Cricetidae / Sigmodontinae indet. & 3 & 3 & 1 \\
\hline Total & 24 & 24 & 12 \\
\hline
\end{tabular}
Tabla 7.27. Composición taxonómica del
micromamíferos de LP-1 (expresada en MNI, MNE y MNI).

\subsubsection{Análisis tafonómico}

En la tabla 7.28 se ilustra las distintas variables tafonómicas analizadas.

\begin{tabular}{|l|c|c|c|c|c|c|c|}
\hline & Digestión & Termoalteración & Meteorización & Raíces & $\begin{array}{c}\text { Óxido } \\
\text { manganeso }\end{array}$ & Fractura & $\begin{array}{c}\text { Corrosión } \\
\text { sedimentaria }\end{array}$ \\
\hline Mandíbula (NISP=1) & - & - & 1 & 1 & - & 1 & - \\
Vértebra (NISP=2) & 2 & - & 2 & - & - & - & - \\
Cúbito (NISP=1) & - & - & 1 & 1 & - & 1 & - \\
Radio (NISP=1) & - & - & - & 1 & - & - & - \\
Falange (NISP=12) & 1 & 3 & 6 & - & - & 3 & 1 \\
Hueso largo indet. (NISP=2) & - & - & - & - & - & 2 & 2 \\
Resto indet. (NISP=3) & - & - & 2 & - & - & - & - \\
Indeterminados (NISP=2) & - & 2 & - & - & - & 2 & - \\
\hline Total & 3 & 5 & 12 & 3 & - & 9 & 3 \\
\hline
\end{tabular}

Tabla 7.28. Variables tafonómicas analizadas en LP-1.

El 12,5\% de los especímenes exhibió marcas de corrosión digestiva, mostrando un ligero poseado en las superficies articulares (Figura 7.23 A), destacando que los mismos correspondieron a roedores indeterminados y a sigmodontinos indeterminados. Con el $50 \%$ las falanges fueron el elemento mejor representado (Tabla 7.29). El 37,5\% de los restos óseos estaban fracturados, con bordes de fractura de ángulos agudos y superficies ásperas. No se hallaron especímenes con marcas de corte, aunque se destaca que el $20,8 \%$ de los mismos estaban termoalterados, los cuales correspondieron a roedores indeterminados (Figura 7.23 B). 


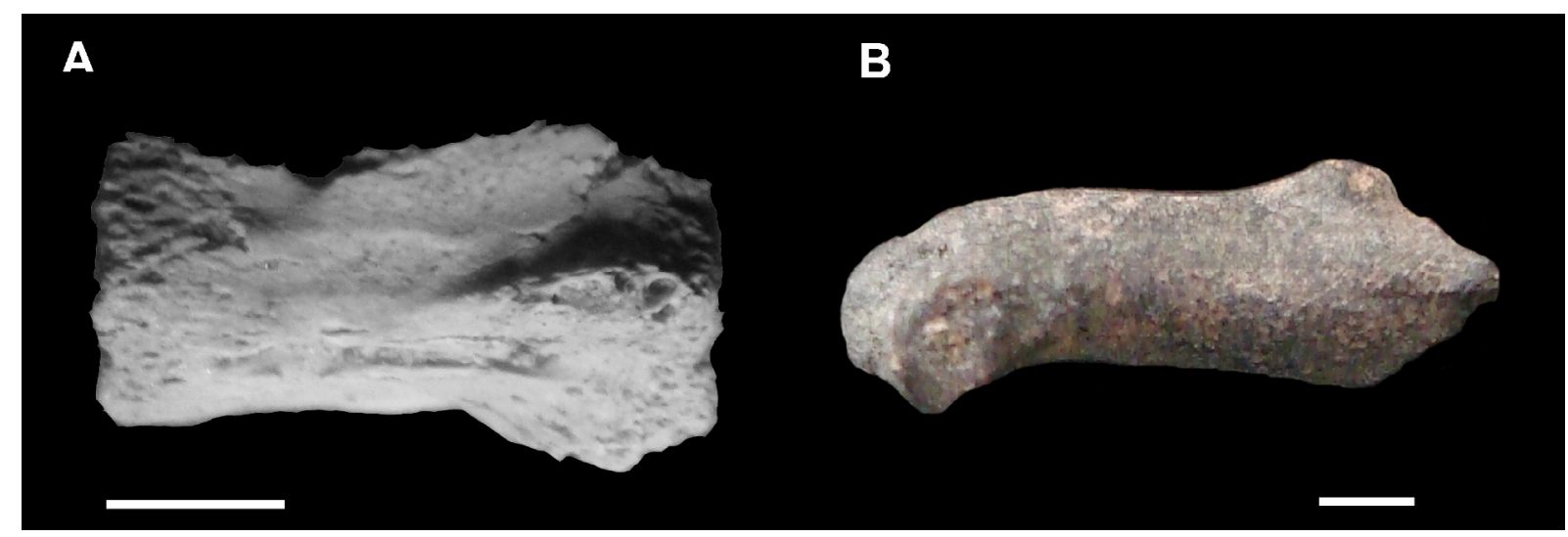

Figura 7.23. Restos óseos con evidencias de corrosión y termoalteración. A: vértebra de Rodentia con marcas de corrosión digestiva ligera en la región anterior y posterior del cuerpo (Nivel 2). B: falange de Rodentia con evidencias de termoalteración en toda la superficie del hueso (Nivel 4). Escalas: $2 \mathrm{~mm}$.

\begin{tabular}{|l|c|c|}
\hline Elementos & NISP & MNE \\
\hline Mandíbula & 1 & 1 \\
Vértebra & 2 & 2 \\
Cúbito & 1 & 1 \\
Radio & 1 & 1 \\
Falange & 12 & 12 \\
Hueso largo indet. & 2 & 2 \\
Resto indet. & 5 & 5 \\
\hline Total & 24 & 24 \\
\hline
\end{tabular}

Tabla 7.29. Representación esqueletaria en LP-1 (expresada en NISP y MNE).

Por otra parte, el 50\% de los especímenes presentaron evidencias de meteorización, correspondiendo en su mayoría a la categoría 2 (29,2\%), seguido por la categoría 1 (16,2\%) y la categoría 3 (8,3\%) (sensu, Andrews, 1990). El 12,5\% de los restos exhibió marcas de raíces del tipo Sphenoichnia, el 12,5\% presentó huellas de corrosión sedimentaria por humedad del suelo y ningún resto mostró evidencias de impresiones de óxido de manganeso, abrasión por transporte hídrico, desplazamientos y rozamientos de los restos contra el sedimento.

\subsubsection{Discusión y conclusión}

Tanto por las características morfológicas del sitio como los atributos tafonómicos emergentes de los ensambles de micromamíferos dejan expuesta el carácter complejo del mismo. En este sentido, se plantea la posibilidad de un origen mixto de los 
ensambles. Por un lado, las evidencias de algunos restos de roedores indeterminados y sigmodontinos con marcas de corrosión digestiva ligera se relacionan con los agregados originados por aves estrigiformes (e.g., Andrews, 1990; Fernández-Jalvo y Andrews, 1992). Asimismo, estos niveles de corrosión no coinciden con los datos obtenidos por Crandall y Stahl (1995) y Deward y Jarardino (2007), quienes mostraron que los micromamíferos consumidos por Homo sapiens presentaron evidencias de elevada corrosión digestiva en casi todos los huesos y dientes. Por otro lado, más allá de estas observaciones y si bien el consumo antrópico no pudo corroborarse fehacientemente con el hallazgo de marcas de corte, el registro de $c a .20 \%$ de restos termoalterados en roedores indeterminados y el hecho de que las especies de microvertebrados correspondan a los taxa de mayor tamaño, sugiere la posibilidad de que los humanos sean uno de los agentes de depositación de los mismos. Además, el hecho de que La Peligrosa-1 sea un sitio a cielo abierto, con un potencialmente menor de depositación natural de especímenes por causas naturales, refuerza la posibilidad de un origen antrópico de una parte de la muestra estudiada. No obstante, cabe notar que los restos pudieron haber sido termoalterados por actividades como limpieza del recinto habitacional, por parte de los grupos humanos (Bond et al., 1981).

El hallazgo de restos con evidencias de meteorización y marcas de raíces del tipo Sphenoichnia, indica que los mismos estuvieron expuestos a los agentes atmosféricos, junto al desarrollo de una cubierta herbácea, previamente a ser enterrados (Behrensmeyer, 1978; Montalvo, 2002b). Otros procesos postdepositacionales, como restos con huellas de corrosión sedimentaria por humedad del suelo, contrasta con la ausencia de impresiones de óxido de manganeso, debido a que esto ocurre cuando hay humedad por oscilaciones en el nivel freático o encharcamientos de agua (Courty et al., 1989; Gómez et al., 1999; Gómez, 2000). Por otro lado, la presencia de restos fracturados con bordes de fractura con ángulos agudos y superficies ásperas, podría indicar acción del pisoteo. Finalmente, se destaca la ausencia de restos con evidencias de abrasión por transporte hídrico, desplazamientos y rozamientos de los restos contra el sedimento (Korth, 1979; Andrews, 1990; Fernández-Jalvo y Andrews, 2003). 


\subsection{Cueva de Luna}

\subsubsection{Contexto arqueológico}

En el año 1986 en el marco de un proyecto de estudios arqueológicos del Dpto. de Malargüe, un equipo de investigadores dirigidos por Víctor Durán inició los trabajos en el curso medio del Río Grande. Uno de los sitios excavados fue Cueva de Luna, ubicado en la margen derecha del Río Grande (Figura 7.24 A), a 1.500 m de su confluencia con el arroyo El Manzano y $27 \mathrm{~km}$ al sur de Bardas Blancas (3604'33,7" S y 6943'22,9" O; 1.300 m.s.n.m.) (Durán y Ferrari, 1991; Neme et al., 1995; Durán, 1997, 2000). La cueva, producto de la erosión de una formación basáltica, presenta $9 \mathrm{~m}$ de frente y 8,5 de profundidad. Se excavó una trinchera que atraviesa la cueva de norte a sur (Figura 7.24 B y C), totalizando una superficie de 3,5 $\mathrm{m}^{2}$ (Durán y Ferrari, 1991; Neme et al., 1995; Durán, 1997, 2000).

El sitio Cueva de Luna presenta un paquete sedimentario de $c a .60 \mathrm{~cm}$ de potencia, donde se distinguieron tres capas naturales y once niveles artificiales (Durán y Ferrari, 1991; Durán, 1997, 2000). La Capa 1 es la más superficial, presenta grandes concentraciones de guano de ovicápridos en una matriz limo-arenosa muy suelta y que además contiene lapilli. La Capa 2 está compuesta por limos arenosos de color pardo grisáceo y es donde aparecen la mayor cantidad de materiales arqueológicos. La Capa 3 comienza a los 50 o $55 \mathrm{~cm}$ de la superficie y contiene escasos restos arqueológicos dentro de un sedimento limoso de color pardo rojizo que rellena las grietas entre los bloques provenientes de un derrumbe (Durán, 1997, 2000). Asimismo, el registro arqueológico del sitio se dividió en cinco componentes culturales (Neme et al., 1995; Durán, 1997, 2000). Dos muestras de carbón se enviaron para ser fechadas las cuales arrojaron edades de $3830 \pm 160$ años ${ }^{14} \mathrm{C}$ AP (Componente 5; muestra LP-341; 40134456 años cal AP) y $1490 \pm 60$ años ${ }^{14} \mathrm{C}$ AP (Componente 4; muestra LP-321; 13371476 años cal AP). Para poder ordenar toda la secuencia en un marco temporal estos autores utilizaron los materiales de origen europeo, los cuales presentan un alto valor cronológico (Tabla 7.30 y Figura 7.25). 

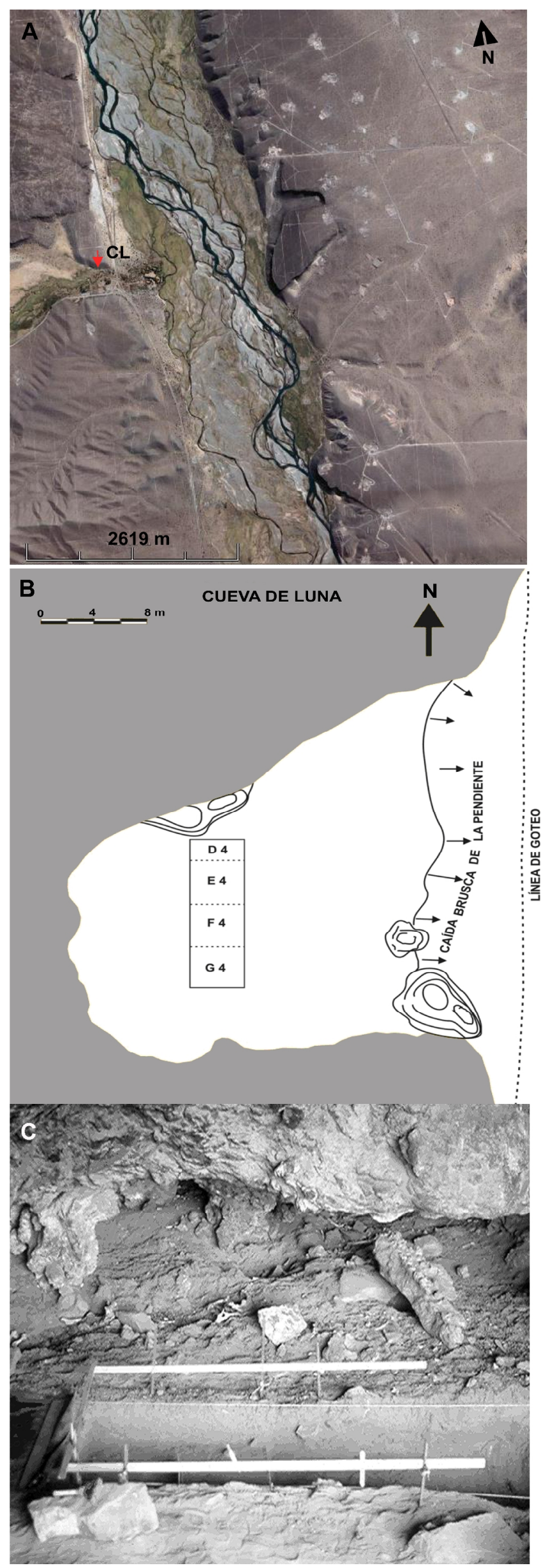
Figura 7.24. Sitio arqueológico Cueva de Luna. A: ubicación del sitio. B: vista en planta, tomada de Durán (2000: 59). C: vista parcial de la excavación, tomada de Giardina (2010: 200).

El Componente 1 es el más reciente y corresponde a la cueva cuando fue ocupada por pastores en los inicios del siglo XX. En este componente se encontraron macrorestos vegetales de Triticum aestivum (trigo), Prosopis sp. (algarrobo), Larrea nitida (jarilla) y Schinus polygamus (molle). El Componente 2 se relaciona con la ocupación Pehuenche en la región (siglos XVIII y XIX), donde posiblemente se establecieron pocos individuos en forma temporal. Según el autor, estas ocupaciones temporarias pudieron pertenecer a una agrupación mayor que viviría en tolderías en áreas abiertas. Se destaca la presencia de materiales manufacturados de origen europeo o hispano-criollo, entre ellos dos tipos de cerámica pintada, textilería industrial europea, un botón de vidrio y semillas de T. aestivum, Phaseolus vulgaris (poroto), Juglans aff. regia (nogal), L. nitida, Prosopis sp., Sphedra sp. (solape) y S. polygamus. El Componente 3 fue definido en forma arbitraria y se lo relacionó tentativamente con ocupaciones de cazadores recolectores previas al contacto. Esto se debe a que la estructura de este componente es muy similar a las anteriores, pero no se encontraron evidencias directas del período posthispánico. En este componente se recuperaron semillas de T. aestivum, Prosopis sp., L. nitida, Sphedra sp. y S. polygamus. El Componente 4 (ca. $1,5 \mathrm{ka}{ }^{14} \mathrm{C}$ AP) fue definido como perteneciente a un contexto de cazadores recolectores que ocuparon la cueva en forma prolongada, haciendo un acondicionamiento del espacio y una división funcional del mismo. Los allazgos del mismo incluyen un fragmento de cerámica no decorada, dos puntas de proyectil apendiculares con lados convexos y base cóncava, varios artefactos formatizados, diversos restos vegetales entre los que se destacan semillas de Prosopis sp., Maihuenia poeppigii y S. polygamus. Por último, el Componente 5 ( $\left.c a .3,8 \mathrm{ka}{ }^{14} \mathrm{C} \mathrm{AP}\right)$ representa varias ocupaciones esporádicas de la cueva por grupos de cazadores-recolectores móviles. En este componenete se registró un cuchillo de filo lateral retocado bifacialmente, una decena de productos de talla, $c a$. de una centena de lascas y algunas semillas de Prosopis sp. y S. polygamus. Es interesante destacar que entre los Componentes 4 y 5 se evidenció un hiatus ocupacional de 2,5 ka ${ }^{14} \mathrm{C}$ (Durán y Ferrari, 1991; Neme et al., 1995; Durán, 1997, 2000; Llano, 2011). Finalmente, Llano (2011) propone un origen antrópico para los macrorestos vegetales. 


\begin{tabular}{|c|c|c|c|c|c|c|c|}
\hline $\begin{array}{c}\text { Capas } \\
\text { Naturales }\end{array}$ & $\begin{array}{c}\text { Componentes } \\
\text { Culturales }\end{array}$ & $\begin{array}{c}\text { Cuad. D4 } \\
\text { Niveles }\end{array}$ & $\begin{array}{c}\text { Cuad. E4 } \\
\text { Niveles }\end{array}$ & $\begin{array}{c}\text { Cuad. F4 } \\
\text { Niveles }\end{array}$ & $\begin{array}{c}\text { Cuad. G4 } \\
\text { Niveles }\end{array}$ & Cronología & Calibrado \\
\hline 1 & II & 1 y 2 & 1 y 2 & $\begin{array}{c}1 \text { y } 2 \\
\text { (sec.SO) }\end{array}$ & $\begin{array}{c}1 \text { y 2; } 3 \text { y } 4 \text { (SO } \\
\text { y NO); } 5 \text { (SO) }\end{array}$ & Siglo XX & \\
\hline 2 & II & 3 & 3 y 4 & 2,3 y 4 & 3 y 4 (SE y NE) & Siglos XVIII y XIX & \\
\hline 2 & III & 4 & 5 & 5 & 5 & $?$ & \\
\hline 2 & IV & 5 y 6 & 6,7 y 8 & 6,7 y 8 & 6,7 y 8 & $1490 \pm 60{ }^{14} \mathrm{C} \mathrm{AP}$ & $1337-1476$ \\
\hline 2 & V & 7,8 y 9 & $8,9,10$ y 11 & 9 & 9 & $3830 \pm 160{ }^{14} \mathrm{C} \mathrm{AP}$ & $4013-4456$ \\
\hline 3 & & & & & $9 b$ & $?$ & \\
\hline
\end{tabular}

Tabla 7.30. Cuadro de correlaciones por cuadrículas y niveles. Modificado de Durán (2000: 63).

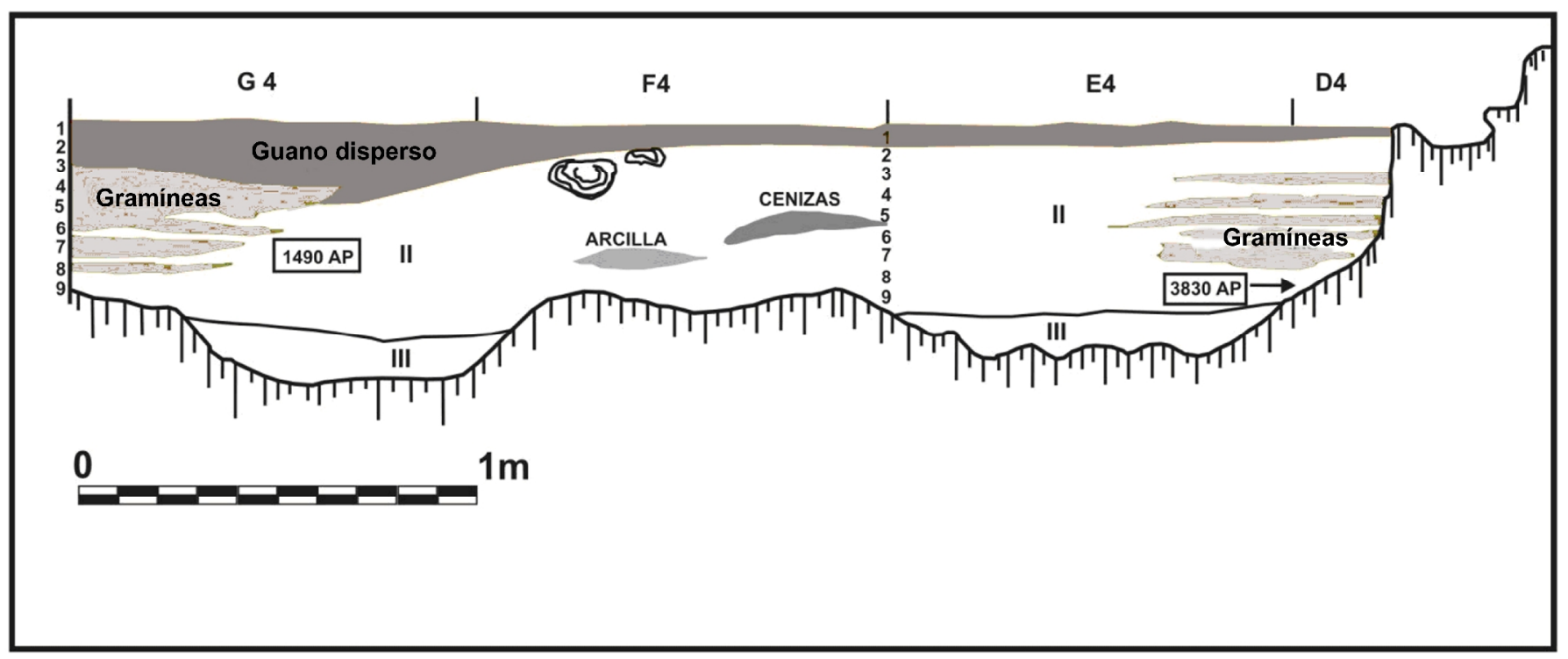

Figura 7.25. Cronoestratigrafía del sitio Cueva de Luna. Tomado de Duran (2000: 60).

La información disponible sobre el registro arqueofaunístico de Cueva de Luna se encuentra en Neme et al. (1995) y Giardina (2010). En síntesis los autores observaron numerosos especímenes óseos ( $c a$. de $7,75 \mathrm{ka}{ }^{14} \mathrm{C}$ AP) que incluyen diversos taxones que actualmente viven en el área, siendo Lama guanicoe el más representado en los cinco componentes. Sin embargo, a lo largo de la secuencia hubo variaciones en las estructuras taxonómicas. En el Componente I, II y III se registraron especies introducidas (Caprinae indeterminados y Equus caballus) y nativas tales como $L$. guanicoe (Camelidae), Chaetophractus villosus, Zaedyus pichiy (Dasypodidae), Puma concolor (Felidae), Conepatus sp. (Mephitidae), Rhea pennata (Rheidae), Anas sp. (Anatidae) y Falconidae indeterminados, entre otros. En el Componente 4 se encuentran L. guanicoe, C. villosus, Carnivora indeterminados y Rheidae indeterminados. El Componente 5 es el más escaso, donde se registraron L. guanicoe y C. villosus (Neme et al., 1995; Giardina, 2010). 
Neme et al. (1995) evaluaron la funcionalidad del sitio en base a los índices de Utilidad Económica y Densidad Global (sensu Binford, 1978) de las partes anatómicas de L. guanicoe. En este sentido, en los Componentes I y II si bien las partes esqueletales de esta especie estuvieron afectadas por la densidad de sus elementos dificultando las interpretaciones culturales de aprovechamiento faunístico, se pudo observar la presencia de la mayoría de las partes esqueletarias. En el Componente III se registró una marcada ausencia de vértebras y costillas y una dominancia de elementos del esqueleto apendicular. El Componente IV presentó un patrón similar, donde los autores no pudieron observar una estrategia definida. En el Componente 5 se registraron tanto elementos del esqueleto axial como apendicular, pero tampoco pudieron observar una estrategia definida (Neme et al., 1995).

En conclusión los autores citados proponen que el aprovechamiento de la fauna en Cueva de Luna ha variado a través del tiempo, indicando cambios en el posicionamiento de la cueva dentro del sistema de subsistencia desde hace $3,8 \mathrm{ka}{ }^{14} \mathrm{C} \mathrm{AP}$, pero no pudieron asegurar ninguna de las estrategias y funcionalidad del sitio según el modelo propuesto por Binford (1978). Por su parte, Giardina (2010) a partir de información taxonómica plantea que tanto depredadores como humanos intervinieron en la formación de los conjuntos avifaunísticos.

Para finalizar Durán $(1997,2000)$ plantea que el valle medio del Río Grande pudo funcionar como un límite interétnico, donde se dieron importantes contactos entre los pobladores de la Payunia y los de la cordillera, en un contexto de un modelo de variación estacional.

\subsubsection{Metodología}

Se estudiaron 107 restos cráneo-mandibulares de micromamíferos correspondientes a los Componentes I, II, III, IV y V, sin embargo, los elementos postcraneales y los dientes aislados no fueron recuperados. Buena parte de la metodología planteada en las secciones de tafonomía del Capítulo 4, no se pudo aplicar debido a la ausencia de elementos postcraneales y dientes aislados. En este sentido, se observaron marcas de corrosión digestiva en las superficies de los restos dentarios (i.e., incisivos y molares in situ). Además, teniendo en cuenta lo exiguo de la muestra solo se pudo calcular el índice que evalúa la proporción de molares aislados [(alvéolos maxilares + alvéolos mandibulares) / (molares)] x 100. Asimismo, se analizó el grado de fractura de los 
cráneos, mandíbulas y dientes, contabilizando los restos completos y las diferentes porciones.

Para este estudio los Componentes I, II y III, debido a su homogeneidad y por corresponder a un período histórico, se tomaron como uno único conjunto y los Componente IV y V se analizaron por separado.

Cabe notar que una parte del ensamble recuperado del sitio no se pudo analizar tafonómicamente debido a que por el momento esa muestra se encuentra extraviada. No obstante, dicha parte del ensamble, había sido determinado por Oliver Pearson y la lista de micromamíferos fue publicada en Neme et al. (1995) en base al cálculo de NISP (ver sección 7.5.3.3). Por ende, el cálculo de MNI de la mencionada muestra se realizó en forma estimada, dividiendo por dos a los valores de NISP (considerando que las determinaciones taxonómicas se hicieron en base a maxilares y mandíbulas). Dicho cálculo estimado, fue efectuado con el objetivo de realizar los índices de diversidad y equitatividad, un grafico comparativo de frecuencias relativas y un PCA.

Para finalizar, la comparación de los ensambles de micromamíferos provenientes del sitio arqueológico con la comunidad de micromamíferos vivientes en el área, se realizó mediante ensambles de micromamíferos generados por aves rapaces provenientes de localidades cercanas al sitio. Uno analizado por el autor [Volcán Malacara (ver apéndice)] y otros publicados en la literatura científica: [10 $\mathrm{km}$ al oeste de Bardas Blancas; Caverna de las Brujas; La Pasarela; Los Frisos (ver apéndice)].

\subsubsection{Resultados}

\subsubsection{Análisis tafonómico}

En todos los componentes se encontraron restos con evidencias de corrosión digestiva, comprendidos en la categoría de modificación ligera (Tabla 7.31; Figura 7.26 A y B). A pesar de lo escaso de la muestra, se puede observar bajos porcentajes de restos afectados (Componente I, II y III: 8,9\%; Componente IV: 11,8\%; Componente V: 16,7\%). Es interesante destacar que en el Componente V se registró un especimen con restos de pelos provenientes de egagrópilas (Figura 7.26 C). 


\begin{tabular}{|c|c|c|c|c|c|c|c|c|c|c|}
\hline \multirow{3}{*}{ Cueva de Luna } & \multicolumn{10}{|c|}{ Clases de digestión sensu Andrews (1990) } \\
\hline & \multicolumn{2}{|c|}{ Ausente } & \multicolumn{2}{|c|}{ Ligera } & \multicolumn{2}{|c|}{ Moderada } & \multicolumn{2}{|c|}{ Fuerte } & \multicolumn{2}{|c|}{ Extrema } \\
\hline & $(\mathrm{N})$ & $\%$ & $(\mathrm{~N})$ & $\%$ & $(\mathrm{~N})$ & $\%$ & $(\mathrm{~N})$ & $\%$ & $(\mathrm{~N})$ & $\%$ \\
\hline Comp I, II y III & & & & & & & & & & \\
\hline Incisivos in situ & 26 & 92,8 & 2 & 7,2 & - & - & - & - & - & - \\
\hline Molares in situ & 25 & 89,3 & 3 & 10,7 & - & - & - & - & - & - \\
\hline Comp IV & & & & & & & & & & \\
\hline Incisivos in situ & 9 & 100 & - & - & - & - & - & - & - & - \\
\hline Molares in situ & 6 & 75 & 2 & 25 & - & - & - & - & - & - \\
\hline Comp V & & & & & & & & & & \\
\hline Incisivos in situ & 4 & 100 & - & - & - & - & - & - & - & - \\
\hline Molares in situ & 8 & 80 & 2 & 20 & - & - & - & - & - & - \\
\hline
\end{tabular}

Tabla 7.31. Representación de las distintas categorías de corrosión digestiva en dientes de micromamíferos recuperados de los distintos componentes de Cueva de Luna.

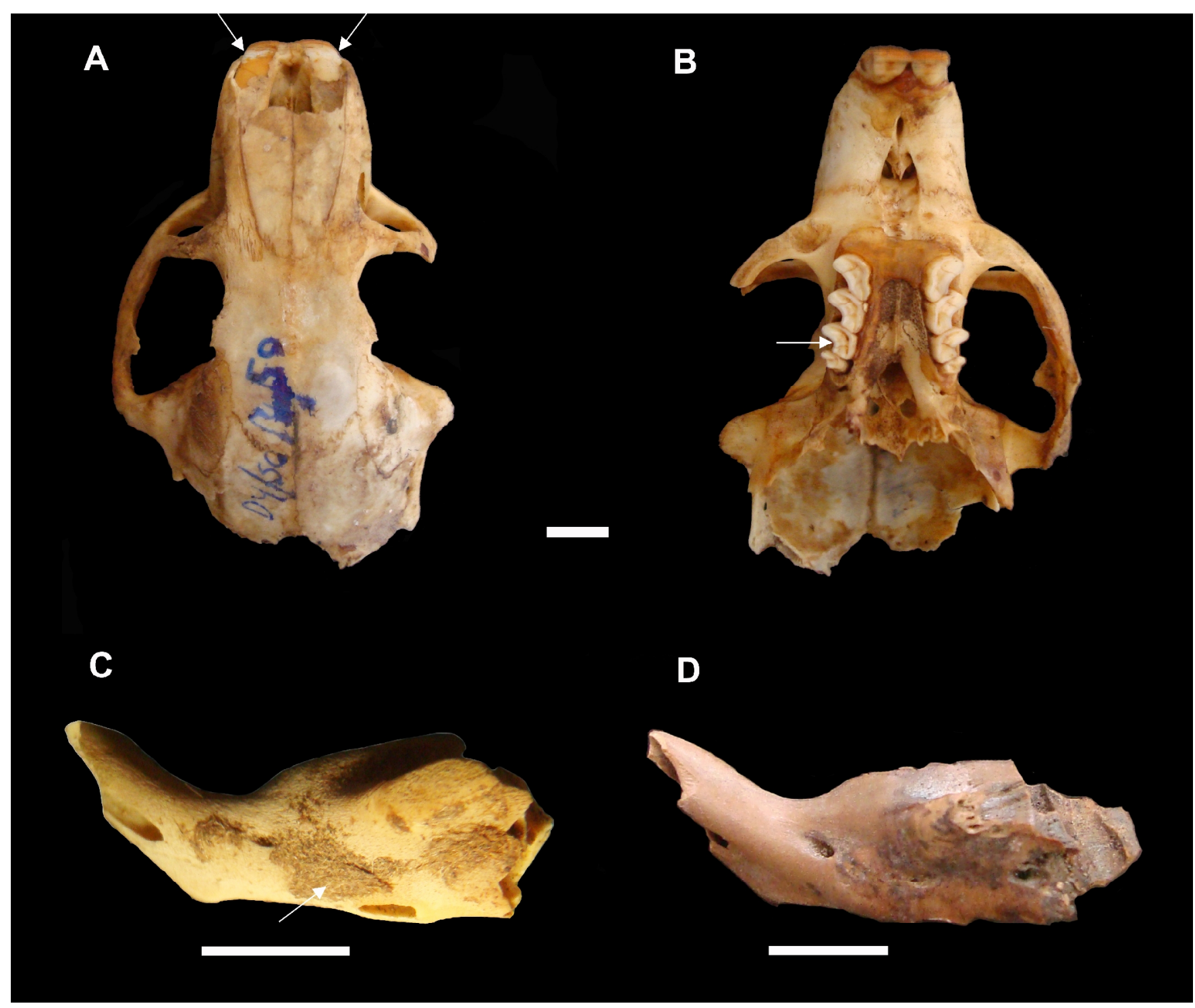


Figura 7.26. Ejemplos de algunos atributos tafonómicos que afectaron a las muestras de Cueva de Luna. A: vista dorsal del cráneo de Ctenomys sp. con marcas de corrosión digestiva ligera en los incisivos (Componente III, Nivel 4). B: vista ventral del cráneo de Ctenomys sp. con digestión ligera en molares (Componente III, Nivel 4). C: vista labial de mandíbula de Microcavia australis con restos de pelos de egagrópilas (Componente V, Nivel 9). D: vista labial de mandíbula de M. australis con evidencias de termoalteración (Componente V, Nivel 7). Escalas: $5 \mathrm{~mm}$.

Las mandíbulas tuvieron mayor representación que los maxilares en todos los componentes (Tabla 7.32).

\begin{tabular}{|l|c|c|c|}
\hline & $\begin{array}{c}\text { Comp I, II y III } \\
\text { MNE }\end{array}$ & $\begin{array}{c}\text { Comp IV } \\
\text { MNE }\end{array}$ & $\begin{array}{c}\text { Comp V } \\
\text { MNE }\end{array}$ \\
\hline Maxilar & 13 & 10 & 2 \\
Mandíbula & 55 & 18 & 9 \\
\hline Total & 68 & 28 & 11 \\
\hline
\end{tabular}

Tabla 7.32. representación de elementos para cada componentes de Cueva de Luna.

En la tabla 7.33 se exhiben los distintos tipos de fractura craneal y dentaria.

Se recuperó un solo cráneo con alto grado de integridad en el Componente I, II y III (Figura 7.26 A y B). El resto de los mismos se encontraron muy fracturados, correspondiendo a maxilares con y sin zigomáticos. La mayor parte de los molares se perdieron de los maxilares y por el contrario a pesar de lo escaso de la muestra se registraron que los incisivos se mantuvieron en los premaxilares.

En todos los componentes, las mandíbulas presentaron altos porcentajes de fracturas, integrando las distintas categorías. En forma similar al caso anterior, se perdieron más molares que incisivos en todos los componentes. 


\begin{tabular}{|l|cc|cc|cc|}
\hline \multicolumn{1}{|c}{ Cueva de Luna } & \multicolumn{2}{c|}{ Comp I, II y III } & \multicolumn{2}{c|}{ Comp IV } & \multicolumn{2}{c|}{ Comp V } \\
& N & $\%$ & N & $\%$ & N & $\%$ \\
\hline Fractura de cráneos & & & & & & \\
Cráneos completos & 1 & 7,7 & - & - & - & - \\
Maxilares con arcos zigomáticos & 6 & 46,1 & 2 & 20 & 2 & 100 \\
Maxilares sin arcos zigomáticos & 6 & 46,1 & 8 & 80 & - & - \\
Pérdida de molares de maxilares & 52 & 69,3 & 36 & 63,2 & 12 & 100 \\
Pérdida de incisivos de premaxilares & 5 & 35,7 & 1 & 25 & - & - \\
Fractura de mandíbulas & & & & & & \\
Mandíbulas completas & 10 & 18,2 & 3 & 16,7 & 1 & 11,1 \\
Mandíbulas con rama ascendente rota & 12 & 21,8 & 9 & 50 & 4 & 44,4 \\
Mandíbulas sin rama ascendente & 26 & 47,3 & 5 & 27,8 & 3 & 33,3 \\
Mandíbulas sin rama ascendente y borde inferior roto & 7 & 12,7 & 1 & 5,5 & 1 & 11,1 \\
Pérdida de molares de las mandíbulas & 169 & 85,8 & 61 & 88,4 & 20 & 66,6 \\
Pérdida de incisivos de la mandíbulas & 22 & 44 & 7 & 43,7 & 6 & 60 \\
Fractura de dientes & & & & & & \\
Molares rotos in situ & 12 & 42,9 & 1 & 12,5 & 6 & 60 \\
Incisivos rotos in situ & 20 & 71,4 & 4 & 44,4 & 2 & 50 \\
\hline
\end{tabular}

Tabla 7.33. Fractura de cráneos, mandíbulas y dientes, recuperados de los componentes portadores de micromamíferos de Cueva de Luna.

Los índices de pérdida dentaria evaluados en todos los componentes, muestran que la mayoría de los molares se desprendieron de los alvéolos y que la mayor parte de los incisivos quedaron retenidos en sus alvéolos (Tabla 7.34).

\begin{tabular}{|l|c|c|c|}
\hline & Comp I, II y III & Comp IV & Comp V \\
\hline Pérdida de dientes & & & \\
Alvéolos mx+ alvéolos mb/m & 433,3 & 334,5 & 320 \\
Alvéolos mx+ alvéolos mb/i & 100 & 66,7 & 75 \\
\hline
\end{tabular}

Tabla 7.34. Valores del índice calculado en los componentes de Cueva de Luna.

Referencias: mx: maxilar; mb: mandíbula; m: molar; i: incisivo.

Se destaca que no se registraron restos con marcas de corte y solo dos elementos provenientes del Componente I, II y III y del Componente V, estaban termoalterados (Figura 7.26 D).

Si bien los índices IT e IP no pudieron ser calculados, debido a la ausencia de datos sobre el MNI de la muestra analizada por O. Pearson, se puede observar que la muestra está integrada tanto por taxones de tamaño chico y crípticos como grandes y gregarios o agrupados. 
En cuanto a los procesos postdepositacionales, se registraron tres restos con evidencias de meteorización (categorías I, II y III sensu Andrews, 1990), recuperados del Componente I, II y II. Tampoco se observaron elementos con marcas de raíces y roedores, ni con evidencias de abrasión hídrica, desplazamientos y rozamientos de los restos contra el sedimento. Además, se observaron tres elementos con corrosión sedimentaria en el Componente I, II y III y tres en el Componente IV. Se recuperaron elementos con impresiones por óxidos de manganeso en todos los componentes (Componente I, II y III: 10,1\%; Componente IV: 17,8\%; Componente V: 27,3\%).

\subsubsection{Asociación de micromamíferos de las muestras actuales}

Como se ilustra en la tabla 7.35, los ensambles de micromamíferos de las muestras actuales están dominados por roedores sigmodontinos, siendo Eligmodontia sp., Phyllotis xanthopygus y Euneomys chinchilloides los taxones más representados, seguidos por Abrothrix olivaceus y en menor medida por Abrothrix longipilis, Chelemys macronyx, Loxodontomys micropus, Reithrodon auritus y Oligoryzomys longicaudatus. Entre los roedores histricognatos, Ctenomys sp. fue el más abundante, seguido por Microcavia australis y Tympanoctomys barrerae. Asimismo, se registraron dos marsupiales (Thylamys pallidior y Lestodelphys halli), destacándose que T. pallidior fue un elemento importante en todas las muestras. 


\begin{tabular}{|c|c|c|c|c|c|c|c|c|c|c|}
\hline Taxones / Procedencia & \multicolumn{2}{|l|}{1} & $\begin{array}{r}2 \\
\mathrm{MNI}\end{array}$ & $\%$ & $\begin{array}{r}3 \\
\mathrm{MNI}\end{array}$ & $\%$ & $\begin{array}{r}4 \\
\mathrm{MNI}\end{array}$ & $\%$ & 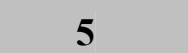 & $\%$ \\
\hline $\begin{array}{l}\text { Mammalia } \\
\text { Didelphimorphia }\end{array}$ & & & & & & & & & & \\
\hline Lestodelphys halli & - & - & - & - & 4 & 1,3 & - & - & - & - \\
\hline $\begin{array}{l}\text { Thylamys pallidior } \\
\text { Rodentia } \\
\text { Ctenomyidae }\end{array}$ & 6 & 14,6 & 7 & 7,3 & 17 & 5,5 & 7 & 19,4 & 2 & 12,5 \\
\hline $\begin{array}{l}\text { Ctenomys sp. } \\
\text { Caviidae }\end{array}$ & 5 & 12,2 & 14 & 14,6 & 43 & 14 & - & - & 2 & 12,5 \\
\hline $\begin{array}{l}\text { Microcavia australis } \\
\text { Octodontidae }\end{array}$ & 1 & 2,4 & - & - & 7 & 2,3 & - & - & 2 & 12,5 \\
\hline $\begin{array}{l}\text { Tympanoctomys barrerae } \\
\text { Cricetidae / Sigmodontinae }\end{array}$ & - & - & - & - & - & - & - & - & 1 & 6,3 \\
\hline Abrothrix olivaceus & 1 & 2,4 & 3 & 3,1 & 14 & 4,5 & 3 & 8,3 & - & - \\
\hline Abrothrix longipilis & - & - & 1 & 1 & - & - & - & - & - & - \\
\hline Abrothrix s & - & - & - & - & 7 & 2,3 & - & - & - & - \\
\hline Chelemys macronyx & - & - & - & - & 6 & 1,9 & - & - & - & - \\
\hline Phyllotis xanthopygus & 8 & 19,5 & 24 & 25 & 80 & 26 & 12 & 33,3 & 2 & 12,5 \\
\hline Loxodontomys micropus & - & - & - & - & 2 & 0,6 & - & - & - & - \\
\hline Eligmodontia sp. & 19 & 46,3 & 17 & 17,7 & 76 & 24,7 & 12 & 33,3 & 7 & 43,7 \\
\hline Oligoryzomys longicaudatus & - & - & - & - & - & - & 1 & 2,8 & - & - \\
\hline Reithrodon auritus & - & - & - & - & 1 & 0,3 & - & - & - & - \\
\hline Euneomys chinchilloides & 1 & 2,4 & 30 & 31,3 & 40 & 13 & 1 & 2,8 & - & - \\
\hline Euneomys sp. & - & - & - & - & 11 & 3,6 & - & - & - & - \\
\hline $\begin{array}{l}\text { Total } \\
\text { Riqueza } \\
\text { H' } \\
\text { Equitatividad }\end{array}$ & $\begin{array}{c}41 \\
7 \\
1,485 \\
0,76\end{array}$ & & $\begin{array}{c}96 \\
7 \\
1,644 \\
0,84\end{array}$ & & $\begin{array}{c}304 \\
11 \\
1,858 \\
0,77\end{array}$ & & $\begin{array}{c}36 \\
6 \\
1,457 \\
0,81\end{array}$ & & $\begin{array}{c}16 \\
6 \\
1,624 \\
0,91\end{array}$ & \\
\hline
\end{tabular}

Tabla 7.35. Composición taxonómica de las muestras actuales de micromamíferos (expresada en MNI y MNI\%). 1: Volcán Malacara. 2: $10 \mathrm{~km}$ al oeste de Bardas Blancas (Pardiñas et al., 2008). 3: Caverna de las Brujas (Gasco et al., 2006). 4: La Pasarela (Pardiñas et al., 2008). 5: Los Frisos (Pardiñas et al., 2008).

\subsubsection{Asociación de micromamíferos de las muestras arqueofaunísticas}

En la muestra arqueofaunística analizada, Ctenomys sp. y M. autralis fueron los taxones dominantes en todos los componentes. Además, T. pallidior fue recuperado en todos los componentes, no obstante L. halli solo fue encontrado en el Componente IV (Tabla 7. 36). 


\begin{tabular}{|l|cccccc|cccccc|}
\hline Taxones / Procedencia & \multicolumn{9}{|c|}{ Componentes I, II y III } & \multicolumn{7}{c|}{ Componente IV } \\
& NISP & $\%$ & MNE & $\%$ & MNI & $\%$ & NISP & $\%$ & MNE & $\%$ & MNI & $\%$ \\
\hline Mammalia & & & & & & & & & & & & \\
Didelphimorphia & & & & & & & & & & & \\
Lestodelphys halli & - & - & - & - & - & - & 3 & 10,7 & 3 & 10,7 & 2 & 11,8 \\
Thylamys pallidior & 3 & 4,4 & 3 & 4,4 & 2 & 5,3 & 2 & 7,1 & 2 & 7,1 & 2 & 11,8 \\
Rodentia & & & & & & & & & & & & \\
Ctenomyidae & & & & & & & & & & & & \\
Ctenomys sp. & 48 & 70,6 & 48 & 70,6 & 22 & 57,9 & 17 & 60,7 & 17 & 60,7 & 8 & 47 \\
Caviidae indet. & 3 & 4,4 & 3 & 4,4 & 3 & 7,9 & 4 & 14,3 & 4 & 14,3 & 3 & 17,6 \\
Microcavia australis & 14 & 20,6 & 14 & 20,6 & 11 & 28,9 & 2 & 7,1 & 2 & 7,1 & 2 & 11,8 \\
\hline Total & 68 & & 68 & & 38 & & 28 & & 28 & & 17 & \\
\hline
\end{tabular}

Tabla 7.36. Composición taxonómica de los ensambles de micromamíferos de los componentes de Cueva de Luna (expresada en NISP, MNE y MNI).

\begin{tabular}{|l|cccccc|}
\hline Taxones / Procedencia & \multicolumn{7}{|c|}{ Componente V } \\
& NISP & $\%$ & MNE & $\%$ & MNI & $\%$ \\
\hline Mammalia & & & & & & \\
Didelphimorphia & & & & & & \\
Lestodelphys halli & - & - & - & - & - & - \\
Thylamys pallidior & 1 & 9,1 & 1 & 9,1 & 1 & 16,7 \\
Rodentia & & & & & & \\
Ctenomyidae & & & & & & \\
Ctenomys sp. & 6 & 54,5 & 6 & 54,5 & 2 & 33,3 \\
Caviidae indet. & - & - & - & - & - & - \\
Microcavia australis & 4 & 36,4 & 4 & 36,4 & 3 & 50 \\
\hline Total & 11 & & 11 & \multicolumn{5}{c|}{6} \\
\hline
\end{tabular}

Tabla 7.36. (Continuación) Composición taxonómica de los ensambles de micromamíferos de los componentes de Cueva de Luna (expresada en NISP, MNE y MNI).

Por otra parte, analizando la muestra de micromamíferos estudiada por O. Pearson y publicada en Neme et al. (1995), se puede observar un ensamble arqueofaunístico compuesto por roedores histricognatos, roedores sigmodontinos y marsupiales (Tabla 7.37). 


\begin{tabular}{|l|cc|cc|cc|}
\hline \multicolumn{1}{|c|}{ Taxones / Procedencia } & \multicolumn{2}{|c|}{ Comp I, II y III } & \multicolumn{2}{|c|}{ Comp IV } & \multicolumn{2}{c|}{ Comp V } \\
& NISP & $\%$ & NISP & $\%$ & NISP & $\%$ \\
\hline Mammalia & & & & & & \\
Didelphimorphia & & & & & & \\
Thylamys pallidior & 6 & 11,1 & 6 & 12 & 1 & 5,3 \\
Rodentia & & & & & & \\
Ctenomyidae & 2 & 3,7 & - & - & - & - \\
Ctenomys sp. & & & & & & \\
Caviidae & 3 & 5,6 & - & - & - & - \\
Microcavia australis & 16 & 29,6 & 7 & 14 & 5 & 26,3 \\
Galea leucoblephara & & & & & & \\
Cricetidae / Sigmodontinae & 2 & 3,7 & 2 & 4 & 4 & 21 \\
Akodon iniscatus & - & - & 3 & 6 & - & - \\
Calomys musculinus & 8 & 14,8 & 1 & 2 & 2 & 10,5 \\
Phyllotis xanthopygus & 10 & 18,5 & 25 & 50 & 4 & 21 \\
Eligmodontia sp. & 4 & 7,4 & 4 & 8 & 2 & 10,5 \\
Reithrodon auritus & 3 & 5,6 & 2 & 4 & 1 & 5,3 \\
Euneomys chinchilloides & 54 & & 50 & & 19 & \\
\hline Total & & & & & \\
\hline
\end{tabular}

Tabla 7.37. Ensambles de micromamíferos de Cueva de Luna determinados por

Oliver Pearson. Modificado de Neme et al. (1997: Figura 2).

Estos datos, junto con los analizados en esta tesis, se exhiben en la tabla 7.38.

Las muestras arqueofaunísticas están dominadas por Ctenomys sp., P. xanthopygus, Eligmodontia sp., E. chinchilloides y $T$. pallidior, con la inclusión de M. australis y $R$. auritus. Asimismo, Ctenomys sp., Galea leucoblephara y Akodon iniscatus se registraron en todos los componentes arqueológicos y Calomys musculinus y L. halli en el Componente IV. Los índices de diversidad y de equitatividad dieron los siguientes valores: Componente I, II y III (H': 1,858; Equitatividad: 0,8455), Componente IV (H': 2,101; Equitatividad: 0,8764) y Componente V (H': 2,203; Equitatividad: 1). 


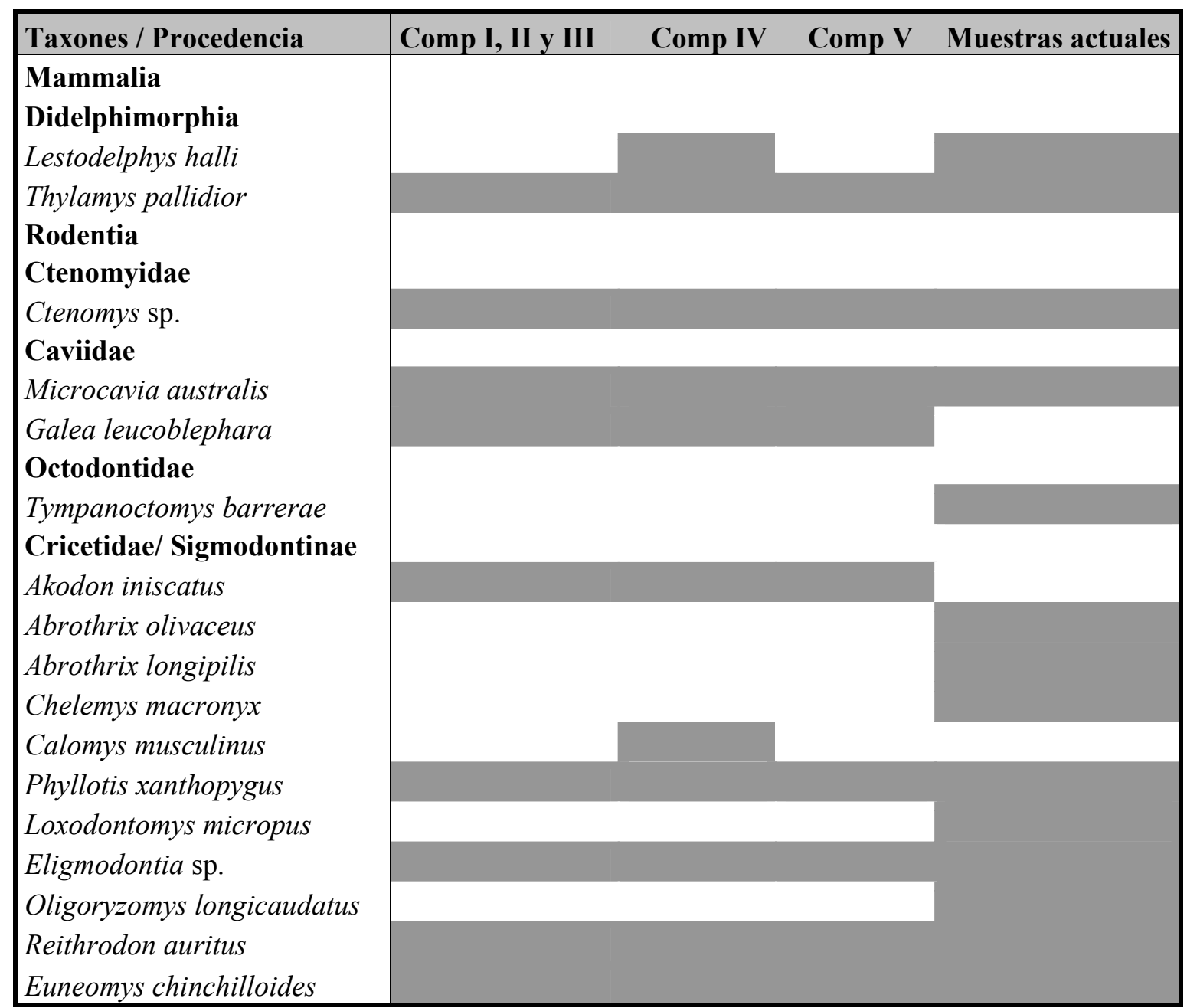

Tabla 7.38. presencia-ausencia de taxones de micromamíferos de los componentes de Cueva de Luna y los parámetros actualísticos.

\subsubsection{Discusión}

\subsubsection{Interpretación tafonómica}

La ausencia de marcas de corte y la presencia de un solo espécimen quemado, sugieren que los grupos humanos que habitaron la cueva no intervinieron en la génesis de los conjuntos de microvertebrados. No obstante, las evidencias de un elemento con resto de pelos de egagrópilas y de elementos con marcas de corrosión digestiva de tipo ligera, coinciden con la información tafonómica actualística sobre aves estrigiformes que comúnmente habitan en aleros o cuevas del sur de Mendoza (e.g., Tyto alba) (Andrews, 1990; Gómez, 2007; Fernández et al., 2009a). En este sentido, a pesar del tamaño chico de las muestras analizadas del sitio Cueva de Luna, los distintos atributos tafonómicos son coherentes con relacionar el origen de los agregados arqueofaunísticos 
principalmente a la acción de aves estrigiformes, posiblemente T. alba. Por otra parte, debido a solo se recolectaron los elementos craneales, la abundancia de roedores histricognatos registrada en Cueva de Luna podría asociarse a sesgos producto de las técnicas de recuperación (véase Pardinas, 1999a, 1999b, Pardinas y Teta, ms. enviado) como fue observado en el sitio Agua de La Mula.

Las escasas evidencias de meteorización, de bioturbación postdepositacional (e.g., marcas de raíces y marcas de roedores) y de transporte hídrico, indican que la mayor parte de los restos de micromamíferos exhumados de Cueva de Luna tuvieron un enterramiento rápido y alto grado de conservación (Korth, 1979; Andrews, 1990; Fernández-Jalvo y Andrews, 2003). Sin embargo, los elevados niveles de fractura registrados en los restos óseos de los componentes arqueológicos, con ángulos agudos y bordes ásperos, son consistentes con la acción de otros procesos postdepositacionales como el pisoteo, frecuentes en aleros o cuevas (e.g., Andrews, 1990; Pardiñas, 1999b).

Por otra parte, el registro de restos con evidencias de corrosión sedimentaria y óxido de manganeso en el Componente I, II y III y Componente IV, sugiere posibles eventos de encharcamiento de agua u oscilaciones del nivel freático, de moderado impacto (Courty et al., 1989; Gómez et al., 1999; Gómez, 2000).

\subsubsection{Interpretación paleoambiental}

Hay una correlación positiva alta y significativa entre la riqueza taxonómica y el tamaño de las muestras $\left(r_{s}=1 ; p>0\right)$, esta situación sumando a los bajos valores de MNI y a que no se pudo observar la muestra estudiada por O. Pearson (cf. Neme et al., 1995), limita el alcance de las conclusiones.

En la figura 7.27 se detallan las frecuencias relativas de los taxones de micromamíferos en las muestras estudiadas y las analizadas por O. Pearson.

La dominancia de P. xanthopygus, Eligmodontia sp., E. chinchilloides, T. pallidior, Ctenomys sp. y M. australis tanto en los componentes de Cueva de Luna como en localidades actuales próximas al sitio, indican que un ambiente con características afines a estepas arbustivas abiertas con alta proporción de suelo desnudo, pedregoso y abundante roca expuesta, se mantuvo constante desde ca. 3.800 años ${ }^{14} \mathrm{C}$ AP hasta la actualidad. No obstante, los registros de G. leucoblephara, A. iniscatus y C. musculinus únicamente en las muestras arqueológicas, sugieren condiciones afines al desierto del Monte en el pasado. Por otra parte, los registros de $R$. auritus en todos los componentes 
y de L. halli en el Componente IV muestran un ambiente de mosaico con la estepa Patagónica.

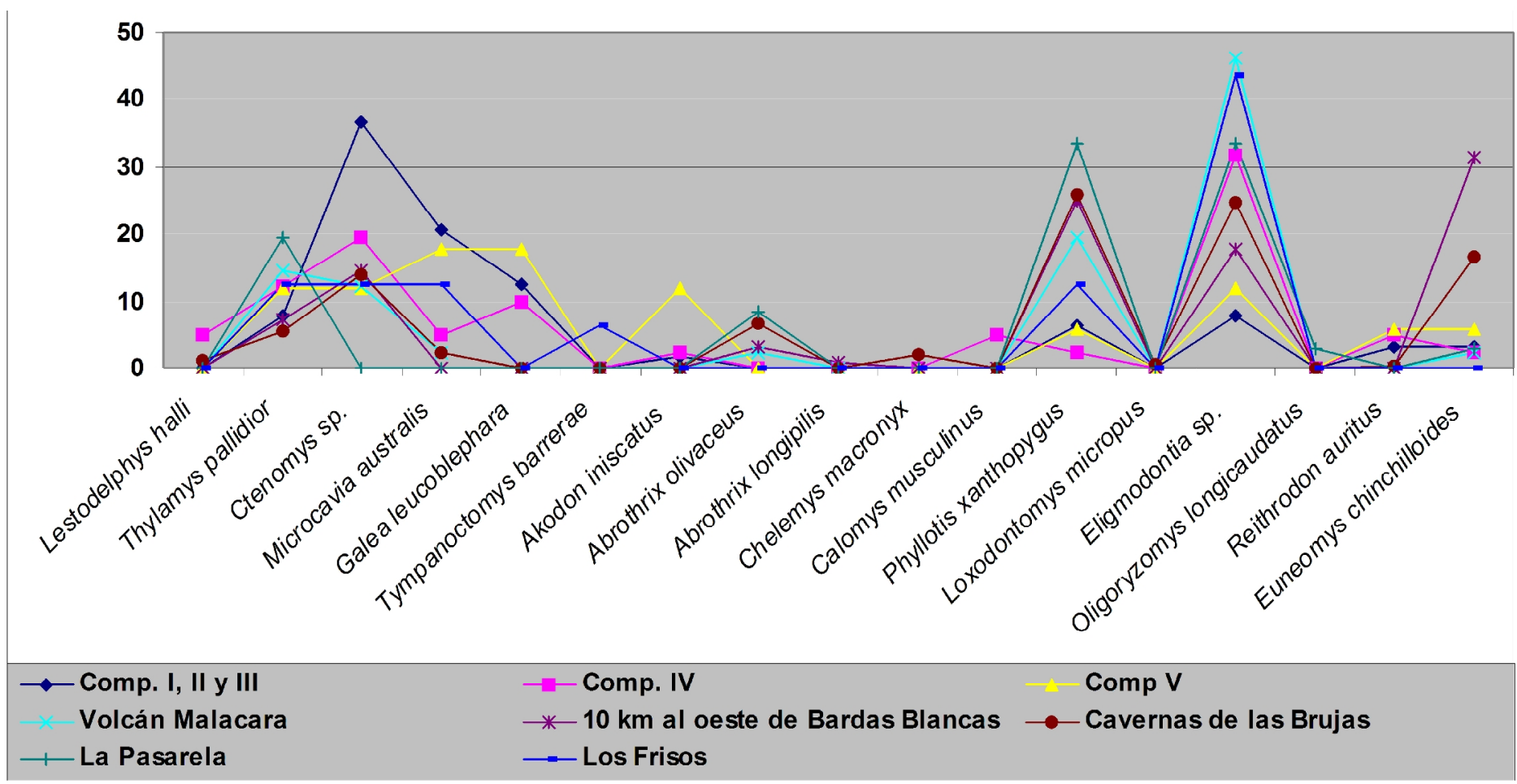

Figura 7.27. Comparación de las frecuencias relativas de los taxones de micromamíferos recuperados de los componentes de Cueva de Luna-3 y sus parámetros actualísticos.

Por otra parte, los registros de A. olivaceus, A. longipilis, C. macronyx, L. micropus y $O$. longicaudatus y T. barrerae, solo en las muestras modernas, sumado a los valores más pobres en términos de diversidad especificas, señalan que el ambiente actual se encuentra marcado por condiciones heterogéneas y antropizadas, que incluye el desarrollo de vegas pedemontanas y pastizales abiertos.

Los resultados del PCA (Figura 7.28) exhiben un agrupamiento de los componentes arqueológicos por un lado y las muestras actuales por el otro, con la excepción de Caverna de Las Brujas. En tal sentido, el primer componente principal (50,953\% de la varianza) pauta un alejamiento hacia la derecha de la muestra de Caverna de Las Brujas, posiblemente debido a la incorporación de algunas especies Patagónicas ( $L$. halli y $R$. auritus) y asociadas a vegas (C. macronyx y L. micropus), como elementos particulares entre los ensambles actuales. El segundo componente (22,586\% de la varianza), exhibe un contraste entre los componentes arqueológicos y las muestras actuales, lo que podría 
corroborar las diferencias entre las estructuras taxonómicas y sus ambientes asociados, explicados arriba.

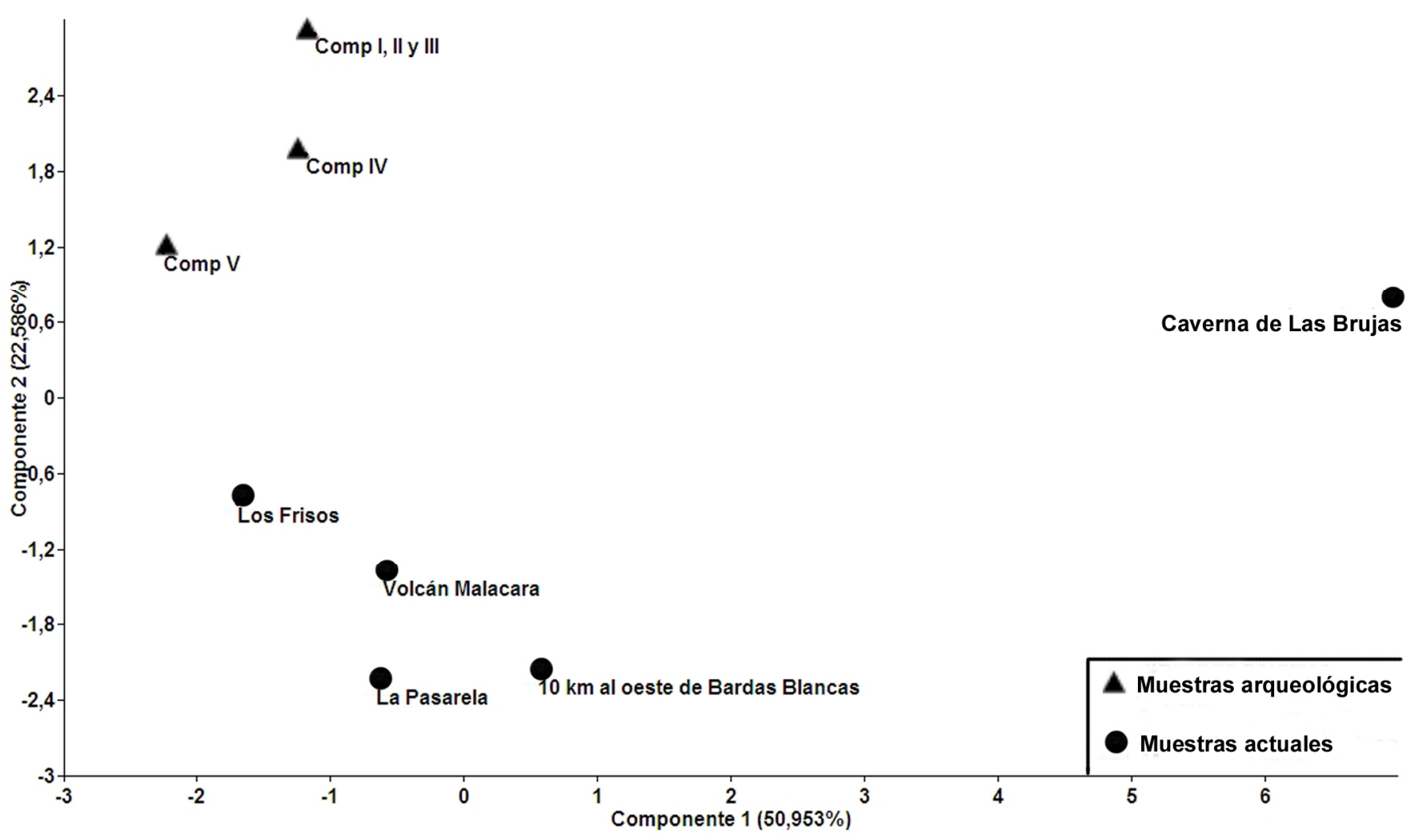

Figura 7.28 Gráfico de las muestras arqueológicas y actuales de micromamíferos de Cueva de Luna sobre el plano definido por los ejes 1 y 2 de un análisis de componente principal.

Finalmente, Durán (2000) enumeró como posibles hipótesis para explicar el hiatus ocupacional registrado entre $c a \cdot 3,8-1,5 \mathrm{ka}{ }^{14} \mathrm{C} \mathrm{AP}$, cambios en las condiciones ambientales e impacto de erupciones volcánicas. No obstante, por falta de datos precisos para ese período no se pudo relacionar con el registro de micromamíferos.

Estas interpretaciones paleoambientales pueden asociarse con los patrones de ocupaciones humanas observados en estudios previos (i.e., Durán y Ferrari, 1991; Neme et al., 1995; Durán, 1997, 2000). En este sentido, el mejoramiento ambiental registrado hacia $c a .1,5 \mathrm{ka}{ }^{14} \mathrm{C}$ AP por los altos valores de riqueza y diversidad taxonómica, podría relacionarse con el período de ocupaciones humanas prehispánicas (Componente IV) más continuas e intensivas observadas en Cueva de Luna.

\subsubsection{Conclusión}


Las características tafonómicas de las muestras indicaron que los ensambles de micromamíferos de Cueva de Luna fueron depositados principalmente por la acción de aves estrigiformes, posiblemente $T$. alba. Los escasos restos con meteorización, marcas de raíces, marcas de roedores y de transporte hídrico, señalan que los ensambles tuvieron un enterramiento rápido y alto grado de conservación. Sin embargo, se encontraron evidencias de pisoteo, corrosión sedimentaria y óxido de manganeso, sugiriendo posibles eventos de encharcamiento de agua u oscilaciones del nivel freático de moderado impacto.

El análisis de los ensambles de micromamíferos señala un ambiente con características afines a estepas arbustivas abiertas con alta proporción de suelo desnudo, pedregoso y abundante roca expuesta, se mantuvo constante desde ca. $3,8 \mathrm{ka}{ }^{14} \mathrm{C}$ AP hasta la actualidad. Las características de un ambiente de Monte se mantienen durante toda la secuencia. Sin embargo, hacia $c a .1,5 \mathrm{ka}{ }^{14} \mathrm{C}$ AP hay evidencias de mejoramiento ambiental con taxones afines al Monte y Patagónica, coincidente con el período de ocupaciones humanas prehispánicas más continuas e intensivas en Cueva de Luna. Actualmente, el ambiente actual es heretogéneo, incluyendo vegas pedemontanas, pastizales abiertos y roquedales. 


\subsection{Cueva Arroyo Colorado}

\subsubsection{Contexto arqueológico}

El sitio arqueológico Cueva Arroyo Colorado está ubicado sobre la margen izquierda del cauce cordillerano del arroyo homónimo, el cual es afluente del arroyo El Desecho, en la cuenca del Río Salado (35²12'10.65" S y 7004'38.91" O; 2.200 m.s.n.m.), importante tributario del Río Atuel (Lagiglia et al., 1994) (Figura 7.29 A y B).

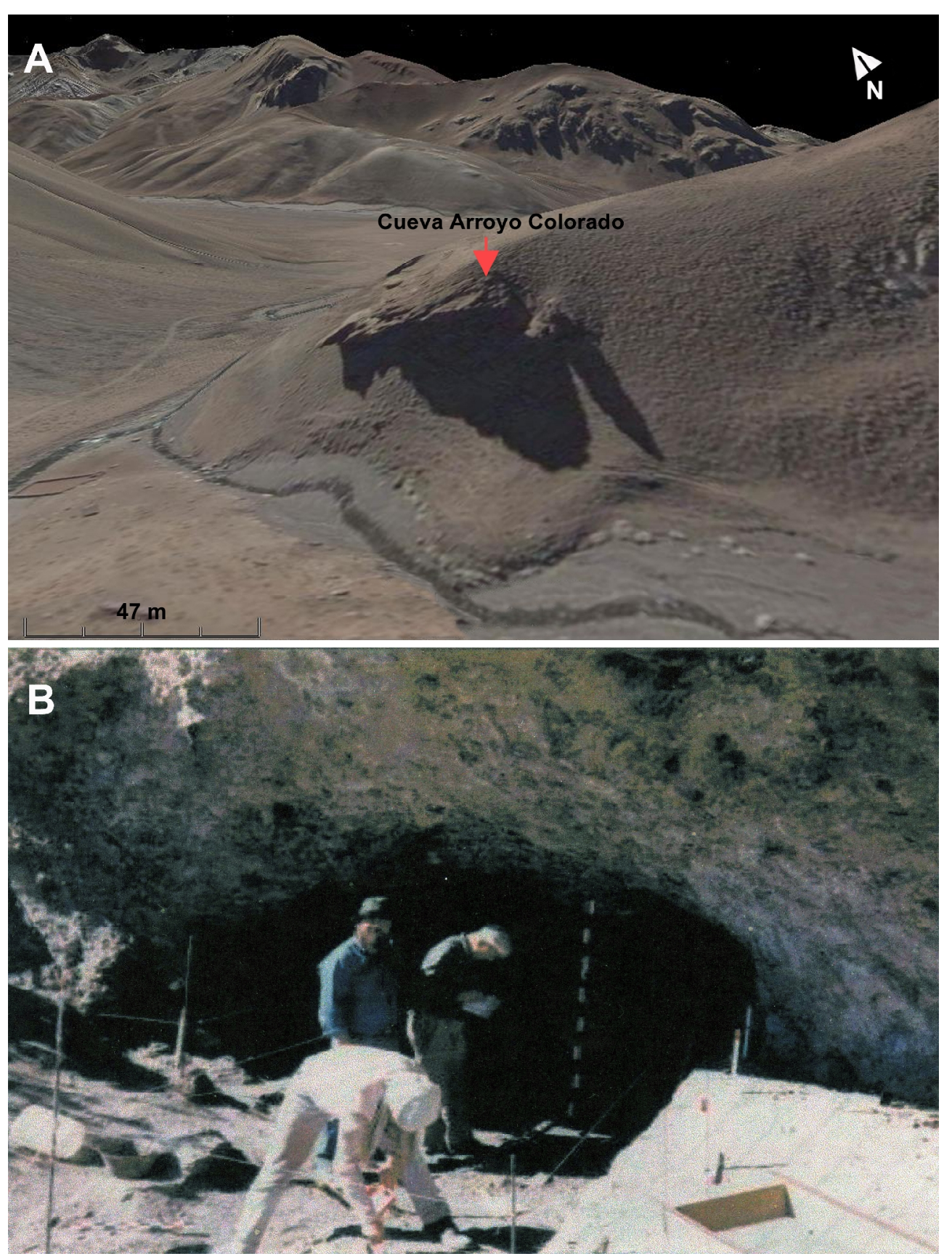

Figura 7.29. Sitio arqueológico Cueva Arroyo Colorado. A: ubicación del sitio. B: Vista de la entrada a la cueva y cuadrícula [Tomada de Atencio (2000: Figura 10A). 
Este sitio fue descubierto en 1989 como parte de las prospecciones que el personal del Museo Municipal de Historia Natural de San Rafael, dirigido por el Dr. Humberto Lagiglia, realizó en el área del valle del Salado y se excavó posteriormente en el verano de 1990 (Neme, 2007). La cueva está formada por sedimentos volcánicos asignados a la Formación Choiyoi (Dessanti, 1978). La misma tiene $4 \mathrm{~m}$ de abertura, alcanzando en su interior un máximo de $5 \mathrm{~m}$ de ancho y 5,5 $\mathrm{m}$ de profundidad. El desnivel desde la cueva al lecho del cauce del arroyo Colorado es de $45 \mathrm{~m}$ con una inclinación de $70^{\circ}$ (Lagiglia et al., 1994). Lagiglia, en sus notas de campo señala la presencia de cuevas de roedores en el sitio y un dormidero con fecas de felidae en el sector este del mismo, el cual permanece activo hasta la actualidad (Figura 7.30).

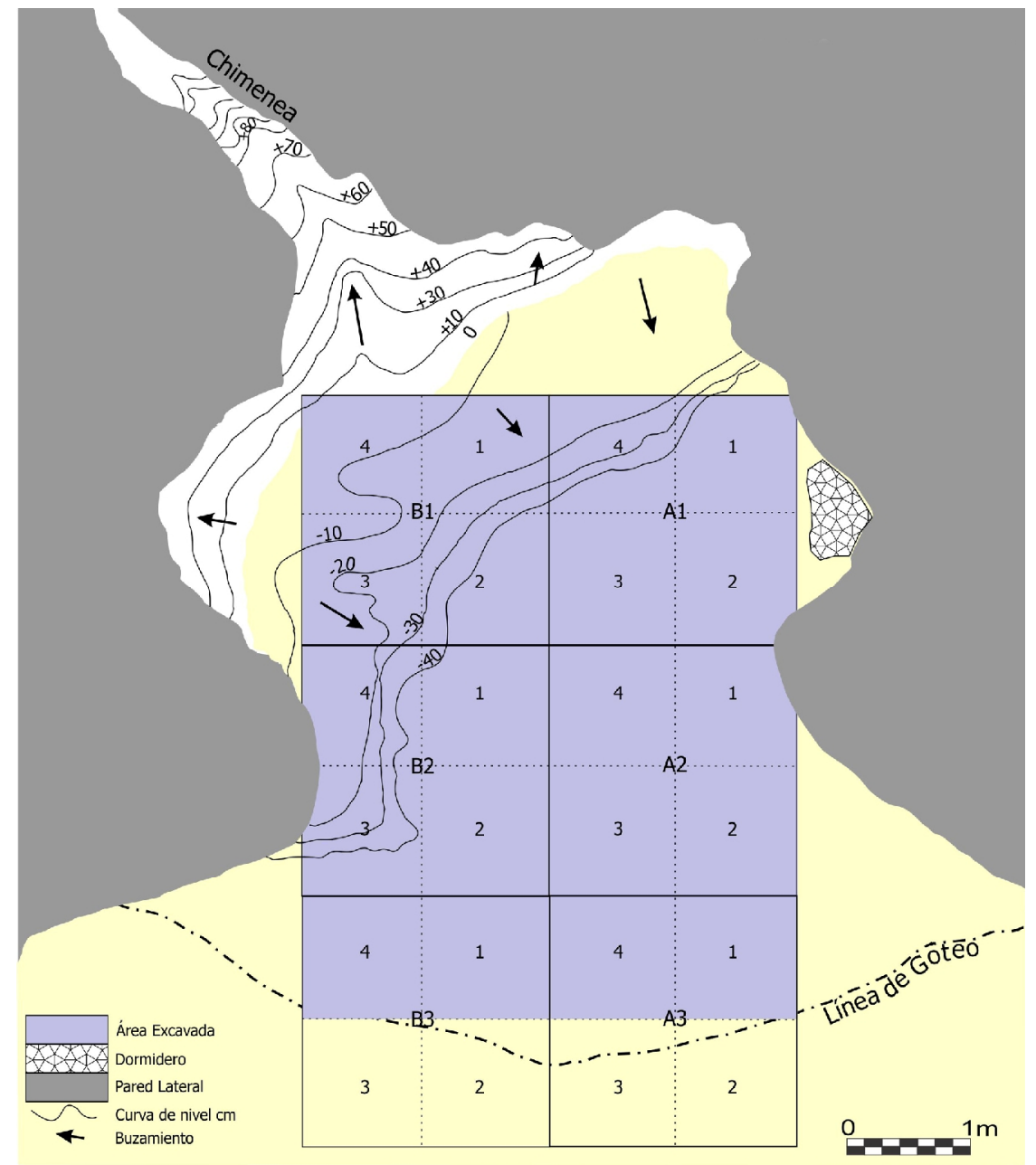

Figura 7.30. Vista en planta del sitio Cueva Arroyo Colorado. Tomado de Paulides (Tesis doctoral en preparación), el cual fuera modificado del relevamiento realizado por Humberto Lagiglia en 1990.

Para la extracción del material se realizaron excavaciones en seis cuadrículas, cuatro de $2 \times 2 \mathrm{~m}$ y dos de $1 \times 2 \mathrm{~m}$, ocupando las mismas casi toda la superficie de la cueva con 
una superficie de $20 \mathrm{~m}^{2}$. La remoción del sedimento se efectuó siguiendo niveles artificiales de $5 \mathrm{~cm}$ hasta alcanzar la roca madre a los $75 \mathrm{~cm}$ de profundidad (nivel 15) (Figura 7.31). El sedimento fue tratado en zarandas con mallas de $2 \mathrm{~mm}$ con el objetivo de extraer la mayor cantidad de restos posibles (Lagiglia et al., 1994).

La estratigrafía del sitio se compone de una serie de niveles que se caracterizan por un sedimento areno-limoso de origen eólico, con presencia de clastos provenientes en su mayoría de desprendimientos rocosos de la misma cueva (Lagiglia et al., 1994; Atencio, 2000).

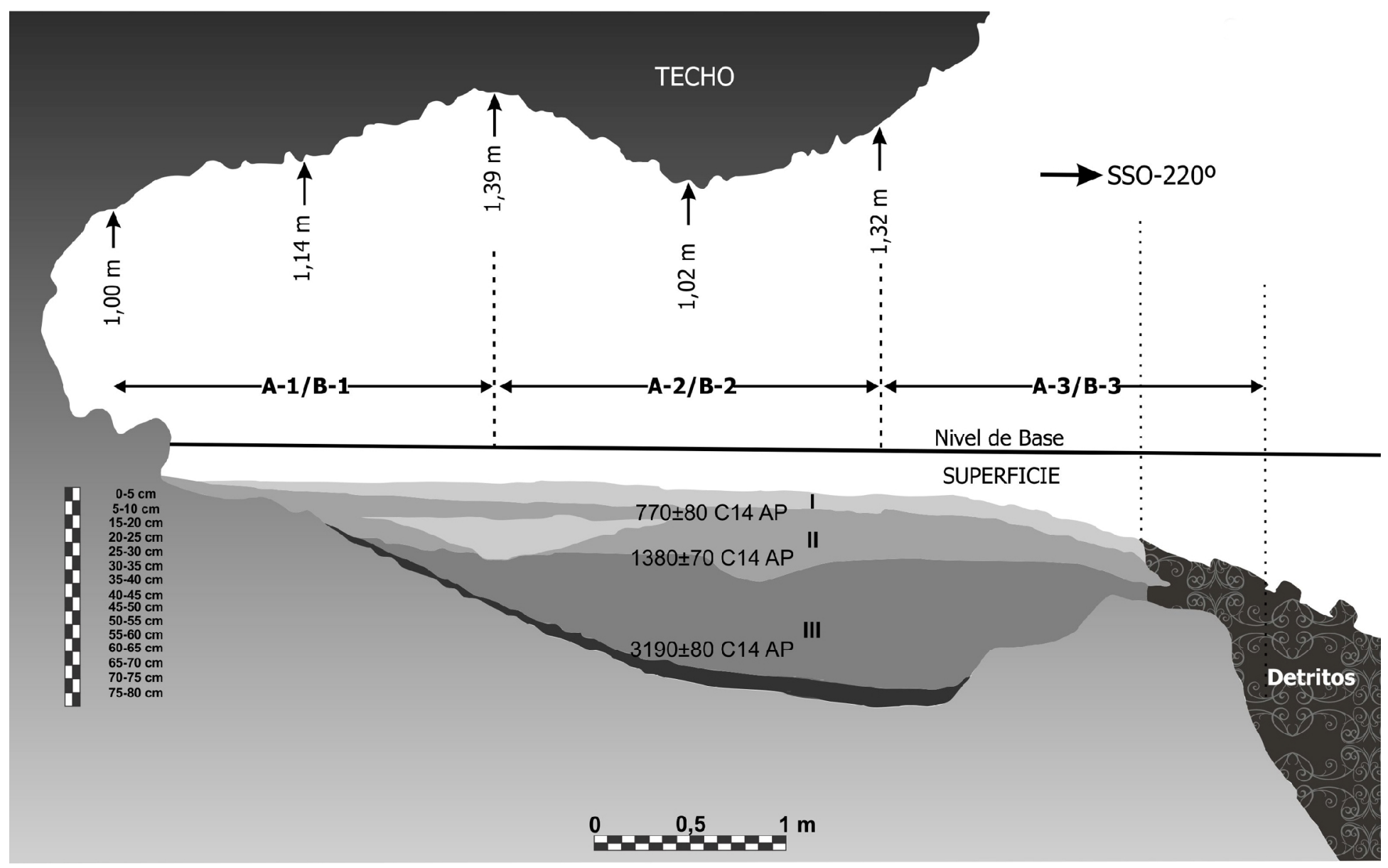

Figura 7.31. Vista del perfil del sitio Cueva Arroyo Colorado. Tomado de Paulides (Tesis doctoral en preparación), el cual fuera modificado del relevamiento realizado por Humberto Lagiglia en 1990.

Utilizando criterios cronológicos y tecnológicos, la secuencia arqueológica fue originalmente dividida en tres componentes culturales (Lagiglia et al., 1994) (Figura 7.31). El Componente I, con dos fechados radiocarbónicos de $770 \pm 80$ años ${ }^{14} \mathrm{C} \mathrm{AP}$ (muestra de carbón LP-447; Cuadrícula A-2; Nivel 3; 667-789 años cal AP) y $1380 \pm$ 70 años ${ }^{14} \mathrm{C}$ AP (muestra de carbón LP-457; Cuadrícula B-2; Nivel 7; 1232-1355 años cal AP), corresponde a los primeros $35 \mathrm{~cm}$ de excavación. Culturalmente fue 
caracterizado como una ocupación prehispánica con tecnología cerámica y puntas triangulares escotadas. El Componente II, registrado entre los 35 y $60 \mathrm{~cm}$ de profundidad, no cuenta con fechados y está definido por la ausencia de tecnología cerámica y puntas de base redondeada. Por último, el Componente III, entre los 60 y 75 cm con un fechado radiocarbónico de $3190 \pm 80$ años ${ }^{14} \mathrm{C}$ AP (muestra de carbón LP472; Cuadrícula A-2; Nivel 13; 3341-3517 años cal AP), se caracteriza por la presencia de puntas triangulares y amigdaloides espesas (Lagiglia et al., 1994).

Para este trabajo de tesis se siguieron los lineamientos del análisis arqueofaunístico previo realizado por Gil y Neme (1996), en el cual los Componentes II y III fueron agrupados en uno solo (en adelante llamado Componente II cuya edad fue estimada entre 3190 y 1380 años ${ }^{14} \mathrm{C}$ AP) debido, a la escasa cantidad de restos arqueofaunísticos recuperados en esos niveles (Neme, 2007).

En el mencionado análisis arqueofaunístico se registraron 1.090 restos óseos, de los cuales se determinaron taxonómicamente el 40\% (Gil y Neme, 1996; Neme, 2007) (Tabla 7.39).

\begin{tabular}{|l|c|c|}
\hline Taxones & Componente I & Componente II \\
\hline Ave indet. & 1 & 1 \\
Mammalia & & \\
Artiodactyla indet. & 25 & 26 \\
Lama guanicoe & 215 & 132 \\
Carnivora indet. & 14 & - \\
Lycalopex culpaeus & 11 & - \\
Lycalopex sp. & 3 & - \\
Dasypodidae indet. & 3 & 1 \\
Rodentia & & \\
Lagidium viscacia & 2 & 1 \\
\hline
\end{tabular}

Tabla 7.39. Lista taxonómica de vertebrados medianos y grandes registrados en Cueva Arroyo Colorado (expresada en NISP). Modificada de Neme (2007: 58).

De los taxones determinados Lama guanicoe fue el más abundante a lo largo de la secuencia. Todas las partes esqueletales de esta especie estaban presentes en ambos componentes, pero los porcentajes de MAU (Unidades Anatómicas Mínimas) observados en el Componente II (más temprano) indican una sobre representación de los cuartos traseros y delanteros (Gil y Neme, 1996). Por otra parte los autores citados evidenciaron un aumento en la diversidad taxonómica hacia los niveles más tardíos de la secuencia (Componente I). Estas diferencias en la diversidad taxonómicas entre los dos componentes de Cueva Arroyo Colorado fueron explicadas como una ampliación en 
el rango de explotación de las especies hacia los momentos más tardíos (Gil y Neme, 1996; Neme, 2007).

Posteriormente, Otaola (tesis doctoral en preparación) estudió una muestra arqueofaunística más grande (12.316 especímenes) y con mayor profundidad. La autora citada identificó taxonómicamente restos de vertebrados medianos y grandes, tales como L. guanicoe (Componentes I y II), Lycalopex culpaeus (Componentes I y II), Lycalopex griseus (Componente I), Dasypodidae (Componentes I y II) y Rheidae (Componente I). Por otra parte, la autora registró evidencias de actividad antrópica (e.g., marcas de corte, negativo de impacto, marcado, instrumentos óseos, lascas óseas, restos termolterados) en ambos componentes culturales, con proporciones similares. Asimismo, documentó marcas de mamíferos carnívoros en ambos componentes, aunque en bajas proporciones (Componente I: 1,39 \% y Componente II: 0,94 \%). Finalmente, plantea que los artiodáctilos fueron los principales integrantes de la dieta de los grupos humanos que habitaron la cueva, aunque en el Componente I observó mayor cantidad de taxones consumidos (Otaola, tesis doctoral en preparación).

\subsubsection{Metodología}

En el marco de los estudios tafonómicos de los micromamíferos se siguió la metodología utilizada por Andrews (1990), Fernández-Jalvo y Andrews (1992). No obstante para el caso de los restos de aves, reptiles y anfibios no se pudo hacer un examen detallado debido a la escasa representación de especímenes recuperados en los dos componentes.

Si bien Andrews (1990) y Fernández-Jalvo y Andrews (1992) proponen observar la corrosión postcraneal sobre la porción proximal del fémur y la distal del húmero, considerando que las muestras estudiadas no cuentan con un número representativo de dichos huesos, se optó por analizar todos los elementos postcraneales.

Como parámetros actualísticos se estudiaron una muestra de 64 egagrópilas de Tyto alba, las cuales fueron recolectadas en enero del 2006 a 1.750 metros al este del sitio arqueológico [Localidad $6 \mathrm{~km}$ al S de Las Leñas (ver apéndice)] y cuatro muestras de egagrópilas de Bubo magellanicus provenientes de una localidad situada a $18 \mathrm{~km}$ al este del sitio, la cual fue publicada en la literatura científica [Laguna de la Niña Encantada (ver apéndice)]. En este estudió se integro la información taxonomica de las cuatro muestras de B. magellanicus en una sola. 


\subsubsection{Resultados}

\subsubsection{Análisis tafonómico}

\subsection{Componente I}

El $16,3 \%$ de los restos sufrieron modificación por digestión, enmarcados principalmente en la categoría ligera y en menor medida en la categoría moderada (Tabla 7.40). De modo que los restos que estaban corroídos presentaron un leve poseado en las superficies (Figura $32 \mathrm{~A}$ ).

\begin{tabular}{|c|c|c|c|c|c|c|c|c|c|c|}
\hline & \multicolumn{10}{|c|}{ Clases de digestión sensu Andrews (1990) } \\
\hline & \multicolumn{2}{|c|}{ Ausente } & \multicolumn{2}{|c|}{ Ligera } & \multicolumn{2}{|c|}{ Moderada } & \multicolumn{2}{|c|}{ Fuerte } & \multicolumn{2}{|c|}{ Extrema } \\
\hline & $(\mathrm{N})$ & $\%$ & $(\mathrm{~N})$ & $\%$ & $(\mathrm{~N})$ & $\%$ & $(\mathrm{~N})$ & $\%$ & $(\mathrm{~N})$ & $\%$ \\
\hline Componente I & & & & & & & & & & \\
\hline Digestión dentaria & & & & & & & & & & \\
\hline Incisivos in situ & 40 & 88,9 & 5 & 11,1 & - & - & - & - & - & - \\
\hline Incisivos aislados & 2 & 22,2 & 6 & 66,7 & 1 & 11,1 & - & - & - & - \\
\hline Incisivos Total & 42 & 77,8 & 11 & 20,4 & 1 & 1,8 & - & - & - & - \\
\hline Molares in situ & 71 & 98,6 & 1 & 1,4 & - & - & - & - & - & - \\
\hline Molares aislados & - & - & - & - & - & - & - & - & - & - \\
\hline Molares Total & 71 & 98,6 & 1 & 1,4 & - & - & - & - & - & - \\
\hline Digestión Postcraneal & & & & & & & & & & \\
\hline Fémur (epífisis proximal) & 11 & 61,1 & 6 & 33,3 & 1 & 5,6 & - & - & - & - \\
\hline Húmero (epífisis distal) & 11 & 64,7 & 5 & 29,4 & 1 & 5,9 & - & - & - & - \\
\hline Otros restos postcraneales & 60 & 83,3 & 11 & 15,3 & 1 & 1,4 & - & - & - & - \\
\hline Componente II & & & & & & & & & & \\
\hline Digestión dentaria & & & & & & & & & & \\
\hline Incisivos in situ & 7 & 58,3 & - & - & 2 & 16,7 & 3 & 25 & - & - \\
\hline Incisivos aislados & 2 & 22,2 & - & - & - & - & 7 & 77,8 & - & - \\
\hline Incisivos Total & 9 & 42,9 & - & - & 2 & 9,5 & 10 & 47,6 & - & - \\
\hline Molares in situ & 27 & 79,4 & - & - & 1 & 2,9 & 6 & 17,6 & - & - \\
\hline Molares aislados & - & - & - & - & - & - & - & - & - & - \\
\hline Molares Total & 27 & 79,4 & - & - & 1 & 2,9 & 6 & 17,6 & - & - \\
\hline Digestión Postcraneal & & & & & & & & & & \\
\hline Fémur (epífisis proximal) & - & - & - & - & 1 & 50 & 1 & 50 & - & - \\
\hline Húmero (epífisis distal) & 1 & 14,3 & 1 & 14,3 & 2 & 28,6 & 2 & 28,6 & 1 & 14,3 \\
\hline Otros restos postcraneales & 13 & 27,1 & 13 & 27,1 & 9 & 18,7 & 8 & 16,7 & 5 & 10,4 \\
\hline
\end{tabular}

Tabla 7.40. Representación de las distintas categorías de corrosión digestiva en micromamíferos de los componentes de Cueva Arroyo Colorado. 


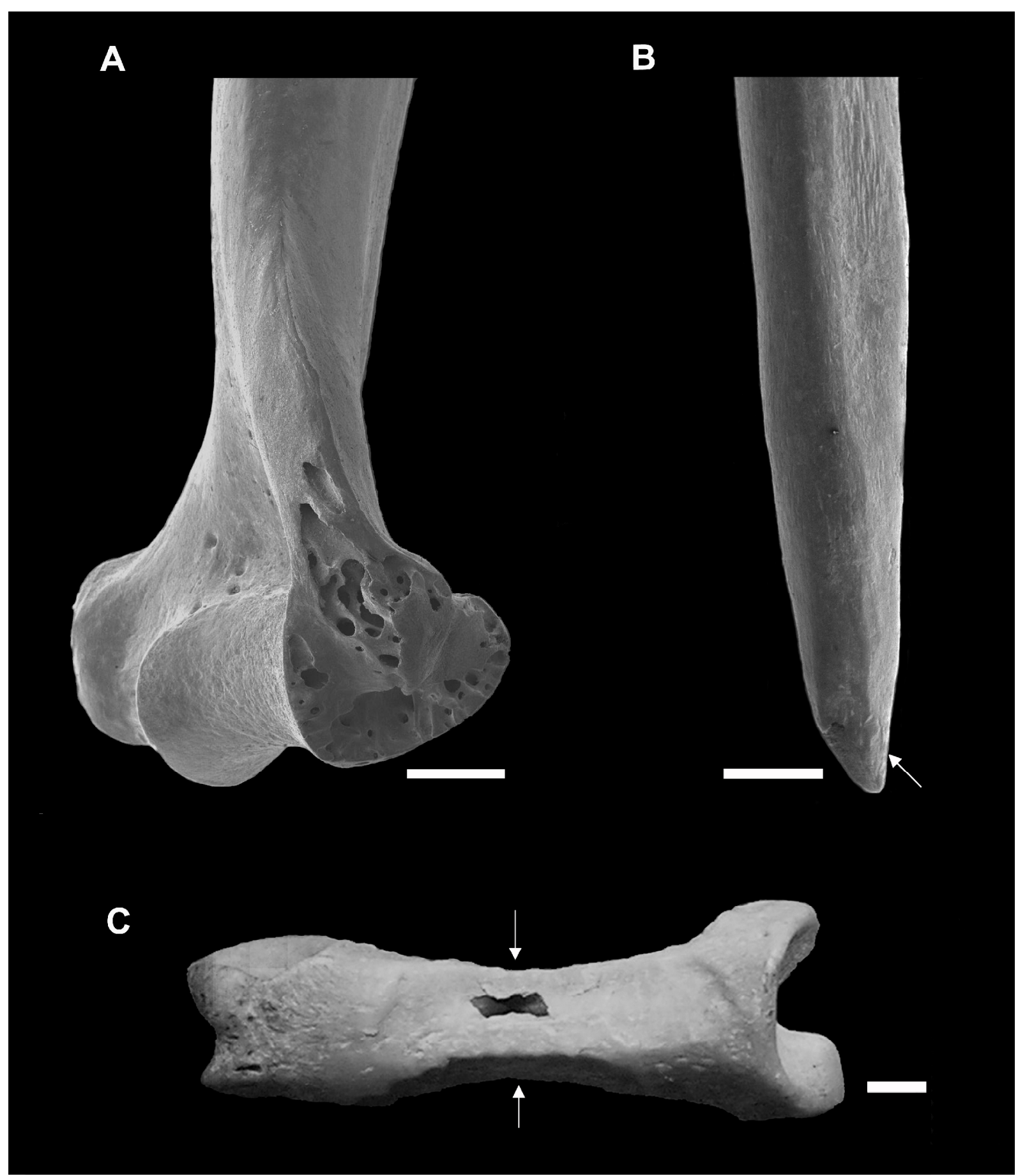

Figura 7.32. Ejemplos de acción de agentes naturales en los distintos componentes de Cueva Arroyo Colorado. A: húmero de Ctenomys sp. con marcas de digestión ligera localizadas en la epífisis distal (Componente I, Nivel 2). B: tibia de Sigmodontinae con adelgazamiento en la epífisis distal producida por corrosión fuerte (Componente II, Nivel 12). C: falange de Lagidium viscacia con marcas de roedores (Componente I, Nivel 1). Escalas: $1 \mathrm{~mm}$. 
La abundancia relativa promedio de la muestra fue baja (8\%) y los elementos mejor representados fueron la mandíbula, maxilar, fémur, húmero y tibia (Tabla $7.41 \mathrm{y}$ Figura 7.33).

\begin{tabular}{|c|c|c|c|c|}
\hline \multirow[t]{2}{*}{ Elemento / procedencia } & \multicolumn{2}{|c|}{ Componente I } & \multicolumn{2}{|c|}{ Componente II } \\
\hline & MNE & $\begin{array}{c}\text { Abundancia } \\
\text { relativa }\end{array}$ & MNE & $\begin{array}{c}\text { Abundancia } \\
\text { relativa }\end{array}$ \\
\hline Maxilar & 19 & 15,3 & 12 & 17,6 \\
\hline Mandíbula & 76 & 61,3 & 34 & 50 \\
\hline Incisivos aislados & 9 & 3,6 & 9 & 2,9 \\
\hline Molares aislados & - & - & - & - \\
\hline Vértebras & 5 & 0,3 & 2 & 0,2 \\
\hline Costillas & - & - & - & - \\
\hline Escápula & 2 & 1,6 & - & - \\
\hline Húmero & 17 & 13,7 & 11 & 16,2 \\
\hline Cúbito & 2 & 1,6 & - & - \\
\hline Radio & - & - & 1 & 1,5 \\
\hline Pelvis & 12 & 9,7 & 6 & 8,8 \\
\hline Fémur & 19 & 15,3 & 9 & 13,2 \\
\hline Tibia & 16 & 12,9 & 9 & 13,2 \\
\hline Calcáneo & - & - & - & - \\
\hline Astrágalo & - & - & - & - \\
\hline Metapodio & 1 & 0,1 & 2 & 0,3 \\
\hline Falanges & 4 & 0,1 & 2 & 0,1 \\
\hline $\begin{array}{l}\text { Total } \\
\text { Promedio }\end{array}$ & 182 & 8 & 97 & 7,3 \\
\hline
\end{tabular}

Tabla 7.41. Número mínimo de elementos (MNE) y abundancia relativa, para los ensambles de micromamíferos de los componentes de Cueva Arroyo Colorado.

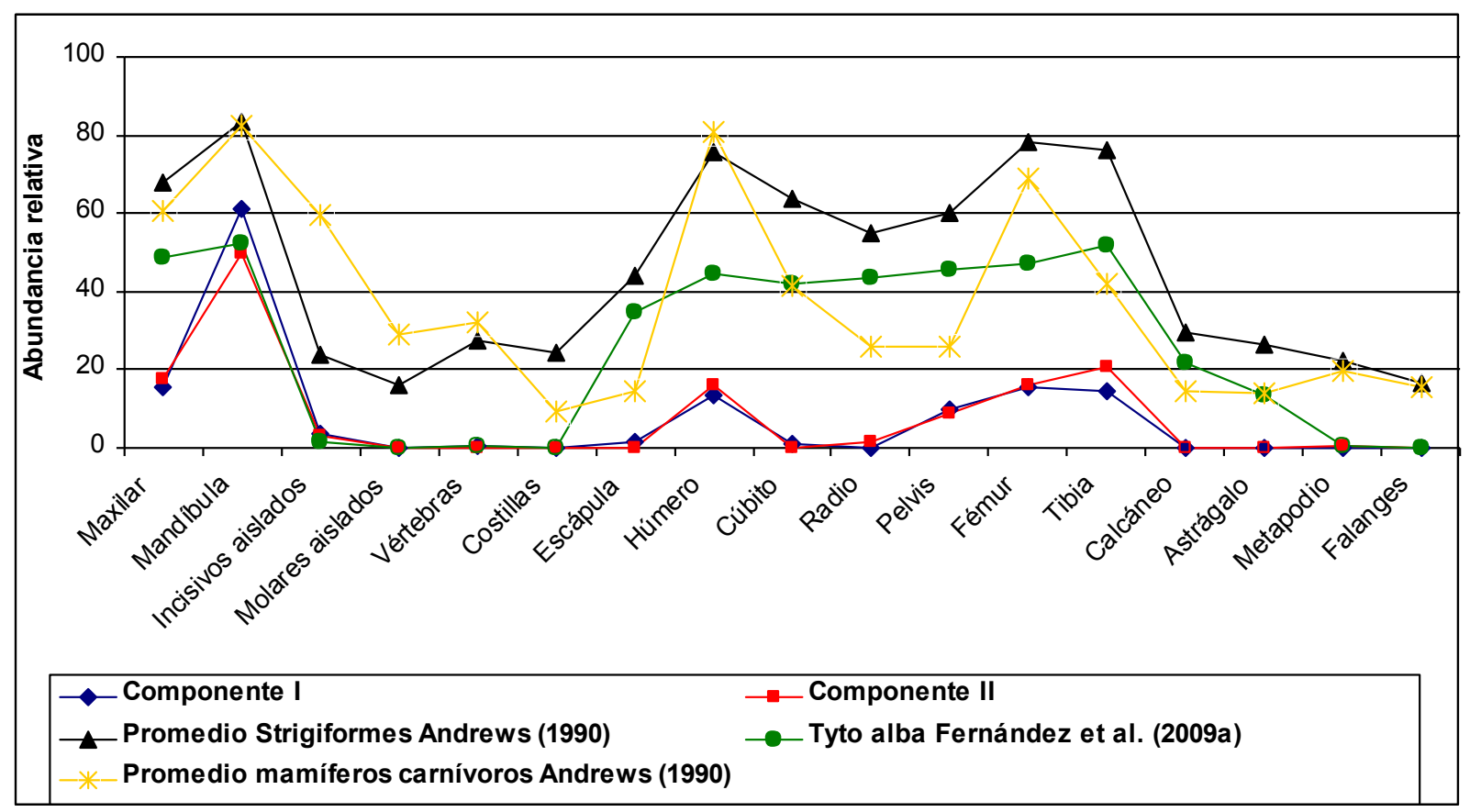


Figura 7.33. Valores de abundancia relativa de los diferentes elementos anatómicos de los componentes de Cueva Arroyo Colorado, comparados con una muestra de Tyto alba analizada por Fernández et al. (2009a) y el promedio de Strigiformes y mamíferos carnívoros realizado por Andrews (1990).

En la tabla 7.42 se muestran los distintos tipos de fractura craneal, dentaria y postcraneal.

No se registraron cráneos completos y la mayor parte de ellos se hallaron fracturados, de este modo que en todos los casos se perdieron los huesos de la bóveda y frontales, y solo un bajo porcentaje de los maxilares mantuvieron los arcos zigomáticos. Una moderada proporción de molares y todos los incisivos se perdieron de los maxilares y premaxilares, respectivamente.

La mayor parte de las mandíbulas estaban fracturadas en distintos grados. Una elevada proporción de molares e incisivos estaban retenidos en las mandíbulas. Asimismo, se recuperaron una baja proporción de dientes fracturados.

El $13,4 \%$ de los elementos postcraneales estaban completos (i.e., húmeros, cúbitos, fémures y tibias, sensu Andrews, 1990). Además, en los fémures prevalecieron los segmentos proximales y en los húmeros los segmentos distales. Las características de los bordes de las fracturas son ásperos y con ángulos bien marcados, sin presentar signos de corrosión por digestión. Todas las vértebras, metapodios y falanges estaban completas. Sin embargo, los elementos más frágiles como las, escápulas y pelvis estaban fracturados.

Teniendo en cuenta los valores obtenidos a partir de los índices calculados (Tabla 7.42), se observa que los que evalúan la relación entre elementos postcraneales y craneales, indican una mejor preservación de los elementos craneales. Por otra parte, el índice que calcula la relación entre elementos distales y proximales de los miembros muestra una pérdida importante de elementos distales, mientras que los que valoran la proporción relativa de dientes aislados sugieren que la mayor parte de los molares e incisivos quedaron retenidos en los alvéolos. 


\begin{tabular}{|c|c|c|c|c|}
\hline & $\begin{array}{c}\text { Componente } \\
\mathrm{N} \\
\end{array}$ & $\begin{array}{c}\text { I } \\
\% \\
\end{array}$ & $\begin{array}{c}\text { Componente } \\
\mathrm{N} \\
\end{array}$ & $\begin{array}{c}\text { II } \\
\% \\
\end{array}$ \\
\hline \multicolumn{5}{|l|}{ Fractura de cráneos } \\
\hline Cráneos completos & - & - & - & - \\
\hline Maxilares con arcos zigomáticos & 4 & 21 & 2 & 16,7 \\
\hline Maxilares sin arcos zigomáticos & 15 & 79 & 10 & 83,3 \\
\hline Pérdida de molares de maxilares & 15 & 42,8 & 10 & 45,5 \\
\hline Pérdida de incisivos de premaxilares & 6 & 100 & 4 & 100 \\
\hline \multicolumn{5}{|l|}{ Fractura de mandíbulas } \\
\hline Mandíbulas completas & 3 & 4 & 2 & 5,9 \\
\hline Mandíbulas con rama ascendente rota & 25 & 32,9 & 8 & 23,5 \\
\hline Mandíbulas sin rama ascendente & 26 & 34,2 & 11 & 32,4 \\
\hline Mandíbulas sin rama ascendente y borde inferior roto & 22 & 28,9 & 13 & 38,2 \\
\hline Pérdida de molares de las mandíbulas & 19 & 26,8 & 19 & 45,2 \\
\hline Pérdida de incisivos de la mandíbulas & 15 & 25 & 22 & 64,7 \\
\hline \multicolumn{5}{|l|}{ Fractura de dientes } \\
\hline Molares rotos in situ & 7 & 9,7 & 27 & 79,4 \\
\hline Molares aislados rotos & - & - & - & - \\
\hline Total de molares rotos & 7 & 9,7 & 27 & 79,4 \\
\hline Incisivos rotos in situ & 2 & 4,4 & 9 & 75 \\
\hline Incisivos aislados rotos & 5 & 55,6 & 8 & 88,9 \\
\hline Total de incisivos rotos & 7 & 12,9 & 17 & 80,9 \\
\hline \multicolumn{5}{|l|}{ Fractura de Postcráneo } \\
\hline \multicolumn{5}{|l|}{ Fémur } \\
\hline Completo & 6 & 26,1 & 1 & 11,1 \\
\hline Segmento proximal & 12 & 52,2 & 1 & 11,1 \\
\hline Diáfisis & 3 & 13 & 6 & 66.7 \\
\hline Segmento distal & 2 & 8,7 & 1 & 11,1 \\
\hline \multicolumn{5}{|l|}{ Húmero } \\
\hline Completo & 3 & 13 & 1 & 8,3 \\
\hline Segmento proximal & 4 & 17,4 & 2 & 16,7 \\
\hline Diáfisis & 2 & 8,7 & 3 & 25 \\
\hline Segmento distal & 14 & 60,9 & 6 & 50 \\
\hline \multicolumn{5}{|l|}{ Tibia } \\
\hline Completo & 2 & 12,5 & 5 & 45,4 \\
\hline Segmento proximal & 3 & 18,7 & 1 & 9,1 \\
\hline Diáfisis & 3 & 18,7 & 1 & 9,1 \\
\hline Segmento distal & 8 & 50 & 4 & 36,4 \\
\hline \multicolumn{5}{|l|}{ Cúbito } \\
\hline Completo & - & - & - & - \\
\hline Segmento proximal & 2 & 50 & - & - \\
\hline Diáfisis & 2 & 50 & - & - \\
\hline Segmento distal & - & - & - & - \\
\hline
\end{tabular}

Tabla 7.42. Fractura de elementos craneales, dentarios y postcraneales, para los micromamíferos provenientes de los componentes de Cueva Arroyo Colorado. 


\begin{tabular}{|l|c|c|}
\hline & Componente I & Componente II \\
\hline Postcráneo / Cráneo & & \\
$\mathrm{f}+\mathrm{t}+\mathrm{h}+\mathrm{r}+\mathrm{c} / \mathrm{mx}+\mathrm{mb}+\mathrm{m}$ & 84,6 & 107,6 \\
$\mathrm{~h}+\mathrm{f} / \mathrm{mx}+\mathrm{mb}$ & 37,9 & 47,8 \\
Elementos distales / proximales & & \\
$\mathrm{t}+\mathrm{r} / \mathrm{f}+\mathrm{h}$ & 50 & 68,2 \\
Pérdida de dientes & & \\
Alvéolos mx+ alvéolos mb/m & 75,3 & 85,2 \\
Alvéolos mx+ alvéolos mb/i & 46,9 & 244,4 \\
Índice de Tamaño (IT) & 780 & 178,6 \\
Índice de Predictibilidad (IP) & 12,8 & 62,5 \\
\hline
\end{tabular}

Tabla 7.43. Valores de los índices calculados en los componentes de Cueva Arroyo Colorado.

Referencias: f: fémur; t: tibia; h: húmero; r: radio; c: cúbito; mx: maxilar; mb: mandíbula; m: molar; i: incisivo.

Por otro lado, en este componente se observaron alteraciones postdepositacionales, entre las que se destacan la meteorización $(7,2 \%)$, manchas de óxido de manganeso $(10,3 \%)$, corrosión sedimentaria por humedad del suelo $(20,2 \%)$, altos niveles de fractura $(68,2 \%)$ posiblemente a causa del pisoteo (véase sección 7.6.4.1) y un resto con marcas de roedores (Figura $7.33 \mathrm{C}$ ). No se hallaron evidencias de redondeamiento en los extremos y protuberancias de los restos óseos, indicando que no actuaron los efectos de la abrasión por transporte hídrico, desplazamientos y rozamientos de los restos contra el sedimento (Korth, 1979; Fernández-Jalvo y Andrews, 2003).

También se destaca la alta cantidad de huesos no articulados de Ctenomys sp.y se detectó la presencia de galerías subterráneas como producto de la acción cavadora de este roedor (véase discusión y conclusiones). Los índices IT e IP indicaron una preeminencia de microvetebrados de menor tamaño y solitarios.

En lo que concierne a los restos de aves recuperados, se observó que el 65\% de los huesos se hallaron fracturados con bordes ásperos y ángulos agudos al eje de la diáfisis (categoría "aguda", sensu Bochenski y Tomek, 1997) y el 31\% exhibieron marcas por acción digestiva localizadas en epífisis, presentando forma de hoyos y depresiones con bordes redondeados (categoría "redondeada", sensu Bochenski y Tomek, 1997). Por su parte, los restos de reptiles también se hallaron fracturados y exhibieron marcas ligeras por acción digestiva.

Una característica para destacar, es el hallazgo de algunas evidencias de actividad antrópica, como huellas de corte en la tibia de un cávido, caracterizadas por una serie de marcas trasversales al eje del hueso, la marca de corte ubicada en la parte proximal 
de la diáfisis, es más profunda que el resto de las marcas, las cuales van disminuyendo en tamaño a medida que se alcanza la parte distal de la misma (Figura 7.34 A-C). Esto coincide con la fisonomía de los raspados sobre huesos de roedores con instrumentos líticos (véase Quintana, 2005). Asimismo, se hallaron huesos quemados en los roedores más grandes, pero en baja representación (3 elementos).

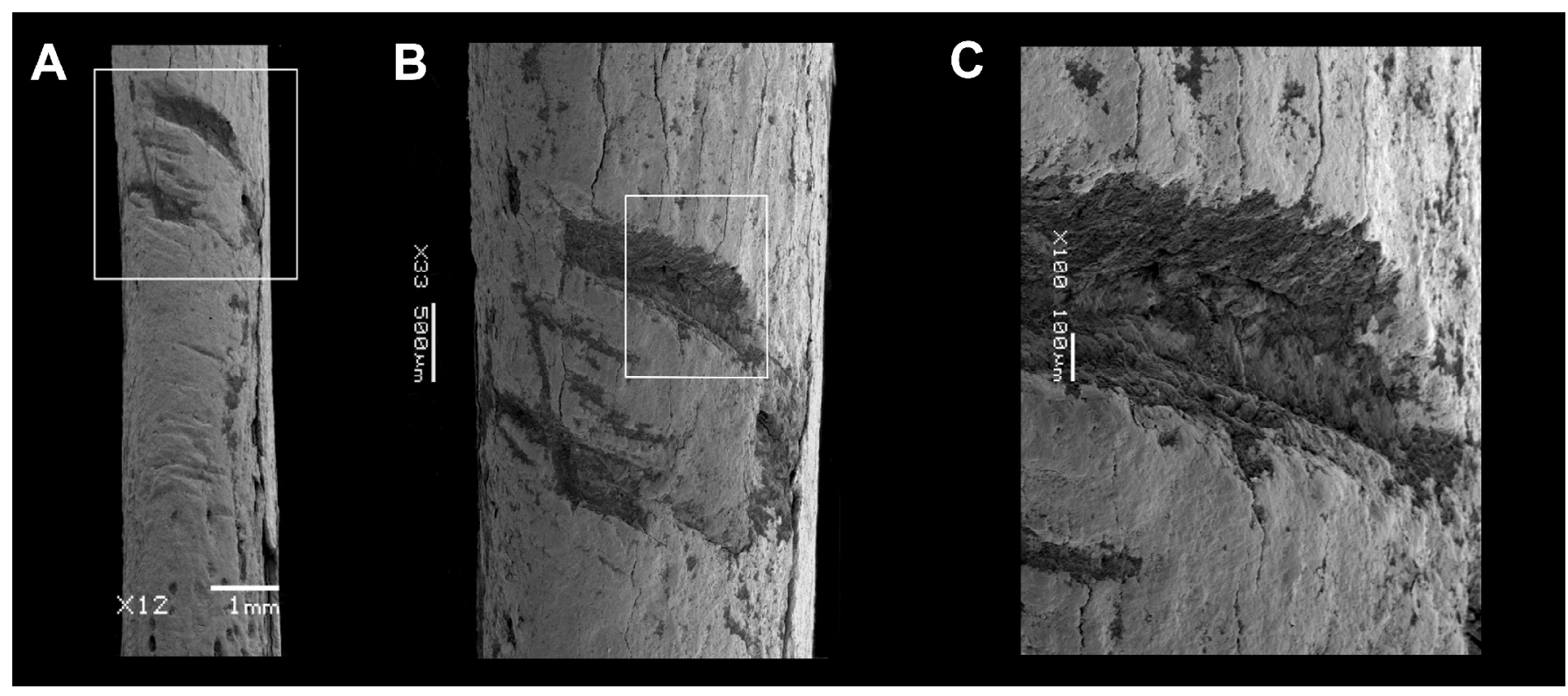

Figura 7.34. Fragmento de diáfisis de una tibia de Caviidae con huellas de corte por acción antrópica (Componente I, Nivel 2). A: vista general de la diáfisis mostrando todas las marcas. B: acercamiento de las tres marcas principales. C: acercamiento de la primera marca caracterizada por forma de V.

\subsection{Componente II}

Se observó que 55,4\% de los restos presentaron marcas de corrosión digestiva, variando entre las categorías de modificación ligera y extrema (Tabla 7.40 y Figura 7.32 B). De manera que, hubo restos que presentaron un ligero poseado en la superficie y otros donde la corrosión afectó a gran parte del elemento.

Los cráneos siempre se encontraron fragmentados; en todos los casos se perdieron los huesos de la bóveda y frontales, y se observó un alto porcentaje de ruptura de incisivos y molares in situ (Tabla 7.42). La mayor parte de las mandíbulas presentaron un alto nivel de fracturadas. Una moderada proporción de molares y una elevada proporción de incisivos se desprendieron de las mandíbulas. Asimismo, se registraron una alta proporción de dientes fracturados. 
La abundancia relativa promedio de la muestra fue baja $(7,3 \%)$ y los elementos mejor representados fueron la mandíbula, maxilar, fémur, húmero y tibia (Tabla 7.41 y Figura $7.33)$.

El grado de fractura de los elementos postcraneales, muestra que solo el 21,9\% de estos elementos fue recuperado en forma completa (Tabla 7.42). Además, en los fémures prevalecieron las diáfisis y en los húmeros y tibias los segmentos distales. Asimismo, todas las vértebras, radios, pelvis, metapodios y falanges estaban fracturados. Las características de los bordes de las fracturas son suaves y con ángulos redondeados, con signos de corrosión digestiva.

Los índices que dan una idea del estado de preservación de los elementos craneales con respecto a los elementos del postcráneo, dieron valores que muestran una preservación pareja en el primero y una mejor preservación de los elementos craneales en el segundo. El índice que valora la relación entre elementos distales y proximales de los miembros exhibe una importante pérdida de elementos distales de los miembros con respecto a los proximales, mientras que los que calculan la proporción relativa de dientes aislados muestran una proporción mayor de permanencia de molares en maxilares y mandíbulas, y una importante pérdida de incisivos, respectivamente (Tabla $7.43)$.

También se destaca la alta cantidad de huesos no articulados de Ctenomys sp. y se detectó la presencia de galerías subterráneas como producto de la acción cavadora de este roedor (véase discusión y conclusiones).

Los índices IT e IP indicaron un marcado predominio de microvetebrados de menor tamaño y solitarios.

En lo que concierne a los escasos restos de aves recuperados en este componente $(\mathrm{NISP}=4)$, se observó que los huesos se hallaron fracturados con bordes suaves, ángulos redondeados y adelgazados (categoría de fractura "redondeada", sensu Bochenski y Tomek, 1997); y exhibieron marcas por acción digestiva en epífisis caracterizada con hoyos y depresiones con bordes redondeados (categoría de superficies dañadas "redondeada" sensu Bochenski y Tomek, 1997). Por su parte, los restos de reptiles y anfibios $(\mathrm{NISP}=2)$ también se hallaron fracturados y con marcas de acción digestiva.

Además, en algunos restos se registraron leves indicios de modificaciones postdepositacionales: meteorización $(1,7 \%)$, manchas de óxido de manganeso $(2,6 \%)$ y corrosión sedimentaria por humedad del suelo $(3,5 \%)$. 


\subsubsection{Asociación de microvertebrados de las muestras actuales}

Como se ilustra en la tabla 7.44, los ensambles de microvertebrados de las muestras actuales están dominados por roedores sigmodontinos, siendo Euneomys chinchilloides, Phyllotis xanthopygus, Abrothrix longipilis y Abrothrix olivaceus, los taxones más representados, seguidos por Chelemys macronyx, Loxodontomys micropus y Eligmodontia sp. con frecuencias menores.

\begin{tabular}{|c|c|c|c|c|}
\hline Taxones / procedencia & $\begin{array}{c}1 \\
\text { MNI }\end{array}$ & $\%$ & $\begin{array}{r}2 \\
\text { MNI }\end{array}$ & $\%$ \\
\hline \multicolumn{5}{|l|}{ Aves } \\
\hline \multicolumn{5}{|l|}{ Columbiformes } \\
\hline Metriopelia melanoptera & 1 & 0,5 & - & - \\
\hline \multicolumn{5}{|l|}{ Passeriformes } \\
\hline Asthenes cf. A. dorbignyi & 1 & 0,5 & - & - \\
\hline Ammodramus humeralis & 2 & 1 & - & - \\
\hline Charadridae indet. & 1 & 0,5 & - & - \\
\hline \multicolumn{5}{|l|}{ Mammalia } \\
\hline \multicolumn{5}{|l|}{ Didelphimorphia } \\
\hline Thylamys pallidior & - & - & 12 & 3,5 \\
\hline \multicolumn{5}{|l|}{ Rodentia } \\
\hline \multicolumn{5}{|l|}{ Ctenomyidae } \\
\hline Ctenomys sp. & 14 & 7,1 & 27 & 7,9 \\
\hline \multicolumn{5}{|l|}{ Caviidae } \\
\hline Microcavia australis & - & - & 1 & 0,3 \\
\hline \multicolumn{5}{|l|}{ Cricetidae / Sigmodontinae } \\
\hline Abrothrix olivaceus & 16 & 8,2 & 36 & 10,5 \\
\hline Abrothrix longipilis & 31 & 15,8 & 27 & 7,9 \\
\hline Chelemys macronyx & 11 & 5,6 & 14 & 4,1 \\
\hline Eligmodontia sp. & 5 & 2,6 & 22 & 6,4 \\
\hline Phyllotis xanthopygus & 32 & 16,3 & 95 & 27,7 \\
\hline Loxodontomys micropus & 8 & 4,1 & 2 & 0,6 \\
\hline Euneomys mordax & 22 & 11,2 & - & - \\
\hline Euneomys chinchilloides & 52 & 26,5 & 107 & 31,2 \\
\hline Total & 196 & & 343 & \\
\hline Riqueza & 13 & & 10 & \\
\hline $\mathbf{H}^{\prime}$ & 2,09 & & 1,87 & \\
\hline Equitatividad & 0,82 & & 0,65 & \\
\hline
\end{tabular}

Tabla 7.44. Tabla x. Muestras actuales (expresadas en MNI y MNI\%). 1: $6 \mathrm{~km}$ al S de Las Leñas; 2: Laguna de la Niña Encantada (Massoia et al., 1994; Nabte et al., 2006; Pardiñas et al., 2008). 
En moderada proporción se registró el roedor histricognato (Ctenomys sp.). Con porcentajes menores se encuentran el marsupial Thylamys pallidior, las aves paseriformes (Asthenes cf. A. dorbignyi y Ammodramus humeralis), columbiformes (Metriopelia melanoptera) y un charádrido indeterminado.

No obstante, por un lado Euneomys mordax únicamente se registró en localidad más cercana al sitio (6 km al S. de Las Leñas) y por el otro Thylamys pallidior y Microcavia australis se recuperaron solo en la localidad mas alejada (Laguna de La Niña Encantada). El índice de diversidad de Shannon arrojó un valor levemente mayor para la muestra de $6 \mathrm{~km}$ al $\mathrm{S}$. de Las Leñas.

\subsubsection{Asociación de microvertebrados de las muestras arqueofaunísticos}

Se analizaron 349 especímenes, 241 correspondientes al Componente I y 108 Componente II. La información correspondiente a las abundancias relativas de los microvertebrados por muestras arqueofaunísticas (expresadas como valores de NISP, MNE y MNI) se detalla en la tabla 7.45.

\subsection{Componente I}

El ensamble de microvertebrados del Componente I está dominado por roedores sigmodontinos, siendo P. xanthopygus, Euneomys chinchilloides y C. macronyx las especies más representadas, seguidas por A. longipilis, L. micropus, E. mordax y Eligmodontia sp. Con frecuencias menores se encontraron los roedores histricognatos Ctenomys sp., M. autralis y Lagidium viscacia (juvenil). En menor proporción se registraron saurios liolaémidos indeterminados y aves paseriformes (Sicalis sp., Phrygilus fruticeti y Pseudoseisura gutturalis). El índice de diversidad de Shannon arrojó un valor de 2, 217 (Tabla 7.45).

\subsection{Componente II}

El ensamble de microvertebrados del Componente II está conformado principalmente por roedores sigmodontinos, siendo E. chinchilloides, $P$. xanthopygus y A. longipilis las especies más representadas, seguidas por C. macronyx, L. micropus, E. mordax y Eligmodontia sp. En este componente Ctenomys sp., fue abundante y también se 
encontraron restos de individuos juveniles de L. viscacia. En bajos porcentajes se registraron, chirópteros, anfibios anuros, saurios liolaémidos y aves paseriformes indeterminados. El índice de diversidad de Shannon arrojó un valor de 2,279 (Tabla 7.45).

\begin{tabular}{|c|c|c|c|c|c|c|c|c|c|c|c|c|}
\hline \multirow[t]{2}{*}{ Taxones / Procedencia } & \multicolumn{6}{|c|}{ Componente I } & \multicolumn{6}{|c|}{ Componente II } \\
\hline & NISP & $\%$ & MNE & $\%$ & MNI & $\%$ & NISP & $\%$ & MNE & $\%$ & MNI & $\%$ \\
\hline Amphibia / Anura indet. & - & - & - & - & - & - & 1 & 0,9 & 1 & 1 & 1 & 2,6 \\
\hline Reptilia / Liolaemidae indet. & 10 & 4,1 & 10 & 4,5 & 8 & 9,1 & 1 & 0,9 & 1 & 1 & 1 & 2,6 \\
\hline Ave indet. & 5 & 2,1 & 5 & 2,2 & 3 & 3,4 & 1 & 0,9 & 1 & 1 & 1 & 2,6 \\
\hline Passeriformes indet. & 15 & 6,2 & 15 & 6,7 & 7 & 8 & 2 & 1,9 & 2 & 1,9 & 1 & 2,6 \\
\hline Oscinae indet. & 1 & 0,4 & 1 & 0,4 & 1 & 1,1 & - & - & - & - & - & - \\
\hline Emberizidae indet. & - & - & - & - & - & - & 1 & 0,9 & 1 & 1 & 1 & 2,6 \\
\hline Sicalis sp. & 1 & 0,4 & 1 & 0,4 & 1 & 1,1 & - & - & - & - & - & - \\
\hline Phrygilus fruticeti & 3 & 1,2 & 3 & 1,3 & 1 & 1,1 & - & - & - & - & - & - \\
\hline Suboscinae indet. & 2 & 0,8 & 2 & 0,9 & 2 & 2,3 & - & - & - & - & - & - \\
\hline Furnariidae indet. & 4 & 1,7 & 4 & 1,8 & 2 & 2,3 & - & - & - & - & - & - \\
\hline Pseudoseisura gutturalis & 1 & 0,4 & 1 & 0,4 & 1 & 1,1 & - & - & - & - & - & - \\
\hline Mammalia / Rodentia indet* & 18 & 7,5 & 7 & 3,1 & - & - & 3 & 2,8 & 1 & 1 & - & - \\
\hline Ctenomyidae & & & & & & & & & & & & \\
\hline Ctenomys sp. & 21 & 8,7 & 21 & 9,4 & 7 & 8 & 35 & 32,4 & 35 & 34 & 12 & 30,7 \\
\hline Caviidae indet. & 1 & 0,4 & 1 & 0,4 & 1 & 1,1 & - & - & - & - & - & - \\
\hline Microcavia australis & 1 & 0,4 & 1 & 0,4 & 1 & 1,1 & - & - & - & - & - & - \\
\hline Chinchillidae & & & & & & & & & & & & \\
\hline Lagidium viscacia & 2 & 0,8 & 2 & 0,9 & 1 & 1,1 & 2 & 1,9 & 2 & 1,9 & 2 & 5,1 \\
\hline Cricetidae / Sigmodontinae indet.* & 64 & 26,6 & 58 & 25,9 & - & - & 30 & 27,8 & 25 & 24,3 & - & - \\
\hline Abrothrix longipilis & 6 & 2,5 & 6 & 2,7 & 4 & 4,5 & 3 & 2,8 & 3 & 2,9 & 3 & 7,7 \\
\hline Chelemys macronyx & 15 & 6,2 & 15 & 6,7 & 10 & 11,4 & 2 & 1,9 & 2 & 1,9 & 2 & 5,1 \\
\hline Eligmodontia sp. & 1 & 0,4 & 1 & 0,4 & 1 & 1,1 & 2 & 1,9 & 2 & 1,9 & 1 & 2,6 \\
\hline Phyllotis xanthopygus & 33 & 13,7 & 33 & 14,7 & 18 & 20,5 & 7 & 6,4 & 7 & 6,8 & 4 & 10,3 \\
\hline Loxodontomys micropus & 6 & 2,5 & 6 & 2,7 & 4 & 4,5 & 2 & 1,9 & 2 & 1,9 & 2 & 5,1 \\
\hline Euneomys mordax & 8 & 3,3 & 8 & 3,6 & 4 & 4,5 & 3 & 2,8 & 3 & 2,9 & 2 & 5,1 \\
\hline Euneomys chinchilloides & 23 & 9,5 & 23 & 10,3 & 11 & 12,5 & 10 & 9,2 & 10 & 9,7 & 5 & 12,8 \\
\hline Chiroptera indet. & - & - & - & - & - & - & 3 & 2,8 & 5 & 4,9 & 1 & 2,6 \\
\hline Total & 241 & & 224 & & 88 & & 108 & & 103 & & 39 & \\
\hline Riqueza & & & & & 14 & & & & & & 13 & \\
\hline $\mathbf{H}^{\prime}$ & & & & & 2,264 & & & & & & 2,279 & \\
\hline Equitatividad & & & & & 0,858 & & & & & & 0,8885 & \\
\hline
\end{tabular}

* principalmente elementos postcraneales, posiblemente correspondientes a los taxones determinados.

Tabla 7.45. Composición taxonómica de los ensambles de microvertebrados de los componentes de Cueva Arroyo Colorado (expresada en NISP, MNE y MNI).

\subsubsection{Discusión}




\subsubsection{Interpretación tafonómica}

Andrews (1990) observó que la digestión de mamíferos carnívoros producía altos valores de corrosión y fractura en restos óseos y dentarios, pérdida de elementos distales y un sesgo en la proporción de elementos craneales respecto de los postcraneales. Estas observaciones son acordes a las evidenciadas del Componente II. Montalvo et al. (2007), en base a un análisis tafonómico sobre restos óseos de mamíferos consumidos por Puma concolor, registraron que este depredador producía altos valores de destrucción sobre los huesos de mamíferos medianos y grandes, sin embargo, los restos de micromamíferos exhibieron una gradación en la preservación, incluyendo tanto restos con alta modificación, como restos bien preservados. Ellos postulan que estas diferencias podrían deberse a que los microvertebrados fueron ingeridos enteros, sin masticación previa. Además, observaron un sesgo de elementos craneales con respecto a los postcraneales, alta representación de mandíbulas y baja representación de vértebras. Por otro lado, Gómez y Kaufmann (2007) en un estudio tafonómico sobre restos óseos ingeridos por L. griseus y Montalvo et al. (2008) al analizar huesos consumidos por Conepatus chinga registraron que ambos depredadores presentaron niveles de modificación extrema (Categoría V, sensu Andrews, 1990), principalmente por la acción de ácidos digestivos y efectos de la masticación. Los restos del Componente II mostraron una gradación en la preservación, alta representación de mandíbulas y baja representación de vértebras, como la obtenida por Montalvo et al. (2007) en la muestra de P. concolor. Por las características de la muestra, el agente acumulador de microvertebrados de este componente podría ser un mamífero carnívoro, probablemente un félido, debido a que éstos son los carnívoros con menores niveles de masticación sobre los restos de microvertebrados. Ergo, la presencia en la cueva de un dormidero de carnívoros registrado por Lagiglia durante sus trabajos de campo robustece esta asunción.

En el Componente I los niveles de digestión fueron ligeros, similares a los observados por Andrews (1990) y por Fernández et al. (2009a) en muestras de T. alba.

Por otro lado, las abundancias relativas de los elementos, los valores de índices, los altos niveles de fractura registrados en los restos óseos de este componente, son inconsistentes con el bajo grado de corrosión digestiva mencionado, de modo que, en base a las características de los bordes de fractura se lo atribuye a procesos postdepositacionales como el pisoteo (véase más adelante cuando se discute sobre este 
tópico). Es importante destacar, que T. alba se considera el mayor acumulador de restos de pequeños vertebrados hallados en cuevas y refugios rocosos (Andrews, 1990; Saavedra y Simonetti, 1998). Asimismo, las especies halladas en el Componente I, son parte de la dieta habitual de T. alba (e.g., Bellocq, 2000).

Conjuntamente, en este componente se encontraron evidencias de actividad antrópica lo que podría estar sujeto a prácticas de consumo de microvertebrados y en especial de roedores cávidos, por parte de los grupos humanos que habitaron la cueva en este período. La explotación de estos roedores presenta ciertas ventajas en relación a su estrategia reproductiva y etología, ya que tienen alta densidad poblacional, son gregarios y predecibles (véase Quintana, 2005 y literatura allí citada). Los estudios zooarqueólogicos de vertebrados de mediano y gran tamaño realizados en Cueva Arroyo Colorado, coinciden en que la diferencia en la diversidad de especies consumidas por los grupos humanos entre los componentes del sitio, puede ser entendida como una ampliación en el rango de explotación de las especies hacia momentos tardíos (Gil y Neme, 1996; Neme, 2007; Otaola, tesis doctoral en preparación) (ver Capítulo 8 para un discusión detallada y regional sobre explotación humana).

En base a estas evidencias, se sugiere que el principal agente acumulador de los microvertebrados del Componente I, habría sido un Strigiformes de acción destructiva ligera, posiblemente $T$. alba y en menor medida los grupos humanos, los cuales también habrían contribuido a la formación del mismo.

Un aspecto a considerar es el referido al hallazgo de numerosos restos no articulados de Ctenomys sp. y galerías subterráneas como producto de la acción cavadora de estos roedores en los dos componentes. Asimismo algunos especímenes de Ctenomys sp. presentaron marcas de corrosión digestiva (véase Figura 7.32 A). Por otro lado la muerte de un roedor en una madriguera generalmente deriva en la conservación de sus restos en posición articulada o semi-articulada (Pardiñas, 1999b). Se infiere que algunos restos de Ctenomys sp. han ingresado al sitio por acción de depredadores, sin descartar que otros hayan sido incorporados por muerte natural en las cuevas.

Entre los restos del Componente II se hallaron escasas evidencias de modificaciones postdepositacionales, las que son frecuentes entre los restos del Componente I, entre ellas se destacan el pisoteo, la corrosión sedimentaria por elevada humedad del suelo y manchas de óxido de manganeso. Estos tipos de modificaciones, podrían confundir en la instancia de indagar acerca del agente causal de la acumulación, ya que las mismas 
perturban la composición original de los conjuntos fósiles, produciendo, entre otras, altos niveles de fractura y alteraciones de las superficies óseas (Matthews et al., 2006). Sin embargo, en diversos estudios realizados sobre conjuntos de microvertebrados, se pudieron observar diferencias entre estos tipos de modificaciones; de modo que, los agentes postdepositacionales producen alteraciones en los restos óseos que afectan de igual forma a toda la superficie de los mismos, esto difiere de la corrosión por digestión que tiene una acción usualmente localizada (Andrews, 1990; FernándezJalvo y Andrews, 1992; Bochenski y Tomek, 1997; Worthy, 2001). Por su parte, el pisoteo proporciona altos niveles de dispersión y fractura en los agregados fósiles, los restos presentan bordes angulosos y ásperos (Korth, 1979; Andrews, 1990; Bochenski y Tomek, 1997); por el contrario, los restos óseos fracturados e ingeridos por depredadores, presentan bordes redondeados, suaves y con huellas de corrosión digestiva (Andrews, 1990; Bochenski y Tomek, 1997). Este tipo de proceso, es habitual en las cuevas, debido a que son unidades espaciales de circulación restringida. No obstante, estos sitios están más protegidos de los agentes meteóricos (i.e., sol, lluvia, viento) que los sitios a cielo abierto (Pardiñas, 1999b).

La impregnación por óxidos de manganeso es un proceso diagenético que actúa sobre los restos formando manchas de color negro en las superficies; el manganeso precipita como óxido en ambientes donde alternan ciclos de reducción-oxidación (Courty et al., 1989). Esta precipitación se produce cuando hay una saturación de estos elementos en agua y una escasez de oxígeno. Este tipo de proceso es común en sitios donde existen oscilaciones del nivel freático o encharcamientos de agua (Gómez et al., 1999; Gómez, 2000). Estas condiciones se habrían dado en los niveles que contienen los restos del Componente I, coincidente con los altos niveles de corrosión sedimentaria por elevada humedad del suelo observada en mismo. Bajo condiciones de permanente humedad en el sedimento, los huesos de micromamíferos son afectados en su totalidad, mientras que en condiciones de sequedad, son mejor preservados (Andrews, 1990).

\subsubsection{Interpretación paleoambiental}

Hay una correlación positiva media y no significativa entre la riqueza taxonómica y el tamaño de las muestras $\left(r_{s}=0,5 ; p>0,66\right)$, esta situación sumado a los bajos valores de MNI, limita parcialmente el alcance de las conclusiones. 
Las diferencias en las estructuras taxonómicas entre los componentes de la muestra fósil, pueden deberse a que los conjuntos de microvertebrados fueron originados por distintos agentes, los cuales presentan diferencias en su ecología trófica. Sin embargo, otros autores citan a las aves Strigiformes como buenas estimadoras de las comunidades de micromamíferos de un área determinada, debido a las características generalistas de su dieta (e.g., Andrews, 1990).

En la figura 7.35 se detallan las frecuencias relativas de los roedores en las muestras estudiadas.

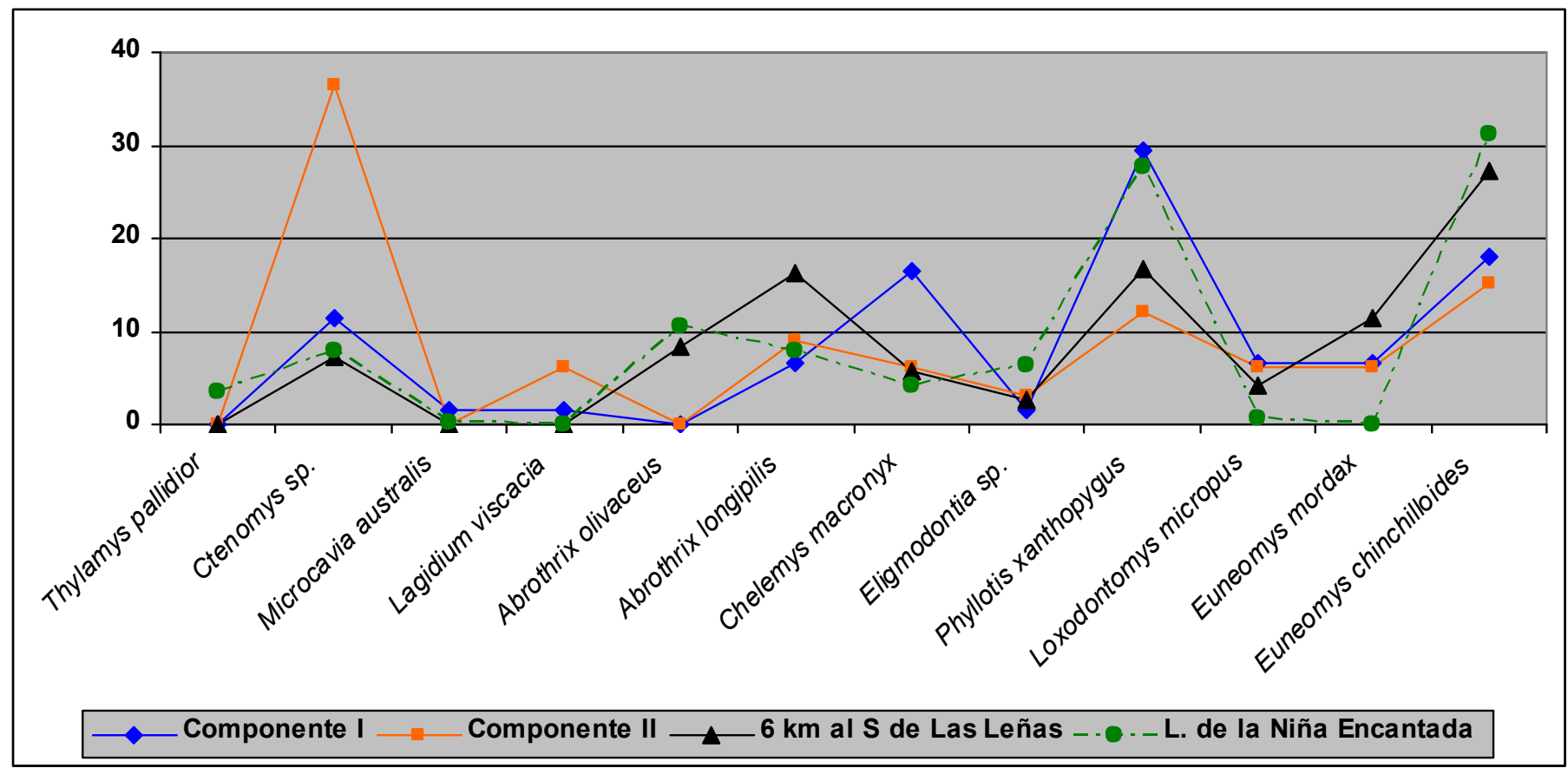

Figura 7.35. Comparación de las frecuencias relativas de los taxones de micromamíferos recuperados de los componentes de Cueva Arroyo Colorado y los parámetros actualísticos.

Euneomys spp. y $P$. xanthopygus fueron elementos abundantes tanto en los componentes arqueológicos como en las muestras actuales, indicando la existencia de un ambiente de estepas arbustivas abiertas con alta proporción de suelo desnudo, pedregoso y abundante roca expuesta, desde $3,2 \mathrm{ka}{ }^{14} \mathrm{C}$ AP hasta la actualidad. No obstante, es interesante destacar el registro en simpatría de E. chinchilloides y E. mordax tanto en el contexto arqueológico como en la muestra actual más cercana al sitio. En este sentido, la ausencia de E. mordax en Laguna de La Niña Encanta posiblemente se asocie a una limitación altitudinal (ver Capítulo 8, para una discusión regional sobre este tópico). 
Por otra parte, las frecuencias de L. micropus, Eligmodontia sp. y A. longipilis fueron similares en los dos componentes arqueológicos y en las muestras actuales. En conjunto estos taxones sugieren un ambiente abierto y pedregoso de estepa Patagónica y vegas cordilleranas. Por otro lado, la frecuencia más elevada de C. macronyx en el Componente I (1380-770 años ${ }^{14} \mathrm{C}$ AP), señala abundante disponibilidad hídrica. La abundancia de Ctenomys sp. en este componente podría esta vinculado a un sesgo tafonómico por actividad depredadora de los félidos (ver Capítulo 6). Asimismo, la similitud entre los valores de los índices de diversidad de los dos componentes, es coherente con la estabilidad taxonómica y ambiental observada.

Por su parte, las especies de aves recuperadas en todas las muestras tienen requerimientos ecológicos-ambientales que son propios del área de estudio en la actualidad (Mazar Barnett y Pearman, 2001).

En las muestra actuales, la aparición -con frecuencia moderada- de una especie oportunista como A. olivaceus, indicaría un deterioro ambiental (Teta et al., 2005a; Cueto et al., 2008; Fernández et al., 2009d) principalmente producido por la introducción del ganado doméstico euroasiático, afianzado en el sur de Mendoza desde el siglo XIX (Gil et al., 2006b), causando la sobre-explotación de la vegetación y un aumento del suelo desnudo (Teta et al., 2005a; Cueto et al., 2008; Fernández et al., 2009d) (ver Capitulo 8 para una discusión detallada). Ergo, A. humeralis fue la especie de ave mejor representada en la muestra actual, la cual se caracteriza por ser abundante en áreas rurales (Narosky e Izurieta, 2003).

\subsubsection{Conclusión}

Las principales características tafonómicas señalan que en el Componente II (3190-1380 años ${ }^{14} \mathrm{C}$ AP), el agente acumulador habría sido un mamífero carnívoro, de acción destructiva fuerte, posiblemente un félido. No obstante, en el Componente I (1380-770 años $\left.{ }^{14} \mathrm{C} \mathrm{AP}\right)$, el principal agente acumulador habría sido un Strigiformes de acción destructiva ligera, quizás $T$. alba. Entre los restos de este componente se encontraron algunas evidencias de actividad antrópica, como huellas de corte y huesos quemados en los roedores más grandes. El Componente II, presentó escasas evidencias de modificaciones postdepositacionales, en tanto el Componente I exhibió importantes características de este tipo de alteración, como pisoteo, corrosión sedimentaria por elevada humedad y manchas de óxido de manganeso. 
En cuanto a la caracterización tafonómica global del sitio, se podría concluir que la asociación arqueofaunística de Cueva Arroyo Colorado constituye un palimpsesto, resultado de la alternancia de los distintos agentes acumuladores mencionados.

El análisis de las características ecológicas de los taxones recuperados indicaría un ambiente de estepas arbustivas abiertas con alta proporción de suelo desnudo, pedregoso $\mathrm{y}$ abundante roca expuesta y vegas cordilleranas, desde $3,2 \mathrm{ka}{ }^{14} \mathrm{C}$ AP hasta la actualidad. No obstante, para el intervalo $c a .1,4-0,77 \mathrm{ka}{ }^{14} \mathrm{C}$ AP se registraron especies asociadas a una mayor disponibilidad hídrica.

A pesar de que en la muestra actual se observó similar diversidad taxonómica respecto de los componentes arqueológicos, la aparición -con frecuencia moderada- de un abrotriquino oportunista como $A$. olivaceus, sugiere un deterioro ambiental posiblemente producido por la introducción del ganado doméstico en el área desde el siglo XIX 


\subsection{Cueva Palulo}

\subsubsection{Contexto arqueológico}

El sitio arqueológico Cueva Palulo, se localiza en el alto valle del Río Atuel, en la margen derecha del arroyo Panchino $\left(34^{\circ} 56^{\prime} 40,40^{\prime \prime} \mathrm{S}\right.$ y $69^{\circ} 50^{\prime} 39,54^{\prime \prime} \mathrm{O} ; 2.304$ m.s.n.m.). Figura 7.36 A y B.
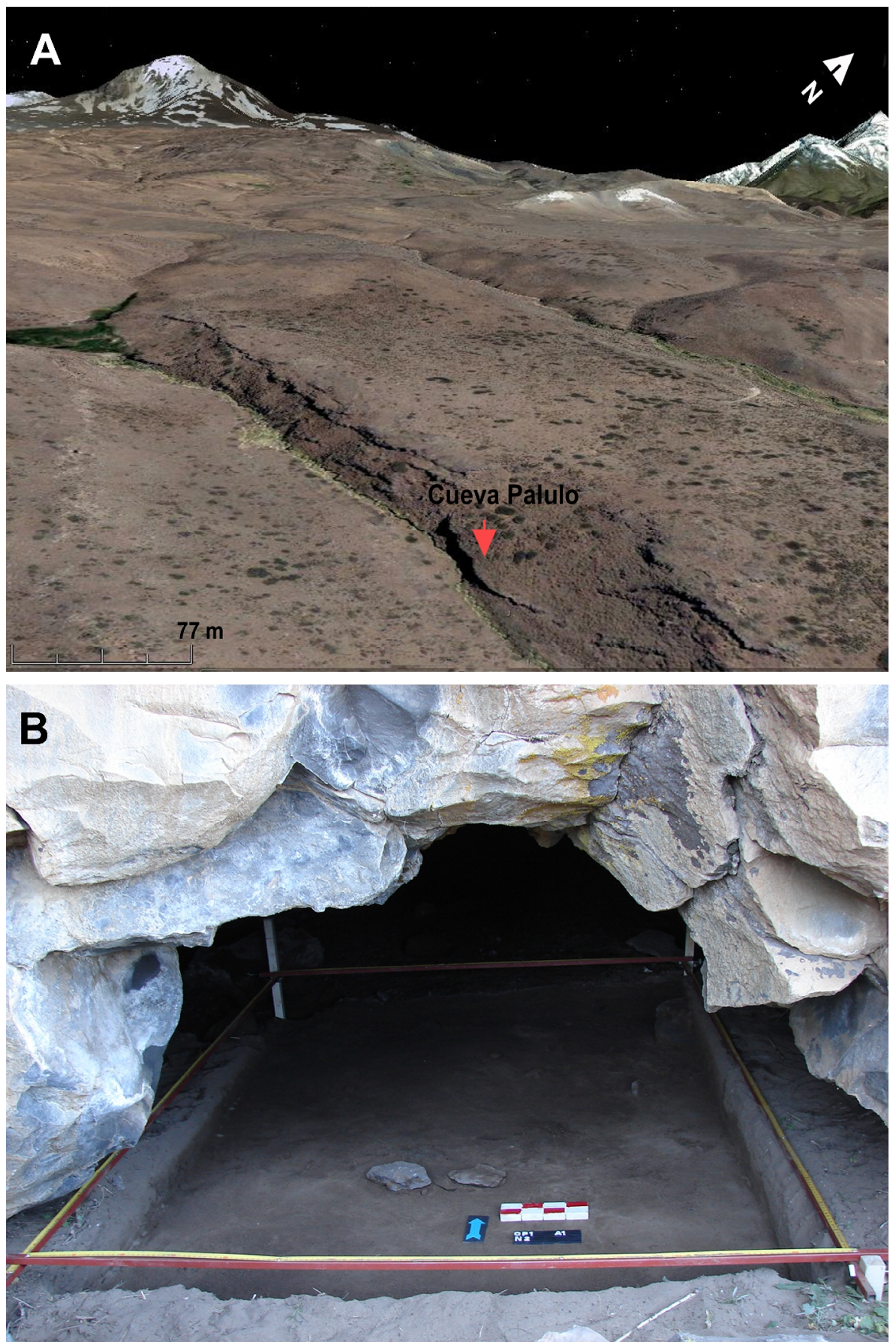

Figura 7.36. Sitio arqueológico Cueva Palulo. A: ubicación del sitio. B: vista de la entrada a la cueva y de la cuadrícula escavada. 
La cueva presenta una abertura de $3 \mathrm{~m}$ de ancho y 1,50 $\mathrm{m}$ de altura, alcanzando en su interior un máximo de $4 \mathrm{~m}$ de ancho y $9 \mathrm{~m}$ de profundidad (Figura 7.37).

La campaña fue realizada en enero del 2007 por un grupo de arqueólogos del cual fui partícipe y estuvo a cargo por los Drs. Gustavo Neme y Adolfo Gil. Se excavó una cuadrícula de $2 \mathrm{~m}$ x 1,5 m, totalizando una superficie de $3 \mathrm{~m}^{2}$ y se extrajeron materiales de 20 niveles artificiales de $5 \mathrm{~cm}$ cada uno (a excepción del último que midió $10 \mathrm{~cm}$ ) hasta alcanzar la roca madre a $110 \mathrm{~cm}$ de profundidad (Figuras 7.38). Para la recolección de restos arqueológicos se utilizaron zarandas de $2 \mathrm{~mm}$.

En la tabla 7.46 se exhibe los fechados radiocarbónicos obtenidos para el sitio Cueva Palulo.

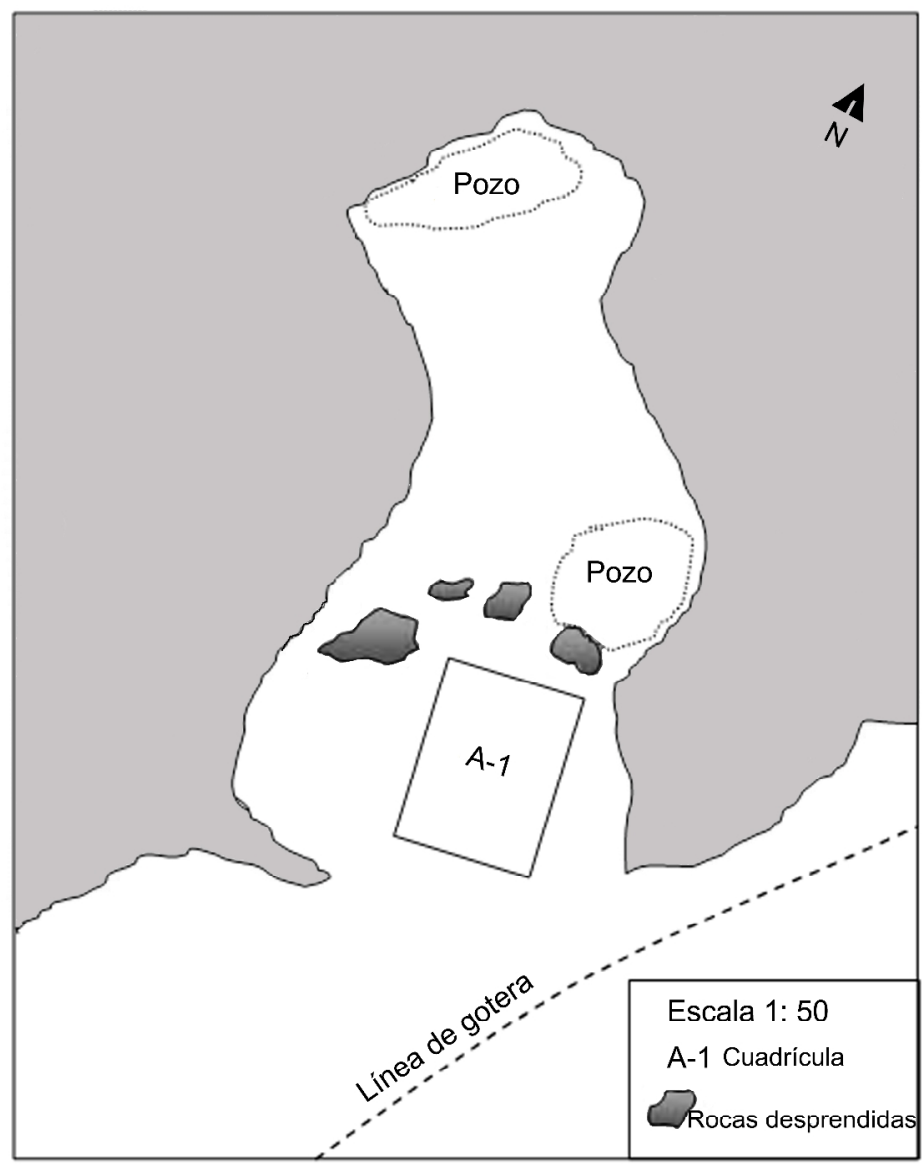

Figura 7.37. Vista en planta del sitio Cueva Palulo.

\begin{tabular}{|c|c|c|c|c|c|}
\hline Cuadrícula & Nivel & Muestras & Código & Datación ${ }^{14}$ C & Calibrado \\
\hline A-1 & 3 & carbón & AA93999 & $130 \pm 33$ & $39-240$ \\
A-1 & 6 & carbón & AA85699 & $2.228 \pm 37$ & $2182-2310$ \\
A-1 & 11 & carbón & AA94000 & $2.030 \pm 36$ & $1945-2042$ \\
A-1 & 16 & carbón & AA85698 & $2.042 \pm 37$ & $1956-2063$ \\
A-1 & 20 & carbón & AA85697 & $3,970 \pm 40$ & $4392-4504$ \\
\hline
\end{tabular}

Tabla 7.46. Fechados radiocarbónicos del sitio Cueva Palulo. 
La estratigrafía del sitio presenta una matriz sedimentaria homogénea a lo largo de toda la secuencia, incluyendo sedimentos arenosos, con clastos de distintos tamaños, principalmente provenientes del techo de la cueva y con materia orgánica proveniente del sector norte. Asimismo, se registraron canales con relleno sedimentario, que podrían ser productos de la acción cavadora de animales fosoriales.

Otaola (tesis doctoral en preparación) definió tres unidades cronoestratigráficas en el sitio. La Unidad A comprende los primeros $25 \mathrm{~cm}$ de la secuencia (Niveles 1-5) y una cronología correspondiente a los últimos 130 años ${ }^{14} \mathrm{C}$ AP de la secuencia. La Unidad B registrada entre 25 y $55 \mathrm{~cm}$ de profundidad (Niveles 6-12), con una base temporal de 2000 años ${ }^{14} \mathrm{C}$ AP. La presencia de un fechado anómalo $\left(2042+37\right.$ años ${ }^{14} \mathrm{C}$ AP) en esta unidad fue interpretado por la autora, como proveniente de un carbón que posiblemente haya migrado verticalmente. Asimismo, la ausencia de sedimento y la amplitud temporal entre las unidades A y B fue explicada por la autora, con la presencia de una discordancia. Finalmente, la Unidad C corresponde a los 55 y $110 \mathrm{~cm}$ de profundidad (Niveles 13-21) y una cronología entre 4000 y 2000 años ${ }^{14} \mathrm{C}$ AP (Figura 7.38).

Hasta el momento no se cuenta con información publicada sobre el registro arqueológico del sitio. En este sentido, se expone de modo general algunos de los materiales exhumados de la excavación. Se recuperaron abundantes materiales líticos y carbón vegetal en toda la secuencia. Se registraron semillas de Schinus polygamus, Maihuenia sp. y Fabaceae. A partir del nivel 16 se recuperaron fragmentos de cerámica tipo overo.

En lo que concierne a los vertebrados de mediano y gran tamaño, Lama guanicoe (Camelidae) fue la especie más representada a lo largo de toda la secuencia. Asimismo, se recuperaron restos óseos de Lycalopex culpaeus (Canidae), Chaetophractus sp. (Dasypodidae) y Rhea pennata (Rheidae) (Otaola, tesis doctoral en preparación). La autora citada registró evidencias de explotación humana en restos óseos (i.e., marcas de corte, negativos de impacto, lascas óseas, instrumentos y restos pulidos) a lo largo de toda la secuencia, con incrementos de los porcentajes de incidencia en los niveles medios y superiores. Sin embargo, observó mayor cantidad de especies consumidas en los niveles inferiores. Resulta interesante destacar el hallazgo de restos asignados a Homo sapiens, correspondientes al nivel 8 . 


\section{Perfil pared Oeste}

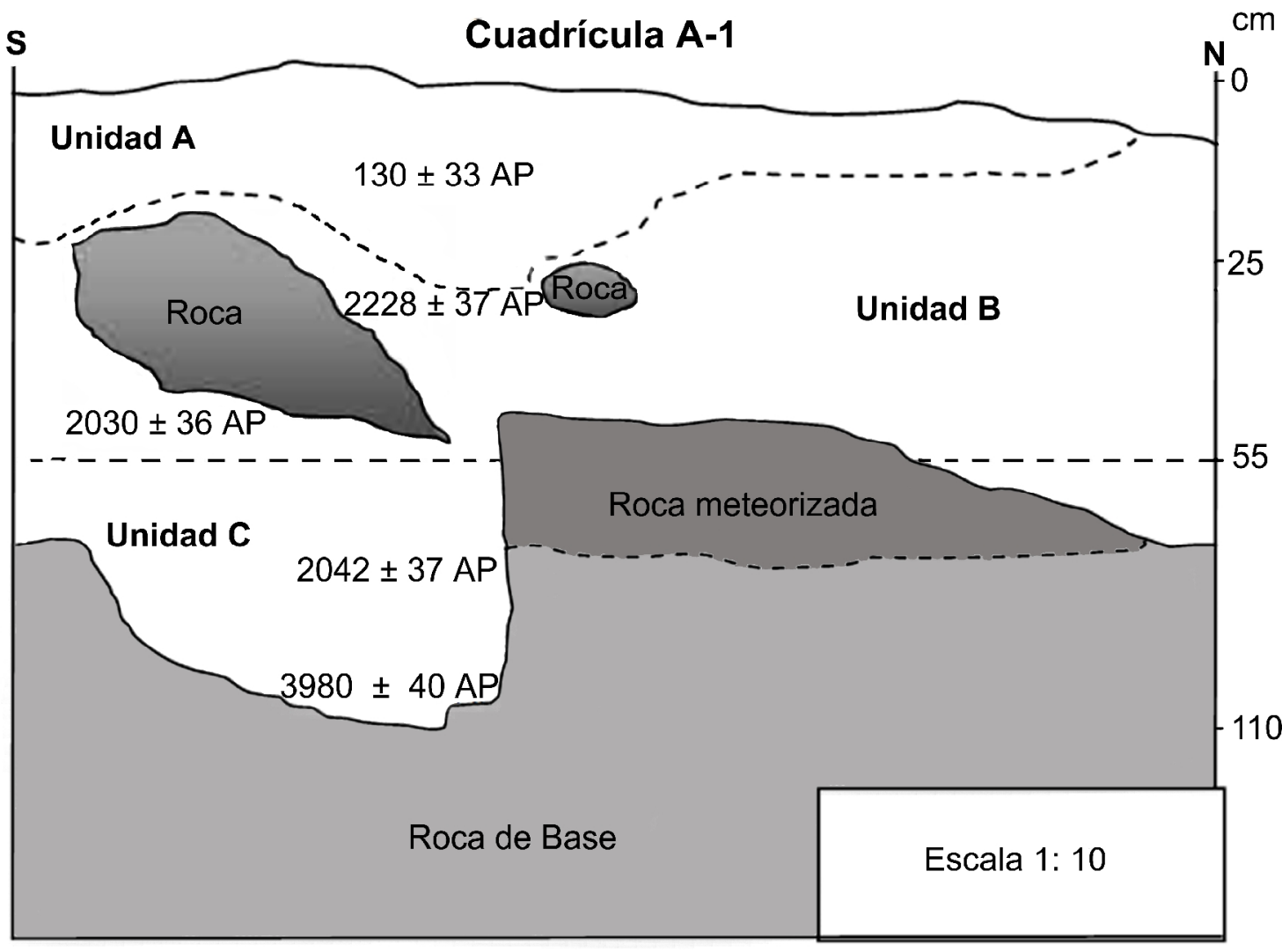

Figura 7.38. Cronoestratigrafía del sitio Cueva Palulo.

\subsubsection{Metodología}

Para el análisis tafonómico se decidió unificar los niveles de excavación en una sola unidad debido a la escasez de restos y a que tafonomicamente presentaron altos niveles de homogeneidad. Para el cálculo de correlación se tuvo en cuenta solo los restos de micromamíferos por ser aquellos utilizados en la interpretación paleoambiental.

Como parámetro actualístico se estudió una muestra de 45 egagrópilas de Buteo polyosoma (aguilucho común) y una muestra de 84 egagrópilas de Bubo magellanicus (tucúrere), las cuales fueron recolectadas en enero del 2007 a pocos metros del sitio arqueológico [Localidades Arroyo Panchino I y Arroyo Panchino II (ver apéndice)].

\subsubsection{Resultados}

\subsubsection{Análisis tafonómico}

\subsection{Micromamíferos}


El $87,4 \%$ de los restos analizados de micromamíferos conforme a la metodología propuesta por Andrews (1990) y Fernández-Jalvo y Andrews (1992) (i.e., incisivos, molares, epífisis proximal del fémur y epífisis distal del húmero; Tabla 7.47) presentaron algún tipo de corrosión digestiva, los cuales se corresponden con las categorías ligera, moderada y fuerte. Todos los elementos postcraneales sufrieron algún grado de digestión, siendo la categoría ligera la más frecuente en húmeros y la categoría fuerte en fémures. Por lo tanto, hubo numerosos restos con evidencias de poseado en las superficies articulares, algunos con aspecto de abrasionado o pulido y otros con diáfisis onduladas y epífisis fuertemente digeridas (Figura 7.39 A y B).

El $86,5 \%$ de los restos dentarios mostraron marcas de digestión. En una parte de los incisivos la corrosión se concentró en los extremos, en otra parte de los mismos se extendió por una mayor superficie, dejándola ondulada y en otra parte el esmalte quedó reducido en pequeños islotes sobre la dentina. Algunos molares exhibieron cúspides con un contorno más redondeado, otros mostraron un ligero poseado en el esmalte y muchos de ellos carecieron de esmalte o presentaron un fuerte poseado.

Los dientes aislados fueron más afectados que aquellos que se recuperaron in situ, esto se debe a que están más expuestos a los ácidos digestivos (Andrews, 1990).

\begin{tabular}{|c|c|c|c|c|c|c|c|c|c|c|}
\hline \multirow{3}{*}{ Cueva Palulo } & \multicolumn{10}{|c|}{ Clases de digestión sensu Andrews (1990) } \\
\hline & \multicolumn{2}{|c|}{ Ausente } & \multicolumn{2}{|c|}{ Ligera } & \multicolumn{2}{|c|}{ Moderada } & \multicolumn{2}{|c|}{ Fuerte } & \multicolumn{2}{|c|}{ Extrema } \\
\hline & $(\mathrm{N})$ & $\%$ & $(\mathrm{~N})$ & $\%$ & $(\mathrm{~N})$ & $\%$ & $(\mathrm{~N})$ & $\%$ & $(\mathrm{~N})$ & $\%$ \\
\hline Digestión dentaria & & & & & & & & & & \\
\hline Incisivos in situ & 25 & 33,8 & 24 & 32,4 & 10 & 13,5 & 15 & 20,3 & - & - \\
\hline Incisivos aislados & 7 & 3,2 & 80 & 36,2 & 78 & 35,3 & 56 & 25,3 & - & - \\
\hline Incisivos Total & 32 & 10,8 & 104 & 35,2 & 88 & 29,3 & 71 & 24,1 & - & - \\
\hline Molares in situ & 6 & 5,4 & 20 & 18,2 & 39 & 35,4 & 45 & 40,9 & - & - \\
\hline Molares aislados & - & - & 43 & 28,1 & 54 & 35,3 & 56 & 36,6 & - & - \\
\hline Molares Total & 6 & 2,3 & 63 & 23,9 & 93 & 35,4 & 101 & 38,4 & - & - \\
\hline Digestión Postcraneal & & & & & & & & & & \\
\hline Fémur (segmento proximal) & - & - & 6 & 30 & 4 & 20 & 10 & 50 & - & - \\
\hline Húmero (segmento distal) & - & - & 17 & 65,4 & 2 & 7,7 & 7 & 26,9 & - & - \\
\hline
\end{tabular}

Tabla 7.47. Representación de las distintas categorías de corrosión digestiva en micromamíferos de Cueva Palulo. 


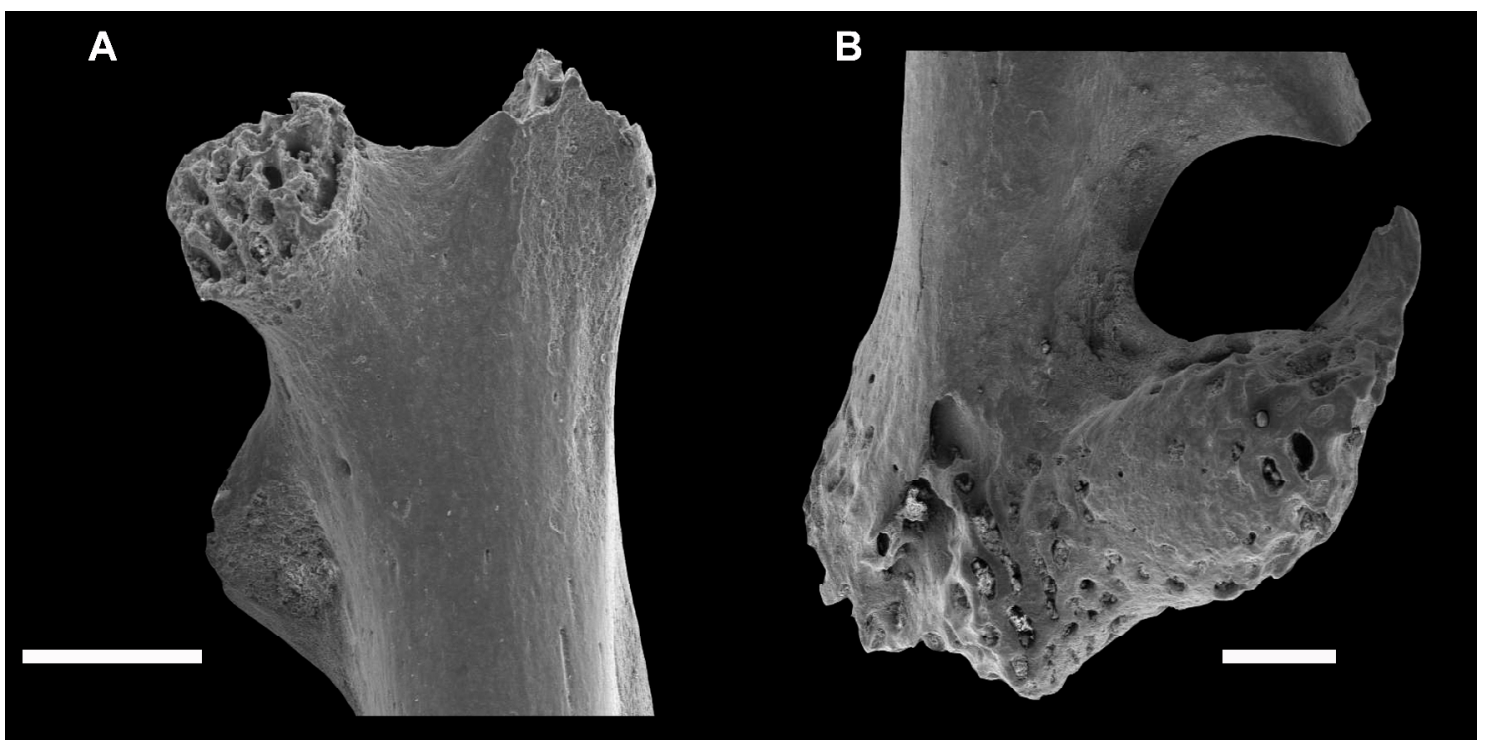

Figura 7.39. Elementos postcraneales con evidencias de corrosión digestiva. A: fémur de Sigmodontinae con marcas de corrosión moderada en la epífisis proximal (Nivel 13). B: húmero de Ctenomys sp. con marcas de corrosión fuerte en la epífisis distal (Nivel 17). Escalas: $1 \mathrm{~mm}$.

La abundancia relativa promedio fue baja. Los elementos más abundantes fueron las mandíbulas, maxilares, incisivos aislados, molares aislados, tibia, húmero y fémur (Tabla 7.48 y Figura 7.40).

\begin{tabular}{|l|cc|}
\hline Elementos / & Cueva & Palulo \\
Procedencia & $\begin{array}{c}\text { Abundancia } \\
\text { relativa }\end{array}$ \\
\hline Maxilar & 37 & 21,8 \\
Mandíbula & 106 & 62,4 \\
Incisivos aislados & 202 & 59,4 \\
Molares aislados & 170 & 12,5 \\
Vértebras & 38 & 1,5 \\
Costillas & 1 & 0,4 \\
Escápula & 5 & 2,9 \\
Húmero & 26 & 15,3 \\
Cúbito & 4 & 2,4 \\
Radio & 7 & 4,1 \\
Pelvis & 16 & 9,4 \\
Fémur & 20 & 11,8 \\
Tibia & 30 & 17,6 \\
Metapodio & 3 & 0,2 \\
Calcáneo & - & - \\
Astrágalo & - & - \\
Falanges & 2 & 0,04 \\
\hline Total & 667 & \\
Promedio & & 13 \\
\hline
\end{tabular}


Tabla 7.48. Número mínimo de elementos (MNE) y abundancia relativa, para el ensamble de micromamíferos recuperados de Cueva Palulo.

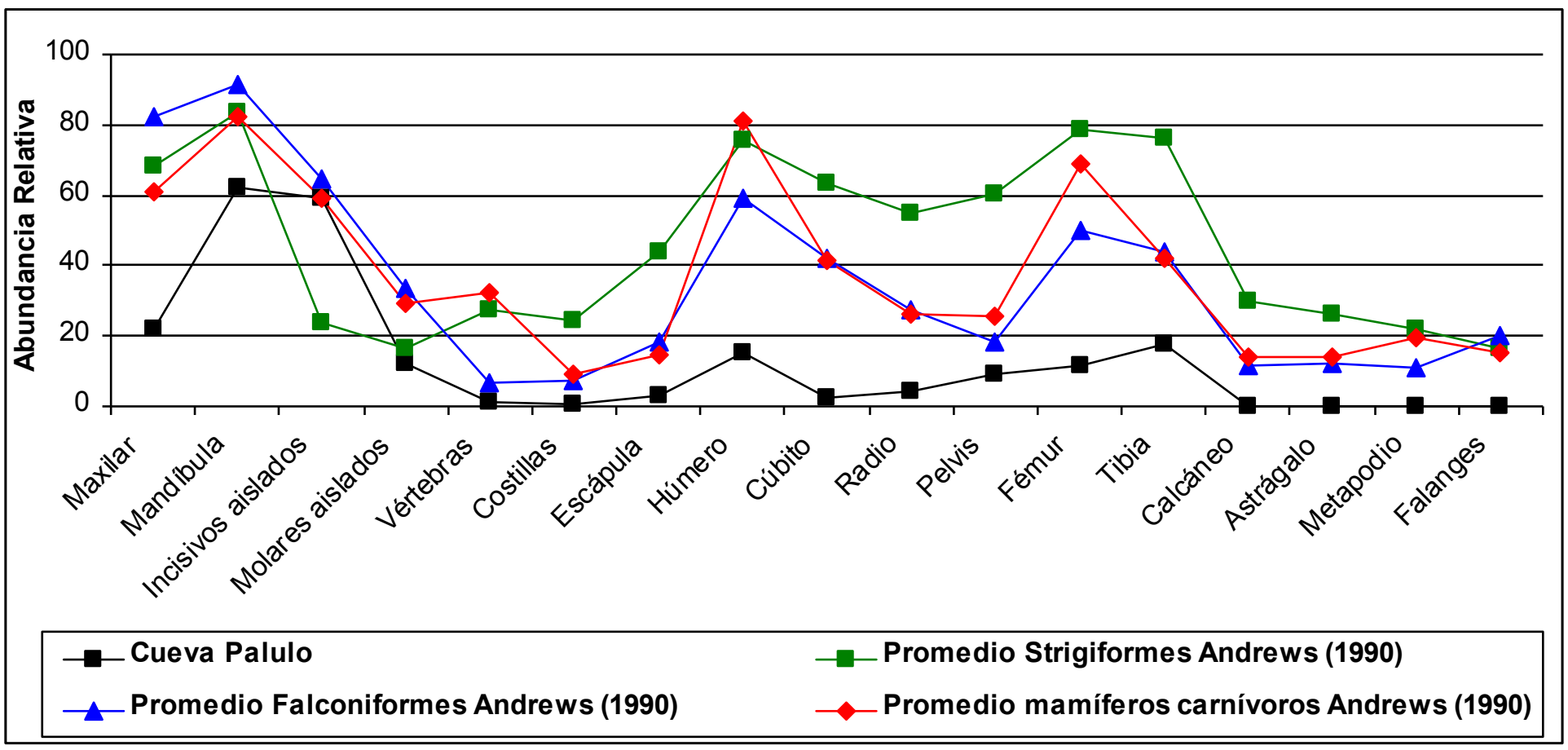

Figura 7.40. Valores de abundancia relativa de los diferentes elementos anatómicos de Cueva Palulo, comparados con datos promedio de distintos agentes acumuladores obtenidos por Andrews (1990).

El 55,1\% de todos los especímenes recuperados de Cueva Palulo estaban fracturados. En la tabla 7.49 se exhibe los distintos tipos de fractura en los elementos contemplados en la metodología propuesta por Andrews (1990) y Andrews y Fernández (1992). No se recuperaron cráneos completos; la mayor parte correspondieron a maxilares sin arcos zigomáticos y algunos a maxilares con arcos zigomáticos. Asimismo, se registró una pérdida elevada de molares y una pérdida moderada de incisivos.

Se recuperaron escasas mandíbulas completas y una alta proporción de las mismas mostraron distintos niveles de fractura. Se registró una pérdida elevada de molares y una exigua pérdida de incisivos.

Se observaron fracturas moderadas en molares y elevada en incisivos, las cuales incrementaron su proporción cuando se encontraron fueron de los alvéolos. El nivel de fractura de los elementos postcraneales fue alto, de modo que solo el $20 \%$ de los fémures, húmeros, tibias y cúbitos estaban completos. Además, se observó una marcada preservación diferencial de los segmentos proximales del fémur. 


\begin{tabular}{|c|c|c|}
\hline & $\mathbf{N}$ & $\%$ \\
\hline \multicolumn{3}{|l|}{ Fractura de cráneos } \\
\hline Cráneos completos & - & - \\
\hline Maxilares con arcos zigomáticos & 9 & 24,3 \\
\hline Maxilares sin arcos zigomáticos & 28 & 75,7 \\
\hline Pérdida de molares de maxilares & 160 & 79,6 \\
\hline Pérdida de incisivos de premaxilares & 5 & 35,7 \\
\hline \multicolumn{3}{|l|}{ Fractura de mandíbulas } \\
\hline Mandíbulas completas & 7 & 6,6 \\
\hline Mandíbulas con rama ascendente rota & 35 & 33 \\
\hline Mandíbulas sin rama ascendente & 41 & 38,7 \\
\hline Mandíbulas sin rama ascendente y borde inferior roto & 23 & 21,7 \\
\hline Pérdida de molares de las mandíbulas & 268 & 77 \\
\hline Pérdida de incisivos de la mandíbulas & 9 & 12,3 \\
\hline \multicolumn{3}{|l|}{ Fractura de dientes } \\
\hline Molares rotos in situ & 6 & 5 \\
\hline Molares aislados rotos & 86 & 50,6 \\
\hline Total de molares rotos & 92 & 31,6 \\
\hline Incisivos rotos in situ & 30 & 41,1 \\
\hline Incisivos aislados rotos & 136 & 67,3 \\
\hline Total de incisivos rotos & 166 & 60,4 \\
\hline \multicolumn{3}{|l|}{ Fractura de Postcráneo } \\
\hline \multicolumn{3}{|l|}{ Fémur } \\
\hline Completo & 7 & 35 \\
\hline Segmento proximal & 13 & 65 \\
\hline Diáfisis & - & - \\
\hline Segmento distal & - & - \\
\hline \multicolumn{3}{|l|}{ Húmero } \\
\hline Completo & 4 & 15,4 \\
\hline Segmento proximal & 0 & 0 \\
\hline Diáfisis & 22 & 84,6 \\
\hline Segmento distal & 0 & 0 \\
\hline \multicolumn{3}{|l|}{ Tibia } \\
\hline Completo & 3 & 10 \\
\hline Segmento proximal & 8 & 26,6 \\
\hline Diáfisis & 5 & 16,7 \\
\hline Segmento distal & 14 & 46,7 \\
\hline \multicolumn{3}{|l|}{ Cúbito } \\
\hline Completo & 2 & 50 \\
\hline Segmento proximal & 2 & 50 \\
\hline Diáfisis & - & - \\
\hline Segmento distal & - & - \\
\hline
\end{tabular}

Tabla 7.49. Fractura de elementos craneales, dentarios y postcraneales, para los micromamíferos recuperados de Cueva Palulo. 
Se destaca que un alto porcentaje $(90,6 \%)$ de los elementos postcraneales estaban rotos, presentando superficies de fracturas con ángulos redondeados y bordes suaves.

Por otra parte, las vértebras, metapodios y falanges estaban completas. Sin embargo, los elementos más frágiles como las cinturas se encontraron fracturados en su totalidad (Tabla 7.50).

\begin{tabular}{|l|cc|}
\hline Fracturas postcraneal & Cueva & Palulo \\
(otros elementos) & $\mathrm{N}$ & $\%$ \\
\hline Vértebras & - & - \\
Escápula & 5 & 100 \\
Radio & 6 & 85,7 \\
Pelvis & 16 & 100 \\
Metapodio & - & - \\
Falanges & - & - \\
\hline
\end{tabular}

Tabla 7.50. Fractura del resto de los elementos postcraneales de micromamíferos recuperados de Cueva Palulo.

Los valores obtenidos a partir de los índices calculados se exhiben en la tabla 7.51. Los dos índices que evalúan la relación entre elementos postcraneales y craneales indican una marcada preservación de los elementos craneales. El índice que valora la relación entre elementos distales y proximales de los miembros indica una ligera pérdida de elementos distales. En cuanto a los índices de pérdida dentaria, se observó una alta pérdida de molares, aunque la mayor parte de los incisivos estaban retenidos en los alvéolos.

A pesar de que se registraron evidencias de posibles cuevas de animales fosoriales, los restos de Ctenomys sp. no se encontraron articulados y presentaron marcas de corrosión digestiva (Figura 7.39 B). Por otra parte, se destaca que no se hallaron especímenes con marcas de corte y sólo el 3\% estaban termoalterados.

Los índices IT e IP, mostraron una representación nivelada entre los distintos grupos de tamaño y comportamiento social de los microvertebrados. 


\begin{tabular}{|l|c|}
\hline & Cueva Palulo \\
\hline Postcráneo / Cráneo & \\
{$[(\mathrm{f}+\mathrm{t}+\mathrm{h}+\mathrm{r}+\mathrm{c}) \times 16 /(\mathrm{mb}+\mathrm{mx}+\mathrm{m}) \times 10] \times 100$} & 55,6 \\
{$[(\mathrm{~h}+\mathrm{f}) /(\mathrm{mb}+\mathrm{mx})] \times 100$} & 32,1 \\
Elementos distales / proximales & \\
{$[(\mathrm{t}+\mathrm{r}) /(\mathrm{f}+\mathrm{h})]$ x 100} & 80,4 \\
Pérdida de dientes & \\
$\%$ molares aislados & 353,7 \\
$\%$ incisivos aislados & 19,2 \\
Índice de Tamaño (IT) & 96,6 \\
Índice de Predictibilidad (IP) & 103,5 \\
\hline
\end{tabular}

Tabla 7.51. Valores de los índices calculados en Cueva Palulo.

En relación a los procesos postdepositacionales, ninguno de los restos recuperados exhibió evidencias de meteorización. El 7,3\% de los especímenes óseos presentaron marcas de pisoteo y el 5,7\% de los restos mostraron marcas de raíces (i.e., categoría Sphenoichnia). Asimismo, no se registraron especímenes con evidencias de corrosión sedimentaria y sólo el $0,3 \%$ presentaron impresiones de óxido de manganeso en sus superficies.

No se hallaron evidencias de redondeamientos en los extremos y protuberancias de los restos óseos y dentarios, indicando que no actuaron los efectos de la abrasión por transporte hídrico, desplazamientos y rozamientos de los restos contra el sedimento (Korth, 1979; Fernández-Jalvo y Andrews, 2003).

\subsection{Reptiles}

Como se ilustra en la tabla 7.52, todos los elementos postcraneales y la mayor parte de los restos craneales presentaron marcas de corrosión digestiva, en grado variable. La mayoría de los dientes se encontraron con el esmalte reducido y removido por sectores y los huesos largos presentaron un poseado en las epífisis que variaban de suave a intenso.

\begin{tabular}{|l|cc|}
\hline Cueva Palulo & N & \% \\
\hline Craneal & 49 & 77,8 \\
Postcraneal & 84 & 100 \\
\hline Total & 133 & 90,5 \\
\hline
\end{tabular}

Tabla 7.52. Corrosión digestiva craneal y postcraneal, para los reptiles de Cueva Palulo. 
Los valores de abundancia relativa se exhiben en la tabla 7.53. Las mandíbulas, maxilares, fémures, húmeros y pelvis estuvieron bien representados y las vértebras y tibias fueron poco abundantes.

\begin{tabular}{|l|cc|}
\hline Cueva Palulo & MNE & $\begin{array}{c}\text { Abundancia } \\
\text { relativa }\end{array}$ \\
\hline Frontal & 7 & 22,6 \\
Parietal & 1 & 3,2 \\
Maxilar & 16 & 25,8 \\
Mandíbula & 39 & 62,9 \\
Vértebras & 7 & 1,4 \\
Húmero & 17 & 27,4 \\
Pelvis & 17 & 27,4 \\
Fémur & 37 & 56,7 \\
Tibia & 6 & 9,7 \\
\hline Total & 147 & \\
\hline
\end{tabular}

Tabla 7.53. Número mínimo de elementos (MNE) y abundancia relativa, para el ensamble de reptiles de Cueva Palulo.

Se destaca que no se halló ningún cráneo completo en toda la secuencia, los mismos correspondieron a maxilares, dentarios (denominados mandíbulas en este trabajo) y frontales sueltos. La mayor parte de los elementos postcraneales estaban completos (Tabla 7.54), donde solo se recuperaron tres húmeros fracturados, con bordes redondeados y superficies suaves.

El índice que evalúa la relación entre elementos postcraneales y craneales, mostró una preservación nivelada entre ambos tipos de elementos. El índice que calcula la relación entre los elementos distales y proximales, indica un fuerte predominio de elementos proximales (Tabla 7.55). 


\begin{tabular}{|lcc|}
\hline & N & \% \\
\hline Fémur & 37 & 100 \\
Completo & - & - \\
Segmento proximal & - & - \\
Diáfisis & - & - \\
Segmento distal & - & \\
Húmero & & 82,3 \\
Completo & 14 & - \\
Segmento proximal & - & - \\
Diáfisis & - & 17,7 \\
Segmento distal & 3 & \\
Tibia & & \\
Completo & 6 & 100 \\
Segmento proximal & - & - \\
Diáfisis & - & - \\
Segmento distal & - & - \\
Cúbito & & \\
Completo & - & - \\
Segmento proximal & - & - \\
Diáfisis & - & - \\
Segmento distal & - & - \\
\hline
\end{tabular}

Tabla 7.54. Fractura de elementos craneales, dentarios y postcraneales, para los reptiles de Cueva Palulo.

\begin{tabular}{|lc|}
\hline & Cueva Palulo \\
\hline $\begin{array}{l}\text { Postcráneo / Cráneo } \\
\mathrm{h}+\mathrm{f} / \mathrm{mx}+\mathrm{mb}\end{array}$ & 98,2 \\
Elementos distales / proximales & \\
$\mathrm{t}+\mathrm{r} / \mathrm{f}+\mathrm{h}$ & 10,9 \\
\hline
\end{tabular}

Tabla 7.55. Valores de los índices calculados para reptiles en Cueva Palulo.

Es interesante destacar que no se registraron restos con marcas de corte en ninguna unidad y que solo dos presentaron rastros de termoalteración. En lo que concierne a los procesos postdepositacionales, cabe aclarar que en toda la secuencia no se hallaron restos con evidencias de meteorización, pisoteo, marcas de raíces, diagénesis y transporte hídrico.

\subsubsection{Asociación de microvertebrados de la muestra actual}

Como se ilustra en la tabla 7.56, los ensambles de microvertebrados de las muestras actuales están dominados por roedores sigmodontinos, siendo Eligmodontia sp, 
Euneomys chinchilloides y Abrothrix olivaceus los taxones más representados, seguidos por Phyllotis xanthopygus, Abrothrix longipilis y Loxodontomys micropus con porcentajes menores. El roedor histricognato Ctenomys sp. también fue muy abundante. Con frecuencias menores se registraron un marsupial (Thylamys pallidior), un lagomorfo introducido, un reptil saurio (Liolaemus sp.) y un ave paseriforme. El índice de diversidad de Shannon arrojó un valor de 1,921.

\begin{tabular}{|c|c|c|c|c|c|c|}
\hline \multirow[t]{2}{*}{ Taxones / procedencia } & \multicolumn{2}{|c|}{ Arroyo Panchino I } & \multicolumn{2}{|c|}{ Arroyo Panchino II } & \multicolumn{2}{|l|}{ Total } \\
\hline & MNI & $\%$ & MNI & $\%$ & MNI & $\%$ \\
\hline Reptilia / Liolaemidae indet. & - & - & 20 & 27 & 20 & 9,8 \\
\hline Liolaemus sp. & 2 & 1,5 & - & - & 2 & 0,9 \\
\hline Aves / Passeriformes indet. & 2 & 1,5 & 2 & 2,7 & 4 & 1,9 \\
\hline Mammalia & & & & & & \\
\hline Didelphimorphia & & & & & & \\
\hline Thylamys pallidior & 1 & 0,8 & - & - & 1 & 0,5 \\
\hline Rodentia & & & & & & \\
\hline Ctenomyidae & & & & & & \\
\hline Ctenomys sp. & 14 & 10,8 & 23 & 31,1 & 37 & 18,1 \\
\hline Cricetidae / Sigmodontinae & & & & & & \\
\hline Abrothrix olivaceus & 18 & 13,8 & 11 & 14,9 & 29 & 14,2 \\
\hline Abrothrix longipilis & 4 & 3,1 & 1 & 1,4 & 5 & 2,5 \\
\hline Phyllotis xanthopygus & 13 & 10 & 1 & 1,4 & 14 & 6,9 \\
\hline Loxodontomys micropus & 4 & 3,1 & - & - & 4 & 1,9 \\
\hline Eligmodontia sp. & 44 & 33,8 & - & - & 44 & 21,6 \\
\hline Euneomys chinchilloides & 28 & 21,5 & 11 & 14,9 & 39 & 19,1 \\
\hline Lagomorpha / Leporidae indet. & - & - & 5 & 6,7 & 5 & 2,5 \\
\hline Total & 130 & & 74 & & 204 & \\
\hline Riqueza & 10 & & 8 & & 11 & \\
\hline $\mathbf{H}^{\prime}$ & & & & & 1,921 & \\
\hline Equitatividad & & & & & 0,801 & \\
\hline
\end{tabular}

Tabla 7.56. Muestras actuales: Panchino I, Panchino II y la sumatoria de ambas.

\subsubsection{Asociación de microvertebrados de la muestra arqueofaunística}

El ensamble arqueofaunístico (NISP $=815 ; \mathrm{MNE}=814 ; \mathrm{MNI}=116$ ) está principalmente conformado por micromamíferos (Tablas 7.57 y 7.58). El roedor histricognato Ctenomys sp. fue el más representado. En proporciones menores se encuentra los sigmodontinos E. chinchilloides, P. xanthopygus y Eligmodontia sp. Es importante destacar la elevada abundancia de reptiles (Liolaemus sp.) registrada en el sitio (Figura 7.41). 


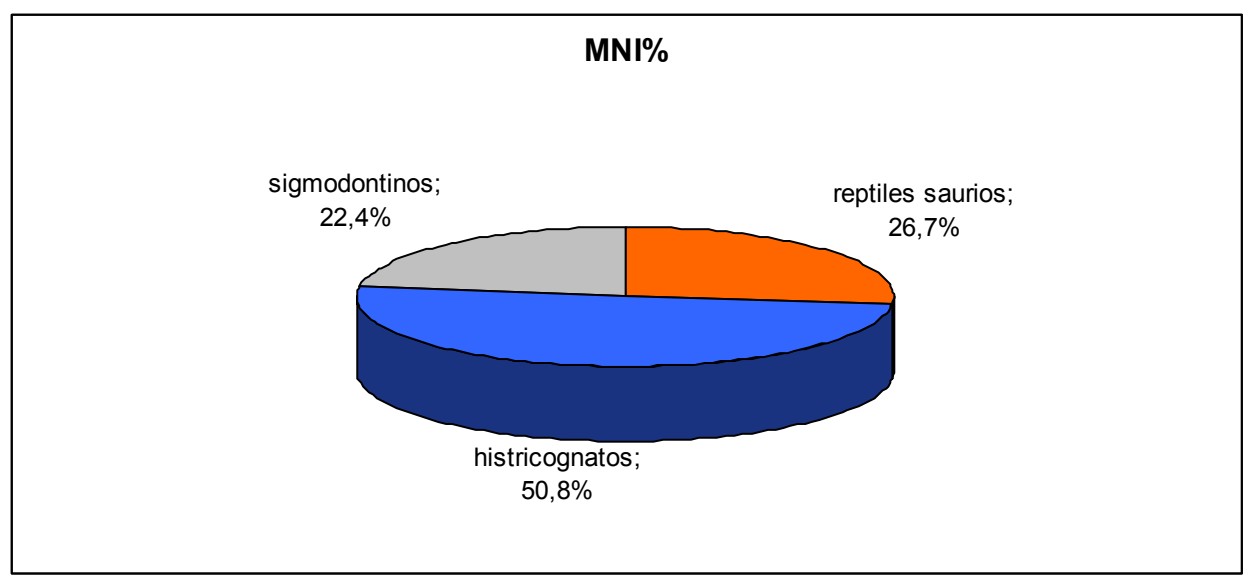

Figura 7.41. Distribución del MNI\% por grupos de microvertebrados de la muestra arqueofaunística total.

\begin{tabular}{|l|ccccccccccccc|}
\hline Cronología (en ka ${ }^{14} \mathbf{C}$ AP) & \multicolumn{1}{|c}{$\mathbf{0 , 1 3}$} & \multicolumn{1}{c|}{$\mathbf{2 , 2}$} & \multicolumn{1}{c|}{$\mathbf{2 . 0 3}$} \\
\hline Niveles & $\mathbf{1}$ & $\mathbf{2}$ & $\mathbf{3}$ & $\mathbf{4}$ & $\mathbf{5}$ & $\mathbf{6}$ & $\mathbf{7}$ & $\mathbf{8}$ & $\mathbf{9}$ & $\mathbf{1 0}$ & $\mathbf{1 1}$ & $\mathbf{1 2}$ \\
\hline $\begin{array}{l}\text { Reptilia / Sauria indet. } \\
\text { Leiolaemidae }\end{array}$ & 2 & 7 & 11 & 6 & 6 & 3 & 14 & 7 & - & 8 & 3 & 6 \\
$\begin{array}{l}\text { Liolaemus sp. } \\
\text { Mammalia / Rodentia }\end{array}$ & 2 & 1 & 7 & 3 & 2 & 7 & 3 & 5 & - & 7 & - & 4 \\
Ctenomyidae & & & & & & & & & & & \\
Ctenomys sp. & & & & & & & & & & & \\
Cricetidae/Sigmodontinae indet. & 2 & 34 & 20 & 21 & 26 & 14 & 24 & 39 & - & 49 & 12 & 53 \\
Phyllotis xanthopygus & 7 & 3 & 20 & 12 & 23 & 28 & 14 & 45 & - & 29 & 11 & 32 \\
Eligmodontia sp. & - & - & - & - & - & 1 & 3 & 3 & - & 2 & 1 & 3 \\
Euneomys chinchilloides & - & - & - & - & - & 1 & 1 & - & - & - & - & - \\
Total & 1 & 3 & 2 & 3 & 1 & 5 & 1 & 5 & - & 4 & - & 2 \\
\hline
\end{tabular}

Tabla 7.57. Composición taxonómica de los ensambles de microvertebrados de Cueva Palulo (expresada en NISP).

\begin{tabular}{|l|cccccccc|cc|}
\hline Cronología (en ka ${ }^{14}$ C AP) & \multicolumn{1}{c|}{$\mathbf{2 , 0 5}$} & & & $\mathbf{4}$ & & \\
\hline Niveles & $\mathbf{1 3}$ & $\mathbf{1 4}$ & $\mathbf{1 5}$ & $\mathbf{1 6}$ & $\mathbf{1 7}$ & $\mathbf{1 8}$ & $\mathbf{1 9}$ & $\mathbf{2 0}$ & Total & $\%$ \\
\hline $\begin{array}{l}\text { Reptilia / Sauria indet. } \\
\text { Leiolaemidae }\end{array}$ & 6 & 2 & - & 4 & 7 & - & - & - & 92 & 11 \\
$\begin{array}{l}\text { Liolaemus sp. } \\
\text { Mammalia / Rodentia }\end{array}$ & 5 & 1 & 3 & 1 & 4 & - & - & - & 55 & 6,7 \\
Ctenomyidae & & & & & & & & & & \\
Ctenomys sp. & 28 & 15 & 11 & 5 & 6 & - & 1 & - & 360 & 44 \\
Cricetidae/Sigmodontinae indet. & 18 & 4 & 10 & 3 & 2 & - & 1 & - & 262 & 32 \\
Phyllotis xanthopygus & & & & & & & & & 13 & 1,6 \\
Eligmodontia sp. & 1 & - & - & - & - & - & - & & 3 & 0,4 \\
Euneomys chinchilloides & 2 & - & - & - & - & - & 1 & - & 30 & 3,7 \\
\hline Total & 60 & 22 & 24 & 13 & 19 & - & 3 & - & 815 & \\
\hline
\end{tabular}


Tabla 7.57. (continuación) Composición taxonómica de los ensambles de microvertebrados de Cueva Palulo (expresada en NISP).

El índice de diversidad de Shannon calculado para toda la muestra arrojó un valor 1,238, más bajo que el ensamble actual de microvertebrados, lo que sugiere que los taxones tienen una representación menos pareja. Incluso, la muestra arqueofaunística exhibió menor riqueza taxonómica. A excepción de los niveles 9 y 18 se recuperaron microvertebrados en todos los niveles. Liolaemus sp. y Ctenomys sp. se mantuvieron constantes en casi toda la secuencia. Por su parte, P. xanthopygus se registró en el sector medio de la secuencia (niveles 6-12). E. chinchilloides presentó una distribución saltuaria con un hiato de ocurrencia entre los niveles 14 y 18. Para finalizar, Eligmodontia sp. exhibió escasos registros en los niveles 6, 7 y 13 (Tabla 7.58).

\begin{tabular}{|c|c|c|c|c|c|c|c|c|c|c|c|c|}
\hline Cronología (en ka ${ }^{14} \mathrm{C}$ AP) & & & 0,13 & & & 2,2 & & & & & 2.03 & \\
\hline Niveles & 1 & 2 & 3 & 4 & 5 & 6 & 7 & 8 & 9 & 10 & 11 & 12 \\
\hline $\begin{array}{l}\text { Reptilia / Sauria indet. } \\
\text { Leiolaemidae }\end{array}$ & - & - & - & - & - & - & 2 & - & - & - & 2 & - \\
\hline $\begin{array}{l}\text { Liolaemus sp. } \\
\text { Mammalia / Rodentia } \\
\text { Ctenomyidae }\end{array}$ & 1 & 1 & 2 & 2 & 1 & 3 & 1 & 2 & - & 4 & - & 2 \\
\hline $\begin{array}{l}\text { Ctenomys sp. } \\
\text { Cricetidae/Sigmodontinae }\end{array}$ & 1 & 3 & 2 & 4 & 6 & 4 & 2 & 5 & - & 7 & 3 & 10 \\
\hline Phyllotis xanthopygus & - & - & - & - & - & 1 & 3 & 2 & - & 1 & 1 & 1 \\
\hline Eligmodontia sp. & - & - & - & - & - & 1 & 1 & - & - & - & - & - \\
\hline Euneomys chinchilloides & 1 & 1 & 1 & 1 & 1 & 2 & 1 & 2 & - & 1 & - & 1 \\
\hline $\begin{array}{l}\text { Total } \\
\text { Riqueza } \\
\text { H' } \\
\text { Equitatividad }\end{array}$ & 3 & 5 & 5 & 7 & 8 & 11 & 10 & 11 & - & 13 & 6 & 14 \\
\hline
\end{tabular}

Tabla 7.58. Composición taxonómica de los ensambles de microvertebrados de Cueva Palulo (expresada en MNI). 


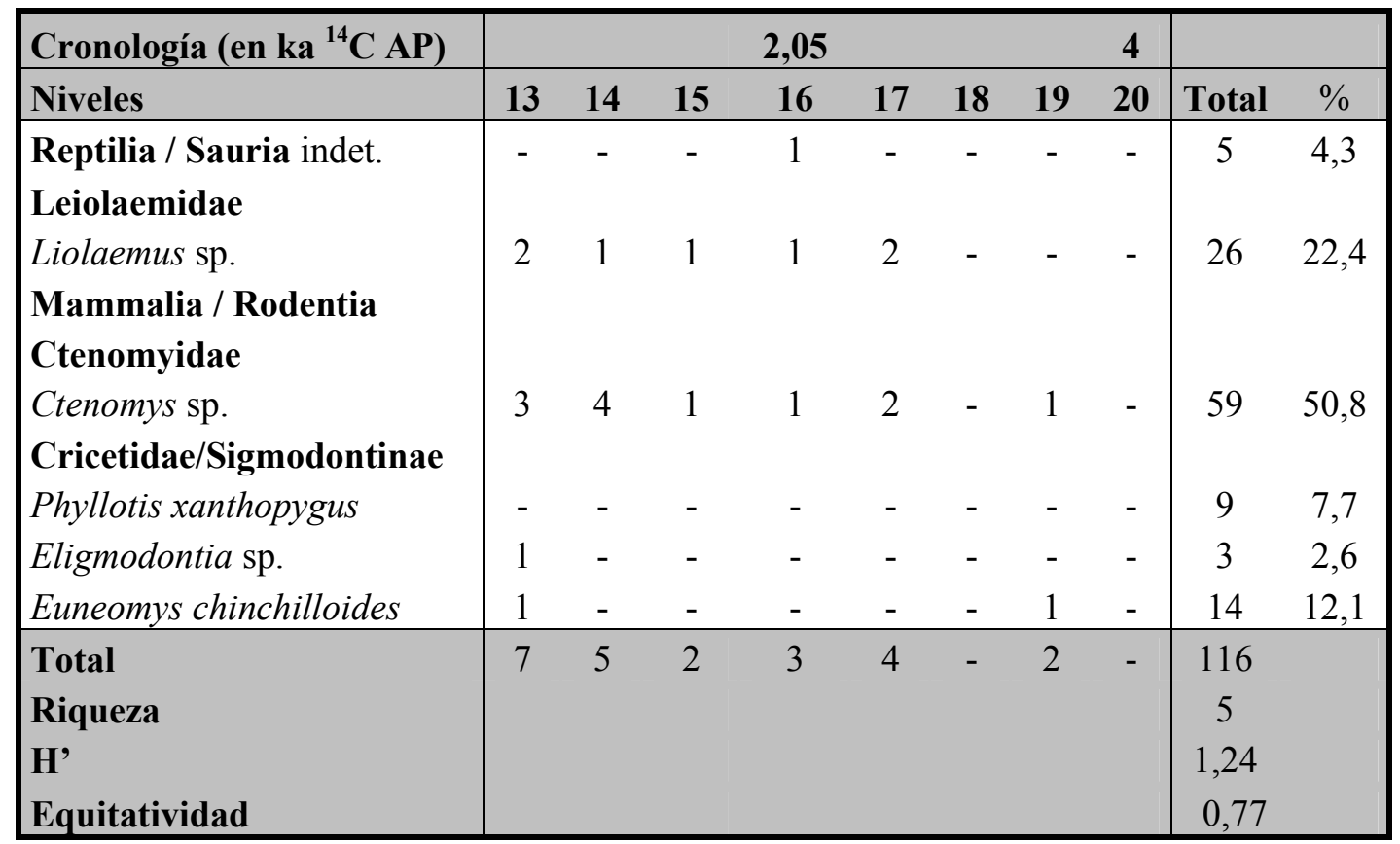

Tabla 7.58. (continuación) Composición taxonómica de los ensambles de microvertebrados de Cueva Palulo (expresada en MNI).

\subsubsection{Discusión}

\subsubsection{Interpretación tafonómica}

La ausencia de marcas de corte y el escaso registro de restos termolaterados señalan que los grupos humanos no habrían participado en la génesis de los conjuntos de microvertebrados (Pardiñas 1999a, 1999b). La alta proporción de restos con huellas de corrosión digestiva en las categorías ligera, modera y fuerte, la alta pérdida de molares y la alta fractura de huesos con ángulos redondeados y bordes suaves son coincidentes con los ensambles originados por la acción de aves rapaces diurnas (Andrews, 1990; Fernández-Jalvo y Andrews, 1992). Asimismo, como se ilustra en la figura 7.40 el patrón de abundancia relativa de partes esqueletales se asemeja más al promedio de Falconiformes observado por Andrews (1990). En esta parte de la cordillera se distribuyen varias especies de aves rapaces diurnas, sin embargo, las que pueden hacer sus nidos en saliente rocosas y que se alimentan principalmente de micromamíferos son Geranoaetus melanoleucus y B. polyosoma (ver Capítulo 6 para mayor detalle). Resulta interesante destacar que los valores registrados en el ensamble arqueofaunístico revelan similitudes con los datos brindados por Iglesias (2009), en su análisis tafonómico de restos de micromamíferos ingeridos por $B$. polyosoma. La autora mostró que esta 
especie produce altos niveles de corrosión digestiva, de fractura y de pérdida dentaria y mejor preservación de elementos craneales. Sin embargo, al carecer de datos tafonómicos sobre G. melanoleucus (ver Capítulo 6), imposibilita una aproximación tafonómica más fina. Por otra parte, la abundancia de restos de Ctenomys sp. a lo largo de toda la frecuencia debido a que los mismos presentaron evidencias de corrosión digestiva (Figura 7.39 B), también podría asociarse a sesgos producto de la acción depredadora de las aves rapaces diurnas (ver Capítulo 6).

Finalmente, se destaca que la ausencia de evidencias de procesos postdepositacionales tales como meteorización, pisoteo, marcas de raíces, diagénesis y transporte hídrico, sugieren que el ensamble de microvertebrados de Cueva Palulo tuvo un enterramiento rápido y buena preservación (Korth, 1979; Pinto Llona y Andrews, 1999; FernándezJalvo y Andrews, 2003).

\subsubsection{Interpretación paleoambiental}

Hay una correlación positiva alta y significativa entre la riqueza taxonómica y el tamaño de las muestras $\left(r_{\mathrm{s}}=0,69 ; \mathrm{p}>0,001\right)$, esta situación sumando a los bajos valores de MNI, limita el alcance de las conclusiones. No obstante, se realizaron algunos comentarios en base a la presencia de determinados taxones.

En la figura 7.42 se detallan las frecuencias relativas de los taxones de micromamíferos en las muestras estudiadas. Los registros de P. xanthopygus E. chinchilloides, Eligmodontia sp. ca. $2 \mathrm{ka}{ }^{14} \mathrm{C}$ AP, indican que el ambiente está asociado a estepas arbustivas abiertas con alta proporción de suelo desnudo, pedregoso y abundante roca expuesta. Asimismo, la presencia de E. chinchilloides en los niveles basales y superiores sugiere un ambiente de peladal tanto en torno a $\operatorname{los} 4 \mathrm{ka}{ }^{14} \mathrm{C} \mathrm{AP}$ como en tiempos recientes.

En la actualidad, la ocurrencia de Eligmodontia sp, E. chinchilloides y P.xanthopygus, sugiere un ambiente actual abierto, pedregoso y con abundante roca expuesta. La mayor diversidad y riqueza taxonómica observada en esta muestra, están relacionadas con una representación más pareja entre taxones y con la incorporación de varias especies tales como L. micropus, A. olivaceus y A. longipilis, señalando un aumento de la disponibilidad hídrica y desarrollo de vegas. Por su parte, la abundancia del abrotriquino oportunista, A. olivaceus y la presencia del lagomorfo introducido indica un impacto antrópico reciente (Cueto et al., 2008; Fernández et al., 2009d). 


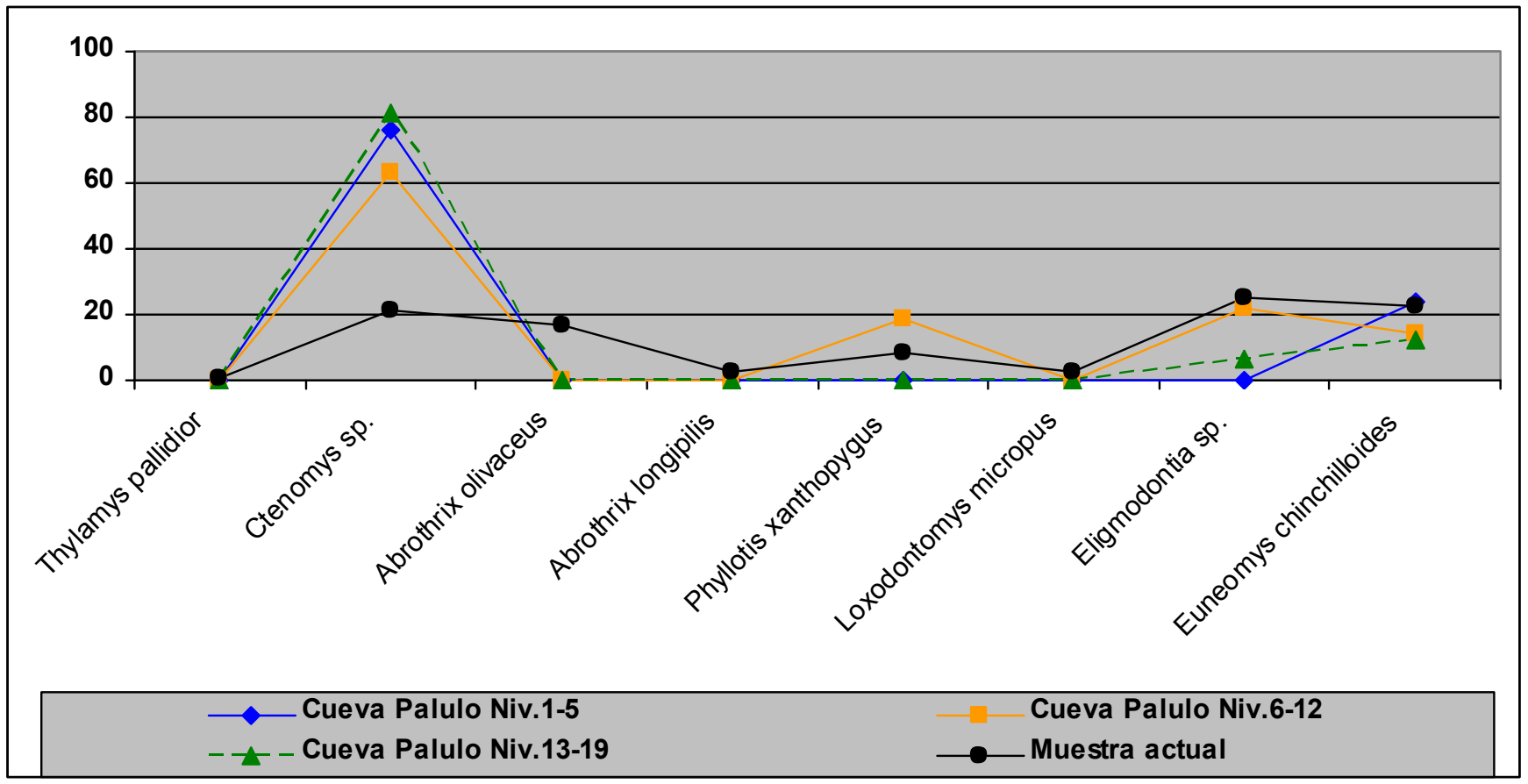

Figura 7.42. Comparación de las frecuencias relativas de los taxones de micromamíferos recuperados de Cueva Palulo y el parámetro actualístico.

\subsubsection{Conclusión}

Las evidencias tafonómicas señalan que el principal responsable de la acumulación del ensamble de microvertebrados recuperados de Cueva Palulo habría sido un rapaz diurna y la ausencia de evidencias de procesos postdepositacionales indica que el ensamble tuvo un enterramiento rápido y buena conservación.

Las condiciones ambientales durante $4-2 \mathrm{ka}{ }^{14} \mathrm{C}$ AP están asociadas a estepas arbustivas abiertas con alta proporción de suelo desnudo, pedregoso y roquedales.

En la actualidad el ambiente es similar, pero con aumento de la disponibilidad hídrica y el desarrollo de vegas cordilleranas, con un marcado deterioro antrópico principalmente producido por el ganado doméstico. 


\subsection{Arroyo Malo 3 (AMA 3)}

\subsubsection{Contexto arqueológico}

El sitio arqueológico Arroyo Malo 3 (AMA 3) es un alero de basalto y andesitas perteneciente a la Formación Cerro Guanaquero (Volkheimer, 1975) y se encuentra ubicado en el alto valle del Río Atuel, próximo a la desembocadura del Arroyo Malo en aquel río (3451'18" S y 6953'00" O; 2.160 m.s.n.m.) y a tres km de la Laguna el Sosneado (Figuras 7.43 A) (Neme, 2007).

El alero tiene $13 \mathrm{~m}$ de abertura, $3 \mathrm{~m}$ de altura y una profundidad de 7,5 $\mathrm{m}$ (Figura 7.44). Las excavaciones en el sitio se efectuaron en cuatro campañas durante los meses de verano de 1992, 1995, 1996 y 2000, por un equipo de arqueólogos dirigidos por Gustavo Neme. En la primera de ellas se practicó un sondeo de $50 \mathrm{~cm}$ x $50 \mathrm{~cm}$ y se excavaron 9 niveles artificiales de $10 \mathrm{~cm}$, cuyo potencial arqueológico fue sustento de las excavaciones posteriores. Entre 1995 y 1996 se abrió la cuadrícula A-1, de 1 x 2 m ubicada en el centro del alero, donde se extrajeron 35 niveles artificiales de $5 \mathrm{~cm}$ hasta alcanzar la roca de base a los 1,75 m de profundidad (Neme, 2007). Finalmente, en el 2000 se excavó la cuadrícula B-1 de $4 \mathrm{~m}^{2}$ (Figura 7.43 B y C), alcanzando una profundidad de $2 \mathrm{~m}$ divididos en 40 niveles artificiales de $5 \mathrm{~cm}$ cada uno (Dieguez y Neme, 2003).

El análisis estratigráfico fue realizado por Dieguez y Neme (2003), quienes en base a cambios en la granulometría y coloración de los sedimentos pudieron diferenciar la secuencia de $2 \mathrm{~m}$ de potencia en tres estratos principales (Figura 7.45). En este sentido, el primer cambio en la estratigrafía tiene lugar a $10545 \mathrm{~cm}$ de profundidad, con el pasaje de un sedimento gris parduzco a uno gris claro, predominando un sedimento arenoso con clastos de variados tamaños procedentes de desprendimientos del techo del alero. Posteriormente, entre los $75 \mathrm{~cm}$ y los $145 \mathrm{~cm}$ de profundidad persiste el mismo sedimento. Sin embargo, debajo de este estrato, el sedimento se hace más fino y homogéneo, de coloración gris oscuro y con una disminución de la fracción psamítica; finalmente este sedimento descansa sobre la roca de base (Dieguez y Neme, 2003). 


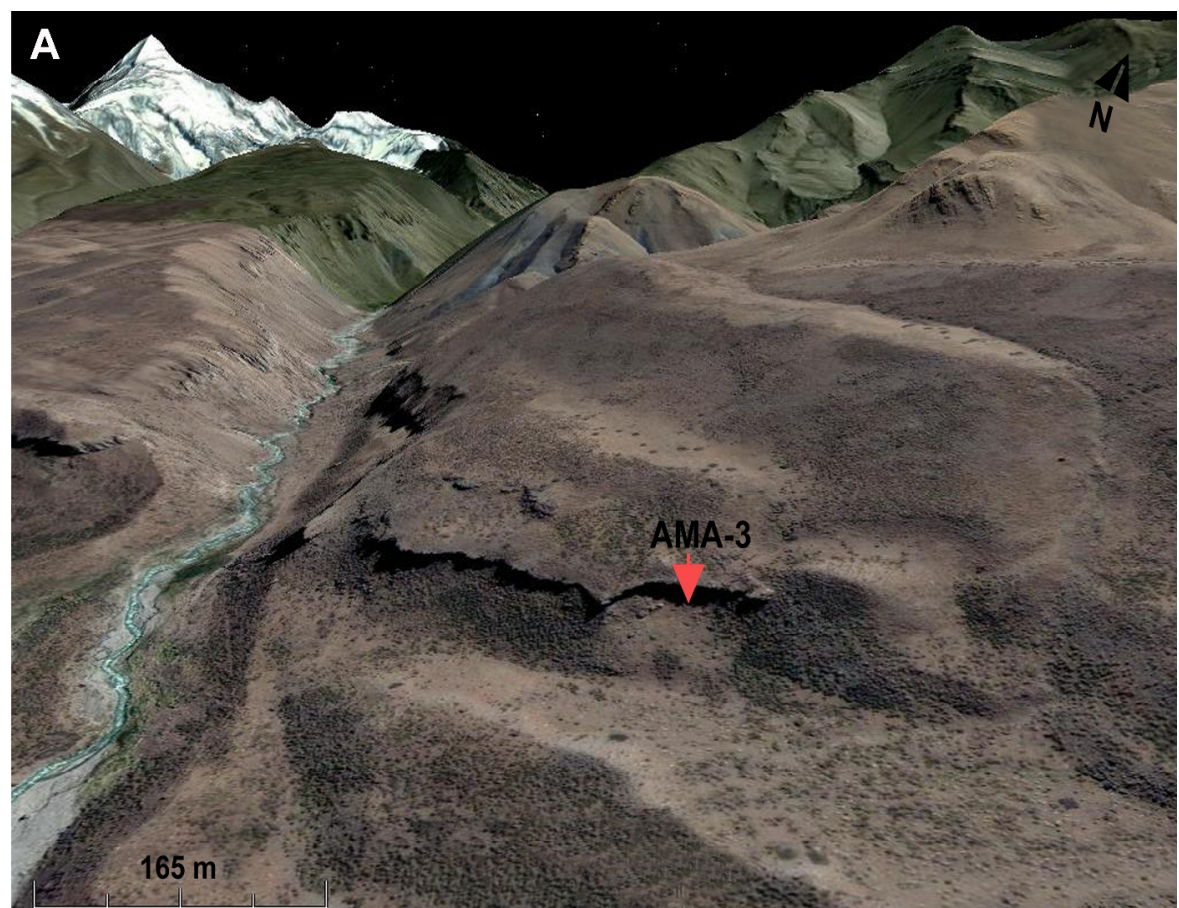

B

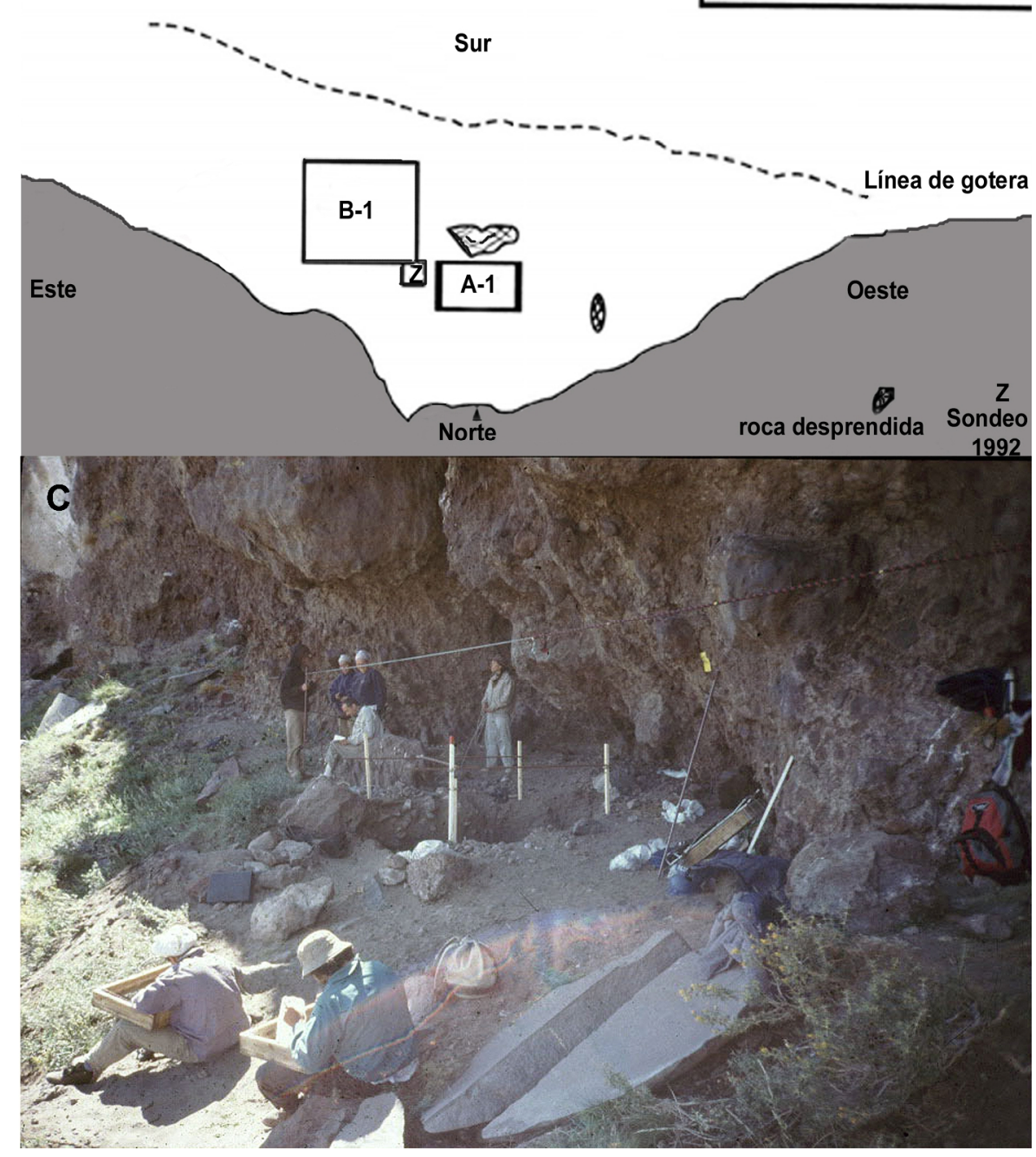

Esc.: 1-100

Vista en Planta

1/96

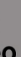

(a)

AMA - 3. 
Figura 7.43. Sitio arqueologico AMA-3. A: ubicación del sitio. B: vista en planta mostrando la disposición de las cuadrículas de excavación, tomado de (Neme, 2007: 60). C: vista de la excavación.

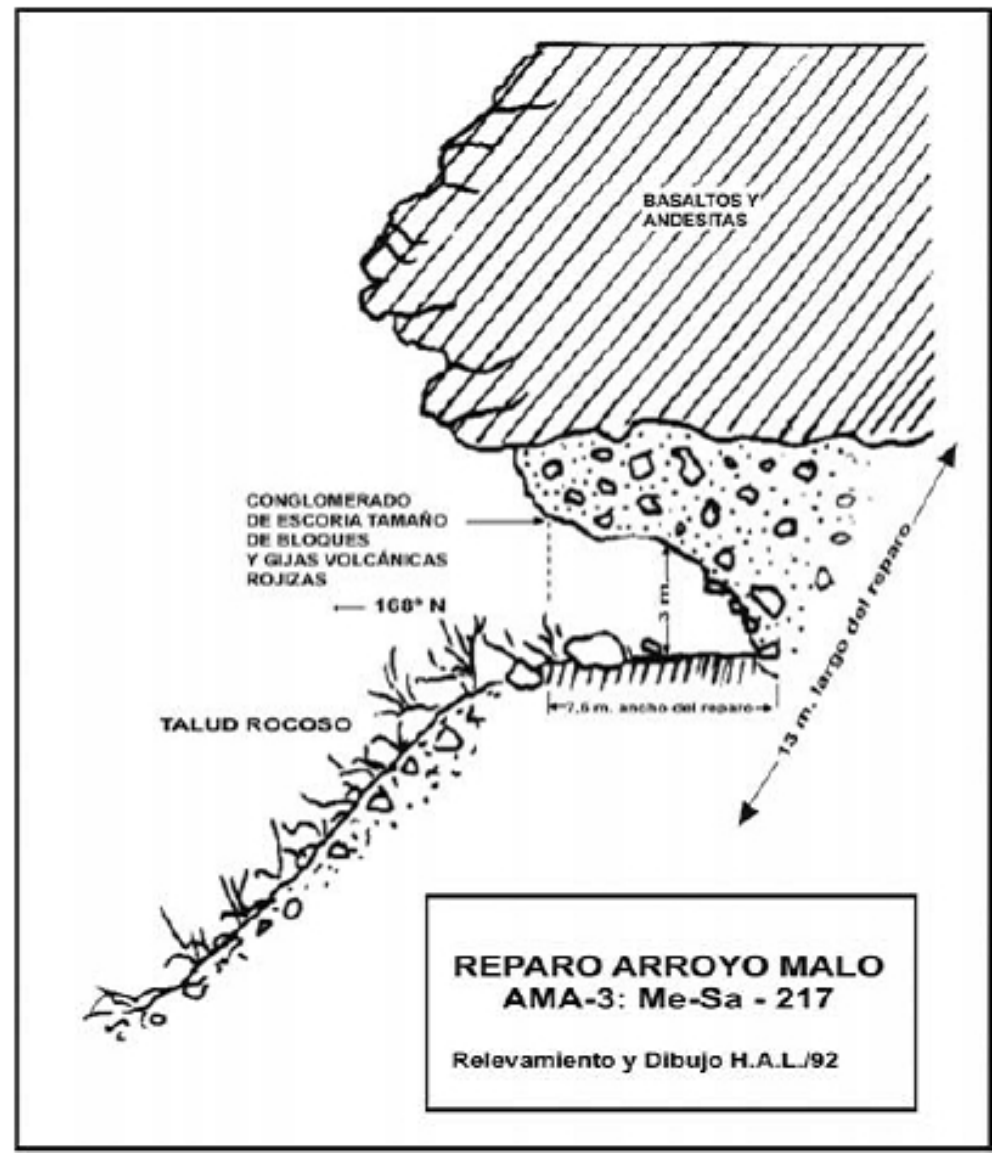

Figura 7.44. Relevamiento del perfil del alero AMA 3 realizado por Lagiglia en 1992. Tomado de Neme (2007: 60).

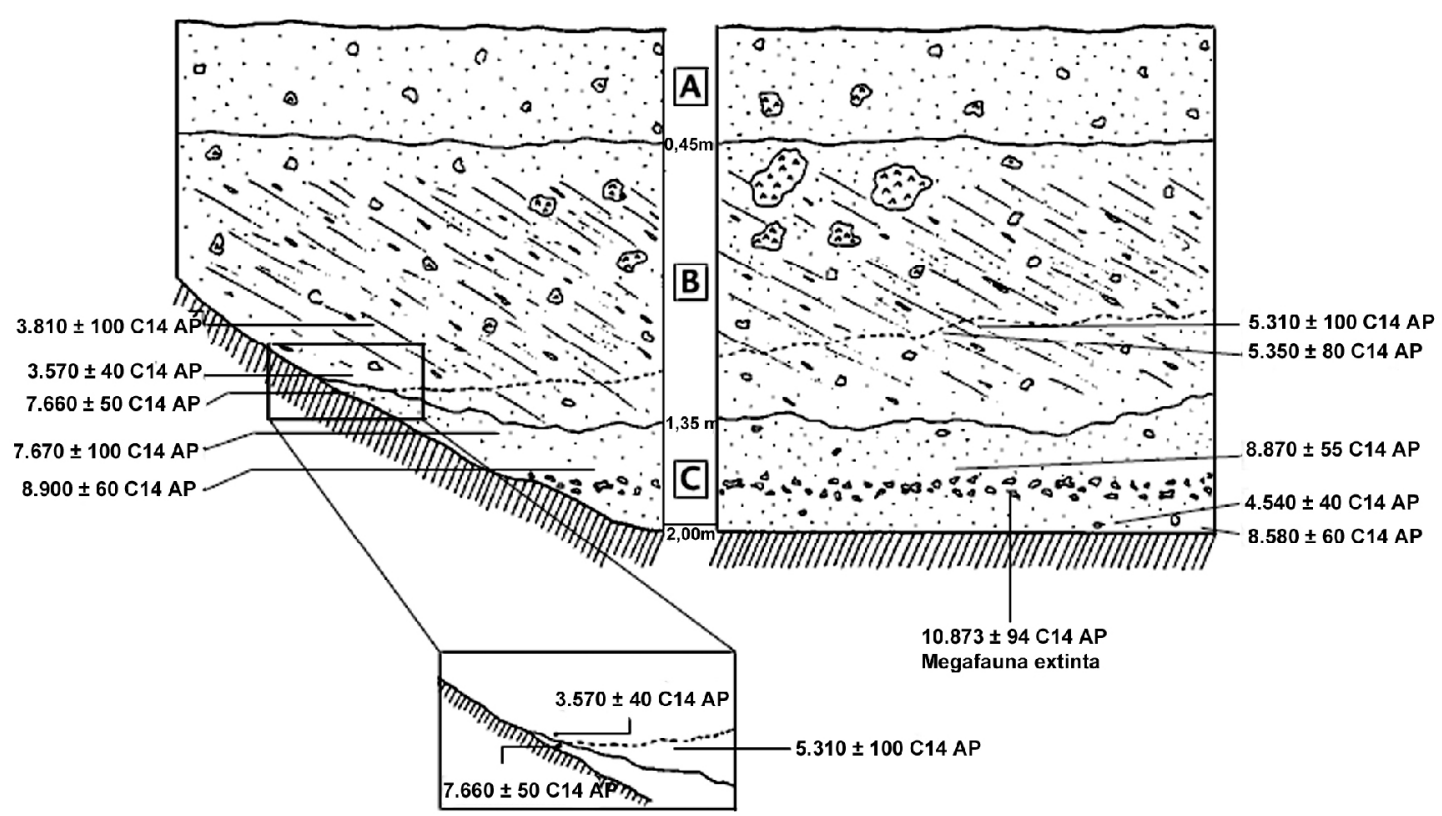

Figura 7.45. Esquema cronoestratigráfico de AMA-3. Modificado de Dieguez y Neme (2003: 88). 
Como se muestra en la tabla 7.59, los fechados radiocarbónicos del sitio fueron obtenidos en base a 11 muestras de carbón vegetal y una sobre un resto óseo referido a un xenartro extinto (Tardigrada indet.) (Dieguez y Neme, 2003).

\begin{tabular}{|c|c|c|c|c|c|c|}
\hline Cuadrícula & Nivel & Muestras & Código & $\begin{array}{c}\text { Unidad } \\
\text { estratigráfica }\end{array}$ & Datación ${ }^{14}$ C & Calibrado \\
\hline A-1 & 12 & carbón & LP-958 & B & $2.200 \pm 50$ & $2155-2298$ \\
A-1 & 24 & carbón & LP-946 & B & $3.810 \pm 100$ & $4057-4362$ \\
A-1 & 27 & carbón & NSRL-11721 & B & $3.570 \pm 40$ & $3810-3927$ \\
A-1 & 28 & carbón & NSRL-11722 & C & $7.660 \pm 50$ & $8419-8518$ \\
A-1 & $31,32,33$ & carbón & LP-783 & C & $7.670 \pm 100$ & $8401-8566$ \\
A-1 & 35 & carbón & AA-26193 & C & $8.900 \pm 60$ & $9918-10142$ \\
B-1 & $23 \mathrm{~N}$ & carbón & LP-1279 & B & $5.350 \pm 80$ & $6029-6239$ \\
B-1 & 23 S & carbón & LP-1267 & B & $5.310 \pm 100$ & $5985-6212$ \\
B-1 & 35 & carbón & NSRL-11723 & C & $8.870 \pm 55$ & $9858-10120$ \\
B-1 & 37 & óseo & AA-58287 & C & $10.873 \pm 94$ & $12748-12944$ \\
B-1 & 39 & carbón & NSRL-11720 & C & $8.580 \pm 60$ & $9519-9619$ \\
B-1 & 40 & carbón & NSRL-11719 & C & $4.540 \pm 40$ & $5094-5292$ \\
\hline
\end{tabular}

Tabla 7.59. Fechados del sitio AMA-3.

Con el propósito de ordenar la información arqueológica de AMA-3, Neme (2007) en base a los fechados radiocarbónicos dividió la secuencia de ocupación en tres conjuntos o unidades temporales (Tabla 7.60).

\begin{tabular}{|c|l|l|c|c|}
\hline Conjuntos & \multicolumn{1}{|c|}{ A-1 } & \multicolumn{1}{|c|}{ B-1 } & $\begin{array}{c}\text { Unidades } \\
\text { estratigráficas }\end{array}$ & Cronología \\
\hline 1 & Niv. 1-12 & Niv. 1-12 & A y B & últimos 2200 años ${ }^{14} \mathrm{C}$ AP \\
2 & Niv. 13-24 & Niv. 13-24 & $\mathrm{C}$ & $2200-3810$ años ${ }^{14} \mathrm{C}$ AP \\
3 & Niv. 25-35 & Niv. 25-40 & C & $3810-8900$ años ${ }^{14} \mathrm{C}$ AP \\
\hline
\end{tabular}

Tabla 7.60. Conjuntos temporales definidos en AMA-3.

Resulta interesante notar que Dieguez y Neme (2003) observaron algunos problemas cronoestatigráficos entre las cuadrículas A-1 y B-1. En el nivel 38 de la cuadrícula B-1, el fechado de $c a .4500$ años ${ }^{14} \mathrm{C}$ AP por debajo de los niveles de $c a .8900$ años ${ }^{14} \mathrm{C} \mathrm{AP}$, fue interpretado por los autores como una migración de material producto de la actividad de animales fosoriales, debido a la distribución de los materiales en el nivel y el tipo de sedimento portador. En la cuadrícula A-1 se registró un hiatus de ca. 3000 años ${ }^{14} \mathrm{C}$ AP entre los niveles 27 y 28 , mostrando la ausencia de fechados correspondientes al Holoceno medio, los que si estuvieron presentes en la cuadrícula B1. Esta anomalía en la cuadrícula A-1 fue explicada por los autores citados, en base a la topografía de la roca base y los eventos de caída de rocas cerca de la línea de goteo, lo 
cual habría provocado una diferencia en la tasa de depositación entre ambas cuadrículas durante el Holoceno medio. Respecto al registro de la falange del xenartro extinto (nivel 37), fechada ca. de 10800 años ${ }^{14} \mathrm{C}$ AP y asociada a los materiales arqueológicos de las primeras ocupaciones humanas del alero, fechados sobre carbón entre 8900-8500 años ${ }^{14} \mathrm{C}$ AP, muestran que el uso del reparo por parte de esta fauna extinta no habría sido contemporáneo a las primeras ocupaciones humanas (Dieguez y Neme, 2003; Neme, 2002, 2007). No obstante, el sitio presenta una coherencia interna estratigráfica y cronológica que permite un adecuado manejo de la información (Dieguez y Neme, 2003; Neme, 2007).

La información disponible sobre el registro arqueológico de AMA-3 muestra cambios importantes a través del tiempo. En este sentido, en los últimos 2200 años ${ }^{14} \mathrm{C}$ AP (Conjunto 1) se observaron un rango de actividades mayor, incluyendo el procesamiento de recursos vegetales (e.g., Chenopodium papulosum, Schinus polygamus), la confección y reparación de instrumentos y el procesamiento intensivo de una fauna más variada (Neme, 2002, 2007; Llano, 2008; Pérez Winter, 2009a, 2009b, 2010; Giardina, 2010). Asimismo, la presencia de elementos de molienda (i.e., molinos y manos de moler) en el conjunto más tardío, además de corroborar el procesamiento de restos vegetales (Llano, 2008), posiblemente indique una recurrencia mayor al lugar (Neme, 2002, 2007). Por otra parte, el incremento de materias primas no locales (obsidiana y sílice) desde los niveles más tempranos a los más tardíos, fue interpretado como un mayor acceso a este tipo de recurso a través de una ampliación de los sistemas de intercambio a nivel regional (Neme, 2002, 2007; Pérez Winter, 2008). Además, resulta interesante destacar que no recuperaron fragmentos de cerámica en toda la secuencia (Neme, 2007).

Respecto al registro arqueofaunístico del sitio, hasta el momento solo existe información publicada sobre el análisis exhaustivo de los restos óseos recuperados de la cuadrícula A-1 (Neme, 2007). No obstante, para la cuadrícula B-1 se cuenta con un informe no publicado (Neme, 2004).

En la cuadrícula A-1 se exhumaron 1.660 especímenes óseos, de los cuales solo el 6,7\% han podido ser determinados en algún nivel taxonómico. Por su parte, en la cuadrícula B-1 se recuperaron 13.918 especímenes y en forma similar con el caso anterior una mínima porción $(5,8 \%)$ pudo determinarse taxonomicamente (Neme, 2004). Este bajo porcentaje de restos determinados se relaciona con el alto nivel de fragmentación observado (Neme, 2004, 2007). 
En líneas generales hay una similitud entre las estructuras taxonómicas de los ensambles recuperados de ambas cuadrículas. El registro de la falange del xenartro extinto en la B-1, correspondiente al Conjunto 3 (Nivel 37, 10800 años ${ }^{14} \mathrm{C}$ AP) marca una diferencia (Dieguez Neme, 2003). Sin embargo, como se mencionó anteriormente a pesar de que estaba asociada a materiales arqueológicos, presentó una antigüedad 2000 años mayor que los mismos y por ende se interpretó que el uso del reparo por parte de esta fauna extinta no habría sido contemporáneo a las primeras ocupaciones humanas (Dieguez y Neme, 2003; Neme, 2002, 2007).

Lama guanicoe fue el taxón más abúndate y la única especie determinada a lo largo de la secuencia del sitio. Los mamíferos carnívoros tuvieron lugar en los conjuntos 1 y 3 , aunque las marcas de los mismos en huesos de otros animales se concentraron principalmente en el conjunto más temprano (Neme, 2004, 2007). Por su parte, el Conjunto 1 (más tardío) es el que presenta la mayor diversidad taxonómica, incluyendo restos de fauna introducida (Caprinae indet.) (Neme, 2007).

Asimismo, se observaron bajos grados de meteorización, que sumado a los altos niveles de fractura podrían estar indicando actividad humana a través del consumo de médula ósea. Como sustento de esto se registraron fracturas y marcas de indudable origen antrópico y se observó una correlación positiva entre restos faunísticos, líticos y vegetales, de modo que los restos faunísticos recuperados en el sitio difícilmente hayan sido depositados en el alero por acción de predadores o por muerte natural (Neme, 2007). Sin embargo, los restos de microvertebrados exhumados de la cuadrícula A-1, exhibieron un patrón inverso en relación a los otros materiales arqueológicos, lo que posiblemente indique que su ingreso al sitio no se debió al consumo humano, sino a agentes naturales (Neme et al., 2002). Por otra parte, la presencia de aves es claramente superior en los momentos más tardíos de ocupación del alero (conjuntos 1 y 2) (Giardina, 2010).

En síntesis, Neme (2007) en base al tipo y abundancia de los materiales recuperados del sitio, planteó una baja pero continua ocupación del alero durante la mayor parte del Holoceno, el cual pudo haber sido utilizado como lugar de refugio en ocasiones especiales como accidentes climáticos y más intensamente en tiempos recientes.

Resulta interesante destacar, que Giardina (2010) en base al registro de restos Falco sparverius y Tyto alba en los conjuntos 1 y 2 , sumado la evidencia de corrosión digestiva, plantea que los restos de aves de menor tamaño podrían haber sido acumulados por la acción de aves rapaces. 


\subsubsection{Metodología}

La secuencia de microvertebrados correspondiente a la cuadrícula A-1 fue analizada por Neme et al. (2002). No obstante, este trabajo se realizó en base a los microvertebrados exhumados de la cuadrícula B-1 y se efectuó una comparación con los resultados alcanzados por Neme et al. (2002).

Como parámetro actualístico se estudió una muestra de 58 egagrópilas y un disgregado de T. alba y una muestra de 60 egagrópilas de Geranoaetus melanoleucus, las cuales fueron recolectadas en enero del 2000 y 2008 respectivamente en las inmediaciones del sitio arqueológico [Localidades Laguna El Sosneado y Arroyo Malo (ver apéndice)].

\subsubsection{Resultados}

\subsubsection{Análisis tafonómico}

\subsection{Micromamíferos}

En los tres conjuntos definidos en AMA-3 más del 90\% de restos exhibieron marcas de corrosión digestiva en las distintas categorías propuestas por Andrews (1990), las cuales se concentraron en la categoría ligera, moderada y fuerte (Tabla 7.61). En una parte de los incisivos la corrosión se concentró en los extremos, en otra parte de los mismos se extendió por una mayor superficie, dejándola ondulada y en otra parte el esmalte quedó reducido en pequeños islotes sobre la dentina. Algunos molares exhibieron cúspides con un contorno más redondeado, otros mostraron un ligero poseado en el esmalte y muchos de ellos carecieron de esmalte o presentaron un fuerte poseado. Hubo numerosos restos postcraneales con evidencias de poseado en las superficies articulares, algunos con aspecto de abrasionado o pulido y otros con diáfisis onduladas y epífisis fuertemente digeridas (Figura 7.46 A-C). Es interesante destacar que en el Conjunto 1, se recuperó un fragmento de egagrópila (Figura 7.46 D) y 138 especimenes con evidencias de pelos provenientes de agagrópilas (3\%, Figura 7.46 E). 


\begin{tabular}{|c|c|c|c|c|c|c|c|c|c|c|}
\hline & \multicolumn{10}{|c|}{ Clases de digestión sensu Andrews (1990) } \\
\hline & \multicolumn{2}{|c|}{ Ausente } & \multicolumn{2}{|c|}{ Ligera } & \multicolumn{2}{|c|}{ Moderada } & \multicolumn{2}{|c|}{ Fuerte } & \multicolumn{2}{|c|}{ Extrema } \\
\hline & $(\mathrm{N})$ & $\%$ & $(\mathrm{~N})$ & $\%$ & $(\mathrm{~N})$ & $\%$ & $(\mathrm{~N})$ & $\%$ & $(\mathrm{~N})$ & $\%$ \\
\hline \multicolumn{11}{|l|}{ Conjunto 1} \\
\hline \multicolumn{11}{|l|}{ Digestión dentaria } \\
\hline Incisivos in situ & 66 & 13,5 & 172 & 35,1 & 84 & 17,1 & 161 & 32,9 & 7 & 1,4 \\
\hline Incisivos aislados & 24 & 7,1 & 85 & 25,1 & 100 & 29,5 & 125 & 36,9 & 5 & 1,5 \\
\hline Incisivos Total & 90 & 10,8 & 257 & 31 & 184 & 22,2 & 286 & 34,5 & 12 & 1,4 \\
\hline Molares in situ & 42 & 2 & 541 & 26 & 773 & 37,2 & 705 & 33,9 & 19 & 0,9 \\
\hline Molares aislados & 3 & 0,9 & 86 & 26,8 & 98 & 30,5 & 134 & 41,7 & - & - \\
\hline Molares Total & 45 & 1,9 & 627 & 26,1 & 871 & 36,3 & 839 & 34,9 & 19 & 0,8 \\
\hline \multicolumn{11}{|l|}{ Digestión Postcraneal } \\
\hline Fémur (epífisis proximal) & 20 & 4,1 & 201 & 41,3 & 151 & 31 & 112 & 23 & 3 & 0,6 \\
\hline Húmero (epífisis distal) & 66 & 18,3 & 186 & 51,7 & 57 & 15,8 & 50 & 13,9 & 1 & 0,3 \\
\hline \multicolumn{11}{|l|}{ Conjunto 2} \\
\hline \multicolumn{11}{|l|}{ Digestión dentaria } \\
\hline Incisivos in situ & 5 & 4,4 & 42 & 37,2 & 24 & 21,2 & 42 & 37,2 & - & - \\
\hline Incisivos aislados & 2 & 1,6 & 30 & 23,4 & 35 & 27,3 & 60 & 46,9 & 1 & 0,8 \\
\hline Incisivos Total & 7 & 2,9 & 72 & 29,9 & 59 & 24,5 & 102 & 42,3 & 1 & 0,4 \\
\hline Molares in situ & 1 & 0,2 & 62 & 12,1 & 219 & 42,6 & 232 & 45,1 & - & - \\
\hline Molares aislados & 14 & 10,6 & 20 & 15,2 & 39 & 29,5 & 59 & 44,7 & - & - \\
\hline Molares Total & 15 & 2,3 & 82 & 12,7 & 258 & 39,9 & 291 & 45 & - & - \\
\hline \multicolumn{11}{|l|}{ Digestión Postcraneal } \\
\hline Fémur (epífisis proximal) & 1 & 0,8 & 45 & 37,8 & 41 & 34,5 & 32 & 26,9 & - & - \\
\hline Húmero (epífisis distal) & 4 & 2,7 & 70 & 47,9 & 45 & 30,8 & 27 & 18,5 & - & - \\
\hline \multicolumn{11}{|l|}{ Conjunto 3} \\
\hline \multicolumn{11}{|l|}{ Digestión dentaria } \\
\hline Incisivos in situ & 4 & 6,1 & 23 & 34,8 & 6 & 9,1 & 33 & 50 & - & - \\
\hline Incisivos aislados & 17 & 16,5 & 20 & 19,4 & 30 & 29,1 & 36 & 35 & - & - \\
\hline Incisivos Total & 21 & 12,4 & 43 & 25,4 & 36 & 21,3 & 69 & 40,8 & - & - \\
\hline Molares in situ & 4 & 1 & 49 & 11,9 & 183 & 44,4 & 176 & 42,7 & - & - \\
\hline Molares aislados & 8 & 9,2 & 9 & 10,3 & 33 & 37,9 & 37 & 42,5 & - & - \\
\hline Molares Total & 12 & 2,4 & 58 & 11,6 & 216 & 43,3 & 213 & 42,7 & - & - \\
\hline Digestión Postcraneal & & & & & & & & & & \\
\hline Fémur (epífisis proximal) & 13 & 16,7 & 35 & 44,9 & 17 & 21,8 & 13 & 16,7 & - & - \\
\hline Húmero (epífisis distal) & 4 & 5,6 & 45 & 62,5 & 14 & 19,4 & 9 & 12,5 & - & - \\
\hline
\end{tabular}

Tabla 7.61. Representación de las distintas categorías de corrosión digestiva en micromamíferos recuperados de los conjuntos de AMA-3. 


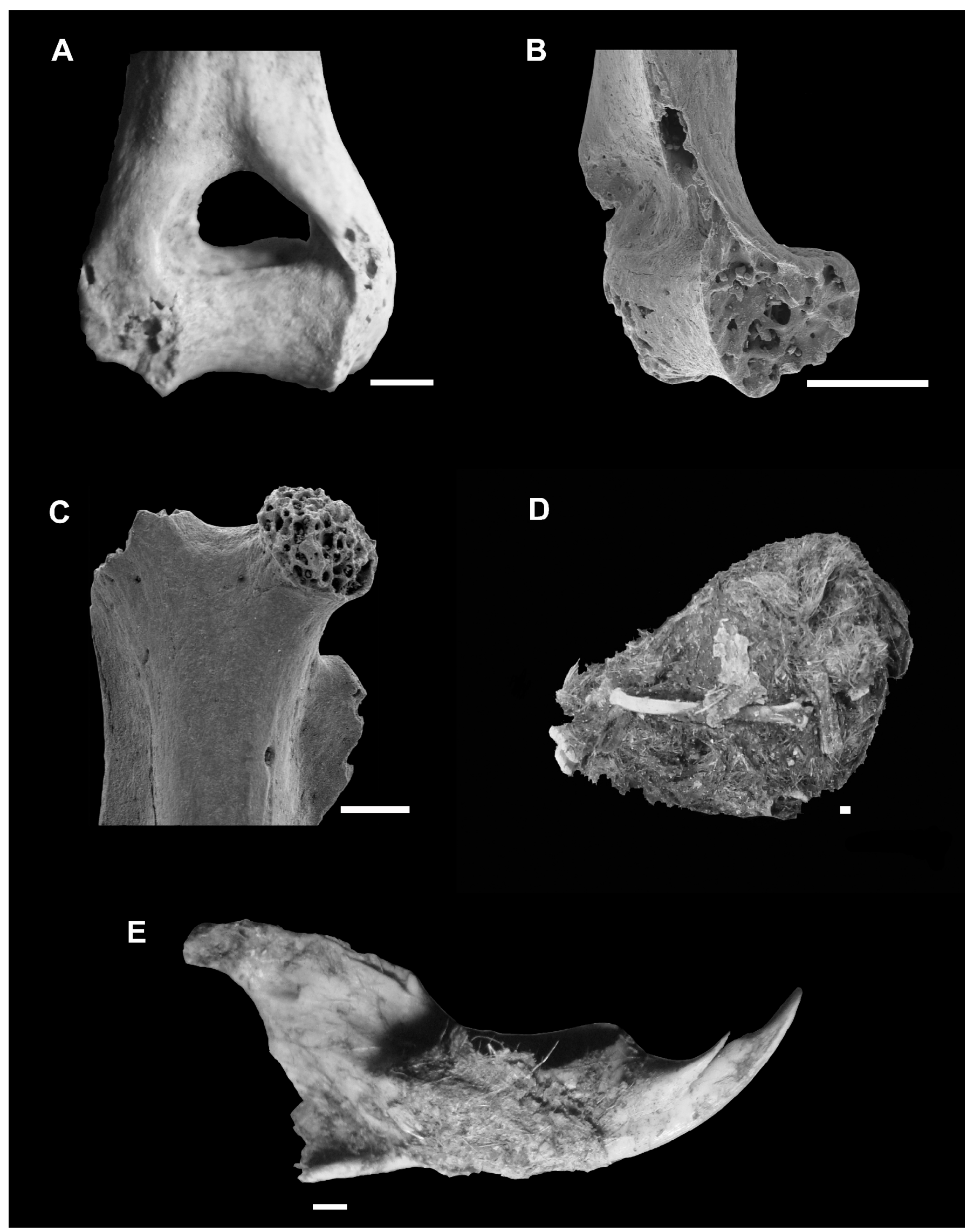


Figura 7.46. Ejemplos de evidencias de acción de aves rapaces en los distintos conjuntos de AMA-3. A: húmero de Caviidae con marcas de corrosión ligera en la epífisis distal (Conjunto 1, Nivel 6). B: húmero de Sigmodontinae con marcas de corrosión fuerte en la epífisis distal (Conjunto 2, Nivel 17). C: fémur de Sigmodontinae con marcas de corrosión fuerte en la epífisis proximal (Conjunto 3, Nivel 26). D: egagrópila fósil (Conjunto 1, Nivel 2). E: mandíbula de Euneomys con restos de pelos de egagrópilas (Conjunto 1, Nivel 1). Escalas: $1 \mathrm{~mm}$.

La abundancia relativa promedio fue baja en todos los conjuntos, siendo aún menor en el Conjunto 3 (Tabla 7.62). En los tres conjuntos se observa un patrón similar de representación de partes esqueletarias, donde los elementos más abundantes fueron los maxilares, mandíbulas, húmeros, pelvis, fémures y tibias y los menos abundantes fueron las costillas, astrágalos, metapodios y falanges (Figura 7.47).

\begin{tabular}{|l|cc|cc|cc|}
\hline Elemento / procedencia & \multicolumn{2}{|c|}{ C-1 } & \multicolumn{2}{c|}{ C-2 } & \multicolumn{2}{c|}{ C-3 } \\
& MNE & $\begin{array}{c}\text { Abundancia } \\
\text { relativa }\end{array}$ & MNE & $\begin{array}{c}\text { Abundancia } \\
\text { relativa }\end{array}$ & MNE & $\begin{array}{c}\text { Abundancia } \\
\text { relativa }\end{array}$ \\
\hline Maxilar & 455 & 52,4 & 138 & 46 & 124 & 42,5 \\
Mandíbula & 645 & 74,3 & 162 & 54 & 129 & 44,2 \\
Incisivos aislados & 339 & 19,5 & 128 & 21,3 & 103 & 17,6 \\
Molares aislados & 321 & 6,2 & 132 & 7,3 & 87 & 5 \\
Vértebras & 653 & 5 & 364 & 8,1 & 261 & 6 \\
Costillas & 21 & 0,2 & 4 & 0,1 & 6 & 0,2 \\
Escápula & 80 & 9,2 & 39 & 13 & 25 & 8,6 \\
Húmero & 369 & 42,5 & 147 & 49 & 75 & 25,7 \\
Cúbito & 138 & 15,9 & 55 & 18,3 & 37 & 12,7 \\
Radio & 83 & 9,6 & 60 & 20 & 28 & 9,6 \\
Pelvis & 251 & 28,9 & 60 & 20 & 58 & 19,9 \\
Fémur & 499 & 57,5 & 124 & 41,3 & 78 & 26,7 \\
Tibia & 379 & 43,7 & 117 & 39 & 63 & 21,6 \\
Calcáneo & 38 & 4,4 & 29 & 9,7 & 15 & 5,1 \\
Astrágalo & 8 & 0,9 & 5 & 1,7 & 4 & 1,4 \\
Metapodio & 89 & 1 & 80 & 2,7 & 60 & 2,1 \\
Falanges & 23 & 0,1 & 15 & 0,2 & 8 & 0,1 \\
Total & 4391 & & 1659 & & 1161 & \\
Promedio & \multicolumn{7}{|c|}{21,8} & & 20,7 & & 14,6 \\
\hline
\end{tabular}

Tabla 7.62. Número mínimo de elementos (MNE) y abundancia relativa, para los ensambles de micromamíferos recuperados de los conjuntos de AMA-3. 


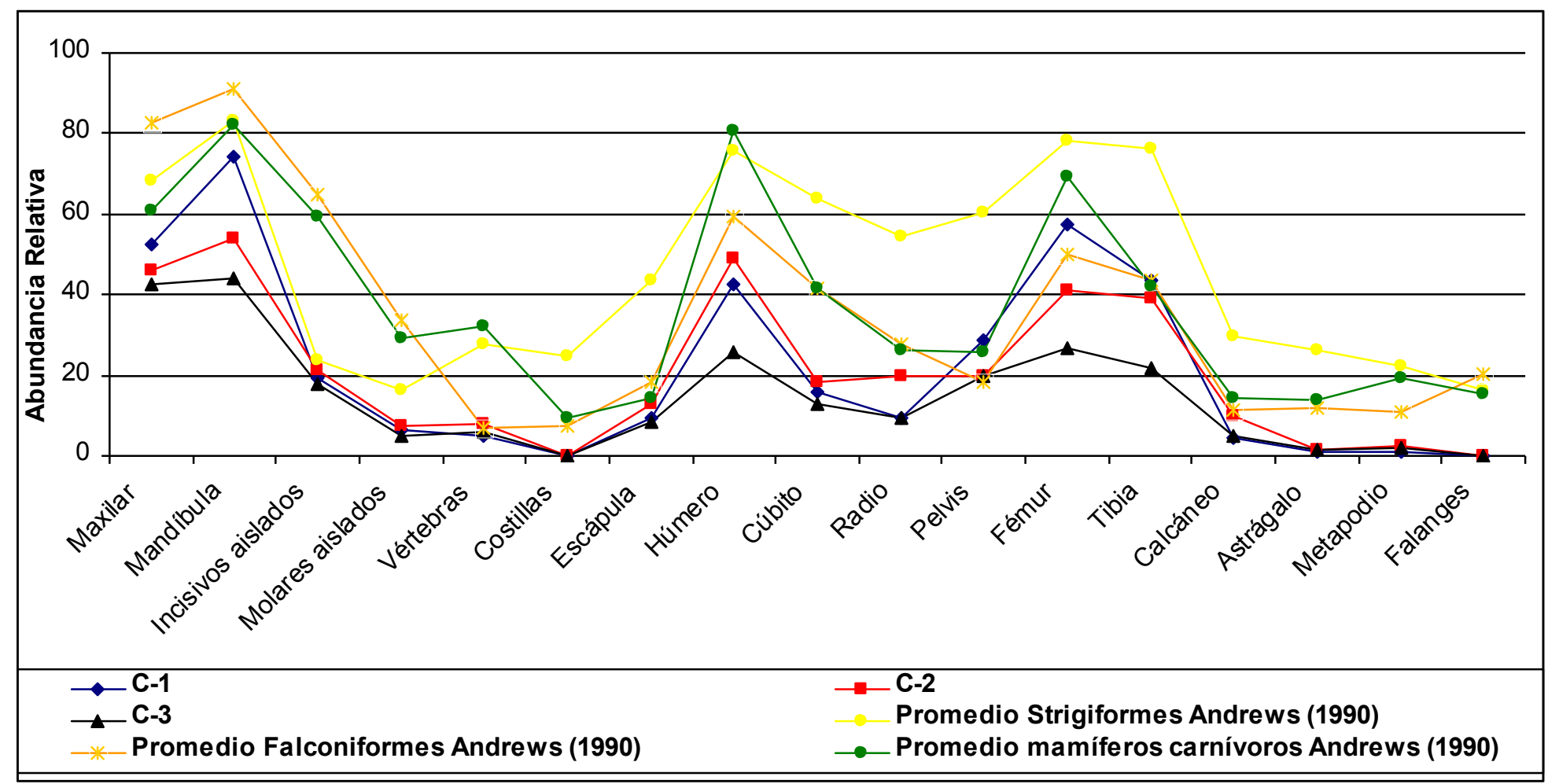

Figura 7.47. Valores de abundancia relativa de los diferentes elementos anatómicos de micromamíferos recuperados de los conjuntos de AMA-3, comparados con el promedio de diferentes depradadores realizado por Andrews (1990).

El 53,3\% de todos los especímenes recuperados de AMA-3 estaban fracturados. El Conjunto $1(57 \%)$ fue el que presentó mayor porcentaje de fractura, seguido por el Conjunto $3(50,7 \%)$ y el Conjunto $2(45,6 \%)$. En la tabla 7.63 se exhibe los distintos tipos de fractura en los elementos contemplados en la metodología propuesta por Andrews (1990) y Andrews y Fernández (1992).

No se recuperaron cráneos completos en ninguno de los conjuntos y la mayor parte de los mismos correspondieron a maxilares sin arcos zigomáticos. Los porcentajes de pérdidas dentarias estuvieron cercanos al 30\%, siendo el Conjunto 2 el que mostró los valores más altos.

Se registraron bajos porcentajes de mandíbulas completas en todos los conjuntos de AMA-3 y las que estaban fracturas exhibieron una representación pareja entre las distintas categorías en todos los conjuntos. Se observó una elevada pérdida de molares y baja de incisivos de las mandíbulas.

Se recuperaron exiguos molares rotos en todos los conjuntos Sin embargo, se registraron porcentajes más altos de incisivos rotos, alcanzando el 60\% en el Conjunto 3. Asimismo, en todos los conjuntos los incisivos y molares aislados presentaron proporciones más altas de fractura comparados con los que estaban in situ. 


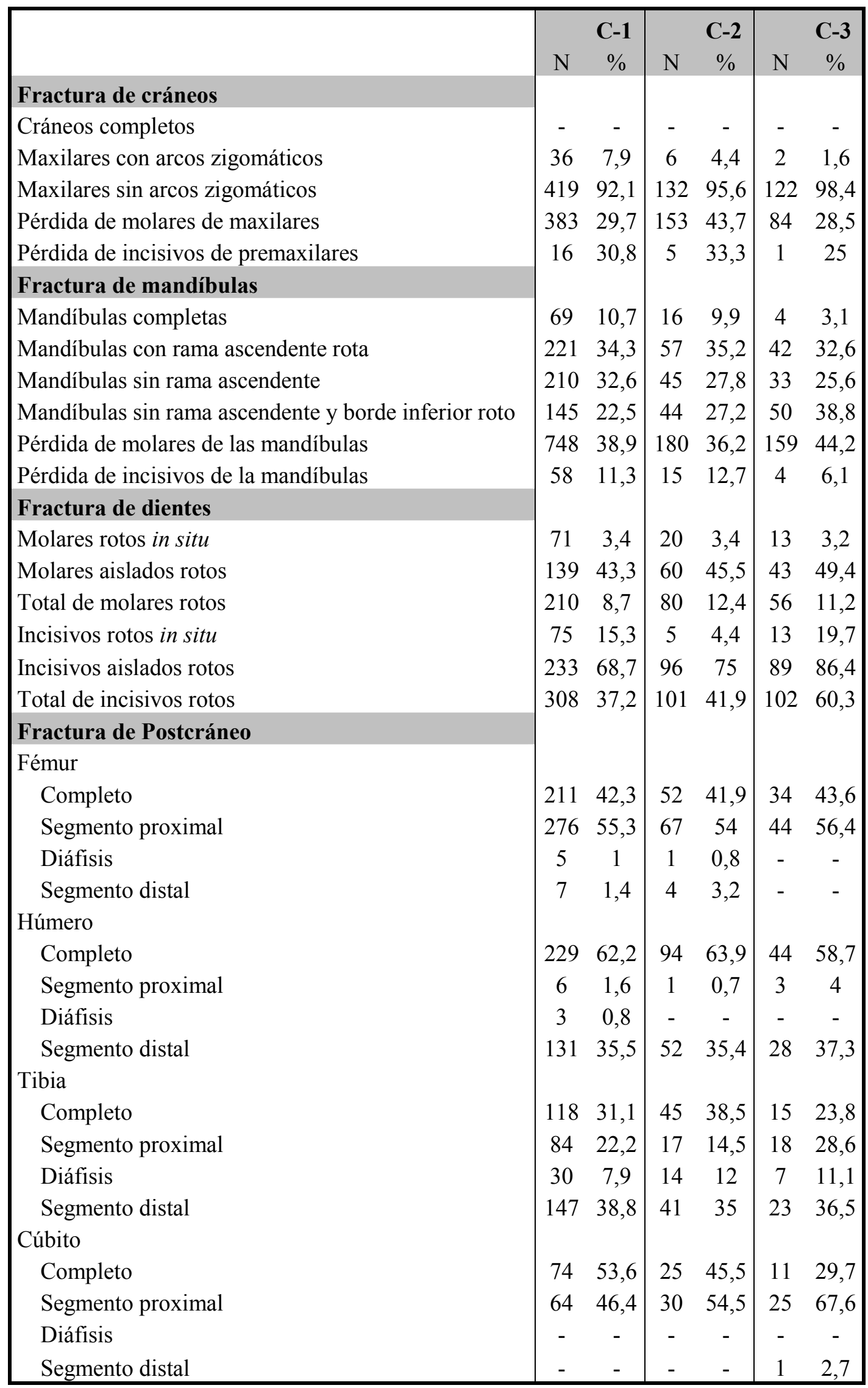

Tabla 7.63. Fractura de elementos craneales, dentarios y postcraneales, para los micromamíferos provenientes de los conjuntos de AMA-3. 
Los valores de fractura de los elementos postcraneales contemplados en la metodología propuesta por Andrews (1990) y Fernández-Jalvo y Andrews (1992) (i.e., fémur, húmero, tibia y cúbito) fue levemente superior al $50 \%$ en todos los conjuntos, siendo el Conjunto 3 el más elevado 58,9\%. Asimismo, se observó una marcada preservación diferencial de los segmentos proximales de fémures y cúbitos y de los segmentos distales de húmeros y tibias.

Se destaca que los conjuntos 2 y 3 presentaron una mayor proporción de los elementos postcraneales rotos con superficies de fracturas con ángulos redondeados y bordes suaves, mientras que el Conjunto 1 exhibió proporciones similares de restos con superficies de fractura con ángulos redondeados y bordes suaves y con ángulos agudos y bordes ásperos (Tabla 7.64).

\begin{tabular}{|c|c|c|c|c|c|c|}
\hline \multirow{2}{*}{$\begin{array}{l}\text { Tipos de Fractura en postcraneal } \\
\text { (Fémur, húmero, tibia y cúbito) }\end{array}$} & \multicolumn{2}{|r|}{ C-1 } & \multicolumn{2}{|r|}{ C-2 } & \multicolumn{2}{|r|}{$\mathrm{C}-3$} \\
\hline & $\mathrm{N}$ & $\%$ & $\mathrm{~N}$ & $\%$ & $\mathrm{~N}$ & $\%$ \\
\hline Fracturas con ángulos agudos y bordes ásperos & 371 & 49,3 & 60 & 26,5 & 38 & 25,5 \\
\hline Fracturas espiral o longitudinal con bordes suaves & 382 & 50,7 & 167 & 73,5 & 111 & 74,5 \\
\hline
\end{tabular}

Tabla 7.64. Tipos de fractura para los elementos postcraneales de los conjuntos de micromamíferos de AMA-3.

Por otra parte, las vértebras, calcáneos, astrágalos, metapodios y falanges se hallaron completos en todos los conjuntos. No obstante, los elementos más frágiles como las cinturas presentaron un alto grado de ruptura (Tabla 7.65).

\begin{tabular}{|c|c|c|c|c|c|c|}
\hline $\begin{array}{l}\text { Fracturas postcraneal } \\
\text { (otros elementos) }\end{array}$ & $\mathrm{N}$ & $\begin{array}{c}\mathrm{C}-1 \\
\% \\
\end{array}$ & $\mathrm{~N}$ & $\begin{array}{c}\mathrm{C}-2 \\
\% \\
\end{array}$ & $\mathrm{~N}$ & $\begin{array}{c}\mathrm{C}-3 \\
\% \\
\end{array}$ \\
\hline Vértebras & - & - & - & - & - & - \\
\hline Costillas & 7 & 33,3 & 2 & 50 & - & - \\
\hline Escápula & 80 & 100 & 39 & 100 & 25 & 100 \\
\hline Radio & 12 & 14,5 & 18 & 30 & 8 & 28,6 \\
\hline Pelvis & 225 & 89,6 & 59 & 98,3 & 57 & 98,3 \\
\hline Calcáneo & - & - & - & - & - & - \\
\hline Astrágalo & - & - & - & - & - & - \\
\hline Metapodio & - & - & - & - & - & - \\
\hline Falanges & - & - & - & - & - & - \\
\hline
\end{tabular}

Tabla 7.65. Fractura del resto de los elementos postcraneales de micromamíferos recuperados de los conjuntos de AMA-3.

En líneas generales no se hallaron diferencias importantes entre los conjuntos definidos 
en AMA-3, solo un leve aumento de los niveles de ruptura en el Conjunto 1.

Los valores obtenidos a partir de los índices calculados se exhiben en la tabla 7.66. El primer índice que evalúa la relación entre elementos postcraneales y craneales sugiere una mejor preservación de los primeros en todos los conjuntos, mientras que el segundo índice indica una disminución de los elementos postcraneales en todos los conjuntos. El índice que valora la relación entre elementos distales y proximales de los miembros indica una predominancia de elementos proximales en todos los conjuntos. En cuanto a los índices de pérdida dentaria se observó que en todos los conjuntos, la mayor parte de los molares e incisivos quedaron retenidos en sus alvéolos.

Los índices IT e IP mostraron un predominio de microvertebrados de menor tamaño y solitarios y crípticos en todos los conjuntos.

\begin{tabular}{|l|c|c|c|}
\hline & C-1 & C-2 & C-3 \\
\hline Postcráneo / Cráneo & & & \\
$\mathrm{f}+\mathrm{t}+\mathrm{h}+\mathrm{r}+\mathrm{c} / \mathrm{mx}+\mathrm{mb}+\mathrm{m}$ & 165,3 & 186,3 & 132,2 \\
$\mathrm{~h}+\mathrm{f} / \mathrm{mx}+\mathrm{mb}$ & 78,9 & 90,3 & 60,5 \\
Elementos distales / proximales & & & \\
$\mathrm{t}+\mathrm{r} / \mathrm{f}+\mathrm{h}$ & 53,2 & 65,3 & 59,5 \\
Pérdida de dientes & & & \\
Alvéolos mx+ alvéolos mb/m & 54,4 & 64,8 & 59 \\
Alvéolos mx+ alvéolos mb/i & 15,1 & 17,7 & 7,6 \\
Índice de Tamaño (IT) & 722,8 & 816,7 & 671,4 \\
Índice de Predictibilidad (IP) & 13,8 & 12,2 & 14,9 \\
\hline
\end{tabular}

Tabla 7.66. Valores de los índices calculados en los conjuntos de AMA-3.

Referencias: f: fémur; t: tibia; h: húmero; r: radio; c: cúbito; mx: maxilar; mb: mandíbula; m: molar; i: incisivo.

Por otra parte, se destaca que en los tres conjuntos no se registraron restos con marcas de cortes y ninguno de los conjuntos superó el $0,5 \%$ de restos con evidencias de termoalteración.

En lo que concierne a los procesos postdepositacionales, los conjuntos 1 y 3 presentaron valores muy bajos de meteorización (0,2\%, correspondientes al estadio de meteorización II sensu Andrews, 1990) y ausente en el Conjunto 2. A los largo de la secuencia no se registraron especímenes óseos con marcas de pisoteo ni de raíces. Asimismo, se recuperaron numerosos especímenes con impresiones de óxido de manganeso en todos los conjuntos (Conjunto $1=38,6 \%$; Conjunto 2=43,8\%; Conjunto $3=35,5 \%$ ). Sin embargo, no se hallaron evidencias de corrosión sedimentaria en 
ninguno de los mismos. A lo largo de la secuencia no se observaron restos óseos con redondeamiento en los extremos y protuberancias de los restos óseos y dentarios, indicando que no actuaron los efectos de la abrasión por transporte hídrico, desplazamientos y rozamientos de los restos contra el sedimento (Korth, 1979; Fernández-Jalvo y Andrews, 2003).

\subsection{Reptiles}

Como si distingue en la tabla 7.67, tanta los restos postcraneales como los restos craneales presentaron marcas de corrosión digestiva por arriba del 90\%. La mayoría de los dientes se encontraron con el esmalte reducido y removido por sectores y los huesos largos presentaron un poseado en las epífisis que variaban de ligero a intenso (Figura $7.48)$.

\begin{tabular}{|l|cc|cc|cc|}
\hline & C-1 & & & \multicolumn{2}{c|}{ C-2 } & \multicolumn{2}{c|}{ C-3 } \\
& N & $\%$ & N & $\%$ & N & $\%$ \\
\hline Craneal & 85 & 95,5 & 24 & 96 & 30 & 100 \\
Postcraneal & 26 & 92,9 & 27 & 96,4 & 30 & 90,9 \\
\hline Total & 111 & 94,9 & 51 & 96,2 & 60 & 95,2 \\
\hline
\end{tabular}

Tabla 7.67. Corrosión digestiva craneal y postcraneal, para los reptiles de los conjuntos de AMA-3.

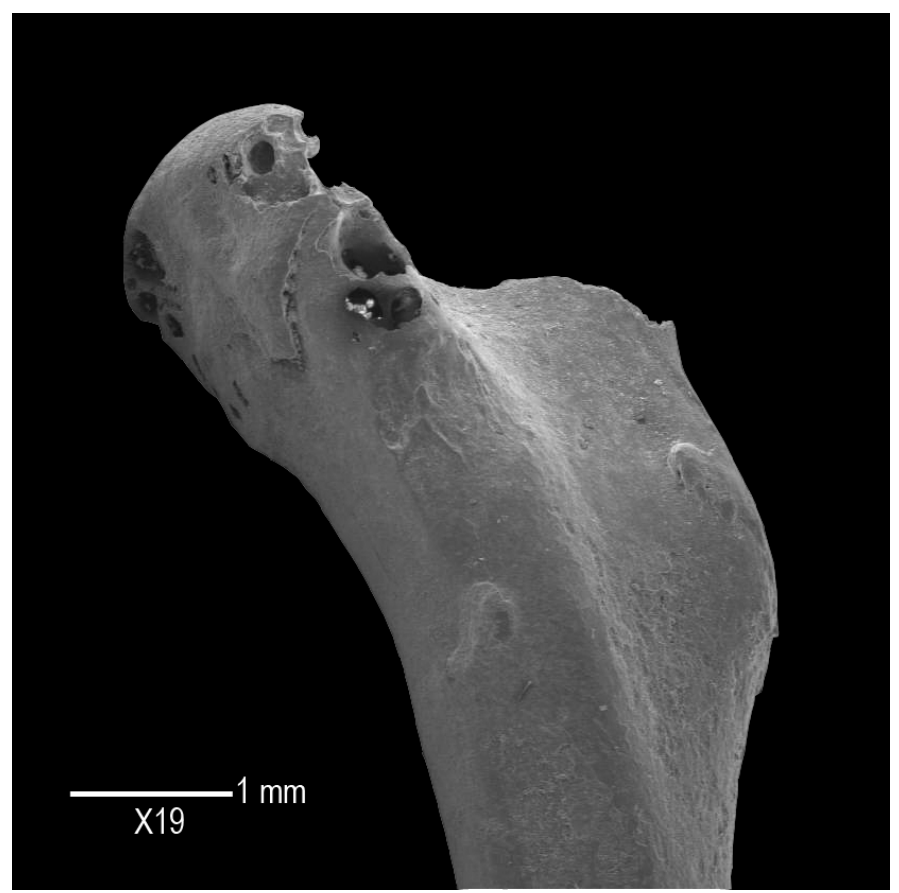

Figura 7.48. Fémur de Sauria exhibiendo marcas de corrosión digestiva en la epífisis proximal. (Unidad 1, Nivel 4). 
Los valores de abundancia relativa se exhiben en la tabla 7.68. Las mandíbulas, maxilares y fémures fueron abundantes en todos los conjuntos. No obstante, los húmeros estuvieron bien representados en los conjuntos 2 y 3 y las pelvis solo en el Conjunto 3 (Figura 7.49).

\begin{tabular}{|l|cc|cc|cc|}
\hline Elemento / procedencia & \multicolumn{2}{|c|}{ C-1 } & \multicolumn{2}{c|}{ C-2 } & \multicolumn{2}{c|}{ C-3 } \\
& $\begin{array}{c}\text { MNE } \\
\text { Abundancia } \\
\text { Frontal }\end{array}$ & $\begin{array}{c}\text { MNE } \\
\text { Abundancia } \\
\text { relativa }\end{array}$ & MNE & $\begin{array}{c}\text { Abundancia } \\
\text { relativa }\end{array}$ \\
Parietal & 5 & 14,3 & 2 & 13,3 & 5 & 31,1 \\
Maxilar & 5 & 14,3 & - & - & 1 & 6,3 \\
Mandíbula & 25 & 35,7 & 9 & 30 & 10 & 31,3 \\
Vértebras & 54 & 77,1 & 14 & 46,7 & 14 & 43,8 \\
Escapulocoracoides & 2 & 0,2 & 7 & 1,6 & 9 & 1,9 \\
Húmero & 1 & 1,4 & 1 & 3,3 & 1 & 3,1 \\
Cúbito & 1 & 1,4 & 5 & 16,7 & 3 & 9,4 \\
Radio & - & - & - & - & - & - \\
Pelvis & - & - & - & - & - & - \\
Fémur & 7 & 10 & 2 & 6,7 & 9 & 28,1 \\
Tibia & 10 & 14,3 & 10 & 33,3 & 11 & 34,4 \\
Total & 7 & 10 & 3 & 10 & - & - \\
\hline
\end{tabular}

Tabla 7.68. Número mínimo de elementos (MNE) y abundancia relativa, para los reptiles de los conjuntos de AMA-3.

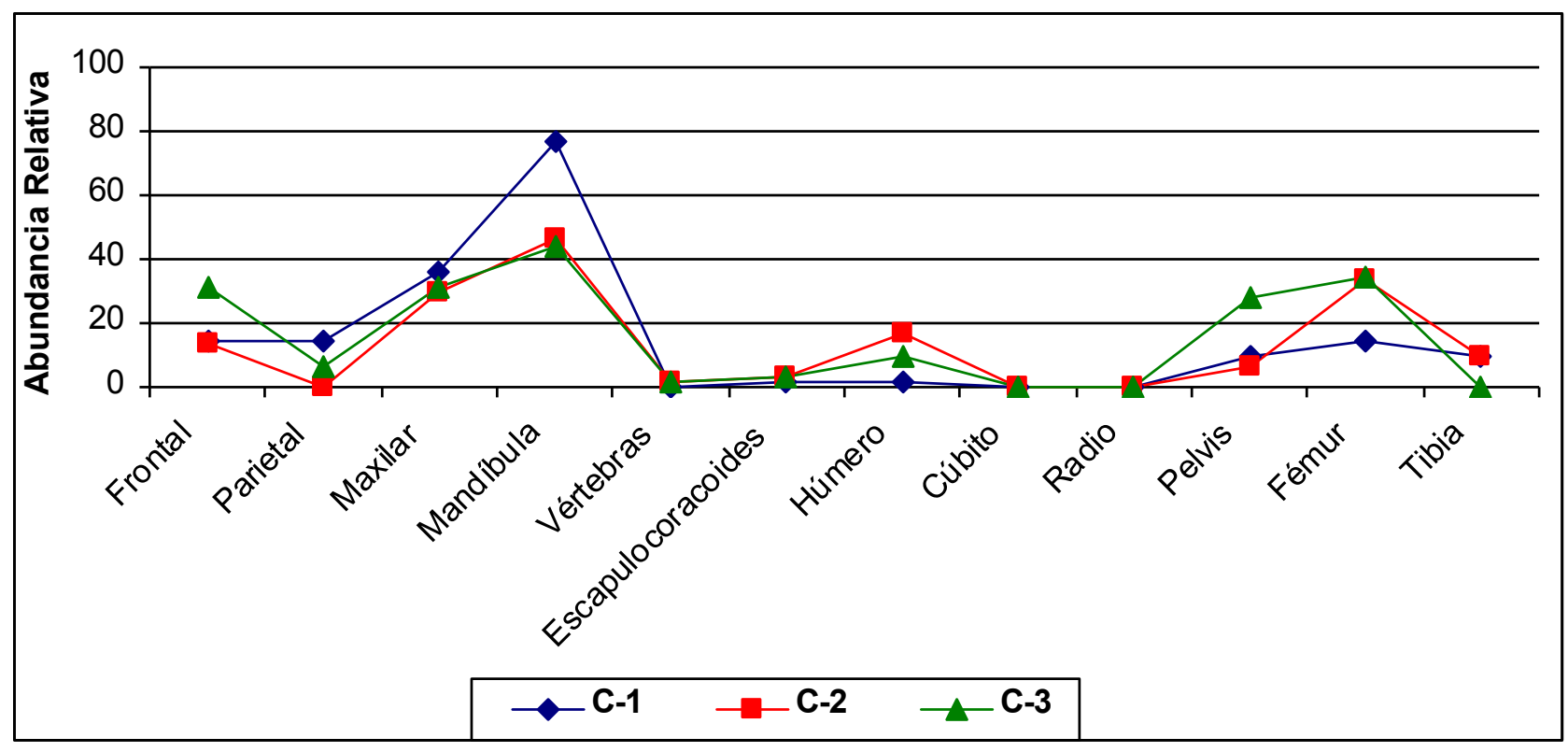

Figura 7.49. Valores de abundancia relativa de los diferentes elementos anatómicos de reptiles recuperados de los conjuntos de AMA-3. 
Se destaca que no se halló ningún cráneo completo en toda la secuencia, los mismos correspondieron a maxilares, dentarios (denominados mandíbulas en este trabajo), parietales y frontales sueltos. Todos los elementos postcraneales contemplados en la metodología se encontraron completos en los tres conjuntos (Tabla 7.69).

\begin{tabular}{|c|c|c|c|c|c|c|}
\hline & \multicolumn{2}{|r|}{ C-1 } & \multicolumn{2}{|r|}{$\mathrm{C}-2$} & \multicolumn{2}{|r|}{ C-3 } \\
\hline & $\mathrm{N}$ & $\%$ & $\mathrm{~N}$ & $\%$ & $\mathrm{~N}$ & $\%$ \\
\hline Fémur & & & & & & \\
\hline Completo & 10 & 100 & 10 & 100 & 11 & 100 \\
\hline Segmento proximal & - & - & - & - & - & - \\
\hline Diáfisis & - & - & - & - & - & - \\
\hline Segmento distal & - & - & - & - & - & - \\
\hline Húmero & & & & & & \\
\hline Completo & 1 & 100 & 5 & 100 & 3 & 100 \\
\hline Segmento proximal & - & - & - & - & - & - \\
\hline Diáfisis & - & - & - & - & - & - \\
\hline Segmento distal & - & - & - & - & - & - \\
\hline Tibia & & & & & & \\
\hline Completo & 7 & 100 & 3 & 100 & - & - \\
\hline Segmento proximal & - & - & - & - & - & - \\
\hline Diáfisis & - & - & - & - & - & - \\
\hline Segmento distal & - & - & - & - & - & - \\
\hline Cúbito & & & & & & \\
\hline Completo & - & - & - & - & - & - \\
\hline Segmento proximal & - & - & - & - & - & - \\
\hline Diáfisis & - & - & - & - & - & - \\
\hline Segmento distal & - & - & - & - & - & - \\
\hline
\end{tabular}

Tabla 7.69. Fractura de elementos craneales, dentarios y postcraneales, para los reptiles de los conjuntos de AMA-3.

El índice que evalúa la relación entre elementos postcraneales y craneales, mostró una mayor preservación de elementos craneales en todos los conjuntos. El índice que calcula la relación entre los elementos distales y proximales, indica que una marcada predominancia de elementos proximales (Tabla 7.70).

\begin{tabular}{|l|c|c|c|}
\hline & C-1 & C-2 & C-3 \\
\hline $\begin{array}{l}\text { Postcráneo / Cráneo } \\
\mathrm{h}+\mathrm{f} / \mathrm{mx}+\mathrm{mb}\end{array}$ & 13,9 & 65,2 & 58,3 \\
$\begin{array}{l}\text { Elementos distales / proximales } \\
\mathrm{t}+\mathrm{r} / \mathrm{f}+\mathrm{h}\end{array}$ & 63,6 & 20 & - \\
\hline
\end{tabular}

Tabla 7.70. Valores de los índices calculados para los reptiles en los conjuntos de AMA-3.

Referencias: h: húmero; f: fémur; mx: maxilar; mb: mandíbula; t: tibia; r: radio; c: cúbito. 
Es interesante destacar que no se registraron restos con marcas de corte ni termoalterados en ningún conjunto.

En lo que concierne a los procesos postdepositacionales, se hallaron restos con evidencias de meteorización únicamente en el Conjunto 1 (17,1\%). No se registraron restos con marcas de pisoteo, de raíces, de corrosión sedimentaria y transporte hídrico en toda la secuencia. No obstante, se observaron restos con impresiones de manganeso en todos los conjuntos (Conjunto $1=1,7 \%$; Conjunto $2=28,3 \%$; Conjunto $3=12,7 \%$ ).

\subsubsection{Asociación de microvertebrados de las muestras actuales}

Como se ilustra en la tabla 7.71, el ensamble de micromamíferos de la muestra actual está conformado principalmente por roedores sigmodontinos, siendo Phyllotis xanthopygus la especie más representada, seguidos por Euneomys chinchilloides, Eligmodontia sp. y Abrothrix olivaceus. Con frecuencias menores se encuentran Abrothrix longipilis y Chelemys macronyx. También, se registraron dos roedores histricognatos (Ctenomys sp. y Microcavia autralis), un marsupial (Thylamys pallidior) y un lagomorfo introducido. Finalmente, se identificaron cuatros especies de aves paseriformes (Cinclodes fuscus, Asthenes cf. A. dorbignyi, Saltator aurantiirostris y Ammodramus humeralis), un charádrido y un columbiforme (Metriopelia melanoptera). El índice de diversidad de Shannon arrojó un valor de 2,014. 


\begin{tabular}{|c|c|c|c|c|}
\hline Taxón / Procedencia & $\begin{array}{c}\text { Laguna EI Sosneado } \\
\text { MNI } \\
\end{array}$ & $\begin{array}{c}\text { Arroyo Malo } \\
\text { MNI }\end{array}$ & \multicolumn{2}{|c|}{ Muestra actual total } \\
\hline $\begin{array}{l}\text { Aves } \\
\text { Passeriformes }\end{array}$ & & & & \\
\hline $\begin{array}{l}\text { Suboscinae indet. } \\
\text { Furnariidae }\end{array}$ & 2 & - & 2 & 1,3 \\
\hline Cinclodes fuscus & 1 & - & 1 & 0,7 \\
\hline $\begin{array}{l}\text { Asthenes cf. A. dorbignyi } \\
\text { Oscinae } \\
\text { Emberizidae }\end{array}$ & 1 & - & 1 & 0,7 \\
\hline $\begin{array}{l}\text { Emberizidae } \\
\text { Saltator aurantiirostris }\end{array}$ & 1 & - & 1 & 0,7 \\
\hline Ammodramus humeralis & 2 & - & 2 & 1,3 \\
\hline Fringillidae indet. & 1 & - & 1 & 0,7 \\
\hline $\begin{array}{l}\text { Charadriidae indet. } \\
\text { Columbiformes }\end{array}$ & 1 & - & 1 & 0,7 \\
\hline $\begin{array}{l}\text { Metriopelia melanoptera } \\
\text { Mammalia } \\
\text { Didelnhimornhia }\end{array}$ & 1 & - & 1 & 0,7 \\
\hline $\begin{array}{l}\text { Thylamys pallidior } \\
\text { Rodentia } \\
\text { Ctenomyidae }\end{array}$ & 4 & 5 & 9 & 5,9 \\
\hline $\begin{array}{l}\text { Ctenomys sp. } \\
\text { Caviidae }\end{array}$ & 5 & 2 & 7 & 4,6 \\
\hline Microcavia autralis & - & 1 & 1 & 0,7 \\
\hline $\begin{array}{l}\text { Cricetidae / Sigmodontinae } \\
\text { Abrothrix olivaceus }\end{array}$ & 17 & 1 & 18 & 11,8 \\
\hline Abrothrix longipilis & 1 & 1 & 2 & 1,3 \\
\hline Chelemys macronyx & 1 & 1 & 2 & 1,3 \\
\hline Phyllotis xanthopygus & 45 & 5 & 50 & 32,9 \\
\hline Eligmodontia sp. & 12 & 13 & 25 & 16,4 \\
\hline Euneomys chinchilloides & 12 & 13 & 25 & 16,4 \\
\hline Lagomorpha / Leporidae indet. & - & 3 & 3 & 1,9 \\
\hline Total & 107 & 45 & 152 & \\
\hline Riqueza & & & 17 & \\
\hline $\mathbf{H}^{\prime}$ & & & 2,014 & \\
\hline Equitatividad & & & 0,711 & \\
\hline
\end{tabular}

Tabla 7.71. Composición taxonómica de las muestras actuales (Localidades Laguna El Sosneado y Arroyo Malo).

\subsubsection{Asociación de microvertebrados de las muestras arqueofaunísticas}

Los ensambles arqueofaunísticos [Conjunto 1 ( $\mathrm{NISP}=4.525 ; \mathrm{MNE}=4.508 ; \mathrm{MNI}=$ 469); Conjunto 2 (NISP $=1.723 ; \mathrm{MNE}=1.712 ; \mathrm{MNI}=165)$; Conjunto 3 (NISP $=$ 1.224; $\mathrm{MNE}=1.224 ; \mathrm{MNI}=162)]$ están principalmente conformados por 
micromamíferos (Tabla 7.72). Los roedores sigmodontinos dominan toda la secuencia, siendo $P$. xanthopygus E. chinchilloides, Eligmodontia sp. los taxones más representados, seguidos por los abrotriquinos A. olivaceus, A. longipilis y C. macronyx.

\begin{tabular}{|c|c|c|c|c|c|c|c|c|c|}
\hline \multirow{3}{*}{$\begin{array}{l}\left.\text { Cronología (en ka }{ }^{14} \mathrm{C} \mathrm{AP}\right) \\
\text { Taxón / Procedencia }\end{array}$} & \multicolumn{3}{|l|}{$0,1-2,2$} & \multicolumn{3}{|c|}{$2,2-3,8$} & \multicolumn{3}{|c|}{$3,8-8,9$} \\
\hline & Conjunto & 1 & & & Conjunto & 2 & & Conjunt & 3 \\
\hline & NISP & MNE & MNI & NISP & MNE & MNI & NISP & MNE & MNI \\
\hline $\begin{array}{l}\text { Reptilia / Sauria indet. } \\
\text { Leiolaemidae }\end{array}$ & 39 & 39 & 1 & 30 & 30 & 1 & 39 & 39 & 2 \\
\hline Liolaemus sp. & 78 & 78 & 34 & 23 & 23 & 14 & 24 & 24 & 14 \\
\hline Mammalia & & & & & & & & & \\
\hline Didelphimorphia & & & & & & & & & \\
\hline Thylamys pallidior & 2 & 2 & 1 & - & - & - & 1 & 1 & 1 \\
\hline Lestodelphys halli & 1 & 1 & 1 & - & - & - & - & - & - \\
\hline Rodentia & & & & & & & & & \\
\hline Ctenomyidae & & & & & & & & & \\
\hline Ctenomys sp. & 108 & 108 & 44 & 22 & 22 & 15 & 25 & 25 & 16 \\
\hline Caviidae & & & & & & & & & \\
\hline Microcavia australis & 18 & 18 & 12 & 3 & 3 & 3 & 7 & 7 & 5 \\
\hline Cricetidae / Sigmodontinae indet.* & 3284 & 3267 & - & 1374 & 1363 & - & 887 & 887 & - \\
\hline Abrothrix olivaceus & 82 & 82 & 38 & 9 & 9 & 4 & - & - & - \\
\hline Abrothrix longipilis & 9 & 9 & 5 & 5 & 5 & 4 & 3 & 3 & 3 \\
\hline Chelemys macronyx & 4 & 4 & 3 & - & - & - & 1 & 1 & 1 \\
\hline Phyllotis xanthopygus & 378 & 378 & 132 & 103 & 103 & 45 & 96 & 96 & 48 \\
\hline Eligmodontia sp. & 131 & 131 & 59 & 62 & 62 & 33 & 69 & 69 & 35 \\
\hline Euneomys chinchilloides & 390 & 390 & 138 & 92 & 92 & 46 & 72 & 72 & 37 \\
\hline Lagomorpha / Leporidae indet. & 1 & 1 & 1 & - & - & - & - & - & - \\
\hline Total & 4525 & 4508 & 469 & 1723 & 1712 & 165 & 1224 & 1224 & 162 \\
\hline Riqueza & & & 12 & & & 8 & & & 9 \\
\hline $\mathbf{H}^{\prime}$ & & & 1,81 & & & 1,72 & & & 1,72 \\
\hline Equitatividad & & & 0,73 & & & 0,83 & & & 0,78 \\
\hline
\end{tabular}

* principalmente restos postcraneales, posiblemente correspondientes a los taxones determinados.

Tabla 7.72. Composición taxonómica de los ensambles de microvertebrados de los conjuntos de AMA-3 (expresada en MNI).

No obstante, resulta interesante notar las ausencias de C. macronyx en el Conjunto 2 y de $A$. olivaceus en el Conjunto 3. En proporciones menores se encuentra los roedores histricognatos (Ctenomys sp. y M. autralis) y los marsupiales T. pallidior (conjuntos 1 y 3) y Lestodelphys halli (Conjunto 1, Nivel 12). El registro de un lagomorfo introducido en la muestra actual y en el Conjunto 1 (nivel 1), estaría indicando la pertenencia de este nivel a cronologías posteriores al siglo XIX. Por último, se destaca la elevada abundancia de reptiles (Liolaemus sp.) registrada en el sitio. 
El Conjunto 1 mostró un leve aumento de la diversidad $(1,809)$ y riqueza taxonómica (12), respecto a el resto de los conjuntos y levemente más baja a la muestra actual.

\subsubsection{Discusión}

\subsubsection{Interpretación tafonómica}

Neme et al. (2002) analizaron la secuencia de microvertebrados de la cuadrícula A-1, desde una perspectiva tafonómica y paleoambiental. Entre sus principales resultados tafonómicos indicaron que no hallaron evidencias de procesos postdepositacionales y que las aves estrigiformes fueron el principal agente acumulador de los restos óseos, aunque sin hacer referencia detallada sobre cuales y cuantos restos fueron afectados por los procesos tafonómicos característicos de estas aves.

No obstante, en este estudio, el cual se llevó a cabo a partir de los restos de microvertebrados recuperados de la cuadrícula B-1, el hallazgo de fragmentos de egagrópilas, elementos con restos de egagrópilas, altos niveles de corrosión digestiva y de fractura mayormente (con ángulos redondeados y bordes suaves), la baja abundancia relativa promedio y el patrón de abundancia relativas de partes esqueletales en todas las unidades, coincide con los estudios realizados por Andrews (1990) en base a restos recuperados de egagrópilas de Falconiformes. Entre las rapaces diurnas que habitan en este sector de la cordillera se encuentran G. melanoleucus, Buteo polyosoma, Caracara plancus, Milvago chimango, Falco peregrinus y F. sparverius. Los análisis efectuados por Iglesias (2009) en B. polyosoma y Montalvo y Tallade (2009) en C. plancus, mostraron que estas aves producen altos niveles de modificación en los restos de micromamíferos ingeridos. Sin embargo, Montalvo y Tallade (2009, 2010) registraron bajos niveles de modificación en restos de micromamíferos no ingeridos por C. plancus. Por otra parte, estudios tafonómicos realizados por Andrews (1990), plantean que $F$. peregrinus produce modificaciones moderadas en ensambles de micromamíferos. El mencionado autor destaca que este halcón no puede considerarse un importante acumulador de micromamíferos. No obstante, de las rapaces mencionadas solo $B$. polyosoma y G. melanoleucus, además de anidar en salientes rocosas consumen principalmente micromamíferos (ver Capítulo 6).

La ausencia de marcas de cortes, el registro de muy exiguos restos quemados y la dominancia de microvertebrados crípticos, solitarios y de menor tamaño, indica que los 
grupos humanos no han intervenido en la génesis de los conjuntos de AMA-3 (Pardiñas, 1999a, 1999b).

Finalmente, el escaso registro de huesos meteorizados sugiere que los mismos tuvieron un enterramiento rápido. Esto sumado a la ausencia de marcas de pisoteo, raíces, corrosión sedimentaria y transporte hídrico, sugiere que los restos tuvieron una alta integridad postdepositacional (Korth, 1979; Andrews, 1990; Fernández-Jalvo y Andrews, 1992; Fernández-Jalvo y Andrews, 2003). No obstante, los numerosos especímenes con impresiones de óxido de manganeso en todos los conjuntos sugieren elevados niveles de humedad, producto de oscilaciones en el nivel freático y encharcamientos de agua en toda la secuencia (Courty et al., 1989; Gómez et al., 1999; Gómez, 2000).

\subsubsection{Interpretación paleoambiental}

Hay una correlación positiva alta y significativa entre la riqueza taxonómica y el tamaño de las muestras $\left(r_{s}=0,66 ; p>0,5\right)$, limitando el alcance de las conclusiones.

En la tabla 7.73 se me muestra el ensamble de micromamíferos documentando por Neme et al. (2002).

En base a estas estructuras taxonómicas de los conjuntos Neme et al. (2002) realizaron una interpretación paleoambiental:

El comienzo de la secuencia ( $c a .9 \mathrm{ka}{ }^{14} \mathrm{C} \mathrm{AP}$ ), teniendo en cuenta el hallazgo de un resto de Andalgalomys, un sigmodontino que habita en zonas áridas del centro y noroeste de Argentina, fue asociado a un ambiente más cálido y seco que el actual. Los periodos posteriores a $4 \mathrm{ka}{ }^{14} \mathrm{C} \mathrm{AP}$, el registro de L. halli y el aumento en la frecuencia relativa de Iguanidae (=Liolaemidae) fueron relacionados a un ambiente patagónico, similar al actual. Finalmente, la presencia de Graomys griseoflavus y M. australis en este segmento temporal fue vinculado a una sobreexplotación del ambiente por parte del hombre a través del sobrepastoreo. 


\begin{tabular}{|l|c|c|c|}
\hline Cronología (en ka ${ }^{14}$ C AP) & $\mathbf{0 , 1 - 2 , 2}$ & $\mathbf{2 , 2 - 3 , 8}$ & $\mathbf{3 , 8 - 8 , 9}$ \\
\hline Taxón / Procedencia & $\begin{array}{c}\text { Conjunto } \\
\text { Conjunto }\end{array}$ & $\begin{array}{c}\text { Conjunto } \\
\mathbf{2}\end{array}$ \\
\hline Reptilia / Sauria & & & \\
Iguanidae (=Liolaemidae) indet. & 84 & 15 & 5 \\
Mammalia & & & \\
Didelphimorphia & 1 & 1 & - \\
Lestodelphys halli & & & \\
Rodentia & & & \\
Ctenomyidae & 31 & 19 & 7 \\
Ctenomys sp. & & & \\
Caviidae & 7 & 2 & 1 \\
Microcavia australis & 17 & 12 & 2 \\
Cricetidae / Sigmodontinae indet. & 40 & 13 & - \\
Abrothrix sp. & 128 & 49 & 31 \\
Phyllotis darwini (= P. xanthopygus) & 3 & - & - \\
Graomys griseoflavus & - & - & 1 \\
Andalgalomys sp. & 32 & 29 & 11 \\
Eligmodontia sp. & 109 & 47 & 25 \\
Euneomys cf. E. mordax & 452 & 187 & 83 \\
\hline Total & & & \\
\hline
\end{tabular}

Tabla 7.73. Lista taxonómica, basada en el cálculo de NISP, de los conjuntos definidos en la Cuadrícula A-1 de AMA-3, modificada de Neme et al. (2002: 412).

Una revisión detallada de la muestra indicó que los ejemplares asignados a Abrothrix sp. corresponden a A. longipilis, A. olivaceus y C. macronyx. Euneomys cf. E. mordax corresponden a E. chinchilloides y los asignados a G. griseoflavus y Andalgalomys sp. corresponden a P. xanthopygus. Para el caso de Andalgalomys sp. se realizó una descripción detallada debido a su alto nivel de relevancia en la interpretación paleoambiental:

Material referido: maxilar derecho incompleto con M2 y M3 (Figura 7.50 A). Actualmente está perdido.

Descripción: Los molares presentan desgaste plano y cúspides opuestas. E1 M2 es subcuadrangular con paraflexo reducido, mesoflexo orientado en forma oblicua e hipoflexo penetrando transversalmente. En el M3, la confluencia del mesoflexo y el hipoflexo determina dos lóbulos, el superior un poco más desarrollado que el inferior.

Observaciones: similar morfología del M2 podemos encontrar tanto en individuos adultos de Andalgalomys olroigi (la única especie que habita en Argentina), como en individuos seniles de Graomys y en juveniles de Phyllotis. Asimismo, estos taxones exhiben dos lóbulos bien marcados en el M3. A. olroigi presenta el lóbulo inferior muy 
reducido respecto al superior (Figura 7.50 B). En Graomys los lóbulos tienen una orientación más oblicua y las cúspides son más turberculares (Figura 7.50 C). En Phyllotis (principalmente en juveniles) el lóbulo superior muestra un tamaño levemente mayor que el inferior (Figura 7.50 D), en coincidencia con el material descripto. En este sentido, se plantea que el fragmento de maxilar asignado por Neme et al. (2002) a Andalgalomys sp. corresponde a un individuo juvenil de Phyllotis sp.
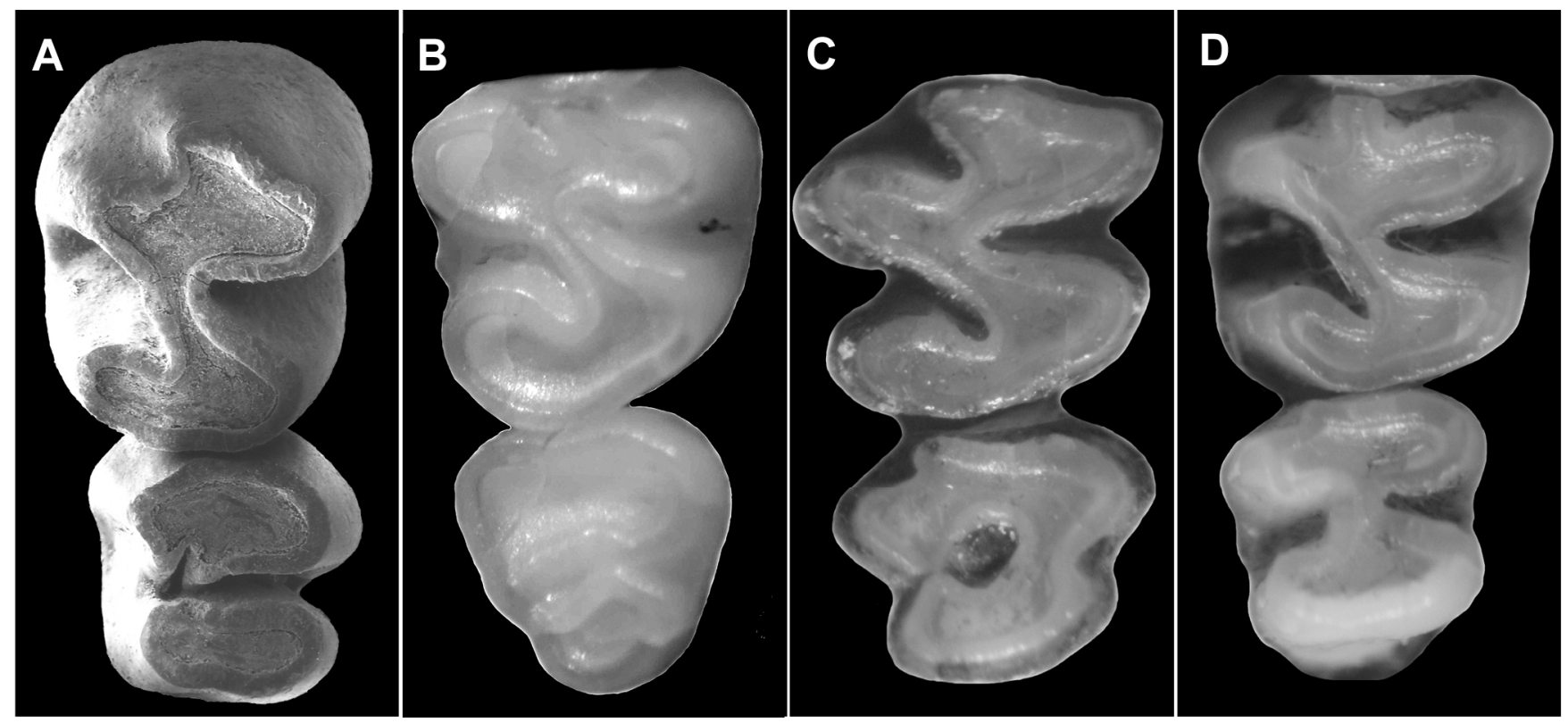

Figura 7.50. Lámina comparativa de molares superiores. A: ejemplar de Arroyo Malo-3 (M1-M2, longitud: 2,9 $\mathrm{mm}$ ). B: Andalgalomys olroigi (M1-M2, longitud: 3,2 mm). C: Graomys griseoflavus (M1-M2, longitud: 2,82 mm). D: ejemplar juvenil de Phyllotis xanthopygus (M1-M2, longitud: 2,72 mm).

En relación al análisis de la cuadrícula B-1. El índice de diversidad de Shannon fueron similares en todas los conjuntos con un leve aumente hacia momentos más tardíos y recientes. Esto sugiere que los taxones tuvieron una representación similar.

En la figura 7.51 se detallan las frecuencias relativas de los taxones de micromamíferos en las muestras estudiadas.

En líneas generales P. xanthopygus E. chinchilloides, Eligmodontia sp. mantienen su dominancia a lo largo de la secuencia, indicando un ambiente afín a estepas arbustivas abiertas con alta proporción de suelo desnudo, pedregoso y abundante roca expuesta. Sin embargo, en la muestra actual el aumentó de frecuencia de P. xanthopygus y $T$. pallidior en detrimento de E. chinchilloides podría asociarse a un proceso de arbustización y disminución de plantas herbáceas en un contexto de roquedales. 
Asimismo, los registros de A. longipilis, C. macronyx y A. olivaceus indican el desarrollo de vegas cordilleranas.

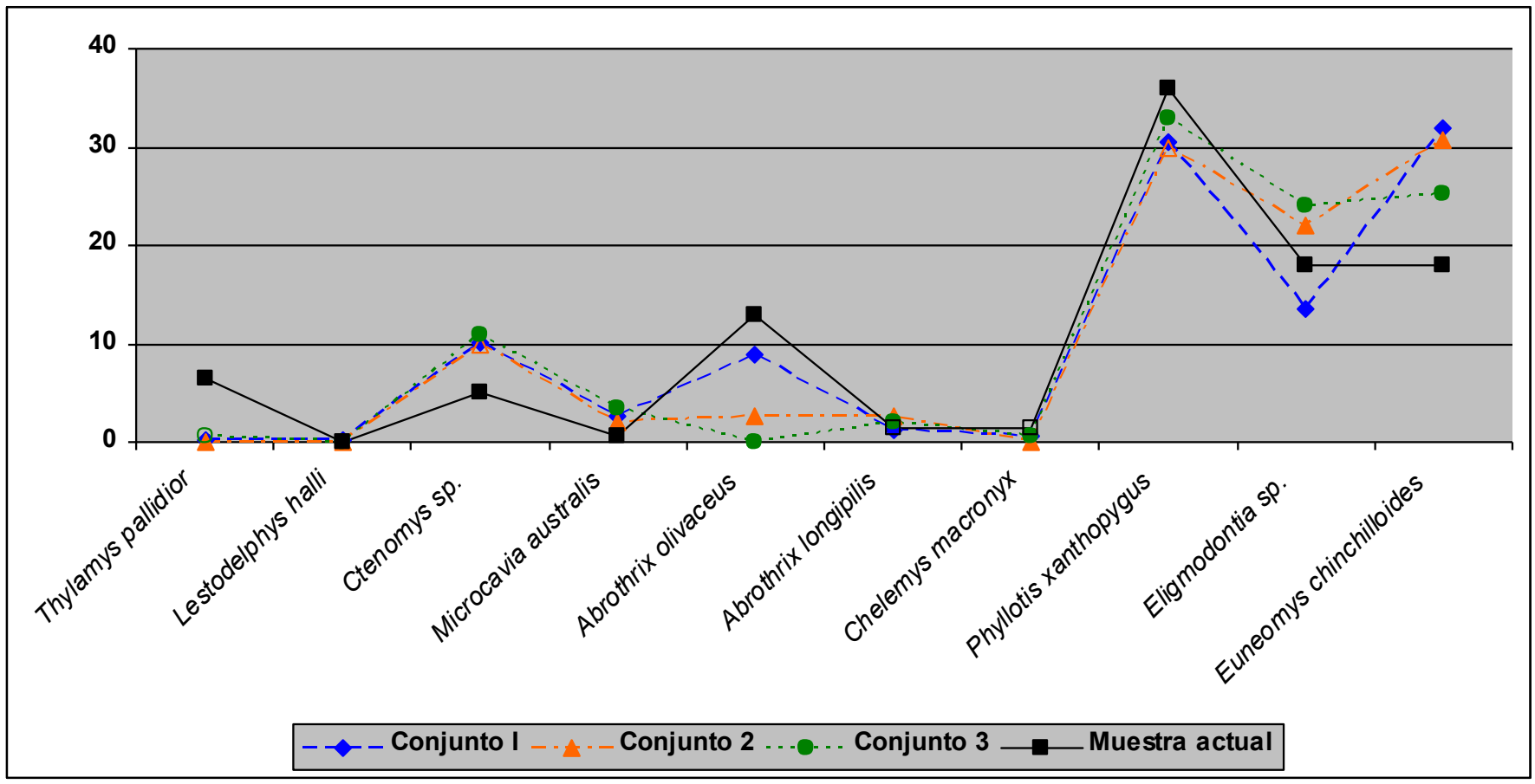

Figura 7.51. Comparación de las frecuencias relativas de los taxones de micromamíferos recuperados de los conjuntos de AMA-3 y su parámetro actualístico.

No obstante, la ausencia del abrotriquino aportunista A. olivaceus en el Conjunto 3, su presencia en el Conjunto 2, el incremento de su frecuencia en el Conjunto 1, podría estar vinculado a una arbustización gradual del ambiente. Incluso su aumento marcado en la muestra actual podría estar asociado con un proceso de impacto antrópico en tiempos recientes (e.g., Cueto et al., 2008; Fernández et al., 2009d). Por otra parte, la presencia de L. halli solo en el Conjunto 1 (Nivel 12) sugiere un ambiente asociado a la estepa Patagónica hacia el 2,2 $\mathrm{ka}{ }^{14} \mathrm{C}$ AP.

Finalmente, el registro del lagomorfo introducido en el Componente I (Nivel 1) y en la muestra actual, indica la pertenencia del Nivel 1 a cronologías posteriores al siglo XIX. En la figura 7.52 se ilustra los resultados del PCA, que corroboran lo expresado anteriormente. El primer componente principal (60,983\% de la varianza) exhibe un contraste entre las muestras arqueofaunísticas y la muestra actual, posiblemente debido al deterioro del ambiental de tiempos recientes. El segundo componente $(29,539 \%$ de la varianza) muestra similitudes entre los conjuntos 2 y 3 , en contraste con el Conjunto 1 , el cual está compuesto por un ensamble de micromamíferos asociados a un ambiente más heterogéneo. 


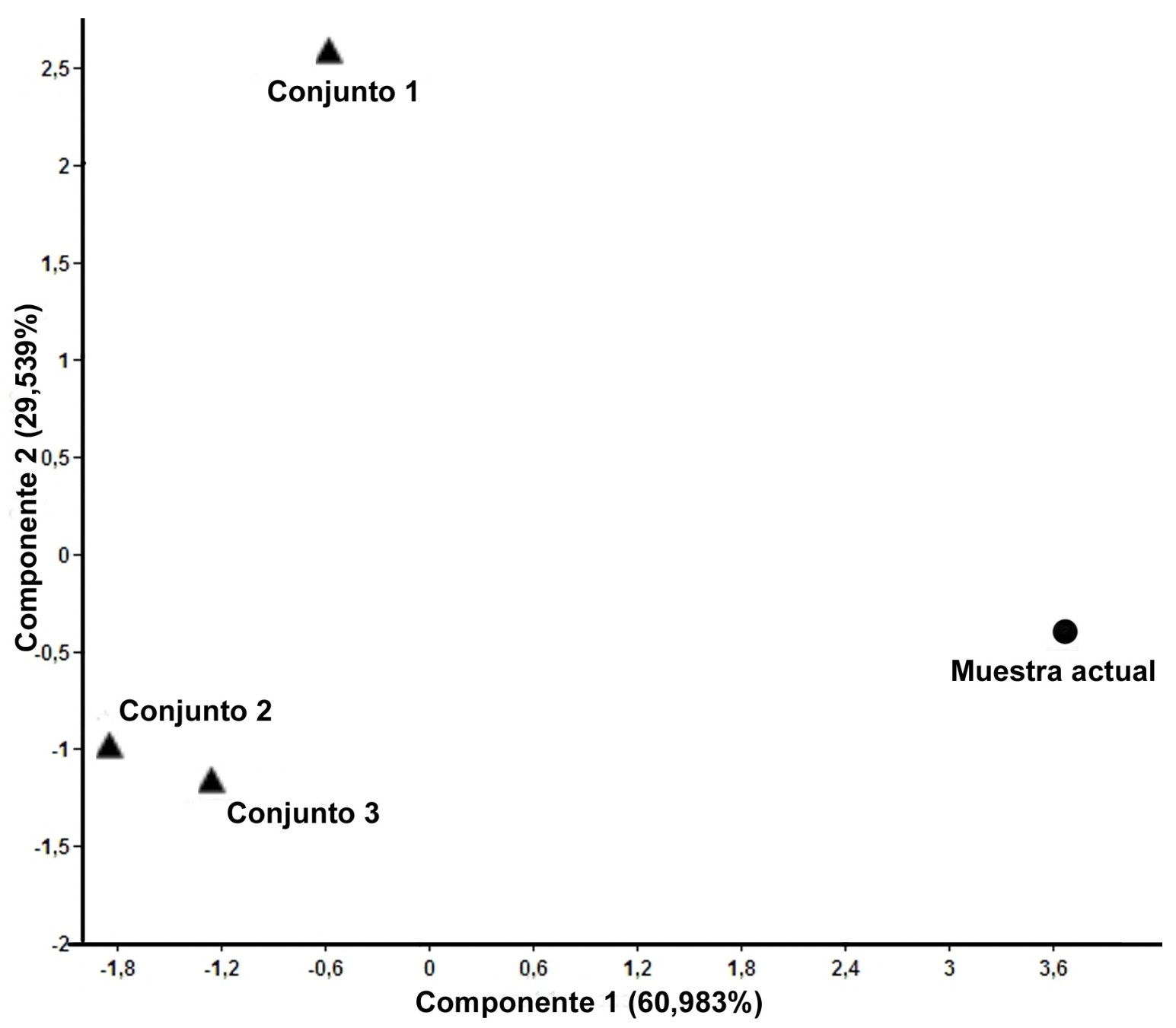

Figura 7.52. Gráfico de las muestras arqueológicas y actuales de micromamíferos de AMA-3 sobre el plano definido por los ejes 1 y 2 de un análisis de componente principal.

\subsubsection{Conclusión}

Las evidencias tafonómicas indican que los principales agentes acumuladores de los ensambles de microvertebrados recuperados de las distintas unidades de AMA-3 habría sido rapaces diurnas (Falconiformes). El escaso registro de huesos meteorizados, la ausencia de marcas de pisoteo, raíces, corrosión sedimentaria y transporte hídrico y el hallazgo de numerosos especímenes con impresiones de óxido de manganeso, sugiere que los restos tuvieron un enterramiento rápido y buena conservación, aunque con elevados niveles de humedad, producto de oscilaciones en el nivel freático y encharcamientos de agua en toda la secuencia.

La interpretación paleoambiental de la secuencia de micromamíferos de AMA-3 puede sintetizarse de la siguiente manera: 
a) Hacia el lapso $8,9-3,8 \mathrm{ka}{ }^{14} \mathrm{C}$ AP el ambiente es a fin a estepas arbustivas abiertas con alta proporción de suelo desnudo, pedregoso y abundante roca expuesta, interrumpido por el desarrollo de vegas cordilleranas.

b) Durante el intervalo $3,8-2,2 \mathrm{ka}{ }^{14} \mathrm{C}$ AP persisten las condiciones ambientales comprendidas en el período anterior, aunque se detectó aumento de arbustización.

c) En el lapso 2,2-0,1 ka ${ }^{14} \mathrm{C}$ AP el ambiente continúa con desarrollo de estepas arbustivas abiertas con alta proporción de suelo desnudo, pedregoso y abundante roca expuesta, interrumpido por el desarrollo de vegas cordilleranas. No obstante en los inicios de este período el ambiente acusa un aumento de la humedad y elementos herbáceos. Luego retornan las condiciones más secas y con progresiva arbustización del ambiente.

e) En la actualidad el ambiente es xérico, asociado a estepas arbustivas abiertas con alta proporción de suelo desnudo, pedregoso y abundante roca expuesta, interrumpido por el desarrollo de vegas cordilleranas. Asimismo, exhibe cierta influencia del desierto de Monte y presenta un deterioro ambiental marcado por arbustización creciente, atribuible al impacto antrópico posiblemente producido por el ganado doméstico. 


\subsection{Laguna el Sosneado-3 (LS-3)}

\subsubsection{Contexto arqueológico}

El sitio Laguna El Sosneado-3 (LS-3) está ubicado en el sudoeste de la provincia de Mendoza ( $\left.34^{\circ} 51^{\prime} \mathrm{S}, 69^{\circ} 53^{\prime} \mathrm{O}\right)$, a $2.100 \mathrm{~m}$ de altitud (Figura $7.53 \mathrm{~A}$ ). Sobre la margen norte de la laguna glaciaria de El Sosneado existen una serie de reparos situados sobre una barda ubicada a unos $200 \mathrm{~m}$ del nivel de la laguna, que corre en dirección sur-sureste $\left(\mathrm{N} 110^{\circ}\right)$ y está compuesta por andesitas de más de $50 \mathrm{~m}$ de altura. Los reparos se encuentran separados entre sí por $c a .100 \mathrm{~m}$, algunos de los cuales se abren en profundidad, formando cuevas o aleros de dimensiones variables que se muestran como lugar de refugio para los seres humanos y la fauna (Neme, 2007).

En el año 1992, el equipo del Departamento de Antropología del Museo de Historia Natural de San Rafael realizó trabajos tendientes a la localización de sitios arqueológicos en el área, que incluyeron sondeos en 4 aleros. En las bardas contiguas a la Laguna El Sosneado se han hallado 5 aleros rocosos. Los aleros sondeados fueron Cueva 3 de la Laguna El Sosneado (LS-3), Arroyo Malo 3 y Cueva del Indio, unos 2 km aguas arriba de la laguna El Sosneado. La elección del sitio LS-3, se debió a que éste es el de mayor área y no presenta filtraciones en su superficie. Para la excavación del mismo, la cual se llevó a cabo en enero del año 2000, se planteó una cuadrícula en forma de "L" cuyos lados estaban conformados por cuadrículas de $2 \times 1 \mathrm{~m}$, totalizando un área de excavación de 4 $\mathrm{m}^{2}$ (Figura $7.53 \mathrm{~B} \mathrm{y} \mathrm{C)}$. Se excavaron un total de 21 niveles de $5 \mathrm{~cm}$, alcanzando así una profundidad de $105 \mathrm{~cm}$. En la estratigrafía del sitio se pueden diferenciar tres componentes litoestratigráficos de distinto espesor pero con características similares. E1 componente I está compuesto por un sedimento arenoso con clastos finos y cenizas, intercalado con guano estratificado. El componente II, también está integrado por un sedimento arenoso fino y con la presencia de algunos clastos de tamaño variable. El componente III está formado por un sedimento arenoso muy húmedo (Figura 7.54).

Con el objetivo de observar las variaciones diacrónicas en la depositación de los especímenes faunísticos, se decidió dividir la secuencia en 4 unidades artificiales de 25 cm de espesor cada una, a excepción de la Unidad 4 que incluye los últimos $30 \mathrm{~cm}$ de la secuencia (Unidad 1=Niveles 1-5; Unidad 2=Niveles 6-10; Unidad 3=Niveles 11-15; Unidad 4=Niveles 16-21). En la tabla 7.74 se exhibe la cronología del sitio. 

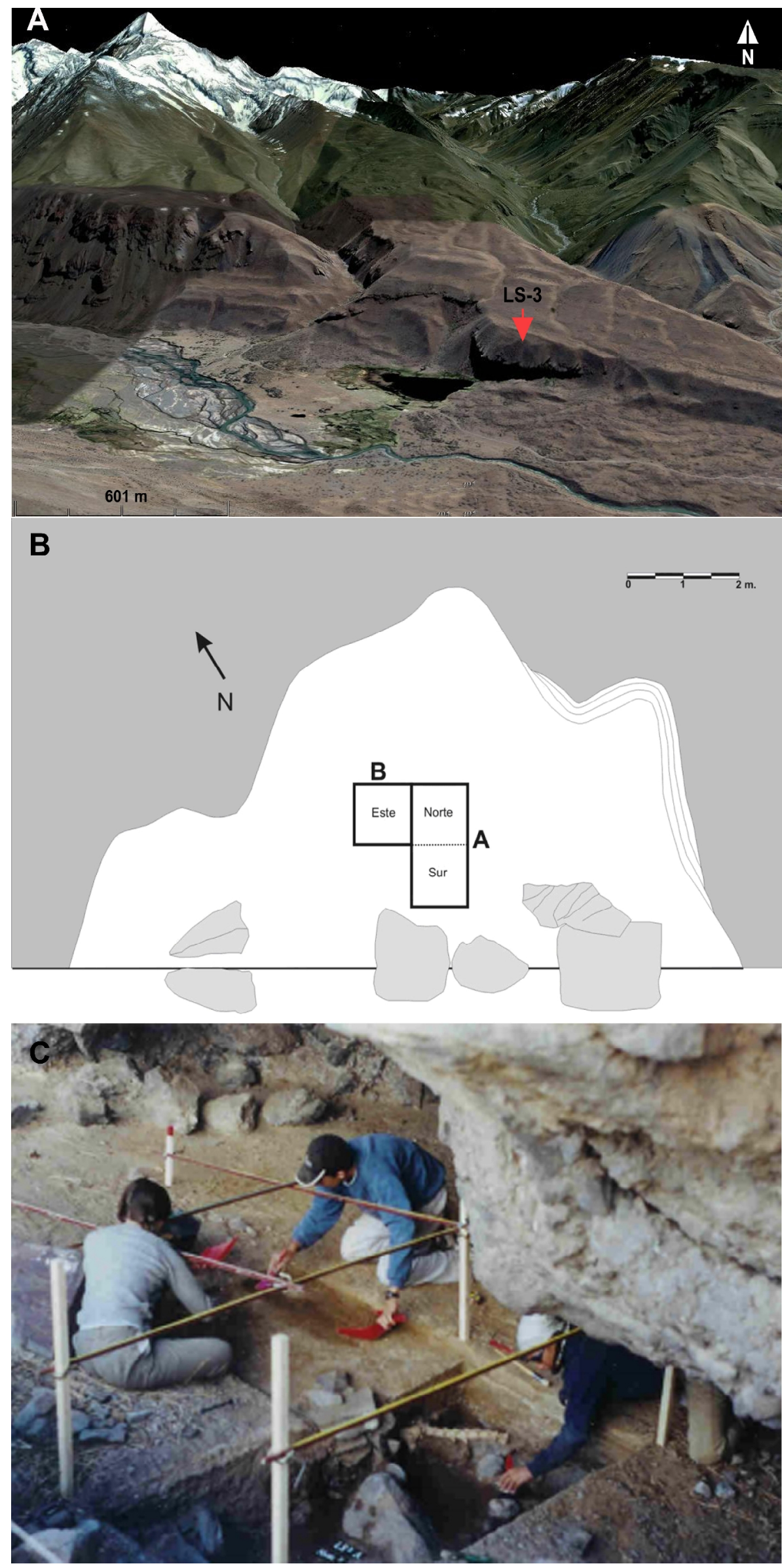
Figura 7.53. Sitio arqueológico LS-3. A: ubicación del sitio. B: vista en planta, tomado de Giardina (2010: 164). C: vista de la excavación, tomado de Giardina (2010: 163).

Si bien en un sondeos previos se habían recuperados algunas lascas y un instrumento lítico (Neme 2007), en esta excavación no se hallaron restos culturales.

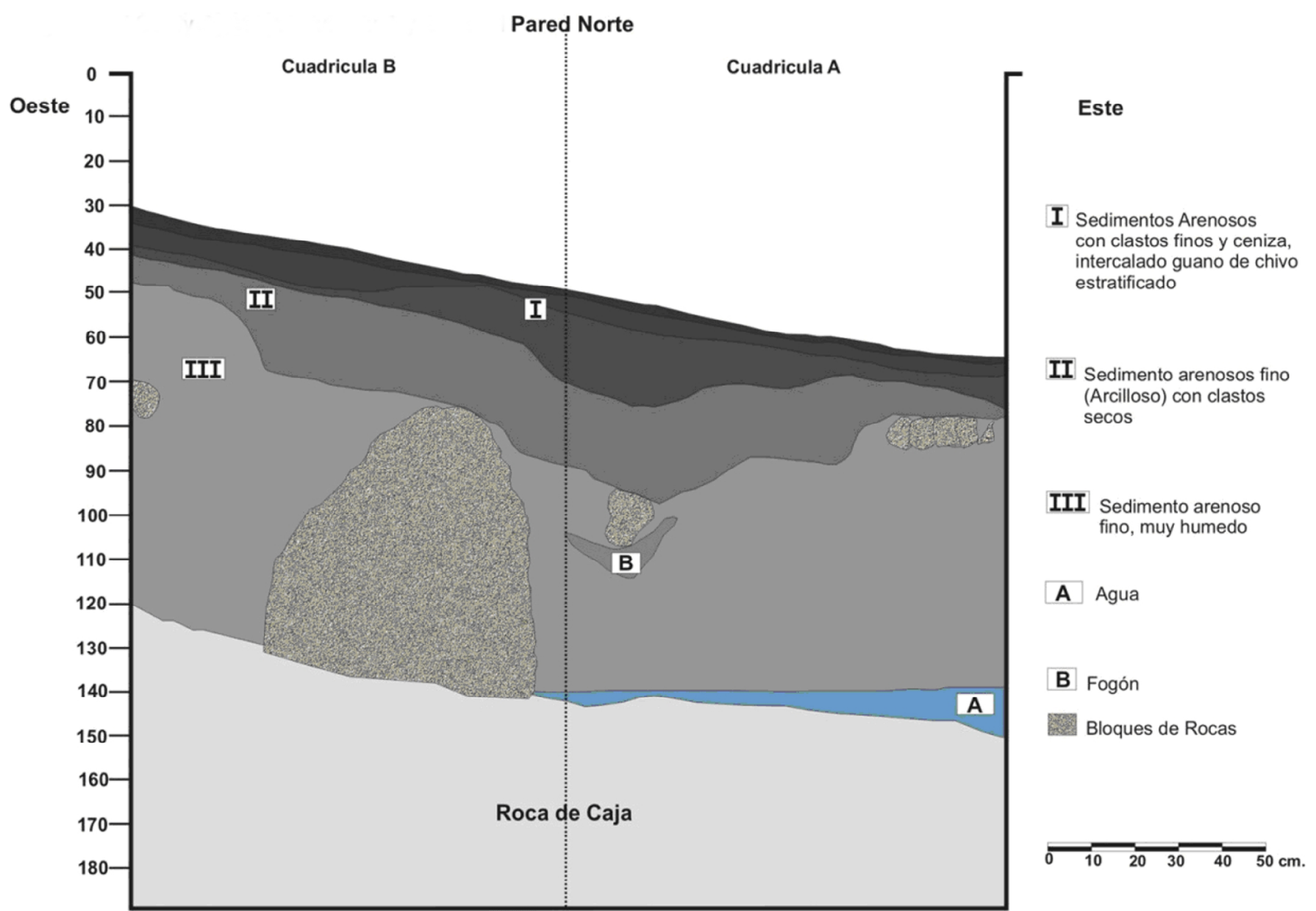

Figura 7.54. Estratigrafía del sitio LS-3. Tomado de Giardina (2010: 165).

\begin{tabular}{|c|c|c|c|c|c|c|}
\hline Cuadrícula & Nivel & Unidad & Muestras & Código & Datación ${ }^{14} \mathbf{C}$ & Calibrado \\
\hline A-1 & 6 y 7 & 2 & hueso & AA90286 & $659 \pm 51$ & $574-663$ \\
A-1 & 15 & 3 & carbón & AA90287 & $1.806 \pm 51$ & $1659-1807$ \\
A-1 & 21 & 4 & carbón & AA58291 & $2.145 \pm 41$ & $2074-2275$ \\
\hline
\end{tabular}

Tabla 7.74. Fechados del sitio LS-3.

En relación al contexto zooarqueológico general, además de los microvertebrados se exhumaron restos de aves medianas y grandes (Podicipedidae indet., Anatidae indet., Tyto alba y Vultur gryphus) (Giardina, 2010). Conjuntamente se recuperaron restos de mamíferos medianos y grandes (Lycalopex griseus y Lama guanicoe). Es interesante notar, que L. guanicoe fue el único taxón que presento evidencias de consumo antrópico 
en toda la secuencia (Otaola, tesis doctoral en preparación). No obstante, la presencia de restos con marcas de carnívoros y de acción digestiva sugiere que la mayor parte del ensamble fue originado por agentes naturales (Giardina, 2010; Otaola, tesis doctoral en preparación).

\subsubsection{Metodología}

Como parámetro actualístico se estudió una muestra de 58 egagrópilas y un disgregado de T. alba y una muestra de 60 egagrópilas de Geranoaetos melanoleucus, las cuales fueron recolectadas en enero del 2000 y 2008 respectivamente en las inmediaciones del sitio arqueológico [Localidades Laguna El Sosneado y Arroyo Malo (ver apéndice)].

Para el análisis tafonómico de los restos de aves de pequeño tamaño se tomaron todos los niveles en conjunto dada la homogeneidad de los mismos y la escasa representación de especímenes óseos de cada unidad. Asimismo, aparte de estudiar la muestra actual $T$. alba, se analizó la muestra de Bubo magellanicus [Localidad Gruta del Indio (ver apéndice)]. Se seleccionaron los huesos de aves del resto de los microvertebrados que la conformaban. Las muestras presentaron un NISP total de 74 para $T$. alba y de 72 para $B$. magellanicus.

\subsubsection{Resultados}

\subsubsection{Análisis tafonómico}

\subsection{Micromamíferos}

Se observaron restos con marcas de corrosión digestiva en toda la secuencia (Tabla 7.75). En las unidades 1 y 4 se hallaron $c a$. del 20\% de los restos con huellas de corrosión principalmente en la categoría ligera. En las unidades 2 y 3 se registró un leve aumento, alcanzando porcentajes del 29\% y 25\% respectivamente, principalmente en la categoría ligera y en menor proporción en la categoría moderada. En tal sentido, en una parte de los incisivos la corrosión se concentró en los extremos y en otra parte de los mismos se extendió por una mayor superficie dejándola ondulada. Algunos molares exhibieron cúspides con un contorno más redondeado y otros mostraron un ligero poseado en el 
esmalte. Un parte de los restos postcraneales exhibieron evidencias de poseado en las superficies articulares y algunos mostraron un aspecto de abrasionado o pulido (Figura 7.55 A y B). Asimismo, en todas las unidades los incisivos y molares aislados fueron más afectados que los que se encontraban in situ (Figura $7.55 \mathrm{C}$ ), esto se debe a que los dientes aislados están más expuestos a los ácidos digestivos (Andrews, 1990).

\begin{tabular}{|c|c|c|c|c|c|c|c|c|c|c|}
\hline & \multicolumn{10}{|c|}{ Clases de digestión sensu Andrews (1990) } \\
\hline & \multicolumn{2}{|c|}{ Ausente } & \multicolumn{2}{|c|}{ Ligera } & \multicolumn{2}{|c|}{ Moderada } & \multicolumn{2}{|c|}{ Fuerte } & \multicolumn{2}{|c|}{ Extrema } \\
\hline & $(\mathrm{N})$ & $\%$ & $(\mathrm{~N})$ & $\%$ & $(\mathrm{~N})$ & $\%$ & $(\mathrm{~N})$ & $\%$ & $(\mathrm{~N})$ & $\%$ \\
\hline \multicolumn{11}{|l|}{ Unidad 1} \\
\hline Incisivos in situ & 33 & 78,6 & 9 & 21,4 & - & - & - & - & - & - \\
\hline Incisivos aislados & 112 & 72,7 & 37 & 24 & 3 & 2 & 2 & 1,3 & - & - \\
\hline Molares in situ & 246 & 94,3 & 15 & 5,7 & - & - & - & - & - & - \\
\hline Molares aislados & 29 & 72,5 & 11 & 27,5 & - & - & - & - & - & - \\
\hline Fémur (epífisis proximal) & 43 & 58,1 & 24 & 32,4 & 6 & 8,1 & 1 & 1,4 & - & - \\
\hline Húmero (epífisis distal) & 74 & 70,5 & 30 & 28,6 & 1 & 0,9 & - & - & - & - \\
\hline \multicolumn{11}{|l|}{ Unidad 2} \\
\hline Incisivos in situ & 31 & 72,1 & 12 & 27,9 & - & - & - & - & - & - \\
\hline Incisivos aislados & 55 & 62,5 & 31 & 35,2 & 2 & 2,3 & - & - & - & - \\
\hline Molares in situ & 189 & 80,8 & 42 & 17,9 & 1 & 0,4 & 2 & 0,9 & - & - \\
\hline Molares aislados & 17 & 65,4 & 9 & 34,6 & - & - & - & - & - & - \\
\hline Fémur (epífisis proximal) & 41 & 44,6 & 31 & 33,7 & 18 & 19,5 & 2 & 2,2 & - & - \\
\hline Húmero (epífisis distal) & 75 & 81,5 & 15 & 16,3 & 2 & 2,2 & - & - & - & - \\
\hline \multicolumn{11}{|l|}{ Unidad 3} \\
\hline Incisivos in situ & 46 & 83,6 & 8 & 14,5 & 1 & 1,8 & - & - & - & - \\
\hline Incisivos aislados & 94 & 72,3 & 24 & 18,5 & 12 & 9,2 & - & - & - & - \\
\hline Molares in situ & 231 & 84,9 & 40 & 14,7 & 1 & 0,4 & - & - & - & - \\
\hline Molares aislados & 40 & 75,5 & 13 & 24,5 & - & - & - & - & - & - \\
\hline Fémur (epífisis proximal) & 43 & 50 & 30 & 34,9 & 10 & 11,6 & 3 & 3,5 & - & - \\
\hline Húmero (epífisis distal) & 71 & 67,6 & 31 & 29,5 & 3 & 2,9 & - & - & - & - \\
\hline \multicolumn{11}{|l|}{ Unidad 4} \\
\hline Incisivos in situ & 32 & 69,6 & 14 & 8,7 & - & - & - & - & - & - \\
\hline Incisivos aislados & 59 & 81,9 & 13 & 18,1 & - & - & - & - & - & - \\
\hline Molares in situ & 167 & 87,4 & 24 & 12,6 & - & - & - & - & - & - \\
\hline Molares aislados & 39 & 81,3 & 9 & 18,7 & - & - & - & - & - & - \\
\hline Fémur (epífisis proximal) & 32 & 51,6 & 26 & 41,9 & 4 & 6,5 & - & - & - & - \\
\hline Húmero (epífisis distal) & 55 & 83,3 & 11 & 16,7 & - & - & - & - & - & - \\
\hline
\end{tabular}

Tabla 7.75. Representación de las distintas categorías de corrosión digestiva en micromamíferos recuperados de las unidades de LS-3. 


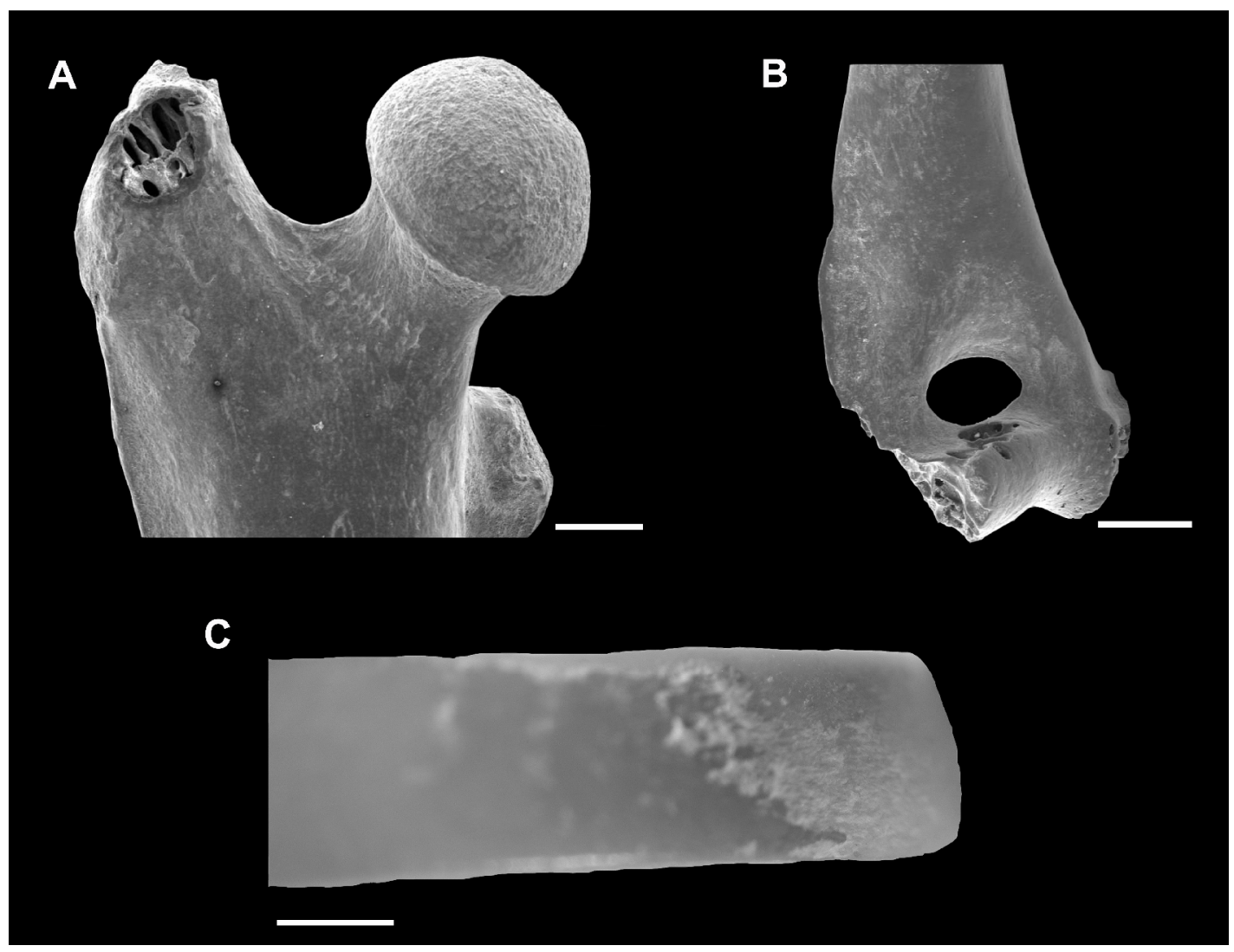

Figura 7.55. Ejemplos de acción de aves rapaces en las muestras de micromamíferos de LS-3. A: fémur de Sigmodontinae con marcas de corrosión digestiva ligera en la epífisis proximal (Unidad 1, Nivel 4). B: húmero de Sigmodontinae con marcas de corrosión digestiva ligera en la epífisis distal (Unidad 1, Nivel 2). C: incisivo de Ctenomys sp. con marcas de corrosión digestiva moderada en la superficie del esmalte (Unidad 1, Nivel 1). Escalas: $1 \mathrm{~mm}$.

La abundancia relativa promedio fue baja en todas las unidades (Tabla 7.76). En las cuatro unidades se observó un patrón similar de representación de partes esqueletarias, donde los elementos más abundantes fueron las mandíbulas, húmeros, fémures y tibias y los menos abundantes fueron las costillas y los huesos del autopodio (Figura 7.56).

El $40,1 \%$ de todos los especímenes recuperados de LS-3 estaban fracturados. La proporción de restos fracturas en las distintas unidades fue similar (U1=42,2\%; $\mathrm{U} 2=39,3 \%$; $\mathrm{U} 3=39,9 \%$ y $\mathrm{U} 4=38,5 \%$ ). En la tabla 7.77 se exhibe los distintos tipos de fractura en los elementos contemplados en la metodología propuesta por Andrews (1990) y Andrews y Fernández (1992). Se halló un solo cráneo completo en la Unidad 4 y la mayoría de ellos se encontraron muy fracturados, de modo que se perdieron los huesos de la bóveda y frontales y la mayor parte de los mismos correspondieron a maxilares sin arcos zigomáticos. En líneas generales las pérdidas de molares de los maxilares e incisivos de los premaxilares fue moderada en todas unidades. 


\begin{tabular}{|c|c|c|c|c|c|c|c|c|}
\hline Elemento / procedencia & MNE & $\begin{array}{c}\mathbf{U}-\mathbf{1} \\
\text { Abundancia } \\
\text { relativa }\end{array}$ & MNE & $\begin{array}{c}\mathbf{U}-2 \\
\text { Abundancia } \\
\text { relativa }\end{array}$ & MNE & $\begin{array}{c}\mathbf{U}-\mathbf{3} \\
\text { Abundancia } \\
\text { relativa }\end{array}$ & MNE & $\begin{array}{c}\mathbf{U}-\mathbf{4} \\
\text { Abundancia } \\
\text { relativa } \\
\end{array}$ \\
\hline Maxilar & 59 & 18,5 & 49 & 19,3 & 71 & 26,3 & 34 & 16,3 \\
\hline Mandíbula & 102 & 32,1 & 79 & 31,1 & 89 & 30,7 & 70 & 33,7 \\
\hline Incisivos aislados & 154 & 24,2 & 88 & 17,3 & 130 & 24,1 & 72 & 17,3 \\
\hline Molares aislados & 40 & 2,1 & 26 & 1,7 & 53 & 3,3 & 48 & 3,8 \\
\hline Vértebras & 330 & 6,9 & 207 & 5,4 & 414 & 10,2 & 263 & 8,4 \\
\hline Costillas & 44 & 1,2 & 20 & 0,6 & 53 & 1,6 & 38 & 1,5 \\
\hline Escápula & 39 & 12,3 & 36 & 14,2 & 46 & 17 & 27 & 13 \\
\hline Húmero & 119 & 37,4 & 92 & 36,2 & 105 & 38,9 & 68 & 32,7 \\
\hline Cúbito & 63 & 19,8 & 58 & 22,8 & 89 & 33 & 43 & 20,7 \\
\hline Radio & 50 & 15,7 & 45 & 17,7 & 64 & 23,7 & 40 & 19,2 \\
\hline Pelvis & 83 & 26,1 & 64 & 25,2 & 88 & 32,6 & 44 & 21,2 \\
\hline Fémur & 75 & 23,6 & 92 & 36,2 & 90 & 33,3 & 67 & 32,2 \\
\hline Tibia & 162 & 50,9 & 103 & 40,6 & 124 & 45,9 & 78 & 37,5 \\
\hline Calcáneo & 26 & 8,2 & 31 & 12,2 & 28 & 10,4 & 23 & 11,1 \\
\hline Astrágalo & 4 & 1,3 & - & - & 10 & 3,7 & 12 & 5,8 \\
\hline Metapodio & 173 & 5,4 & 147 & 5,8 & 158 & 5,8 & 133 & 6,4 \\
\hline Falanges & 13 & 0,1 & 16 & 0,2 & 29 & 0,4 & 21 & 0,4 \\
\hline Total & 1536 & & 1153 & & 1641 & & 1081 & 281,2 \\
\hline Promedio & & 16,8 & & 16,8 & & 20 & & 16,5 \\
\hline
\end{tabular}

Tabla 7.76. Número mínimo de elementos (MNE) y abundancia relativa, para los ensambles de micromamíferos recuperados de las unidades de LS-3.

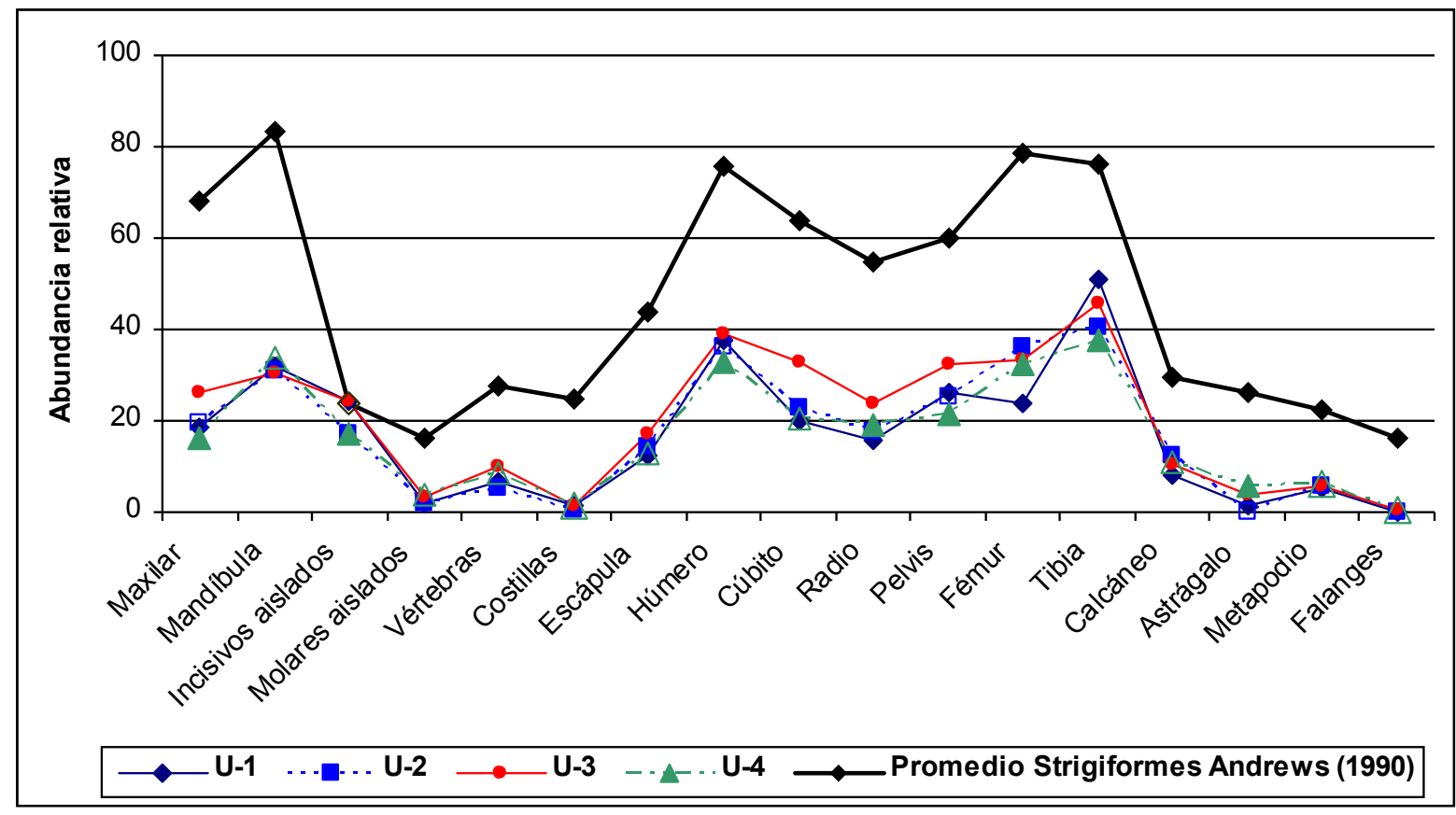

Figura 7.56. Valores de abundancia relativa de los diferentes elementos anatómicos de micromamíferos provenientes de las unidades de LS-3, comparados con el promedio de Strigiformes realizado por Andrews (1990). 


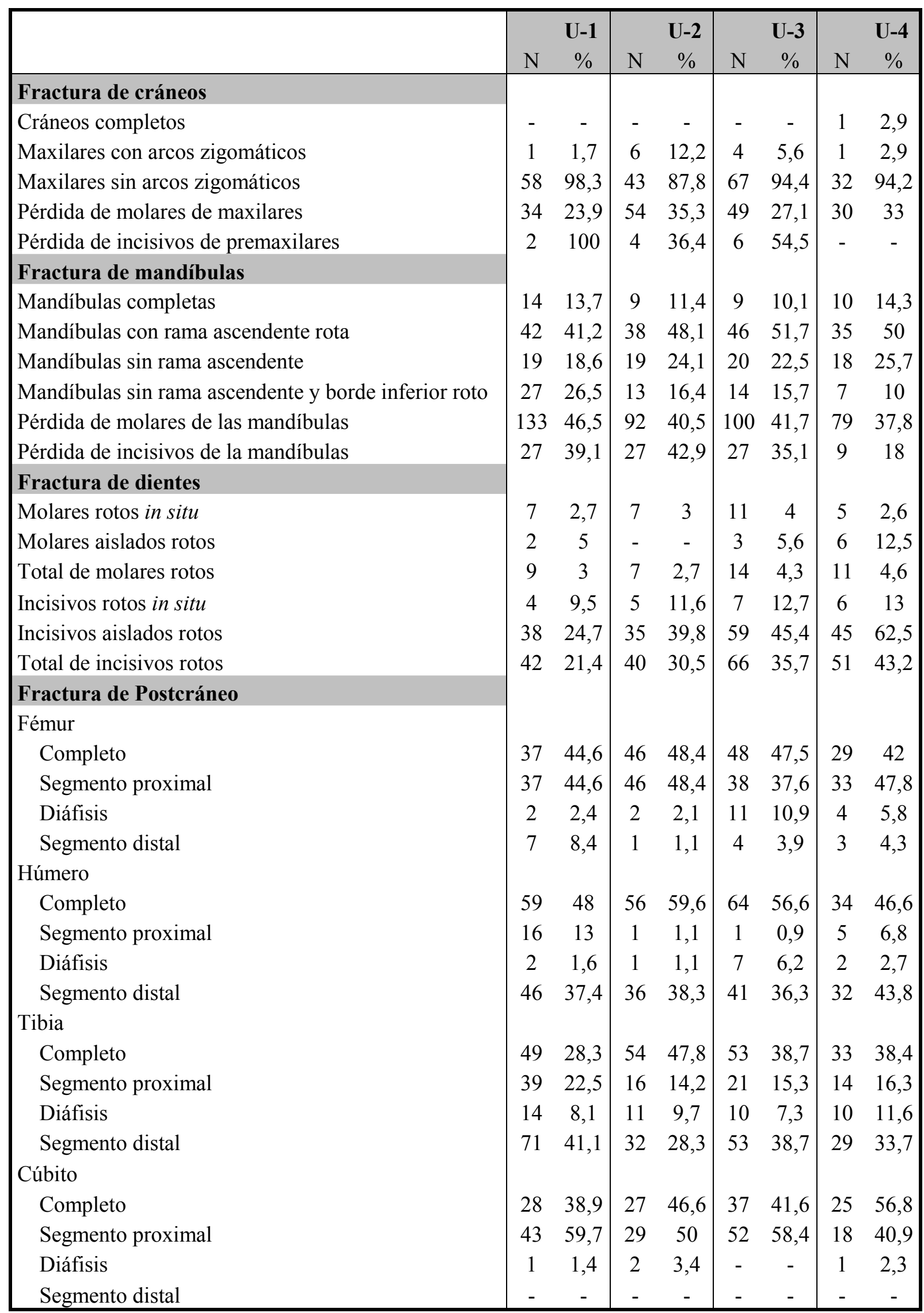

Tabla 7.77. Fractura de elementos craneales, dentarios y postcraneales, para los micromamíferos provenientes de las unidades de LS-3. 
En todas las unidades se registraron escasas mandíbulas completas. Una parte de las que estaban fracturadas conservaron las ramas ascendentes y otras presentaron el borde inferior de la rama mandibular roto. Además, un moderado porcentaje de molares e incisivos se perdieron de las mandíbulas. En las unidades 1, 2 y 3 la proporción de dientes fracturados fue escasa en los molares y moderada en los incisivos y en la Unidad 4 fue exigua en los molares y elevada en los incisivos. Asimismo, en ambos casos los que se hallaron aislados estaban más rotos que los que se encontraban in situ.

Los valores de fractura de los elementos postcraneales contemplados en la metodología propuesta por Andrews (1990) y Fernández-Jalvo y Andrews (1992) (i.e., fémur, húmero, tibia y cúbito) fue similar en todas las unidades, variando desde $38,4 \%$ en la Unidad 1 hasta $50,8 \%$ en la Unidad 2. Además, en fémur y cúbito prevalecieron los segmentos proximales y contrariamente en húmero y tibia prevalecieron los segmentos distales.

Se destaca que todas las unidades presentaron una mayor proporción de los elementos postcraneales rotos con superficies de fracturas con ángulos agudos y bordes ásperos (Tabla 7.78).

\begin{tabular}{|c|c|c|c|c|c|c|c|c|}
\hline \multirow{2}{*}{$\begin{array}{l}\text { Tipos de Fractura en postcraneal } \\
\text { (Fémur, húmero, tibia y cúbito) }\end{array}$} & \multicolumn{2}{|r|}{ U-1 } & \multicolumn{2}{|r|}{$\mathbf{U}-2$} & \multicolumn{2}{|r|}{$\mathbf{U}-\mathbf{3}$} & \multicolumn{2}{|r|}{ U-4 } \\
\hline & $\mathrm{N}$ & $\%$ & $\mathrm{~N}$ & $\%$ & $\mathrm{~N}$ & $\%$ & $\mathrm{~N}$ & $\%$ \\
\hline Fracturas con ángulos agudos y bordes ásperos & 252 & 90,6 & 187 & 91,7 & 230 & 96,6 & 147 & 97,4 \\
\hline Fracturas espiral o longitudinal con bordes suaves & 26 & 9,4 & 17 & 8,3 & 8 & 3,4 & 4 & 2,6 \\
\hline
\end{tabular}

Tabla 7.78. Tipos de fractura para los elementos postcraneales de los micromamíferos de las unidades de LS-3.

Por otra parte, la totalidad de los elementos del autopodio (calcáneos, astrágalos, metapodios y falanges) estaban completos y se hallaron pocas vértebras fracturadas. Sin embargo, los elementos más frágiles como las costillas, escápulas, pelvis y radios presentaron un grado alto de fractura (Tabla 7.79).

\begin{tabular}{|c|c|c|c|c|c|c|c|c|}
\hline \multirow{2}{*}{$\begin{array}{l}\text { Fracturas postcraneal } \\
\text { (otros elementos) }\end{array}$} & \multicolumn{2}{|r|}{ U-1 } & \multicolumn{2}{|r|}{ U-2 } & \multicolumn{2}{|r|}{ U-3 } & \multicolumn{2}{|r|}{$\overline{U-4}$} \\
\hline & $\mathrm{N}$ & $\%$ & $\mathrm{~N}$ & $\%$ & $\mathrm{~N}$ & $\%$ & $\mathrm{~N}$ & $\%$ \\
\hline Vértebras & 30 & 6 & 10 & 4,8 & 29 & 6,9 & 16 & 6,1 \\
\hline Costillas & 36 & 81,8 & 12 & 60 & 38 & 75,7 & 23 & 60,5 \\
\hline Escápula & 37 & 94,9 & 35 & 97,2 & 46 & 100 & 27 & 100 \\
\hline Radio & 9 & 18 & 10 & 22,2 & 20 & 30,8 & 21 & 52,5 \\
\hline Pelvis & 85 & 98,8 & 63 & 95,5 & 89 & 96,7 & 41 & 89,1 \\
\hline Calcáneo & - & - & - & - & - & - & - & - \\
\hline Astrágalo & - & - & - & - & - & - & - & - \\
\hline Metapodio & - & - & - & - & - & - & - & - \\
\hline Falanges & - & - & - & - & - & - & _ & - \\
\hline
\end{tabular}

Tabla 7.79. Fractura del resto de los elementos postcraneales de micromamíferos de las unidades de LS-3. 
Los valores obtenidos a partir de los índices calculados se exhiben en la tabla 7.80. Los dos índices que evalúan la relación entre elementos postcraneales y craneales sugieren una mejor preservación de los primeros en todas las unidades. El índice que valora la relación entre elementos distales y proximales de los miembros indica un predominio de elementos proximales en todas las unidades a excepción de la primera. En cuanto a los índices de pérdida dentaria se observó que en todas las unidades la mayor parte de los molares e incisivos quedaron retenidos en sus alvéolos. Los índices IT e IP mostraron un predominio de microvertebrados de menor tamaño y solitarios y crípticos en todas las unidades.

\begin{tabular}{|l|c|c|c|c|}
\hline & U-1 & U-2 & U-3 & U-4 \\
\hline Postcráneo / Cráneo & & & & \\
$\mathrm{f}+\mathrm{t}+\mathrm{h}+\mathrm{r}+\mathrm{c} / \mathrm{mx}+\mathrm{mb}+\mathrm{m}$ & 373,3 & 405,2 & 567,8 & 311,6 \\
$\mathrm{~h}+\mathrm{f} / \mathrm{mx}+\mathrm{mb}$ & 120,5 & 143,7 & 121,8 & 129,8 \\
Elementos distales / proximales & & & & \\
$\mathrm{t}+\mathrm{r} / \mathrm{f}+\mathrm{h}$ & 109,3 & 80,4 & 96,4 & 87,4 \\
Pérdida de dientes & & & & \\
Alvéolos mx+ alvéolos mb/m & 61 & 62,4 & 54,8 & 57,1 \\
Alvéolos mx+ alvéolos mb/i & 69 & 72,1 & 60 & 19,6 \\
Índice de Tamaño (IT) & 1887,5 & 2440 & 3275 & 2500 \\
Índice de Predictibilidad (IP) & 5,3 & 4,1 & 3,1 & 4 \\
\hline
\end{tabular}

Tabla 7.80. Valores de los índices calculados en las unidades de LS-3.

Referencias: f: fémur; t: tibia; h: húmero; r: radio; c: cúbito;

mx: maxilar; mb: mandíbula; m: molar; i: incisivo.

Por otra parte, se destaca que en los tres conjuntos no se registraron restos con marcas de cortes en toda la secuencia y escasos restos presentaron evidencias de termoalteración $(\mathrm{U} 1=0,6 \% ; \mathrm{U} 2=0,2 \% ; \mathrm{U} 3=1,3 \%$ y $\mathrm{U} 4=2,3 \%)$.

En lo que concierne a los procesos postdepositacionales, se encontraron muy exiguos restos con evidencias de meteorización a lo largo de toda la secuencia (U1=2 restos estadio II; U2=0; U3= 2 restos estadios I y II; U4=8 estadios I y II).

A lo largo de la secuencia no se registraron especímenes óseos con marcas de pisoteo. Se registraron restos con marcas de raíces de tipo"Sphenoichnia" en todas las unidades (U1=6,3\%; U2=7,7\%; U3=24,2\% y U4=35,5\%) (Figura 7.57 A y B). Asimismo, se recuperaron especímenes con evidencias de corrosión sedimentaria a lo largo de toda la secuencia (U1=7,4\%; U2=7,9\%; U3=24\% y U4=36,1\%) (Figura 7.57 C). 


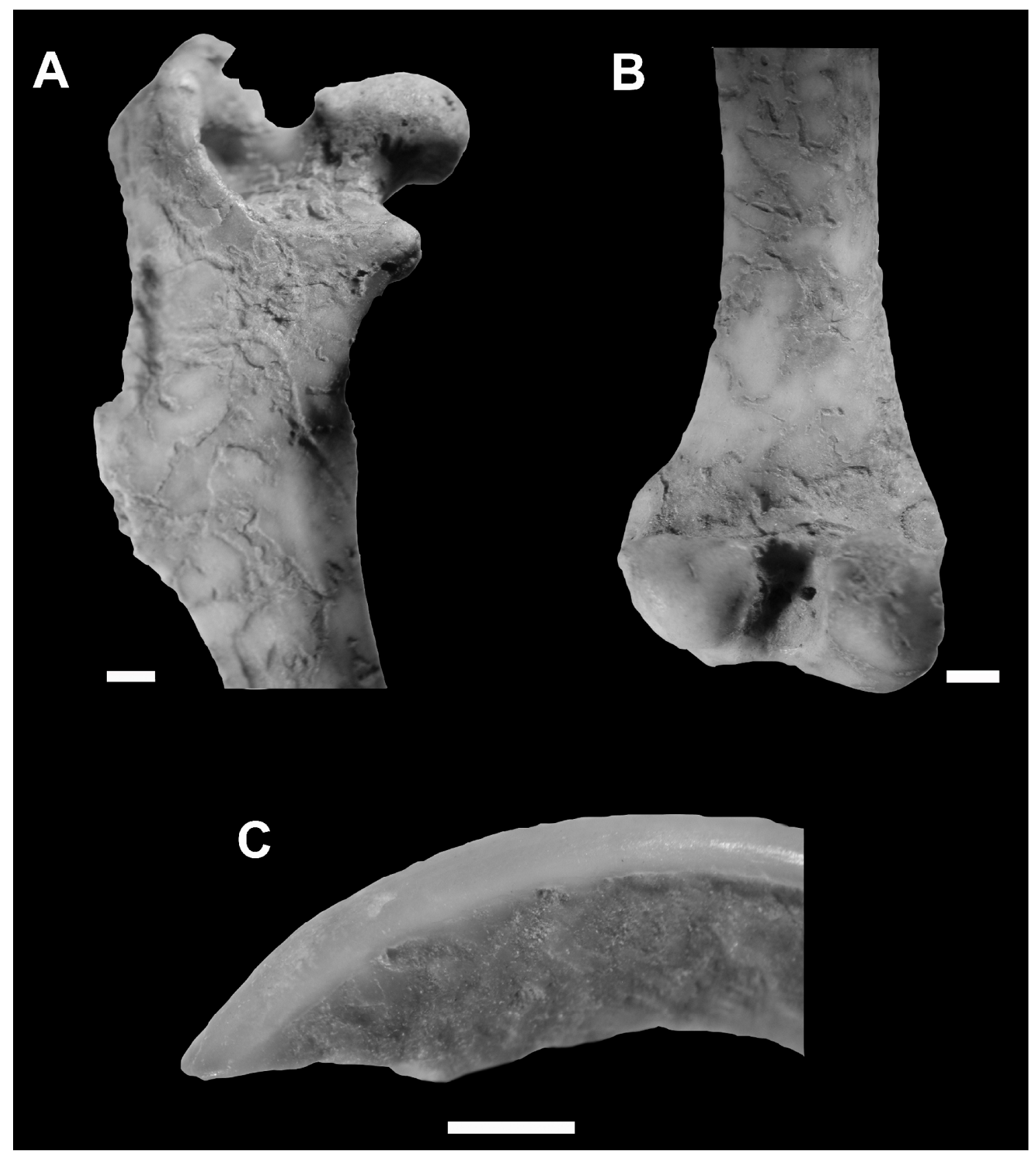

Figura 7.57. Restos de micromamíferos con evidencias de procesos postdepositacionales. A: fémur de Sigmodontinae con marcas de raíces y corrosión sedimentaria en la epífisis proximal y diálisis (Unidad 3, Nivel 12). B: fémur de Sigmodontinae con marcas de raíces y corrosión sedimentaria en la epífisis distal y diáfisis (Unidad 3, Nivel 12). C: incisivo de Sigmodontinae con marcas de corrosión sedimentaria en la dentina (Unidad 2, Nivel 7). Escalas: 1 mm.

No obstante, se hallaron restos con impresiones de óxido de manganeso solo en la Unidad $4(6,6 \%)$. A lo largo de la secuencia no se observaron restos óseos con redondeamiento en los extremos y protuberancias de los restos óseos y dentarios, indicando que no actuaron los efectos de la abrasión por transporte hídrico, desplazamientos y rozamientos de los restos contra el sedimento (Korth, 1979; Fernández-Jalvo y Andrews, 2003). 


\subsection{Aves}

Actividad antrópica y relación entre elementos del miembro anterior y posterior

No se hallaron evidencias de actividad antrópica, como huellas de corte, huesos quemados y fractura intencional (Higgins, 1999; y bibliografía allí citada). El cálculo sobre la relación entre elementos del miembro anterior y miembro posterior de la muestra arqueofaunística fue del 49,15\%. La desviación del 50\% esperado (proporción 1:1) es estadísticamente no significativo $\left(\chi^{2}=0,289, \mathrm{gl}=1, \mathrm{P}>0,05\right)$. Asimismo, en las muestras actuales tampoco se observó una desviación estadísticamente significativa del 50\% esperado (T. alba: $45,65 \%, \chi^{2}=0,7569, \mathrm{gl}=1, \mathrm{P}>0,05 ;$ B. magellanicus: $54,76 \%, \chi^{2}=$ $0,9063, \mathrm{gl}=1, \mathrm{P}>0,05)$.

\section{Relación entre elementos proximales y distales}

En la muestra arqueofaunística los elementos proximales del esqueleto representaron el $54,54 \%$ de la suma de elementos proximales y distales. La predominancia de elementos proximales no fue estadísticamente significativa $\left(\chi^{2}=0,433911, \mathrm{gl}=1, \mathrm{P}>0,05\right)$. En coincidencia con estos resultados, los valores de los elementos proximales de la muestra de $T$. alba fue del 56,46\% $\left(\chi^{2}=1,882384, \mathrm{gl}=1, \mathrm{P}>0,05\right)$. Sin embargo, en la muestra de B. magellanicus los elementos proximales del esqueleto representaron el $65,22 \%$, con un predominio estadísticamente significativo $\left(\chi^{2}=7,619536, \mathrm{gl}=1, \mathrm{P}<0,01\right)$.

\section{Modificación por digestión}

En la muestra arqueofaunística se han registrado marcas de corrosión por digestión en las superficies de los huesos, presentando forma de hoyos y depresiones con bordes redondeados localizados en los extremos de los huesos (categoría de modificación "redondeada" sensu Bochenski y Tomek, 1997), con una incidencia del 32,1\% del NISP total (Tabla 7.81, Figura 7.58 A). Si comparamos estos valores con los obtenidos en las muestras de egagrópilas, vemos que no se observan diferencias estadísticamente significativas con la muestra de T. alba $\left(\chi^{2}=0,2758\right.$, gl= $\left., \mathrm{P}>0,05\right)$. Por el contrario, se observaron diferencias estadísticamente significativas con la muestra de B. magellanicus 
$\left(\chi^{2}=24,9399, \mathrm{gl}=2, \mathrm{P}<0,001\right)($ Tabla 7.81). En la figura 7.58 B y C se puede observar las diferencias en las marcas de digestión producidas por ambas especies de lechuzas.

\begin{tabular}{|c|c|c|c|c|c|c|c|c|c|c|}
\hline & \multicolumn{6}{|c|}{ Superficie del hueso } & \multicolumn{4}{|c|}{ Fractura } \\
\hline & $\begin{array}{c}\mathbf{A} \\
\sin \text { daño } \\
\end{array}$ & $\%$ & $\begin{array}{c}\text { B } \\
\text { redondeada } \\
\end{array}$ & $\%$ & $\begin{array}{c}\text { C } \\
\text { aguda }\end{array}$ & $\%$ & $\begin{array}{c}\text { A } \\
\text { aguda }\end{array}$ & $\%$ & \begin{tabular}{|c|} 
B \\
redondeada \\
\end{tabular} & $\%$ \\
\hline \multicolumn{11}{|l|}{ LS-3 } \\
\hline Cráneo & 2 & 100 & - & - & - & - & 2 & 100 & - & - \\
\hline Mandíbula & 4 & 100 & - & - & - & - & 4 & 100 & - & - \\
\hline Vértebras & 7 & 100 & - & - & - & - & 4 & 100 & - & - \\
\hline Pelvis & 2 & 100 & - & - & - & - & 2 & 100 & - & - \\
\hline Huesos largos & 40 & 60,6 & 26 & 39,4 & - & - & 35 & 83,3 & 7 & 16,7 \\
\hline Total & 55 & 67,9 & 26 & 32,1 & - & - & 47 & 87,1 & 7 & 12,9 \\
\hline \multicolumn{11}{|l|}{ Tyto alba } \\
\hline Cráneo & 6 & 75 & 2 & 25 & - & - & - & - & - & - \\
\hline Mandíbula & 5 & 62,5 & 3 & 37,5 & - & - & - & - & - & - \\
\hline Vértebras & 5 & 100 & - & - & - & - & - & - & - & - \\
\hline Pelvis & 2 & 100 & - & - & - & - & - & - & - & - \\
\hline Huesos largos & 29 & 63 & 17 & 37 & - & - & - & - & 8 & 100 \\
\hline Total & 47 & 70,3 & 22 & 29,7 & - & - & - & - & 8 & 100 \\
\hline \multicolumn{11}{|l|}{ Bubo magellanicus } \\
\hline Cráneo & 9 & 75 & 3 & 25 & - & - & - & - & 3 & 100 \\
\hline Mandíbula & 6 & 60 & 4 & 40 & - & - & - & - & 2 & 100 \\
\hline Vértebras & 1 & 33,3 & 2 & 66,7 & - & - & - & - & - & - \\
\hline Pelvis & 1 & 100 & - & - & - & - & - & - & 1 & 100 \\
\hline Huesos largos & 15 & 32,7 & 26 & 56,5 & 5 & 10,9 & - & - & 13 & 100 \\
\hline Total & 32 & 44,4 & 35 & 48,6 & 5 & 6,9 & - & - & 19 & 100 \\
\hline
\end{tabular}

Tabla 7.81. Representación de las distintas categorías de modificación de restos de aves (sensu Bochenski y Tomek 1997) en las muestras estudiadas.

Los altos porcentajes de fractura observados en la muestra arqueofaunística, tanto en los elementos del esqueleto axial como apendicular (Tablas 7.82-7.85), son inconsistentes con el bajo porcentaje de corrosión digestiva. Además, las fracturas presentan ángulos agudos y ásperos al eje de la diáfisis, sin presentar signos de corrosión por digestión (i.e., categoría de modificación "Aguda" indicada para procesos postdepositacionales, sensu Bochenski y Tomek, 1997). 


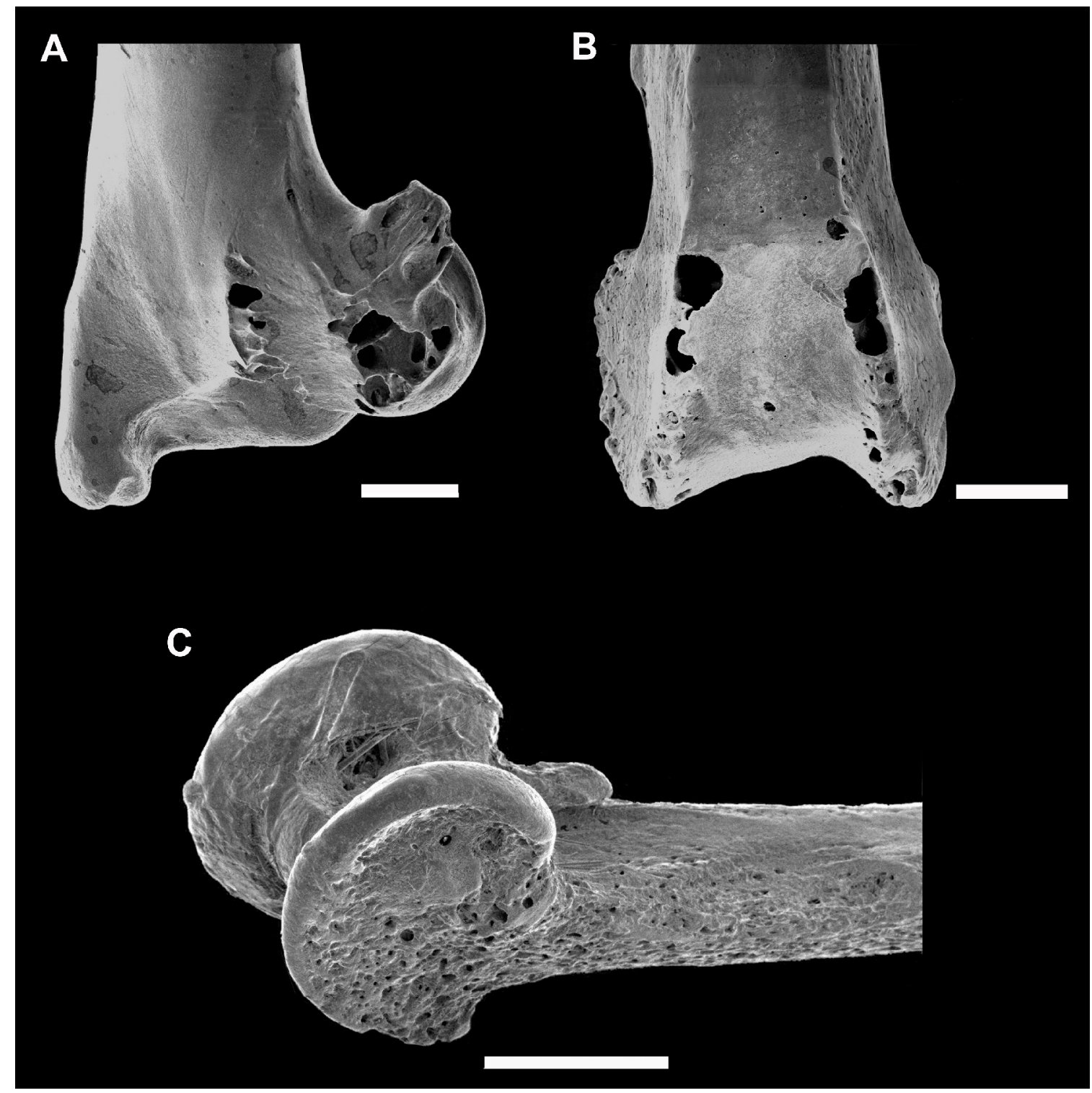

Figura 7.58. Ejemplos de corrosión digestiva en las muestras de aves de LS-3 y en muestras actuales de Strigiformes. A: húmero con marcas de corrosión digestiva en la epífisis distal (Unidad 3, Nivel 13). B: tibiotarso de Passeriformes con marcas de corrosión digestiva el la epífisis distal (muestra de Tyto alba). C: Tibiotarso de Passeriformes con marcas de corrosión digestiva el la epífisis distal y en la diáfisis (muestra de Bubo magellanicus). Escalas: $1 \mathrm{~mm}$.

\begin{tabular}{|l|c|c|c|c|c|c|c|c|c|c|}
\hline & $\begin{array}{c}\text { Cráneo } \\
\text { completo } \\
(\mathrm{N})\end{array}$ & $\begin{array}{c}\text { Cráneo } \\
\text { completo, sin } \\
\text { parte posterior } \\
(\mathrm{N})\end{array}$ & $\begin{array}{c}\text { Bóveda } \\
\text { craneal sin } \\
\text { parte posterior } \\
(\mathrm{N})\end{array}$ & $\begin{array}{c}\text { Bóveda } \\
\text { craneal } \\
(\mathrm{N})\end{array}$ & $\begin{array}{c}\text { Pico } \\
\text { completo } \\
(\mathrm{N})\end{array}$ & $\begin{array}{c}\text { Fragmento } \\
\text { del pico } \\
(\mathrm{N})\end{array}$ & MNE & $\%$ & MNI & $\%$ \\
\hline LS-3 & - & - & - & - & 2 & - & 2 & 3,3 & 2 & 40 \\
Tyto alba & 2 & 6 & - & - & - & - & 8 & 12,1 & 8 & 100 \\
Bubo magellanicus & 1 & 7 & 1 & 2 & 1 & - & 10 & 15,9 & 11 & 100 \\
\hline
\end{tabular}

Tabla 7.82. Fragmentación del cráneo (sensu Bochenski et al., 1993: Tabla 1) en las muestras estudiadas. 


\begin{tabular}{|l|cc|c|c|c|c|c|c|c|}
\hline & $\begin{array}{c}\text { Completa } \\
\text { (ambas } \\
\text { mandíbulas }) \\
(\mathrm{N})\end{array}$ & $\begin{array}{c}\text { Una rama } \\
\text { mandibular } \\
(\mathrm{N})\end{array}$ & $\begin{array}{c}\text { Porción } \\
\text { articular } \\
(\mathrm{N})\end{array}$ & $\begin{array}{c}\text { Extremo } \\
\text { de la } \\
\text { mandíbula } \\
(\mathrm{N})\end{array}$ & $\begin{array}{c}\text { Porción } \\
\text { media de la } \\
\text { mandíbula } \\
(\mathrm{N})\end{array}$ & MNE & $\%$ & MNI & $\%$ \\
\hline LS-3 & - & 2 & 2 & - & - & 4 & 6,7 & 2 & 40 \\
Tyto alba & 8 & - & - & - & - & 8 & 12,1 & 8 & 100 \\
Bubo magellanicus & 8 & 2 & - & - & - & 10 & 15,9 & 9 & 81,8 \\
\hline
\end{tabular}

Tabla 7.83. Fragmentación de la mandíbula (sensu Bochenski et al., 1993: Tabla 2) en las muestras estudiadas.

\begin{tabular}{|l|c|c|c|c|c|c|c|c|}
\hline & $\begin{array}{c}\text { Sinsacro con 1 o 2 } \\
\text { huesos del íleon, } \\
\text { isquion y pubis } \\
(\mathrm{N})\end{array}$ & $\begin{array}{c}\text { Huesos } \\
\text { íleon, isquion } \\
\text { y pubis } \\
(\mathrm{N})\end{array}$ & $\begin{array}{c}\text { Sinsacro } \\
\text { entero o } \\
\text { parcial } \\
(\mathrm{N})\end{array}$ & $\begin{array}{c}\text { Región } \\
\text { del } \\
\text { acetábulo } \\
(\mathrm{N})\end{array}$ & MNE & $\%$ & MNI & $\%$ \\
\hline LS-3 & - & - & 2 & - & 2 & 3,3 & 2 & 40 \\
Tyto alba & 2 & - & - & - & 2 & 3 & 2 & 25 \\
Bubo magellanicus & - & 1 & - & - & 1 & 1,6 & 1 & 9,1 \\
\hline
\end{tabular}

Tabla 7.84. Fragmentación de la pelvis (sensu Bochenski et al., 1993: Tabla 4) en las muestras estudiadas.

\section{Numero mínimo de individuos (MNI)}

Las últimas columnas de las Tablas 7.82-7.85, muestran el MNI calculado para cada elemento esqueletal, expresado en porcentajes respecto del valor más alto. En la muestra arqueofaunística se registraron mayores porcentajes de MNI en huesos largos, siendo el tibiotarso, el cúbito, carpometacarpo y fémur los elementos con valores más altos. Posiblemente, esta supervivencia diferencial se deba a que los huesos largos poseen una mayor densidad ósea que el resto de los elementos anatómicos (e.g., Ericson, 1987; Livingston, 1989).

Como se ilustra en la figura 7.59, se puede observar una mayor semejanza con la muestra de T. alba. No obstante, ambas muestras actuales exhibieron un aumento en la representación de elementos craneales en relación a la muestra arqueofaunística. 


\begin{tabular}{|c|c|c|c|c|c|c|c|c|c|c|c|c|}
\hline & $\begin{array}{c}\text { Hueso } \\
\text { Completo } \\
(\mathrm{N}) \\
\end{array}$ & $\%$ & $\begin{array}{c}\text { Epífisis } \\
\text { proximal } \\
(\mathrm{N}) \\
\end{array}$ & $\%$ & $\begin{array}{c}\text { Epífisis } \\
\text { distal } \\
(\mathrm{N}) \\
\end{array}$ & $\%$ & $\begin{array}{c}\text { Diáfisis } \\
(\mathrm{N})\end{array}$ & $\%$ & MNE & $\%$ & MNI & $\%$ \\
\hline \multicolumn{13}{|l|}{ LS-3 } \\
\hline Escápula & - & - & 1 & 50 & 1 & 50 & - & - & 1 & 1,7 & 1 & 20 \\
\hline Coracoides & 1 & 33,3 & 2 & 66,7 & - & - & - & - & 3 & 5 & 1 & 20 \\
\hline Húmero & 3 & 37,5 & 3 & 37,5 & 2 & 25 & - & - & 6 & 10 & 3 & 60 \\
\hline Cúbito & 7 & 58,3 & 2 & 16,7 & 3 & 25 & - & - & 10 & 16,7 & 5 & 100 \\
\hline Radio & - & - & - & - & 2 & 100 & - & - & 2 & 3,3 & 1 & 20 \\
\hline Carpometacarpo & 7 & 77,8 & 2 & 22,2 & - & - & - & - & 9 & 15 & 5 & 100 \\
\hline Fémur & 2 & 22,2 & - & - & 6 & 66,7 & 1 & 11,1 & 8 & 13,3 & 4 & 80 \\
\hline Tibiotarso & 1 & 7,1 & 4 & 28,6 & 8 & 57,2 & 1 & 7,1 & 9 & 15 & 5 & 100 \\
\hline Tarsometatarso & - & - & 3 & 42,9 & 4 & 57,1 & - & - & 4 & 6,7 & 2 & 40 \\
\hline Total & 21 & 31,8 & 17 & 25,7 & 26 & 39,4 & 2 & 3,1 & - & - & - & - \\
\hline \multicolumn{13}{|l|}{ Tyto alba } \\
\hline Escápula & - & - & 1 & 50 & 1 & 50 & - & - & 1 & 1,5 & 1 & 12,5 \\
\hline Coracoides & 2 & 100 & - & - & - & - & - & - & 2 & 3 & 1 & 12,5 \\
\hline Húmero & 7 & 100 & - & - & - & - & - & - & 7 & 10,6 & 4 & 50 \\
\hline Cúbito & 6 & 75 & 1 & 12,5 & 1 & 12,5 & - & - & 7 & 10,6 & 4 & 50 \\
\hline Radio & - & - & - & - & 1 & 100 & - & - & 1 & 1,5 & 1 & 12,5 \\
\hline Carpometacarpo & 6 & 100 & - & - & - & - & - & - & 6 & 9,1 & 3 & 37,5 \\
\hline Fémur & 8 & 100 & - & - & - & - & - & - & 8 & 12,1 & 4 & 50 \\
\hline Tibiotarso & 9 & 90 & - & - & 1 & 10 & - & - & 10 & 15,2 & 5 & 62,5 \\
\hline Tarsometatarso & 5 & 71,4 & 1 & 14,3 & 1 & 14,3 & - & - & 6 & 9,1 & 4 & 50 \\
\hline Total & 43 & 84,3 & 4 & 7,8 & 4 & 7,8 & - & - & - & - & - & - \\
\hline \multicolumn{13}{|l|}{ Bubo magellanicus } \\
\hline Escápula & - & - & 1 & 50 & 1 & 50 & - & - & 1 & 1,6 & 1 & 9,1 \\
\hline Coracoides & - & - & 1 & 50 & 1 & 50 & - & - & 1 & 1,6 & 1 & 9,1 \\
\hline Húmero & 14 & 100 & - & - & - & - & - & - & 14 & 22,2 & 7 & 63,6 \\
\hline Cúbito & 2 & 50 & 1 & 25 & 1 & 25 & - & - & 3 & 4,8 & 2 & 18,2 \\
\hline Radio & - & - & - & - & 1 & 100 & - & - & 1 & 1,6 & 1 & 9,7 \\
\hline Carpometacarpo & 3 & 60 & - & - & 2 & 40 & - & - & 5 & 7,9 & 3 & 27,3 \\
\hline Fémur & 6 & 100 & - & - & - & - & - & - & 6 & 9,5 & 3 & 27,3 \\
\hline Tibiotarso & 5 & 71,4 & 1 & 14,3 & 1 & 14,3 & - & - & 6 & 9,5 & 4 & 36,4 \\
\hline Tarsometatarso & 4 & 66,6 & 1 & 16,7 & 1 & 16,7 & - & - & 5 & 7,9 & 3 & 27,3 \\
\hline Total & 34 & 72,3 & 5 & 10,6 & 8 & 17,1 & - & - & - & - & - & - \\
\hline
\end{tabular}

Tabla 7.85. Fragmentación de los huesos largos (sensu Bochenski et al., 1993: Tabla 5) en las muestras estudiadas. 


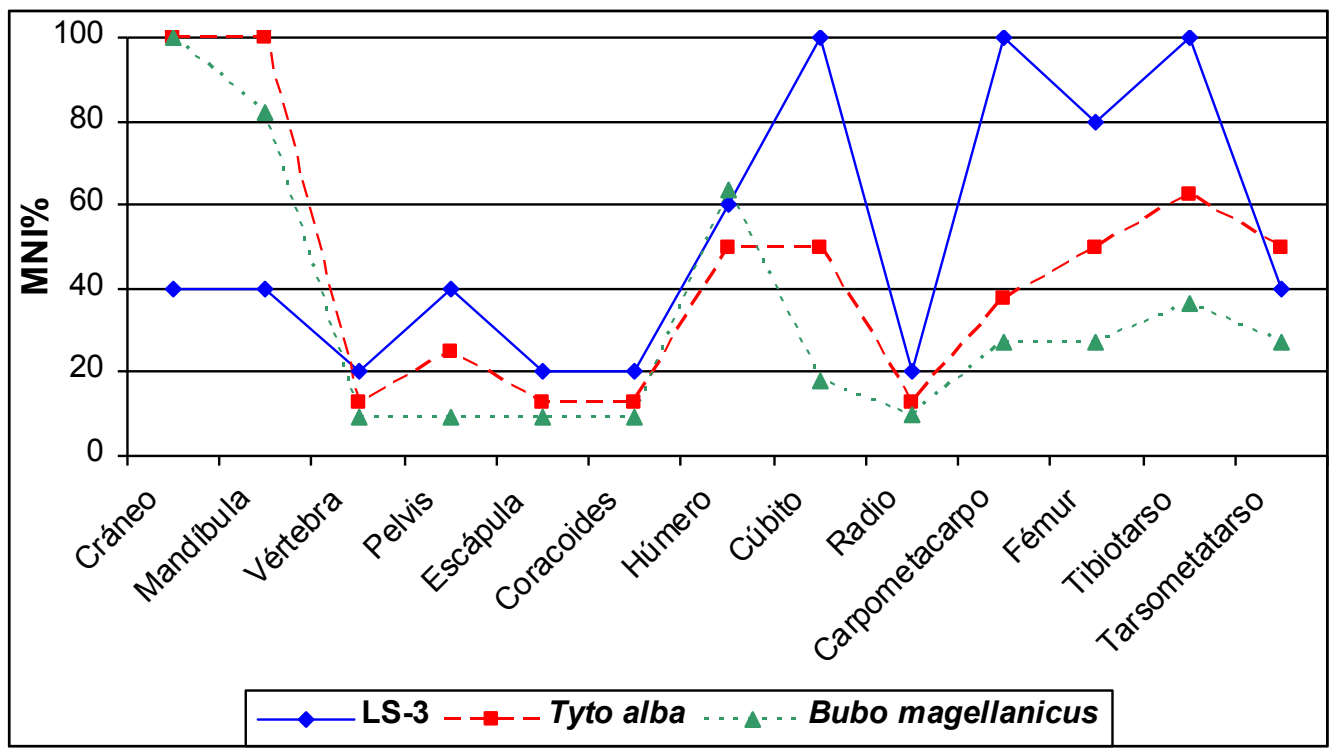

Figura 7.59. Comparación del MNI\% para cada elemento en las muestras de aves estudiadas.

Numero mínimo de elementos (MNE)

En las tablas 7.82-7.85 se exhiben el MNE calculado para cada tipo de hueso. Como en el caso anterior, en la muestra arqueofaunística se registraron mayores porcentajes de MNE en huesos largos, siendo el tibiotarso, el cúbito, carpometacarpo y fémur los elementos con valores más altos. Como se ilustra en la figura 7.60, se puede ver una mayor similitud con la muestra de T. alba. No obstante, como en el caso anterior, ambas muestras actuales exhibieron un aumento en la representación de elementos craneales en relación a la muestra arqueofaunística.

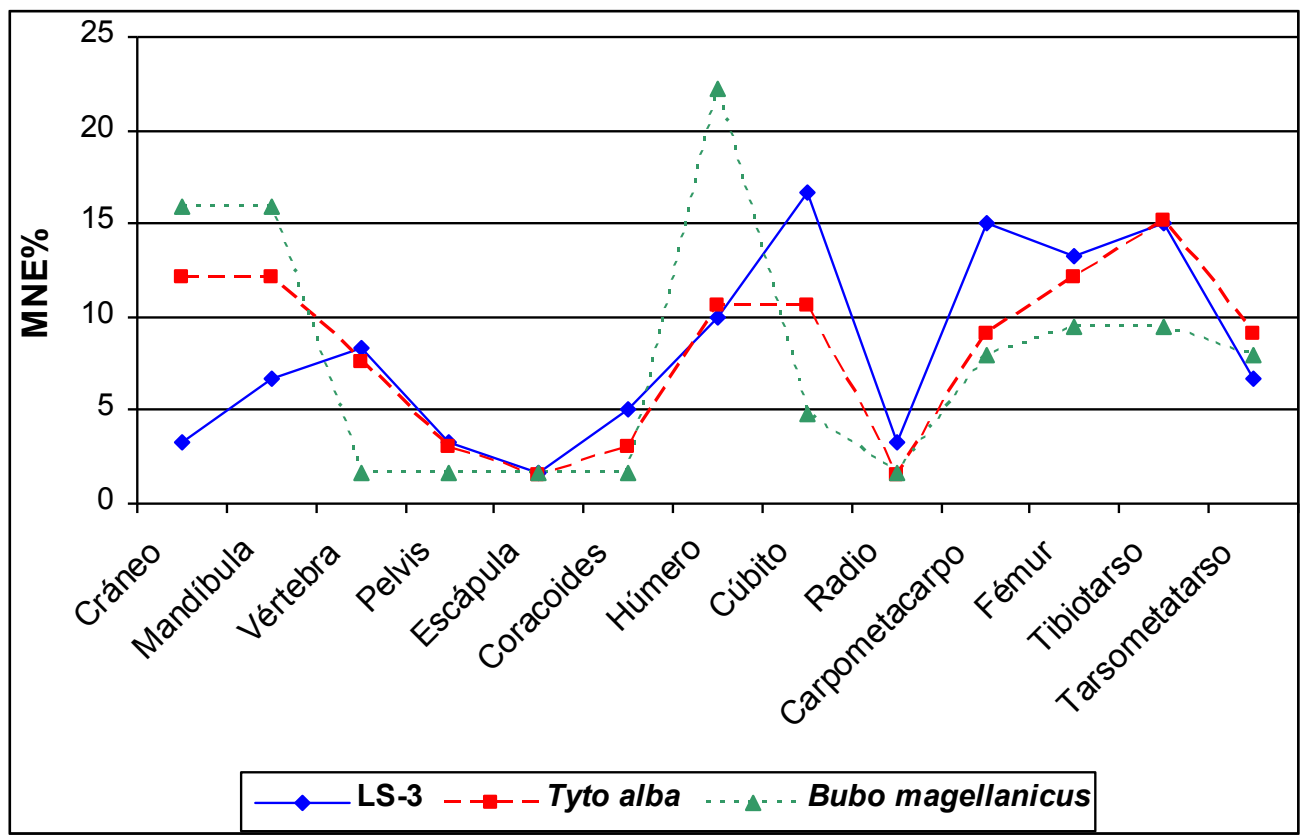

Figura 7.60. Comparación del MNE\% para cada elemento en las muestras de aves estudiadas. 


\section{Alteraciones por procesos postdepositacionales}

En lo que se refiere a los agentes y procesos postdepositacionales, primero es necesario tener en cuenta, para la evaluación de estos resultados, el impacto de los factores bioestratinómicos (e.g., exposición a la intemperie, acción de ácidos húmicos, pisoteo y destrucción por raíces) que afecta a las muestras fósiles (e.g., Pardiñas et al., 2000). Muy pocos restos $(1,3 \%)$, exhibieron evidencias de resquebrajamiento, agrietamiento $\mathrm{y}$ exfoliación en sus superficies, lo que sugiere que la meteorización no afectó significativamente al agregado arqueofaunístico. Además el 58\% del material se encuentra fracturado, posiblemente a causa del pisoteo y/o la caída de bloques del techo de la cueva (Tablas 7.82-7.85). Por otro lado, no se hallaron evidencias de redondeamientos en los extremos y protuberancias de los restos óseos, indicando que no actuaron los efectos de la abrasión por transporte hídrico, desplazamientos y rozamientos de los restos contra el sedimento (Korth, 1979; Trapani, 1998; Pinto Llona y Andrews, 1999; Fernández-Jalvo y Andrews, 2003).

La muestra presenta una alta proporción de huesos con marcas de raíces (36,5\%); la acción de los ácidos húmicos de las mismas produjo bioerosión leve en la superficie cortical de los huesos (Figura 7.61 A), las cuales podrían corresponder a la categoría de marcas de raíces "Sphenoichnia" (Andrews, 1990; Lyman, 1994). Este tipo de marcas indica el desarrollo de una cubierta herbácea durante la formación del suelo cuando los huesos fueron depositados y enterrados (Montalvo, 2002b). Asimismo, se registró una leve incidencia $(4,1 \%)$ de impresiones de óxido de manganeso. Es importante destacar la elevada proporción $(85,1 \%)$ de elementos con marcas de corrosión sedimentaria, posiblemente causada por la humedad del suelo (Figura 7.61 B). 


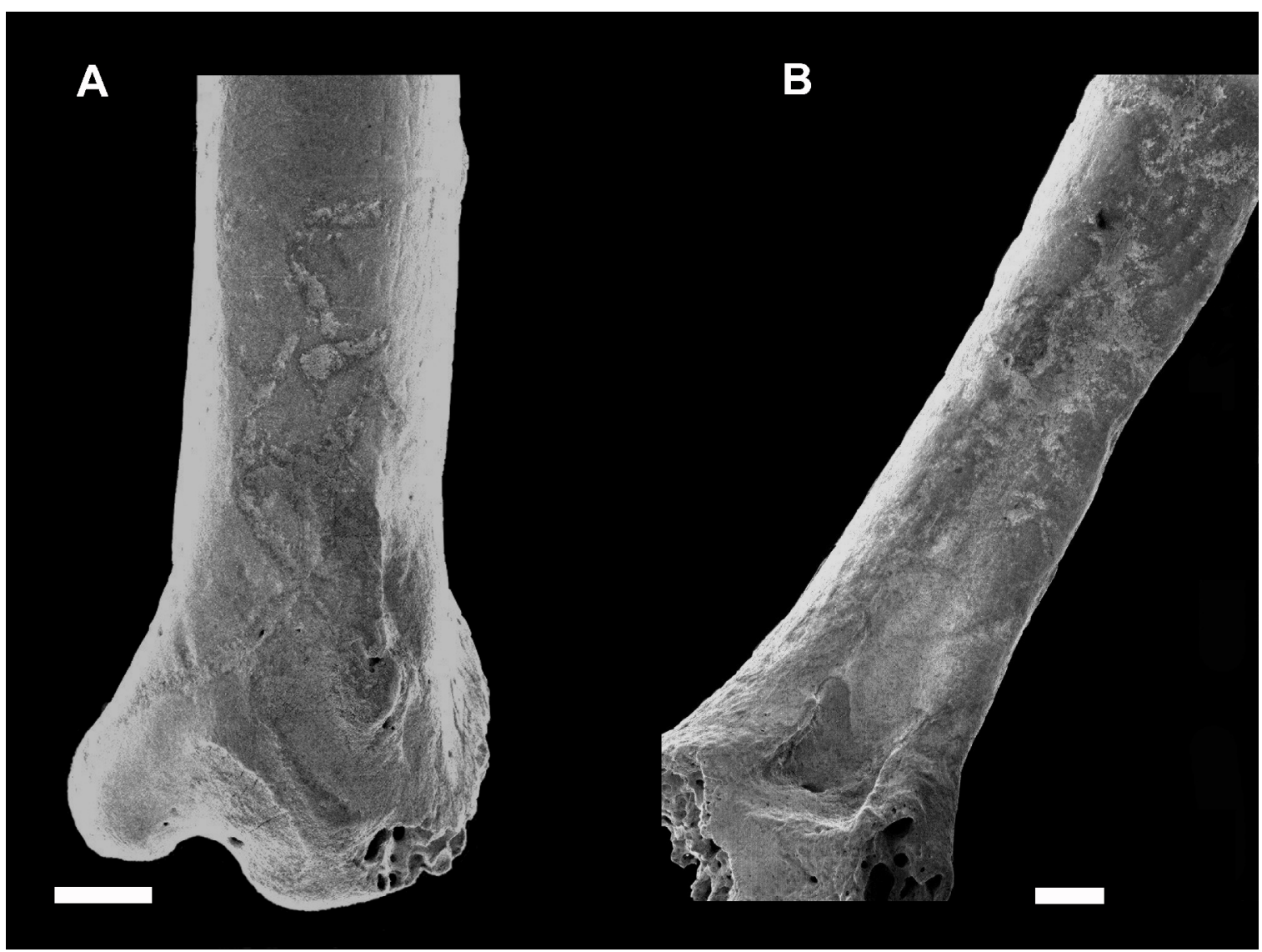

Figura 7.61. Restos de aves con evidencias de procesos postdepositacionales. A: cubito de Passeriformes con marcas de raíces en la diálisis (Unidad 3, Nivel 13). B: tibiotarso de Passeriformes con marcas de corrosión sedimentarias en toda la superficie del hueso (Unidad 4, Nivel 16). Escalas: $1 \mathrm{~mm}$.

\subsection{Reptiles}

Un total de 64 especímenes óseos de reptiles fueron recuperados en LS-3. Como se ilustra en la tabla 7.86, los porcentajes de los restos afectados por la corrosión digestiva en las cuatro unidades variaron entre $28 \%$ y $22,9 \%$, mostrando que no hubo grandes diferencias entre las mismas.

\begin{tabular}{|c|c|c|c|c|c|c|c|c|}
\hline \multirow{2}{*}{ Digestión / procedencia } & \multicolumn{2}{|r|}{ U-1 } & \multicolumn{2}{|r|}{ U-2 } & \multicolumn{2}{|r|}{ U-3 } & \multicolumn{2}{|r|}{ U-4 } \\
\hline & $\mathrm{N}$ & $\%$ & $\mathrm{~N}$ & $\%$ & $\mathrm{~N}$ & $\%$ & $\mathrm{~N}$ & $\%$ \\
\hline Craneal & 1 & 5 & 3 & 6,4 & 1 & 16,7 & - & - \\
\hline Postcraneal & 7 & 46,7 & 41 & 30,1 & 4 & 33,3 & 7 & 33,3 \\
\hline Total & 8 & 22,9 & 44 & 24 & 5 & 27,8 & 7 & 28 \\
\hline
\end{tabular}

Tabla 7.86. Corrosión digestiva craneal y postcraneal, para los reptiles provenientes de las unidades arqueológicas. 
Asimismo, se destaca que en todos los casos las huellas de digestión fueron ligeras y en este sentido, los restos presentaron un leve poseado. Para el caso específico de los huesos largos, las huellas de digestión nunca se extendieron más allá de las epífisis.

Los valores de abundancia relativa fueron similares en todas las unidades. Las mandíbulas, húmeros y fémures estuvieron bien representados y las vértebras, cubitos, radios y peronés fueron poco abundantes. No obstante, la U-1 fue la que más se diferenció, exhibiendo una mejor representación de maxilares y menor abundancia de tibias (Tabla 7.87 y Figura 7.62).

\begin{tabular}{|l|cc|cc|cc|cc|}
\hline $\begin{array}{l}\text { Elemento / } \\
\text { procedencia }\end{array}$ & MNE & $\begin{array}{c}\text { U-1 } \\
\text { Abundancia } \\
\text { relativa }\end{array}$ & MNE & $\begin{array}{c}\text { U-2 } \\
\text { Abundancia } \\
\text { relativa }\end{array}$ & MNE & $\begin{array}{c}\text { U-3 } \\
\text { Abundancia } \\
\text { relativa }\end{array}$ & MNE & $\begin{array}{c}\text { U-4 } \\
\text { Abundancia } \\
\text { relativa }\end{array}$ \\
\hline Frontal & 1 & 7,7 & 3 & 6,9 & - & - & - & - \\
Maxilar & 8 & 30,8 & 8 & 9,1 & 1 & 5,6 & - & - \\
Mandíbula & 11 & 42,3 & 36 & 40,9 & 5 & 27,8 & 4 & 25 \\
Vértebras & 2 & 1 & - & - & - & - & 1 & 0,8 \\
Húmero & 7 & 26,9 & 47 & 53,4 & 9 & 50 & 7 & 43,8 \\
Cúbito & - & - & 5 & 5,7 & - & - & - & - \\
Radio & - & - & 4 & 4,5 & - & - & - & - \\
Pelvis & 1 & 3,8 & 19 & 21,6 & 1 & 5,6 & 3 & 18,7 \\
Fémur & 5 & 19,2 & 41 & 46,6 & 1 & 5,6 & 6 & 37,5 \\
Tibia & - & - & 18 & 20,4 & 1 & 5,6 & 4 & 25 \\
Peroné & - & - & 2 & 2,3 & - & - & - & - \\
\hline Total & 35 & & 183 & & 18 & & 25 & \\
\hline
\end{tabular}

Tabla 7.87. Número mínimo de elementos (MNE) y abundancia relativa, para los ensambles de reptiles provenientes de las unidades de LS-3.

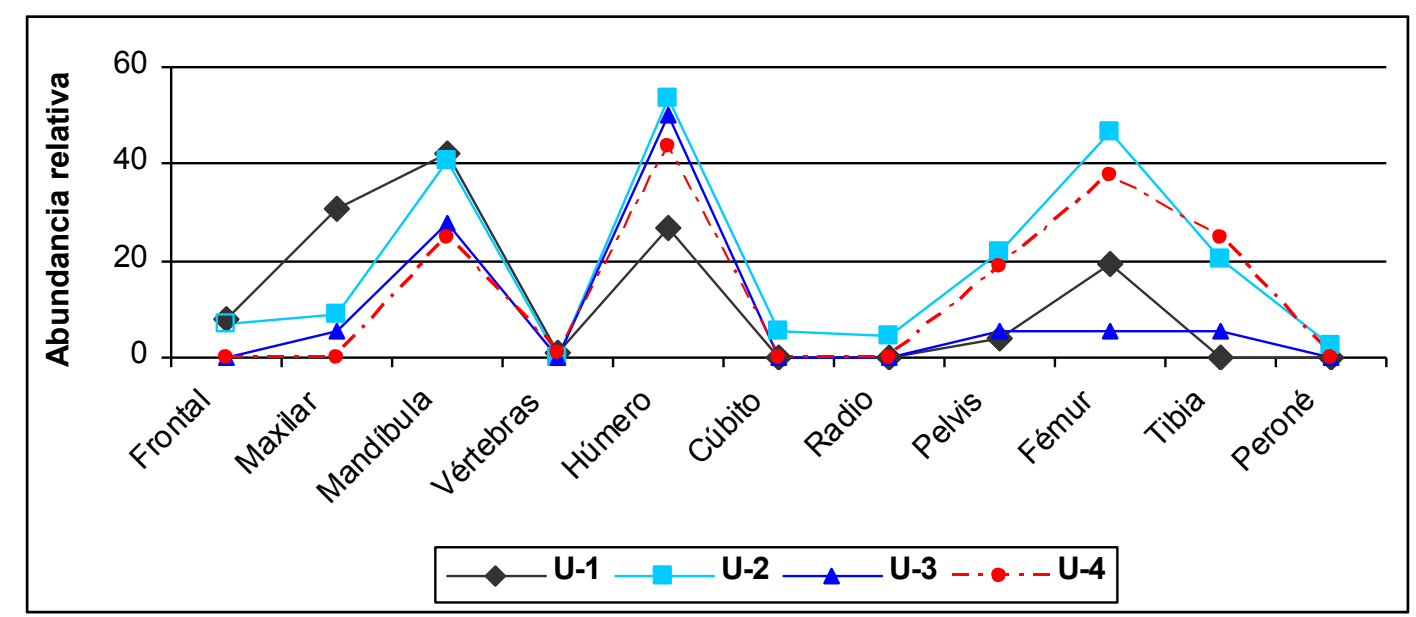

Figura 7.62. Valores de abundancia relativa de los diferentes elementos anatómicos de los reptiles provenientes de las unidades de LS-3. 
Con respecto a las fracturas, se destaca que no se halló ningún cráneo completo en toda la secuencia, los mismos correspondieron a maxilares, dentarios (denominados mandíbulas en este trabajo) y algunos frontales sueltos. Por otra parte, el nivel de fractura de los elementos postcraneales fue escaso en todas las unidades (Tabla 7.88). Asimismo, se destaca que todos los elementos postcraneales rotos, presentaron superficies de fractura con ángulos agudos y bordes ásperos y sin marcas de digestión.

\begin{tabular}{|c|c|c|c|c|c|c|c|c|}
\hline & $\mathrm{N}$ & $\begin{array}{c}\text { U-1 } \\
\%\end{array}$ & $\mathrm{~N}$ & $\begin{array}{c}\text { U-2 } \\
\%\end{array}$ & $\mathrm{~N}$ & $\begin{array}{c}\mathbf{U}-3 \\
\%\end{array}$ & $\mathrm{~N}$ & $\begin{array}{c}\text { U-4 } \\
\%\end{array}$ \\
\hline \multicolumn{9}{|l|}{ Fémur } \\
\hline Completo & 5 & 100 & 38 & 92,7 & 1 & 100 & 6 & 100 \\
\hline Segmento proximal & - & - & 3 & 7,3 & - & - & - & - \\
\hline Diáfisis & - & - & - & - & - & - & - & - \\
\hline Segmento distal & - & - & - & - & - & - & - & - \\
\hline \multicolumn{9}{|l|}{ Húmero } \\
\hline Completo & 6 & 86 & 31 & 66 & 8 & 88,9 & 6 & 85,7 \\
\hline Segmento proximal & 1 & 14 & 5 & 10,6 & 1 & 11,1 & - & - \\
\hline Diáfisis & - & - & 1 & 2,1 & - & - & - & - \\
\hline Segmento distal & - & - & 10 & 21,3 & - & - & 1 & 14,3 \\
\hline \multicolumn{9}{|l|}{ Tibia } \\
\hline Completo & - & - & 12 & 66,7 & 1 & 100 & 4 & 100 \\
\hline Segmento proximal & - & - & 6 & 33,3 & - & - & - & - \\
\hline Diáfisis & - & - & - & - & - & - & - & - \\
\hline Segmento distal & - & - & - & - & - & - & - & - \\
\hline \multicolumn{9}{|l|}{ Cúbito } \\
\hline Completo & - & - & 5 & 100 & - & - & - & - \\
\hline Segmento proximal & - & - & - & - & - & - & - & - \\
\hline Diáfisis & - & - & - & - & - & - & - & - \\
\hline Segmento distal & - & - & - & - & - & - & - & - \\
\hline
\end{tabular}

Tabla 7.88. Fractura de elementos craneales, dentarios y postcraneales, para los reptiles provenientes de las unidades de LS-3.

El resto de los elementos postcraneales que no se muestran en la tabla 7.88 (vértebras, radios, pelvis y peronés), estaban completos.

Los valores obtenidos a partir de los índices calculados se exhiben en la tabla 7.89.

El índice que evalúa la relación entre elementos postcraneales y craneales, mostró que a excepción de la U-2, todas las unidades presentaron una mejor preservación de elementos craneales. El índice que calcula la relación entre los elementos distales y proximales, indica que en toda la secuencia arqueológica hubo un fuerte predominio de elementos 
proximales.

\begin{tabular}{|l|c|c|c|c|}
\hline & U-1 & U-2 & U-3 & U-4 \\
\hline $\begin{array}{l}\text { Postcráneo / Cráneo } \\
\mathrm{h}+\mathrm{f} / \mathrm{mx}+\mathrm{mb}\end{array}$ & 63,2 & 200 & 62,5 & 325 \\
$\begin{array}{l}\text { Elementos distales / proximales } \\
\mathrm{t}+\mathrm{r} / \mathrm{f}+\mathrm{h}\end{array}$ & - & 25 & 10 & 30,8 \\
\hline
\end{tabular}

Tabla 7.89. Valores de los índices calculados para reptiles de las unidades de LS-3.

Referencias: h: húmero; f: fémur; mx: maxilar; mb: mandíbula; t: tibia; r: radio; c: cúbito.

Es interesante destacar que no se registraron restos con marcas de corte en ninguna unidad y que solo tres huesos de la U-1 presentaron rastros de termoalteración.

En lo que concierne a los procesos postdepositacionales, cabe aclarar que en toda la secuencia no se hallaron restos con evidencias de meteorización. Por otro lado, los ensambles presentaron restos óseos con marcas de raíces del tipo "Sphenoichnia" (Andrews 1990; Lyman 1994), exhibiendo un 2,9\% de especimenes afectados en la U-1, un $8,2 \%$ en la U-2, un $22,2 \%$ en la U-3 y un $36 \%$ en la U-4. Asimismo, se registraron especímenes con marcas de corrosión sedimentaria, posiblemente causada por la humedad del suelo, mostrando un $5,7 \%$ en la U-1, un $11,5 \%$ en la U-2, un $22,2 \%$ en la U3 y un $20 \%$ en la U-4.

En toda la secuencia no se hallaron evidencias de redondeamientos en los extremos y protuberancias de los huesos.

\subsubsection{Asociación de microvertebrados de las muestras actuales}

Como se ilustra en la tabla 7.90, el ensamble de micromamíferos de la muestra actual está conformado principalmente por roedores sigmodontinos, siendo Phyllotis xanthopygus la especie más representada, seguidos por Euneomys chinchilloides, Eligmodontia sp. y Abrothrix olivaceus. Con frecuencias menores se encuentran Abrothrix longipilis y Chelemys macronyx. También, se registraron dos roedores histricognatos (Ctenomys sp. y Microcavia autralis), un marsupial (Thylamys pallidior) y un lagomorfo introducido. Finalmente, se identificaron cuatros especies de aves paseriformes (Cinclodes fuscus, Asthenes cf. A. dorbignyi, Saltator aurantiirostris y Ammodramus humeralis), un charádrido y un columbiforme (Metriopelia melanoptera). El índice de diversidad de Shannon arrojó un valor de 2,014 


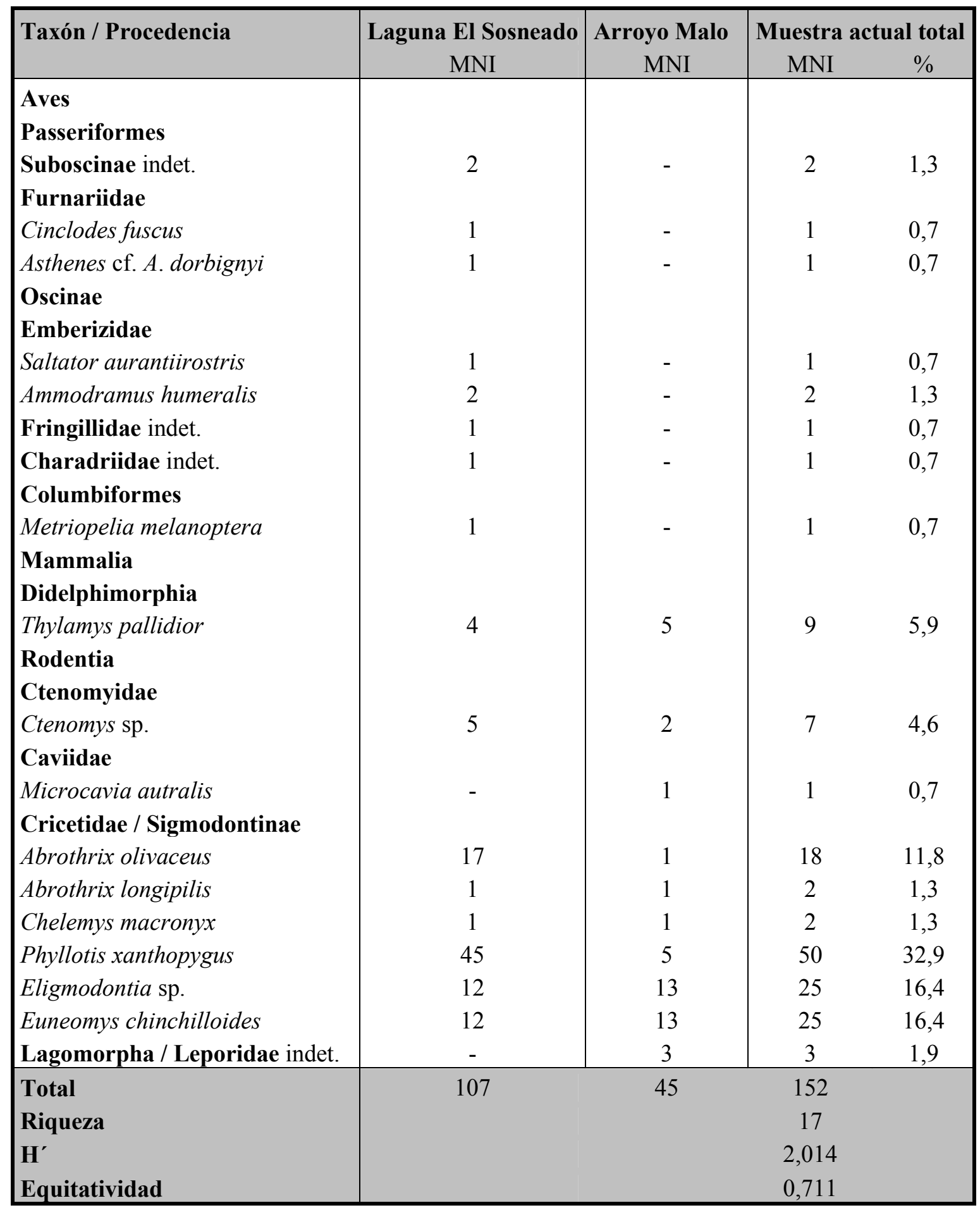

Tabla 7.90. Composición taxonómica de las muestras actuales (Localidades Laguna El Sosneado y Arroyo Malo).

\subsubsection{Asociación de microvertebrados de las muestras arqueofaunísticas}




\begin{tabular}{|c|c|c|c|c|c|c|c|c|c|c|c|c|}
\hline \multirow[t]{2}{*}{ Taxones / Procedencia } & \multicolumn{3}{|c|}{$\mathrm{U}-1$} & \multicolumn{3}{|c|}{$\mathrm{U}-2$} & \multicolumn{3}{|c|}{$\mathrm{U}-3$} & \multicolumn{3}{|c|}{$\mathrm{U}-4$} \\
\hline & NISP & MNE & MNI & NISP & MNE & MNI & NISP & MNE & MNI & NISP & MNE & MNI \\
\hline Reptilia / Sauria & 16 & 16 & 4 & 137 & 137 & 24 & 13 & 13 & 5 & 21 & 21 & 4 \\
\hline Leiosauridae & & & & & & & & & & & & \\
\hline Pristidactylus cf. P. scapulatus & 10 & 10 & 6 & 4 & 4 & 1 & - & - & - & - & - & - \\
\hline Leiolaemidae & & & & & & & & & & & & \\
\hline Liolaemus sp. & 8 & 8 & 2 & 42 & 42 & 19 & 5 & 5 & 4 & 4 & 4 & 4 \\
\hline Gekkonidae & & & & & & & & & & & & \\
\hline Homonota cf. H. darwini & 1 & 1 & 1 & - & - & - & - & - & - & - & - & - \\
\hline Aves indet. & 1 & 1 & 1 & 4 & 4 & 3 & 12 & 6 & 5 & 2 & 2 & 2 \\
\hline Passeriformes indet. & 6 & 4 & 3 & 4 & 3 & 2 & 6 & 5 & 5 & 7 & 4 & 3 \\
\hline Suboscinae indet. & 1 & 1 & 1 & 2 & 2 & 2 & 3 & 3 & 2 & - & - & - \\
\hline Furnaridae & & & & & & & & & & & & \\
\hline Upucerthia dumetaria & 1 & 1 & 1 & - & - & - & - & - & - & - & - & - \\
\hline Cinclodes cf. C. patagonicus & - & - & - & - & - & - & 1 & 1 & 1 & - & - & - \\
\hline Asthenes sp. & - & - & - & - & - & - & 1 & 1 & 1 & - & - & - \\
\hline Oscinae indet. & 1 & 1 & 1 & - & - & - & 3 & 3 & 2 & 1 & 1 & 1 \\
\hline Emberizidae indet. & 3 & 3 & 2 & - & - & - & 1 & 1 & 1 & - & - & - \\
\hline Phrygilus cf. P. fruticeti & 1 & 1 & 1 & - & - & - & - & - & - & - & - & - \\
\hline Phrygilus sp. & 1 & 1 & 1 & - & - & - & - & - & - & - & - & - \\
\hline Zonotrichia capensis & - & - & - & - & - & - & 3 & 3 & 1 & - & - & - \\
\hline Icteridae & & & & & & & & & & & & \\
\hline Agelaioides badius & - & - & - & - & - & - & 2 & 2 & 1 & - & - & - \\
\hline Agelaius thilius & - & - & - & - & - & - & - & - & - & 1 & 1 & 1 \\
\hline Charadriformes indet. & 1 & 1 & 1 & - & - & - & 2 & 2 & 1 & - & - & - \\
\hline Tinocoridae indet. & - & - & - & - & - & - & 1 & 1 & 1 & - & - & - \\
\hline Scolopacidae indet. & - & - & - & - & - & - & 2 & 2 & 1 & - & - & - \\
\hline Gruiformes / Rallidae indet. & - & - & - & - & - & - & - & - & - & 1 & 1 & 1 \\
\hline Columbiformes & & & & & & & & & & & & \\
\hline Metriopelia malanoptera & 1 & 1 & 1 & 3 & 3 & 2 & - & - & - & 2 & 2 & 1 \\
\hline Rodentia & & & & & & & & & & & & \\
\hline Ctenomyidae & & & & & & & & & & & & \\
\hline Ctenomys sp. & 29 & 29 & 8 & 7 & 7 & 5 & 14 & 14 & 4 & 8 & 8 & 4 \\
\hline Cricetidae / Sigmodontinae indet. * & 1384 & 1352 & - & 1040 & 1020 & - & 1520 & 1475 & - & 988 & 969 & - \\
\hline Abrothrix sp. & 2 & 2 & 2 & - & - & - & 9 & 9 & 5 & - & - & - \\
\hline Abrothrix longipilis & 15 & 15 & 10 & 5 & 5 & 4 & 8 & 8 & 6 & 5 & 5 & 2 \\
\hline Chelemys macronyx & 4 & 4 & 1 & - & - & - & 3 & 3 & 3 & 5 & 5 & 3 \\
\hline Phyllotis xanthopygus & 59 & 59 & 21 & 65 & 65 & 26 & 64 & 64 & 24 & 59 & 59 & 29 \\
\hline Loxodontomys micropus & 1 & 1 & 1 & - & - & - & 2 & 2 & 1 & 1 & 1 & 1 \\
\hline Eligmodontia sp. & 18 & 18 & 9 & 18 & 18 & 10 & 17 & 17 & 10 & 8 & 8 & 6 \\
\hline Euneomys chinchilloides & 56 & 56 & 24 & 38 & 38 & 19 & 49 & 49 & 19 & 26 & 26 & 16 \\
\hline Total & 1620 & 1586 & 102 & 1369 & 1348 & 117 & 1741 & 1689 & 103 & 1139 & 1117 & 78 \\
\hline Riqueza & & & 14 & & & 9 & & & 14 & & & 11 \\
\hline H' & & & 2,09 & & & 1,85 & & & 2,11 & & & 1,74 \\
\hline Equitatividad & & & 0,77 & & & 0,89 & & & 0,78 & & & 0,73 \\
\hline
\end{tabular}


* principalmente restos postcraneales, posiblemente correspondientes a los taxones determinados.

Tabla 7.91. Composición taxonómica de los ensambles de microvertebrados de las unidades de LS-3 (expresada en NISP, MNE y MNI).

Los ensambles arqueofaunísticos [Unidad $1(\mathrm{NISP}=1.620 ; \mathrm{MNE}=1.586 ; \mathrm{MNI}=102)$; Unidad $2(\mathrm{NISP}=1.369 ; \mathrm{MNE}=1348 ; \mathrm{MNI}=117)$; Unidad $3(\mathrm{NISP}=1.741 ; \mathrm{MNE}=$ 1.689; $\mathrm{MNI}=103) ;$ Unidad $4(\mathrm{NISP}=1.139 ; \mathrm{MNE}=1.117 ; \mathrm{MNI}=78)]$ están principalmente conformados por micromamíferos (Tabla 7.91). Los roedores sigmodontinos dominan toda la secuencia, siendo P. xanthopygus y E. chinchilloides los taxones más representados, seguidos por Eligmodontia sp. y A. longipilis. No obstante, resulta interesante notar las ausencias de C. macronyx y Loxodontomys micropus en la Unidad II. En proporciones menores se encuentra el roedor histricognato (Ctenomys sp.). Los reptiles fueron escasos y se encuentran representados por saurios leiolaémidos (Liolaemus sp.) en toda la secuencia, con el agregado de un leiosáurido (Pristidactylus cf. P. scapulatus), en las unidades I y II y un gekkónido (Homonota cf. H. darwini) en la Unidad I. Finalmente, se identificaron dos taxones de aves paseriformes en la Unidad I (Upucerthia dumetaria y Phrygilus cf. P. fruticeti), cuatro en la Unidad III (Asthenes sp., Cinclodes cf. C. patagonicus, Zonotrichia capensis y Agelaioides badius) y uno en la Unidad IV (Agelaius thilius). Asimismo, se determinaron restos de un columbiforme ( $M$. malanoptera) en las unidades I, II y IV, de tinocóridos, escolopácidos (Unidad III) y rállidos (Unidad IV).

La Unidad I y la Unidad III fueron las que presentaron valores más elevados de diversidad y riqueza taxonómica respecto a las unidades restantes y levemente respecto de la muestra actual.

\subsubsection{Discusión}

\subsubsection{Interpretación tafonómica}

\subsection{Micromamíferos}

En ninguna unidad arqueológica se halló evidencia directa de consumo humano sobre micromamíferos (e.g., marcas de cortes). Asimismo, si bien se observa un leve aumento de restos termoalterados en las unidades más profundas, los mismos nunca alcanzan el 
3\% del Nisp total, y en su integridad corresponden a roedores sigmodontinos. Relacionado a esto, Pardiñas (1999b) plantea que un conjunto de huesos termoalterados de micromamíferos, asociados al consumo humano, presenta entre otras cosas un elevado porcentaje de restos afectados y una dominancia de roedores histricognatos. Por ende, la posible vinculación de los restos quemados provenientes de las unidades arqueológicas al consumo humano, queda prácticamente descartada. Procesos naturales, limpieza del recinto, el encendido de fuego sobre los conjuntos de bolos y su posible uso como combustible, pueden ser una mejor explicación al tema (ver Pardiñas, 1999b).

Estudios actualísticos sobre tafonomía de varias especies de estrigiformes, revelan que estas aves se caracterizan porque la acción de sus ácidos gástricos afecta de manera ligera a moderada a los restos óseos y dentarios (e.g., Andrews, 1990; Gómez 2005, 2007; Carrera y Fernández, 2010). En congruencia, a lo largo de toda la secuencia se observaron bajos niveles de modificación por corrosión digestiva, de modo que la categoría ligera fue la más frecuente en todos los casos. Coincidentemente, investigaciones realizadas sobre restos óseos de micromamíferos consumidos por T. alba (e.g., Andrews, 1990; Gómez, 2007; Fernández et al., 2009a), concluyen que esta rapaz produce niveles de digestión correspondientes a la categoría I. Sin embargo, en las unidades 2 y 3 , seguido de esta categoría, existió un elevado porcentaje de restos con marcas de digestión moderada. En este sentido, Gómez $(2005,2007)$ halló que algunos búhos y lechuzas (B. virginianus y A. cunicularia) causaban mayor acción digestiva en los restos de micromamíferos. Coherentemente, Montalvo y Tejerina (2010) observaron que $A$. cunicularia produce niveles de digestión leve a moderada en restos de roedores. Por su parte Fernández et al. (2009b) al analizar restos de aves consumidos por $B$. magellanicus, concluyeron que este búho produce valores similares de alteración al de su par congenérico $B$. virginianus.

En forma contraria a lo que ocurre en ensambles originados por estrigiformes, la abundancia relativa promedio de todas las unidades arqueológicas fue baja. A su vez, las mandíbulas, fémures, tibias y húmeros fueron los elementos mejor representados y las vértebras, astrágalos, metapodios y falanges los menos abundantes. No obstante, si comparamos estos datos con el valor promedio obtenido por Andrews (1990) en base a diferentes especies de estrigiformes, se puede observar patrones de representación de partes esqueletales similares entre si (Figura 7.56). Los valores bajos de abundancia relativa promedio registrados en todas las unidades, posiblemente se deba a que la acción de los agentes postdepositacionales alteraron la composición original de los ensambles 
(ver más adelante cuando se discute sobre este tópico), reduciendo la preservación integral del conjunto.

A lo largo de toda la secuencia se observó una mejor preservación de elementos postcraneales (Tabla7.80). En coincidencia, Andrews (1990) y Gómez (2007) observaron que la mayoría de los ensambles derivados de estrigiformes presentaban proporciones más elevadas de estos elementos. Por otra parte, estos autores sostienen que los falconiformes y mamíferos carnívoros se diferencian porque en general producen conjuntos con mayor cantidad de elementos craneales.

A excepción de la Unidad 1, todas las unidades exhibieron una ligera pérdida de elementos distales de los miembros (Tabla 7.80). Estos resultados son acordes a los evidenciados por Andrews (1990), quien observó una mayor pérdida de estos elementos en ensambles originados por depredadores, debido a que son más frágiles que los elementos proximales. Además, este autor registró que los conjuntos generados por lechuzas muestran una ligera pérdida de los elementos distales. Esta situación, fue hallada por Gómez (2007) en su análisis tafonómico sobre restos de micromamíferos consumidos por T. alba.

En todas las unidades se registró una mayor proporción de molares e incisivos retenidos en sus alvéolos (Tabla 7.80), carácter que tanto Andrews (1990) como Gómez (2007) observaron en los numerosos ensambles originados por estrigiformes.

Las lechuzas y búhos posiblemente sean los depredadores que más contribuyen a generar acumulaciones de microvertebrados en sitios arqueológicos y paleontológicos de cuevas o refugios rocosos (e.g. Andrews, 1990), y dentro de este grupo, T. alba ocupa un lugar preponderante (Andrews, 1990; Saavedra y Simonetti, 1998; entre otros). Los taxones hallados a lo largo de la secuencia, están dominados por micromamíferos de tamaño chico y mediano (sensu, Pardiñas, 1999b), coincidiendo con el rango de tamaño de presas de las aves estrigiformes (Pardiñas, 1999b y literatura allí citada). En tal sentido, T. alba, B. magellanicus y A. cunicularia son las especies más frecuentes habitando la zona en la actualidad (ver Capítulo 6).

El hallazgo de restos óseos de estrigiformes indeterminados en las unidades 3 y 4 y de $T$. alba en las unidades 2 y 3 , constituye un elemento de cabal importancia. La presencia de restos de aves rapaces en sitios arqueológicos, no establece una evidencia directa de que el lugar haya servido de habitación para las mismas. Sin embargo, en ciertas ocasiones las lechuzas, búhos, halcones, águilas, etc, mueren por causas naturales en sus sitios de nidificación y/o descanso, donde sus restos pueden acumularse con los de sus presas 
(e.g., Pardiñas, 1999b). Otros autores sugieren que los restos de estrigiformes recuperados de los sitios arqueológicos podrían relacionarse a una conducta ritual por parte de grupos humanos (véase Tonni, 1983 y literatura allí citada).

Andrews (1990) en base estudios experimentales sobre restos de micromamíferos, observó que el pisoteo es un proceso muy destructivo y del cual emergen patrones de fractura, tales como la ausencia de cráneos completos, reducción del número de maxilares, importante grado de fractura y cierta pérdida de elementos postcraneales, pero con los elementos más chicos en buen estado de integridad. Al respecto, los niveles elevados de fractura registrados en los huesos de todas las unidades son inconsistentes con el bajo grado de corrosión digestiva. Además, gran parte de los restos presentaron fracturas con ángulos agudos y bordes ásperos sin huellas de digestión, y la mayoría de los elementos de menor tamaño (i.e., vértebras, calcáneos, astrágalos, metapodios y falanges) estaban completos. De esta manera, posiblemente este patrón esté más asociado a procesos postdepositacionales como el pisoteo que a los agentes acumuladores. Por otra parte, la exigua cantidad de huesos con evidencia de meteorización a lo largo de toda la secuencia, sugiere que los restos posiblemente hayan tenido un enterramiento rápido, luego de haber sido alterados por el pisoteo. Estos tipos de eventos son habituales en las cuevas o refugios rocosos, debido a que son unidades espaciales con circulación restringida, donde los restos fósiles están en parte protegidos de los agentes meteóricos (i.e., sol, lluvia, viento y cambios de temperatura), pero a su vez están más expuestos a los efectos del pisoteo (e.g., Andrews, 1990; Pardiñas, 1999b).

Con respecto a otros procesos postdepositacionales, cabe destacar que tanto las marcas de raíces como la corrosión sedimentaria evidenciaron un incremento a medida que aumentó la profundidad del sitio, siendo más notorio en las unidades 3 y 4 . El primero de ellos, siempre correspondió a la categoría "Sphenoichnia" (Andrews, 1990; Lyman, 1994). Este tipo de marcas indica el desarrollo de una cubierta herbácea durante la formación del suelo cuando los huesos fueron depositados y enterrados (Montalvo 2002b). El segundo, posiblemente ocurrió por la elevada humedad del suelo registrada en el sitio. Andrews (1990) observó que bajo condiciones de permanente humedad en el sedimento, los huesos de micromamíferos son afectados en su totalidad, mientras que en condiciones de sequedad, son mejor preservados. En congruencia, se registraron restos afectados por óxido de manganeso sólo en la parte más profunda del sitio (U-4). Los huesos hallados en cuevas o refugios rocosos están frecuentemente muy alterados y uno de los problemas más usuales para la interpretación de estos ensambles fósiles es la dificultad para 
diferenciar las modificaciones de los conjuntos producidos por la depredación y las modificaciones acaecidas por los procesos postdepositacionales (e.g., Andrews, 1990; Mondini, 1995, 2000, 2001). En este alero, la alta humedad del suelo y los ácidos húmicos de las raíces (principalmente en las unidades 3 y 4) produjo una importante alteración en los huesos, afectando toda su superficie, contrariamente a lo que ocurre con la corrosión por digestión, donde los efectos de la misma son localizados (Andrews, 1990; Fernández-Jalvo y Andrews, 1992).

Para finalizar, expresamos que a lo largo de toda la secuencia no se hallaron restos con evidencias de abrasión por transporte hídrico, desplazamientos y rozamientos de los restos contra el sedimento (Korth, 1979; Fernández-Jalvo y Andrews, 2003).

\subsection{Aves}

Andrews (1990), sobre la base de estudios tafonómicos realizados sobre restos óseos de micromamíferos consumidos por Strigiformes, observó que $T$. alba produce los niveles más bajos de acción corrosiva por digestión, generando bajas frecuencias en elementos postcraneales (6-20\%) (Categoría I, sensu Andrews 1990). Estas observaciones son acordes a las evidenciadas en las muestras arqueofaunísticas y de T. alba analizadas en este trabajo, pero con incrementos en los porcentajes de incidencia (Tabla 7.81). Posiblemente esta diferencia se deba a que, por su estructura ósea, los huesos de aves tienden a ser más ligeros y más quebradizos que los de otros grupos de vertebrados (Duke et al. 1973); por lo cual podrían ser más susceptibles a las alteraciones por digestión.

Por su parte, la muestra de B. magellanicus exhibió un aumento de huesos con marcas de digestión (Categoría II, sensu Bochesnki et al., 1998). Investigaciones conducidas por Bochenski y Tomek (1997) sobre alteración digestiva en huesos de aves, muestran que $B$. bubo corresponde a la categoría II de digestión postcraneal. Por otro lado, Andrews (1990) en un estudio tafonómico sobre restos óseos de micromamíferos ingeridos por $B$. bubo, y Gómez (2005) al analizar huesos de micromamíferos consumidos por $B$. virginianus registraron que ambas lechuzas presentaron niveles de modificación intermedia (Categoría II, sensu Andrews, 1990).

Varios autores han discutido sobre patrones de representación de partes esqueletales de aves. Algunos de ellos han considerado que el mismo, no es un método adecuado para discriminar el agente acumulador de un conjunto óseo en contextos arqueológicos y naturales (e.g., Serjeantson et al., 1993; Savanti, 1994; Muñoz y Savanti, 1998; Cruz, 
2005). Sin embargo, otros investigadores sobre la base de estudios sobre aves de pequeño y mediano tamaño, tanto en conjuntos arqueofaunísticos como actuales, han planteado lo contrario (e.g., Mourer-Chauviré, 1983; Ericson, 1987; Livingston, 1989; Baales, 1992; Bochenski et al., 1993, 1997, 1998, 1999, 2009; Bochenski y Tomek, 1994; Bochenski 1997, 2005; Bochenski y Nekrasov, 2001; Laroulandie, 2002; Bochenski y Tornberg, 2003). No obstante, estos autores coinciden que para identificar el agente acumulador de un depósito, no se deben tomar los diferentes atributos en forma aislada.

La relación entre los elementos del miembro anterior y posterior en todas las muestras estudiadas no se desviaron del $50 \%$ esperado. Estos resultados son coincidentes con los obtenidos por Bochenski (1997) sobre restos de aves consumidos por lechuzas. Esta proporción no fue hallada por Ericson (1987), quien registró mayor abundancia de elementos del miembro posterior, a causa de actividad antrópica en sitios arqueológicos. No obstante Livingston (1989) ha sugerido que las frecuencias de los elementos podría estar relacionada con la robustez de cada hueso y ha señalado que la supervivencia de los elementos del miembro anterior y posterior depende de las adaptaciones de locomoción de cada especie implicada, por esta razón una mayor abundancia de huesos del miembro anterior no necesariamente estaría vinculada a depositación humana. Asimismo, Cruz (2005) plantea que las diferencias en la representación de partes esqueletales entre tres grupos de aves patagónicas (i.e., aves voladoras, aves exclusivamente corredoras y aves exclusivamente nadadoras), estarían dadas por la densidad mineral de cada uno de los elementos, variando de acuerdo al tipo de locomoción. Esto implica que los elementos con mayor densidad ósea serán más resistentes a los procesos tafonómicos, mientras que los de menor densidad serán más afectados (Lyman, 1994; Cruz, 2005; entre otros). Por otro lado, las observaciones de Bovy (2002) acerca de la anatomía funcional de aves usando datos numéricos de sitios arqueológicos de la Costa Noroeste del Pacífico de EEUU, sugieren que la densidad ósea diferencial no puede explicar la abundancia de elementos del miembro anterior hallados en los sitios arqueológicos analizados. Además, el autor propone otras explicaciones, tales como alteraciones por carroñeros, prácticas de consumo, transporte diferencial y carroñeo humano.

Teniendo en cuenta la relación entre elementos proximales y distales, Bochenski y Nekrasov (2001) y Bochenski (2005) distinguen tres grupos de aves rapaces. El grupo I, incluye restos óseos de egagrópilas de Falconiformes (relación 1:1), el grupo II, corresponde a restos óseos de egagrópilas de Strigiformes y restos no digeridos de muchas especies de Falconiformes, donde el predominio de elementos proximales es 
cercano al $60 \%$, y el grupo III consiste en restos no digeridos de algunas especies de Falconiformes, donde los elementos proximales alcanzan o sobrepasan el $80 \%$. En coincidencia, se observa que los valores de la muestra de B. magellanicus presentada en este trabajo caen en el grupo II. Sin embargo, la muestra de T. alba analizada en este trabajo cae en el grupo I, en conjunto con la muestra arqueofaunística.

La comparación del MNI calculado para cada elemento del esqueleto muestra la relativa importancia de cada hueso en el análisis de las muestras estudiadas (Bonchenski et al., 1993). Bonchenski et al. (1993), Bochenski y Tomek (1994) y Bochenski (1997) registraron que los restos óseos de egagrópilas de Strigiformes presentaban valores elevados de $\mathrm{MNI} \%$ en carpometarcarpo, fémur, tibiotarso y tarsometatarso. Estos resultados son acordes a los evidenciados en la muestras arqueofaunística y de T. alba (Figura 7.59).

En lo que concierne al MNE, Bochenski et al. (2009) sugieren que los valores de este tipo de cálculo pueden ser comparables con los de MNI. De esta manera, en las tres muestras estudiadas se observaron una similitud entre ambos tipos de cálculos (Figura 7.60). Mourer-Chauviré (1983) y Baales (1992) plantearon que los conjuntos óseos de aves de pequeño tamaño acumulados por humanos, difieren de aquellos depositados por aves rapaces. De este modo, registraron que en los conjuntos generados por humanos los elementos frecuentes en términos del $\mathrm{MNE} \%$ son el húmero y el fémur, mientras que en los originados por aves rapaces son el tarsometatarso y carpometacarpo. Por su parte Bochenski (2005) indicó que los tres elementos con los valores más altos de MNE\% en acumulaciones derivadas de aves rapaces son coracoides, húmero y tarsometatarso. Sin embargo, en este trabajo el tibiotarso, el cúbito, el carpometacarpo y el fémur fueron los elementos con valores más altos en las muestras arqueofaunística y de T. alba. Bochenski (2005) al estudiar materiales procedentes de tres muestras de $B$. bubo observó que existe variabilidad entre las mismas, pero destaca como factor común el predominio de tarsometatarsos en valores de $\mathrm{MNE} \%$. No obstante, en la muestra de B. magellanicus analizada en este trabajo el elemento con el registro más alto de MNE\% fue el húmero.

La escasa cantidad de huesos con evidencia de meteorización y el considerable número de huesos fracturados sin marcas de corrosión digestiva, sugiere que los restos posiblemente hayan tenido un enterramiento rápido, luego de haber sido afectados por el pisoteo. En este alero, la alta humedad del suelo produjo una importante alteración en los huesos, afectando toda su superficie, contrariamente a lo que ocurre con la corrosión por 
digestión, donde los efectos de la misma son localizados (Andrews, 1990; FernándezJalvo y Andrews, 1992; Bochenski y Tomek, 1997; Worthy, 2001).

Otro punto importante a tener en cuenta cuando indagamos acerca del origen de la acumulación de microvertebrados es estudiar la composición taxonómica del conjunto fósil, para observar si existen similitudes con los conjuntos de depredadores previamente conocidos (Worthy, 2001; Lorenc, 2006). El conjunto de aves representado en el sitio arqueológico LS-3, mostró predominancia de Passeriformes, y entre ellos, destacamos la presencia de ciertas especies que habitualmente son consumidas por $T$. alba, como $Z$. capensis, P. fruticeti y U. dumetaria (Noriega et al., 1990, 1993) y especies de los géneros Cinclodes y Asthenes que fueron halladas en las egagrópilas de T. alba analizadas en este trabajo (Tabla 7.90). Esta observación junto con la presencia de restos óseos de T. alba hallados en el sitio arqueológico, robustece nuestra hipótesis sobre el origen del agregado arqueofaunístico (los restos óseos de T. alba no formaron parte del análisis tafonómico).

\subsection{Reptiles}

Acorde a los resultados arribados del análisis de los ensambles de micromamíferos y aves chicas del sitio, no se observaron evidencias de actividad antrópica (e.g., huellas de corte) en ninguna parte de la secuencia.

Los valores bajos de digestión registrados a lo largo de toda la secuencia, son coherentes con datos emanados por otros trabajos sobre restos de microvertebrados acumulados por T. alba, los cuales muestran corrosión digestiva ligera, tanto en peces (Broughton et al., 2006), como en anfibios (Pinto Llona y Andrews, 1999), reptiles (Castillo et al., 2001), aves (Fernández et al., 2009c) y micromamíferos (Andrews, 1990; Gómez, 2007; Fernández et al., 2009a). Asimismo, estos resultados coinciden con los obtenidos en el análisis de micromamíferos y aves chicas de este sitio.

Teniendo en cuenta los valores de abundancia relativa, se pudo observar que a lo largo de la secuencia las mandíbulas, húmeros y fémures fueron los elementos mas abundantes y las vértebras, cubitos, radios y peronés los menos frecuentes. Estos patrones son similares a los registrados en los ensambles de micromamíferos del sitio (Figura 7.62). Del mismo modo, estos resultados son coherentes con los datos presentados por Castillo et al. (2001), en un análisis de restos fósiles de reptiles depositados por T. alba, provenientes de un sitio paleontológico (i.e., La Cueva del Llano) de las Islas Canarias (España). 
En todos los niveles se registró un fuerte predominio de elementos proximales. En este sentido, la pérdida de elementos distales es mucho más alta en reptiles que en los ensambles de micromamíferos recuperados del sitio. Coincidentemente, Castillo et al. (2001) observaron esta misma situación en muestras de microvertebrados fósiles del sitio expresado anteriormente. Estos autores, postulan que estas variaciones pueden deberse a diferencias en las estructuras óseas de ambos grupos de vertebrados.

Como se ilustra en la figura 7.63 los reptiles correspondieron a una pequeña fracción del total de los microvertebrados recuperados del sitio LS-3. Por este motivo, resulta interesante destacar que $T$. alba es una rapaz crepuscular y nocturna que se alimenta principalmente de micromamíferos y ocasionalmente de otros microvertebrados e insectos. En consecuencia, los reptiles sólo ocupan una parte complementaria en la dieta de esta lechuza (véase Bellocq, 2000 y literatura allí citada). Algo similar ocurre con otras estrigiformes (Athene cunicularia y B. magellanicus), en casos registrados en la Patagonia (ver Nabte et al., 2006, 2009 y referencias allí citadas).

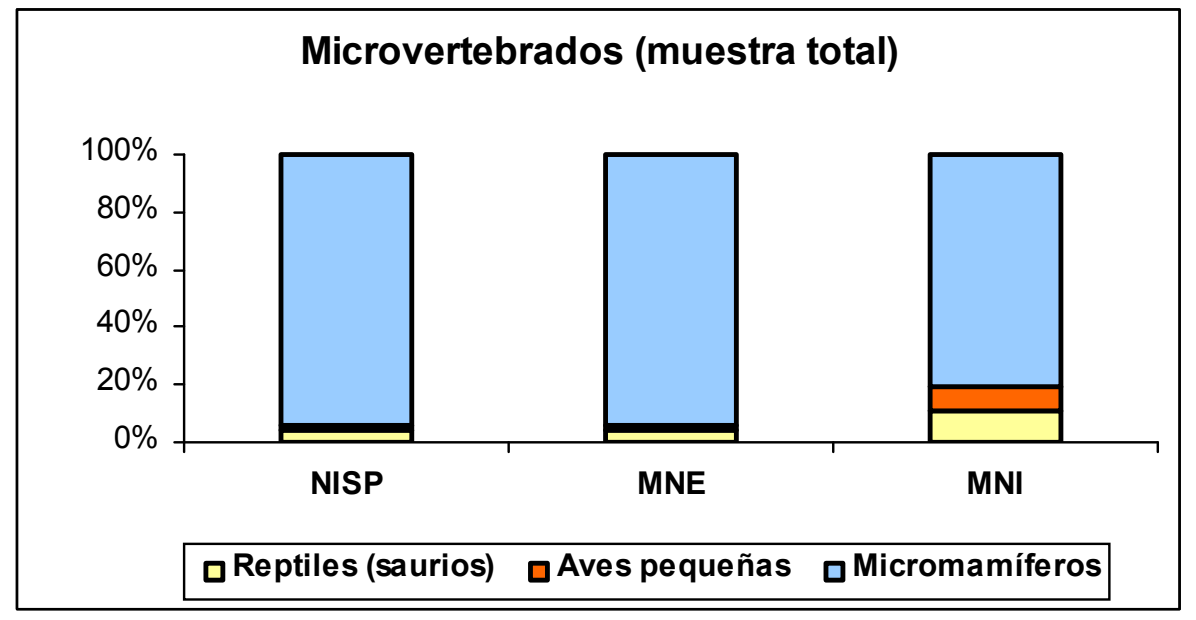

Figura 7.63. Porcentajes de las distintas clases de microvertebrados recuperados del sitio LS-3 (expresadas en NISP, MNE y MNI).

Con respecto a los procesos postdepositacionales, cabe destacar que de manera similar a lo ocurrido en los ensambles de micromamíferos y aves chicas del sitio, los elementos postcraneales rotos, presentaron superficies de fractura con ángulos agudos y bordes ásperos, sin marcas de digestión. De este modo, posiblemente este patrón esté más asociado a procesos postdepositacionales como el pisoteo que a los agentes acumuladores (e.g., Andrews, 1990). 
Por otra parte, la ausencia de huesos con evidencia de meteorización a lo largo de toda la secuencia, indica posiblemente que los restos han tenido un enterramiento rápido, como fue explicado en los ensambles de micromamíferos.

Para terminar, explicamos que en coincidencia con los resultados procedentes del análisis de los ensambles de micromamíferos del sitio, la ausencia de redondeamientos en los extremos y protuberancias de los huesos en toda la secuencia, indica que no actuaron los efectos de la abrasión por transporte hídrico, desplazamientos y rozamientos de los restos contra el sedimento (Korth, 1979; Pinto Llona y Andrews, 1999; Fernández-Jalvo y Andrews, 2003).

\subsubsection{Interpretación paleoambiental}

Hay una correlación positiva alta y no significativa entre la riqueza taxonómica y el tamaño de las muestras $\left(r_{s}=0,73 ; p>0,26\right)$, limitando el alcance de las conclusiones. Debido al carácter generalista de la dieta de estrigiformes, varios autores las han citado como buenas estimadoras de las comunidades de micromamíferos de un área determinada (e.g., Andrews, 1990). Sin embargo, hay que considerar los sesgos producidos por sus hábitos y preferencias en la caza, entre los que se destacan una subrepresentación de micromamíferos estrictamente diurnos y aquellos de tamaño grande ( $>150 \mathrm{~g})$ y una mayor proporción de especies que ocupan ambientes abiertos con elevada exposición (Andrews, 1990; Pardiñas, 1999b; Pardiñas et al., 2003, entre otros).

En la figura 7.64 se detallan las frecuencias relativas de los taxones de micromamíferos en las muestras estudiadas.

Los ensambles de micromamíferos de todas las unidades arqueológicas están dominados por P. xanthopygus, E. chinchilloides y Eligmodontia sp. Estas observaciones son acordes a las evidenciadas en el ensamble de micromamíferos de la muestra actual, el cuál también está integrado por estos taxones, aunque con una caída moderada en la frecuencia de E. chinchilloides. En conjunto, estos roedores sugieren ambientes xéricos, afines a estepas arbustivas abiertas con alta proporción de suelo desnudo, pedregoso y abundante roca expuesta.

A lo largo de la secuencia no se observaron elementos principalmente asociados al desierto del Monte como T. pallidior, Akodon molinae o Graomys griseoflavus. Sin embargo, en la muestra actual de micromamíferos el registro de T. pallidior podría 
indicar que el ambiente presenta cierta influencia del Monte. En tal sentido, García Esponda et al. (2009), hallaron restos de A. molinae en esta localidad.

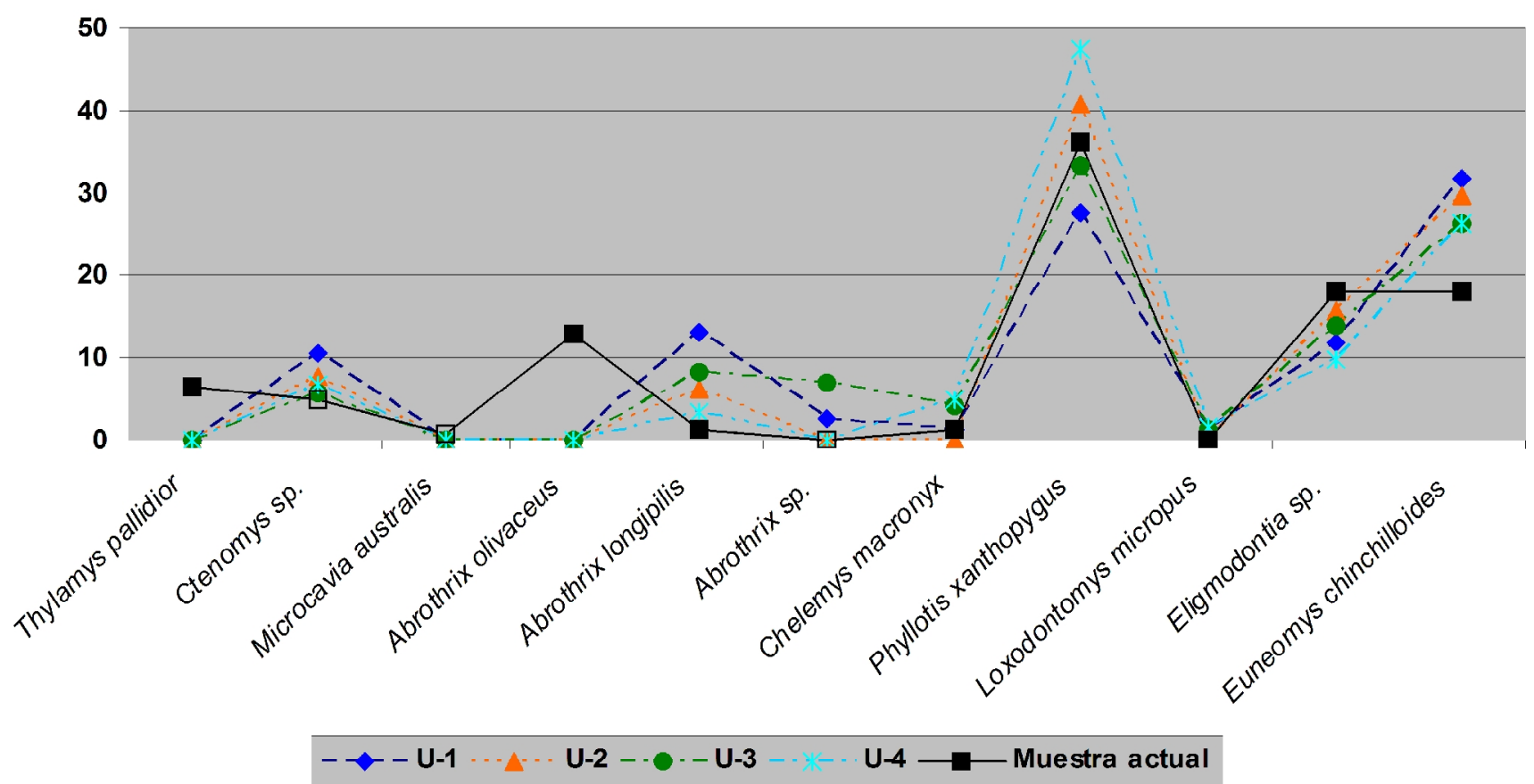

Figura 7.64. Comparación de las frecuencias relativas de los taxones de micromamíferos recuperados de las unidades de LS-3 y su parámetro actualístico.

En las unidades 1, 3 y 4, los registros de especies asociadas a bosques de Nothofagus, áreas ecotonales, estepas patagónicas y vegas cordilleranas (i.e., L. micropus, $C$. macronyx y A. longipilis), sugieren condiciones de mayor humedad en esos intervalos. Por el contrario, la desaparición de C. macronyx y L. micropus en la U-2, podría estar sujeto a una disminución en la disponibilidad hídrica hacia $c a .0,6 \mathrm{ka}{ }^{14} \mathrm{C} \mathrm{AP}$. Asimismo, en el ensamble actual, las frecuencias elevadas de A. olivaceus y Eligmodontia sp. podrían relacionarse con la disminución de A. longipilis y la ausencia de L. micropus, indicando una expansión de la estepa arbustiva o sub-arbustiva bajo condiciones locales posiblemente algo menos húmedas que en la U-1.

Es interesante destacar que A. olivaceus solo se registró en el ensamble actual. Este abrotriquino está vinculado a una amplia variedad de hábitats, incluyendo matorrales semi-áridos, bosques de Nothofagus spp., pastizales, estepa patagónica y vegas cordilleranas. Además, esta especie es abundante en áreas disturbadas por el sobrepastoreo y en Mendoza ha sido registrada en áreas rocosas con arbustos dispersos en altos Andes (Cueto et al., 2008; Fernández et al., 2009d). 
En la figura 7.65 se ilustra los resultados del PCA. El primer componente principal $(55,113 \%$ de la varianza) muestra un claro contraste entre las muestras arqueofaunísticas y la muestra actual. Esta tendencia posiblemente este relacionada a los cambios en la estructura taxonómica del ensamble actual debido al deterioro ambiental (ver arriba). El segundo componente $(23,087 \%$ de la varianza) exhibe similitudes entre las unidades 3 y 4, mostrando pocos cambios en la composición de los ensamble de micromamíferos en los inicios de la secuencia de LS-3.

En lo que concierne a los roedores histricognatos, Ctenomys sp. presentó proporciones bajas y similares en todo la secuencia arqueológica y en el ensamble actual. Las especies de este género en el sur de Mendoza estarían constituidas por $C$. mendocinus y $C$. pontifex, presentan hábitos fosoriales y son comunes en hábitats abiertos, requiriendo suelos arenosos para poder realizar sus galerías (ver Capítulo 5). Por otra parte, la ausencia de roedores cávidos (e.g., M. australis) podría deberse a sesgos producidos por aves estrigiformes, las cuales presentan depredación crepuscular y nocturna (ver Capítulo $6)$.

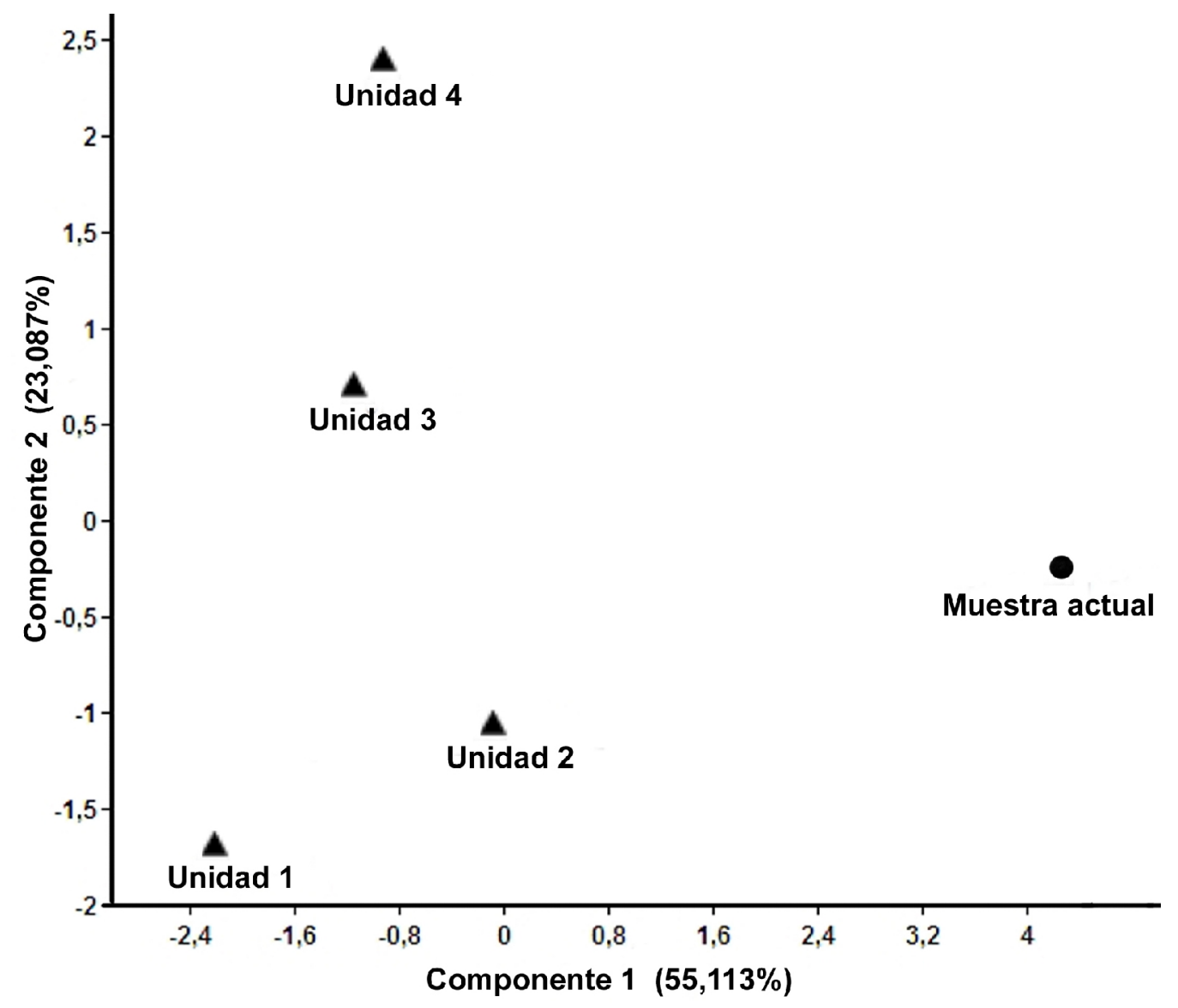

Figura 7.65. Gráfico de las muestras arqueológicas y actuales de micromamíferos de LS-3 sobre el plano definido por los ejes 1 y 2 de un análisis de componente principal. 
De las especies de aves recuperadas, Z. capensis, U. dumetaria, A. badius, A. thilius, Asthenes sp. y los representantes de las familias Scolopacidae, Thinocoridae poseen una amplia distribución. Phrygilus cf. P. fruticeti está restringida a áreas ecotonales entre los Dominios Andino Patagónico y Chaqueño, Provincia del Monte. Además, se observan elementos del Dominio Andino-Patagónico, como Cinclodes cf. C. patagonicus y $M$. melanoptera. De los taxones mencionados, Z. capensis, A. badius y Asthenes sp. ocupan diversos tipos de ambientes (i.e., desierto del Monte, Espinal, estepas). A. thilius también presenta una amplia distribución, aunque siempre asociada con ámbitos lagunares, mientras que Cinclodes cf. C. patagonicus es un ave básicamente Andino Patagónica y está vinculada ampliamente con ambientes acuáticos. $U$. dumetaria y Phrygilus cf. $P$. fruticeti se encuentran presentes en estepas Altoandinas, Patagónicas y del desierto del Monte; M. melanoptera y las especies de Thinocoridae, se distribuyen en estepas y vegas Altoandinas, mientras que los Scolopacidae se asocian con ambientes acuáticos. Finalmente, se destaca que todos los taxones mencionados se distribuyen actualmente en el área (ver Capítulo 5).

Debido al carácter fragmentario de los elementos diagnósticos (cráneos) de los restos de los saurios exhumados del sitio LS-3, se hizo difícil algunas determinaciones taxonómicas a nivel genérico o específico. Asimismo, a excepción de P. scapulatus los taxones presentan características eurioicas. De este modo, el análisis paleoambiental se vio limitado, aun así, las exiguas inferencias paleoambientales arribadas pueden ser complementarias de aquellas alcanzadas por el registro de micromamíferos del sitio.

En la figura 7.66 se detallan las frecuencias relativas de los reptiles (saurios) en las unidades estudiadas.

Todas las unidades están integradas por una elevada frecuencia de saurios indeterminados y Liolaemus sp. No obstante, la U-1 es la que muestra mayor riqueza taxonómica, constituida además por Homonota cf. H. darwini y una alta proporción de Pristidactylus cf. P. scapulatus. Esta última especie también formó parte de la U-2, pero en baja representación.

Liolaemus sp. es un género que en Mendoza tiene especies representadas en una amplia variedad de ambientes. Asimismo, P. scapulatus es una especie de hábitos diurnos, frecuente en roquedales del piedemonte cordillerano y estepas arbustivas de altos Andes, siendo endémica de la provincia de Mendoza y $H$. darwini es un gekkónido de hábitos nocturnos, habita en multiplicidad de ambientes de la Patagonia (ver Capítulo 5) 


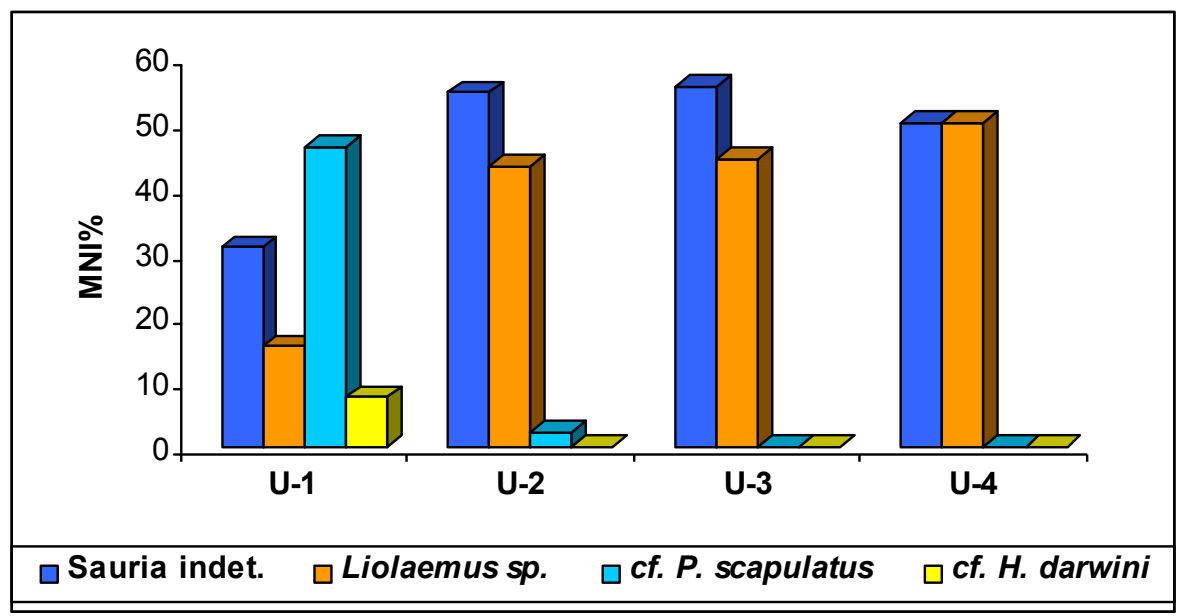

Figura 7.66. Frecuencias relativas de los reptiles (saurios) comparando las unidades arqueológicas.

\subsubsection{Conclusión}

Los resultados alcanzados en este estudio nos permiten erigir que los grupos humanos no habían intervenido en la génesis de los ensambles de micromamíferos del sitio LS-3. No obstante, se postula que los conjuntos recuperados a lo largo de la secuencia habrían tenido su origen por la actividad depredadora de aves estrigiformes, siendo T. alba la principal especie involucrada. Sin embargo, en las unidades 2 y 3 existen indicios de que otras lechuzas y búhos de mayor categoría de modificación (A. cunicularia y $B$. magellanicus), posiblemente también estuvieron implicadas en la formación de los ensambles de micromamíferos de esas unidades.

Es importante resaltar que la baja representación de Passeriformes en los contextos arqueofaunísticos puede estar dada, no sólo por el bajo porcentaje que estos representan en la dieta de los humanos y de las rapaces nocturnas, sino también, por su estructura ósea, que dificultaría su preservación. Es decir, la representación de los Passeriformes y otras pequeñas aves en los sitios arqueológicos podría estar bastante sesgada con respecto a los demás microvertebrados.

Los agentes y procesos postdepositacionales que tuvieron mayor incidencia en la formación de los ensambles arqueofaunísticos fueron el pisoteo, la acción corrosiva de las raíces y los efectos corrosivos de la humedad del suelo, que habrían contribuido a alterar la composición original del conjunto cuando fue depositado, destruyendo con mayor rapidez los elementos óseos. La escasa representación de restos meteorizados a lo largo de toda la secuencia, indica que tuvieron un enterramiento rápido, luego de haber 
sido alterados por el pisoteo, siendo estos tipos de eventos habituales en las cuevas o refugios rocosos. Por su parte, tanto las marcas de raíces como la corrosión sedimentaria se incrementaron a medida que aumentó la profundidad del sitio, (principalmente unidades 3 y 4). El primero de ellos, siempre correspondió a la categoría "Sphenoichnia", indicando el desarrollo de una cubierta herbácea durante la formación del suelo cuando los huesos fueron depositados y enterrados. El segundo, posiblemente ocurrió por la elevada humedad del suelo registrada en el sitio. Asimismo, el hallazgo de restos afectados por óxido de manganeso en la parte más profunda del sitio (U-4), es coherente con las posibles oscilaciones del nivel freático o encharcamientos de agua que pudieron afectar al mismo.

Otros agentes y procesos postdepositacionales como la abrasión por transporte hídrico, desplazamientos y rozamientos de los restos contra el sedimento no tuvieron incidencia en ninguna parte de la secuencia arqueológica.

A modo de síntesis la interpretación paleoambiental de la secuencia de microvertebrados de LS-3 puede delinearse de la siguiente manera:

a) Hacia el $2,1 \mathrm{ka}{ }^{14} \mathrm{C}$ AP condiciones climáticas-ambientales más templadas que en la actualidad con incrementos en los regímenes de humedad. El ambiente es a fin a estepas arbustivas abiertas con alta proporción de suelo desnudo, pedregoso y abundante roca expuesta, interrumpido por el desarrollo de vegas cordilleranas.

b) En torno al $1,8 \mathrm{ka}{ }^{14} \mathrm{C} \mathrm{AP}$ persisten las condiciones climáticas-ambientales comprendidas en el período anterior.

c) Hacia $0,6 \mathrm{ka}{ }^{14} \mathrm{C}$ AP existe un aumento de la aridez. El ambiente es xérico, con desarrollo de estepas arbustivas abiertas con alta proporción de suelo desnudo, pedregoso y abundante roca expuesta.

d) En tiempos previos a la actualidad retornan las condiciones climáticoambientales más templadas. Ambiente asociado a estepas arbustivas abiertas con alta proporción de suelo desnudo, pedregoso y abundante roca expuesta, interrumpido por el desarrollo de vegas cordilleranas.

e) En la actualidad el ambiente es xérico, asociado a estepas arbustivas abiertas con alta proporción de suelo desnudo, pedregoso y abundante roca expuesta, interrumpido por el desarrollo de vegas cordilleranas. Asimismo, exhibe cierta influencia del desierto de Monte y presenta un deterioro ambiental marcado por arbustización creciente, atribuible al atribuible al impacto antrópico posiblemente producido por el ganado doméstico. 



\section{Capítulo 8}

\section{DISCUSIÓN GENERAL}

"For the maintenance of " dynamic equilibrium" it is necessary that the rates of processes be exactly harmonized... “"

Ludwig Von Bertalanffly

[General system Theory. 1968: 126] 



\section{DISCUSIÓN GENERAL}

A pesar que en cada uno de los sitios arqueológicos estudiados tuvo lugar una discusión detallada tanto de los aspectos tafonómicos como paleoambientales, en este capitulo se intentará establecer una discusión general que integre la información emanada de todos los sitios arqueológicos. En este sentido, esta información integrada será el punto de partida para retomar los principales objetivos e hipótesis erigidas a comienzos de esta tesis y finalmente se discutirán los modelos de ocupaciones humanas planteados en el sur de la provincia de Mendoza en investigaciones previas.

\subsection{Tafonomía de microvertebrados}

\subsubsection{Agentes depositacionales}

La primera hipótesis de esta tesis doctoral intentaba dar cuenta de patrones en la formación de los depósitos de microvertebrados acumulados en diferentes sitios arqueológicos del sur de Mendoza. De esta forma se planteó:

H-1 Los agentes causantes de la incorporación de los agregados de microvertebrados en sitios arqueológicos están estrechamente relacionados con las características morfológicas del sitio (

Fundamentación: los trabajos llevados adelante por diferentes investigadores han mostrado que los distintos tipos de depredadores que actúan sobre microvertebrados ocupan diferentes ambientes tanto para cazar como para consumir sus presas (Andrews, 1990; Fernández-Jalvo y Andrews, 1992; Stahl, 1996; Pardiñas, 1999a, 1999b). En este sentido, se espera que los conjuntos de microvertebrados del sur de Mendoza respondan a las características etológicas de los depredadores intervinientes, más que a la etología de las especies de microvertebrados que habitan esos lugares, o a la acción de procesos de destrucción diferencial, etc. 
En la tabla 8.1 se detallan los principales agentes responsables de las acumulaciones de microvertebrados, por cada unidad de análisis de los sitios arqueológicos estudiados en esta tesis, agrupados según su tipología (i.e., a cielo abierto; cueva, alero o refugio rocoso).

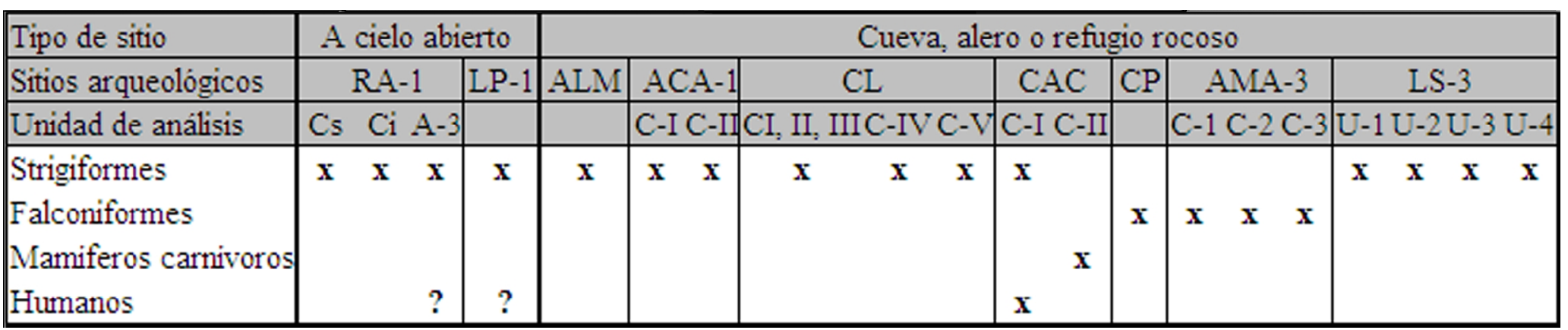

Tabla 8.1. Agentes responsables de las acumulaciones de microvertebrados de los sitios arqueológicos estudiados en esta tesis.

Referencias: RA-1: Rincón del Atuel 1 (Cs: Cuadrículas A-1 y A-2 Conjunto superior; Ci: Cuadrículas A-1 y A-2 Conjunto inferior; A-3: Cuadrícula A-3); LP-1: La Peligrosa 1; ALM: Agua de La Mula; ACA-1: Agua de Los Caballos 1 (C-I: Componente I; C-II: Componente II); CL: Cueva de Luna (CI, II, III: Componentes I, II y III; C-IV: Componente IV; C-V: Componente V); CAC: Cueva Arroyo Colorado (C-I: Componente I; C-II: Componente II); CP: Cueva Palulo; AMA-3: Arroyo Malo 3 (C-1: Conjunto 1; C-2: Conjunto 2; C-3: Conjunto 3); LS-3: Laguna El Sosneado 3 (U-1: Unidad 1; U-2: Unidad 2; U-3: Unidad 3; U-4: Unidad 4).

El registro de marcas de corrosión digestiva ligera a moderada y bajos niveles de pérdida de elementos (sensu Andrews, 1990), indicaron una marcada actividad de aves Strigiformes en la génesis de los ensambles de microvertebrados de numerosos sitios arqueológicos cordilleranos y de la planicie oriental (Cueva Arroyo Colorado, LS-3, Cueva de Luna, Agua de La Mula, ACA-1, RA-I y LP-I). Congruentemente, en esta categoría de agente acumulador se incluye un sitio arqueológico ubicado en el piedemonte del sur de Mendoza

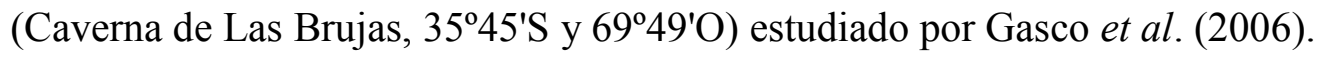

La observación de marcas de corrosión digestiva moderada a fuerte y elevada pérdida de elementos y fragmentación, sugirieron actividad de aves Falconiformes en los ensambles de los sitios cordilleranos AMA-3 y Cueva Palulo. Por otra parte, se hallaron evidencias de actividad de mamíferos carnívoros (e.g., corrosión digestiva fuerte a extrema y alta pérdida de elementos y fragmentación) en Cueva Arroyo Colorado. En este sitio, también se encontraron marcas de corte en una tibia de Caviidae, en un lapso de la secuencia (1.380770 años $\left.{ }^{14} \mathrm{C} \mathrm{AP}\right)$, lo que está sujeto a prácticas de explotación de microvertebrados por parte de grupos humanos (ver sección 8.1.3). Asimismo, en los sitios RA-1 y LP-1 en base 
al registro de restos termoalterados, abundancia de restos de taxa del grupo de tamaño grande y por el hecho que corresponden a sitios a cielo abierto, se plantea la posibilidad de que parte de los ensambles tenga un origen antrópico (ver sección 8.1.3).

Las egagrópilas y huesos con restos de pelos exhumados de Agua de la Mula y AMA-3 constituyen los primeros registros en la provincia de Mendoza. El hallazgo de egagrópilas fósiles constituye un indicador directo de que las aves rapaces intervinieron en la formación del ensamble de micromamíferos (e.g., Andrews, 1990; Pardiñas, 1999a, 1999b). Asimismo, la conservación de las egagrópilas en los sitios arqueológicos o paleontológicos se relaciona con sus características intrínsecas, principalmente con la humedad, temperatura y velocidad de enterramiento (Pardiñas, 1999a, 1999b). Por este motivo, se han recuperados egagrópilas fósiles y/o huesos con restos de pelo en otros sitios arqueológicos de ambientes áridos de la Patagonia, como Cueva Grande del Arroyo Feo, Cueva del Milodón, Cerro Casa de Piedra 5, Cueva Epullán Grande, Cueva Epullán Chica, Alero de los Sauces, Casa de Piedra Ortega, Cueva Huenul 1 y Orejas de Burro 1 (Silveira, 1979; Aschero, 19811982; Bond et al., 1981; Crivelli Montero et al., 1996; Pardiñas, 1996-1998, 1999a, 1999b; L’Heureux, 2008; Fernández et al., 2011b, en prensa; Pardiñas y Teta, en prensa).

En líneas generales, se observó a las aves rapaces como los principales actores involucrados en la génesis de los conjuntos. Entre este tipo de depredadores, las aves estrigiformes fueron las más representativas, donde Tyto alba tuvo un lugar central. Esta ave ha sido ampliamente reconocida como el mayor acumulador de restos de pequeños vertebrados hallados en cuevas y refugios rocosos (Andrews, 1990; Saavedra y Simonetti, 1998; Pardiñas, 1999a, 1999b).

Asimismo, no se registró una asociación clara entre el tipo de agente acumulador y los tipos de sitios. Sin embargo, se observó que los sitios de tipo cueva presentaron mayor variabilidad de agentes acumuladores que los sitios a cielo abierto. Posiblemente esto se deba, a que las cuevas y aleros ofrecen protección y refugio, son susceptibles a ser reutilizados por los humanos y los depredadores en mayor medida que los sitios a cielo abierto (e.g., Mondini, 1995, 2000, 2001; Kligmann et al., 1999). Un ejemplo de esto, se presenta en el sitio Cueva Arroyo Colorado, resultado de la alternancia en la ocupación por parte de los humanos y dos tipos de depredadores. 
Estas diferencias observadas en la formación de los conjuntos de microvertebrados entre los sitios tipo cueva y a cielo abierto del sur de Mendoza, pueden relacionarse con los estudios de Denys (1997) en sitios del este y sur de África. Este autor, registró que los sitios tipo cuevas exhibieron mayor diversidad de hábitats y de depredadores que los sitios a cielo abierto. Ergo, el autor citado señala que la paleodiversidad de los micromamíferos podría sesgarse por los hábitos de caza, dietarios y niveles de digestión de distintos depredadores que actúan en la formación de los conjuntos. Finalmente, indica que los procesos tafonómicos además de modificar la estructura original de los ensambles, puede alterar los patrones de diversidad por mezcla de los diferentes depredadores y/o niveles portadores de micromamíferos y por el tiempo promediado.

Por otra parte, Terry (2007) mediante el análisis de un número importante de muestras de aves rapaces comprobó estadísticamente que los patrones de fracturas son uno de los atributos más significativos para diferenciar agregados de micromamíferos generados por aves falconiformes, estrigiformes y mamíferos carnívoros. Sin embargo, en el análisis de las muestras arqueofaunísticas del sur de Mendoza, principalmente en los sitios de tipo cueva, alero o refugio rocoso, se registraron que los patrones de fractura y de abundancia relativa de partes esqueletales pueden ser alterados posteriormente a la depositación, por procesos como el pisoteo (ver sección 8.1.2). En coincidencia, Terry (2004) en un estudio actualístico de tres tipos de conjuntos de egagrópilas (i.e., enteras, parcialmente disgregadas y totalmente disgregadas) de Bubo virginianus, señaló que los patrones de fractura y de abundancia relativa de partes esqueletales cambian cuando las egagrópilas están disgregadas. De este modo, la observación de las distintas categorías de marcas de corrosión digestiva, posiblemente sea el atributo más confiable para estudiar los orígenes de las acumulaciones en los sitios arqueológicos afectados por procesos postdepositacionales.

A partir de esta discusión general sobre los principales actores tafonómicos intervinientes, resulta necesario tener en cuenta los sesgos que producen cada tipo de depredador con sus respectivas ecologías tróficas, generando ensambles de microvertebrados con estructuras taxonómicas particulares, de donde se emanan las interpretaciones paleoambientales. En este sentido, cuando más oportunista es el depredador (e.g., T. alba, ver Capítulo 6) menor serán los sesgos tafonómicos, contrariamente a lo que ocurre con los depredadores selectivos (Andrews, 1990, 1995; Denys, 1997). Asimismo, se destaca que algunos sitios 
arqueológicos estudiados presentaron sesgos metodológicos debido a que fueron excavados en otras épocas, donde las preguntas sobre los micromamíferos se orientaban únicamente a registrar que taxones se encontraban en los sitios arqueológicos y por ende, sólo se recuperaban restos craneanos y mandibulares, los cuales son los más indicados para la mencionada tarea (ver Capitulo 5 para más detalle). En relación a lo expuesto, Pardiñas (1999a, 1999b) y Pardiñas y Teta (en prensa) plantean que los roedores histricognatos presentan cráneos y mandíbulas más robustas que los roedores sigmodontinos y por ende, son más resistentes a procesos postdepositacionales como el pisoteo. Esto podría explicar la abundancia de roedores histricognatos en sitios como Agua de La Mula y Cueva de Luna, donde desde la tafonomía se registró la acción de aves rapaces y no de humanos, como se hubiese esperado dadas las expectativas del modelo de explotación humana en micromamíferos (ver sección 8.1.3). Adicionalmente, estudios realizados en Patagonia demostraron que las poblaciones de Ctenomys era muchos más abundantes en el registro fósil del Pleistoceno / Holoceno, incluso hasta comienzos del siglo XX, respecto a la actualidad, las cuales se encuentran en franco retroceso desde la introducción del ganado ovino (ver sección 8.2.2), el cual produce una compactación del suelo por pisoteo y la eventual destrucción de las galerías subterráneas de este roedor fosorial (Pardiñas, 1999a; Udrizar Sauthier, 2009; Pardiñas y Teta, en prensa). Esta situación pudo ocurrir en Mendoza con el ganado ovino y caprino (ver sección 8.2.2) y de este modo, podría explicar complementariamente los altos valores de este roedor en los sitios arqueológicos mencionados respecto a los ensambles actuales de aves rapaces, donde en general no superan el $10 \%$ de su dieta.

De lo expuesto se desprende que los datos apoyan el enunciado de la hipótesis 1 dado que los sitios con una tipologia de cueva, alero o refugio rocoso mostraron mayor variabilidad en los agentes acumuladores implicados. Sin embargo, se necesita estudiar más sitios a cielo abierto para establecer una comparación más ecuánime entre ambos tipos de sitios.

\subsubsection{Agentes postdepositacionales}

La segunda hipótesis de esta tesis apuntó a entender como las características de los sitios arqueológicos afectaban la conservación de los conjuntos de microvertebrados recuperados. 
De esta forma, se enunció la siguiente hipótesis:

H-2 Dadas las diferencias en el tipo de procesos postdepositacionales intervinientes, se espera una preservación diferencial de los conjuntos de microvertebrados de acuerdo a si estos se encuentran en sitios a cielo abierto; o en reparos (e.g., aleros, cuevas).

Fundamentación: en los sitios arqueológicos, cuya morfología corresponde a la de una cueva o alero, los conjuntos de microvertebrados son mayormente afectados por procesos postdepositacionales como la corrosión por la humedad, transporte y aumento de los niveles de pisoteo debido a que son ambientes de circulación restringida (Korth, 1979; FernándezJalvo 1988; Andrews, 1990; Pardiñas, 1999b). Por su parte, los conjuntos de microvertebrados en sitios arqueológicos a cielo abierto se encuentran más afectados por procesos postdepositacionales como la meteorización y transporte (Korth, 1979; FernándezJalvo, 1988; Andrews, 1990).

En la tabla 8.2 se detallan los principales procesos postdepositacionales que afectaron a los ensambles de microvertebrados provenientes de las unidades de análisis de los sitios arqueológicos estudiados en esta tesis, agrupados según su tipología (i.e., a cielo abierto; cueva, alero o refugio rocoso).

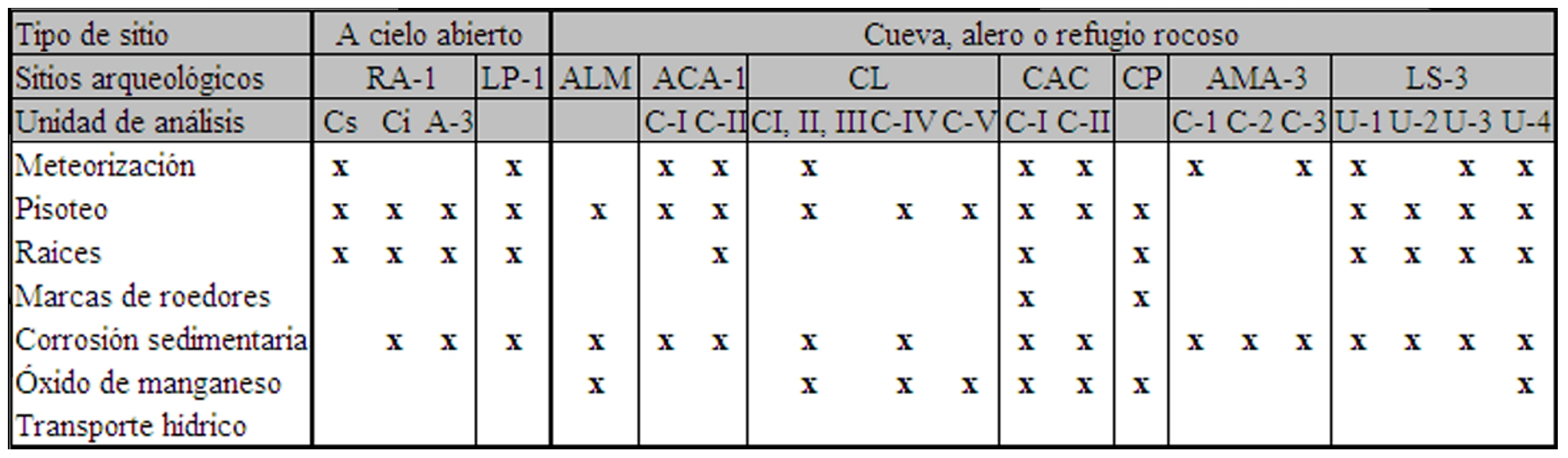

Tabla 8.2. Agentes postdepositacionales estudiados en los sitios arqueológicos de esta tesis.

Referencias: véase tabla 8.1. 
Teniendo en cuenta que la cantidad de sitios estudiados en cada categoría de sitio se encuentra un tanto desbalanceada, es muy difícil encontrar una tendencia clara. En líneas generales, no se registró una asociación clara entre los procesos postdepositacionales y los tipos de sitios, mas allá de algunos casos puntuales que se discuten a continuación.

Todos los sitios arqueológicos a cielo abierto exhibieron evidencias de meteorización. Particularmente en dos unidades de RA-1 y en LP-1, destacando que en este último sitio los restos meteorizados alcanzaron el 50\%. Sin embargo, en dos sitios arqueológicos tipo cueva (i.e, Agua de La Mula y Cueva Palulo) no se registraron evidencias de esta clase de proceso. Asimismo, se encontraron restos meteorizados en Cueva de Luna, Cueva Arroyo Colorado, AMA-3 y LS-3, aunque en porcentajes muy bajos (ver Capitulo 7). Si bien como se mencionó anteriormente resulta difícil establecer comparaciones entre estas categorías de sitios, se pudo corroborar parcialmente la hipótesis debido a que los restos provenientes de los sitios tipo cueva estuvieron protegidos de los agentes meteóricos (i.e., sol, lluvia, viento y cambios de temperatura) en la mayoría de los casos (véase Andrews, 1990; Pardiñas, 1999b, Mondini, 2001 entre otros).

A continuación, se registraron procesos de pisoteo en numerosos sitios arqueológicos, tanto en tipo cueva (Agua de La Mula, ACA-1, Cueva Arroyo Colorado, Cueva Palulo y LS-3) como a cielo abierto (RA-1 y LP-1), lo que no corrobora la hipótesis. Sin embargo, hay que aclarar que este tipo de proceso fue inferido indirectamente mediante el contexto del ensamble (ver Capitulo 7) y por ende no pudo ser cuantificado intrínsicamente en cada sitio.Por otra parte, a pesar que se registraron restos con marcas de corrosión sedimentaria por humedad en los sitios arqueológicos RA-1, LP-1, Agua de La Mula, ACA-1, Cueva de Luna, Cueva Arroyo Colorado, AMA-3 y LS-3 y restos con impregnaciones por óxidos de manganeso en los sitios Agua de La Mula, Cueva de Luna, Cueva Arroyo Colorado, Cueva Palulo y LS-3, no se recuperaron restos con evidencias de transporte hídrico, desplazamientos y rozamientos de los restos contra el sedimento, en ninguno de los sitios arqueológicos analizados. Esto indica, que los sitios mencionados posiblemente presentaron encharcamientos de agua, con oscilaciones del nivel freático (Courty et al., 1989; Gómez et al., 1999; Gómez, 2000), pero sin flujos activos de corriente de agua que produzcan los rasgos típicos de abrasión en huesos de micromamíferos, tales como redondeamientos en los extremos de los huesos y hoyos en la cara externa de las mandíbulas (ver Capítulo 4 para 
más detalle) (Korth, 1979; Andrews, 1990; Fernández-Jalvo y Andrews, 2003). En relación a la hipótesis, solo se pudo sustentar parcialmente para el caso de los procesos de impregnación por oxido de manganeso, debido a su asociación única con sitios tipo cueva. Por el contrario, se registraron restos con corrosión sedimentaria tantos en sitios a cielo abierto como en cuevas.

Tampoco se observó que los sitios de tipo cueva presentasen mayor tendencia hacia el desarrollo de marcas de raíces en los restos óseos. De manera que, se recuperaron restos con esta clase de marcas tanto en sitios a cielo abierto (RA-1, LP-1) como en cuevas (Cueva de Luna, Cueva Arroyo Colorado, AMA-3 y LS-3).

Se hallaron escasos restos con marcas de roedores únicamente en los sitios Cueva Arroyo Colorado y Cueva Palulo. Esto indica, que existió poca actividad de roedores fosoriales dentro de los sitios, que pudieran desgastar sus incisivos con los huesos de otros roedores. Esto sustenta que los restos de microvertebrados ingresaron a los sitios arqueológicos por causas depredacionales y antrópicas (ver sección 8.1.1) y no por causas eto-ecológicas, como muerte natural in situ (véase Pardiñas, 1999b).

Finalmente, como se mencionó en la sección anterior, los procesos postdepositacionales modifican la estructura original de los ensambles, afectando a ciertos atributos más que a otros. En tal sentido, su detección es de suma relevancia para una buena interpretación de los agentes causales de la formación del registro microfaunístico.

\subsection{3. ¿Explotación humana y procesos de intensificación de los recursos?}

La tercera hipótesis apuntó a vincular los resultados de los estudios realizados sobre microvertebrados con planteos arqueológicos previos, vinculados a los cambios en la dieta humana de las poblaciones de cazadores recolectores del sur de Mendoza. De esta forma la hipótesis afirmaba:

H-3 Dadas las expectativas del modelo de intensificación propuesto para la región, alrededor de 2000 años AP, se espera que los sitios arqueológicos presenten evidencias de consumo de microvertebrados por parte de las poblaciones humanas. 
Fundamentación: según se ha podido observar en diferentes conjuntos arqueofaunísticos de la región, hay una disminución en el consumo de camélidos hacia los últimos 2.000 años $\mathrm{AP}$, en relación al resto de las especies de animales de la región. Esto ha sido entendido como un aumento en la amplitud de dieta de las poblaciones humanas, probablemente relacionado a un desbalance entre la población y los recursos (Neme, 2007; y literatura allí citada). Este aumento en la amplitud de dieta pudo haber llevado a los grupos de cazadores recolectores a incorporar presas de menor rendimiento económico como los microvertebrados.

Las marcas de cortes son un indicador tafonómico de indudable origen antrópico y a pesar que son frecuentes en huesos de vertebrados de mediano y gran tamaño (e.g., Salemme, 1987; Miotti, 1998; Mengoni Goñalons, 1999; Martínez y Gutiérrez, 2004; Prates, 2008), en los restos de micromamíferos podrían ser escasas o estar ausentes y no por ello descartar su relación con la explotación humana. En este sentido, el tamaño pequeño de sus esqueletos permite consumirlos sin necesidad de despostarlos o sin utilizar instrumentos de filo en caso de procesamiento (e.g., Stahl, 1986; Pardiñas, 1999a, 1999b; Acosta y Pafundi, 2005; Prates, 2008). Incluso, cuando las huellas de corte están presentes, su identificación no es tarea sencilla debido al elevado nivel de equifinalidad de sus rasgos cualitativos (ver Capítulo 4), pudiendo confundirse con otros procesos tafonómicos tales como el pisoteo (e.g., Stahl, 1982, 1986; Behrensmeyer et al., 1986; Olsen y Shipman, 1988; Quintana, 2005; Domínguez-Rodrigo et al., 2005, 2009; Lloveras et al., 2009).

Asimismo, el elevado rendimiento cárnico en relación al peso vivo y la abundancia de ciertos micromamíferos - como pueden ser Galea, Microcavia y Ctenomys- son atributos importantes a la hora de evaluar a los mismos como presas de potencial interés para los cazadores-recolectores (Stahl, 1982). Algunos autores han propuesto otras evidencias tafonómicas para detectar la acción antrópica sobre restos de micromamíferos, tales como marcas de roído producidos por dientes de humanos (Landt, 2007; Martínez, 2009) y huellas de corrosión digestivas acaecidas por los ácidos digestivos de los mismos (Crandall y Stahl, 1995; Deward y Jarardino, 2007; ver Capítulo 4 para más detalles).

En el centro de Chile, Simonetti y Cornejo (1991) observaron una asociación entre roedores gregarios y coloniales y el aprovechamiento antrópico. Ergo, señalan una correlación 
significativa entre estos tipos de roedores y el número de restos quemados, los cuales no alcanzan el 35\% del NISP total en ninguno de los sitios arqueológicos estudiados. Por otra parte, es interesante destacar que el trabajo experimental realizado por Medina et al. (2012), donde reconocieron patrones de termolateración en restos de Cavia porcellus (cobaya) y Galea leucoblephara. Estos autores, registraron el quemado y fractura de los segmentos distales de elementos con escasa musculatura, tales como el radio y la tibia, además de un quemado íntegro y desintegración en elementos del autopodio. Asimismo, observaron una fractura y quemado en los extremos dístales de los incisivos. Contrariamente, los elementos del esqueleto axial permanecieron intactos. Esto es congruente, con información etnográfica sobre la etnia Tehuelche en tiempos post-hispánicos en relación al consumo de roedores, donde se describe que los mismos eran cocidos sobre las brasas, sin procesamiento previo (véase Aguerre, 2000: 127). No obstante, estos patrones de termoalteración no fueron registrados en ninguno de los sitios arqueológicos estudiados en Mendoza, donde la única señal tafonómica fehaciente de explotación humana sobre restos de micromamíferos fueron las marcas de corte sobre una tibia de un Caviidae (posiblemente Microcavia australis), recuperadas del sitio Cueva Arroyo Colorado hacia ca. $1.4 \mathrm{ka}{ }^{14} \mathrm{C} \mathrm{AP}$ (ver Capítulo 7). Asimismo, la sitios analizados presentaron bajos porcentajes de restos termoalterados (Figura 8.1). De manera que, esto parece ser otra línea de evidencia acerca de la escasa participación de los grupos humanos en la génesis de los conjuntos de microvertebrados del sur de Mendoza. La única excepción la constituye LP-1, con el 20,8\% de restos quemados, coincidente con el valor a partir del cual podría interpretarse una acumulación de origen antrópico (véase Pardiñas, 1999b). Asimismo, LP-1 y RA-1 corresponden a sitios a cielo abierto y por ende, presentan un potencial menor de depositación natural de especímenes por causas naturales, dejando abierta la posibilidad de que parte de esos ensambles hayan sido incorporados por humanos. Sin embargo, cabe destacar que los restos pudieron haber sido termoalterados por actividades como preparación de fogones y limpieza del recinto habitacional, por parte de los grupos humanos (Bond et al., 1981).

En el sur de Mendoza se ha propuesto un proceso de intensificación de los recursos hacia el Holoceno tardío. Este proceso implicó un conjunto de estrategias adaptativas por parte de las poblaciones humanas, disparadas posiblemente por un aumento demográfico y de la territorialidad, que les permitieron extraer una mayor cantidad de recursos del ambiente. 


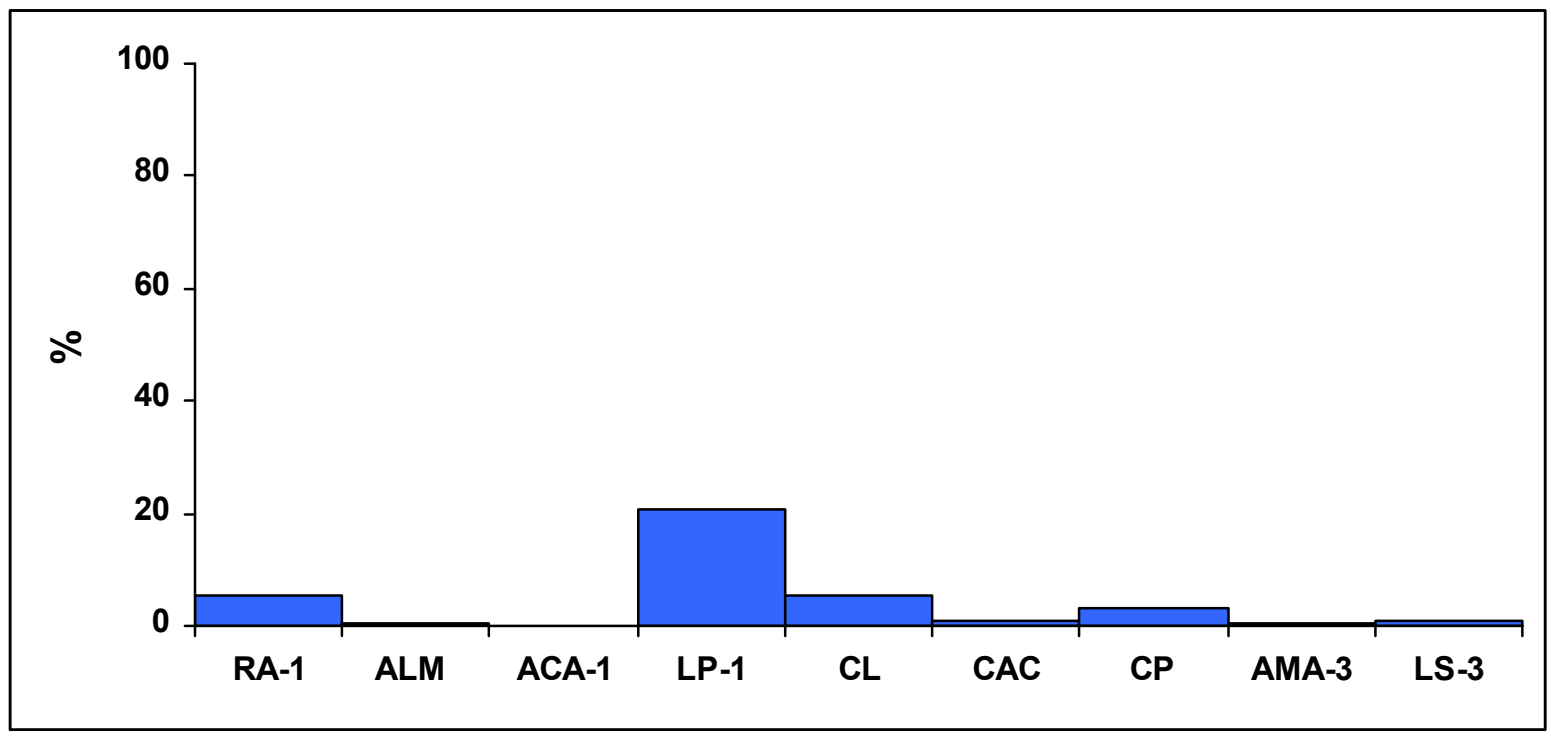

Figura 8.1. Porcentajes de restos termoalterados en los sitios analizados en el sur de Mendoza. Abreviaturas de los sitios arqueológicos en tabla 8.1.

Estas estrategias incluyeron la ocupación de todos los ambientes, estructuras de almacenamiento, reducción de rangos de movilidad, aumentos de los costos de extracción y procesamientos, incrementos de los sistemas de intercambio, aparición de tecnología cerámica, regionalización de estilos, aumento en el uso de elementos de molienda y mayor amplitud de dieta. Este último caso implicó el consumo de recursos de menor retorno energético tales como vegetales y vertebrados de mediano tamaño, en detrimento de aquellos mejor rankeados tales como Lama guanicoe (Neme, 2002, 2007, 2009; Gil, 2006; Neme et al., 2008a, 2008b). A través de este proceso se alcanzó una completa adaptación a las áreas ecológicamente marginales (sensu Borrero, 2004; ver Capítulo 2) del sur de Mendoza (Neme, 2002, 2007, 2009; Gil, 2006; Neme et al., 2008a, 2008b). No obstante, el proceso de intensificación de los recursos no se estableció simultáneamente en toda la región, sino que comenzó hacia el $2 \mathrm{ka}{ }^{14} \mathrm{C}$ AP a lo largo de toda la cuenca del Río Atuel (Neme, 2002, 2007, 2009; Llano, 2008; Gil y Neme, 2010) y en la cuenca media del Río Grande (Neme, 2007; Llano, 2011; Neme et al., 2011; Llano y Neme, 2012) y aproximadamente 1000 años después en el área de la Payunia, posiblemente debido a que la misma sería ecológicamente marginal respecto de las áreas circundantes (Gil, 2006; Neme y Gil, 2008b). Sin embargo, como se expresó anteriormente, Cueva Arroyo Colorado fue el único registro de comprobada acción antrópica sobre restos de microvertebrados. Además, 
el consumo de micromamíferos tampoco fue sustentado desde fuentes etnográficas provenientes tanto de la etnia Huarpe en el centro norte de la provincia de Mendoza, como de las etnias Puelche y Pehuenches en el sur de la provincia (Cabrera, 1929; Rosales, 1937; Métraux, 1937; Michieli, 1978, 1982; Durán, 2000). En tal sentido, el proceso de intensificación posiblemente pudo no haber sido tan marcado como para que los cazadoresrecolectores tuvieran que explotar este tipo de recurso sistemáticamente, como fuera sustentado en otras regiones de Argentina, tales como en las Sierras Centrales (e.g., Rivero et al., 2008; Medina et al., 2011, 2012), en la Región Patagónica (e.g., Bond et al., 1981; Pardiñas, 1999a, 1999b; Teta et al., 2005; Prates, 2008; Fernández et al., 2011a; Pardiñas et al., 2011b), en la Región Pampeana (e.g., Pardiñas, 1999a; Quintana et al., 2002; Acosta y Pafundi, 2005; Quintana, 2005) y en otras áreas más distantes del norte del país (e.g., Santiago, 2004; Santini, 2009).

En la Región de las Sierras Centrales, Rivero et al. (2008) y Medina et al. (2011, 2012) registraron ensambles de micromamíferos recuperados de sitios arqueológicos en la Pampa de Achala (Arroyo El Gaucho 1; Quebrada del Real 1), caracterizados por la dominancia de G. leucoblephara, M. australis y Ctenomys spp., hallazgos de marcas de corte en restos craneales y postcraneales y patrones de termoalteración equivalentes al estudio experimental mencionado anteriormente (cf. Medina et al., 2012). Estos autores, han reconocido esta explotación de micromamíferos en el marco de una economía más diversificada hacia el límite Holoceno medio-Holoceno tardío. Este proceso de intensificación de los recursos, en una escala temporal amplia incluyó una tendencia a la reducción de la movilidad y mayor aprovechamiento de los espacios por parte de los cazadores-recolectores de las sierras de Córdoba, el cual se fue complejizando hacia finales del Holoceno tardío, con la incorporación de prácticas agrícolas, cambios en las tecnologías líticas y cerámicas (Berberián et al., 2008; Rivero et al., 2010; Medina et al., 2011).

En la Región Patagónica, Pardiñas (1999a, 1999b) postula un origen antrópico de ensambles de micromamíferos recuperados de sitios arqueológicos del Holoceno tardío en la provincia de Neuquén (Alero IV del Tromen, Chenque Haichol, Piedra del Águila 11, niveles inferiores de Cuyín Manzano), los cuales estaban dominados ampliamente por Ctenomys spp. Un nuevo análisis de los micromamíferos de Cueva Epullán Grande realizado por Pardiñas y Teta (en prensa), demostró la participación de humanos en la génesis de los 
ensambles, mostrando patrones de quemado diferencial en roedores del grupo de tamaño grande (Ctenomys spp., G. leucoblephara y M. australis) similares al experimento efectuado por Medina et al. (2012).

Estos rasgos particulares de termoalteración en roedores gregarios y coloniales, también fue observado en sitios arqueológicos del noroeste de la provincia de Río Negro durante el Holoceno tardío (Cueva Sarita IV, Cueva y Paredón Loncomán, Casa de Piedra de Ortega y Paso de los Molles), avalando la hipótesis de consumo humano (Pardiñas, 1999a, 1999b; Teta et al., 2005a).

Por otra parte, los estudios realizados por Prates (2008) y Fernández et al. (2011a) en el valle medio e inferior del Río Negro (Negro Muerto y La Angostura 1) han demostrado la explotación de los micromamíferos (Holochilus brasiliensis, M. australis y $G$. leucoblephara) por parte de las poblaciones humanas hacia el final del Holoceno tardío, mediante el hallazgo de marcas de corte, huesos termoalterados (sin un patrón definido, cf. Medina et al., 2012) y asociaciones de los mismos con restos culturales. Estos autores, esgrimen que el uso de roedores se estableció en un contexto de una dieta diversificada, que albergó vertebrados grandes, medianos y chicos, moluscos y plantas. Sin embargo, advierten que al carecer de información de períodos previos, no se puede hablar de un proceso de intensificación de los recursos.

En sitios arqueológicos de la cuenca superior (Campo Cerda 1; Pardiñas, 1999a, 1999b; Udrizar Sauthier, 2009) e inferior (Ea. San Pablo; Udrizar Sauthier, 2009) del Río Chubut, también indicaron un consumo humano en base a la abundancia de roedores coloniales y gregarios y de restos quemados, hacia el Holoceno tardío.

Pardiñas et al. (2011b), en sitios arqueológicos del extremo austral de la provincia de Santa Cruz (Orejas de Burro 1, El Condor 1) y Tierra del Fuego (San Julio 2) del Holoceno tardío, observaron un patrón de termoalteración en restos de Ctenomys magellanicus semejantes al trabajo experimental (cf. Medina et al., 2012). La explotación antrópica de esta especie, coincide con la información etnográfica brindada por Gusinde (1982: 258-259) para los habitantes indígenas de Tierra del Fuego. Asimismo, estas evidencias de consumo de micromamíferos se encuentran enmarcadas en un contexto de economías diversificadas de los cazadores recolectores del extremo sur de Sudamérica hacia el Holoceno tardío (Barberena, 2008; L’Heureux, 2008; entre otros). 
En la Región Pampeana, Pardiñas (1999a) asume un consumo humano de micromamíferos en un sitio a cielo abierto del final del Holoceno tardío ubicado en el nordeste de Buenos Aires (La Higuera), en base al dominio de roedores del grupo de tamaño grande (en su mayoría adultos) y a la presencia de numerosos restos termoalterados. Asimismo, en dos sitios arqueológicos del humedal del río Paraná inferior (La Bellaca 2 y Las Vizcacheras), Acosta y Pafundi (2005) encontraron evidencias de consumo de Cavia aperea en sociedades indígenas con economías ampliamente diversificadas hacia fines del Holoceno tardío, basados principalmente en asociaciones culturales y abundancia de los mismos respecto de otros taxones. No obstante, es interesante destacar que estos autores señalan que no registraron huellas de corte y que los pocos restos quemados estaban fracturados, razón por la cual argumentan que podría haber un patrón de supervivencia diferencial.

A continuación, en sitios arqueológicos del sistema de Tandilia Oriental (Cueva Tixi y Cueva El Abra), Quintana et al. (2002) y Quintana (2005) comprobaron la explotación intensiva de micromamíferos, mediante la observación de marcas de corte con un patrón definido tanto en restos craneales como postcraneales de C. aparea y Galea tixiensis (especie extinguida y endémica del área), hacia el Holoceno tardío final. Esta explotación es congruente con una economía más diversificada hacia finales del Holoceno tardío, donde se registró un incremento bien marcado en la riqueza y diversidad de los vertebrados explotados (e.g., Quintana et al., 2002; Quintana, 2005). A una escala espacial más amplia, coincide con el proceso de intensificación de los recursos que tuvo lugar en la Región Pampeana para este período (Quintana et al., 2002; Quintana, 2005; Martínez y Gutiérrez, 2004; Acosta y Pafundi, 2005; entre otros).

Por otra parte, hacia la parte norte de Argentina, tanto en sitios arqueológicos del Chaco húmedo (Cachapé Potrero V y Puesto Fantín; Santini, 2009) como en sitios del norte de la provincia de Santa Fé (Cerro Aguará; Santiago, 2004), también se han encontrado evidencias de consumo de $C$. aperea en sociedades indígenas con economías diversificadas hacia fines del Holoceno tardío, en base al hallazgo de marcas de corte, escasos huesos quemados y abundancia de los mismos.

Finalmente, se destaca que buena parte de los sitios mencionados con evidencias tafonómicas de explotación de micromamíferos corresponden a ensambles con orígenes 
mixtos, con la participación de aves rapaces o de mamíferos carnívoros en menor medida, tal como se observó en el sitio Cueva Arroyo Colorado.

Por todo lo expuesto, puede afirmarse que la hipótesis tres es falsa dada las escasas evidencias del consumo de microvertebrados por parte del hombre en los sitios arqueológicos del sur de Mendoza. Entonces, estos taxa no habrían formado parte de la dieta humana, o al menos no de forma sistemática como para asociarlo al proceso de intensificación de los recursos que se habría dado en la región según estudios previos.

\subsection{Paleoambientes en el sur de Mendoza}

La cuarta hipótesis intentaba utilizar al registro de micromamíferos como indicador de condiciones paleoambientales dentro de la región. De esta manera, se enunció la siguiente hipótesis:

H-4 Se esperan cambios en la frecuencia y diversidad de los taxones de microvertebrados en relación a las variaciones en la estructura ambiental regional.

Fundamentación: En este sentido cuatro cambios ambientales principales han sido propuestos hasta la fecha para todo el Holoceno. El primero de ellos, está relacionado a los procesos de cambio ocurridos hacia finales de la última glaciación (límite PleistocenoHoloceno) ca. 12000-10000 años AP. El segundo tiene que ver con el proceso aridización sufrido durante el Holoceno medio, ca. 8000-4000 años AP. El tercero con el establecimiento de las condiciones climáticas actuales $c a .4000$ años AP y el cuatro con los cambios ambientales acaecidos en los últimos siglos durante la Pequeña Edad de Hielo (e.g.,

D`antoni, 1983; Markgraf, 1983; Stingl y Garleff, 1985; Zárate, 2002; Zárate et al., 2010 y literatura allí citada).

\subsubsection{Síntesis general de micromamíferos y significación paleoambiental en el sur de} Mendoza

Para efectuar interpretaciones paleoambientales, a partir de fauna fósil, hay que tener en cuenta los sesgos tafonómicos que se producen en la génesis de los ensambles (e.g., 
Andrews, 1995). Teniendo en consideración, que las aves estrigiformes -entre ellas T. albafueron las que tuvieron mayor incidencia en la formación de los ensambles de microvertebrados de los sitios arqueológicos del sur de Mendoza, es importante resaltar que la especie mencionada presenta hábitos generalistas y oportunistas, con un área de captura de 1-5 km y en Argentina depreda principalmente sobre roedores sigmodontinos (ver Capitulo 6). Esto asegura una adecuada comparación con las muestras de egagrópilas de estrigiformes (principalmente, T. alba y B. magellanicus) tomadas como parámetros actualísticos (e.g., Andrews, 1990, 1995; Pardiñas et al., 1999a). Sin embargo, estas rapaces producen ensambles con una subrepresentación de micromamíferos estrictamente diurnos y una mayor proporción de especies que ocupan ambientes abiertos con elevada exposición (Pardiñas, 1999a, 1999b; Pardiñas et al., 2003; entre otros).

El estudio integral de los conjuntos de micromamíferos procedentes de contextos arqueológicos del sur de Mendoza, señala la ausencia de especies extintas (Tabla 8.3) y en líneas generales muestra cierta estabilidad en un rango temporal. Sin embargo, se detectaron algunas variaciones taxonómicas a lo largo de las secuencias que pueden ser entendidas como respuestas a ligeros cambios en las estructuras ambientales locales.

En la tabla 8.3 se presentan los taxa de micromamíferos identificados en el sur de Mendoza, ordenado por lapso temporal.

En los sitios arqueológicos del área cordillerana, tales como LS-3 (2,1-0,6 ka $\left.{ }^{14} \mathrm{C} \mathrm{AP}\right) \mathrm{y}$ AMA-3 (8,9-0,1 ka ${ }^{14} \mathrm{C}$ AP), se observó la dominancia de los roedores sigmodontinos Euneomys chinchilloides, Phyllotis xanthopygus y Eligmodontia sp. a lo largo de ambas secuencias, señalando ambientes Patagónicos de estepas arbustivas abiertas, con alta proporción de suelo desnudo, pedregoso y abundante roca expuesta. Se han registrado especies asociadas a vegas cordilleranas desde el Holoceno temprano al Holoceno tardío, en AMA-3 (Chelemys macronyx y Abrothrix longipilis). El hallazgo del marsupial Lestodelphys halli hacia $2,2 \mathrm{ka}{ }^{14} \mathrm{C}$ AP en este último sitio, sugiere condiciones más Patagónicas. En LS-3, el registro de C. macronyx y Loxodontomys micropus en la secuencia, con excepción hacia $0,6 \mathrm{ka}{ }^{14} \mathrm{C} \mathrm{AP}$, indica un retroceso de las vegas hacia esa época. Por otra parte, en otro sitio cordillerano cercano al alto valle del Río Atuel (Cueva Arroyo Colorado; 3,2-0,75 ka ${ }^{14} \mathrm{C}$ AP) y en otro sitio cercano al valle medio del Río Grande (Caverna de Las Brujas; 5 TL-3,7 ka ${ }^{14} \mathrm{C}$ AP; Gasco et al., 2006) los ensambles mostraron 
cierta estabilidad y taxonomicamente similares a los anteriores, aunque en el último sitio no se registraron taxones asociados a vegas (ver sección 8.2.3).

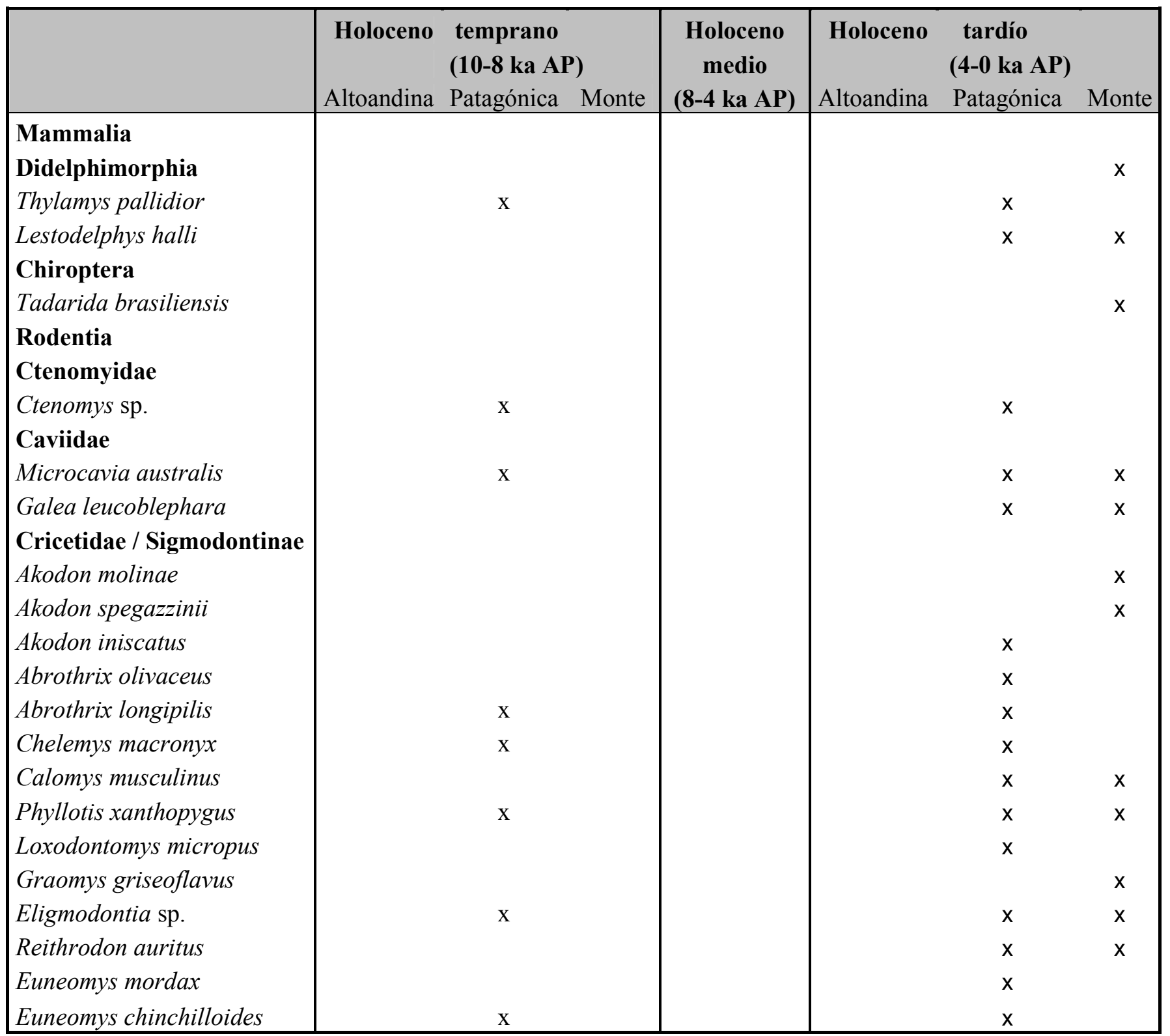

Tabla 8.3. Presencia-ausencia de taxones de micromamíferos recuperados de los sitios arqueológicos por período geológico y por unidad fitogeográfica donde se encuentran enclavados los sitios en la actualidad.

No obstante, es interesante destacar la abundancia de E. chinchilloides y la ausencia de Euneomys mordax en los sitios arqueológicos de LS-3, AMA-3, Cueva Palulo y Caverna de Las Brujas (cf. Gasco et al., 2006) y en sus parámetros actualísticos correspondientes. Sin embargo, ambas especies fueron registradas conjuntamente en el sitio arqueológico Cueva 
Arroyo Colorado y en tres localidades actuales cercanas al mismo, en un rango altitudinal entre ca. 1.850 y 2.500 m. (i.e., Laguna de la Niña Encantada, Pardiñas et al., 2008; 6 km al $\mathrm{S}$ de Las Leñas, Fernández et al., 2009d; Valle Hermoso, Ojeda et al., 2005). E. mordax habita en ambientes más húmedos y con mayor cubierta herbácea que E. chichilloides (Pearson y Christie, 1991; Pardiñas, 1999a; Jayat et al., 2006), lo que sugiere que el área que circunda a Cueva Arroyo Colorado pudo haberse mantenido con mayor disponibilidad hídrica desde el Holoceno tardío hasta la actualidad tal vez como producto del extenso sistema fluvial que lo recorre, en oposición a los valles cercanos donde se enclavan los otros sitios mencionados.

En el valle medio del Río Grande, los conjuntos exhumados de la secuencia del sitio Cueva de Luna (ca. 3,8-Presente ka ${ }^{14} \mathrm{C}$ AP) presentaron dominancia de P. xanthopygus, Eligmodontia sp., E. chinchilloides, Thylamys pallidior, Ctenomys sp. y M. australis tanto en los componentes arqueológicos como en localidades actuales próximas al sitio. Esto sugiere que un ambiente con características afines a estepas arbustivas abiertas con alta proporción de suelo desnudo, pedregoso y abundante roca expuesta, se mantuvo constante desde comienzos del Holoceno tardío hasta la actualidad. No obstante, los registros de $G$. leucoblephara, Akodon iniscatus y Calomys musculinus únicamente en las muestras arqueológicas, sugieren condiciones afines al desierto del Monte en el pasado. Por otra parte, los registros de Reithrodon auritus en todos los componentes y de L. halli en el Componente IV muestran un ambiente de mosaico con la estepa Patagónica.

Por otro lado, las muestras actuales de la planicie oriental están dominadas por taxones asociados al desierto del Monte. Coincidentemente, los ensambles de los sitios LP-1 [ 1,5 ka AP (datación relativa)-0,4 ka ${ }^{14} \mathrm{C}$ AP)], RA-1 (1,5-0,35 ka ${ }^{14} \mathrm{C}$ AP) y ACA-1 (1,2-0,25 ka ${ }^{14} \mathrm{C}$ AP) presentaron especies que habitan principalmente en este ambiente (T. pallidior, $G$. leucoblephara, M. australis, Graomys griseoflavus). Sin embargo, en el sitio Agua de La Mula (1,6-1 ka $\left.{ }^{14} \mathrm{C} \mathrm{AP}\right)$, además de registrarse taxones del Monte, se recuperaron algunas especies Patagónicas (L. halli y R. auritus), lo que sugiere condiciones ecotonales entre estos dos biomas.

Con el objetivo de integrar la información vertida de los sitios arqueológicos y muestras actuales se realizaron análisis de agrupamiento y ordenamiento. 
En primer lugar, el análisis de agrupamiento (Figura 8.2) efectuado a partir de todas las muestras arqueológicas del sur de Mendoza, exhibe una separación marcada entre los ensambles de la cordillera de aquellos de las planicies. Sin embargo, se puede observar a los ensambles de Cueva de Luna están agrupados junto a los sitios de las planicies, posiblemente debido a la presencia de elementos del Monte como G. leucoblephara, C. musculinus y A. iniscatus.

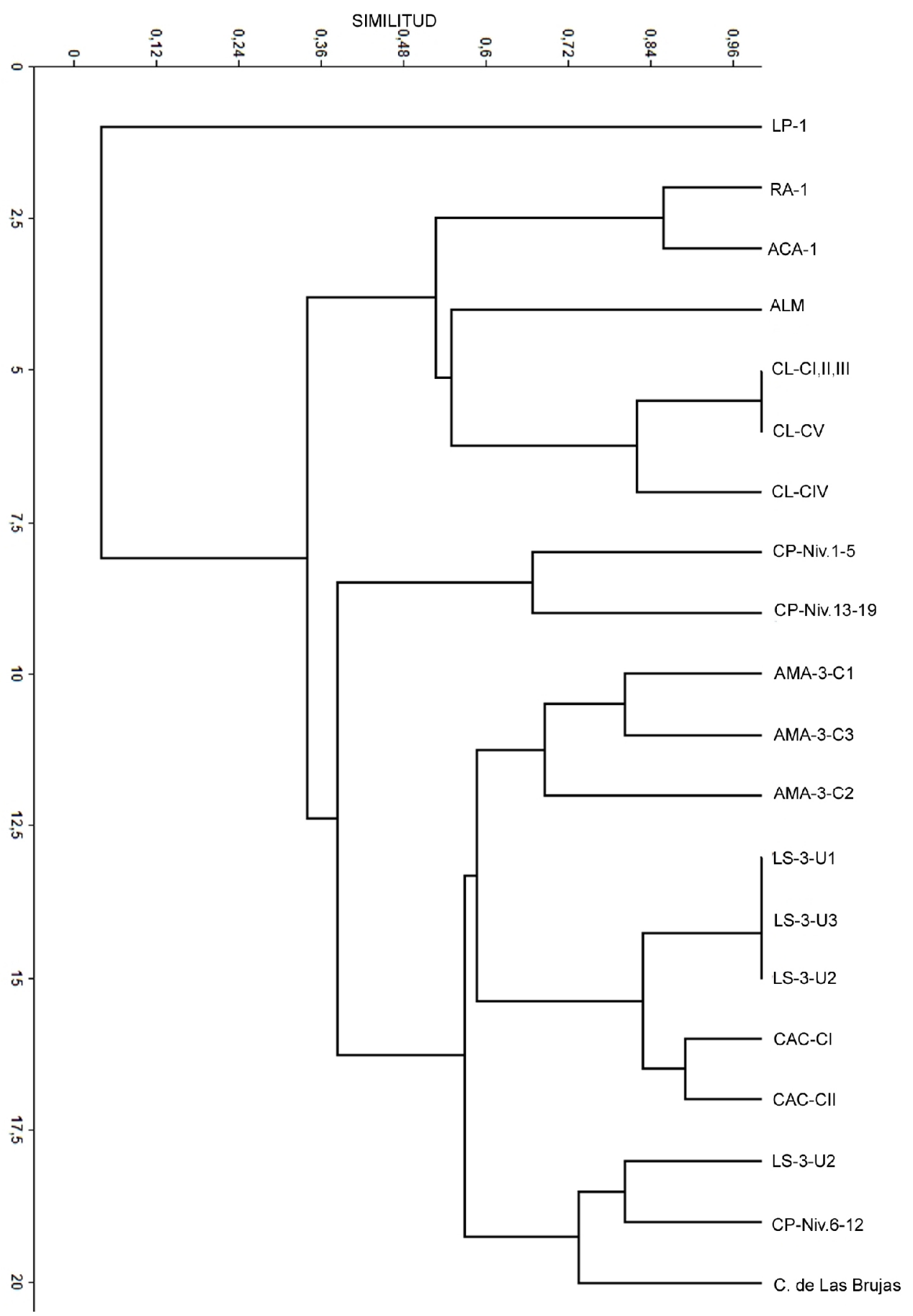


Figura 8.2. Relaciones fenéticas entre muestras de micromamíferos de los sitios arqueológicos del sur de Mendoza [matriz básica de presencia-ausencia; Cluster Analysis, medida de similitud Jaccard, método de unión de distancias promedios entre todos los miembros de los pares de grupos (UPGMA-Unweighted pair-group average), $\mathrm{ccc}=0,9099]$.

Una relación entre valores de diversidad y riqueza de todas las muestras arqueológicas (Figura 8.3), muestra los valores más altos en los ensambles, donde se han planteado condiciones paleoambientales de ecotono entre el desierto del Monte y la estepa Patagónica (Cueva de Luna y Agua de La Mula).

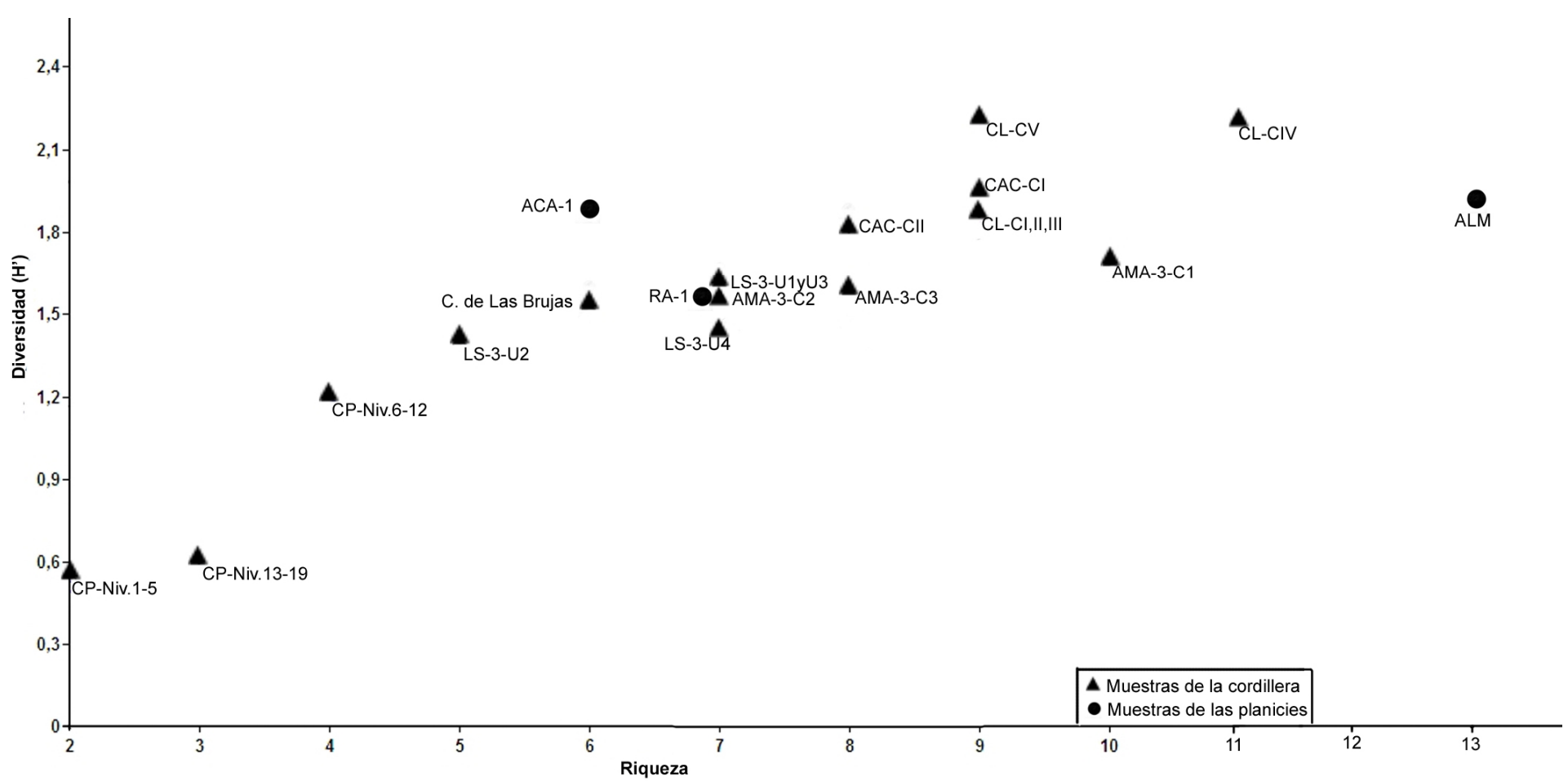

Figura 8.3. Relaciones entre valores de Diversidad ( $\left.\mathrm{H}^{\prime}\right)$ y Riqueza taxonómica de las muestras arqueológicas de micromamíferos de la cordillera y de las planicies del sur de Mendoza (exceptuando LP-1 por sus bajos valores). Abreviaturas de los sitios arqueológicos en tabla 8.1 .

El análisis de agrupamiento realizado mediante frecuencias de micromamíferos de muestras actuales (más representativas) y todas las muestras arqueológicas y de la cordillera, exhibe grupos diferenciados (Figura 8.4). Por un lado, se encuentran los ensambles de Cueva Palulo, disímiles del resto posiblemente por una estabilidad de especies en el marco temporal y bajos valores de diversidad y riqueza taxonómica (Figura 8.5). 
Otro grupo, está constituido por AMA-3 (Conjunto I), LS-3 (unidades 1 y 3), y con menor similitud LS-3 (unidades 2 y 4) y Cueva Arroyo Colorado (Componente I). El Conjunto 1 de AMA-3 coincide cronológicamente con LS-3 y se encuentra muy cerca del mismo, lo que nos permite trazar una observación integral de los últimos $2,1 \mathrm{ka}{ }^{14} \mathrm{C}$ AP en este sector del Atuel. Este conjunto de AMA-3, fue el que presentó mayor diversidad y riqueza taxonómica (Figura 8.5), con la presencia de L. halli y aumento de frecuencia de A. olivaceus como elementos característicos, que lo distancian de los conjuntos más antiguos (2 y 3 ) de este sitio y de los parámetros actualísticos locales. A pesar, que estas especies no fueron recuperadas de LS-3, esta asociación podría estar marcando un ambiente Patagónico con el desarrollo de vegas como factor común para este sector del Atuel hacia el $2,1 \mathrm{ka}{ }^{14} \mathrm{C}$ AP, aunque posiblemente con oscilaciones de los niveles de humedad en algunos periodos (ver arriba). Por su parte, el Componente I de Cueva Arroyo Colorado también coincide cronológicamente y presenta un ensamble asociado a vegas, peladales y roquedales, lo que sugiere la ocurrencia de similares condiciones en la vertiente opuesta del río (valle de Las Leñas) hacia $1,4 \mathrm{ka}{ }^{14} \mathrm{C} \mathrm{AP}$.

Por otro lado, el Componente II de Cueva Arroyo Colorado está asociado al sitio arqueológico Caverna de Las Brujas y distante de los parámetros actualístico locales. Esta agrupación es coherente con los bajos valores de diversidad y riqueza taxonómicas (Figura 8.5).

Finalmente, por un lado Cueva de Lula (Componente IV) se agrupa junto a varios ensambles actuales cercanos al Río Grande. A pesar que las estructuras taxonómicas de los ensambles son diferentes, esta asociación podría deberse al carácter heterogéneo tanto de la muestra arqueológica -con elementos del Monte y Patagónicos- acusando los valores de diversidad y riqueza más altos (Figura 8.5), y las muestras actuales con taxones Patagónicos y de vegas cordilleranas. Por otro lado, se agrupan los otros componentes Cueva de Luna, los cuales presentaron estructuras taxonómicas similares y diferenciadas del Componente IV de los parámetros actuales. 


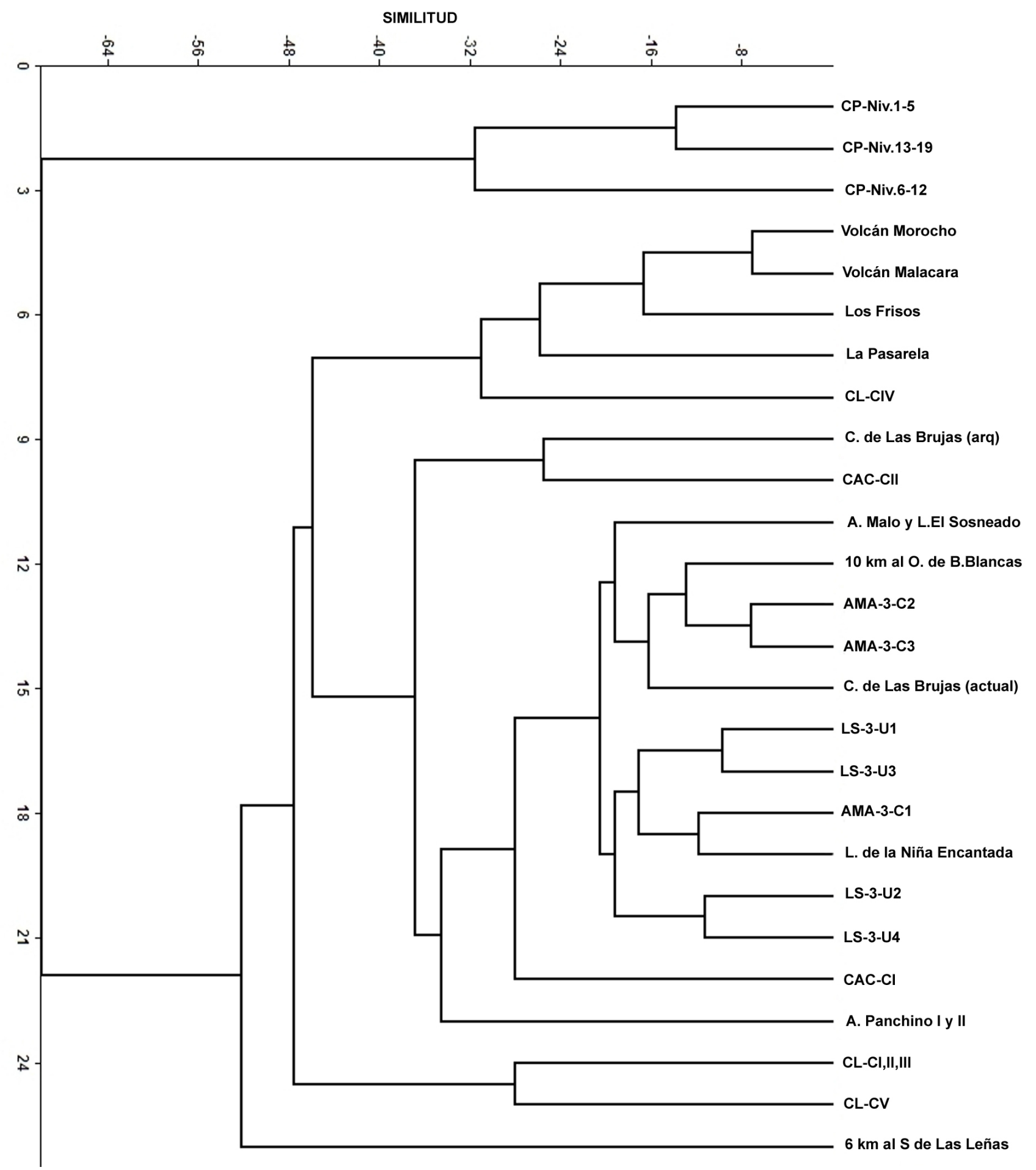

Figura 8.4. Relaciones fenéticas entre muestras actuales (más representativas) y arqueológicas de los micromamíferos de la cordillera del sur de Mendoza, teniendo en cuenta los valores de MNI\% [matriz básica de frecuencias, Cluster Analysis, coeficiente Euclidean distance, método de unión de distancias promedios entre todos los miembros de los pares de grupos (UPGMA-Unweighted pair-group average), ccc $=0,8946$ ]. Abreviaturas de los sitios arqueológicos en tabla 8.1. 


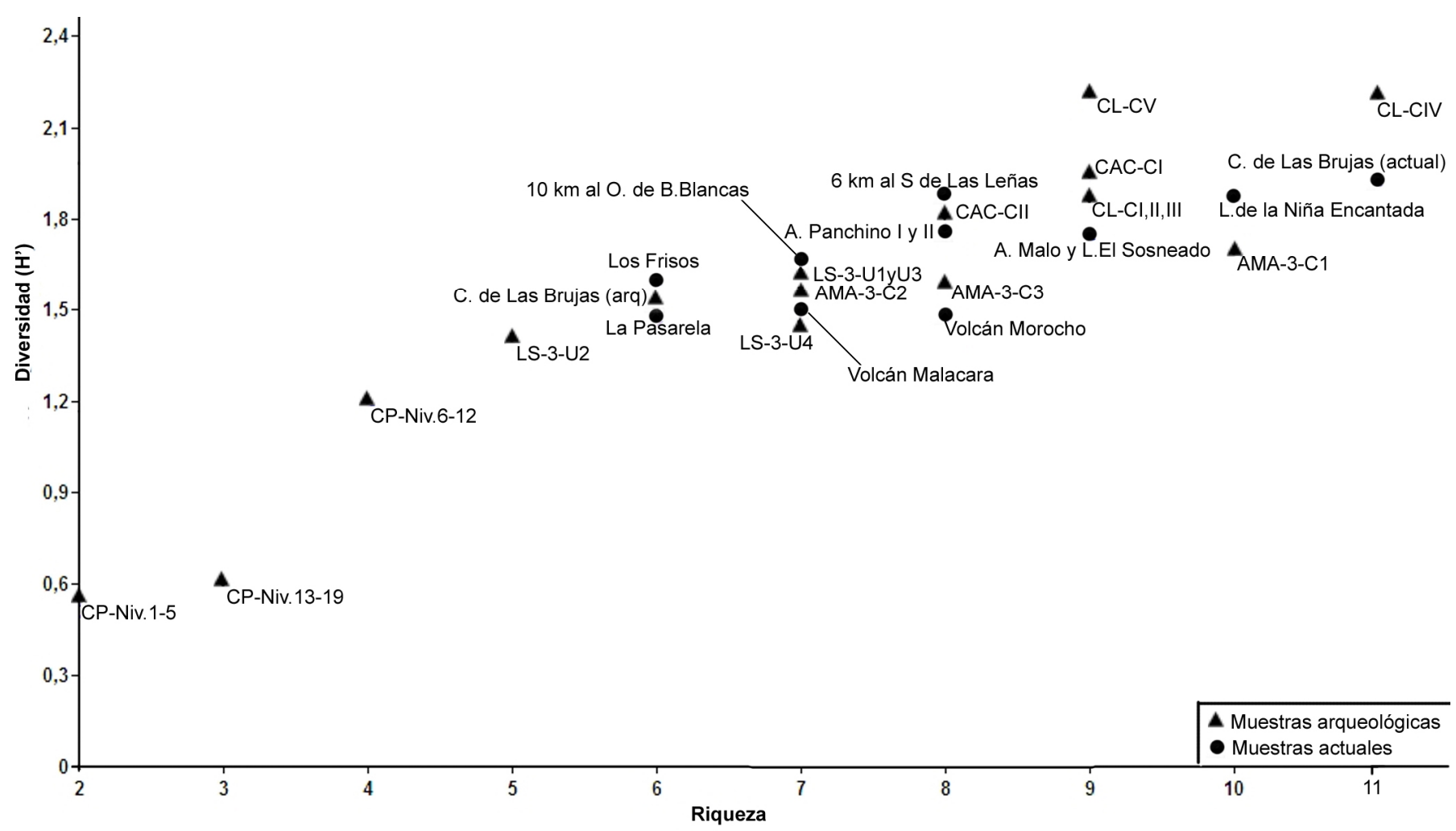

Figura 8.5. Relaciones entre valores de Diversidad $\left(\mathrm{H}^{\prime}\right)$ y Riqueza taxonómica de las muestras actuales (más representativas) y arqueológicas de micromamíferos de la cordillera del sur de Mendoza. Abreviaturas de los sitios arqueológicos en tabla 8.1 .

Este escenario complejo entre las muestras arqueológicas y actuales que integran al suroeste mendocino no se expresa en el análisis de PCA (Figura 8.6), el cual alude a un esquema más simplificado de la región cordillerana. En tal sentido, se observan pocas variaciones entre los ensambles que incluyen cada sitio arqueológico, aunque diferenciándose de las muestras actuales, posiblemente debido a la influencia del impacto antrópico en el ambiente (ver sección 8.2.2). El componente 1 (29,238\% de la variancia), exhibe una separación de las muestras de Cueva de Luna y el componente 2 (16,461\% de la variancia), una diferenciación de los ensambles de Cueva Arroyo Colorado y su parámetro actualístico local. Resulta interesante destacar, que las muestras arqueológicas y actuales de Caverna de Las Brujas (cf. Gasco et al., 2006), resultaron más relacionadas a los ensambles arqueológicos del alto valle del Río Atuel que a los del Río Grande (Cueva de Luna), a pesar de su cercanía a este último. Esto refuerza lo discutido previamente, debido a que en Caverna de Las Brujas se registraron ensambles asociados a ambientes abiertos, rocosos y pedregosos hacia fines del 
Holoceno medio, sin presencia de elementos del Monte (C. musculinus, A. iniscatus y G. leucoblephra), como fueron registrados en Cueva de Luna durante el Holoceno tardío.

Posiblemente, este análisis de ordenamiento señale que los ensambles de los sitios arqueológicos presentan una estabilidad taxonómica a través del tiempo a una escala local, con variaciones mínimas y con cambios en la actualidad. No obstante, a una supraescala regional se observa que los ensambles correspondientes a cada sitio de cordillera se diferencian entre si, indicando que cada valle donde se ubican los mismos presentan características particulares -posiblemente por diferencias en altitudes, topografía, sistemas hídricos y vegetacionales- que promueven la conformación de ensambles de micromamíferos específicos, los cuales fueron acumulados principalmente por aves rapaces con radios de captura acotados (ver Capitulo 6).

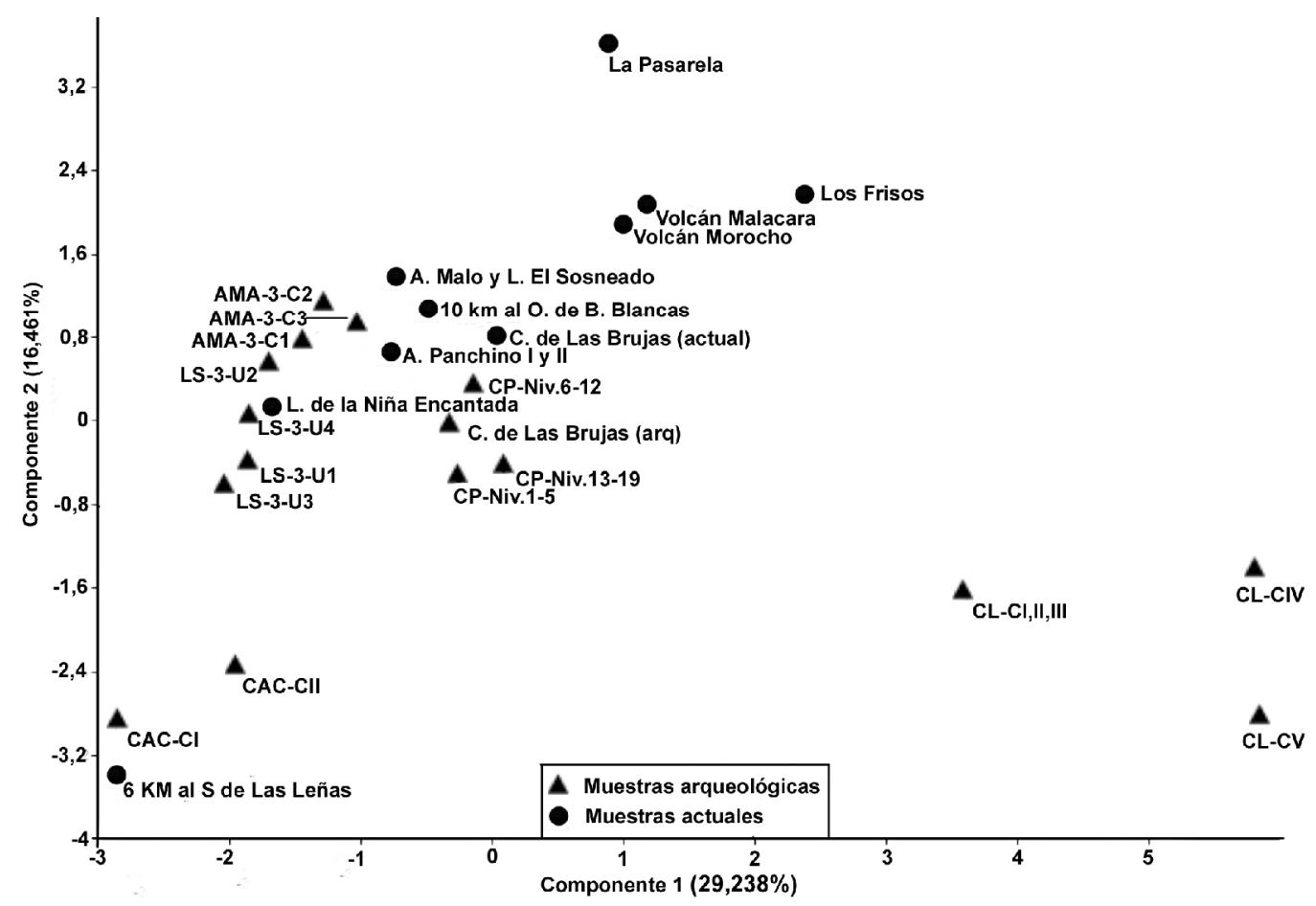

Figura 8.6. Gráfico de las muestras actuales (más representativas) y arqueológicas de micromamíferos de la cordillera del sur de Mendoza, sobre el plano definido por los ejes 1 y 2 de un análisis de componente principal. Abreviaturas de los sitios arqueológicos en tabla 8.1.

Los análisis de agrupamiento (Figura 8.7) y de componentes principales (Figura 8.8) realizados mediante frecuencias de micromamíferos de las muestras arqueológicas (tomadas en su totalidad debido a los escasos valores de MNI) y actuales (más representativas) de la 
llanura del sur de Mendoza, exhiben una asociación estrecha entre las muestras arqueológicas. La separación de LP-1 del grupo de sitios, posiblemente obedezca a un sesgo de tamaño muestral. No obstante, la información emanada de la comparación entre riqueza y diversidad taxonómicas (Figura 8.9), muestra que el ensamble arqueológico de Agua de La Mula fue el que exhibió valores más altos, en forma coherente con el esquema paleoambiental de transición entre el desierto del Monte y estepa Patagónica, propuesto para el sitio.

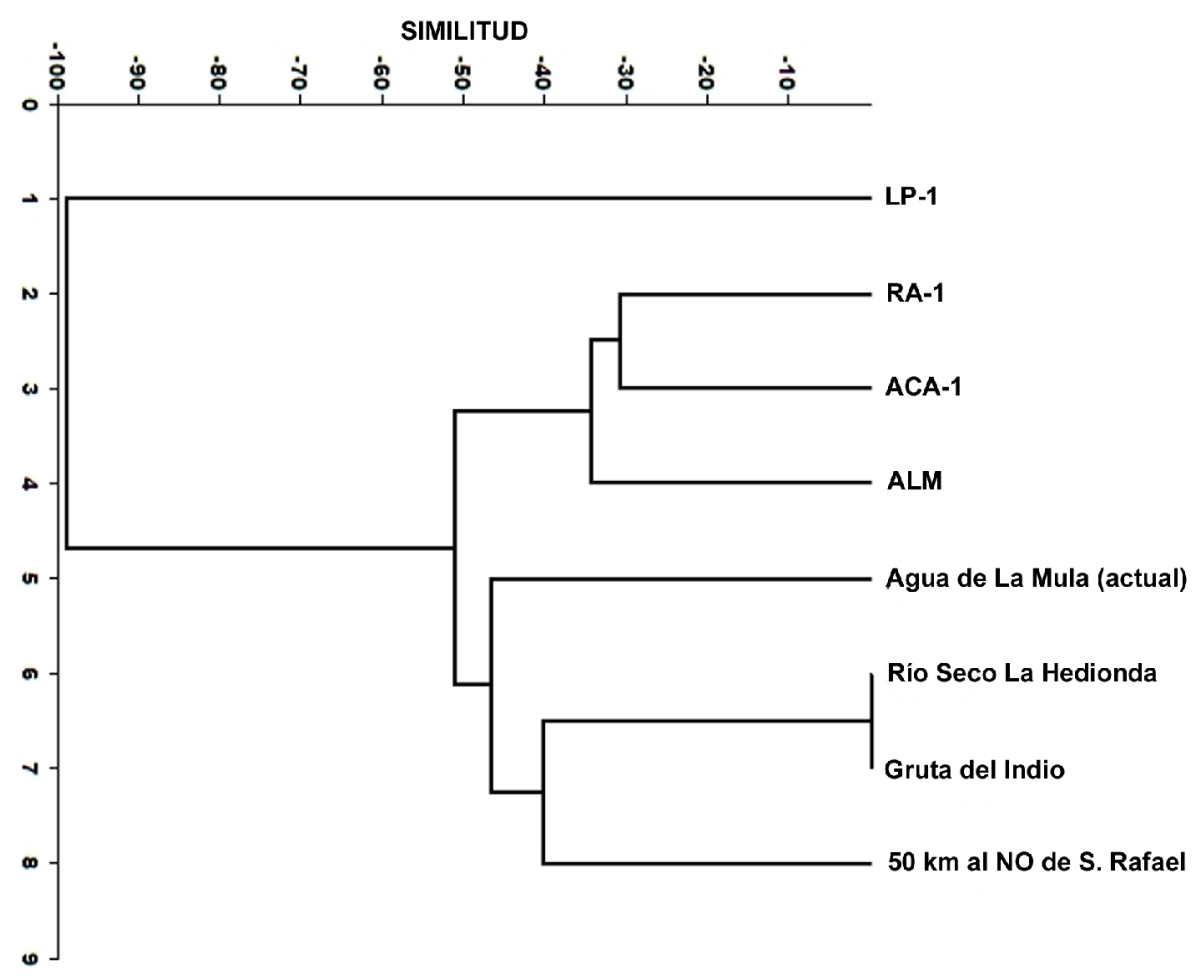

Figura 8.7. Relaciones fenéticas entre muestras actuales (más representativas) y arqueológicas de los micromamíferos de las llanuras del sur de Mendoza, teniendo en cuenta los valores de MNI\% [matriz básica de frecuencias, Cluster Analysis, coeficiente Euclidean distance, método de unión de distancias promedios entre todos los miembros de los pares de grupos (UPGMA-Unweighted pairgroup average), $\mathrm{ccc}=0,9453]$. Abreviaturas de los sitios arqueológicos en tabla 8.1. 


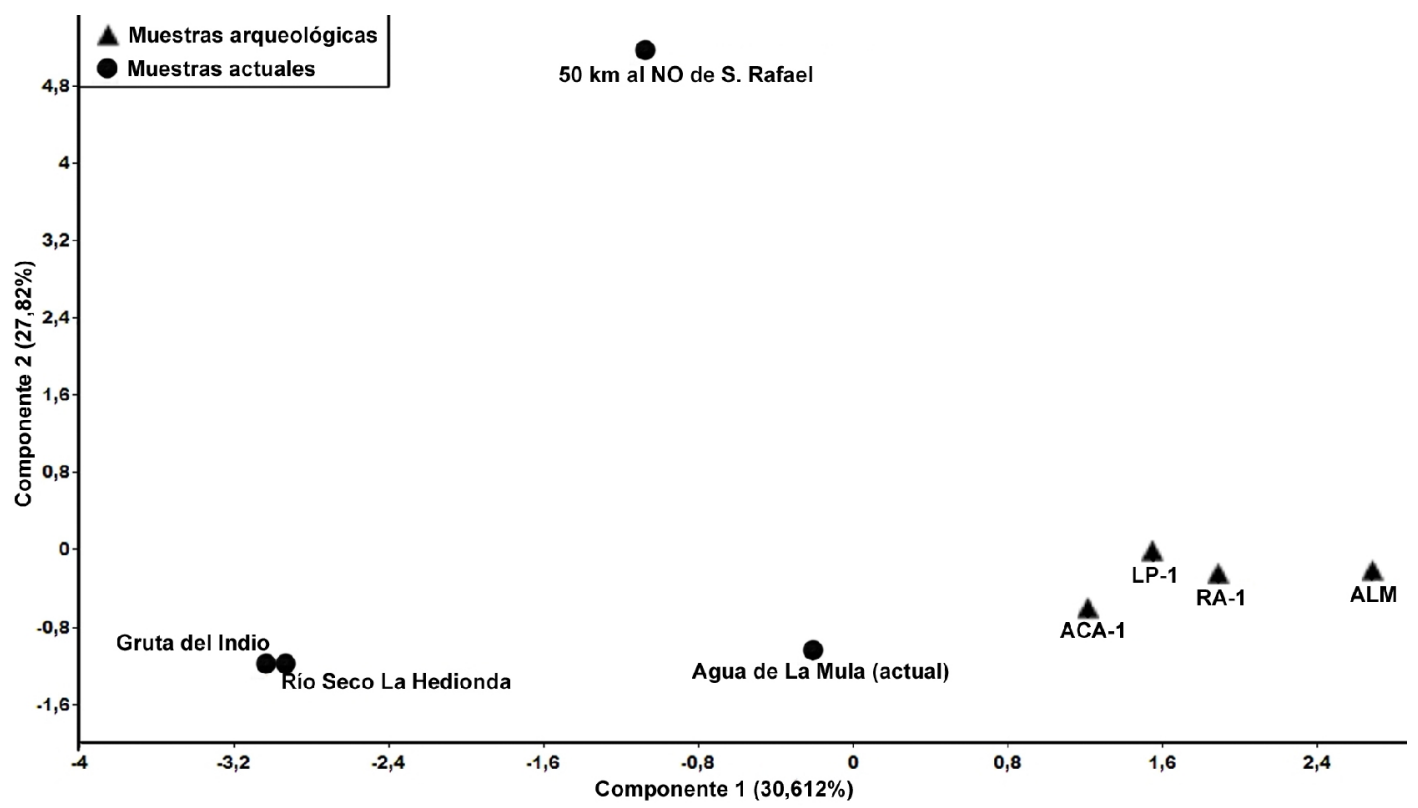

Figura 8.8. Gráfico de las muestras actuales (más representativas) y arqueológicas de micromamíferos de la llanura del sur de Mendoza, sobre el plano definido por los ejes 1 y 2 de un análisis de componente principal. Abreviaturas de los sitios arqueológicos en tabla 8.1.

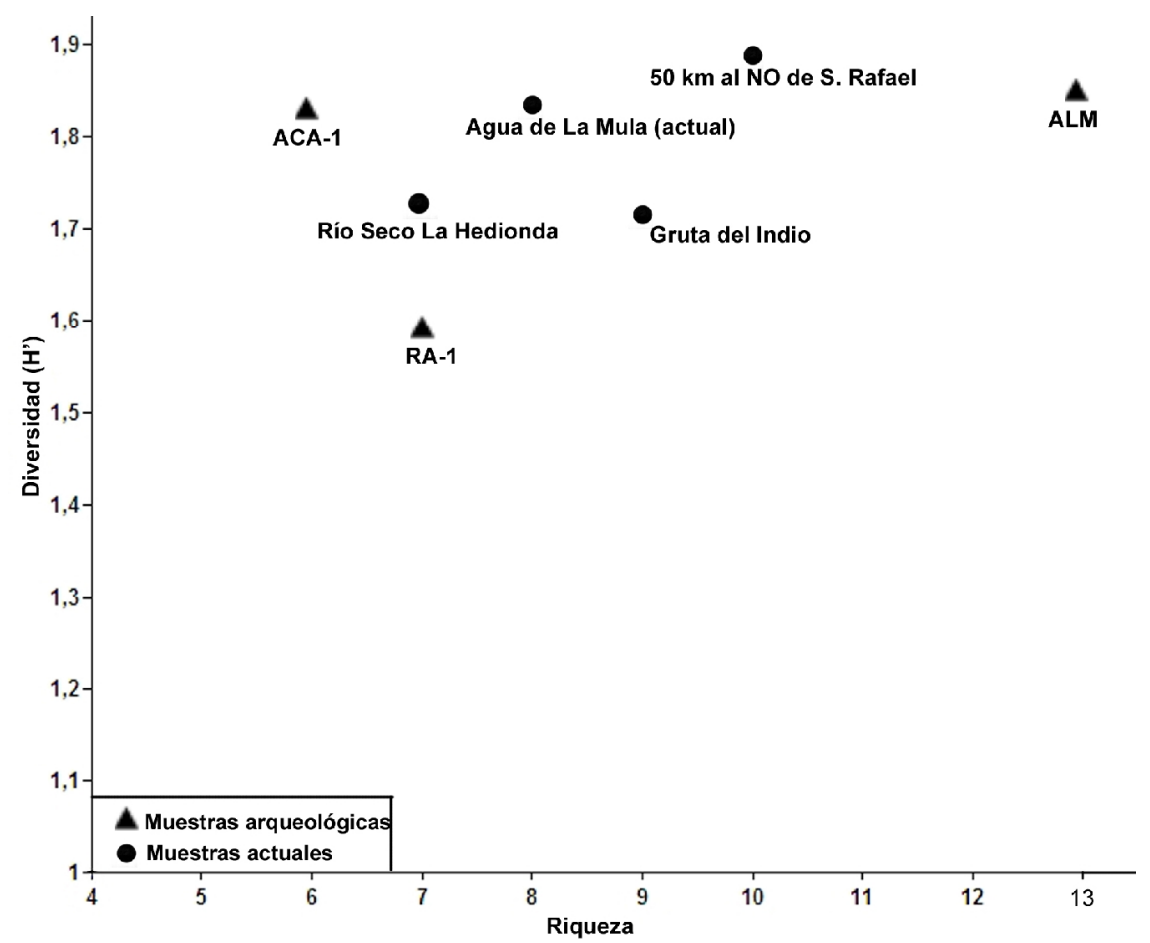

Figura 8.9. Relaciones entre valores de Diversidad (H’) y Riqueza taxonómica de las muestras actuales (más representativas) y arqueológicas de micromamíferos de la llanura del sur de Mendoza. Abreviaturas de los sitios arqueológicos en tabla 8.1. 
Retomando el enunciado de hipótesis paleoambiental, en base a la evidencia de los nueve sitios arqueológicos analizados correspondientes al Holoceno tardío (a excepción de AMA-3 que alcanza el Holoceno temprano) y sus parámetros actualístico, podemos argumentar que las estructuras taxonómicas de los micromamíferos líneas generales mostraron en una estabilidad en el tiempo. No obstante, la existencia de variaciones puntuales en algunas secuencias (e.g., AMA-3, LS-3, Cueva de Luna, Agua de La Mula), podría indicar que durante el Holoceno tardío existieron algunos pulsos climáticos que promovieron el movimiento dinámico de las unidades fitogeográficas y sus ensambles asociados.

Teniendo en cuenta las diferencias observadas entre los ensambles de las planicies y los de cordillera se correlacionan los valores de diversidad y riqueza taxonómica con la altitud. De esta forma se pretende evaluar si ambos valores pueden ser explicados por la distribución diferencial de los taxones entre los distintos niveles altitudinales (Figuras 8.10 y 8.11). El resultado obtenido exhibe una correlación negativa entre ambas variables, donde el valor de $\mathrm{R}^{2}$ indica que la altitud estaría explicando un $25 \%$ de la diversidad observada en los diferentes ensambles analizados. En tal sentido, a medida que aumenta la altitud disminuyen los valores de riqueza y diversidad. No obstante, cabe notar que muchas de las muestras estudiadas -principalmente en las planicies- son muy escasas, lo que podría estar sesgando este análisis.

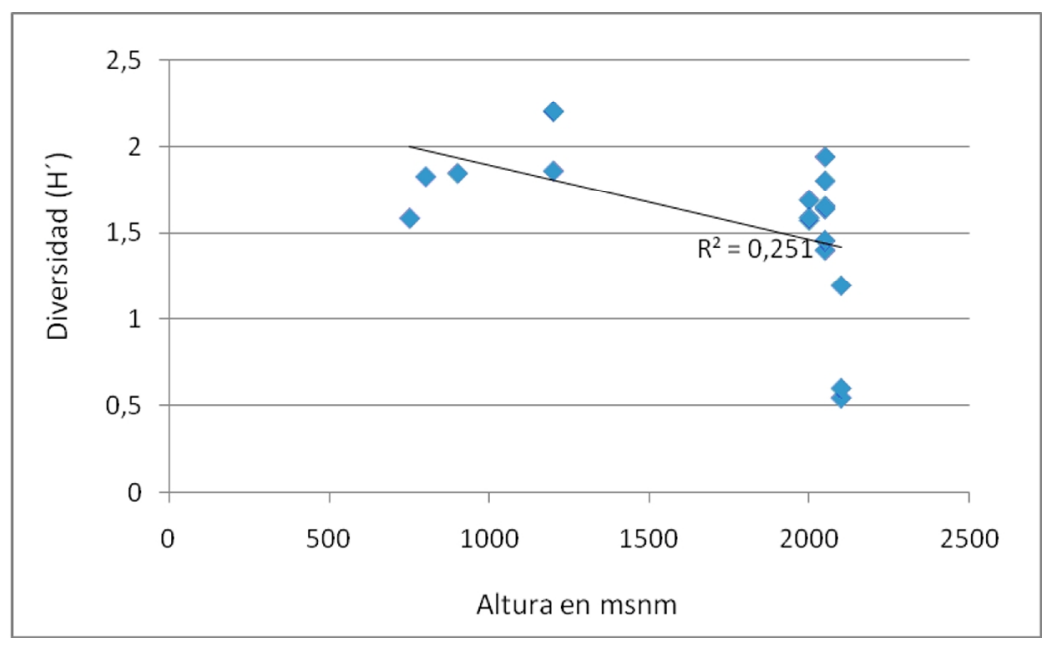

Figura 8.10. Correlación entre la diversidad taxonómica y altitud en los ensambles de micromamíferos de los sitios arqueológicos analizados en esta tesis. 


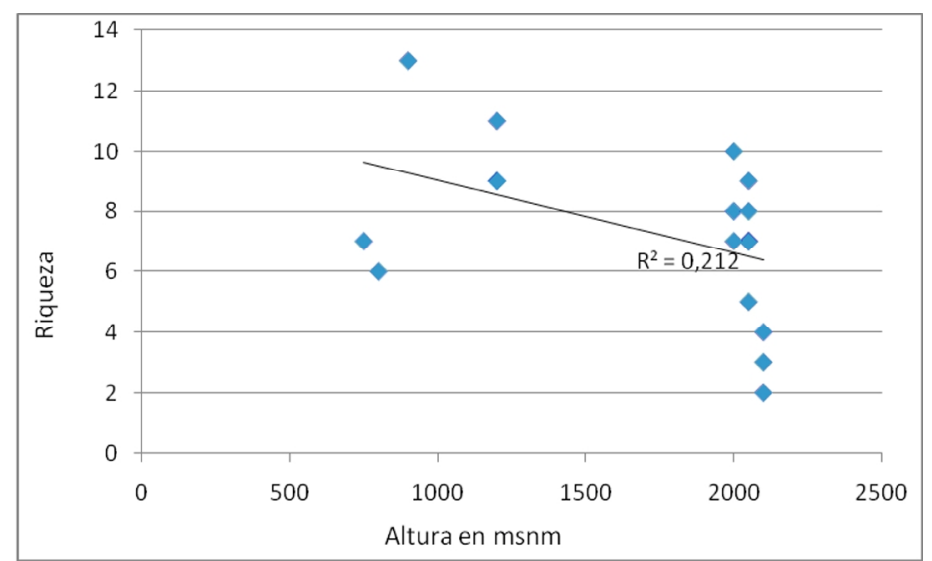

Figura 8.11. Correlación entre riqueza taxonómica y altitud en los ensambles de micromamíferos de los sitios arqueológicos analizados en esta tesis.

Esto es coherente con lo discutido en el Capítulo 5, donde en base a la información de los ensambles de micromamíferos que habitan en Mendoza en la actualidad, se observó que aquellos provenientes de los sectores identificados en el desierto del Monte presentaron valores de riqueza taxonómica por arriba de la media de todos los sectores definidos en la provincia (ver Figura 5.60).

Debido a que en el transcurso del Holoceno se registraron fluctuaciones ambientales (ver sección 8.2.3), se decidió corroborar si la tendencia observada -en la figura 8.10- no ha sido influenciada por dichos procesos de cambio. En este sentido, nuevamente se correlacionaron los valores de diversidad, pero acotándolo a las muestras correspondientes a los últimos 2.000 años ${ }^{14} \mathrm{C}$ AP (Figura 8.12). Los resultados fueron similares a los anteriores (Figura 8.10 ), con un valor de $\mathrm{R}^{2}$ que aún explica el $20 \%$ de la variación observada. De esta forma, se estaría eliminando el "ruido" potencial que pudieron establecer los cambios ambientales más importantes que tuvieron lugar dentro de la región durante el Holoceno.

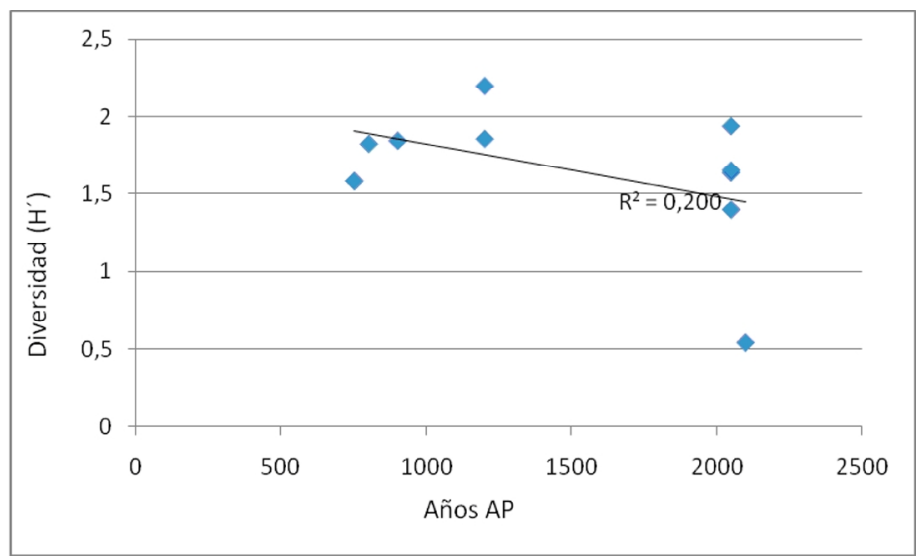


Figura 8.12. Correlación de los valores de diversidad y altura considerando solamente los ensambles de micromamíferos provenientes de las unidades arqueológicas de los últimos 2.000 años ${ }^{14} \mathrm{C} \mathrm{AP}$.

La figura 8.13 muestra que no hay un aumento o disminución en la diversidad taxonómica a través del tiempo. Esto es congruente con lo discutido previamente, donde se observó una estabilidad ambiental, con ligeras fluctuaciones mediante el registro de los ensambles de micromamíferos recuperados de los sitios arqueológicos del sur de Mendoza durante el Holoceno

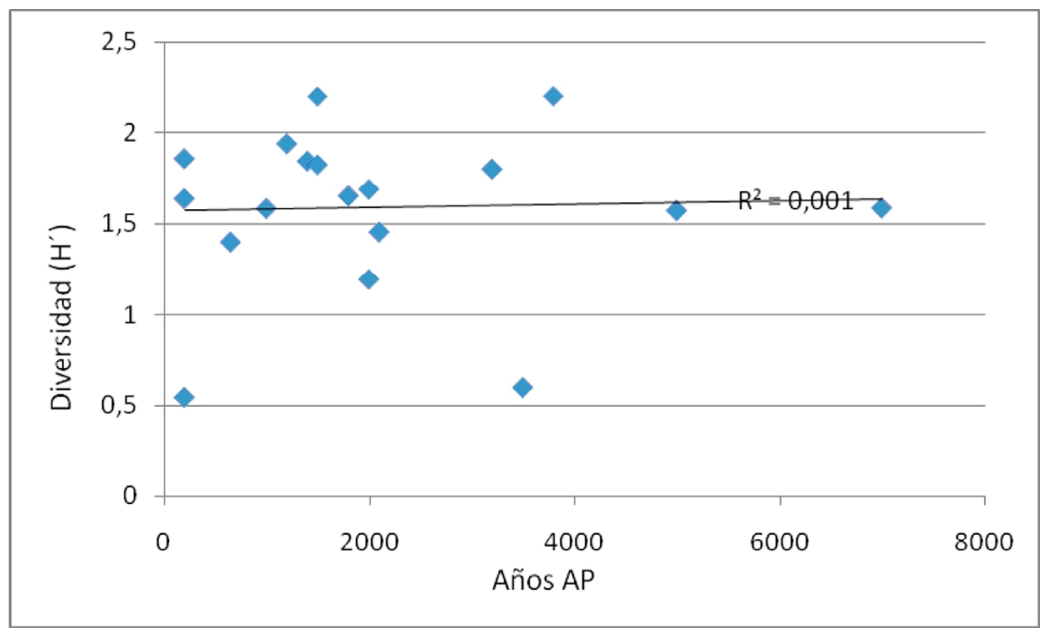

Figura 8.13. Correlación entre los valores de diversidad taxonómica en los ensambles de micromamíferos de los sitios arqueológicos analizados en esta tesis y la variable temporal (expresada en $\left.\mathrm{Años}{ }^{14} \mathrm{C} \mathrm{AP}\right)$.

\subsubsection{Micromamíferos como indicadores de deterioro Antropico}

Entre las numerosas actividades antrópicas que modifican el ambiente, las extensas áreas cultivadas, el sobrepastoreo y la consecuente desertificación producen notables cambios en las estructuras taxonómicas de los ensambles de micromamíferos a través de amplias regiones de Argentina. Esta restructuración se observa principalmente en la pérdida de la diversidad y riqueza específica e incrementos marcados de especies oportunistas, en detrimento de otras y en algunos casos llegando a producirse extinciones locales y regionales (e.g., véase Pardiñas et al., 2010b, 2010c, 2011a; Ortiz et al., 2011b; y literatura citada en estos trabajos). En este sentido, la relación entre algunas especies de roedores sigmodontinos y el impacto ambiental ocasionado por los avances de los sistemas 
agropecuarios fue demostrado en numerosos trabajos delineados principalmente en las regiones Pampeana (e.g., Pardiñas, 1999a; Pardiñas et al., 2004, 2010b, 2010c; Teta et al., 2010; Fernández et al., 2012), Patagónica (e.g., Pearson, 1983; Monjeau, 1989; Pardiñas et al., 2000, 2011a; Teta et al., 2005a; Cueto et al., 2008; Udrizar Sauthier, 2009) y Puneña (e.g., Teta y Ortiz, 2002; Ortiz et al., 2011b), aunque también fue propuesto como hipótesis en otras regiones (e.g., Pardiñas y Teta, 2005, 2006).

Los ensambles actuales en la Región Pampeana presentan diversidades y riquezas taxonómicas muy pobres comparados con el registro fósil del Holoceno, en virtud de la amplia dominancia de Calomys spp., Oligoryzomys flavescens y Akodon azarae (e.g., Pardiñas, 1999a; Pardiñas et al., 2004, 2010b, 2010c; Teta et al., 2010; Fernández et al., 2012). No obstante, la información disponible sobre el registro fósil del Holoceno muestra frecuencias de Calomys spp. con niveles mínimos en comparación con otras especies, que desde los siglos XIX y XX se encuentran en proceso de retracción (e.g., R. auritus, Necromys lasiurus) o regionalmente extinguidas (e.g., Bibimys torresi y Pseudoryzomys simplex) (e.g., Pardiñas, 1999a; Pardiñas et al., 2010b, 2010c; Scheifler et al., en prensa). Estudios genéticos de la estructura de las poblaciones de C. laucha y C. musculinus, confirman la hipótesis de esta reciente expansión geográfica (e.g., Chiappero et al., 2002; González-Ittig et al., 2007).

Una situación similar se observó en los ensambles de micromamíferos del centro y este de la Región Patagónica, donde taxones oportunistas como C. musculinus y Oligoryzomys longicaudatus dominan las muestras actuales en comparación con los registros del Holoceno, donde también se ocasionaron extinciones locales (L. micropus, A. longipilis y Notiomys edwardsii) (Udrizar Sauthier, 2009; Pardiñas et al., 2011a). Como un ejemplo de esto, C. musculinus alcanzó frecuencias muy altas ( $>95 \%)$ cerca de la desembocadura del Río Chubut (García-Esponda et al., 1998; Pardiñas et al., 2000; Udrizar Sauthier, 2009). En tanto, en áreas de la estepa Patagónica del sector oeste y a lo largo de Río Santa Cruz $A$. olivaceus y Eligmodontia spp. exhibieron incrementos notables de sus frecuencias en ensambles actuales (e.g., Pearson, 1983; Monjeau, 1989; Teta et al., 2005a; Cueto et al., 2008; Pardiñas et al., 2011a; Pardiñas y Teta, en prensa). Otro caso parangonable, es la disminución abrupta de Euneomys spp. en ensambles actuales de algunos sectores del noroeste Patagónico, después de ca. 10 ka de dominancia (Pearson, 1987; Pearson y 
Pearson, 1993; Pardiñas, 1999a; Pardiñas et al., 2011a; Pardiñas y Teta, en prensa). En toda la región Patagónica, aparte de la influencia de la ganadería ovina (desde fines del siglo XVIII) y los extensos campos cultivados (desde el siglo XIX), estos cambios estuvieron vinculados a eventuales alteraciones de los regimenes de quemas de ambientes, desertificación e introducción de especies exóticas animales y vegetales (Pardiñas et al., 2011a, 2011b).

Finalmente, en la Región Puneña se registraron menor diversidad especifica, incrementos importantes en las frecuencias de Eligmodontia puerulus y aumentos moderados de $C$. musculinus (ca. 15\%) en ensambles actuales de micromamíferos comparados con los registros fósiles del Pleistoceno y Holoceno, en compás con algunas extinciones locales (Teta y Ortiz, 2002; Ortiz et al., 2011b).

En el sur de la provincia de Mendoza se distribuyen algunas de estas especies oportunistas. Por un lado, C. musculinus habita en las llanuras asociadas a una vegetación arbustiva del desierto del Monte y por el otro, A. olivaceus se encuentra en la zona de piedemonte y alta cordillera asociada a vegetación Patagónica y Altoandina (ver Capítulo 5). En tal sentido, para tener una visión integral de la relación entre estos roedores oportunistas y el impacto antrópico, producido en primer término por el ganado (principalmente Capra hircus y Ovis aries) y afianzado en Mendoza desde el siglo XIX (ver Capítulo 3), se compararon los registros arqueológicos de ambas especies con los principales ensambles actuales en las áreas mencionadas.

Si bien no se obtuvieron valores muy bajos de diversidad y riqueza taxonómica en los ensambles actuales comparados con ensambles los arqueológicos (Figuras 8.5 y 8.9), hay razones para pensar que las actividades ganaderas en el sur de Mendoza afectaron a las comunidades de micromamíferos. En las figuras 8.14 y 8.15 se observa que tanto los porcentajes de C. musculinus y A. olivaceus en las áreas mencionadas, fueron mayores en las muestras actuales comparados con las muestras arqueológicas. Aunque se destaca, que no alcanzaron los niveles altos registrados en numerosos sectores de las regiones discutidas arriba. 


\section{Calomys musculinus}

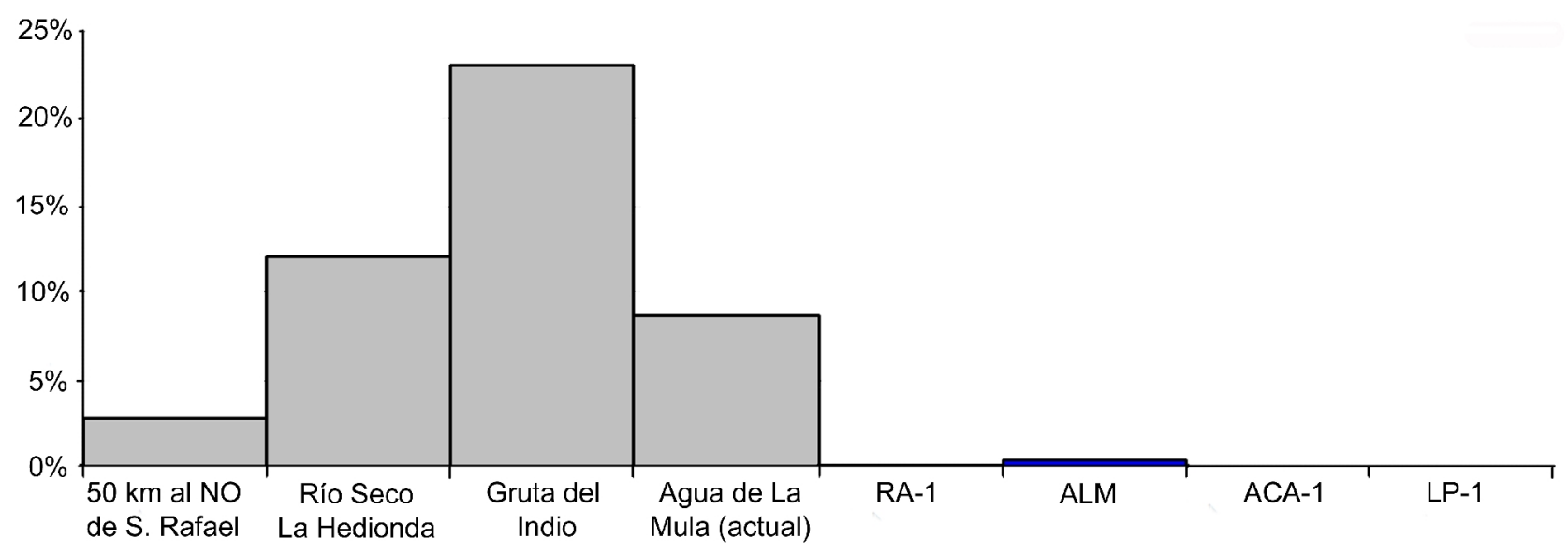

Figura 8.14. Comparación de los porcentajes de Calomys musculinus de los sitios arqueológicos (a la derecha) y las muestras actuales (más representativas) de las llanuras del sur de Mendoza. Abreviaturas de los sitios arqueológicos en tabla 8.1 .

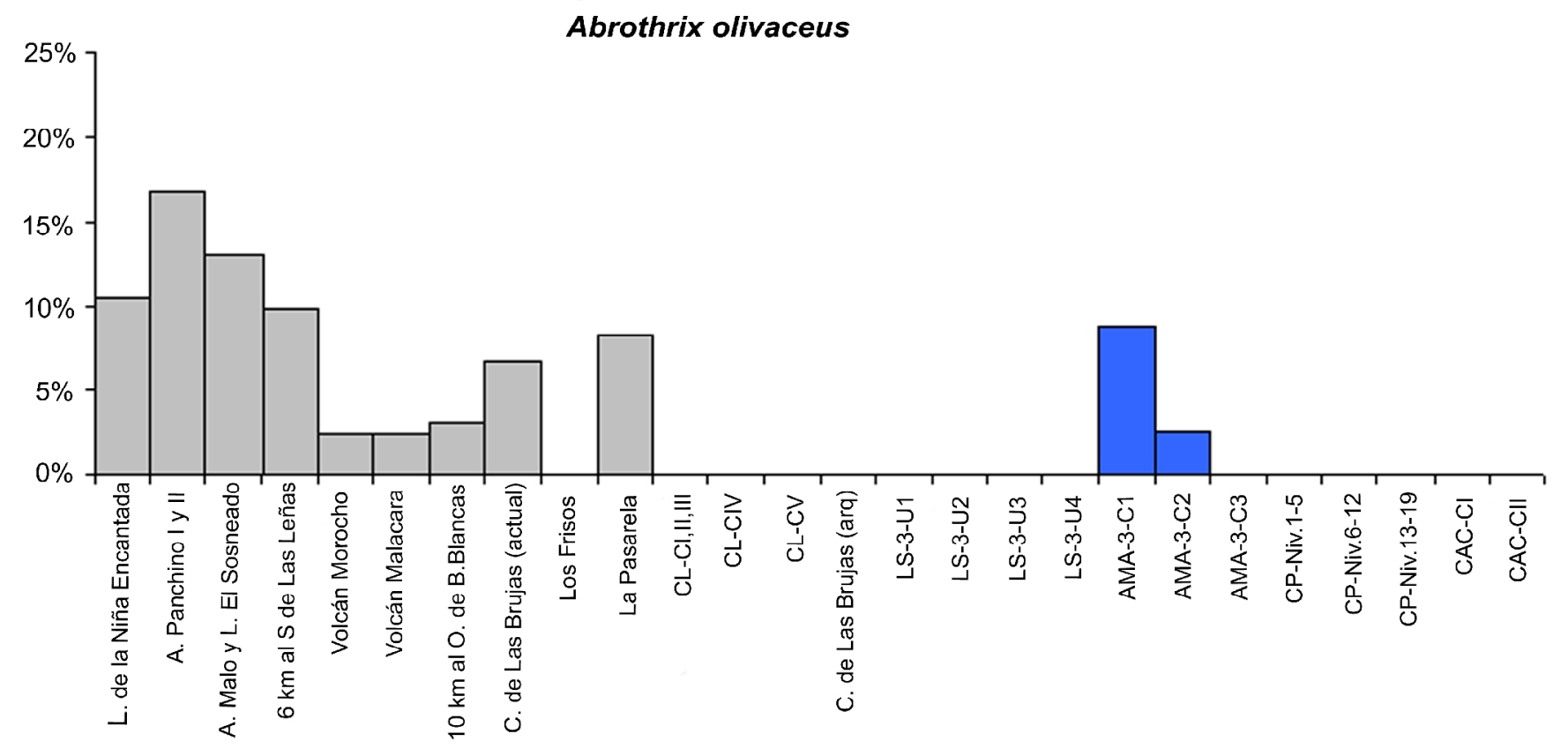

Figura 8.15. Comparación de los porcentajes de Abrothrix olivaceus de los sitios arqueológicos (a la derecha) y las muestras actuales (más representativas) de la cordillera del sur de Mendoza. Abreviaturas de los sitios arqueológicos en tabla 8.1. 
En las figuras 8.16 y 8.17 se observa en líneas generales un agrupamiento diferenciado entre las muestras arqueológicas y las muestras actuales. Como excepciones, por un lado la muestra actual de Los Frisos (Figura 8.17) se ubica con el grupo de muestras arqueológicas por no presentar A. olivaceus y por otro lado, dos muestras de AMA-3, único sitio arqueológico donde se recuperaron restos de esta especie, se ubican con otros subgrupos de muestras actuales con porcentajes bajos de ocurrencia.

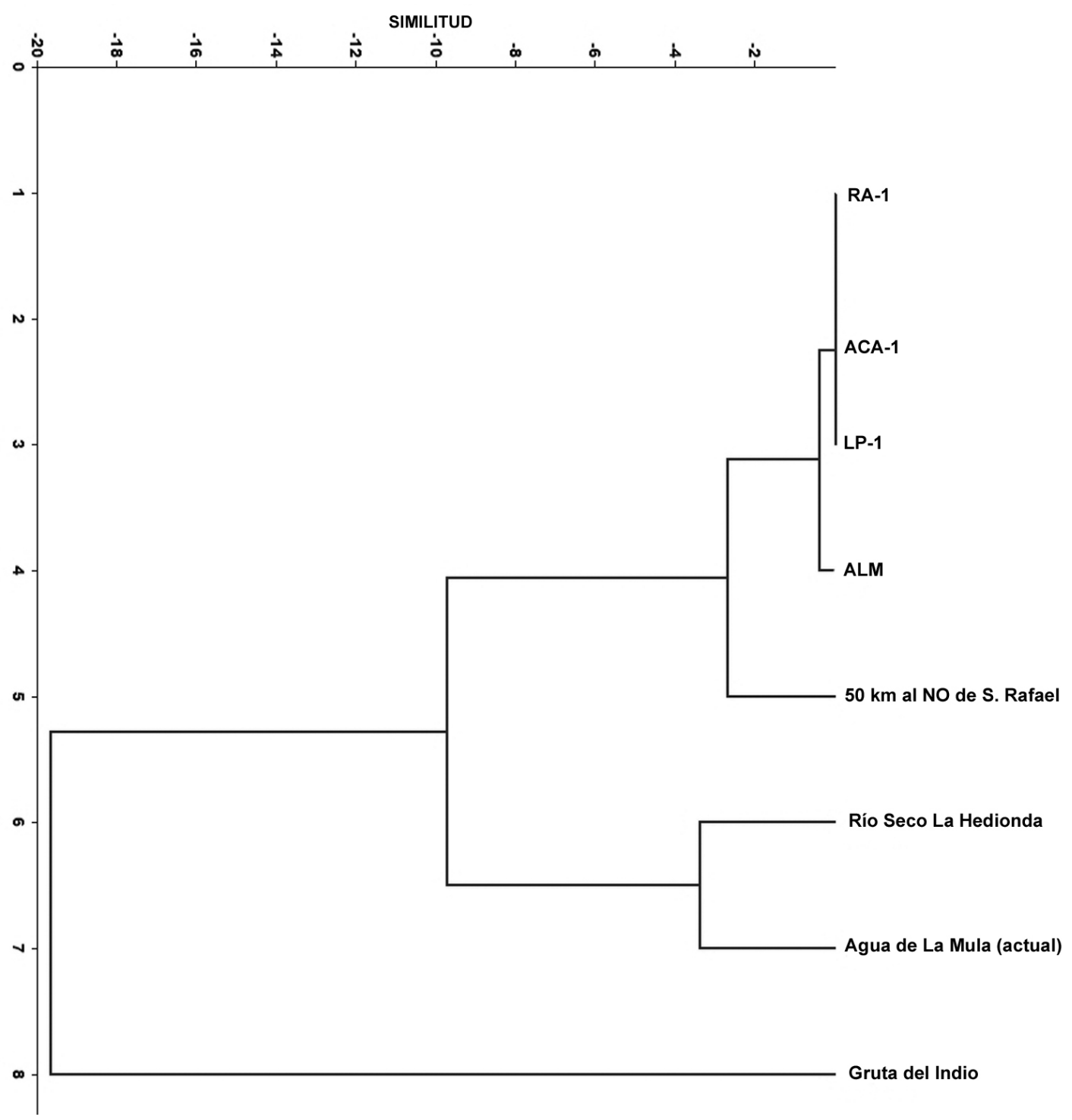

Figura 8.16. Relaciones fenéticas entre muestras actuales (más representativas) y arqueológicas de las llanuras del sur de Mendoza, teniendo en cuenta los valores de MNI\% de Calomys musculinus [matriz básica de frecuencias, Cluster Analysis, coeficiente Euclidean distance, método de unión de distancias promedios entre todos los miembros de los pares de grupos (UPGMA-Unweighted pair-group average), $\mathrm{ccc}=0,9409]$. Abreviaturas de los sitios arqueológicos en tabla 8.1. 
Se destaca, que la frecuencia de A. olivaceus en AMA-3 aumenta en los niveles superiores donde se recuperaron restos de fauna doméstica (Neme, 2002, 2007; Gil et al., 2006b) y fauna silvestre introducida (ver Capítulo 7), representando momentos de post contacto hispano-indígena, donde el impacto antrópico ya se habría hecho notar. Por otra parte, muestras de A. olivaceus aparecen en los parámetros actualísticos cercanos al sitio (Arroyo Malo y Laguna El Sosneado).

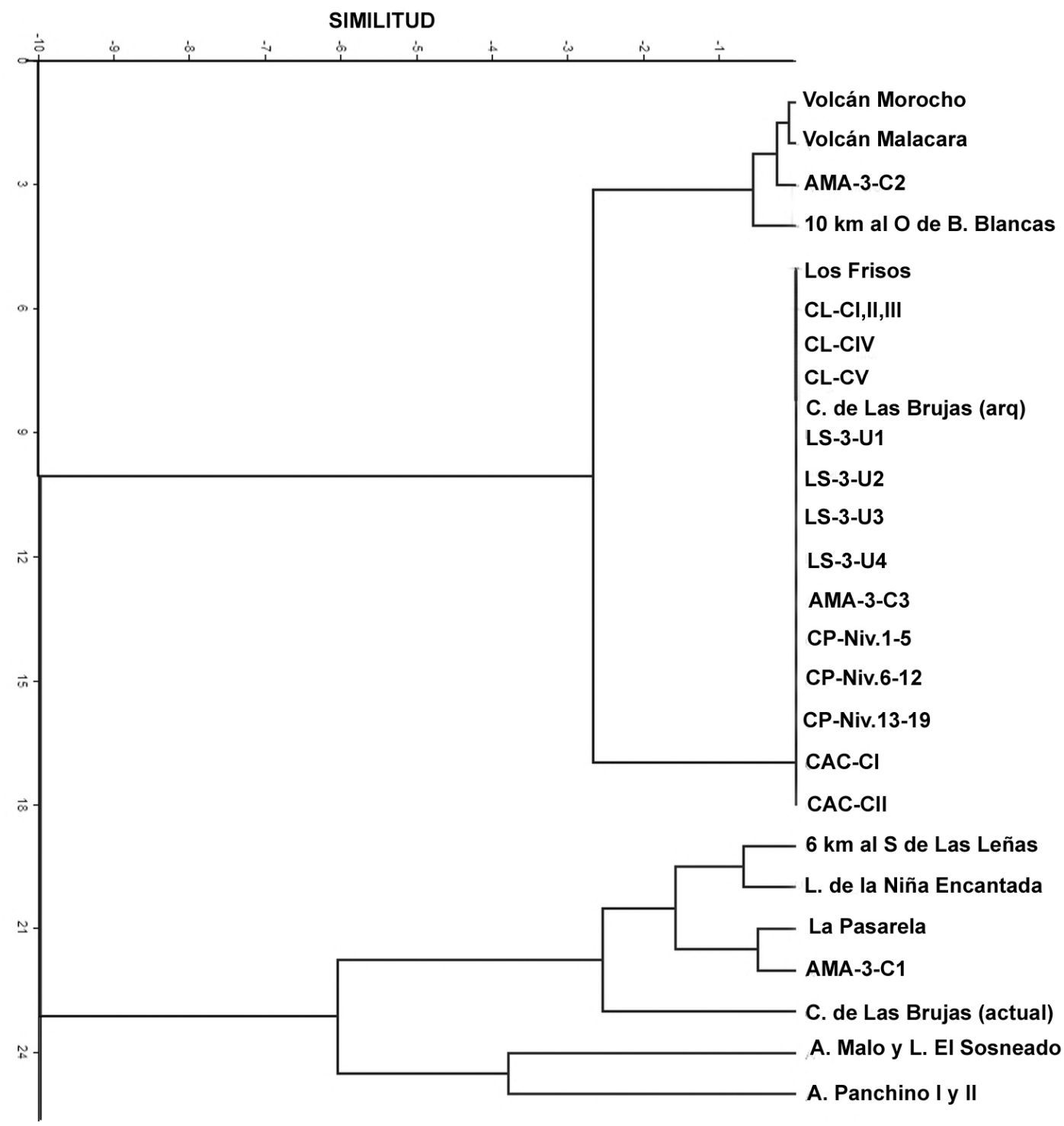

Figura 8.17. Relaciones fenéticas entre muestras actuales (más representativas) y arqueológicas de la cordillera del sur de Mendoza, teniendo en cuenta los valores de MNI\% de Abrothrix olivaceus [matriz básica de frecuencias, Cluster Analysis, coeficiente Euclidean distance, método de unión de distancias promedios entre todos los miembros de los pares de grupos (UPGMA-Unweighted pairgroup average), $\operatorname{ccc}=0,8974]$. Abreviaturas de los sitios arqueológicos en tabla 8.1. 
Finalmente, a pesar que los ensambles actuales de micromamíferos del sur de Mendoza presentaron evidencias de cambios en sus estructuras taxonómicas producto de la modificación antrópica, esta restructuración no fue tan pronunciada como en algunos sectores de las regiones Patagónica, Pampeana y Puneña.

\subsubsection{Integrando información de diferentes proxies paleoambientales del sur de Mendoza}

La información paleoambiental preexistente para la provincia de Mendoza y áreas circundantes fue descripta exhaustivamente en el Capítulo 3 (sección 3.8). No obstante, en este apartado se pretende integrar en un marco temporal parte de esa información con la obtenida a partir del análisis de micromamíferos (Tabla 8.4). A pesar de que este tipo de esquemas simplificados indefectiblemente llevan a una pérdida del detalle de las numerosas investigaciones realizadas, resultan necesarios para observar los procesos en forma conjunta y permitir a otros investigadores disponer de la información a modo de síntesis parcial (Pardiñas, 1999a).

Para tal propósito, la información será tratada en períodos temporales de acuerdo a los modelos propuestos por Zárate (2002) y Zárate et al. (2010). Estos autores, integrando la mayor parte de los datos paleoambientales proponen una serie de cambios para la región durante el final del Pleistoceno tardío $\left(21-10 \mathrm{ka}{ }^{14} \mathrm{C}\right.$ AP), Holoceno temprano $\left(10-8 \mathrm{ka}{ }^{14} \mathrm{C}\right.$ AP), Holoceno medio (8-4 ka ${ }^{14} \mathrm{C}$ AP) y Holoceno tardío $\left(4-0 \mathrm{ka}{ }^{14} \mathrm{C}\right.$ AP). El primero de ellos, está relacionado al Último Máximo Glacial (21-18 ka $\left.{ }^{14} \mathrm{C} \mathrm{AP}\right)$, mostrando un ambiente más árido y frío que el presente. Posteriormente, en el Tardiglacial (14-10 ka ${ }^{14} \mathrm{C} \mathrm{AP}$ ), existe un retroceso glaciar con temperaturas más altas que el período anterior. Durante el Holoceno temprano la temperatura continúa en ascenso y disminuyen las precipitaciones, presentando un régimen estival. Hacia el Holoceno medio, se produce un proceso de aridización y reavances glaciarios, indicando un aumento de la temperatura y disminución de las precipitaciones en el sector de la planicie y un incremento de las precipitaciones níveas con descenso de la temperatura en el área de montaña. En el Holoceno tardío se establecen las condiciones climáticas actuales, las cuales están influenciadas por los eventos ENSO (El Niño Southern Oscillation), produciendo un aumento de las precipitaciones invernales en los Andes e incrementando los caudales de los sistemas fluviales durante el verano. En este 
período transcurre la denominada Pequeña Edad de Hielo (siglos XVI-XIX), caracterizada por un clima más frío y árido y finalmente en los siglos siguientes el ambiente sufrió modificaciones significativas producto de la acción antrópica

Como se puede observar en la tabla 8.4, la mayor parte de la información paleoambiental disponible para esta área corresponde principalmente al Holoceno tardío.

\begin{tabular}{|c|c|c|c|c|}
\hline & $\begin{array}{c}\text { Pleistoceno tardío final } \\
\left(21-10 \mathrm{ka}^{14} \mathrm{C} \mathrm{AP}\right)\end{array}$ & $\begin{array}{c}\text { Holoceno temprano } \\
\left(10-8 \mathrm{ka}^{14} \mathrm{C} \mathrm{AP}\right)\end{array}$ & $\begin{array}{l}\text { Holoceno medio } \\
\left(8-4 \mathrm{ka}^{14} \mathrm{C} \mathrm{AP}\right)\end{array}$ & $\begin{array}{l}\text { Holoceno tardío } \\
\left(4-0 \text { ka }{ }^{14} \mathrm{C} \mathrm{AP}\right)\end{array}$ \\
\hline \multicolumn{5}{|l|}{ Alto andina } \\
\hline $\begin{array}{l}\text { Registro de } \\
\text { micromamíferos }\end{array}$ & sin datos & sin datos & sin datos & sin datos \\
\hline $\begin{array}{l}\text { Registro } \\
\text { polínico }\end{array}$ & sin datos & sin datos & sin datos & $\begin{array}{c}\text { condiciones similares a las } \\
\text { actuales, gran variabilidad } \\
\text { ambiental influenciada } \\
\text { por ENSO } \\
2,8 \text { ka mayor disponibilidad } \\
\text { hídrica (Agua Buena) }\end{array}$ \\
\hline $\begin{array}{l}\text { Registro } \\
\text { glacial }\end{array}$ & sin datos & sin datos & $\begin{array}{c}\text { 5,7-4,4 ka avances } \\
\text { glaciarios } \\
\text { (alto valle Río Grande) }\end{array}$ & $\begin{array}{l}2,5-2,2 \text { ka y } 0,4 \mathrm{ka} \\
\text { reavances glaciarios } \\
\text { (alto valle Río Grande) }\end{array}$ \\
\hline $\begin{array}{l}\text { Registro } \\
\text { sedimentológico }\end{array}$ & sin datos & sin datos & sin datos & sin datos \\
\hline $\begin{array}{l}\text { Registro } \\
\text { malacológico }\end{array}$ & sin datos & sin datos & sin datos & sin datos \\
\hline
\end{tabular}

Tabla 8.4. Diferentes proxies paleoambientales en el sur de Mendoza, desde el Pleistoceno tardío final hasta el Holoceno tardío. Información emanada de este trabajo y copilada de diversas fuentes. Abreviaturas de los sitios arqueológicos en tabla 8.1 . 


\begin{tabular}{|c|c|c|c|c|}
\hline & $\begin{array}{c}\text { Pleistoceno tardío final } \\
\left(21-10 \mathrm{ka}{ }^{14} \mathrm{C} \mathrm{AP}\right) \\
\end{array}$ & $\begin{array}{c}\text { Holoceno temprano } \\
\left(10-8 \mathrm{ka}^{14} \mathrm{C} \mathrm{AP}\right)\end{array}$ & $\begin{array}{l}\text { Holoceno medio } \\
\left(8-4 \text { ka }{ }^{14} \mathrm{C} \mathrm{AP}\right) \\
\end{array}$ & $\begin{array}{l}\text { Holoceno tardío } \\
\left(4-0 \text { ka }{ }^{14} \mathrm{C} \mathrm{AP}\right)\end{array}$ \\
\hline \multicolumn{5}{|l|}{ Patagónica } \\
\hline $\begin{array}{l}\text { Registro de } \\
\text { micromamíferos }\end{array}$ & sin datos & $\begin{array}{c}8,9 \text { ka ambiente estepas } \\
\text { arbustivas abiertas, } \\
\text { rocoso y pedregoso, } \\
\text { con desarrollo de vegas } \\
\text { (AMA-3) }\end{array}$ & $\begin{array}{c}5-3,8 \text { ka menor } \\
\text { heterogeneidad ambiental } \\
\text { (Caverna de Las Brujas) } \\
\text { estepas arbustivas abiertas, } \\
\text { rocoso y pedregoso } \\
\text { (AMA-3) }\end{array}$ & $\begin{array}{c}\text { 3,8-2,2 ka aumento de la } \\
\text { arbustización } \\
\text { 2,2-0,1 ka continúa el ambiente } \\
\text { abierto, pedregoso, rocoso y } \\
\text { con vegas, aunque con } \\
\text { variabilidad ambiental } \\
\text { (AMA-3) } \\
\text { 2,1-0,6 ka ambiente abierto, } \\
\text { pedregoso, rocoso y con vegas } \\
0,6 \text { ka un retroceso de vegas } \\
\text { (LS-3) } \\
4 \text { ka ambiente estepas } \\
\text { arbustivas abiertas, rocoso } \\
\text { y pedregoso (CP) } \\
\text { 3,2-0 ka ambiente abierto, } \\
\text { pedregoso y rocoso } \\
1,4-0,77 \text { ka mayor } \\
\text { disponibilidad hídrica (CAC) } \\
3,8 \text { ka ambiente abierto, rocoso } \\
\text { pedregoso, relacionado al Monte } \\
1,5 \text { ka evidencias de } \\
\text { mejoramiento ambiental (CL) } \\
\text { actualmente deterioro } \\
\text { antrópico por el ganado }\end{array}$ \\
\hline $\begin{array}{l}\text { Registro } \\
\text { polínico }\end{array}$ & sin datos & sin datos & sin datos & $\begin{array}{l}3 \text { ka aumento de la temperatura } \\
\text {-condiciones similares a las } \\
\text { actuales- (turbera en Río Salado) }\end{array}$ \\
\hline $\begin{array}{l}\text { Registro } \\
\text { glacial }\end{array}$ & $\begin{array}{l}\text { 13-10 ka período de } \\
\text { menor glaciación luego } \\
\text { del Último Máximo } \\
\text { Glaciar (alto valle } \\
\text { Río Atuel) }\end{array}$ & $\begin{array}{l}\text { glaciares en retroceso } \\
\text { (alto valle Río Atuel) }\end{array}$ & $\begin{array}{c}\text { 6-4,5 ka avances glaciarios } \\
\text { (alto valle Río Atuel) } \\
5,7-4,4 \text { ka avances } \\
\text { glaciarios (alto valle } \\
\text { Río Grande) }\end{array}$ & $\begin{array}{c}3 \text { ka retracción glaciar (alto } \\
\text { valle Río Atuel) } \\
2,5-2,2 \text { ka y } 0,4 \text { ka reavances } \\
\text { glaciarios (alto valle Río Grande) }\end{array}$ \\
\hline
\end{tabular}

Tabla 8.4. (continuación) Diferentes proxies paleoambientales en el sur de Mendoza, desde el Pleistoceno tardío final hasta el Holoceno tardío. Información emanada de este trabajo y copilada de diversas fuentes. Abreviaturas de los sitios arqueológicos en tabla 8.1. 


\begin{tabular}{|c|c|c|c|c|}
\hline & $\begin{array}{c}\text { Pleistoceno tardío final } \\
\left(21-10 \mathrm{ka}{ }^{14} \mathrm{C} \mathrm{AP}\right)\end{array}$ & $\begin{array}{l}\text { Holoceno temprano } \\
\left(10-8 \mathrm{ka}^{14} \mathrm{C} \mathrm{AP}\right)\end{array}$ & $\begin{array}{l}\text { Holoceno medio } \\
\left(8-4 \mathrm{ka}^{14} \mathrm{C} \text { AP }\right)\end{array}$ & $\begin{array}{l}\text { Holoceno tardío } \\
\left(4-0 \text { ka }{ }^{14} \mathrm{C} \text { AP) }\right.\end{array}$ \\
\hline $\begin{array}{l}\text { Registro } \\
\text { sedimentológico }\end{array}$ & sin datos & $\begin{array}{c}\text { sistema fluvial o lacustre } \\
\text { de mayor circulación - } \\
\text { condiciones homólogas } \\
\text { a las actuales- } \\
\text { (Puesto Vicencio, } \\
\text { laguna Llancanelo) }\end{array}$ & $\begin{array}{l}\text { 6,4-1,9 ka condiciones } \\
\text { más húmedas y frías } \\
\text { que el presente } \\
\text { (Laguna El Sosneado) }\end{array}$ & $\begin{array}{c}\text { 6,4-1,9 ka ídem Holoceno medio } \\
\text { 1,9-0,5 ka AP aridez y mayor } \\
\text { temperatura, vegetación } \\
\text { ecotono Monte-Patagonia } \\
0,5 \text { ka AP mas humedad, } \\
\text { vegetación ecotono Monte- } \\
\text { Patagonia (L. El Sosneado) } \\
\text { 4,1-2,8 ka AP desarrollo de vegas } \\
\text { 2,8 ka menor disponibilidad } \\
\text { hídrica(Agua Buena) } \\
\text { 3,8-1,4 ka AP microambiente } \\
\text { húmedo (Vega de la Cueva) }\end{array}$ \\
\hline $\begin{array}{l}\text { Registro } \\
\text { malacológico }\end{array}$ & sin datos & $\begin{array}{c}\text { ídem -sedimentológico- } \\
\text { (Puesto Vicencio, } \\
\text { laguna Llancanelo) }\end{array}$ & sin datos & $\begin{array}{c}\text { cuerpo de agua muy somero y } \\
\text { vegetado de tipo palustre } \\
\text { ambiente semejante al actual } \\
\text { (Puesto Moya, } c a \text {. Laguna } \\
\text { Llancanelo) }\end{array}$ \\
\hline \multicolumn{5}{|l|}{ Monte } \\
\hline $\begin{array}{l}\text { Registro de } \\
\text { micromamíferos }\end{array}$ & sin datos & sin datos & sin datos & $\begin{array}{c}\text { 1,6-1 ka ecotono Monte- } \\
\text { estepa Patagónica (ALM) } \\
\text { 1,5-0,25 ka taxones } \\
\text { asociados al Monte } \\
\text { (RA-1, ACA-1, LP-1) }\end{array}$ \\
\hline $\begin{array}{l}\text { Registro } \\
\text { polínico }\end{array}$ & $\begin{array}{l}\text { 12-10 ka cambio de } \\
\text { condiciones de estepa } \\
\text { Patagónica a Monte } \\
\text { (Gruta del Indio) }\end{array}$ & $\begin{array}{l}\text { 9-5 ka aumento de la } \\
\text { vegetación del Monte } \\
\text { (Gruta del Indio) } \\
\text { mayor disponibilidad } \\
\text { hídrica (La Guevarina) }\end{array}$ & $\begin{array}{c}5 \text { ka vegetación del } \\
\text { Monte (Gruta del Indio) }\end{array}$ & $\begin{array}{c}\text { vegetación del Monte en todo } \\
\text { el periodo, como en la actualidad } \\
\text { 1,6-1,2 ka ecotono Monte- } \\
\text { Patagonia (Gruta del Indio) }\end{array}$ \\
\hline $\begin{array}{l}\text { Registro } \\
\text { glacial }\end{array}$ & sin datos & sin datos & sin datos & sin datos \\
\hline $\begin{array}{l}\text { Registro } \\
\text { sedimentológico }\end{array}$ & $\begin{array}{c}\text { 21,7-14,4 ka reactivación } \\
\text { eólica asociada aridez } \\
\text { a mayor } \\
\text { (planicie sanrafaelina) }\end{array}$ & sin datos & $\begin{array}{c}\text { reactivación eólica } \\
\text { asociada mayor aridez } \\
\text { (planicie } \\
\text { sanrafaelina) }\end{array}$ & sin datos \\
\hline $\begin{array}{l}\text { Registro } \\
\text { malacológico }\end{array}$ & sin datos & $\begin{array}{c}\text { ambientes lacustres } \\
\text { someros y vegetados } \\
\text { en la planicie de } \\
\text { inundación (Villa Atuel } \\
\text { La Guevarina) } \\
\end{array}$ & $\begin{array}{c}\text { condiciones más } \\
\text { áridas que las actuales } \\
\text { (Villa Atuel = } \\
\text { La Guevarina) } \\
\end{array}$ & sin datos \\
\hline
\end{tabular}

Tabla 8.4. (continuación) Diferentes proxies paleoambientales en el sur de Mendoza, desde el Pleistoceno tardío final hasta el Holoceno tardío. Información emanada de este trabajo y copilada de diversas fuentes. Abreviaturas de los sitios arqueológicos en tabla 8.1 .

\subsubsection{Pleistoceno tardio final (21-10 ka AP)}


En el área de la planicie del sur de Mendoza, los estudios realizados por Tripaldi (2010) y Tripaldi et al. (2010) en los extensos campos de dunas, señalan condiciones más áridas entre 21,7-14,4 ka AP (basado en dataciones OSL), a partir de la reactivación de sedimentos eólicos. Coincidentemente, Tripaldi et al. (2011) en base a registros sedimentarios de la misma área, documentaron una importante actividad eólica durante ca. 24-12 ka AP (basado en dataciones OSL). Por su parte, el registro polínico del sitio Gruta del Indio analizado por D’Antoni (1980, 1983) y Markgraf (1983) mostró un cambio de condiciones climáticas frías y semiáridas a una de mayor temperatura y aridez hacia $12-10 \mathrm{ka}{ }^{14} \mathrm{C} \mathrm{AP}$, pasando de una vegetación Patagónica a una de tipo Monte.

En el alto valle del Río Atuel, cerca del Sosneado, Stingl y Garleff (1985) observaron un retroceso glaciar hacia $13-10 \mathrm{ka}{ }^{14} \mathrm{C} \mathrm{AP}$, posteriormente al Último Máximo Glaciar.

En otras áreas cercanas como el norte de Mendoza y oeste de San Luis, Gonzáles (1994) De Francesco et al. (2007) y De Francesco (2010), a partir de las sucesiones malacológicas de sitios del arroyo La Estacada, Río Desaguadero y Salinas del Bebedero, señalan un ambiente árido con escasa vegetación, desarrollándose un proceso de agradación fluvial en los ríos Mendoza y Tunuyán entre ca. 20-10 ka ${ }^{14} \mathrm{C}$ AP. Asimismo, en un sector del Río Desaguadero cercano a la desembocadura del Río Tunuyán, Chiesa et al. (2010) analizaron la sucesión sedimentaria de los perfiles La Guasquita y Río Jarilla. Estos autores, a partir del desarrollo de una red de drenaje de envergadura con niveles lacustres altos, indicaron incrementos en la temperatura relacionados a un proceso de deglaciación pero con precipitaciones en cordillera para el Pleistoceno tardío. Por su parte, Mehl (2010) observó que los depósitos aluviales de los arroyos La Estacada y Anchayuyo (cuenca del Río Tunuyán, Valle de Uco) presentaron una agregación fluvial activa, con aportes eólicos, desde entre $14-10 \mathrm{ka}{ }^{14} \mathrm{C}$ AP. La autora concluyó que la reactivación de los sistemas fluviales del piedemonte hacia el Pleistoceno tardío podría vincularse con cambios ambientales ocurridos luego del Último Máximo Glaciar.

Sin bien no se cuenta con registros fósiles de micromamíferos para el Pleistoceno final en el sur de Mendoza (Tabla 8.4), un análisis reciente del sitio arqueológico Cueva Huenul 1, ubicado en el extremo norte de Neuquén y a pocos kilómetros de la margen sur del Río Colorado (36 56'45" S, 6947'32" O), mostró una marcada estabilidad taxonómica desde el Pleistoceno tardío ( $c a .13,8-11,8 \mathrm{ka}{ }^{14} \mathrm{C}$ AP / 17-13,7 ka cal AP) hasta el Holoceno tardío 
(1,4 ka ${ }^{14} \mathrm{C}$ AP / 1,3 ka cal AP) (Fernández et al., 2011b, en prensa). Los autores citados, registraron un secuencia dominada por Eligmodontia sp., P. xanthopygus, M. australis, Ctenomys sp. y T. pallidior, sugiriendo condiciones de estepa arbustiva abierta y roquedales. No obstante, el hallazgo de A. iniscatus y E. chinchilloides a partir del Holoceno, sugieren un ligero cambio en el ambiente hacia condiciones más heterogéneas, incluyendo un mosaico de estepas arbustivas abiertas, peladales y áreas rocosas (Fernández et al., 2011b, en prensa). En coincidencia, el análisis polínico preliminar realizado en el mismo sitio exhibió cambios menores a través de la secuencia (Pompei et al., 2011). En este sentido, los estudios llevados a cabo en Cueva Huenul 1, mostraron una marcada estabilidad ambiental durante la transición Pleistoceno-Holoceno y una alta resiliencia del desierto del Monte a los cambios climáticos (Fernández et al., 2011b, en prensa; Pompei et al., 2011). En coincidencia, en el noroeste de Neuquén la secuencia polínica de Mallín Vaca Lauquen se mantuvo estable, con expansión de la zona boscosa durante la transición PleistocenoHoloceno (14,8-8,9 ka cal AP), indicando condiciones de mayor humedad y temperatura que tiempos precedentes (Markgraf et al., 2009). No obstante, la secuencia de micromamíferos de Cueva Huenul 1 parece no haber sido afectada por el evento frío Huelmo/Mascardi Cold Reversal, registrado entre 11,4-10,2 ka ${ }^{14} \mathrm{C}$ AP o 13,5-13,2 / 12,811,5 ka cal AP (Hajdas et al., 2003).

Resulta interesante destacar, que recientes estudios filogeográficos con marcadores moleculares señalan para el norte de Neuquén y sur de Mendoza, un área de refugio para varias especies de roedores sigmodontinos tales como A. olivaceus, A. longipilis, C. macronyx, L. micropus y $P$. xanthopygus, diferenciadas genéticamente de poblaciones más australes (Cañón et al., 2010; Lessa et al., 2010; Abud, 2011; Alarcón et al., 2011; Riberón, 2011). Según estos autores, las poblaciones de estas especies se expandieron hacia el sur hasta alcanzar el rango de distribución actual, posteriormente al Último Máximo Glaciar. Asimismo, las poblaciones con refugios en el norte de Neuquén y Mendoza fueron más estables y las correspondientes a latitudes mayores posiblemente fueron más susceptibles a los cambios climáticos ocurridos en relación a los ciclos del Neógeno (Lesa et al., 2010). Estas evidencias filogeográficas podrían indicar que el área que involucra al norte de Neuquén y sur de Mendoza no fueron tan afectadas por las retracciones glaciarias, de modo que produjeran cambios en las estructuras génicas de las poblaciones de algunas especies de 
sigmodontinos, como si ocurrió en poblaciones más australes, dejando expuesta la posibilidad de que está región se excluya de la conformación del ambiente patagónico típico.

\subsubsection{Holoceno temprano $(10-8 \mathrm{ka} \mathrm{AP})$}

En el alto valle del Río Atuel, Stingl y Garleff (1985) señalan un continuo retroceso glacial para el Holoceno temprano. Por otra parte, De Francesco y Dieguez (2006) y De Francesco (2010) en base al análisis malacológico y sedimentológico del perfil Puesto Vicencio (laguna Llancanelo), sugieren un paleoambiente similar al ambiente actual durante el Holoceno temprano, con un sistema fluvial o lacustre de mayor circulación. En cuanto a los micromamíferos de este sector cordillerano, solo se cuenta con datos provenientes de AMA3, donde se registraron taxones (ver sección 8.2.1), asociados a estepas arbustivas abiertas, rocosos y pedregosos, con desarrollo de vegas cordilleranas hacia el 8,9 ka ${ }^{14} \mathrm{C}$ AP.

En el Río Desaguadero cercano a la desembocadura del Río Tunuyán (oeste de San Luis), Chiesa et al. (2010) al estudiar los perfiles La Guasquita y Río Jarilla, registraron una disminución del régimen fluvial y bajos niveles lacustres, posiblemente debido a un aumento en la temperatura en la planicie y a escasas precipitaciones durante la transición Pleistoceno-Holoceno temprano.

\subsubsection{Holoceno medio $(8-4 \mathrm{ka} \mathrm{AP})$}

En la planicie del sur de Mendoza, D’Antoni (1980, 1983) y Markgraf (1983) en Gruta del Indio, observaron un aumento de la vegetación del Monte entre 5-2 ka ${ }^{14} \mathrm{C} \mathrm{AP}$, indicando niveles de temperatura en ascenso. Asimismo, Tripaldi (2010) y Tripaldi et al. (2010) a partir de la reactivación eólica en la planicie sanrafaelina, sugieren pulsos de mayor aridez durante este período. En coincidencia, De Francesco y Dieguez (2006) y De Francesco (2010), en base a la ausencia de moluscos en la sección media del Río Atuel (Villa Atuel = La Guevarina) indicaron condiciones más áridas para el Holoceno medio.

En el área cordillerana, Stingl y Garleff (1985) señalan una etapa de avances glaciarios hacia el 6-4,5 ka ${ }^{14} \mathrm{C}$ AP, asociado a incrementos de las precipitaciones. En relación al registro de micromamíferos de esta área, si bien en los intervalos temporales de las unidades de análisis 
del sitio AMA-3 no se tuvo en cuenta el Holoceno medio, se destaca que el nivel 23 de la secuencia presentó una datación $c a .5,4$ ka ${ }^{14} \mathrm{C}$ AP (ver Capítulo 7), con registro de Ctenomys sp., P. xanthopygus, E. chinchilloides y Eligmodontia sp., taxones asociados a un ambiente de estepas arbustivas abiertas rocoso y pedregoso, indicando posiblemente un ambiente más árido que el período anterior.

En la cuenca superior del Río Grande, los trabajos de Espizua (2003, 2005), sobre drift de los valles El Azufre y El Peñón del sistema Río Valenzuela, documentaron reavances neoglaciarios durante el 5,7-4,4 $\mathrm{ka}{ }^{14} \mathrm{C} \mathrm{AP}$, asociados a un proceso de mayor aridez. Congruentemente, en lo que concierne a los micromamíferos, Gasco et al. (2006) al analizar el sitio arqueológico Caverna de Las Brujas $\left[5 \pm 0,5 \mathrm{ka} \mathrm{AP}(\mathrm{TL})\right.$ y $3,7 \mathrm{ka}{ }^{14} \mathrm{C}$ AP (4 ka cal AP)], observaron un ensamble caracterizado por la abundancia de Ctenomys sp. y $P$. xanthopygus, la presencia de E. chinchilloides, Eligmodontia sp., Abrothrix sp. у M. australis y la ausencia de L. halli, T. pallidior, L. micropus, R. auritus, C. macronyx y A. olivaceus (presentes en el parámetro actualístico local). Esta situación de baja riqueza y diversidad taxonómica (Figuras 8.3 y 8.5 ), fue interpretada por los autores como un proceso de menor heterogeneidad ambiental hacia finales del Holoceno medio y comienzos del Holoceno tardío, aunque no descartan que procesos tafonómicos y diferencias de tamaño muestral hallan producido sesgos en los ensambles.

Este proceso de mayor aridez en el sur de Mendoza, es apoyado por numerosos trabajos realizados en la otra vertiente de la cordillera (ver Capitulo 3), entre los que se destaca el estudio multiproxy de laguna Aculeo en Chile central (Jenny et al., 2002; Villa-Martínez et al., 2003, 2004). Como también, en el norte de Mendoza (e.g., turbera Salina 2, Markgraf, 1983; Agua de La Cueva, García et al., 1999; Paez y Zárate, 2000), centro de Mendoza (La

Escala y Brazo Abandonado, Rojo et al., 2012) y noroeste de Neuquén (Mallín Vaca Lauquen, Markgraf et al., 2009).

\subsubsection{Holoceno tardio (4-0 $\mathrm{ka} \mathrm{AP)}$}

En la planicie del sur de Mendoza, D’Antoni (1980, 1983) y Markgraf (1983) señalan que desde $c a$. 3-2 ka ${ }^{14} \mathrm{C}$ AP se habrían establecido la fisonomía actual de la vegetación en el área circundante a Gruta del Indio. No obstante, estos autores indican un avance de las 
vegetación Patagónica y un retroceso de la vegetación del Monte entre 1,6-1,2 ka ${ }^{14} \mathrm{C}$ AP (ver detalles en Capítulo 3). En coincidencia, el registro de micromamíferos de Agua de La Mula exhibió un ensamble (ver sección 8.2.1) con características ecotonales entre el desierto del Monte y la estepa Patagónica. En tanto, el resto de los sitios arqueológicos de la planicie Mendocina (RA-1, ACA-1 y LP-1) estuvieron representados por taxones (ver sección 8.2.1) afines al desierto del Monte, ambiente imperante en la actualidad.

En el área cordillerana, Markgraf (1983) en base al estudio de la turbera Salado (río Salado, los Molles), distinguió un cambio hacia el $3 \mathrm{ka}{ }^{14} \mathrm{C}$ AP con la presencia de elementos polínicos más diversos hacia una zona de transición, evidenciando un cambio en la altitud entre el límite de la vegetación Andina y del Monte, un incremento en la temperatura y condiciones similares a las actuales. Asimismo, Stingl y Garleff (1985) proponen un rápido retroceso glaciar hacia $3 \mathrm{ka}{ }^{14} \mathrm{C} \mathrm{AP}$, cuando los glaciares del alto valle del Río Atuel alcanzan su posición actual. Asimismo, Páez et al. (2010) a partir de la secuencia de polínica de Agua Buena (cuenca superior del Atuel), señalan un ambiental similar al actual hacia el Holoceno tardío. Sin embargo, indican que luego de $c a .2,8 \mathrm{ka}{ }^{14} \mathrm{C}$ AP hubo un aumento en la disponibilidad de agua en los sistemas fluviales, posiblemente bajo la influencia del evento ENSO. En coincidencia, numerosos estudios realizados en áreas cercanas al sur de Mendoza relacionaron la variabilidad climática de finales del Holoceno tardío con el evento ENSO (e.g., Cobos y Boninsegna, 1983; Boninsegna y Delgado de Brun, 2002; Jenny et al., 2002; Villa-Martínez et al., 2003, 2004; Markgraf et al., 2009; Masiokas et al., 2009). Por otra parte, Navarro et al. (2010) realizaron estudios sedimentológicos, palinológicos y geomorfológicos en sitios localizados en las inmediaciones de El Sosneado. A partir del registro de depósitos de turba señalan el desarrollo de vegas y condiciones más estables entre 4,1-2,8 ka cal AP. Después de 2,8 ka cal AP, observaron menor disponibilidad hídrica para el desarrollo de vegas cordilleranas. A partir de la sección media del perfil Vega de la Cueva, indicaron un microambiente húmedo entre 3,8-1,4 ka cal AP. Datos de Laguna El Sosneado revelaron una alta combustión de madera y el desarrollo de una estepa Patagónica entre el Holoceno medio y tardío (6,4-1,9 ka cal AP), indicando condiciones más húmedas y frías que en el presente. Entre 1,9-0,5 ka cal AP, existen condiciones más áridas y de mayor temperatura y escasa actividad del fuego, indicada por aumentos de la vegetación dispersa de tipo ecotono Monte-Patagónica. A partir 
del 0,5 ka cal AP, continua el ambiente de transición entre Monte y estepa Patagónica, exhibiendo un ligero repunte de la humedad y el establecimiento de las condiciones ambientales modernas (Navarro et al., 2009; Navarro y Whitlock, 2010). Una constante entre los ensambles de micromamíferos recuperados de los sitios arqueológicos del alto valle del Río Atuel, (AMA-3, LS-3, Cueva Palulo), es su relación a los ambientes abiertos, pedregosos y con afloramientos rocosos durante todo el Holoceno tardío. En el sitio AMA3, se observó un desarrollo estable de vegas durante todo el Holoceno tardío (ver sección 8.2.1), en congruencia con datos provenientes del perfil Vega de la Cueva (cf. Navarro et al., 2010). No obstante, en coincidencia con la información emanada del perfil Laguna El Sosneado (cf. Navarro et al., 2010), en AMA-3 se detectó un aumento de la arbustización entre 3,8-2,2 ka ${ }^{14} \mathrm{C}$ AP (4,2-2,2 ka cal AP) y mayor variabilidad ambiental, alternando condiciones húmedas y secas entre $2,2 \mathrm{ka}{ }^{14} \mathrm{C}$ AP $(2,2 \mathrm{ka}$ cal AP) y 0,1 ka AP (cronología relativa, véase Capítulo 7). Por su parte, en el sitio LS-3 (ver sección 8.2.1) se registró el desarrolló de vegas cordilleranas entre 2,1-0,6 ka ${ }^{14} \mathrm{C}$ AP (2,1-0,6 cal AP) y un retroceso de las mismas hacia $0,6 \mathrm{ka}{ }^{14} \mathrm{C}$ AP $(0,6 \mathrm{ka}$ cal $\mathrm{AP})$, lo cual es parangonable con el perfil Laguna El Sosneado (cf. Navarro et al., 2010). En tanto que en el valle de Las Leñas, los ensambles de micromamíferos de Cueva Arroyo Colorado (ver sección 8.2.1) también se relacionan a un ambiente de estepas arbustivas abiertas con alta proporción de suelo desnudo, pedregoso, abundante roca expuesta y vegas cordilleranas, desde $3,2 \mathrm{ka}{ }^{14} \mathrm{C} \mathrm{AP}$ (3,4 ka cal AP) hasta la actualidad. Aunque, con una ligera variación para el intervalo ca. 1,4-0,77 ka ${ }^{14} \mathrm{C}$ AP (1,3-0,73 ka cal AP), donde se registró mayor disponibilidad hídrica.

En el piedemonte, De Francesco y Dieguez (2006) y De Francesco (2010), en base al registro malacológico en secciones del Río Atuel (Puesto Moya, ca. $20 \mathrm{~km}$ aguas arriba de Puesto Vicencio), sugieren un cuerpo de agua muy somero y vegetado de tipo palustre, semejante a la actualidad. Espizua (2003, 2005), en base al drift de los valles El Azufre y El Peñón del sistema Río Valenzuela, en la cuenca superior del Río Grande, documentaron un segundo avance entre 2,5-2,2 $\mathrm{ka}{ }^{14} \mathrm{C}$ AP y un tercero hacia ca. $0,4 \mathrm{ka}{ }^{14} \mathrm{C} \mathrm{AP}$, vinculado con la Pequeña Edad de Hielo. Los ensambles de micromamíferos recuperados del sitio Cueva de Luna (ver sección 8.2.1), indicaron que un ambiente con características afines a estepas arbustivas abiertas con alta proporción de suelo desnudo, pedregoso y abundante roca expuesta, se mantuvo constante desde comienzos del Holoceno tardío hasta la actualidad. 
Sin embargo, se registraron taxones afines al desierto del Monte y a la estepa Patagónica, con mayores niveles de riqueza hacia $1,5 \mathrm{ka}{ }^{14} \mathrm{C}$ AP.

En un sector del Río Desaguadero cercano a la desembocadura del Río Tunuyán (San Luis), Chiesa et al. (2010) analizaron la sucesión sedimentaria de los perfiles La Guasquita y Río Jarilla. Los autores señalan que los cambios climáticos y el riego artificial de los últimos siglos produjeron la desvinculación hidrológica entre los ríos Desaguadero y Bermejo, la disminución del caudal del Río Tunuyán, bajantes en lagunas del sistema y la modificación geomorfológica y biótica del Río Desaguadero.

En síntesis, durante el Holoceno tardío se establecen las condiciones climáticas actuales, aunque con algunas fluctuaciones ambientales influenciadas por los eventos ENSO y procesos de escala global como la Pequeña Edad de Hielo (siglos XVI-XIX). En los siglos siguientes, el ambiente sufrió modificaciones producto de la acción antrópica.

\subsection{Isótopos estables}

Si bien originalmente este plan de tesis no consideraba el uso de isótopos estables en la discusión de las hipótesis propuestas, en los últimos años se ha generado una importante cantidad de información sobre el tema que puede ayudar en la contrastación de las ideas presentadas. Previamente a abordar el análisis de los isótopos estables en relación al los micromamíferos del sur de Mendoza, se expondrán algunos conceptos teóricos y metodológicos para alcanzar un mayor compresión al tema.

En sus inicios este tipo de investigación se orientó a evaluar la importancia del consumo de Zea mays en la dieta de las poblaciones humanas del sur de Mendoza (Gil, 2003, 2006; Novellino et al., 2004; Gil et al., 2006a, 2009a, 2010) y posteriormente estos estudios se ampliaron para discutir el consumo de diferentes tipos de recursos animales y vegetales de la región (Llano, 2009; Gil et al., 2011). De esta forma, se generó una importante cantidad de datos sobre restos óseos humanos, recursos animales y vegetales del sur de Mendoza.

Las plantas utilizan el $\mathrm{CO}_{2}$ atmosférico e incorporan fracciones del carbono $\left({ }^{13} \mathrm{C} /{ }^{12} \mathrm{C}\right)$ mediante tres tipos de vías fotosintéticas: Ciclo de Calvin-Benson $\left(\mathrm{C}_{3}\right)$, Ciclo de HatchSlack $\left(\mathrm{C}_{4}\right)$ y Crasuláceas de Metabolismo Ácido (CAM). La mayor parte de las plantas usan la ruta metabólica $\mathrm{C} 3$, las cuales están asociadas a ambientes fríos y templados (e.g., 
Apiaceae, Asteraceae, Ephedraceae, Fabaceae) y tendrán valores entre -20 y -35\%o en el colágeno. Las $\mathrm{C}_{4}$, incluyen plantas de ambientes tropicales, cálidos y secos como la especie doméstica Z. mays, algunas especies de Poaceae y especies arbustivas pertenecientes a Chenopodiaceae, y sus valores oscilan entre -9 y $-17 \%$. Finalmente, las CAM son plantas suculentas de zonas áridas (Crassulaceae, Cactaceae) y presentan valores entre -10 y -22\%, solapando los rangos de plantas $\mathrm{C}_{3}$ y $\mathrm{C}_{4}$ debido a que alternativamente utilizan ambos tipos de fotosíntesis (véase Barberena, 2002; y literatura allí citada). Resulta interesante que los valores de $\delta{ }^{13} \mathrm{C}$ del colágeno de los grandes herbívoros están enriquecidos (más positivos) cerca de 5\% del promedio dietario. En los mamíferos carnívoros la señal isotópica de su dieta proteica deriva de animales herbívoros. En los animales omnívoros los valores de $\delta{ }^{13} \mathrm{C}$ del colágeno representan la contribución de las proteínas animales y vegetales en su dieta (Gil et al., 2011). Tanto en humanos como en la fauna, los valores de $\delta{ }^{13} \mathrm{C}$ obtenidos de los tejidos se correlacionan positivamente con aquellos de las especies consumidas, de manera que los estudios de isótopos estables son una buena herramienta para conocer la dieta (véase Barberena, 2002; entre otros).

Por otro lado, la mayor parte del nitrógeno atmosférico se da en forma $\mathrm{N}_{2}$ y tiene una composición isotópica homogénea con un valor de $\delta{ }^{15} \mathrm{~N}$ tendiente a $0 \%$. Asimismo, las plantas asimilan el nitrógeno que se encuentra en el suelo. A medida que avanza la descomposición de la materia orgánica se produce una pérdida relativa del ${ }^{14} \mathrm{~N}$ respecto del ${ }^{15} \mathrm{~N}$, cuya proporción aumenta entre 5 y $10 \%$ (véase Barberena, 2002). Por otra parte, la proporción de $\delta{ }^{15} \mathrm{~N}$ se incrementa cuando se sube en la cadena trófica de modo que los valores de los animales carnívoros son más altos que los herbívoros (Schoeninger y DeNiro, 1984; Barberena, 2002). Los estudios de isótopos estables del nitrógeno, son utilizados frecuentemente para observar diferencias en los niveles tróficos entre individuos (Ambrose y De Niro, 1986; Hedges y Reynard, 2006). Asimismo, se ha demostrado efectos del clima y el ambiente en los valores de $\delta{ }^{15} \mathrm{~N}$ tanto en plantas como en animales (Ambrose y De Niro, 1986; Ambrose, 2000; Hedge y Reynard, 2006). Tanto los valores de $\delta{ }^{13} \mathrm{C}$ como los de $\delta$ ${ }^{15} \mathrm{~N}$ se obtuvieron a partir de estándares internacionales y se expresan en 1 por $1.000(\%)$ (Ambrose, 1993; Tykot, 2006). La abundancia relativa de los isótopos del carbono $\left({ }^{13} \mathrm{C} /{ }^{12} \mathrm{C}\right)$ y del nitrógeno $\left({ }^{15} \mathrm{~N} /{ }^{14} \mathrm{~N}\right)$ en la fracción orgánica del hueso (colágeno; $\delta{ }^{13} \mathrm{Ccol}$.) se relaciona con el componente proteico de la dieta, mientras que la abundancia relativa de la fracción 
inorgánica (hidroxiapatita; $\delta{ }^{13}$ Capat.) se asocia a la dieta total, incluyendo proteínas, lípidos y carbohidratos (Ambrose y Norr, 1993).

En este trabajo se utilizan los datos de isótopos estables $\delta{ }^{13} \mathrm{Ccol}$. y $\delta{ }^{15} \mathrm{~N}$, que incluyen un total de 60 muestras de esqueletos humanos de diferentes sitios arqueológicos del sur de la provincia de Mendoza previamente publicados (véase Gil et al., 2010: Tabla 1) y 48 muestras de micromamíferos de diferentes ambientes del sur de Mendoza y extremo norte de Neuquén. Estos últimos, incluyen tanto muestras actuales $(n=23)$ como arqueológicas $(\mathrm{n}=25)$ de G. leucoblephara, M. australis y Ctenomys spp. (Tabla 8.5). La mayor parte de las muestras de micromamíferos fueron seleccionadas y determinadas taxonomicamente por el autor de esta tesis, posteriormente cedidas a Andrew Ugan y Clara Otaola para su procesamiento en el laboratorio de Arqueología del Museo de Historia Natural de San Rafael y finalmente enviadas al Stable Isotope Facilities Lab de la University of Utah para la obtención de los valores isotópicos.

En la figura 8.18 se plotearon los valores de $\delta{ }^{13} \mathrm{Ccol}$. y $\delta{ }^{15} \mathrm{~N}$ de muestras humanas y de micromamíferos de la región. La misma exhibe un importante rango de superposición en los valores de $\delta{ }^{13}$ Ccol. de ambos tipos de muestras. Sin embargo, los valores de micromamíferos se agrupan principalmente por debajo de $-18 \%$ (menos enriquecidas) mientras que la mayor parte de las muestras de humanos se agrupan por encima de este valor (más enriquecidas).

\begin{tabular}{|c|c|c|c|c|c|}
\hline Sitios arqueológicos & Coordenadas & Cod. de inden. & $\delta^{13}$ Ccol. & $\delta^{15} \mathbf{N}$ & Taxón \\
\hline Agua de La Mula / Niv.6 & $35^{\circ} 22^{\prime} 24,9^{\prime \prime}$ у $68^{\circ} 15^{\prime} 04,2^{\prime \prime O}$ & MHNSR-ID-69 & 20,54 & 11,73 & Microcavia australis \\
\hline Agua de La Mula / Niv. s/d & $35^{\circ} 22^{\prime} 24,9^{\prime \prime}$ у $68^{\circ} 15^{\prime} 04,2^{\prime \prime} \mathrm{O}$ & MHNSR-ID-71 & 14,53 & 13,34 & Galea leucoblephara \\
\hline Agua de La Mula / Niv.4 & $35^{\circ} 22^{\prime} 24,9^{\prime \prime}$ у $68^{\circ} 15^{\prime} 04,2^{\prime \prime O}$ & MHNSR-ID-72 & 17,3 & 13,84 & Galea leucoblephara \\
\hline Agua de La Mula / Niv.4 & $35^{\circ} 22^{\prime} 24,9^{\prime \prime}$ у $68^{\circ} 15^{\prime} 04,2^{\prime \prime} \mathrm{O}$ & MHNSR-ID-73 & 13,51 & 13,68 & Galea leucoblephara \\
\hline Agua de La Mula / Niv.9 & $35^{\circ} 22^{\prime} 24,9^{\prime \prime}$ у $68^{\circ} 15^{\prime} 04,2^{\prime \prime O}$ & MHNSR-ID-74 & 12,46 & 13,29 & Galea leucoblephara \\
\hline Agua de La Mula / Niv.7 & $35^{\circ} 22^{\prime} 24,9^{\prime \prime}$ у $68^{\circ} 15^{\prime} 04,2^{\prime \prime} \mathrm{O}$ & MHNSR & 16,66 & 13,39 & Galea leucoblephara \\
\hline Agua de La Mula / Niv.7 & $35^{\circ} 22^{\prime} 24,9^{\prime \prime}$ у $68^{\circ} 15^{\prime} 04,2^{\prime \prime} \mathrm{O}$ & MHNSR-ID-66 & 16,86 & 14,54 & Ctenomys sp. \\
\hline Agua de La Mula / Niv.6 & $35^{\circ} 22^{\prime} 24,9^{\prime \prime}$ у $68^{\circ} 15^{\prime} 04,2^{\prime \prime} \mathrm{O}$ & MHNSR-ID-67 & 13,97 & 14,75 & Ctenomys sp. \\
\hline Agua de La Mula / Niv.7 & $35^{\circ} 22^{\prime} 24,9^{\prime \prime}$ у $68^{\circ} 15^{\prime} 04,2^{\prime \prime O}$ & MHNSR-ID-68 & 16,45 & 12,69 & Ctenomys sp. \\
\hline Agua de La Mula / Niv. s/d & $35^{\circ} 22^{\prime} 24,9^{\prime \prime}$ у $68^{\circ} 15^{\prime} 04,2^{\prime \prime} \mathrm{O}$ & MHNSR-ID-76 & 19,81 & 14,66 & Ctenomys sp. \\
\hline Agua de La Mula / Niv.9 & $35^{\circ} 22^{\prime} 24,9^{\prime \prime}$ у $68^{\circ} 15^{\prime} 04,2^{\prime \prime} \mathrm{O}$ & MHNSR-ID-77 & 19,69 & 14,65 & Ctenomys sp. \\
\hline Agua de La Mula / Niv.6 & $35^{\circ} 22^{\prime} 24,9^{\prime \prime}$ у $68^{\circ} 15^{\prime} 04,2^{\prime \prime O}$ & MHN & 10,01 & 14 & Ctenomys sp. \\
\hline Agua de La Mula / Niv.9 & $35^{\circ} 22^{\prime} 24,9^{\prime \prime}$ у $68^{\circ} 15^{\prime} 04,2^{\prime \prime} \mathrm{O}$ & MHNSR-ID-79 & 10,71 & 14,19 & Ctenomys sp. \\
\hline
\end{tabular}

Tabla 8.5. Valores de $\delta{ }^{13} \mathrm{Ccol}$. y $\delta{ }^{15} \mathrm{~N}$ para las muestras de micromamíferos analizadas en esta tesis. Además, se proporcionan datos de procedencia, código de identificación e información taxonómica. 


\begin{tabular}{|c|c|c|c|c|c|}
\hline Sitios arqueológicos & Coordenadas & Cod. de inden. & $\delta^{13}$ Ccol. & $\delta^{15} \mathrm{~N}$ & Taxón \\
\hline Reparo Morado / s/d & $34^{\circ} 45^{\prime} 50^{\prime \prime} \mathrm{S}$ y $68^{\circ} 22^{\prime} 21^{\prime \prime O}$ & MHNSR-ID-258 & 20,41 & 14,22 & Ctenomys sp. \\
\hline Cueva Arroyo Colorado /s/d & $35^{\circ} 12^{\prime} 10,6^{\prime \prime S}$ y $70^{\circ} 04^{\prime} 38,9^{\prime \prime} \mathrm{O}$ & MHNSR-ID-80 & 19,55 & 12,72 & Ctenomys sp. \\
\hline Cueva Arroyo Colorado/CI & $35^{\circ} 12^{\prime} 10,6^{\prime \prime S}$ y $70^{\circ} 04^{\prime} 38,9^{\prime \prime O}$ & MHNSR-ID-81 & 22,06 & 14,11 & Ctenomys sp. \\
\hline Cueva Arroyo Colorado/CI & $35^{\circ} 12^{\prime} 10,6^{\prime \prime S}$ y $70^{\circ} 04^{\prime} 38,9^{\prime \prime} \mathrm{O}$ & MHNSR-ID-82 & 19,49 & 14,47 & Ctenomys sp. \\
\hline Cueva Arroyo Colorado/CII & $35^{\circ} 12^{\prime} 10,6^{\prime \prime S}$ y $70^{\circ} 04^{\prime} 38,9^{\prime \prime} \mathrm{O}$ & MHNSR-ID-83 & 20,61 & 13,76 & Ctenomys sp. \\
\hline Alero Puesto Carrasco / s/d & $36^{\circ} 06^{\prime} 13^{\prime \prime S}$ y $69^{\circ} 41^{\prime} 32^{\prime \prime O}$ & MHNSR-ID-256 & 21,09 & 15,17 & Ctenomys sp. \\
\hline Alero Puesto Carrasco / s/d & $36^{\circ} 06^{\prime} 13^{\prime \prime S}$ y $69^{\circ} 41^{\prime} 32^{\prime \prime O}$ & MHNSR-ID-257 & 20,66 & $\mathrm{~s} / \mathrm{d}$ & Ctenomys sp. \\
\hline Cueva Huenul 1/Cuad A1/U-III & $36^{\circ} 56^{\prime} 45^{\prime \prime S}$ y $69^{\circ} 47^{\prime} 32^{\prime \prime O}$ & MHNSR-ID-234 & 20,34 & 13,98 & Ctenomys sp. \\
\hline Cueva Huenul 1/Cuad A1/U-III & $36^{\circ} 56^{\prime} 45^{\prime \prime S}$ y $69^{\circ} 47^{\prime} 32^{\prime \prime O}$ & MHNSR-ID-235 & 18,68 & 15,38 & Ctenomys sp. \\
\hline Cueva Huenul 1/Cuad A1/U-III & $36^{\circ} 56^{\prime} 45^{\prime \prime S}$ y $69^{\circ} 47^{\prime} 32^{\prime \prime O}$ & MHNSR-ID-238 & 19,94 & 15,23 & Ctenomys sp. \\
\hline Cueva Huenul 1/Cuad B1/Niv.6 & $36^{\circ} 56^{\prime} 45^{\prime \prime S}$ y $69^{\circ} 47^{\prime} 32^{\prime \prime O}$ & MHNSR-ID-245 & 19,77 & 14,65 & Ctenomys sp. \\
\hline Cueva Huenul 1/Cuad B1/Niv.6 & $36^{\circ} 56^{\prime} 45^{\prime \prime S}$ y $69^{\circ} 47^{\prime} 32^{\prime \prime O}$ & MHNSR-ID-246 & 19,76 & 15,32 & Ctenomys sp. \\
\hline \multicolumn{6}{|l|}{ Muestras actuales } \\
\hline Domuyo & $36^{\circ} 36^{\prime} 53^{\prime \prime S}$ y $70^{\circ} 18^{\prime} 21^{\prime \prime O}$ & MHNSR-ID-117 & 20,7 & 15,42 & Microcavia australis \\
\hline Gruta del Indio & $34^{\circ} 45^{\prime} \mathrm{S}$ y $68^{\circ} 21^{\prime} \mathrm{O}$ & MHNSR-ID-87a & 20,11 & 13,45 & Microcavia australis \\
\hline Gruta del Indio & $34^{\circ} 45^{\prime} \mathrm{S}$ y $68^{\circ} 21^{\prime} \mathrm{O}$ & MHNSR-ID-87b & 20,08 & 13,86 & Microcavia australis \\
\hline Gruta del Indio & $34^{\circ} 45^{\prime} \mathrm{S}$ y $68^{\circ} 21^{\prime} \mathrm{O}$ & MHNSR-ID-84 & 19,98 & 15,14 & Galea leucoblephara \\
\hline Agua de La Mula & $35^{\circ} 22^{\prime} 34^{\prime \prime S}$ y $68^{\circ} 14^{\prime} 42^{\prime \prime O}$ & MHNSR-ID-210a & 20,95 & 13,27 & Galea leucoblephara \\
\hline Agua de La Mula & $35^{\circ} 22^{\prime} 34^{\prime \prime S}$ y $68^{\circ} 14^{\prime} 42^{\prime \prime O}$ & MHNSR-ID-210b & 21,39 & 13,44 & Galea leucoblephara \\
\hline Agua de La Mula & $35^{\circ} 22^{\prime} 34^{\prime \prime S}$ y $68^{\circ} 14^{\prime} 42^{\prime \prime O}$ & MHNSR-ID-212 & 20,56 & 13,42 & Galea leucoblephara \\
\hline Agua de La Mula & $35^{\circ} 22^{\prime} 34^{\prime \prime S}$ y $68^{\circ} 14^{\prime} 42^{\prime \prime O}$ & MHNSR-ID-213 & 19,86 & 12,51 & Galea leucoblephara \\
\hline Agua de La Mula & $35^{\circ} 22^{\prime} 34^{\prime \prime S}$ y $68^{\circ} 14^{\prime} 42^{\prime \prime O}$ & MHNSR-ID-214 & 20,78 & 8,22 & Galea leucoblephara \\
\hline Agua de La Mula & $35^{\circ} 22^{\prime} 34^{\prime \prime S}$ y $68^{\circ} 14^{\prime} 42^{\prime \prime O}$ & MHNSR-ID-215 & 19,47 & 13,91 & Galea leucoblephara \\
\hline Gruta del Indio & $34^{\circ} 45^{\prime} \mathrm{S}$ y $68^{\circ} 21^{\prime} \mathrm{O}$ & MHNSR-ID-85 & 11,13 & 15,49 & Ctenomys sp. \\
\hline Gruta del Indio & $34^{\circ} 45^{\prime} \mathrm{S}$ y $68^{\circ} 21^{\prime} \mathrm{O}$ & MHNSR-ID-86a & 10,71 & 15,37 & Ctenomys sp. \\
\hline Gruta del Indio & $34^{\circ} 45^{\prime} \mathrm{S}$ y $68^{\circ} 21^{\prime} \mathrm{O}$ & MHNSR-ID-86b & 10,7 & 15,49 & Ctenomys sp. \\
\hline Arroyo Malo & $34^{\circ} 51^{\prime} 18^{\prime \prime S}$ y $69^{\circ} 53^{\prime} 00^{\prime \prime O}$ & MHNSR-ID-314 & $\mathrm{s} / \mathrm{d}$ & 16,93 & Ctenomys sp. \\
\hline Arroyo Malo & $34^{\circ} 51^{\prime} 18^{\prime \prime S}$ y $69^{\circ} 53^{\prime} 00^{\prime \prime O}$ & MHNSR-ID-90 & 18,53 & 15,43 & Ctenomys sp. \\
\hline Arroyo Malo & $34^{\circ} 51^{\prime} 18^{\prime \prime S}$ y $69^{\circ} 53^{\prime} 00^{\prime \prime O}$ & MHNSR-ID-91 & 20,03 & 13,93 & Ctenomys sp. \\
\hline Arroyo Malo & $34^{\circ} 51^{\prime} 18^{\prime \prime S}$ y $69^{\circ} 53^{\prime} 00^{\prime \prime O}$ & MHNSR-ID-92 & 19,05 & 14,21 & Ctenomys sp. \\
\hline Arroyo Malo & $34^{\circ} 51^{\prime} 18^{\prime \prime S}$ y $69^{\circ} 53^{\prime} 00^{\prime \prime O}$ & MHNSR-ID-93 & 19,29 & 13,95 & Ctenomys sp. \\
\hline Arroyo Malo & $34^{\circ} 51^{\prime} 18^{\prime \prime S}$ y $69^{\circ} 53^{\prime} 00^{\prime \prime O}$ & MHNSR-ID-94 & 19,01 & 14,41 & Ctenomys sp. \\
\hline Arroyo Malo & $34^{\circ} 51^{\prime} 18^{\prime \prime S}$ y $69^{\circ} 53^{\prime} 00^{\prime \prime O}$ & MHNSR-ID-96 & 18,84 & 14,62 & Ctenomys sp. \\
\hline Arroyo Malo & $34^{\circ} 51^{\prime} 18^{\prime \prime S}$ y $69^{\circ} 53^{\prime} 00^{\prime \prime O}$ & MHNSR-ID-97 & 19,93 & 15,29 & Ctenomys sp. \\
\hline Arroyo Malo & $34^{\circ} 51^{\prime} 18^{\prime \prime S}$ y $69^{\circ} 53^{\prime} 00^{\prime \prime O}$ & MHNSR-ID-98 & 18,41 & 15,21 & Ctenomys sp. \\
\hline Cueva Huenul & $36^{\circ} 56^{\prime} 45^{\prime \prime S}$ y $69^{\circ} 47^{\prime} 32^{\prime \prime O}$ & MHNSR-ID-65 & 19,55 & 14,36 & Ctenomys sp. \\
\hline
\end{tabular}

Tabla 8.5. (continuación) Valores de $\delta{ }^{13} \mathrm{Ccol}$. y $\delta{ }^{15} \mathrm{~N}$ para las muestras de micromamíferos analizadas en esta tesis. Además, se proporcionan datos de procedencia, código de identificación e información taxonómica. 
Este desacople entre los valores de la mayoría de las muestras de humanos y de micromamíferos sugiere una escasa incidencia de estos animales en la dieta de las poblaciones humanas. Esto coincide con los resultados obtenidos a partir de los análisis tafonómicos discutidos previamente (véase sección 8.1.3). De todas formas, es necesario tener en cuenta que algunas muestras (especialmente de Ctenomys) con valores más enriquecidos pueden explicar los valores obtenidos en las muestras de humanos.

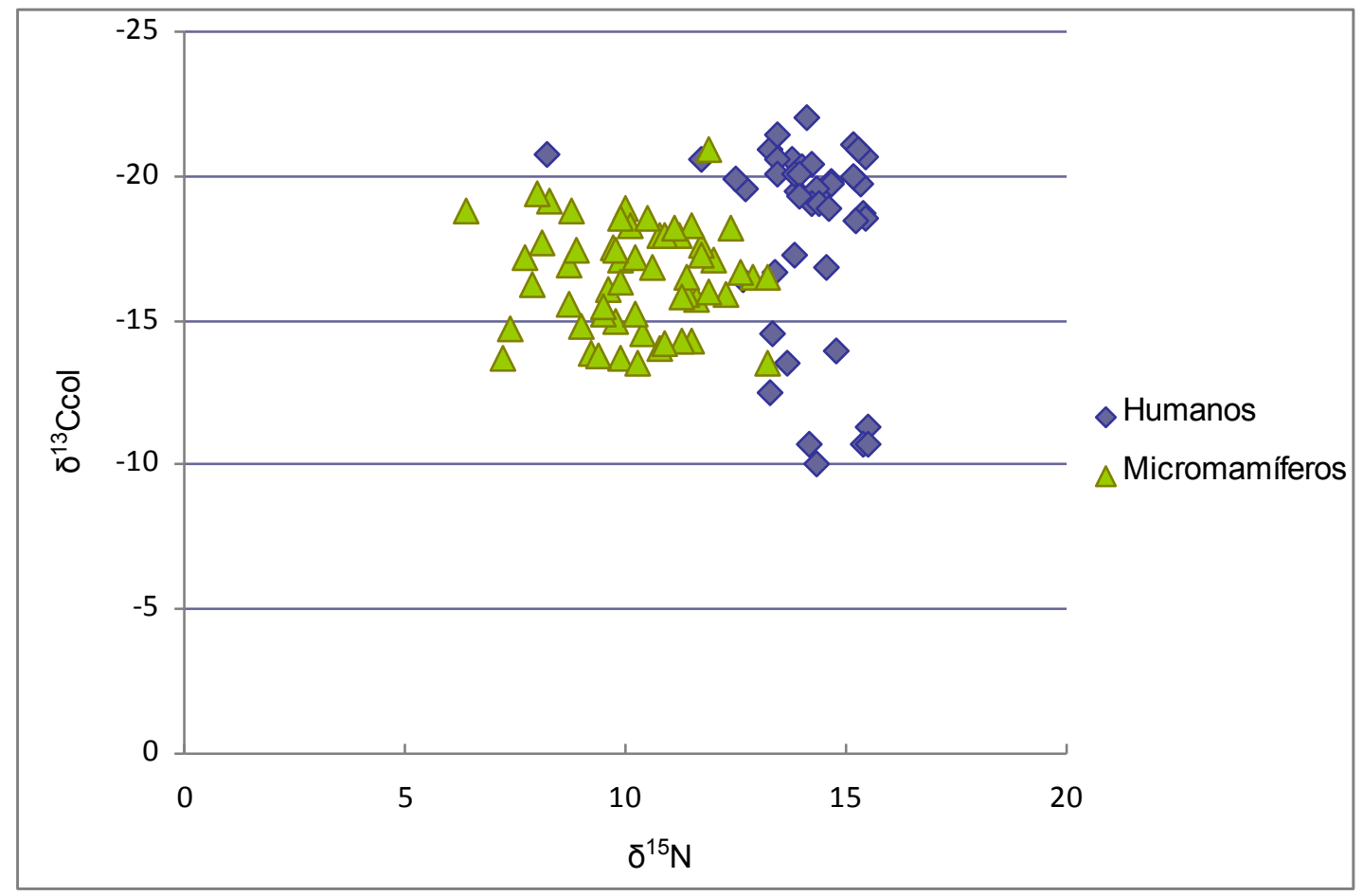

Figura 8.18. Isótopos estables de $\delta{ }^{13} \mathrm{Ccol}$. y $\delta{ }^{15} \mathrm{~N}$ en muestras de micromamíferos y de humanos provenientes del sur de Mendoza. Los valores de las muestras humanas fueron tomados de Gil et al. (2010: Tabla 1).

Con el propósito de evaluar posibles cambios en la dieta de los taxones de micromamíferos analizados, a través del tiempo, se correlacionaron las muestras provenientes de sitios arqueológicos con aquellas provenientes de muestreos actuales (Figura 8.19). Los resultados señalan que no existen diferencias entre ambos tipos de muestras, lo que sugiere una marcada estabilidad a través del tiempo, en congruencia con los resultados paleoambientales discutidos previamente (ver sección 8.2). 


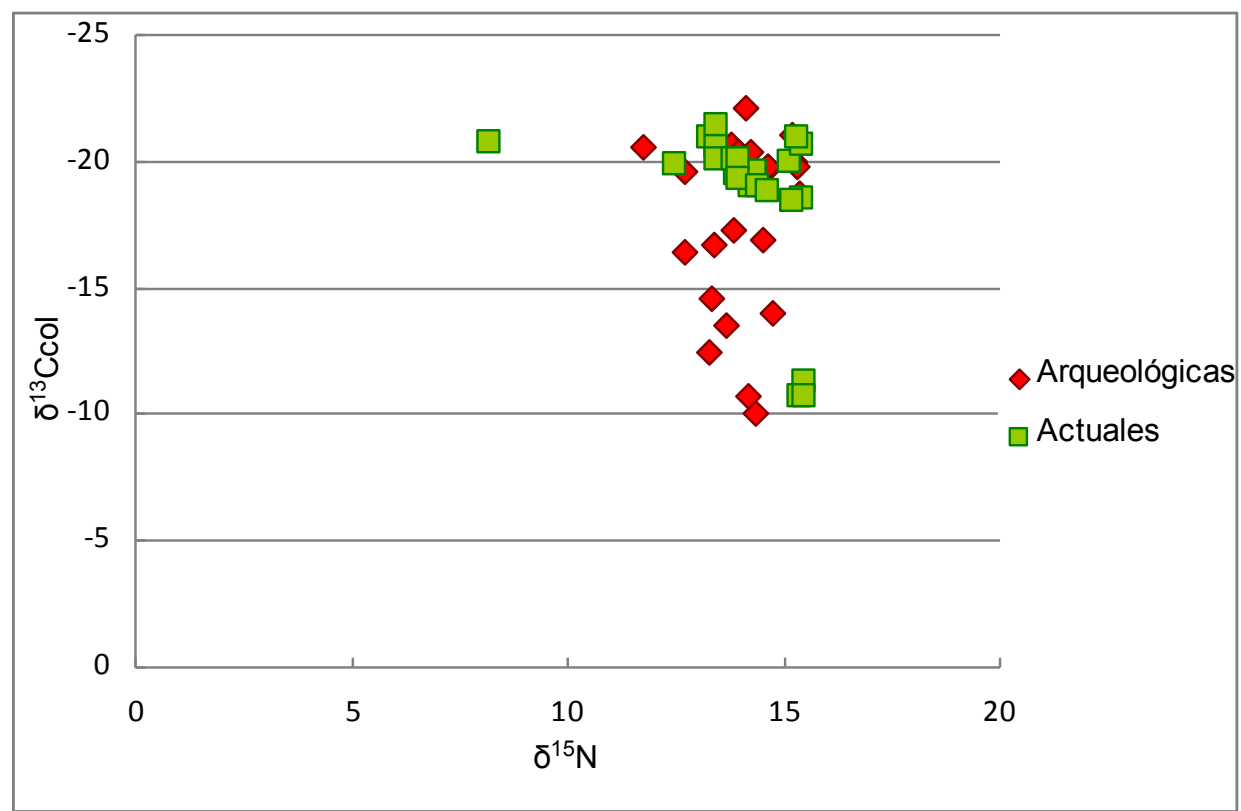

Figura 8.19. Valores de $\delta{ }^{13} \mathrm{Ccol}$. y $\delta{ }^{15} \mathrm{~N}$ de muestras arqueológicas y actuales de los micromamíferos de la región.

Sin embargo, cuando evaluamos los valores de los diferentes taxa de micromamíferos analizados se observa una diferencia significativa entre los mismos. Mientras Galea y Ctenomys tienen una fuerte variación en el rango de recursos consumidos (en términos de plantas $\mathrm{C}_{3} \mathrm{y} \mathrm{C}_{4}$ ), Microcavia presenta solo valores empobrecidos asimilables al consumo de planta $\mathrm{C}_{3}$ (Figura 8.20).

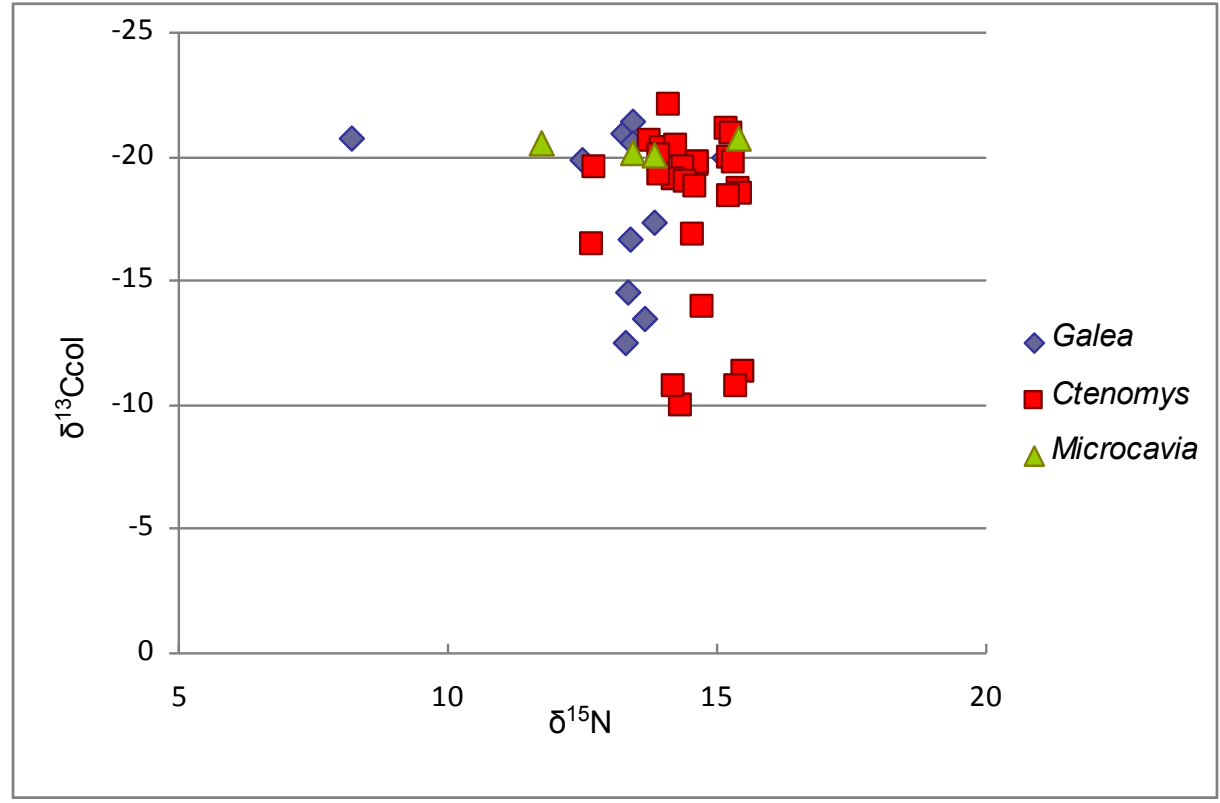


Figura 8.20. Valores de isótopos estables de $\delta{ }^{13} \mathrm{Ccol}$. y $\delta{ }^{15} \mathrm{~N}$ en las muestras de micromamíferos analizadas (actuales y arqueológicas), discriminados por taxa.

Posteriormente, se compararon los valores de las muestras de Ctenomys (taxa con mayor número de muestras analizadas) obtenidas en la estepa Patagónica, con aquellas procedentes del desierto del Monte (Figura 8.21). Los resultados exhiben que las muestras de Ctenomys más enriquecidas provienen del Monte, algo que es esperable dada la mayor presencia de plantas C4 en esa área. Mientras que las muestras menos enriquecidas proceden en su mayoría de estepa Patagónica. Como se ha mostrado en trabajos previos, existe una fuerte correlación entre el nivel altitudinal y el mecanismo fotosintético de las plantas C3 y C4 en regiones áridas y semiáridas de Mendoza. En tal sentido, la distribución de plantas C3 aumentan con la altitud, en detrimento de las plantas C4 (Cavagnaro, 1988; Llano, 2009).

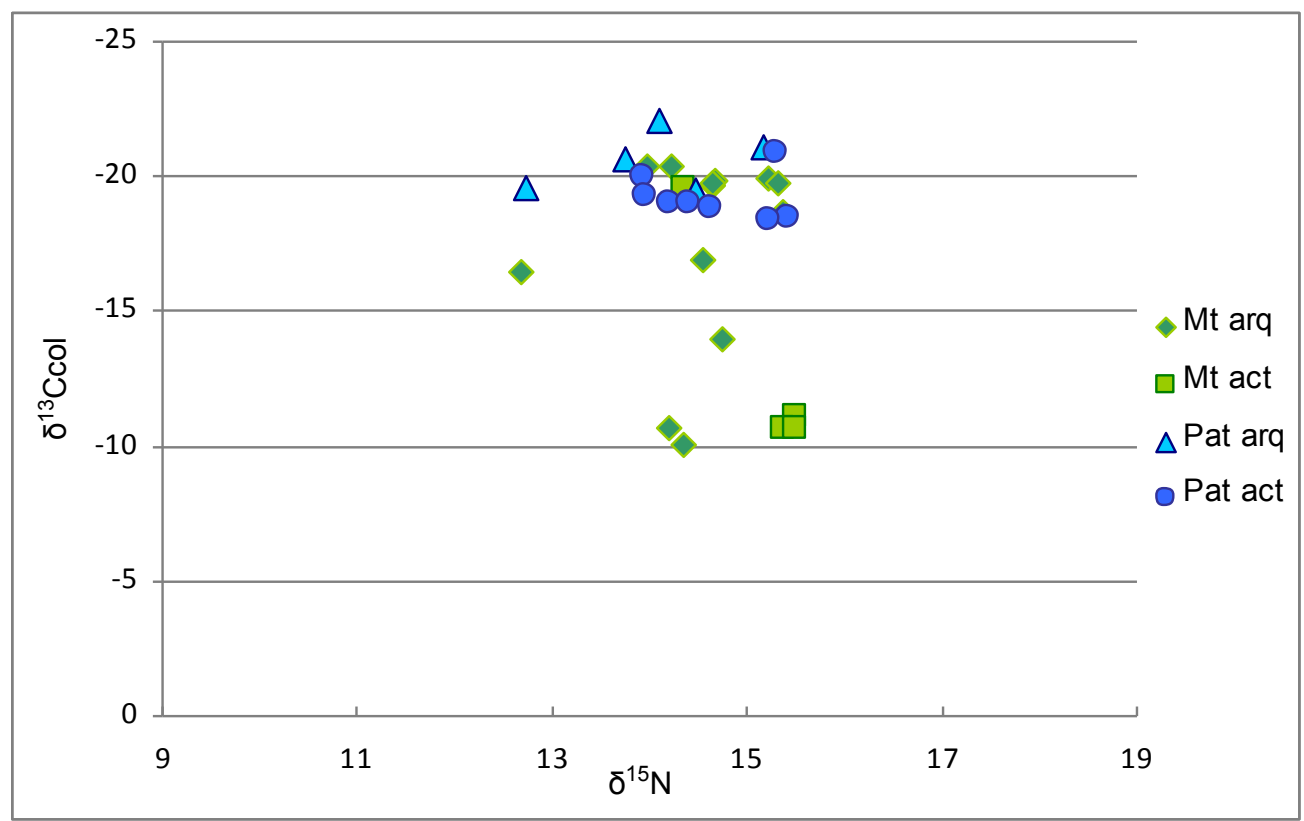

Figura 8.21. Valores isotópicos de las muestras de Ctenomys (arqueológicas y actuales) discriminados por región fitogeográfica.

Referencias: Mt arq: muestras de sitios arqueológicos del Monte; Mt act: muestras actuales del Monte; Pat arq: muestras de sitios arqueológicos de la estepa Patagónica; Pat act: muestras actuales de la estepa Patagónica. 
Finalmente, resulta interesante destacar que si bien aquellas muestras de Ctenomys provenientes del Monte presentan una amplia variabilidad, donde los valores más negativos (ca. -20\%o) sólo han sido obtenidos en muestras arqueológicas, a excepción de una muestra que proviene de Cueva Huenul 1, un sitio localizado en el desierto del Monte aunque muy cercano a la estepa Patagónica. A pesar que el número de muestras no es muy grande, esto podría indicar que los sitios arqueológicos emplazados en el desierto del Monte, donde se exhumaron los ejemplares de Ctenomys analizados (Tabla 8.5), pudieron tener una configuración vegetacional diferente a la actual, con una mayor cantidad de elementos de la estepa Patagónica. Esto coincide con los resultados paleoambientales emanados del registro de micromamíferos del sitio arqueológico Agua de La Mula (ver sección 8.2).

\subsection{Ocupaciones Humanas}

Las diferentes características tafonómicas y cambios paleoambientales observados mediante el registro de microvertebrados recuperados de numerosos sitios arqueológicos emplazados en distintos ambientes de sur de Mendoza, en concomitancia con la información paleoambiental y arqueológica provenientes de otras fuentes, pueden ser de sumo interés para un mejor entendimiento de los sistemas de subsistencia y las dinámicas ocupacionales de los grupos cazadores-recolectores que habitaron la región.

Existen numerosos trabajos que desde una perspectiva arqueológica relacionaron las ocupaciones humanas con condiciones paleoambientales en el sur de Mendoza, observando discontinuidades en el registro (e.g., Gil et al., 2005, 2009b; Gil, 2006; Neme y Gil, 2008b, 2009, 2010; Gil y Neme, 2010). Estos autores, mediante frecuencias de fechados radiocarbónicos señalaron una disminución en la intensidad de la ocupación humana en esta área durante el período de marcada aridez del Holoceno medio y un incremento, incluso en la diversidad espacial para el Holoceno tardío, cuando el clima no fue tan severo. No obstante, otros autores argumentan que estas discontinuidades en el registro arqueológico pueden deberse a otros factores tales como procesos de preservación diferencial (e.g., García, 2005, 2010) y erupciones volcánicas (e.g., Durán, 2000; Durán y Mikkan, 2009).

La mayor parte de los ambientes del sur de Mendoza habrían estado disponibles para las ocupaciones humanas hacia la transición Pleistoceno-Holoceno (Neme y Gil, 2008b). Las 
primeras evidencias de actividades antrópicas se registraron en el sitio Gruta del Indio (cultura Atuel IV) entre 11,5 y 9,5 $\mathrm{ka}{ }^{14} \mathrm{C} \mathrm{AP}$, en sector extracordillerano de la cuenca media del Río Atuel (e.g., Semper y Lagiglia, 1962-1968; García y Lagiglia, 1999; Lagiglia, 2001, 2002), en un contexto de cambio de condiciones climáticas frías y semiáridas a una de mayor temperatura y aridez (ver sección 8.2.3). Este sitio, es el único lugar con ocupaciones humanas asociadas a megafauna extinta (e.g., Long et al., 1998; Lagiglia y García, 1999; García, 2003), incluyendo pocos artefactos líticos de baja especificidad funcional, esperable para una fase de exploración del área (Gil y Neme, 2010). Asimismo, Gruta del Indio es el único sitio de esta área con registro de ocupaciones durante el Holoceno medio, aunque con un hiatus entre ca. 7,5-4 ka ${ }^{14} \mathrm{C}$ AP (Lagiglia, 2001, 2002), posiblemente asociado a un contexto de mayor aridez ambiental (ver sección 8.2.3; Gil y Neme, 2010). Lagiglia (2001, 2002), definió a estas ocupaciones como cultura Pre-Atuel III y las interpretó como grupos de baja demografía y alta movilidad. Hacia el Holoceno tardío, en un marco de estabilidad ambiental (ver sección 8.2.3), además de Gruta del Indio (culturas Atuel III, II y I) se incluyen una numerosa variedad de sitios arqueológicos ubicados en la cuenca media e inferior del Río Atuel [RA-1, Cañada Seca, Las Tinajas, El Morado, Reparo de las Pinturas Rojas, Parapetos del Atuel, Escondrijo, Jaime Prats, Los Gallegos 1, La Olla, El Bosquecillo 3, El Bosquecillo 5, Los Jilgueros, MDA 72-75, MDA 114-116, MDA 20-129-134, El Nihuil, Nihuil 07, La Junta, La Huertita, Arbolito, Valle Grande, Respolar, Tamando Estir, Loma del Eje, El Rincón, Cerro Negro (véase Gil y Neme, 2010; y literatura allí citada)]. Esta diversidad de sitios, abarcan la presencia de entierros humanos (e.g., RA-1, Gruta del Indio, Jaime Prats, Cañada Seca, Cerro Negro), campamentos de actividades múltiples (e.g., RA-1, La Olla), campamento de actividades específicas (e.g., El Morado, Parapetos del atuel) y sitios con arte rupestre (e.g., Las Tinajas, Reparo de las Pinturas Rojas, Gruta del Indio) (Gil y Neme, 2010). Asociados a este contexto, aparecen restos de cordelería, variedad de tecnologías líticas y cerámicas. Asimismo, se destaca que a partir de ca. 2 ka AP existe una fuerte diversidad espacial y temporal en el tipo de recursos y estrategias de subsistencias, incluyendo el uso de plantas domesticas y silvestres con evidencias de consumo antrópico y una amplia variedad de recursos animales de mediano y gran tamaño, aunque sin evidencias fehacientes de explotación de microvertebrados, por lo menos en lo 
que concierne a RA-1, donde solo se dejó expuesta como posibilidad (ver secciones 8.1.1 y 8.1.3).

Teniendo en consideración la densidad de los depósitos, diversidad arqueológica y cronología, Gil (2006) plantea cuatro contextos que incluyen el registro de distintos sitios arqueológico y que reflejarían las fases biogeográficas en el poblamiento (sensu Borrero, 1989-1990, 1994-1995, 1999; ver Capítulo 2) de la región de la Payunia. A comienzos del Holoceno medio (7,6 ka AP, cf. Cueva Delerma), observó un registro arqueológico con evidencias de una ocupación efímera, posiblemente correspondiente a una etapa de exploración. Posteriormente, indica un hiatus ocupacional de 5 ka en toda la región. A mediados del Holoceno tardío (2-1,2 ka ${ }^{14} \mathrm{C}$ AP; cf. Cueva Ponontrehue, La Corredera, niveles inferiores de Agua de La Mula), señala una reexploración o colonización de la Payunia, con un uso más intenso de la región. Hacia finales del Holoceno tardío (1,2-0,25 ka ${ }^{14} \mathrm{C}$ AP; cf. Cueva Zanjón del Buitre, Cueva Los Leones-3, Cueva Los Leones-5, Puesto Ortubia-1, ACA-1, LP-1, niveles superiores de Agua de La Mula), indica las primeras ocupaciones efectivas de la Payunia, evidenciado por el establecimiento de sitios de actividades múltiples, con registro arqueológico más diverso y denso que los anteriores, incorporación de tecnología cerámica, utilización de plantas domésticas y productos no locales (Gil, 2006). Por otra parte, el proceso de intensificación de los recursos registrado en el área cordillerana en torno al 2 ka AP (Neme, 2000, 2007, 2009), se habría extendido a la Payunia hacia el 1 ka AP (ver sección 8.1.3), aunque sin abarcar la explotación de los microvertebrados como fue observado en Agua de La Mula, ACA-1 y posiblemente LP-1 (ver secciones 8.1.1 y 8.1.3). Esta demora podría explicarse por las jerarquías de los ambientes (e.g., Borrero, 2005), donde la Payunia sería ecológicamente marginal (sensu Borrero, 2004; ver Capítulo 2) y con mayores problemas para su ocupación respecto de las regiones vecinas (Gil, 2006; Neme y Gil, 2008b). Sin embargo, Borrero (2002) y Durán y Mikkan (2009) plantean que no necesariamente se pueden explicar las ocupaciones tardías en la Payunia por este tipo de procesos, en cambio proponen que se habrían dado por una ampliación de rangos en la explotación de recursos. De modo que, la Payunia habría alcanzado una productividad semejante a la de regiones vecinas luego de la recuperación del ambiente (Borrero, 2002), tras intensas actividades volcánicas durante el Holoceno medio (Durán y Mikkan, 2009). Otra línea de explicación plausible para este proceso de ocupación 
diferencial, es la emanada del registro de micromamíferos de Agua de La Mula, donde se observó un avance de la estepa Patagónica hacia el desierto del Monte entre 1,6-1 ka ${ }^{14} \mathrm{C}$ AP (ver secciones 8.2.1 y 8.2.3). En tal sentido, este mejoramiento ambiental podría haber favorecido la transición entre las fases colonización y ocupación efectiva en la Payuna.

Neme (2002, 2007), utiliza el modelo biogeográfico de Borrero (1989-1990, 1994-1995, 1999) para describir las etapas de poblamiento del área cordillerana. El autor señala que luego del retroceso de los glaciares hacia Pleistoceno tardío final (ca. 12-11 ka AP), los sectores por debajo de los $3.000 \mathrm{~m}$. de altitud habrían sido lugares favorables para el establecimiento de grupos humanos (ver sección 8.2.3). Sin embargo, las primeras ocupaciones humanas se registraron a principios del Holoceno temprano en el sitio AMA-3 $\left(8,9 \mathrm{ka}{ }^{14} \mathrm{C} \mathrm{AP}\right)$, donde se observó una continuidad temporal, altas tasas de depositación y densidad de restos culturales recuperados en los niveles inferiores del sitio, sugiriendo que se habría dado la etapa de colonización del área. Asimismo, este sitio se encuentra en un plano estratégico entre el piedemonte y alta cordillera, con una amplia visión del valle alto del Río Atuel, con acceso a fuentes hídricas, líticas, vegetales y animales, lo que sugiere la elección de lugares óptimos dentro del paisaje regional por parte de los grupos humanos (Neme, 2002, 2007). El autor concluye que las estrategias utilizadas por los cazadoresrecolectores estarían caracterizadas por una alta movilidad, dedicados a tareas específicas como la caza -principalmente de L. guanicoe- y abastecimiento de materias primas. Las ocupaciones humanas en AMA-3 continúan durante el Holoceno medio, aunque con un hiatus entre 7-5,4 ka ${ }^{14} \mathrm{C}$ AP (Diéguez y Neme, 2003). Hacia el 5,5 ka ${ }^{14} \mathrm{C}$ AP, también existen evidencias culturales en el sitio Arroyo el Desecho en el valle del río Salado (Lagiglia, 2005). Gil et al. (2005), destacaron que el hiatus arqueológico del Holoceno medio no fue tan marcado en el sector cordillerano como en la planicie oriental. Estos autores señalan que existen evidencias de ocupación humana de los valles pedemontanos utilizados como refugios. No obstante, Navarro et al. (2009) y Navarro y Whitlock (2010) plantean que en este período la cuenca superior del Atuel (Laguna El Sosneado) presentó condiciones ambientales más húmedas, de modo que el hiatus arqueológico podría indicar bajas poblaciones dispersas, alta movilidad o una mala preservación de los sitios, en vez de un abandono regional (Navarro et al., 2009; Navarro y Whitlock, 2010). El registro arqueológico de AMA-3 durante el Holoceno medio, se destaca por un predominio de 
materias primas líticas locales, aprovechamiento de L. guanicoe y a pesar que no presenta mayores cambios respecto al Holoceno temprano, muestra un aumento en la movilidad, menor intensidad de ocupación y un cambio en la utilización de las materias primas, como respuesta a las condiciones climáticas de aridez (Pérez Winter, 2009b, 2010; Neme, 2007). Esto fue entendido por los autores, como una persistencia de la etapa de colonización (Neme, 2007) o reexploración del área (Pérez Winter, 2009b, 2010). A comienzos del Holoceno tardío (4-2 ka ${ }^{14} \mathrm{C}$ AP), en un marco de estabilidad ambiental (ver sección 8.2.3) se pueblan numerosos valles (cf. AMA-3-C2, Cueva Arroyo Colorado-CII, Cueva PaluloNiv.13-19), a excepción de los altamente variables, con mayores niveles de riesgo para la actividad humana (i.e., valles de alturas por encima de los 3.000 m.s.n.m.). Para este lapso, se produce una ocupación efectiva del área cordillerana, se mantiene el consumo de $L$. guanicoe como principal recurso y el uso de materias primas locales, aunque aparece mayor cantidad de elementos de molienda (Neme, 2002, 2007). Hacia fines del Holoceno tardío (2$0,1 \mathrm{ka}{ }^{14} \mathrm{C} \mathrm{AP}$ ), todos los ambientes cordilleranos estarían ocupados (cf. AMA-3-C1, AMA1, Cueva Arroyo Colorado-CI, LS-3, Cueva Palulo-Niv.1-12, Los Peuquenes, El Indígeno, Ojo de Agua, Puesto Rivero, El Sauce). En este período, se produce la aparición de la tecnología cerámica, utilización de materias primas no locales y aumento en la cantidad de elementos de molienda. Asimismo, se amplían el espectro de recursos explotados, incluyendo plantas y animales de tamaño medio, lo cual fue entendido como un proceso de intensificación (Neme, 2002, 2007; Llano, 2008). Los resultados mostrados en esta tesis doctoral sugieren que este proceso de intensificación no habría sido lo suficientemente marcado como para explotar los microvertebrados en forma sistemática, debido a que solo se recuperaron evidencias de aprovechamiento en Cueva Arroyo Colorado (ver secciones 8.1.1 y 8.1.3). Este proceso de intensificación se habría dado en un contexto de estabilidad paleoambiental, aunque con algunos pulsos húmedos y secos posiblemente asociados a los eventos ENSO (ver sección 8.2.3), los cuales pudieron aportar mayor variabilidad ambiental para el establecimiento de las ocupaciones humanas.

En el sector pedemontano del cause medio del Río Grande, las primeras ocupaciones humanas se registraron en el sitio Gruta de El Manzano hacia comienzos del Holoceno medio entre 8 y 7 ka ${ }^{14} \mathrm{C}$ AP (Gambier, 1980, 1985; Neme et al., 2011). Gambier (1980, 1985), describe a esta primera etapa de ocupación como cazadores-recolectores asociados a 
una industria lítica de tipo Morrillos. Si bien se recuperaron restos de megafauna extinta en la base de la cueva, su asociación con actividades antrópicas ha sido descartada (Neme et al., 2011). Duran (2000), relaciona a esta cultura con una fase biogeográfica de exploración de la región. Sin embargo, Neme (2007) y Neme et al. (2011) sugieren que de acuerdo al modelo de Borrero (1989-1990, 1994-1995, 1999), estaríamos frente a una etapa de colonización del área, debido a la observación de tasas más altas de depositación de materiales, especialmente líticos, óseos y moluscos, respecto de los componentes más tardíos. En coincidencia con las otras áreas, existe un hiatus ocupacional en Gruta de El Manzano ca. 7-2,1 ka ${ }^{14} \mathrm{C}$ AP, el cual fue vinculado a un proceso de aridez del Holoceno medio y erupciones volcánicas (ver arriba). Gambier $(1980,1985)$ definió a las ocupaciones correspondientes al Holoceno tardío como la etapa Agro-alfarera. Asimismo, Neme et al. (2011) observaron que a partir del $2 \mathrm{ka}{ }^{14} \mathrm{C}$ AP disminuye la explotación de L. guanicoe y aumenta la fauna de mediano tamaño, además de restos vegetales con evidencias de explotación antrópica, entre otros. Por su parte, Durán $(1997,2000)$ elabora un modelo regional de esta área en base al registro arqueológico de Gruta de El Manzano y de otros reparos cercanos al mismo (Cueva de Luna, Alero Puesto Carrasco y Cañada de Cachi). Estos últimos, presentan secuencias asociadas únicamente para el Holoceno tardío y tienen una marcada ocupación humana con alta densidad de materiales hacia los últimos $2 \mathrm{ka}{ }^{14} \mathrm{C}$ AP. Los autores mencionados plantean que el valle medio del Río Grande pudo funcionar como un límite interétnico, donde se dieron importantes contactos entre los pobladores de la Payunia y los de la cordillera, en un contexto de un modelo de variación estacional. Por otra parte, a pesar que hacia el Holoceno tardío se habrían establecido las condiciones ambientales actuales (ver sección 8.2.3), Durán (2000) propone cambios potenciales en las condiciones ambientales e impacto de erupciones volcánicas, como posibles hipótesis para explicar el hiatus ocupacional registrado en Cueva de Luna entre ca. 3,8-1,5 ka ${ }^{14} \mathrm{C}$ AP. Es interesante destacar, que el mejoramiento ambiental observado hacia $c a .1,5 \mathrm{ka}{ }^{14} \mathrm{C}$ AP en base al registro de micromamíferos de Cueva de Luna (ver secciones 8.2.1 y 8.2.3), coincide con el período de ocupaciones humanas prehispánicas (Componente IV) más continuas e intensivas observadas en este sitio. Finalmente, en base a la información arqueológica Neme (2007) y Neme et al. (2011) señalan que un proceso de intensificación de los recursos tuvo lugar en esta área hacia el $2 \mathrm{ka}{ }^{14} \mathrm{C} \mathrm{AP}$, en forma parangonable con el alto valle del Río 
Atuel. No obstante, este proceso no pudo ser corroborado desde los ensambles de micromamíferos recuperado de Cueva de Luna estudiados para esta tesis (ver sección 8.1.3). $\mathrm{La}$ integración entre los datos arqueológicos previos y los resultados obtenidos en esta tesis muestran una interesante relación a través del tiempo, tanto desde un punto de vista paleoambiental como en la subsistencia humana, y su correlación con las ocupaciones humanas. Asimismo, como se ha dejado claro, la principal asociación entre los ensambles de microvertebrados y los contextos arqueológicos fue producto de la convergencia de diferentes agentes naturales de depositación, los cuales en algunos casos posiblemente hayan sido posteriormente alterados por otras actividades antrópicas como la acción del pisoteo, el encendido de fuegos dentro de los sitios y probablemente la limpieza de los espacios habitacionales. Más allá de algunas posibilidades aisladas, la única evidencia clara de uso humano se limita a un conjunto de marcas de corte sobre una tibia de un Caviidae en un sitio de la cordillera (Cueva Arroyo Colorado). Esta indica, que en el sur de Mendoza no fue necesario la explotación de los microvertebrados, los cuales se encuentran más bajo en el ranking de recursos de la región, ya sea por la falta de una tecnología adecuada para su caza, tabúes, o por la escasez de especies con comportamientos gregarios que faciliten el incremento de su rendimiento mediante prácticas de captura masiva. 


\section{Capítulo 9}

\section{CONCLUSIONES}

“...el asombroso poder de transformación del propio mundo que poseemos gracias a nuestra formidable facultad, que es la reflexión consciente..."

Humberto R. Maturana y Francisco G. Varela

[El árbol del conocimiento. Las bases biológicas del entendimiento humano. 1984: 14] 



\section{CONCLUSIONES}

El presente trabajo de tesis ha mostrado la utilidad de los estudios de microvertebrados proveniente de contextos arqueológicos. A través de estos se ha discutido en primer lugar los aspectos tradicionales de su uso, como la sistemática, paleoecología, tafonomía y dieta de depredadores. En segundo lugar, se ha integrado esta evidencia al resto del registro arqueológico discutiéndose a través de la misma las hipótesis arqueológicas acerca de la subsistencia y ocupaciones humanas. Con lo cual se demostró la poca importancia que tuvieron estos recursos en la dieta de los cazadores recolectores del sur de Mendoza.

A continuación se enumeran las principales conclusiones emanadas de este trabajo que permitieron discutir las hipótesis propuestas:

- Como parte del estudio actual de los microvertebrados de la provincia de Mendoza, se pudieron observar tendencias en las afinidades ecológicas y ambientales para algunas especies y en general por unidad geográfica.

- Los roedores cricétidos sigmodontinos constituyen el grupo de micromamíferos dominante en la provincia de Mendoza, destacándose en diversidad los integrantes de la tribu Abrotrichini (Abrothrix y Chelemys) y Phyllotini (Eligmodontia, Phyllotis, Loxodontomys, Graomys y Calomys).

- El sur de Mendoza presentó todos los taxones de micromamíferos que habitan en la provincia a excepción de una especie Puneña (Abrothrix andinus). Por otro lado, el norte de la provincia, a excepción de Euneomys chinchilloides, exhibió la ausencia de especies Patagónicas tales como Euneomys mordax, Chelemys macronyx, Loxodontomys micropus, Abrothrix longipilis, Abrothrix olivaceus, Reithrodon auritus, lo que sugiere que el centro de Mendoza podría ser el deslinde entre los elementos Puneños y Patagónicos. No obstante, la faja este de la provincia, fitogeográficamente incluida en el Monte, se mantiene sin mayores cambios en cuanto a su estructura taxonómica (e.g., Galea leucoblephara, 
Akodon molinae, Graomys griseoflavus, Calomys musculinus, Oligoryzomys flavescens).

- Asimismo, en el sur de Mendoza se encontraron taxones asociados a la estepa Patagónica (Lestodelphys halli, R. auritus, A. longipilis), tanto a la estepa Patagónica como al desierto del Monte (Thylamys pallidior, Eligmodontia spp.), a estepas Altoandinas (C. macronyx, y E. mordax), tanto a estepas Patagónicas como Altoandinas (E. chinchilloides, L. micropus y Abrothrix olivaceus) y a todas las unidades fitogeográficas (Phyllotis xanthopygus y Ctenomys spp.).

- Entre los hallazgos importantes, se documentaron los primeros registros para Holochilus en la provincia de Mendoza, extendiendo su geonemia $480 \mathrm{~km}$ hacia el oeste. Un estudio taxonómico reciente de los ejemplares, indicó que corresponden a una nueva entidad específica, la cual fue nominada Holochilus lagigliai (Pardiñas, Teta, Voglino y Fernández, en prensa).

- Desde un punto de vista tafonómico, se observó una marcada actividad de aves Strigiformes en la génesis de los ensambles de microvertebrados de numerosos sitios arqueológicos cordilleranos y de la planicie oriental (Cueva Arroyo Colorado, Laguna El Sosneado-3, Caverna de Las Brujas, Cueva de Luna, Agua de La Mula, Agua de los Caballos, Rincón del Atuel I y La Peligrosa I). Se registró actividad de aves Falconiformes en los ensambles de los sitios cordilleranos Arroyo Malo-3 y Cueva Palulo. Por otra parte, se hallaron evidencias de actividad de mamíferos carnívoros en Cueva Arroyo Colorado.

- En relación al consumo antrópico de las especies de microvertebrados, fueron identificadas marcas de corte en una tibia de Caviidae de la Cueva Arroyo Colorado, en un lapso de la secuencia (1380-770 años ${ }^{14} \mathrm{C}$ AP). Esta es la única evidencia arqueológica clara de su uso por parte de las poblaciones humanas. Sin embargo, la moderada frecuencia de huesos quemados, así como la abundancia de roedores del grupo de tamaño grande, plantea la posibilidad que esto pudo ocurrir en sitios como La Peligrosa I y Rincón del Atuel I (ambos sitios localizados en el desierto del Monte). De todas formas esta débil evidencia no alcanza para defender un uso sistemático de los microvertebrados vinculado 
al proceso de intensificación propuesto en el sur de Mendoza para los últimos 2000 años AP.

- Se considera que en primer término el análisis de marcas de ácidos digestivos y en segundo término los patrones de abundancia relativa de partes esqueletales son los atributos tafonómicos más eficaces a la hora de evaluar el origen de una acumulación de microvertebrados de contextos arqueofaunísticos. Esto se debe a que las marcas de corrosión digestivas en los restos óseos y dentarios no parecen alterarse con los procesos postdepositacionales, como otros atributos tafonómicos, entre los que se destacan los patrones de fractura y la pérdida dentaria.

- Se documentaron algunos procesos postdepositacionales que pudieron modificar la estructura original de los ensambles. A excepción de la meteorización y las impregnaciones por oxido de manganeso, donde se observó mayor incidencia en sitios a cielo abierto y en cuevas, respectivamente. El resto de los procesos tales como corrosión sedimentaria, pisoteo, acción de raíces y de roedores, afectaron a los restos sin relación aparente entre los distintos tipos de sitios.

- En este trabajo se registraron numerosos taxones que no habían sido documentados en contextos arqueológicos previos en la provincia de Mendoza: los reptiles Pristidactylus cf. P. scapulatus, Liolaemus sp. y Homonota $\mathrm{cf}$. $H$. darwini; el quiróptero Tadarida brasiliensis; y los roedores sigmodontinos Akodon spegazzinii, A. molinae, A. olivaceus, A. longipilis, C. macronyx, L. micropus, G. griseoflavus y E. mordax.

- Desde un perspectiva paleoambiental, en los sitios del área cordillerana de Laguna El Sosneado-3 (2100 años ${ }^{14} \mathrm{C}$ AP-Presente) y Arroyo Malo-3 (8900 años ${ }^{14} \mathrm{C}$ AP-Presente) se observó la dominancia de los roedores sigmodontinos E. chinchilloides, P. xanthopygus y Eligmodontia sp. a lo largo de ambas secuencias, señalando ambientes abiertos Patagónicos, con alta proporción de suelo desnudo, pedregoso y abundante roca expuesta. Se han registrado especies asociadas a vegas cordilleranas desde el Holoceno temprano al Holoceno tardío en Arroyo Malo-3 (C. macronyx y A. longipilis). Asimismo, el hallazgo del 
marsupial L. halli hacia 2200 años ${ }^{14} \mathrm{C}$ AP en este último sitio, sugiere condiciones más Patagónicas. En Laguna El Sosneado-3, el registro de $C$. macronyx y L. micropus en la secuencia, con excepción hacia 600 años ${ }^{14} \mathrm{C} \mathrm{AP}$, indica un evento más árido para esa época. Por otra parte, en los sitios cordilleranos Cueva Arroyo Colorado (3200-750 años ${ }^{14} \mathrm{C}$ AP) y Caverna de Las Brujas $\left[5 \pm 0,5 \mathrm{ka}\right.$ AP (TL) y $3,7 \mathrm{ka}{ }^{14} \mathrm{C}$ AP] los ensambles mostraron cierta estabilidad y son taxonomicamente similares a los anteriores. En el valle medio del Río Grande, los conjuntos exhumados de la secuencia del sitio Cueva de Luna (3800 años ${ }^{14} \mathrm{C}$ AP-Presente) presentaron especies Patagónicas (L. halli, $R$. auritus y E. chinchilloides) y otras afines al desierto del Monte (T. pallidior, $M$. australis y C. musculinus), en claro contraste con las muestra actuales donde únicamente se encontraron taxones Patagónicos, señalando un ambiente más árido que el actual. Las muestras actuales de la planicie oriental están dominadas por taxones asociados al desierto del Monte. Coincidentemente, los ensambles de los sitios La Peligrosa-1 ( 1500-400 años ${ }^{14} \mathrm{C}$ AP), Rincón del Atuel 1 (1500350 años ${ }^{14} \mathrm{C}$ AP) y Agua de los Caballos (1200-250 años ${ }^{14} \mathrm{C}$ AP) presentaron especies que habitan principalmente en este ambiente ( $T$. pallidior, $G$. leucoblephara, M. australis, G. griseoflavus). Sin embargo, en el sitio Agua de La Mula (1600-1000 años ${ }^{14} \mathrm{C}$ AP), además de registrarse taxones del Monte, se recuperaron algunas especies Patagónicas (L. halli y R. auritus), lo que sugiere condiciones ecotonales entre estos dos biomas.

- Se observaron cambios en las estructuras taxonómicas de los ensambles actuales de micromamíferos. Estos cambios podrían deberse al deterioro ambiental posiblemente producido por la acción del ganado domestico (principalmente Capra hircus y Ovis aries), afianzado en el sur de Mendoza desde el siglo XIX. Esta alteración antrópica pudo haber favorecido el avance de especies oportunistas como C. musculinus en las llanuras y A. olivaceus en la cordillera del sur de Mendoza. Sin embargo, esta restructuración de los ensambles no fue tan pronunciada como en algunos sectores de las regiones Patagónica y Pampeana.

- Un primer acercamiento desde los isótopos estables ha permitido discutir gran parte de las hipótesis propuestas desde una nueva línea de evidencia. En 
coincidencia con la información tafonómica obtenida, los datos analizados sugieren que el consumo humano de taxa con potencial interés (Ctenomys, Galea y Microcavia) no habría sido muy importante. Por otro lado, la comparación de muestras arqueológicas vs actuales sugieren una estabilidad ambiental general, con el posible avance de elementos de la estepa Patagónica en algunos sectores del desierto del Monte, hacia el Holoceno tardío final.

- Los datos de isótopos estables a nivel etológico muestran dietas diferentes entre los micromamíferos de la estepa Patagonia y los del desierto del Monte, incluso para una misma especie que ocupa hábitats diferentes. Este acercamiento novedoso permitirá abrir una nueva línea de abordaje a la dieta de las poblaciones de estos animales.

Finalmente, las diferentes características tafonómicas y cambios paleoambientales observados mediante el registro de microvertebrados recuperados de numerosos sitios arqueológicos emplazados en distintos ambientes de sur de Mendoza, fueron un aporte al conocimiento de los sistemas de subsistencia y las dinámicas ocupacionales de los grupos de cazadores-recolectores que habitaron el sur de Mendoza.

A partir de las principales problemáticas abordadas en esta tesis, se desarrollaron numerosas líneas de investigación tendientes a resolverlas, sin embargo, una vez alcanzado los objetivos, se han generado más preguntas que imperiosamente necesitan ser respondidas. El análisis de nuevas muestras arqueológicas especialmente en las regiones del Monte y Payunia, ayudará a entender mejor cuestiones vinculadas a los procesos tafonómicos y a discutir en mayor profundidad el rol de los micromamíferos en la dieta humana. Esta tesis ha mostrado también la importancia de las técnicas de recuperación a la hora de interpretar los conjuntos de microvertebrados y la necesidad de homogeneizar la toma de las mismas como una forma de hacer más comparables los ensambles estudiados.

También será necesario incrementar la cantidad de muestras de ensambles de micromamíferos actuales para tener un mejor control de la distribución y abundancia de las especies en la geografía regional. Esto servirá de base para las interpretaciones emanadas en futuros estudios paleoambientales. 



\section{Bibliografía citada}

Abdala V. 1992. Aportes a la osteologia comparada en el género Homonota (Sauria: Gekkonidae). I, cráneo. Acta Zoológica Lilloana 41: 247-256.

Abdala C.S. 2005. Dos nuevas especies del género Liolaemus (Iguania, Liolaemidae) y redescripción de Liolaemus boulengeri (Koslowsky, 1998). Cuadernos de Herpetología 19: 3-33.

Abraham E.M. 2000. Recursos y problemas ambientales de la provincia de Mendoza. En: M.E. Abraham y F. Rodríguez Martínez (eds.), Recursos y problemas ambientales de zona árida. Primera parte: provincias de Mendoza, San Juan y La Rioja. Tomo I: Caracterización ambiental, pp. 15-23. IDIZA, Mendoza.

Abraham de Vázquez E., K. Garleff, H. Liebricht, A. Regairaz, F. Schabitz, F. Squeo, H. Stingl, H. Veitz y C.Villagrán. 2000. Geomorphology and paleoecology of the arid diagonal in South America. En H. Miller y F. Hervé (eds.), Zietschrift für Angewandte Geologie : 5562 .

Abud C. 2011. Variación genética y estructura filogeográfica de Abrothrix olivaceus en la patagonia argentina y el sur chileno. Tesis de Maestría, PEDECIBA, Montevideo, Uruguay.

Acosta J.C. Ávila L.J. y R. Martori. 1991. Ecología trófica de Teius oculatus (Sauria: Teidae) en el sur de la provincia de Córdoba. Composición, variación anual y estacional de la dieta. Cuadernos de Herpetología 6: 12-22.

Acosta A. y L. Pafundi. 2005. Zooarqueología y tafonomía de Cavia aperea en el humedal del Paraná inferior. Intersecciones en Antropología 6: 59-74.

Acosta G., D. Cossios, M. Lucherini y L. Villalba. 2008. Leopardus jacobita. In: IUCN 2011. IUCN Red List of Threatened Species. Version 2011.1. www.iucnredlist.org. 13 de Julio 2011.

Agnolin F.L., S.O. Lucero y S. Bogan. 2007. Galea musteloides en la Provincia de Santa Cruz, Argentina. Mastozoología Neotropical 15: 113-115.

Alarcón O., G. D'Elía, E.P. Lessa y U.FJ. Pardiñas. 2011. Phylogeographic structure of the fossorial long-clawed mouse Chelemys macronyx (Cricetidae, Sigmodontinae). Zoological Studies 50: 682-688.

Albino A.M. 2005. A late Quaternary lizard assemblage from the southern Pampean Region of Argentina. Journal of Vertebrate Paleontology 25: 185-191.

Albino A.M. 2008. Lagartos iguanios del Colhuehuapense (Mioceno Temprano) de Gaiman (provincia del Chubut, Argentina). Ameghiniana 45: 775-782. 
Albino A.M. y D.M. Kligmann. 2007. An accumulation of bone remains of two Liolaemus species (Iguanidae) in the Holocene archaeological site of the Argentine Puna. AmphibiaReptilia 28: 154-158.

Alvarez B.B., M.E. Tedesco y E. Porcel. 1987. Osteología craneana de Teius teyou (Daudin, 1802) (Reptilia: Teiidae). Cuadernos de Herpetología 2: 7-31.

Álvarez M.C., C.A. Kaufmann, A. Massigoge, M.A. Gutiérrez, D.J. Rafuse, N.A. Scheifler y M.E. González. En prensa. Bone modification and destruction patterns of leporid carcasses by Geoffroy's cat (Leopardus geoffroyi): An experimental study. Quaternary International.

Ambrose S. 1993. Isotopic Analysis of Paleodiets: Methodological and Interpretative Considerations. En: M. Sandford (ed.), Investigations of Ancient Human Tissue: Chemical Analysis in Anthropology, pp. 59-129. Gordon and Breach Science Publishers, Langhorne.

Ambrose S. 2000. Controlled diet and climate experiments on nitrogen isotope ratios of rats. En: S. Ambrose y M. Katzenberg (eds.), Biogeochemical Approaches to Paleodietary Analysis, pp 243-267. Advances in Archaeological and Museum Science 5. Kluwer Academic/Plenum Press, New York.

Ambrose S. y M. De Niro. 1986. Reconstruction of African human diet using bone collagen carbon and nitrogen isotope ratios. Nature 319: 321-324.

Ambrose S. y L. Norr. 1993. Experimental evidence for the relationship of the carbon isotope ratios of whole diet and dietary protein to those of bone collagen and carbonate. En: J. Lambert, y G. Grupe (eds.), Prehistoric Human Bone: Archaeology at the Molecular Level, pp. 1-37. Springer-Verlag, New York.

Anderson S. y T.L. Yates. 2000. A new genus and species of phyllotine rodent from Bolivia. Journal of Mammalogy 81: 18-36.

Andrade A., D.E. Udrizar Sauthier, U.J.F. Pardiñas. 2004. Vertebrados depredados por la lechucita vizcachera (Athene cunicularia) en la meseta de Somuncura (Río Negro, Argentina). El Hornero 19: 91-93.

Andrade A., M.J. Nabte y M.E. Kun. 2010. Diet of the Burrowing Owl (Athene cunicularia) and its seasonal variation in Patagonian steppes: implications for biodiversity assessments in the Somuncura Plateau Protected Area, Argentina. Studies on Neotropical Fauna and Environment 45: 101-110.

Andrews P. 1990. Owls, caves and fossils. University of Chicago Press.

Andrews P. 1995. Mammals as palaeocological indicators. Acta Zoológica Cracovensia 38: 5972.

Andrews P. y E.M. Evans.1983. Small mammal bone accumulations produced by mammalian carnivores. Paleobiology 9: 289-307. 
Aliaga-Rossel E. y T. Tarifa. 2005. Cavia sp. como principal presa de la lechuza de campanario (Tyto alba) al final de la estación seca en una zona intervenida al norte del Departamento de La Paz, Bolivia. Ecología en Bolivia 40: 35-42.

Apfelbaum L.I. y O.A. Reig. 1989. Allozyme genetic distances and evolutionary relationships in species of akodontine rodents (Cricetidae: Sigmodontinae). Biological Journal of the Linnean Society 38: 257-280.

Aschero C. 1981-1982. Nuevos datos sobre la arqueología del Cerro Casa de Piedra, sitio CCP. Relaciones 14: 267-284.

Atencio A.G. 2000. Registro de microvertebrados del sitio arqueológico Arroyo Colorado, Mendoza Argentina. Trabajo de Tesis de licenciatura. Universidad Nacional de Córdoba, Córdoba.

Avery M.D. 2001. The Plio-Pleistocene vegetation and climate of Sterkfontein and Swartkrans, South Africa, based on micromammals. Journal of Human Evolution 41: 113-132.

Ávila L.J. 2002. Geographic distribution of lizard of genus Teius (Squamata, Teiidae, Teiinae) in southern South America. Biogeographica 78: 15-33.

Ávila L.J., C.H.F. Perez, M. Morando y N. Frutos. 2002. New records of Liolaemus grosseorum Etheridge, 2001 (Reptilia, Squamata, Liolaemidae) from Northwestern Patagonia. Bulletin Chicago Herpetological Society 37: 100-101.

Baales M. 1992. Accumulation of bones of Lagopus in late Pleistocene sediments. Are they caused by Man or Animals?. Cranium 9: 17-22.

Baladrón A.V., M.S. Bó y A.I. Malizia 2006. Winter diet and time-activity budgets of Redbacked Hawk (Buteo polyosoma) in the coastal grasslands of Buenos Aires Province, Argentina. Journal of Raptor Research 40: 65-70.

Barberena R. 2002. Los límites del mar. Isótopos estables en la Patagonia meridional. Sociedad Argentina de Antropología, Buenos Aires.

Barberena R. 2008. Arqueología y biogeografía humana en Patagonia meridional. Sociedad Argentina de Antropología, Buenos Aires.

Barquez R. 2006. Orden Chiroptera Blumenbach, 1779. En: R.M. Barquez, M.M. Díaz y R.A. Ojeda (eds.), Mamíferos de Argentina: Sistemática y Distribución, pp 56-86. Sociedad Argentina para el estudio de los Mamíferos, Tucumán.

Barquez R. y M. Diaz. 2011. Myotis dinellii. En: IUCN 2011. IUCN Red List of Threatened Species. Version 2011.1. www.iucnredlist.org. 21 de Septiembre 2011.

Barquez R.M., M.A. Mares, J.K. Braun. 1999. The bats of Argentina. Special Publications 42, Museum of Texas Tech University, Texas.

Barquez R.M., M.M. Díaz y R.A. Ojeda (eds). 2006. Mamiferos de Argentina: Sistemática y Distribución. Sociedad Argentina para el estudio de los Mamíferos, Tucumán. 
Barquez R., M. Diaz, E. Gonzalez, A. Rodriguez, S. Incháustegui y J. Arroyo-Cabrales. 2011a. Tadarida brasiliensis. En: IUCN 2011. IUCN Red List of Threatened Species. Version 2011.1. www.iucnredlist.org. 21 Septiembre 2011.

Barquez R.M., M.S. Sánchez y M.L. Sandoval. 2011b. Nuevos registros de murciélagos (Chiroptera) en el norte de Argentina. Mastozoología Neotropical 18: 11-24.

Baumel J.J. y L.W. Witmer. 1993. Osteología. En: J.J. Baumel, A.S. King, J.E. Breazile, H.E. Evans y J.C. Vanden Berge (eds.), Handbook of avian anatomy: nomina anatomica avium Nuttal, pp. 45-132. Ornithological Club 234 Editors, Cambridge.

Behrensmeyer A. K. 1978 Taphonomic and ecologic information on bone weathering. Paleobiology 4: 150-162.

Behrensmeyer A.K., K.D. Gordon y G.T. Yanagi. 1986. Trampling as a cause of bone surface damage and pseudo cutmarks. Nature 319: 768-771.

Behrensmeyer A.K., K.D. Gordon y G.T. Yanagi. 1989. Nonhuman bone modification in Miocene fossils from Pakistan. En: R. Bonnichsen y M.H. Sorg Orono (eds.), Bone modification, pp. 99-120. Center for the Study of the First American, Orono, Maine.

Behrensmeyer A.K., C.T. Stayton y R.E. Chapman. 2003. Taphonomy and ecology of modern avifaunal remains from Amboseli Park, Kenya. Paleobiology 29: 52-70.

Bellocq M.I. 1987. Selección de hábitat de caza y depredación diferencial de Athene cunicularia sobre roedores en ecosistemas agrarios. Revista Chilena de Historia Natural 60: 81-86.

Bellocq M.I. 2000. A review of the trophic ecology of the Barn Owl in Argentina. Journal of Raptor Research 34: 108-119.

Beltzer A.H. 1990. Biología alimentaria del Halconcito común Falco sparverius en el valle aluvial del Río Paraná Medio, Argentina. Hornero 13: 134-136.

Bennàsar Serra M. 2005. Tafonomía de micromamíferos. Metodología y criterios taxonómicos para las interpretaciones paleoecológicas. Tesis de Master inédito. Universitat Rovira I Virgili. Terragona.

Berberián E., S. Pastor, D. Rivero, M. Medina, A. Recalde, L. López y F. Roldán. 2008. Últimos avances de la investigación arqueológica en las Sierras de Córdoba. Comechingonia 11: 135-164.

Bermúdez A., D. Delpino, F. Frey y A. Saal. 1993. Los basaltos de retroarco extraandinos. En: V. Ramos (ed.), Relatorio, Geología y Recursos Naturales de Mendoza, pp. 161-172. XII Congreso Geológico Argentino, Buenos Aires.

Betancourt T.P, V. Devender y P.S. Martin. 1990. Packrat Middens. The last 40,000 years of biotic change. University of Arizona Press, Tucson.

Bettinger R.L. 1991a. Hunter - gatherer: Archaeological and Evolutionary Theory. Plenum Press, Nueva York. 
Bettinger R. 1991b. Aboriginal occupation at high altitude: Alpine villages in the White Mountains of Eastern California. American Anthropologist 93: 657-679.

Bettinger R. 1994. When, How, and Why Numic Spread?. En: D. Madsen y D. Rode (eds.), Across the West: human population movements and the expansion of the Numa, pp. 4455. University of Utah Press, Salt Lake city.

Bettinger R. 2001. Holocene Hunter-Gatherers. En: G. Feinman y T. Douglas Price (eds.), Archaeology at the Millennium: A Sourcebook. pp. 137-195. Plenum Press, Springer.

Bettinger R.L. 2009. Hunter-Gatherer Foraging: Five Simple Models. Percheron Press, New York.

Bettinger R. y M. Baumhoff. 1982. The Numic Spread: Great Basin cultures in competition. American Antiquity 47: 485-503.

Bianchi N.O. y J.R. Contreras. 1968. Sex chromosome polymorphism in two species of Akodon (Rodentia, Cricetidae). Proceedings 12 International Congress of Genetic 1, pp 205. Tokyo.

Bianchi N.O., O.A. Reig, O.J. Molina y F. Dulout. 1971. Cytogenetics of the South American akodont rodents (Cricetidae). A progress report on Argentinian and Venezuelan forms. Evolution 21: 724-736.

Bidau C.J. 2006. Familia Ctenomyidae, Lesson, 1842. En: R.M. Barquez, M.M. Díaz y R.A. Ojeda (eds.), Mamíferos de Argentina: Sistemática y Distribución, pp. 212-231. Sociedad Argentina para el estudio de los Mamíferos, Tucumán.

Bidau C., E. Lessa y R. Ojeda, 2011. Ctenomys validus. En: IUCN 2011. IUCN Red List of Threatened Species. Version 2011.1. www.iucnredlist.org. 21 Septiembre 2011.

Binford L. 1978. Nunamiut Etnoarchaeology. Academic Press, New York.

Binford L.R. 1981. Bones: ancient men and modern myths. Academic Press, New York.

Biondi L.M., Bó M.S. y M. Favero 2005. Dieta del Chimango (Milvago chimango) durante el periodo reproductivo en el sudeste de la provincia de Buenos Aires. Ornitología Neotropical 15: 31-42.

Birney E.C., R.S. Sikes, J.A. Monjeau, N. Guthmann y C.J. Phillips. 1996. Comments on Patagonian marsupials from Argentina. En: H.H. Genoways y R.J. Baker (eds.), Contributions in mammalogy: a memorial volume honoring Dr. J. Knox Jones, pp. 149154. Museum of Texas Tech University, Lubbock.

Bisceglia S., J. Pereira, P. Teta y R. Quintana 2008. Food habits of Geoffroy's cat (Leopardus geoffroyi) in the central Monte desert of Argentina. Journal of Arid Environments 72: $1117-1122$

Blanco G.M. y J.C. Acosta 1998. Ecología reproductiva de Teius oculatus en la provincia de Córdoba, Argentina. Boletín de la Sociedad de Biología de Concepción, Chile 69: 33-38. 
Bó M., A. Baladrón y L. Biondi. 2007. Ecología trófica de Falconiformes y Strigiformes: tiempo de síntesis. Hornero 22: 97-115.

Bochenski Z.M. 1997. Preliminary taphonomic studies on damage to bird bones by snowy owls Nyctea scandiaca, with comments on the survival of bones in palaeontological sites. Acta Zoologica Cracoviensia 40: 279-292.

Bochenski Z.M. 2005. Owls, diurnal raptors and humans: signature on avian bones. En: T. O'Connor (ed.), Biosphere and Lithosphere. New studies in vertebrate taphonomy, pp. 31-45. Oxbow Books, Oxford.

Bochenski Z.M. y T. Tomek. 1994. Patterns of bird bone fragmentation in pellets of the Longeared Owl Asio otus and its taphonomic implications. Acta Zoologica Cracoviensia 37: 177-190.

Bochenski Z.M. y T. Tomek. 1997. Preservation of bird bones: erosion versus digestion by owls. International Journal of Osteoarchaeology 7: 372-387.

Bochenski Z.M. y A.E. Nekrasov. 2001. The taphonomy of Sub-Atlantic bird remains from Bazhukovo III, Ural Mountains, Russia. Acta Zoologica Cracoviensia 44: 93-106.

Bochenski Z.M. y R. Tornberg. 2003. Fragmentation and preservation of bird bones in uneaten food remains of the Gyrfalcon Falco rusticolus. Journal of Archaeological Science 30: $1665-1671$

Bochenski Z.M., T. Tomek, Z. Boev e I. Mitev. 1993. Patterns of bird bone fragmentation in pellets of the tawny owl (Strix aluco) and the eagle owl (Bubo bubo) and their taphonomic implication. Acta Zoologica Cracoviensia 36: 313-328.

Bochenski Z.M., V.A. Korovin, A.E. Nekrasov y T. Tomek. 1997. Fragmentation of bird bones in food remains of imperial eagles (Aguila heliaca). International Journal of Osteoarchaeology 7: 165-171.

Bochenski Z.M., K. Huhtala, P. Jussila, E. Pulliainen, R. Tornberg y P.S. Tunkkari. 1998. Damage to bird bones in pellets of Gyrfalcon Falco rusticolus. Journal of Archaeological Science 25: 425-433.

Bochenski Z.M., K. Huhtala, S. Sulkaba y R. Tornberg. 1999. Fragmentation and preservation of bird bones in food remains of the golden eagle Aguila chrysaetos. Archaeofauna 8: 3139.

Bochenski Z.M., T. Tomek, R. Tornberg y K. Wertz. 2009. Distinguishing nonhuman predation on bird: pattern of damage done by the white-tailed eagle Haliaetus albicilla, with comments on the punctures made by the golden eagle Aquila chrysaetos. Journal of Archaeological Science 36: 122-129.

Bond M., S. Caviglia y L. Borrero. 1981. Paleoetnozoología del Alero de los Sauces (Neuquén, Argentina) con especial referencia a la problemática presentada por los roedores en sitios patagónicos. Trabajos de Prehistoria (Argentina) 1: 93-109. 
Bonino N.A. 2006. Estado actual del conocimiento sobre la liebre europea y el conejo europeo introducidos en la Argentina. INTA, Área Recursos Naturales dieta, Series Comunicaciones Técnicas 61: 1-29.

Boninsegna J. y S. Delgado de Brun. 2002. Variaciones en el caudal del Río Atuel desde 1575 hasta el presente reconstruidas con series de anillos de árboles y sus relaciones con la oscilación del sur. En: D. Trombotto y R. Villalba (eds.), IANIGLA, 30 años de investigación básica y aplicada en ciencias ambientales, pp. 31-34, Instituto Argentino de Nivología, Glaciología y Ciencias Ambientales, Mendoza, Argentina.

Boone J.L. y E.A. Smith. 1998. It is evolution yet? A critique of evolutionary archaeology. Current Anthropology 39: 141-173.

Borrero L.A. 1989-1990. Evolución cultural divergente en la Patagonia austral. Anales del Instituto de la Patagonia; Serie Ciencias Sociales 19: 133-140.

Borrero L.A. 1994-1995. Arqueología de la Patagonia. Palimsesto 4: 9-69.

Borrero L.A. 1999. Prehistoric Exploration and Colonization of Fuego-Patagonia. Journal of World Prehistory 13: 321-355.

Borrero L.A. 2002. Arqueología y biogeografía humana en el sur de Mendoza (comentario crítico). En: A. Gil y G. Neme (eds.), Entre Montañas y Desiertos: Arqueología del Sur de Mendoza, pp.195-102. Sociedad Argentina de Antropología, Buenos Aires.

Borrero L.A. 2004. Archaeozoology of the Andean "Dead Ende" in Patagonia: Living near the Continental Ice. En: Mondini, M., S. Muñoz, and S. Wickler (eds). Colonisation, Migration and Marginal Areas. A Zooarchaeological Approach. Oxbow Books, Oxford. 55-61 pp.

Borrero L.A. 2005. The Archaeology of the Patagonian Deserts Hunter-Gatherers in the Cold Desert. En: P. Veth, M. Smith y P. Hiscock (eds), Desert Peoples. Archaeological Perspectives, pp.142-158. Blackwell Publishing London.

Borrero L.A. y F.M. Martín 1996. Tafonomía de carnívoros: un enfoque regional. En: J. Gómez Otero (ed.), Arqueología, Sólo Patagonia, pp. 189-206. CENPAT (CONICET), Puerto Madryn.

Borrero L.A., F.M. Martín y J. Vargas. 2005. Tafonomía de la interacción entre pumas y guanacos en el Parque Nacional Torres del Paine, Chile. Magallania 33: 95-114.

Bousman C.B. 2005. Coping with Risk: Later stone age technological strategies at Blydefontein Rock Shelter, South Africa. Journal of Anthropological Archaeology 24: 193-226.

Bovy K.M. 2002. Differential avian skeletal part distribution: Explaining the abundance of wings. Journal of Archaeological Science 29: 965-978.

Braun J.K. 1993. Systematic relationships of the tribe Phyllotini (Muridae: Sigmodontinae) of South America. Special Publication Oklahoma Museum of Natural History, Oklahoma. 
Braun J.K. y M.A. Mares. 1995. A new genus and species of Phyllotine rodent (Rodentia: Muridae: Sigmodontinae: Phyllotini) from South America. Journal of Mammalogy 76: 504-521.

Braun J.K., B.S. Coyner, M.A. Mares y R.A. Van Den Bussche. 2008. Phylogenetic relationships of South American grass mice of the Akodon varius group (Rodentia, Cricetidae, Sigmodontinae) in South America. Journal of Mammalogy 89: 768-777.

Braun J.K., M.A. Mares y R.A. Ojeda. 2000. A new species of grass mouse, genus Akodon (Muridae: Sigmodontinae), from Mendoza Province, Argentina. Zeitschrift für Säugetierkunde 65: 216-225.

Broughton J.M. 1994. Late Holocene resource intensification in the Sacramento Valley: The vertebrate evidence. Journal of Archaeological Science 21: 501-514.

Broughton J.M. 2002. Prey spatial structure and behavior affect archaeological tests of optimal foraging models: examples from the Emeryville Shellmound vertebrate fauna. World Archaeology 34: 60-83.

Broughton J.M. 2004. Prehistoric Human Impacts on California Birds: Evidence from the Emeryville Shellmound Avifauna. Ornithological Monographs 56, American Ornithologists" Union, Washington D.C.

Broughton J.M., V.I. Cannon, S. Arnold, R.J. Bogiatto y K. Dalton. 2006. The taphonomy of owl-deposited fish remains and the origin of the Homestead Cave ichthyofauna. Journal of Taphonomy 4: 69-95.

Brown L. 1976. Birds of Prey: Their biology and ecology. Hamlyn, London.

Bruniard E. 1982. La diagonal árida argentina. Un límite climático real. Revista Geográfica IPGH 95: 5-20.

Bryson R. 1994. On integratin Climatic change and Culture change study. Human Ecology 22: $115-128$.

Burger O., M.J. Hamilton y R. Walker. 2005. The prey as patch model: optimal handling of resources with diminishing returns. Journal of Archaeological Science 32: 1147-1158.

Burn H. 1999. Burrowing Owl/Athene cunicularia. En: J. del Hoyo, A. Elliott y J. Sargatal (eds.), Handbook of the Birds of the World, Volume 5, Barn Owl to Hummingbirds, pp. 227228. Lynx Editions, Barcelona.

Burton J.A. (ed.). 1984. Owls of the world. Tanager Books, Dover, Delaware.

Butzer K. 1989. Arqueología: una ecología del hombre. Ediciones Bellaterra, Barcelona.

Cabezas V.M. y R.P. Schlatter. 1987. Hábitos y comportamiento alimentario de Milvago chimango Vieillot, 1816 (Aves, Falconidae). Anales del Museo de Historia Natural de Valparaíso 18: 131-141. 
Cabrera A. 1953. Los roedores argentinos de la Familia Caviidae. Publicación de la Escuela de Veterinaria 7: 1-93.

Cabrera A. 1961. Catálogo de los mamíferos de América del Sur. Revista del Museo Argentino de Ciencias Naturales "Bernardino Rivadavia” 4: 309-732.

Cabrera A.L. 1976. Regiones fitogeográficas argentinas. Enciclopedia Argentina de Agricultura y Jardinería 1: 1-85.

Cabrera M.R. 2009. Lagartos del centro de la Argentina. Edición del autor. Córdoba.

Cabrera P. 1929. Los aborígenes del país de Cuyo. Imprenta de la Universidad de Córdoba, Córdoba.

Cade T. 1982. The falcons of the world. Cornell University Press, Ithaca NY.

CalPal Online (Cologne Radiocarbon Calibration \& Paleoclimate Research Package). 2007. http://www.calpal-online.de/.

Campos C., M. Tognelli y R. Ojeda. 2001. Dolichotis patagonum. Mammalia Species 652: 1-5.

Cañón C, G. D'Elía, U.F.J. Pardiñas y E.P. Lessa. 2010. Phylogeography of Loxodontomys micropus with comments on the alpha taxonomy of Loxodontomys (Cricetidae: Sigmodontinae). Journal of Mammalogy 91: 1449-1458.

Capitanelli R.G. 1967. Climatología de Mendoza. Editorial de la Facultad de filosofía y Letras de la Universidad Nacional de Cuyo, Mendoza.

Capitanelli R.G. 1972. Geomorfología y Clima de la provincia de Mendoza. En: F.A. Roig, (ed.), Geología, Geomorfología, Climatología, Fitogeografía y Zoogeografía de la provincia de Mendoza. Reedición especial del Boletín de la Sociedad Argentina de Botánica 8: 1548.

Cavagnaro JB. 1988. Distribution of $\mathrm{C}_{3}$ and $\mathrm{C}_{4}$ grasses at different altitudes in a temperature arid region of Argentina. Oecologia 76: 273-277.

Carbajo A.E. y U.F.J. Pardiñas. 2007. Spatial distribution model of a hantavirus reservoir, the Long-Tailed Colilargo (Oligoryzomys longicaudatus) in Argentina. Journal of Mammalogy 88: 1555-1568.

Carleton M.D. y G.G. Musser. 1989. Systematic studies of oryzomyine rodents (Muridae, Sigmodontinae): a synopsis of Microryzomys. Bulletin of the American Museum of Natural History 191: 1-83.

Carreira S., M. Meneghel y F. Achával. 2005. Reptiles de Uruguay. Ed. Dirac Faculta de Ciencias, universidad de la República, Montevideo.

Carrera J.D. y F.J. Fernández. 2010. Análisis tafonómico de egragrópilas producidas por el lechuzón orejudo (Asio clamator): un caso experimental. En: M. De Nigris, P.M. Fernández, M. Giardina, A.F. Gil, M.A. Gutiérrez, A. Izeta, G. Neme y H.D. Yacobaccio (eds.), Zooarqueología a principios del siglo XXI: aportes teóricos, metodológicos y casos de estudio, pp. 381-386. Ediciones del Espinillo, Buenos Aires. 
Caso A., C. Lopez-Gonzalez, E. Payan, E. Eizirik, T. de Oliveira, R. Leite-Pitman, M. Kelly, C. Valderrama y M. Lucherini. 2008a. Puma concolor. En: IUCN 2011. IUCN Red List of Threatened Species. Version 2011.1. www.iucnredlist.org. 13 Julio 2011.

Caso A., C. Lopez-Gonzalez, E. Payan, E. Eizirik, T. de Oliveira, R. Leite-Pitman, M. Kelly y C. Valderrama. 2008b. Puma yagouaroundi. En: IUCN 2011. IUCN Red List of Threatened Species. Version 2011.1. www.iucnredlist.org. 14 de Julio 2011.

Cassalins L. y N.R. Ibargüengoytía. 2004. Biología reproductiva del lagarto nocturno Homonota darwinii (Gekkonidae): ciclos femenino/masculino y dimorfismo sexual. Resumenes del V Congreso argentino de Herpetología, San Juán, 17-18.

Castillo C., E. Martín y J.J. Coello, 2001. Small vertebrate taphonomy of La Cueva del Llano, a volcanic cave of Fuerteventura (Canary Islands, Spain). Palaeogeography, Palaeoclimatology and Palaeoecology 166: 277-291.

Castillo D.F., M. Lucherini, E.M. Luengos Vidal, C. Manfredi y E.B. Casanave. 2011. Spatial organization of Molina's hog-nosed skunk (Conepatus chinga) in two landscapes of the Pampas grassland of Argentina. Canadian Journal of Zoology 89: 229-238.

Cei J.M. 1973. Comentarios sobre algunos géneros de iguanidos: Diplolaemus, Leiosaurus, Aperopristis y Cupriguanus. Physis 32: 269-276.

Cei J.M. 1974. Revision of the Patagonian iguanids of the Liolaemus elongates complex. Journal of Herpetology 8: 219-229.

Cei J.M. 1978. Estado taxonómico y distribución geográfica de las especies del género Homonota (Sauria, Gekkonidae). Publicación Ocasional del Instituto de Biología Anima, Universidad Nacional de Cuyo 9: 1-4.

Cei J.M. 1986. Reptiles del centro, centro-oeste y sur de la Argentina. Museo Regionale di Scienze Naturali, Monografie.

Cei J.M. 1993. Reptiles del noroeste, nordeste y este de la Argentina. Herpetofauna de las selvas subtropicales, Puna y Pampas. Museo Regionale di Scienze Naturali Torino, Monografia 14: 1-949.

Cei J.M. y L.P. Castro. 1973. Taxonomic serological researches on the Phymaturus patagonicus complex. Journal of Herpetology 7: 237-247.

Cei J.M y LP. Castro 1978. Atlas de los vertebrados inferiores de la región de Cuyo. Serie Científicas $\mathrm{N}^{\circ}$ 2. Publicaciones del Instituto de Biología Animal. Facultad de Ciencias Agrarias y Universidad Nacional de Cuyo, Mendoza.

Cei J.M. y J.A. Scolaro 1999. Speciation of the "darwini Complex" (genus Liolaemus "patch group" in the southernmost area of its distribution (Reptilia: Tropiduridae). Revue Francaise d'Aquariologie 26: 79-82. 
Cei J.M., J.A. Scolaro y F.Videla 2001. The present status of Argentinian Polychrotid species of the genus Pristidactylus and description of its southernmost taxon as a new specie. Journal of Herpetology 35: 597-605.

Cei J.M. y F. Videla 2003. A new Phymaturus species from volcanic cordilleran mountains of the south-western Mendoza Province Argentina (Liolaemidae, Iguania, Lacertilia, Reptilia). Museo Regionale di Scienze Naturali Torino, Monografia 20: 291-314.

Cei J.M., J.A. Scolaro y F. Videla 2003. A taxonomic revision of recognized argentine species of the Leiosaurid genus Diplolaemus (Reptilia, Squamata, Leiosauridae). Facena 19: 163134.

Cei J.M., J.A. Scolaro y F. Videla. 2004. An updated biosystematic approach to the Leiosaurid genus Pristidactylus. Museo Regionale di Scienze Naturali Torino, Monografia 21: 159192.

Charnov E.L. 1976. Optimal foraging: the marginal value theorem. Theoretical Population Biology 9: 129-136.

Chiappero M.B., A. Blanco, G.E. Caldero, M.S. Sabattini y C.N. Gardenal. 2002. Genetic structure of populations of Calomys laucha (muridae, sigmodontinae) from central Argentina. Biochemical Systematics and Ecology 30: 1023-1036.

Chiesa J., E. Strasser y D. Gómez. 2010. Estratigrafía de la cuenca media del Río Desaguadero, San Luis, Argentina. En: M. Zárate, G. Neme y A. Gil (eds.), Paleoambientes y ocupaciones humanas del centro-oeste de Argentina durante la transición PleistocenoHoloceno y Holoceno de Mendoza, pp. 41-64. Sociedad Argentina de Antropología, Buenos Aires.

Cirignoli S., D.H. Podestá y U.F.J. Pardiñas. 2001. Diet of the Short-eared Owl in northwestern Argentina. Journal of Raptor Research 35: 68-69.

Cirignoli S., P. Teta, U.F.J. Pardiñas y G. D’Elía. 2006. Tribu Oryzomyini Vorontsov 1959 (sensu Voss y Carleton, 1993). En: R.M. Barquez, M.M. Díaz y R.A. Ojeda (eds.), Mamiferos de Argentina: Sistemática y Distribución, pp. 166-175. Sociedad Argentina para el estudio de los Mamíferos, Tucumán.

Clark R.J. 1975. A field study of the Short-eared Owl, Asio flammeus, in North America. Wildlife Monographs 47: 1-67.

Cobos D. y J. Boninsegna. 1983. Fluctuations of some glaciers in the upper Atuel River basin, Mendoza-Argentina. En: J. Rabassa (ed.), Quaternary of South America and Antarctic Peninsula 1, pp. 61-81. Holanda.

Contreras J.R. 1968. Akodon molinae una nueva especie de ratón de campo del sur de la provincia de Buenos Aires. Zoología Platense, Investigaciones Zoológicas y Paleontológicas 1: 912. 
Contreras J.R. 1979. Lista faunística preliminar de los vertebrados de la Reserva Ecológica de Ñacuñan. IADIZA, Cuaderno Técnico 79: 39-47.

Contreras J.R. y V.G. Roig. 1975. Ctenomys eremophilus, una nueva especie de tuco-tuco de la región de Ñacuñán, provincia de Mendoza (Rodentia, Octodontidae). Resúmenes de las $X$ Jornadas Argentinas de Zoología, pp.17. Corrientes.

Contreras J.R., V.G. Roig y C.M. Suzarte. 1977. Ctenomys validus, una nueva especie de "tunduque" de la provincia de Mendoza (Rodentia; Octodontidae). Physis Sección C 36: 159-162.

Contreras J.F. y M.I. Rosi. 1980a. Acerca de la presencia en la provincia de Mendoza del ratón de campo Akodon molinae Contreras, 1968 (Rodentia: Cricetidae). Historia Natural 26: 181184.

Contreras J.F. y M.I. Rosi. 1980b. Comportamiento territorial y fidelidad al hábitat en una población de roedores del centro de la provincia de Mendoza. Ecología Argentina 5: 1729.

Contreras J.F. y M.I. Rosi. 1980c. Una Nueva Subespecie del ratón Colilargo para la provincia de Mendoza: Oligoryzomys flavescens occidentalis (Mammalia: Rodentia, Cricetidae). Historia Natural 22: 181-184.

Contreras J.F. y M.I. Rosi. 1981. Notas sobre los Akodontini argentinos (Rodentia, Cricetidae).II. Akodon andinus andinus (Philipi, 1868) en la provincia de Mendoza. Historia Natural 32: 233-236.

Corbalán V.E. 2004. Uso de hábitat y ecología poblacional de pequeños mamíferos del desierto del Monte central, Mendoza, Argentina. Tesis Doctoral inédita, Facultad de Ciencias Naturales y Museo, Universidad Nacional de La Plata.

Corbalán V.E. y R.A. Ojeda. 2004. Spatial and temporal organization of small mammal communities in the Monte desert, Argentina. Mammalia 68: 5-14.

Corbalán V.E. y R.A. Ojeda. 2005. Áreas de acción de un ensamble de roedores del desierto del Monte (Mendoza, Argentina). Mastozoología Neotropical 12: 145-152.

Corbalán V.E., S. Tabeni y R.A. Ojeda. 2006. Assessment of habitat quality for four small mammal species of the Monte desert, Argentina. Mammalian Biology 71: 227-237.

Corbat M., F. Zangrando y A. Gil. 2009. El estudio de restos de peces en conjuntos arqueológicos del sur de Mendoza: primeros resultados y perspectivas. En: M. Salemme, F. Santiago, M. Álvarez, E. Piana, M. Vázquez y M.E. Mansur (eds.), Arqueología de Patagonia: una mirada desde el último confín, pp. 717-728. Mansur. Editorial Utopías, Ushuaia.

Cortegoso V., V. Durán, O. Pelagatti y G. Lucero. 2010. La cría y tráfico de ganado mayor como factores de cambio ambiental en la cordillera central y piedemonte oriental de Mendoza (siglos XVII a XX). Una aproximación arqueológica e histórica. En: M. Zárate, A. Gil y G. Neme (eds.), Condiciones paleoambientales y ocupaciones humanas durante la 
transición Pleistoceno-Holoceno y Holoceno de Mendoza, pp 277-308. Publicaciones de la Sociedad Argentina de Antropología, Buenos Aires.

Courtin J. y P. Villa. 1982. Une expérience de piétinement. Bulletin, Société Préhistorique Francaise 79: 117-123.

Courty M.A., P. Goldberg y R. Macphail. 1989. Soil and micromorphology in archaeology. Cambridge University Press, Cambridge.

Crandall B.D y P.W. Stahl. 1995. Human digestive effects on a micromammalian skeleton. Journal of Archeological Science 22: 789-797.

Crespo, J. y J. De Carlo. 1963. Estudio ecológico de una población de zorros colorados en el oeste de la provincia de Neuquén. Revista del Museo Argentino de Ciencias Naturales Bernardino Rivadavia, Ecología 1: 1-55.

CrivellI-Montero E.A., U.F.J. Pardiñas, M. Fernández, M. Bogazzi, A. Chauvin, V.M. Fernández y M. Lezcano. 1996. La Cueva Epullán Grande (Provincia de Neuquén, Argentina) Informe de avance. Prehistoria 2: 185-240.

Cruz I. 2005. La representación de partes esqueléticas de aves. Patrones naturales e interpretación arqueológica. Archaeofauna 14: 69-81.

Cueto G.R., P. Teta y P. De Carli. 2008. Rodents from southern Patagonian semi-arid steppes (Santa Cruz Province, Argentina). Journal of Arid Environments 72: 56-61.

Currier M.J.P. 1983. Felis concolor. Mammalian Species 200: 1-7.

D’Antoni H. 1980. Los últimos 30.000 años en el sur de Mendoza. III Coloquio de Paleobotánica y Palinología: 83-108.

D'Antoni H. 1983. Pollen analysis of Gruta del Indio. En: J. Rabassa (ed.), Quaternary of South America and Antartic Peninsula 1: 83-104.

D' Elía G. 2003. Phylogenetics of Sigmodontinae (Rodentia, Muroidea, Cricetidae), with special reference to the akodont group, and with additional comments on historical biogeography. Cladistics 19: 307-323.

D' Elía G., P. Teta y U.F.J. Pardiñas. 2006. Sigmodontinae Incertae Sedis. En: R.M. Barquez, M.M. Díaz y R.A. Ojeda (eds.), Mamíferos de Argentina: Sistemática y Distribución, pp. 197-202. Sociedad Argentina para el estudio de los Mamíferos, Tucumán.

D’Elía G., U.F.J. Pardiñas, P. Teta y J.L. Patton. 2007. Definition and diagnosis of a new tribe of sigmodontine rodents (Cricetidae: Sigmodontinae), and a revised classification of the subfamily. Gayana 71: 187-194.

De Francesco C.G. 2010. Moluscos y paleoambientes del centro-oeste de Argentina durante el cuaternario. En: M. Zárate, A. Gil y G. Neme (eds.), Paleoambientes y ocupaciones humanas del centro-oeste de Argentina durante la transición Pleistoceno-Holoceno y Holoceno de Mendoza, pp. 151-174. Sociedad Argentina de Antropología, Buenos Aires. 
De Francesco C.G. y S. Diéguez. 2006. Paleoambientes del Cuaternario tardío del sur de Mendoza: estado del conocimiento, problemas y perspectivas. En: V. Durán y V. Cortegoso (eds.), Arqueología y Ambiente de Áreas Naturales Protegidas de la Provincia de Mendoza, pp. 69-80. Anales de Arqueología y Etnología, Volumen especial № 61, Mendoza.

De Francesco C.G., M. Zárate y S.E. Miquel. 2007. Late Pleistocene mollusc assemblages inferred from paleoenvironments from the Andean Piedmont of Mendoza, Argentina. Palaeogeography, Palaeoclimatology, Palaeoecology 257: 461-469.

De La Barrera J.M. 1939. Contribución al conocimiento de la peste selvática en la Argentina. Caracteres del brote en Mendoza de 1937. Revista del Instituto Bacteriológico 8: 430454.

De La Barrera J.M. 1940. Estudios sobre la peste selvática en Mendoza. Revista del Instituto Bacteriológico 9: 565-596.

De La Barrera J.M. 1941. El último brote de peste selvática en Mendoza (1941). Revista del Instituto Bacteriológico 10: 390-393.

Dessanti R. 1978. Descripción geológica de la Hoja 28 b, Malargüe. Carta Geológico-Económica de la República Argentina. Servicio Geológico Nacional, Secretaria de Estado de Minería.

De Santis L.J.M, V. Roig y E. Justo. 1991. La anatomía cráneodentaria de Tympanoctomys barrerae (Lawrence). Comparación con Octomys mimax y consideraciones acerca de su estado taxonómico (Rodentia: Octodontidae). Neotropica 37: 113-122.

De Santis L.J.M., M.F. Tejedor y P.C. Straccia. 1995. Nuevos registros de Lestodelphys halli (Marsupialia: Didelphidae). Neotrópica 41: 82.

De Santis L.J.M, G. Moreira y E. Justo. 1998. Anatomía de la musculatura branquiomérica de algunas especies de Ctenomys Blainville, 1826 (Rodentia, Ctenomyidae): caracteres adaptativos. Bolentín de la Sociedad Biológica de Concepción 69: 89-107.

Denys C. 1997. Rodent faunal lists in karstic and open-air sites of Africa: an attempt to evaluate predation and fossilisation biases on paleodiversity. Cuadernos de Geología Ibérica 23: 73-94.

Denys C. 2002. Taphonomy and experimentation. Archaeometry 44: 469-484.

Devillers C. y P. Clairambault. 1977. Vertebrados. Anatomía Comparada. En P.P. Grassé (ed.), Zoología, pp. 1-545. Toray-Masson SA, Barcelona.

Deward G. y A. Jarardino. 2007. Micromammals: when humans are the hunters. Journal of Taphonomy 5: 1-14.

Díaz G.B. y Verzi D. 2006. Familia Octodontidae. En: R.M. Barquez, M.M. Díaz y R.A. Ojeda (eds.), Mamiferos de Argentina: Sistemática y Distribución, pp. 231-236. Sociedad Argentina para el estudio de los Mamíferos, Tucumán. 
Díaz M. y M. Lucherini. 2006a. Familia Canidae G. Fisher, 1817. En: R.M. Barquez, M.M. Díaz y R.A. Ojeda (eds.), Mamíferos de Argentina: Sistemática y Distribución, pp. 89-93. Sociedad Argentina para el estudio de los Mamíferos, Tucumán.

Díaz M. y M. Lucherini. 2006b. Mephitidae, Mustelidae, Procyonidae. En: R.M. Barquez, M.M. Díaz y R.A. Ojeda (eds.), Mamíferos de Argentina: Sistemática y Distribución, pp.100107. Sociedad Argentina para el estudio de los Mamíferos, Tucumán.

Diaz M. y P. Teta. 2011. Thylamys pallidior. En: IUCN 2011. IUCN Red List of Threatened Species. Version 2011.1. www.iucnredlist.org. 22 Septiembre 2011.

Diaz G.B., R.A. Ojeda, M.H. Gallardo y S.M. Giannoni. 2000. Tympanoctomys barrerae. Mammalian Species 646: 1-4.

Díaz M.M., P. Teta, U.F.J. Pardiñas y R.M. Barquez. 2006. Tribu Phyllotini Vorontsov, 1959. En R.M. Barquez, M.M. Díaz y R.A. Ojeda (eds.), Mamíferos de Argentina: Sistemática y Distribución, pp. 175-189. Sociedad Argentina para el estudio de los Mamíferos, Tucumán.

Diéguez S. y G. Neme. 2003. Geochronology of the Arroyo Malo 3 site and the first human occupations in North Patagonia in the Early Holocene. En: L. Miotti, M. Salemme y N. Flegenheimer (eds.), Ancient Evidence for Paleo South Americans: From Where the South Winds Blows, pp. 87-92. Center for the Study of the First Americans: Texas A\&M University Press, College Station.

Dieguez S., A. Gil, G. Neme, M. Zárate, C. De Francesco y E. Strasser. 2004. Cronoestratigrafía del sitio Rincón del Atuel-1 (San Rafael, Mendoza): Formación del sitio y ocupación humana. Intersecciones en Antropología 5: 71-80.

Dincauze D. 2000. Environmental Archaeology. Cambridge University Press, Cambridge.

Dodson P. y D. Wexlar. 1979. Taphonomic investigations of owl pellets. Paleobiology 5: 275284.

Domínguez-Rodrigo M. y R. Barba. 2005. A study of cut marks on small-sized carcasses and its application to the study of cut-marked bones from small mammals at the FLK Zinj site. Journal of Taphonomy 2-3: 11-24.

Domínguez-Rodrigo M., S. de Juana, A. Galán y M. Rodriguez. 2009. A new protocol to differenciate trampling marks from butchery cut marks. Journal of Archaeological Science 36: 2643-2654.

Donázar J.A., O. Ceballos, A. Travaini y F. Hiraldo. 1993. Roadside raptor surveys in the Argentinean Patagonia. Journal of Raptor Research: 106-110.

Donadio E., Di Martino S., Aubone M. y Novaro A.J. 2001. Activity patterns, home-range, and habitat selection of the common hog-nosed skunk, Conepatus chinga (Mammmalia, Mustelidae), in northwestern Patagonia. Mammalia 65: 49-54. 
Donadío E., S. Di Martino, M. Aubone, A.J. Novaro. 2004. Feeding ecology of the Andean hognosed skunk (Conepatus chinga) in areas under different land use in north-western Patagonia. Journal of Arid Environments 56: 709-718.

Donoso Barros R. 1965. El género Diplolaemus Bell en Sudamérica. Anais II. Congreso Latinoamericano de Zoología, pp. 219-222. Sao Paulo.

Dorn R.I. y T.M. Oberlander. 1981. Microbial origin of desert Varnish. Science 213: 1245-1247.

Duke G.E., J.G. Ciganek y O.A. Evanson. 1973. Food consumption and energy, water, and nitrogen budgets in captive Great Horned Owls (Bubo virginianus). Comparative Biochemistry and Physiology 44: 283-292.

Duke G.E., A.A. Jegers, G. Loft, y O.A. Evanson. 1975. Gastric digestion in some systems. Comparative Biochemistry and Physiology 50: 649-656.

Dunnum J.L. y J. Salazar-Bravo. 2010. Phylogeny, evolution, and systematics of the Galea musteloides complex (Rodentia: Caviidae). Journal of Mammalogy 91: 243-259.

Dunnum J., U.F.J. Pardiñas, H. Zeballos y R. Ojeda. 2011. Galea musteloides. En: IUCN 2011. IUCN Red List of Threatened Species. Version 2011.1. www.iucnredlist.org. 22 Septiembre 2011.

Durán V. 1997. Arqueología del Valle del Río Grande, Malargüe, Mendoza. Tesis Doctoral inédita. Facultad de Ciencias Naturales y Museo. Universidad Nacional de La Plata.

Durán V. 2000. Poblaciones Indigenas de Malargüe: su Arqueología e Historia. CEIDER, Serie Libros No. 1. Mendoza: Argentina.

Durán V. 2004. Poblaciones Indígenas de Malargüe: su Arqueología e Historia. CEIDER, Universidad Nacional de Cuyo, Mendoza, Argentina. Segunda reimpresión.

Durán V. y J. Ferrari. 1991. El proceso de araucanización en el sur mendocino desde una perspectiva arqueológica. Actas del XI Congreso Nacional de Arqueología Chilena III, pp. 165-188. Chile.

Efremov I.A. 1940. Taphonomy: a new branch of paleontology. Pan American Geologist 74: 8193.

Ellis D.H., B.A. Sabo, J.K. Fackler y B.A. Millsap. 2002. Prey of the Peregrine Falcon (Falco peregrinus cassini) in Southern Argentina and Chile. Journal of Raptor Research 36: 315-319.

Emmons L. y K. Helgen. 2008. Conepatus chinga. En: IUCN 2011. IUCN Red List of Threatened Species. Version 2011.1. www.iucnredlist.org. 14 de Julio 2011.

Ericson P.G.P. 1987. Interpretations of archaeological birds remains a taphonomic approach. Journal of Archaeological Science 14: 65-75.

Espinoza R.E. y F. Lobo. 2003. Two new species of Liolaemus lizard fron northwestern Argentina: Speciation within yhe northern subclade of the elongates group (Iguania, Liolaemidae). Herpetologica 59: 89-105. 
Espizua L. 1993a. Glaciaciones Cuaternarias. XII Congreso Geológico Argentino y II Congreso de Exploración de Hidrocarburos. Geología y Recursos Naturales de Mendoza, pp. 217224. Mendoza.

Espizua L. 1993b. Quaternary Glaciations in the Río Mendoza Valley, Argentine Andes. Quaternary Research 40: 150-162.

Espizua L. 2003. Holocene glaciar fluctuations in the south of Mendoza Andes, Argentina. Actas II Congreso Argentino de Cuaternario y Geomorfología, pp. 87-92. Tucumán.

Espizua L. 2005. Holocene glacier chronology of Valenzuela Valley, Mendoza Andes, Argentina. The Holocene 15: 1079-1085.

Estes R., K. de Quiroz y J. Gauthier. 1988. Phylogenetic relationships within Squamata. En: R. Estes y G. Pregill (eds.), Phylogenetic relationships of the lizard families: essay commemorating Charles L. Camp, pp. 119-281. Stanford University Press, Stanford..

Estes R. y E.E. Williams. 1998. Ontogenetic variation in the molariform teeth of lizards. Journal of Vertebrate Paleontology 4: 96-107.

Etheridge R. 1958. Pleistocene Lizard of the Cragin Quarry Fauna of Meade County, Kansas. Copeia 2: 94-101.

Etheridge R. 1993. Lizard of the Liolaemus darwinii complex (Squamata: Iguania: Tropiduridae) in Northern Argentina. Museo Regionale di Scienze Naturali Torino, Monografia 11: 137-1999.

Etheridge R. 1995. Redescription of Ctenoblepharys adspersa Tschudi, 1845, and the taxonomy of Liolaeminae (Reptilia: Squamata: Tropiduridae). American Museum Novitates 3142: 134.

Etheridge R. 2000. A review lizards of the Liolaemus wiegmannii group(Squamata: Iguania: Tropiduridae), and a history of morphological change in the sand-dwelling species. Herpetological monographs 14: 293-352.

Etheridge R. 2001. A new species of Liolaemus (Reptilia: Squamata: Tropiduridae) from Mendoza province Argentina. Cuadernos de Herpetología 15: 3-15.

Etheridge R. y E.E. Williams 1985. Notes of Pristidactylus (Squamata, Iguanidae). Breviora 483: $1-18$.

Fernández F.J. 2010. Paleozoogeography of the wine mouse (Akodon oenos) \& late Holocene paleoenvironments in south-central of Mendoza, Argentina. Ethnobiology Letters 1: 5257.

Fernández F.J., G.J. Moreira, G.A. Neme y L.J.M. De Santis. 2009a. Microvertebrados exhumados del sitio arqueológico "Cueva Arroyo Colorado" (Mendoza, Argentina): aspectos tafonómicos y significación paleoambiental. Archaeofauna 18: 99-118.

Fernández F.J., G.J. Moreira, F. Ballejo y L.J.M. De Santis. 2009b. Novedosos registros de aves exhumadas del sitio arqueológico "Laguna El Sosneado (LS-3)" para el Holoceno tardío 
en el sur de Mendoza: aspectos tafonómicos. Intersecciones en Antropología 10: 327342.

Fernández F.J., M.A. Giardina y C. Otaola. 2009c. El registro faunístico del sitio Laguna El Sosneado 3 (LS-3) (Mendoza, Holoceno tardío): Aspectos tafonómicos y significación paleoambiental. Resúmenes Ameghiniana 46: 23-24.

Fernández F.J., J.D. Carrera, C. García-Esponda, G.J. Moreira y L.J.M. De Santis. 2009d. Micromamíferos registrados en tres localidades del centro-oeste de Mendoza (Didelphimorphia y Rodentia). Multequina 18: 3-14.

Fernández F.J., G.J. Moreira, D. Ferraro y L.J.M. De Santis. 2009e. Microvertebrados consumidos por la lechuza de campanario (Tyto alba) en la localidad de Olavarría (Buenos Aires): un caso de elevada batracofagia. Nuestras Aves 54: 20-21.

Fernández F.J., L. del Papa, G.J. Moreira, L. Prates y L.J.M. De Santis. 2011a. Small mammal remains recovered from two archaeological sites in the middle and lower Negro River valley (Late Holocene, Argentina): Taphonomic issues and paleoenvironmental implications. Quaternary International 245: 136-147.

Fernández F.J., U.F.J. Pardiñas, P. Teta y R. Barberena. 2011b. Environmental stability during the Pleistocene-Holocene transition in northwest Patagonia. Small mammals as evidence. Current Research in the Pleistocene 28: 154-156.

Fernández, F.J., F. Ballejo, G.J. Moreira, E. Tonni, L.J.M. De Santis 2011c. Roedores cricétidos de la provincia de Mendoza. Guía cráneo-dentaria orientada para su aplicación en estudios zooarqueológicos. Sociedad Argentina de Antropología y Universitas Sarmiento, Córdoba.

Fernández F.J., F. Idoeta, C. García-Esponda, J.D. Carrera, G.J. Moreira, F. Ballejo y L.J.M. De Santis. 2012. Micromammals (Didelphimorphia, Rodentia and Chiroptera) from Pampean Region, Argentina. Check List 8: 130-134.

Fernández F., P. Teta, R. Barberena y U.F.J. Pardiñas. En prensa. Small mammal remains from Cueva Huenul 1, Argentina. Taphonomy and paleoenvironments since the Late Pleistocene. Quaternary International.

Fernández-Jalvo Y. 1996: Small mammal taphonomy and the Middle Pleistocene environments of Dolina, Northern Spain. Quaternary International 33: 21-34.

Fernández-Jalvo Y. y P. Andrews. 1992. Small Mammal Taphonomy of Gran Dolina, Atapuerca (Burgos), Spain. Journal of Archaeological Science 19: 407-428.

Fernández-Jalvo Y., P. Andrews y C. Denys. 1999. Cut mark on small mammals at Olduvai Gorge Bed-I. Journal of Human Evolution 36: 587-589.

Fernández-Jalvo Y. y P. Andrews. 2003 Experimental effects of water abrasion on bone fragments. Journal of Taphonomy 1: 147-163. 
Fernández-Jalvo J., B. Sánchez-Chillón, P. Andrews, S. Fernández-López, y L. Acalá Martínez. 2002. Morphological taphonomic transformations of fossil bones in continental environments and repercussions on their Chemical composition. Archaeometry 44: 353361.

Figueroa Rojas R.A., S. Corales Stappung, J. Cerda Cordero y E. Saldivia Pérez. 2001. Roedores, rapaces y carnívoros de Aysen. Servicio Agrícola y Ganadero, Aysen.

Figueroa Rojas R.A., E. Soraya Corales Stappung y S. Alvarado. 2003. Diet of the red-backed hawk (Buteo polyosoma) in a forested area of the Chilean Patagonia and its relation to the abundance of rodent prey. Hornero 18: 43-52.

Figueroa Rojas R.A. y E. Soraya Corales Stappung. 2004. Summer diet comparison between the american kestrel (Falco sparverius) and aplomado falcon (Falco femoralis) in an agricultural area of araucanía, southern chile. Hornero 19: 53-60.

Fiorillo A.R. 1989. An experimental study of trampling: implications for the fossil record, En: R. Bonnichsen y M.H Sorg (eds.), Bone modification, pp. 61-71. University of Maine Center for the Study of the First American, Orono.

Fischer G. 1814. Zoognosia tabulis synopticis illustrate. Nicolai Sergeidis Vsevolozsky Moscow 3: $1-732$.

Flores D.A., M.M. Diaz y R.M. Barquez. 2007. Systematics and Distribution of Marsupials in Argentina: A Review. En: D.A. Kelt, E.P. Lessa, J. Salazar-Bravo y J.L. Patton (eds.), The Quintessential Naturalist. Honoring the Life and Legacy of Oliver P. Pearson, pp. 134, 981. University of California Publications in Zoology, California.

Formoso A.E., D.E. Udrizar Sauthier, P. Teta y U.F.J. Pardiñas. 2011. Dense-sampling 'reveals a complex distributional pattern between the southernmost marsupials Lestodelphys and Thylamys in Patagonia, Argentina. Mammalia 75: 371-379.

Frost D.R y R. Etheridge. 1989. A Phylogenetic Analvsis And Taxonomy of lguanian Lizards (Reptilia: Squamata). Miscellaneous Publications 18, Museum of Natural History, The University of Kansas, Kansas.

Frost D.R., R., Etheridge E. Janies y T.A. Titus. 2001. Total Evidence, Sequence Alignment, Evolution of Polychrotid Lizards, and a Reclassification of the Iguania (Squamata: Iguania). American Museum Novitates 3344: 1-38.

Gallardo J.M. 1961. Estudio zoogeográfico del género Leiosaurus (Reptilia, Sauria). Physis 22: $113-118$

Gallardo J.M. 1964. Los géneros Urostropus D. et B. y Cupriguanus gen. Nov. (Sauria, Iguanidae) y sus especies. Neotropica 10: 125-136.

Gallardo J.M. 1966. Liolaemus lentus nov. sp. (Iguanidae) de La Pampa y algunas observaciones sobre los saurios de dicha provincia Argentina y del oeste de Buenos Aires. Neotropica 12: $15-29$. 
Gallardo M.H. y B.D. Patterson. 1985. Chromosomal differences between two nominal subspecies of Oryzomys longicaudatus Bennet. Mammalian Chromosomes Newsletter 25: 49-53.

Gallardo M.H. y R.E. Palma. 1990. Systematics of Oryzomys longicaudatus (Rodentia: Muridae) in Chile. Journal of Mammalogy 71: 333-343.

Gallardo M.H., G. Aguilar y O. Goicoechea. 1988. Systematics of sympatric cricetid Akodon (Abrothrix) rodents and their taxonomic implications. Medio Ambiente 9: 65-74.

Gallardo M.H., D.E. Udrizar Sauthier, A.A. Ojeda y U.F.J. Pardiñas. 2009. Discovery of desertadapted Tympanoctomys barrerae in Central Patagonia, Argentina. Mammalia 73: 158161.

Galliari C.A., U.F.J. Pardiñas y F.J. Goin. 1996. Lista comentada de los mamíferos argentinos. Mastozoología Neotropical 3: 39-61.

Gambier M. 1980. Excavaciones arqueológicas en la Gruta de El Manzano, Río Grande, Mendoza. Boletín del Museo de Ciencias Naturales y Antropológicas "Juan Cornelio Moyano" 1: 45-55.

Gambier M. 1985. La Cultura de los Morrillos. Instituto de Investigaciones Arqueológicas y Museo Facultad de filosofía, humanidades y Artes, Universidad Nacional de San Juan, San Juan.

García A.A. 2003. Reevaluación de los niveles de género y especie asignados al filotino Andalgalomys (Muridae: Sigmodontinae): evidencias citogenéticas y moleculares. Tesis Doctoral inédita, Universidad Nacional de San Luis.

García A. 2003. On the coexistence of man and extinct Pleistocene megafauna at Gruta del Indio (Argentina). Radiocarbon 45: 33-39.

García A. 2005. Human occupation of the central Andes of Argentina $\left(32^{\circ}-34^{\circ} \mathrm{S}\right)$ during the midHolocene. Quaternary International 132: 61-70.

García A. 2010. Human occupation during the mid-Holocene in western Argentina: a comment on Neme and Gil. Current Anthropology 51: 415-416.

García A. y H. Lagiglia. 1999. A 30,000-year-old megafauna dung layer from Gruta del Indio (Mendoza, Argentina). Current Research in the Pleistocene 16: 116-118.

García A., M. Zárate y M. Páez. 1999. The Pleistocene/Holocene transition and human occupation in the Central Andes of Argentina: Agua de la Cueva locality. Quaternary International 53-54: 43-52.

García-Esponda C.M., L.J.M. De Santis, J.I. Noriega, G.O. Pagnoni, G.J. Moreira y M. Bertelloti. 1998. The diet of Tyto alba (Strigiformes, Tytonidae) at the lower valley of the Chubut river (Chubut Province, Argentina). Neotrópica 44: 57-63. 
García-Esponda C., J.D. Carrera, G.J. Moreira y L.J.M. De Santis. 2009. Microvertebrados depredados por Leopardus pajeros (Carnivora: Felidae) en el sur de la provincia de Mendoza, Argentina. Mastozoología Neotropical 16: 455-457.

García Perea R. 1994. The Pampas cat group (genus Lynchailurus Severtzov, 1858) (Carnivora: Felidae), a systematic and biogeographic review. American Museum Novitates 3096: 136.

Gasco A., M.I. Rosi y V. Durán. 2006. Análisis arqueofaunístico de microvertebrados en "Caverna de las Brujas" (Malargüe-Mendoza-Argentina). Anales de Arqueología y Etnología, Volumen especial 61: 135-162.

Germa A., X. Quidelleur, P.Y. Gillotv y P. Tchilingurian. 2010. Volcanic evolution of the backarc Pleistocene Payun Matru volcanic field (Argentina). Journal of South American Earth Sciences 29: 717-730.

Giannoni S.M., C.E. Borghi y R.A. Ojeda. 2000. Foraging ecology of Tympanoctomys barrerae. Journal of Arid Environments 46:117-121.

Giardina M. 2006. Anatomía económica de Rheidae. Intersecciones en Antropología 7: 263-276.

Giardina M. 2010a. El aprovechamiento de la avifauna entre las sociedades cazadorasrecolectoras del sur de Mendoza: un enfoque arqueozoológico. Tesis Doctoral inédita, Facultad de Ciencias Naturales y Museo, Universidad Nacional La Plata.

Giardina M. 2010b. Registro zooarqueológico en el Alero Puesto Carrasco: un aporte para discutir la explotación de reidos en Nordpatagonia. M. De Nigris, P.M. Fernández, M. Giardina, A. Gil, M.A. Gutiérrez, A. Izeta, G. Neme y H.D. Yacobaccio (eds), pp. 133143. Zooarqueología a principios del siglo XXI: aportes teóricos, metodológicos y casos de estudio, Ediciones del Espinillo, Buenos Aires.

Giardina M. 2010c. Rheidae Human Exploitation in North Patagonia, Argentina (South America). Groningen Archaeological Studies 10: 97-102.

Giarla T.C., R.S. Voss y S. Jansa. 2010. Species limits and phylogenetic relationships in the didelphid marsupial genus Thylamys based on mitochondrial DNA sequences and morphology. Bulletin of the American Museum of Natural History Number 346: 1-67.

Gifford-Gonzales D. 1991. Bones are not enough: Knowledge, and interpretive strategies in Zooachaeology. Journal of Anthropological Archaeology 19: 215-254.

Gifford-Gonzales D. 2007. Thoughts on a method for zooarchaeological study of quotidian life. Treballs d'Arqueologia 13: 5-27

Gil A. 1997-98. Cultígenos prehispánicos en el sur de Mendoza. Discusiones en torno al límite meridional de la agricultura andina. Relaciones 22-23: 295-313.

Gil A. 2003. Zea mays on the South american periphery: chronology and diet important. Current Anthropology 44: 295-300. 
Gil A. 2006. Arqueología de la Payunia (Mendoza, Argentina): El poblamiento humano en los márgenes de la agricultura. British Archaeological Reports 1477. Archaeopress, Oxford.

Gil A. y G.A. Neme. 1996. Transporte vs. Destrucción: interpretando las frecuencias de partes esqueléticas del registro arqueofaunístico Nordpatagónico (Argentina). Actas de la II Reunión de Tafonomía y Fosilización, pp. 123-128. Zaragoza.

Gil A. y G. Neme. 2010. Registro arqueológico en la cuenca media del Atuel: viejos y nuevos problemas; viejos y nuevos datos. En: M. Zárate, A. Gil y G. Neme (eds.), Paleoambientes y ocupaciones humanas del centro-oeste de Argentina durante la transición Pleistoceno-Holoceno y Holoceno en Mendoza, pp. 239-275. Sociedad Argentina de Antropología, Buenos Aires.

Gil A., M. Zárate y G. Neme. 2005. Mid-Holocene Paleoenvironments and the Archaeological record of Southern Mendoza, Argentina. Quaternary International 132: 81-94.

Gil A., R. Tykot G., Neme y N. Schelmut. 2006a. Maize on the frontier. Isotopic and macrobotanical data from Central-Western Argentina. En: J. Staller, R. Tykot, y B. Benz (eds.), Histories of Maize Multidisciplinary Approaches to the Prehistory, Biogeography, Domestication, and Evolution of Maize, pp 199-214. Elsevier Inc., Burlington.

Gil A., G.A. Neme y V. Durán. 2006b. Explotación faunística e incorporación de ganado doméstico euroasiático: el registro arqueológico en la frontera nordpatagónica. Comechingonia 9: 5-18.

Gil A., G. Neme, A. Hernández, P. Novellino, M. Giardina, L. Salgán, H. Tucker y E. Albarrán. 2008. Rincón del Atuel-1 (San Rafael, Mendoza): evidencias arqueológicas e implicancias regionales. Intersecciones en Antropología 9: 113-132.

Gil A., G. Neme, R.H. Tykot, P. Novellino, V. Cortegoso y V. Durán, 2009a. Stable isotopes and maize consumption in central western Argentina. International Journal of Osteoarchaeology 19: 215-236.

Gil A., A. Guerci y G. Neme. 2009b. Human occupation, environmental structure and the archaeofaunal record during the mid-Holocene in west-central Argentina. Before Farming 3: 1-16.

Gil, A.F., G.A. Neme y R.H. Tykot. 2010. Isótopos estables y consumo de maíz en el centro occidente argentino: tendencias temporales y espaciales. Chungara, Revista de Antropología Chilena 42: 497-513.

Gil A.F., G.A. Neme y R.H. Tykot. 2011. Stable isotopes and human diet in central western Argentina. Journal of Archaeological Science 38: 1395-1404.

Goin F.J. 1991. Los Didelphoidea (Mammalia, Marsupialia) del Cenozoico Tardío de la Región Pampeana. Tesis Doctoral Inédita. Facultad de Ciencias Naturales y Museo, Universidad Nacional de La Plata. 
Goin F.J. 1995. Los Marsupiales. En: M.A. Alberdi, G. Leone y E.P. Tonni (Eds.), Evolución biológica y climática de la Región Pampeana durante los últimos cinco millones de años. Un ensayo de correlación con el Mediterráneo occidental, pp. 165-179. Museo Nacional de Ciencias Naturales, Consejo Superior de Investigaciones Científicas, Madrid.

Goin F.J. 1999. Quaternary Marsupials from Southern South America. Quaternary of South America and Antarctic Peninsula 11: 137-147.

Goin F.J. 2001. Marsupiales (Didelphidae: Marmosinae y Didelphinae). En: D.L. Mazzanti y C.A. Quintana (eds.), Cueva Tixi: cazadores y recolectores de las sierras de Tandilia oriental. 1. Geología, paleontología y zooarqueología, pp. 75-113. Laboratorio de Arqueología. UNMdP, publicación especial, Mar del Plata.

Gómez G.N. 2000. Análisis tafonómico y paleoecológico de los micro y mesomámiferos del sitio arqueológico Arroyo Seco 2 (Buenos Aires, Argentina) y su comparación con la fauna actual. Tesis Doctoral inédita, Facultad de Ciencias Biológicas. Universidad Complutense de Madrid.

Gómez G.N. 2005. Analysis of bone modification of Bubo virginianus pellets from Argentina. Journal of Taphonomy 3: 1-16.

Gómez G. 2007. Predators categorizations based on taphonomic analysis of micromammals bones: a comparison to proposed models. En: M.A. Gutierrez, L. Miotti, G. Barrientos, G. Mengoni Goñalons, M. Salamme, (eds.), Taphonomy and Zooarqueology in Argentina, pp. 89-103. BAR, International Series 1601, Oxford.

Gómez G.N. y C.A. Kaufmann. 2007. Taphonomic analysis of Pseudalopex griseus (Gray, 1837) Scat assemblages and their archaeological implications. Journal of Taphonomy 5: 59-70.

Gómez G.N. y P. Messineo. 2008. Análisis tafonómico de micromamíferos y mesomamíferos del Sitio Laguna La Barrancosa 1 (Pdo de Benito Juárez, Provincia de Buenos Aires. Intersecciones en Antropología 9: 71-91.

Gómez G.N., J.L. Prado y M.T. Alberdi. 1999. Micromamíferos del sitio Arroyo Seco 2 (provincia de Buenos Aires, Argentina). Sus implicaciones tafonómicas paleoambientales. Estudios Geológicos 55: 273-281.

González M.A. 1994. Salinas del Bebedero Basin (República Argentina). En: E. GierlowskiCordesch y K. Kelts (eds.), Global Geological Records of Lake Basins. Volumen 1, pp. 381-386. Cambridge University Press, Cambridge.

González del Solar R. y J. Rau 2004. Chilla. Pseudalopex griseus (Gray, 1837). En: C. SilleroZubiri, M. Hoffmann y W.D. Macdonald (Eds.), Canids: Foxes, Wolves, Jackals and Dogs, pp. 56-63. The Wildlife Conservation Research Unit, Oxford.

González Díaz E. 1969. Un puente natural en el ambiente lávico oriental del Volcán Payún Matrú, Provincia de Mendoza. Revista de la Asociación Geológica Argentina XXIV: 8589. 
González Díaz E. 1970. Rasgos morfológicos del área volcánica del cerro volcán Payún-Matrú. Opera Lilloana XX: 1-102.

González Díaz E. 1972. Descripción geológica de la Hoja 30 d Payún Matrú, provincia de Mendoza. Dirección Nacional de Geología y Minería, Boletín 130, Buenos Aires.

González-Ittig R.E., J.L. Patton y C.N. Cardenal. 2007. Analysis of cytochrome-b nucleotide diversity confirms a recent range expansion in Calomys musculinus (Rodentia, Muridae). Journal of Mammalogy 88: 777-783.

Gould S.J. 1965. Is Uniformitarianism necessary? American Journal of Science 263: 223-228.

Gould S.J. 1979. Agassiz's marginalia in Lyell's Principles, or the perils of uniformity and the ambiguity of heroes. Studies in the History of Biology 3: 119-138.

Grayson D.K. 1984. Quantitative Zooarchaeology: topics in the analysis of archaeological faunas. Academics Press, Orlando, Florida.

Guevara J.C., O.R. Estevez y C.R. Stasi. 2006. Respuesta de la vegetación en un gradiente de intensidad de pastoreo en Mendoza, Argentina. Multequina 15: 27-36.

Gusinde M. 1982. Los indios de Tierra del Fuego. Tomo I, Volumen 1. Centro Argentino de Etnología Americana, Consejo Nacional de Investigaciones Científicas y Técnicas, Buenos Aires.

Guthmann N., M. Lozada, J.A. Monjeau y K.M. Heinemann. 1997. Population dynamics of five sigmodontine rodents of northwester Patagonia. Acta Theriologica 42: 143-152.

Gutiérrez M.A. 2001. Bone Diagenesis and Taphonomic History of the Paso Otero 1 Bone Bed, Pampas of Argentina. Journal of Archaeological Science 28: 1277-1290.

Gutiérrez M.A. 2004. Análisis tafonómicos en el área interserrana (provincia de Buenos Aires). Tesis Doctoral inédita, Facultad de Ciencias Naturales y Museo, Universidad Nacional de La Plata.

Gutiérrez M.A. 2007. Preservación ósea diferencial a través del análisis diagenético: perspectivas, alcances e implicaciones arqueológicas. Cazadores-Recolectores del Cono Sur. Revista de Arqueología 2: 35-66.

Hajdas I., G. Bonani, P.I. Moreno y D. Ariztegui. 2003. Precise radiocarbon dating of LateGlacial cooling in mid-latitude South America. Quaternary Research 59:70-78.

Halstead P. y J. O'Shea. 1989. Introduction: cultural responses to risk and uncertainty. En: P. Halstead y J. O'Shea (eds.), Bad year Economics, pp 1-7. Cambridge University Press, Cambridge.

Hammer Ø. 1999-2011. PAST PAleontological STatistics Version 2.07. Reference manual. Natural History Museum, University of Oslo, Oslo.

Hawkes K. y J. O'Connell. 1992. On Optimal Foraging Models and Subsistence Transitions. Current Anthropology 33: 63-66. 
Hayden B. 1981. Research and development back in the stone age: Technological transition mong Pleistocene Hunter-Gatherer. Current Anthropology 22: 519-548.

Hedges R. y L. Reynard. 2006. Nitrogen isotope and the trophic Level of human in archaeology. Journal of Archaeological Science 34: 1240-1251.

Hershkovitz P. 1955. South American marsh rats genus Holochilus, with a summary of sigmodont rodents. Fieldiana, Zoology 37: 639-673.

Hershkovitz P. 1959. Nomenclature and taxonomy of the Neotropical mammals described by Olfers 1818. Journal of Mammalogy 40: 337-353.

Hershkovitz P. 1962. Evolution of Neotropical cricetine rodents (Muridae) with special reference to the phyllotine group. Fieldiana: Zoology 46: 1-524.

Heusser C. 1983. Late-glacar-Holocene climate of the lake district of Chile. Quaternary Research 17: 71-92.

Higgins J. 1999. Túnel: A case study of avian Zooarchaeology and Taphonomy. Journal of Archaeological Science 26: 1449-1457.

Hiraldo F., J.A. Donázar, O. Ceballos, A. Traviani, J. Bustamante y M. Funes. 1995. Breeding biology of a Grey Eagle-Buzzard population in Patagonia. Wilson Bulletin 107: 675-685.

Hiscock P. 1994. Technological responses to risk in Holocene Australia. Journal of World Prehistory 8: 267-292.

Hockett B.S. y N.F. Bicho. 2000. The rabbits of Picareiro Cave: small mammal hunting Turing the late Upper Palaeolithic in the Portuguese Estremadura. Journal of Archaeological Science 27: 715-723.

Hoffman R. 1988. The contribution of raptorial birds to patterning in small mammal assemblages. Paleobiology 14: 81-90.

Hogan K.M., M.L. Hogan, I.J. Gable y M. Bray. 1996. Notes on the diet of short-eared owls (Asio fiammeus) in Texas. Journal of Raptor Research 30: 102-104.

Holmberg E. 1973. Descripción geológica de la hoja 29d, Cerro Nevado: provincia de Mendoza. Servicio Nacional Minero Geológico, Boletín 144, Buenos Aires.

Ibargüengoytía N.R. y V. Cussac. 2002. Body temperature of two viviparous Liolaemus lizard species in Patagonian rain forest and steppe. Herpetological Journal 12: 131-134.

Iglesias A.C. 2009. Tafonomía de pequeños vertebrados depredados por Buteo polyosoma (Aves, Falconiformes). Tesis de Licenciatura inédita, Facultad de Ciencias Exactas y Naturales, Universidad Nacional de La Pampa.

Inbar M. y C. Risso. 2001. A morphological and morphometeric analysis of a high density cinder cone volcanic field - Payun Matru, south-central Andes, Argentina. Zeitschrift fur geomorphologie 45: 321-343.

Iriarte J.A., W.L. Franklin y W.E. Johnson. 1990a. Diets of sympatric raptors in southern Chile. Journal of Raptor Research 24: 41-46. 
Iriarte J.A., W.L. Franklin, W.E. Johnson, K.H. Redford. 1990b. Biogeographic variation of food habits and body size of the America puma. Oecología 85: 185-190.

Iriarte J.A., W.E. Johnson, W.L. Franklin. 1991. Feeding ecology of the Patagonia puma in southernmost Chile. Revista Chilena de Historia Natural 64: 145-156.

Jaksic F.M. 1997. Ecología de los vertebrados de Chile. Ediciones Universidad Católica de Chile, Santiago.

Jayat J.P. 2009. Roedores sigmodontinos de los pastizales de neblina de las Yungas de Argentina. Tesis Doctoral inédita, Facultad de Ciencias Naturales e Instituto Miguel Lillo, Universidad Nacional de Tucumán.

Jayat P.J., P.E. Ortiz, P. Teta, U.F.J. Pardiñas y G. D’Elía. 2006. Nuevas localidades Argentinas para algunos roedores sigmodontinos (Rodentia: Cricetidae). Mastozoología Neotropical 13: 51-67.

Jayat J.P., P.E. Ortiz, J. Salazar-Bravo, U.F.J. Pardiñas y G. D’Elía. 2010. The Akodon boliviensis species group (Rodentia: Cricetidae: Sigmodontinae) in Argentina: species limits and distribution, with the description of a new entity. Zootaxa 2409: 1-61.

Jenny B., B.L. Valero-Garcés, R. Villa-Martínez, R. Urrutia, M. Geyh y H. Veit. 2002. Early to Mid-Holocene Aridity in Central Chile and the Southern Westerlies: The Laguna Aculeo Record (34으. Quaternary Research 58: 160-170.

Jiménez J.E. y A.J. Novaro. 2004. Culpeo. Pseudalopex culpaeus (Molina, 1782). En: C. SilleroZubiri, M. Hoffmann y W.D. Macdonald (eds.), Canids: Foxes, Wolves, Jackals and Dogs, pp. 44-49. The Wildlife Conservation Research Unit, Oxford.

Jiménez J.E., M. Lucherini y A.J. Novaro. 2008a. Pseudalopex culpaeus. En: IUCN 2011. IUCN Red List of Threatened Species. Versión 2011.1. www.iucnredlist.org. 08 de Julio 2011.

Jiménez J.E., M. Lucherini y A.J. Novaro. 2008b. Pseudalopex griseus. En: IUCN 2011. IUCN Red List of Threatened Species. Version 2011.1. www.iucnredlist.org.14 de Julio 2011.

Jochim M. 1981. Strategies for Survival, Cultural Behavior in an Ecological Context. Academic Press, New York.

Justo E., C.I. Montalvo y L.J.M. De Samtis. 1985. Nota sobre la precencia de Tympanoctomys barrerae (Lawrence, 1941) en La Pampa (Rodentia: Octodontidae). Historia Natural 5: 43-44.

Kaplan H. y K. Hill. 1992. The evolutionary ecology of food acquisition. En: E.A. Smith y B. Winterhalder (eds.), Evolutionary Ecology and Human Behavior, pp. 167-201. Hawthorne, Aldine de Gruyter, New York.

Kardong K.V. 1999. Vertebrados: Anatomía Comparada, Función y Evolución. Mc. Graw Hill, Interamericana, Madrid.

Kelly R.L. 1995. The foraging spectrum. Diversity in hunter-gatherer lifeway. Simthsonian Institution Press, Washington D.C. 
Kelt D.A., R.E. Palma, M.H. Gallardo y J.A. Cook. 1991. Chromosomal multiformity in Eligmodontia (Muridae, Sigmodontinae), and verification of the status of E. morgani. Zeitschrift für Säugetierkunde 56: 352-358.

Kligmann D.M., C. Sesé y J. Barbadillo. 1999. Análisis tafonómico de la fauna de microvertebrados del Alero 12 (Puna Meridional Catamarqueña Argentina) y sus implicancias para el comportamiento humano. Arqueología 9: 9-48.

Kluge A.G. 1964. A revision of South American Gekkonid Lizard genus Homonota. American Museum Novitates 2193: 1-41.

Korth W. 1979. Taphonomy of Microvertebrate Fossil Assemblages. Annals of Carnegie Museum 15: 235-285.

Kraglievich L. 1930. Diagnosis osteológico-dentaria de los géneros vivientes de la subfamilia Caviinae. Anales del Museo Nacional de Historia Natural de Buenos Aires 36: 59-96.

Kramer K.M., J.A. Monjeau, E.C. Birney y R.S. Sises. 1999. Phyllotis xanthopygus. Mammalian Species, American Society of Mammalogist 617: 1-7.

Krebs C.J. 1989. Ecological methodology. University of British Columbia, Harper y Row Publishers, New York.

Lagiglia H. 1956. Estudios arqueológicos en el Rincón del Atuel, Departamento de San Rafael, Mendoza. Anales de Arqueología y Etnología 12: 229-288.

Lagiglia H. 1977. Arqueología y Ambiente Natural de los Valles del Atuel y Diamante. Tesis Doctoral inédita. Facultad de Ciencias Naturales y Museo, Universidad Nacional de La Plata.

Lagiglia H. 1980. El proceso de agriculturización en el sur de Mendoza: la Cultura del Atuel II. Actas del V Congreso Nacional de Arqueología Argentina, pp. 231-252. San Juan.

Lagiglia H. 1999a. Nuevos fechados radiocarbónicos para los agricultores incipientes del Atuel. Actas del XII Congreso Nacional de Arqueología Argentina, pp. 239-250. La Plata.

Lagiglia H. 1999b. Estudios y excavaciones arqueológicas en Ponontrehue y en el área del Nevado (Mendoza). Resúmenes del XII Congreso Nacional de Arqueología Argentina, pp. 327. Córdoba.

Lagiglia H. 2001. El paleoindio del Atuel en Sudamérica (Análisis de la cronología absoluta del paleoindio del Atuel). Notas del Museo de Historia Natural de San Rafael 48: 1-12.

Lagiglia H. 2002. Arqueología prehistórica del sur Mendocino y sus relaciones con el centro oeste Argentino. En: A. Gil y G. Neme (eds.), Entre Montañas y Desiertos: Arqueología del sur Mendocino, pp 43-64. Sociedad Argentina de Antropología, Buenos Aires.

Lagiglia H. 2005. Exploraciones arqueológicas y ambientales en los altos valles de Las Leñas y aledaños. III Taller Binacional argentino-chileno "Arqueología de la Cordillera de Los Andes $32^{\circ} / 40^{\circ}$ Latitud Sur. Museo Municipal de Historia Natural Notas del Museo 58: $37-40$. 
Lagiglia H., A. Gil y G.A. Neme. 1994. El sitio Cueva Arroyo Colorado. Actas del XI Congreso Nacional de Arqueología Argentina, pp. 114-115. San Rafael.

Lahille F. 1899. Ensayo sobre la distribución geográfica de los mamíferos en la República Argentina. Primera Reunión del Congreso Científico Latino Americano 3, pp.165-2³. Buenos Aires.

Lamy F., D. Hebbeln y G. Wefer. 1999. High-Resolution Marine Record of Climatic Change in Mid-latitude Chile during the Last 28,000 Years Based on Terrigenous Sediment Parameters. Quaternary Research 51: 83-93.

Lanata J.L. 2002. Humans and Evolutionary Dynamics. The Last Decades in Archaeology and Anthropology. En: G. Martinez y J.L. Lanata (eds.), Perspectivas Integradoras entre Arqueología y Evolución. Teoría, Método y Casos de Aplicación, pp. 255-286. INCUAPA, Olavarria.

Landt M. 2007. Tooth marks and human consumption: ethnoarchaeological mastication research among foragers of the Central African Republic. Journal of Archaeological Science 34: 1629-1640.

Lanzone C. y R.A. Ojeda. 2005. Citotaxonomía y distribución del género Eligmodontia (Rodentia, Cricetidae, Sigmodontinae). Mastozoología Neotropical 12: 73-77.

Lanzone C., R.A. Ojeda, S. Albanese, D. Rodríguez y M. Dacar. 2005. Karyotypic characterization and new geographical record of Salinomys delicatus (Rodentia, Cricetidae, Sigmodontinae). Mastozoología Neotropical 12: 257-260.

Lanzone C., A. Novillo, N.S. Suárez y R.A. Ojeda. 2007. Cytogenetics and redescription of Graomys (Rodentia, Sigmodontinae) From Chumbicha, Catamarca, Argentina. Mastozoología Neotropical 14: 249-255.

Laroulandie V. 2002. Damage to Pigeon bones in pellets of the Eagle Owl Bubo bubo and food remains of Peregrine Falcon Falco peregrinus: zooarchaeological implications. Acta Zoologica Cracoviensia 45: 331-339.

Le Quesne C., C. Acuña, J.A. Boninsegna, A. Rivera y J. Barichivich. 2009. Long-term glacier variations in the Central Andes of Argentina and Chile, inferred from historical records and tree-ring reconstructed precipitation. Palaeogeography, Palaeoclimatology, Palaeoecology 281: 334-344.

Lessa E.P., G. D’Elía y U.F.J. Pardiñas. 2010. Genetic footprints of late Quaternary climate change in the diversity of Patagonian-Fueguian rodents. Molecular Ecology 19: 30313037.

L’Heureux G.L. 2008. La arqueofauna del campo volcánico Pali Aike. El sitio Orejas de Burro 1, Santa Cruz, Argentina. Magallania (Chile) 36: 65-78.

Livingston S.D. 1989. The taphonomic interpretation of avian Skeletal Part frequencies. Journal of Archaeological Science 16: 537-547. 
Llambías J. 1966. Geología y Petrografía del volcán Payún Matrú. Acta Geológica Lilloana VIII: 265-310.

Llano C. 2008. El registro arqueobotánico en el sitio Arroyo Malo 3, alto valle del Atuel, Mendoza, Argentina. Intersecciones en Antropología 9: 133-143.

Llano C. 2009. Photosynthetic pathways, spatial distribution, isotopic ecology, and implications for Pre-Hispanic human diets in Central-Western Argentina. International Journal of Osteoarchaeology 19: 130-143.

Llano C. 2011. Aprovechamiento de los recursos vegetales entre las sociedades cazadorasrecolectoras del sur de Mendoza. Tesis Doctoral inédita, Universidad Nacional del Comahue, Centro Regional Universitario Bariloche.

Llano C y G. Neme. 2012. El registro arqueobotánico en el valle del Salado, Mendoza: problemas tafonómicos y explotación humana. Chungara, Revista de Antropología Chilena 44: 319.

Lloveras L., M. Moreno-Garcia y J. Nadal. 2009. Butchery, cooking and human consumption marks on rabbit (Oryctolagus cuniculus) bones: An experimental study. Journal of Taphonomy 7: 179-201.

Long A., P. Martin y H. Lagiglia. 1998. Ground Sloth extintion and human occupation at Gruta del Indio, Argentina. Radiocarbon 40: 693-700.

López N., P.J. Padula, C. Rossi, M.E. Lázaro y M.T. Franze-Fernandez. 1996. Genetic identification of a new hantavirus causing severe pulmonary syndrome in Argentina. Virology 220: 223-226.

Lorenc M. 2006. On the taphonomic origins of Vistulian bird remains from cave deposits in Poland. Acta Zoológica Cracoviensia 49: 63-82.

Lozada M., A. Monjeau, K. Heinemann, N. Guthmann y E.C. Birney. 1996. Abrothrix xanthorhinus. Mammalian Species 540: 1-6.

Lucherini M., T. de Oliveira y G. Acosta. 2008. Leopardus geoffroyi. En: IUCN 2011. IUCN Red List of Threatened Species. Version 2011.1. www.iucnredlist.org. 13 de Julio 2011.

Lyell C. 1930. Principles of de Geology, Being an Attempt to Explain Former Changes of the Earth's Surface with Reference to Causes Now in Operation. Volume 1. Murray, London.

Lyman R.L. 1987. Zooarchaeology and taphonomy: a general consideration. Journal of Ethnobiology 7: 93-117.

Lyman R.L. 1994. Vertebrate taphonomy. Cambridge University Press, Cambridge.

Lyman R.L. 2004. The concept of equifinality in taphonomy. Journal of Taphonomy 2: 15-26.

Lyman R.L. 2010. What taphonomy is, what it isn't, and why taphonomists should care about the difference. Journal of Taphonomy 8: 1-16.

MacArthur R.H. y E.R Pianka. 1966. On optimal use of a patchy environment. American Naturalist 100: 603-609. 
Manfredi C., M. Lucherini, A. Canepuccia, E. Casanave. 2004. Geographical variation in the diet of Geoffroys cat (Oncifelis geoffroyi) in pampas grassland of Argentina. Journal of Mammalogy 85: 1111-1115.

Mann Fisher G. 1978. Los pequeños mamíferos de Chile. Marsupiales, quirópteros, edentados y roedores. Gayana, Zoología 40: 1-342.

Mares M.A y J.K. Braun. 1996. A new species of Phyllotine rodent, genus Andalgalomys (Muridae: Sigmodontinae), from Argentina. Journal of Mammalogy 77: 928-941.

Mares M.A., J.K. Braun, B. Coyner y R.A. Van Den Bussche. 2008. Phylogenetic and biogeographic relationships of gerbil mice Eligmodontia (Rodentia, Cricetidae) in South America, with a description of a new species. Zootaxa 1753: 1-33.

Markgraf V. 1983. Late and postglacial vegetational and paleoclimatic change in subantartic and arid environments in Argentina. Palynology 7: 43-70.

Markgraf V., C. Whitlock, R.S. Anderson y A. García. 2009. Late Quaternary vegetation and fire history in the northernmost Nothofagus forest region: Mallín Vaca Lauquen, Neuquén Province, Argentina. Journal of Quaternary Science 24: 248-258.

Marks J.S., R.J. Cannings y H. Mikkola. 1999. Family Strigidae. (Typical Owls). En: J. del Hoyo, A. Elliott y J. Sargatal (eds.), Handbook of the birds of the world. Volume 5: Barn-owls to hummingbirds, pp. 76-151. Lynx Edicions, Barcelona.

Marshall L.G. 1977. Lestodelphys halli. Mammalia Species 81: 1-3.

Martin G. 2003. Nuevas localidades para marsupiales patagónicos (Didelphimorphia y Microbiotheria) en el noroeste de la provincia del Chubut, Argentina. Mastozoología Neotropical 10: 148-153.

Martin G. 2008. Sistemática, distribución y adaptaciones de los marsupiales patagónicos. Tesis Doctoral inédita, Facultad de Ciencias Naturales y Museo, Universidad Nacional de La Plata.

Martin G. 2009. Sobre la identidad de Thylamys (Marsupialia, Didelphidae) del oeste Pampeano y centrosur del Espinal, Argentina. Mastozoología Neotropical 16: 333-346.

Martin G.M., L.J.M. De Santis y G.J Moreira. 2008. Southernmost record for a living marsupial. Mammalia 72: 131-134.

Martín F.M., L.A. Borrero, 2007. A puma lair in Southern Patagonia: implications for the archaeological record. Current Anthropology 38: 453-461.

Marquet P.A., L. Contreras, J. Torres Mura, S. Silva y F.M. Jaksic. 1993. Food habits of Pseudalopex foxes in the Atacama Desert, pre-Andean ranges, and the high-Andean plateau of northernmost Chile. Mammalia 57: 130-135.

Martínez G. 1999. Tecnología, Subsistencia y Asentamiento en el Curso Medio del Río Quequén Grande: Un Enfoque Arqueológico. Tesis Doctoral Inédita. Facultad de Ciencias Naturales y Museo, Universidad Nacional de La Plata. 
Martínez G. 2009. Human chewing bone surface modification and processing of small and medium prey amongst the Nukak (foragers of the Colombian Amazon). Journal of Taphonomy 7: 1-20.

Martínez G. y M.A. Gutiérrez. 2004. Tendencias en la explotación humana de la fauna durante el Pleistoceno final y Holoceno en la Región Pampeana (Argentina). En: G.L. Mengoni Goñalons (ed.), Zooarchaeology of South America, pp. 81-98. BAR International Series 1298, Oxford

Martínez D., J. Rau y F. Jaksic. 1993. Respuesta numérica y selectividad dietaria de zorros (Pseudalopex sp.) ante una reducción de sus presas en el norte de Chile. Revista Chilena de Historia Natural 66: 195-202.

Martínez D.R., R.A. Figueroa C.L. Ocampo y F.M. Jaksic. 1998. Food habits and hunting ranges of short-eared owls (Asio flammeus) in agricultural landscapes of southern Chile. Journal of Raptor Research 32: 111-115.

Martínez J.J. y V. Di Cola. 2011. Geographic distribution and phenetic skull variation in two close species of Graomys (Rodentia, Cricetidae, Sigmodontinae). Zoologischer Anzeiger 250: 175-194.

Martínez J.J., R.E. González-Ittig, G.R. Theiler, R. Ojeda, C. Lanzone, A. Ojeda y C.N. Gardenal. 2010. Patterns of speciation in two sibling species of Graomys (Rodentia, Cricetidae) based on mtDNA sequences. Journal of Zoological Systematics and Evolutionary Research 48: 159-166.

Martínez J.J., L.I. Ferro, M.I. Mollerach y R.M. Barquez. 2012. The phylogenetic relationships of the Andean swamp rat genus Neotomys (Rodentia, Cricetidae, Sigmodontinae) based on mitochondrial and nuclear markers. Acta Theriologica DOI 10.1007/s13364-011-0070-9.

Martori R. y J.C. Acosta 1994. Variación anual de la estructura poblacional y crecimiento de una población de Teius oculatus (Sauria: Teiidae) en Río Cuarto, Córdoba. Revista Española de Herpetología 8: 37-44.

Masiokas M.H., A. Rivera, L.E. Espizua, R. Villalba, S. Delgado y J.C. Aravena. 2009. Glacier fluctuations in extratropical South America during the past 1000 years. Palaeogeography, Palaeoclimatology, Palaeoecology 281: 242-268.

Massarini A.I., M.A. Barros, M.O. Ortells y O.A. Reig. 1991. Chromosomal polymorphism and small karyotypic differentiation in a group of Ctenomys species from Central Argentina (Rodentia: Octodontidae). Genetica 83: 131-144.

Massoia E. 1971. Caracteres y rasgos bioecológicos de Holochilus brasiliensis chacarius Thomas ("rata nutria") de la provincia de Formosa y comparaciones con Holochilus brasiliensis vulpinus (Brants) (Mammalia, Rodentia, Cricetidae). Revista de Investigaciones Agropecuarias, INTA, Serie 1, Biología y Producción Animal 8: 13-40. 
Massoia E. 1973a. Descripción de Oryzomys fornesi, nueva especie y nuevos datos sobre algunas especies y subespecies argentinas del subgénero Oryzomys (Oligoryzomys) (MammaliaRodentia-Cricetidae). Revista de investigaciones agropecuarias, INTA, Serie1, Biología y Producción Animal 10: 21-37.

Massoia E. 1973b. Presencia y rasgos bioecológicos de Oryzomys longicaudatus pampanus, nueva subespecie en la provincia de Buenos Aires. (Mammalia-Rodentia-Cricetidae). Revista de investigaciones agropecuarias, INTA, Seriel, Biología y Producción Animal 10: 41-49.

Massoia E. 1976. Mammalia. En: R. Ringuelet (ed.), Fauna de agua dulce de la República Argentina, pp. 1-128. Fundación Editorial Ciencia y Cultura, Buenos Aires,

Massoia E. 1981a. Notas sobre los cricétidos mendocinos (Mammalia, Rodentia). Historia Natural 29: 205-208.

Massoia E. 1981b. El estado sistemático y zoogeografía de Mus brasiliensis Desmarest y Holochilus sciureus Wagner (Mammalia - Rodentia - Cricetidae). Physis 39: 31-34.

Massoia E. 1990. Zooarqueología 1 Mammalia. Anales de Arqueología y Etnología 2: 43-45.

Massoia E., C. Reboledo y A.J. Dieguez. 1997. Análisis de bolos de Tyto alba del Río Seco La Hedionda, Depto. San Rafael, Mendoza. Aprona, Boletín Cientifico 31: 2-7.

Massoia E., J.K. Chebez y D.H. Fortabat. 1994. La depredación de algunos mamíferos por Bubo virginianus en el Departamento de Malargüe, Mendoza. Aprona, Boletín Científico 26: 25.

Matthews T., J.E. Parkington y C. Denys. 2006. The Taphonomy of micromammals from the late middle Pleistocene site of Hoedjiespunt 1 (Cape province, south Africa). Journal of Taphonomy 4: 1-16.

Mazar Barnett J. y M. Pearman. 2001. Lista comentada de las aves Argentinas. Lynx Edicions, Barcelona.

Mc Nutt J.W. 1981. Selección de presa y comportamiento de caza del Halcón Peregrino (Falco peregrinus) en Magallanes y Tierra del Fuego. Anales del Instituto de la Patagonia 12: 221-228.

Medel R.G. y F.M. Jaksic. 1988. Ecología de los cánidos sudamericanos: una revisión. Revista Chilena de Historia Natural 61: 67-79.

Medina M., D. Rivero y P. Teta. 2011. Consumo antrópico de pequeños mamíferos en el Holoceno de Argentina central: perspectivas desde el abrigo rocoso Quebrada del Real 1 (Pampa de Achala, Córdoba). Latin American Atiquity 22: 618-631.

Medina M., P. Teta y D. Rivero. 2012. Burning damage and small-mammal human consumption in Quebrada del Real 1 (Cordoba, Argentina): an experimental approach. Journal of Archaeological Science 39: 737-743. 
Mehl A. 2010. Ambientes aluviales del Pleistoceno tardío - Holoceno del Valle de Uco, cuenca del Río Tunuyán. En: M. Zárate, A. Gil y G. Neme (eds.), Paleoambientes y ocupaciones humanas del centro-oeste de Argentina durante la transición Pleistoceno-Holoceno y Holoceno de Mendoza, pp 11-40. Sociedad Argentina de Antropología, Buenos Aires.

Mengoni Goñalons G.L., 1999. Cazadores de guanacos de la estepa patagónica. Sociedad Argentina de Antropología, Buenos Aires.

Mengoni Goñalons G.L. 2006-2010. Zooarqueología en la práctica: algunos temas metodológicos. Xama 19-23: 83-113.

Mercer J.H. 1982. Holocene glacier variations in Southern South America. Striae 8: 35-40.

Métraux A. 1937. Contribución a la etnografía y arqueología de la Provincia de Mendoza. Revista de la Junta de Estudios Históricos de Mendoza VI (1929) 15-16: 1-66.

Mikkola H. 1983. Owls of Europe. T \& A.D. Poyser press, London.

Miotti L. 1998. Zooarqueología de la meseta central y costa de Santa Cruz. Un enfoque de las estrategias adaptativas aborigenes y los paleoambientes. Museo Municipal de Historia Natural, San Rafael.

Mondini N.M. 1995. Artiodactyl prey transport by foxes in Puna rock shelters. Current Anthropology 36: 520-524.

Mondini N.M. 2000. Tafonomía de abrigos rocosos de la Puna. Formación de conjuntos escatológicos por zorros y sus implicaciones arqueológicas. Archaeofauna 9: 151-164.

Mondini N.M. 2001 Taphonomic Action of Foxes in Puna Rockshelters: A Case Study in Antofagasta de la Sierra (Province of Catamarca, Argentina). En: L.A. Kuznar (eds), Ethnoarchaeology of Andean South America. Contributions to Archaeological Method and Theory, pp. 266-295. International Monographs in Prehistory, Ethnoarchaeological Series 4, Ann Arbor.

Mondini N.M. y S. Muñoz. 2004. Behavioural Variability in the So-Called Marginal Areas from a Zooarchaeological Perspectiva: An Introduction. En: N.M. Mondini, S. Muñoz y S. Wickler (eds.), Colonisation, Migration and Marginal Areas. A Zooarchaeological Approach, pp. 42-45. Oxbow Books, Oxford.

Mondini N.M., S. Muñoz. 2008. Pumas as taphonomic agents: A comparative analysis of actualistic studies in the Neotropics. Quaternary International 180: 52-62.

Monjeau J.A. 1989. Ecología y distribución geográfica de los pequeños mamíferos del Parque Nacional Nahuel Huapi y áreas adyacentes. Tesis Doctoral inédita, Facultad de Ciencias Naturales y Museo, Universidad Nacional de La Plata.

Montalvo C.I. 2002a. Taphonomic analysis of the Mio-Pliocene micromammal assemblage (Cerro Azul Formation), Caleufú, La Pampa, Argentina. En: M. De Renzi, M. Pardo Alonso, M. Belinchón, E. Peñalver, P. Montoya y A. Márquez-Arriaga (eds.), Current 
Topics on Taphonomy and Fossilization, pp. 353-359. Ayuntamiento de Valencia, Series Col.lecció Encontres, Valencia.

Montalvo C.I. 2002b. Root traces in fossil bones from the Huayquerian (Late Miocene) faunal assemblage of Telén, La Pampa, Argentina. Acta geológica Hispánica 37: 37-42.

Montalvo C.I. y P. Tallade 2009. Taphonomy of the accumulations produced by Caracara plancus (Falconidae). Analysis of prey remains and pellets. Journal of Taphonomy 7: 235-248.

Montalvo C.I y P. Tallade 2010. Análisis tafonómico de restos no ingeridos de roedores presa de Caracara plancus (Aves, Falconidae). En: M. De Nigris, P.M. Fernández, M. Giardina, A.F. Gil, M.A. Gutiérrez, A. Izeta, G. Neme y H.D. Yacobaccio (eds.), Zooarqueología a principios del siglo XXI: aportes teóricos, metodológicos y casos de estudio, pp. 419-428. Ediciones del Espinillo, Buenos Aires.

Montalvo C.I. y P. Tejerina. 2009. Análisis tafonómico de los huesos de anfibios y roedores depredados por Athene cunicularia (Strigiformes, Strigidae) en La Pampa, Argentina. En: M. Berón, L. Luna, M. Bonomo, C.I. Montalvo, C. Aranda y M. Carrera Aizpitarte (eds.), Mamül Mapu: pasado y presente desde la arqueología pampeana, pp. 323-334. Editorial Libros del Espinillo, Buenos Aires.

Montalvo C.I., M.E.M. Pessino y V.H. González. 2007. Taphonomic analysis of mammals remains eaten by pumas (Puma concolor Carnivora, Felidae) in central Argentina. Journal of Archaeological Science 34: 2151-2160.

Montalvo C.I., M.E.M. Pessino y F.C. Bagato. 2008. Taphonomy of the bones of rodents consumed by Andean hog-nosed Skunks (Conepatus chinga, Carnivora, Mephitidae) in central Argentina. Journal of Archaeological Science 35: 1481-1488.

Montalvo C.I., P. Tallade, F.J. Fernández, G.J. Moreira y L.J.M. De Santis. 2011. Pattern of damage done by Caracara plancus (Aves, Falconiformes) on bird bones. Journal of Archaeological Science 38: 3541-3548.

Montalvo C.I., S. Bisceglia, M.S. Kin y R.A. Sosa. En prensa a. Taphonomic analysis of rodent bone accumulations produced by Geoffroy's cat (Leopardus geoffroyi, Carnivora, Felidae) in Central Argentina. Journal of Archaeological Science.

Montalvo C.I., L. Cheme Arriaga, P.O. Tallade y R.A. Sosa. En prensa b. Owl pellet dispersal by wind: observations and experimentations. Quaternary International.

Morrison J.L. 1998. Effects of double brooding on productivity of crested caracaras. The Auk 115: 979-987.

Mourer-Chauviré C. 1983. Les oiseaux dans les habitats paléolithiques: gibier des hommes ou proies des rapaces?. En : C. Grigson y J. Clutton-Brock (eds.), Animals and Archaeology: 2- Shell Middens Fishes and Birds, pp. 111-124. BAR International Series 183. Archaeopress, Oxford. 
Muñoz S. y F. Savanti. 1998. Observaciones tafonómicas sobre restos avifaunísticos de la costa noreste de Tierra del Fuego. Actas y Memorias del XI Congreso Nacional de Arqueología Argentina ( 8 a Parte). Revista del Museo de Historia Natural de San Rafael 20: 107-121.

Muñoz S., M. Mondini, V. Durán, A. Gasco. 2008. Los pumas (Puma concolor) como agentes tafonómicos. Análisis actualístico de un sitio de matanza en los Andes de Mendoza, Argentina. Geobios 41: 123-131.

Mura R. y L.A. Gonzáles. 1982. Microhabitat selection in two Chilean cricetid rodents. Oecologia 52: 12-15.

Musser G.M. y M.D. Carleton. 2005. Superfamily Muroidea. En: D.E. Wilson y D.M. Reeder (eds.), Mammalia species of the world: A Taxonomic and Geographic reference, pp. 8941531. Third edition, Johns Jopkins University press, Baltimore.

Myers P. 1989. A preliminary revision of the varius group of Akodon (A. dayi, dolores, molinae, neocenus, simulator, toba and varius). En: K. Redford y J.F. Eisenberg (eds.), Advances in Neotropical Mammalogy, pp. 5-54. Sandhill Crane Press, Gainesville, Florida.

Nabte M.J., S.L. Saba y U.F.J. Pardiñas. 2006. Dieta del búho magallánico (Bubo magellanicus) en el Desierto del Monte y la Patagonia Argentina. Ornitología Neotropical 17: 27-38.

Nabte M.J., U.J.F. Pardiñas y S.L. Saba 2008. The diet of the Burrowing Owl, Athene cunicularia, in the arid lands of northeastern Patagonia, Argentina. Journal of Arid Environments 72: 1526-1530.

Nabte M.J. A. Andrade, S.L. Saba y A. Monjeau. 2009. Mammalia, Rodentia, Sigmodontinae, Akodon molinae Contreras, 1968: New locality records and filling gaps. Check List 5: 320-324.

Narosky T. y D. Izurieta. 2003. Guía para la identificación de las aves de Argentina y Uruguay. Vazquez Mazzini Editores. XV edición, Buenos Aires.

Navarro D. y C. Whitlock. 2010. Changes in climate vegetation and fire regimes in SW Mendoza, Argentina over the last 6400 Cal-yr-BP: The Laguna El Sosneado record. Abstract book for the PAGES Long-Term Climate Reconstruction and Dynamics of South America (LOTRED-SA) symposium, pp. 27-30. Valdivia.

Navarro D., C. Whitlock, M. Paez y M. Zarate. 2009. Examining the mid-late Holocene environments of west-central Argentina 3rd PAGES Open Science Meeting: Retrospective Views on Our Planet's Future 8-11 Julio 2009, Corvallis USA, p 104.

Navarro D., A. Mehl, M. Zárate y M.M. Paez. 2010. Mid-late Holocene environments of Agua Buena locality $\left(34^{\circ} 50^{\prime} \mathrm{S} ; 69^{\circ} 56^{\prime} \mathrm{W}\right)$, Mendoza, Argentina. "Proceedings of the PAGES 1st Young Scientists Meeting: Retrospective views on our planet's future”. IOP Conference Series: Earth and Environmental Science, Institute of Physics Publishing, UK. Volumen 9 (1): 012014. http://iopscience.iop.org/1755-1315/9/1/012014. 
Navas J. 1987. Los vertebrados exóticos introducidos en la Argentina. Revista del Museo Argentino de Ciencias Naturales Bernardino Rivadavia 14: 7-38.

Neme G. 2002. Arqueología del Alto Valle del Río Atuel: Modelos, Problemas y Perspectivas en el Estudio de las Regiones de Altura del Sur de Mendoza. En: A. Gil y G. Neme (eds.), Entre Montañas y Desiertos: Arqueología del Sur de Mendoza, pp. 65-83. Sociedad Argentina de Antropología, Buenos Aires.

Neme G. 2004. Procesos de adaptación humana en el alto valle del río Atuel. Informe final Antorchas. Subsidio de apoyo a proyectos No 14116/182.

Neme G. 2007. Cazadores recolectores de altura en los andes meridionales: el Alto valle del río Atuel. British Archaeological Reports 1591. Archaeopress, Oxford.

Neme G.A. 2009. Un enfoque regional en cazadores-recolectores del oeste argentino: el potencial de la ecología humana. En: R. Barberena, K. Borrazzo y L.A. Borrero (eds.), Perspectivas Actuales en Arqueología Argentina, pp. 305-326. Editorial Dunken, IMHICIHU, Buenos Aires.

Neme G. y A. Gil. 2002. La explotación faunística y la frecuencia de partes esqueletarias en el registro arqueológico del sur mendocino. A. Gil y G. Neme (eds.), Entre Montañas y Desiertos: Arqueología del Sur de Mendoza, pp. 101-118. Sociedad Argentina de Antropología, Buenos Aires.

Neme G. y A. Gil. 2008a. Faunal Exploitation and Agricultural Transitions in the South American Agricultural Limit. International Journal of Osteoarchaeology 17: 1-15.

Neme G. y A. Gil. 2008b. Biogeografía Humana en los Andes Meridionales: Tendencias arqueológicas en el Sur de Mendoza. Chungara 40: 5-18.

Neme G. y A. Gil. 2009. Human Occupation and Increasing Mid-Holocene Aridity. Southern Andean Perspectives. Current Anthropology 50: 149-163.

Neme G. y A. Gil. 2010. What Happened during the Mid-Holocene in Arid Western Argentina? A Reply to García. Current Anthropology 51: 417-419.

Neme G., V. Durán y A. Gil. 1995. Análisis arqueofaunístico del sitio Cueva de Luna (MalargüeMendoza, Argentina). Actas del XIII Congreso Nacional de Arqueología Chilena. Hombre y Desierto, pp. 363-370. Antofagasta.

Neme G., A. Gil y V. Durán. 1999. El Registro Arqueofaunístico del Alero Puesto Carrasco (Malargüe-Mendoza). Soplando el Viento. Actas de las Terceras Jornadas de Arqueología de la Patagonia, pp. 491-514. Neuquén.

Neme G., G.J. Moreira, A. Atencio y L.J.M. De Santis. 2002. El registro de microvertebrados del sitio arqueológico Arroyo Malo 3 (Provincia de Mendoza., Argentina). Revista Chilena de Historia Natural 75: 409-421.

Neme G., A. Gil y V. Durán. 2005. Late Holocene in southern Mendoza (northwestern Patagonia): radiocarbon pattern and human occupation. Before Farming 2: 1-18. 
Neme G., A. Gil, R. Garvey, C. Llano, A. Zangrando, F. Franchetti, C. De Francesco y T. Michieli. 2011. El registro arqueológico de la Gruta de El Manzano y sus implicancias para la arqueología de Nordpatagonia. Magallania (Chile) 39: 243-265.

Noriega J.I., L.J.M. De Santis y G.O. Pagnoni. 1990. Passeriformes presentes en egagrópilas de Tyto alba (Aves: Tytonidae) para la localidad de Laguna Blanca (Provincia de Chubut, Argentina). Neotrópica 36: 33-34.

Noriega J.I., R.M. Aramburú, E.R. Justo y L.J.M. De Santis. 1993. Birds present in pellets of Tyto alba (Strigiformes, Tytonidae) from Casa de Piedra, Argentina. The Journal of Raptor Research 27: 37-38.

Novaro A.J., M.C. Funes y R.S. Walker. 2000. Ecological extinction of native prey of a carnivore assemblage in Argentine Patagonia. Biological Conservation 92: 25-33.

Novillo A. y R. Ojeda. 2008. The exotic mammals of Argentina. Biological Invasion 8: 13331344.

Novellino P. y A. Gil. 2007. Estrés Nutricional, hipoplasia y explotación de recursos en el Centro Sur de Mendoza (Argentina). Intersecciones en Antropología 8: 17-29.

Novellino P., A., Gil, G. Neme y V. Durán. 2004. El Consumo de maíz en el Holoceno tardío del oeste argentino: Isótopos estables y caries. Revista Española de Antropología Americana 34: $85-110$.

Novillo A., A. Ojeda y R. Ojeda. 2009. Loxodontomys pikumche (Rodentia, Cricetidae). A new species for Argentina. Mastozoología Neotropical 16: 239-242.

Nowak R. y J. Paradiso.1983. Walker`s Mammals of the World. 4th edition The Johns Hopkins University Press, London.

Nuñez E. 1979. Descripción geológica de la Hoja 28D, Estación Soitué. Boletín Nơ166. Servicio Geológico Nacional, Buenos Aires.

Odum E.P. 1985. Ecología. 3ra. Ed. Interamericana, Mexico.

Odum E.P. y G.W. Barret. 2006. Fundamentos de Ecología (5 ${ }^{\text {ta }}$ edición). Editorial Thomson, Mexico.

Ojeda A.A., G. D’Elía y R.A. Ojeda. 2005. Taxonomía alfa de Chelemys y Euneomys (Rodentia: Cricetidae): el número diploide de ejemplares topotípicos de C. macronyx y E. mordax. Mastozoología Neotropical 12: 79-82.

Ojeda R. 2006. Familia Caviidae. En: R.M. Barquez, M.M. Díaz y R.A. Ojeda (eds.), Mamíferos de Argentina: Sistemática y Distribución, pp. 206-210. Sociedad Argentina para el estudio de los Mamíferos, Tucumán.

Ojeda R.A. y S. Tabeni. 2009. The mammals of the Monte Desert revisited. Journal of Arid Environments 73: 173-181. 
Ojeda R.A., M.C. Navarro, C.E. Borghi y A.M. Scollo. 2001. Nuevos registros de Salinomys y Andalgalomys (Rodentia, Muridae) para la provincia de La Rioja, Argentina. Mastozoología Neotropical 8: 69-71.

Olds N. 1988. A revision of the Genus Calomys (Rodentia: Muridae). PH. D. Dissertation unpublished, City University of New York.

Olds N. y S. Anderson. 1989. A diagnosis of the tribe Phyllotini (Rodentia, Muridae). En: K. Redford y J.F. Eisenberg (eds), Advances in Neotropical Mammalogy, pp. 55-75. Sandhill Crane Press, Gainesville, Florida.

Oliveira T.G. 1994. Neotropical cats: ecology and conservation. EDUFMA, São Luís.

Olrog C.Ch. y E.A. Pescetti. 1991. Las aves del Gran Cuyo. Mendoza, San Juan, San Luis y La Rioja. Mendoza, CRICYT, IADIZA.

Olsen S.L. y P. Shipman. 1988. Surface modification on bone: trampling versus Butchery. Journal of Archaeological Science 15: 535-553.

Ortíz P.E. 2000. Roedores del Pleistoceno superior del Valle de Tafí (provincia de Tucumán), implicancias paleoambientales y paleobiogeográficas. Tesis Doctoral inédita, Facultad de Ciencias Naturales e Instituto Miguel Lillo, Universidad Nacional de Tucumán.

Ortiz P.E. y P. Jayat. 2007. Sigmodontinos (Rodentia: Cricetidae) del límite PleistocenoHoloceno en el valle del Tafí (Tucumán, Argentina): taxonomía, tafonomía y significación paleoambiental. Ameghiniana 44: 641-660.

Ortiz J.C., W. Vanegas, J.A. Sandoval, P. Chandía y F. Torres-Pérez. 2004. Hantavirus en la Octava región de Chile. Revista Chilena de Historia Natural 77: 251-256.

Ortiz P.E., P. Jayat y U.F.J. Pardiñas. 2011a. Roedores y marsupiales en torno al límite Pleistoceno / Holoceno en Catamarca, Argentina: extinciones y evolución ambiental. Ameghiniana 48: 336-357.

Ortiz P.E., J.P. Jayat y U.F.J. Pardiñas. 2011b. Fossil sigmodontine rodents of northwestern Argentina: taxonomy and paleoenvironmental meaning. En: J.A. Salfity y R.A. Marquillas (eds.), Cenozoic geology of the Central Andes of Argentina, pp. 301-315. SCS Publisher, Salta.

Ortiz P.E., M.C. Madozzo Jaén y J.P. Jayat. 2012. Micromammals and paleoenvironments: Climatic oscillations in the Monte desert of Catamarca (Argentina) during the last two millenia. Journal of Arid Environments 77: 103-109.

Osgood W.H. 1943. The mammals of Chile. Field Museum of Natural History (Zoology) 30: 1268.

Otaola, C. Tafonomía y Zooarqueologia en el Sur de Mendoza. Tesis Doctoral en preparación. Facultad de Filosofía y Letras. Universidad Nacional de Buenos Aires. 
Overpeck J.T., T. Webb y I.C. Prentice. 1985. Quantitative interpretation of fossil pollen spectra: Dissimilarity coefficients and the method of modern analogs. Quaternary Research 23: 87-108.

Paez M. y M. Zárate. 2000. Condiciones Paleoambientales durante la transición PleistocenoHoloceno en el noroeste de Mendoza, Argentina. XI Simposio Argentino de Paleobotánica y Palinología, pp. 81. Tucumán.

Paez M., D. Navarro, L. Rojo y A. Guerci. 2010. Vegetación y Paleoambientes durante el Holoceno en Mendoza. En: Z. Marcelo, A. Gil y G. Neme (eds.), Paleoambientes y ocupaciones humanas del centro-oeste de Argentina durante la transición PleistocenoHoloceno y Holoceno de Mendoza, pp. 175-211. Sociedad Argentina de Antropología, Buenos Aires.

Palma R.E., E. Rivera-Milla, J. Salazar-Bravo, F. Torres-Pérez, U.F.J. Pardiñas, P.A. Marquet, A.E. Spotorno, A.P. Meynard y T.L. Yates. 2005. Phylogeography of Oligoryzomys longicaudatus (Rodentia: Sigmodontinae) in temperate South America. Journal of Mammalogy 86: 191-200.

Palma R.E., F. Torres-Pérez y D. Boric-Bargetto. 2007. The ecology and evolutionary history of Oligoryzomys longicaudatus in southern South America. En: P. Pearson, D.A. Kelt, E.P. Lessa, J. Salazar-Bravo y J.L. Patton (eds), The quintessential naturalist: honoring the life and legacy of Oliver P. Pearson, pp. 671-694. University of California Publications in Zoology 134, California.

Palma R.E., F. Torres-Pérez y D. Boric-Bargetto. 2007. The Ecology and Evolutionary History of Oligoryzomys longicaudatus in Southern South America. En: P. Pearson, D.A. Kelt, E.P. Lessa, J. Salazar-Bravo y J.L. Patton (eds), The quintessential naturalist: honoring the life and legacy of Oliver P. Pearson, pp. 671-693. University of California Publications in Zoology 134, California.

Parada A., G. D’Elía, C.J. Bidau y E.P. Lessa. 2011. Species groups and the evolutionary diversification of tuco-tucos, genus Ctenomys (Rodentia: Ctenomyidae). Journal of Mammalogy 92: 671-682.

Pardiñas U.F.J. 1996-1998. Roedores holocénicos del sitio Cerro Casa de Piedra 5 (Santa Cruz, Argentina): tafonomía y paleoambientes. Palimpsesto. Revista de Arqueología 5: 66-90.

Pardiñas U.F.J. 1999a. Los roedores muroideos del Pleistoceno Tardío-Holoceno en la Región Pampeana (sector este) y Patagonia (República Argentina): aspectos taxonómicos, importancia bioestratigráficas y significación paleoambiental. Tesis Doctoral inédita, Facultad de Ciencias Naturales y Museo, Universidad Nacional La Plata.

Pardiñas U.F.J. 1999b. Tafonomía de microvertebrados en yacimientos arqueológicos de Patagonia. Arqueología 9: 265-308. 
Pardiñas U.F.J. 2009. El género Akodon (Rodentia: Cricetidae) en Patagonia: estado actual de su conocimiento. Mastozoología Neotropical 16: 135-151.

Pardiñas U.F.J. y C.A. Galliari. 1998. Sigmodontinos (Rodentia, Muridae) del Holoceno inferior de Bolivia. Revista Española de Paleontología 13: 17-25.

Pardiñas U.F.J y C.A Galliari. 1999. Akodon iniscatus (Mammalia: Rodentia) en la provincia de Buenos Aires (Argentina). Neotrópica 45: 115-117.

Pardiñas U.F.J y C.A Galliari. 2001. Reithrodon auritus. Mammalian Species 664: 1-8.

Pardinas U.F.J y Ojeda., R. 2011. Microcavia australis. En: IUCN 2011. IUCN Red List of Threatened Species. Version 2011.1. www.iucnredlist.org. 22 de Septiembre 2011.

Pardiñas U.F.J. y E.P. Tonni. 1998. Procedencia estratigráfica y edad de los más antiguos muroideos (Mammalia, Rodentia) de América del Sur. Ameghiniana 35: 473-475.

Pardinas U.F.J. y P. Teta. 2005. Roedores Sigmodontinos del Chaco Húmedo de Formosa: aspectos taxonómicos y distribución geográfica. En: A.G. Di Giacomo y S.F. Krapovickas (eds.), Historia natural y paisaje de la Reserva El Bagual, Provincia de Formosa, Argentina. Inventario de la fauna de vertebrados y de la flora vascular de un área protegida del Chaco Húmedo. Temas de Naturaleza y Conservación 4, pp. 501-517. Asociación Ornitológica del Plata, Buenos Aires.

Pardiñas U.F.J. y P. Teta. 2006. Roedores sigmodontinos de la provincia de Misiones: estado actual de su conocimiento nomenclatural y taxonómico. En: E. Massoia, J.C. Chebez y A. Bosso (eds.), Los mamíferos silvestres de la provincia de Misiones, Argentina, pp. 483490. Ediciones de los Autores, Buenos Aires.

Pardiñas U.F.J. y P. Teta. 2008. Small mammals and paleoenvironments around the PleistoceneHolocene boundary in Patagonia. Current Research in the Pleistocene 25: 30-32.

Pardiñas U.F.J. y P. Teta. 2010. Graomys hypogaeus Cabrera, 1934 es un sinónimo de Eligmodontia moreni (Thomas, 1896). Mastozoología Neotropical 17: 201-205.

Pardiñas U.F.J. y P. Teta. 2011. Fossil history of the marsh rats of the genus Holochilus and Lundomys (Cricetidae, Sigmodontinae) in southern South America. Estudios Geológicos 67: 111-129.

Pardiñas U.F.J. y P. Teta. En prensa. Holocene stability and recent dramatic changes in micromammalian communities of northwestern Patagonia. Quaternary International.

Pardiñas U.F.J., G.J. Moreira, C. García-Esponda y L.J.M. De Santis. 2000. Deterioro ambiental y micromamíferos durante el Holoceno en el nordeste de la estepa patagónica (Argentina). Revista Chilena de Historia Natural 73: 541-556.

Pardiñas U.F.J., S. Cirignoli y D. Podestá. 2001. Nuevos micromamíferos en la península Valdés (Provincia de Chubut), Argentina. Neotrópica 47: 101-102. 
Pardiñas U.F.J., G. D’ Elía y P.E. Ortiz. 2002. Sigmodontinos fósiles (Rodentia, Muroidea, Sigmodontinae) de América del Sur: Estado actual de su conocimiento y prospectiva. Mastozoología Neotropical 9: 209-252.

Pardiñas U.F.J., P. Teta, S. Cirignoli y D.H. Podestá. 2003. Micromamíferos (Didelphimorphia y Rodentia) de Norpatagonia Extra Andina, Argentina: taxonomía alfa y biogeografía. Mastozoología Neotropical 10: 69-113.

Pardiñas U.F.J., A.M. Abba y M.L. Merino. 2004. Micromamíferos (Didelphimorphia y Rodentia) del sudoeste de la provincia de Buenos Aires (Argentina): taxonomía alfa y distribución. Mastozoología Neotropical 11: 211-232.

Pardiñas U.F.J., G. D’Elía, P. Teta, P.E. Ortiz, P.J. Jayat y S. Cirignoli. 2006a. Tribu Akodontini Vorontsov 1959 (sensu D’Elía, 2003). En: R.M. Barquez, M.M. Díaz y R.A. Ojeda (eds.), Mamiferos de Argentina: Sistemática y Distribución, pp. 146-166. Sociedad Argentina para el estudio de los Mamíferos, Tucumán.

Pardiñas U.F.J., P. Teta y G. D' Elía. 2006b. Tribu Reithrodontini Vorontsov, 1959. En R.M. Barquez, M.M. Díaz y R.A. Ojeda (eds.), Mamíferos de Argentina: Sistemática y Distribución, pp. 189-191. Sociedad Argentina para el estudio de los Mamíferos, Tucumán.

Pardiñas U.F.J., P. Teta y D.E. Udrizar Sauthier. 2008. Mammalia, Didelphimorphia and Rodentia Southwest of the province of Mendoza, Argentina. Check List 4: 218-225.

Pardiñas U.F.J., P. Teta, J.C. Chebez, F.D. Martínez, S. Ocampo, D.O. Navas. 2010a. Mammalia, Rodentia, Sigmodontinae, Euneomys chinchilloides (Waterhouse, 1839): Range extention. Check List 6: 167-169.

Pardiñas U.F.J., P. Teta y G. D’Elía. 2010b. Roedores sigmodontinos de la región pampeana: Historia evolutiva, sistemática y taxonomía. En: J.J. Polop y M. Busch (eds.), Biología y Ecología de pequeños roedores en la región pampeana de Argentina, pp. 9-36. Universidad Nacional de Córdoba, Córdoba.

Pardiñas U.F.J., P. Teta y D. Bilenca. 2010c. Roedores Sigmodontinos de la Región Pampeana: una introducción zoogeográfica. En: J.J. Polop y M. Busch (eds.), Biología y Ecología de pequeños roedores en la región pampeana de Argentina, pp. 37-57. Universidad Nacional de Córdoba, Córdoba.

Pardiñas U.F.J., P. Teta, G. D’Elía y E.P. Lessa. 2011a. The evolutionary history of sigmodontine rodents in Patagonia and Tierra del Fuego. Biological Journal of the Linnean Society 103: 495-513.

Pardiñas U.F.J., P. Teta, A.E. Formoso y R. Barberena. 2011b. Roedores del extremo austral: tafonomía, diversidad y evolución ambiental durante el Holoceno tardío. En: L.A. Borrero y K. Borrazo (eds.), Bosques, montañas y cazadores. Investigaciones 
Arqueológicas en Patagonia Meridional, pp 61-84. Editorial Dunken, Capital Federal, Argentina.

Pardiñas U.F.J., P. Teta, G. D’Elía y G.B. Diaz. 2011c. Taxonomic status of Akodon oenos (Rodentia, Sigmodontinae), an obscure species from West Central Argentina. Zootaxa 2749: 47-61.

Pardiñas U.F.J., P. Teta, D. Voglino y F.J. Fernández. En prensa. Unexpected diversity in west-central Argentina: A new marsh rat of the genus Holochilus (Cricetidae, Sigmodontinae). Journal of Mammalogy.

Pasquaré G., A. Bistacchi, L. Francalanci, G.W. Bertotto, E. Boari, M. Massironi y A. Rossotti. 2008. Very long Pahoehoe inflated basaltic lava flows in the Payenia volcanic province (Mendoza and La Pampa, Argentina). Revista de la Asociación Geológica Argentina 63: 131-149.

Paulides, S. Movilidad y Organización Tecnológica durante el Holoceno tardío en los valles cordilleranos del sur de Mendoza. Tesis Doctoral en preparación. Facultad de Filosofía y Letras. Universidad Nacional de Buenos Aires.

Pearson O.P. 1958. A taxonomic revision of the rodent genus Phyllotis. University of California Publications in Zoology 56: 391-496.

Pearson O.P. 1983. Characteristics of a mammalian fauna from forest in Patagonia, southern Argentina. Journal of Mammalogy 64: 476-492.

Pearson O.P. 1984. Taxonomy and natural history of some fossorial rodents of Patagonia, southern Argentina. Journal of Zoology 202: 225-237.

Pearson O.P. 1987. Mice and the postglacial history of the Traful valley of Argentina. Journal of Mammalogy 68: 469-478.

Pearson O.P. 1988. Biology and feeding dynamics of a South American herbivorous rodent, Reithrodon. Studies on Neotropical Fauna and Environment 23: 25-39.

Pearson O.P. 1995. Annotated keys for identifyng small mammals living in or near Nahuel Huapi National Park or Lanin National Park southern Argentina. Mastozoología Neotropical 2: 99-148.

Pearson O.P. y A.K Pearson. 1982. Ecology and biogeographic of the southern rainforest of Argentina. En: M.A. Mares y H.H. Genoways (eds.), Mammalian biology in South American, pp. 129-142. Special Publication of Pymatuning Laboratory of Ecology 6, Linesville, Pennsylvania.

Pearson O.P. y M.I. Christie. 1991. Sympatric species of Euneomys (Rodentia, Cricetidae). Studies on Neotropical Fauna and Environment 26: 121-127.

Pearson O.P. y H.A. Lagiglia. 1992. "Fuerte de San Rafael": Una localidad tipo ilusoria. Revista del Museo de Historia Natural de San Rafael (Mendoza) 12: 35-43. 
Pearson A.K. y O.P. Pearson. 1993. La fauna de mamíferos pequeños de la Cueva Traful I, Argentina, pasado y presente. Prehistoria 1: 211-224.

Pearson O.P. y M. Smith. 1999. Genetic similarity between Akodon olivaceus and Akodon xanthorhinus (Rodentia: Muridae) in Argentina. Journal of Zoology 247: 43-52.

Pereira J., M. Lucherini, T. de Oliveira, E. Eizirik, G. Acosta y R. Leite-Pitman. 2008. Leopardus colocolo. En: IUCN 2011. IUCN Red List of Threatened Species. Version 2011.1. www.iucnredlist.org. 13 de Julio 2011.

Pérez Winter C. 2009a. Estructuración de los recursos líticos en el sur de la provincia de Mendoza, Argentina: una perspectiva arqueológica. Caminhos de Geografia 9: 1-12.

Pérez Winter C. 2009b. Cambios climáticos y estrategias tecnológicas: caso arqueológico Arroyo Malo 3, sur de Mendoza, Argentina. Sociedade \& Natureza, Uberlândia 21: 289-304.

Pérez Winter C. 2010. Tendencias en el registro lítico durante el Holoceno medio: sitio Arroyo Malo 3, alto valle del río Atuel, sur de Mendoza. Intersecciones en Antropología 11: 159172 .

Perovic P.G. y J.A. Pereira. 2006. Familia Felidae G. Fisher, 1817. En: R.M. Barquez, M.M. Díaz y R.A. Ojeda (eds.), Mamíferos de Argentina: Sistemática y Distribución, pp. 93-100. Sociedad Argentina para el estudio de los Mamíferos, Tucumán.

Peters J. y R. Donoso-Barros. 1970. Catalogue of the Neotropical Squamata. Part. II. Lizards and Amphisbaenians. Bulletin of the United States National Museum 297: 1-293.

Pierce B.M. y V.C. Bleich. 2003. Mountain Lion. En: G.A. Feldhamer, B.C. Thompson y J.A. Chapman (eds.), Wild Mammals of North America, pp. 744-757. Johns Hopkins University Press, Baltimore, Maryland.

Pine R.H., S.D. Miller y M.L. Schamberger. 1979. Contributions of the mammalogy of Chile. Mammalia 43: 339-376.

Pinto Llona A.C. y P. Andrews. 1999. Amphibian taphonomy and its application to the fossil record of Dolina (middle Pleistocene, Atapuerca, Spain). Paleoecology 149: 411-429.

Polanski J. 1954. Rasgos geomorfológicos del territorio de la provincia de Mendoza. Cuaderno de Investigaciones y Estudios 4: 4- 10.

Polanski J. 1963. Estratigrafía, neotectónica y geomorfología del Pleistoceno pedemontano entre los ríos Diamante y Mendoza. Revista de la Asociación Geológica Argentina 17: 127349.

Pompei M.P., R. Barberena, M.E. de Porras, K. Borrazzo, A. Rughini y A. Gil. 2011. Late Quaternary Ecosystems and Humans in Northern Patagonia (Neuquén, Argentina). Current Research in the Pleistocene. Special Volume Guest Edited by L. Miotti, N. Flegenheimer y M. Salemme, Center for the Study of the First Americans, Texas A\&M University. 
Potter R.M. y G.R. Rossman. 1979. The manganese and iron-oxide mineralogy of desert varish. Chemical Geology 25: 79-94.

Prado J., F. Goin, E. Tonni. 1985. Lestodelphys halli (Mammalia, Didelphidae) in Holocene deposits of southeastern Buenos Aires province, Argentina. Morphological and palaeoenvironmental considerations. Quaternary of South America and Antarctic Peninsula 3: 93-106.

Prates L. 2008. Los indígenas del río Negro. Un enfoque arqueológico. Sociedad Argentina de Antropología, Buenos Aires.

Prevosti J.F. y U.F.J. Pardiñas. 2009. Comment on "The oldest South American Cricetidae (Rodentia) and Mustelidae (Carnivora): Late Miocene faunal turnover in central Argentina and the Great American Biotic Interchange" by D.H. Verzi and C.I. Montalvo [Palaeogeography, Palaeoclimatology, Palaeoecology 267 (2008) 284-291]. Palaeogeography, Palaeoclimatology, Palaeoecology 280: 543-547.

Prieto M. y E. Abraham. 1993-1994. Indios, chilenos y estancieros en el sur de Mendoza. Historia de un proceso de desertificación. Anales de Arqueología y Etnología 48-49: 11-29.

Prieto M. y E. Abraham. 2000. Caminos y comercio como factores de cambio ambiental en las planicies áridas de Mendoza (Argentina) entre los siglos XVII y XIX. Theomai 2 (http://www.unq.edu.ar/revista-theomai/numero2/index.htm). Universidad Nacional de Quilmes.

Quidelleur X., J. Carlut, P. Tchilinguiriann, A. Germa, P. Gillot. 2009. Paleomagnetic directions from mid-latitude sites in the southern hemisphere (Argentina): Contribution to Time Averaged Field models. Physics of the Earth and Planetary Interiors 172: 199-209.

Quintana C.A. 2005. Despiece de microroedores en el Holoceno Tardío de las Sierras de Tandilia (Argentina). Archaeofauna 14: 227-241.

Quintana C.A., F. Valverde y D.L. Mazzanti. 2002. Roedores y lagartos como emergentes de la diversificación de la subsistencia durante el Holoceno tardío en sierras de la región Pampeana Argentina. Latin American Antiquity 4: 455-473.

Raise D. y M.H. Gallardo. 1990. A taxonomic study of the South American genus Eunemys (Cricetidae, Rodentia). Revista Chilena de Historia Natural 63: 73-82.

Rapoport E., J.A. Monjeau, B. Drausal, L. Guermandi y V. Arrechea. 2001. Flora y vegetación de una localidad del sur de Mendoza, Argentina. Resultados de un estudio de impacto ambiental por actividades mineras. Multequina 10: 51-66.

Ratallack G.J. 1983. Late Eocene and Oligocene paleosols from Badlands National Park, south Dakota. Geological Society of America. Special Paper 193.

Ratallack G.J. 1990. Soils of the past. An introduction to paleopedology. Unwin Hyman, Boston.

Ratcliffe D.A. 1980. The Peregrine Falcon. Buteo Books, Vetmillion, SD. 
Rau J., M. Tillería, D. Martínez, A. Muñoz. 1991. Dieta de Felis concolor (Carnivora: Felidae) en áreas silvestres protegidas de sur de Chile. Revista Chilena de Historia Natural 64: 139144.

Rau J.R., M.C.Villagra, M.L. Mora, D.R. Martinez y M.S. Tillería. 1992. Food Habits of the short-eared owl (Asio flammeus) in southern South America. Journal of Raptor Research 26: 35-36.

Rau J.R., D.R. Martínez, J.R. Low y M.S. Tilleria. 1995. Depredación por zorros chillas (Pseudalopex griseus) sobre micromamíferos cursoriales escansoriales y arborícolas en un área silvestre protegida del sur de Chile. Revista Chilena de Historia Natural 68: 333340 .

Raunkiaer C.H. 1934. The life-forms of plants and statistical plant geography. Oxford Universty Press, Oxford.

Redford K.H. y J.F. Eisenberg. 1992. Mammals of the Neotropics. The Southern Cone. The University of Chicago Press, Chicago.

Reig O.A. 1977. A proposed unified nomenclature for the enameled components of the molar teeth of the Cricetidae (Rodentia). Journal of Zoology 181: 227-241.

Reig O.A. 1978. Roedores cricétidos del Plioceno superior de la provincia de Buenos Aires (Argentina). Publicación del Museo Municipal de Ciencias Naturales de Mar del Plata "Lorenzo Scaglia” 2: 164-190.

Reig O.A. 1981. Teoría y desarrollo de la fauna de mamíferos de América del Sur. Monographie Naturae (Museo Municipal de Ciencias Naturales "Lorenzo Scaglia”, Mar del Plata, Argentina) 11: 1-162.

Reig O.A. 1987. An assessment of the systematics and evolution of the Akodontini, with the description of new fossil species of Akodon (Cricetidae: Sigmodontinae). En: B.D. Patterson y R. Timm (eds.), Studies in Neotropical mammalogy. Essays in honor of Philip Hershkovitz, pp. 347-399. Fieldiana, Zoology, new series 39, Chicago.

Ringuelet R. 1961. Rasgos fundamentales de la zoogeografía Argentina. Physis 22: 151-170.

Ringuelet R.A., R.H. Aramburu y A.A. de Aramburu. 1967. Los peces argentinos de agua dulce. Comisión de Investigación Científica, La Plata.

Rivera P.C., R.E. González Ittig, H.J. Rossi Fraire, S. Livis y C.N. Gardenal. 2007. Molecular identification and phylogenetic relationships among the species of the genus Oligoryzomys (Rodentia, Cricetidae) present in Argentina, putative reservoirs of hantaviruses. Zoologica Scripta: 1-9.

Rivero D., V.F. Salvi y H. Paradela. 2008. Cambios en la funcionalidad del sitio Arroyo El Gaucho 1 durante el Holoceno (pcia. de Córdoba, Argentina). Revista Arqueología 14: 77-101. 
Rivero D., S. Pastor y M. Medina. 2010. Intensificación en las Sierras de Córdoba. El Abrigo Rocoso Quebrada del Real 1 (ca. 6000-500 AP, Córdoba, Argentina). Anales de Arqueología y Etnología de la Universidad Nacional de Cuyo 63-64: 227-246.

Riverón S. 2011. Estructura poblacional e historia demográfica del "pericote patagónico", Phyllotis xanthopygus (Rodentia: Sigmodontinae) en la Patagonia argentina. Tesis de Maestría, PEDECIBA, Montevideo, Uruguay.

Roig F.A. 1972. Bosquejo Fisionómico de la vegetación de la provincia de Mendoza. En: F.A. Roig (ed.), Geología, Geomorfología, Climatología, Fitogeografia y Zoogeografía de la provincia de Mendoza, pp. 49-80, Reedición especial del Boletín de la Sociedad Argentina de Botánica 8, Mendoza.

Roig V.G. 1965. Elenco sistemático de los mamíferos y aves de la provincia de Mendoza y notas sobre su distribución geográfica. Boletin de Estudios Geográficos 12: 175-222.

Roig V.G. 1972. Esbozo general del poblamiento animal en la provincia de Mendoza. En: F.A. Roig (ed.), Geología, Geomorfología, Climatología, Fitogeografia y Zoogeografía de la provincia de Mendoza, pp. 81-88. Reedición especial del Boletín de la Sociedad Argentina de Botánica 8, Mendoza.

Roig V.G. 1991. Desertification and distribution of mammals in the southern cone of South America. En: M.A. Mares y D. Schmidly (eds.), Latin American Mammalogy, pp. 239279. University of Oklahoma Press, Norman, Oklahoma.

Rojo L.D., A.E. Mehl, M.M. Paez y M.A. Zárate. 2012. Mid- to Late Holocene pollen and alluvial record of the arid Andean piedmont between $33^{\circ}$ and $34^{\circ} \mathrm{S}$, Mendoza, Argentina: Inferences about floodplain evolution. Journal of Arid Environments 77: 110-122.

Romano M., R. Biasatti y L.J.M. De Santis. 2002. Dieta comparada de ejemplares de Tyto alba en una zona urbana respecto a una rural-Santa Fe, Argentina. El Hornero 17: 25-29.

Rosales D. 1937. Historia general de Reyno de Chile desde la época aborigen hasta la Gran Rebelión del siglo XIX (Reimpresión Parcial). Revista de la Junta de Estudios Históricos de Mendoza VIII: 231-252.

Rosi M.I. 1983. Notas sobre la ecología y distribución y sistemática de Graomys griseoflavus griseoflavus (Waterhouse, 1837) (Rodentia, Cricetidae) en la provincia de Mendoza. Historia Natural 3:161-167.

Rosi M.I., M.I. Cona, S. Puig, F. Videla y V.G. Roig. 1996. Size and structure of burrow systems of the fossorial rodent Ctenomys mendocinus in the piedmont of Mendoza province, Argentina. Zeitschrift für Säugetierkunde 61: 352-364.

Rosi M.I., M.I. Cona, F. Videla, S. Puig y V.G. Roig. 2000. Architecture of Ctenomys mendocinus (Rodentia) burrows from two habitats differing in abundance and complexity of vegetation. Acta Theriologica 45: 491-505. 
Rosi M.I., M.I. Cona y V.G. Roig. 2002. Estado actual del conocimiento del roedor fosorial Ctenomys mendocinus Philippi 1869 (Rodentia: Ctenomyidae). Mastozoología Neotropical 9: 277-295.

Röthlisberger F. 1987. 10000 Jahre Gletschergeschichte der Erde. Verlag Sauerländer Aarau, Frankfurt.

Saavedra B. 1994. Tafonomía de micromamíferos de Chile central. Actas del $2^{\circ}$ taller de Arqueología de Chile Central, pp. 1-22. Santiago.

Saavedra B. y J.A Simonetti. 1998. Small mammals taphonomy: Intraspecific bone assemblage comprasion between South and North American Barn Owl, Tyto alba, populations. Journal of Archaeological Science 25: 165-170.

Saavedra B. y J.A Simonetti. 2003. Holocene distribution of Octodontid in central Chile. Revista Chilena de Historia Natural 76: 383-389.

Saba S., D. Perez, E. Cejuela, V. Quiroga y A. Toyos. 1995. La biósfera ovina en el extremo austral del desierto del Monte. Naturalia Patagonia, Ciencias Biológicas 3: 153-174.

Salazar-Bravo J., J.W. Dragoo, D.S. Tinnin y T.L. Yates. 2001. Phylogeny and evolution of the Neotropical rodent genus Calomys: inferences from Mitochondrial DNA sequence data. Molecular Phylogenetics and Evolution 20: 173-184.

Salemme M.C. 1987. Paleoetnozoología del sector bonaerense de la región pampeana, atención a los mamiferos. Tesis Doctoral inédita. Facultad de Ciencias Naturales y Museo, Universidad Nacional de La Plata.

Santiago F.C. 2004. Los roedores en el "menú" de los habitantes de Cerro Aguará (provincia de Santa Fe): su análisis arqueofaunístico. Intersecciones en Antropología 5: 3-18.

Santini M. 2009. Prehistoria de la región meridional del Gran Chaco: aportes del análisis de restos faunísticos en la reconstrucción de las estrategias adaptativas de los grupos aborígenes. Tesis Doctoral inédita, Facultad de Ciencias Naturales y Museo, Universidad Nacional de La Plata.

Sarasola J.H., M.A. Santillán y M. Galmes. 2003. Food habits and foraging ecology of American Kestrels in the semiarid forest of Central Argentina. Journal of Raptor Research 37: 236243.

Savanti F. 1994. Las aves en la dieta de los cazadores-recolectores terrestres de la costa fueguina. Temas de Arqueología, CONICET/PREP, Buenos. Aires.

Schiffer M.B. 1987. Formation processes of the archaeological record. Albuquerque. University of New Mexico Press, New Mexico.

Scheifler N. 2010. Resultados preliminares del estudio zooarqueológico y tafonómico de los restos óseos de roedores del sitio Calera (Sierras Bayas, partido de Olavarría, provincia de Buenos Aires). La Zaranda de Ideas 6: 117-128. 
Scheifler N., P. Teta, U.F.J. Pardiñas. En prensa. Small mammals (Didelphimorphia and Rodentia) of the archaeological site Calera (Pampean region, Buenos Aires Province, Argentina): taphonomic history and Late Holocene environments. Quaternary International.

Schmid E. 1970. Cave sediments and prehistory. En: D. Brothwll y E. Higgs (eds.), Science in Archaeology. A Survey of Progress and Research, pp. 151-166 Preager Publishers, New York.

Schoeninger M. y M. DeNiro. 1984. Nitrogen and carbon isotopic composition of bone collagen from marine and terrestrial animals. Geochimica et Cosmochimica Acta 48: 625-639.

Semper J. y H. Lagiglia. 1968. Excavaciones arqueológicas en el Rincón del Atuel (Gruta del Indio) Departamento de San Rafael (Mendoza). Revista Científica de Investigaciones 1: $89-158$.

Serjeantson D., B. Irving y S. Hamilton-Dyer. 1993. Bird bone taphonomy from the inside out: the evidence of gull predation on the Manx Shearwater Puffinus puffinus. Archaeofauna 2: 191-204.

Shipman P. y J. Rose. 1983. Early hominid hunting, butchering and carcasses processing behaviors: approaches to the fossil record. Journal of Anthropological Archives 2: 57-98.

Shipman P. y J. Rose. 1988. Bone tools: an experimental approach. En: S.L. Olsen (ed.), Scanning electron microscopy in archaeology, pp. 303-335, British Archaeological Reports International Series 452, Oxford.

Scolaro A. 1976. Lista sistemática de reptiles de Península Valdés (ch).I. Sáuria. Physis 35: 267271.

Scolaro A. 2005. Reptiles Patagónicos: Sur. Una Guia de Campo. Universidad Nacional de la Patagonia, Comodoro Rivadavia.

Scolaro A. 2006. Reptiles Patagónicos: Norte. Una Guia de Campo. Universidad Nacional de la Patagonia, Comodoro Rivadavia.

Semper J. y H. Lagiglia. 1962-1968. Excavaciones arqueológicas en el Rincón del Atuel. Revista Científica de Investigaciones 1: 89-158.

Sikes R.S., E.C. Monjeau, C.J. Phillips y J.R. Hillyard. 1997. Morphological versus chromosomal and molecular divergence in two species of Eligmodontia. Zeitschrift für Saugetierkunde 62: $265-280$.

Silva S.I., F.M. Jaksic y F. Bozinovic. 2005. Nutritional ecology and digestive response to dietary shift in the large South American fox, Pseudalopex culpaeus. Revista Chilena de Historia Natural 78: 239-246.

Silveira M.J. 1979. Análisis e interpretación de los conjuntos faunísticos de la Cueva Grande del Arroyo Feo. Relaciones 13: 229-253. 
Simonetti J.A. 1988. The carnivorous predatory guild of central Chile: a human-induced community trait?. Revista Chilena de Historia Natural 61: 23-25.

Simonetti J.A. 1989. Small mammals as paleoenvironmental indicators: validation for species of central Chile. Revista Chilena de Historia Natural 62: 109-114.

Simonetti J.A. y A.E. Spotorno. 1980. Posición taxonómica de Phyllotis micropus (Rodentia: Cricetidae). Anales del Museo de Historia Natural de Valparaíso 13: 285-297.

Simonetti J.A. y L.E. Cornejo. 1991. Archaeological evidence of rodent consumption in central Chile. Latin American Antiquity 2: 92-96.

Simpson G. 1970. Uniformitarianism. An inquiry into principle, theory, and method in geihistory. En: M.K. Hecht y W.C. Steere (eds.), Essays in Evolution and Genetics in Honor of Theodosius Dobzhansky, pp. 43-96. Appleton-Century-Grofts, New York.

Sissons R.A., K.L. Scalise y T.I. Wellicome. 2001. Nocturnal foraging and habitat use by male burrowing owls in a heavily-cultivated region of southern Saskatchewan. Journal of Raptor Research 35: 304-309.

Smith M.F. y J.L. Patton. 1999. Phylogenetic relationships and the radiation of sigmodontine rodents in South America: evidence from cytochrome b. Journal of Mammalian Evolution 6: 89-128.

Smith M.F. y J.L. Patton. 2007. Molecular phylogenetics and diversification of South American grass mice, genus Akodon. En: D.A. Kelt, E.P. Lessa, J.A. Salazar-Bravo y J.L. Patton (eds.), The quintessential naturalist: honoring the life and legacy of Oliver P. Pearson, pp. 827-858. University of California Publications in Zoology 134, California.

Smith M.F., D.A. Kelt y J.L. Patton. 2001. Testing models of diversification in mice in the Abrothrix olivaceus/xanthorhinus complex in Chile and Argentina. Molecular Ecology 10: 397-405.

Smithsonian Institution. Abril 2011. Global Vulcanism Programan. http://www.volcano.si.edu/index.cfm.

Smoke N.D. y P.W. Stahl. 2004. Post-burial fragmentation of microvertebrate skeletons. Journal of Archaeological Science 31: 1093-1100.

Solmsdorff K., D. Kock, C. Hohoff y N. Sachser. 2004. Comment of the genus Galea Meyen, 1931 with description of Galea monasteriensis n. sp. From Bolivia (Mammalia, Rodentia, Caviidae). Senckenbergiana biologica 84: 137-156.

Spalletti L.A. y F.I. Isla. 2003. Características y evolución del delta del Río Colorado ("ColúLeuvú"), Provincia de Buenos Aires, República Argentina. Asociación Argentina de Sedimentología 10: 23-37.

Spotorno A.E., H. Cofré, G.M. Manríquez, Y. Vilina, P. Marquet y L.I. Walker. 1998. Nueva especie de mamífero filotino Loxodontomys en Chile Central. Revista Chilena de Historia Natural 71: 359-374. 
Spotorno A.E., J. Sufan-Catalan y L.I. Walker. 1994. Cytogenetic diversity and evolution of Andean species of Eligmodontia (Rodentia, Muridae). Zeitschrift für Säugetierkunde 59: 299-308.

Spotorno A.E., R.E. Palma y J.P. Valladares. 2000. Biología de roedores reservorios de hantavirus en Chile. Revista Chilena de Infectología 17: 197-210.

Steppan S.J. 1995. Revision of the Tribe Phyllotini (Rodentia, Sigmodontinae), with a phylogenetic hypotesis for the Sigmodontinae. Fieldiana: Zoology (new series) 80: 1112.

Stahl P.W. 1982. On small mammals remains in archaeological context. American Antiquity 4: $822-829$.

Stahl P.W. 1996. The recovery and interpretation of microvertebrate bone assemblages from Archaeological contexts. Journal of Archaeological Method and Teory 3: 31-75.

Stephens D. y Y.J. Krebs. 1986. Foraging theory. Princeton University Press, Princeton.

Steppan S.J. 1998. Phylogenetic relationship and species limits within Phyllotis (Rodentia: Sigmodontinae): Concordance between MTDNA sequence and morphology. Journal of Mammalogy 79: 573-593.

Steppan S.J y J. Sullivan. 2000. The emerging statistical perspective in systematics: A comment on Mares and Braun. Journal of Mammalogy 81: 260-270.

Steppan S.J., O. Ramirez, J. Banbury, D. Huchon, V. Pacheco, L.I. Walker y A.E. Spotorno. 2007. A Molecular Reappraisal of the Systematics of the Leaf-eared Mice Phyllotis and their Relatives. En: D.A. Kelt, E.P. Lessa, J.A. Salazar-Bravo y J.L. Patton (eds.), The Quintessential Naturalist: Honoring the Life and Legacy of Oliver P. Pearson, pp. 799826. University of California Publications in Zoology 134, California.

Stiner M.C., N.D. Munro y M. Sanz. 2012. Carcass damage and digested bone from mountain lions (Felis concolor): implications for carcass persistence on landscapes as a function of prey age. Journal of Archaeological Science 39: 896-907.

Stingl H. y K. Garleff, 1978. Gletscherschwankugen in den subtropisch-semiaride Hochaden Argentiies. Zeitschrift für Geomorphologie NF30: 115-131.

Sting H. y K. Garleff. 1985. Glacier variations and climate of the late quaternary in the subtropical and mide- latitude andes of Argentina. Aeitschrift für Gletscherkunde 21: 225228.

Straus L. G. 1990. Underground archaeology: perspectives on caves and rockshelters. En: M.B. Schiffer (ed.), Archaeological Method and Theory 2, pp. 255-304. University of Arizona Press, Tucson.

Sunquist M. y F. Sunquist. 2002. Wild cats of the world. The University of Chicago Press, Chicago and London. 
Tate G.H.H. 1933. A systematic revision of the marsupial genus Marmosa. Bulletin of the American Museum of Natural History 66: 1-66.

Taylor I. 2004. Barn Owls: Predator-Prey Relationships and Conservation. Cambridge University Press, Cambridge.

Terry R.C. 2004. Owl Pellet Taphonomy: A Preliminary Study of the Post-Regurgitation Taphonomic History of Pellets in a Temperate Forest. Palaios 19: 497-506.

Terry R.C. 2007. Inferring predator identity from skeletal damage of small-mammal prey remains. Evolutionary Ecology Research 9: 199-219.

Teta P. y P.E. Ortiz. 2002. Micromamíferos andinos holocénicos del sitio arqueológico Inca Cueva 5, Jujuy, Argentina: tafonomía, zoogeografía y reconstrucción paleoambiental. Estudios Geológicos 58: 117.135.

Teta P., A. Andrade y U.F.J. Pardiñas. 2005a. Micromamíferos (Didelphimorphia y Rodentia) y paleoambientes del Holoceno tardío en la Patagonia noroccidental extra-andina (Argentina). Archaeofauna 14: 183-197.

Teta P., M. Medina, S. Pastor, D. Rivero, H. Paradela. 2005b. Holochilus brasiliensis (Rodentia, Cricetidae) en conjuntos arqueofaunísticos del Holoceno tardío de la Provincia de Córdoba (Argentina). Mastozoología Neotropical 12: 271-275.

Teta P., U.F.J. Pardiñas y G. D’Elía. 2006. “Abrotrichinos”. En: R.M. Barquez, M.M. Díaz y R.A. Ojeda (eds.), Mamiferos de Argentina: Sistemática y Distribución, pp. 192-197. Sociedad Argentina para el estudio de los Mamíferos, Tucumán.

Teta P., U.F.J. Pardiñas, D.E. Udrizar Sauthier y G. D'Elía. 2009. Loxodontomys micropus (Rodentia: Cricetidae). Mammalian Species 837: 1-11.

Teta P., C.M. Gonzáles-Fischer, M. Codecido y D.N. Bilenca. 2010. A contribution from Barn Owl Pellets analisys to known micromammalian distributions in Buenos Aires province, Argentina. Mammalia 74: 97-103.

Teta P., U.F.J. Pardiñas y G. D'Elía. 2011. On the composite nature of the holotype of Loxodontomys pikumche Spotorno et al., 1998 (Rodentia, Cricetidae, Sigmodontinae). Zootaxa 3135: 55-58.

Thomas O. 1919. On small mammals collected by Sr. E. Budin in North-wester Patagonia. Annals and Magazine of Natural History (9) 3: 199-212.

Thomas O. 1920. On small mammals from the Famatina Chain, Northwestern Rioja. Annals and Magazine of Natural History (9) 6: 417-422.

Tiranti S.I. 1989. Tres roedores cricétidos nuevos para la fauna de la provincia de La Pampa. Primeras Jornadas Nacionales de Fauna Silvestre, pp. 489-494. Santa Rosa.

Tiranti S.I. 1996. Cytogenetics of some mammals species from central Argentina. Master Thesis unpublished, Texas Tech University, Lubbock, United State of America. 
Tiranti S.I. 1997. Cytogenetic of silky desert mice Eligmodontia spp. (Rodentia, Sigmodontinae ) in central Argentina. Zeitschrift für Säugetierkunde 62: 37-42.

Tiranti S.I. 1998. Chromosomal variation in the Scrub mouse Akodon molinae (Rodentia: Sigmodontinae) in central Argentina. Texas Journal of Science 50: 223-228.

Tognelli M.F., C.M Campos y R.A. Ojeda. 2001. Microcavia australis. Mammalian Species 648: $1-4$.

Tonni E.P., A.L. Cione y A.J. Figini. 1999. Predominance of arid climates indicated by mammals in the pampas of Argentina during the Late Pleistocene and Holocene. Palaeogeography, Palaeoclimatology, Palaeoecology 147: 257-281.

Trapani J. 1998. Hydrodynamic sorting of avian skeletal remains. Journal of Archaeological Science 25: 477-487.

Travaini A., M. Delibes, O. Cevallos. 1998. Summer foods of the Andean hog-nosed skunk (Conepatus chinga) in Patagonia. Journal of Zoology (London) 246: 457-460.

Travaini A., J.A. Donázar, O. Ceballos y F. Hiraldo. 2001. Food habits of the Crested Caracara (Caracara plancus) in the Andean Patagonia: the role of breeding constraints. Journal of Arid Environments 48: 211-219.

Trejo A. y D. Grigera 1998. Food habits of the Great Horned Owl (Bubo virginianus) in a Patagonian steppe in Argentina. Journal of Raptor Research 32: 306-311.

Trejo A., M. Kun y S. Seijas. 2006. Dieta del águila mora (Geranoaetus melanoleucus) en una transecta oeste-este en el ecotono Norpatagónico. Hornero 21: 31-36.

Tripaldi A. 2010. Campos de dunas de la planicie sanrafaelina: patrones de dunas e inferencias paleoclimáticas durante el Pleistoceno tardío-Holoceno. En: M. Zarate, A. Gil y G. Neme (eds.), Paleoambientes y ocupaciones humanas del centro-oeste de Argentina durante la transición Pleistoceno-Holoceno y Holoceno de Mendoza, pp. 65-93. Sociedad Argentina de Antropología, buenos Aires.

Tripaldi A., M. Zárate y G.A. Brook. 2010. Sucesiones eólicas y fluviales del pleistoceno tardíoholoceno de la planicie sanrafaelina: paleoambientes y paleoclima. En: M. Zarate, A. Gil y G. Neme (eds.), Paleoambientes y ocupaciones humanas del centro-oeste de Argentina durante la transición Pleistoceno-Holoceno y Holoceno, pp. 95-121. Sociedad Argentina de Antropología, Buenos Aires.

Tripaldi A., M.A. Zárate, G.A. Brook, G.Q. Li. 2011. Late Quaternary paleoenvironments and paleoclimatic conditions in the distal Andean piedmont, southern Mendoza, Argentina. Quaternary Research 76: 253-263.

Tykot R.H. 2006. Isotope analyses and the histories of maize. En: J. Staller R.H. Tykot y B. Benz (eds.), Histories of Maize, Multidisciplinary Approaches to the Prehistory, Biogeography, Domestication, and Evolution of Maize, pp. 131-142. Academic Press,New York. 
Udrizar Sauthier D.E. 2009. Los micromamíferos y la evolución ambiental durante el Holoceno en el río Chubut (Chubut, Argentina). Tesis Doctoral inédita, Facultad de Ciencias Naturales y Museo, Universidad Nacional de La Plata.

Udrizar Sauthier D.E. y U.F.J. Pardiñas. 2006. Micromamíferos terrestres de Puerto Lobos, Chubut, Argentina. Mastozoología Neotropical 13: 259-262.

Udrizar Sauthier D.E., A. Andrade y U.F.J. Pardiñas. 2005. Predation of small mammals by Rufous legged Owl, Barn Owl, and Magellanic Horned Owl in Argentinean Patagonia forests. Journal of Raptor Research 39: 163-166.

Udrizar Sauthier D.E., M. Carrera y U.F.J. Pardiñas. 2007. Mammalia, Marsupialia, Didelphidae, Lestodelphys halli: New records, distribution extension and filling gaps. Check List 3: 137-140.

Udrizar Sauthier D.E., P. Teta, P. Wallace y U.F.J. Pardiñas. 2008. Mammalia, Rodentia, Sigmodontinae, Loxodontomys micropus: New locality record. Check List 4: 171-173.

Udrizar Sauthier D.E., A. Formoso, P. Teta y U.F.J. Pardiñas. 2011. Enlarging the knowledge on Graomys griseoflavus (Rodentia: Sigmodontinae) in Patagonia: distribution and environments. Mammalia 75: 185-193.

Van den Bosch M.E. 2008. Zonas Agroeconómicas Homogéneas. San Juan y Mendoza. Ediciones INTA. Colección: Estudios socioeconómicos de la sustentabilidad de los sistemas de producción y recursos naturales $\mathrm{N}^{\circ} 4$, Buenos Aires.

Vargas R.J., M.S. Bó y M. Fave. 2007. Diet of the Southern Caracara (Caracara plancus) in Mar Chiquita Reserve, southern Argentina. Journal of Raptor Research 41: 113-121.

Verzi D.H. y C.I. Montalvo. 2008. The oldest South American Cricetidae (Rodentia) and Mustelidae (Carnivora): Late Miocene faunal turnover in central Argentina and the Great American Biotic Interchange. Palaeogeography, Palaeoclimatology, Palaeoecology 267: 284-291.

Veth P. 1989. Islands in the interior: a model for the colonization of Australia's arid zone. Archaeology in Oceania 24: 81-92.

Veth P. 1993. Islands in the Interior: The Dynamic of Prehistoric Adaptations within the Arid Zone of Australia. International Monographs in Prehistory. Archaeological Series 3, Michigan.

Vianna M.F., M.C. Mosto y F.J. Fernández. 2011. Ensamble de micromamíferos (Rodentia: Cricetidae) recuperados de una muestra de egagrópilas de Tyto alba del sudoeste de la provincia de San Juan, Argentina. Libro de Resúmenes de las XXIV Jornadas Argentinas de Mastozoología, pp. 160. La Plata.

Videla F. 1983. Hábitos alimentarios en iguánidos del oeste árido de la Argentina. Deserta 7: 192-202. 
Villa-Martínez R. y C. Villagrán. 1997. Historia de la vegetación de bosques pantanosos de la costa de Chile central durante el Holoceno medio y tardío. Revista Chilena de Historia Natural 70: 291-401.

Villa-Martínez R., C. Villagrán y B. Jenny. 2003. The last 7500 cal yr B.P. of westerly rainfall in Central Chile inferred from a high-resolution pollen record from Laguna Aculeo (34 $\mathrm{S})$. Quaternary Research 60: 284-293.

Villa-Martínez R., C. Villagrán y B. Jenny. 2004. Pollen evidence for late-Holocene climatic variability at Laguna de Aculeo, Central Chile (lat. $34^{\circ} \mathrm{S}$ ). The Holocene 14: 361-367.

Villanueva M., A. de la Mota. 1994. Peces II: Ictiogeografía de Mendoza. En: V.G. Roig (ed.), Serie Monográfica Pichiciego, pp. 1-10. Iadiza. Mendoza.

Villanueva M. y V. Roig. 1995. La ictiofauna de Mendoza. Reseña histórica, introducción y efectos de especies exóticas. Multequina 4: 93-104.

Voglino D., U.F.J. Pardiñas y P. Teta. 2004. Holochilus chacarius chacarius (Rodentia, Cricetidae) en la Provincia de Buenos Aires, Argentina. Mastozoología Neotropical 11: 243-247.

Volkheimer W. 1978. Descripción geológica de la Hoja 27b, Cerro Sosneado, provincia de Mendoza. Ministerio de Economía, Secretaría de Estado de Minería. Servicio Geológico Nacional, Buenos Aires.

Von Bertalanffly L. 1949. Problems of organic growth. Nature 163: 156-158.

Von Bertalanffly L. 1968. General system Theory. George Brazillier, New York.

Voss R.S. y M.D. Carleton. 1993. A new genus for Hesperomys molitor Winge and Holochilus magnus Hershkovitz (Mammalia, Muridae) with and analysis of its phylogenetic relationships. American Museum Novitates 3085: 1-39.

Walker S.R., J.A. Novaro, P. Perovic, R. Palacios, E. Donadío, M. Lucherini, M. Pía y M.S. López. 2007. Diets of three species of Andean carnivores in high-altitude deserts of Argentina. Journal of Mammalogy 88: 519-525.

Weissbrod L., T. Dayan, D. Kaufman, M. Weinstein-Evron. 2005. Micromammal taphonomy of el-Wad Terrace, Mount Carmel, Israel: distinguishing cultural from natural depositional agents in the Late Natufian. Journal of Archaeological Science 32: 1-17.

White C.M., P.D. Olsen y L.F. Kiff. 1994. Falcons. En: J. del Hoyo, A. Elliott y J. Sartagal (eds.), Handbook of the birds of the world. Volume 2: New World vultures to Guinea Fowl, pp. 216-275. Lynx Editions, Barcelona.

Williams D.E y M.A. Mares. 1978. A new genus and species of phyllotine rodent (Mammalia: Muridae) from northwestern Argentina. Annals of Carnegie Museum 47: 193-221.

Wilson D.E. y D.M. Reeder (eds.). 2005. Mammals species of the world. Third edition. The Johns Hopkins University Press, Baltimore. 
Wittouck P., E. Pinna Senn, C. Soñez, M. Provensal, J. Polop y J. Lisanti. 1995. Chromosomal and synaptonemal complex analysis of robertsonian polymorphisms in Akodon dolores and Akodon molinae (Rodentia, Cricetidae) and their hybrids. Cytologia 60: 93-102.

Worthy T.H. 2001. A fossil vertebrate fauna accumulated by laughing owls (Sceloglaux albifacies) on the Gouland Downs, northwest Nelson, South Island. Notornis 48: 225233.

Ximenez A. 1975. Felis geoffroyi. Mammalian Species 54: 1-4.

Yacobaccio H.D. 2003. Procesos de intensificación y de domesticación de camélidos en los Andes Centro-Sur. Memorias del Tercer Congreso Mundial sobre Camélidos, pp. 211216. Potosí.

Yáñez J.L., H. Núñez y F.M. Jaksic. 1982. Food habits and weight of Chimango Caracara in central Chile. Auk 99: 170-171.

Yapur L.B. y L.S. Gutiérrez. 1979. Ciclo espermatogénico anual del lagarto Liolaemus darwinii (Bell). Revista de la Sociedad Argentina de Biología 54-55: 82-89.

Yepes J. 1936a. Los mamíferos de Mendoza y sus relaciones con las faunas limítrofes. Novena Reunión de la Sociedad Argentina de Patología Regional 31: 689-725.

Yepes J. 1936b. Mamíferos coleccionados en la parte central y occidental de la Provincia de la Rioja. Physis 12: 31-42.

Yorio P. y M. Giaccardi. 2002. Urban and fishery waste tips as food sources for birds in northern coastal Patagonia, Argentina. Ornitologia Neotropical 13: 283-292.

Young J.Z. 1971. La Vida de los Vertebrados. Ediciones Omega, Barcelona.

Zárate M. 2002. Los ambientes del tardiglacial y Holoceno en Mendoza. En: A. Gil y G. Neme (eds.), Entre Montañas y Desiertos: Arqueología del Sur de Mendoza, pp. 9-42. Sociedad Argentina de Antropología, Buenos Aires.

Zárate M.A. y M.M. Páez. 2002. Los paleoambientes del Pleistoceno tardío-Holoceno en la cuenca del arroyo La Estacada, Mendoza. En: D. Trombotto y R. Villalba, (eds.), 30 años de investigación básica y aplicada en ciencias ambientales, pp.117-121. Instituto Argentino de Nivología (IANIGLA), Glaciología y Ciencias Ambientales, Mendoza.

Zárate M.A. y A. Mehl. 2008. Estratigrafía y geocronología de los depósitos del Pleistoceno tardío/Holoceno de la cuenca del arroyo La Estacada, Departamentos de Tunuyán y Tupungato (Valle de Uco), Mendoza. Revista de la Asociación Geológica Argentina 63: 407-416.

Zárate M., A. Gil y G. Neme. 2010. Integrando los registros: generalizaciones, alcances y limitaciones. En: M. Zárate, A. Gil y G. Neme (eds), Condiciones paleoambientales y ocupaciones humanas del centro-oeste de Argentina durante la transición PleistocenoHoloceno y Holoceno de Mendoza, pp. 309-330, Sociedad Argentina de Antropología, Buenos Aires. 



\section{APÉNDICE}

Listado, ordenado alfabéticamente, de las localidades con muestras de microvertebrados estudiadas en este trabajo de tesis doctoral: cuando fue posible se indicaron coordenadas, altitud, número de colección, ave generadora y fuente bibliográfica.

\section{Muestras arqueofaunísticas}

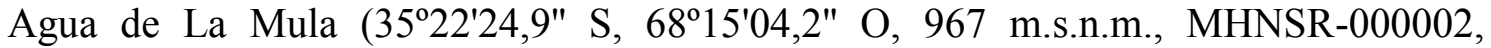
Sección Arqueología).

Agua de los Caballos-1 (3522'03" S y 68¹8'07" O, 1.025 m.s.n.m., MHNSR-000003, Sección Arqueología).

Arroyo Malo 3 (3451'18" S y 6953'00" O, 2.160 m.s.n.m., MHNSR-000005; Sección Arqueología).

Cueva Arroyo Colorado (3512'10.65" S y 7004'38.91" O, 2.200 m.s.n.m., MHNSR000008, Sección Arqueología).

Cueva de Luna (36 04'33,7" S y 69²4'22,9" O, 1.300 m.s.n.m., MHNSR-000009, Sección Arqueología).

Cueva Palulo (3456'40.40" S y 6950'39.54" O, 2.304 m.s.n.m., MHNSR-000007, Sección Arqueología).

Laguna El Sosneado-3 (3451' S, 6953' O, 2.100 m.s.n.m., MHNSR-000006, Sección Arqueología).

La Peligrosa-1 (36³1'00" S y 68³1'50" O, 1.160 m.s.n.m., MHNSR-000004, Sección Arqueología).

Rincón del Atuel-1 (3445'31" S y 68²2'14" O, 747 m.s.n.m., MHNSR-000001, Sección Arqueología).

\section{Muestras actuales}

\section{Egagrópilas}

$6 \mathrm{~km}$ al S de Las Leñas (35¹1'59" S y 70³'27" O, 2.200 m.s.n.m., MHNSR-0100, Sección Arqueología, Tyto alba, Fernández et al., 2009d). 
10 km al oeste de Bardas Blancas (3552'28" S y 6952'46" O, 1.152 m.s.n.m., CNP-E289, Ave rapaz indeterminada, Pardiñas et al., 2008).

Agua de La Mula (35²2'34,6" S y 68¹4'42,1" O, 970 m.s.n.m., MHNSR-0093, Sección Arqueología, Geranoaetus melanoleucus).

Arroyo Malo (3451'18" S y 6953'00" O, 2.160 m.s.n.m., MHNSR-0096, Sección Arqueología, Geranoaetos melanoleucus).

Arroyo Panchino I (3456'45" S y 6950'55" O, 2.341 m.s.n.m., MHNSR-0098, Sección Arqueología, Bubo magellanicus.

Arroyo Panchino II (3456'37" S y 6950'7" O, 2.270 m.s.n.m., MHNSR-0099, Sección Arqueología, Buteo polyosoma).

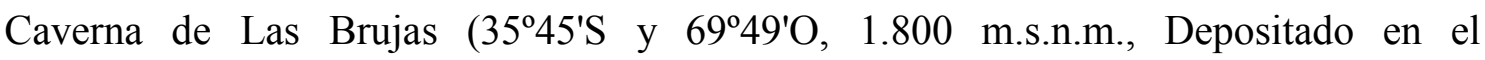
Laboratorio de Geo-arqueología de la Facultad de Filosofía y Letras UNCUYO, Ave rapaz indeterminada, Gasco et al., 2006).

Gruta del Indio $\left(34^{\circ} 45^{\prime} \mathrm{S}\right.$ y $68^{\circ} 21^{\prime}$ O, 700 m.s.n.m., MHNSR-0095, Sección Arqueología, Bubo magellanicus, Fernández et al., 2009d).

Laguna de la Niña Encantada (3509'38"S y 6952'09"O, 1.826 m.s.n.m., Colección Mastozoológica Elio Massoia, Fundación de Historia Natural Félix de Azara, Bubo magellanicus, Massoia et al., 1994).

Laguna de la Niña Encantada (3509'38"S y 6952'09"O, 1.826 m.s.n.m., CNP-E-55-56409, Bubo magellanicus, Nabte et al., 2006; Pardiñas et al., 2008).

Laguna El Sosneado (3450'34"S y 6954'34"O), 2.160 m.s.n.m., MHNSR-0097, Sección Arqueología, Tyto alba, Fernández et al., 2009d).

La Pasarela (36018'46" S y 69040'03" O, 1.250 m.s.n.m., CNP-E-198, Ave rapaz indeterminada, Pardiñas et al., 2008).

Los Frisos (36²8'20" S y 69³8'54" O, 1.101 m.s.n.m., CNP-E-199, Ave rapaz indeterminada, Pardiñas et al., 2008).

Río Seco La Hedionda (34²9'S y 68³3'O, 940 m.s.n.m., Colección Mastozoológica Elio Massoia, Fundación de Historia Natural Félix de Azara, Tyto alba, Massoia et al., 1997).

Volcán Malacara (3547'26"S y 69²9'13"O, MHNSR-0101, Sección Arqueología, Ave rapaz indeterminada).

\section{Trampeo}


Agua de La Mula (35²2'34,6" S, 68¹4'42,1" O, 900 m.s.n.m., MHNSR-0094, Sección Arqueología).

\section{Holochilus lagigliai, sp. nov.}

El Nihuil 3502' S y 68\%40' O, 1.300 m.s.n.m.), holotipo colectado a orillas del lago por Felipe Faliti 15 de enero de 1955: Piel (MHNSR-558, Sección Zoología, Mamíferos); Cráneo y Mandíbula (MHNSR-564, Sección Zoología, Mamíferos).

Gruta del Indio ( $34^{\circ} 45^{\prime} \mathrm{S}$ y $68^{\circ} 21^{\prime} \mathrm{O}, 700$ m.s.n.m.), 3 especimenes óseos recolectados en el suelo de la cueva por Humberto Lagiglia en enero de 1974: Mandíbula derecha (MHNSR-231, Sección Zoología, Mamíferos); Mandíbula derecha (MHNSR-650, Sección Zoología, Mamíferos); Mandíbula derecha (MHNSR-674, Sección Zoología, Mamíferos).

\section{Tympanoctomys barrerae}

Gruta del Indio (34 $45^{\prime}$ S y 68 $21^{\prime}$ O, 700 m.s.n.m.), 2 especimenes óseos recolectados en el suelo de la cueva por Humberto Lagiglia en enero de 1974: Fragmento anterior de cráneo (MHNSR-649, Sección Zoología, Mamíferos); Mandíbula izquierda (MHNSR778, Sección Zoología, Mamíferos). 